\title{
Compilation of Surface-Water and Water-Quality Data-Collection Sites on Selected Streams in Virginia
}

By Byron J. Prugh, Jr., and Clairiece G. Humphrey

U.S. GEOLOGICAL SURVEY

Open-File Report 93-462

Prepared in cooperation with the

VIRGINIA DEPARTMENT OF ENVIRONMENTAL QUALITY

WATER DIVISION

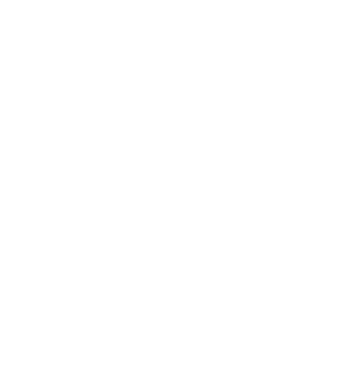

Richmond, Virginia 


\title{
U.S. DEPARTMENT OF THE INTERIOR BRUCE BABBITT, Secretary
}

\author{
U.S. GEOLOGICAL SURVEY
}

ROBERT M. HIRSCH, Acting Director

For additional information write to:

District Chief

U.S. Geological Survey

3600 West Broad Street, Room 606

Richmond, VA 23230
Copies of this report can be purchased from:

U.S. Geological Survey

Earth Science Information Center

Open-File Reports Section

Box 25286, MS 517

Denver Federal Center

Denver, CO 80225 


\section{CONTENTS}

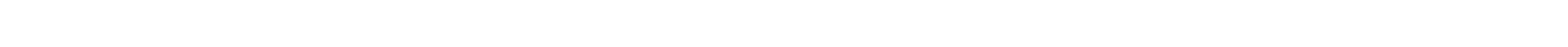

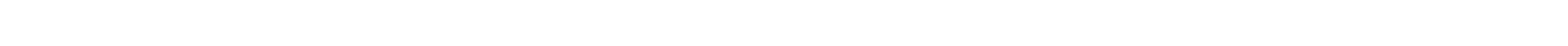

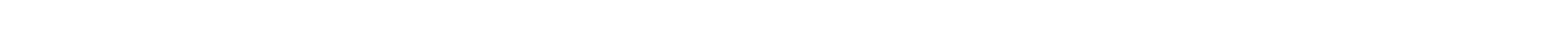

Acknowledgments . . . . . . . . . . . . . . . . . . . . . . . . . . . . . . .

Explanation of surface-water and water-quality data-collection site symbols and terms $\ldots \ldots \ldots \ldots 2$

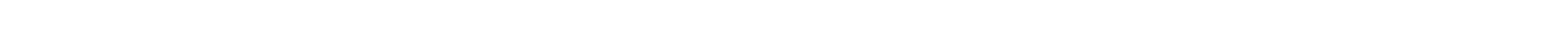

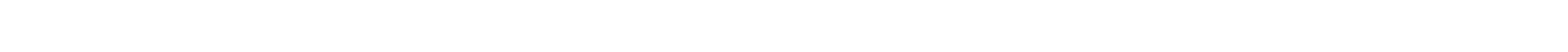

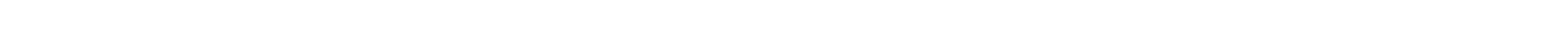

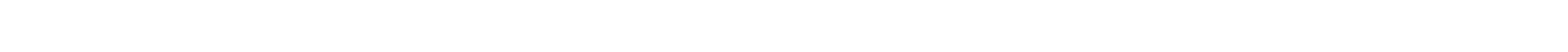

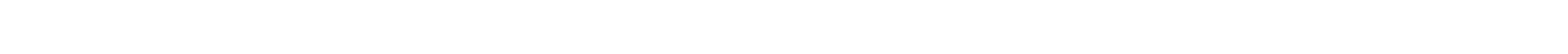

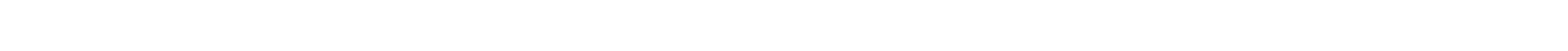

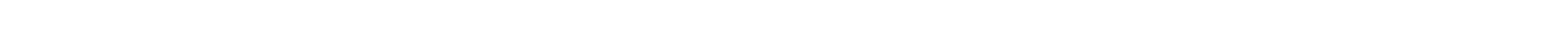

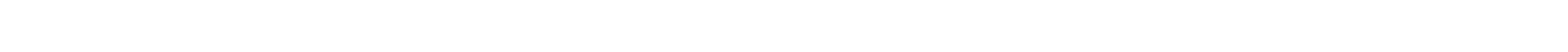

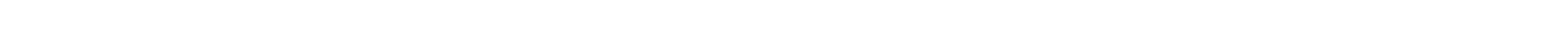

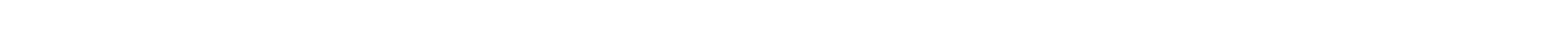

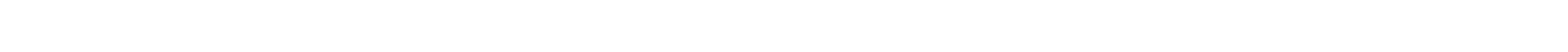

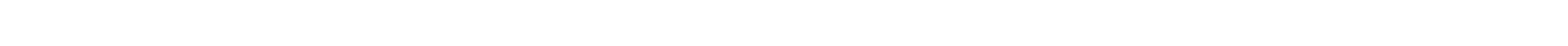

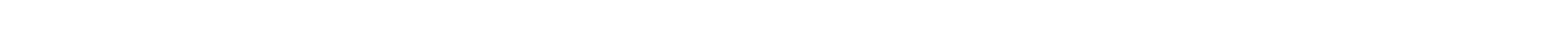

\section{FIGURE}

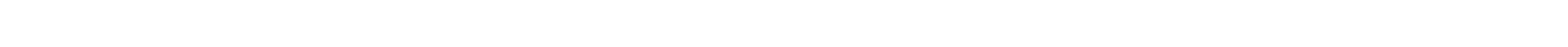

\section{TABLES}

[Surface-water and water-quality data-site locations by river basin]

\section{Atlantic Ocean, Chesapeake Bay, and Albemarle Sound Basins}

1. Eastern Shore Basins. . . . . . . . . . . . . . . . . . . . . . . . . . . . . . .

2. Potomac River Basin to Shenandoah River Basin . . . . . . . . . . . . . . . . . . 20

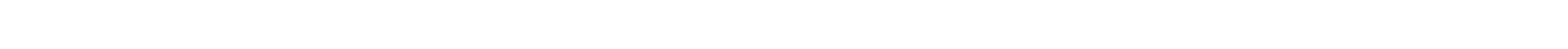

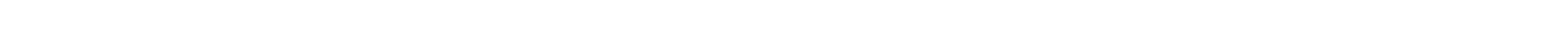

5. Potomac River Basin to Rappahannock River Basin $\ldots \ldots \ldots \ldots \ldots \ldots \ldots \ldots$

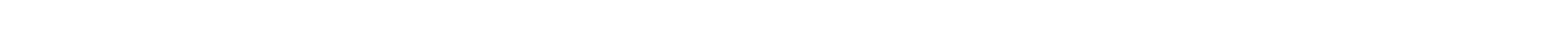

7. Rappahannock River Basin to York River Basin $\ldots \ldots \ldots \ldots \ldots \ldots$

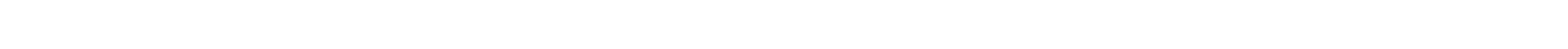

9. York River Basin to James River Basin . . . . . . . . . . . . . . . . . . . . . . . 202

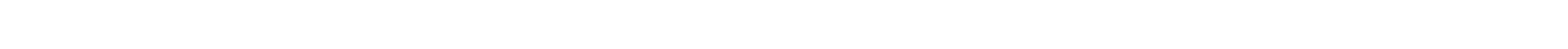

11. James River Basin to Chowan River Basin. . . . . . . . . . . . . . . . . . . . . . 314

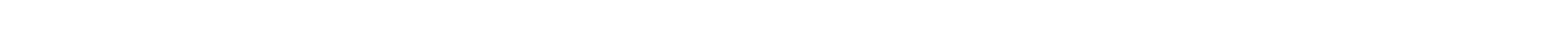

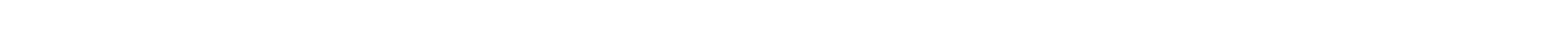

14. Yadkin River Basin (head of Pee Dee River) $\ldots \ldots \ldots \ldots \ldots \ldots \ldots \ldots$ 


\section{TABLES - Continued}

\section{Ohio River Basin}

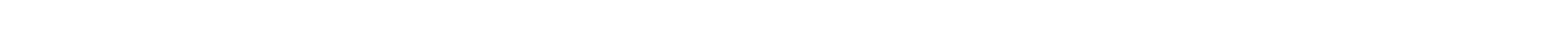

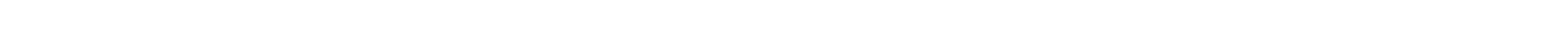

\section{Tennessee River Basin}

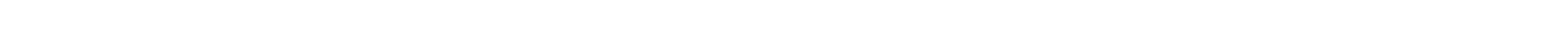

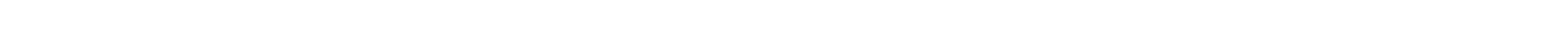

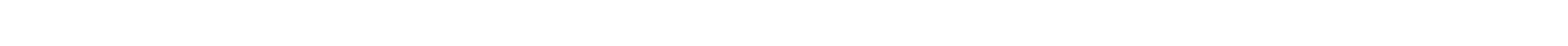




\title{
COMPILATION OF SURFACE-WATER AND WATER-QUALITY DATA-COLLECTION SITES ON SELECTED STREAMS IN VIRGINA
}

\author{
By Byron J. Prugh, Jr., and Clairiece G. Humphrey
}

\begin{abstract}
The report presents a listing of about 8,900 selected surface-water and water-quality datacollection site locations in Virginia. The listing includes, if available, an agency station/siteidentification number, station/site name. drainage area, datum, source agency, type of data collected, period of record of data collection, latitude and longitude of the site location, county. and the name of the 7.5-minute topographic quadrangle containing the site location.
\end{abstract}

\section{INTRODUCTION}

The initial compilation effort for this report was begun as the first step in designing a low-flow monitoring network for Virginia. The intent of the effort was to minimize the need for collecting new hydrologic data by making optimum use of previously collected hydrologic data. Although U.S. Geological Survey (USGS) continuous-record stations and most partial-record sites for Virginia are listed in USGS Circulars 651. 652, and 653, there is no listing of any of the hundreds of miscellaneous sites were hydrologic data have been collected during the past 100 years. The first draft of this report included a listing of miscellaneous data-collection sites compiled from USGS WaterSupply Papers, Water-Data Reports. Open-File Reports, and unpublished project data in the Virginia District files. During the preparation of the first draft, it became apparent that a complete listing of all data-collection locations, including sites with known drainage areas, would be beneficial, not only for the low-flow study, but for other future studies by the Virginia District and other water-resources data users in Virginia.

The decision to add the locations of waterquality data-collection sites to the compilation was made during a meeting with representatives of the Virginia Water Control Board (predecessors of the Virginia Department of Environmental QualityWater Division), the cooperating agency on the low-flow study. Additional State and Federal agencies were contacted and asked to review the current listing and to submit other pertinent sites for listing in the report.

This report represents a summary compilation of locations in Virginia where hydrologic data have been collected during the last 100 years. The work for this report was done by the U.S. Geological Survey, in cooperation with the Virginia Department of Environmental Quality-Water Division (DEQ-WD).

\section{Purpose and Scope}

The purpose of this report is to serve as a comprehensive compilation of the locations of surface-water and water-quality data-collection sites in Virginia. Knowledge of the location of these sites minimizes the need to collect new data by making optimum use of previously collected data and thus increase the cost-effectiveness of hydrologic data programs.

This report presents a listing of about 8,900 selected surface-water and water-quality datacollection sites in Virginia. The listing includes, if available, an agency station/site-identification 
number, station/site name, drainage area, datum, source agency, type of data collected, period of record of data collection, latitude and longitude of the site location, the county, and 7.5-minute topographic quadrangle containing the site location.

The data-collection sites are grouped by basin to facilitate their use in hydrologic studies. Sites are listed in downstream order with a given basin. The major river basins and interbasin areas in Virginia are shown in figure 1. An alphabetical index of the sites is appended to the report to assist the user in quickly determining if data are available for a given stream.

This report will be periodically updated, so that new locations and revisions can be added. Users are encouraged to contribute new data-site listing to the compilation report by submitting them to the U.S. Geological Survey, Virginia District, 3600 West Broad Street, Room 606, Richmond, Virginia, 23230.

\section{Acknowledgments}

The authors gratefully acknowledge the assistance of the many individuals in the State and Federal agencies who contributed their time and efforts in supplying data and reviewing draft copies of this report. Special appreciation is extended to the late Steve Williams of the former Virginia Water Control Board for his efforts in reviewing water-quality data-site locations.

\section{EXPLANATION OF SURFACE- WATER AND WATER-QUALITY DATA- COLLECTION SITE SYMBOLS AND TERMS}

This report was prepared by compiling data from more than a dozen references and sources containing hydrologic data for Virginia. Data sources include USGS Water-Supply Papers, annual Water-Data Reports, Open-File Reports, and unpublished project data of the USGS; river basin studies and published and unpublished data reports from two predecessors of the Virginia DEQ - the Virginia Water Control Board and the Virginia Division of Water Resources; drainage- area reports by the Tennessee Valley Authority; various oral and written communications with the U.S. Army Corps of Engineer Districts: Norfolk. Wilmington, Huntington, and Baltimore; National Weather Service; USGS Water Resources Division Districts: North Carolina, Tennessee, West Virginia, Kentucky, and Maryland; and USGS research personnel located in Reston, Va. The published sources are listed in the section on "Selected References."

In the following sections, the column headings for the site entries in the tables are described, any special abbreviations used are defined, and limitations on the data are discussed.

\section{Station/Site-Identification Number}

One or two agency identification codes are listed for each location, if available. The USGS uses an 8-digit (for most sites), 9-digit, or 10-digit identification number that is composed of two parts (example: 02040500). The first two digits designate the major river drainage region where the site is located: 01-North Atlantic slope basins, 02 South Atlantic slope basins, 03-Ohio River basin. The remaining digits are assigned in downstream order with the smallest number representing the farthermost upstream location within a basin. The Virginia DEQ uses a nine character identification number (for example, JMS345.73). The first three letters are an abbreviated form of the stream name; the remaining digits are the distance in miles above the mouth of the particular stream. An exception to this terminology is used with unnamed tributaries where an " $\mathrm{X}$ " is used for the initial letter abbreviation.

\section{Station/Site Name}

In this heading, stations are defined as those locations where water-level measurements are associated with some physical reference point or where some physical structure is located to house sampling, measuring, or recording equipment; for example, a water-quality monitor or crest-stage gage. A site is defined as any location where hydrologically significant data are available; for example, a drainage area. 


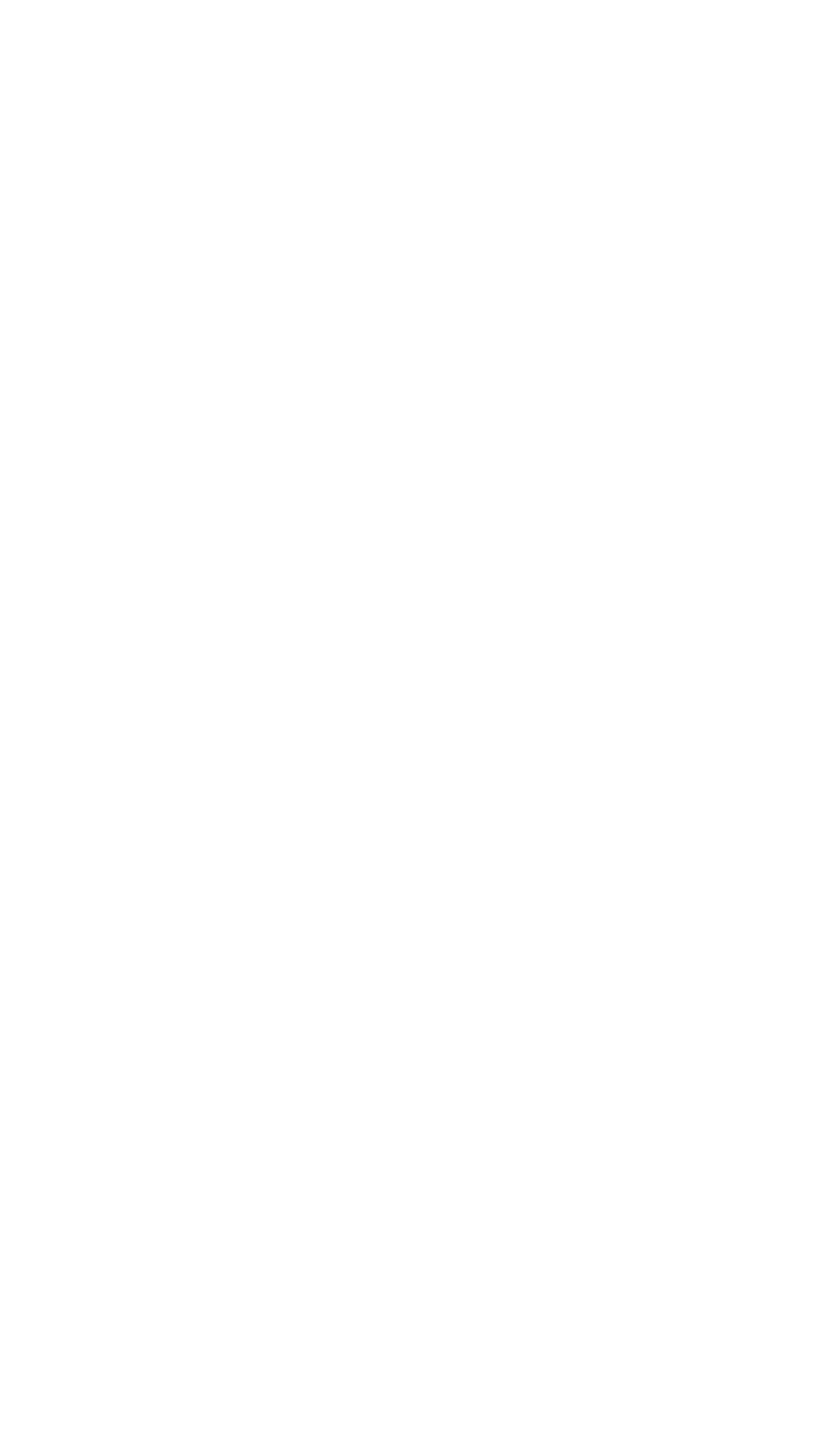

Explanation of Symbote and Terme 3 
The station or site name is composed of three major parts in addition to various modifiers. The first part is the stream name obtained from the most recent topographic map or from the U.S. Board on Geographic Names. The second part consists of the words "at" (within 1 mile of the referencing feature), "near" (more than 1 mile from the referencing feature), "below" (downstream from), or "above" (upstream from). These terms describe the proximity of the site to the nearest town or geographical reference. The final part is the name of the town or other prominent geographical feature found on the most current edition of the State base map. Various additional modifiers also are used to help clarify the site location and to assist the user in finding sites of interest.

Parenthetical names or descriptions shown as part of the station/site name indicate those names or descriptions formerly used for this location. The sites are within the State of Virginia unless otherwise noted.

Some adjacent sites in the field are so close together physically (within a few hundred feet or so) that they have been listed as one site in this report to conserve space in the listing. However, when there is a hydrologic reason to differentiate between these sites, they are listed separately.

The asterisk symbol $\left(^{*}\right)$ after a site name indicates that the specific site location is uncertain. The site has been placed in the most likely downstream order listing that the authors could determine.

Some common descriptive terms have been abbreviated to save space in the listing. A summary of these is provided in the "Conversion Factors, Vertical Datum, and Abbreviations" list at the front of the report.

\section{Drainage Area}

The drainage area of the basin upstream from the site is listed in square miles. At a few locations near the State border, only that part of the drainage area entirely within the State of Virginia is listed. The symbol " $\mathrm{A}$ " is used in place of the standard symbol "DA" in the "Type" column to alert the user that only a part of the total drainage area is listed. Values shown are the most recent determinations prepared by an agency and are listed on the same line in the table as the agency identification code. Slight differences in areas calculated for a given site by different agencies are due to either the different interpretations and delineations of basin boundaries or the techniques employed to measure the area. The user should decide which agency's determination to use.

\section{Datum}

At many continuous-record stations and some partial-record sites, an arbitrary datum has been established, so that gage heights can be reported as relatively small numbers instead of in hundreds or thousands of feet. The datums are referenced to the National Geodetic Vertical Datum of 1929. Once established, datums at a specific location are generally not changed unless the site is physically relocated or the reference benchmark elevation is revised because of a geodetic network readjustment.

\section{Source Agency}

This section identifies the agency that collected and (or) generated the data available for the particular site. For some continuous-recording surface-water sites, data have been collected by several agencies. Data requests should be addressed to the agency currently operating the site. The USGS and the Virginia DEQ in several instances have transferred responsibility between themselves for selected sites in order to achieve maximum efficiency in field data-collection activities and to accommodate changing priorities in their data-collection programs. The following abbreviations for source agencies are used in the tables:

$\begin{array}{ll}\text { APCO } & \text { Appalachian Power Company } \\ & \text { P. O. Box 2021 } \\ & \text { Roanoke, VA 24022 } \\ \text { CAMP } & \text { Union Camp Corporation } \\ & \text { P. O. Box 178 } \\ & \text { Franklin, VA 23851 } \\ \text { CEHT } & \text { U.S. Amy Corps of Engineers } \\ & \text { Huntington District } \\ & \text { 502 8th Street } \\ & \text { Huntington, WV 25701 }\end{array}$


CENA U.S. Army Corps of Engineers

Nashville District

P. O. Box 1070

Nashville, TN 37202

CENO U.S. Army Corps of Engineers

Norfolk District

803 Front Street

Norfolk, VA 23510

CEWL U.S. Army Corps of Engineers

Wilmington District

P. O. Box 1890

Wilmington, NC 28402

CNOR City of Norfolk

Division of Water Production

6040 Waterworks Road

Norfolk, VA 23502

DANV City of Danville

Public Utilities Department

Danville, VA 24541

FAXC Fairfax County, Department of

Environmental Management

4050 Legato Road

Fairfax, VA 22033

FCWA Fairfax County Water Authority

P. O. Box 1500

Merrifield, VA 22116

FERC Federal Energy Regulatory Commission 730 Peachtree Street, NE

Atlanta, GA 30308

NDEM North Carolina Division of

Environmental Management

P. O. Box 27687

Raleigh, NC 27611

NEWS City of Newport News

Department of Public Utilities

P. O. Box 76

Newport News, VA 23607

NWS National Weather Service

Washington Forecast Office

Route 1, Box 107

Sterling, VA 22170

OCCN Occoquan Watershed Monitoring

Laboratory

9408 Prince William Street

Manassas, VA 22110

PTWD City of Portsmouth Water Department

P. O. Box 490

Portsmouth, VA 23705
RICH City of Richmond

Department of Health

600 East Broad Street, Room 629

Richmond, VA 23219

SYN Synergics, Inc.

191 Main Street

Annapolis, MD 21401

TVA Tennessee Valley Authority

Data Services Branch

400 Summit Hill Drive

Knoxville, TN 37902

URCH University of Richmond

Department of Biology

Richmond, VA 23173

USGS U.S. Geological Survey

3600 West Broad Street, Room 606

Richmond, VA 23230

Virginia DEQ (VDEQ)-(formerly, Virginia Water Control Board)

Virginia Department of Environmental Quality-Water Division

1936 Arlington Boulevard, Suite 210

Charlottesville, VA 22903

(Surface-water data)

Virginia Department of Environmental

Quality-Water Division

Southwest Regional Office

P. O. Box 888

Abingdon, VA 24210

(Water-quality data)

Virginia Department of Environmental Quality-Water Division

West Central Regional Office

3015 Peters Creek Road

Roanoke, VA 24019

(Water-quality data)

Virginia Department of Environmental

Quality-Water Division

Valley Regional Office

117 North Main Street

Bridgewater, VA 22812

(Water-quality data) 
Virginia DEQ (VDEQ):-continued

Virginia Department of Environmental Quality-Water Division

Piedmont Regional Office

P.O. Box 11143

Richmond, VA 23230-11143

(Water-quality data)

Virginia Department of Environmental Quality-Water Division

Tidewater Regional Office

287 Pembroke Office Park

Suite 310, Pembroke II

Virginia Beach, VA 23462

(Water-quality data)

Virginia Department of Environmental Quality-Water Division

Northern Regional Office

1519 Davis Ford Road, Suite 14

Woodbridge, VA 22192

(Water-quality data)

VEPC Virginia Power

P. O. Box 26666

Richmond, VA 23261

VPI Virginia Polytechnic Institute and State University

Department of Agriculture

Blacksburg, VA 24061

\section{Type}

The type of hydrologic data available at a particular site is shown by the following abbreviations:

A-Partial drainage area, in square miles: only the contributing drainage area within the State of Virginia determined for many streams located along the borders of the State is listed. Total drainage area at such a site will be at least this great.

BS-Bridge-study: data available from a special study made at site to determine peak flows and flow distribution for various bridge-design altematives.

BW-Backwater; data available from a special study made of backwater conditions during floods.
C-Crest-stage partial-record: data from site with a peak-stage indicator usually inspected on a quarterly basis. Peak-flow values have been published with some secondary peak values available; time and duration of peaks, however, are not well defined.

DA-Drainage area in square miles: drainage area of basin upstream from the site. Different agencies may have calculated slightly different values either due to different interpretations and delineation of basin boundaries and (or) due to different techniques employed.

E-Miscellaneous observation of flow: data from site with no systematic frequency of data collection where the flow was estimated from a field observation.

F-Flood-profile, partial-record: data from site operated for special studies. Peak-flow values only are published. Some short segments of continuous records collected but generally not analyzed.

FP-Forecast point: location of site for riverstage prediction by National Weather Service.

G-Stage: data from site where there is a systematic recording of gage heights. Data consist of daily average or once-daily gage heights and are usually published.

GU-Stage: data from site where continuousrecording or observer readings are made. The bulk of the data, except possibly the annual maximum, are not published.

GV-Stage and contents: data from a site where levels of a lake or reservoir are systematically recorded. Monthend gage height and contents (volume) are published.

HW-High-water, partial-record: data available from a site where a staff gage is read by an observer during periods of high water.

L-Low-flow, partial-record: data from a site where discharge measurements are systematically made during periods of base flow to help define low-flow characteristics.

MQ-Miscellaneous measurement or observation of flow: data from a partial-record site that is not part of peak-flow or low-flow network and which has no specific frequency of observation. Could be of either high or low flows and is usually part of a special study. 
$\mathbf{N}$-Noncontinuous record: data from a site with once-daily or twice-daily observations of water-surface elevation, usually associated with systematic measurements of discharge. Discharge or stage published on a daily, monthly, and annual basis.

PS-Provisional site number: site number reserved or site considered as future data-collection location.

QW-Quality-water: data from where waterquality observations, measurements, and samples are collected. No attempt is made to differentiate as to what or how many physical characteristics or parameters are measured or analyzed.

R-Continuous-recording: data from site where water-surface elevation is continuously recorded along with systematic measurements of discharge. Discharge published on a daily, monthly, and annual basis but instantaneous discharges generally available upon request.

S-Spring: data from a spring that has singular or multiple observations of water level and (or) discharge.

SED-Sediment: data from a site where sediment samples are collected and loads published usually on a daily or weekly basis.

SR-Partial-record: data from a site operated for rainfall-runoff modeling. Peak flows only published. Some short segments of continuous records collected for storm events but not published.

X-Special: data available from a special study at site to define channel cross-sectional properties.

\section{Period of Record}

Date(s) represent the period when, or between which, data have been collected; shown as month and year $(8 / 69$ or $8 / 69-9 / 72)$. If a zero appears $(0 / 69)$ instead of the expected number for the specific month, then the month is unknown or was unavailable from the data-reference source. If the date ends in dash (8/69-), this indicates that the site is still active. For miscellaneous and low-flow data, a dash between two dates $(8 / 69-9 / 72)$ indicates three or more observations or measurements during the period. For some VDEQ and OCCN water- quality sites, beginning and ending dates of data collection were not available and " $0 / 00$ " was used to describe the known status of these sites as of 1993.

\section{Latitude}

Latitude (north) in degrees, minules, and seconds. At USGS continuous-record sites. latitude represents the location of the recorder; at miscellaneous and partial-record sites at bridges, latitude represents the midpoint of the stream. Other agencies may use slightly different criteria and (or) base maps to determine location that can result in differences in the order of several seconds. In general, the first determination of the location is listed unless subsequent assessment shows that it was significantly in error.

\section{Longitude}

Longitude (west) in degrees, minutes, and seconds. At USGS continuous-record sites, longitude represents the location of the recorder; at miscellaneous and partial-record sites at bridges, longitude represents the midpoint of the stream. Other agencies may use slightly different criteria and (or) base maps to determine location that can result in differences in the order of several seconds. In general, the first determination of the location is listed unless subsequent assessment shows that it was significantly in error.

\section{County}

The county or city where the site is located. Because streams often serve as political boundaries, many sites are listed in both adjoining jurisdictions to facilitate geographic retrievals of the listings. Counties not located in Virginia are specifically identified by the appropriate State.

\section{Quadrangle}

The 7.5-minute USGS topographic map on which the site is located. 


\section{SELECTED REFERENCES}

Collins, W.D., Foster, M.D., Reaves. Frank, and Meacham. R.P., 1930, Springs of Virginia: Virginia Division of Water Resources Bulletin 1, 55 p.

Nuckels. E.H., 1970. Virginia streamflow data program analysis: U.S. Geological Survey Open-File Report, $54 \mathrm{p}$.

Prugh. B.J., Jr., Nuckels, E.H., and Humphrey, C.G., 1991. Annual maximum stages and discharges of selected streams in Virginia through 1990: U.S. Geological Survey Open-File Report 90-587, 462 p.

Tennessee Valley Authority, 1962, Drainage areas of streams in Tennessee and Cumberland River basins: Tennessee Valley Authority Report 0-5829-R-1. $73 \mathrm{p}$.

U.S. Geological Survey, 1898-1960, Surface-water records of Virginia: U.S. Geological Survey WaterSupply Papers (published annually). 1962-65, Part 1, surface-water records: U.S. Geological Survey Water-Data Report VA-62-1 to VA-65-1 (published annually). 1965-75, Water resources data for Virginia. 196574: U.S. Geological Survey, Water-Data Reports VA-65-1 to VA-74-1 (published annually). 1976-92. Water resources data, Virginia, water years 1975-92: U.S. Geological Survey Water-Data Reports VA-75-1 to VA-92-1 (published annually). 1967, Index to gaging stations in Virginia: U.S.

Geological Survey Open-File Report, 35 p. 1971, Index of surface-water records to September 30, 1970. Part 1-North Atlantic slope basins: U.S. Geological Survey Circular 651, 89 p. 1971, Index of surface-water records to September 30, 1970, Part 3-Ohio River basin: U.S. Geological Survey Circular 653, 71 p.
1972, Index of surface-water records to September 30, 1970. Part 2-South Atlantic slope and Eastern Gulf of Mexico basins: U.S. Geological Survey Circular 652.88 p.

State Water Control Board, 1966. Comprehensive water resources plan. New River basin, Vol. 1Introduction: State Water Control Board Planning Bulletin 201, 78 p.

1968. Comprehensive water resources plan. Potomac-Shenandoah River basins. Vol. 1Introduction: State Water Control Board Planning Bulletin 207, 157 p.

1969. Comprehensive water resources plan, James River basin, Vol. 1-Introduction: State Water Control Board Planning Bulletin 213, 193 p.

1970, Comprehensive water resources plan, Rappahannock River basin, Vol. 1-Introduction: State Water Control Board Planning Bulletin 219. $122 \mathrm{p}$.

1970, Comprehensive water resources plan. York River basin, Vol. 1-Introduction: State Water Control Board Planning Bulletin 225, 112 p.

1972. Comprehensive water resources plan, Roanoke River basin, Vol. 1-Introduction: State Water Control Board Planning Bulletin 243, 184 p.

1972, Comprehensive water resources plan, Tennessee and Big Sandy River basins, Vol. 1Introduction: State Water Control Board Planning Bulletin 231, $218 \mathrm{p}$.

1972. Comprehensive water resources plan, Chowan River-Dismal Swamp basins, Vol. 1Introduction: State Water Control Board Planning Bulletin 237, 136 p. 
TABLES 1-19 



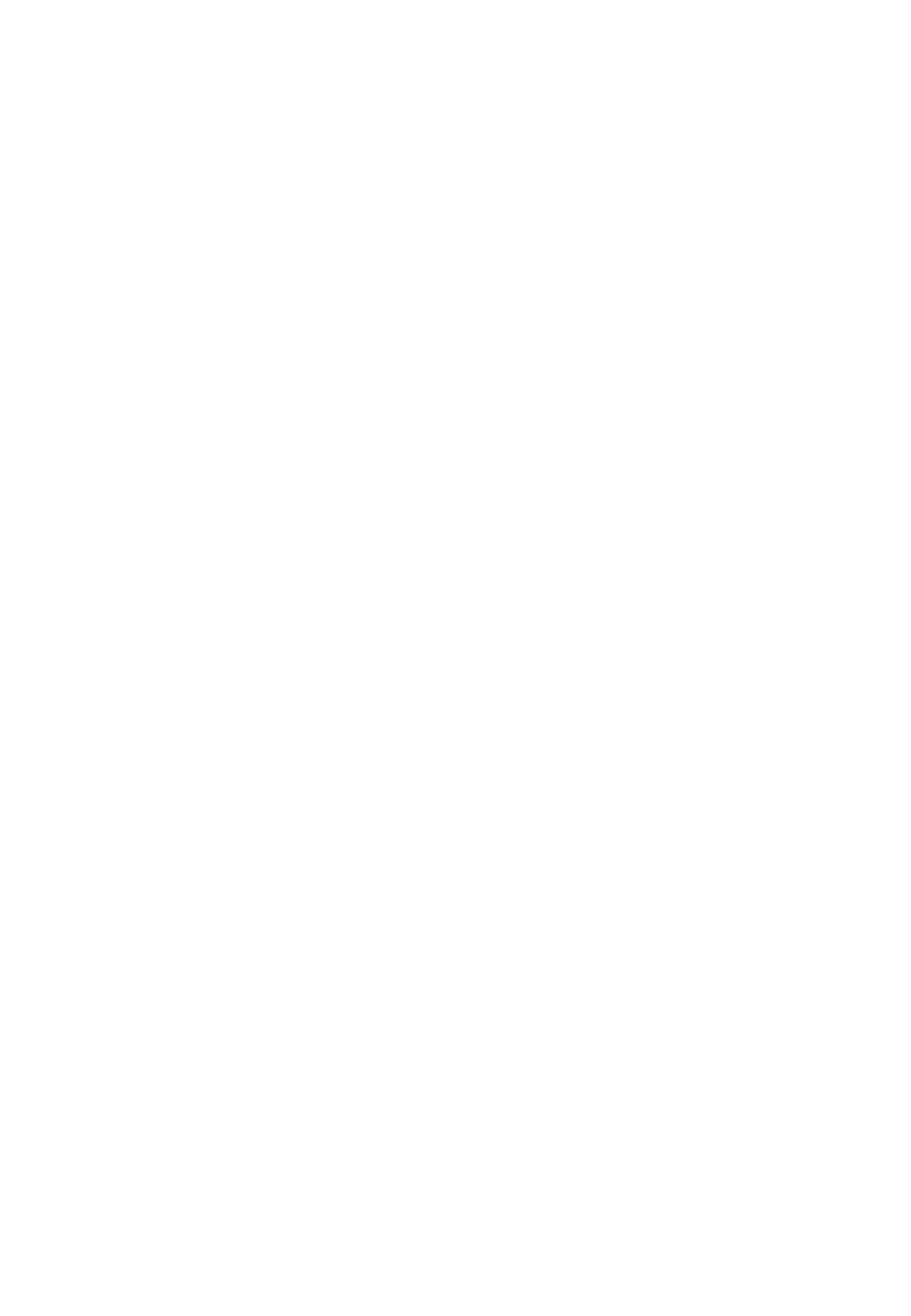




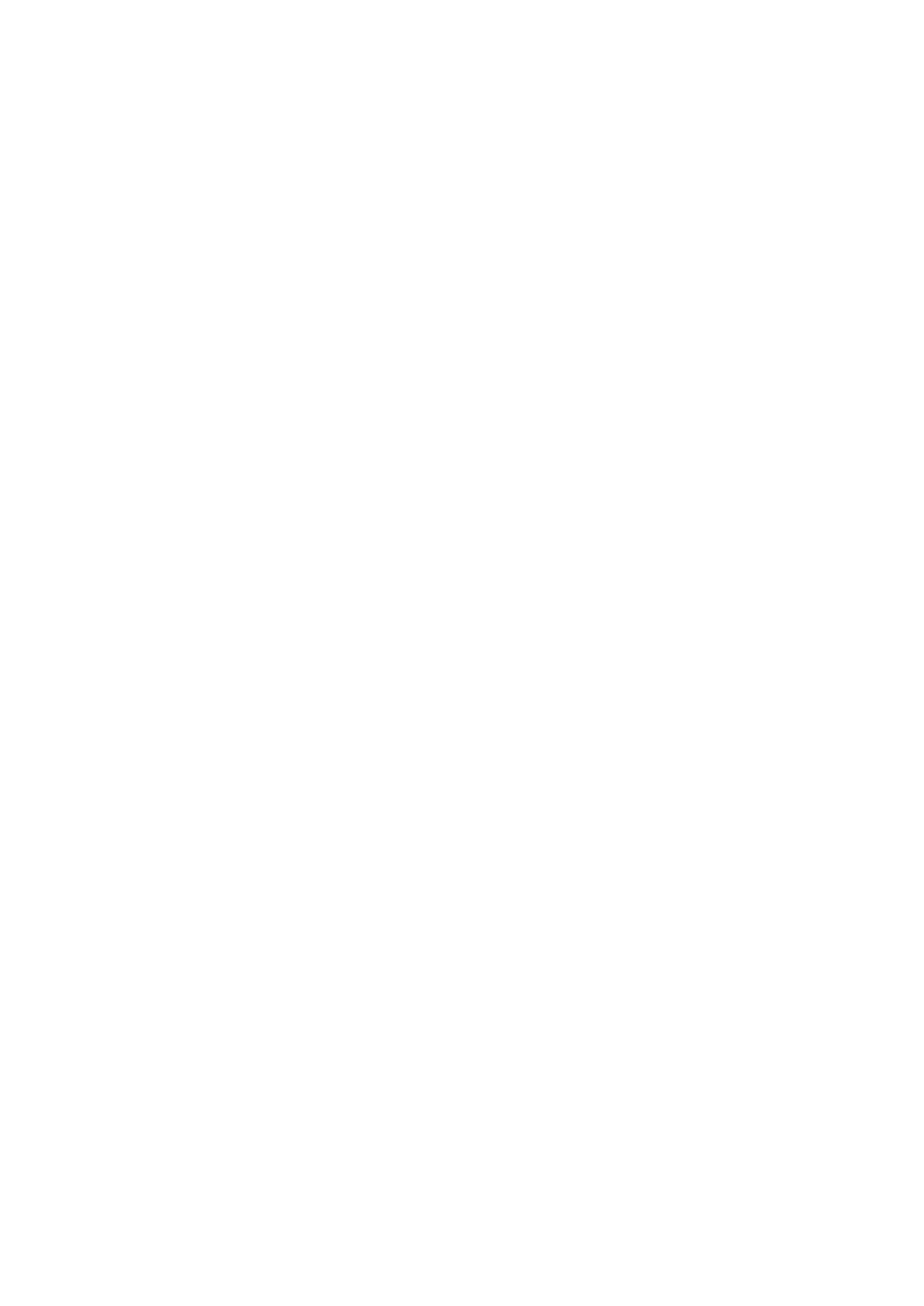




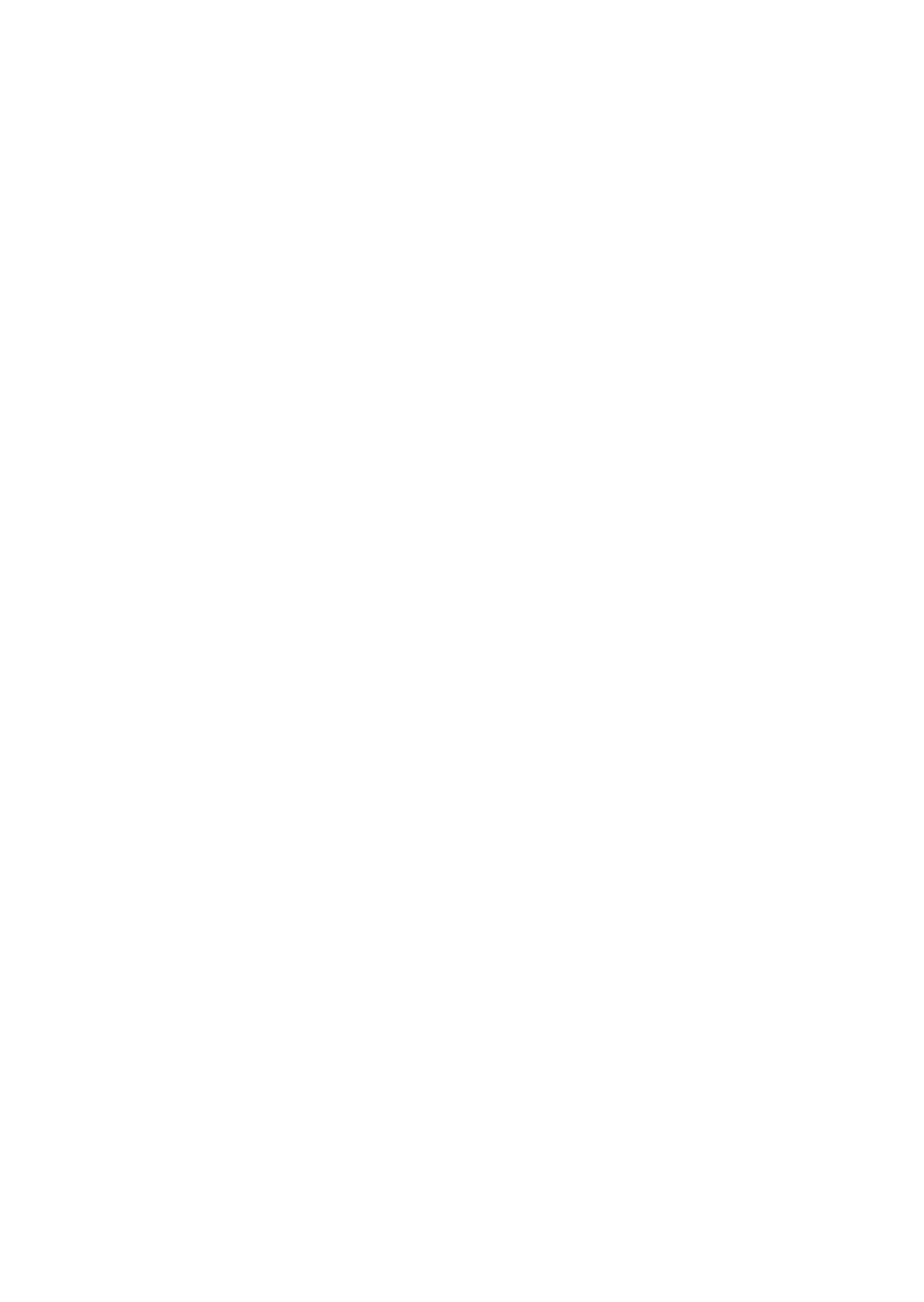




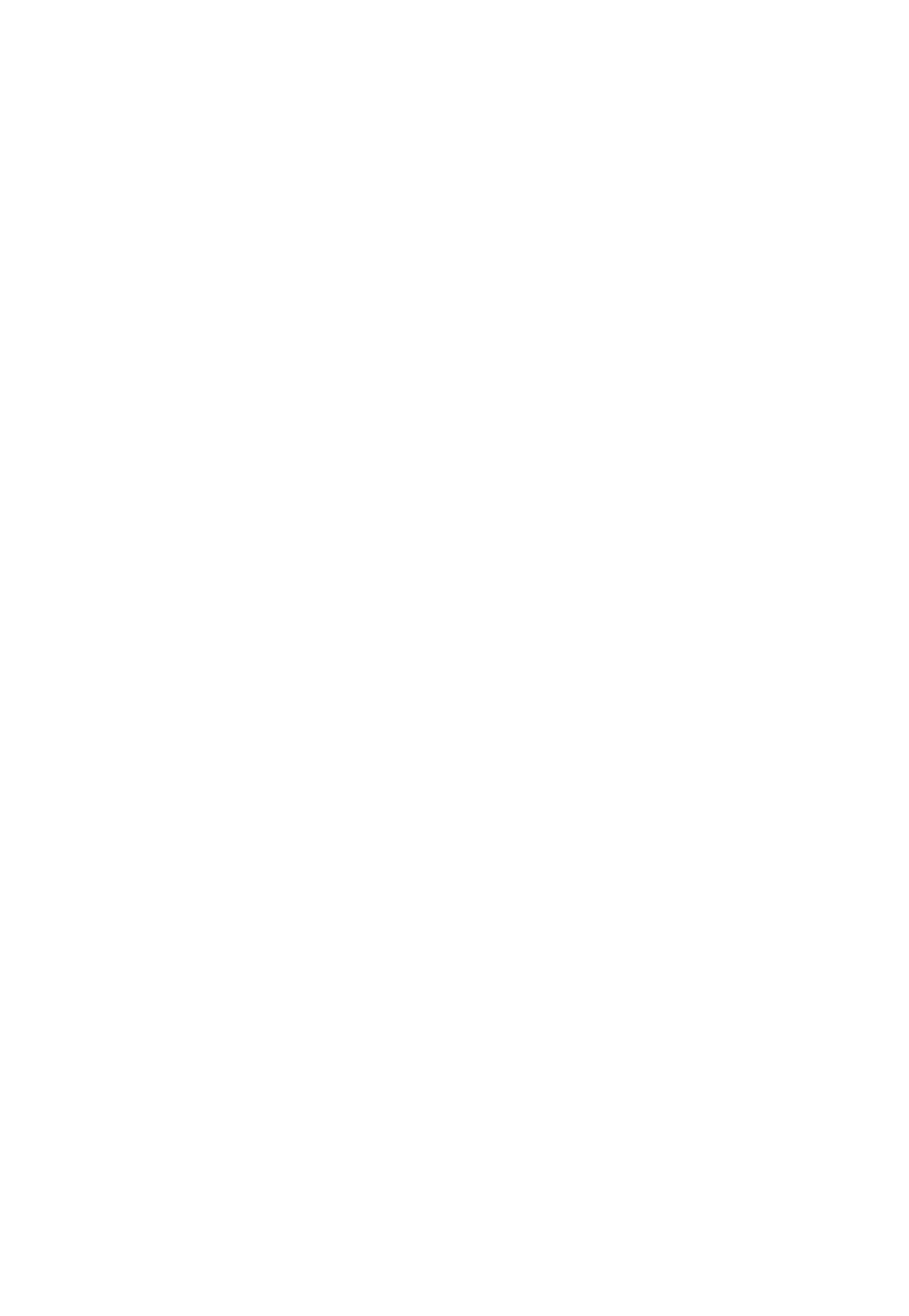




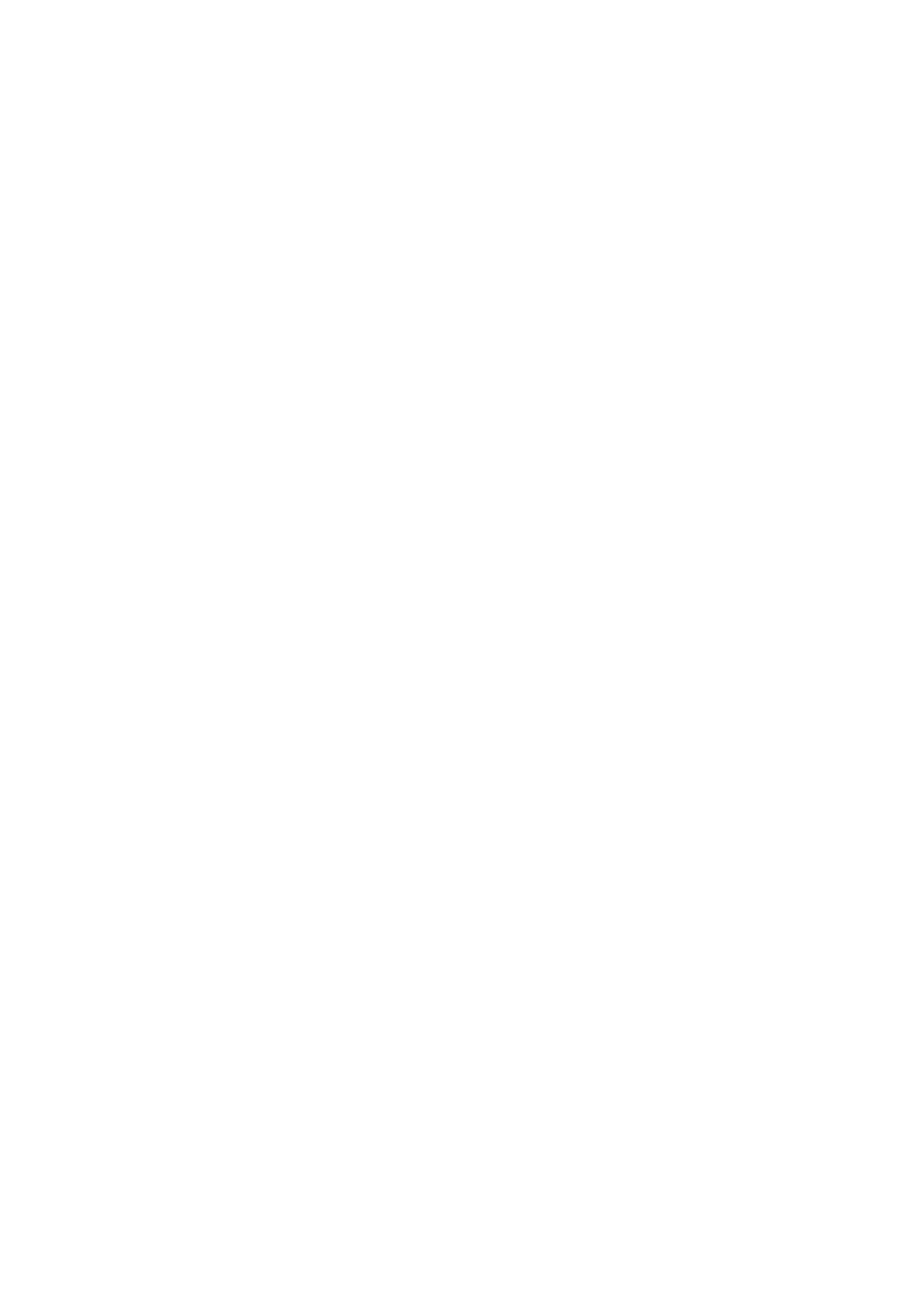




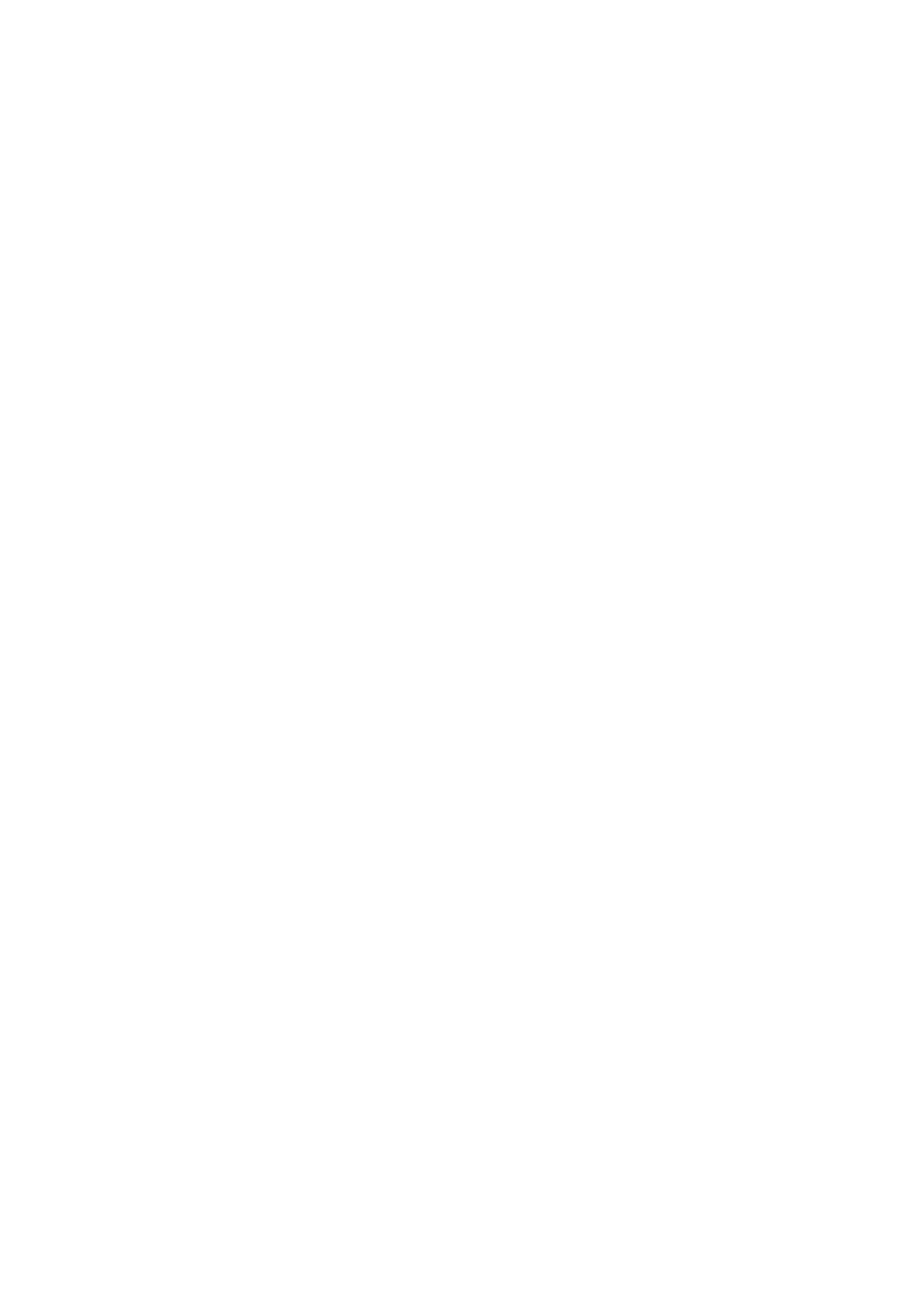




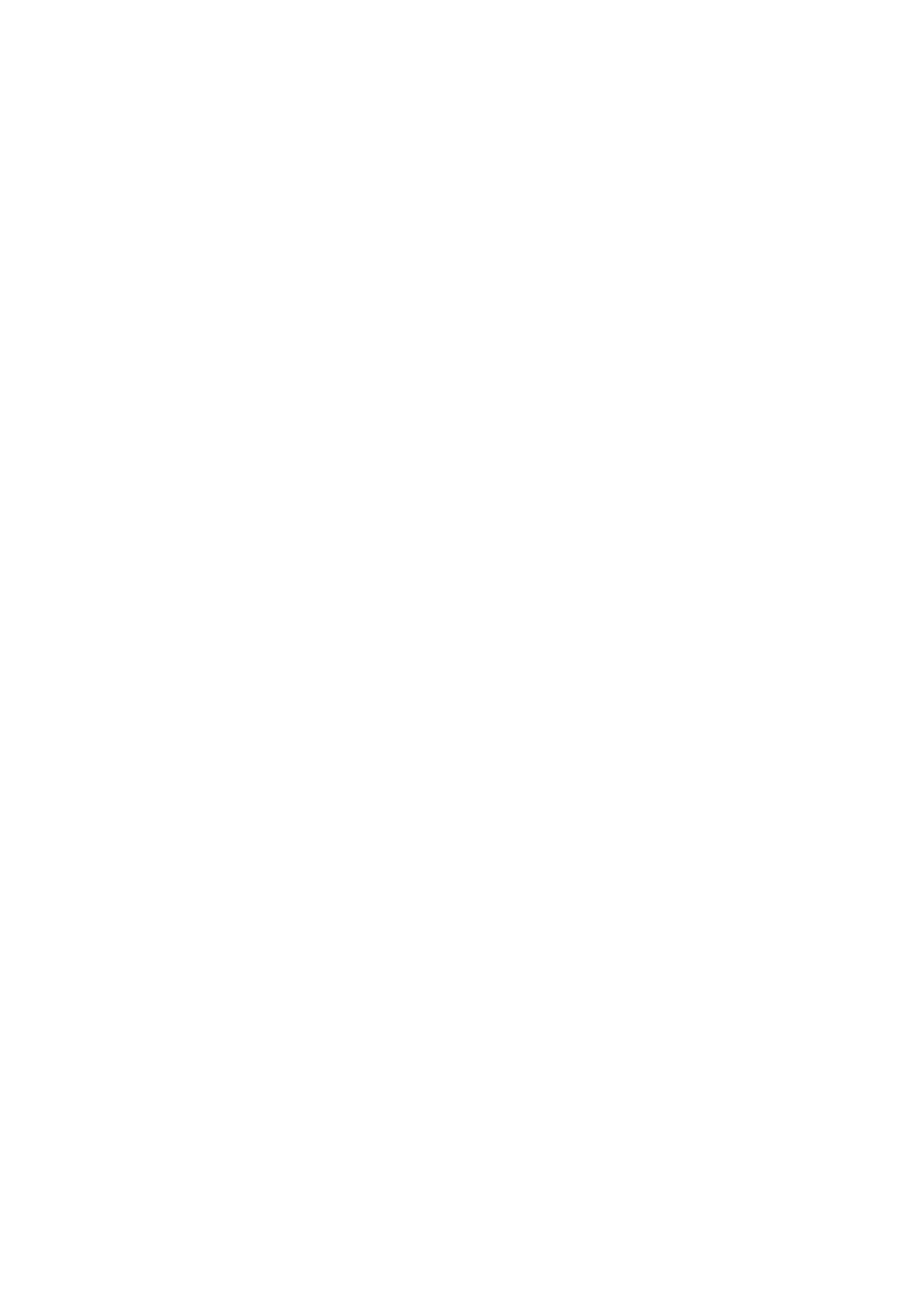




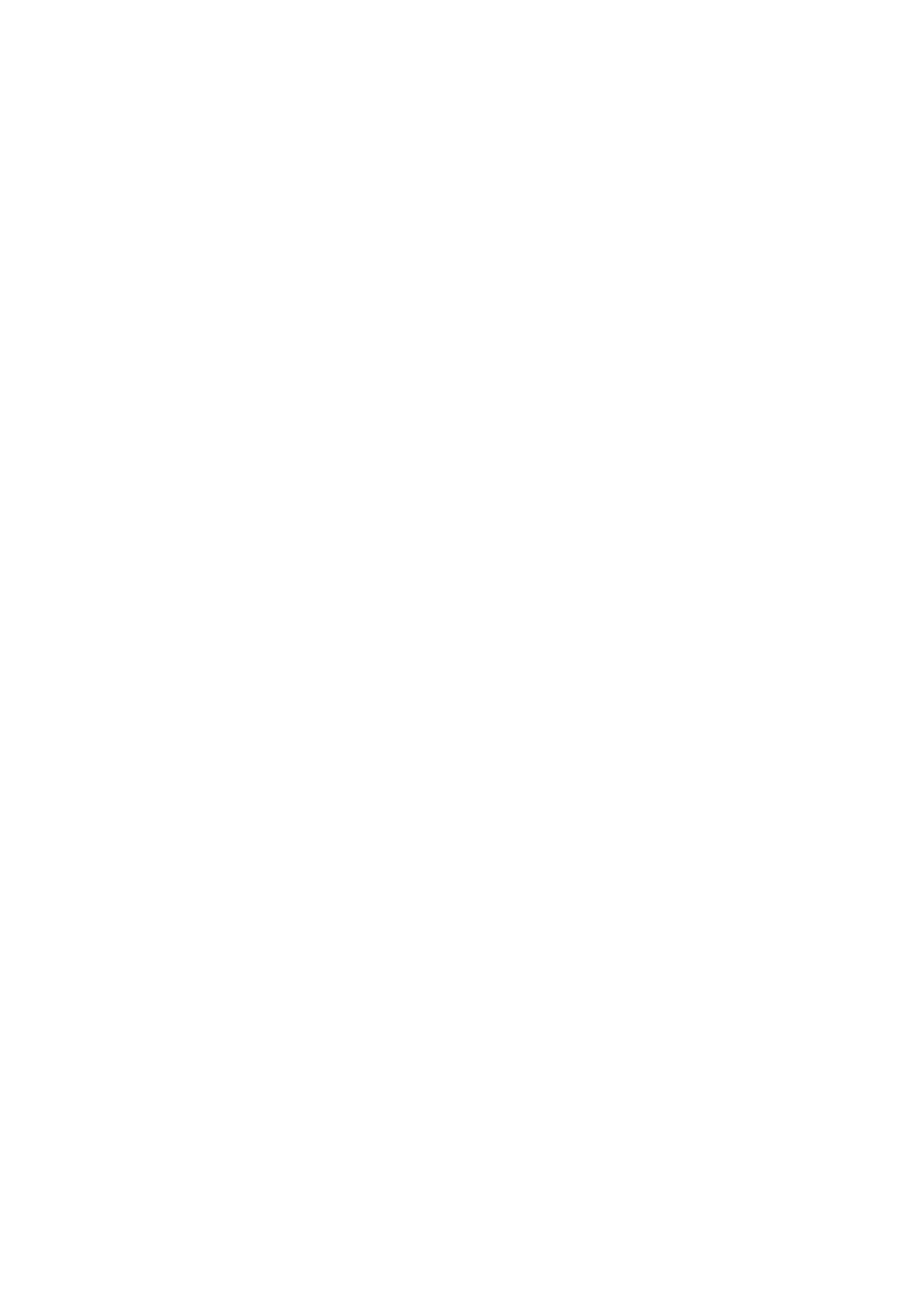




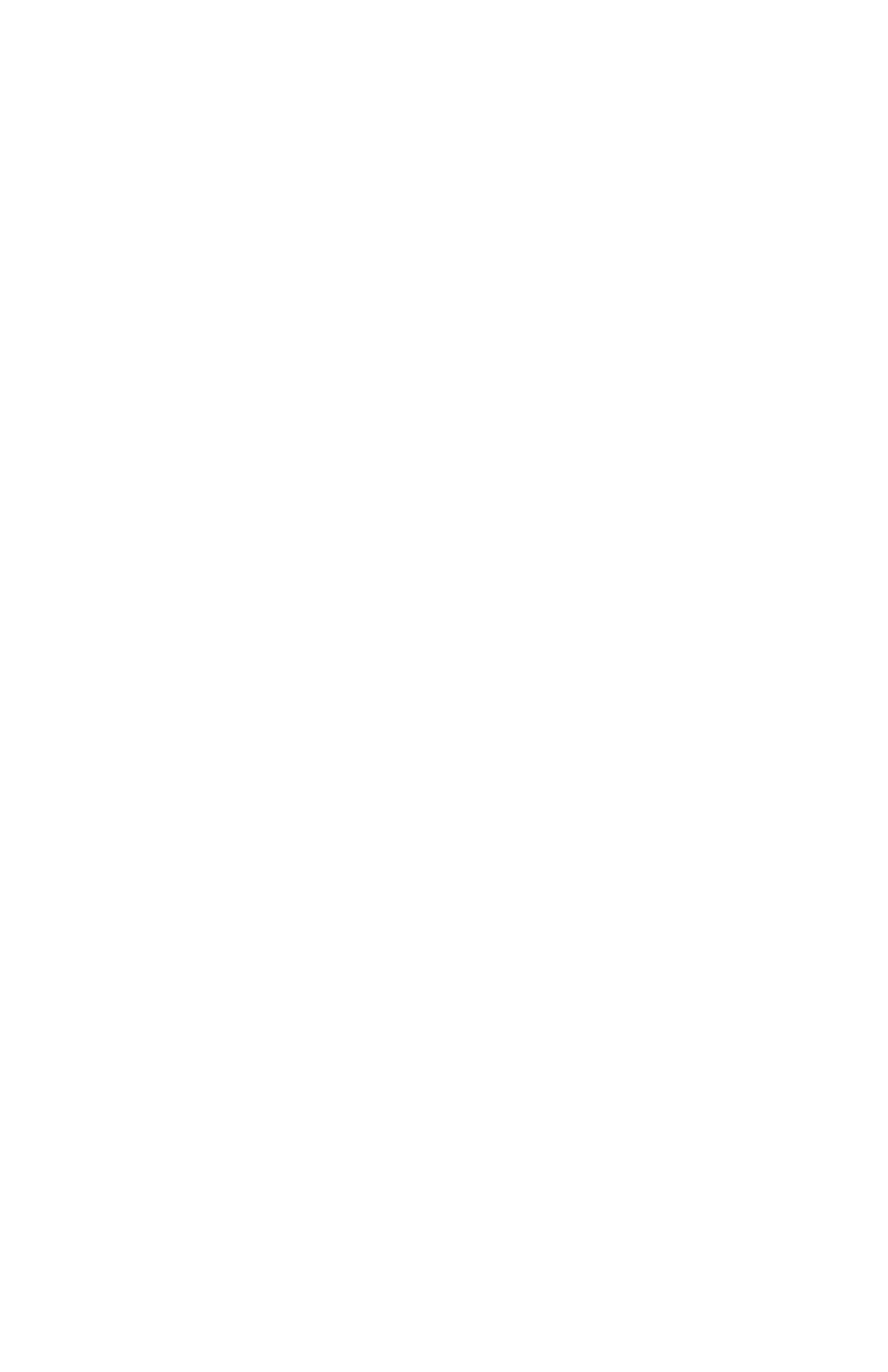




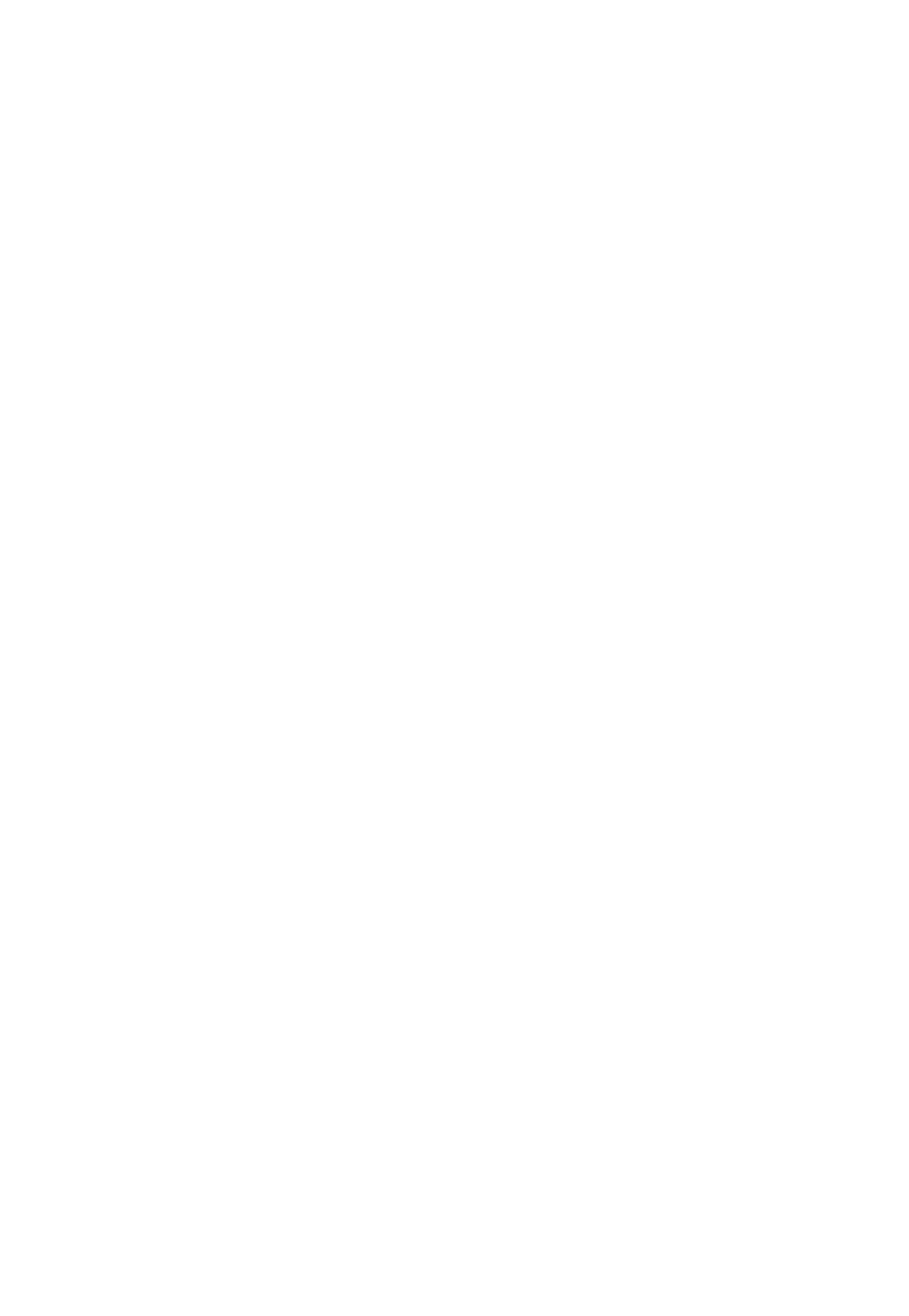




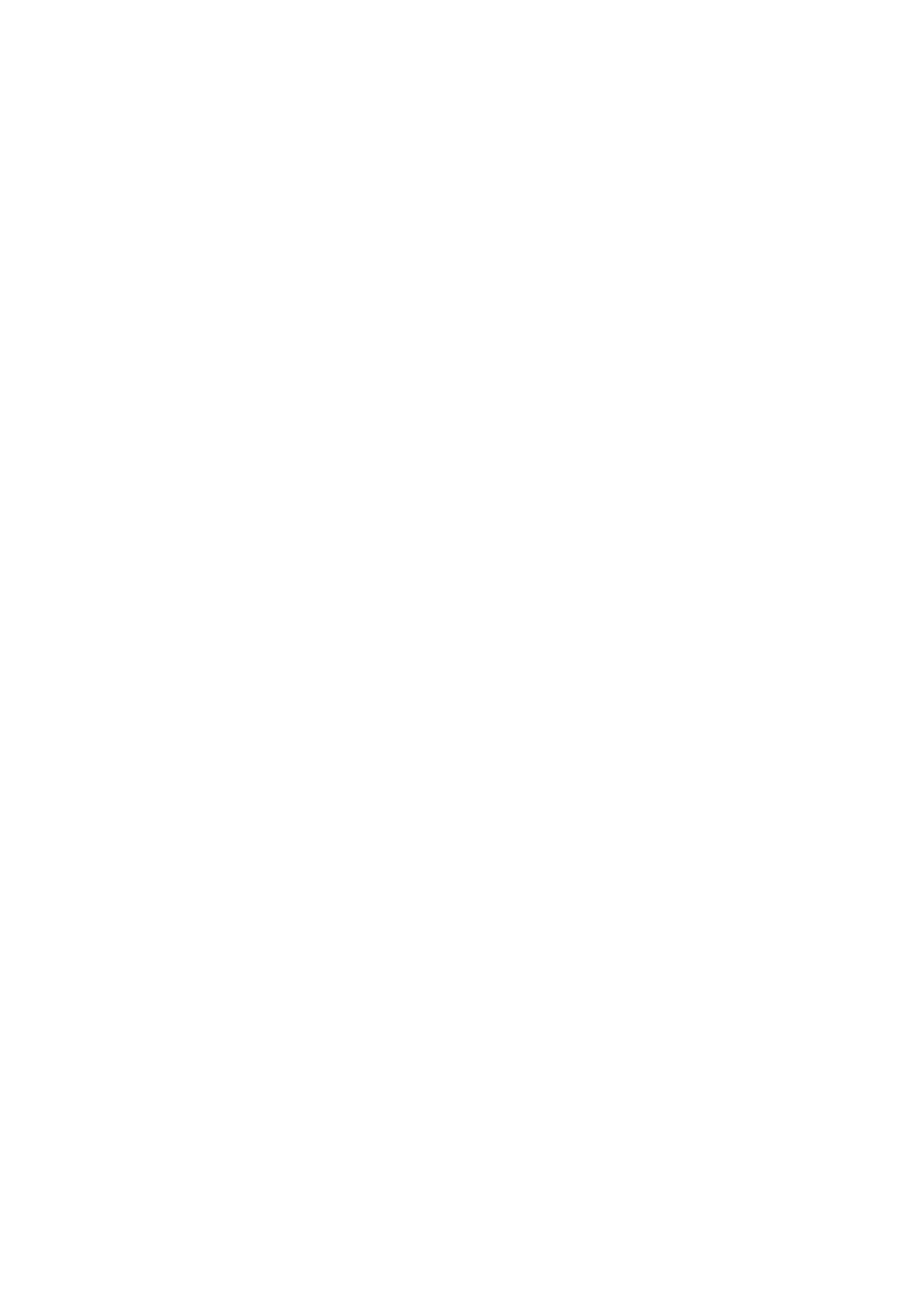




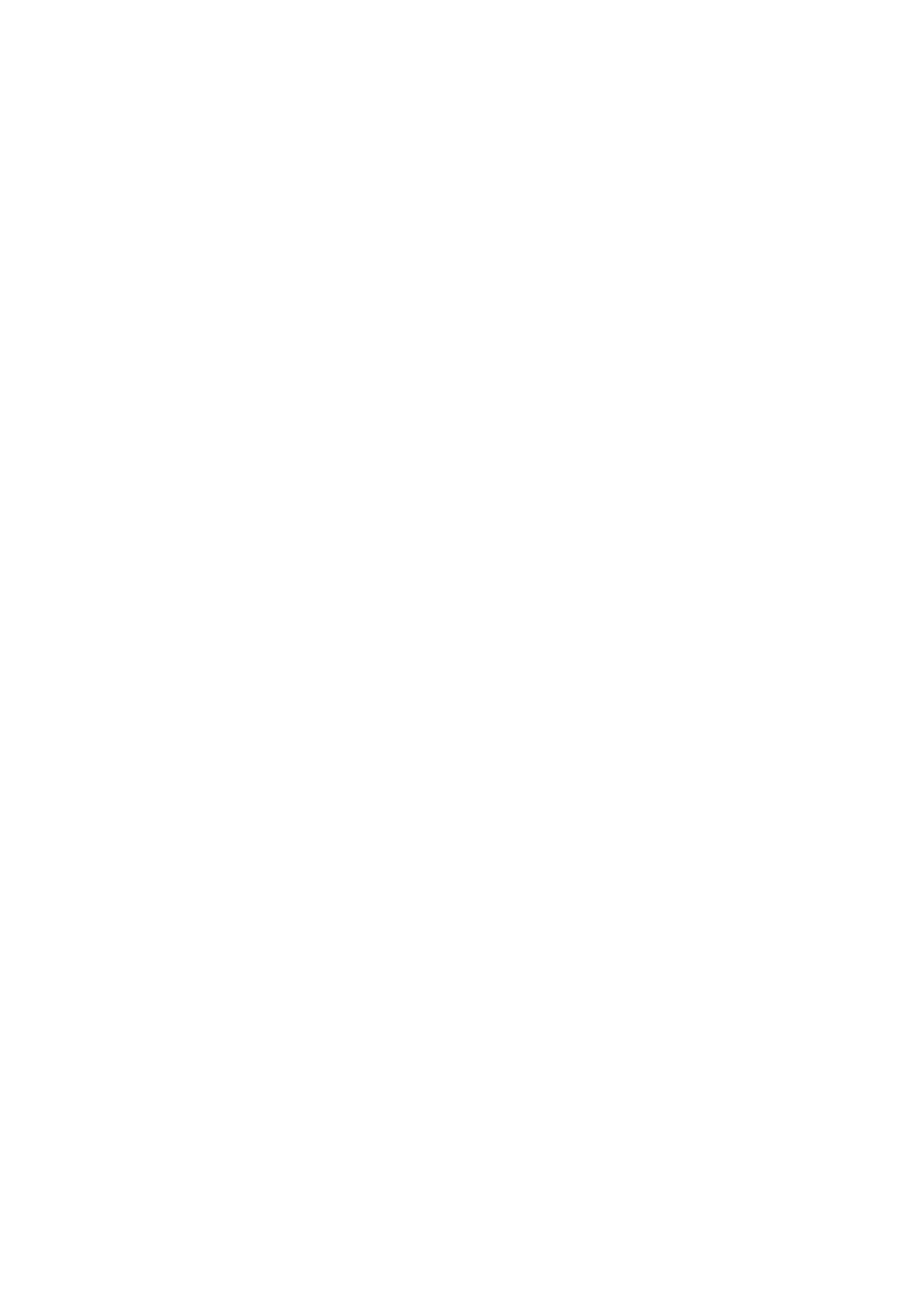




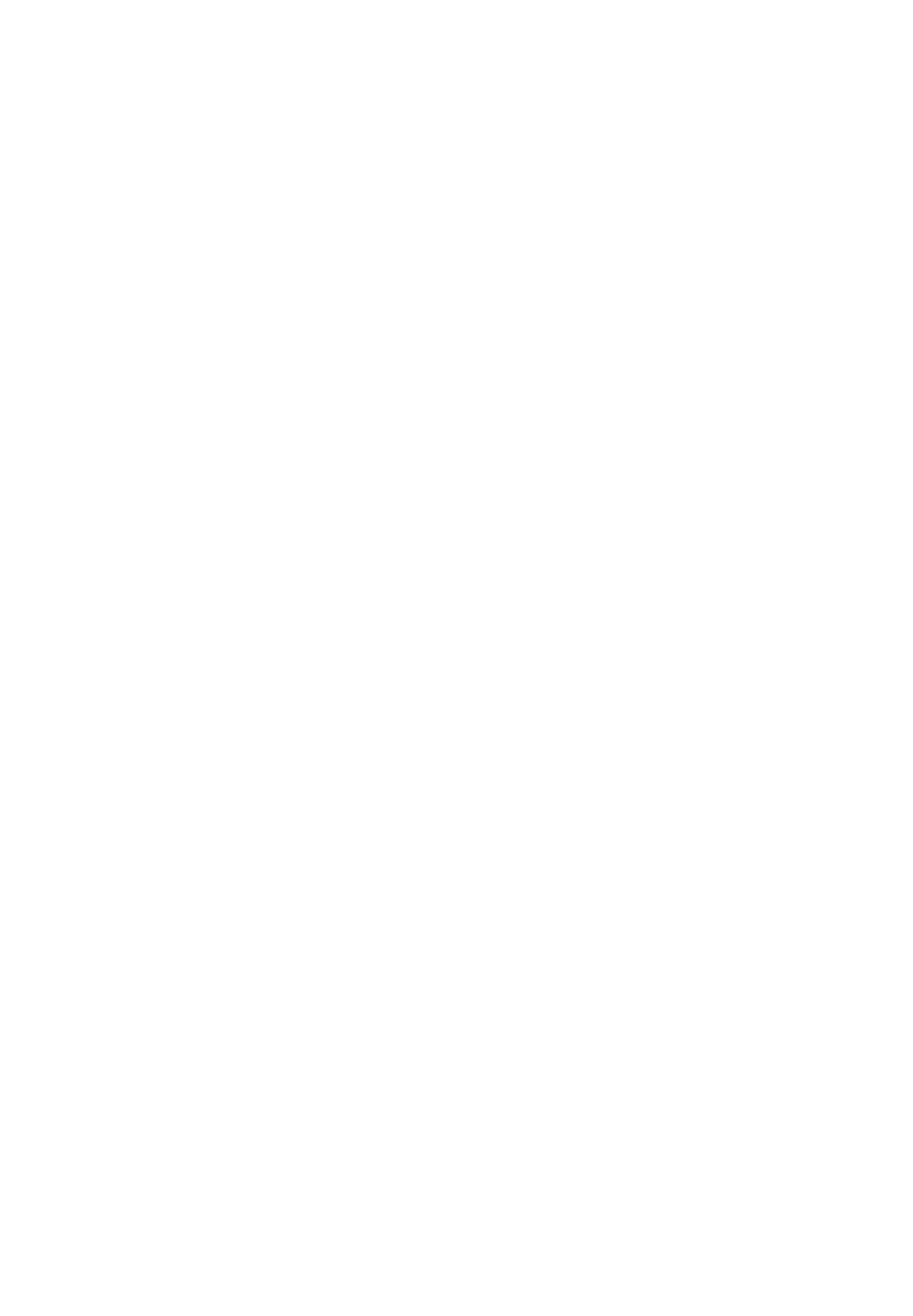




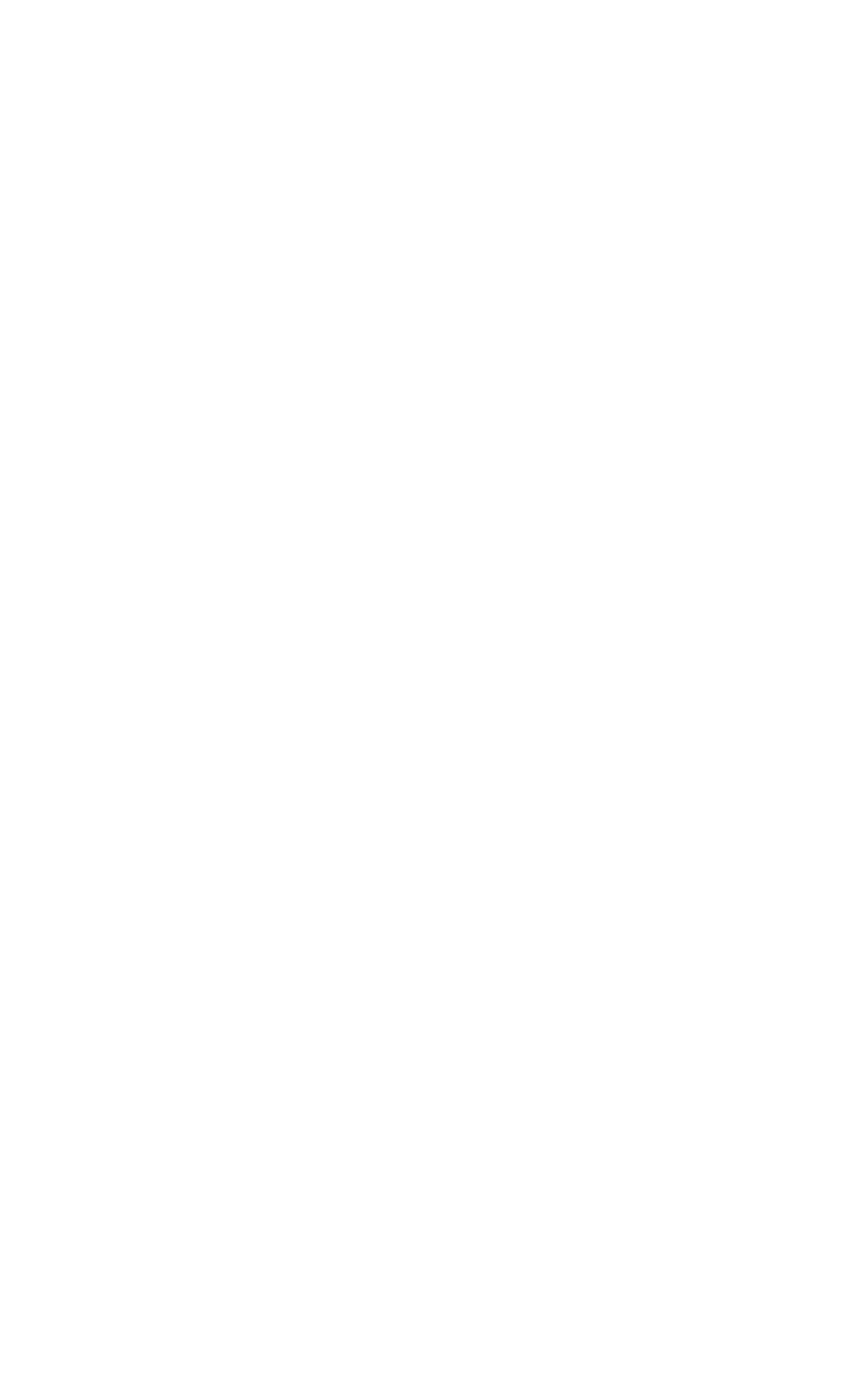




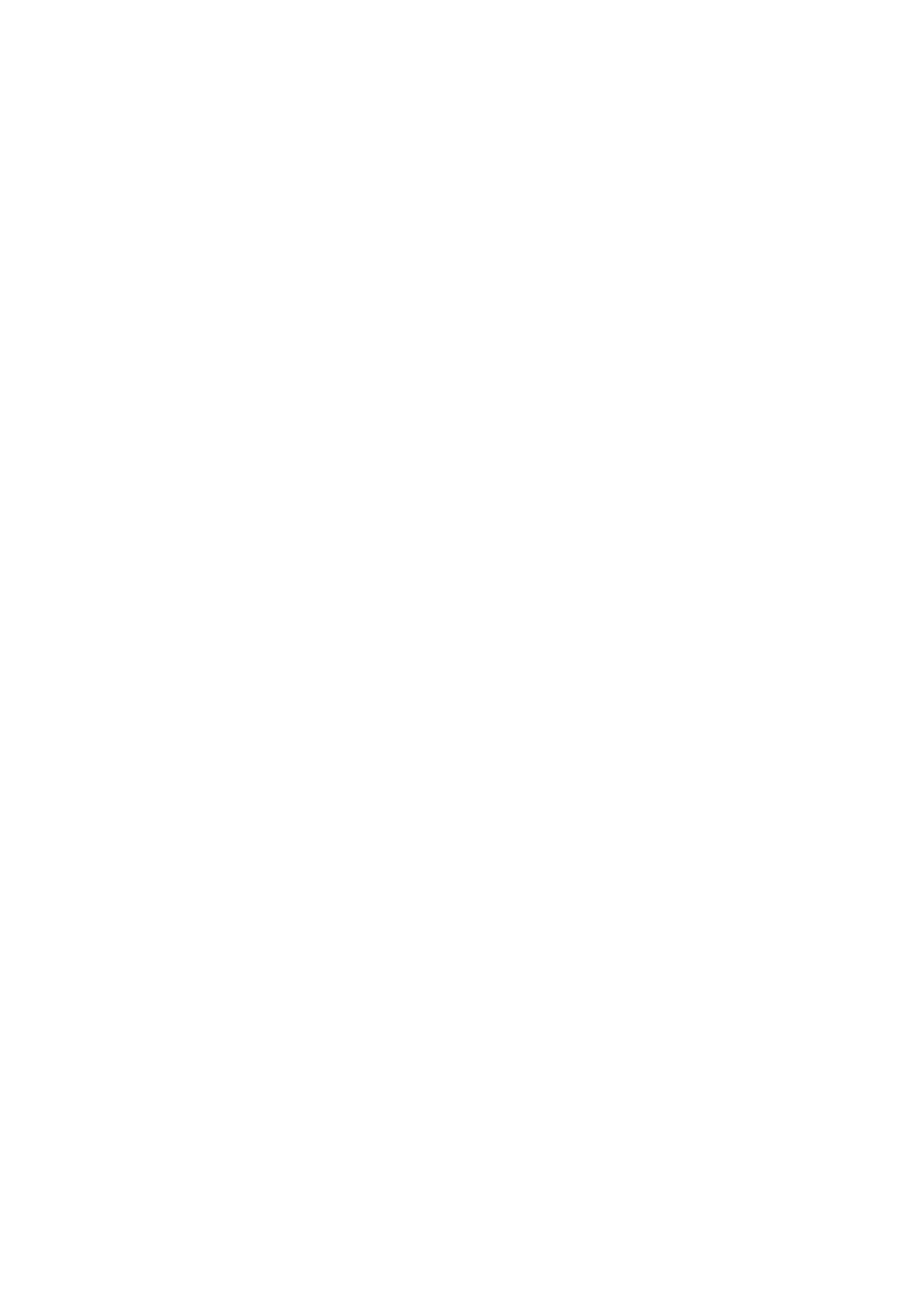




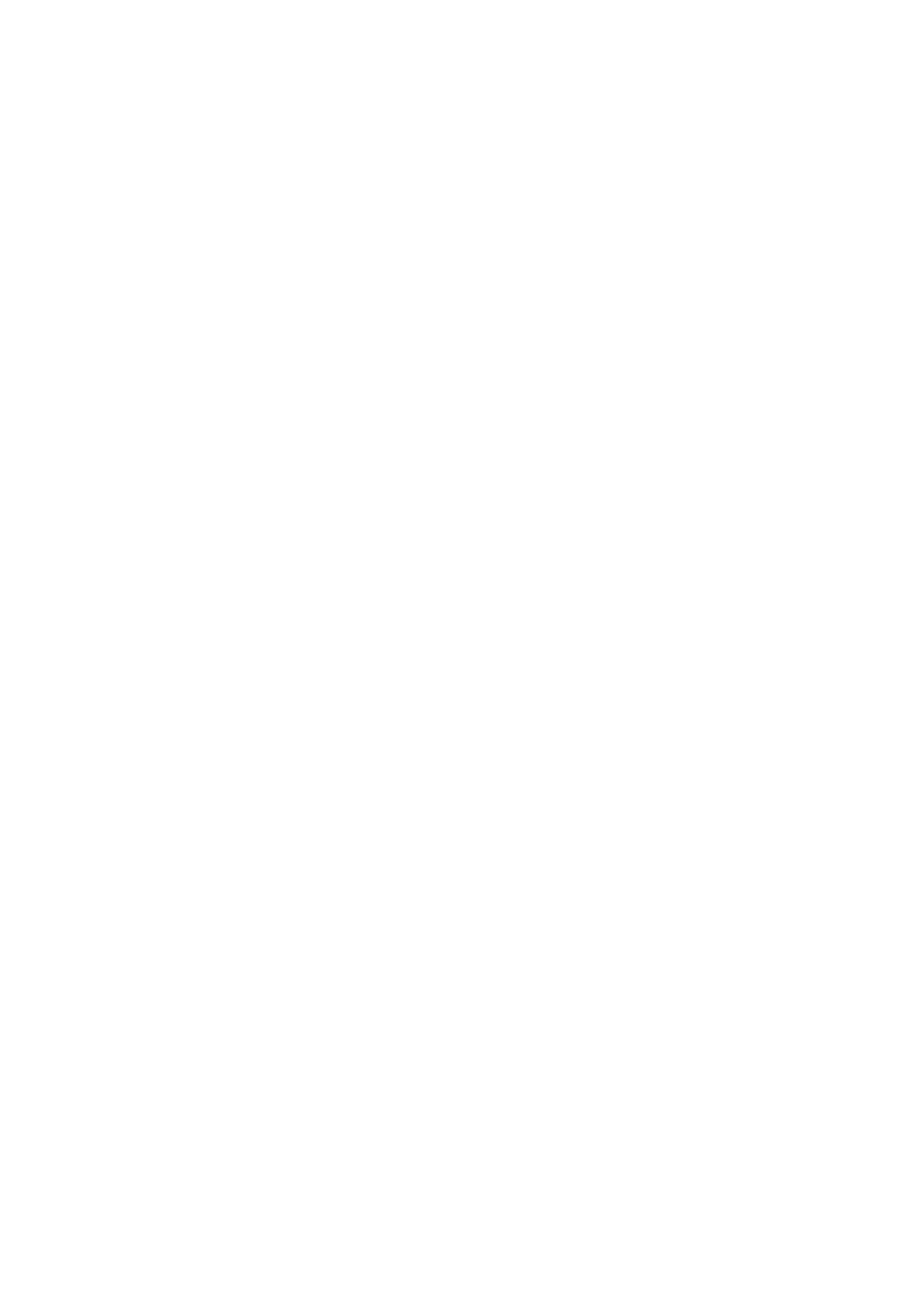




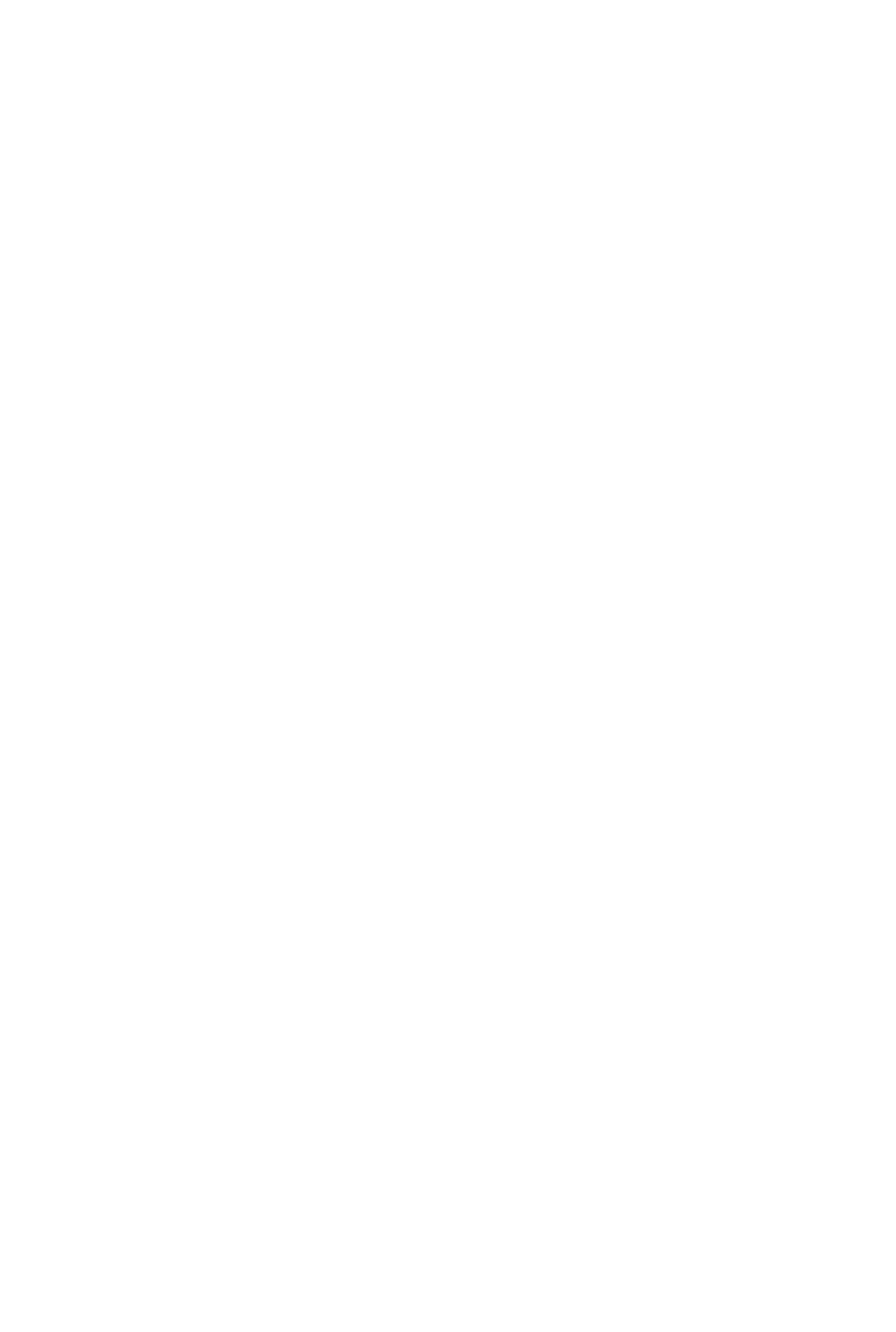




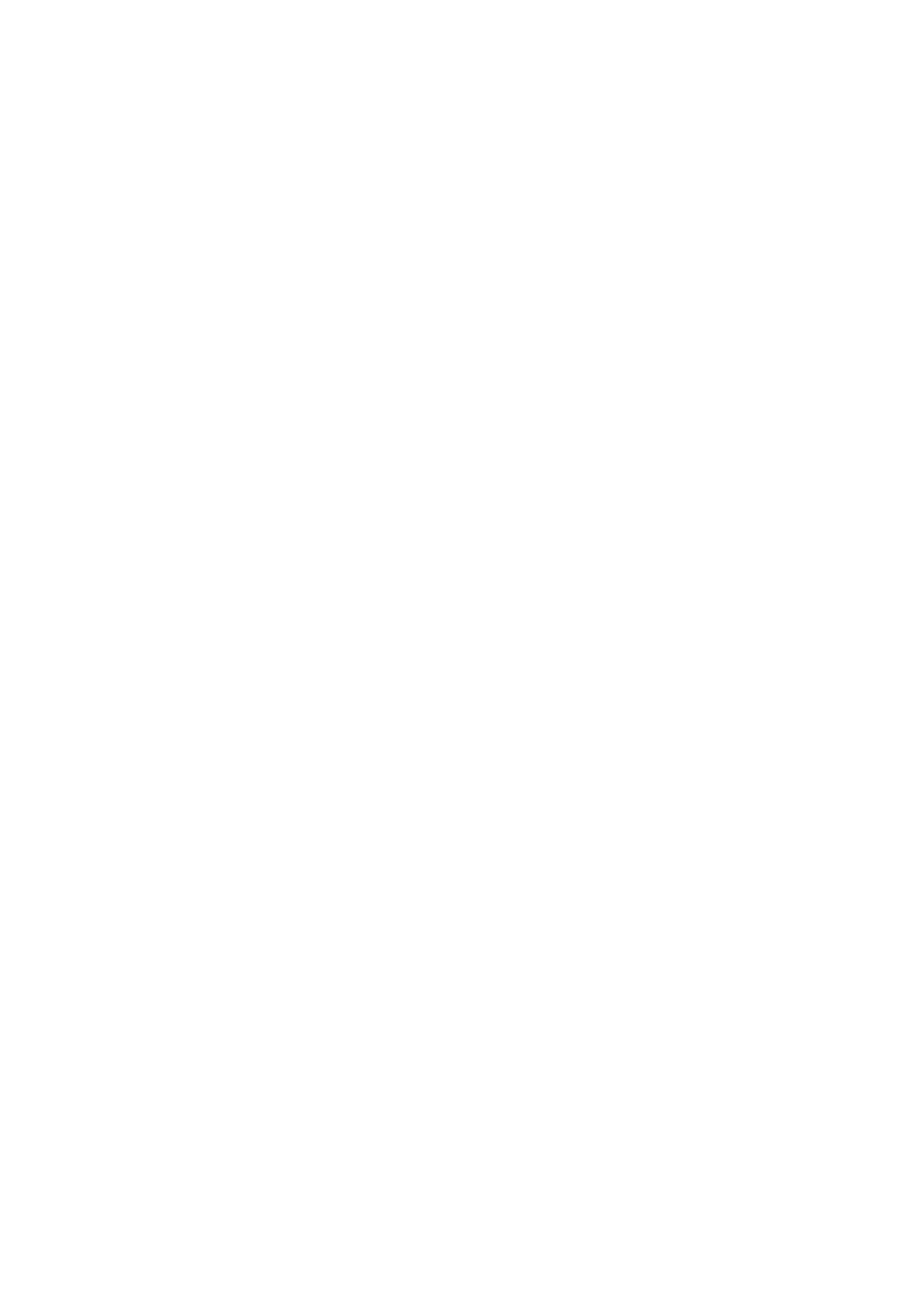




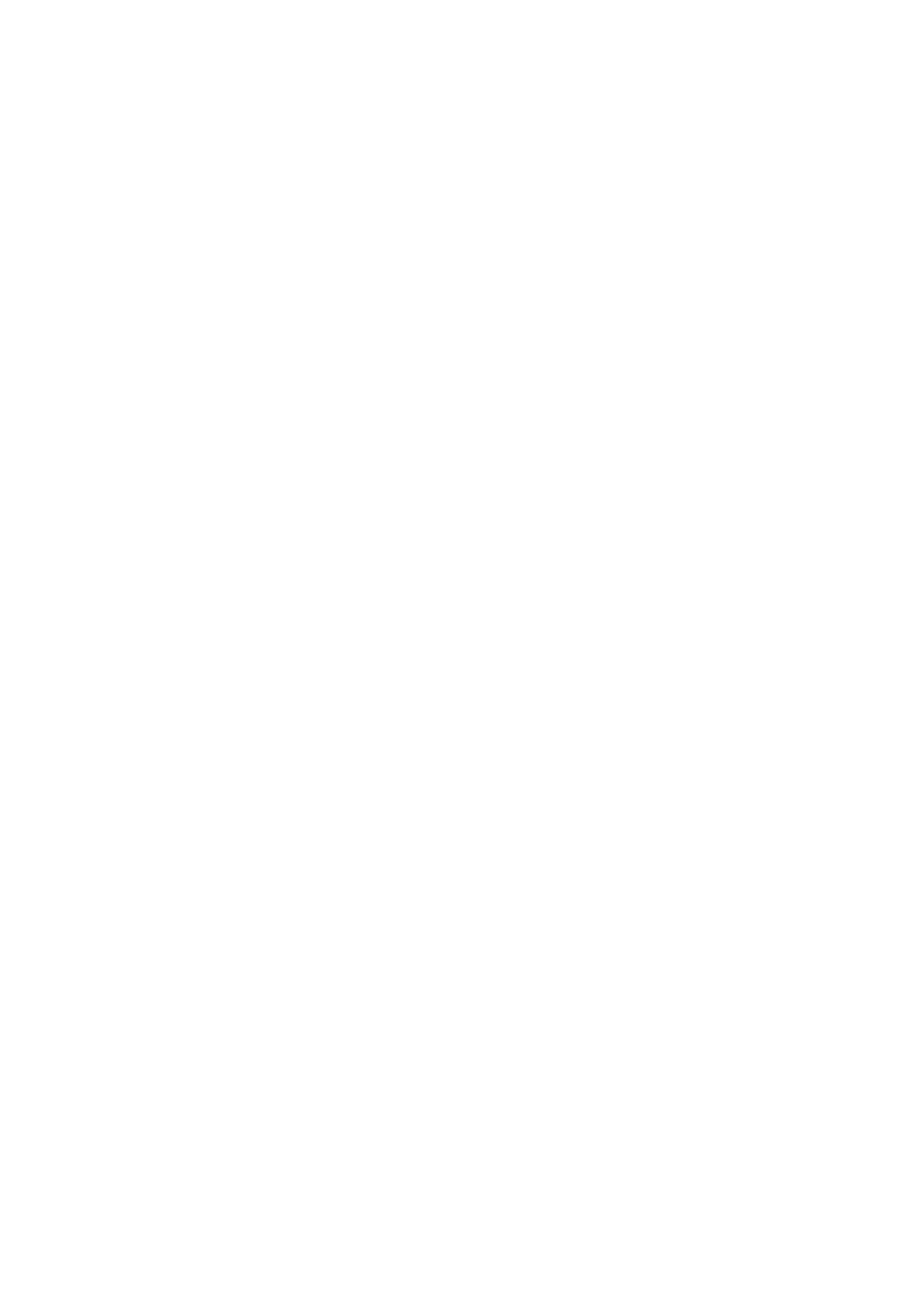




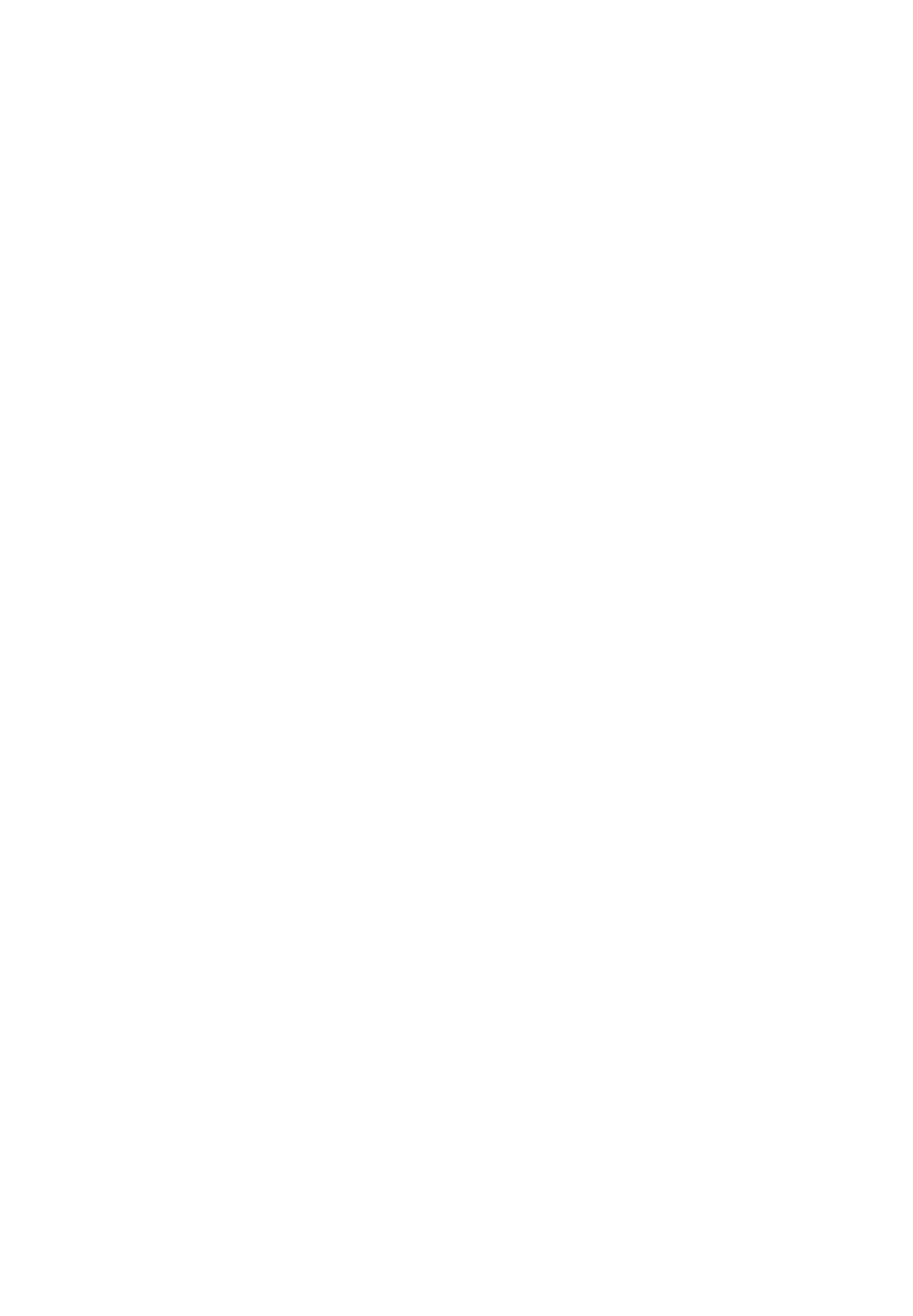




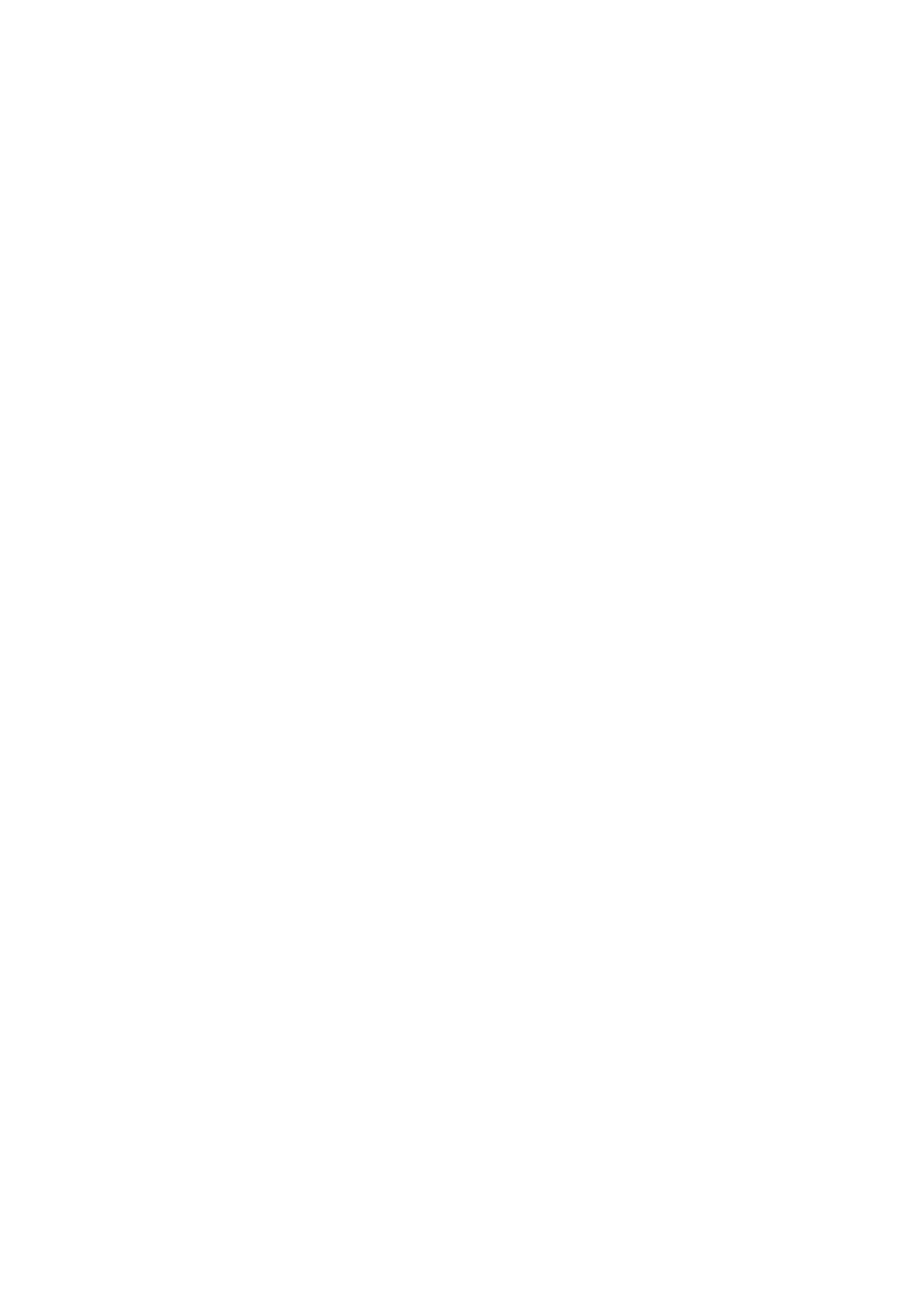




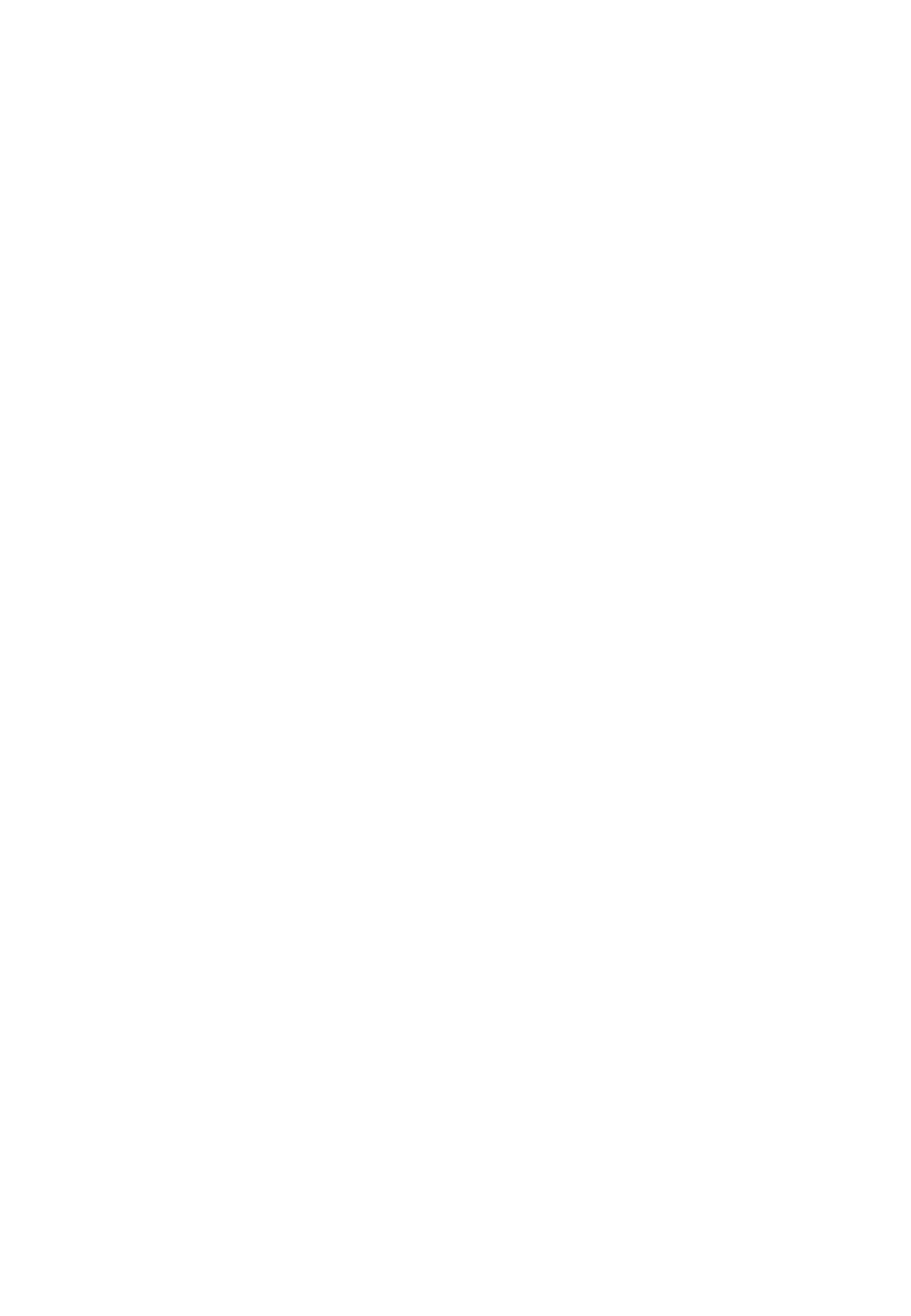




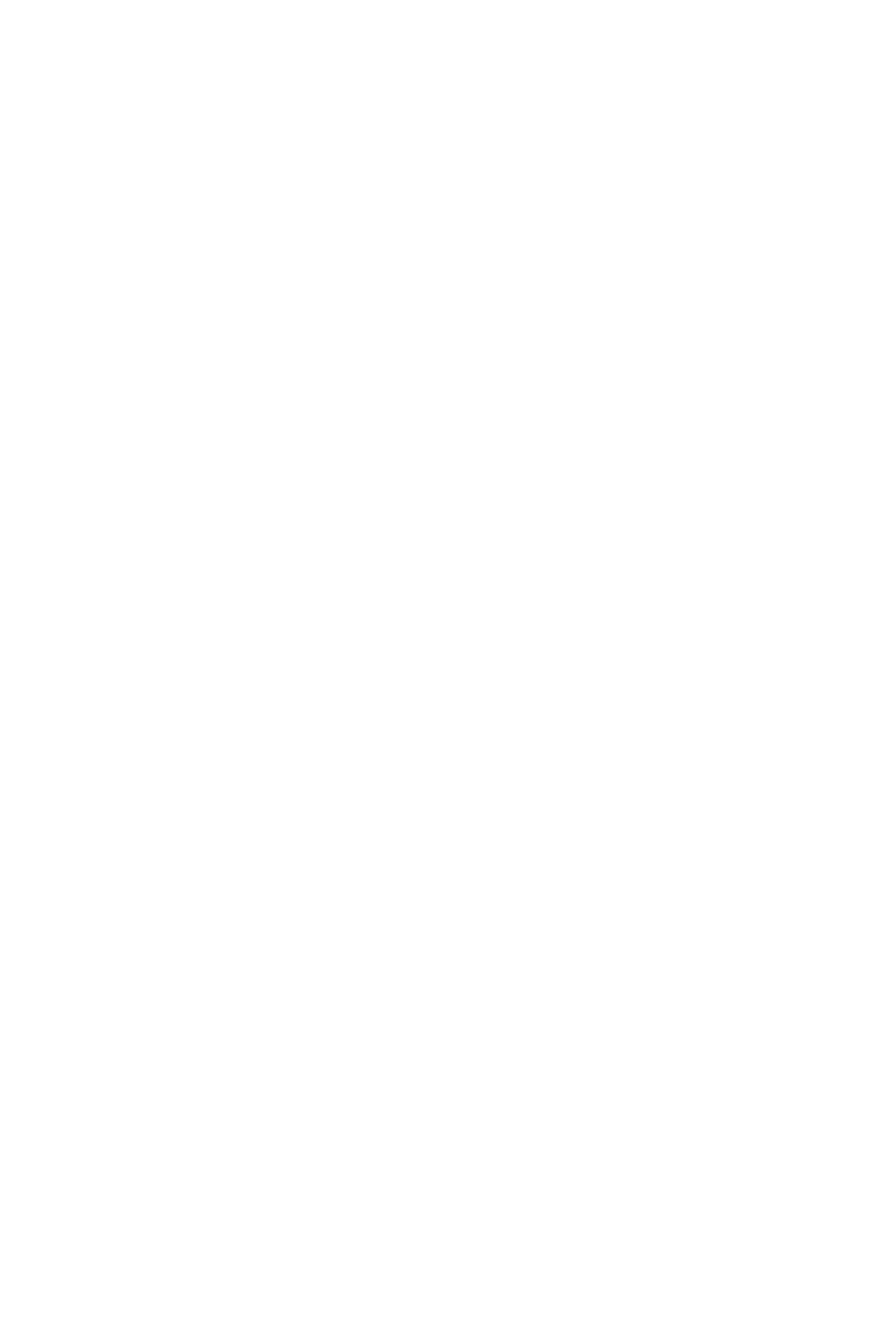

Tables 33 


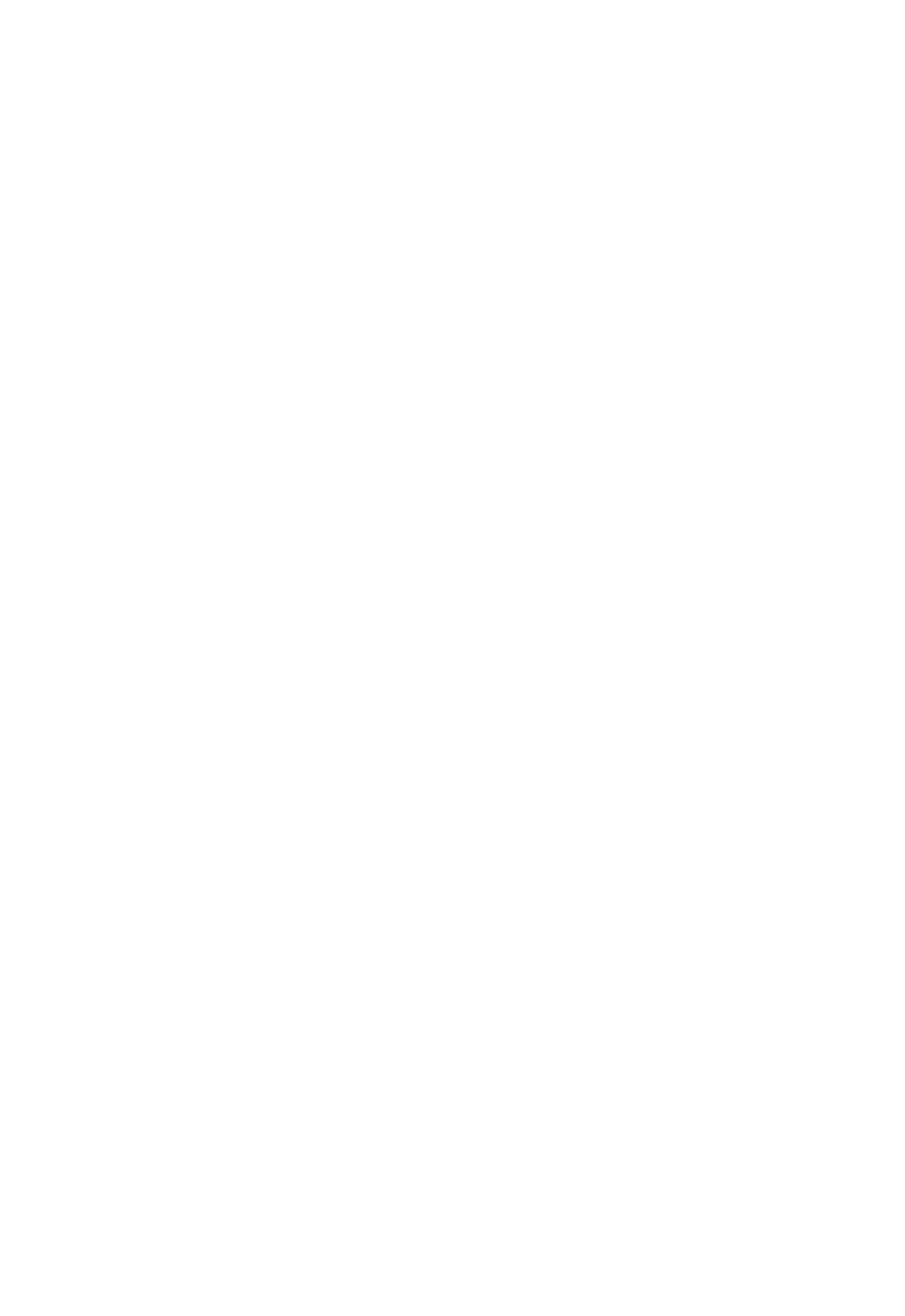




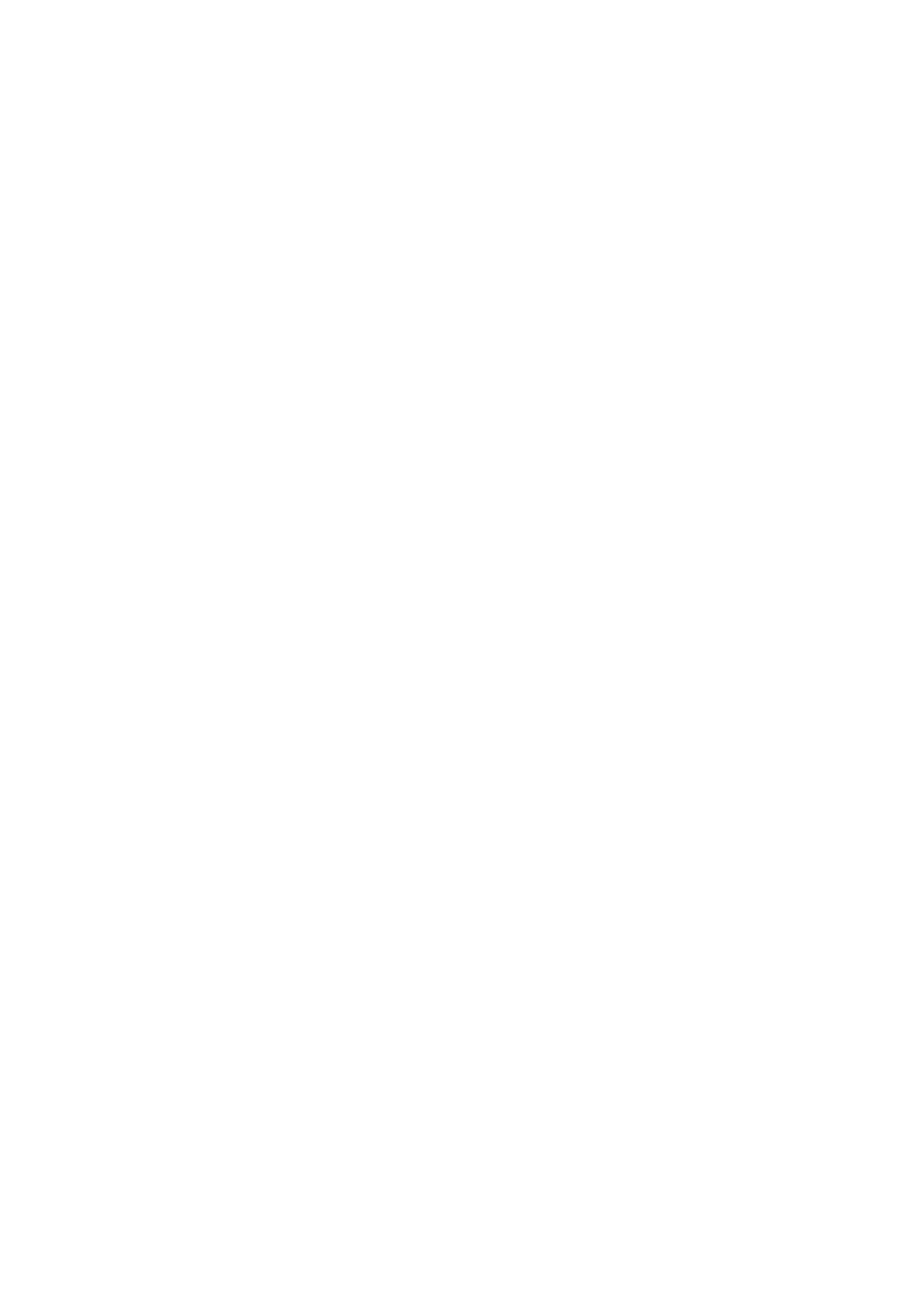




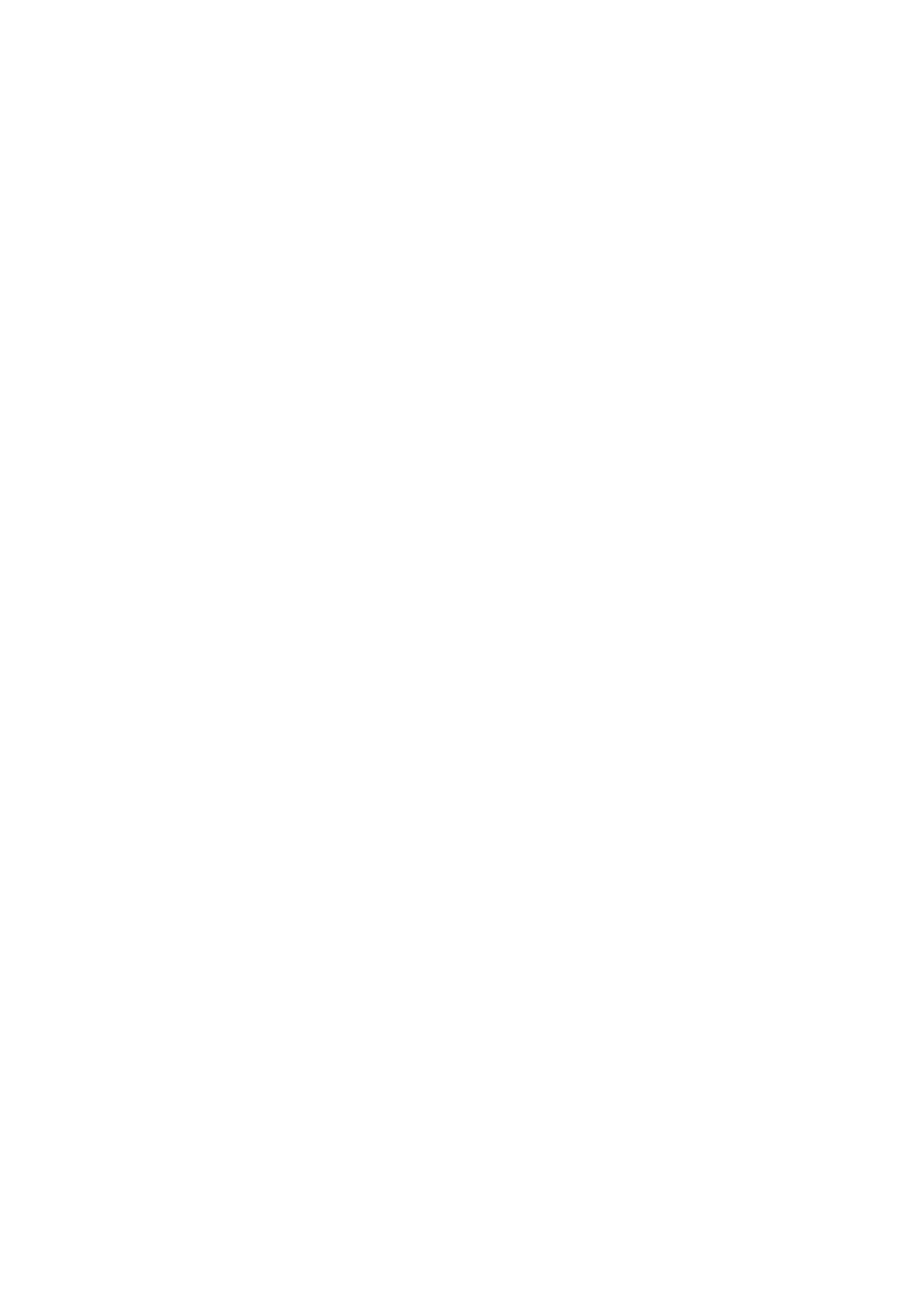




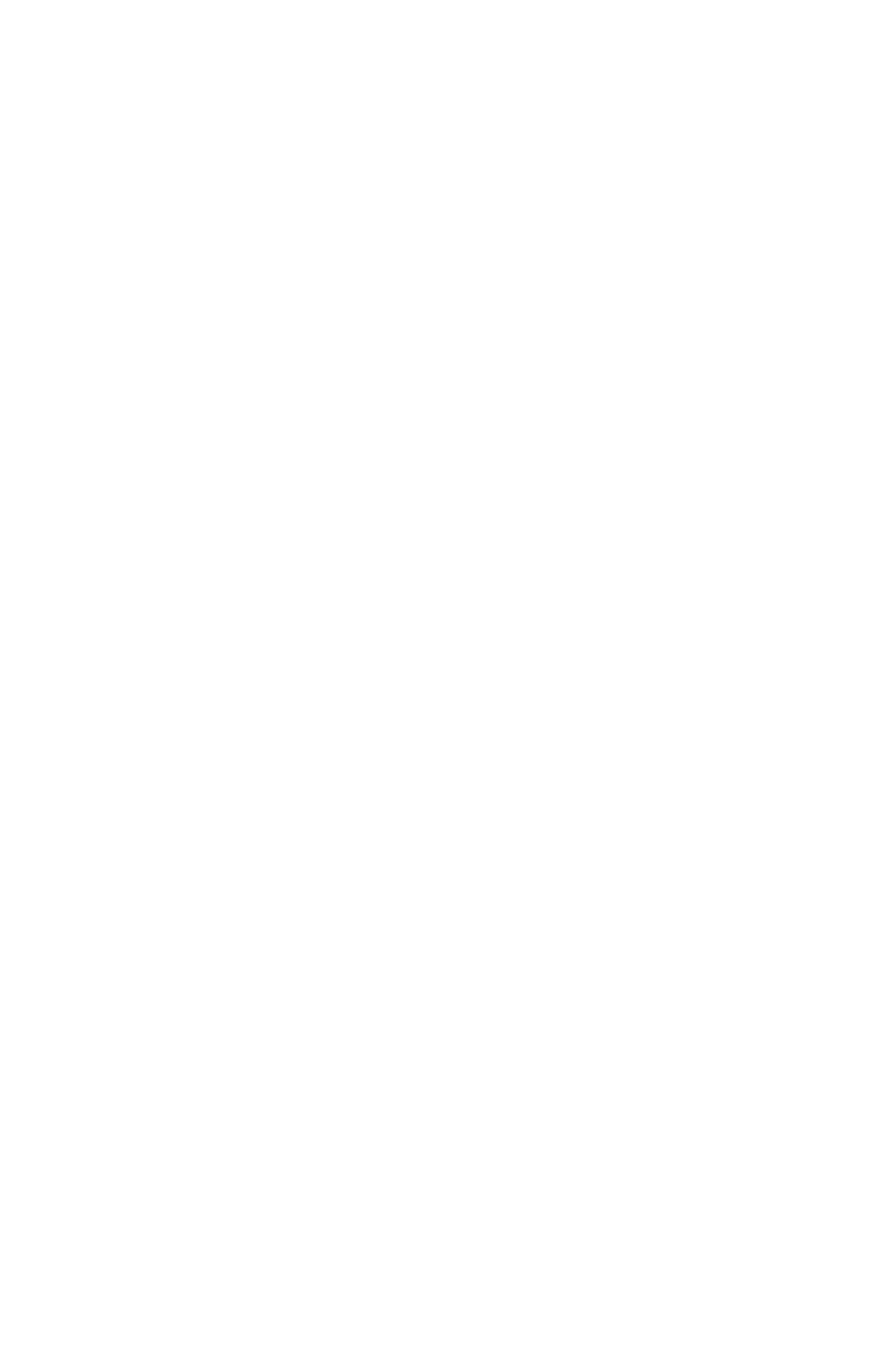




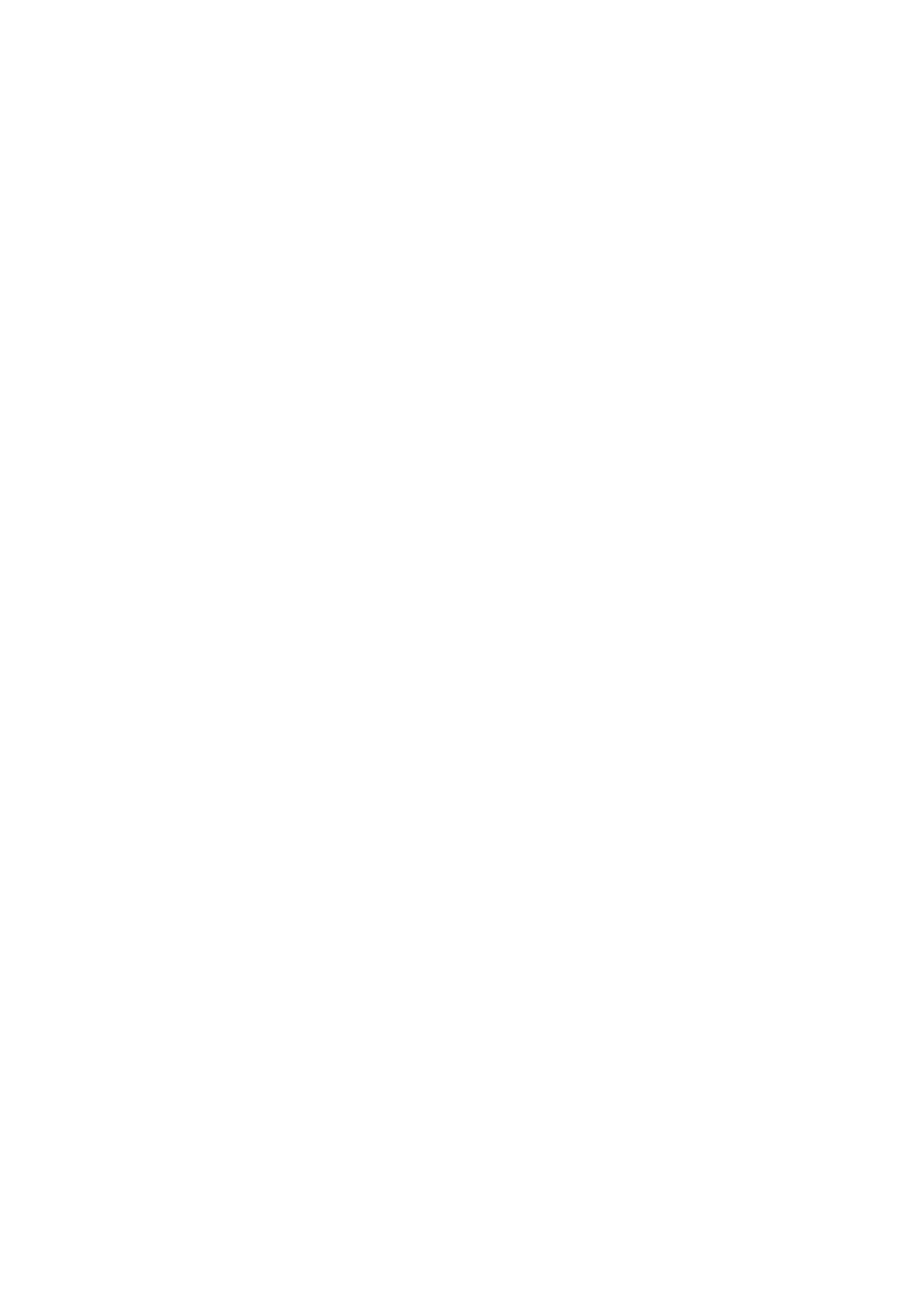




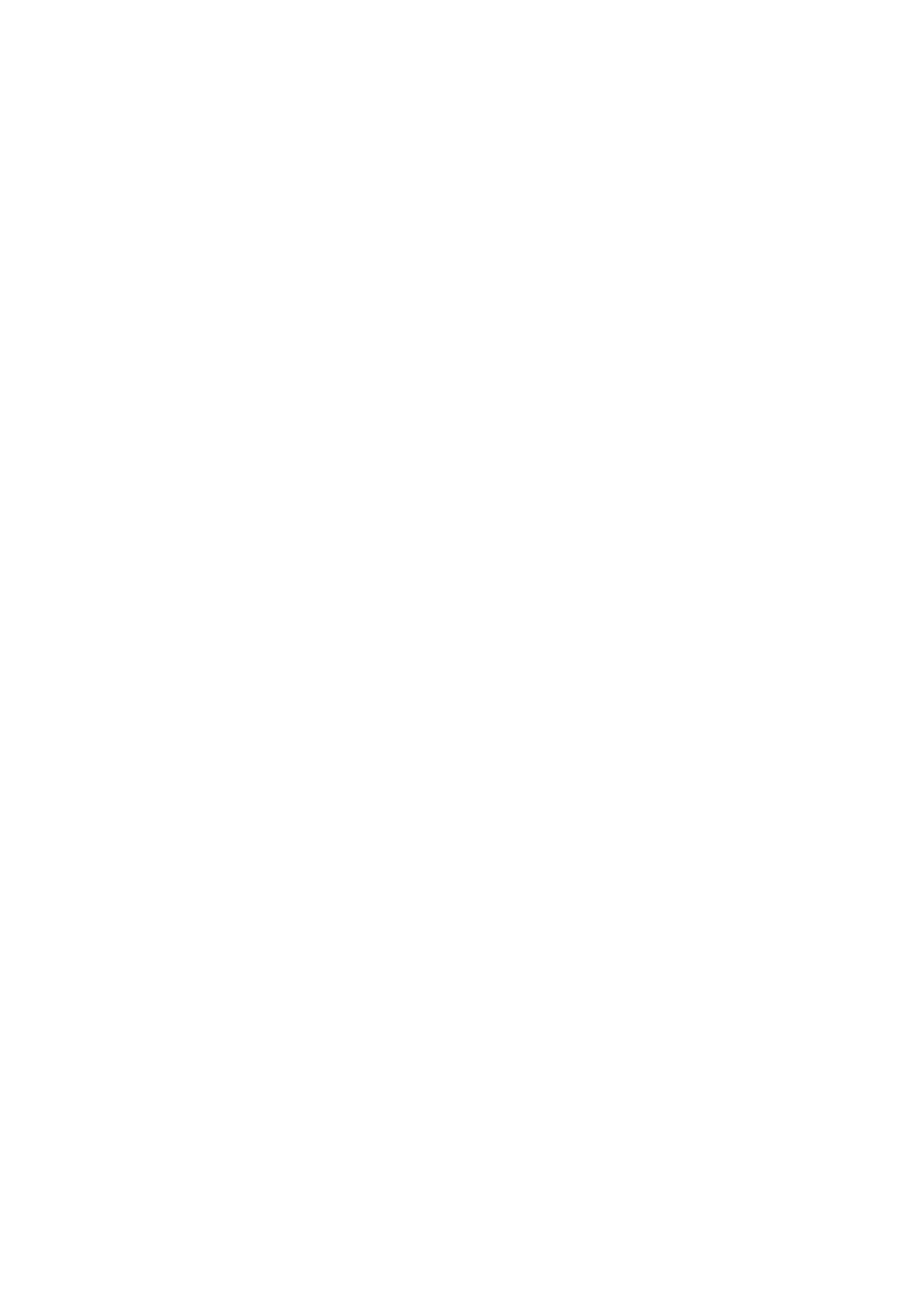




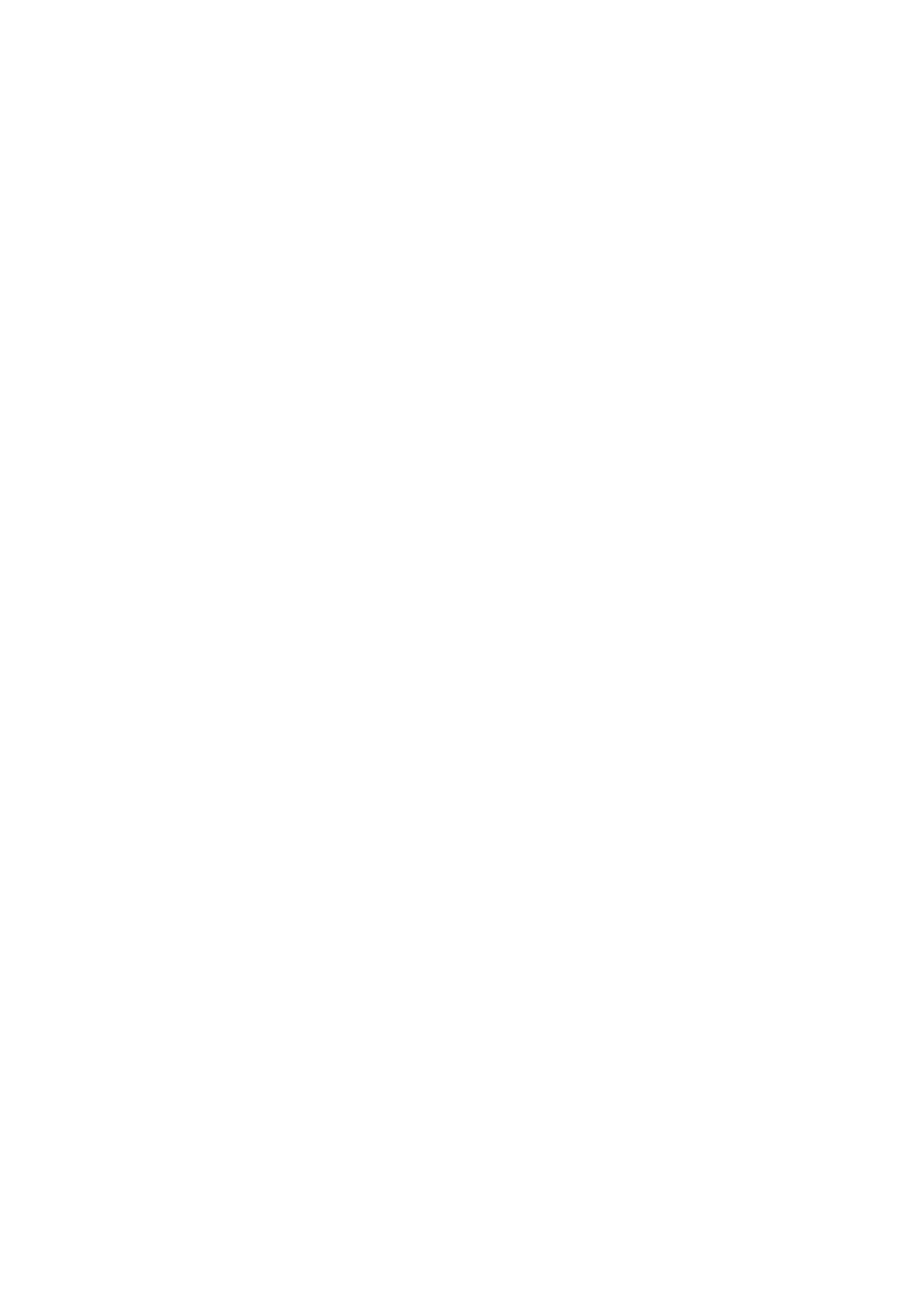




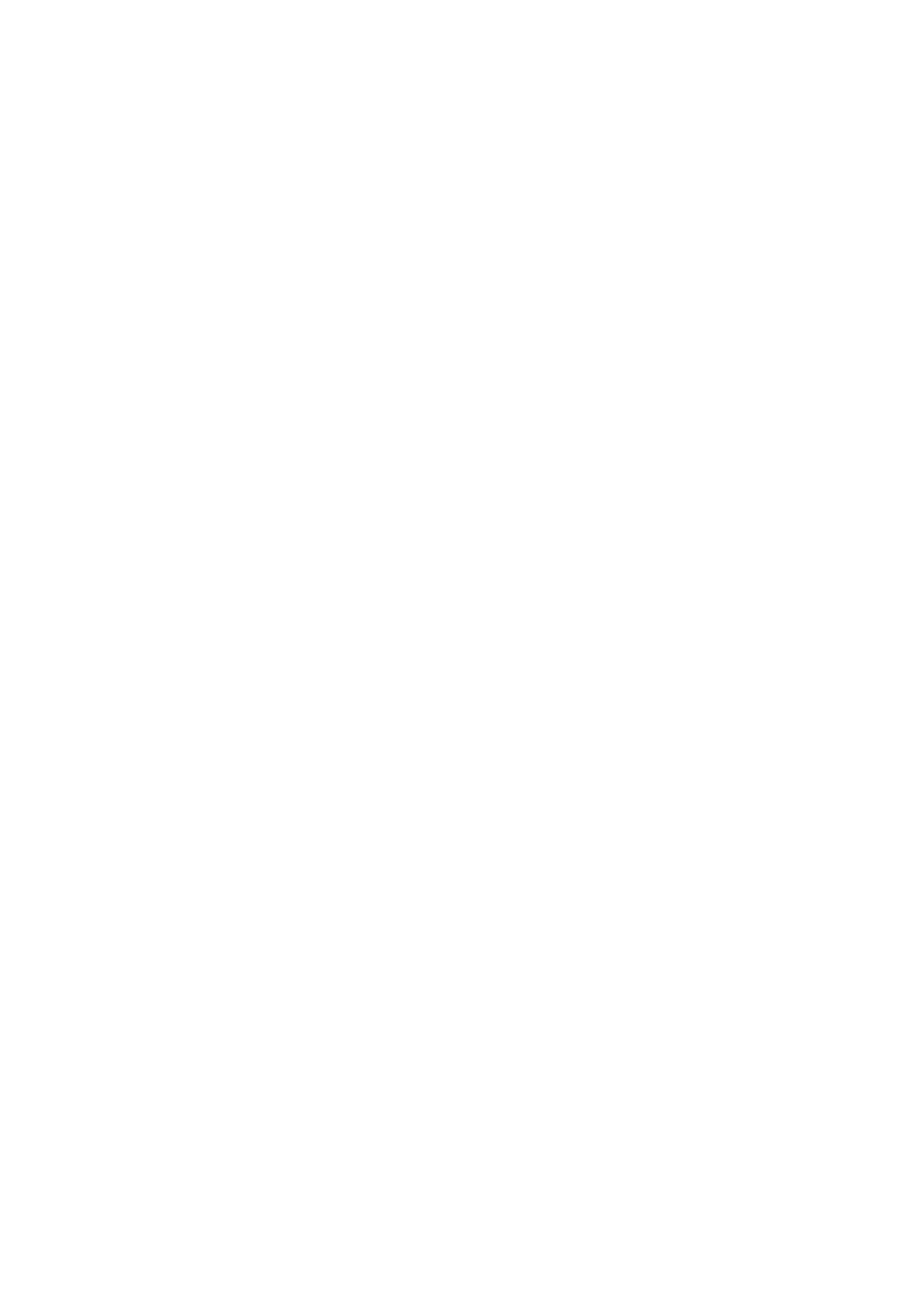




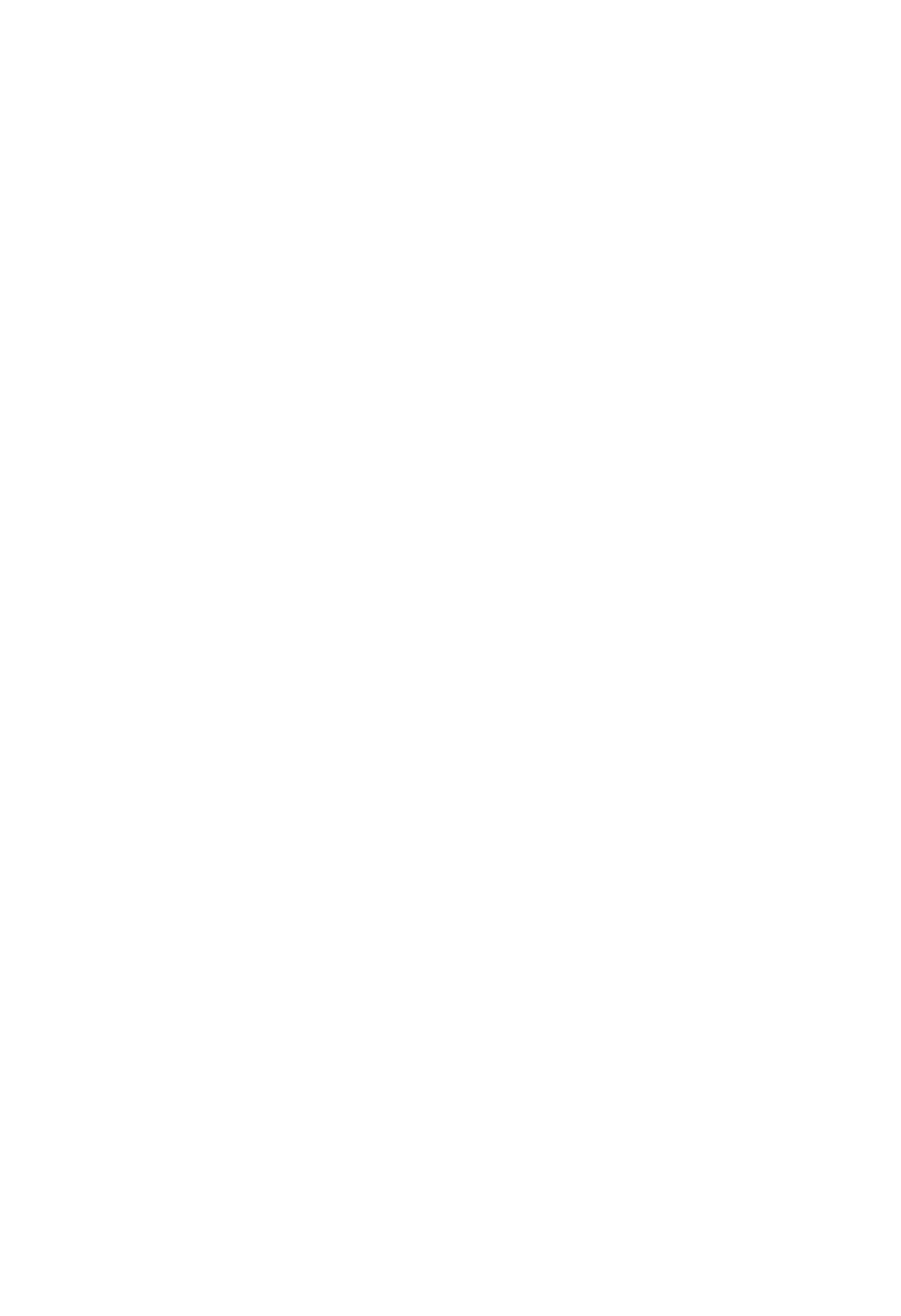




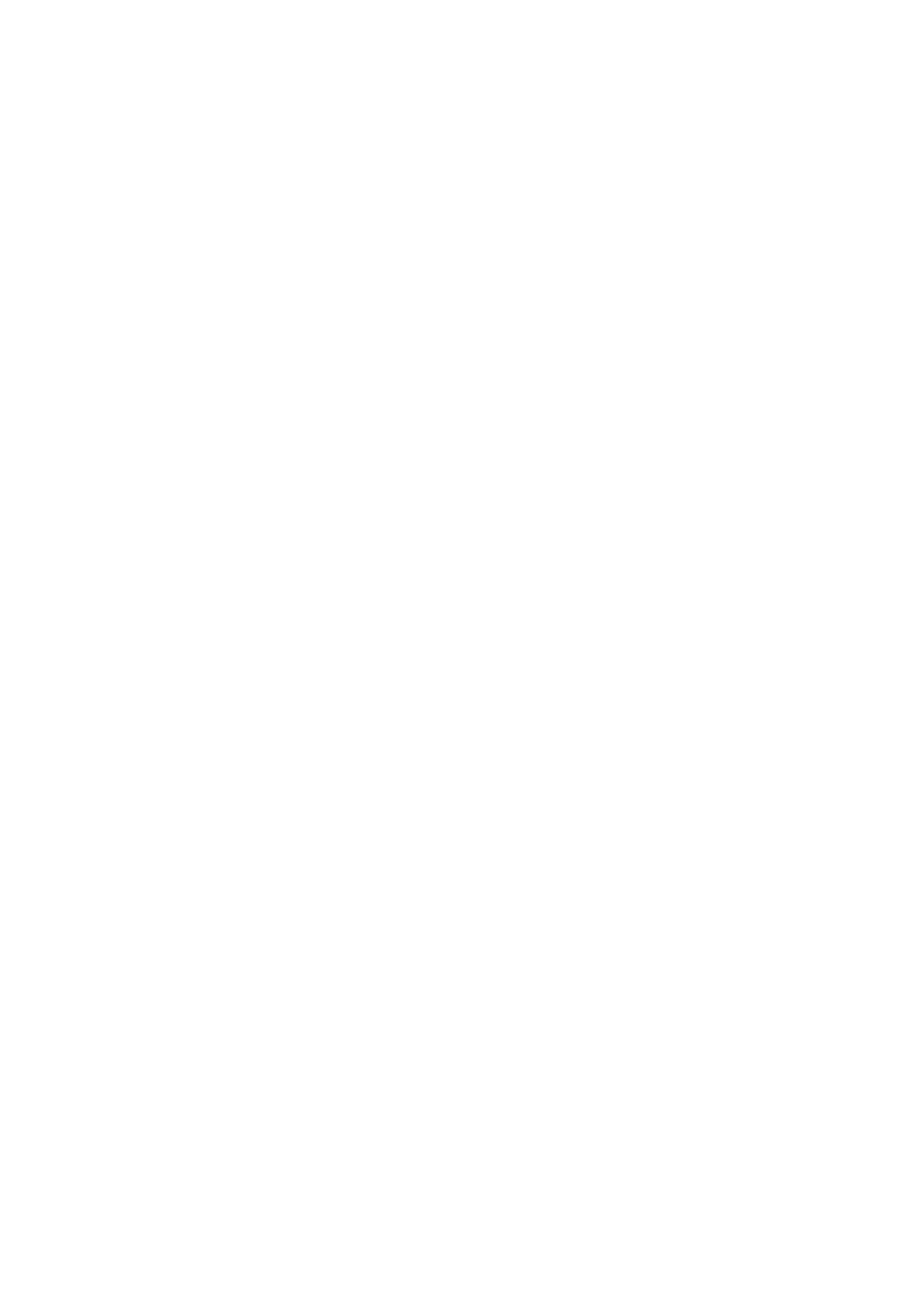




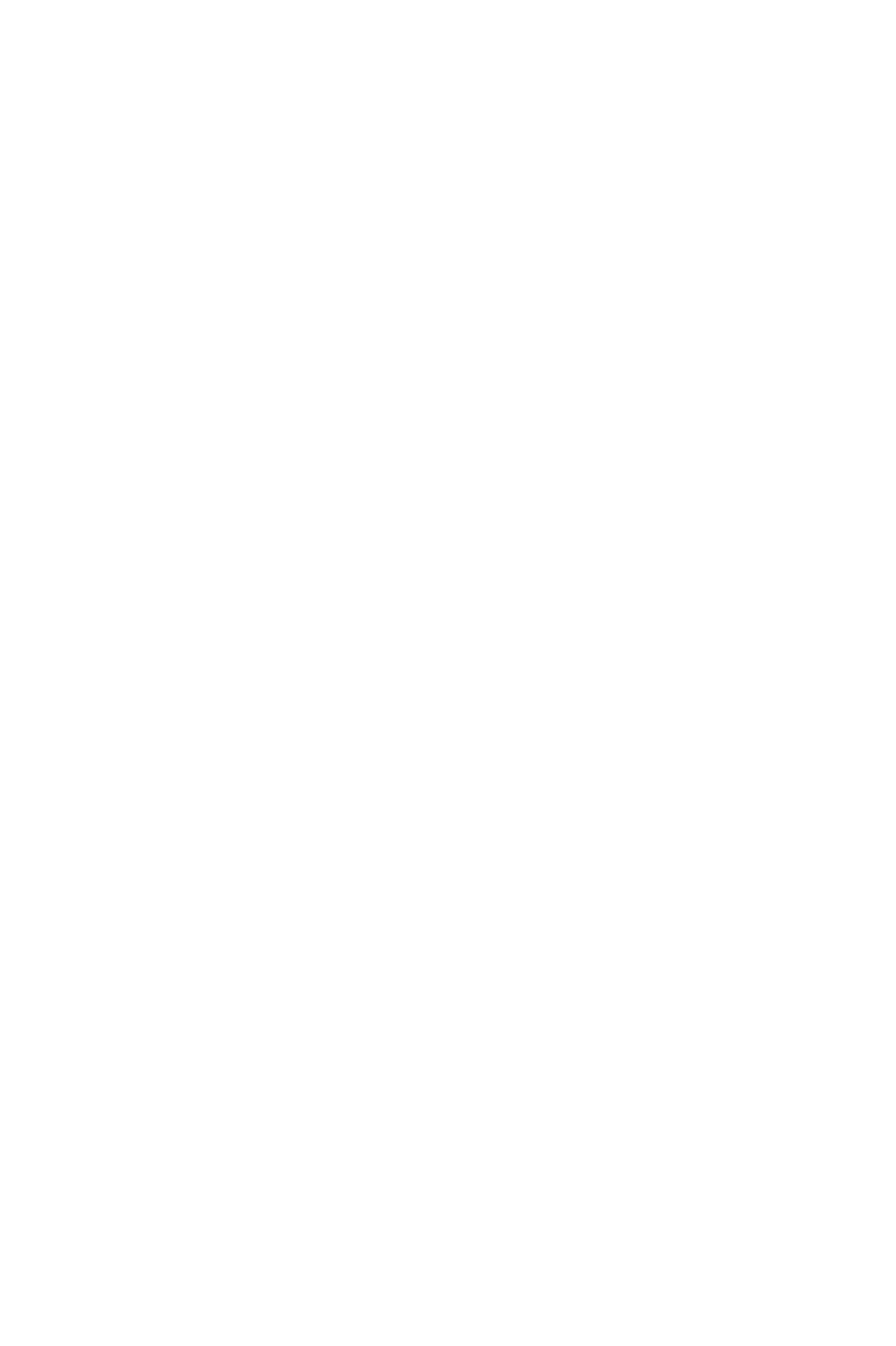




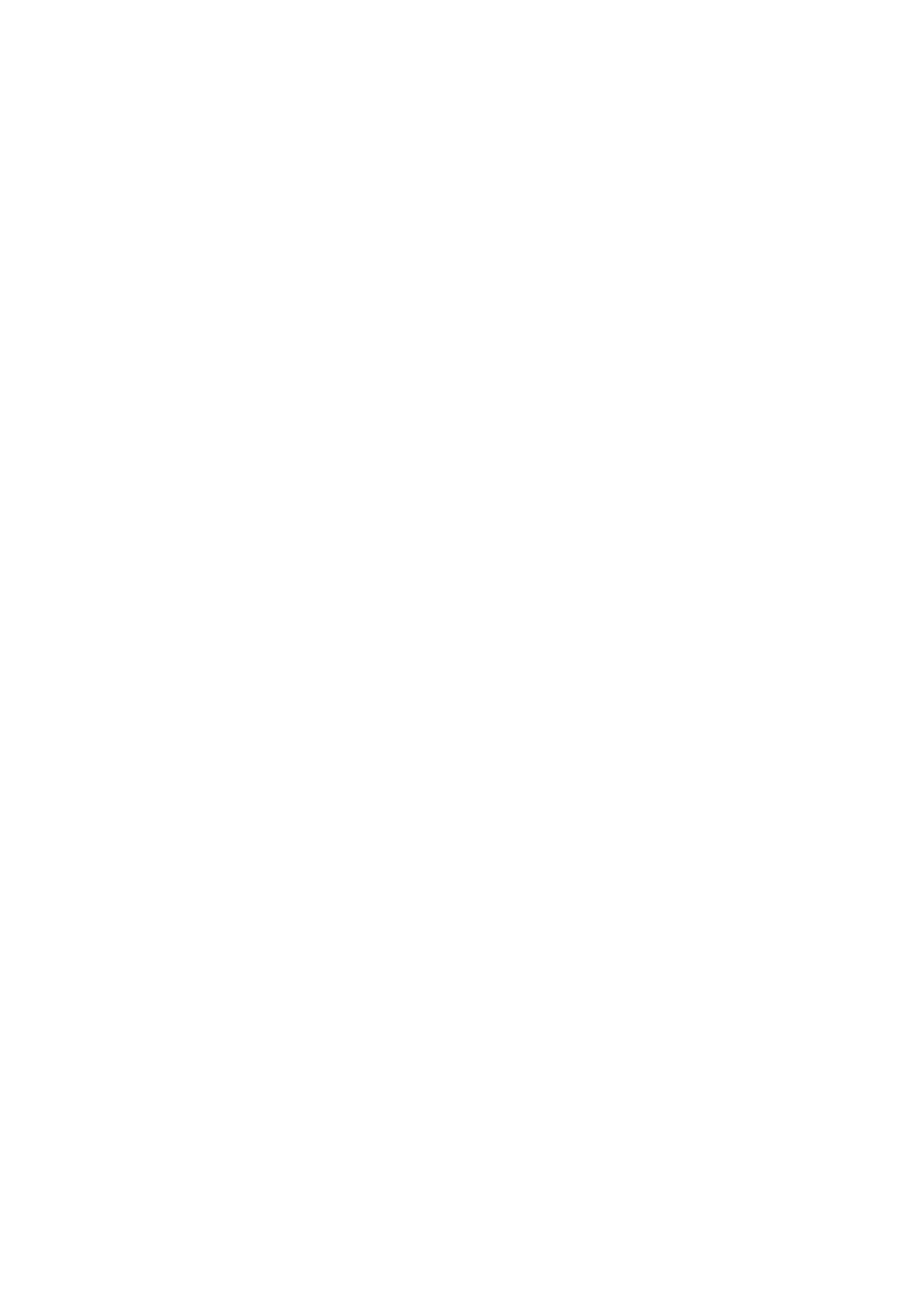




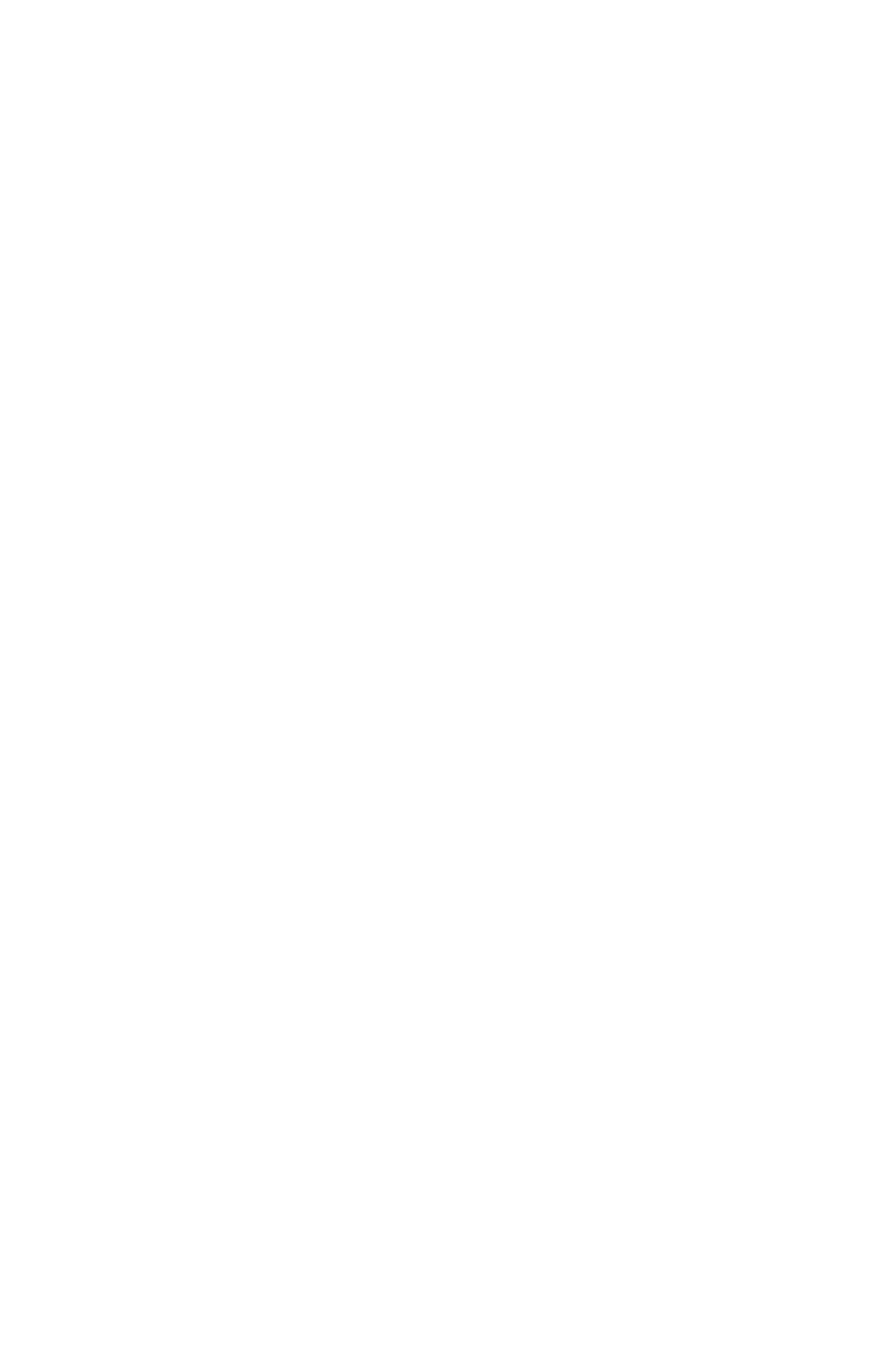




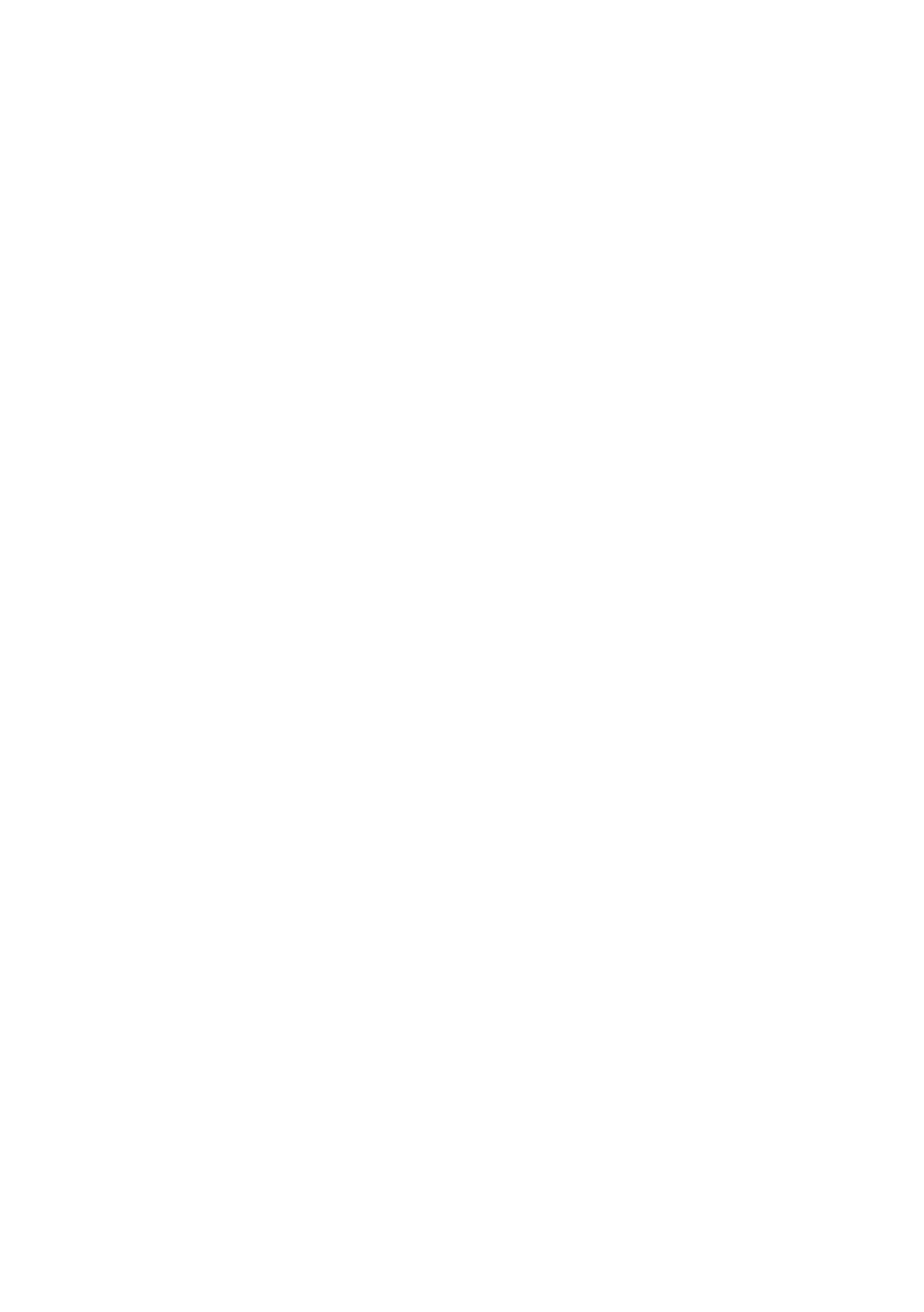




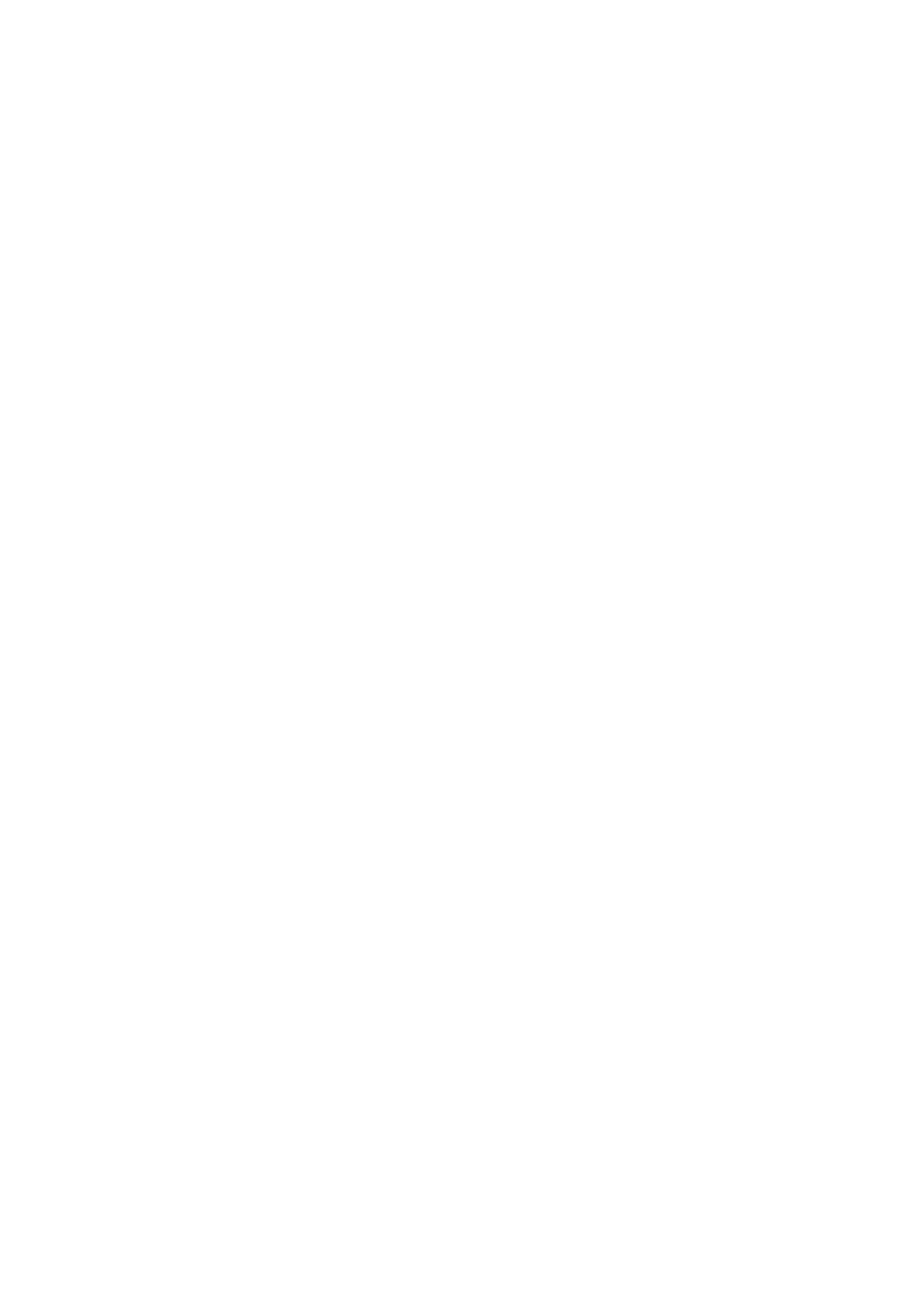




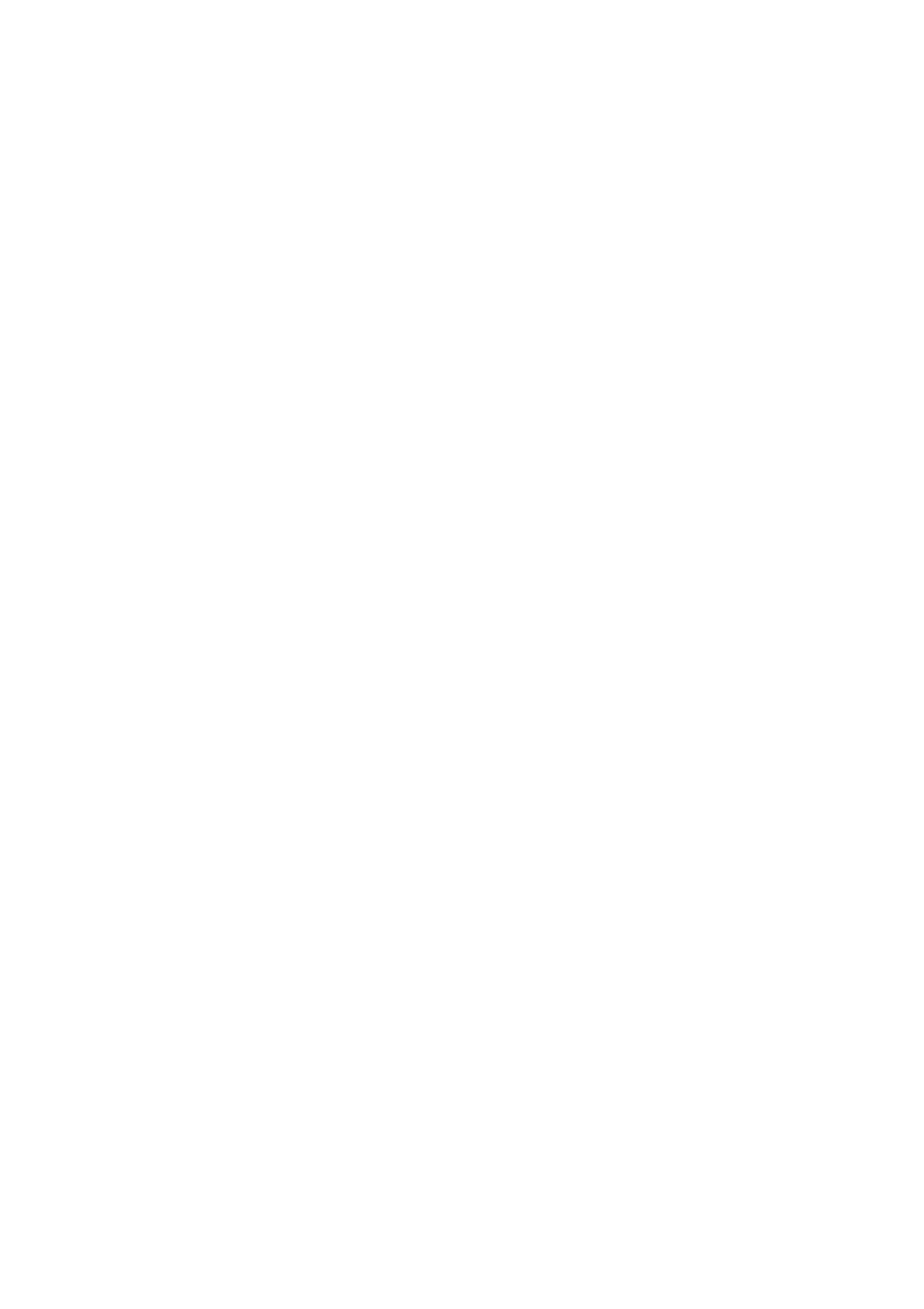




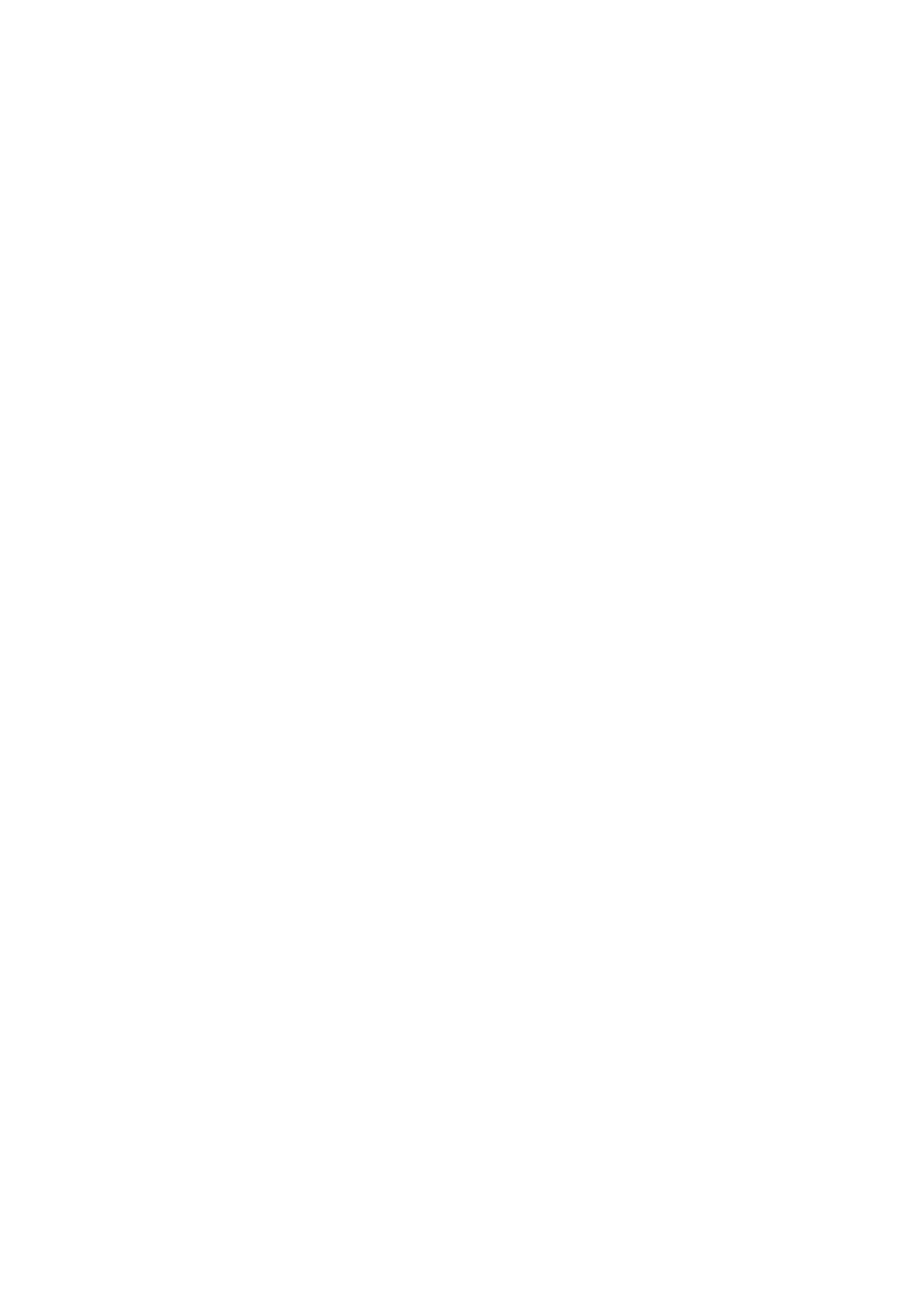




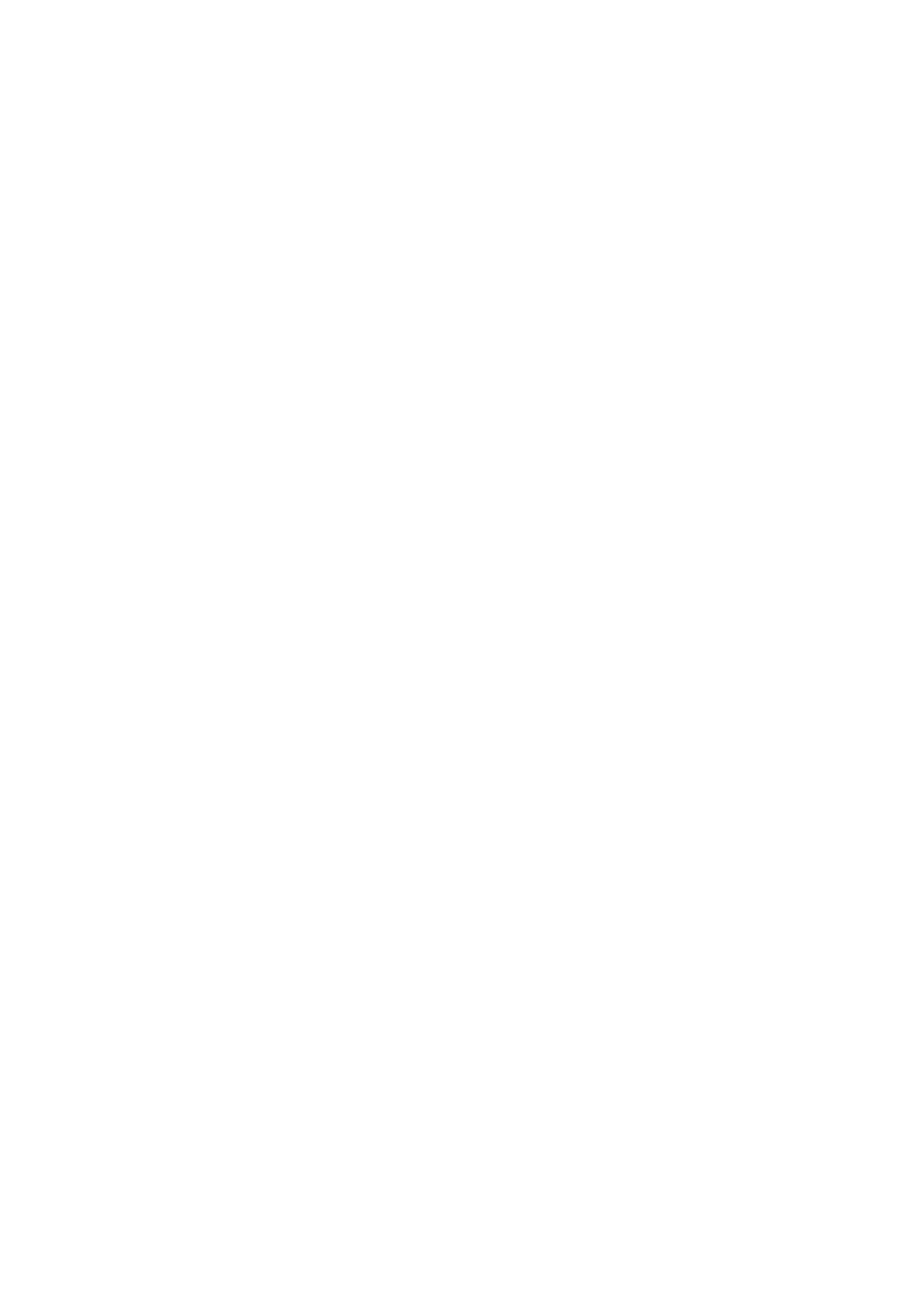




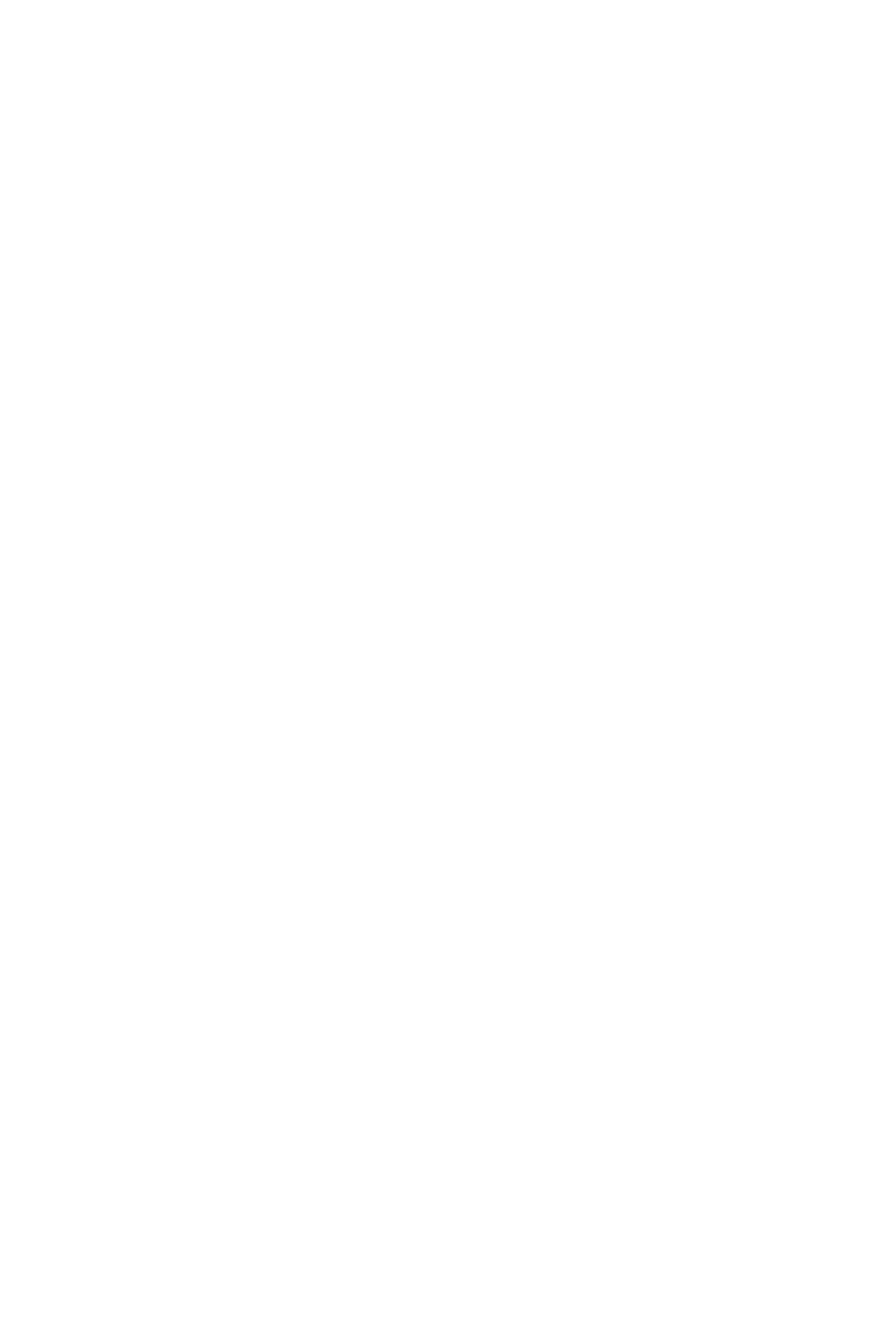




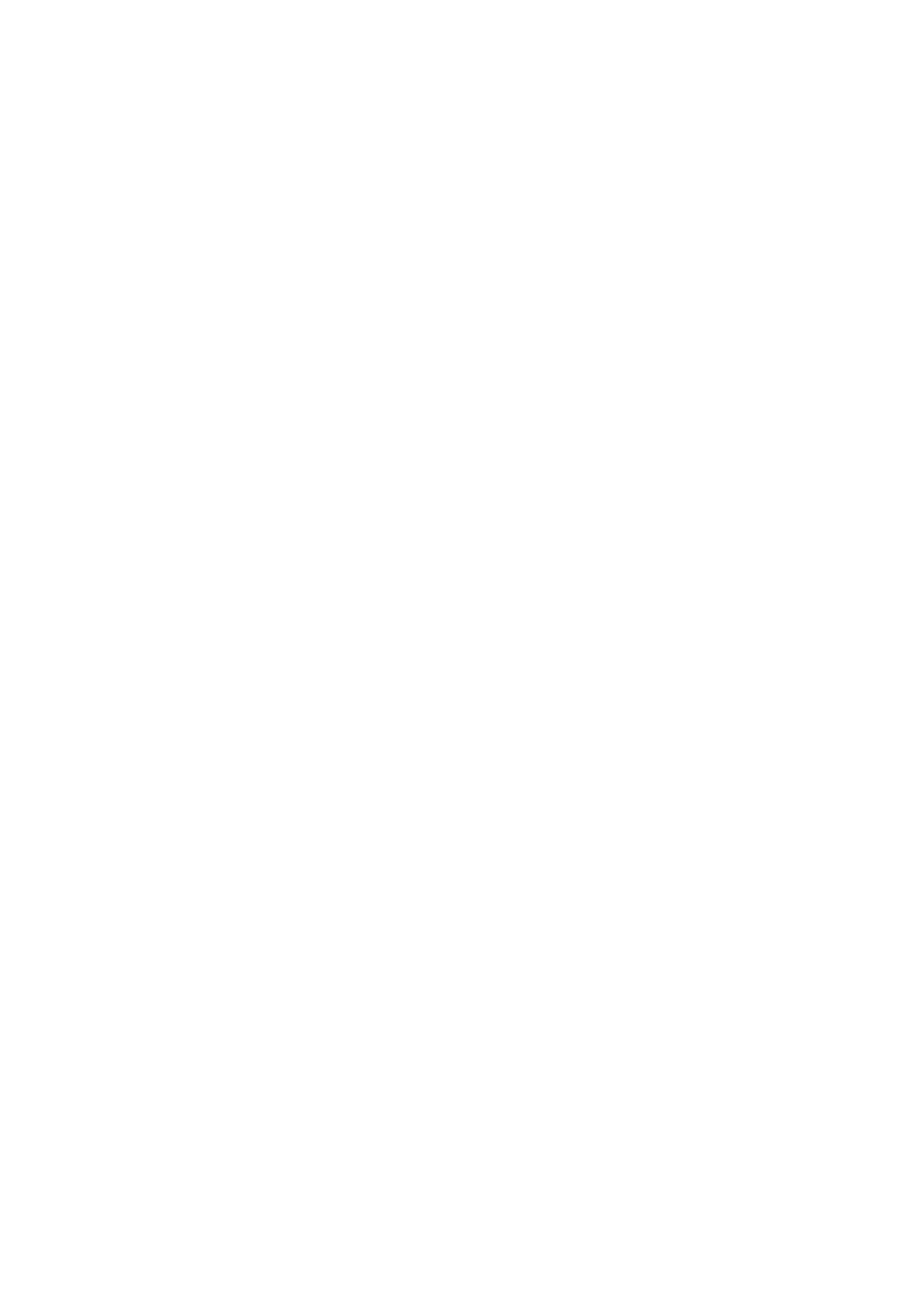




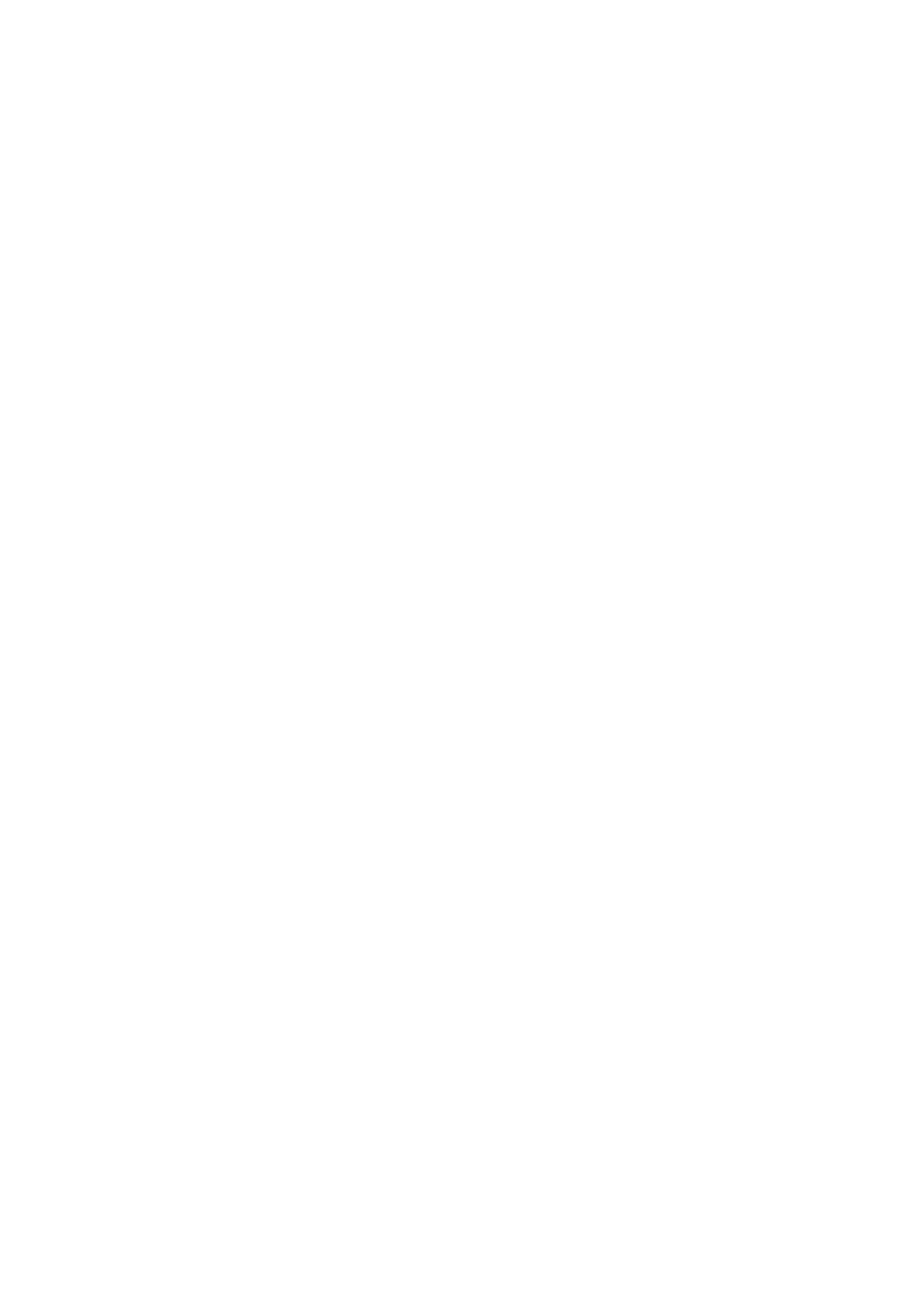




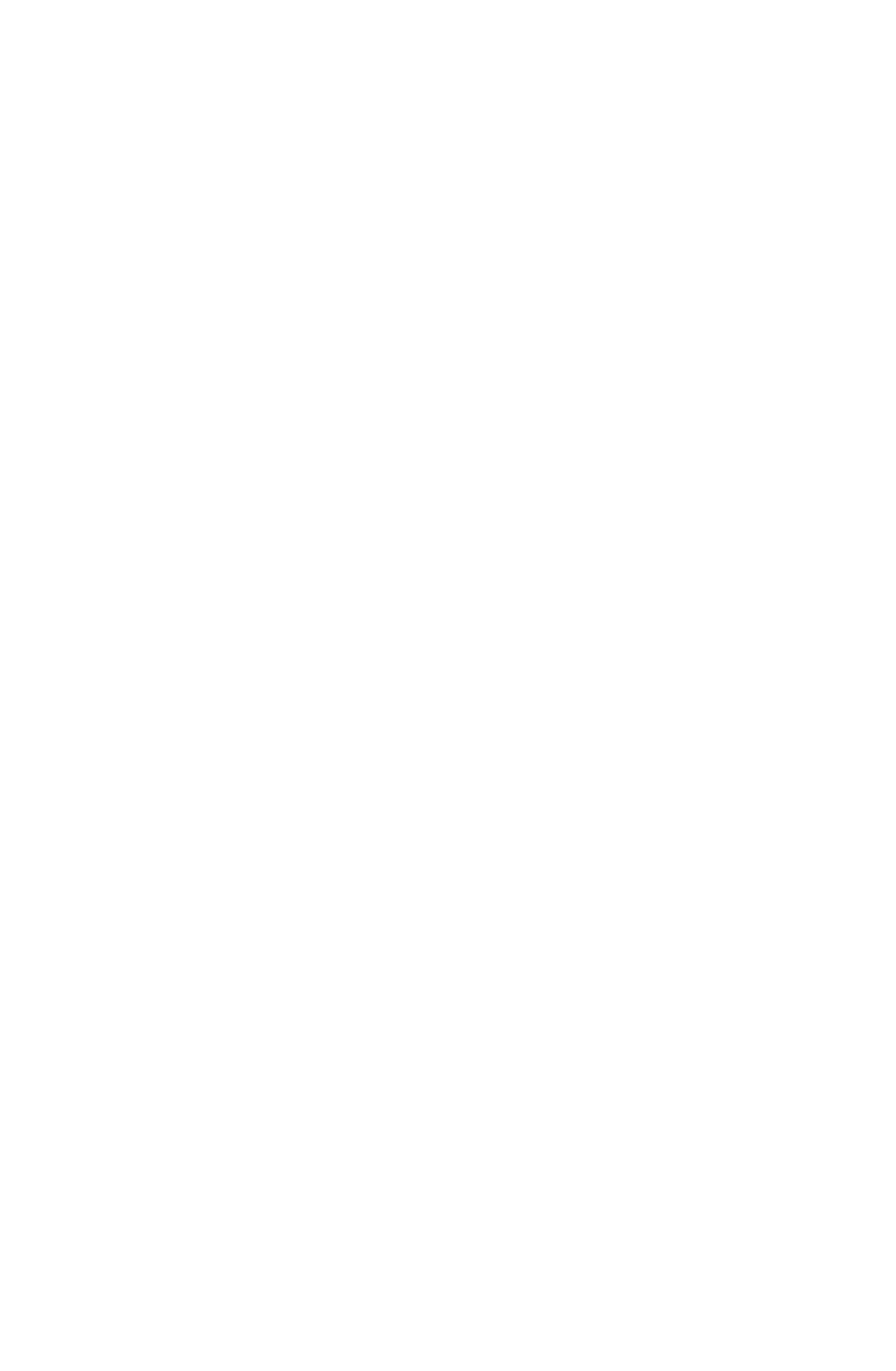




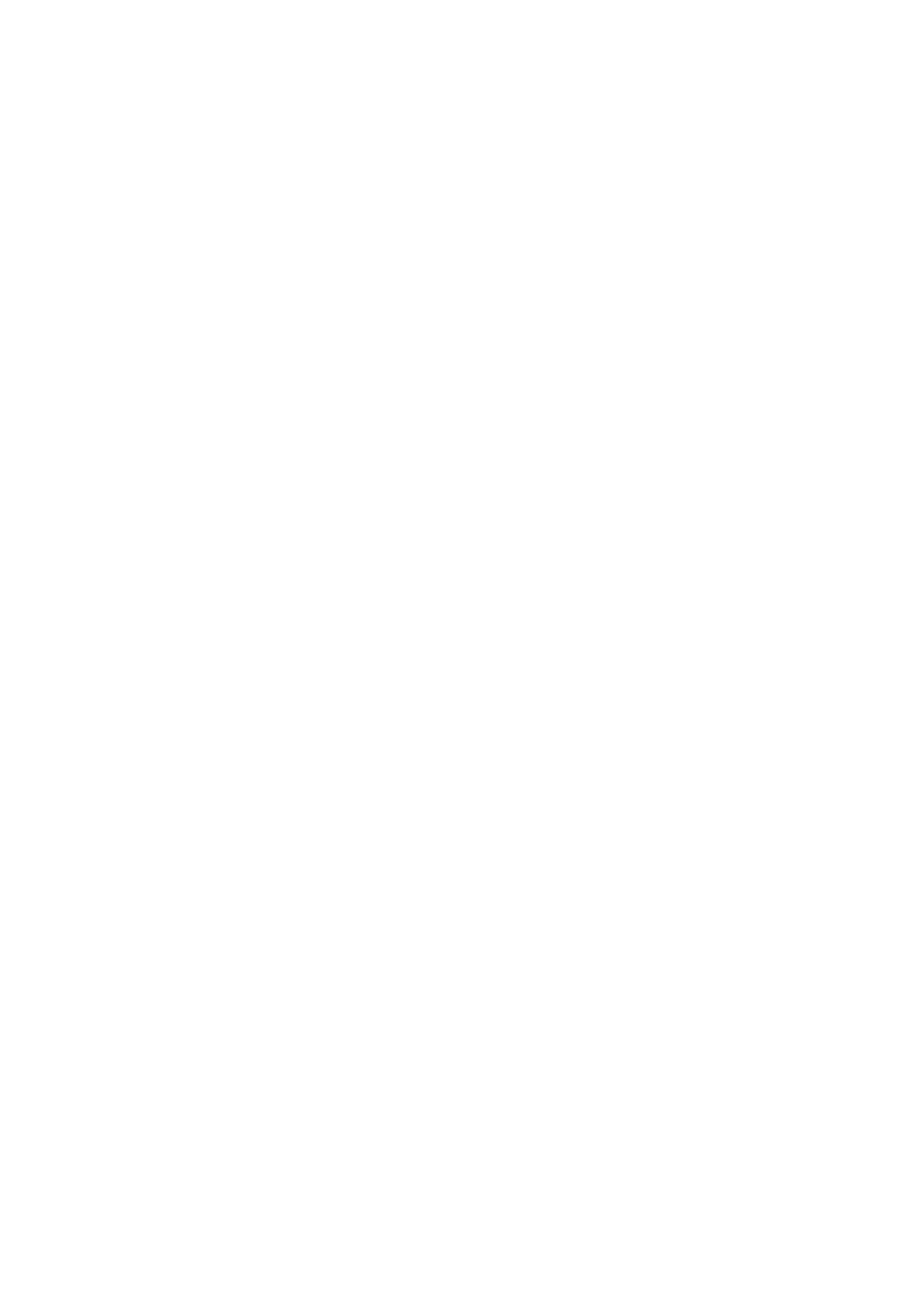




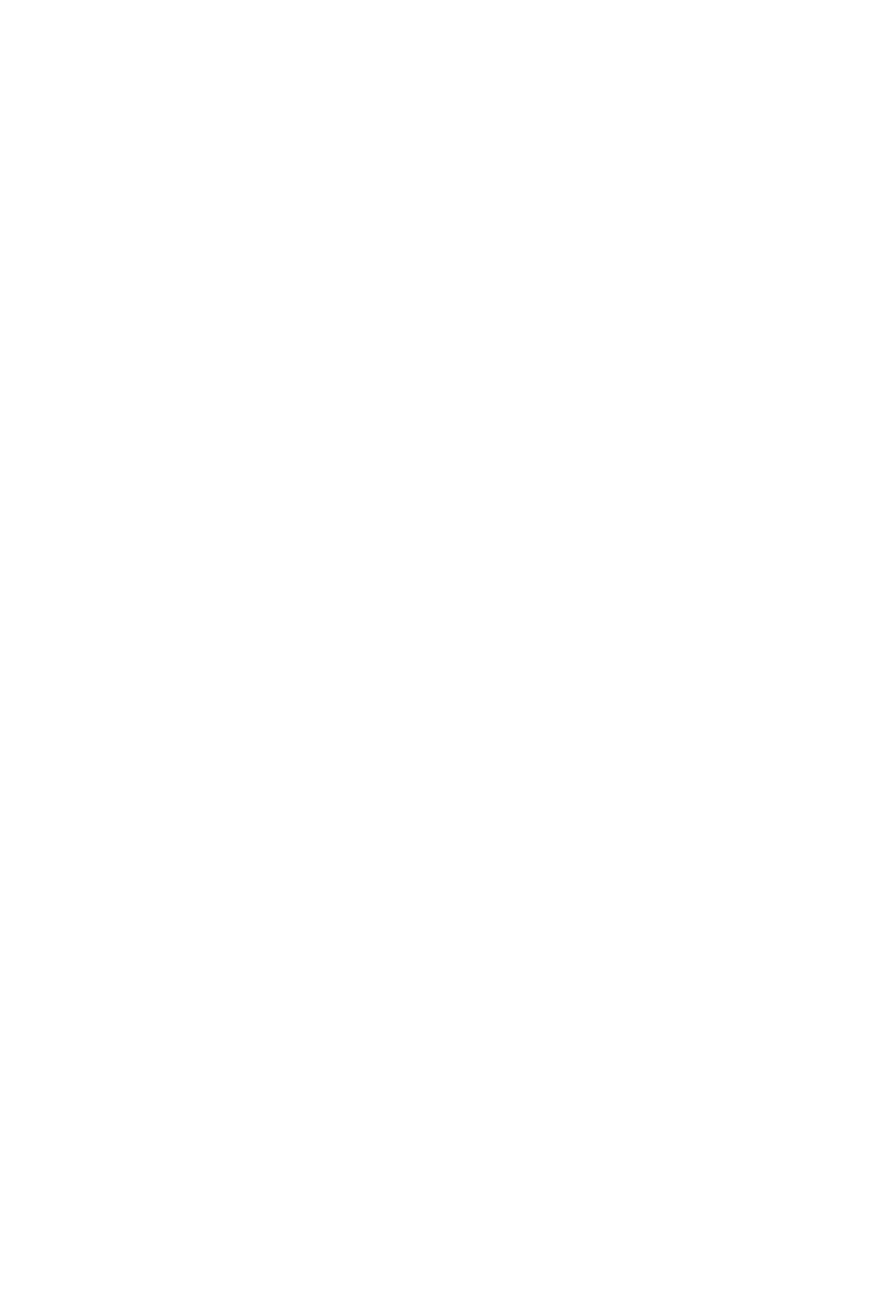




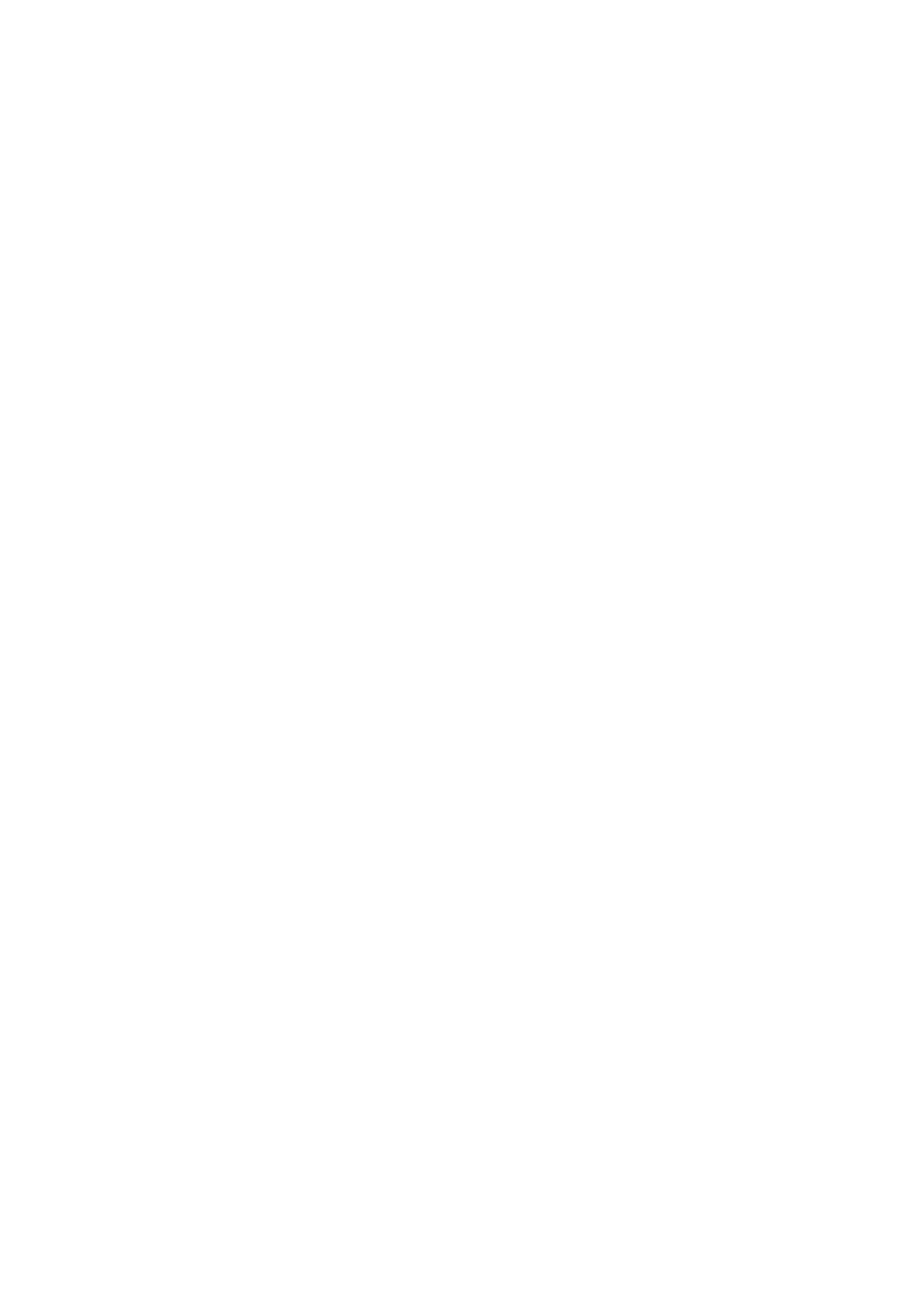




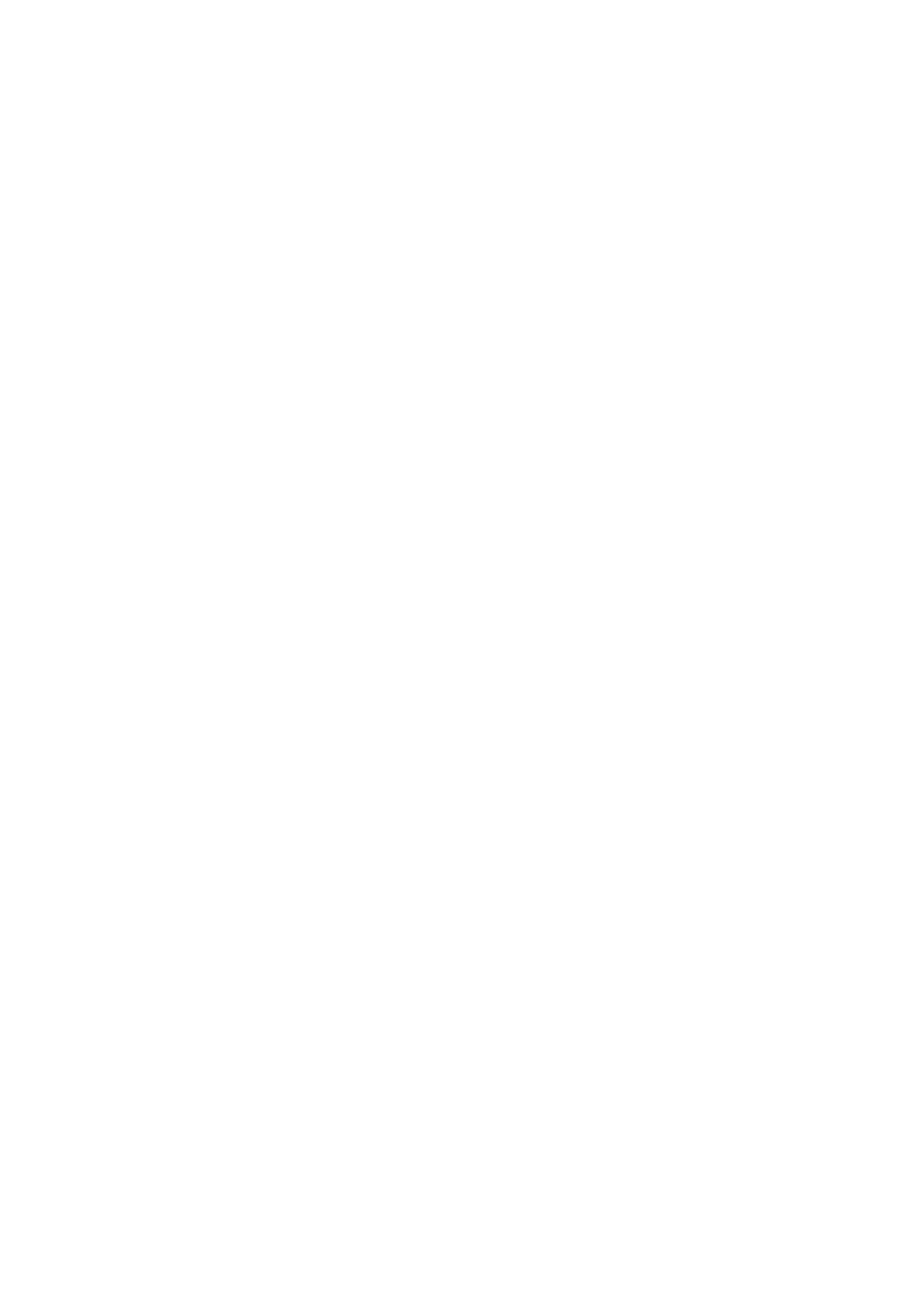




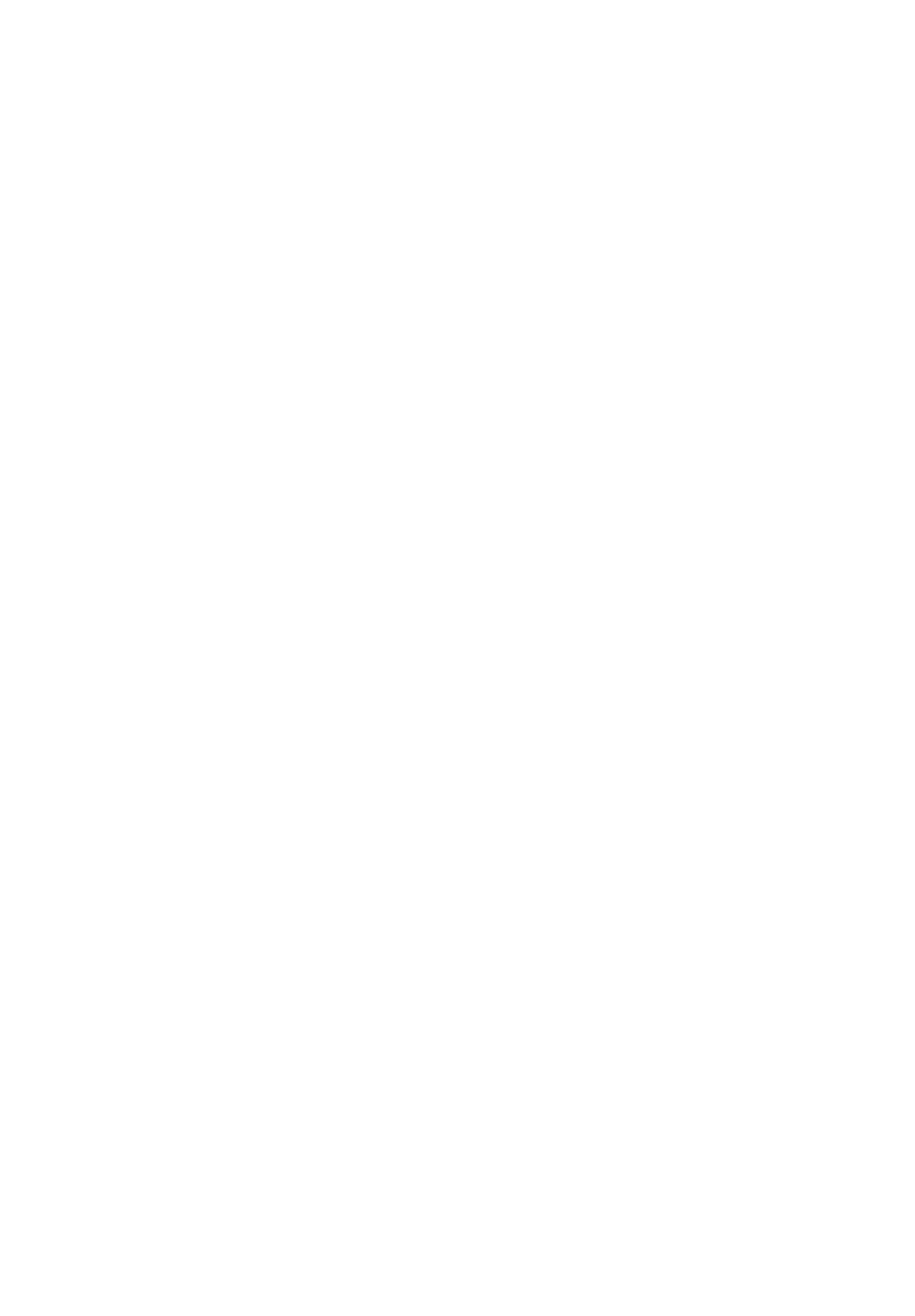




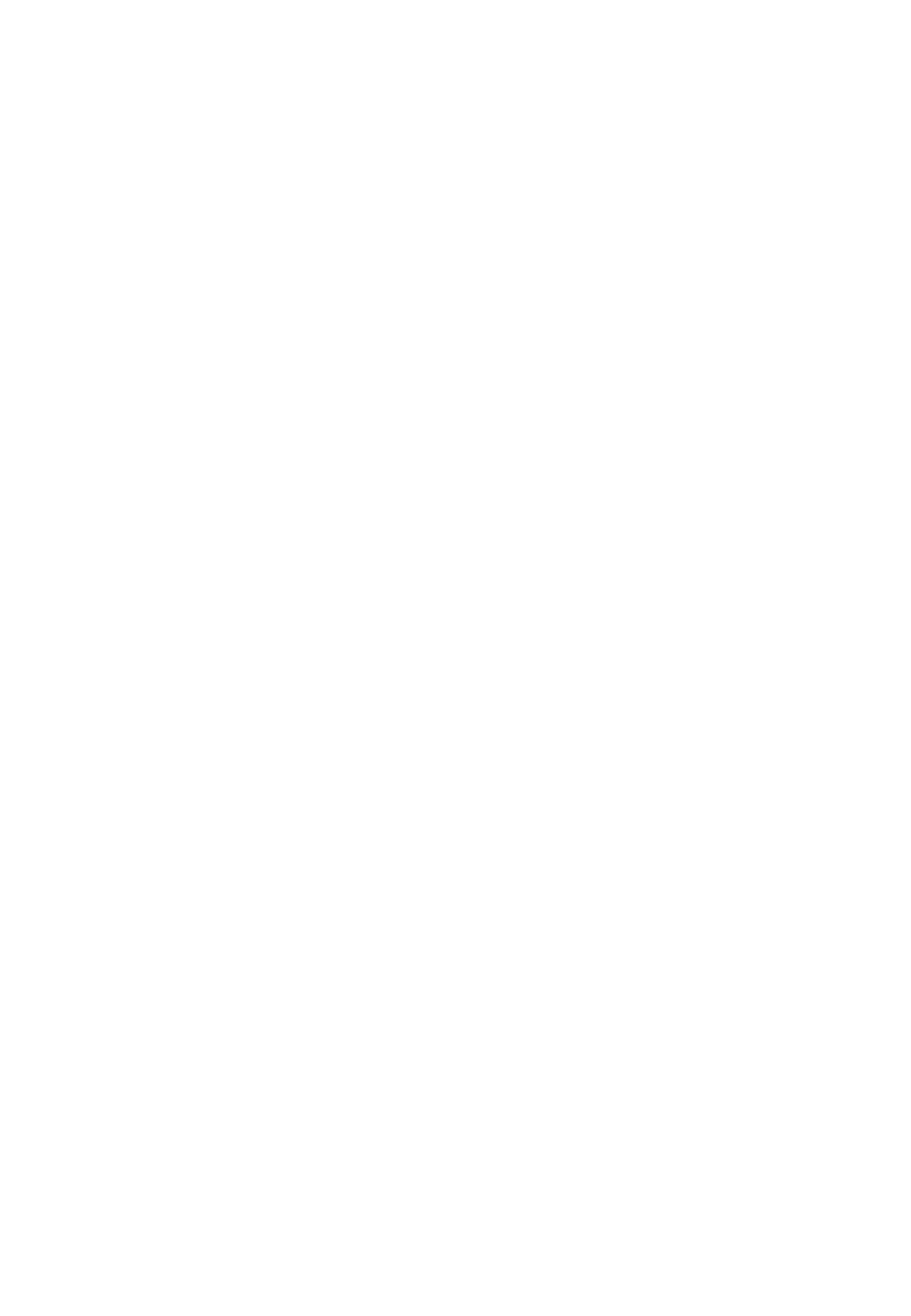




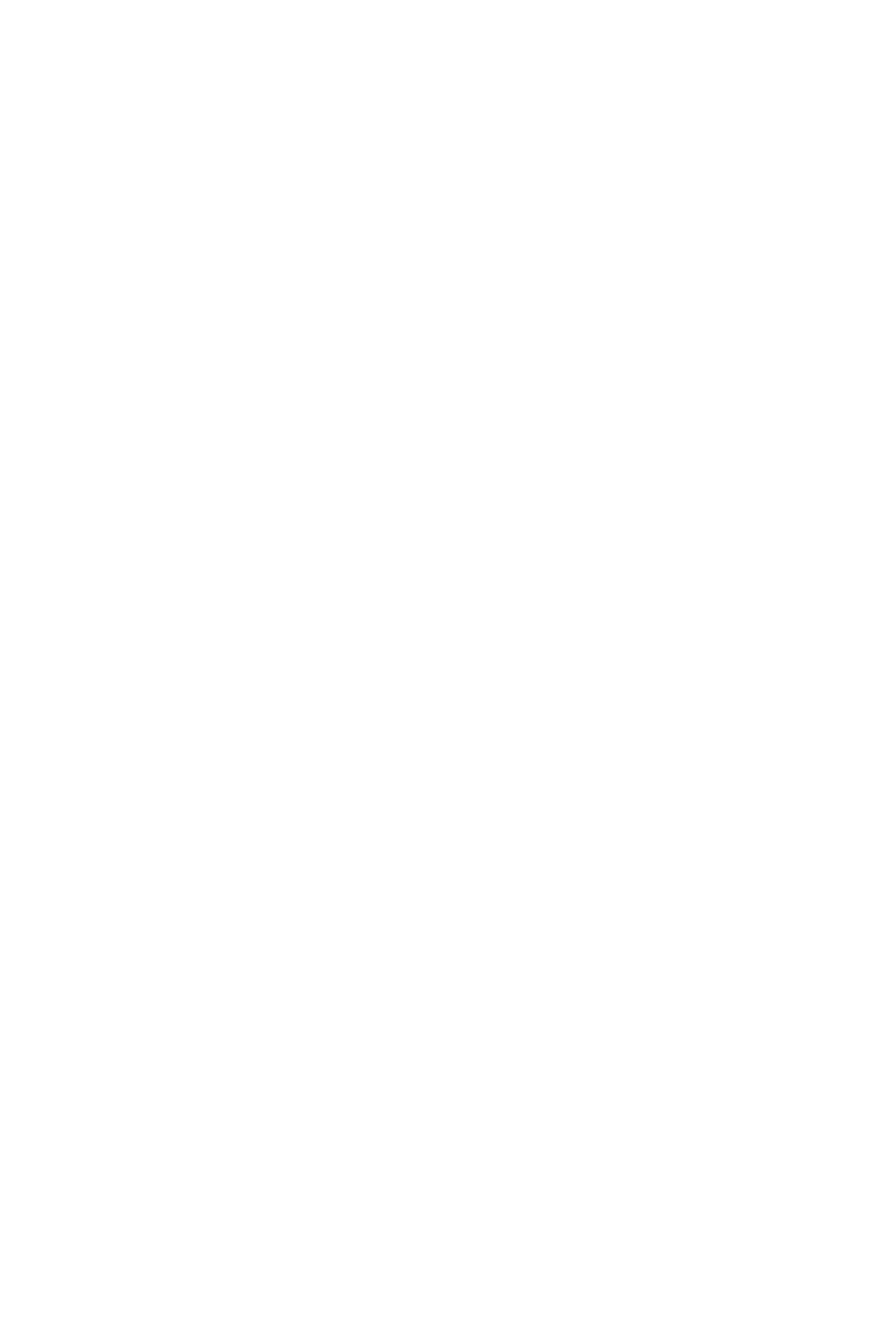




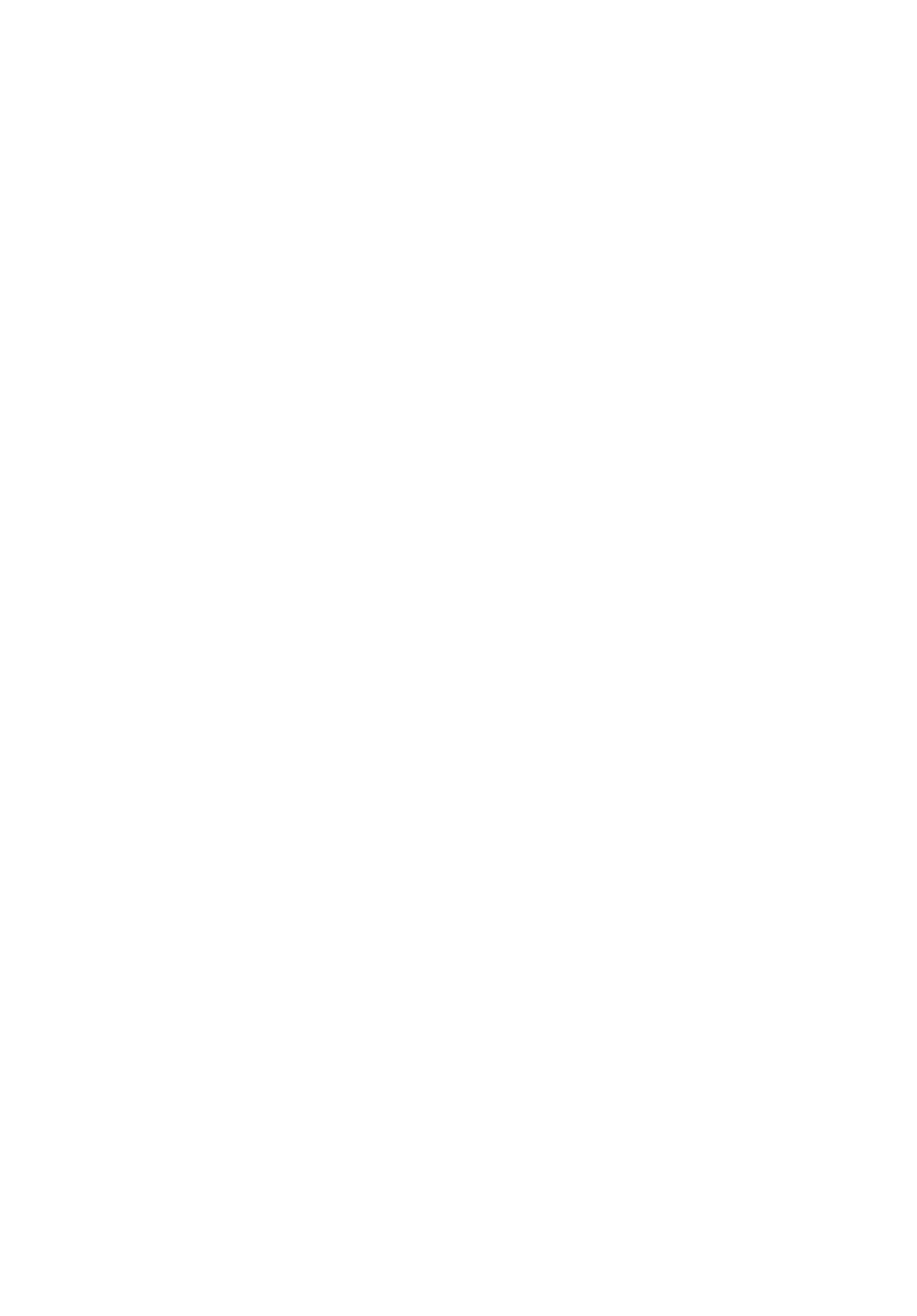




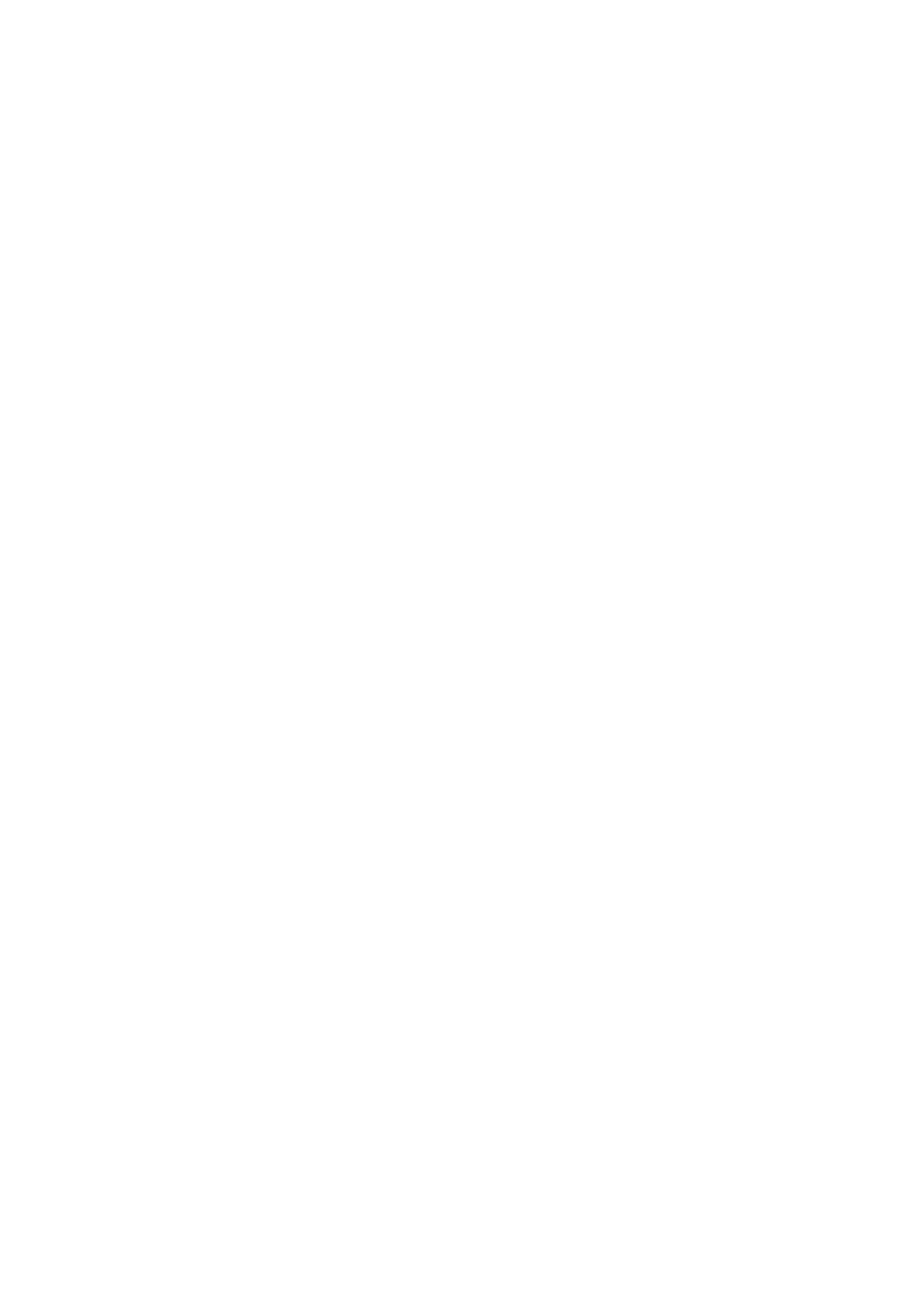




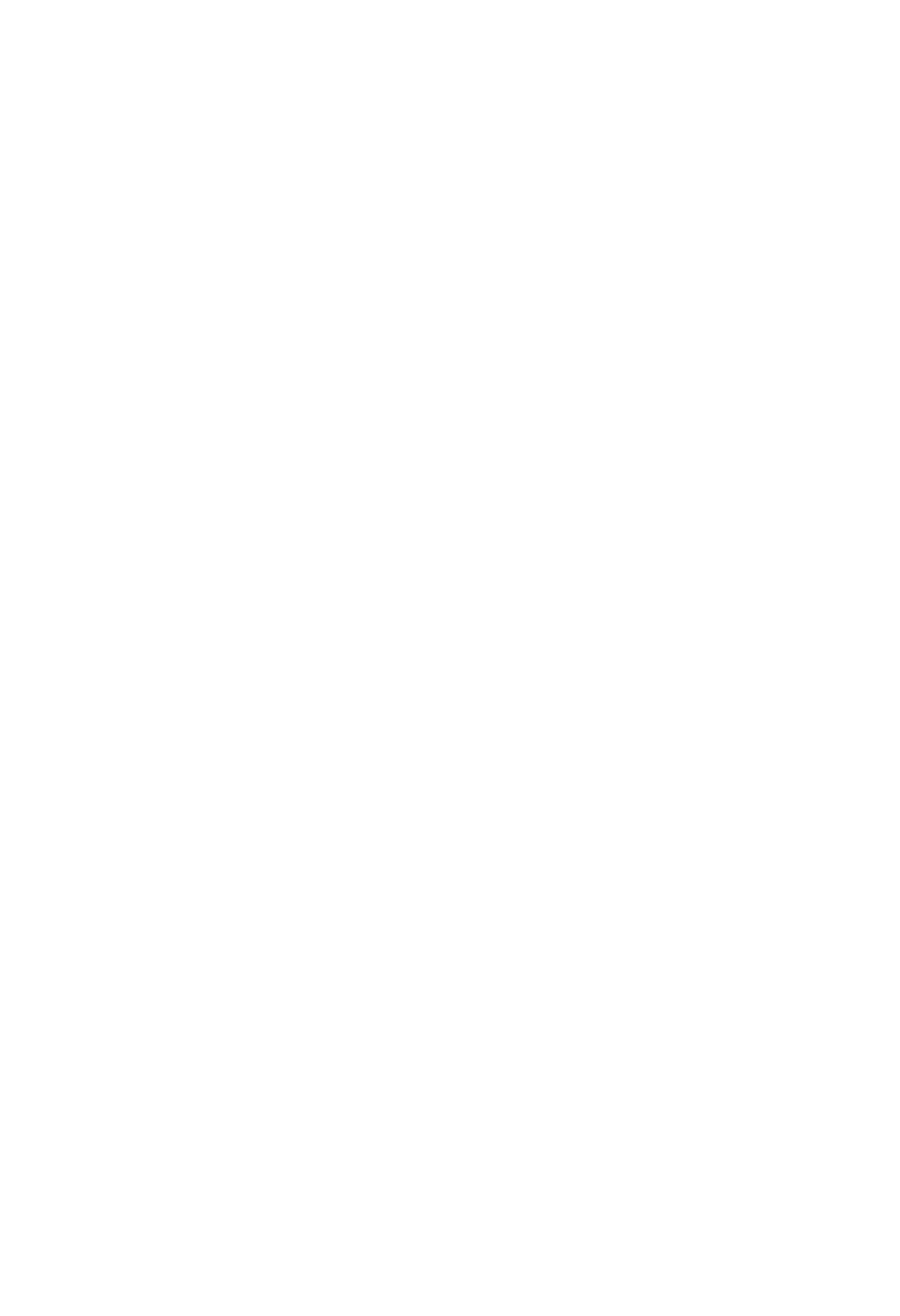




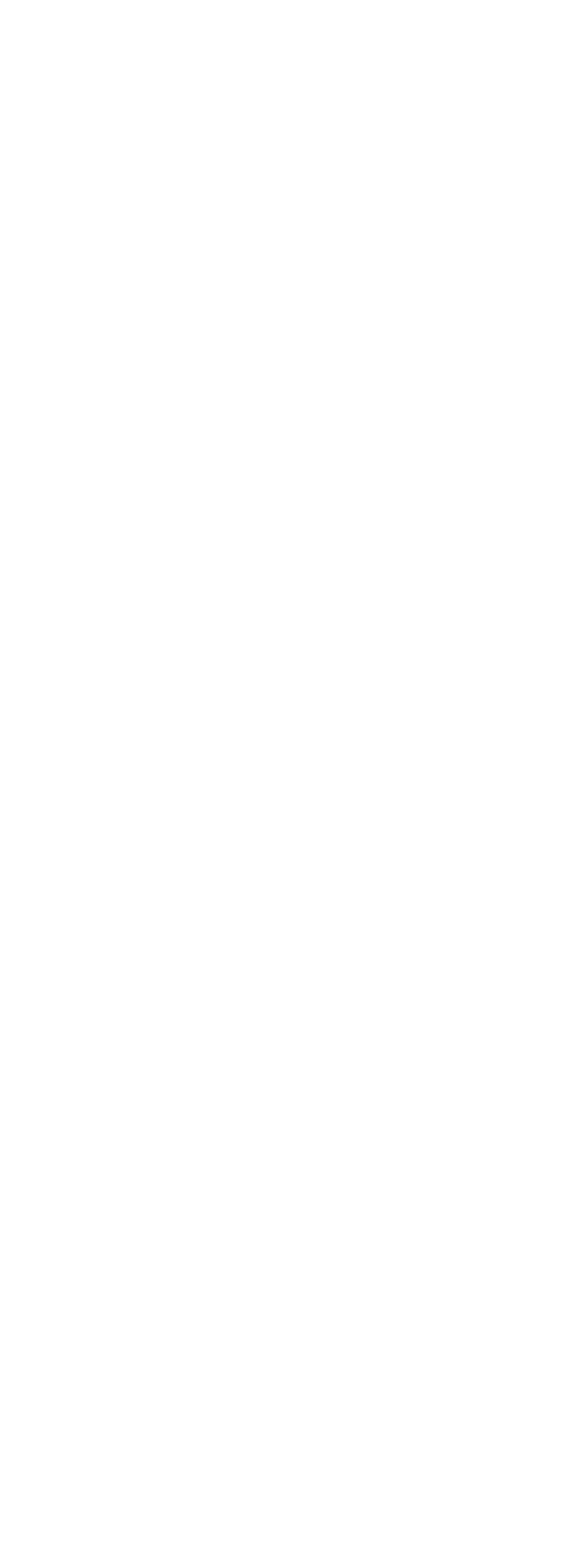




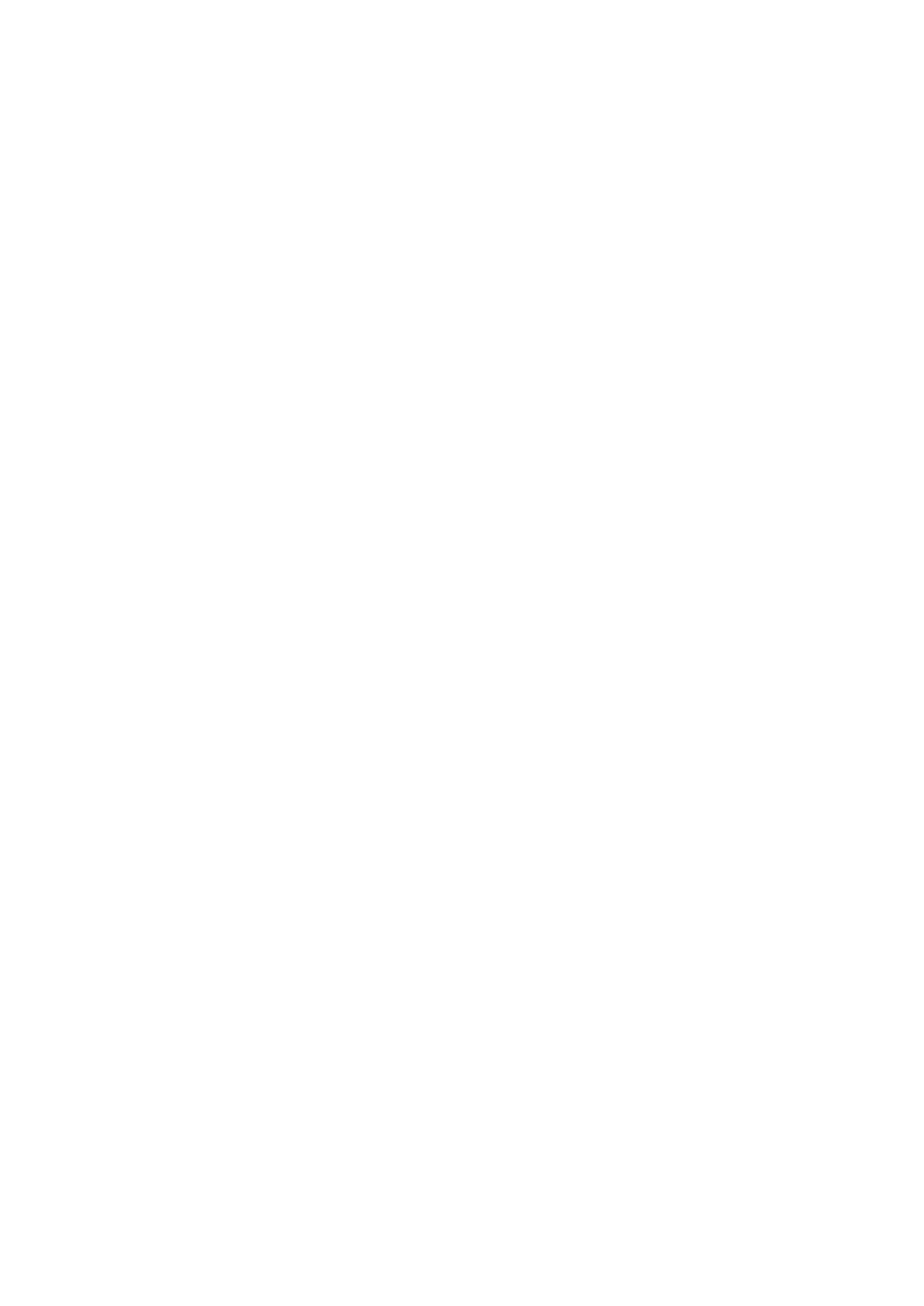




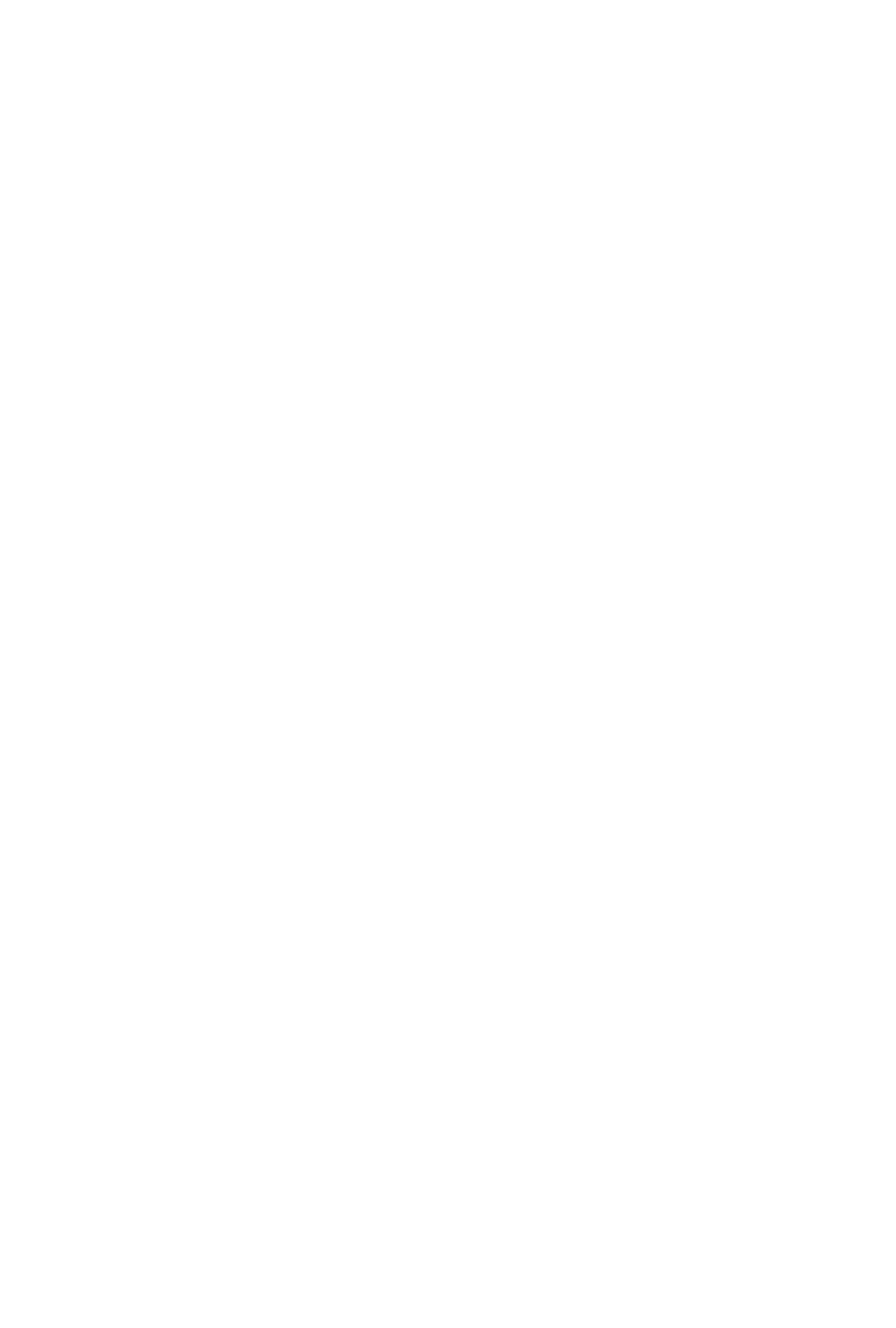




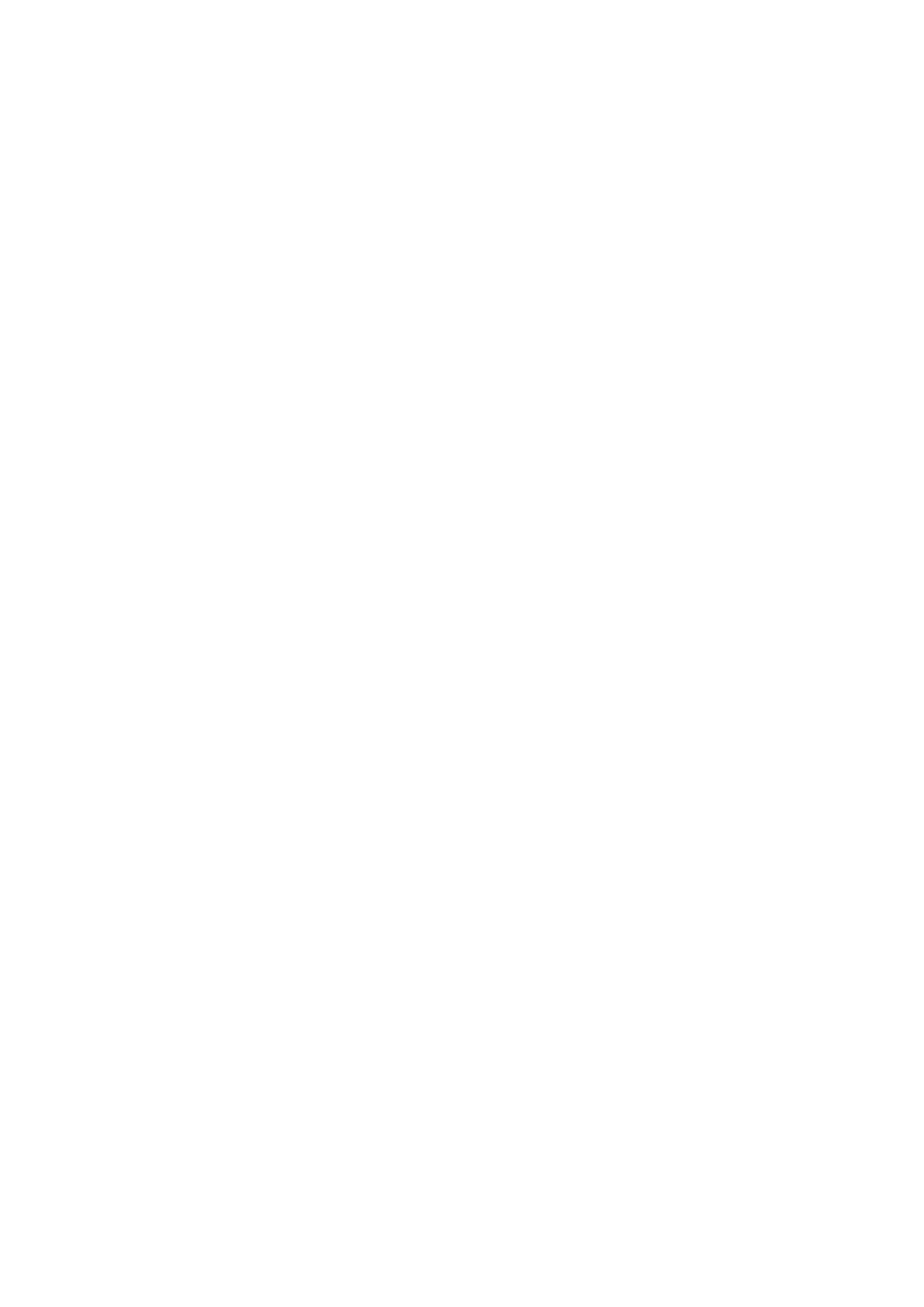




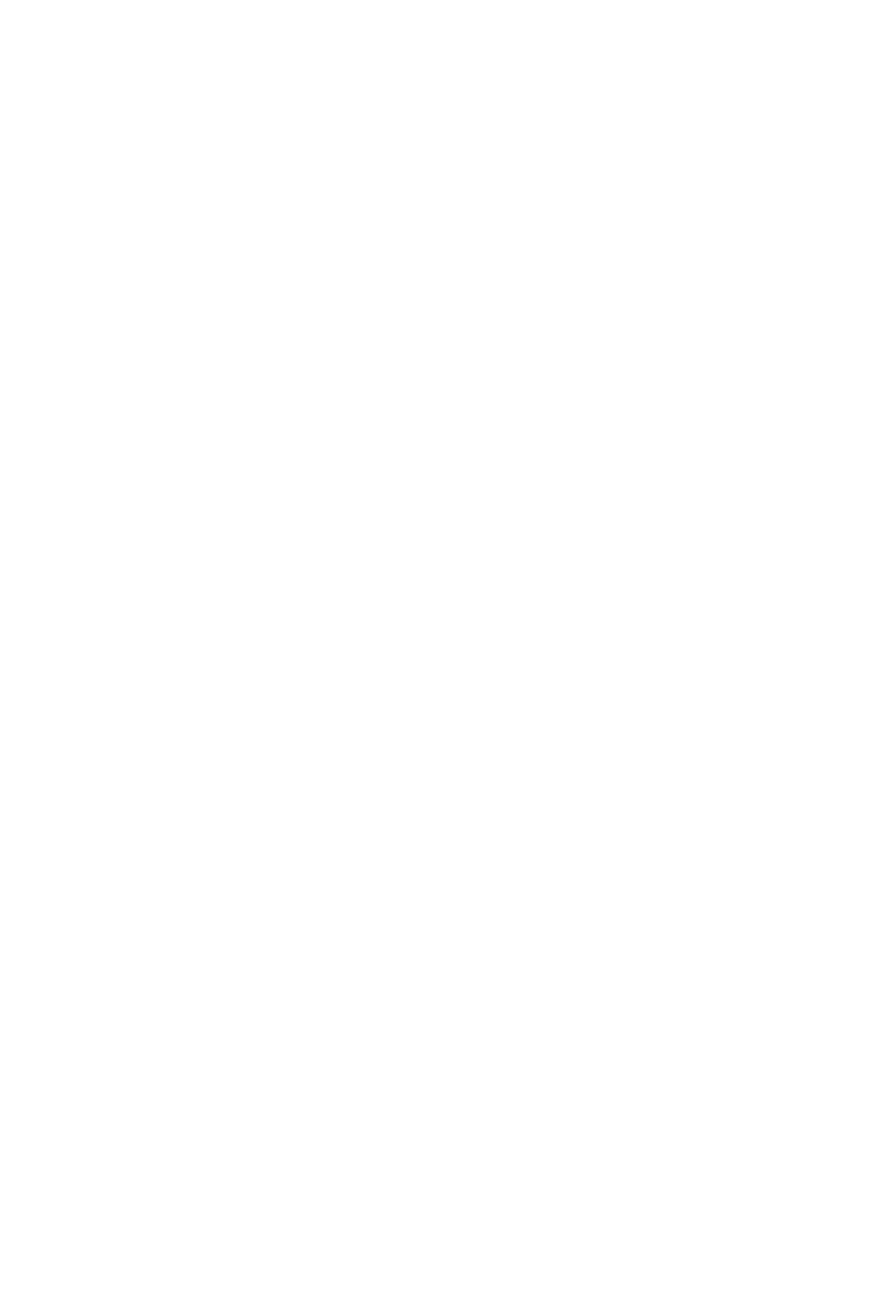




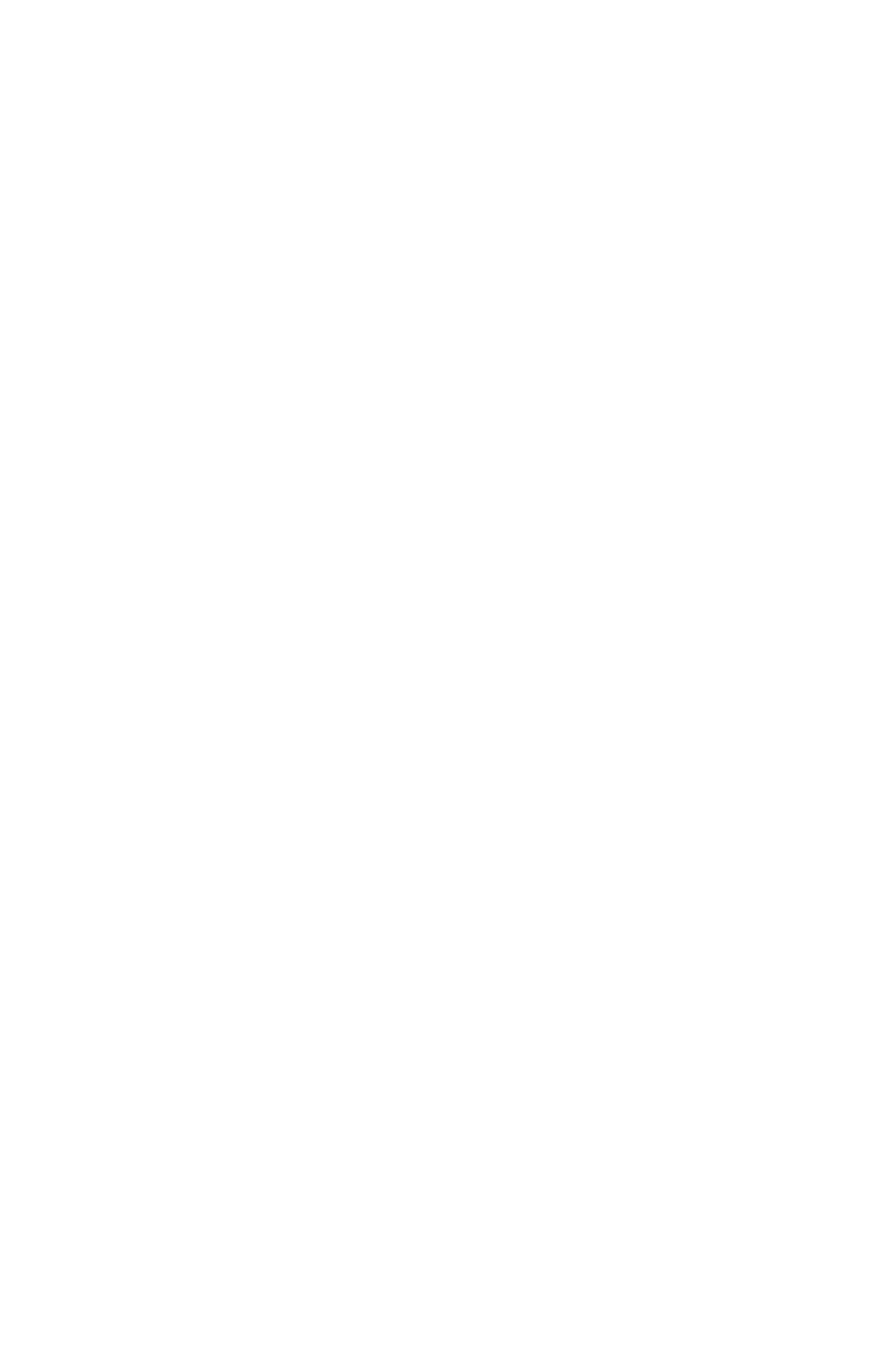




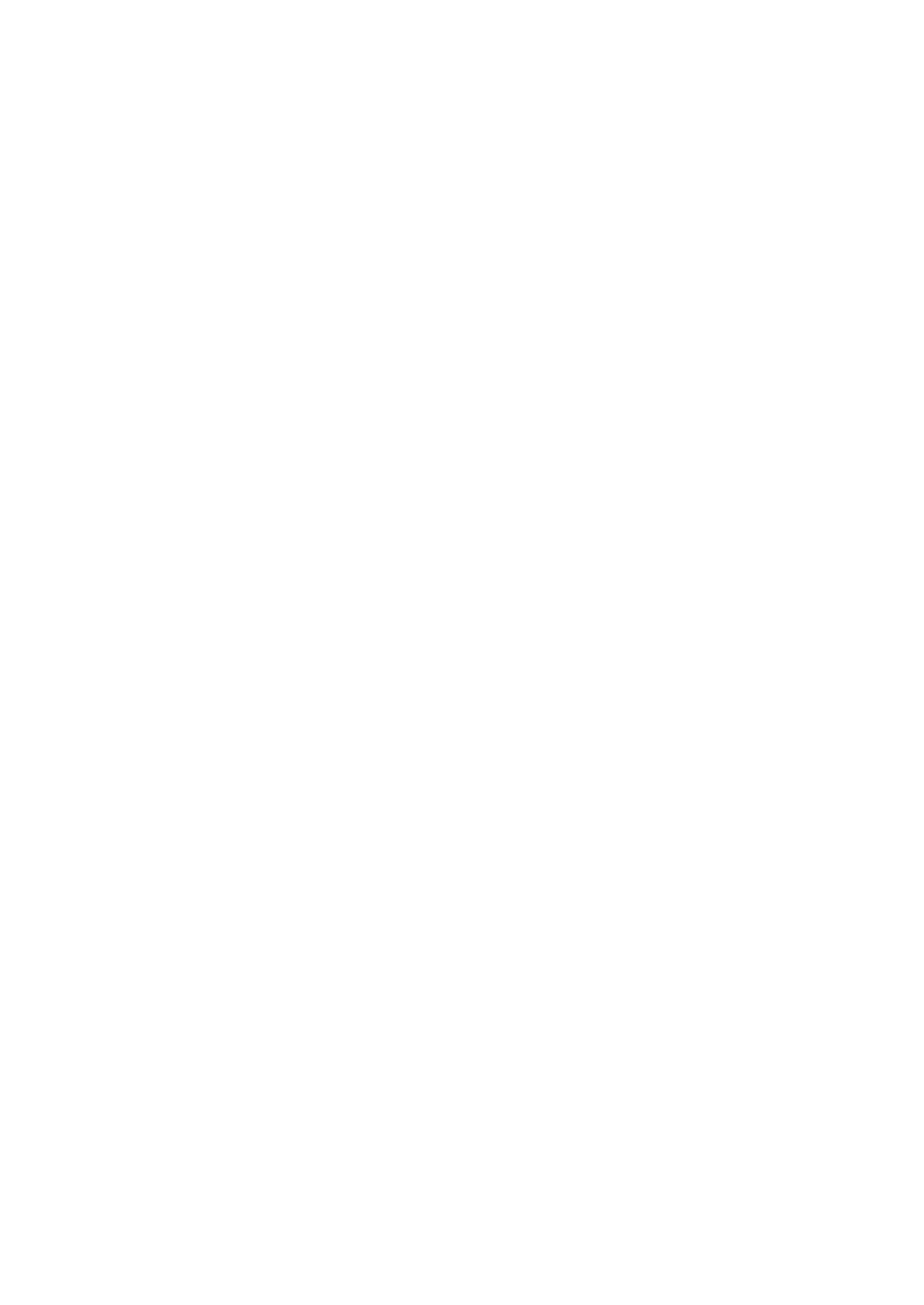




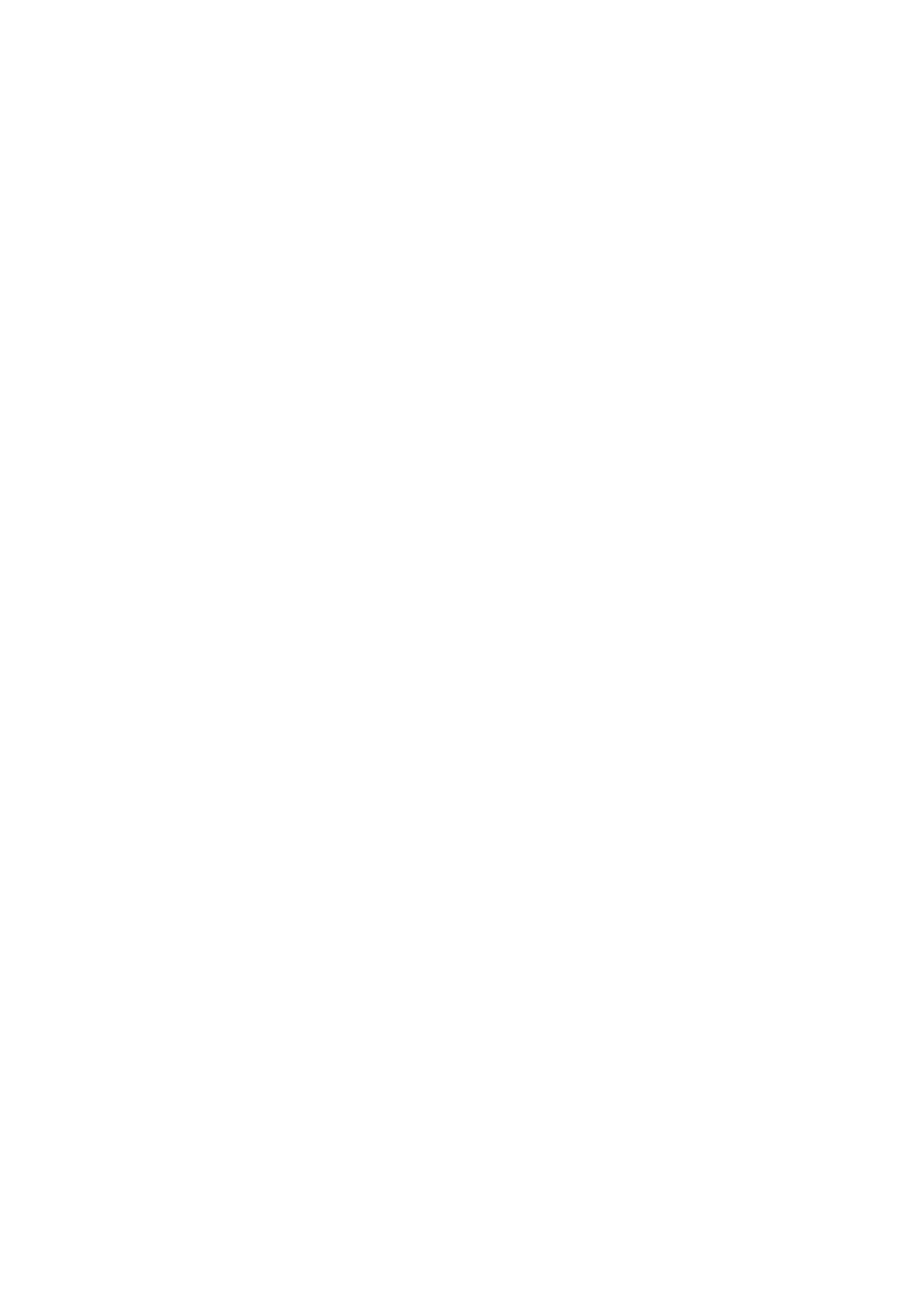




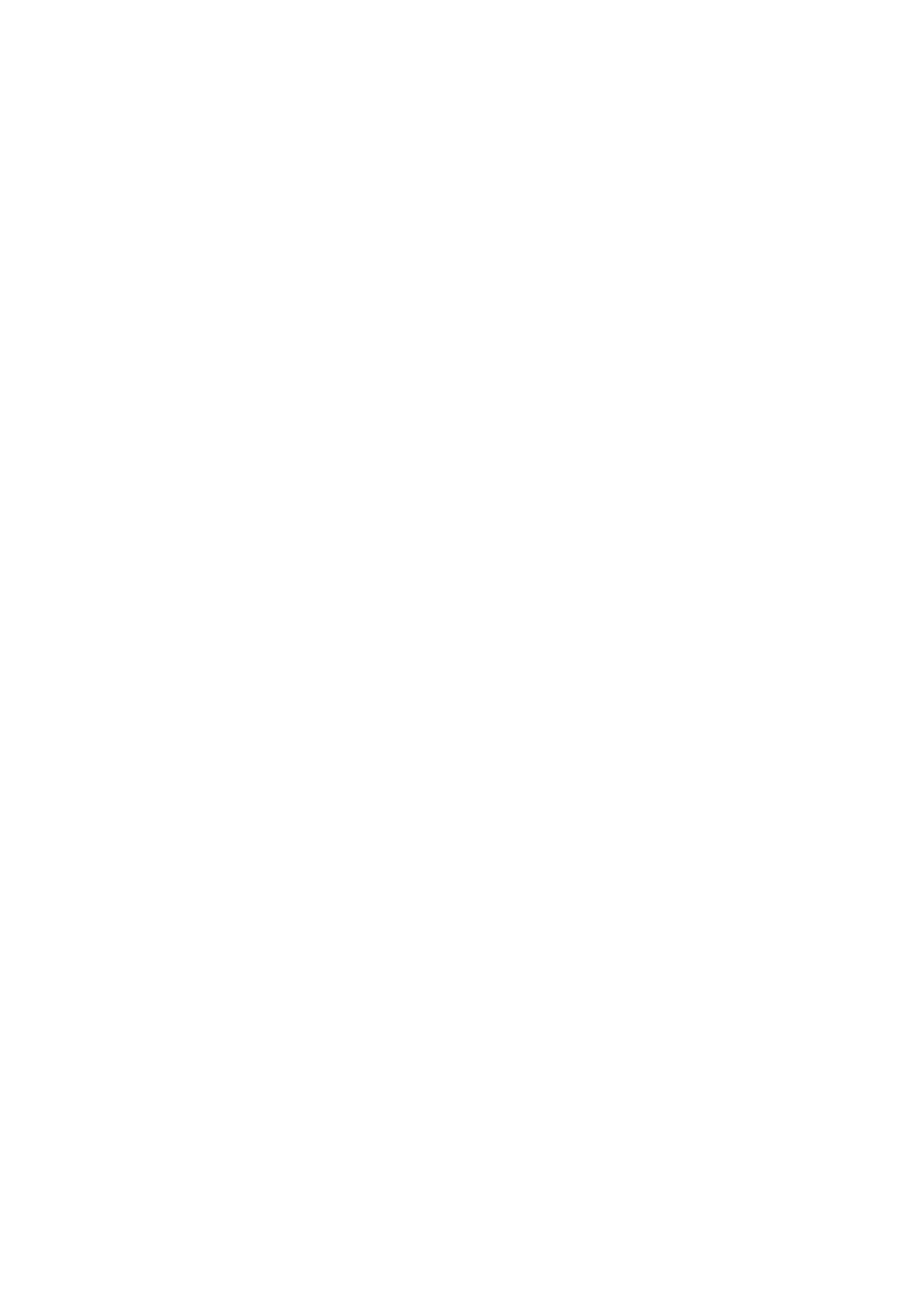




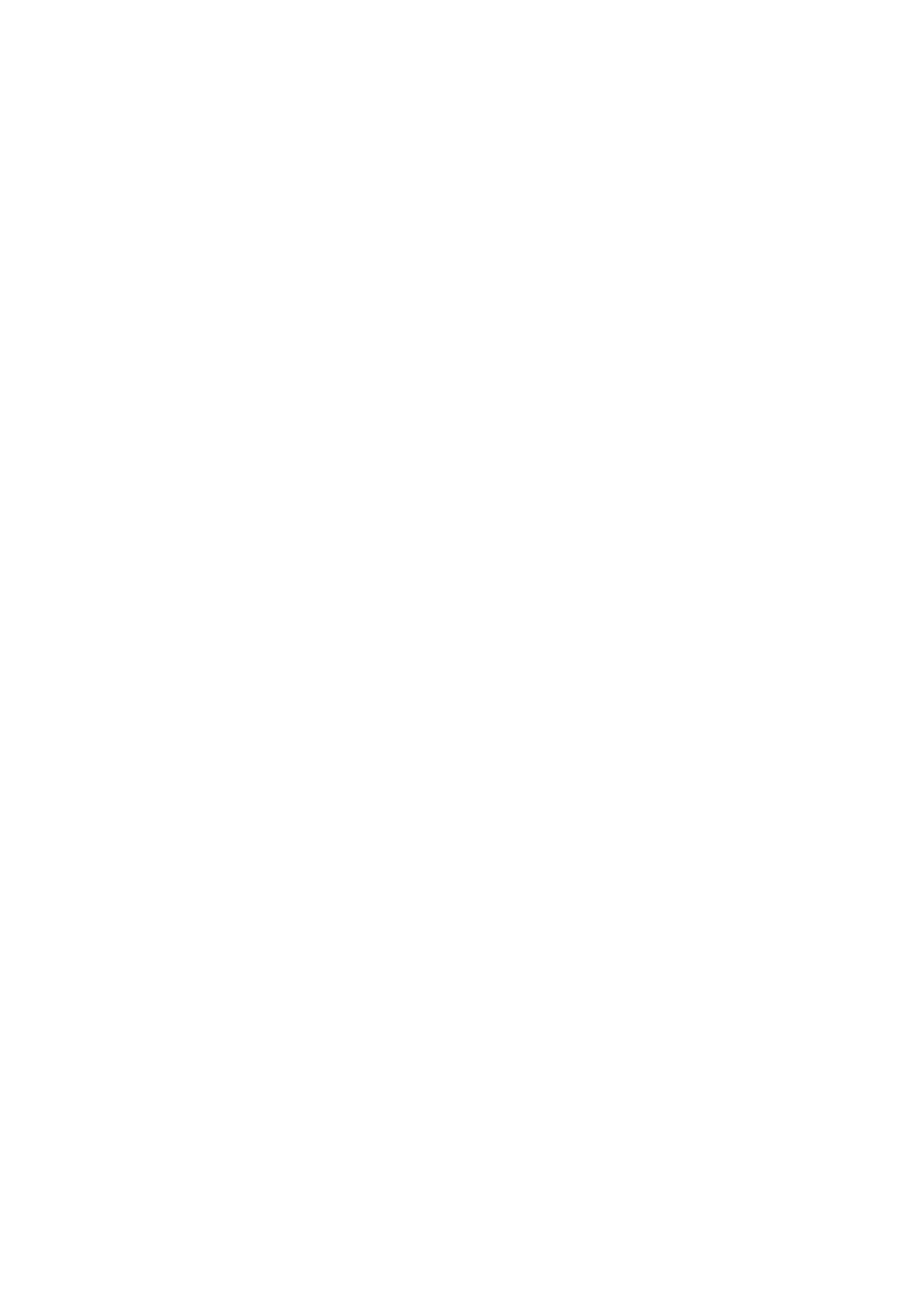




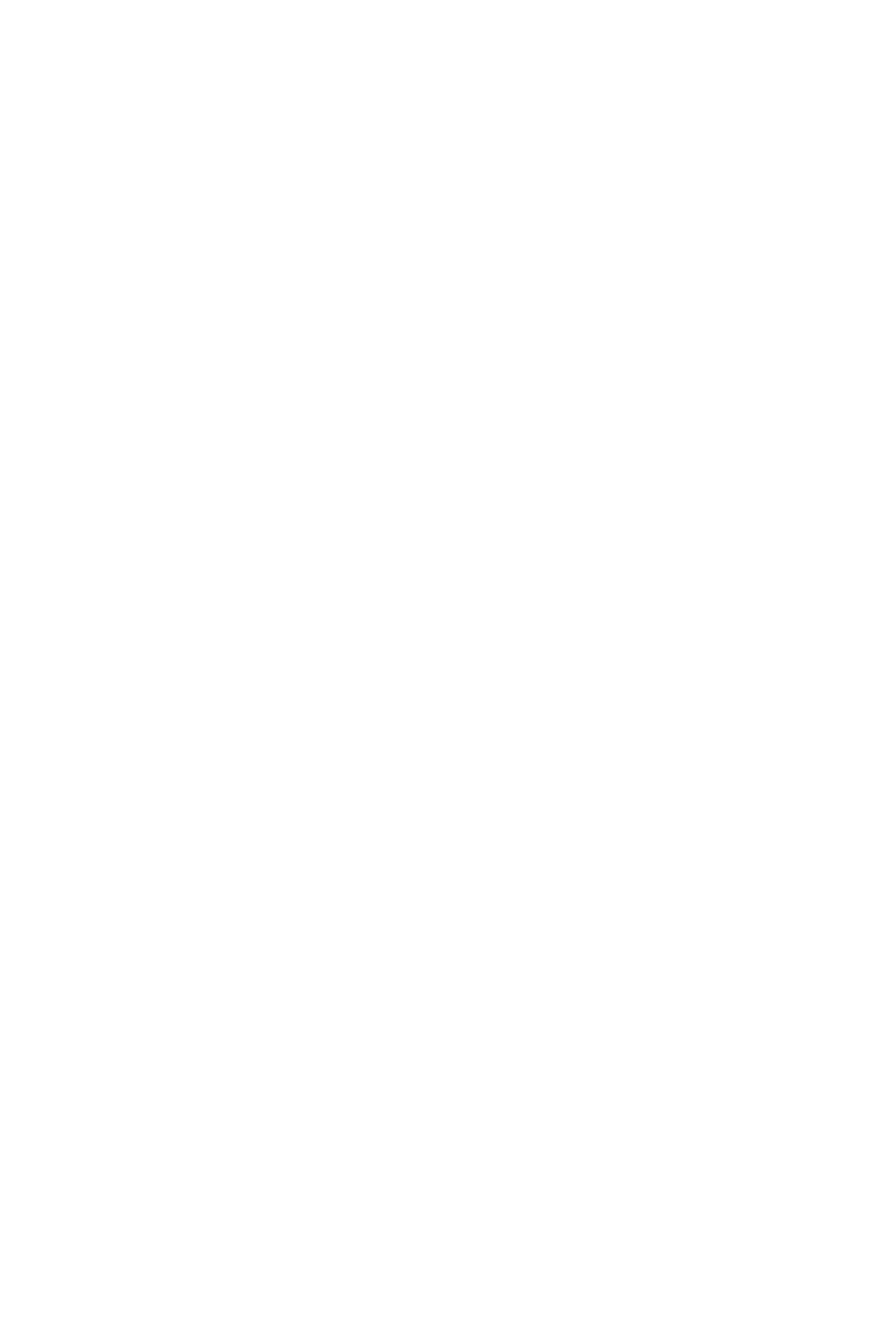




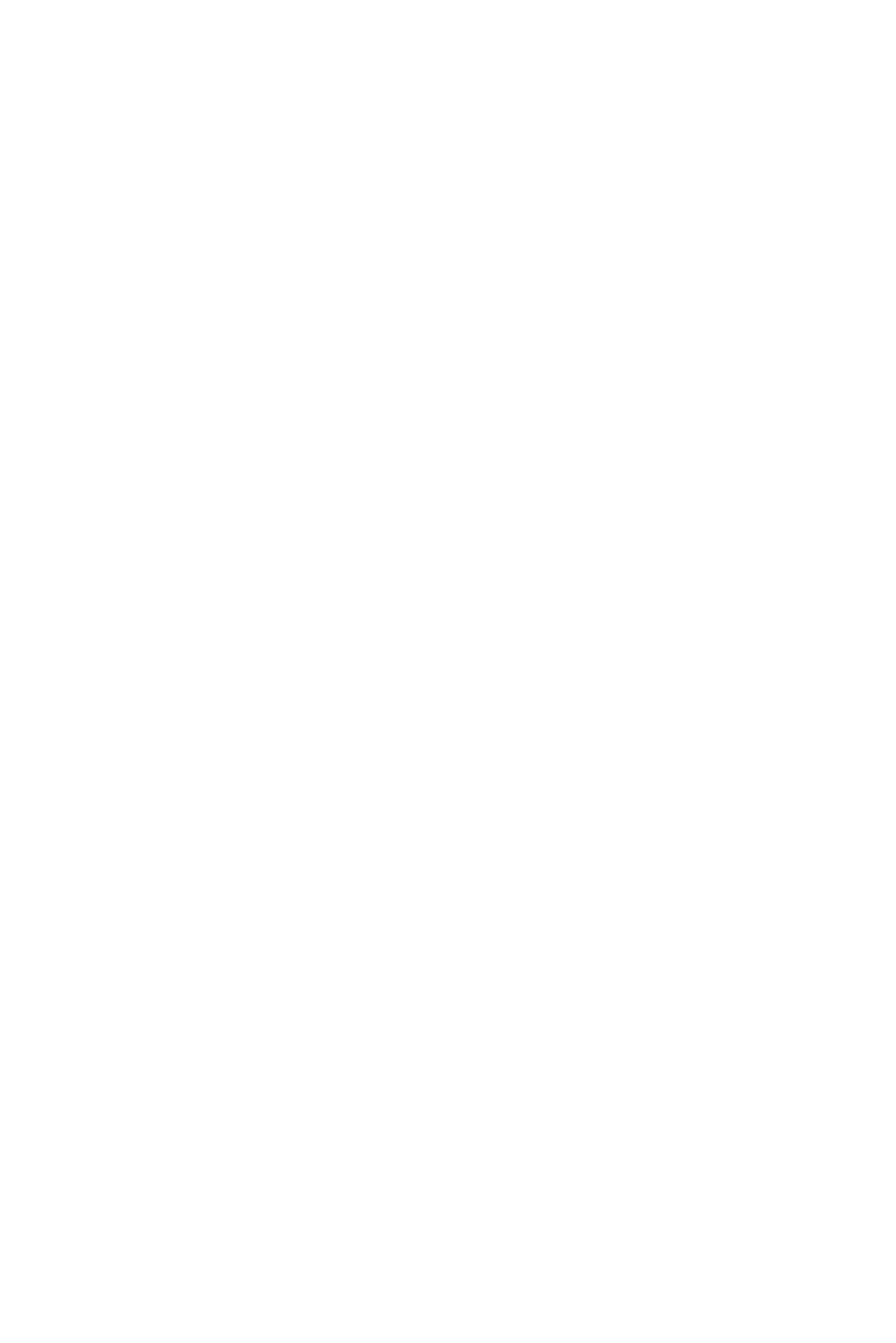




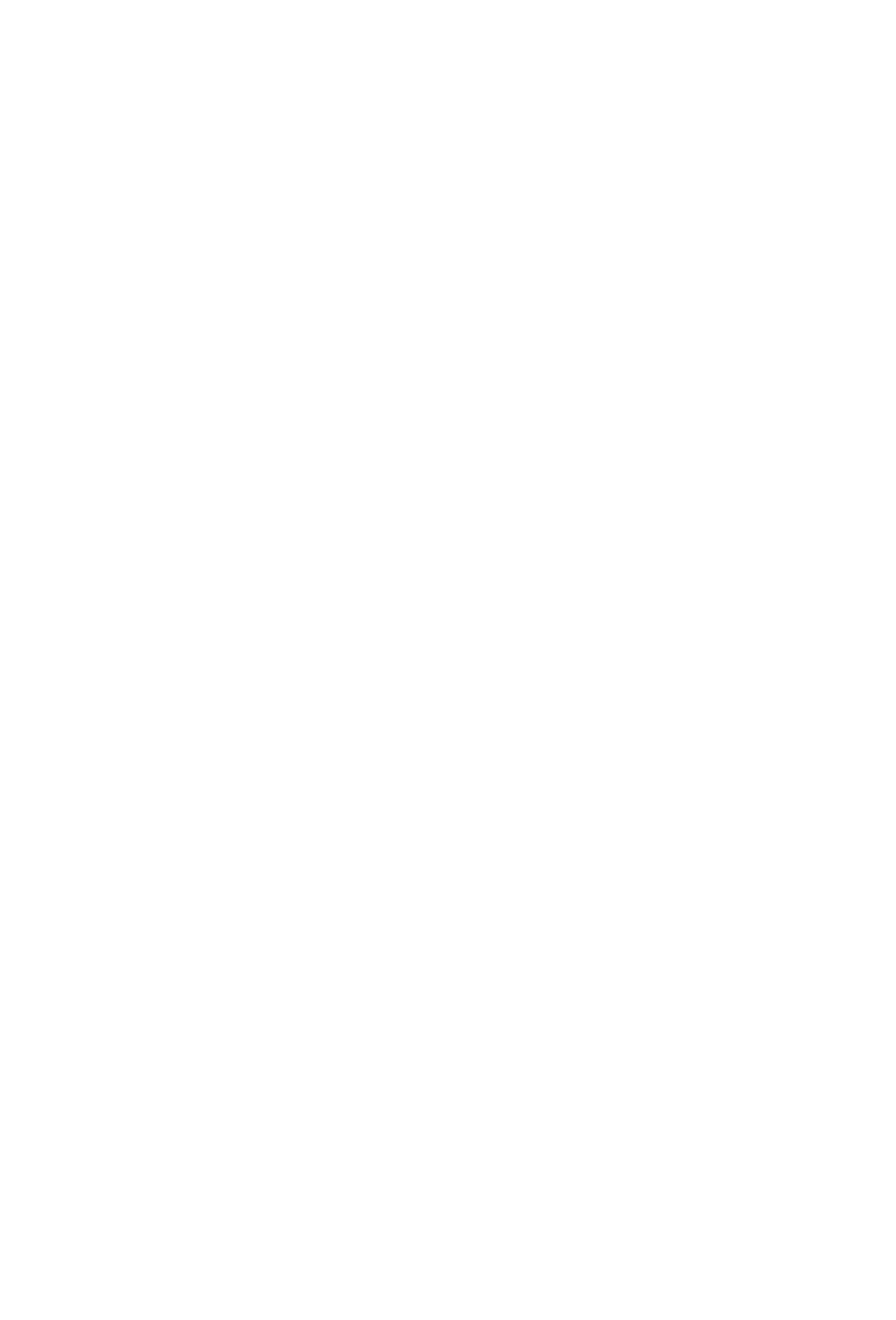




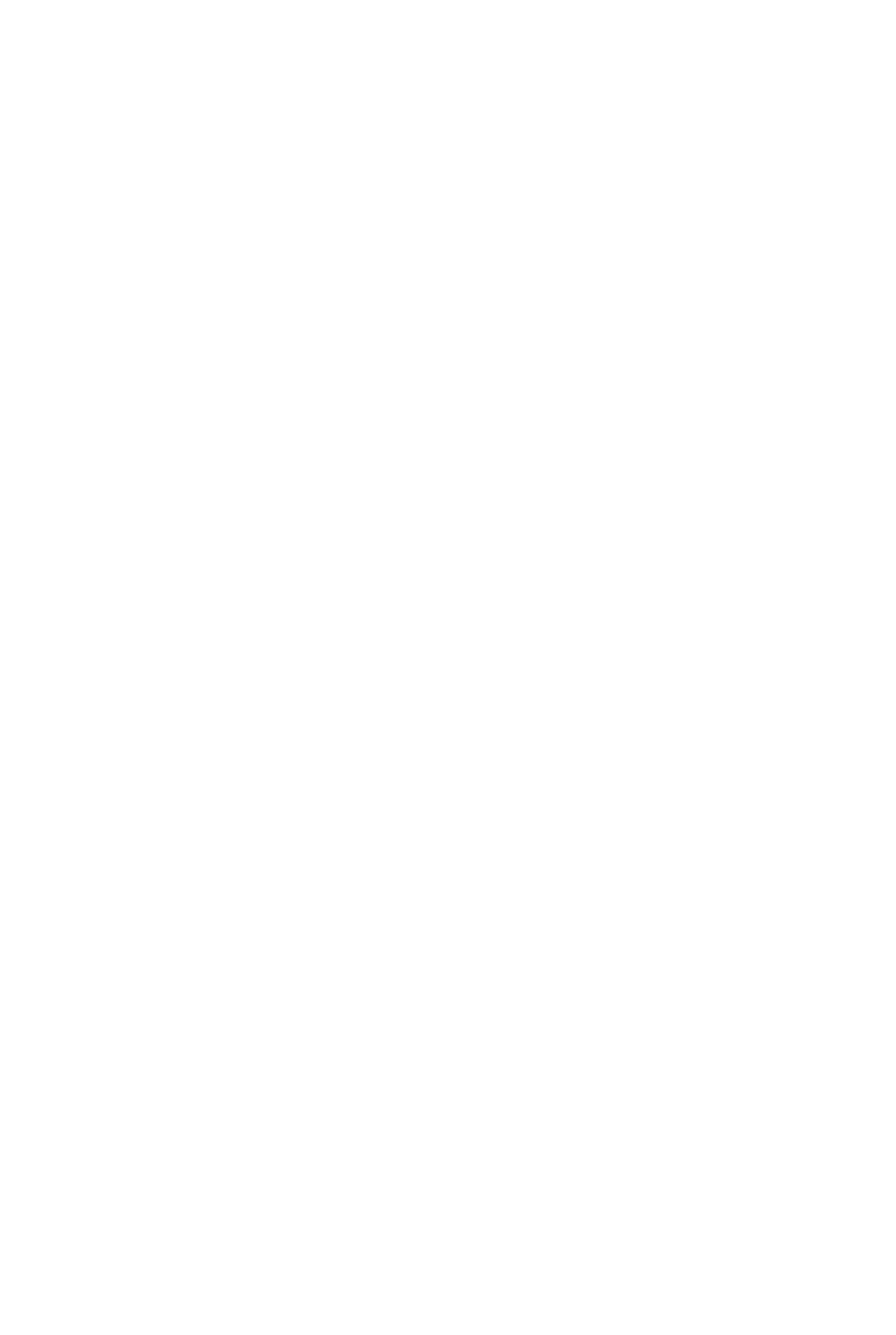




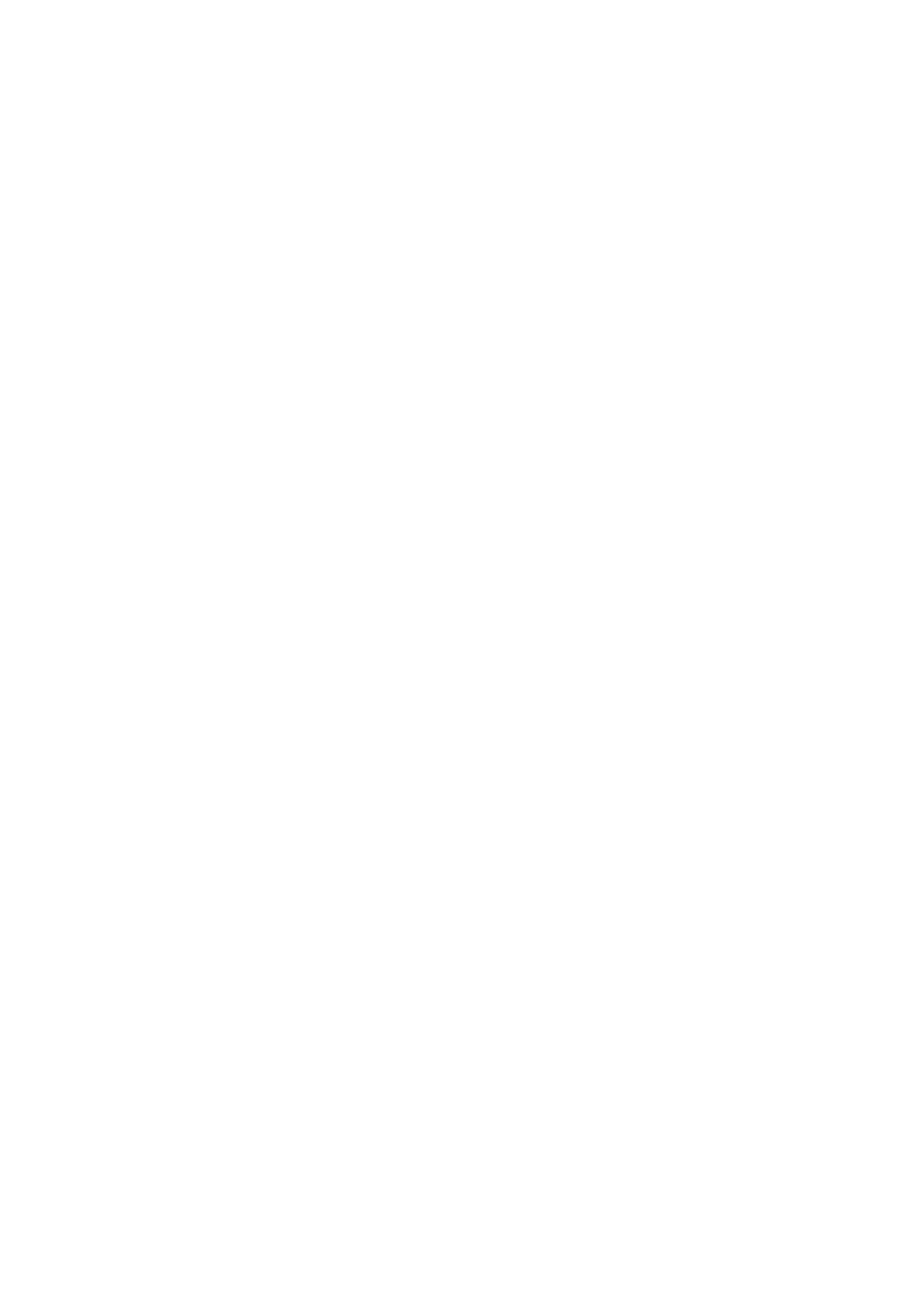




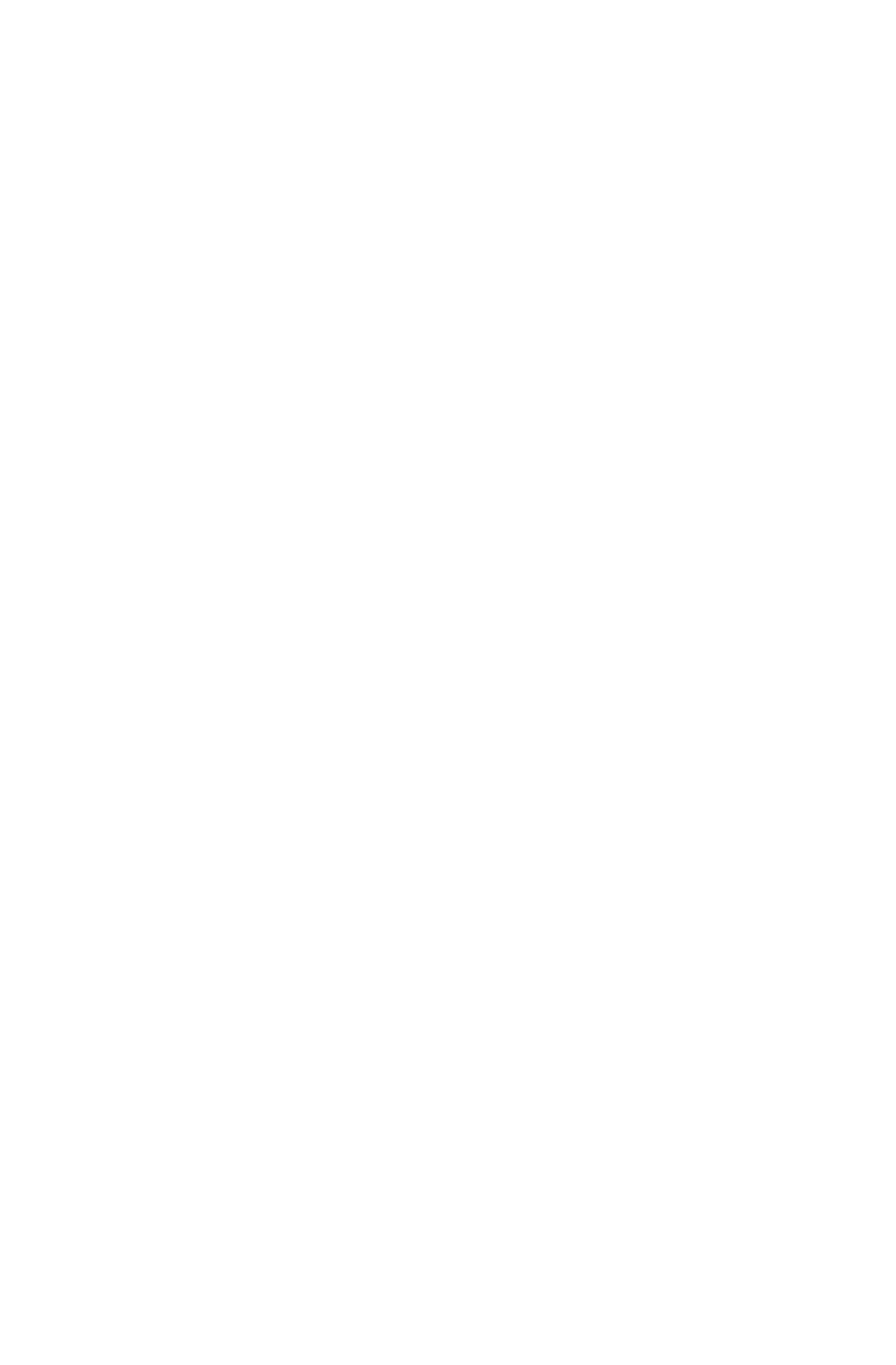




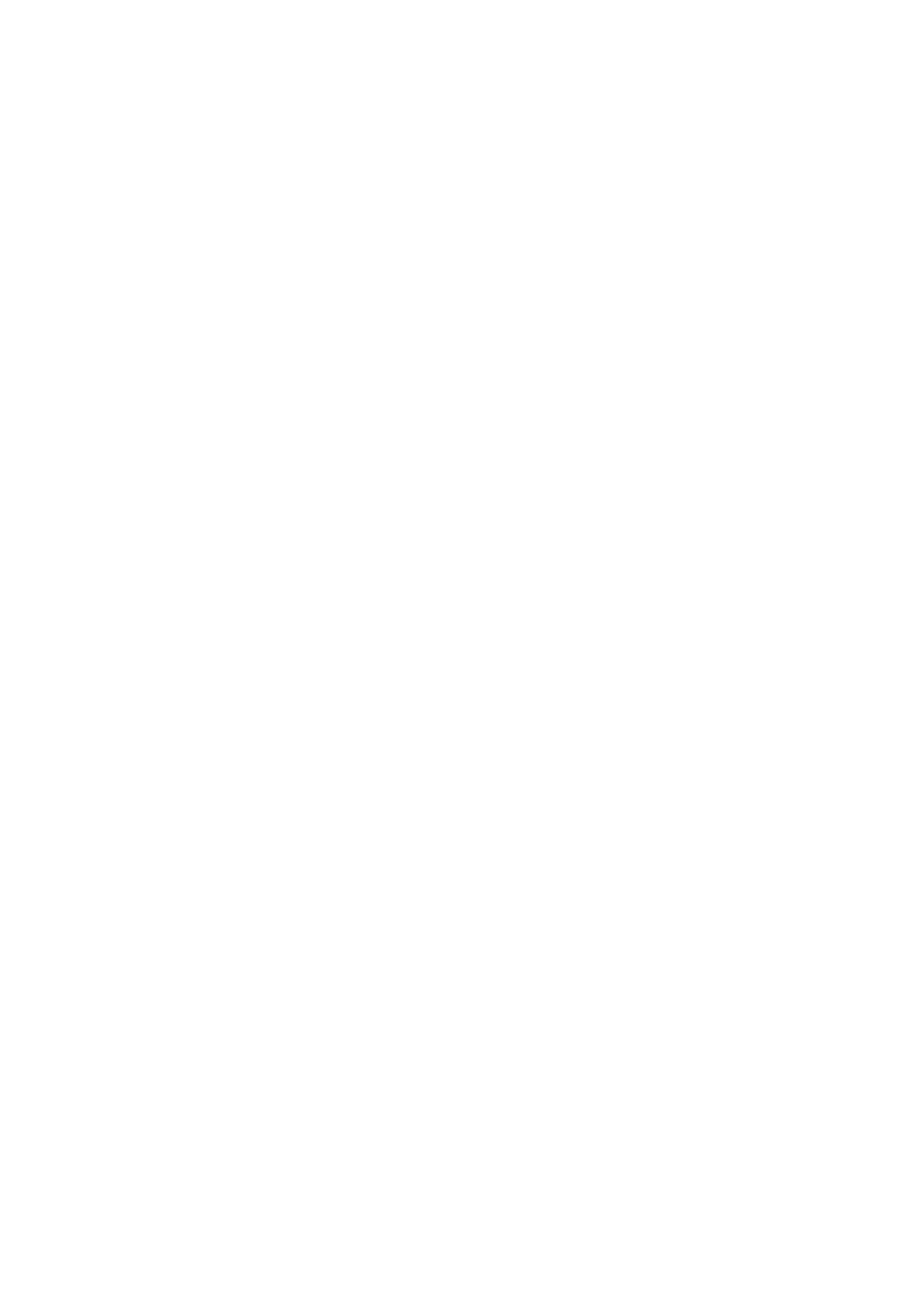




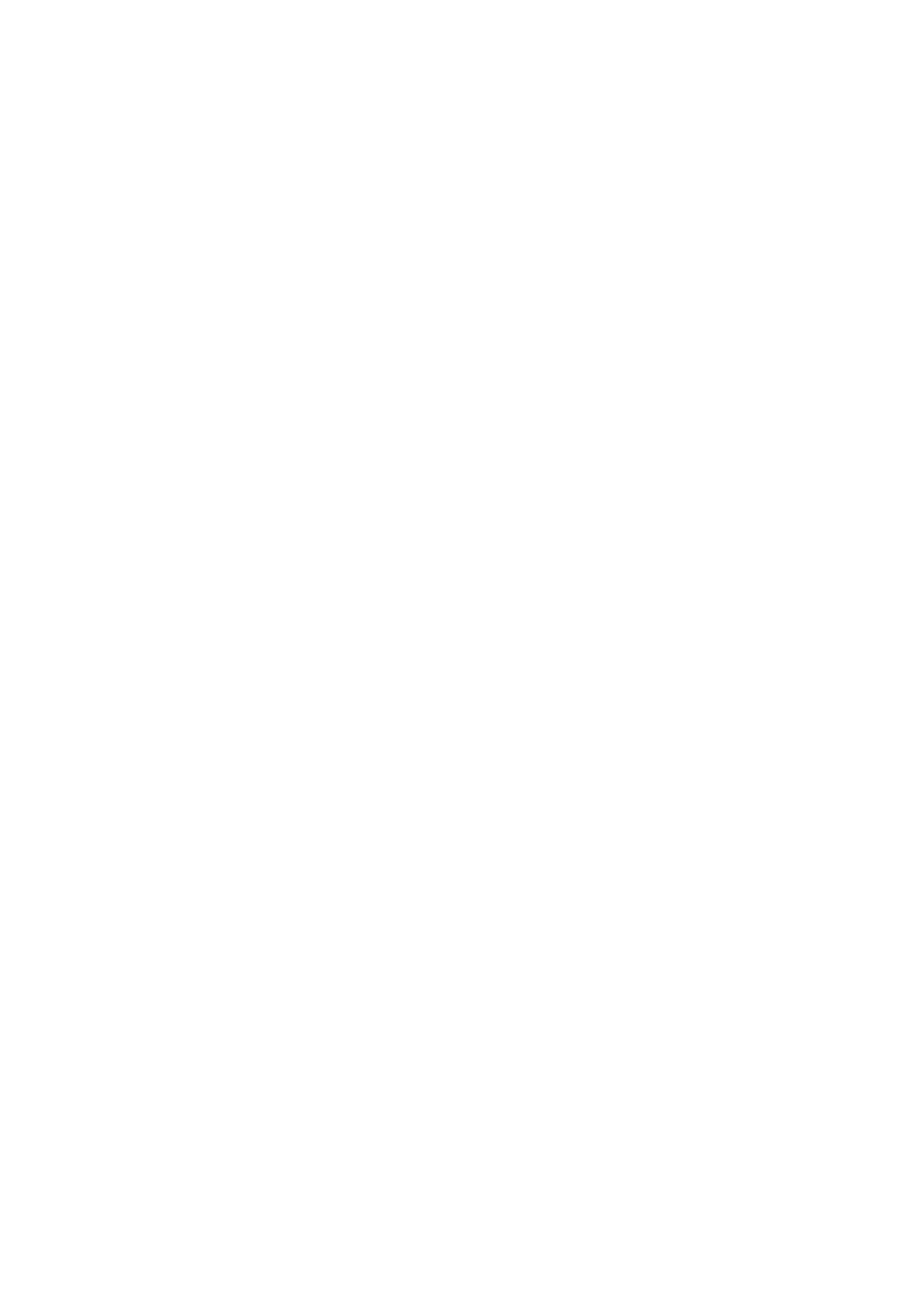




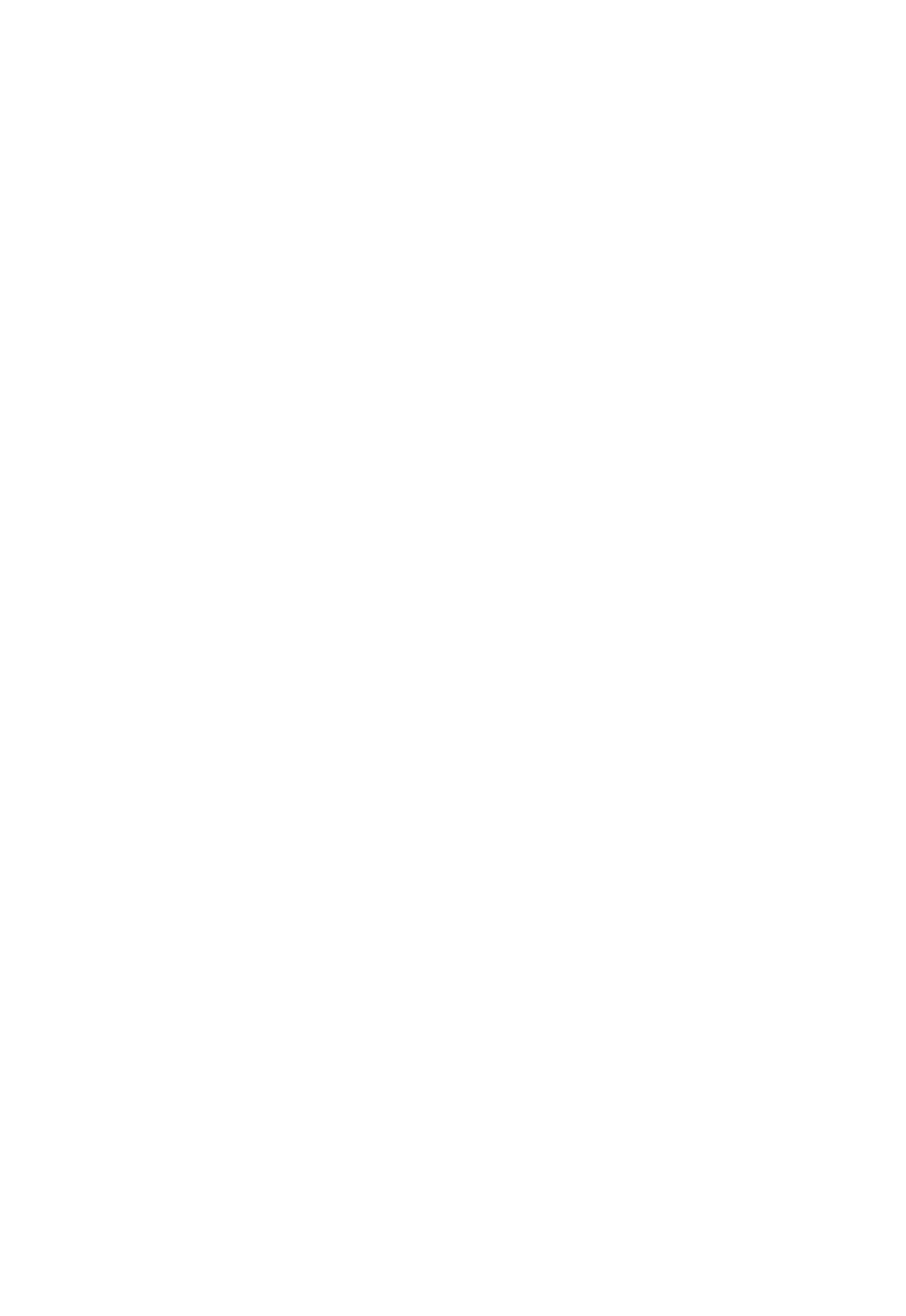




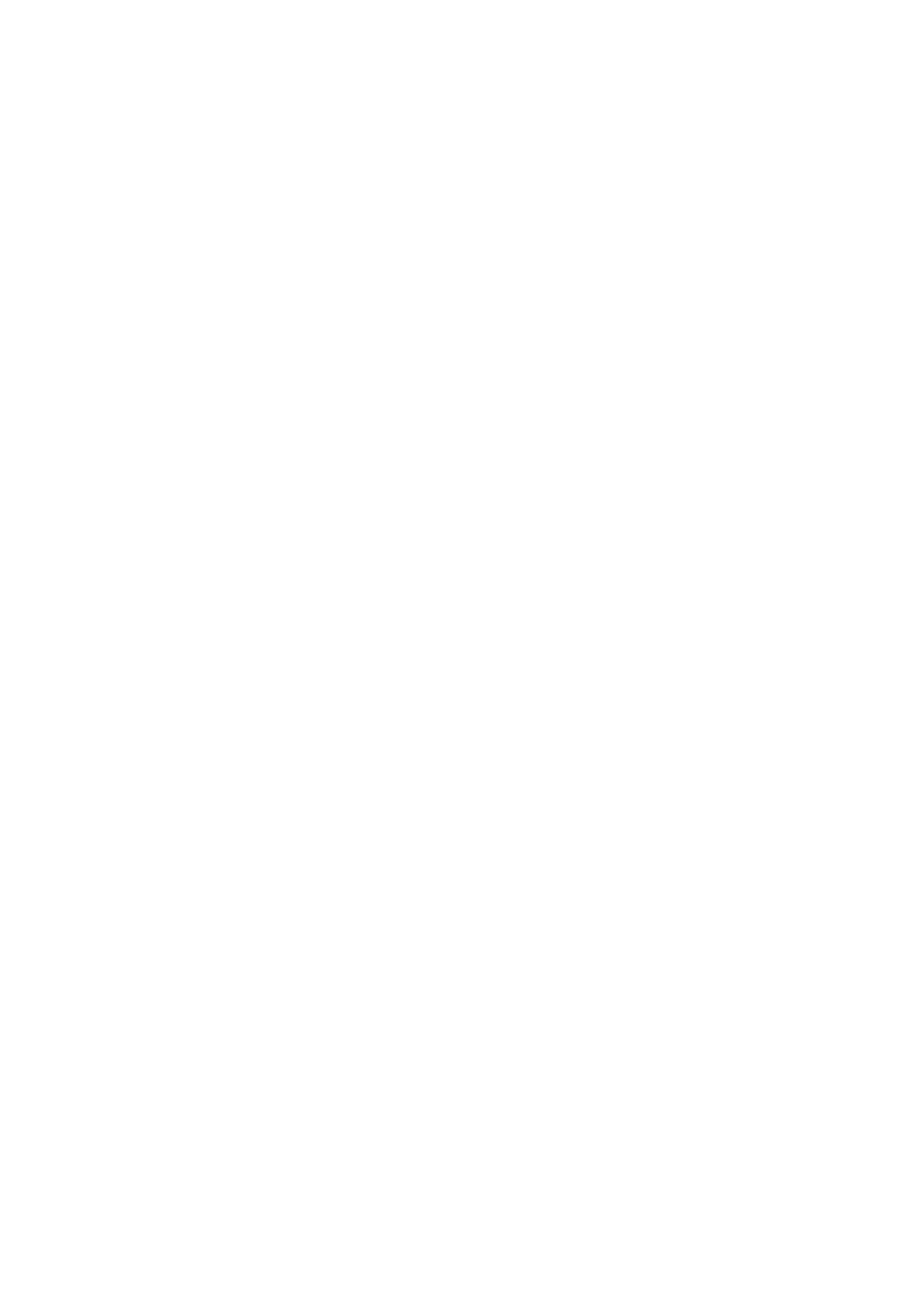




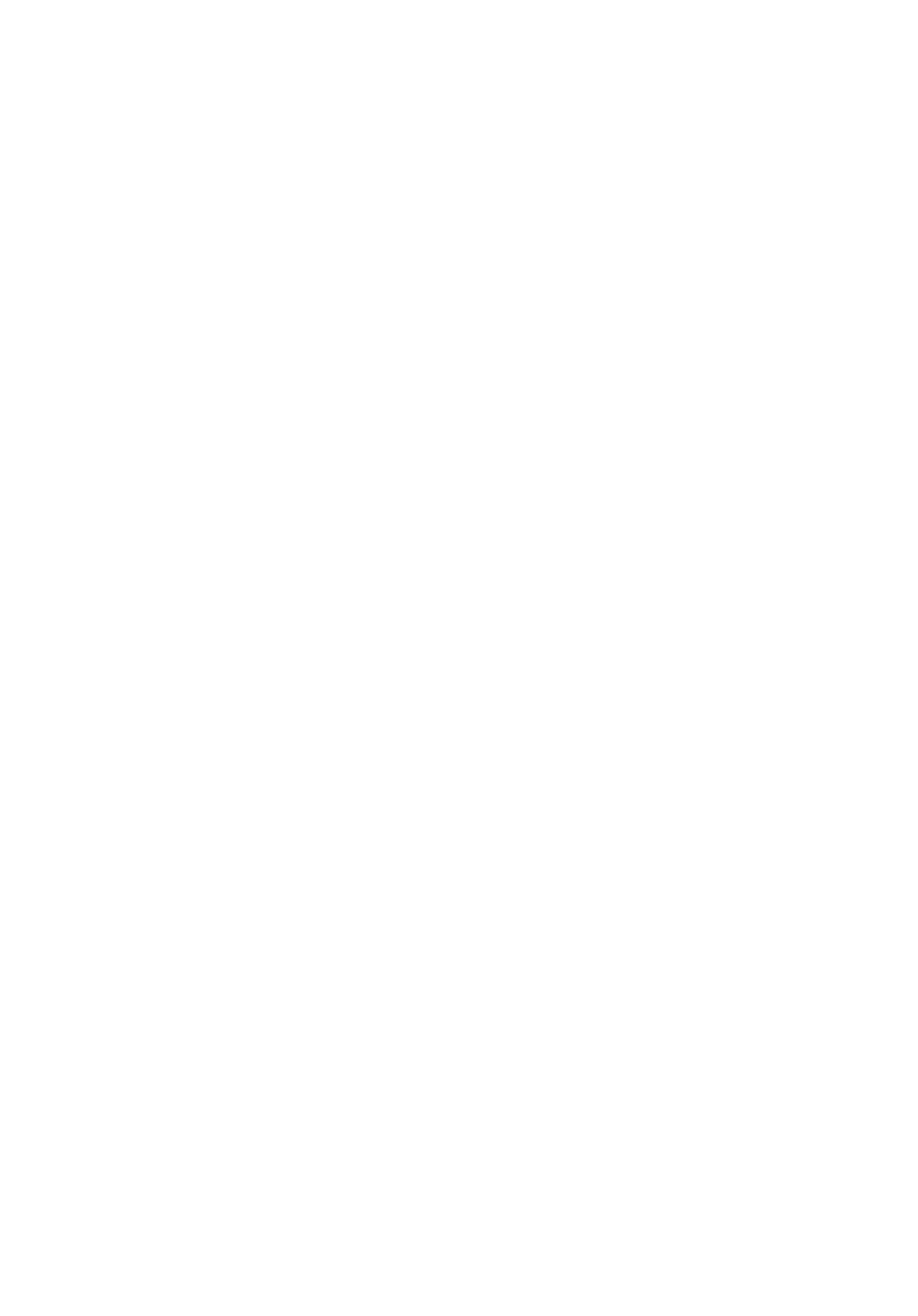




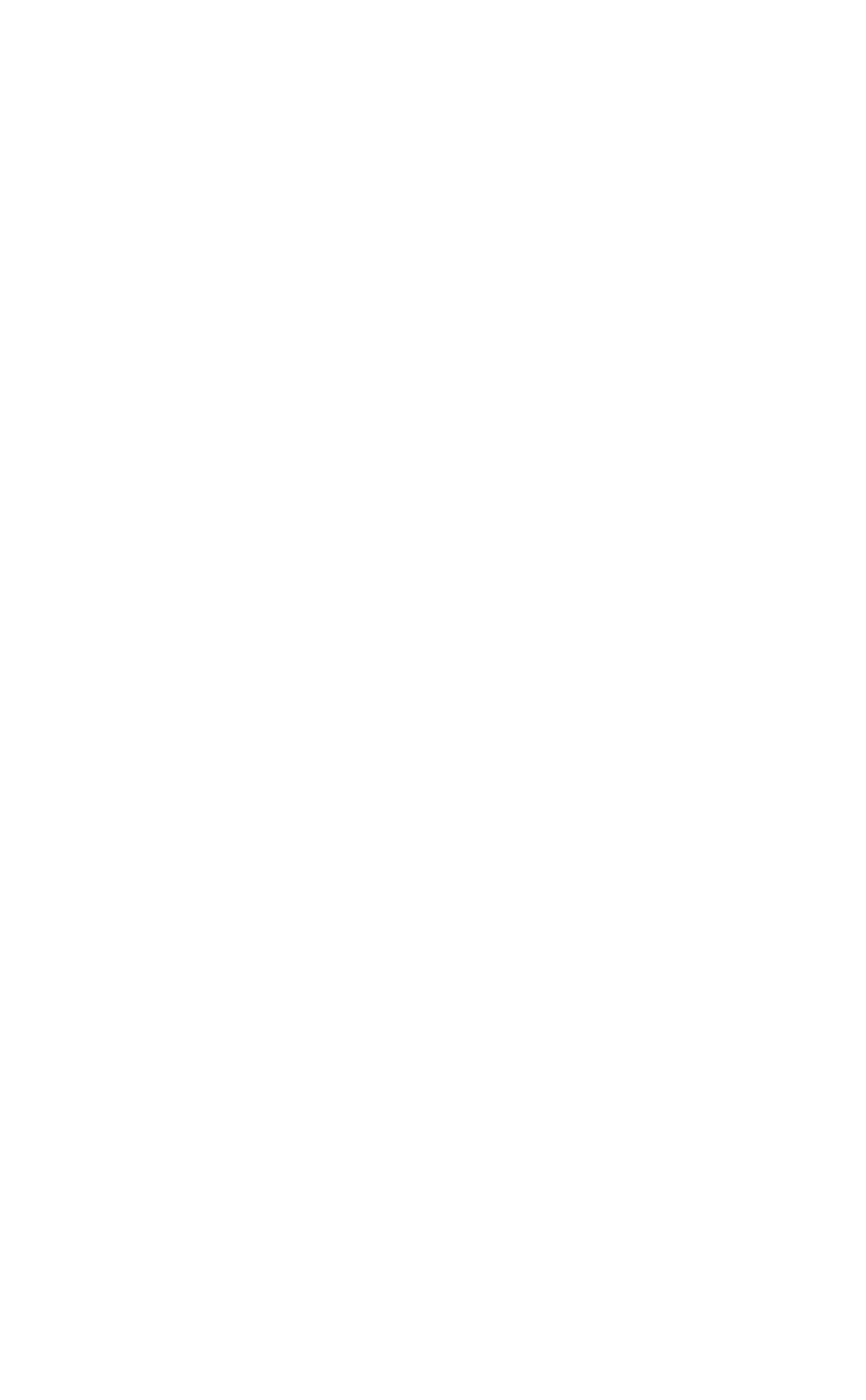




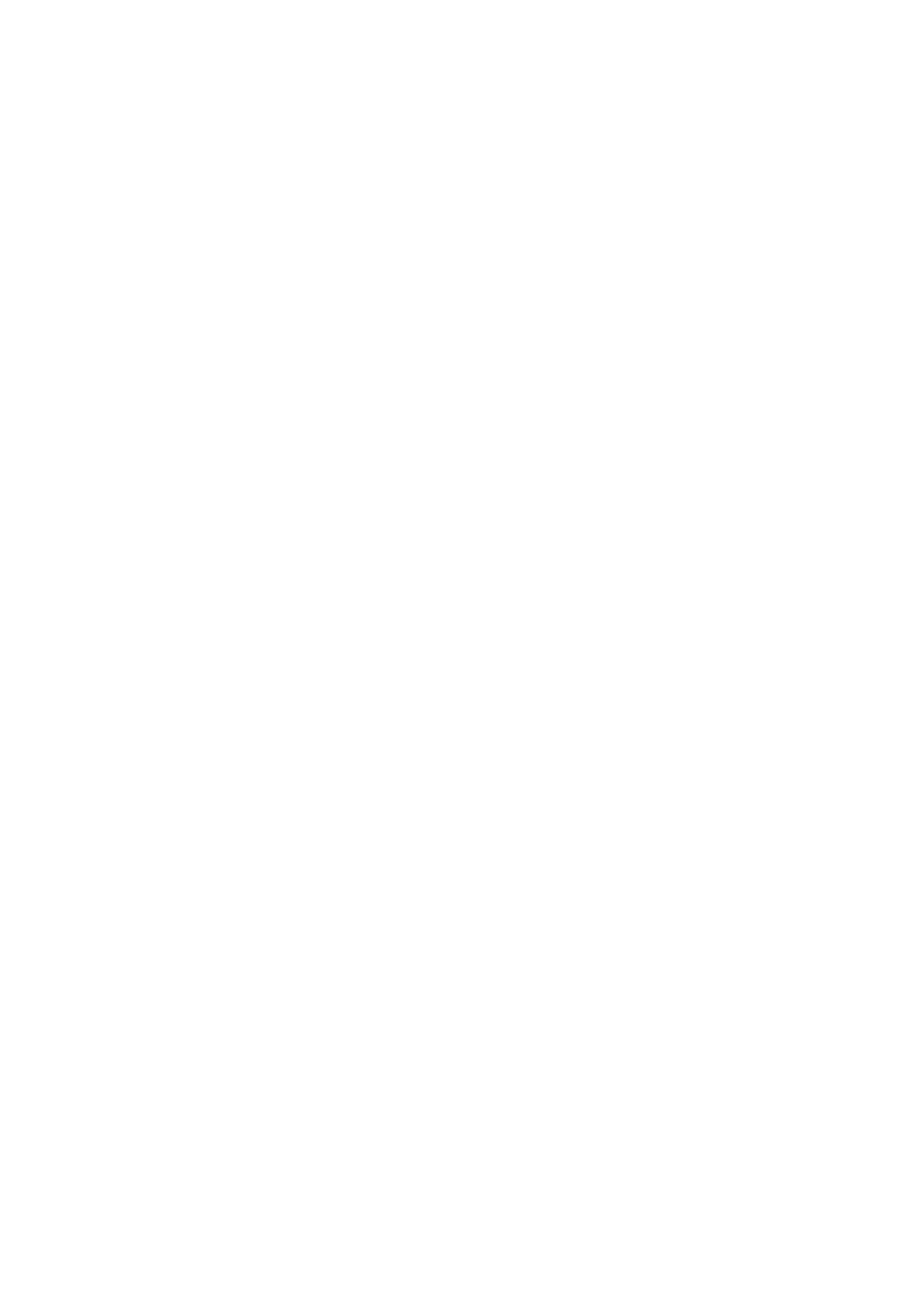




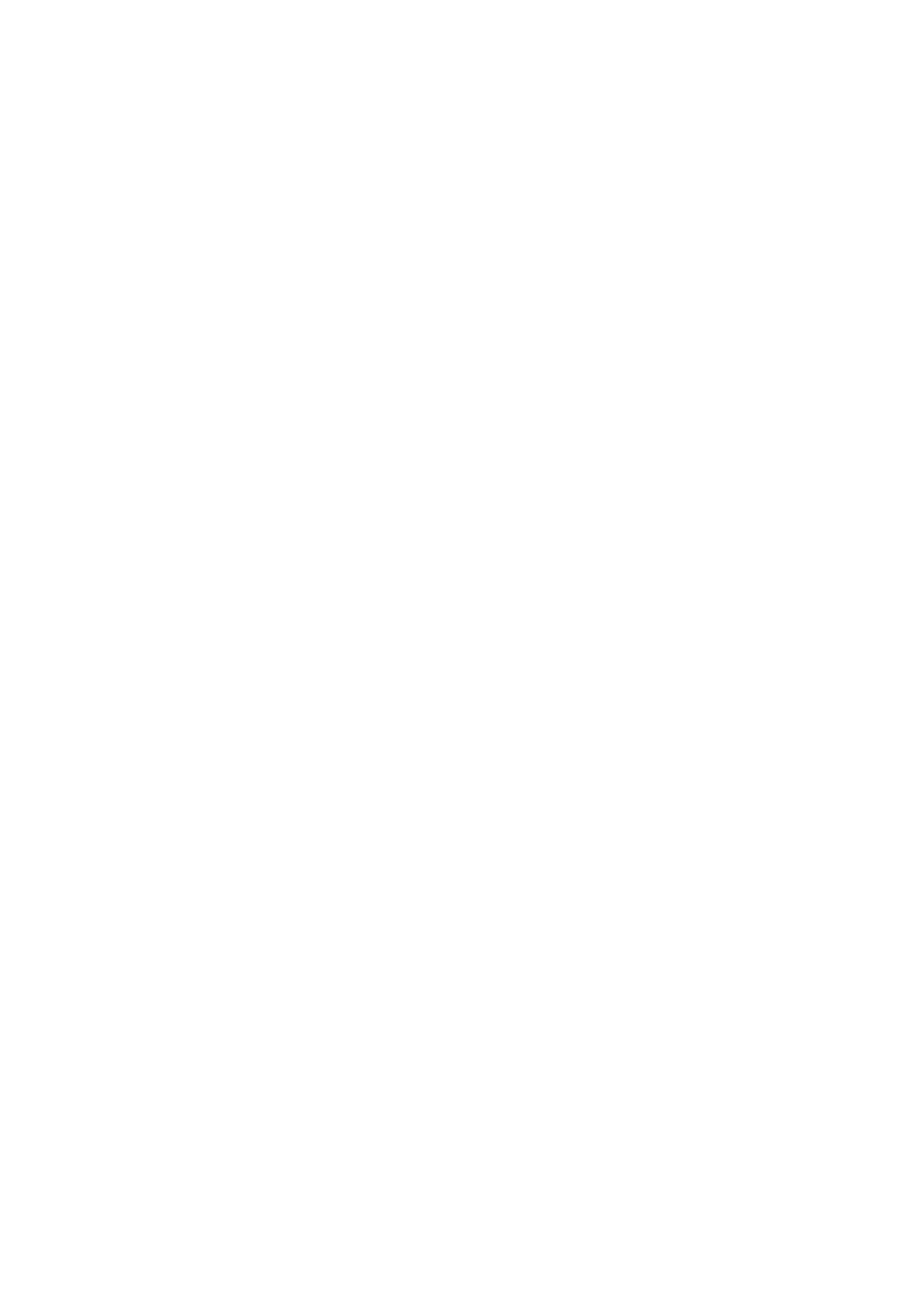




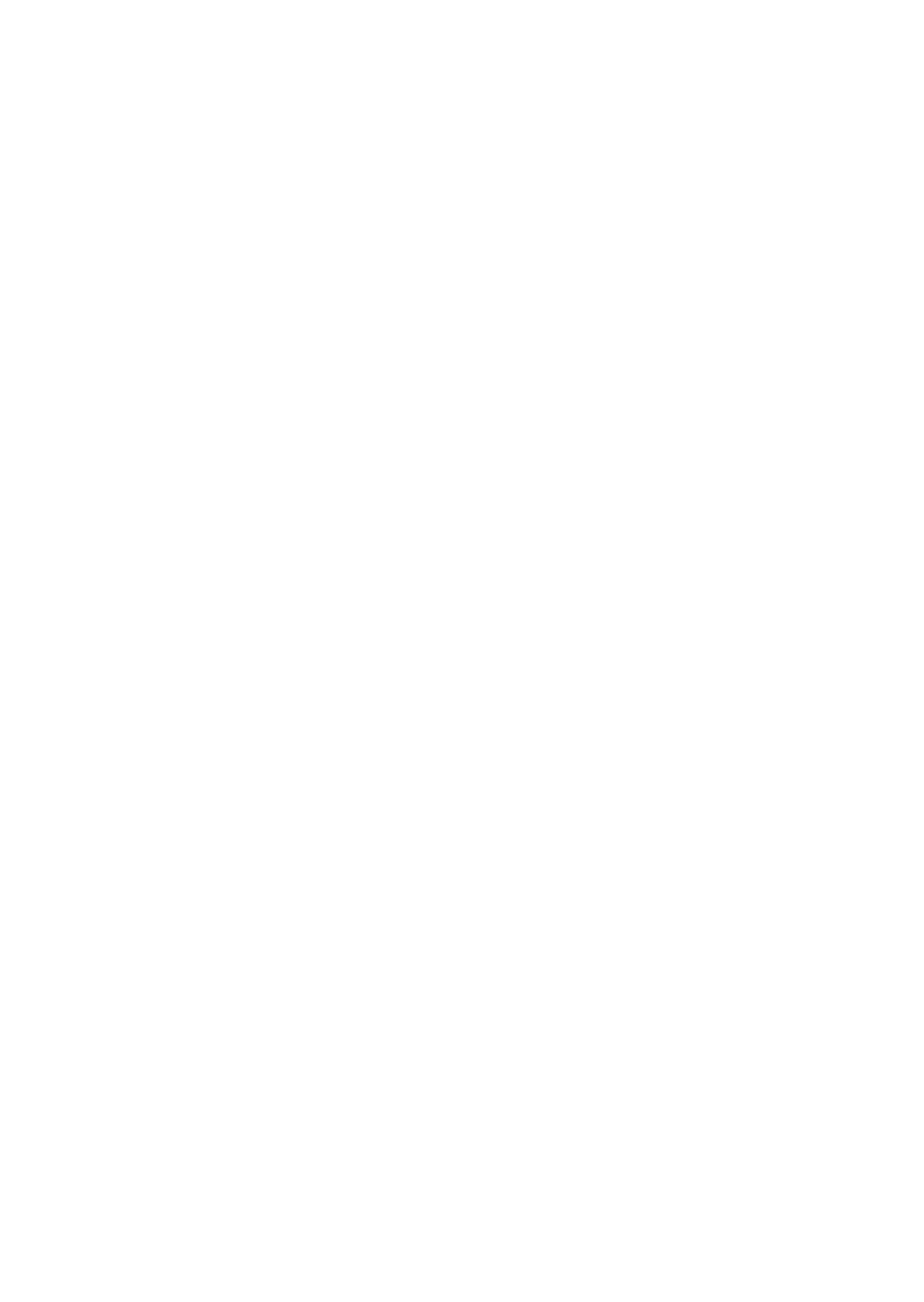




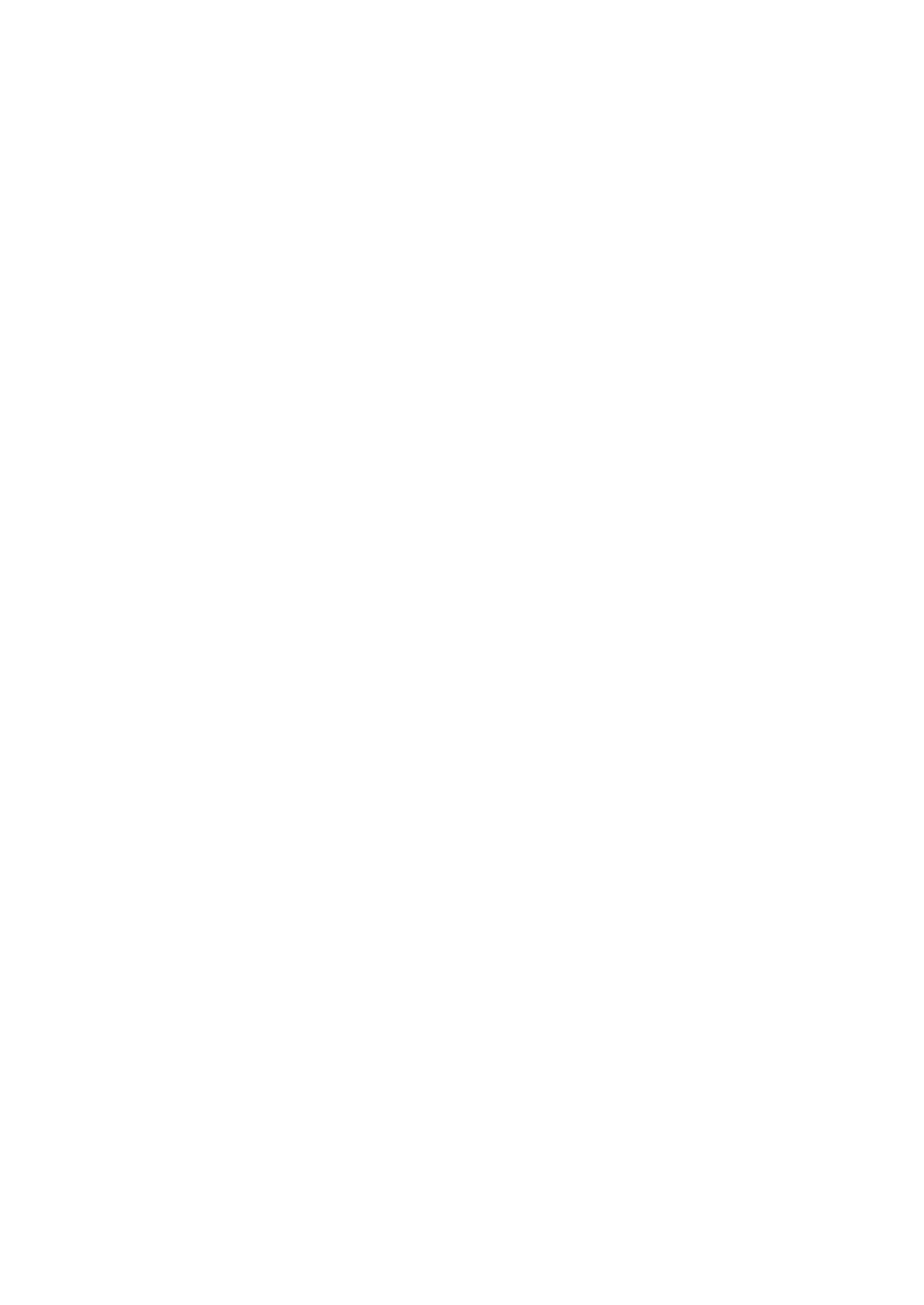




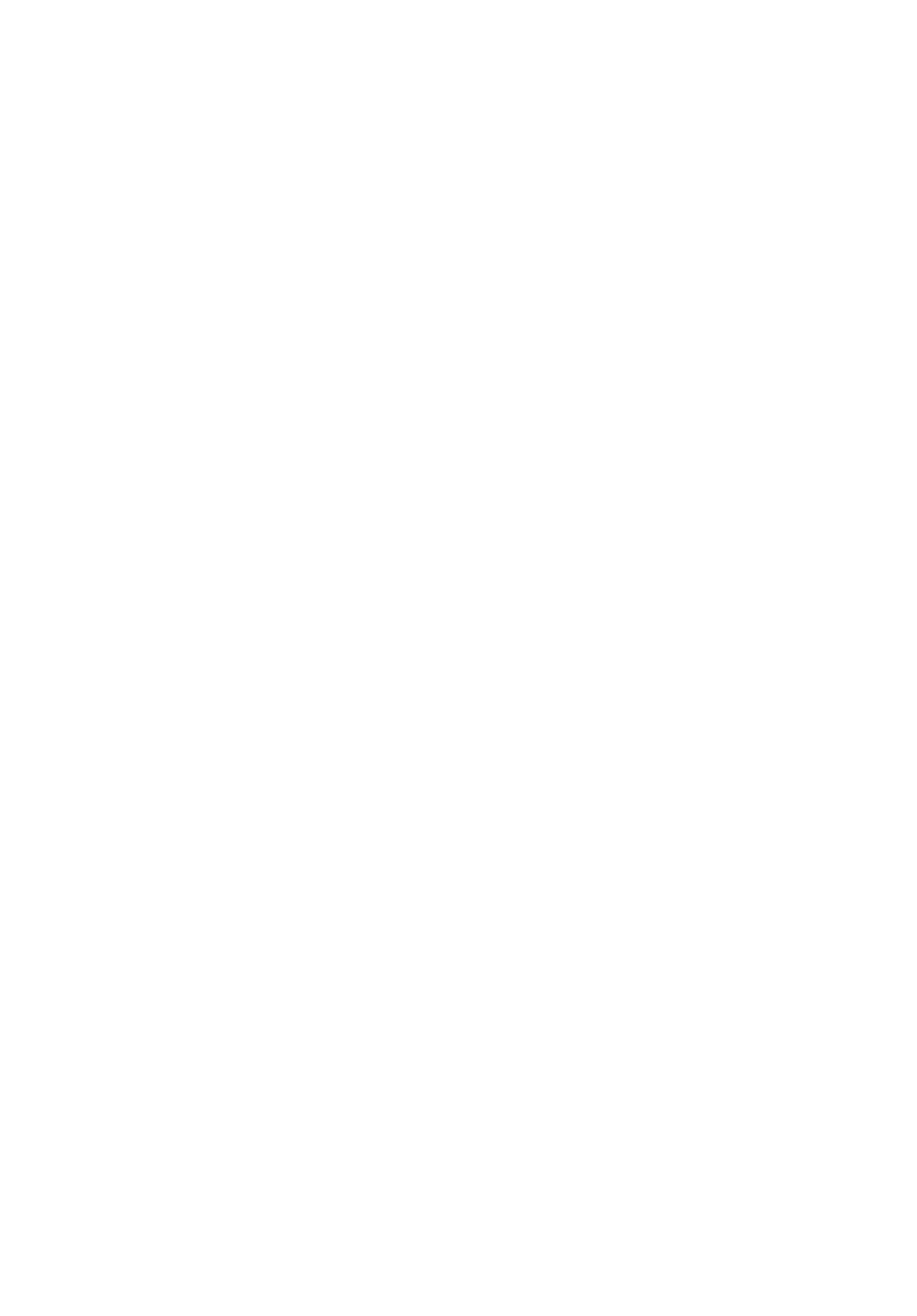




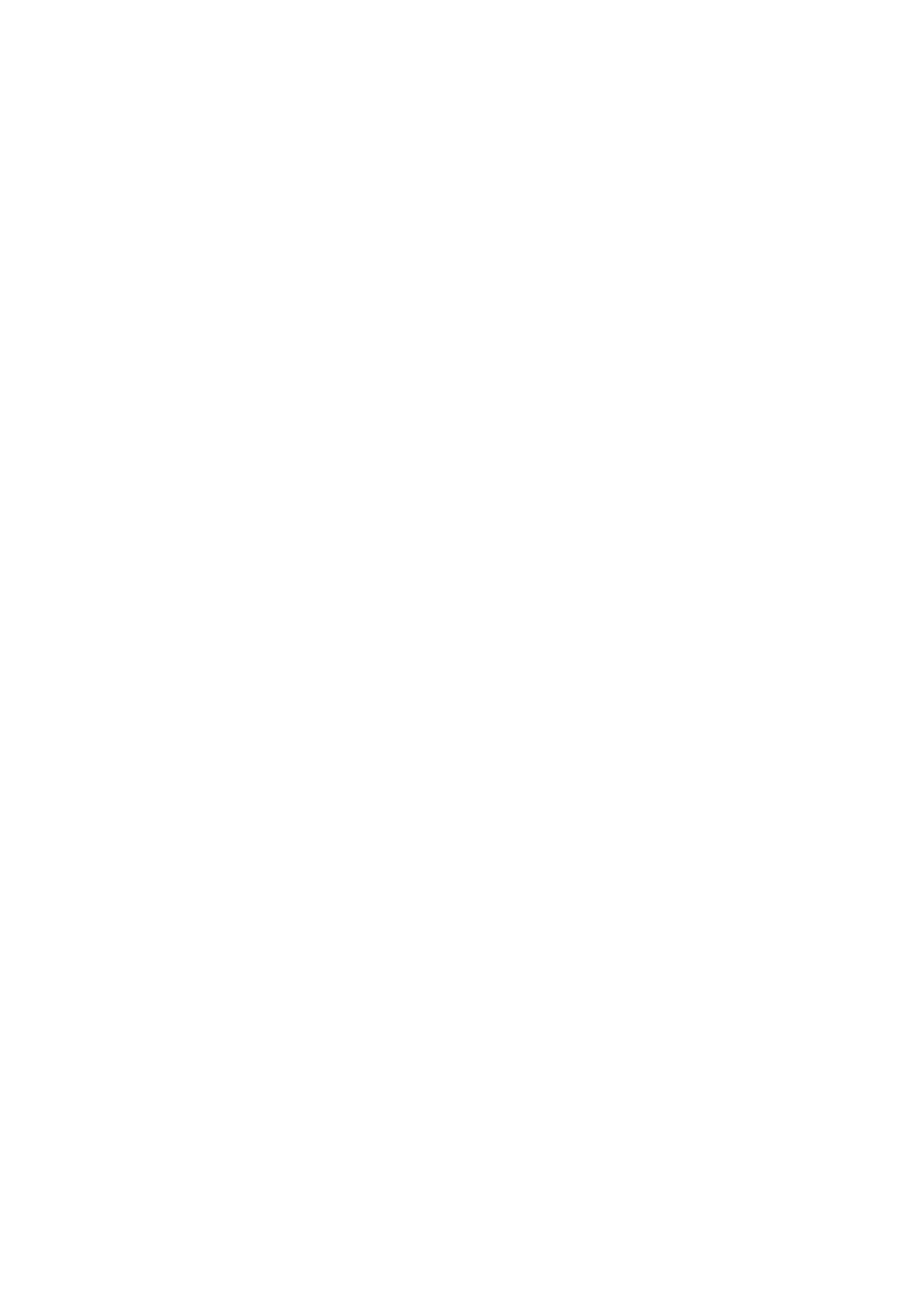




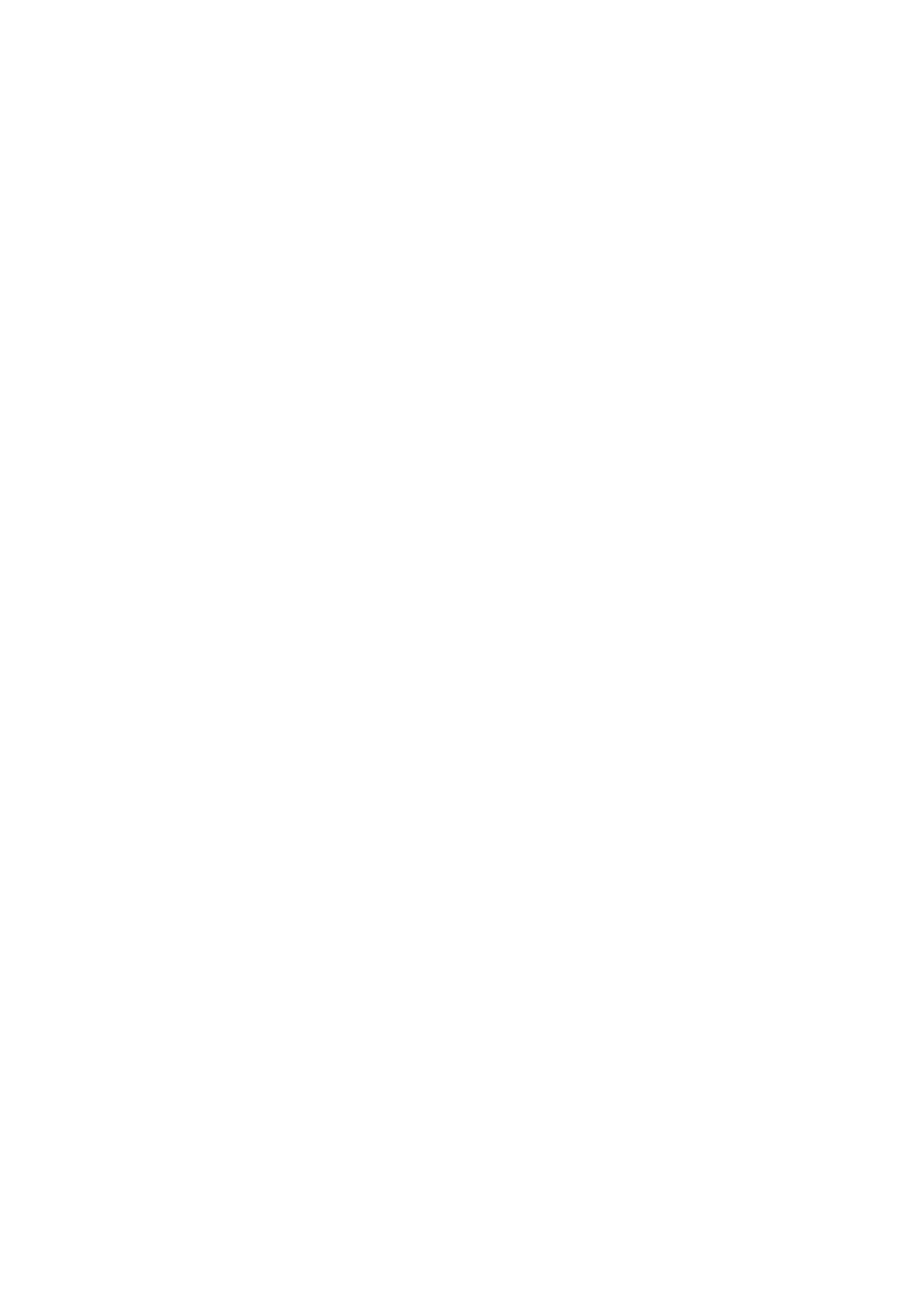




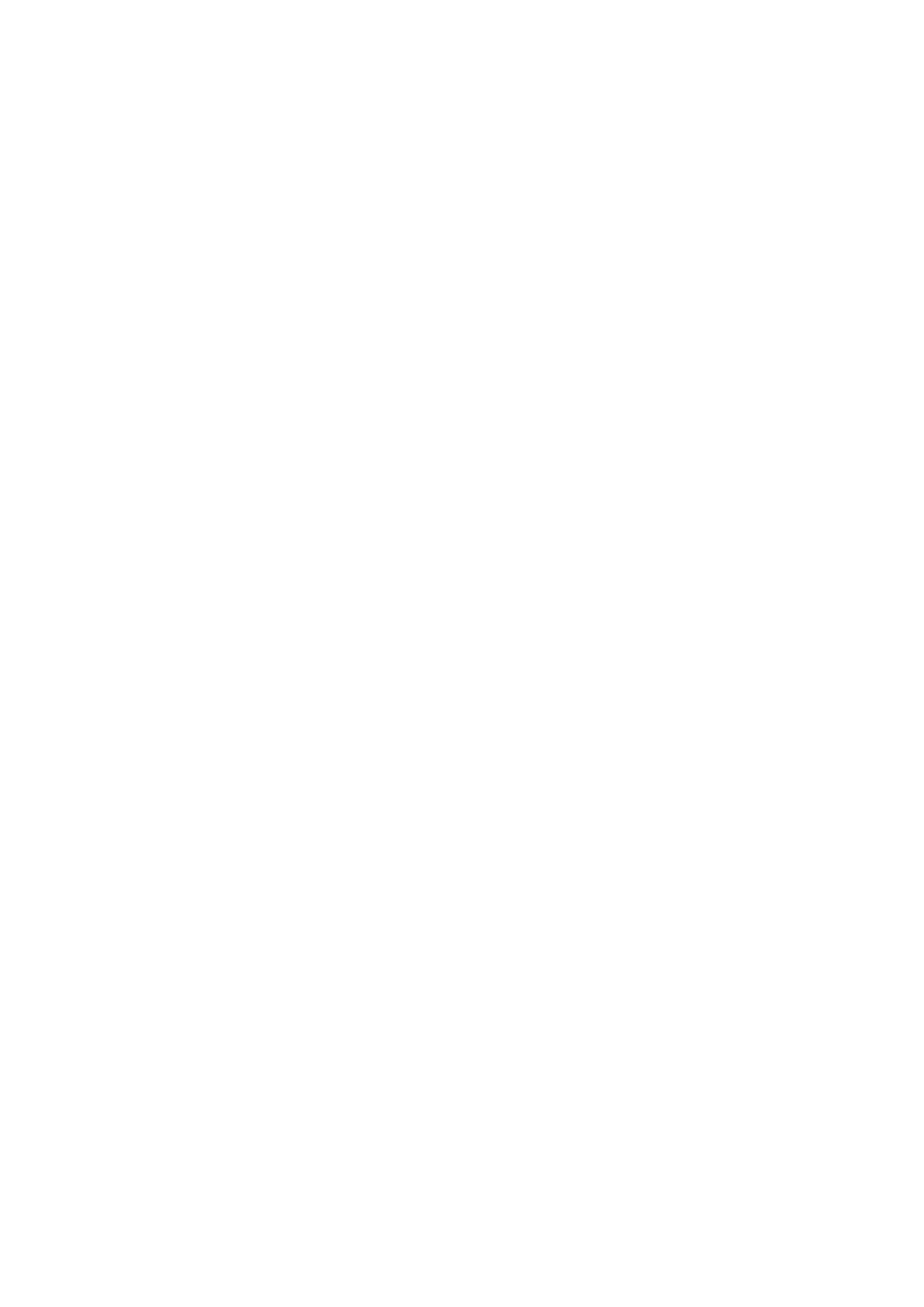




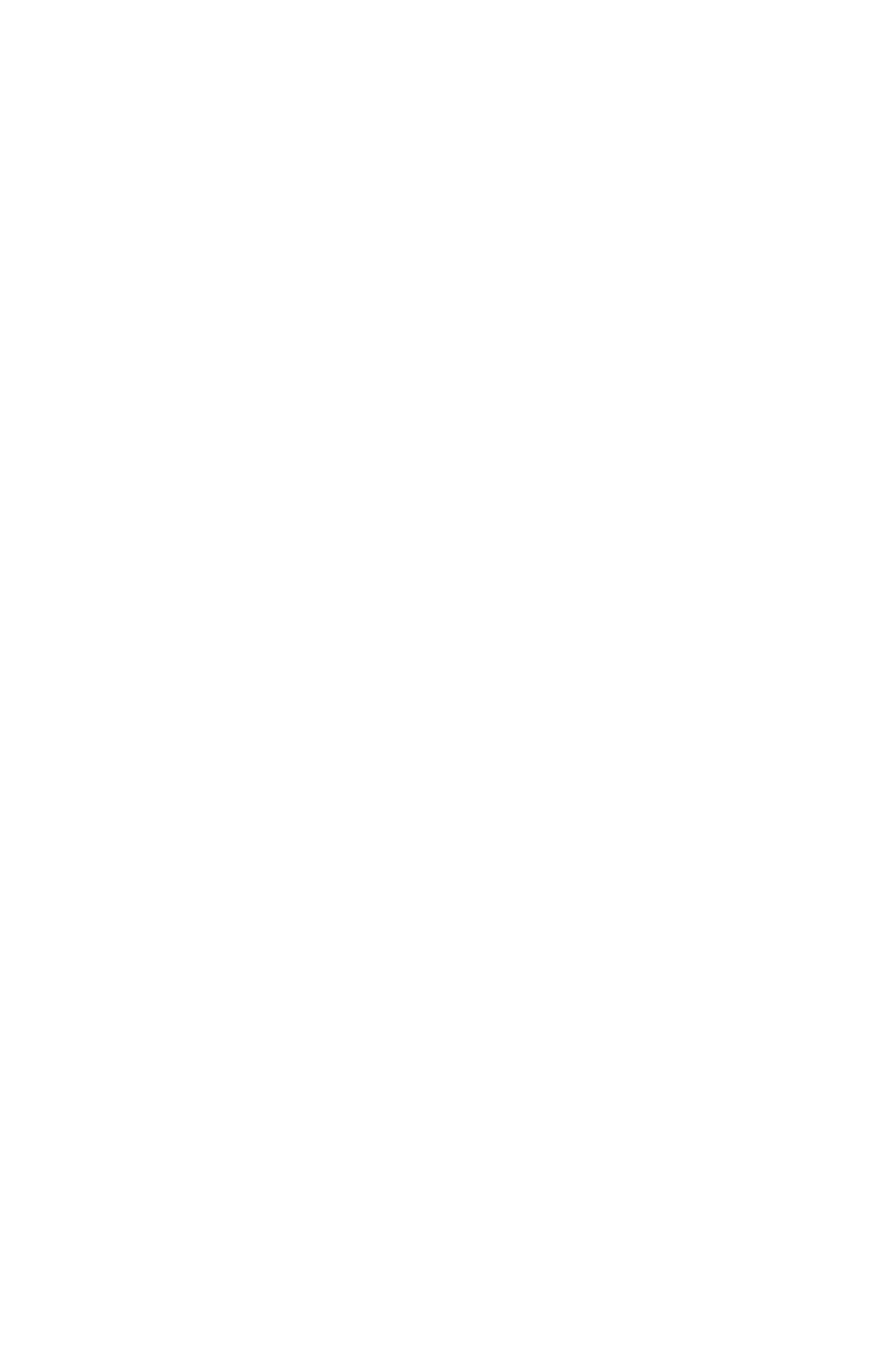




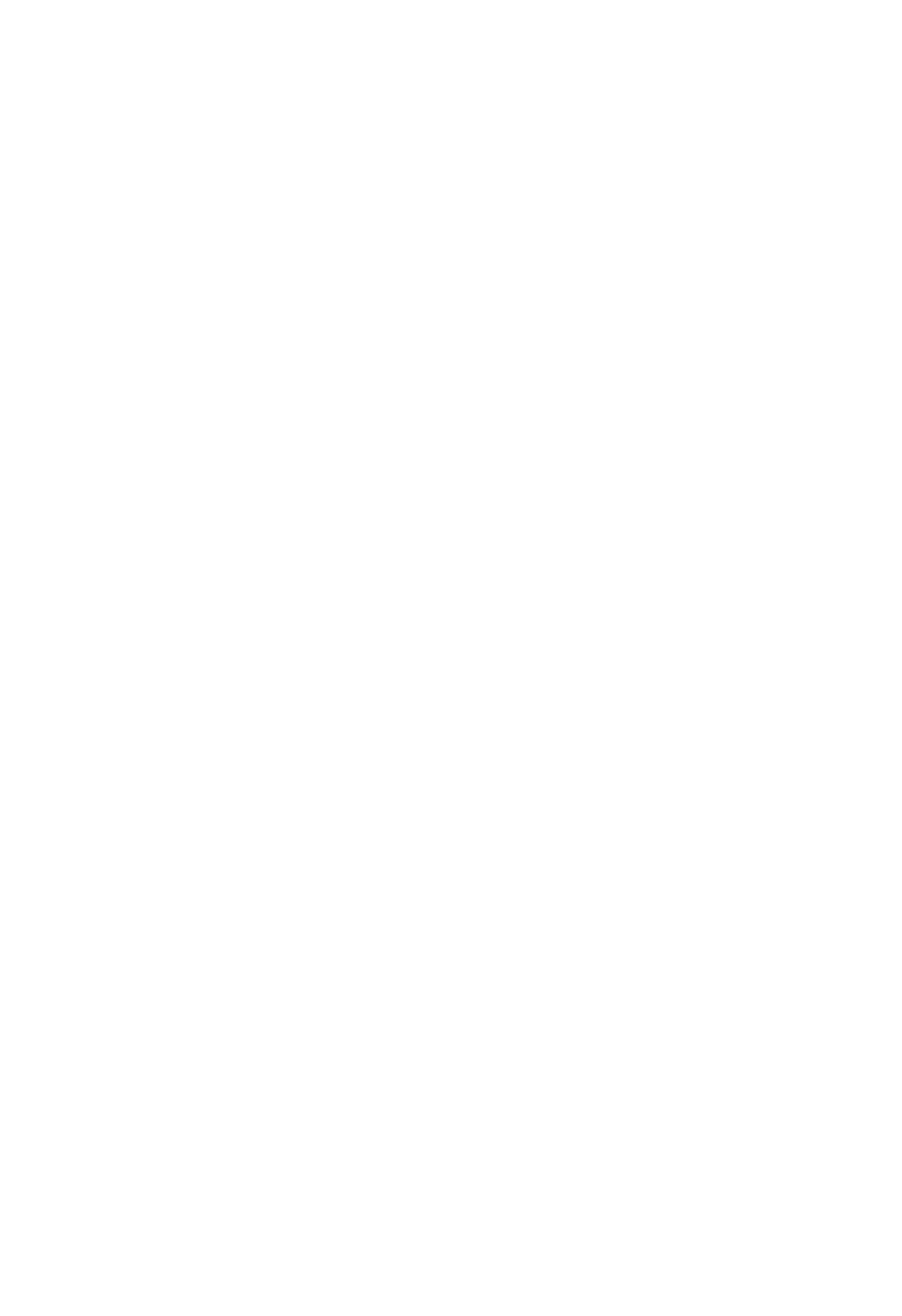




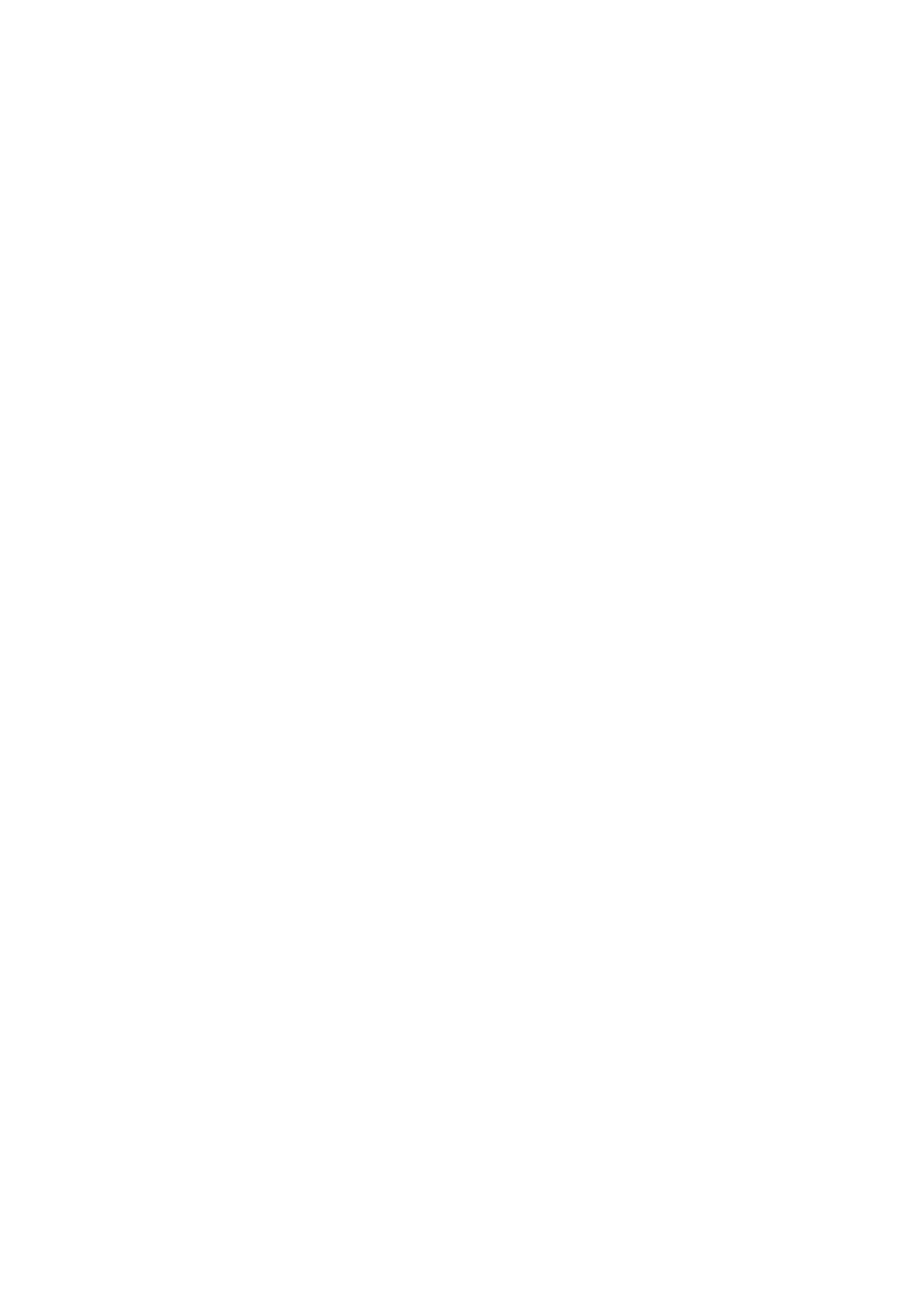




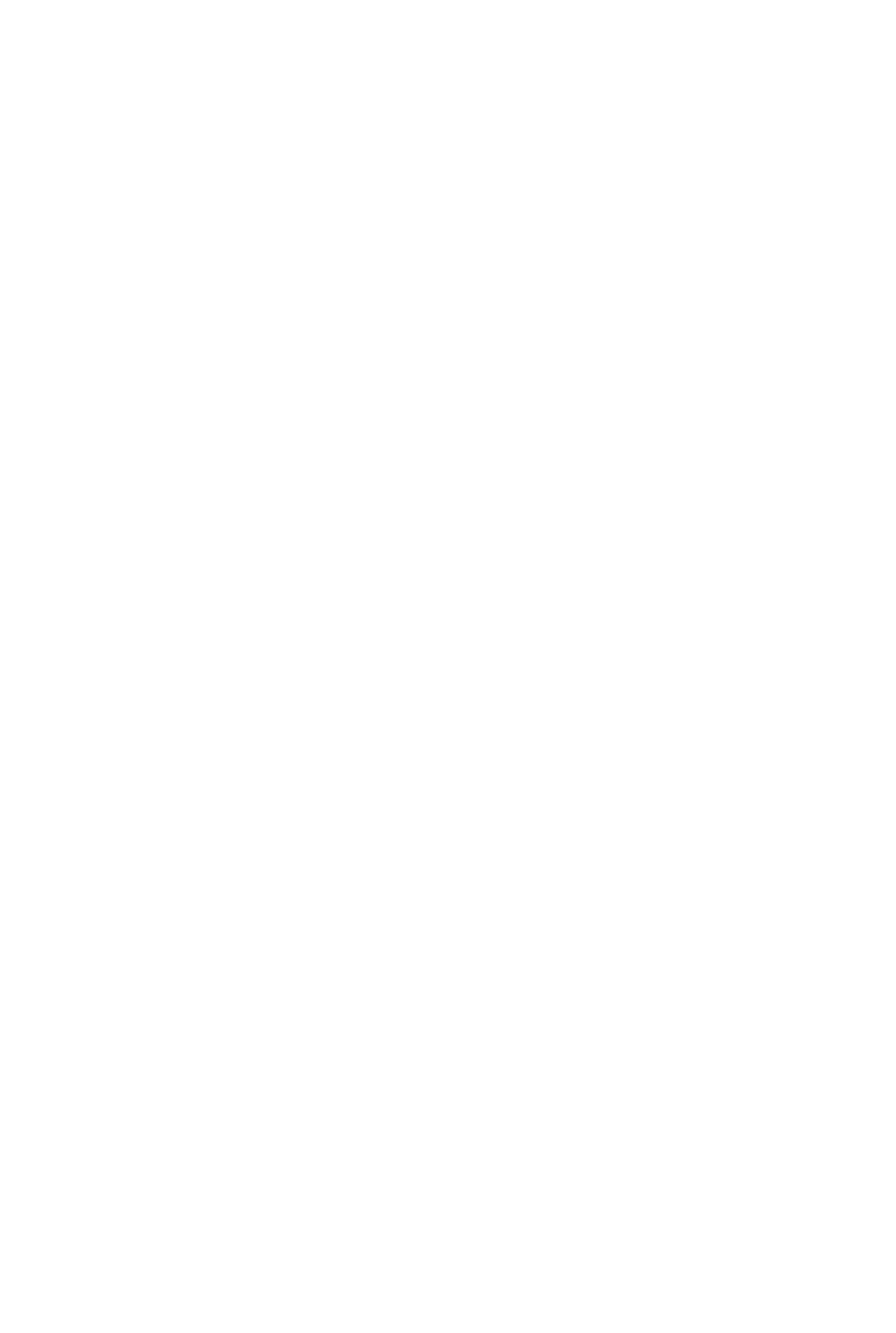




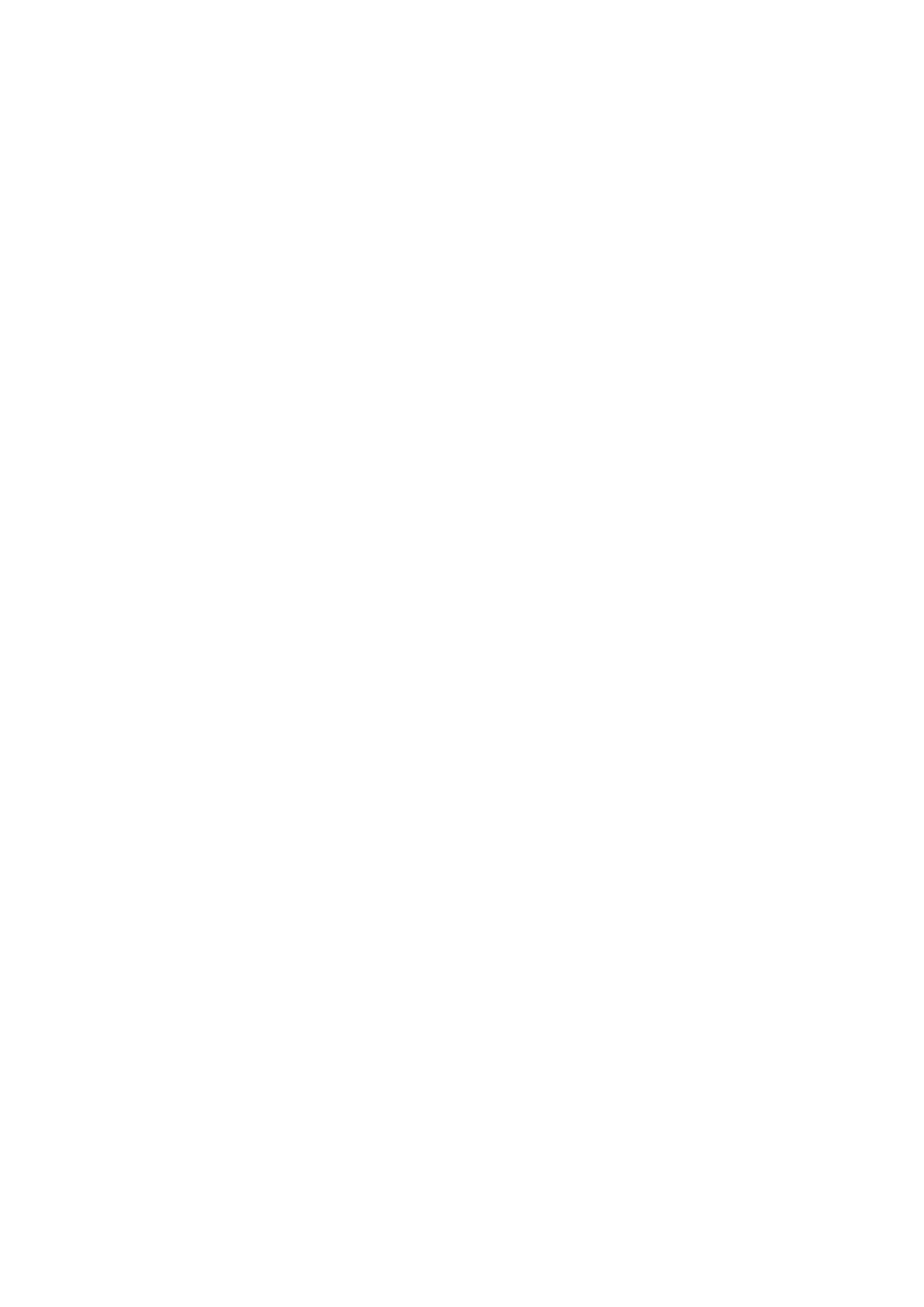




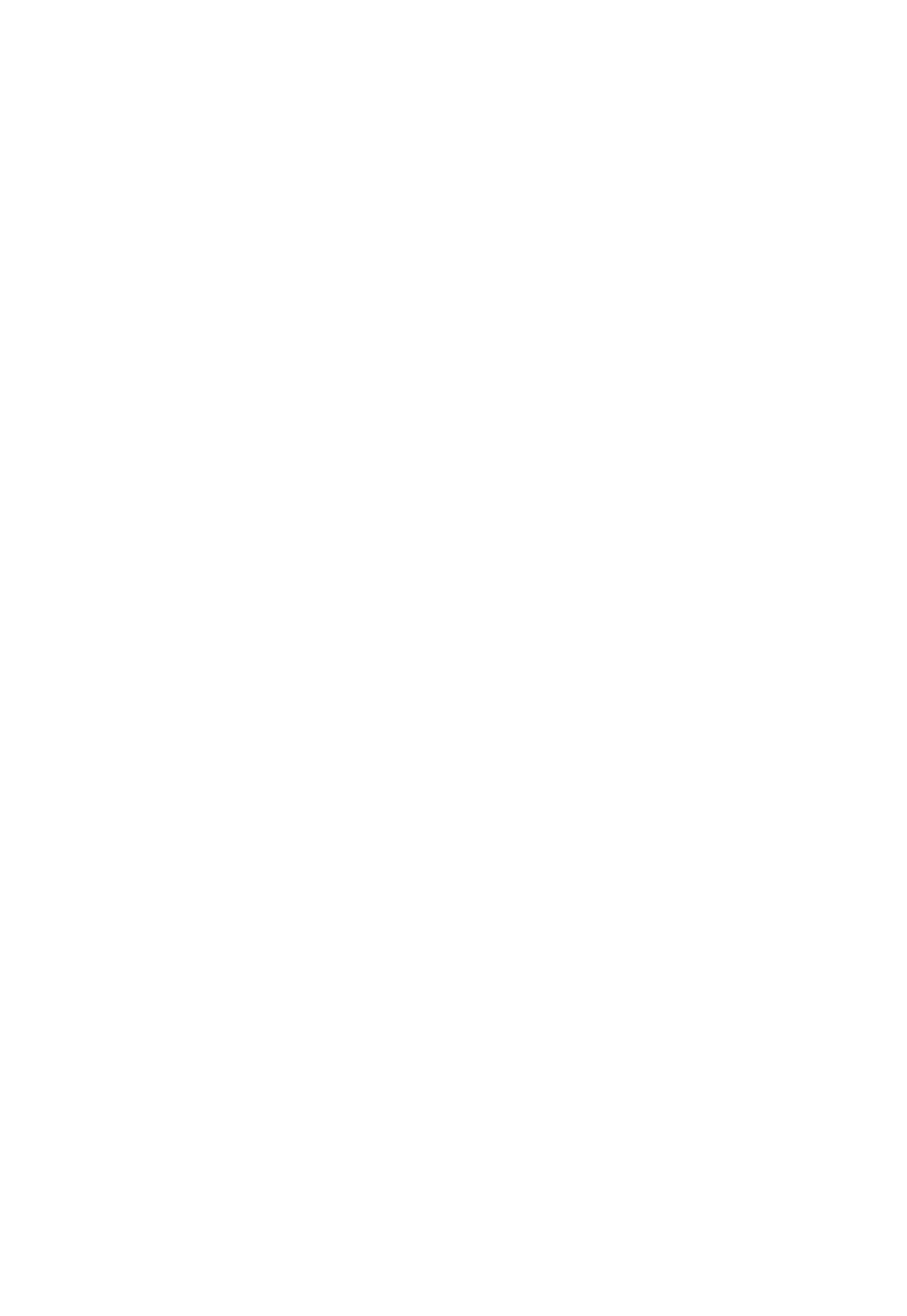




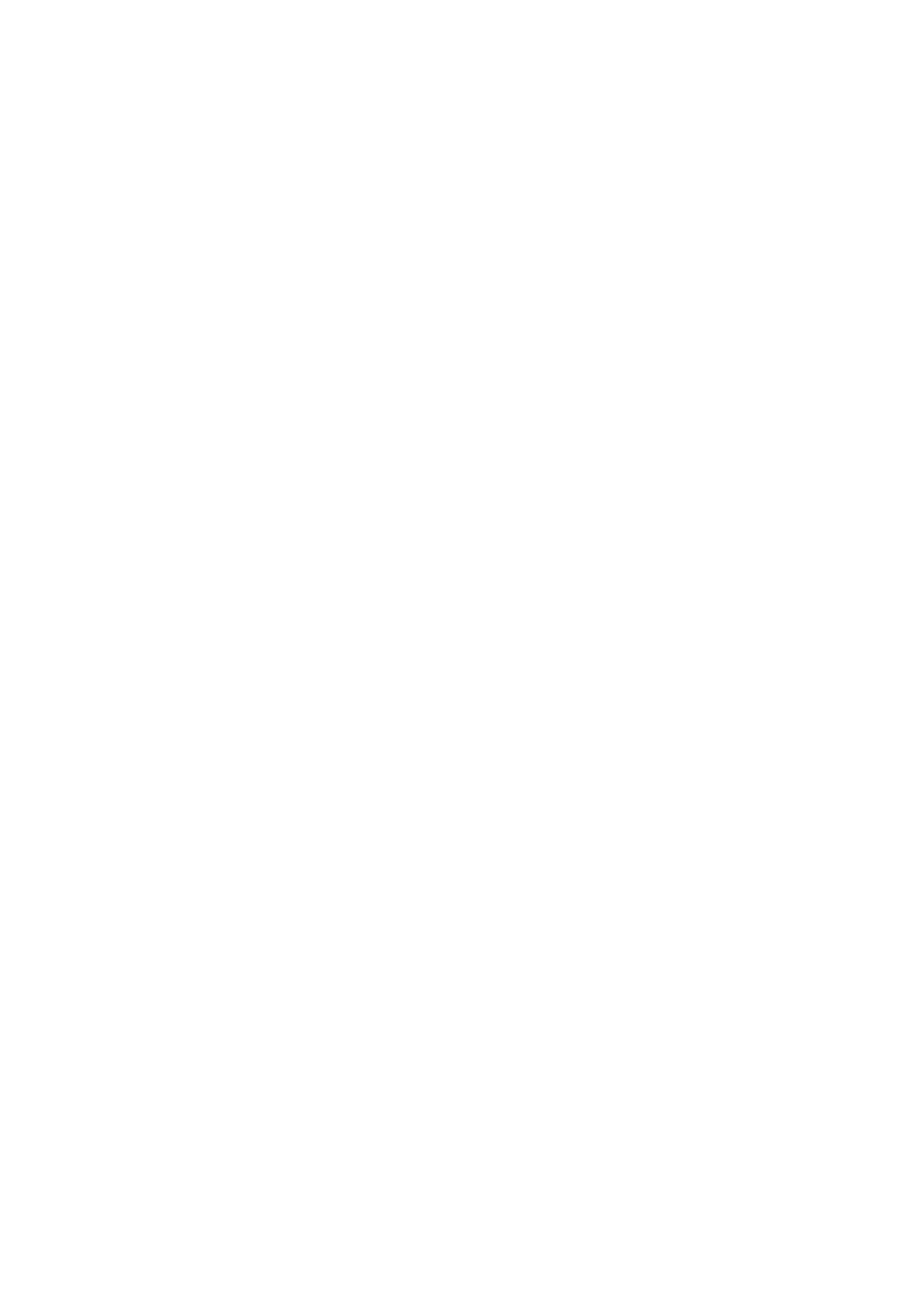




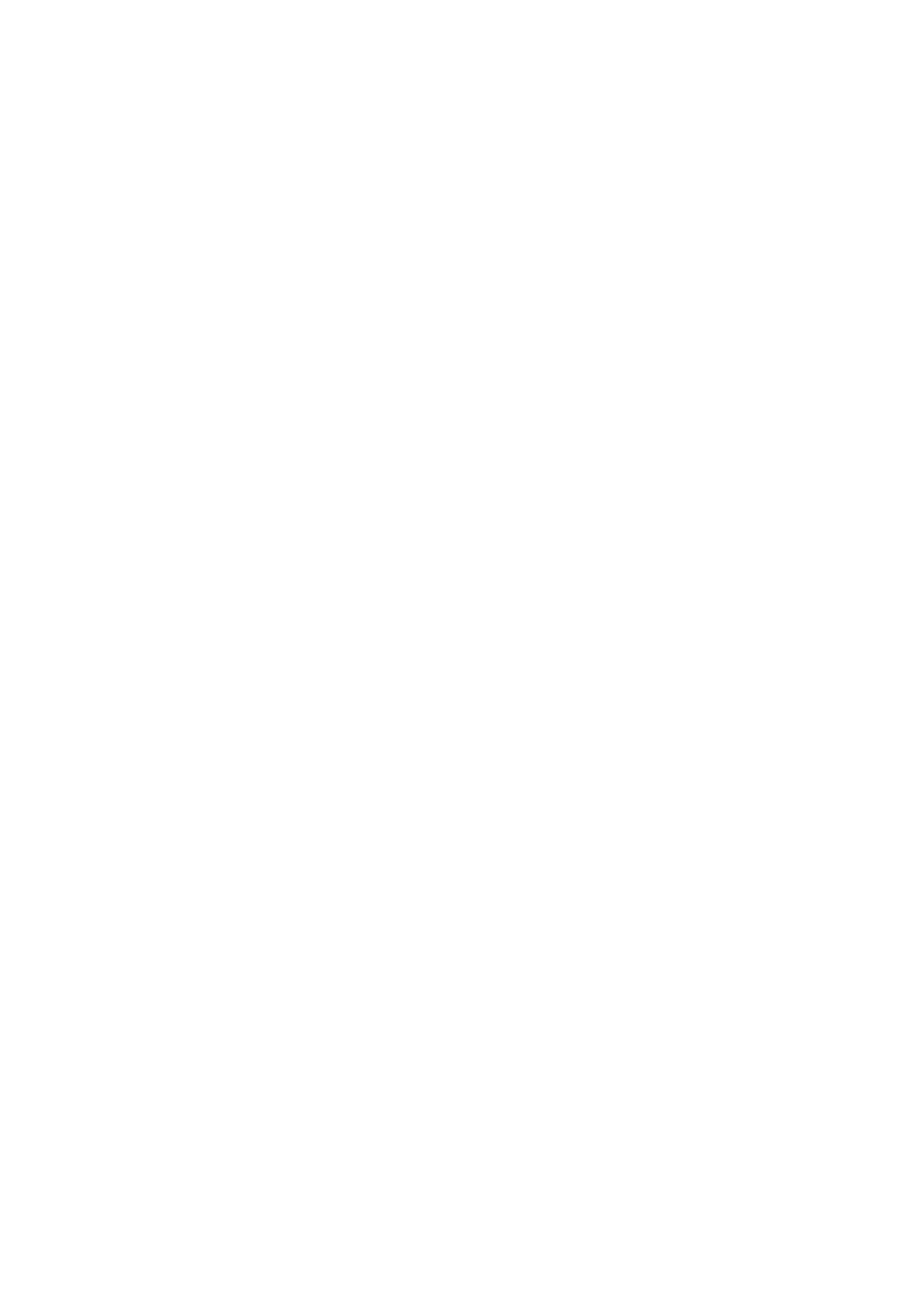




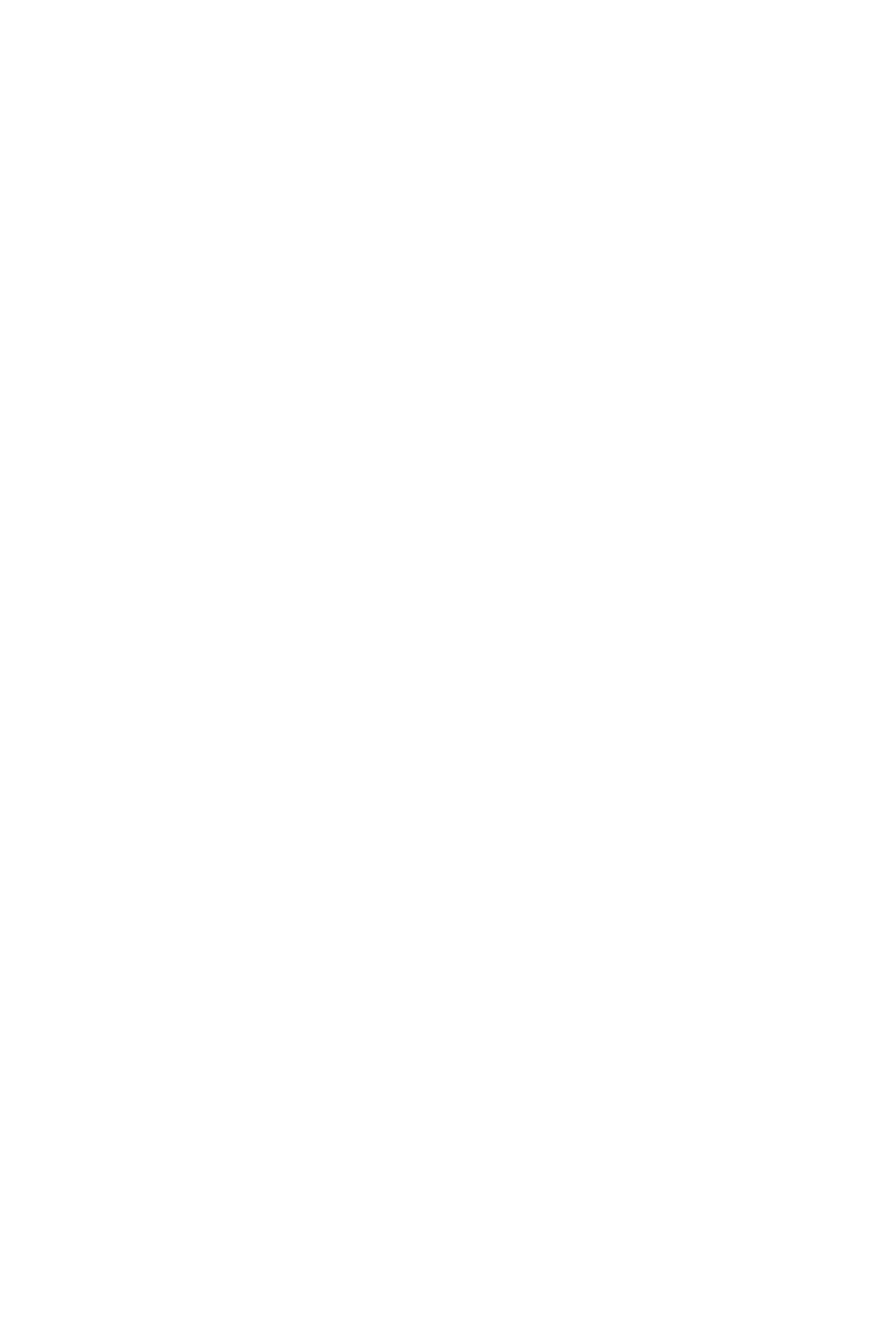




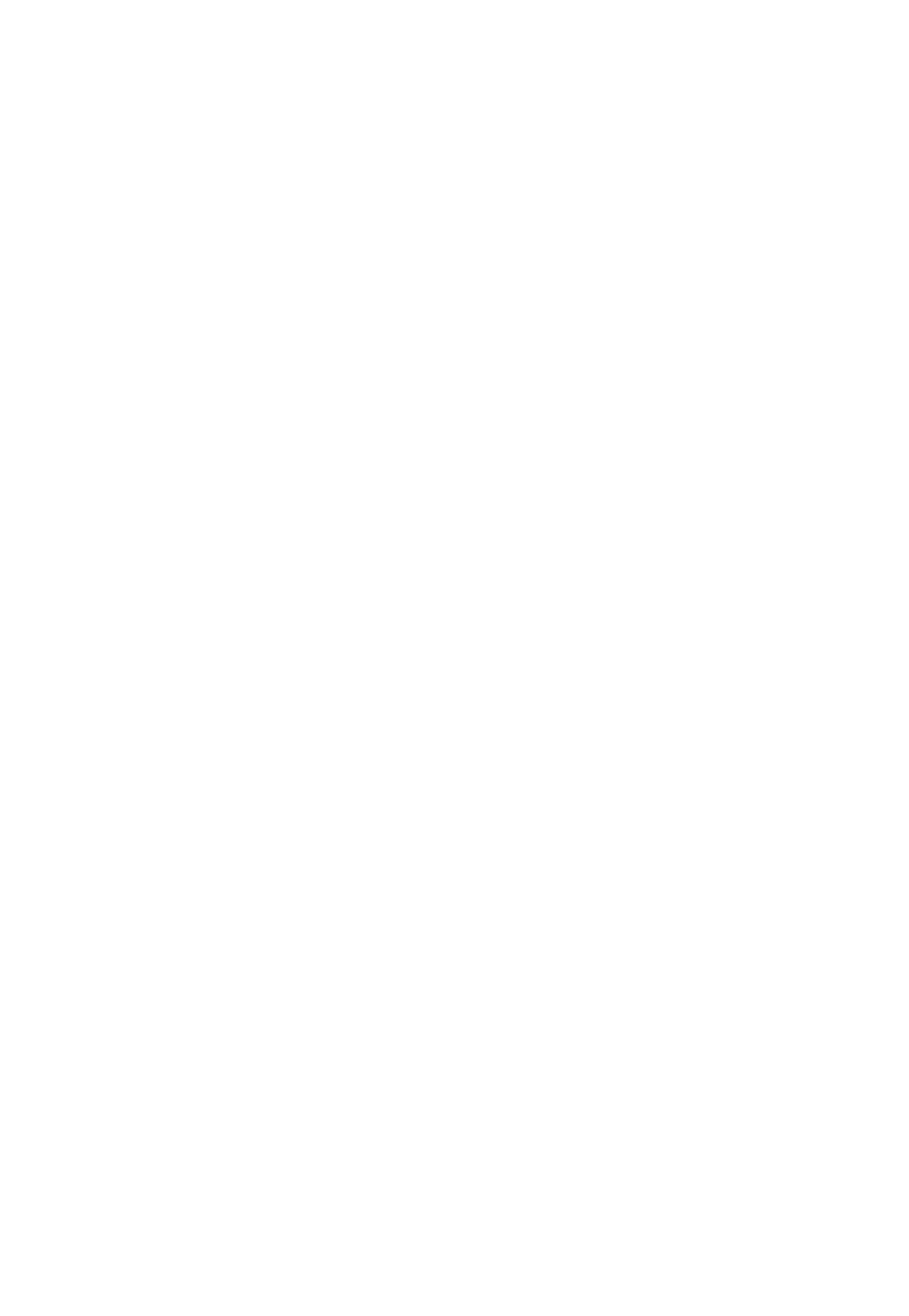




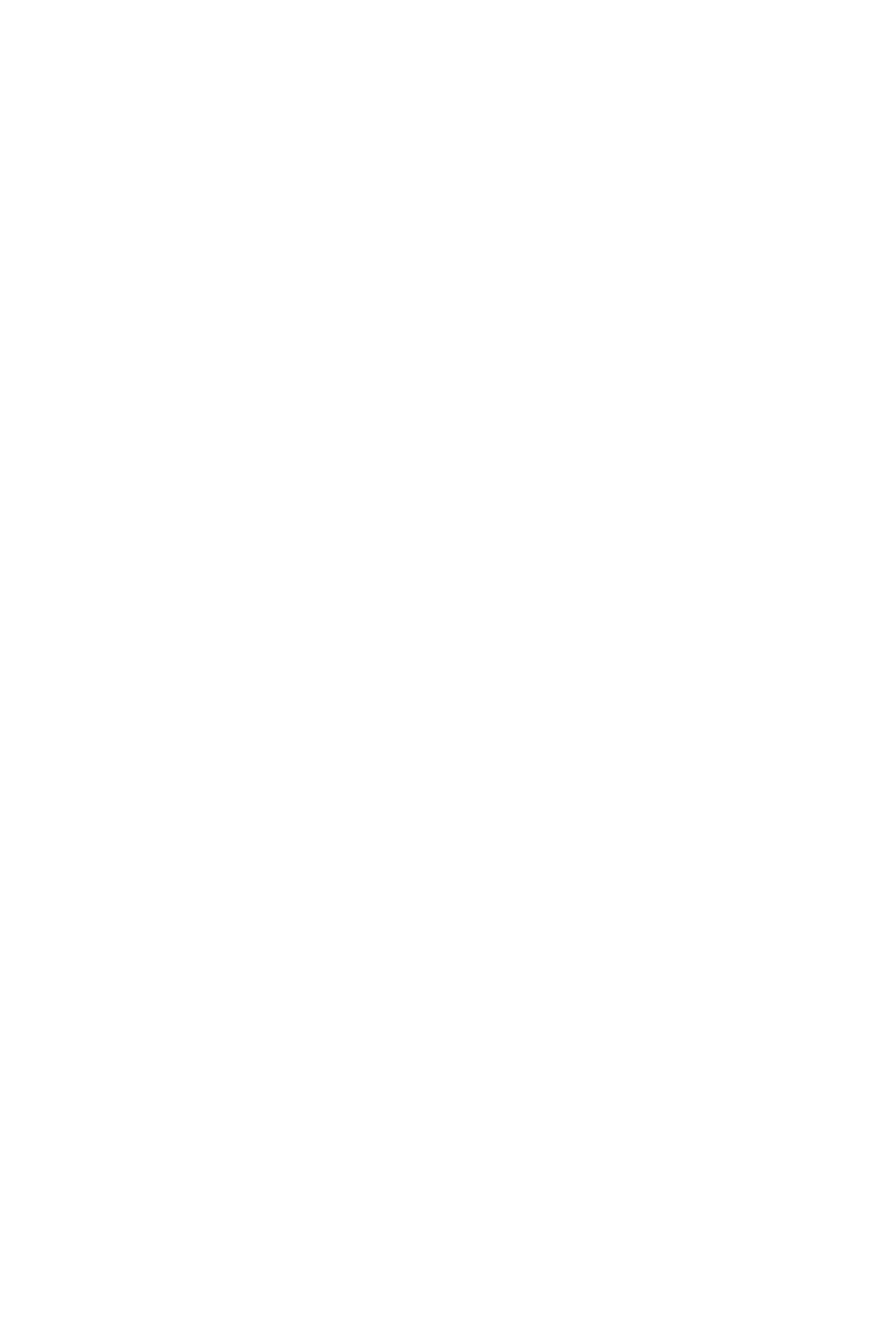




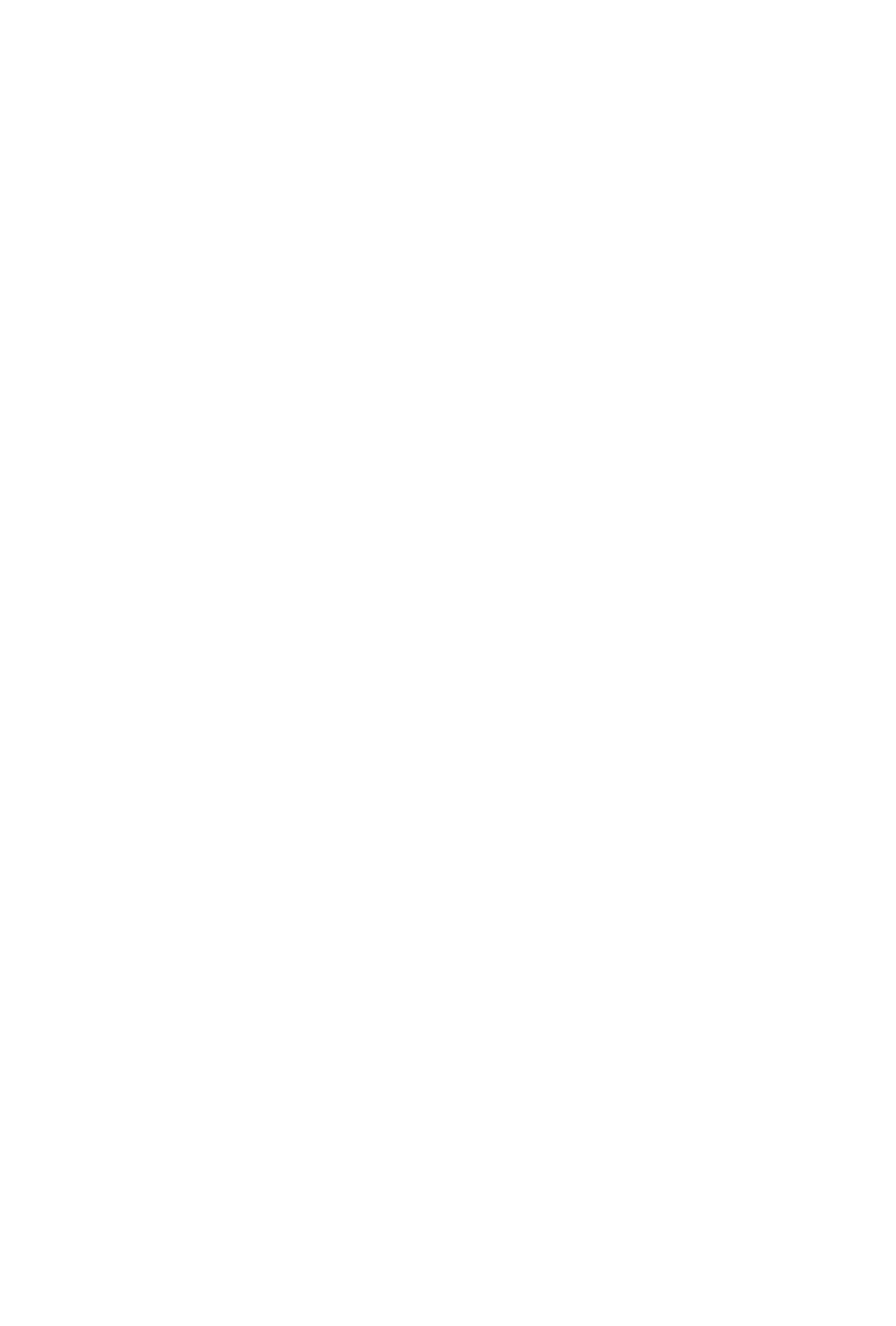




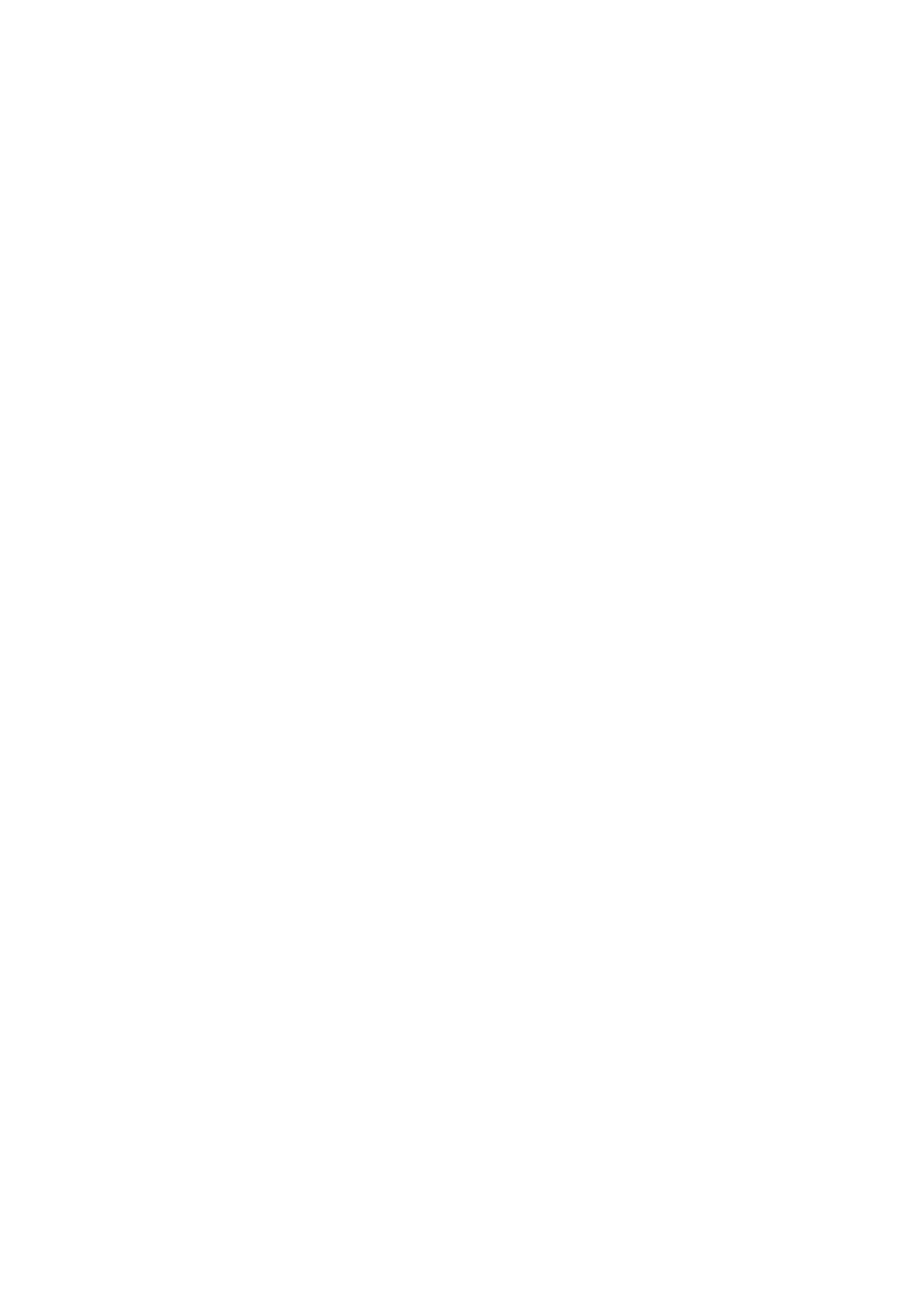




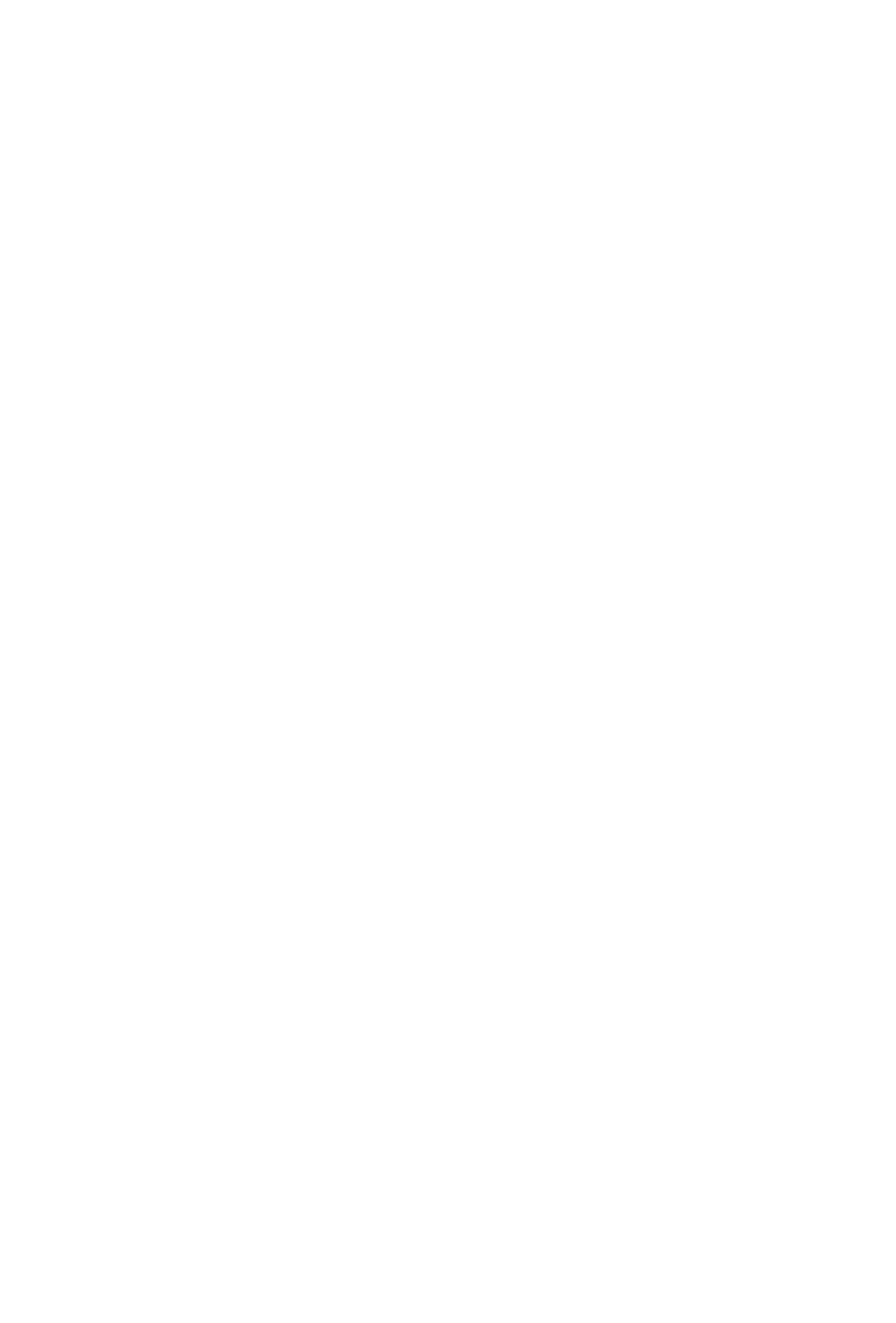




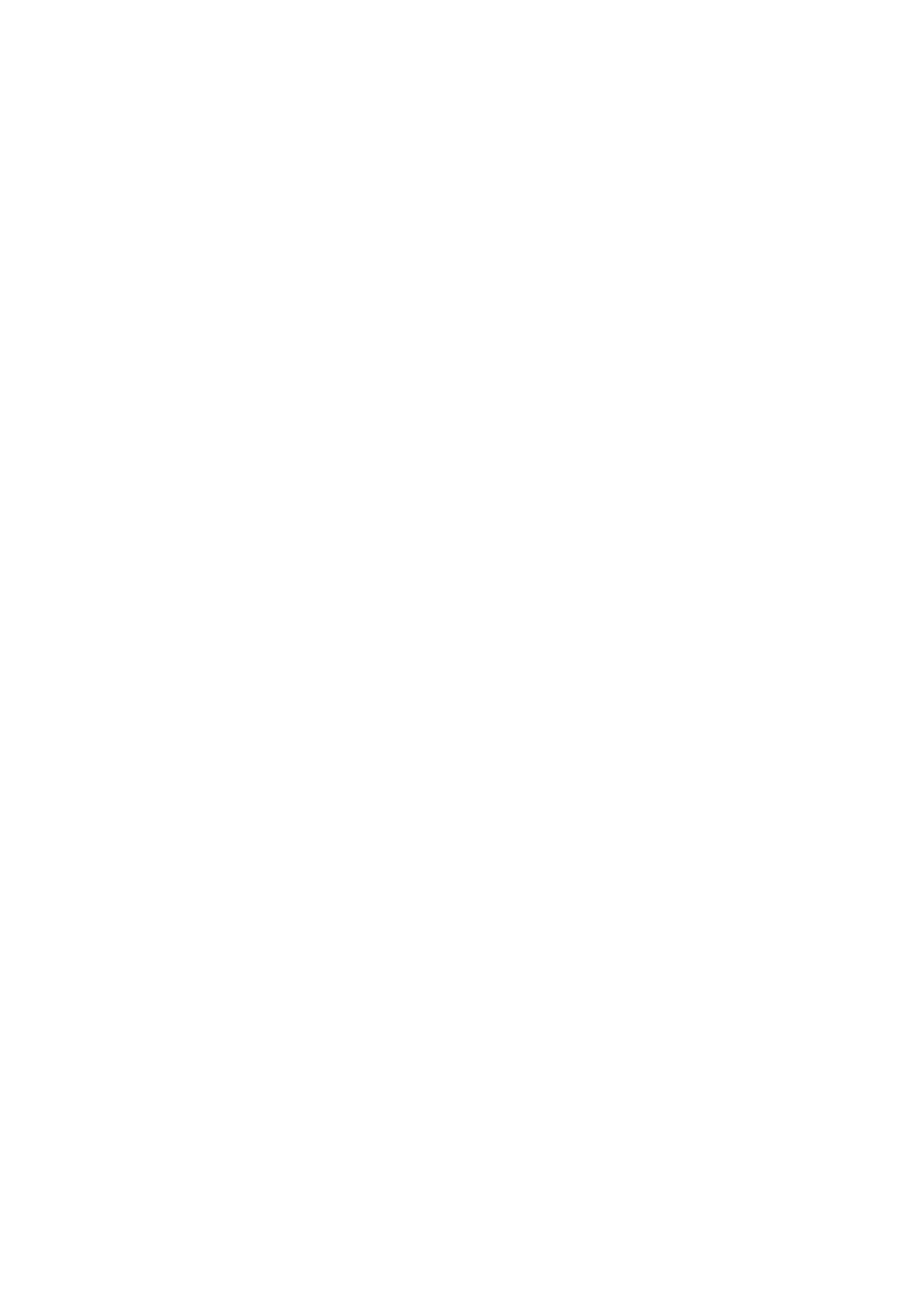




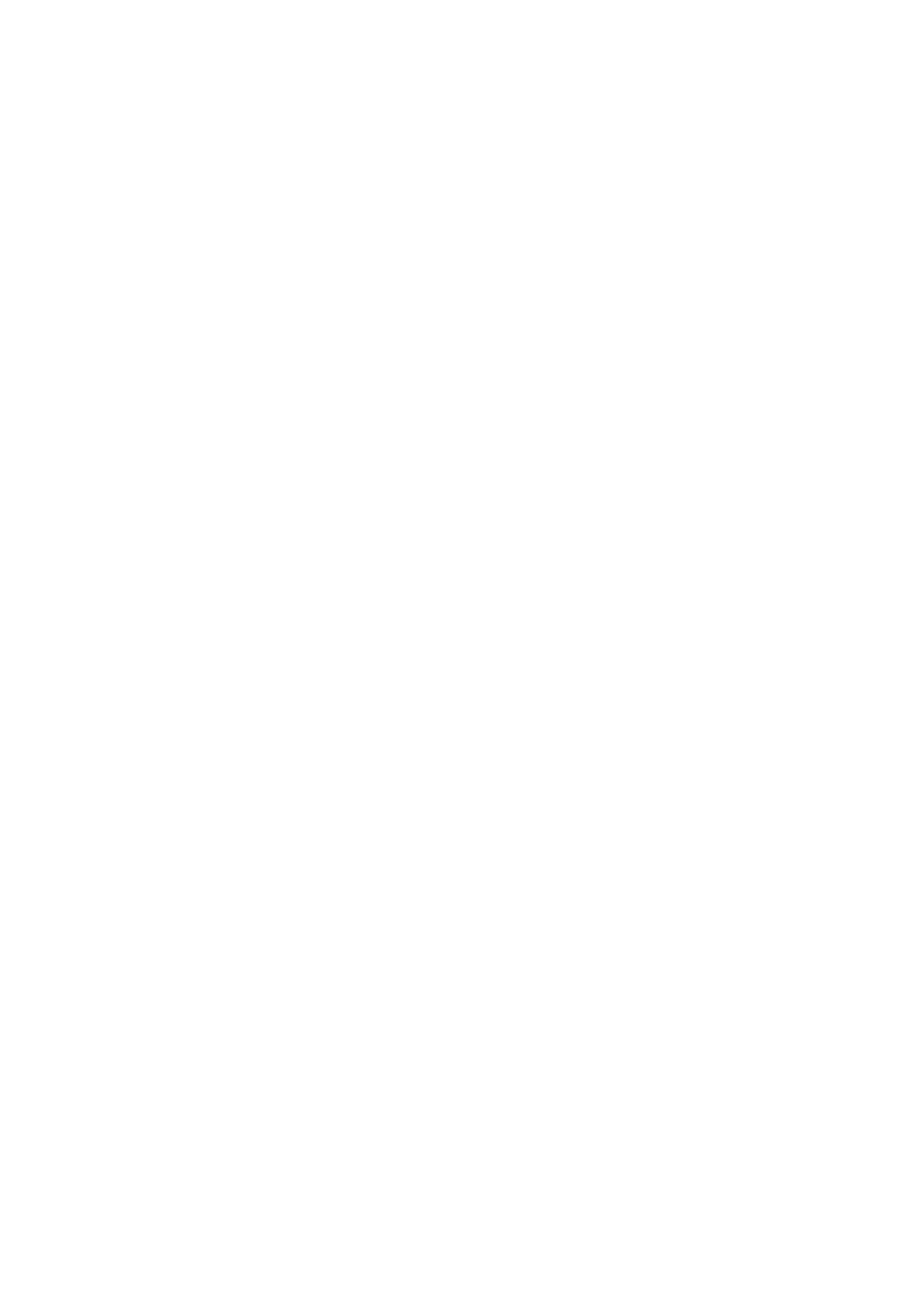




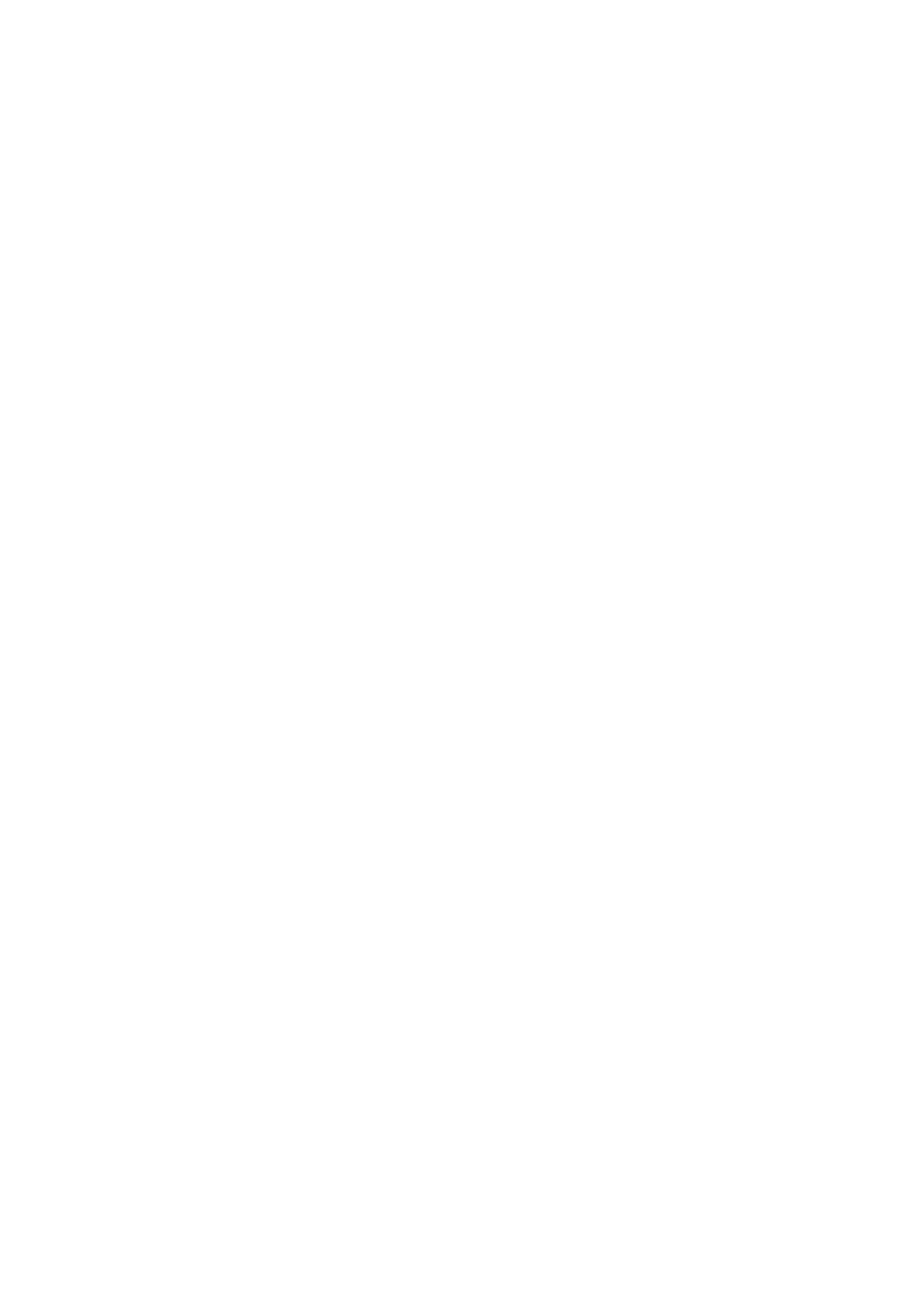




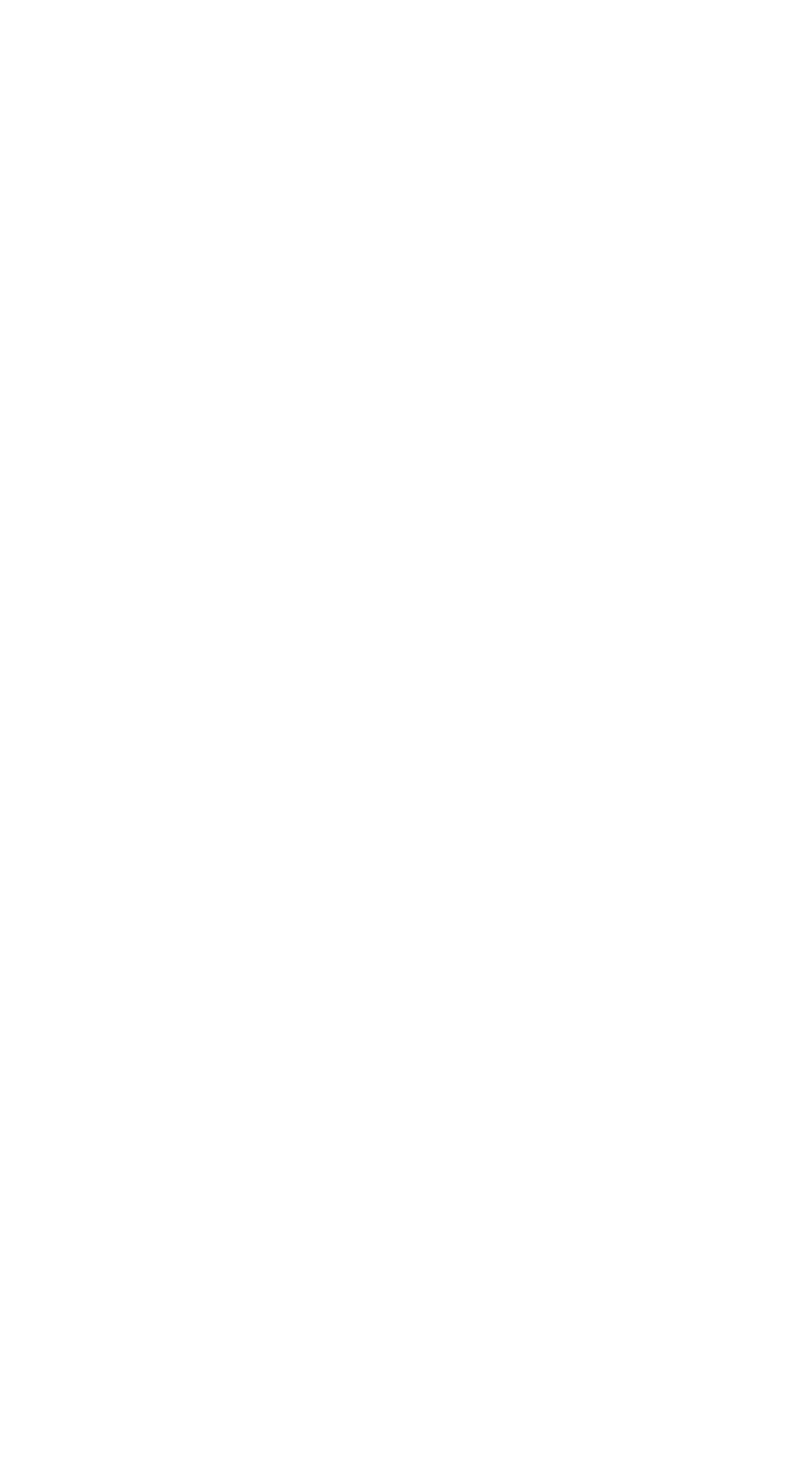




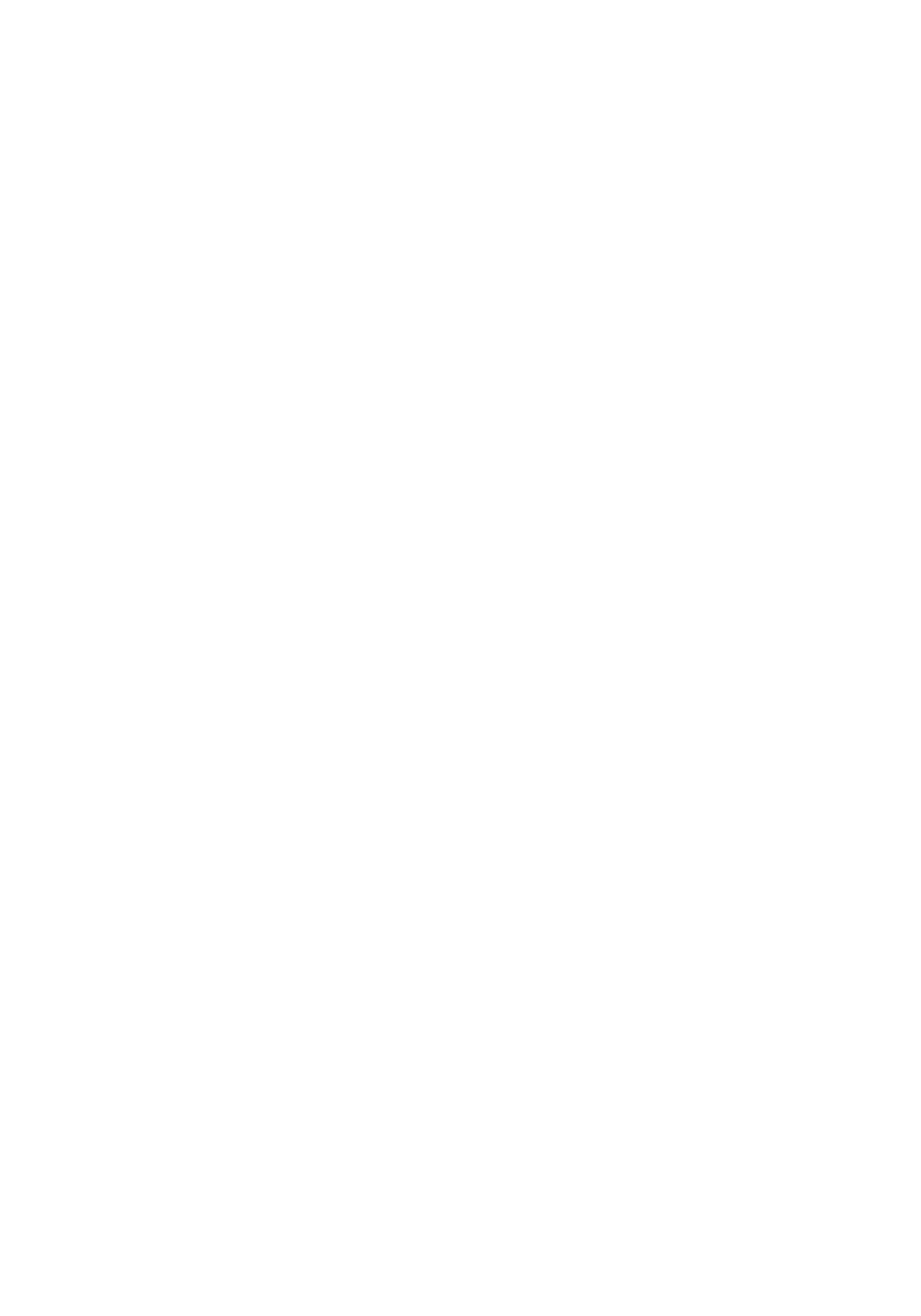




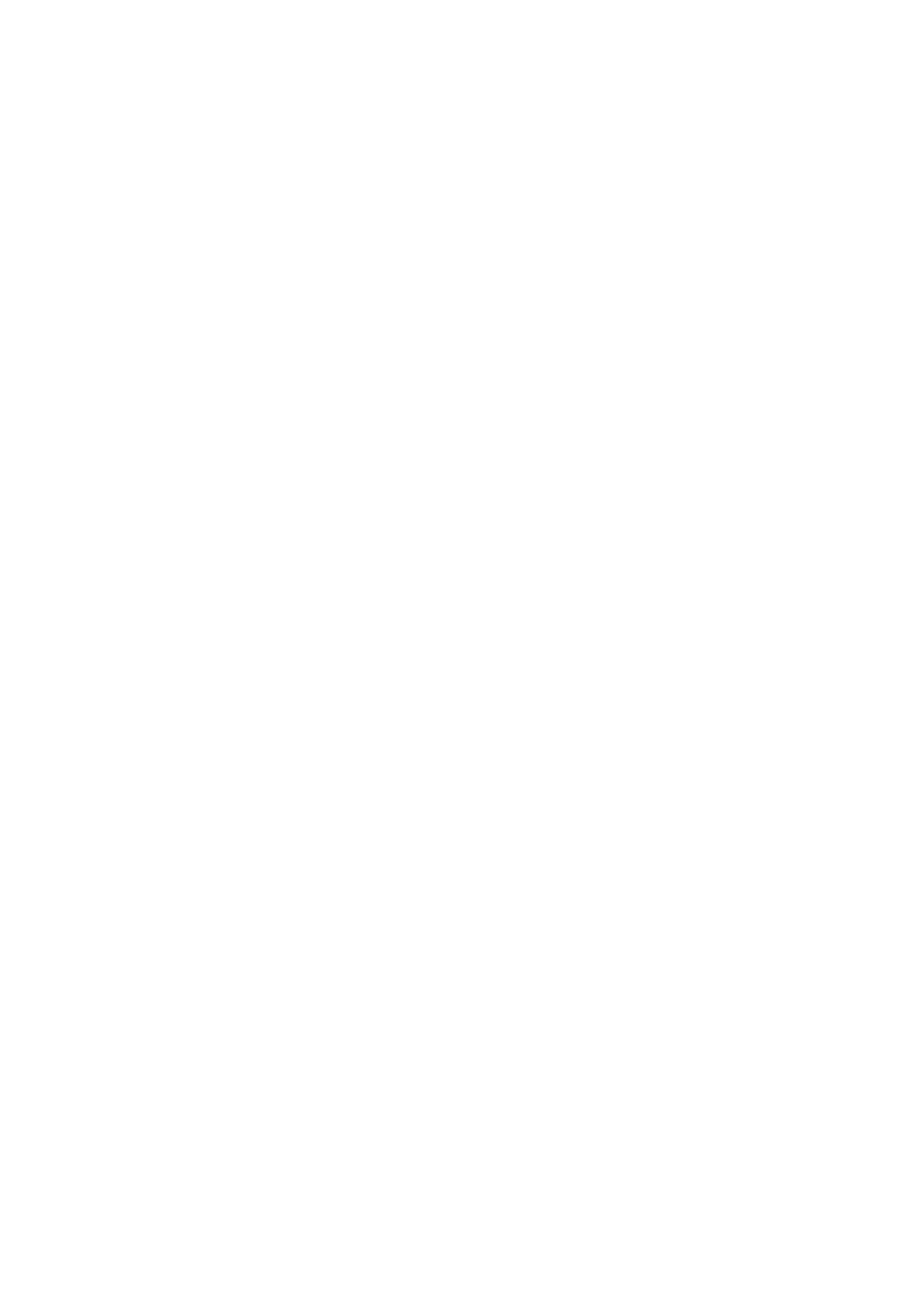




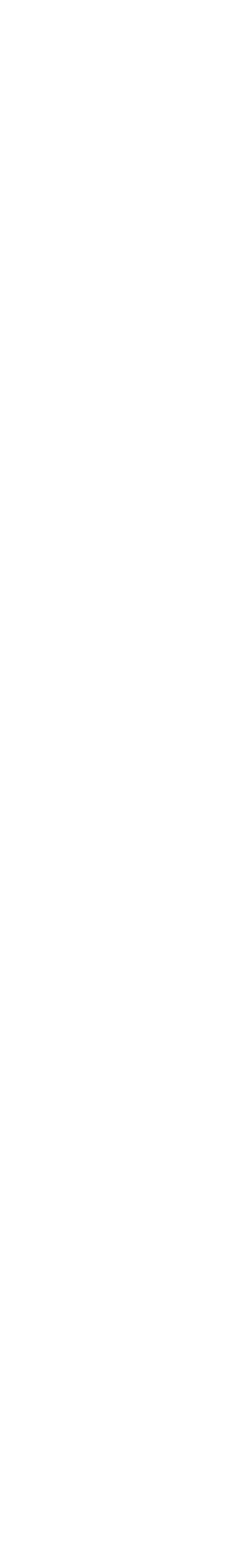

116 Data-Site Locations in the Potomac River Basin to Rappahannock River Bas in 


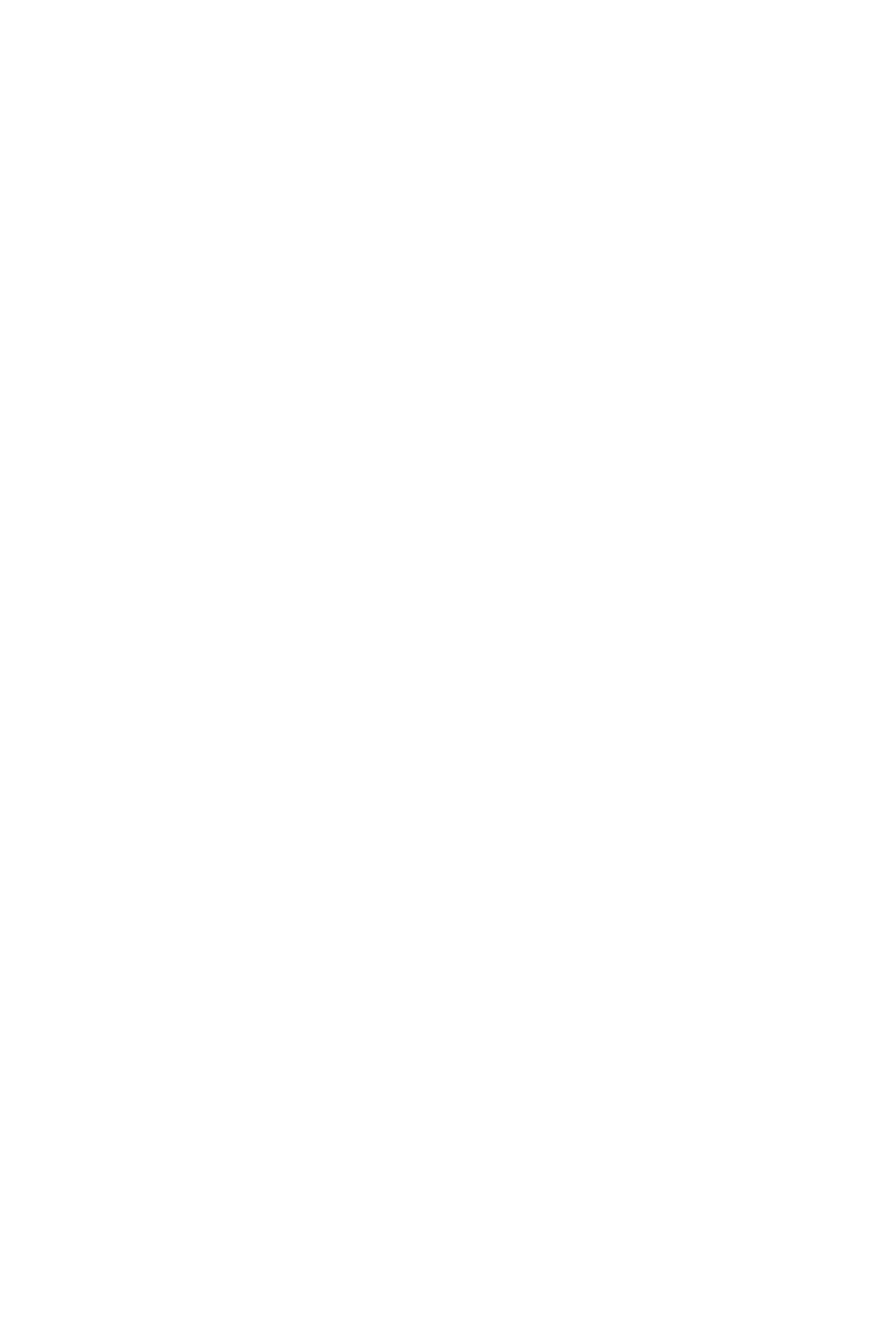




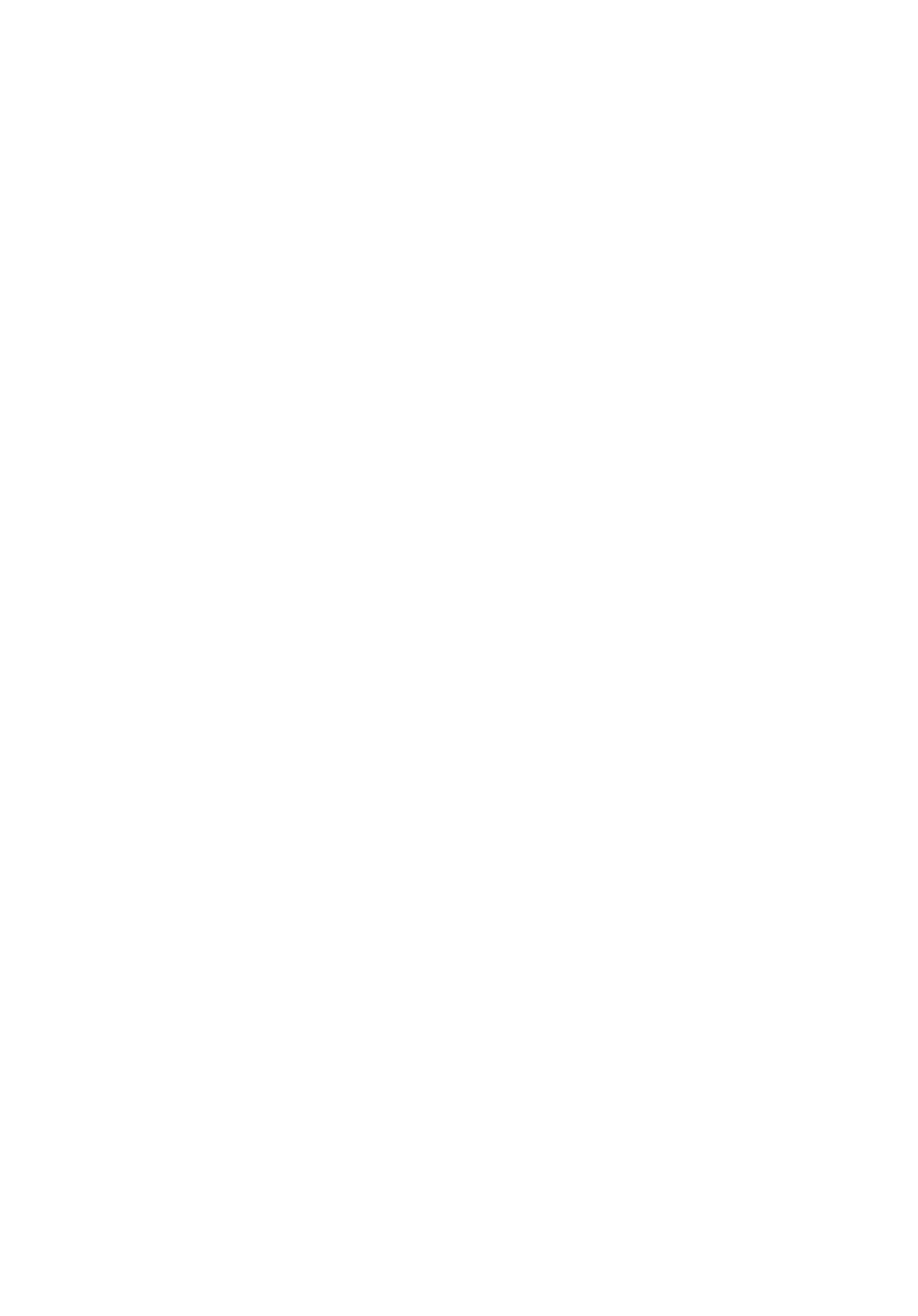




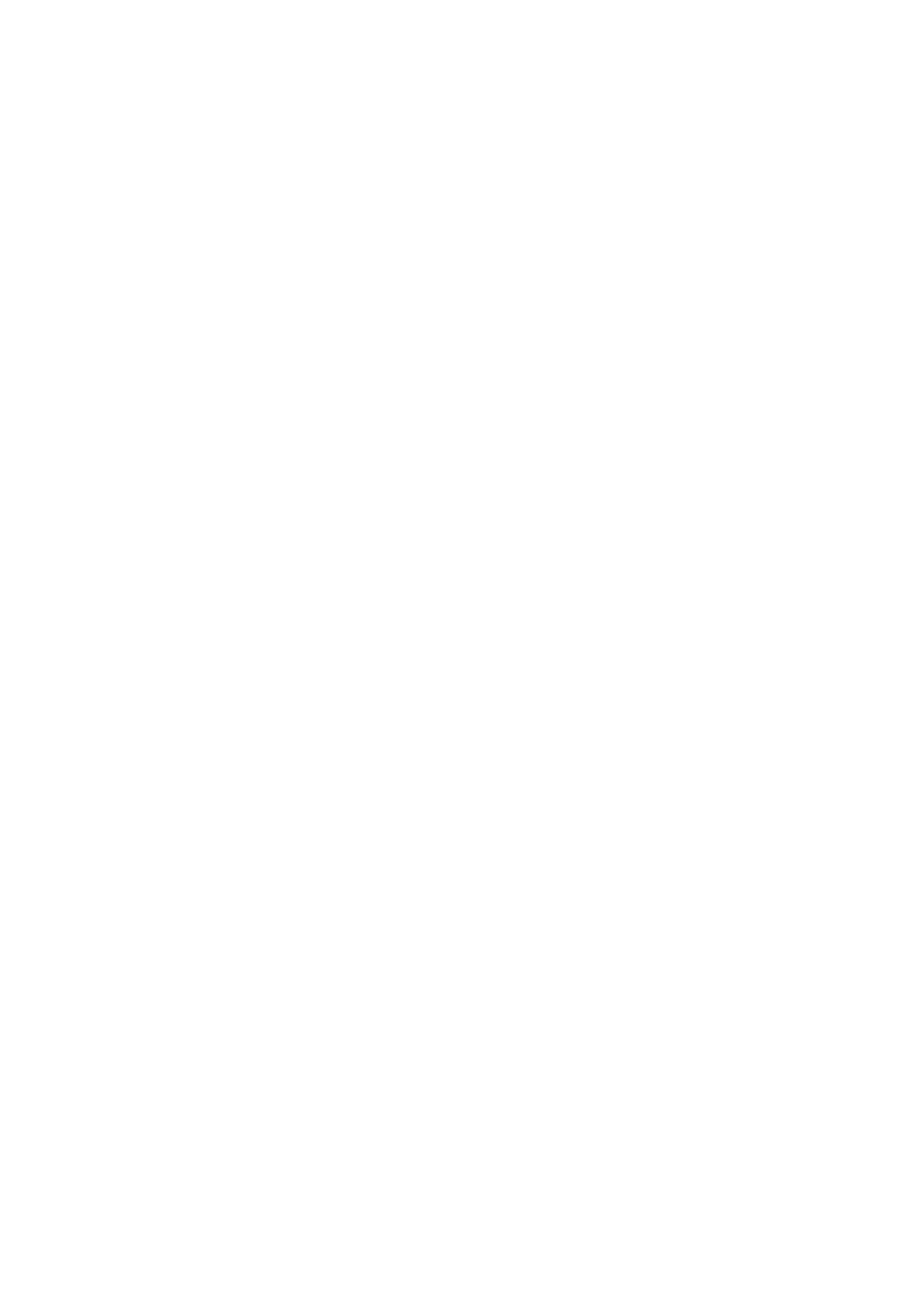




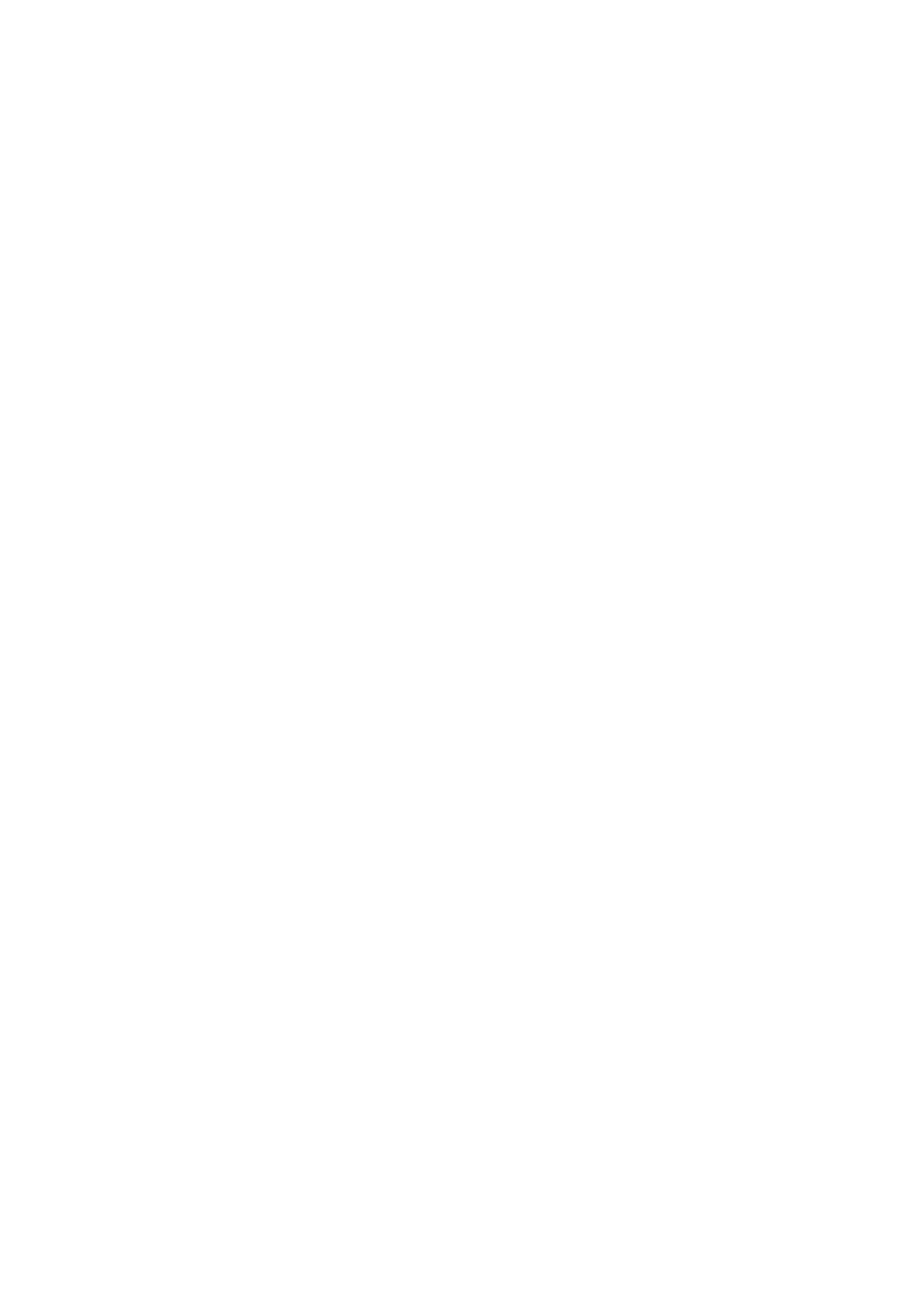




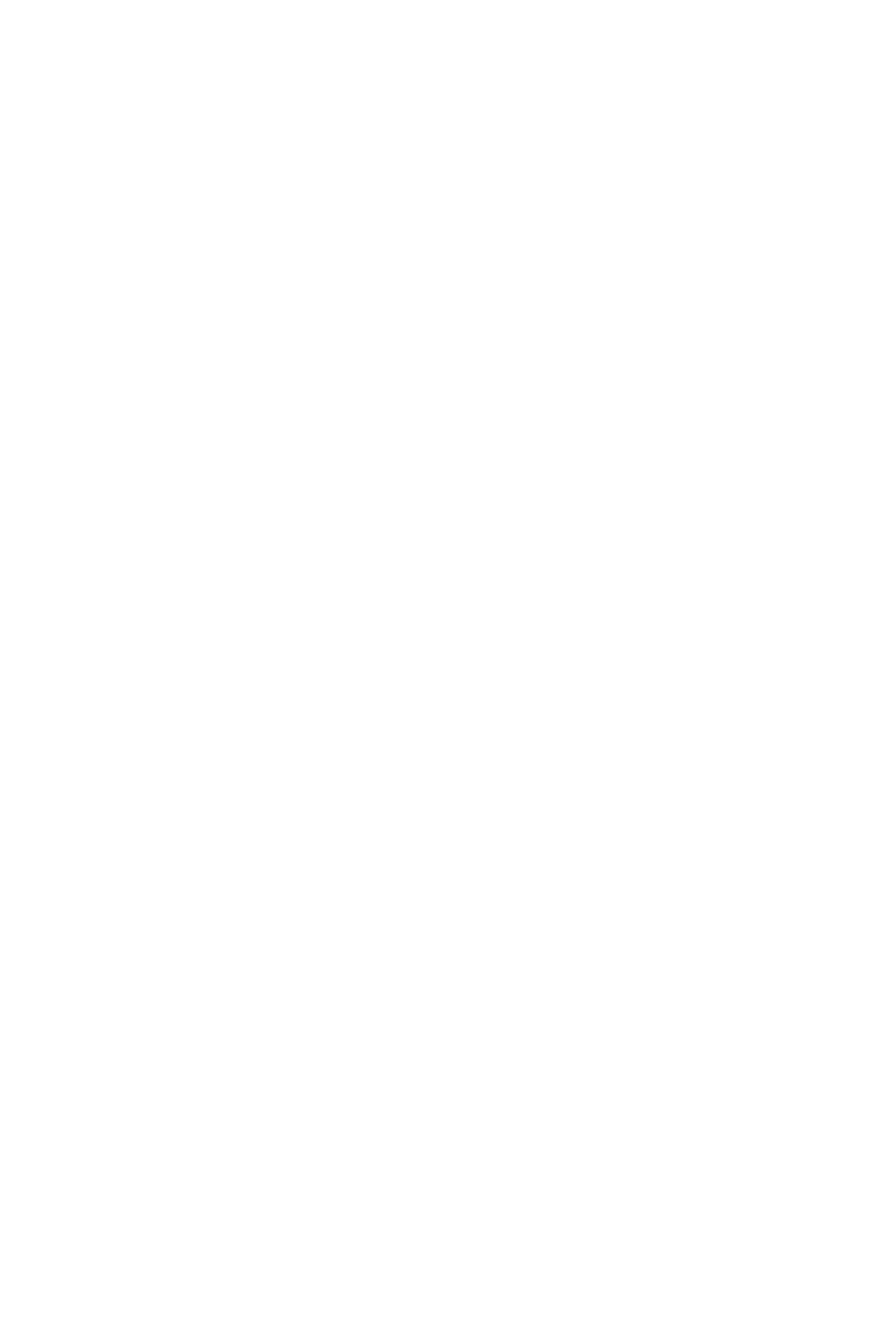




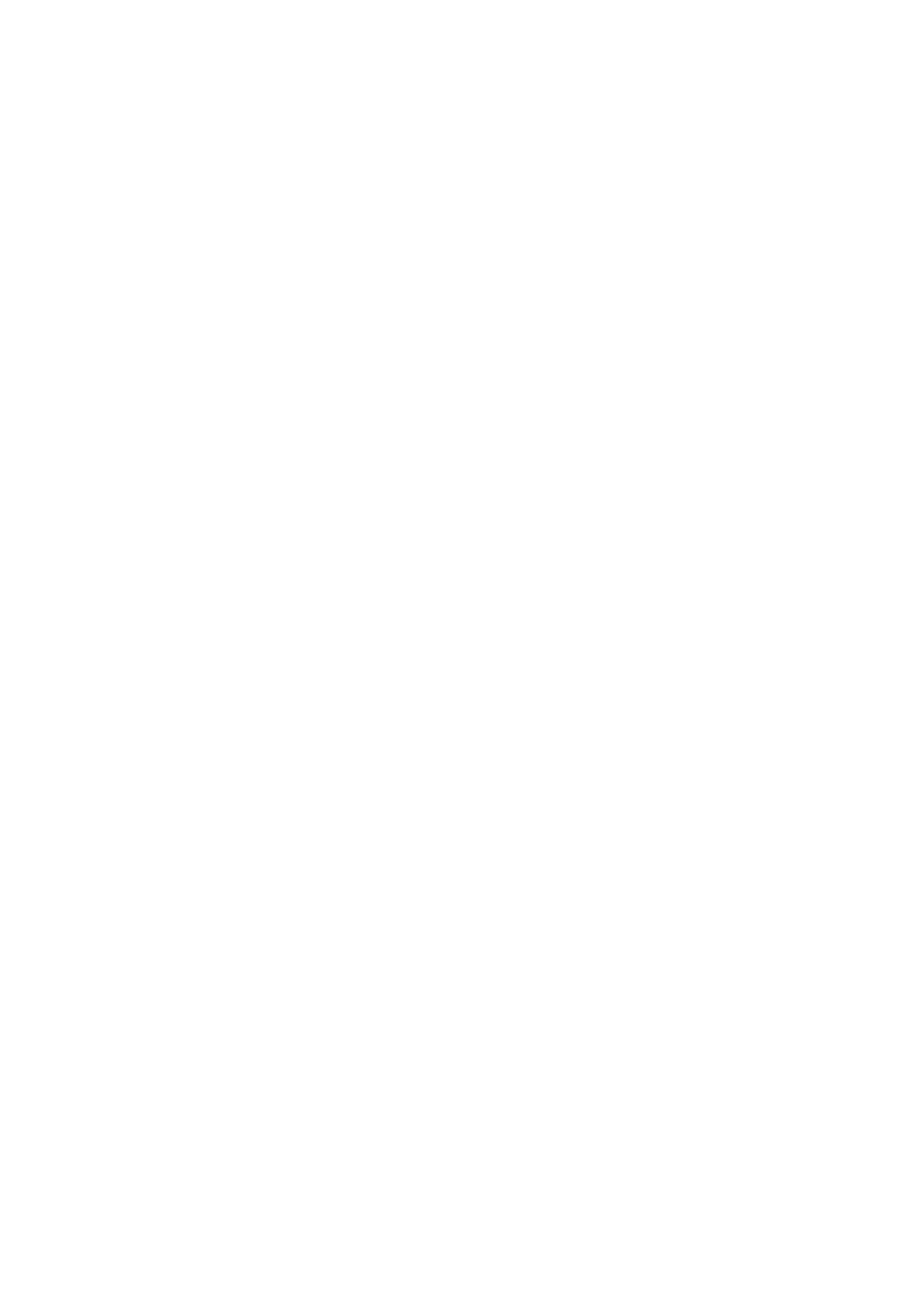




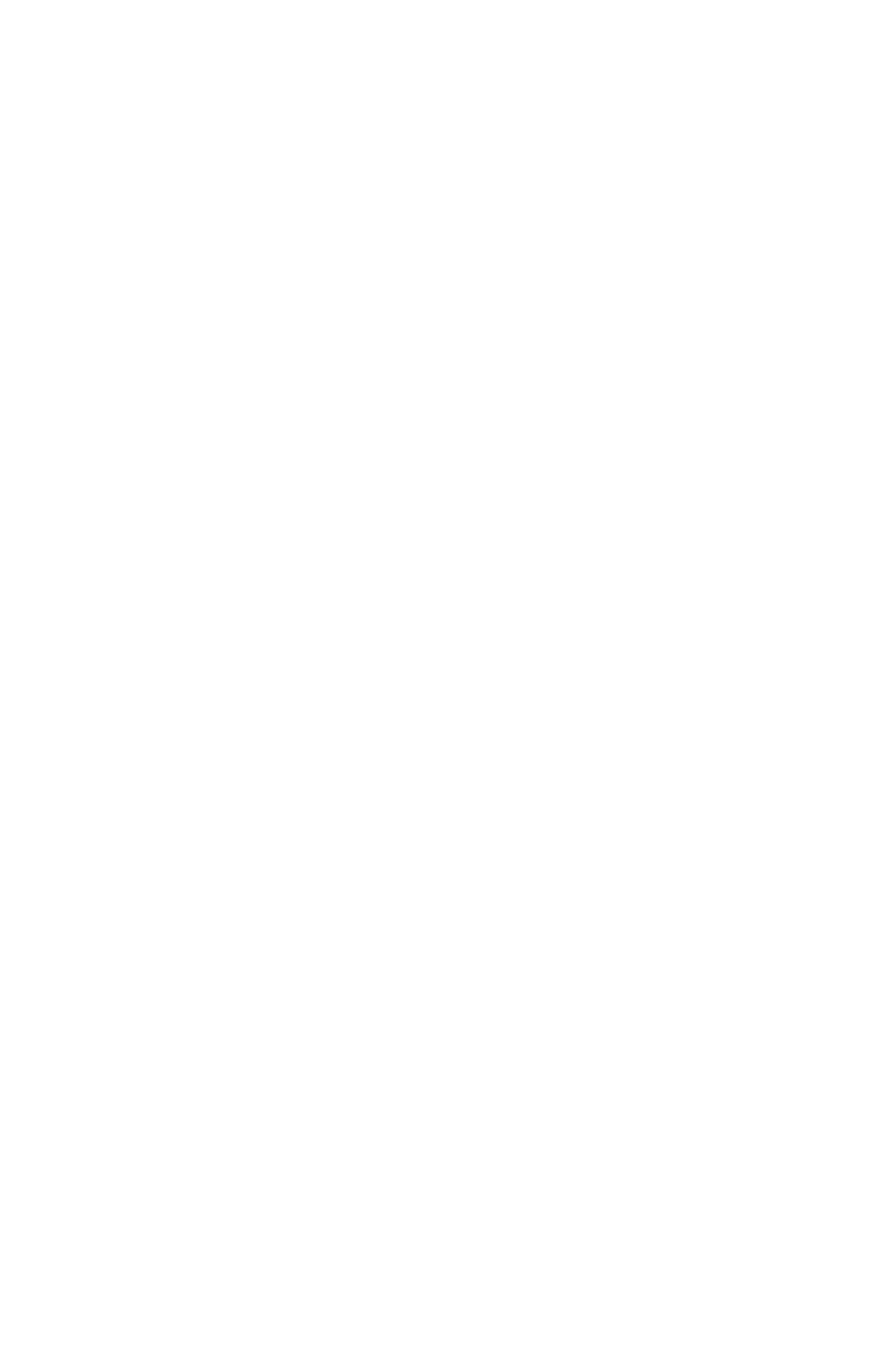




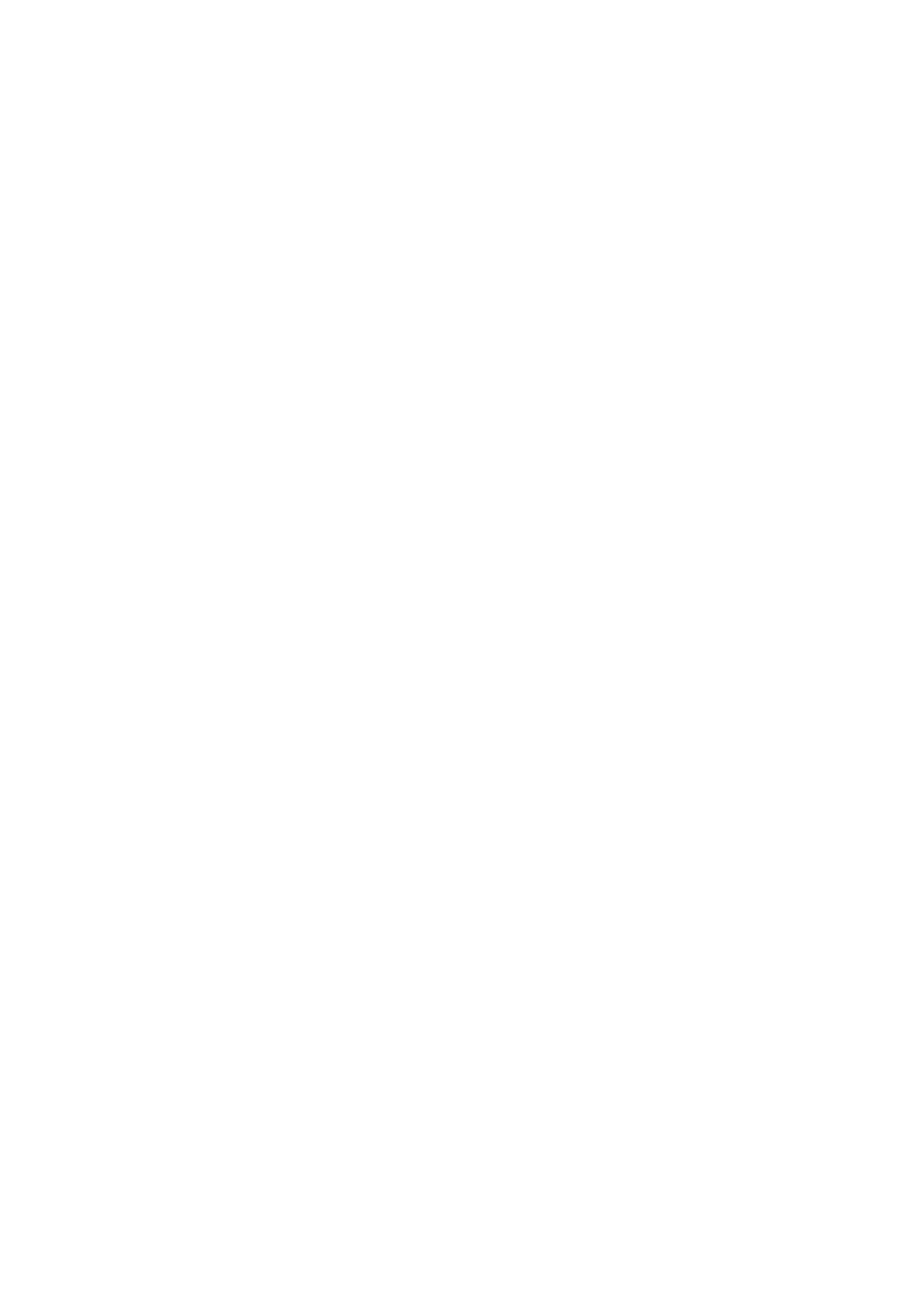




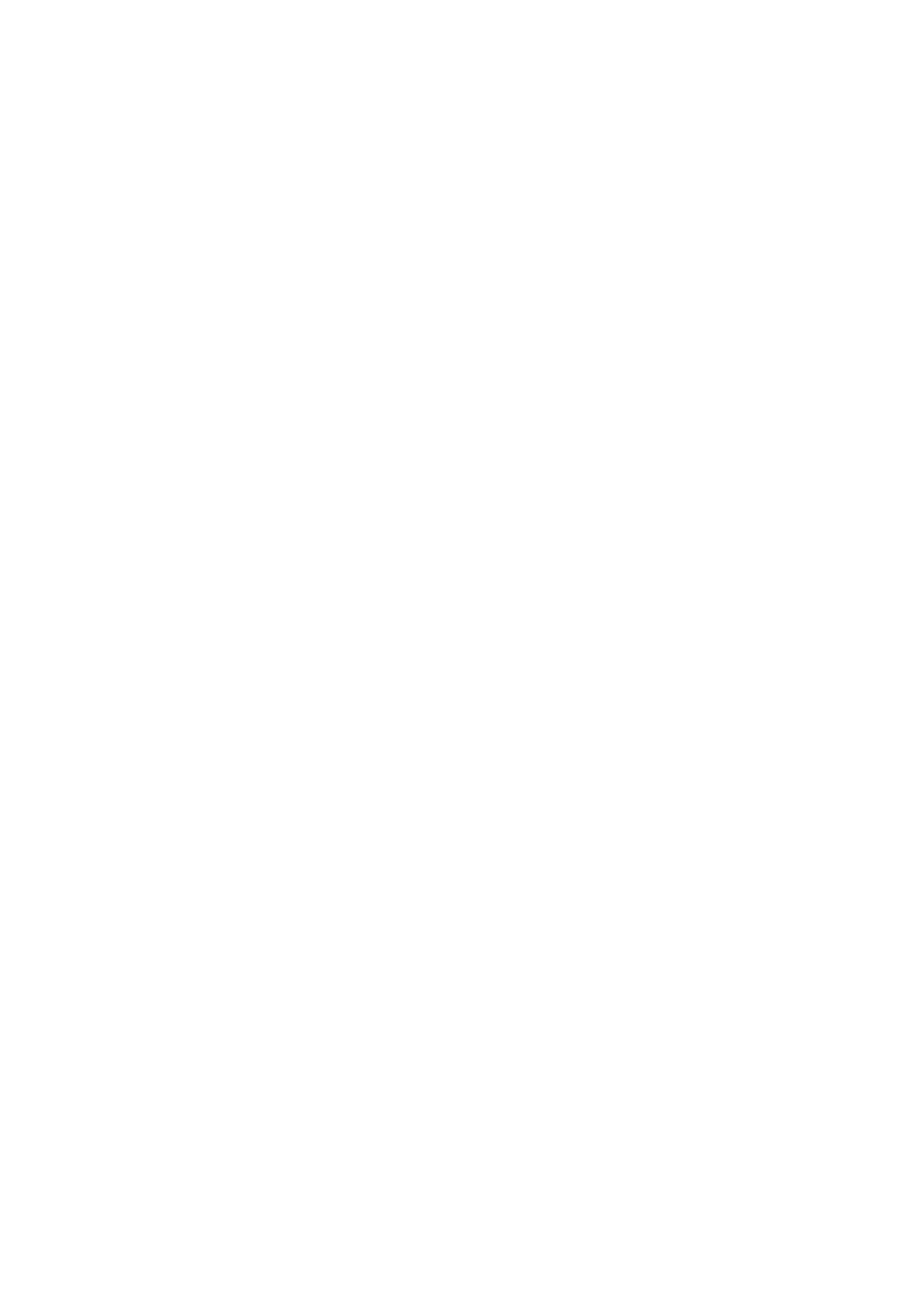




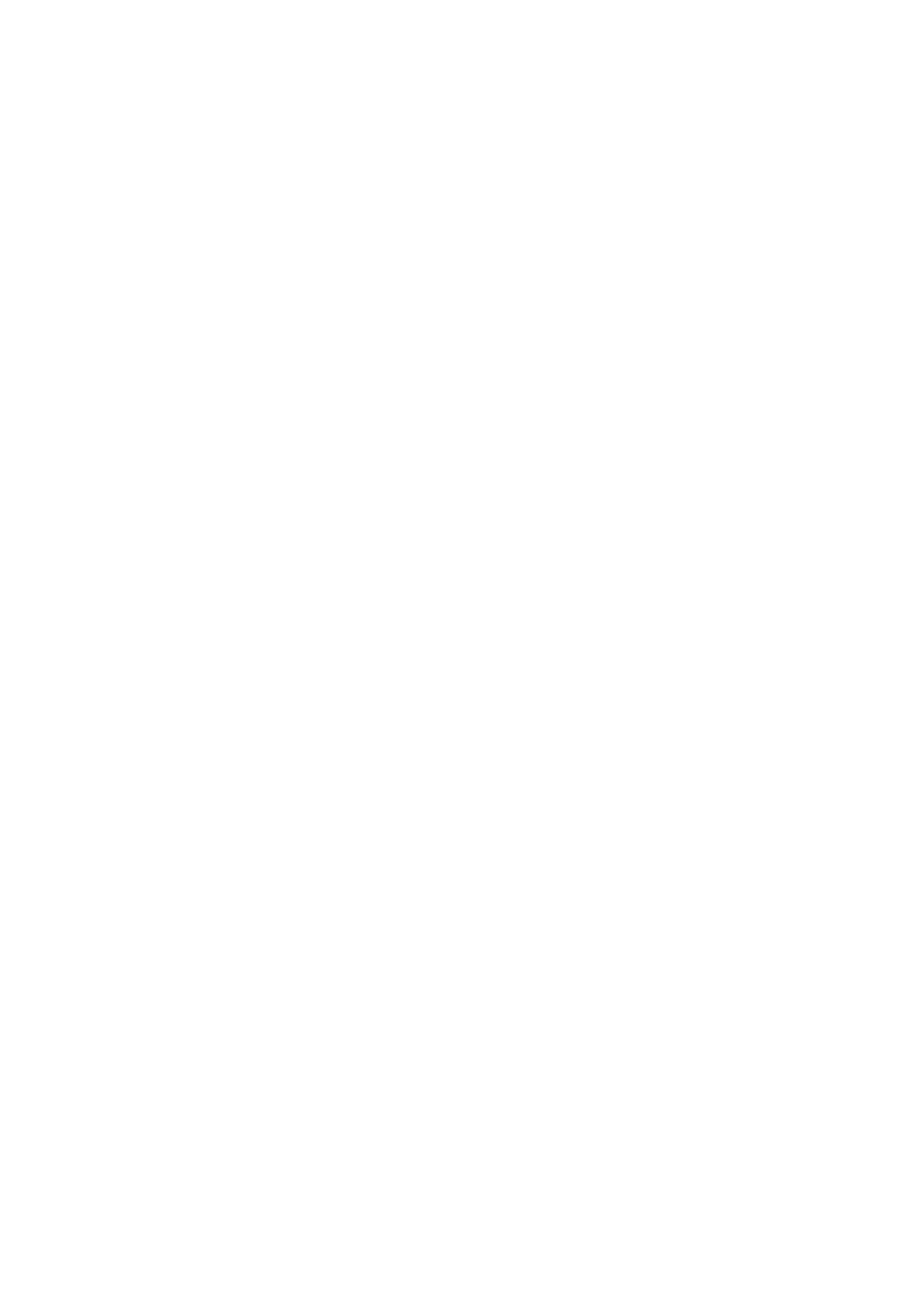




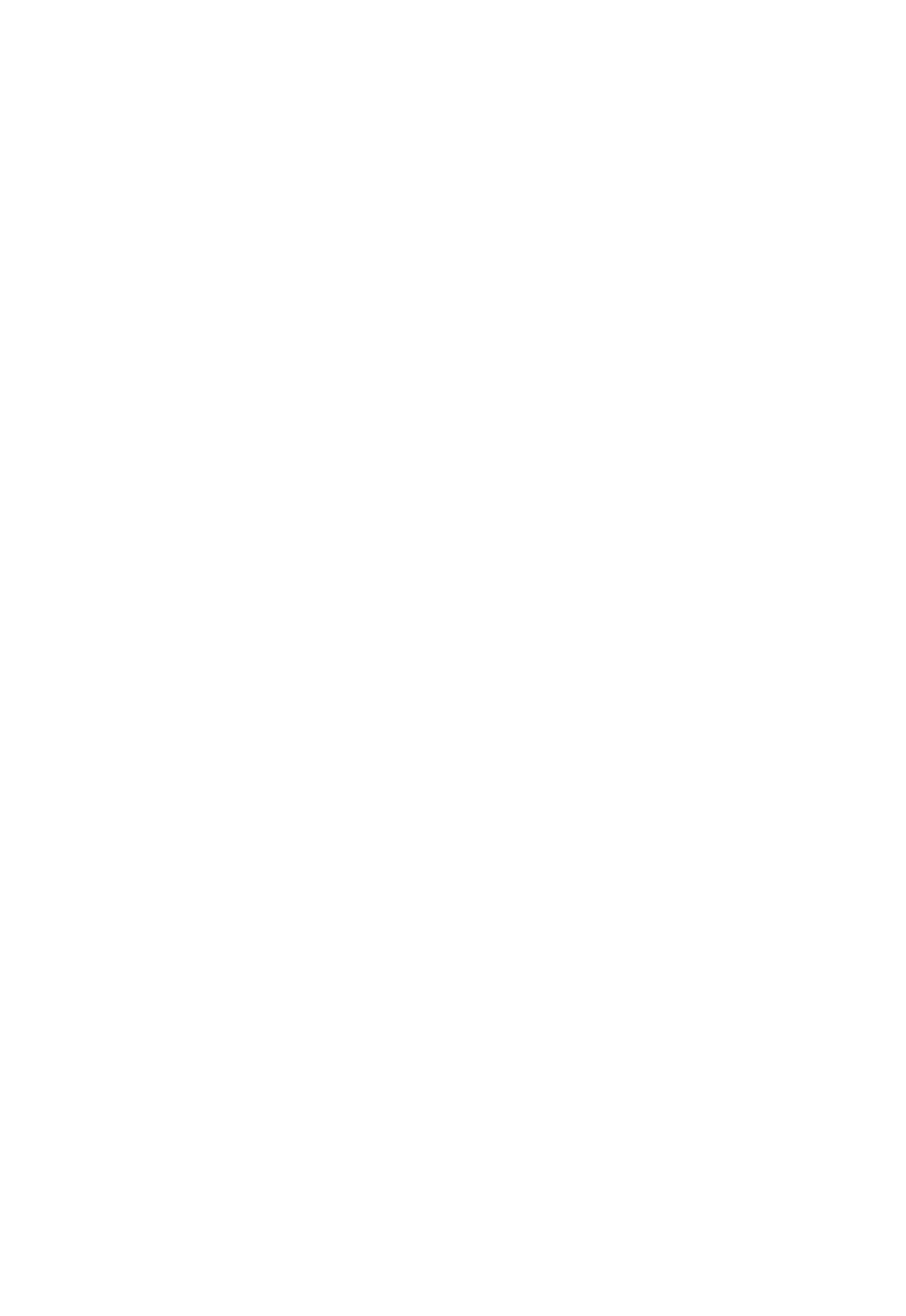




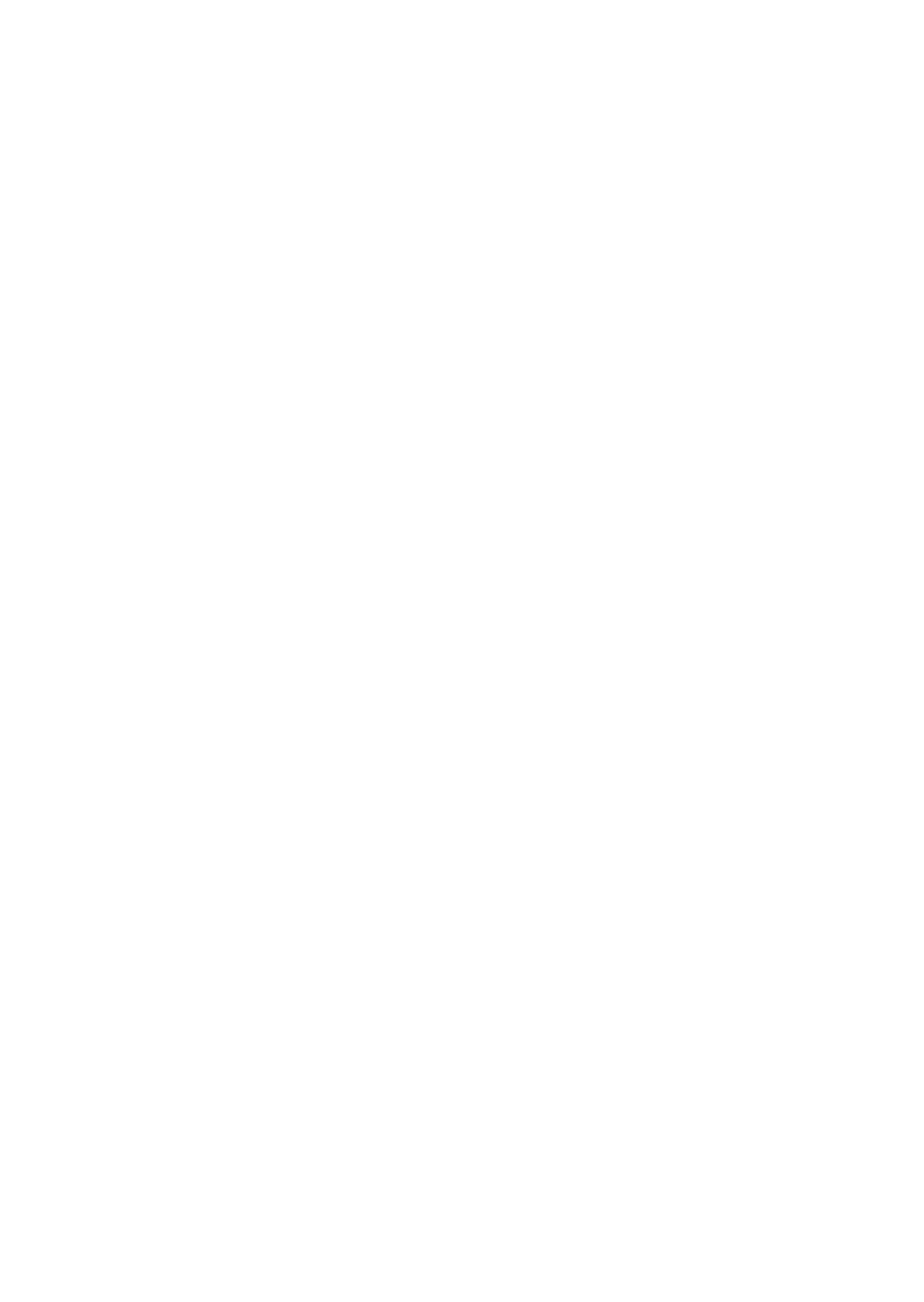




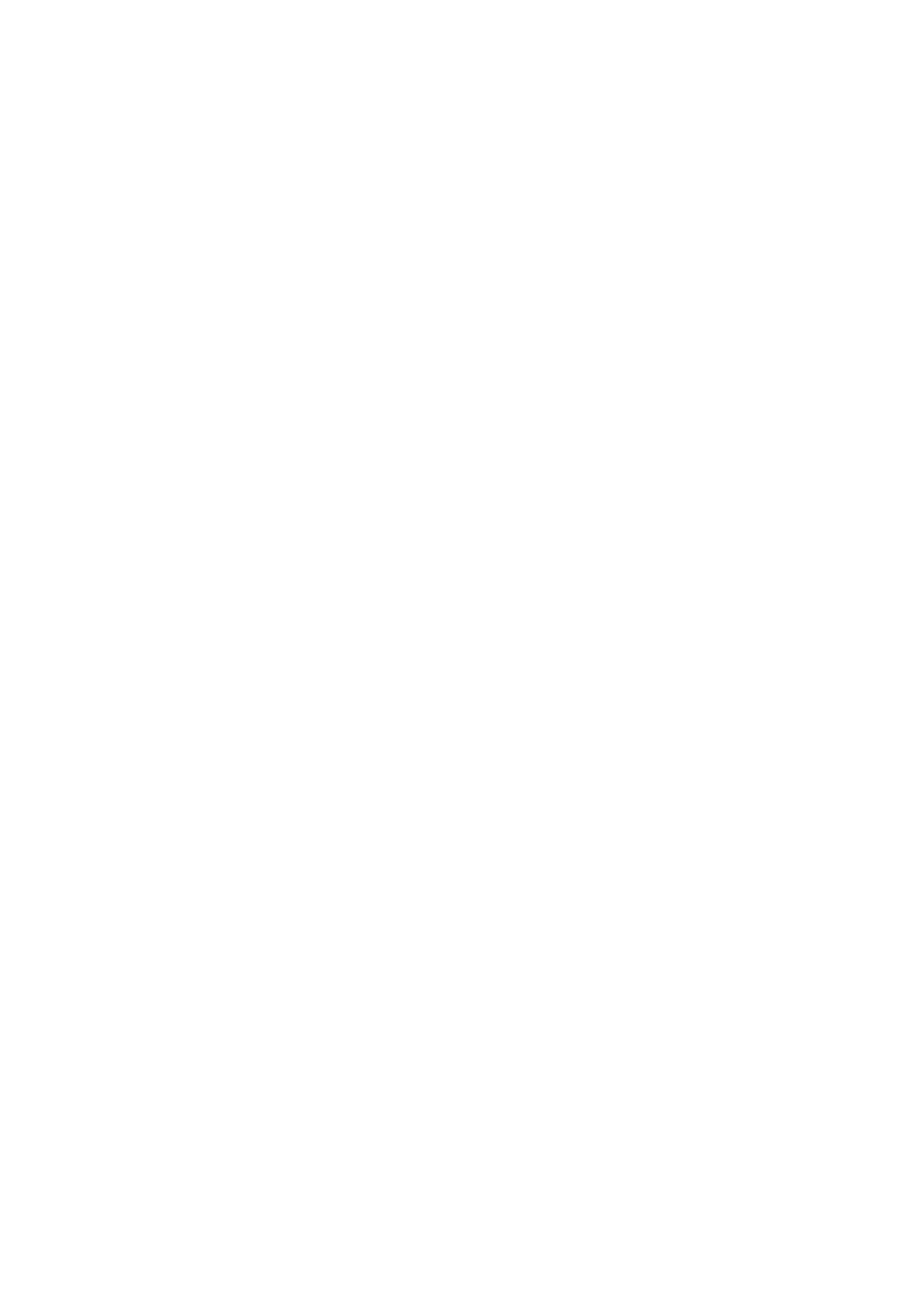




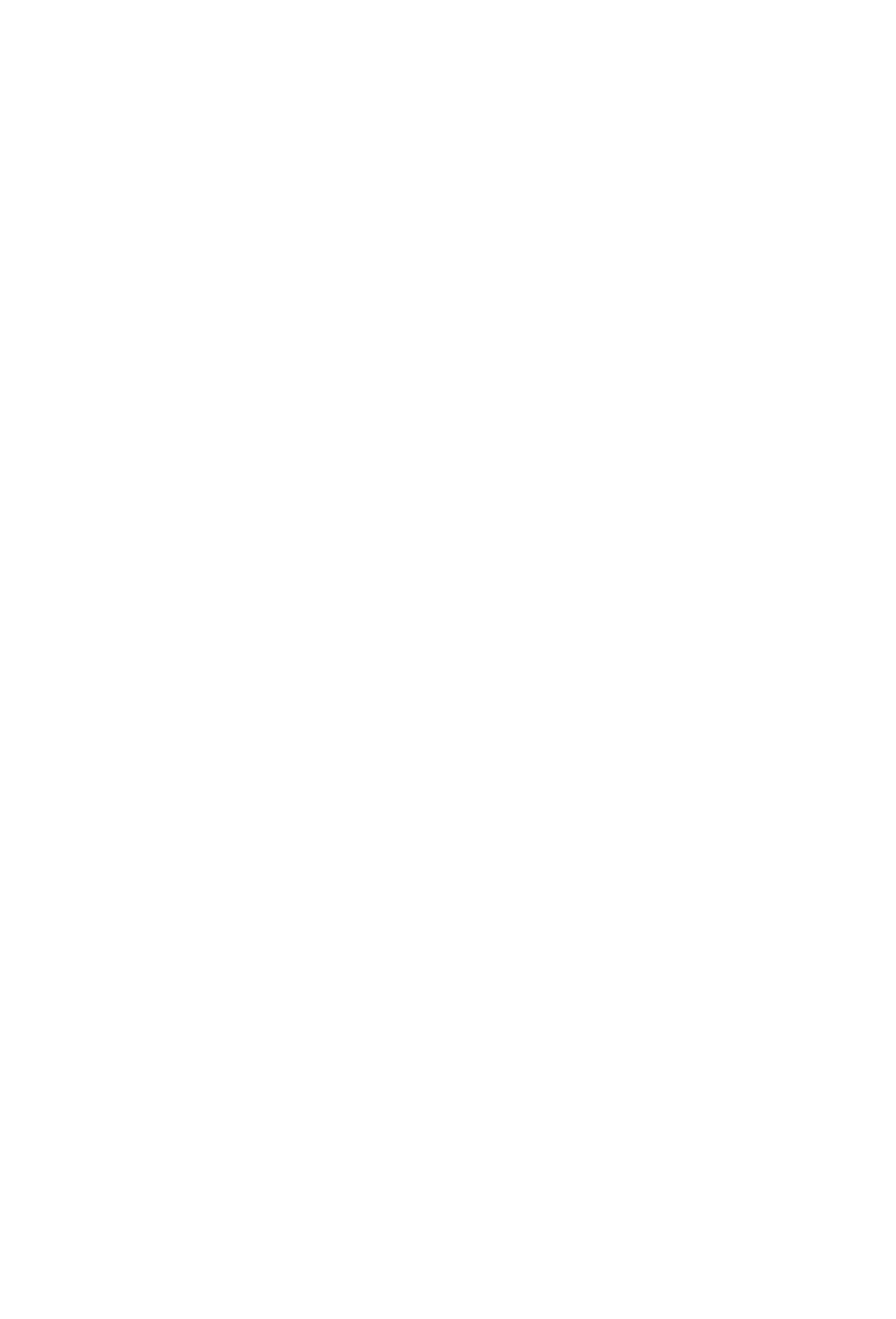




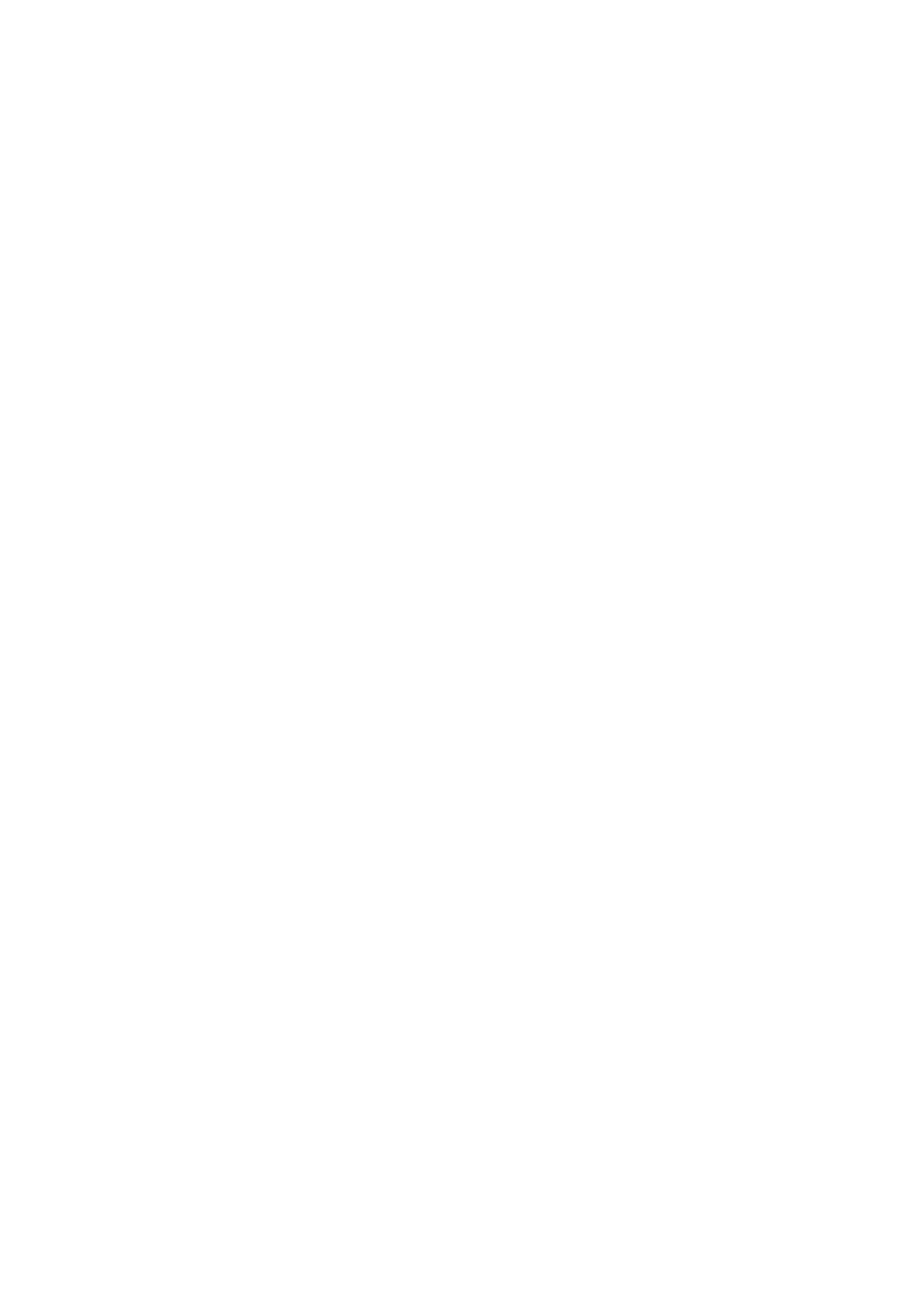




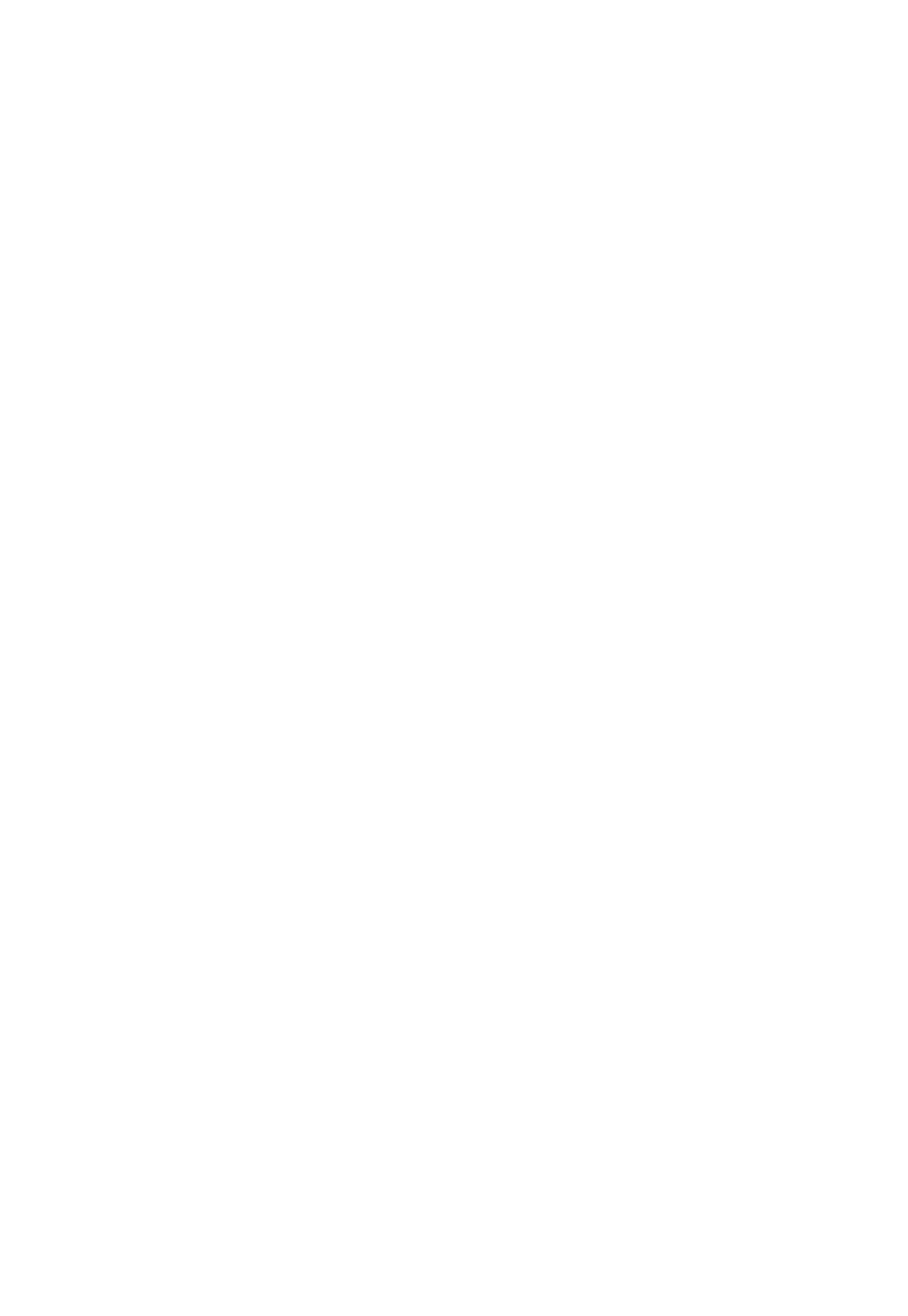




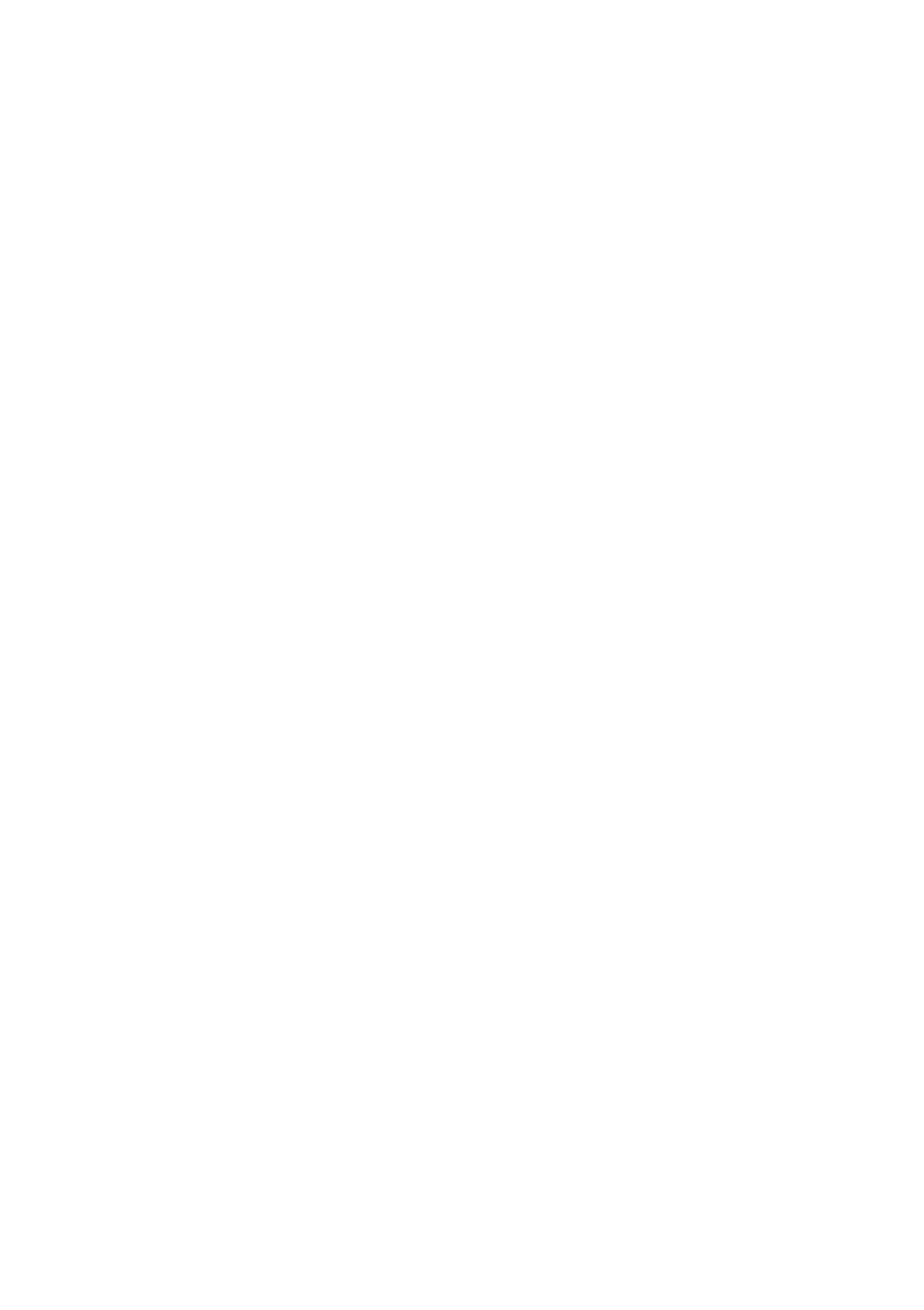




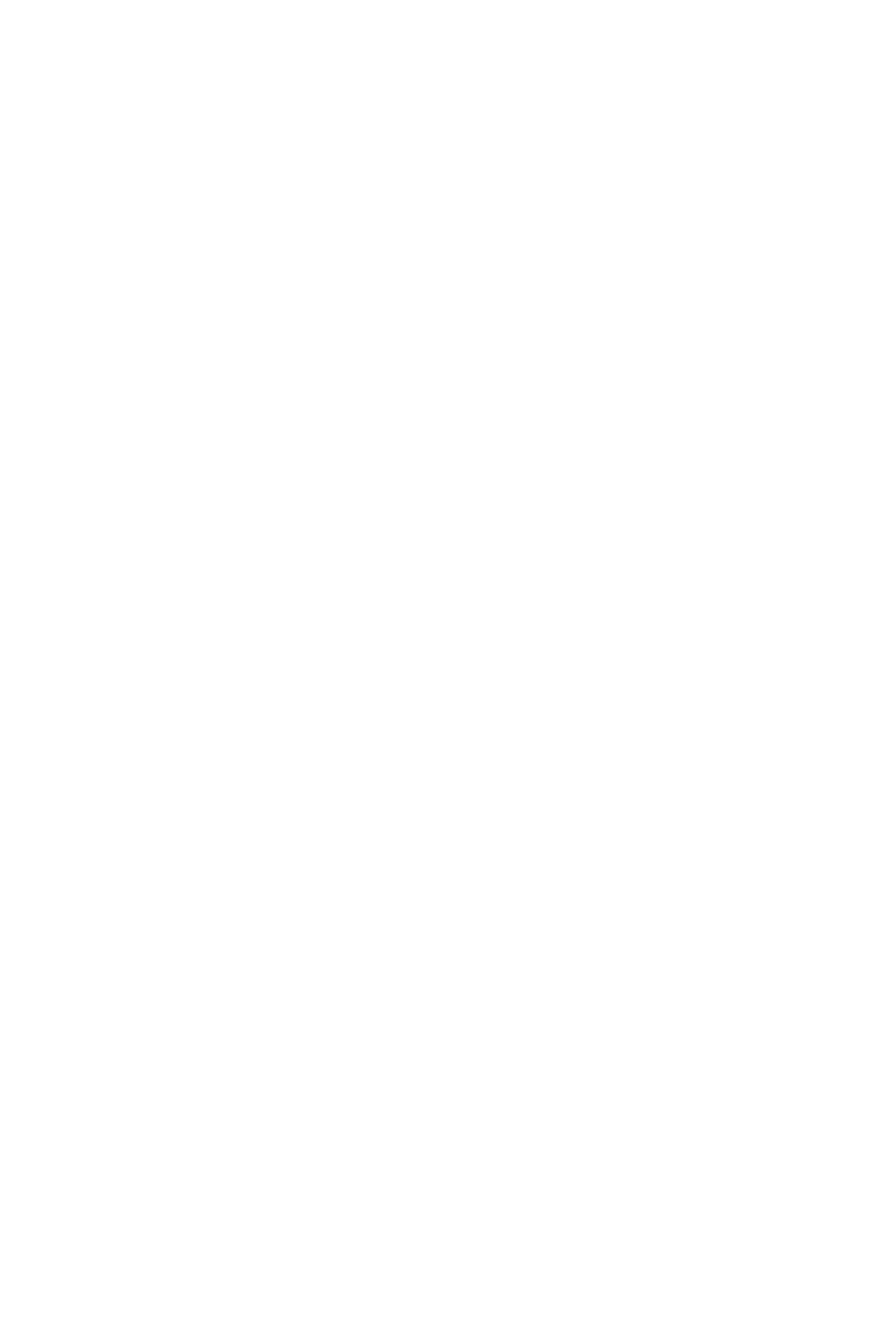




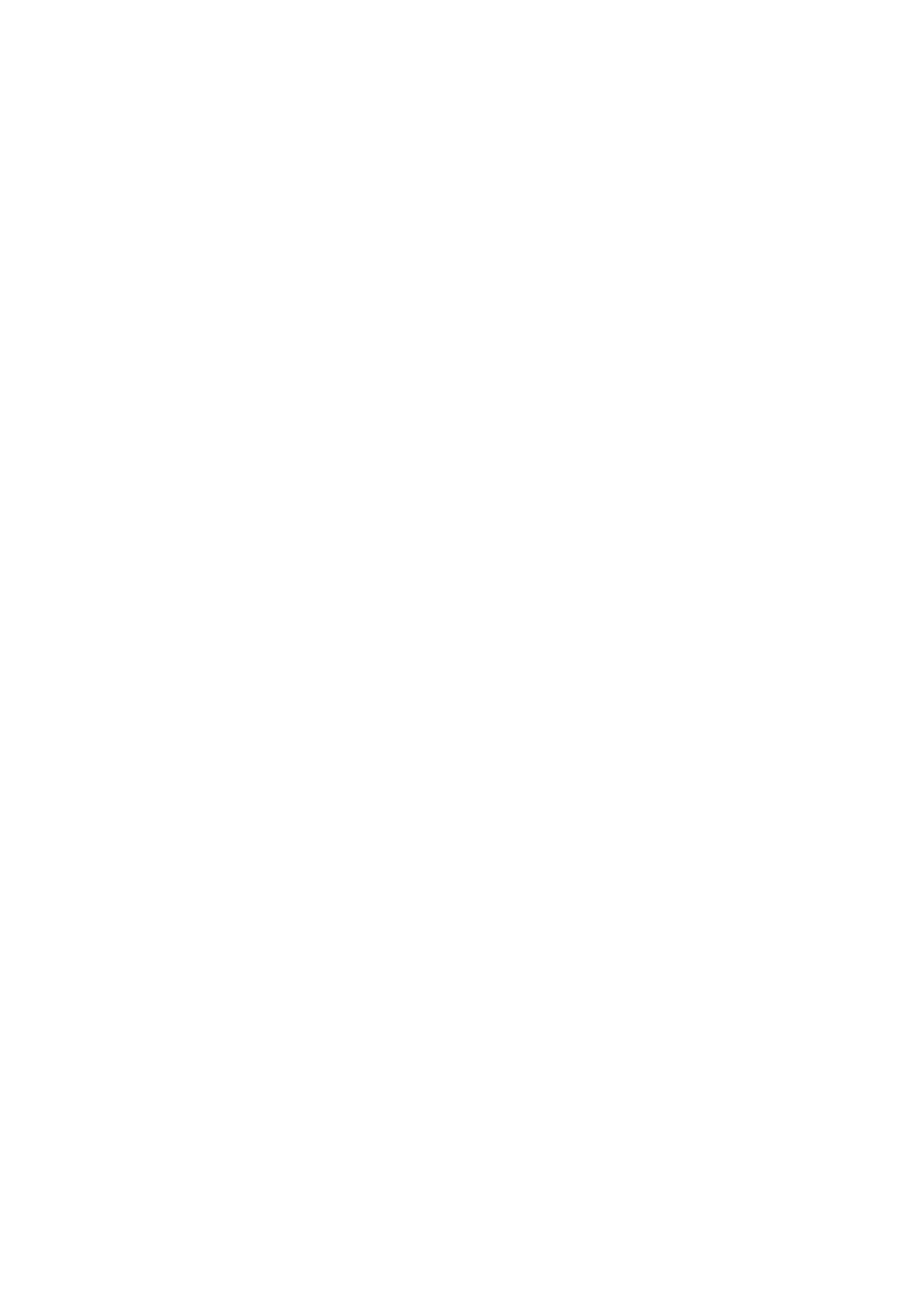




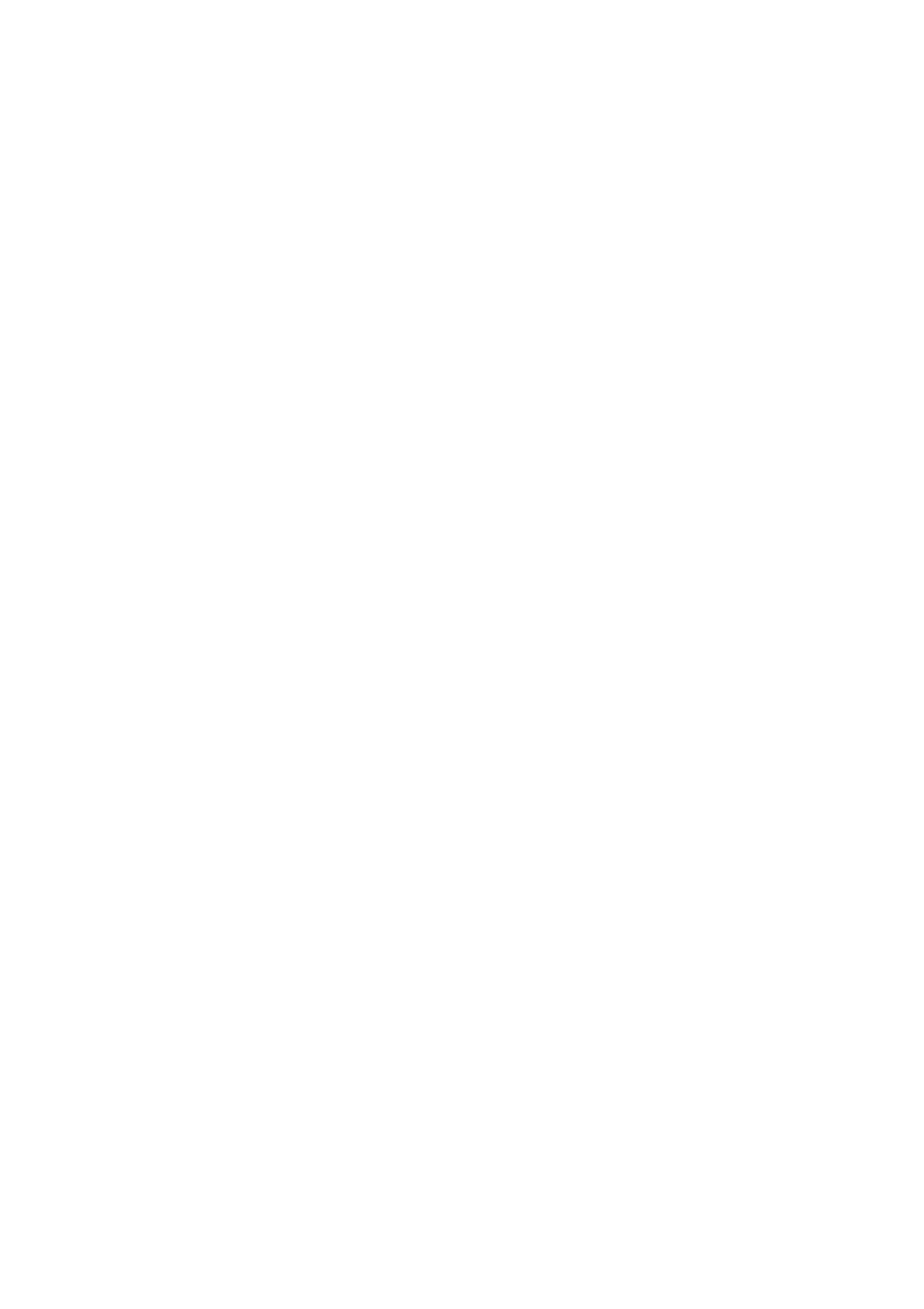




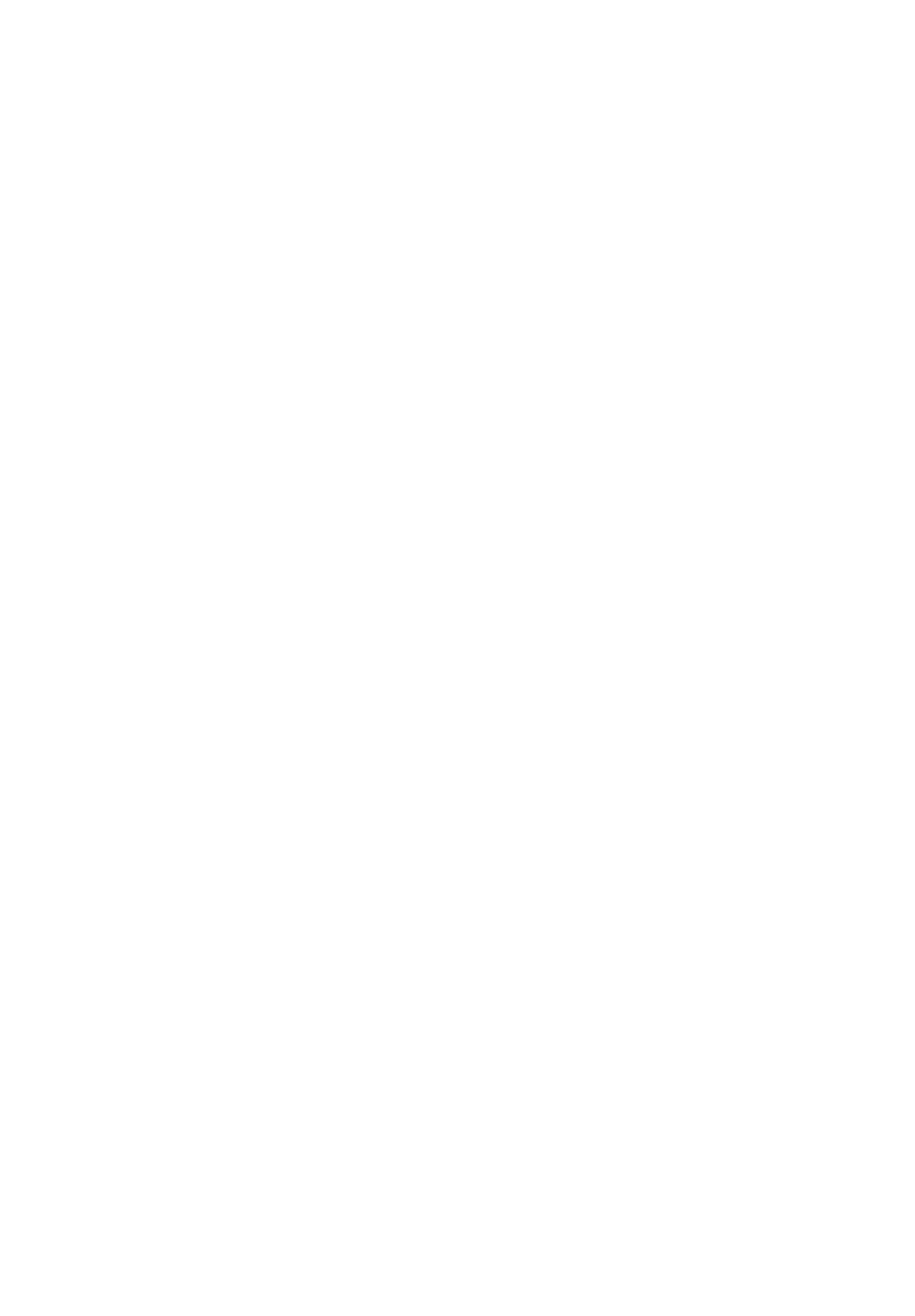




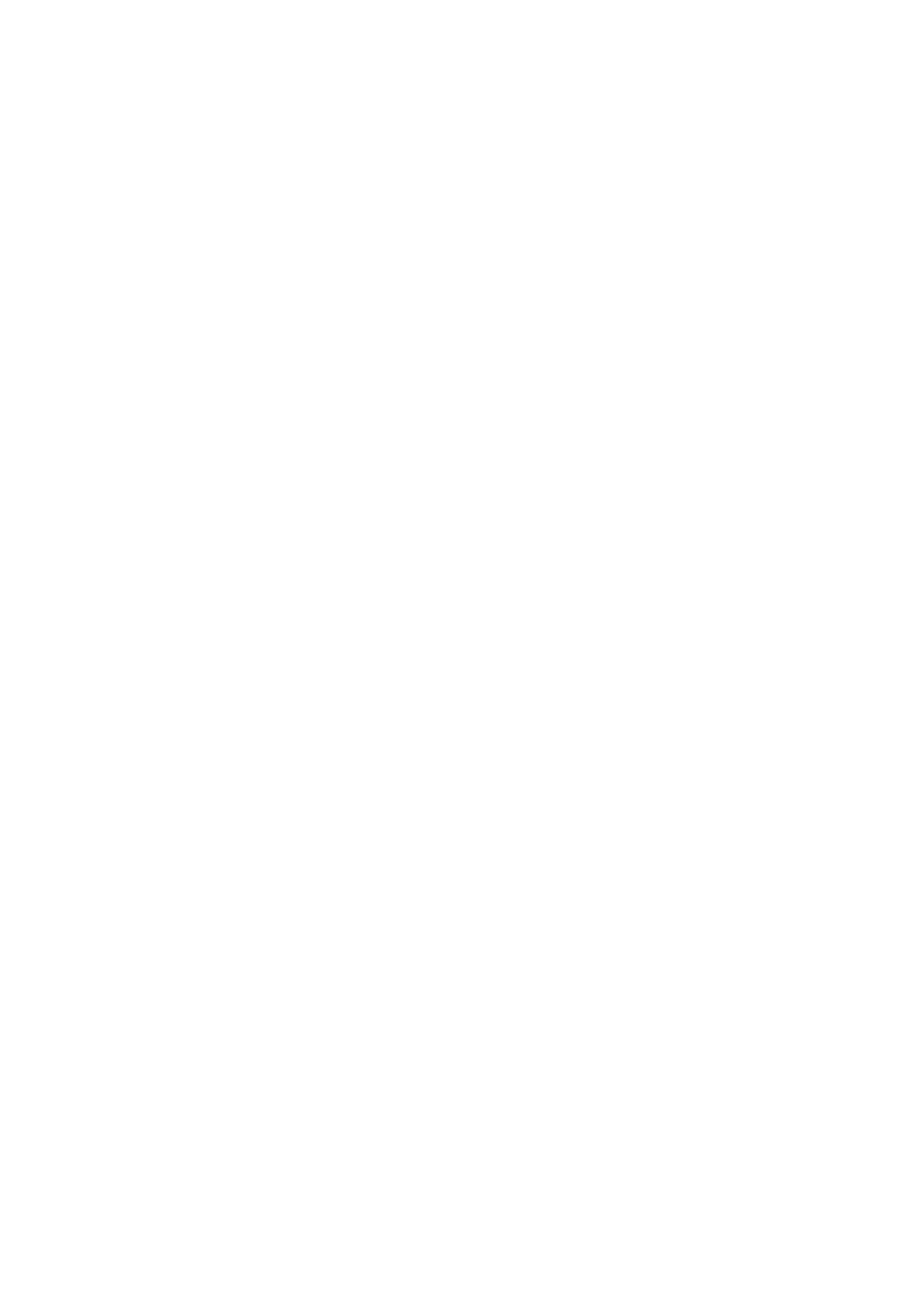




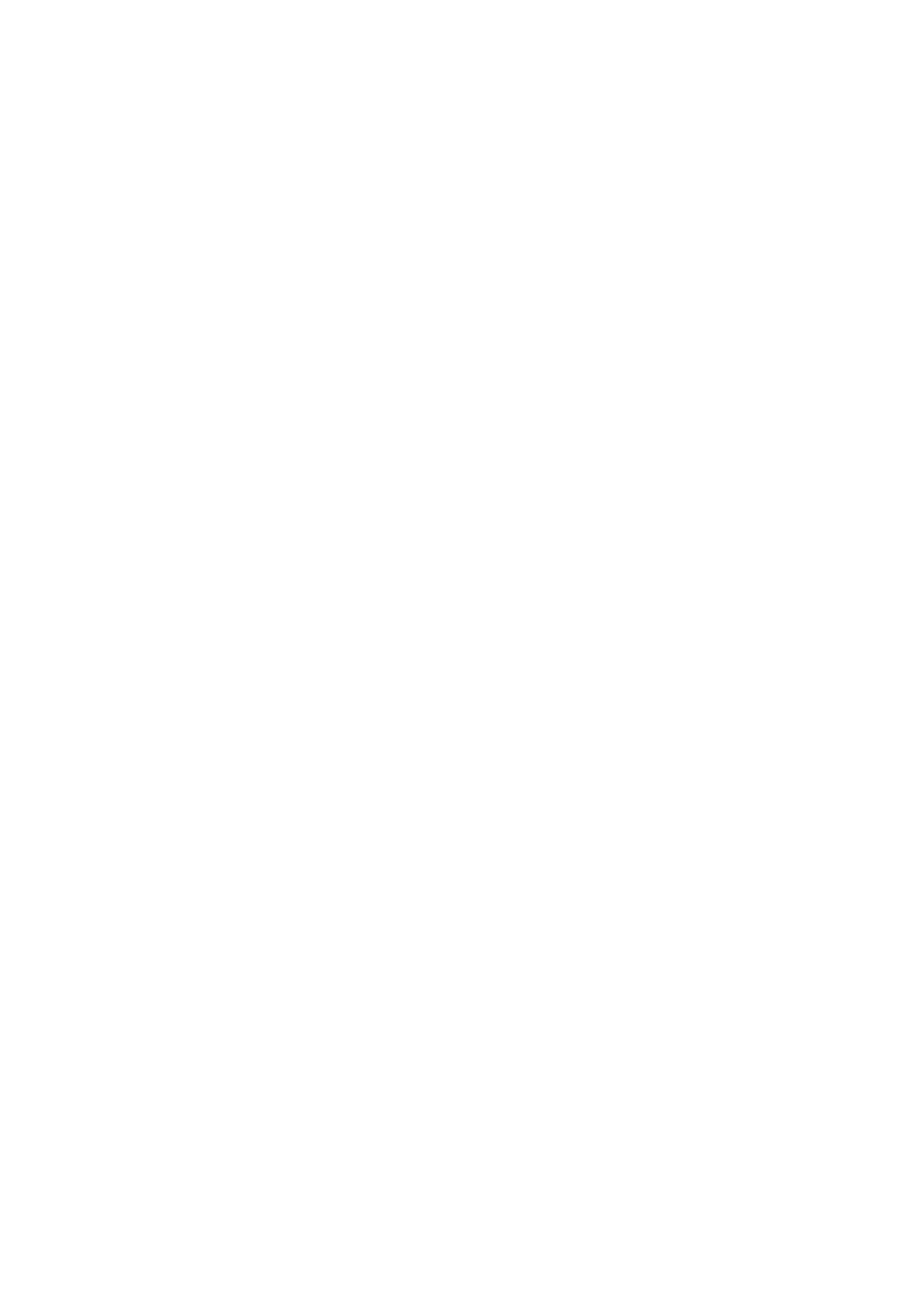




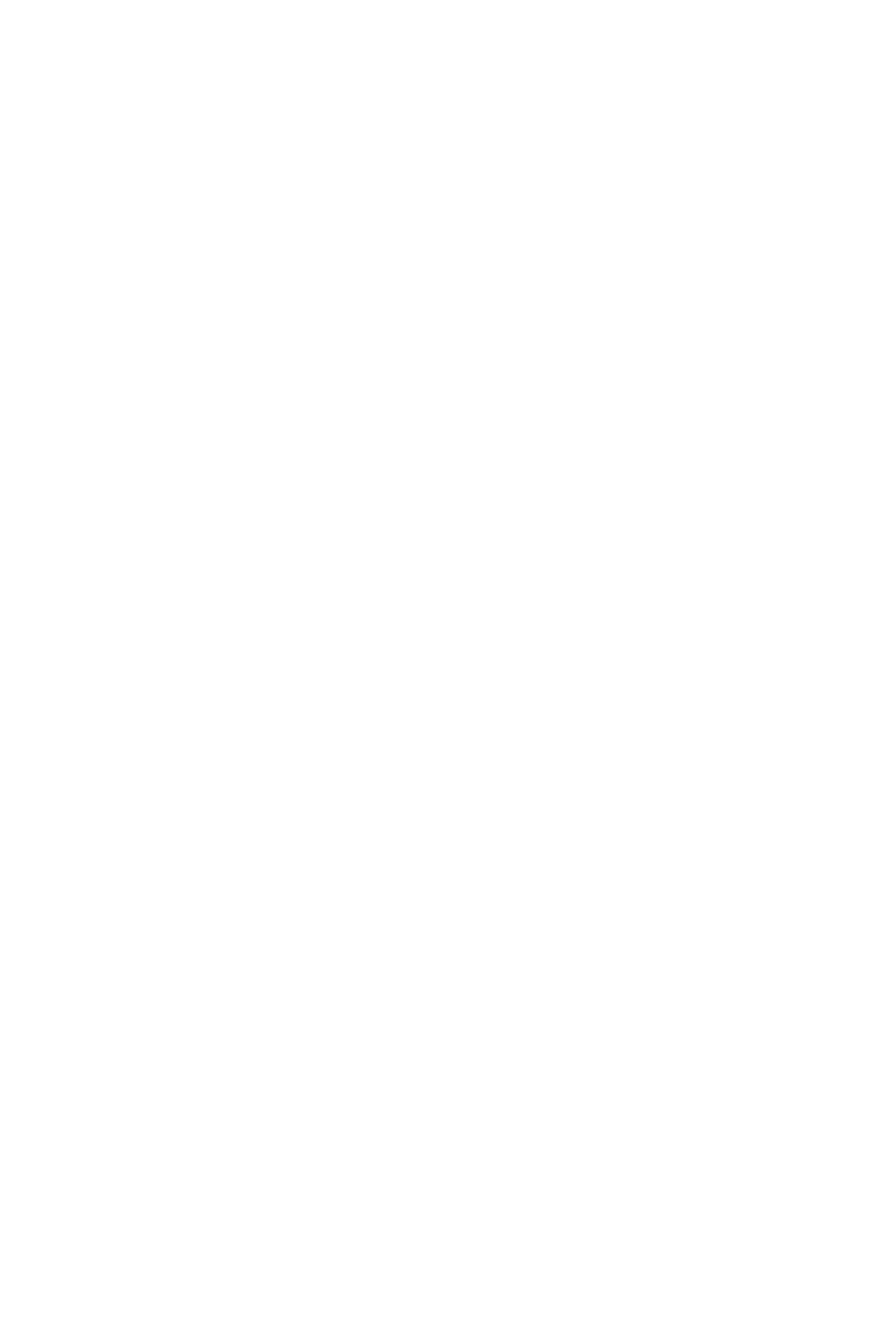




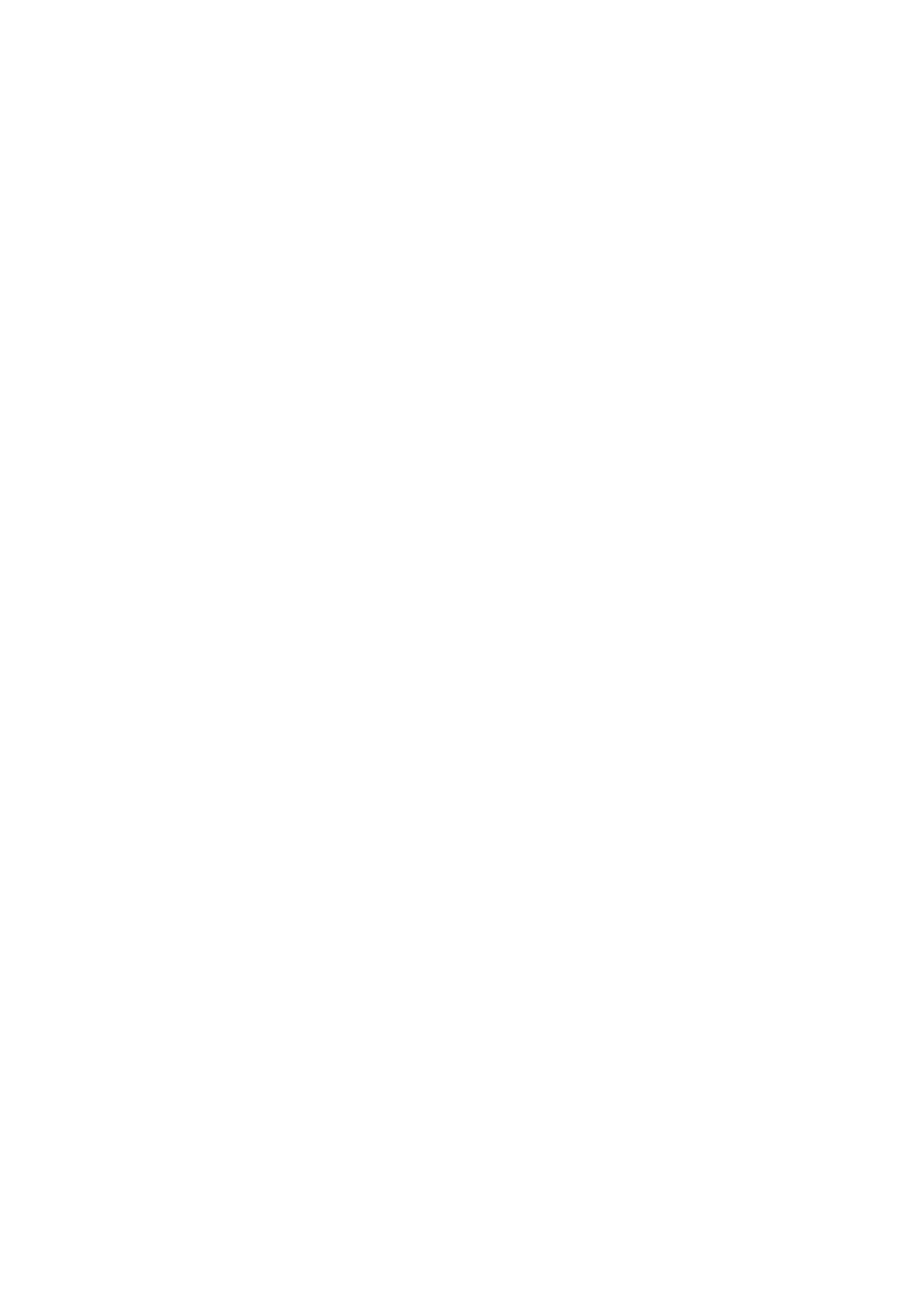




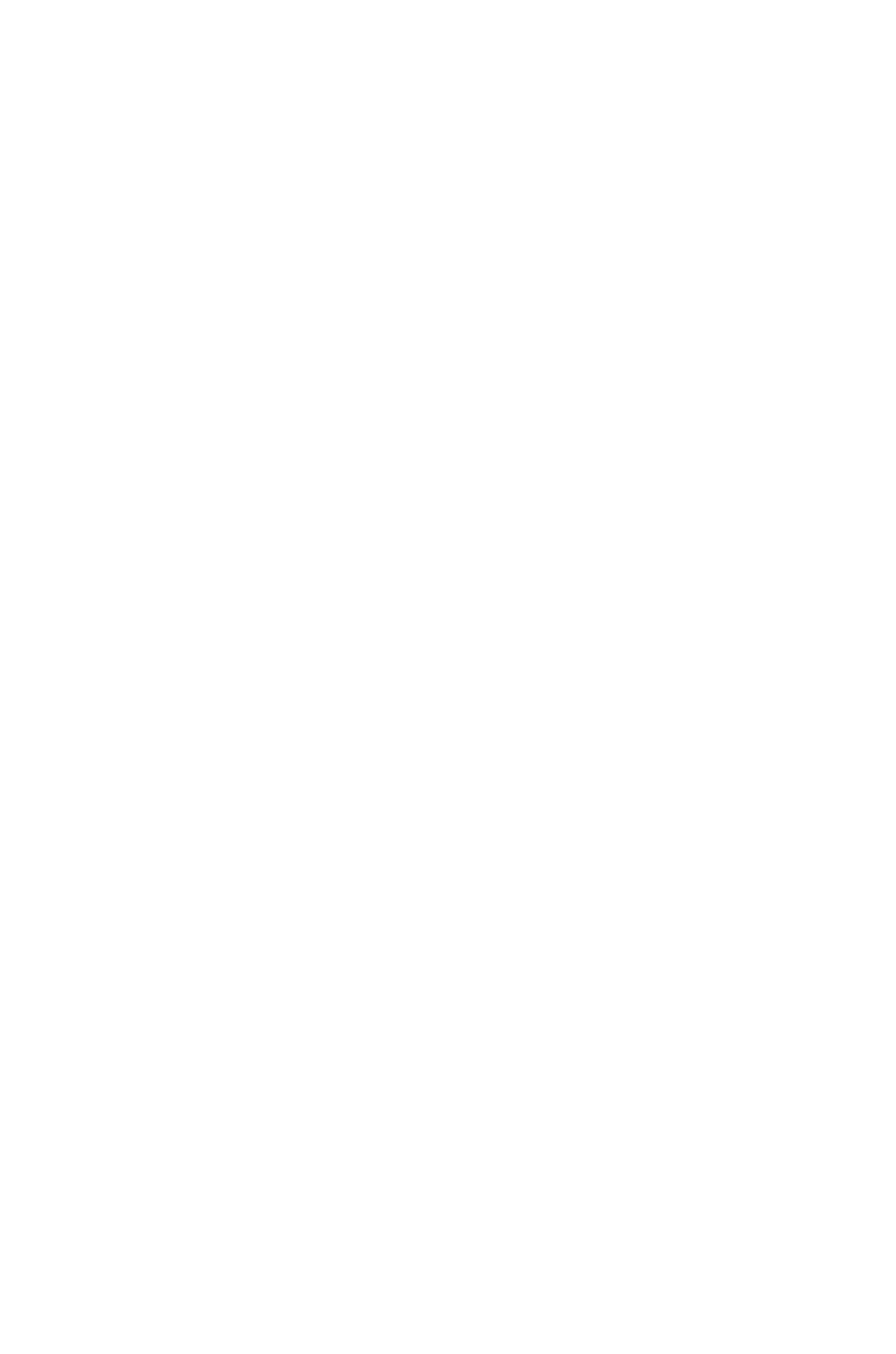




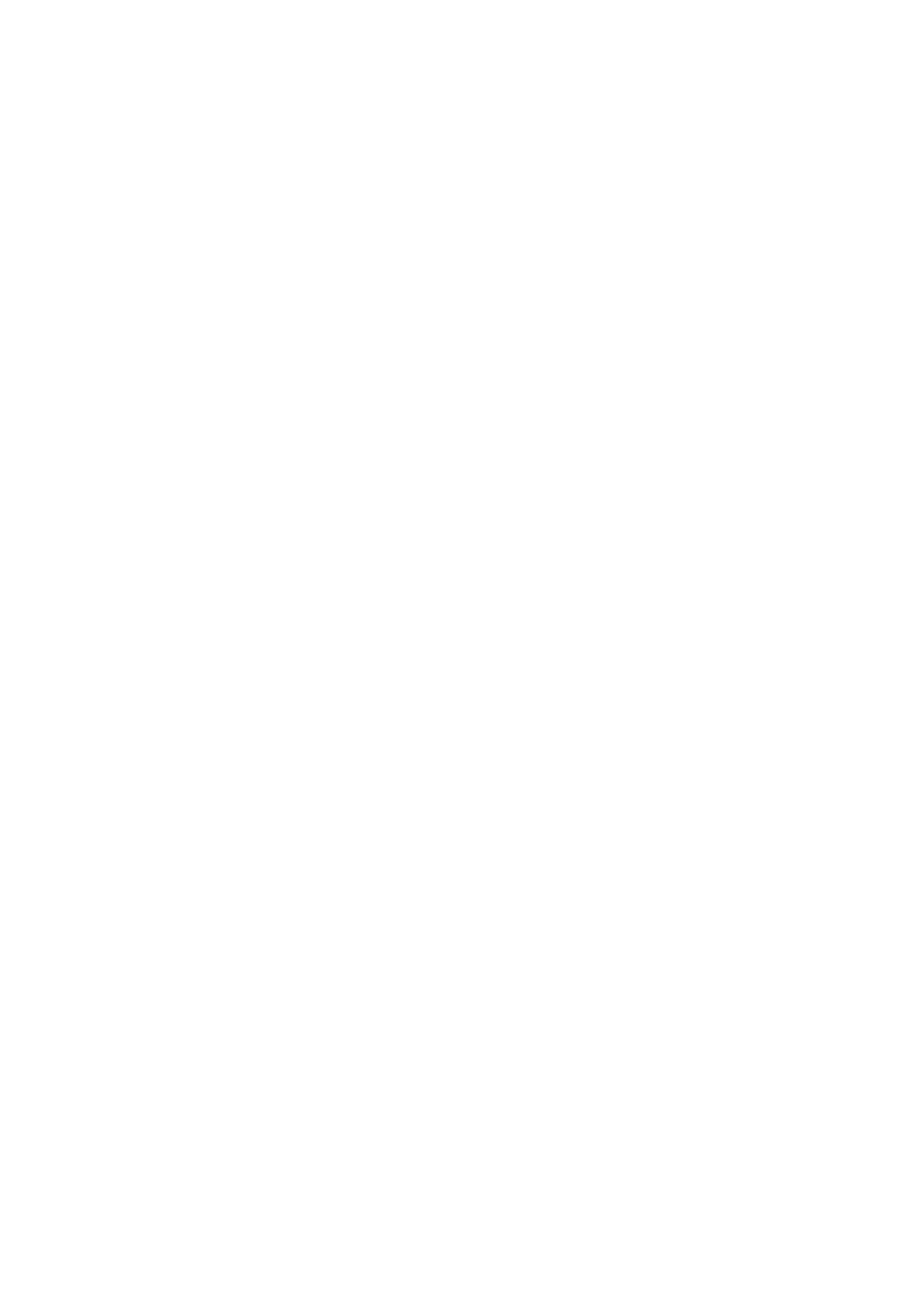




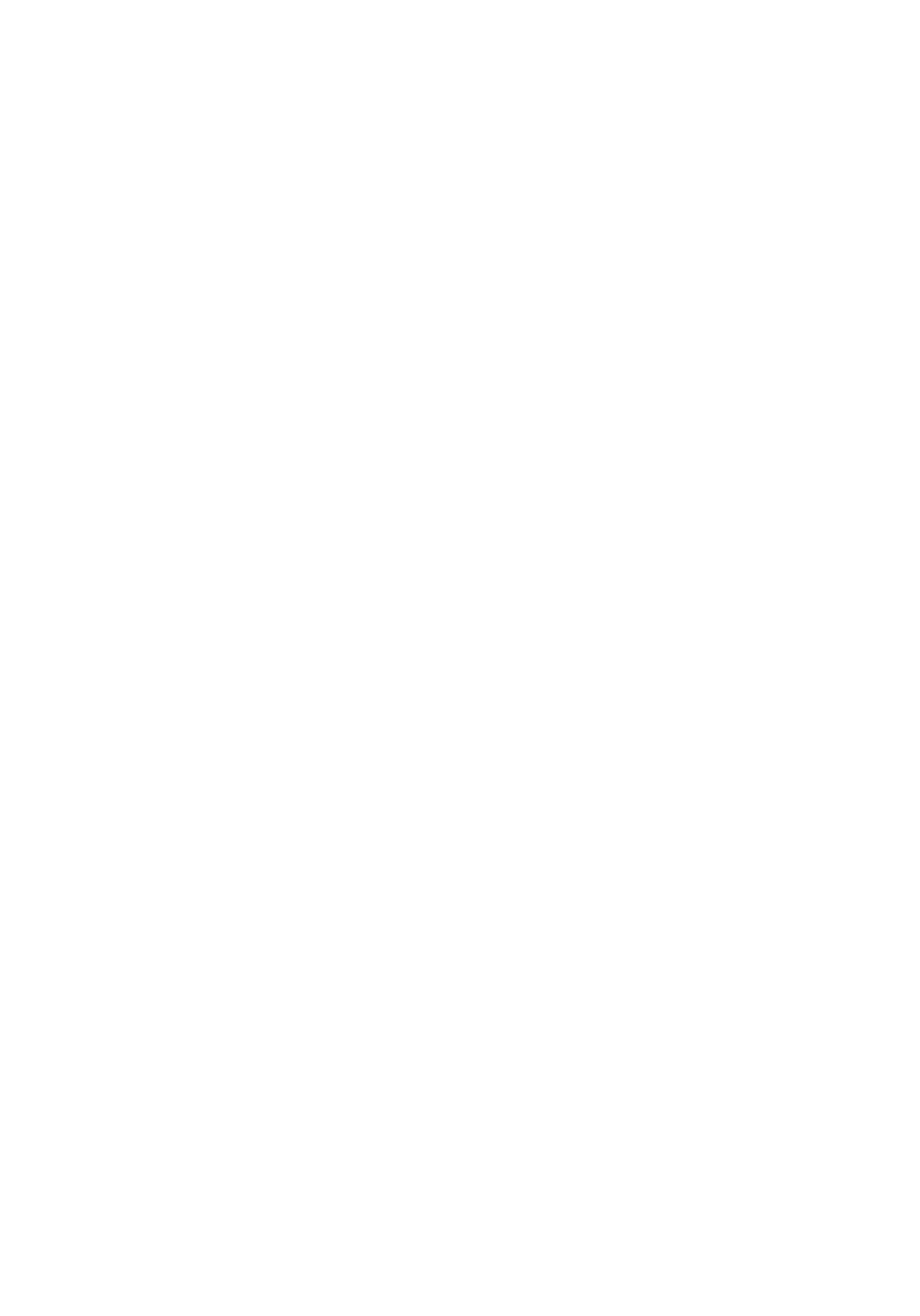




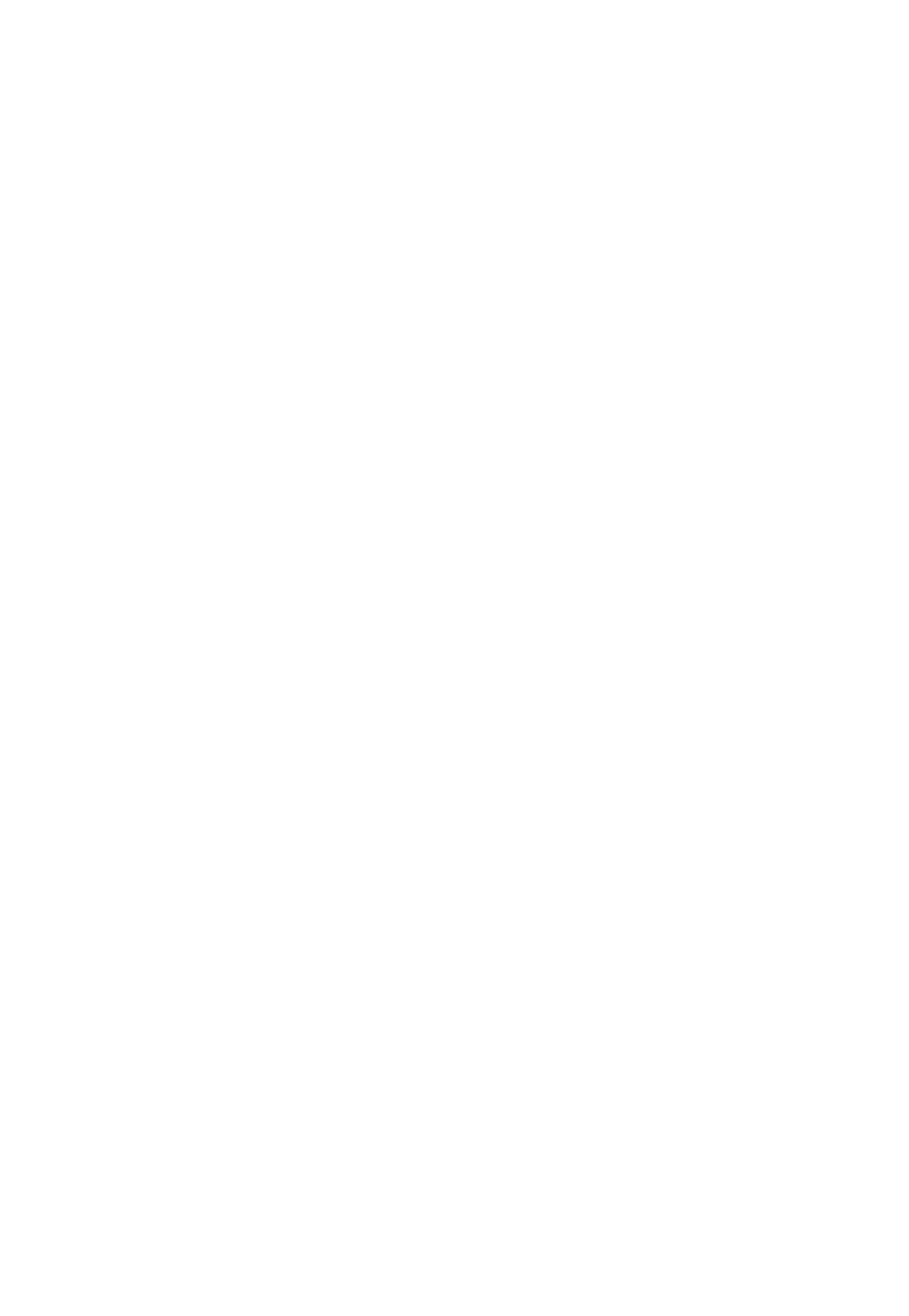




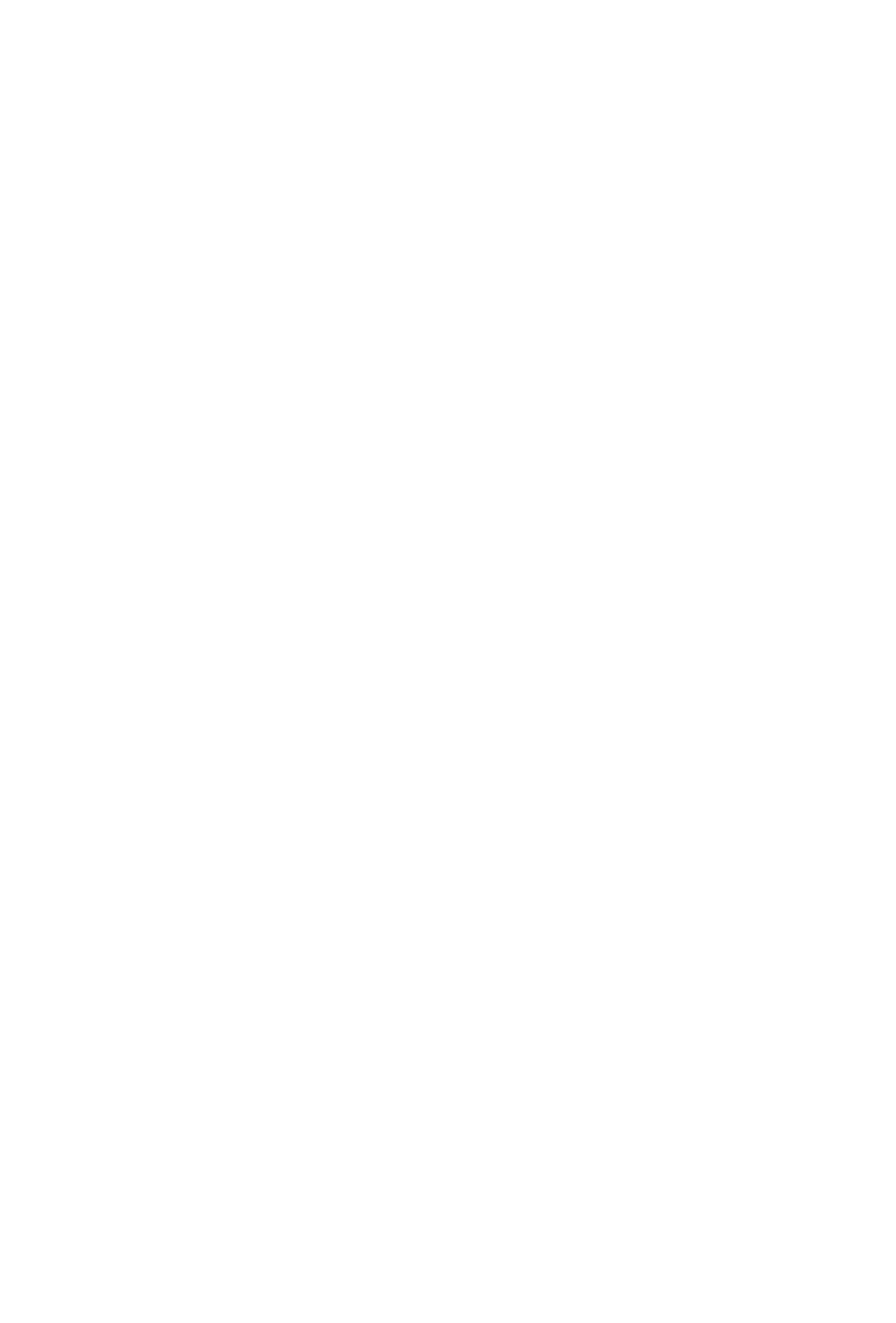




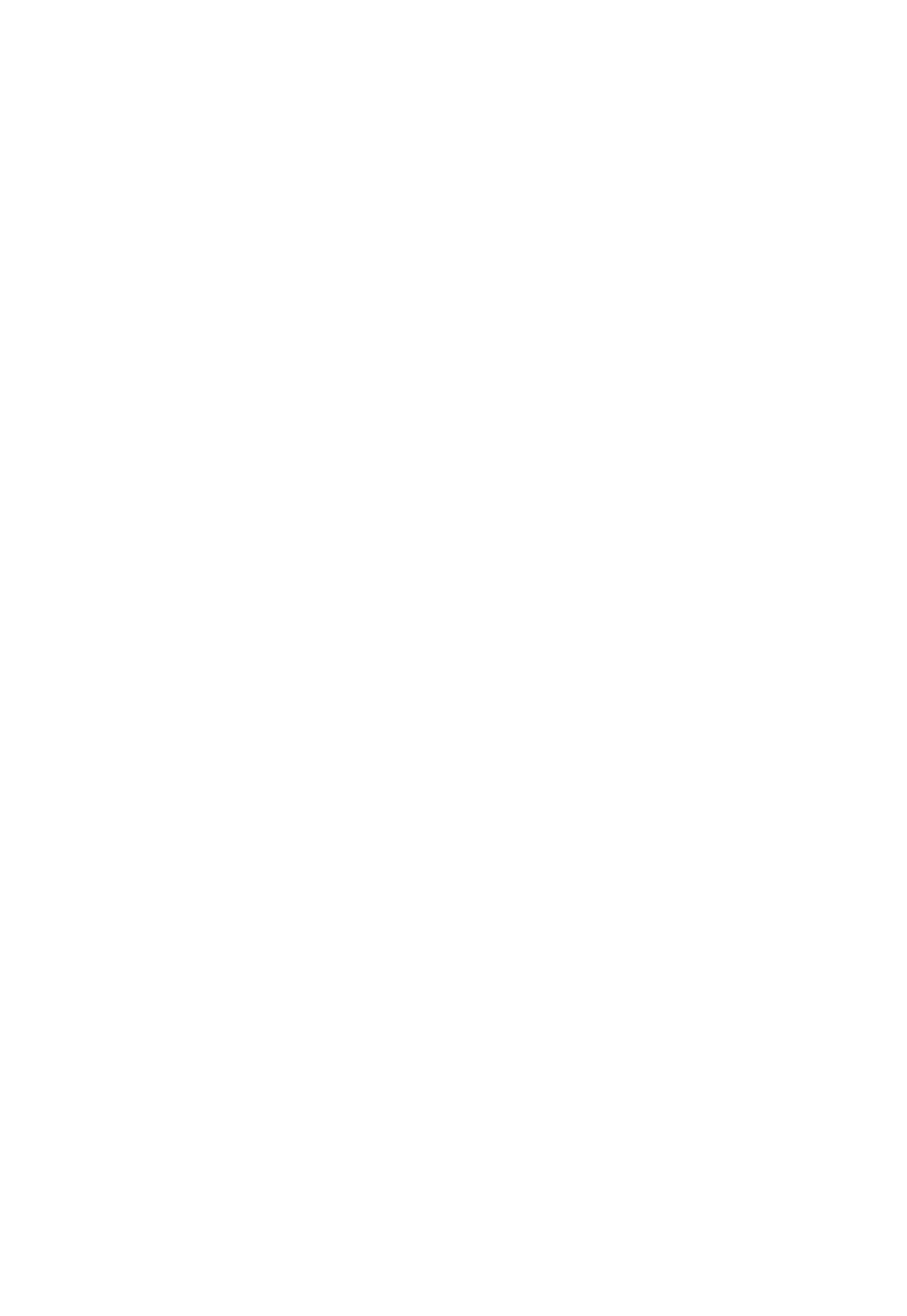




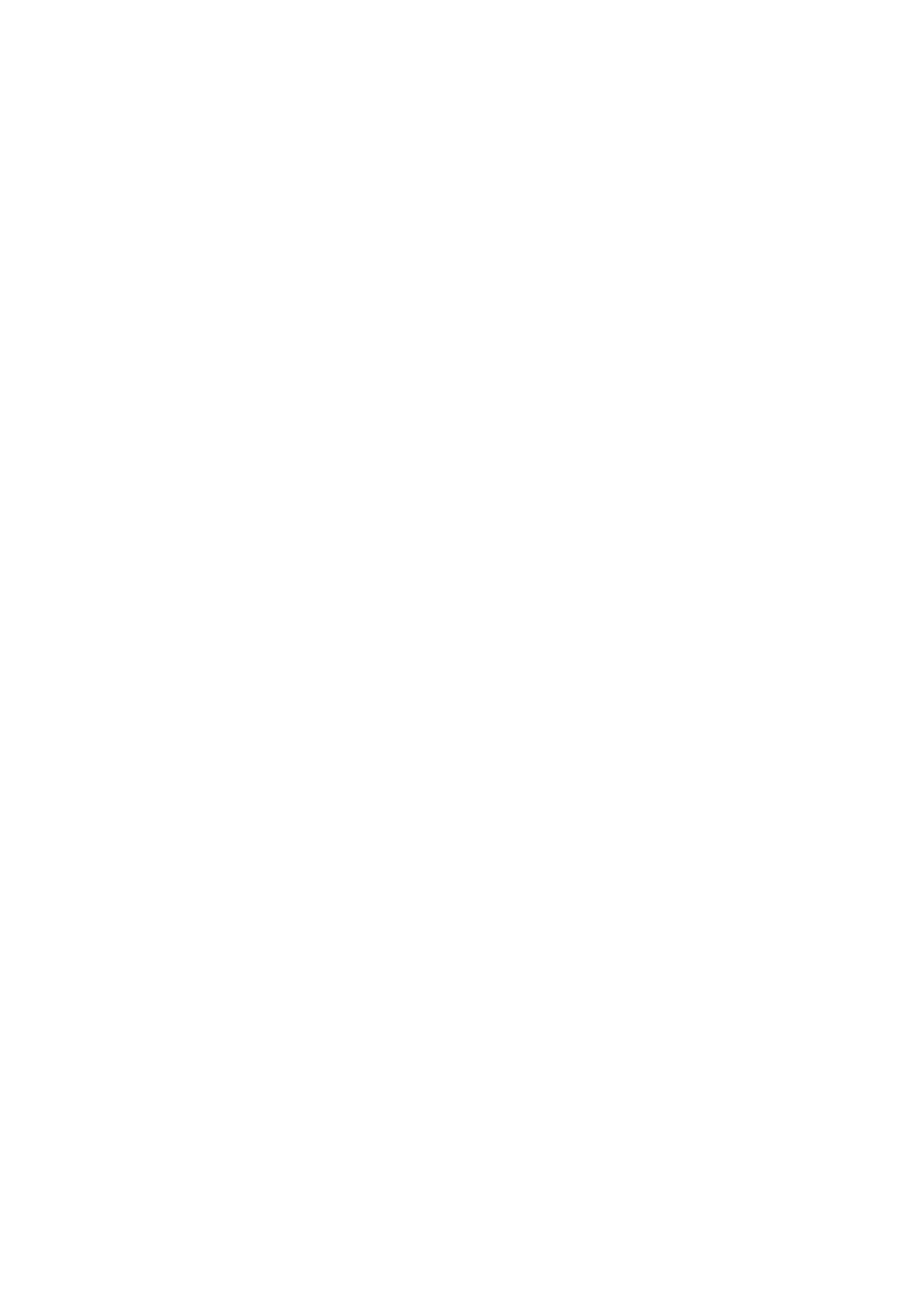




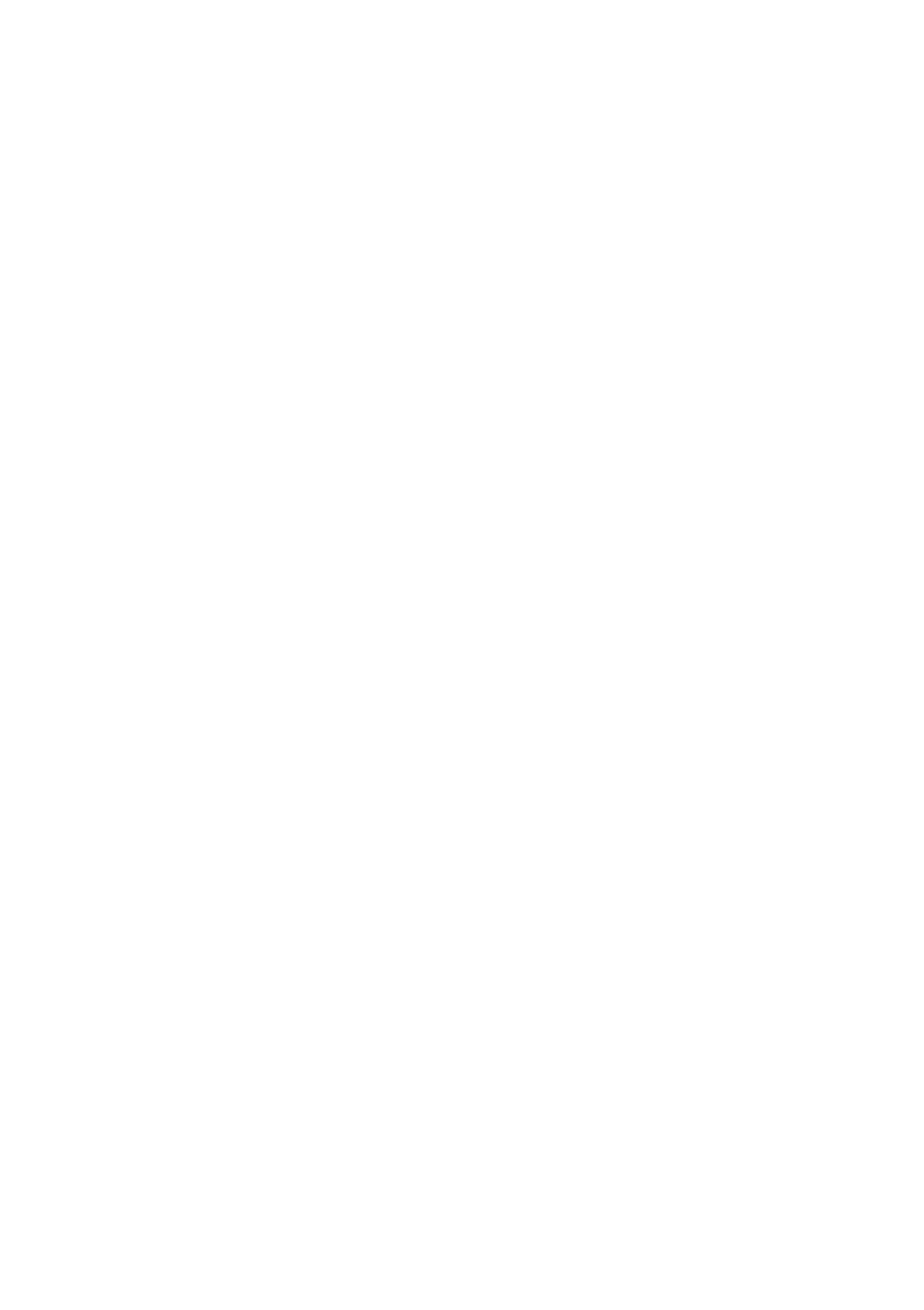




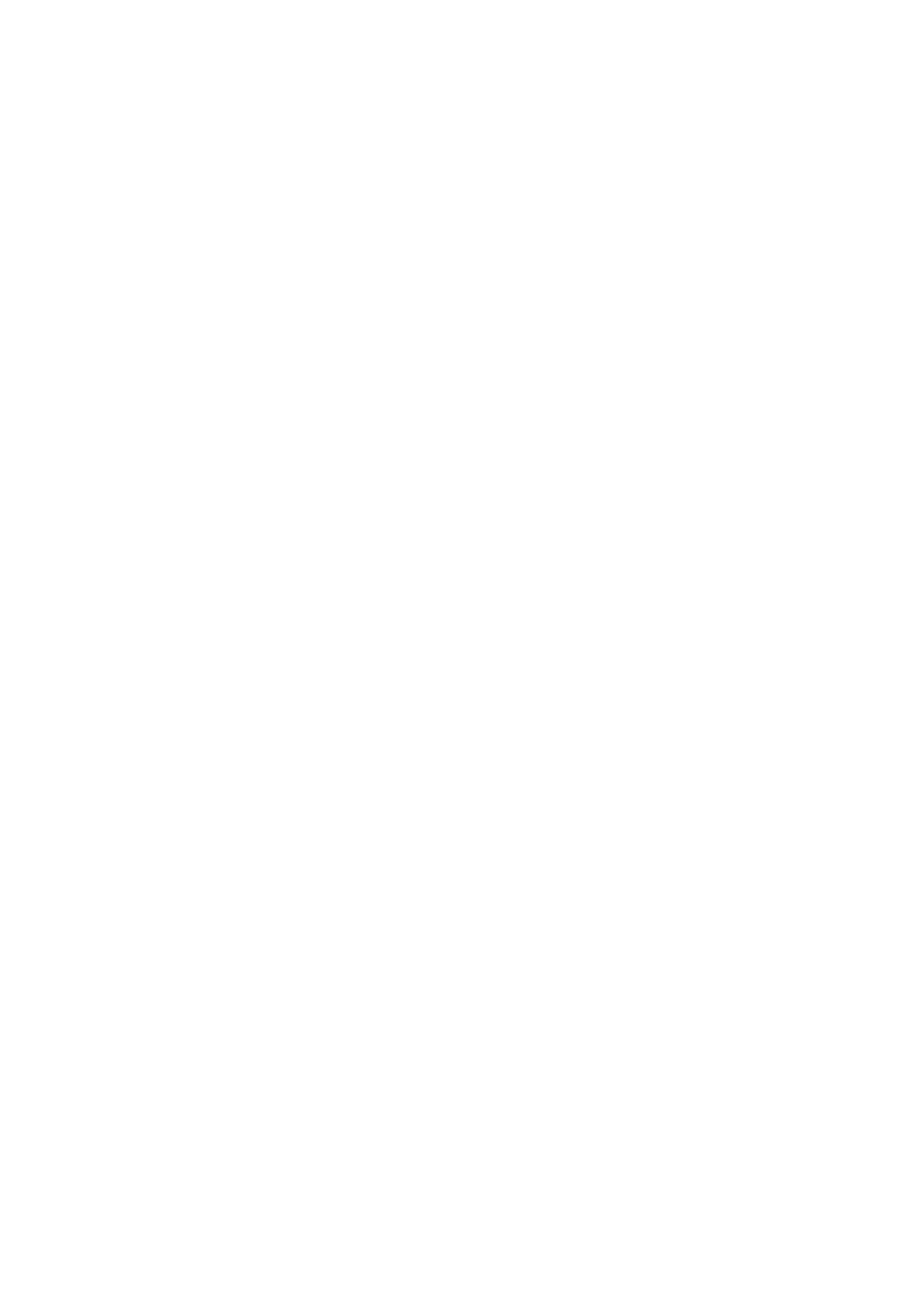




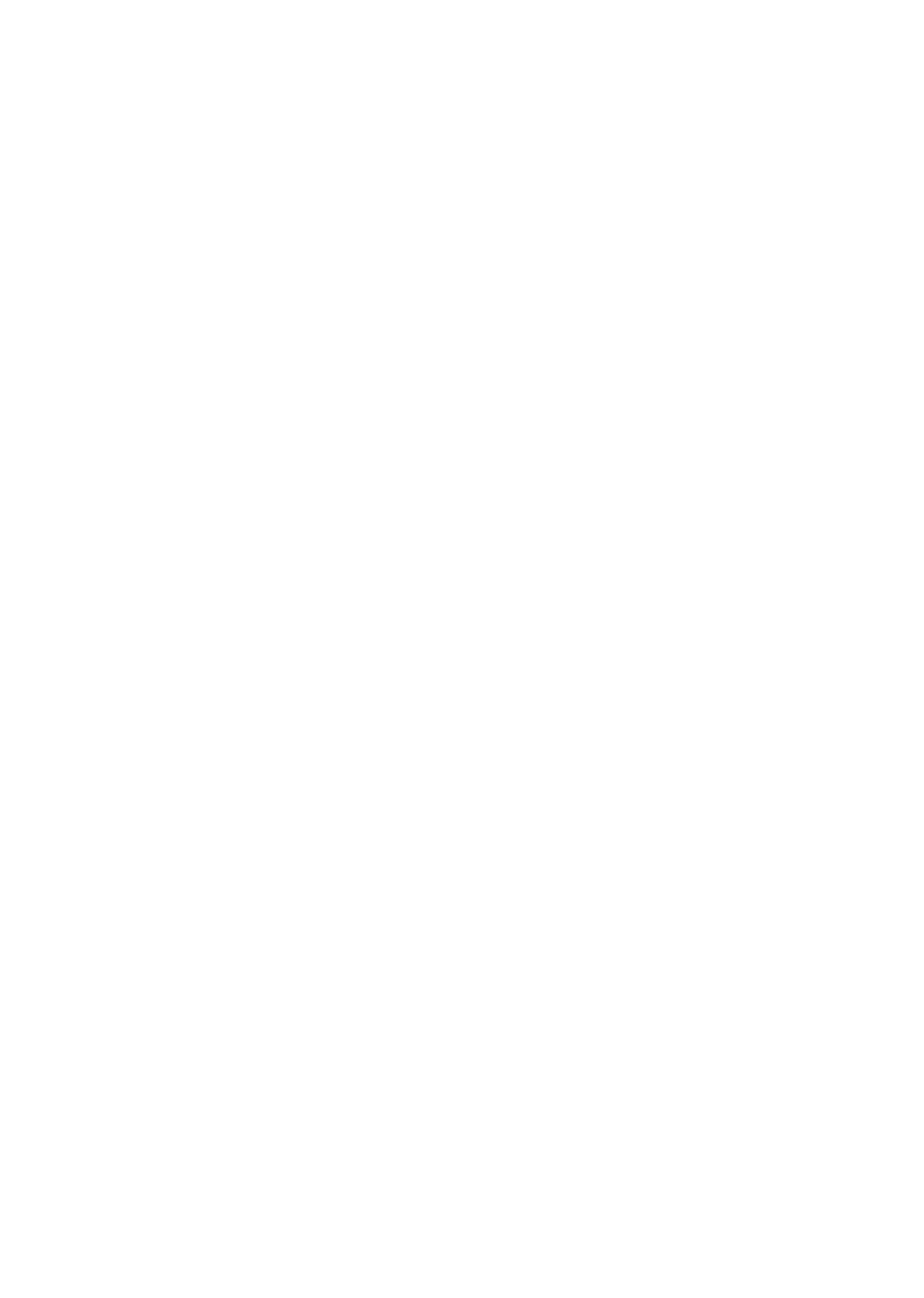




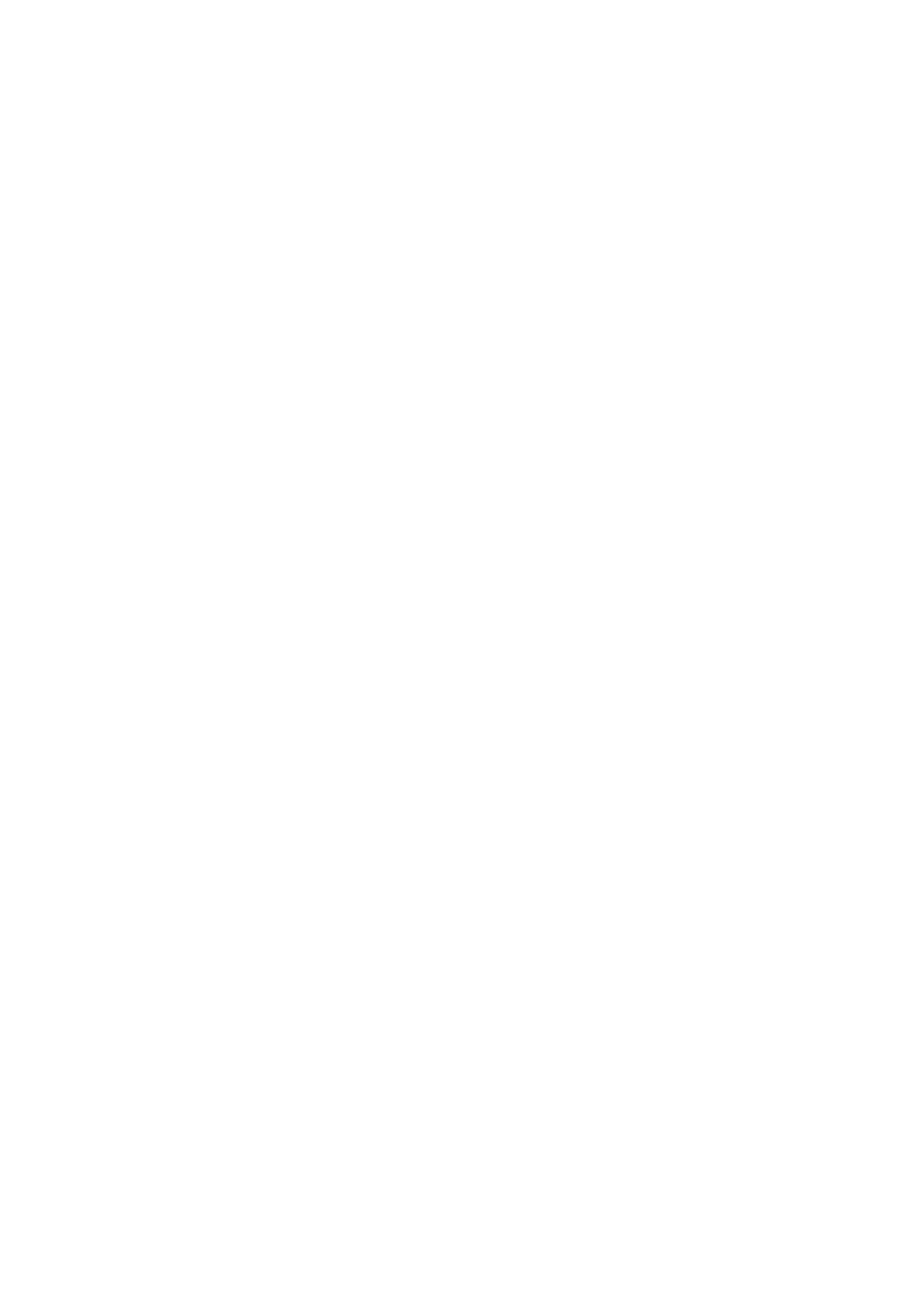




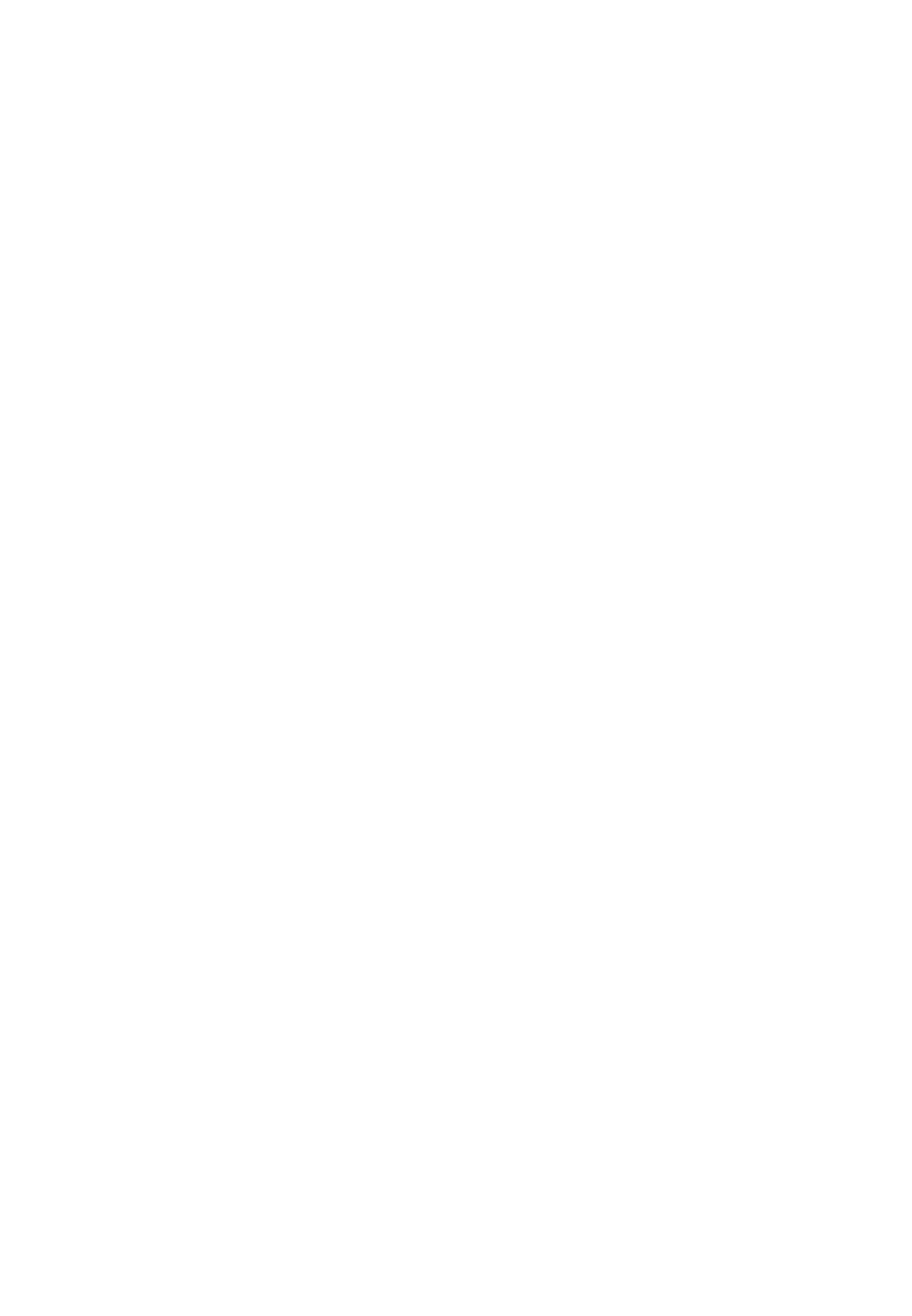




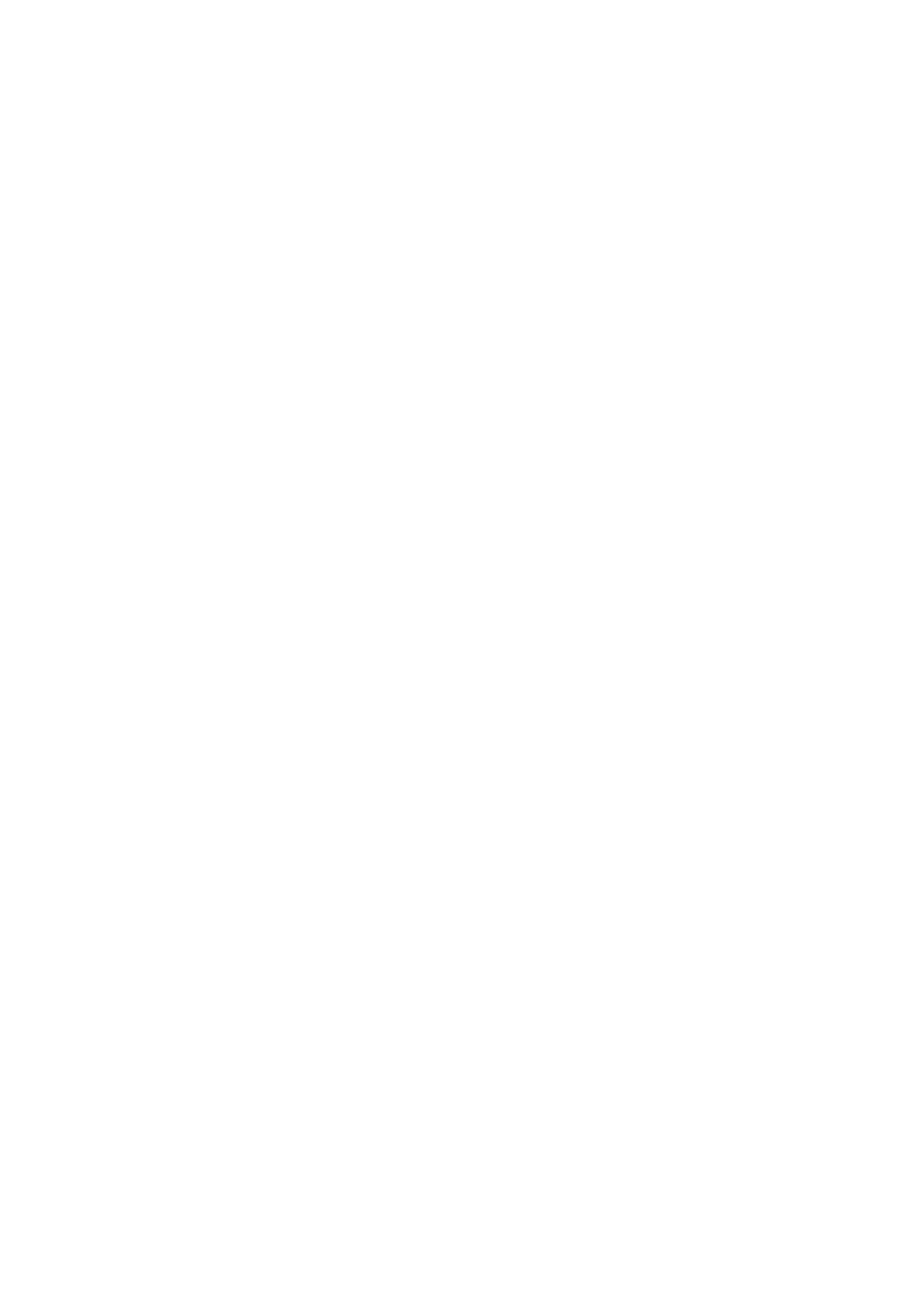




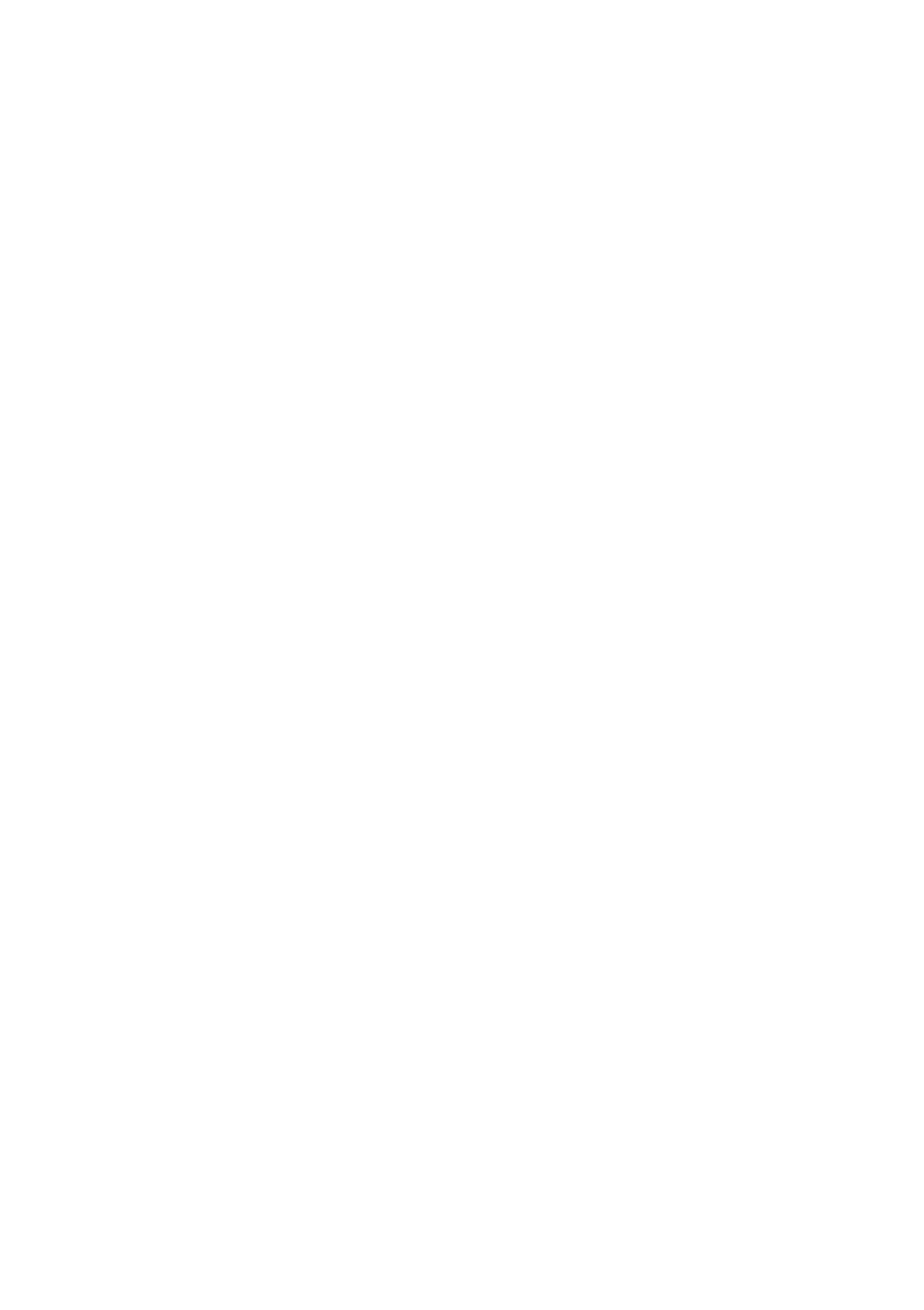




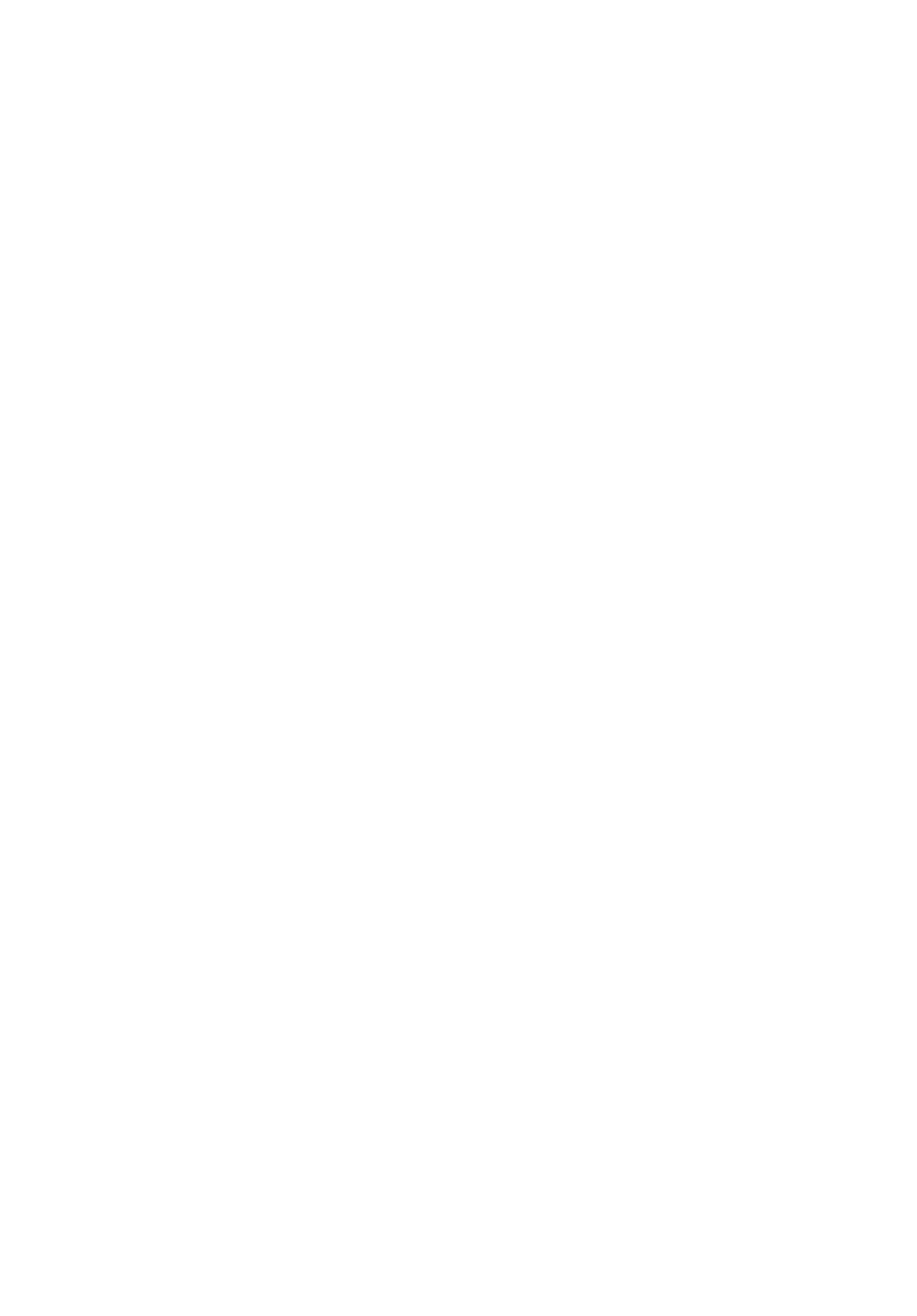




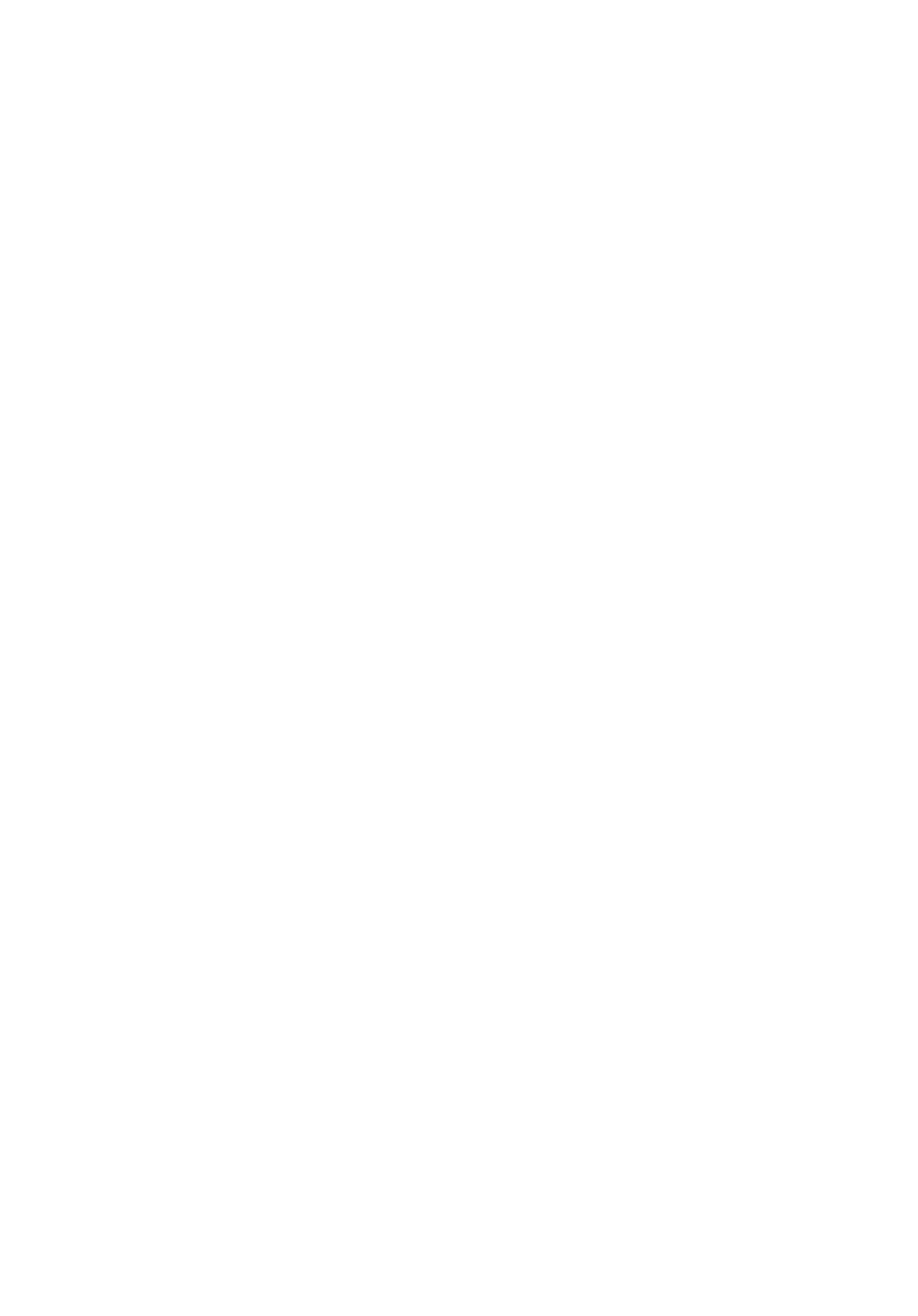




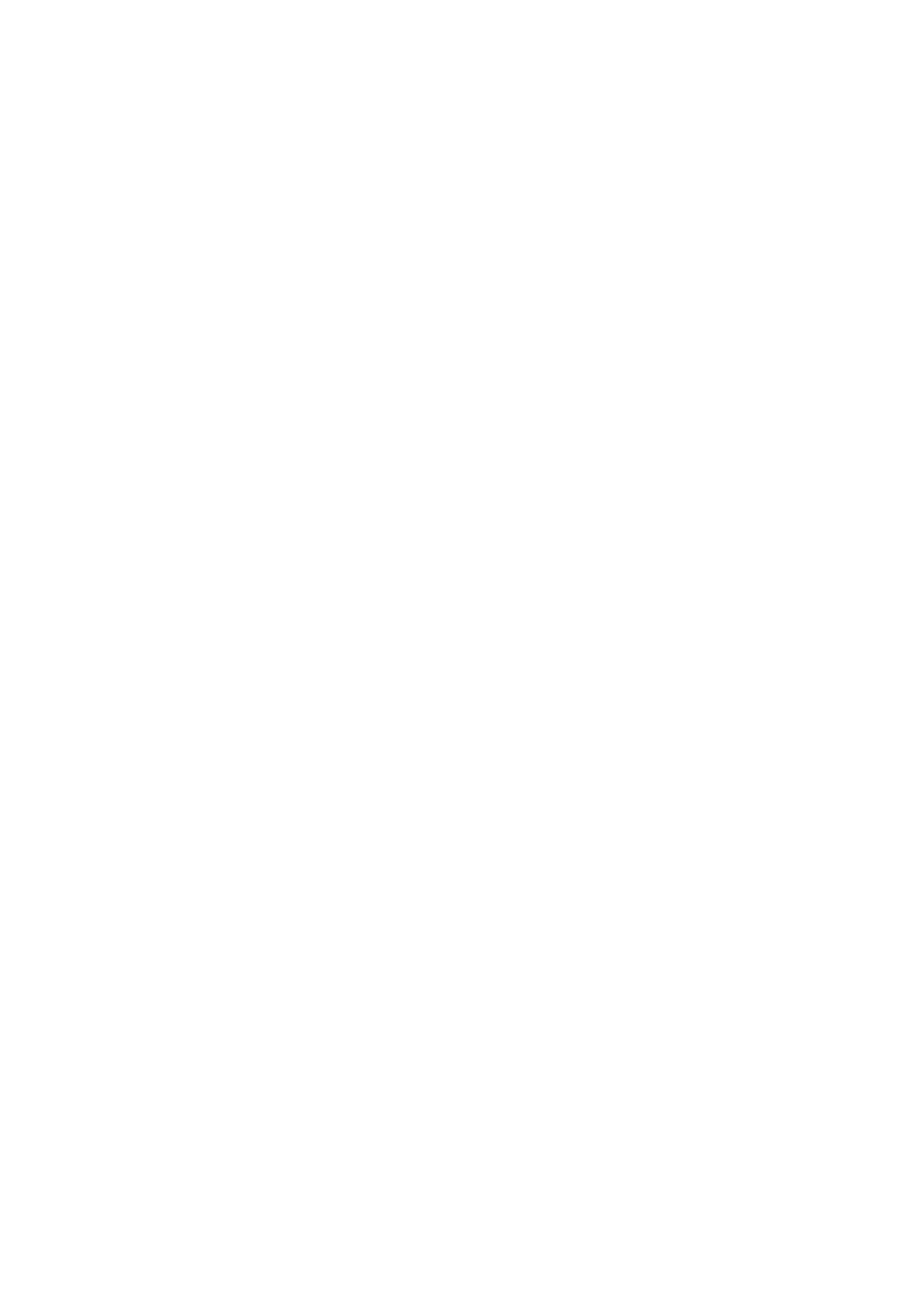




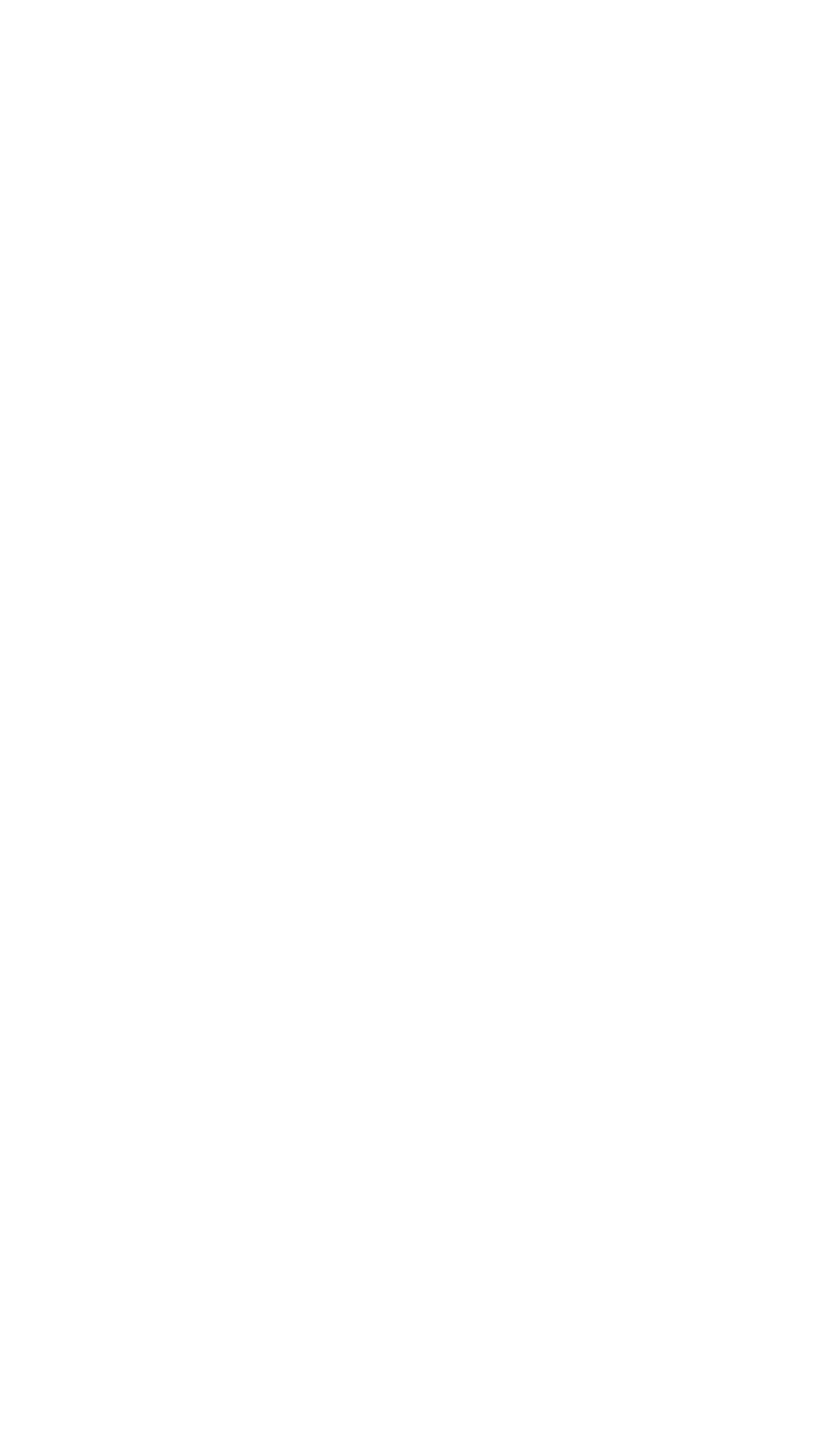




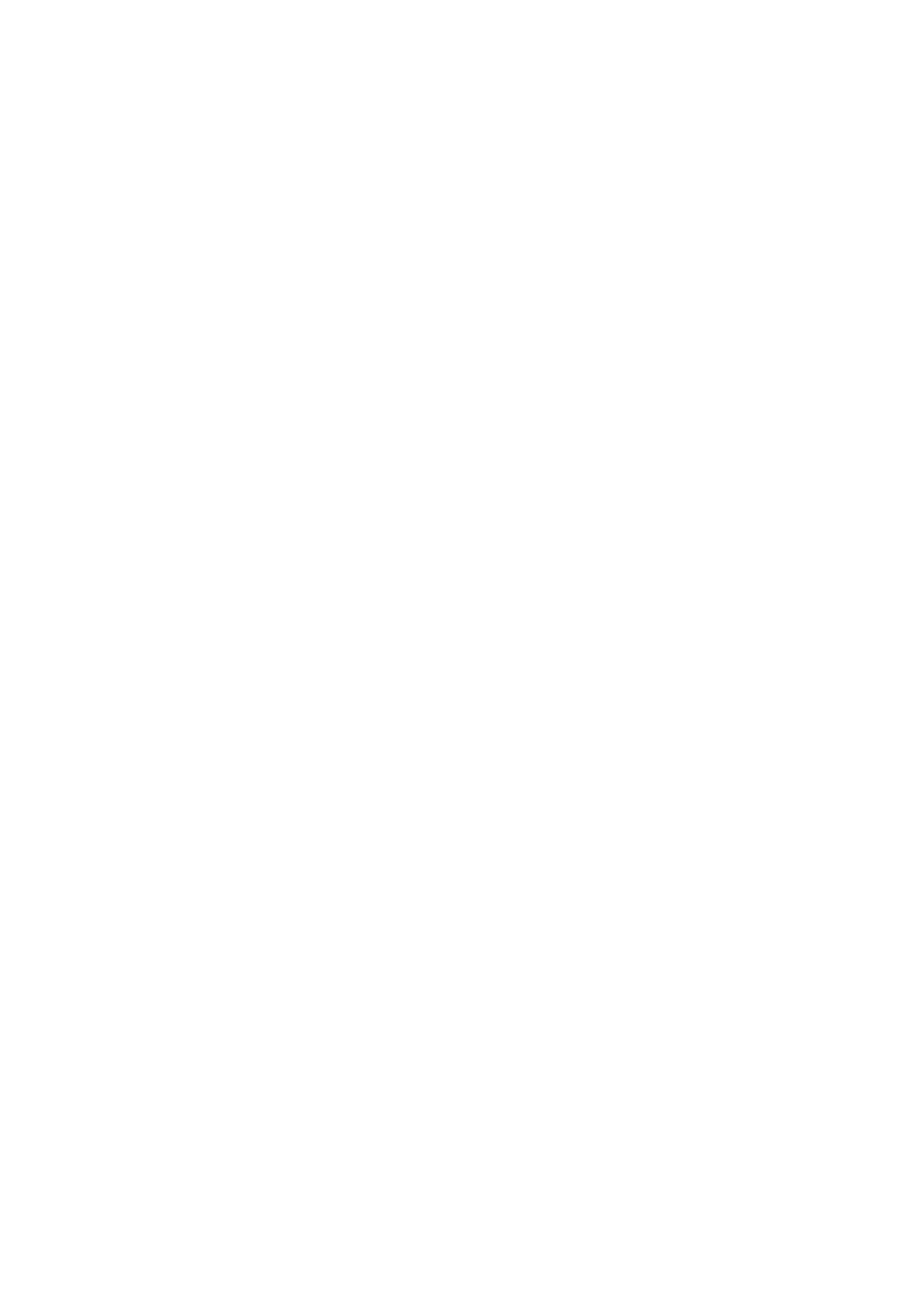




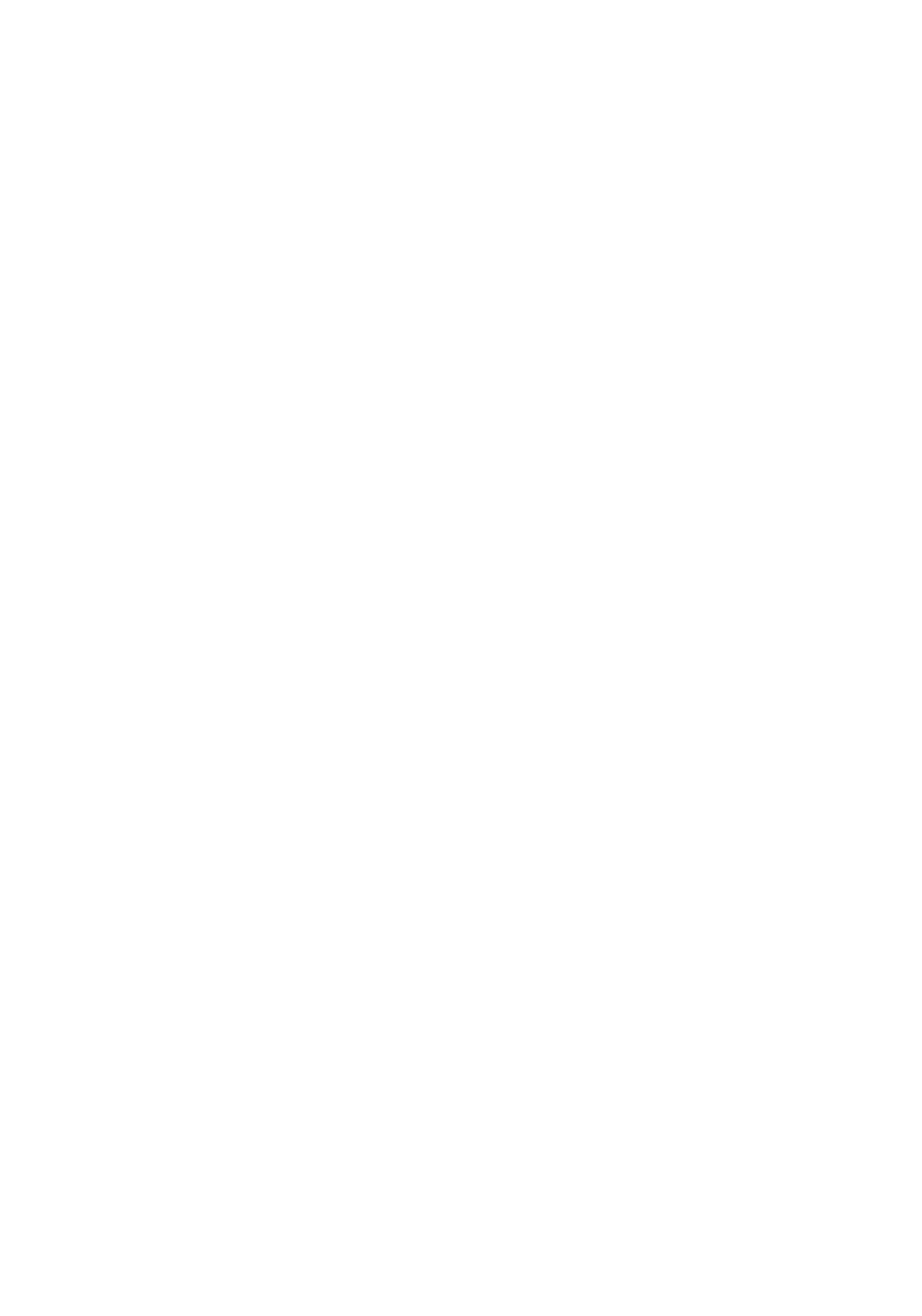




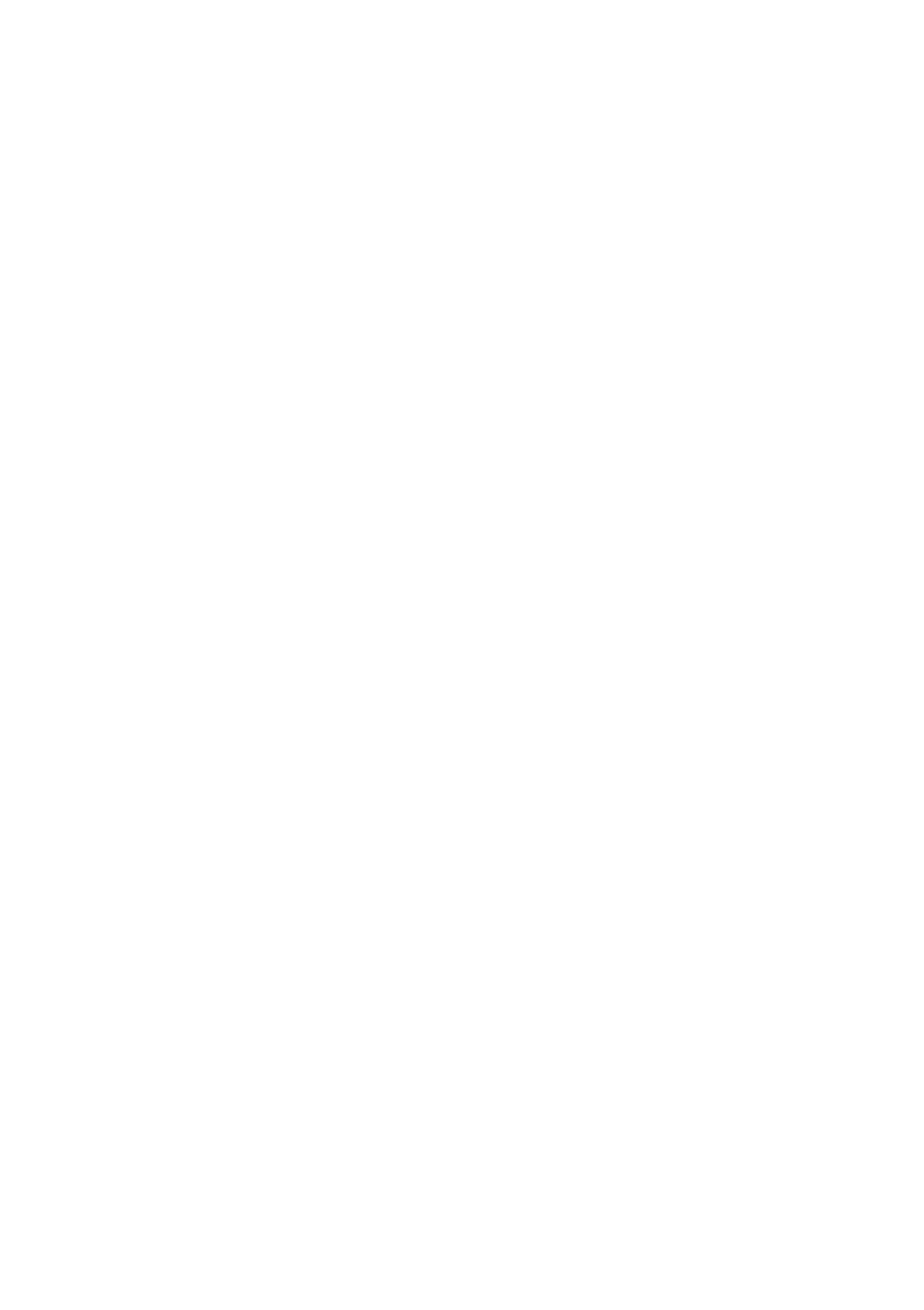




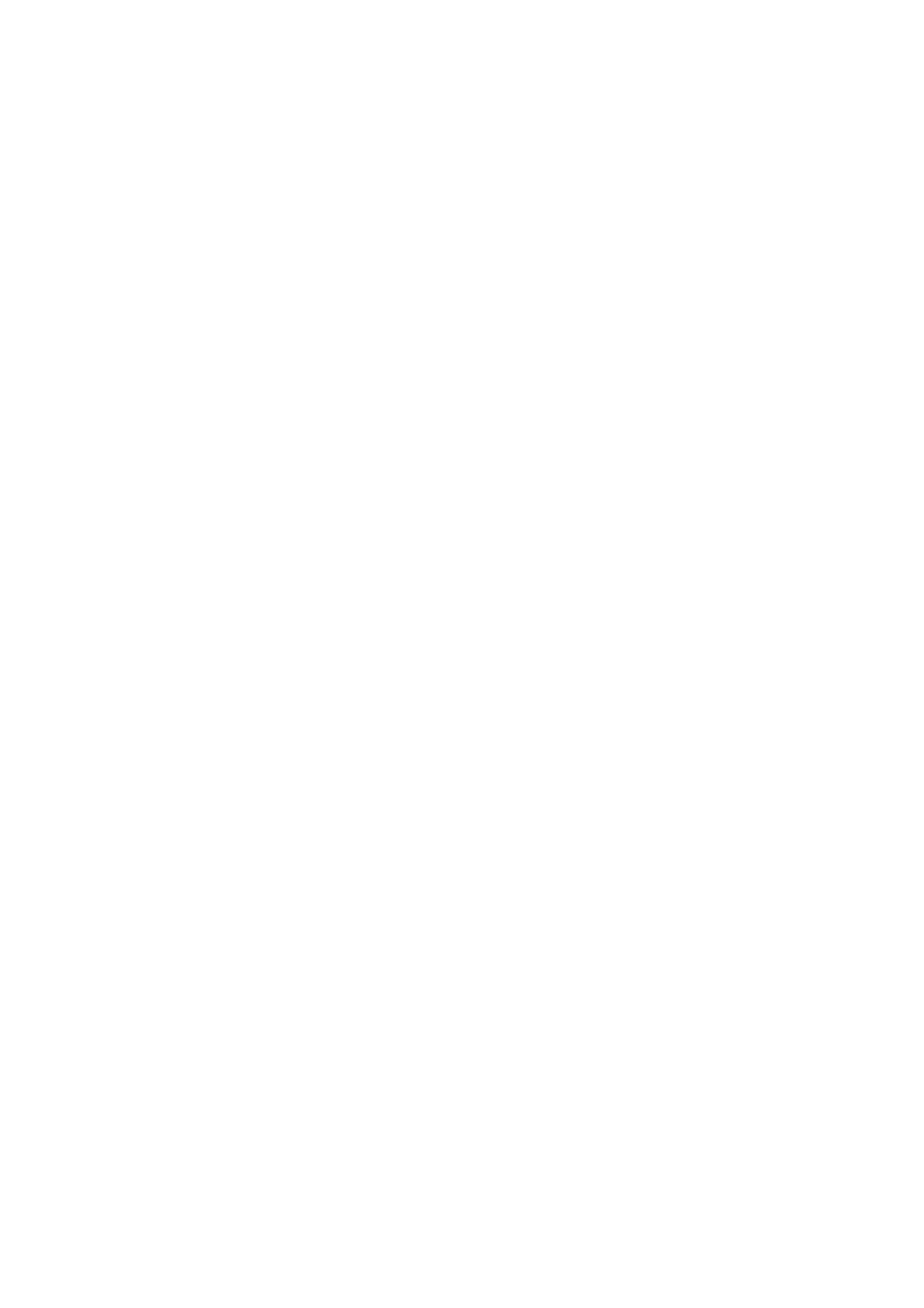




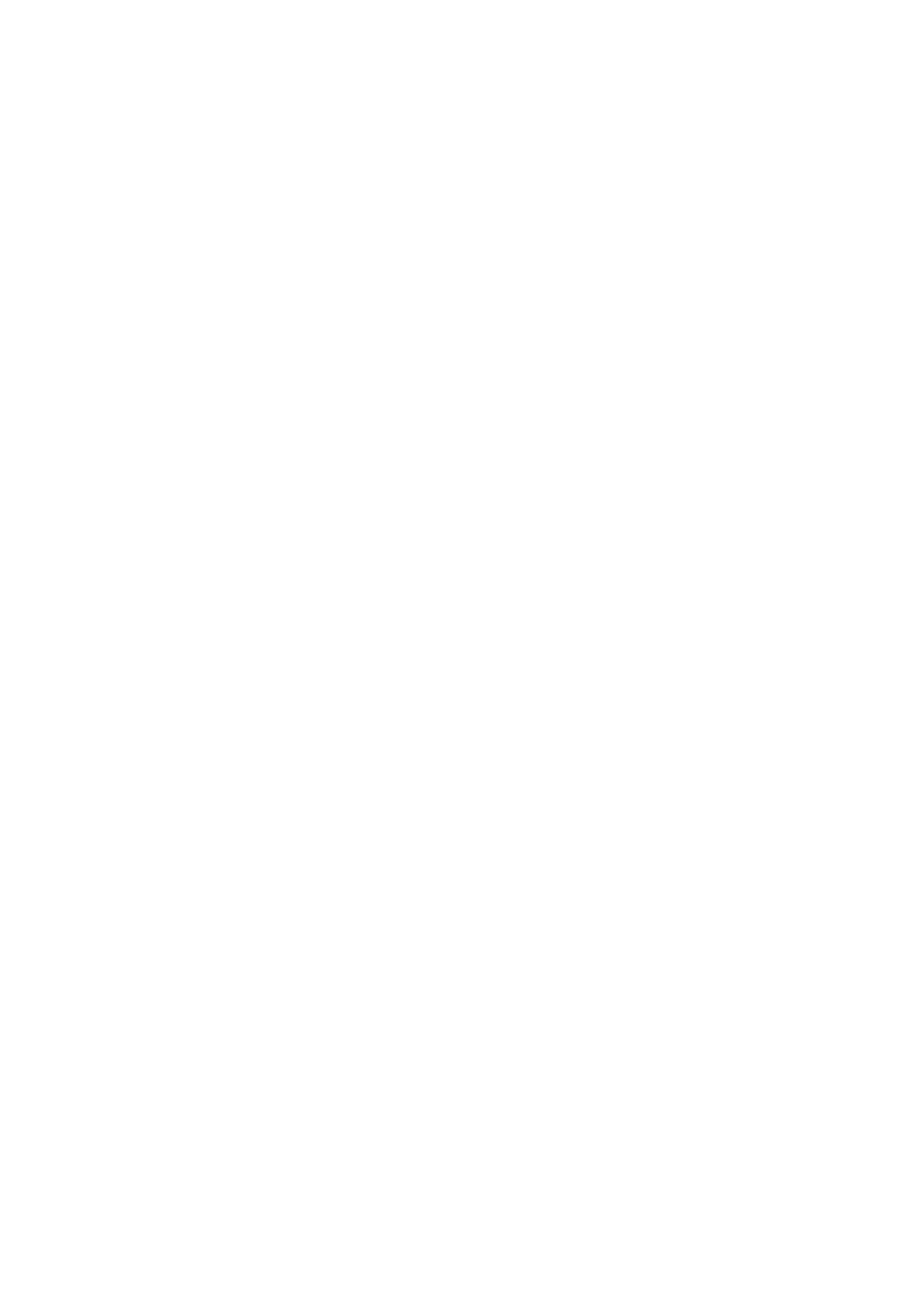




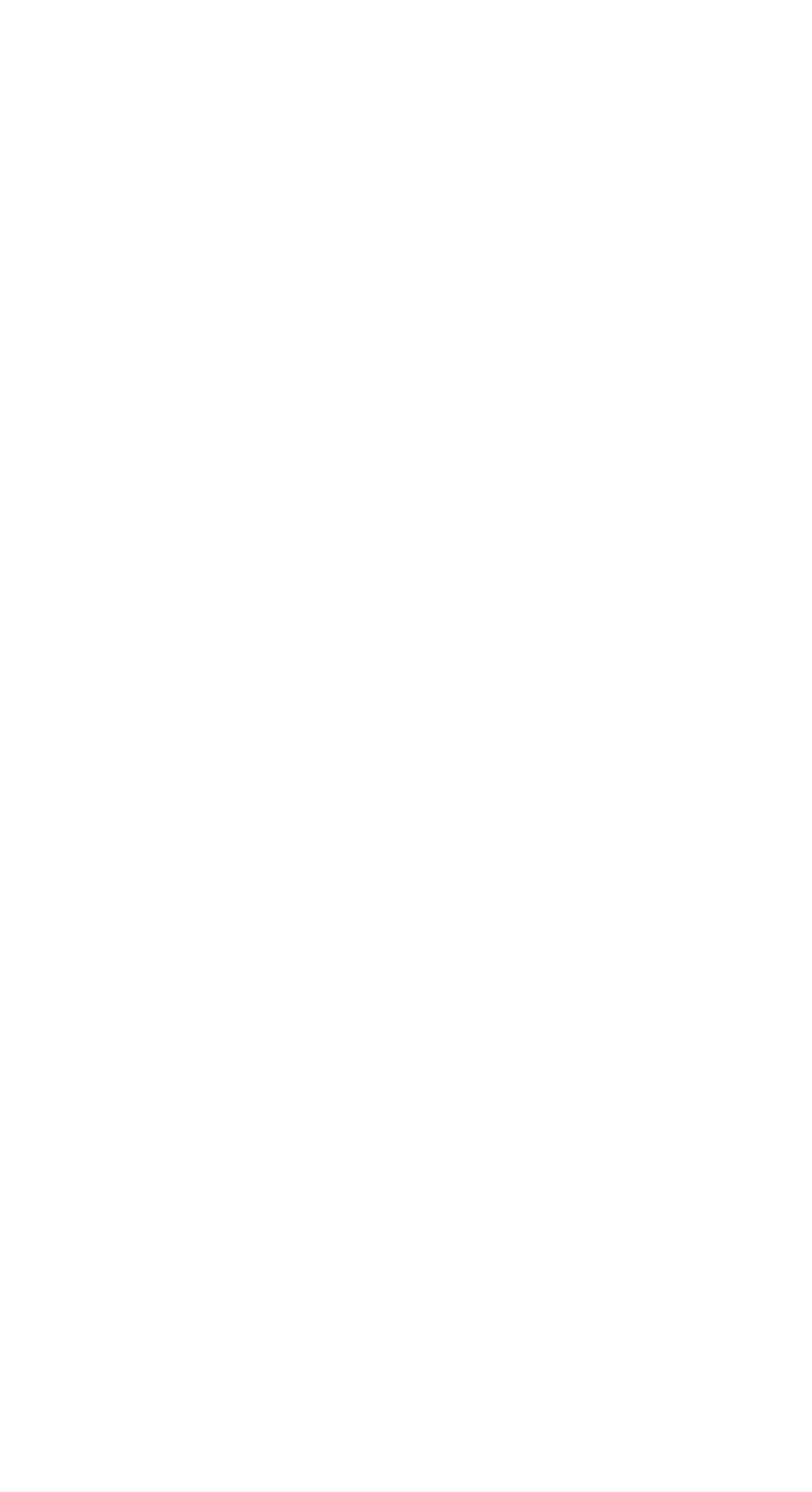




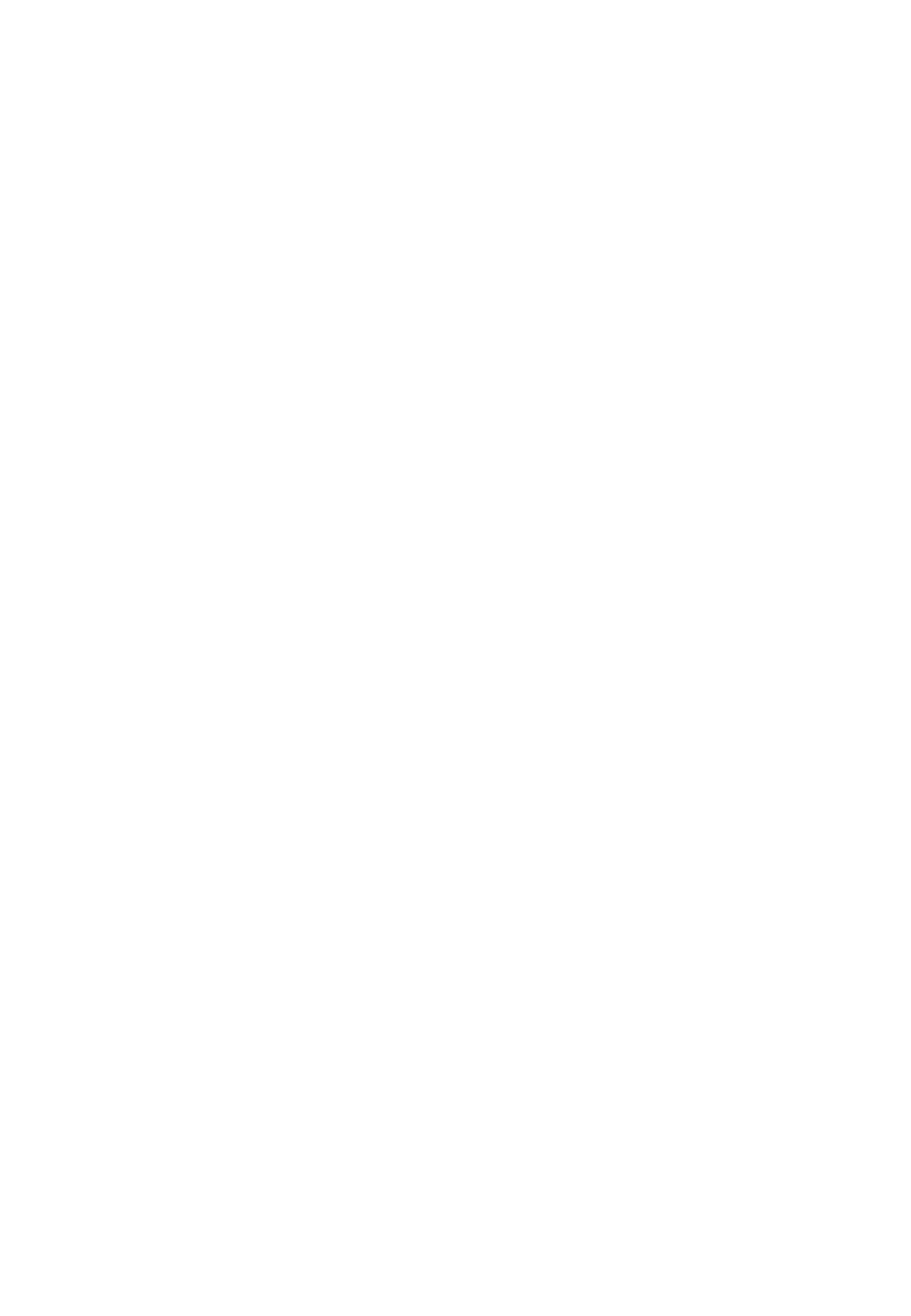




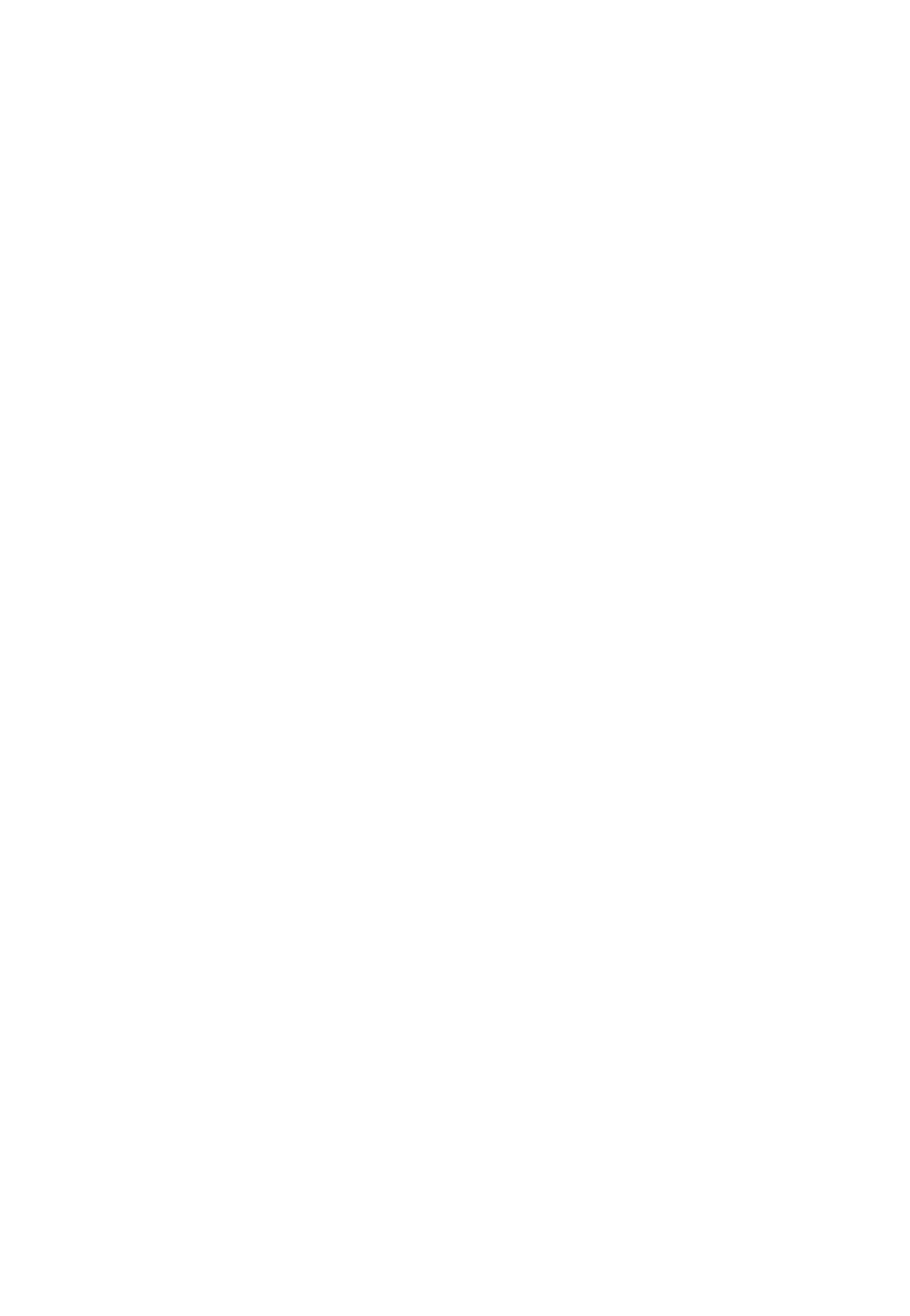




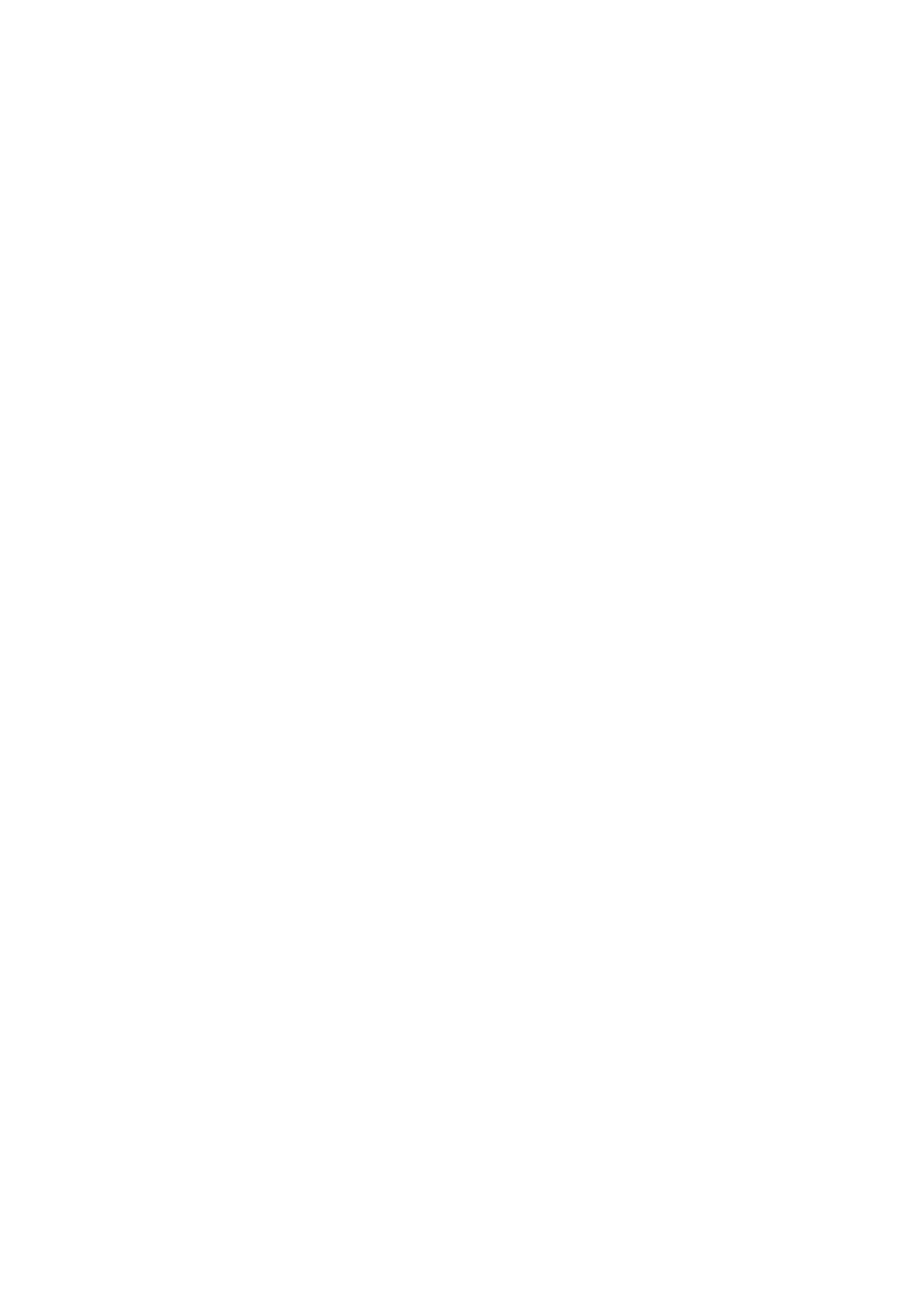




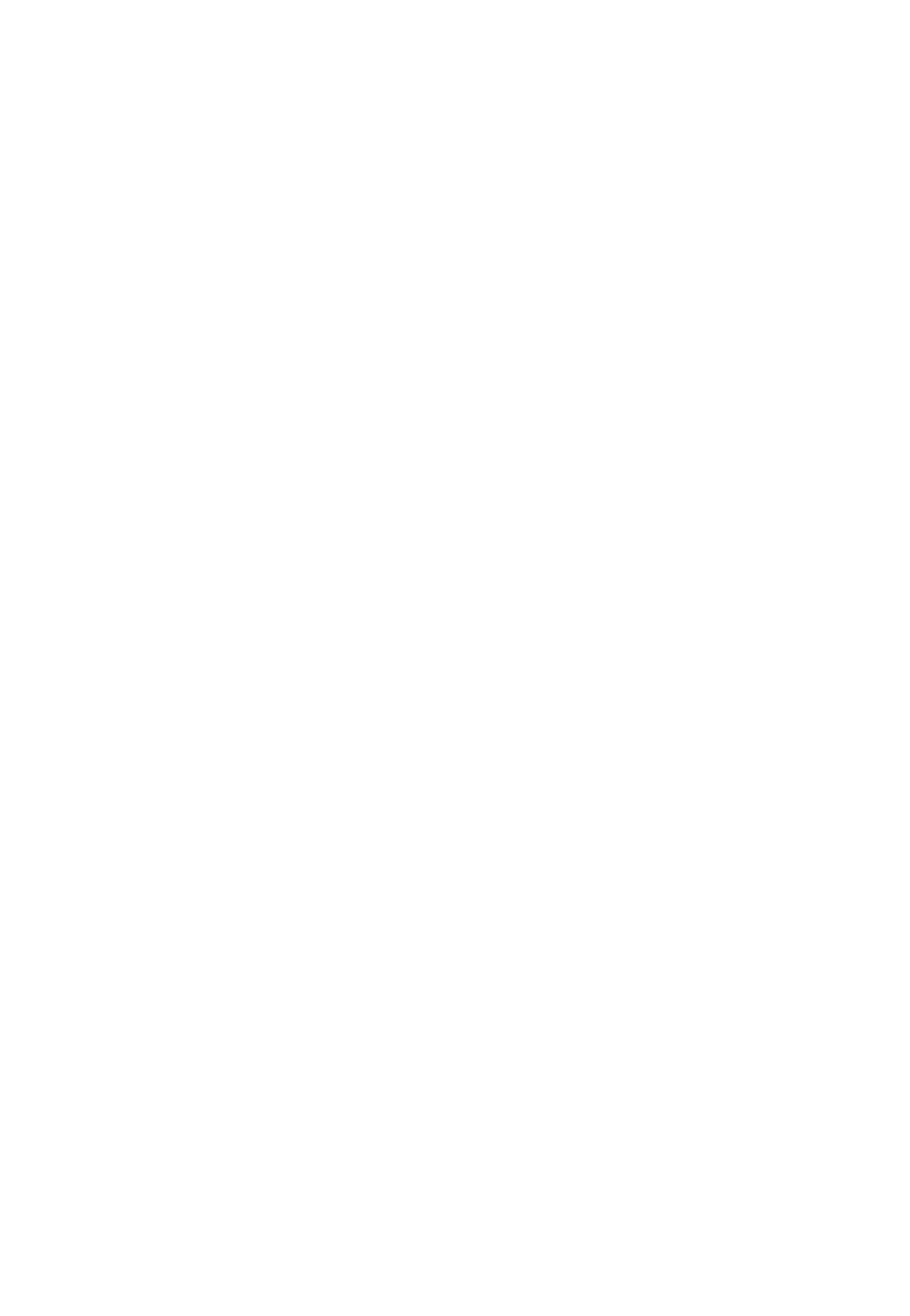




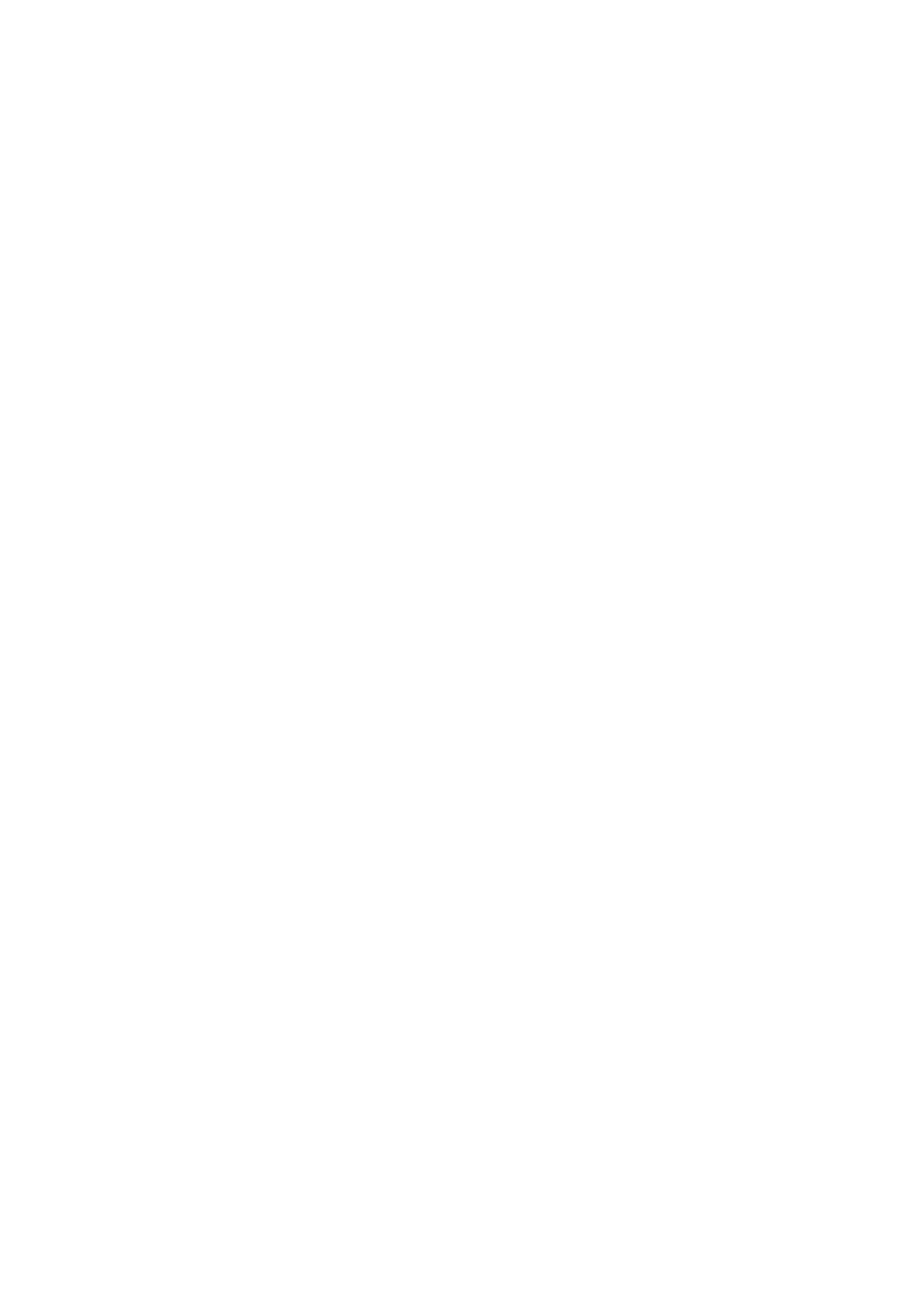




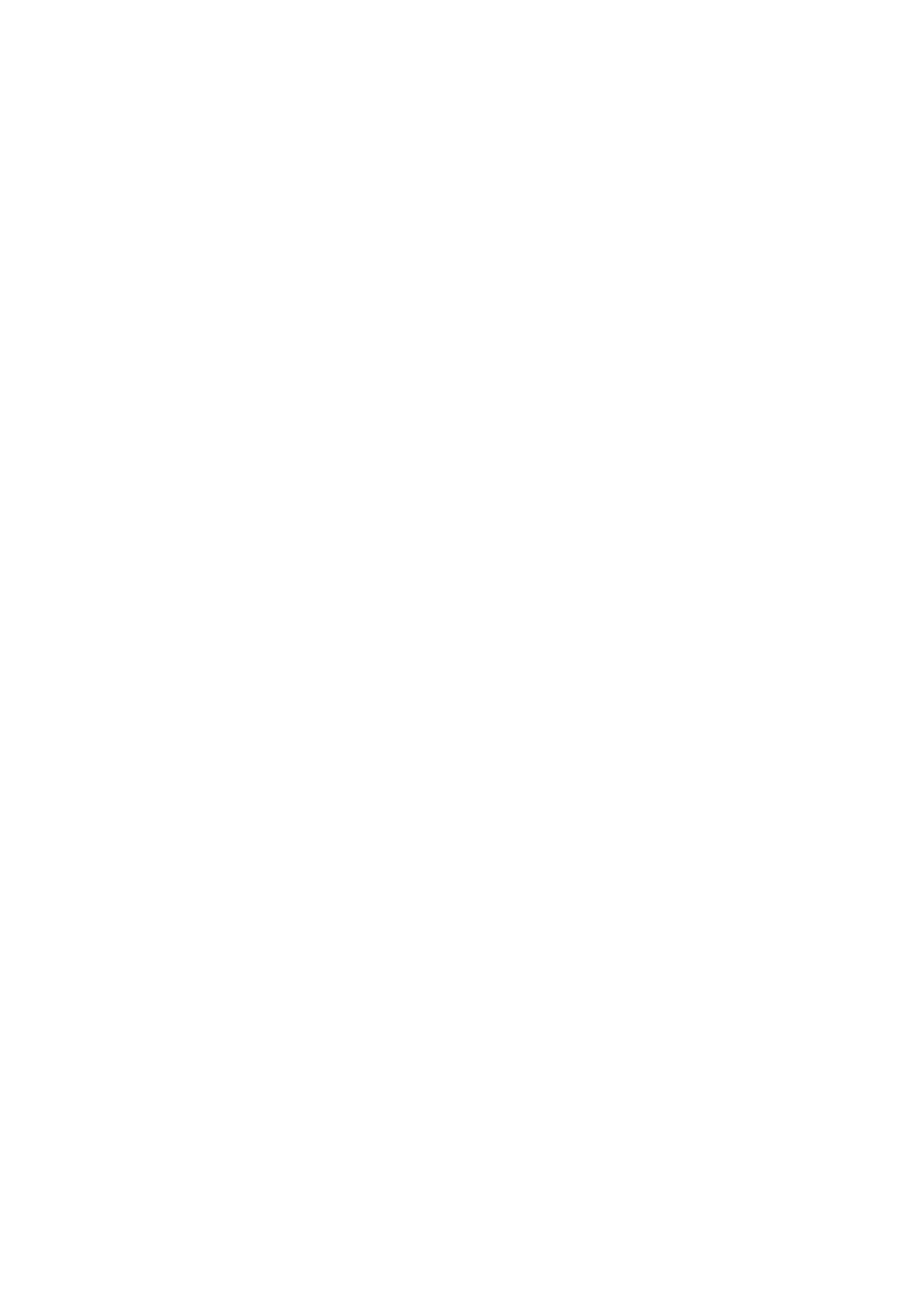




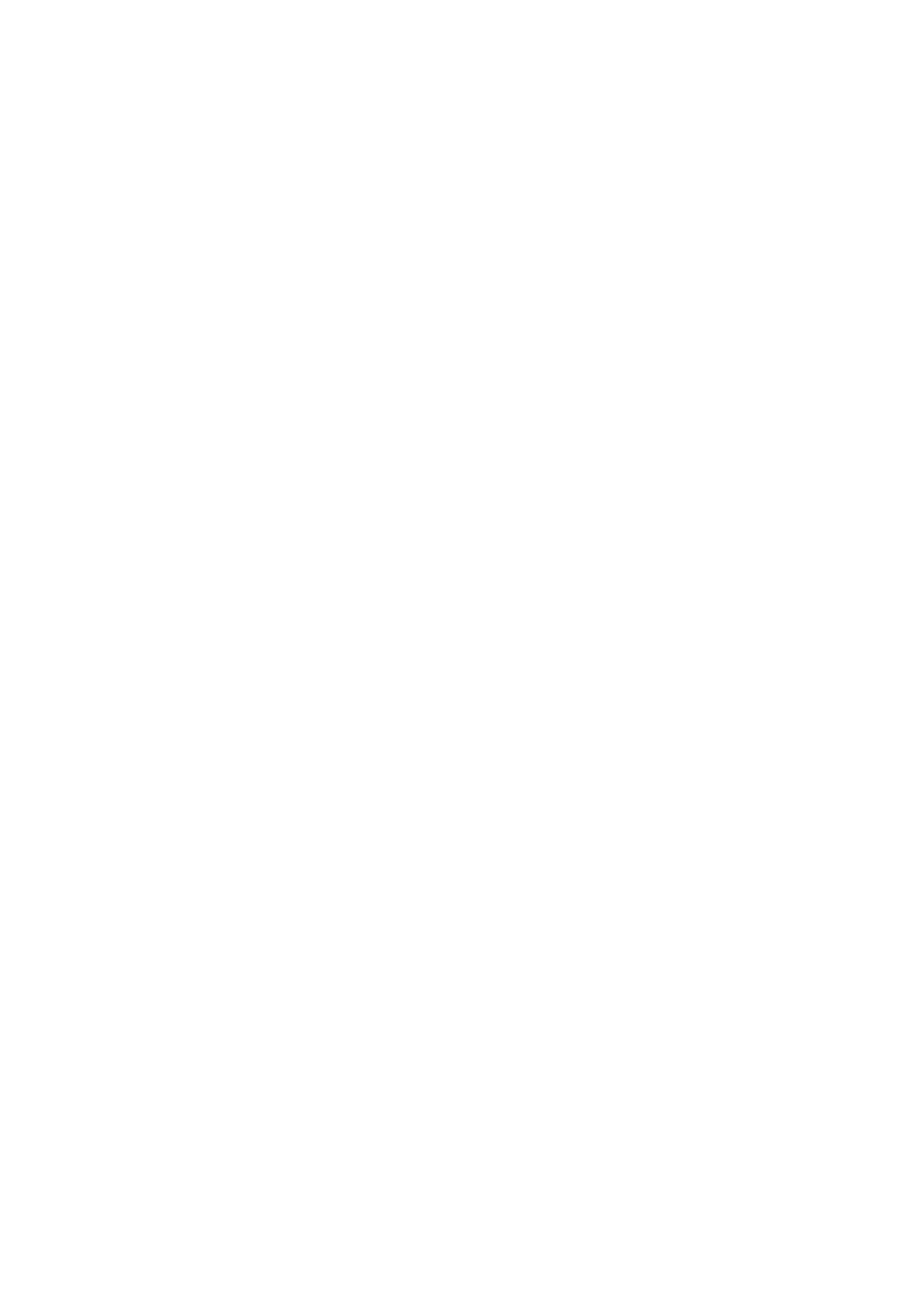




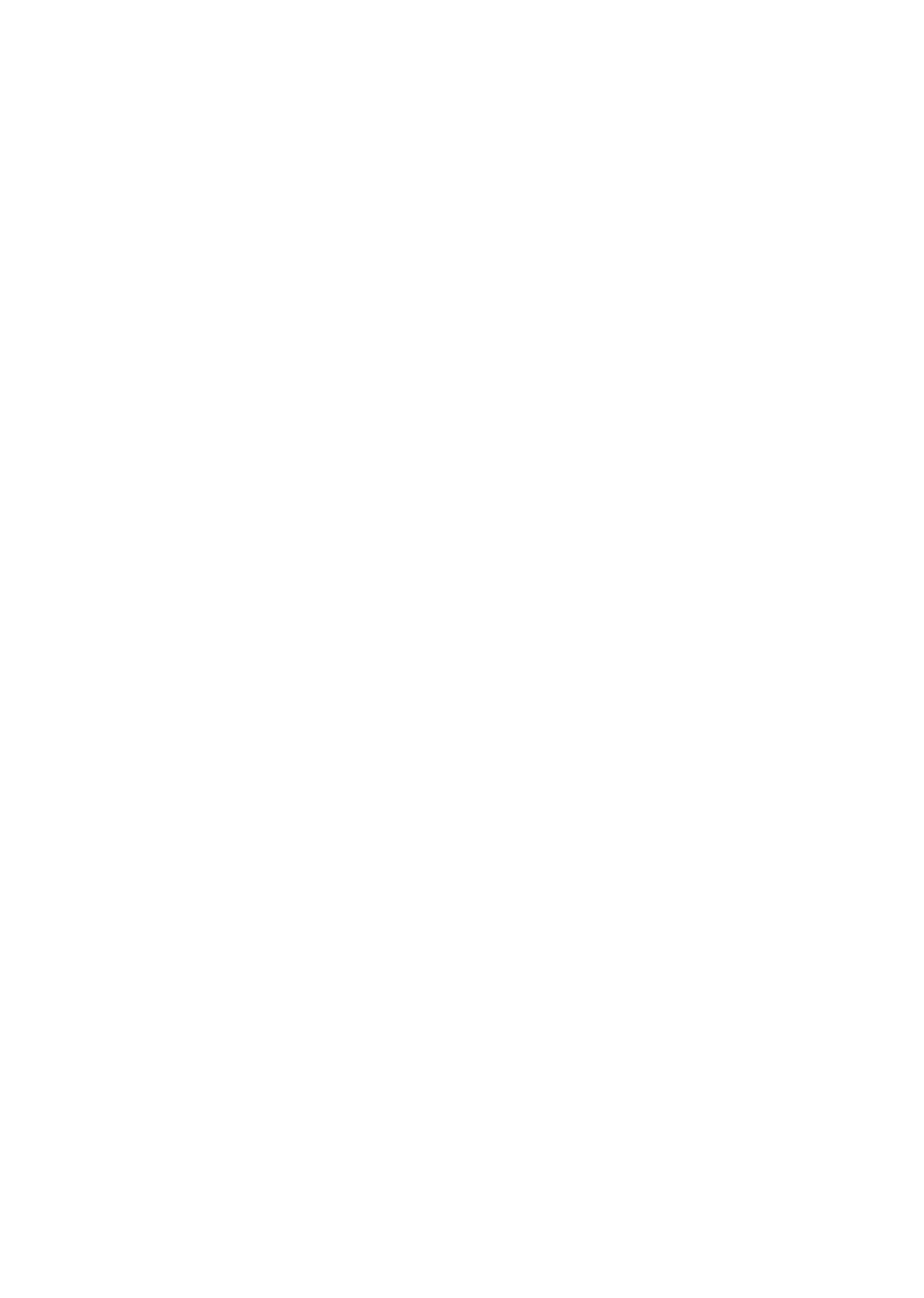




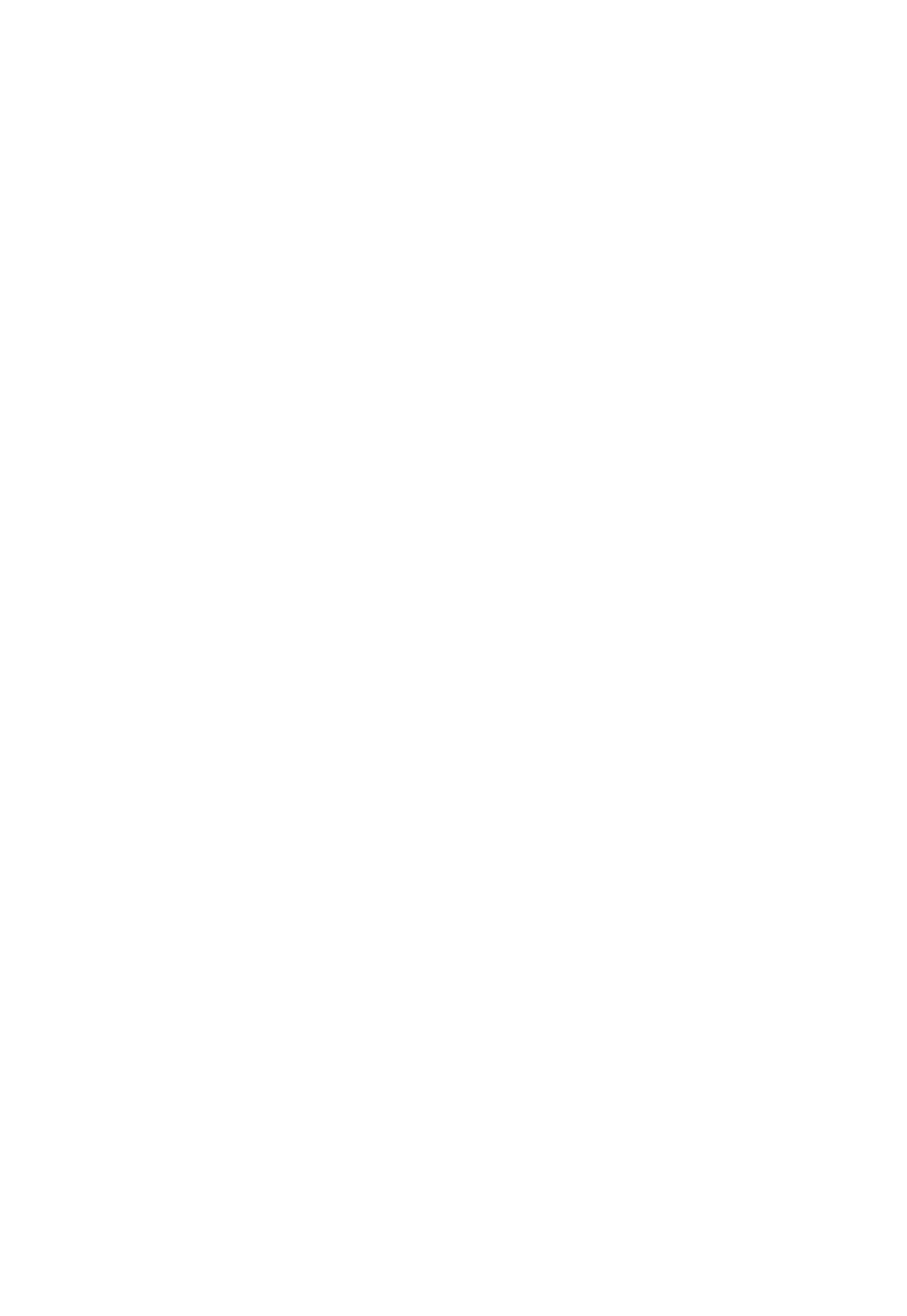




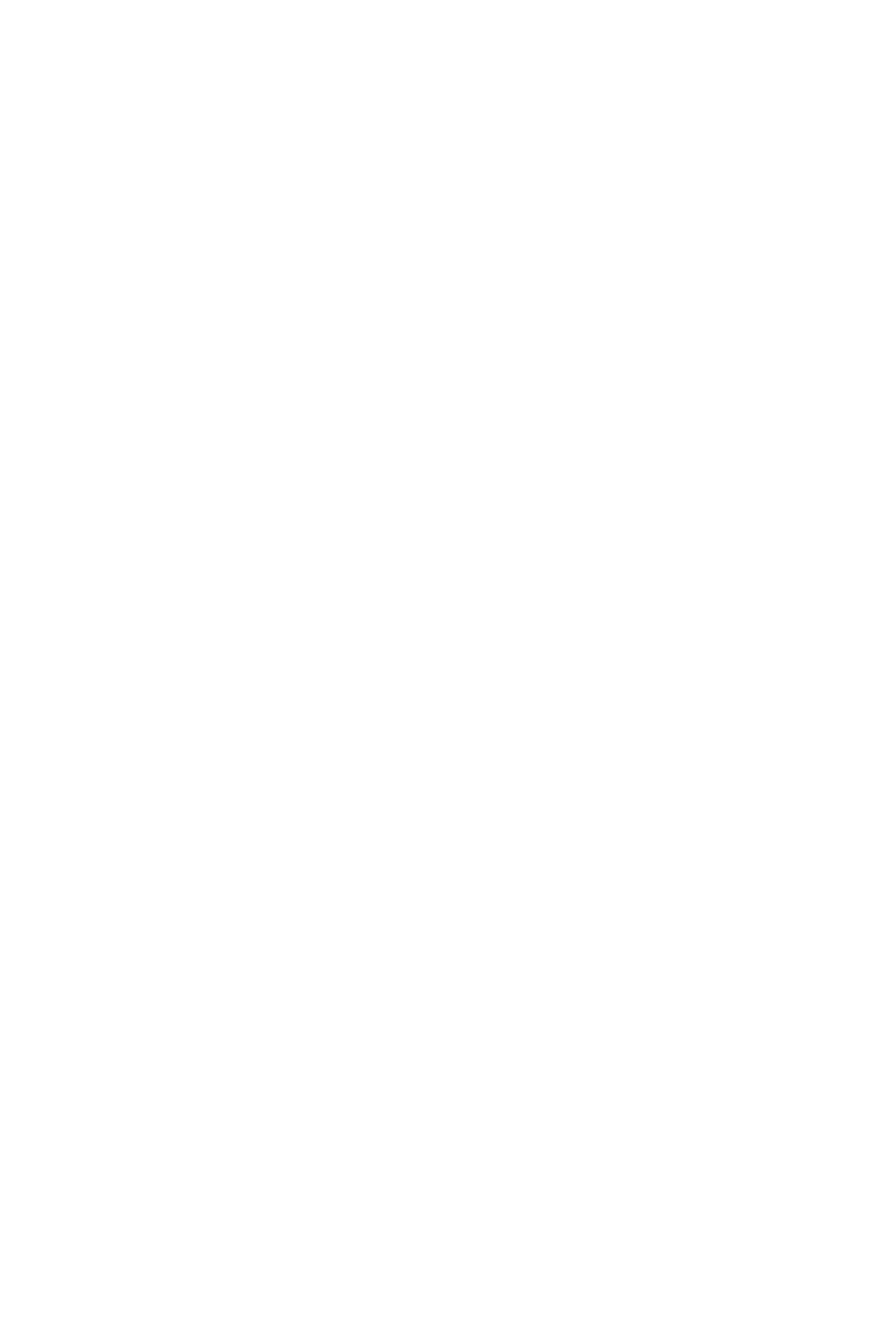




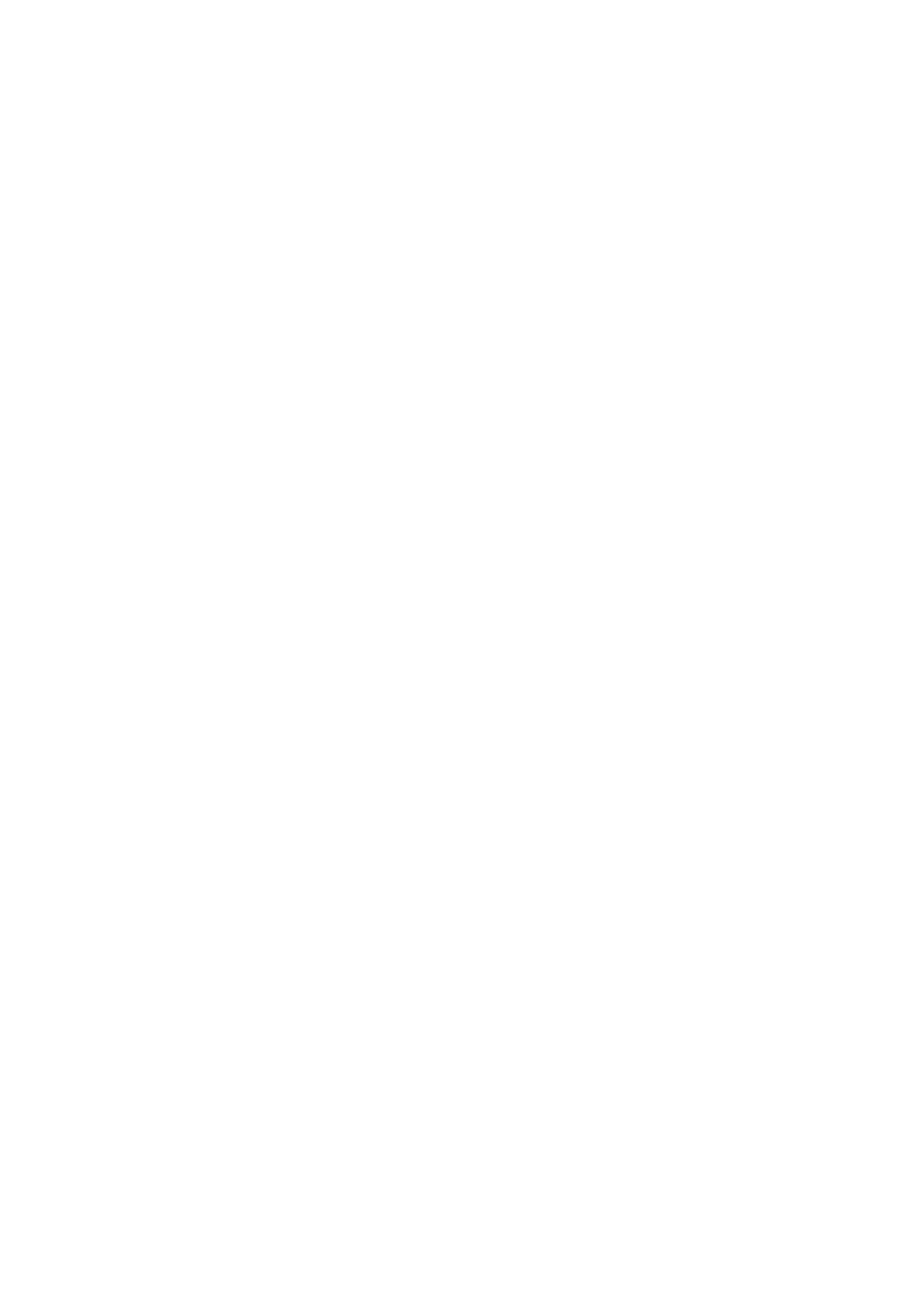




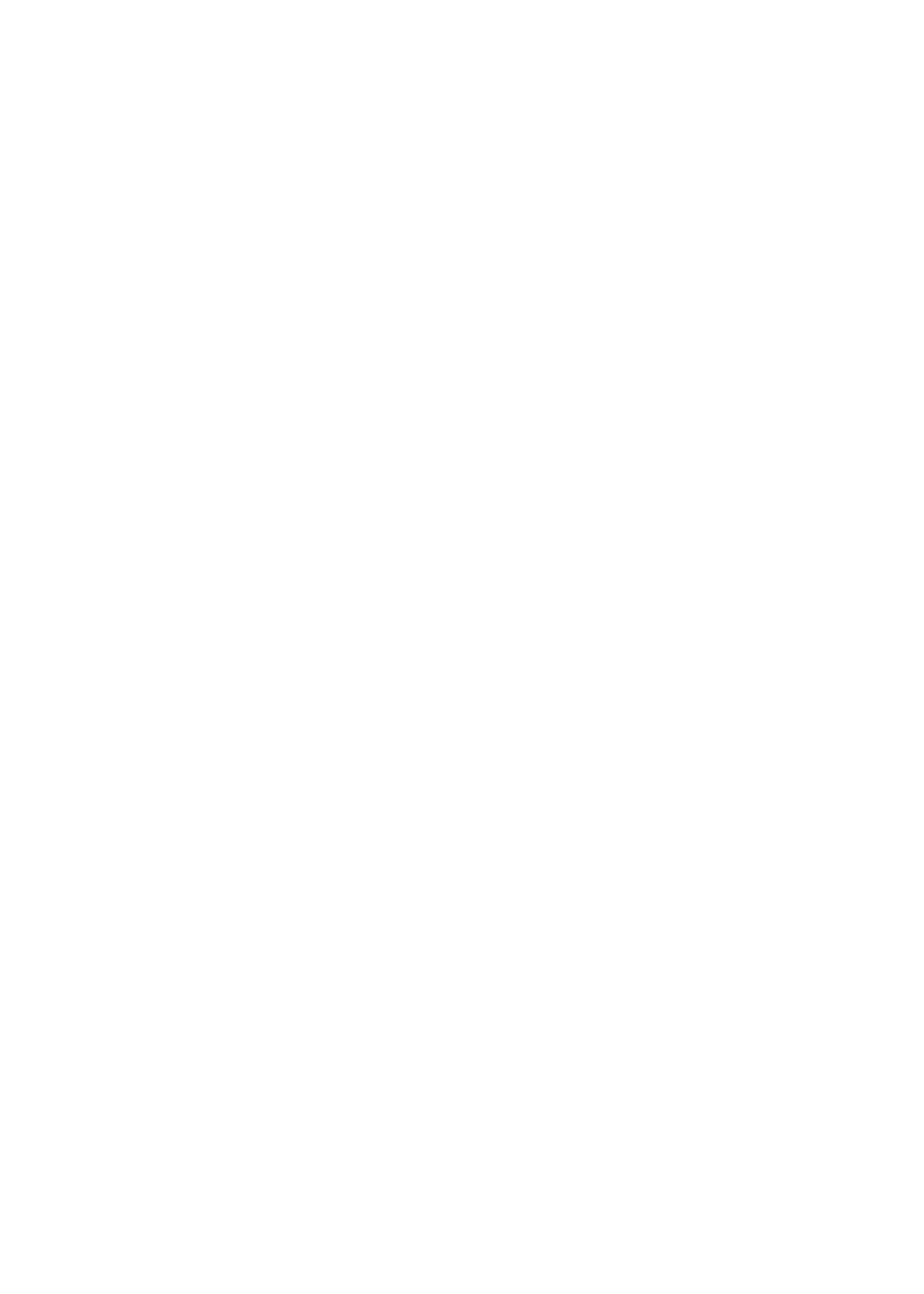




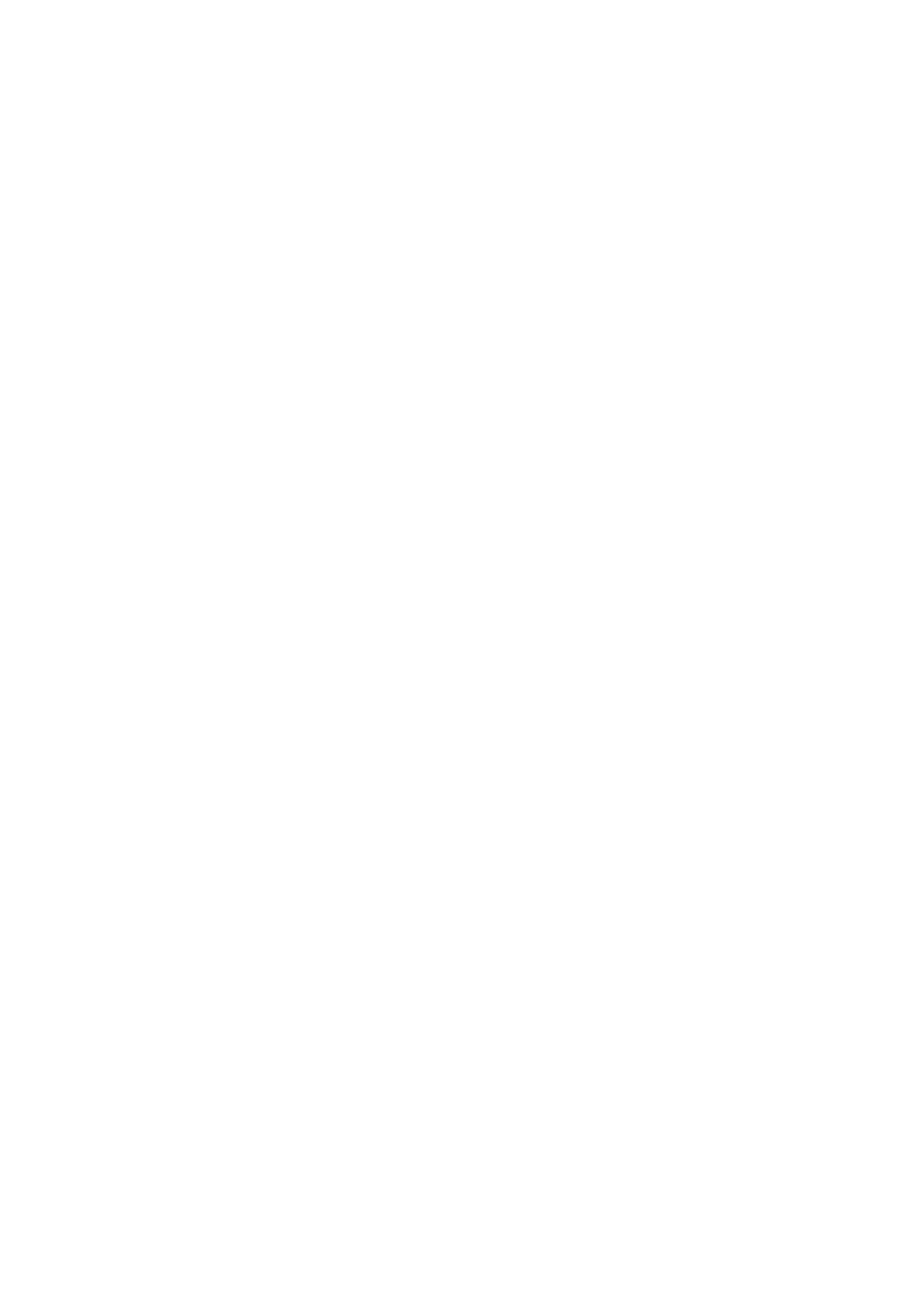




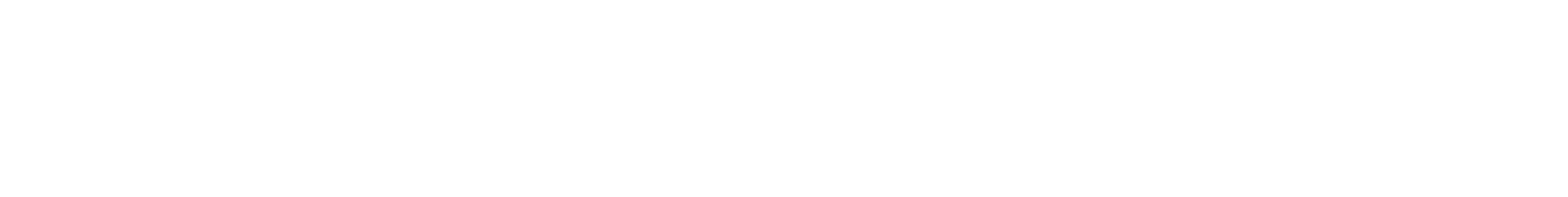

I

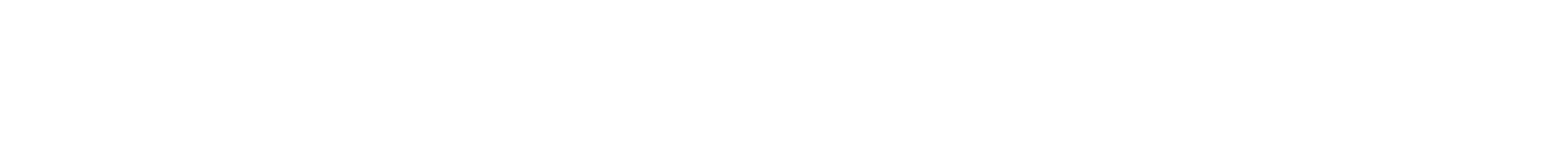

an

m

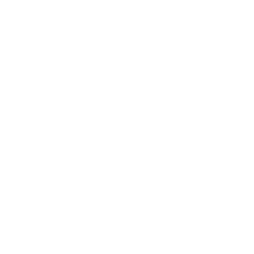

总

总

芦

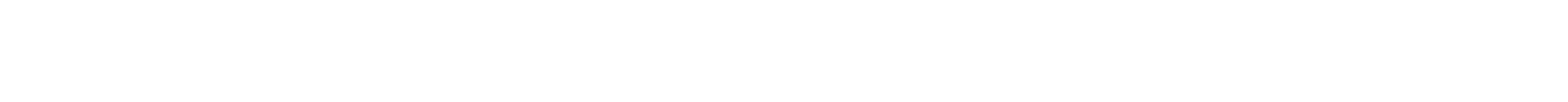

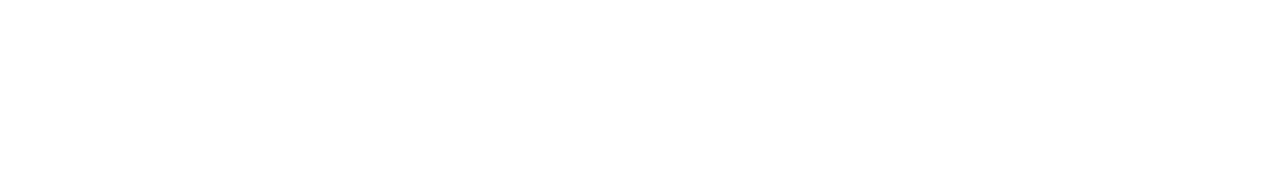

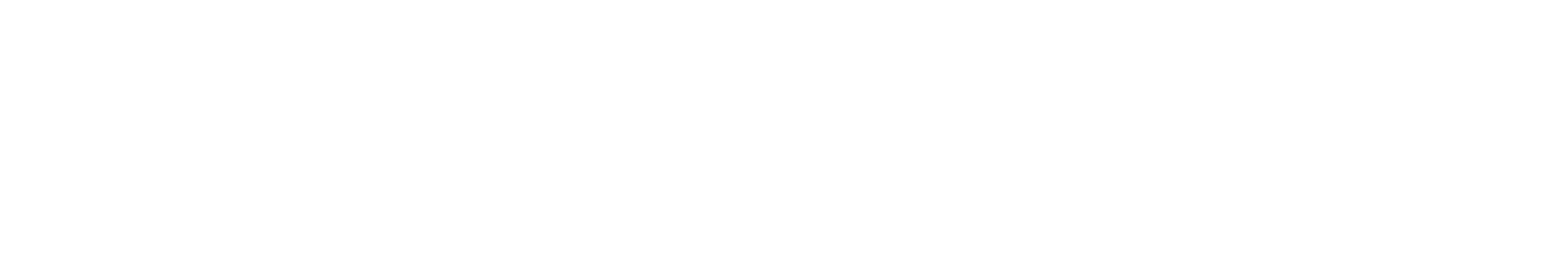

要

政

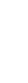

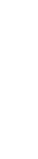

总

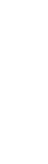

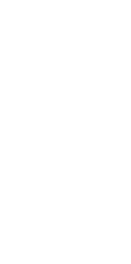

危

$\underset{\infty}{\infty} \frac{\overrightarrow{0}}{\sigma}$

$\stackrel{\infty}{=} \frac{1}{\infty}$

$\cong$

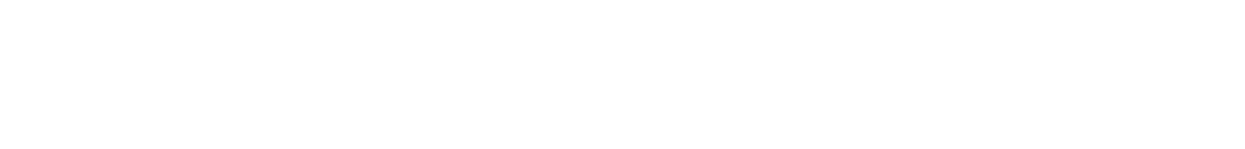

悹

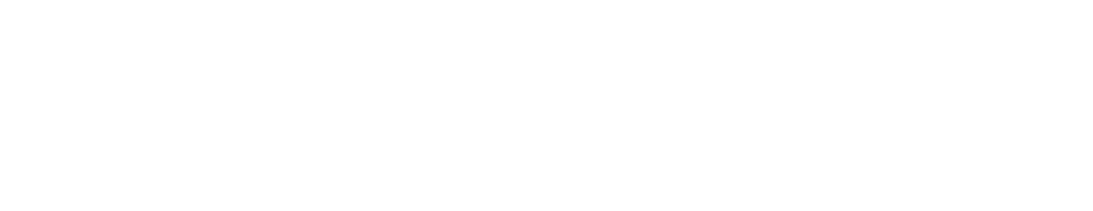

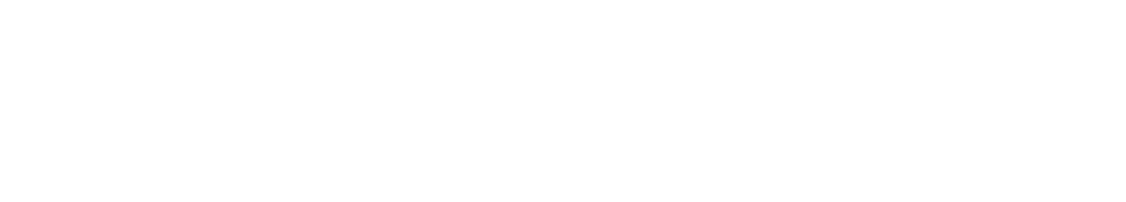

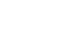

离

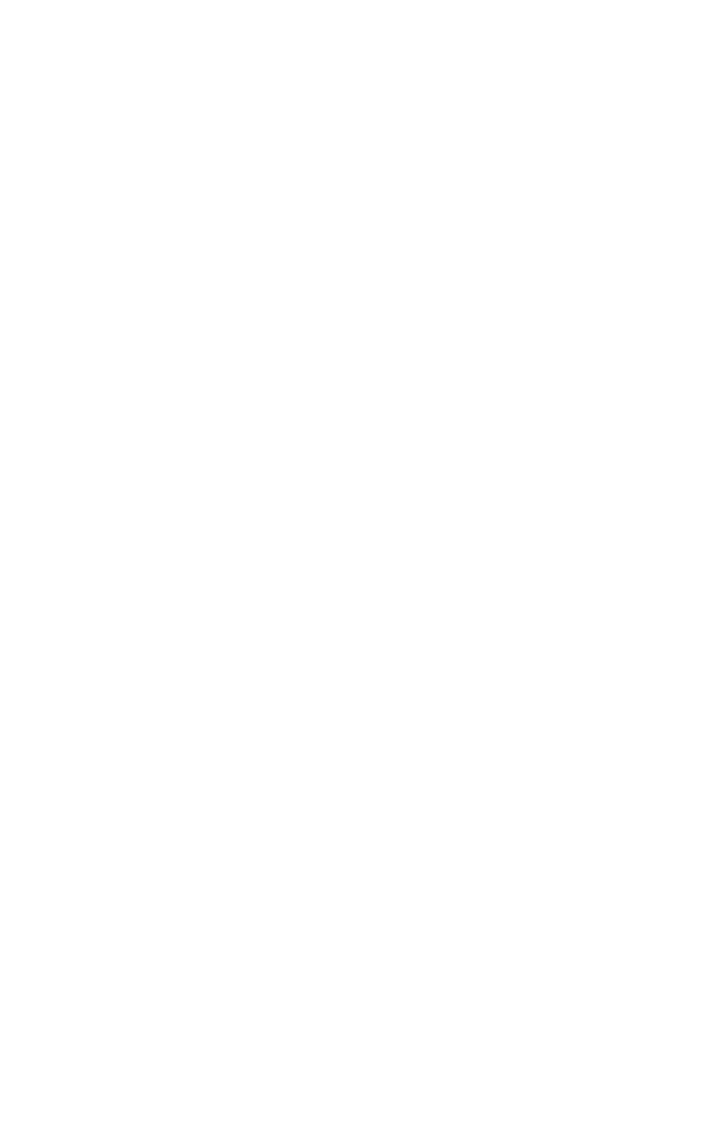

Tables

179 


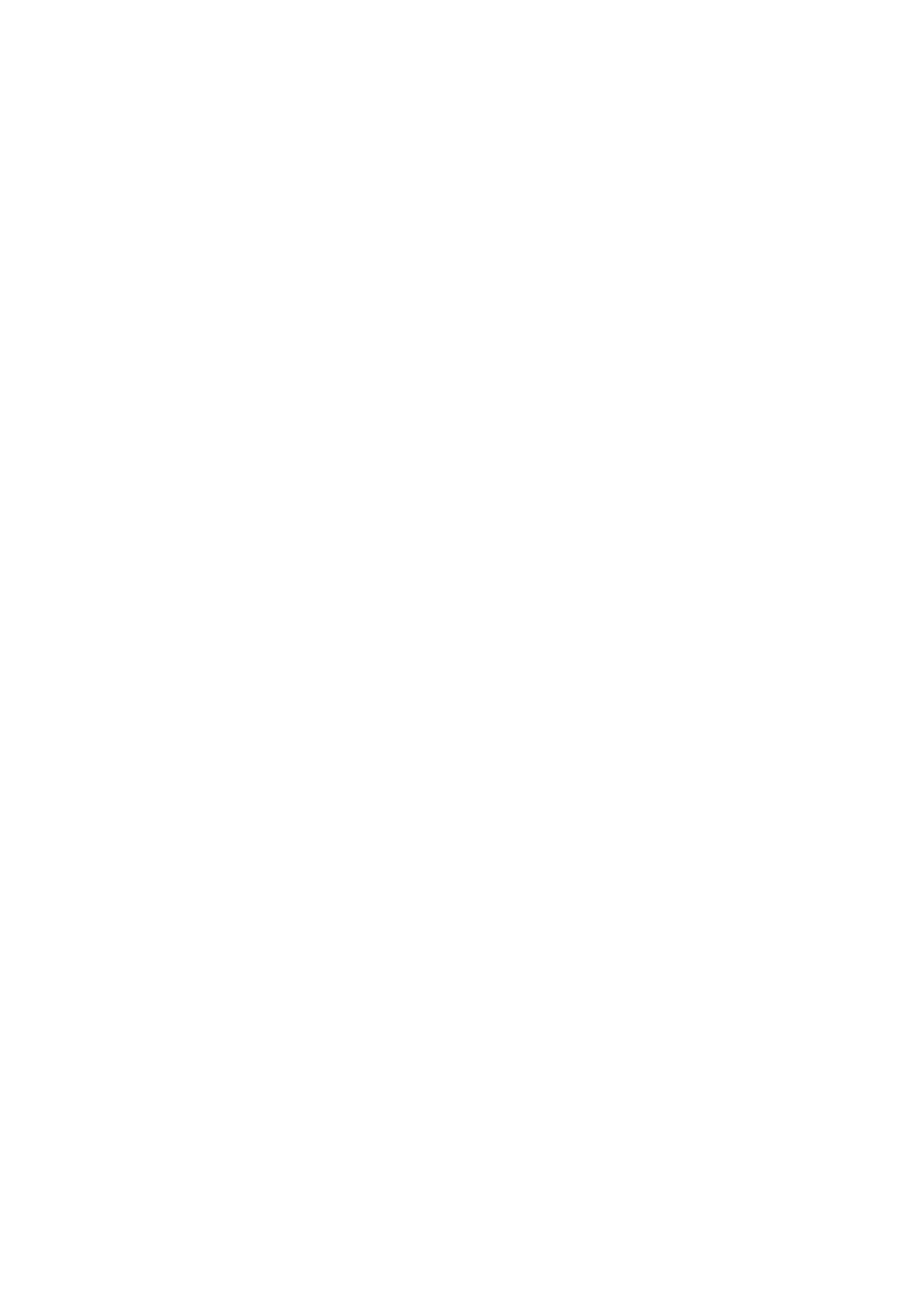




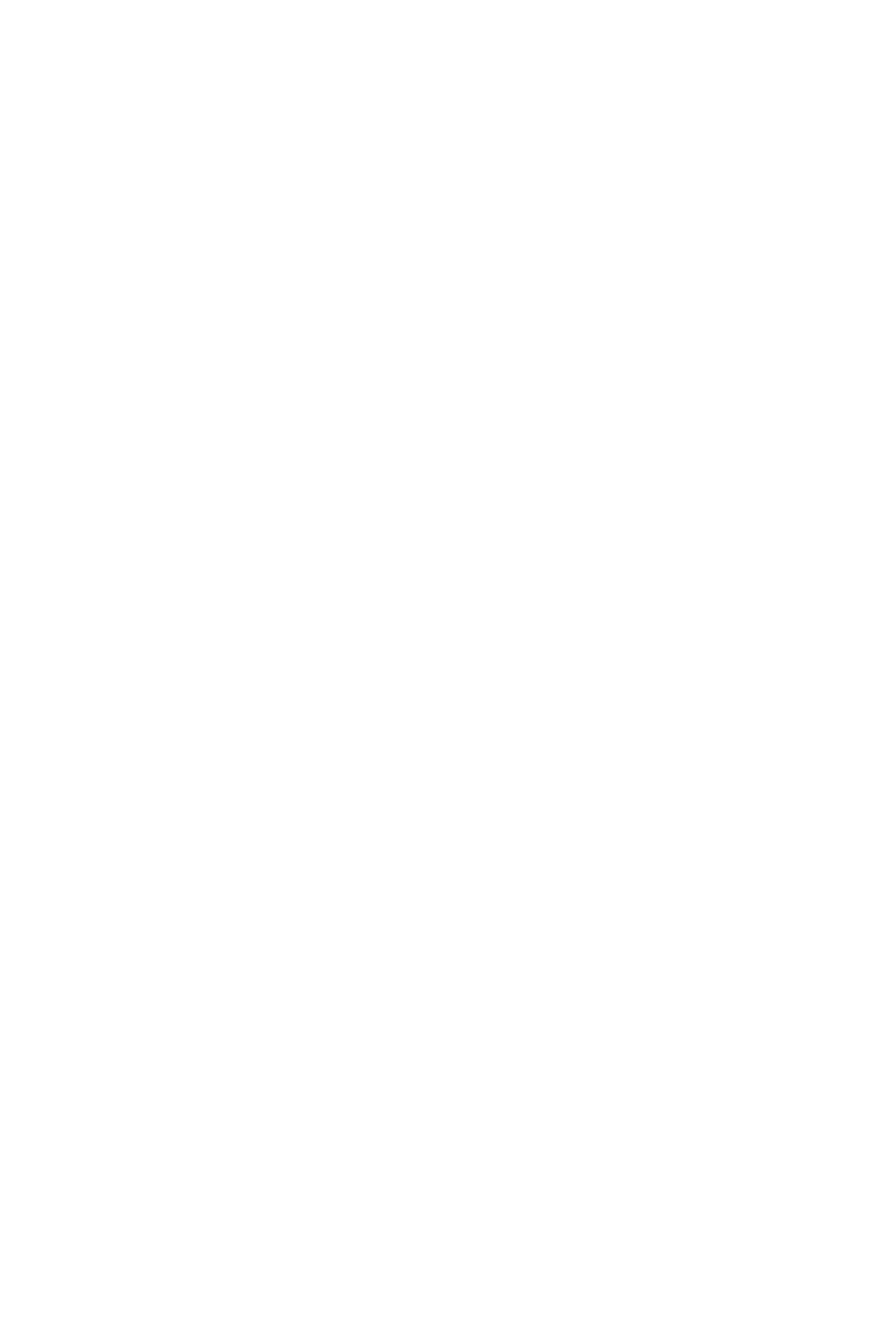




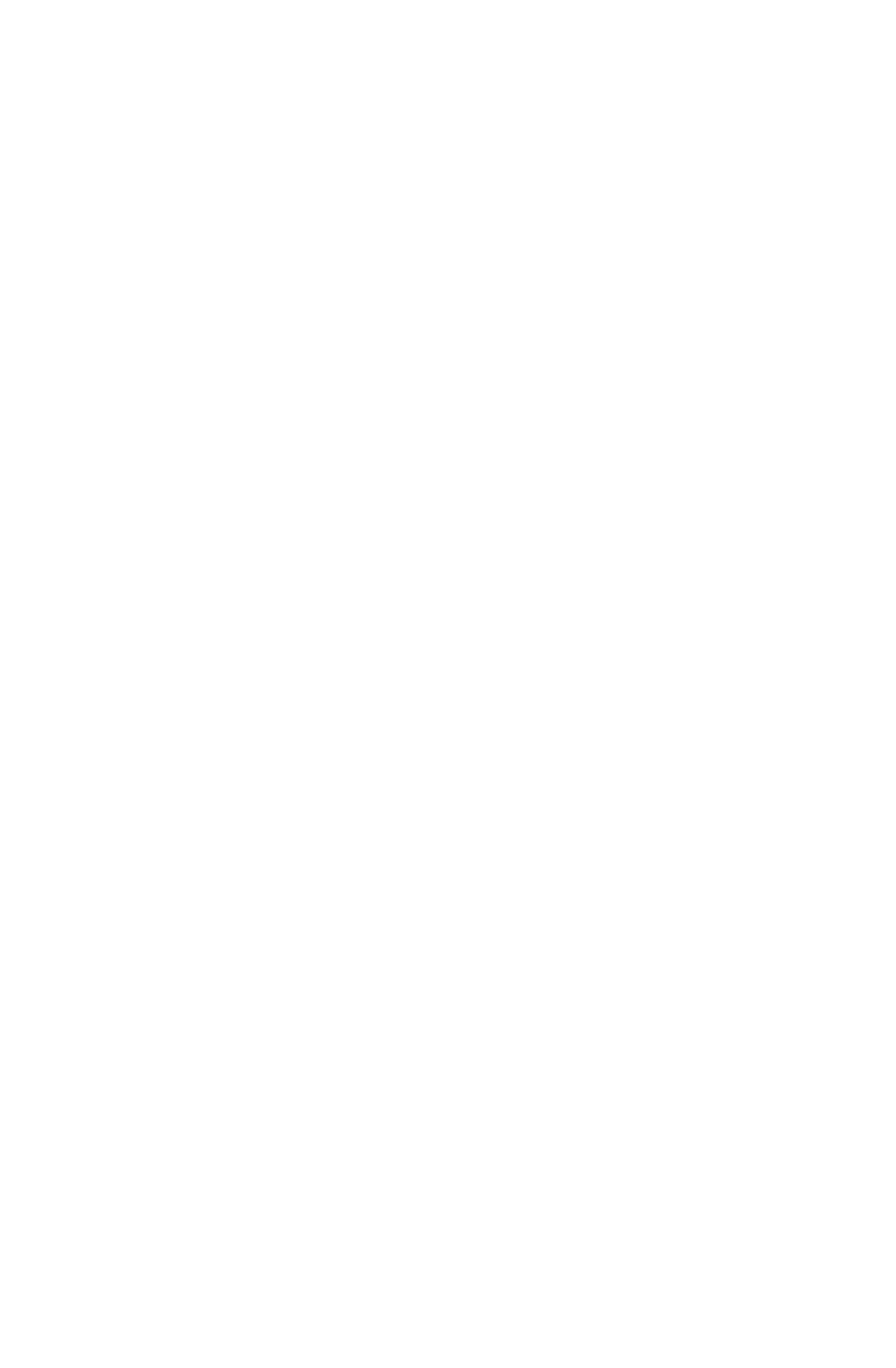




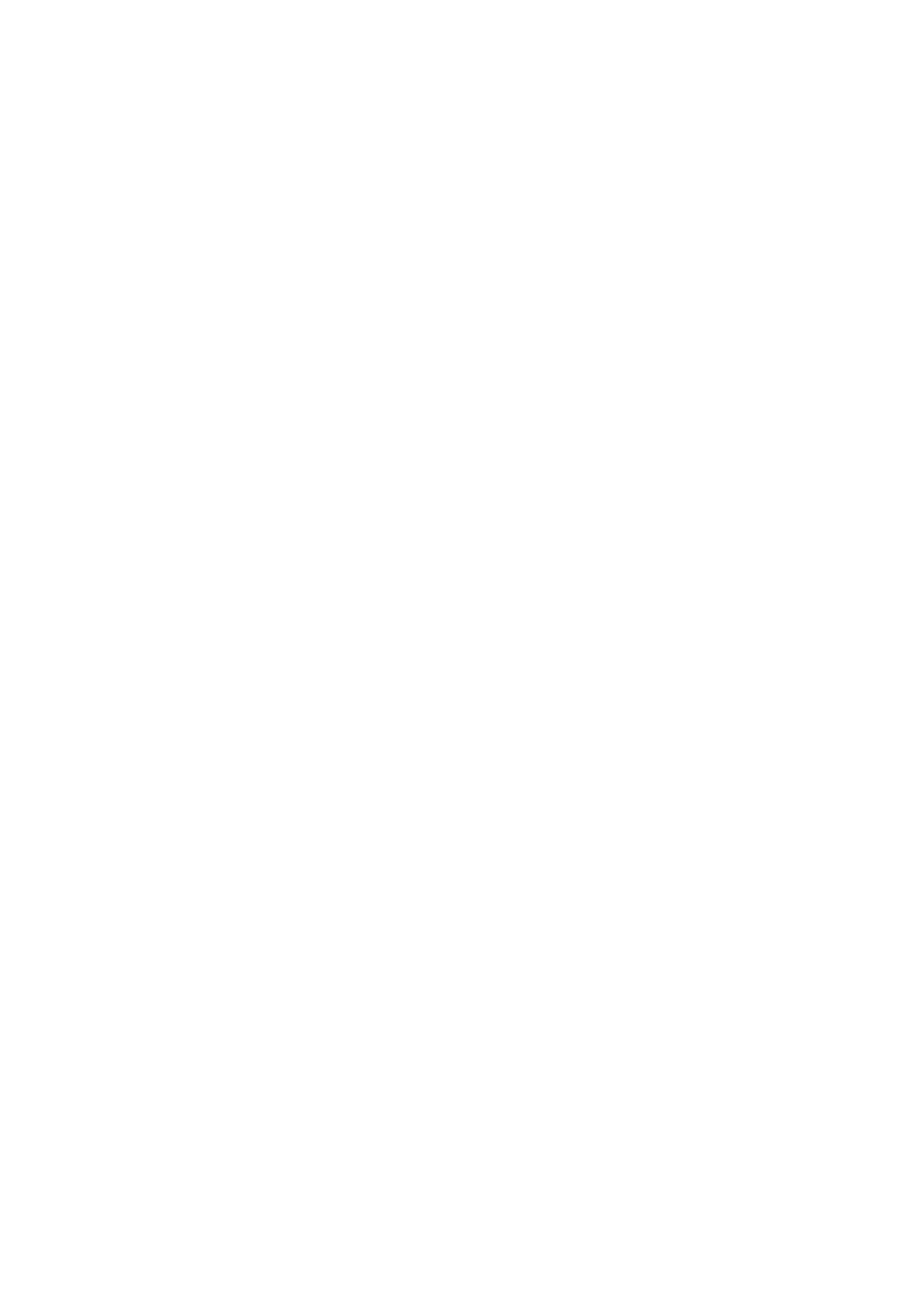




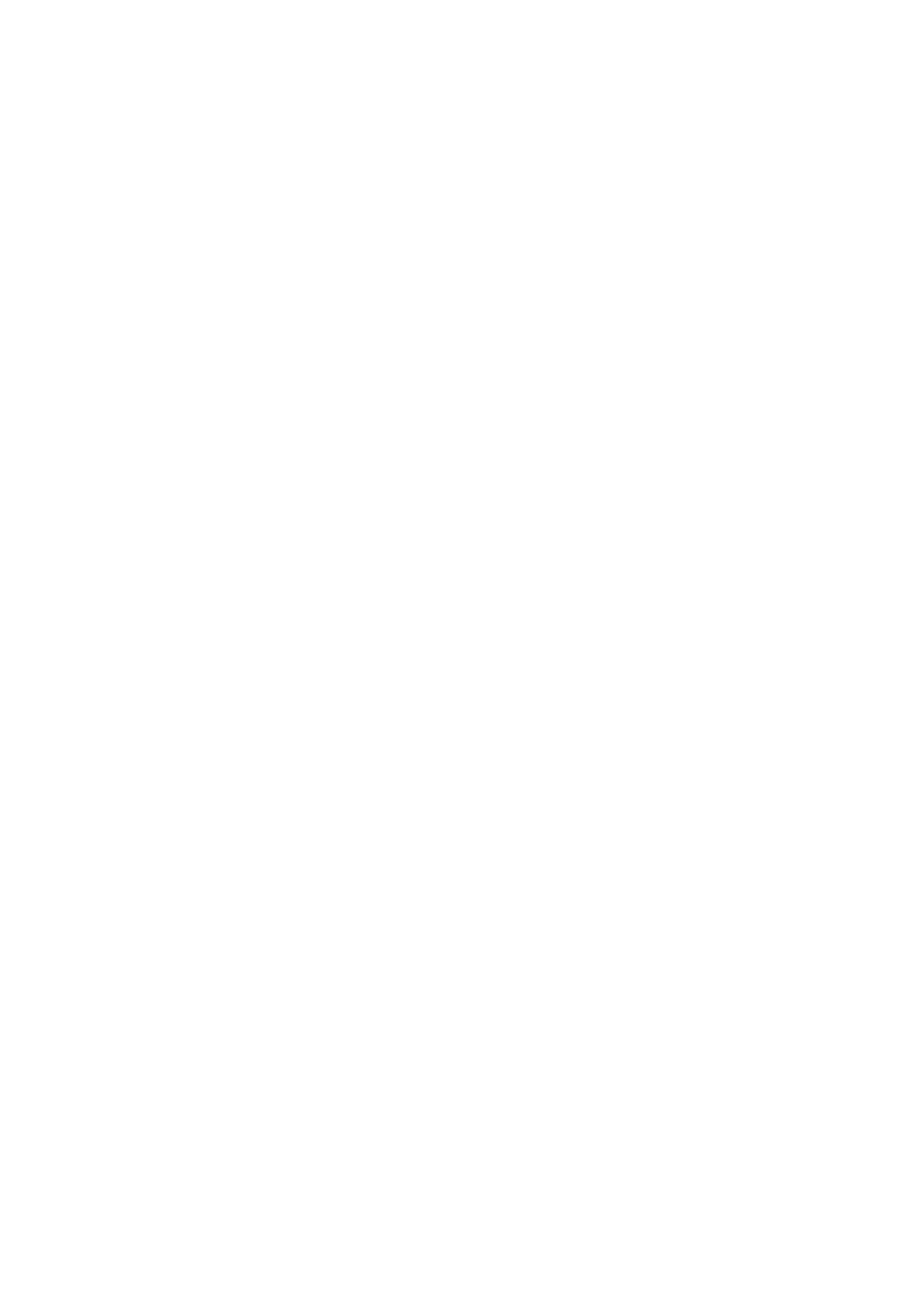




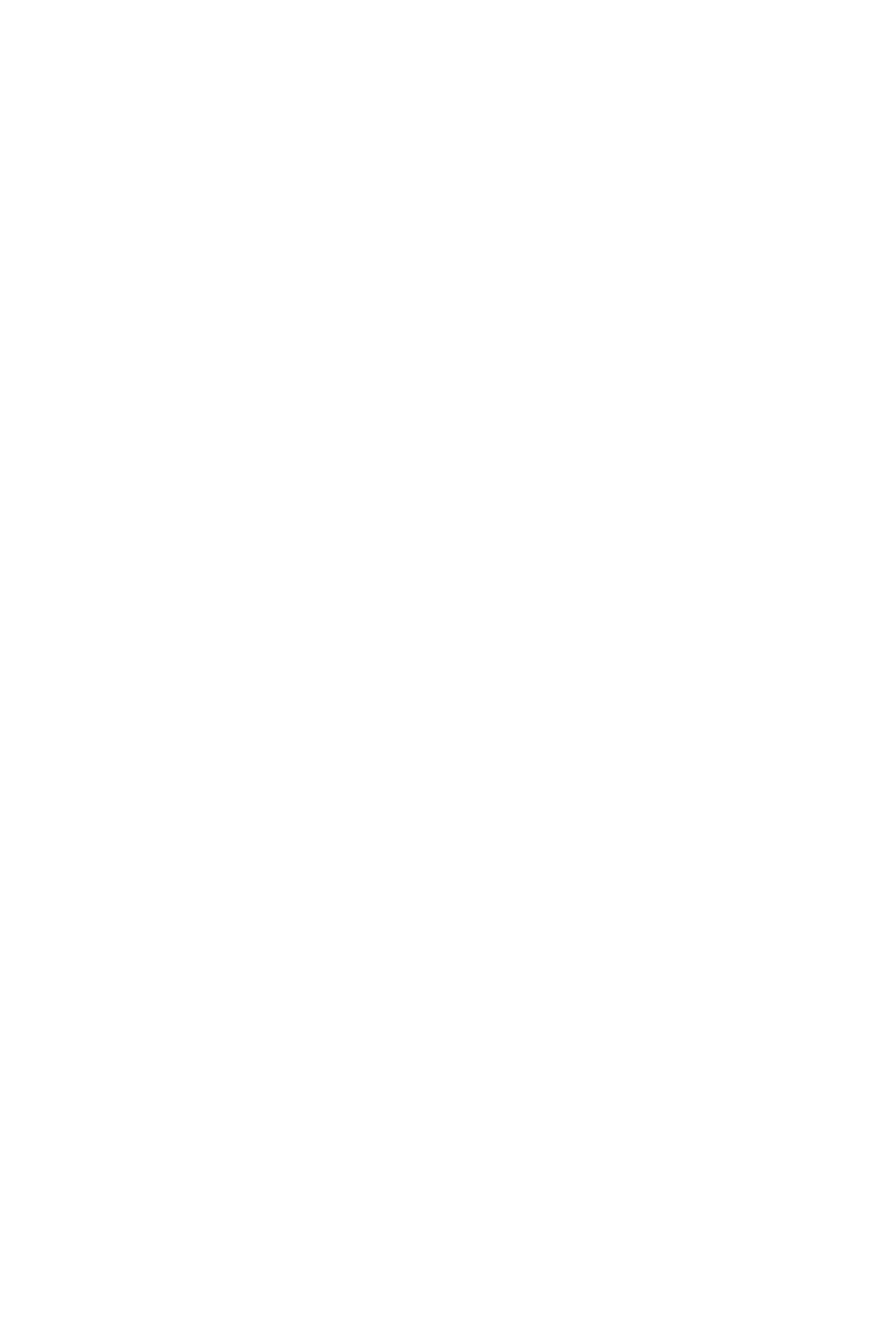




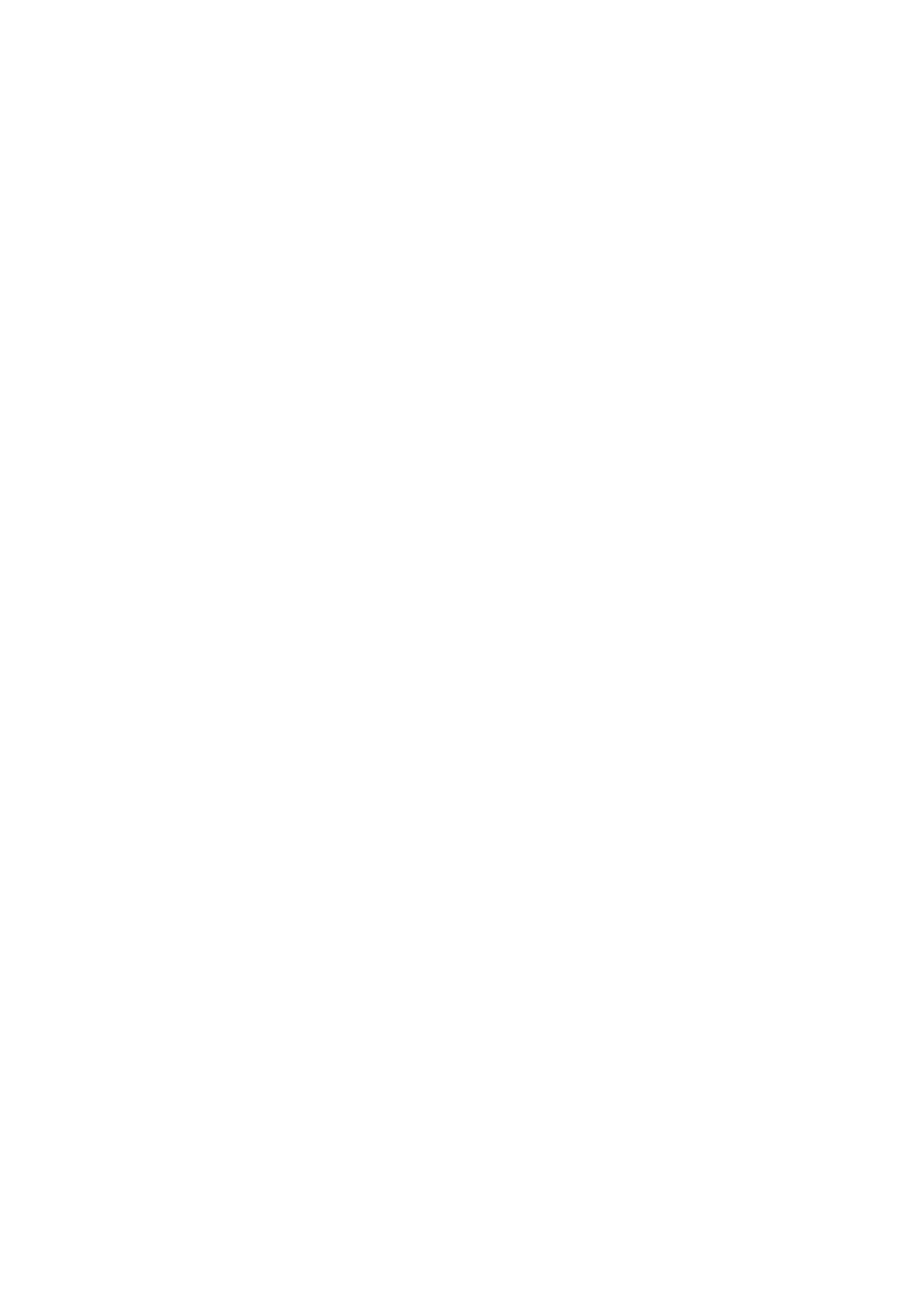




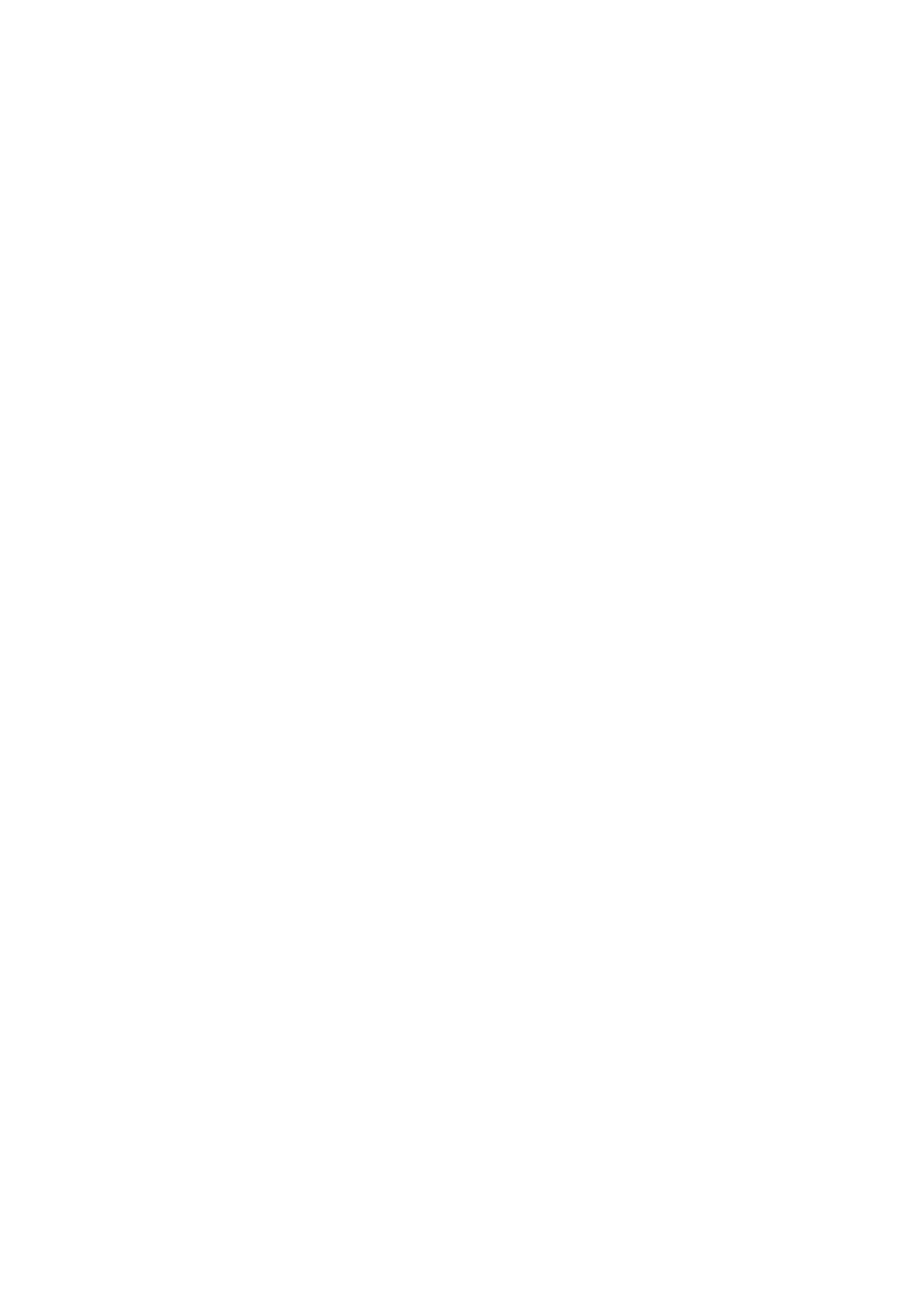




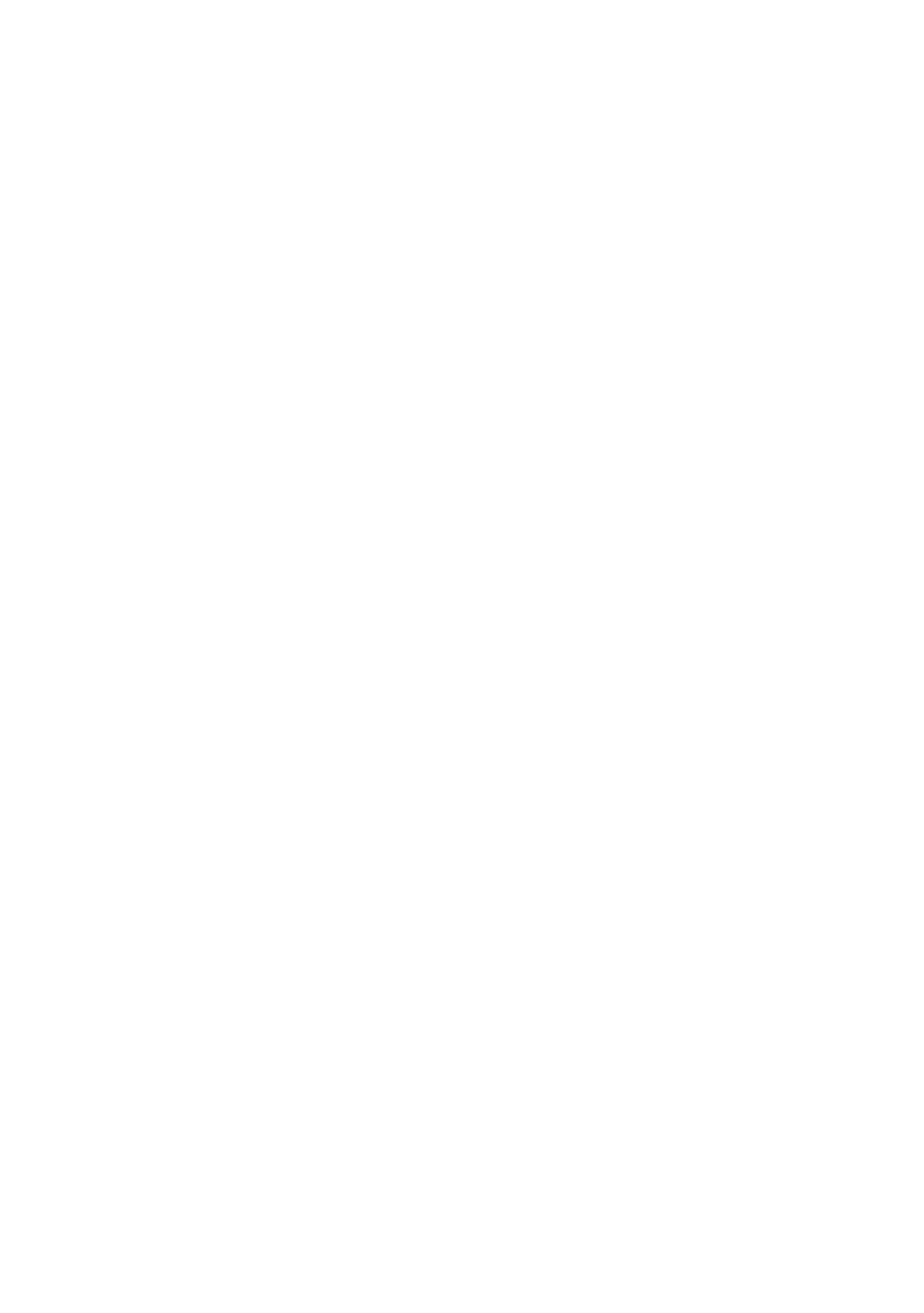




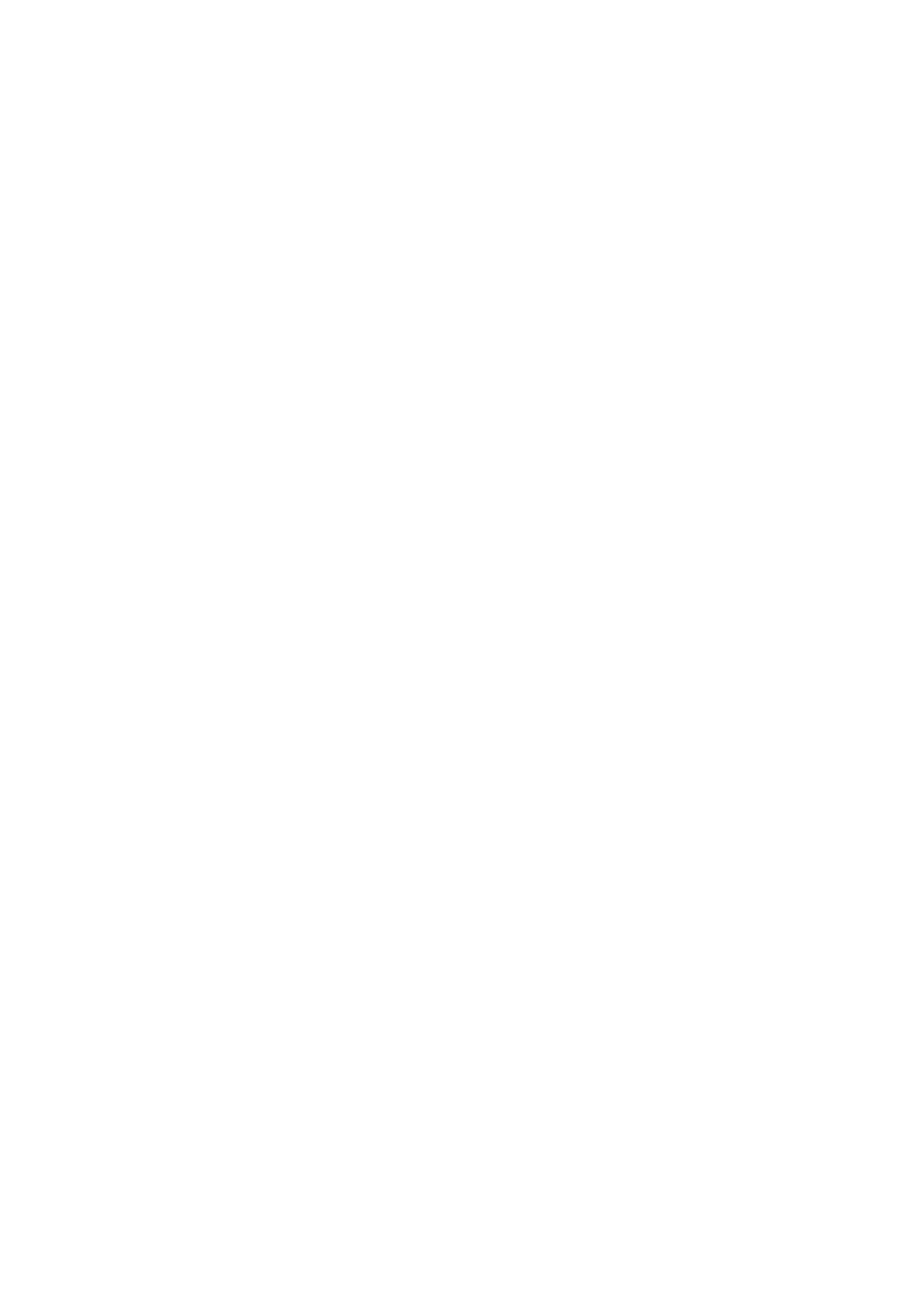




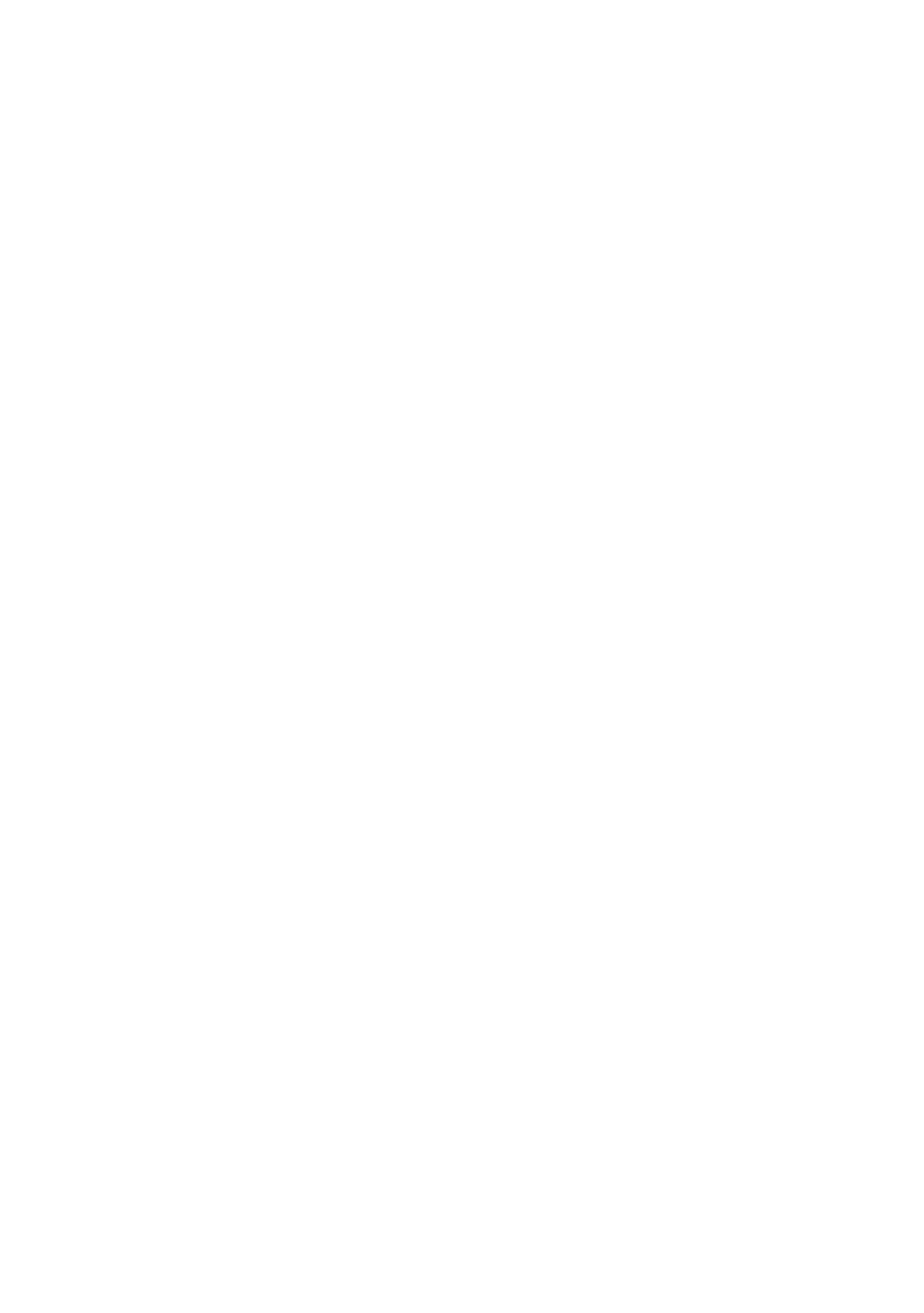




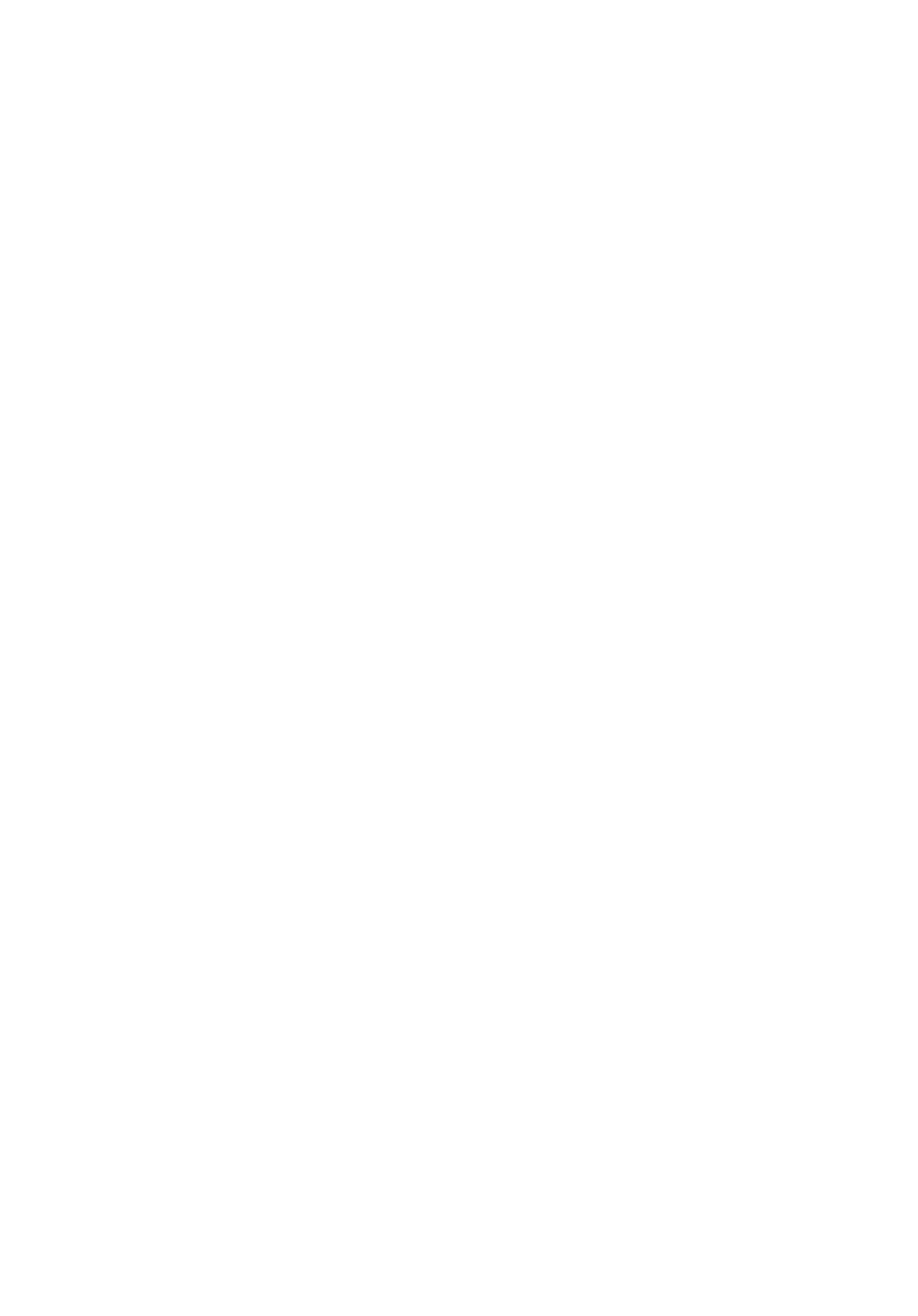




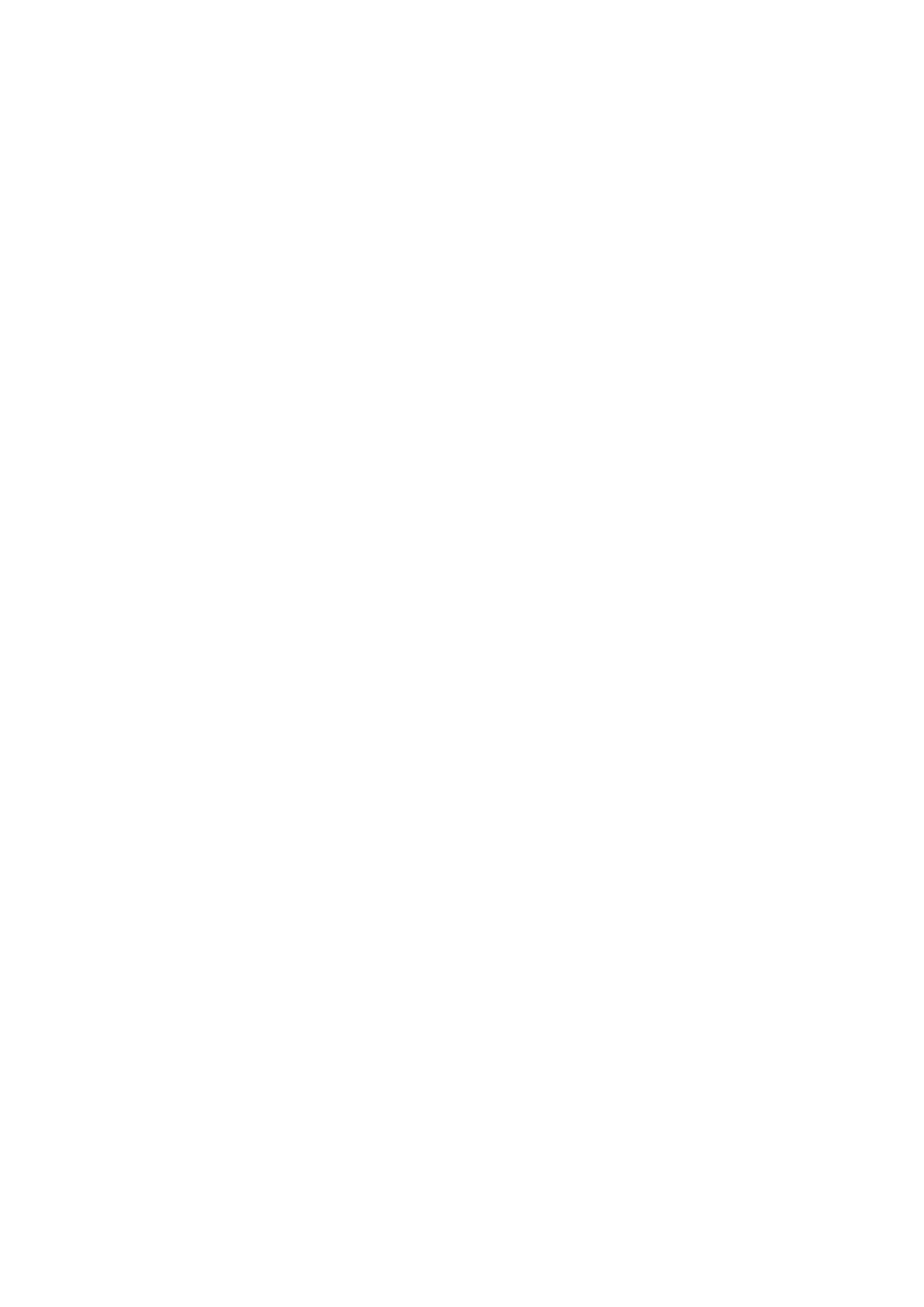




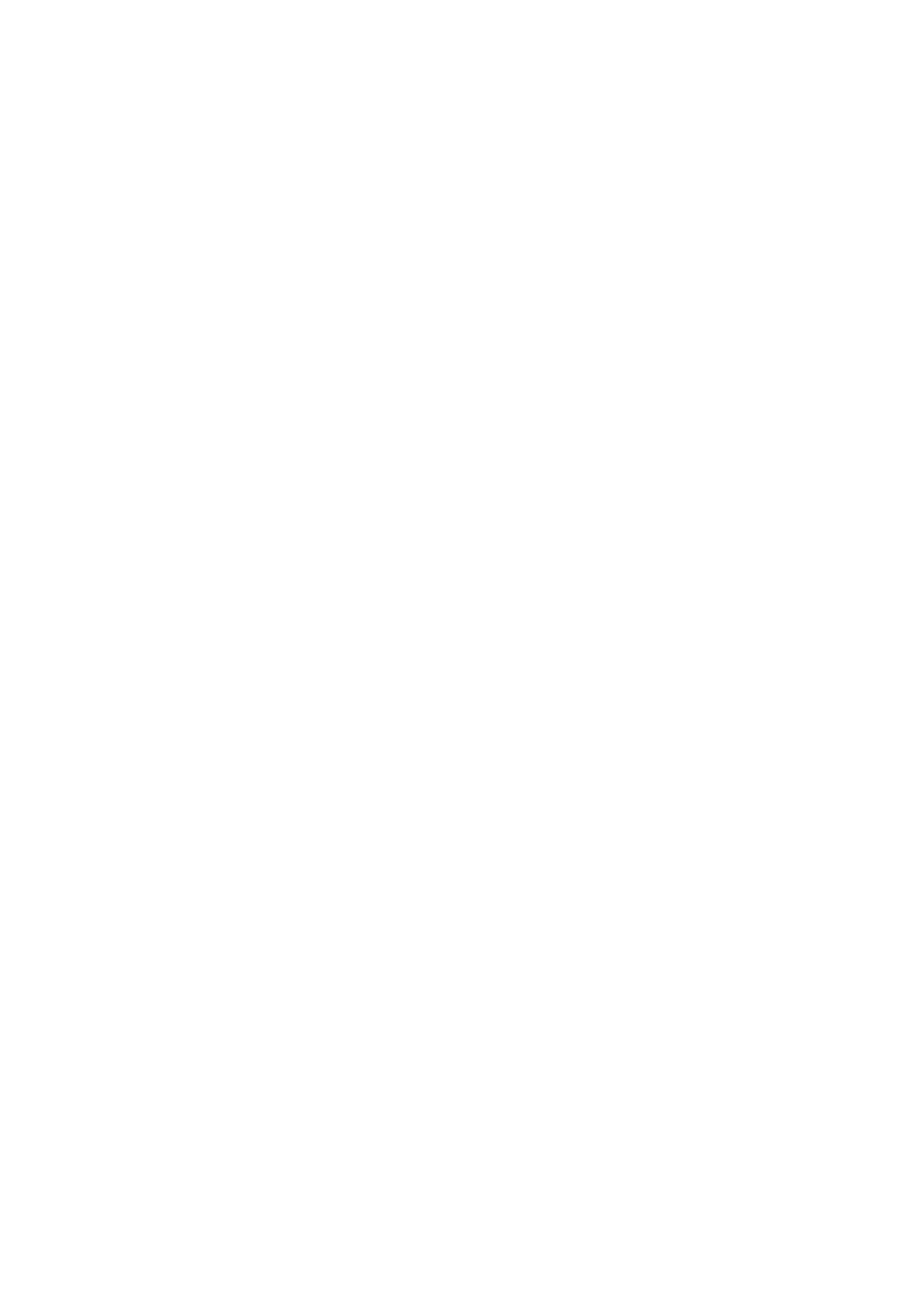




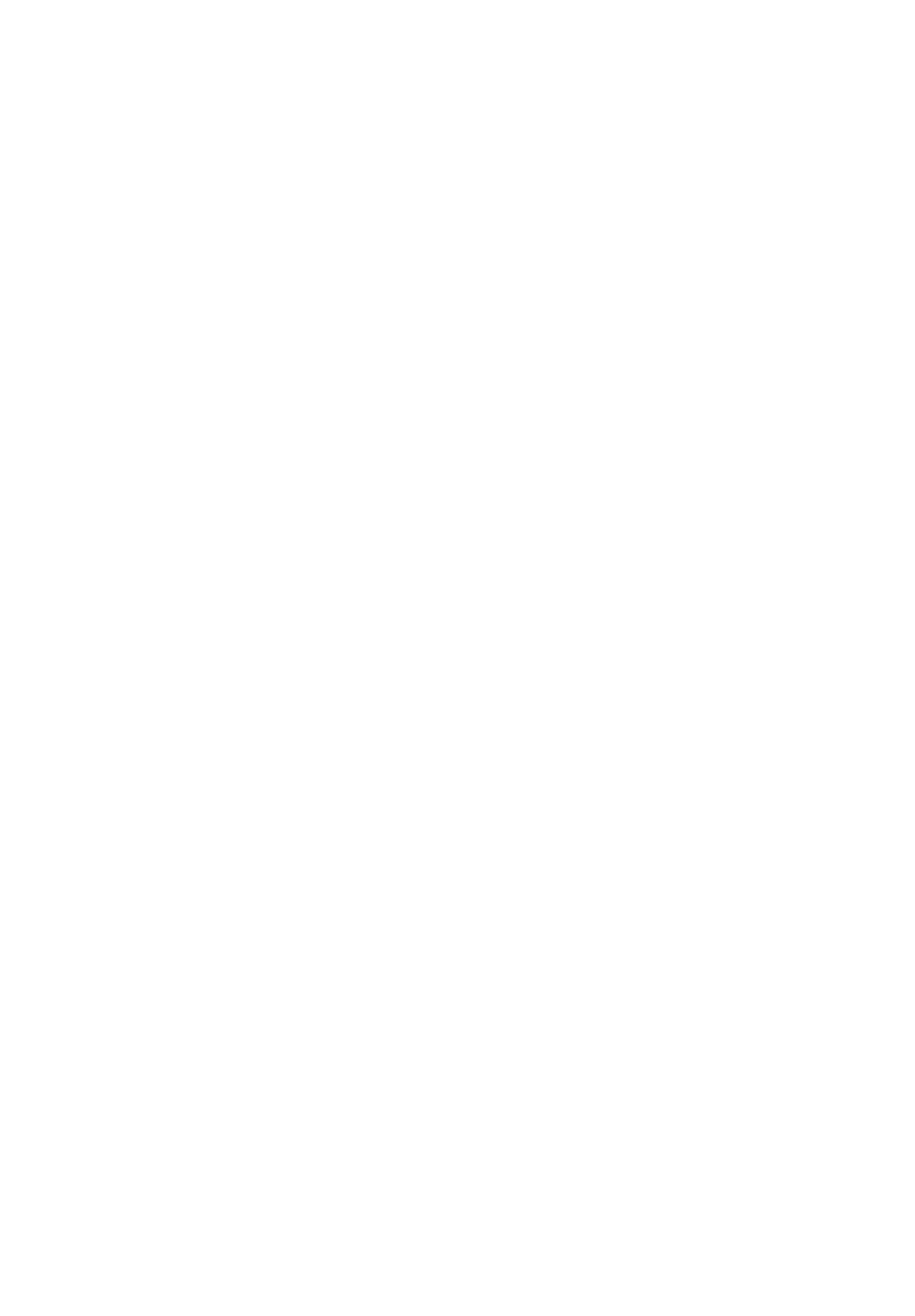




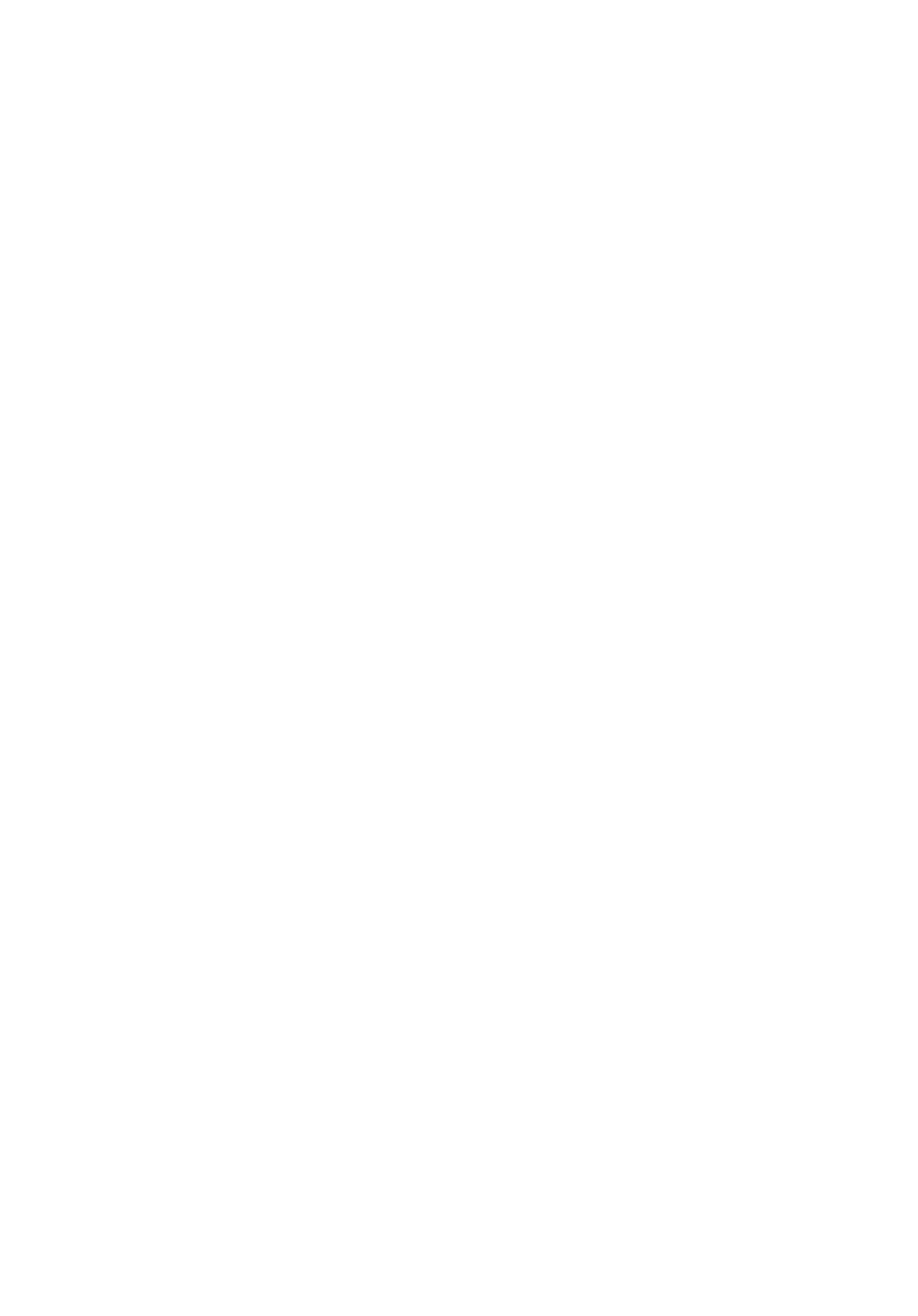




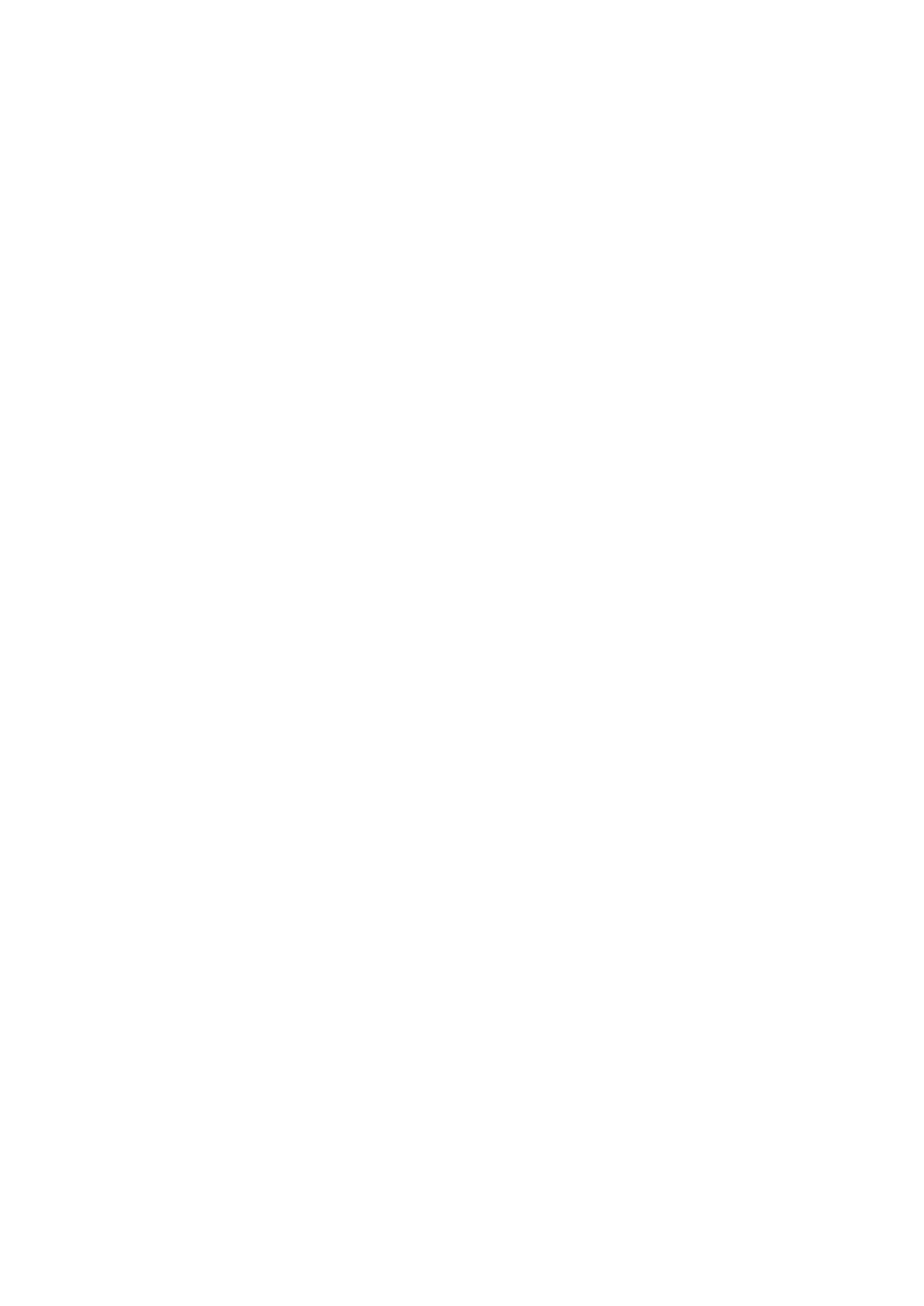




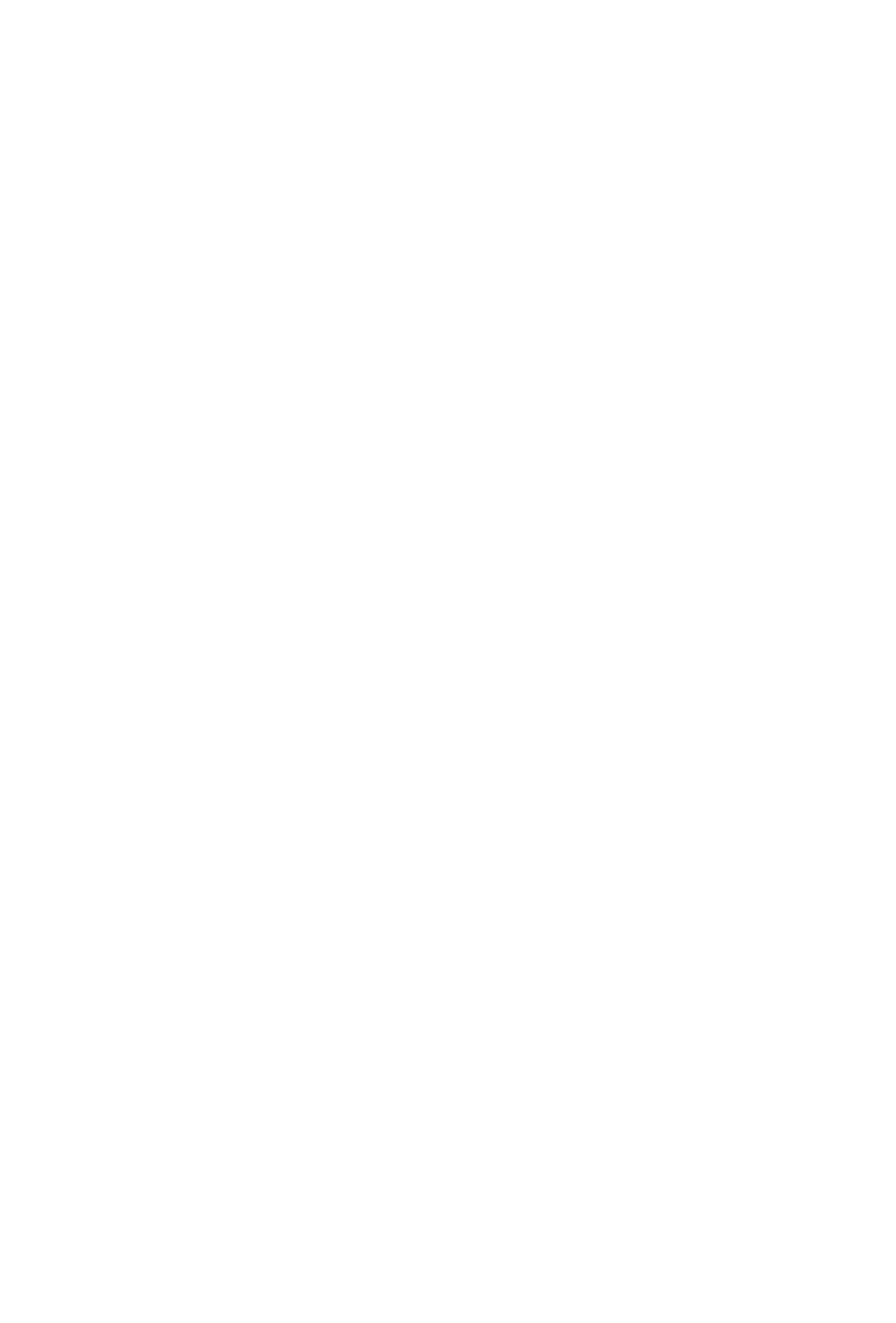




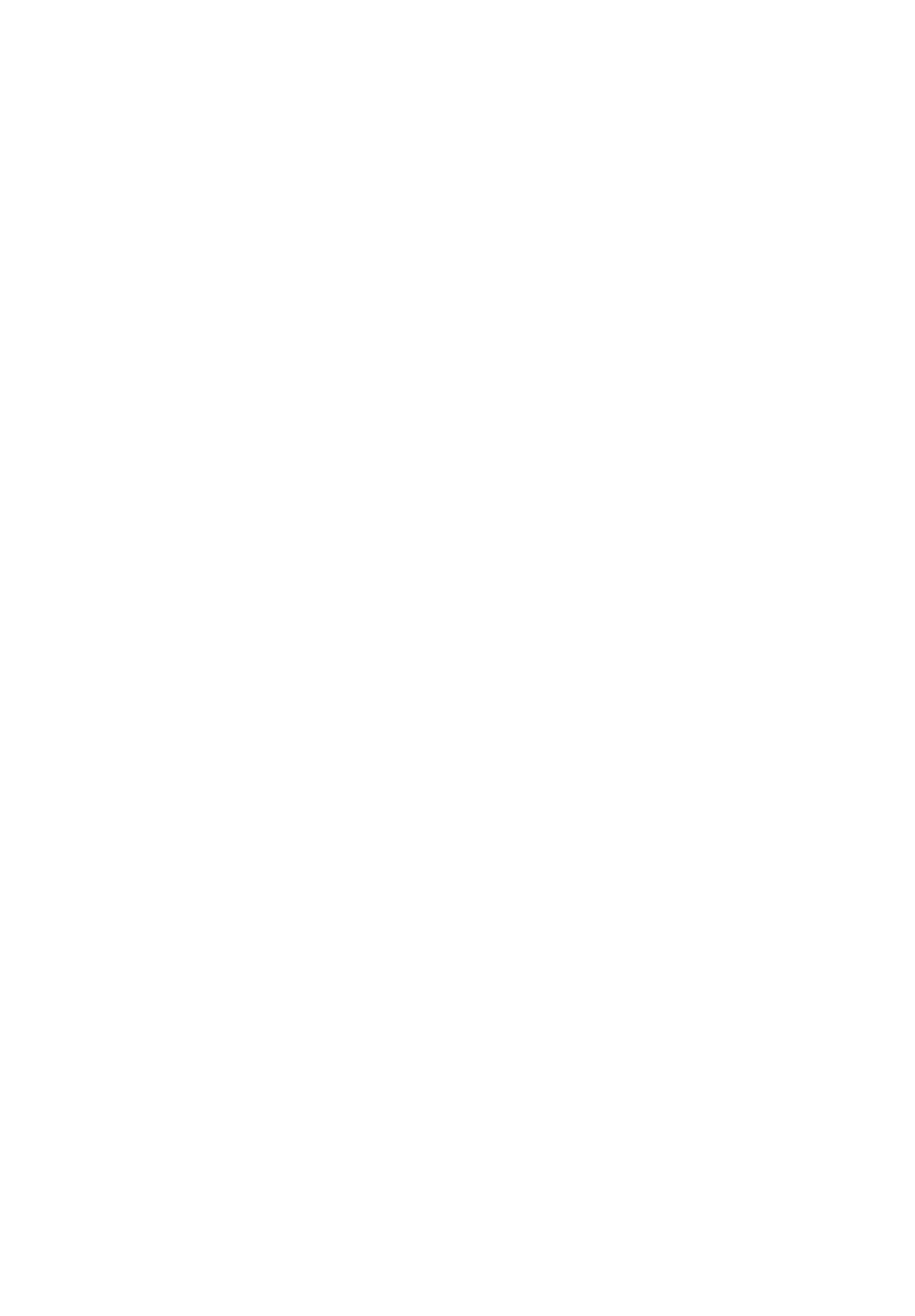




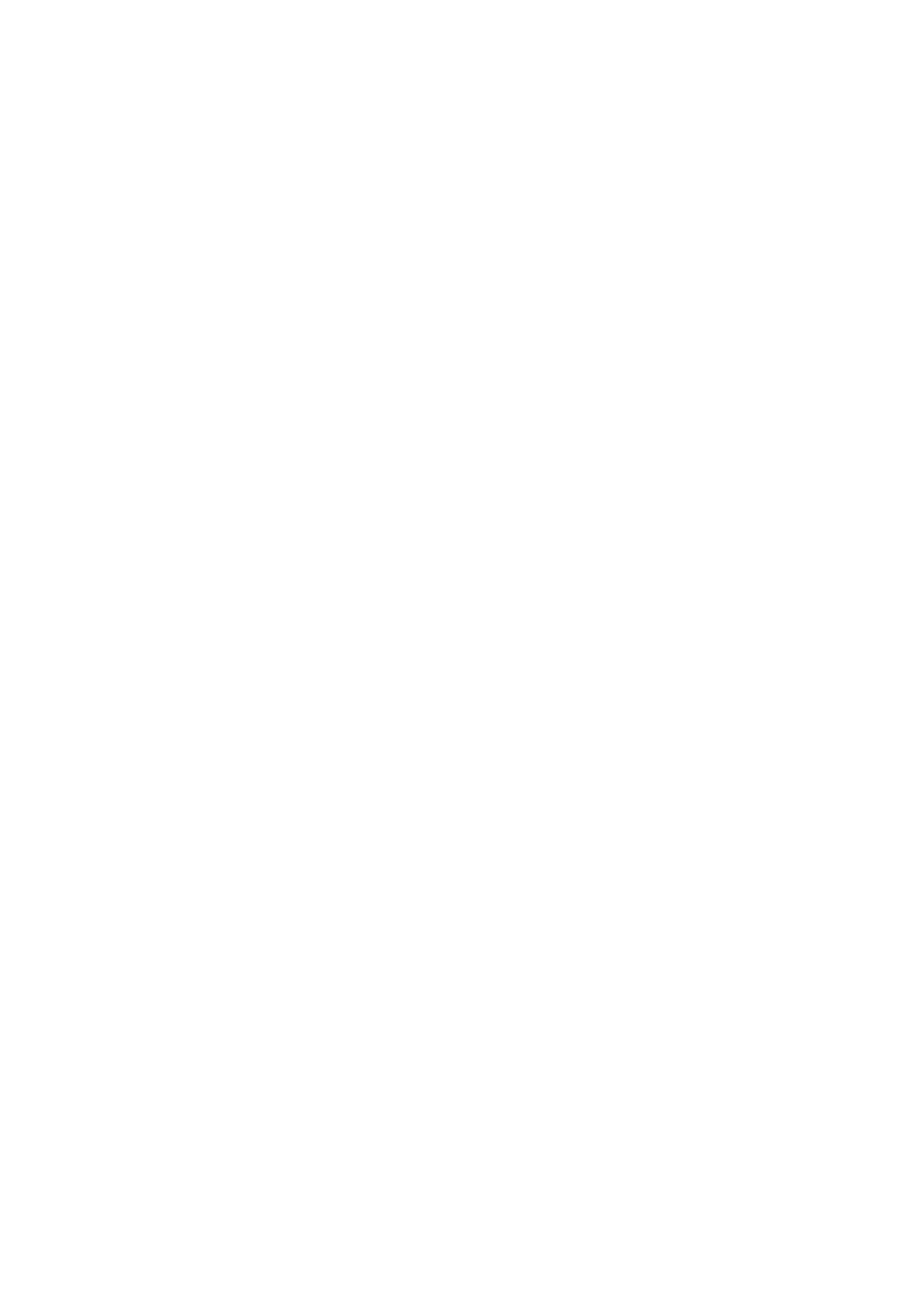




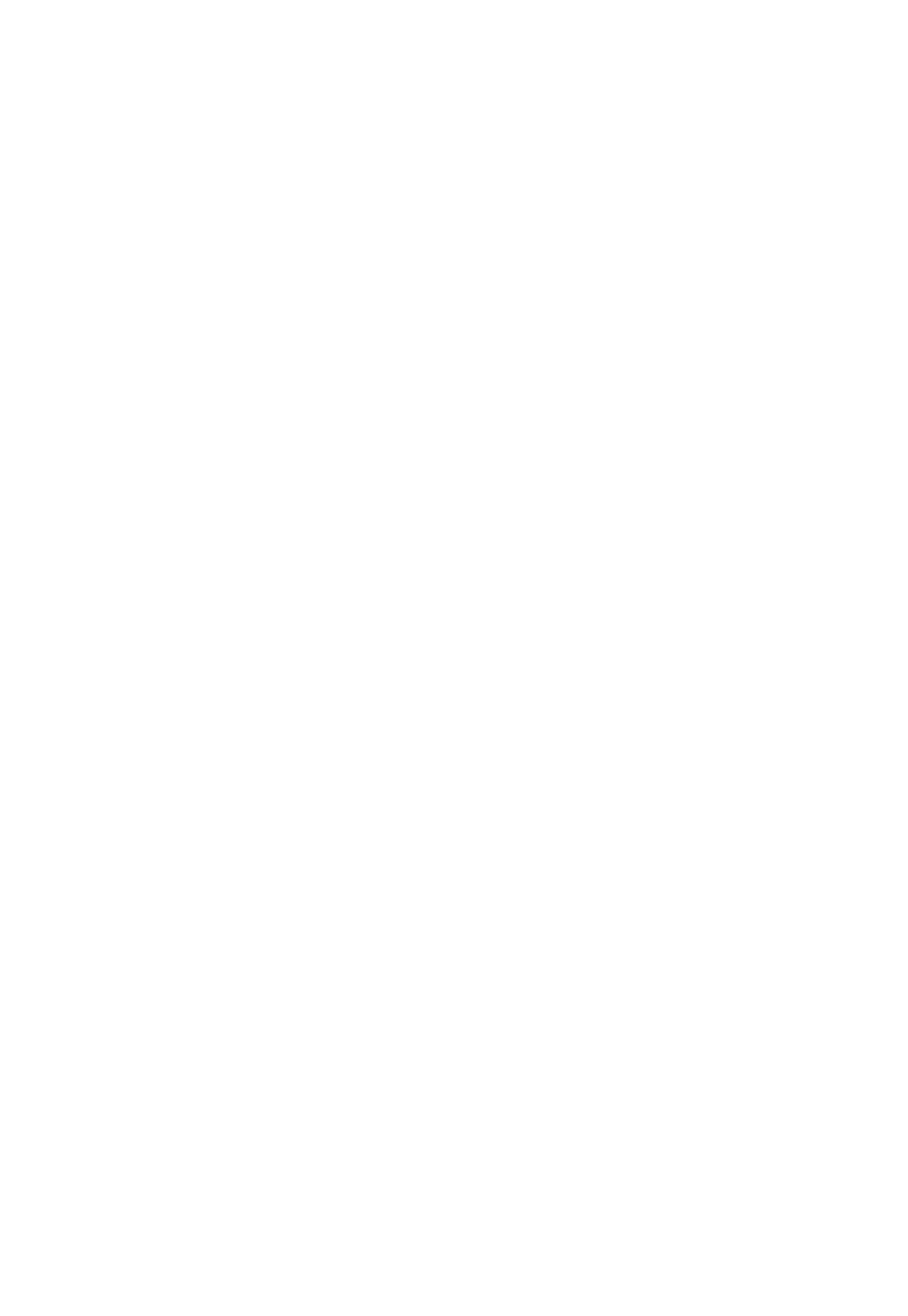




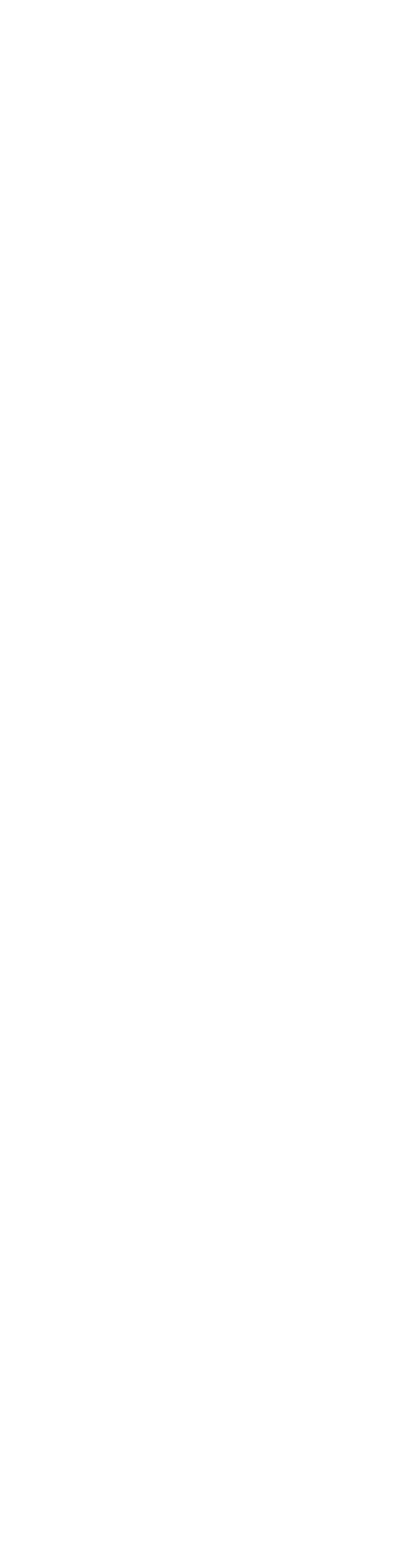




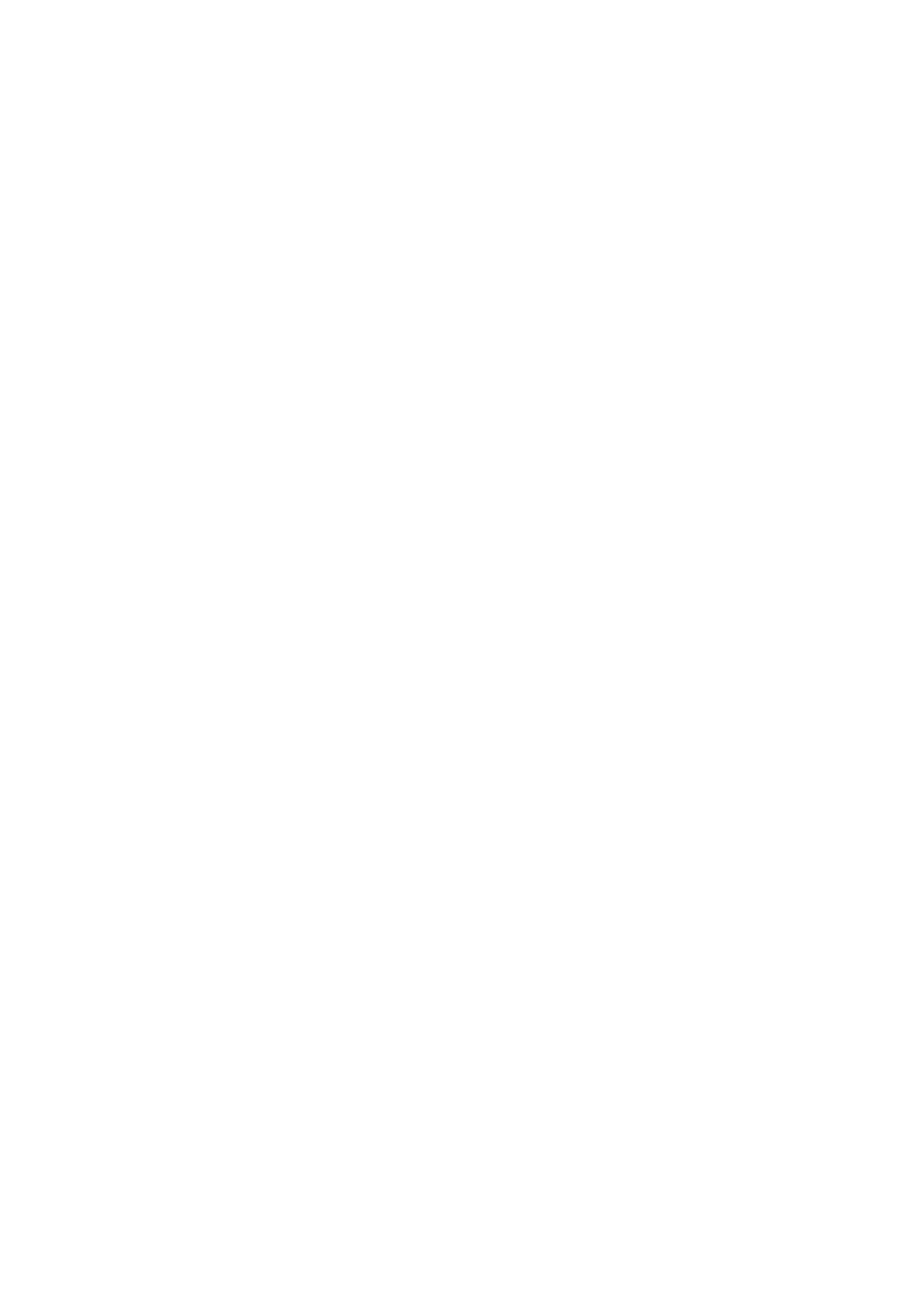




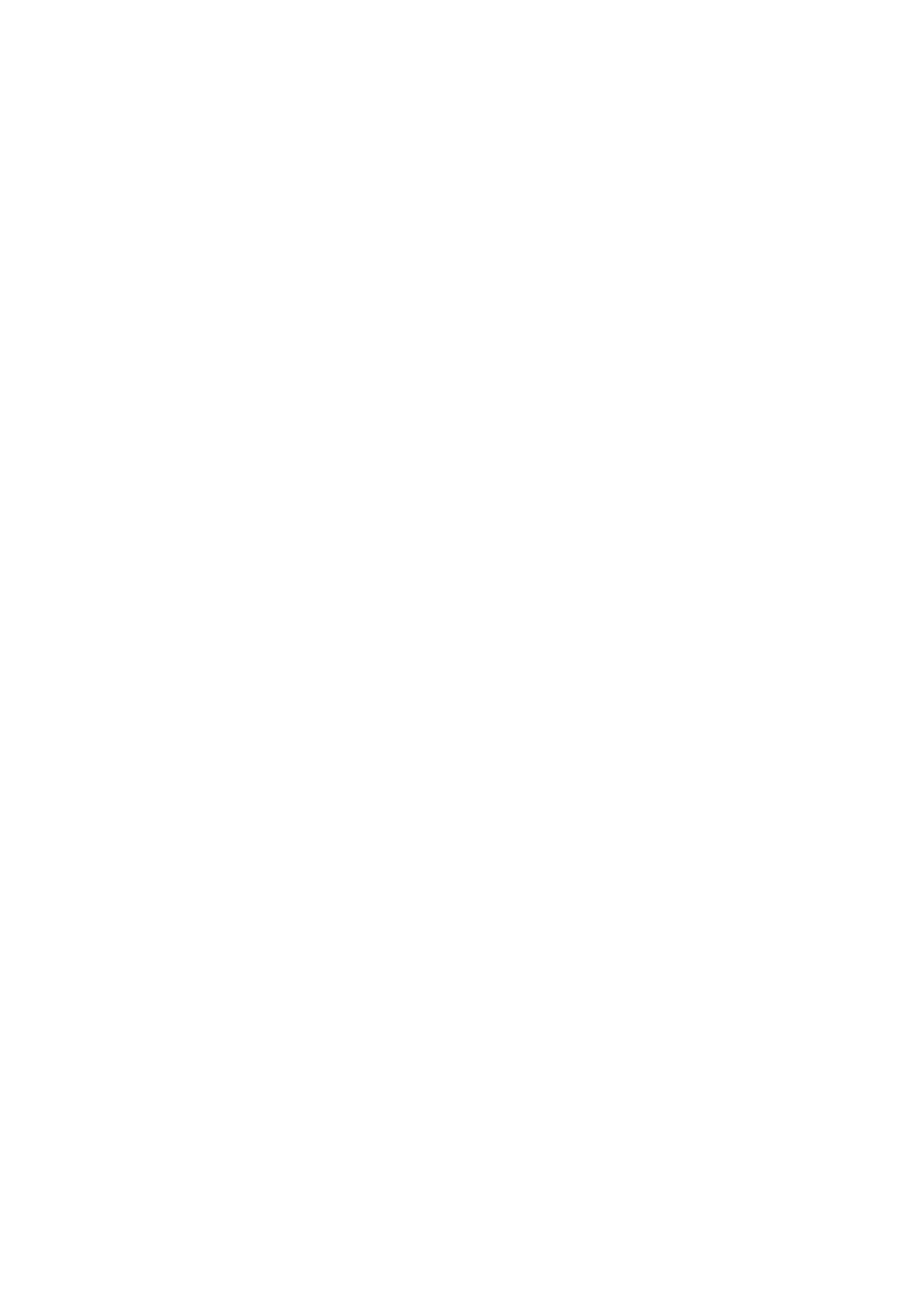




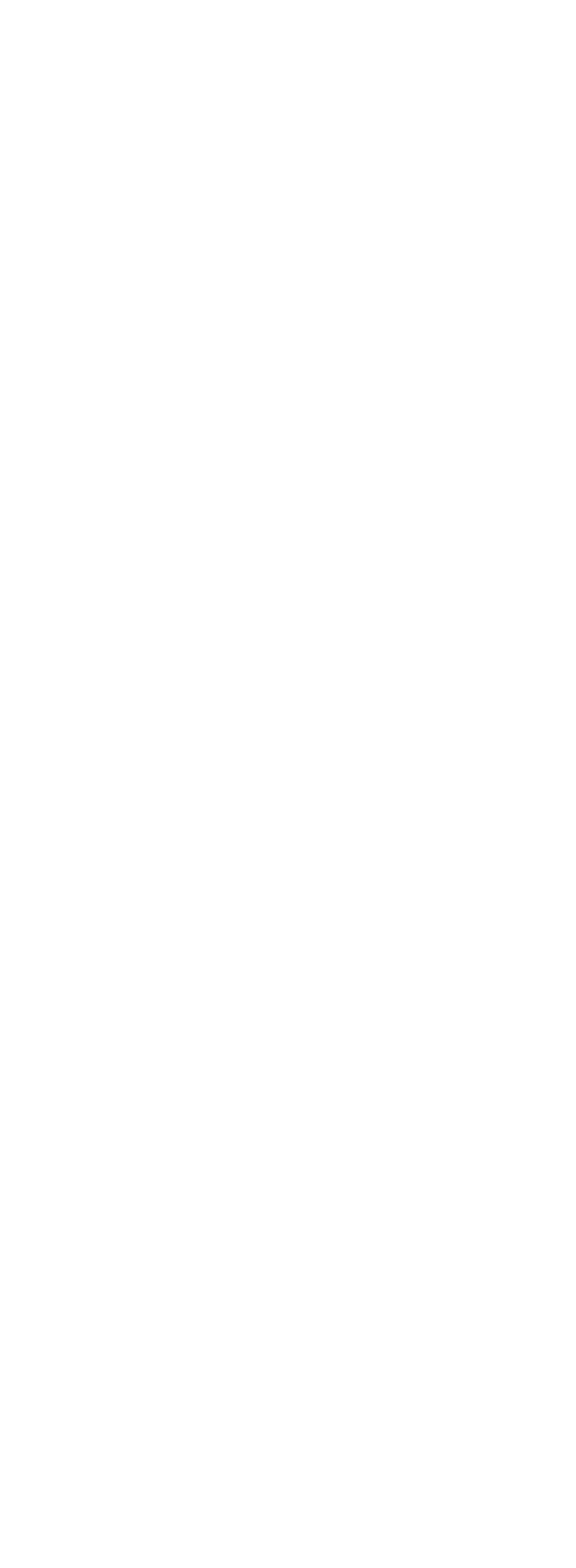




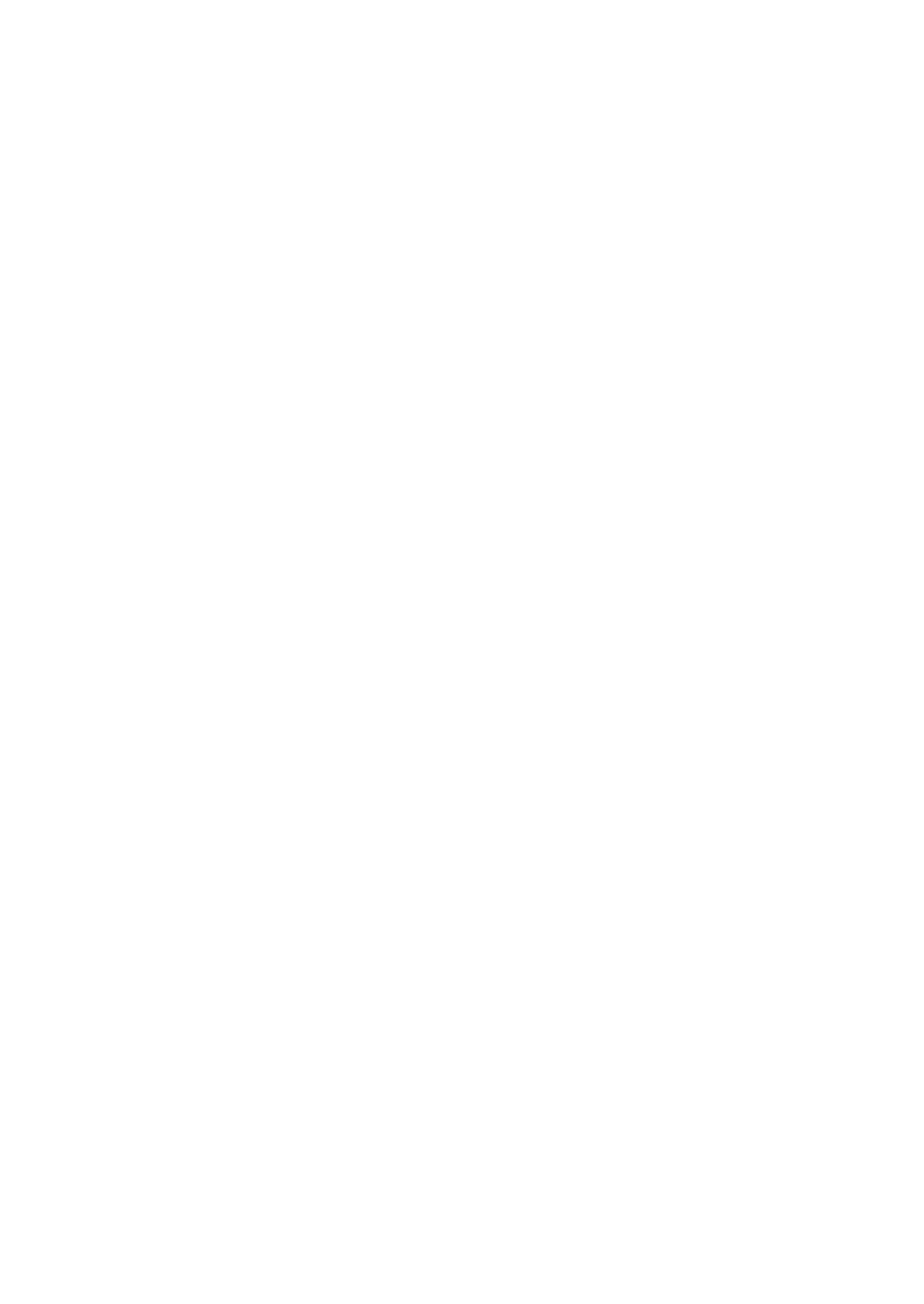




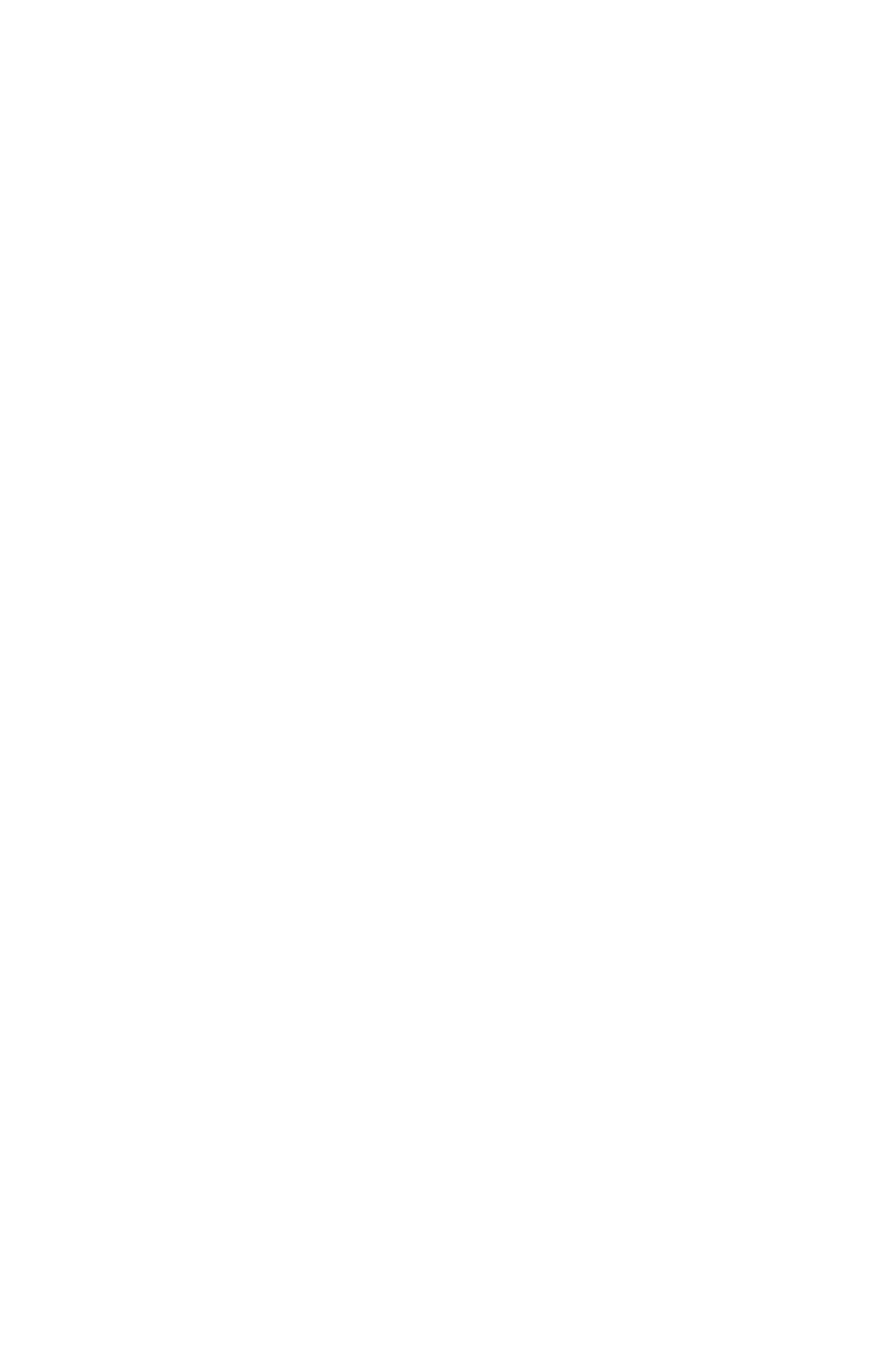




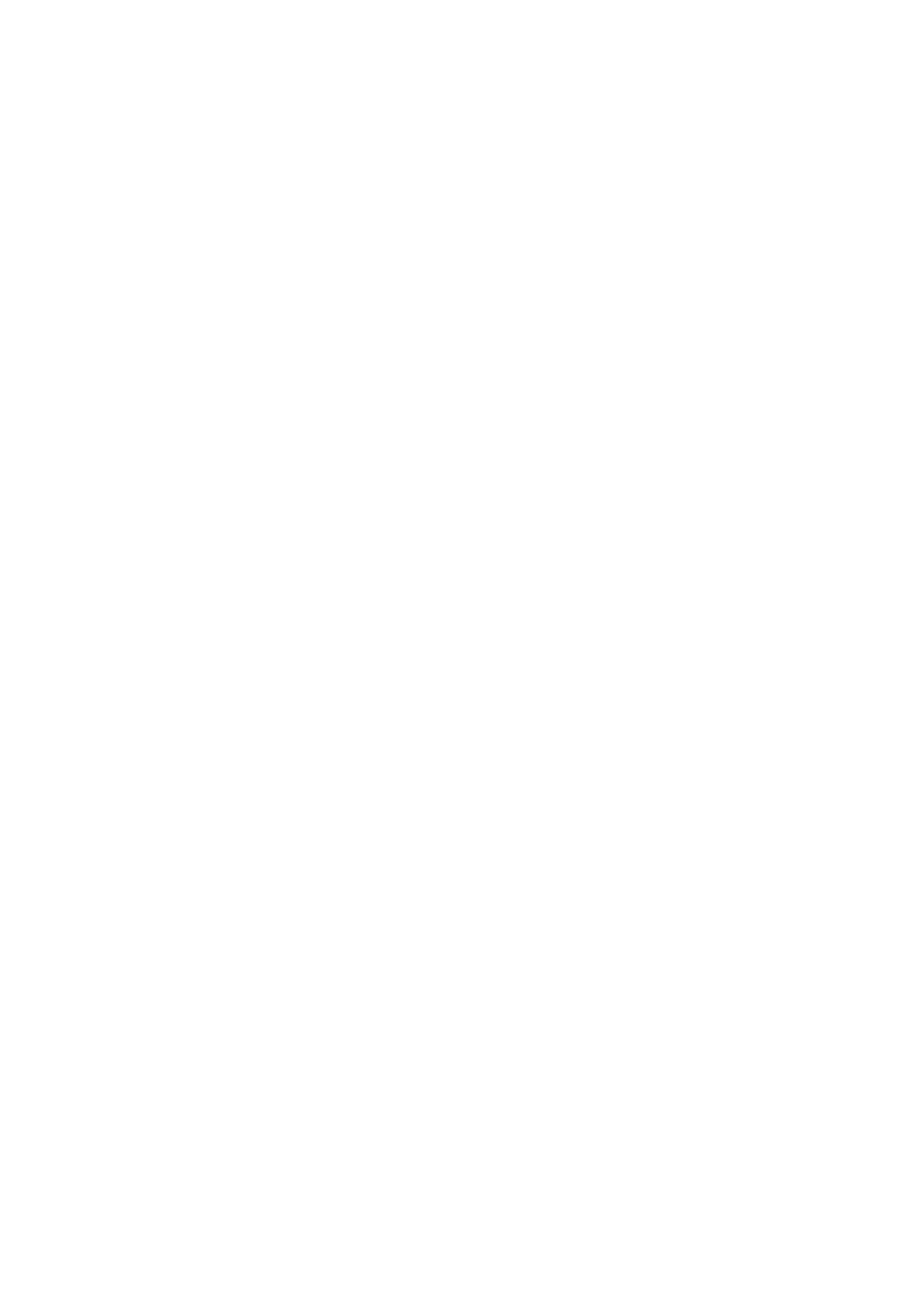




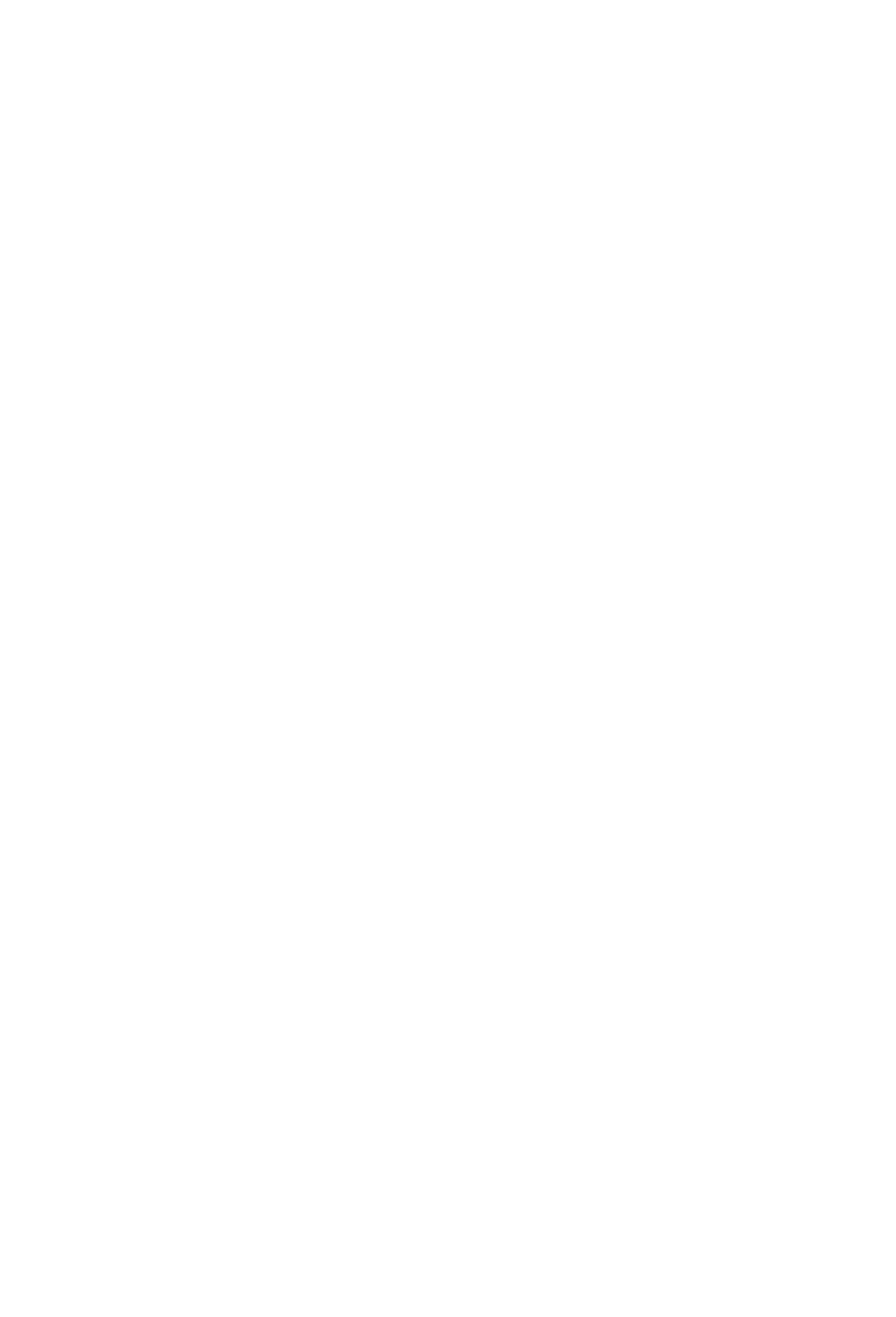




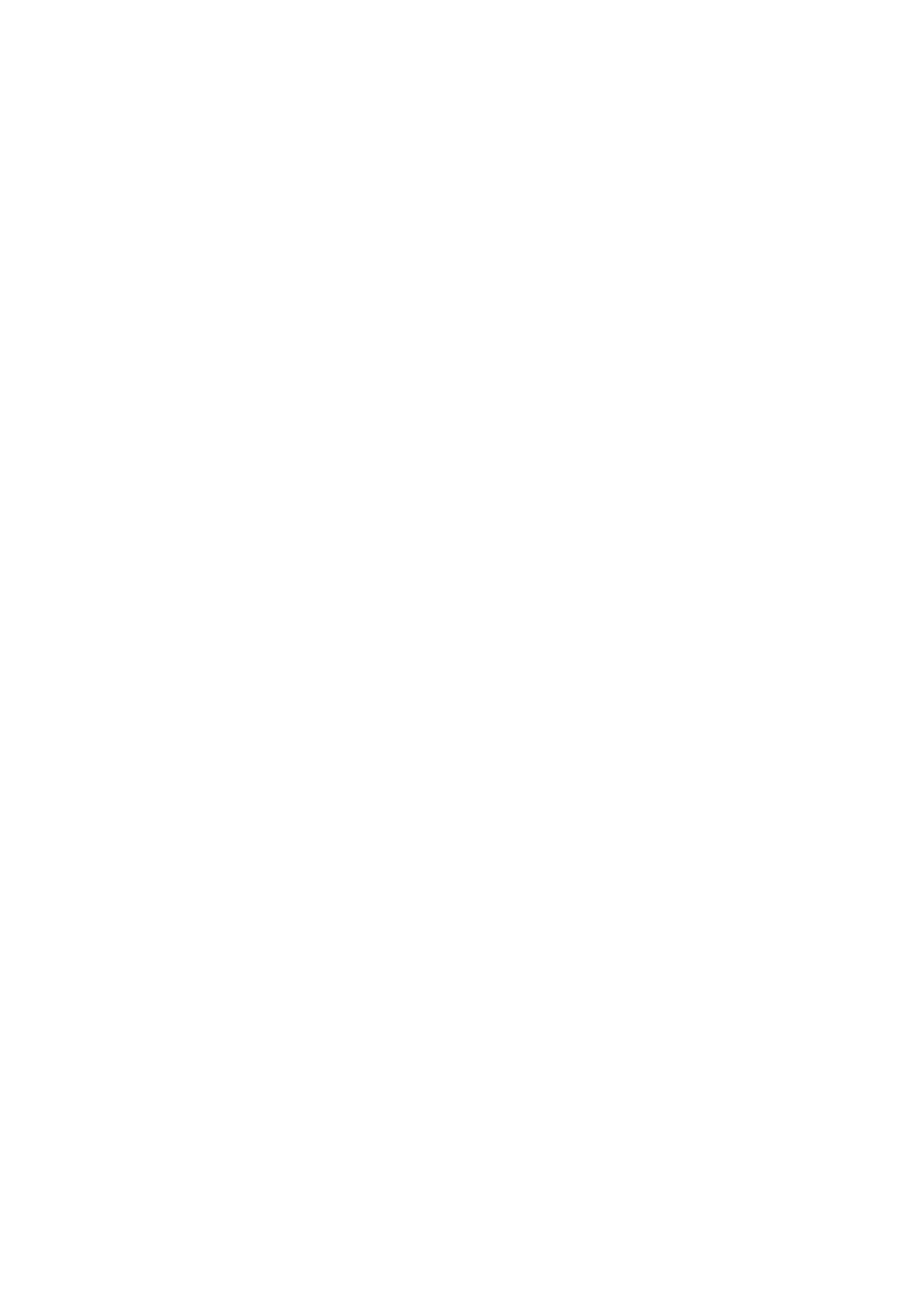




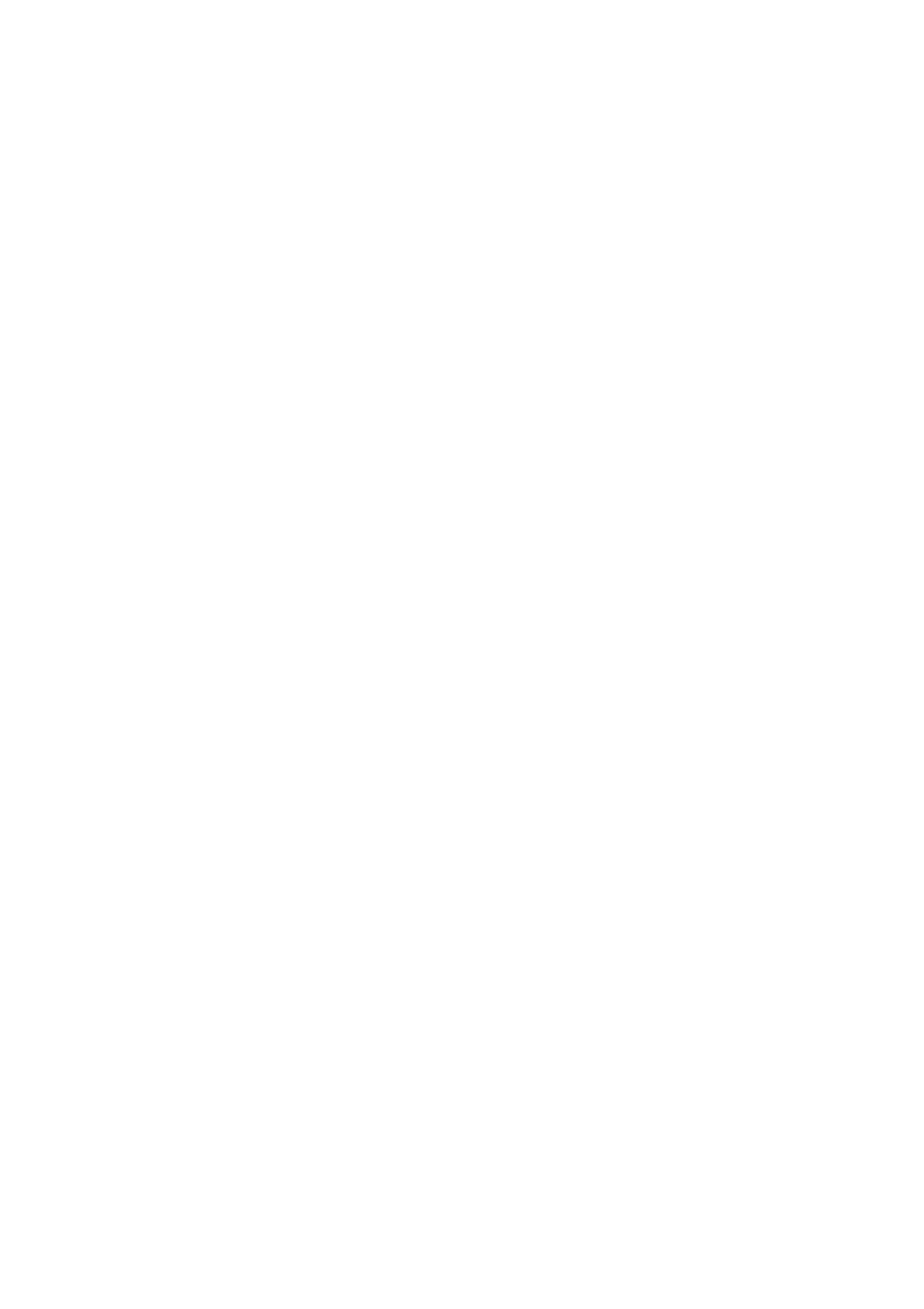




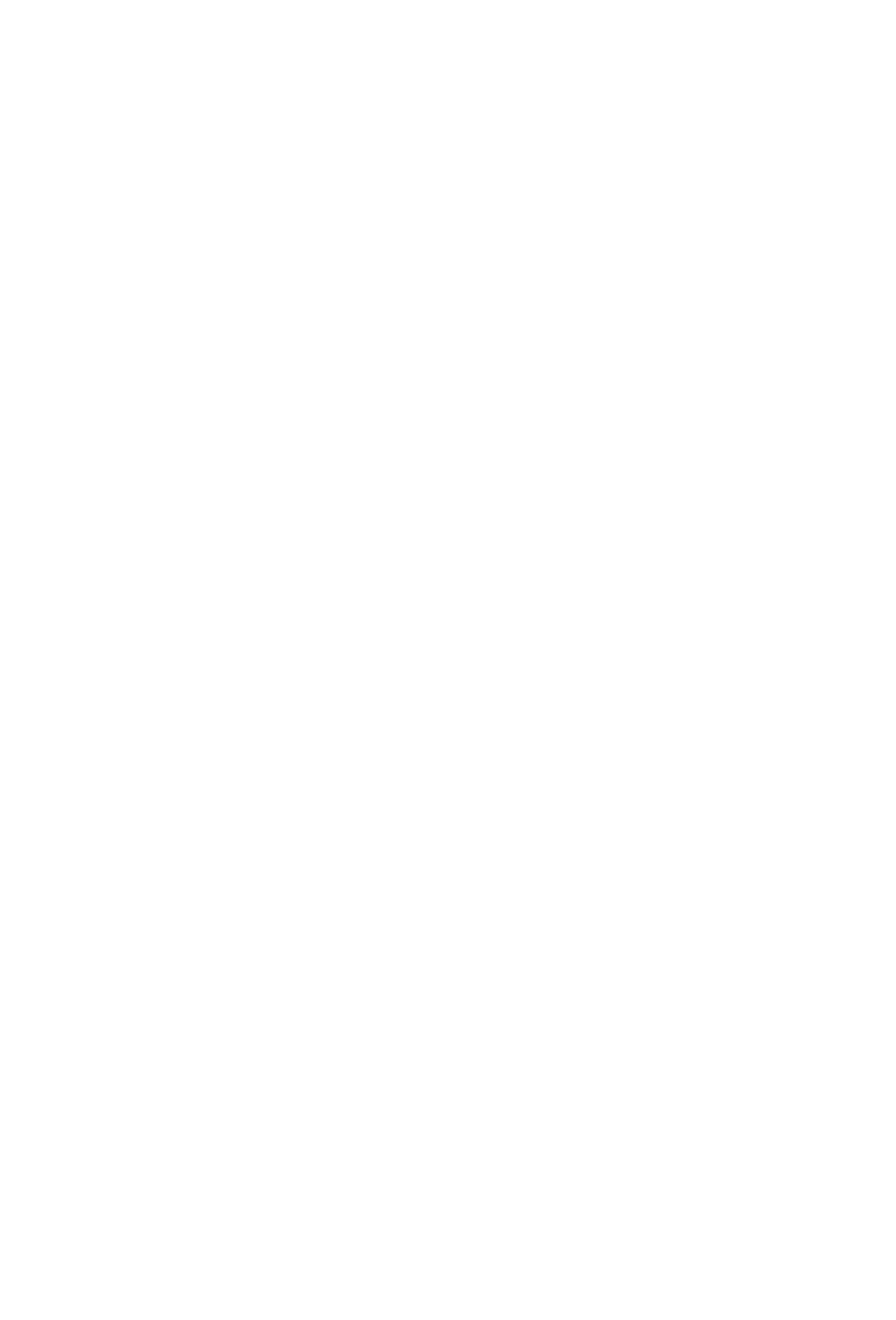




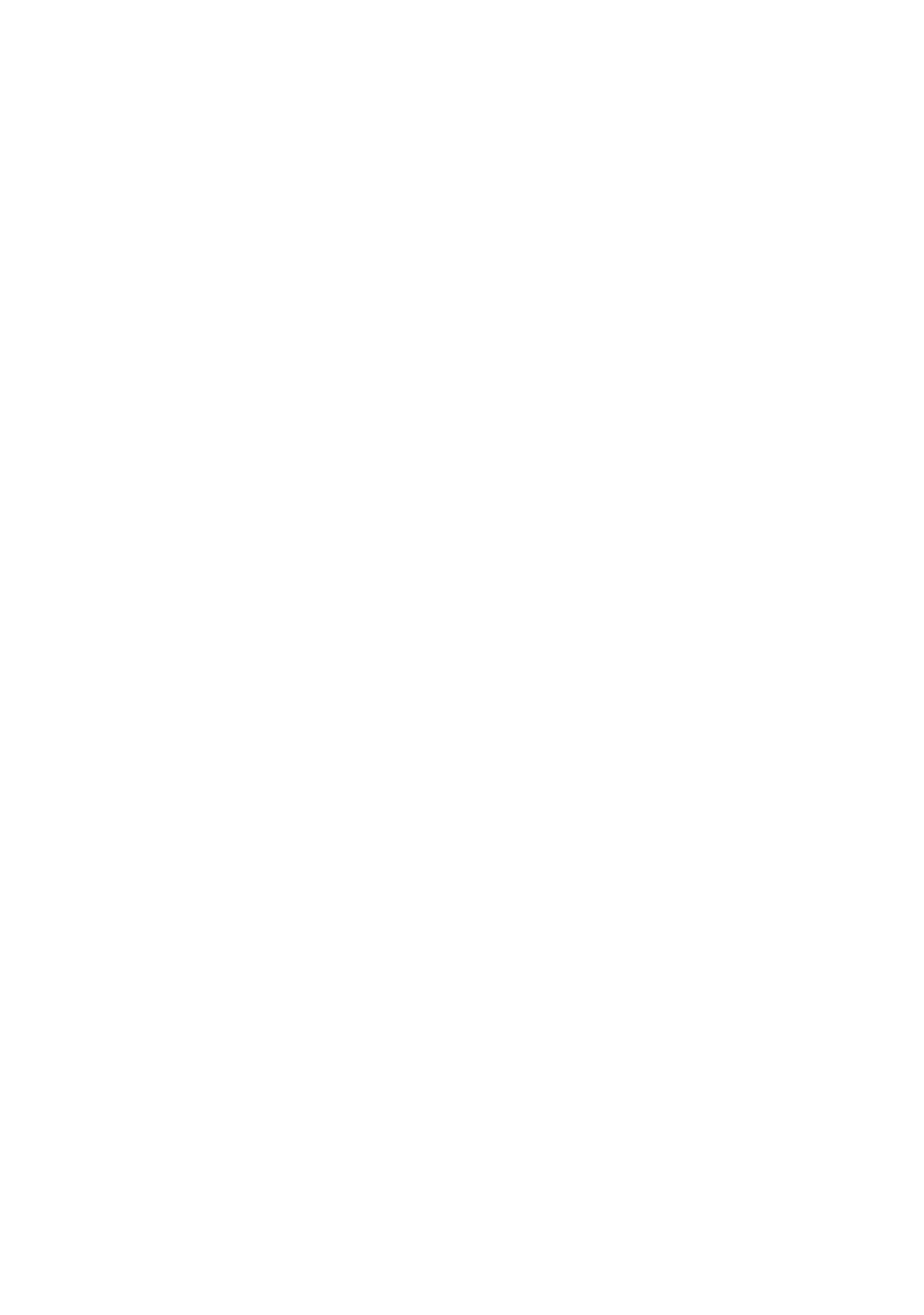




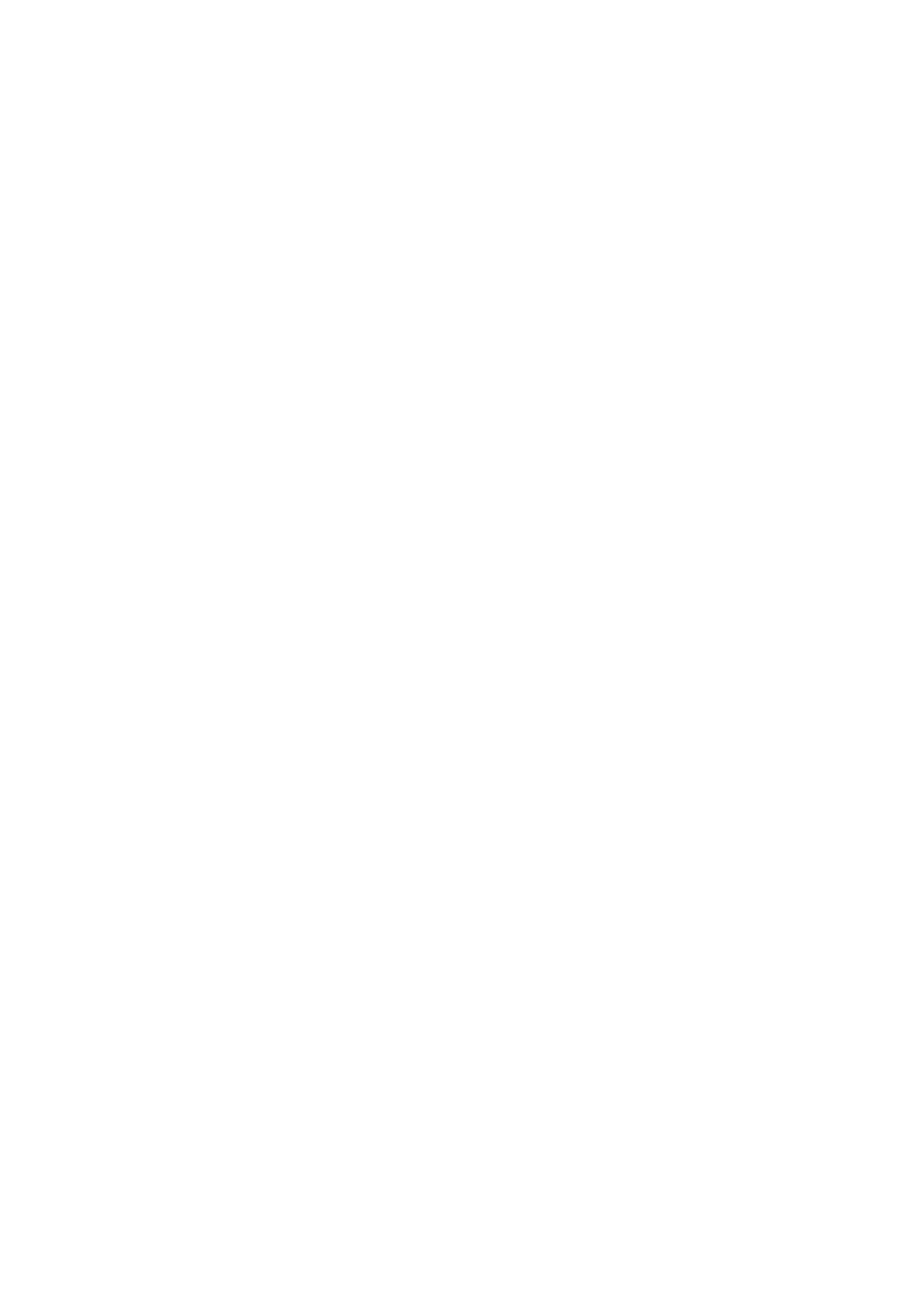




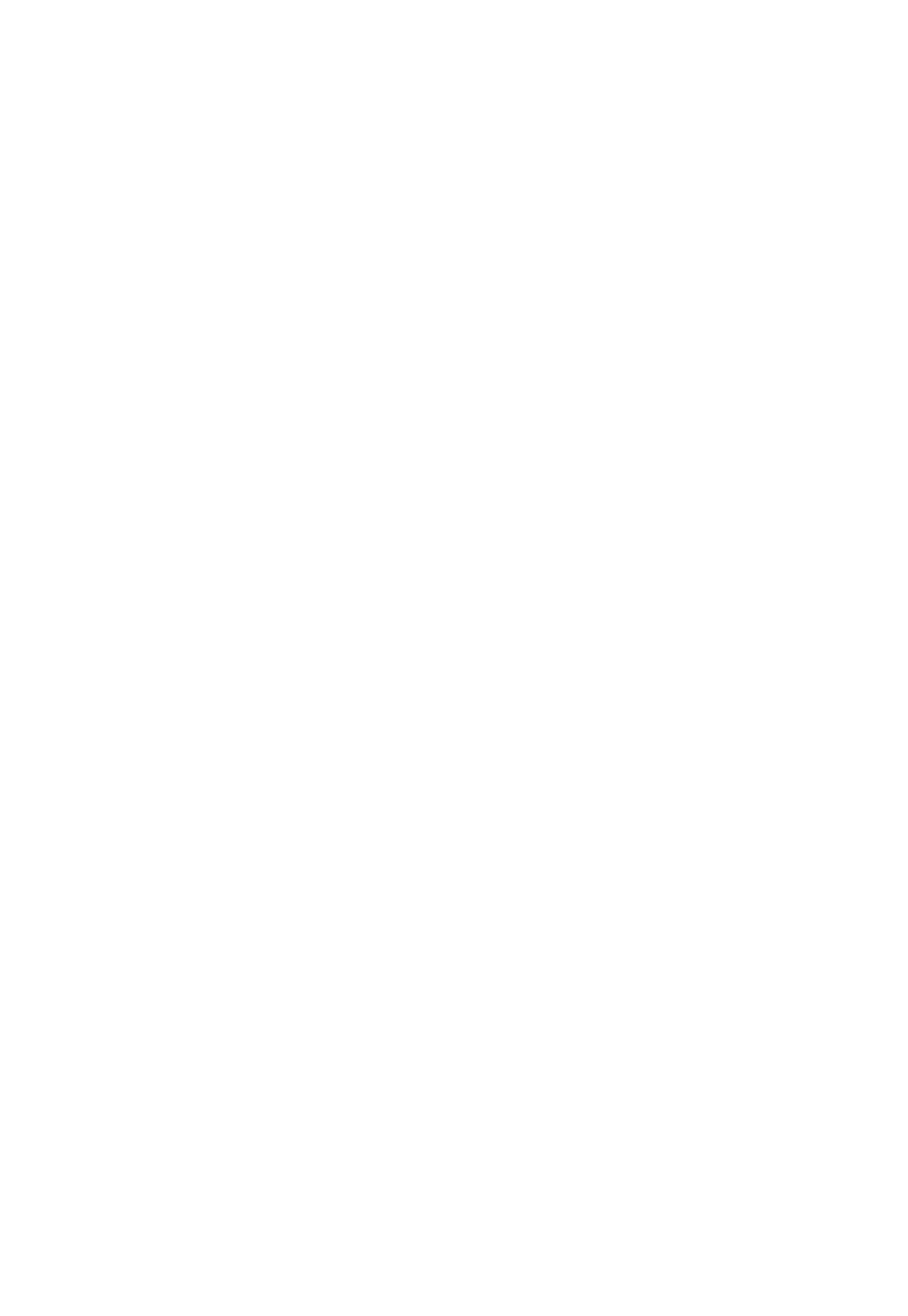




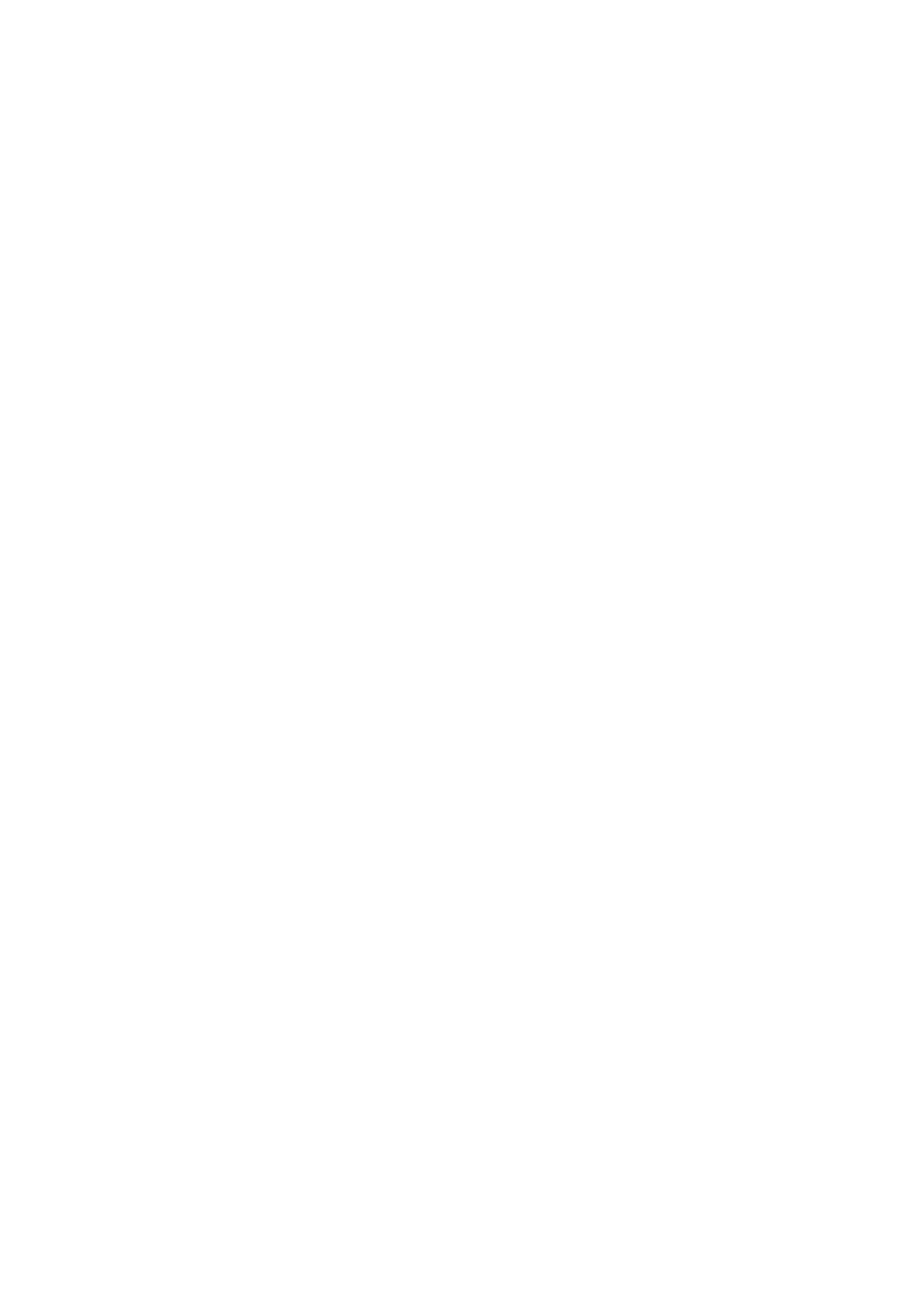




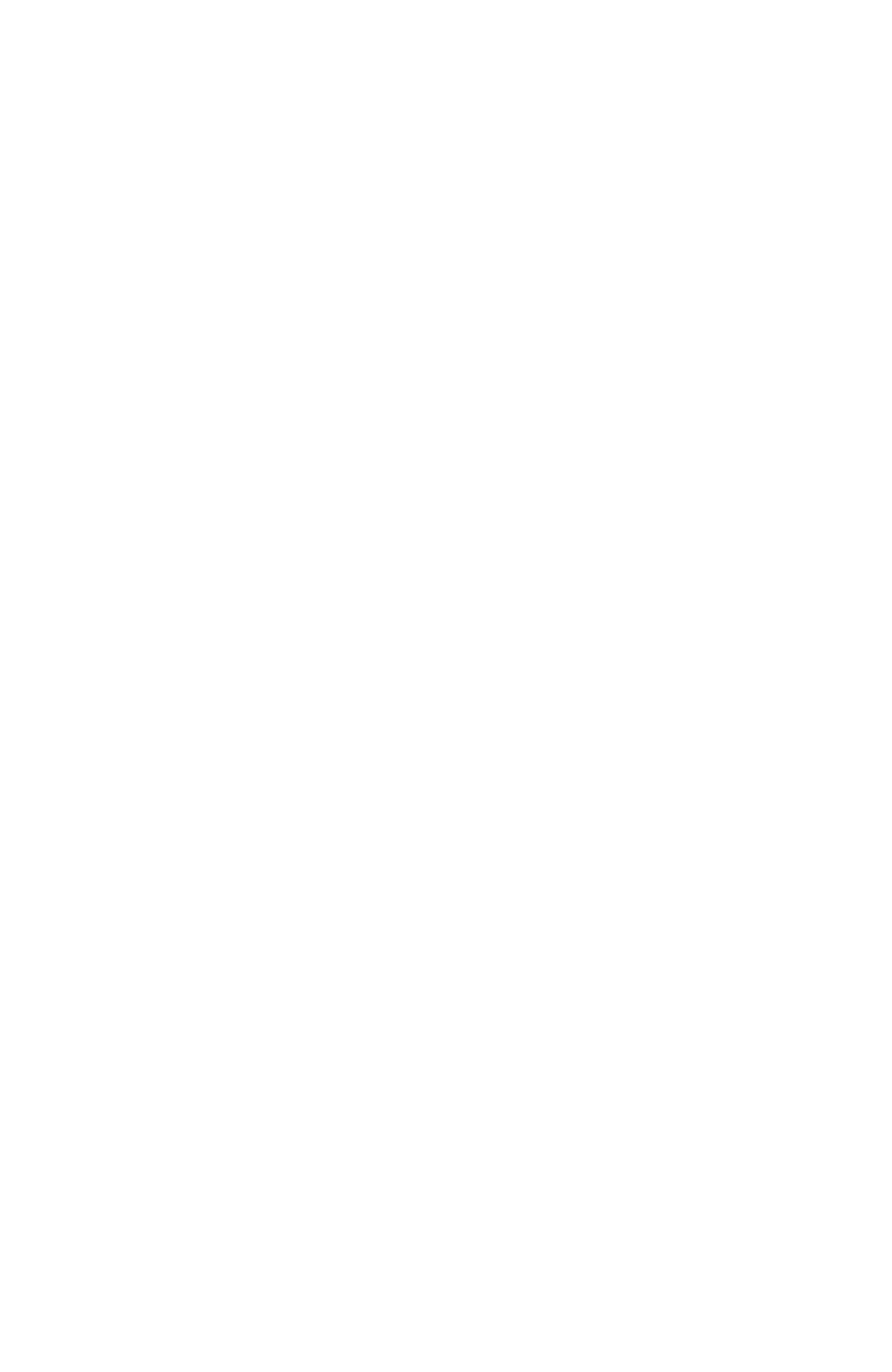




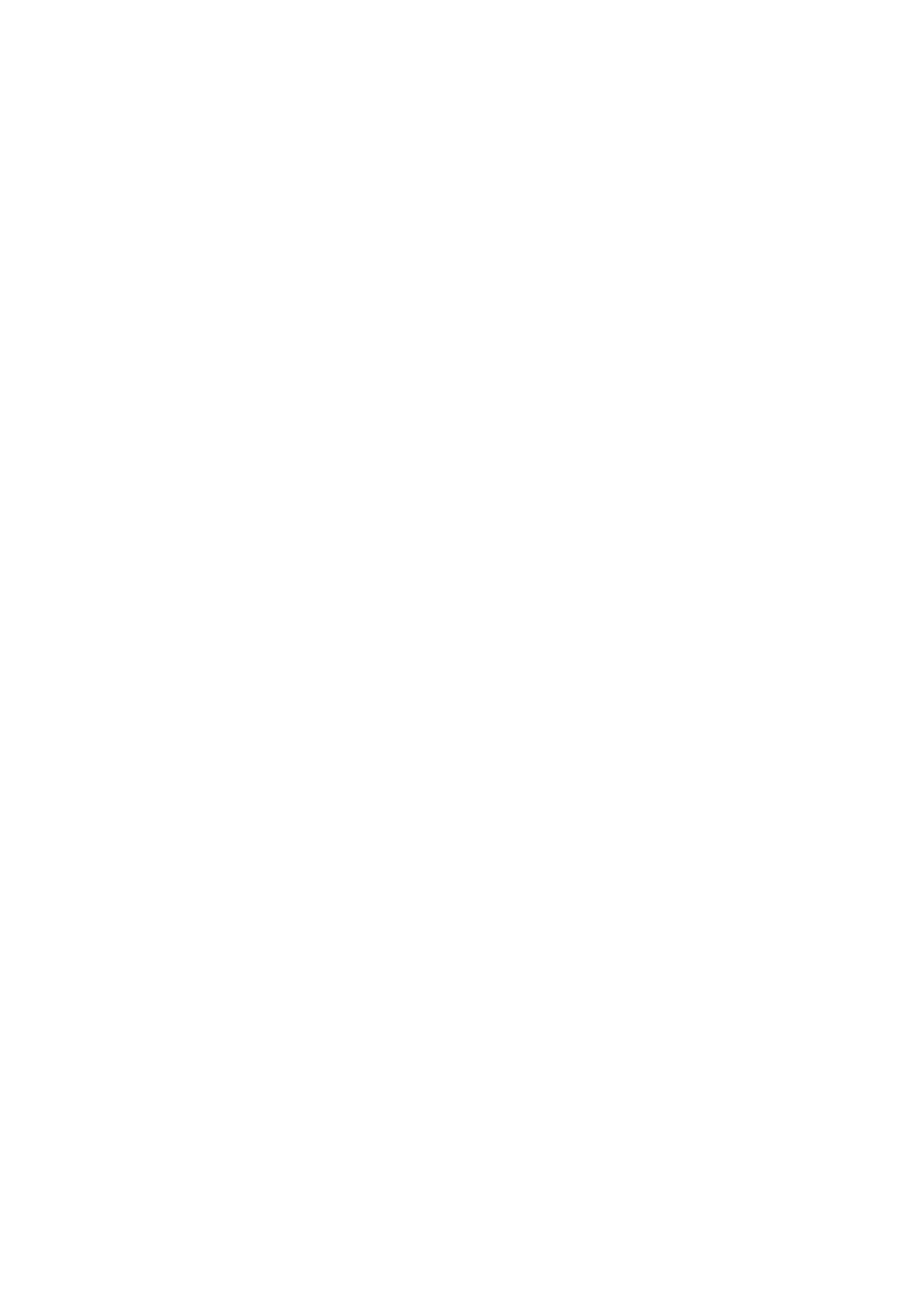




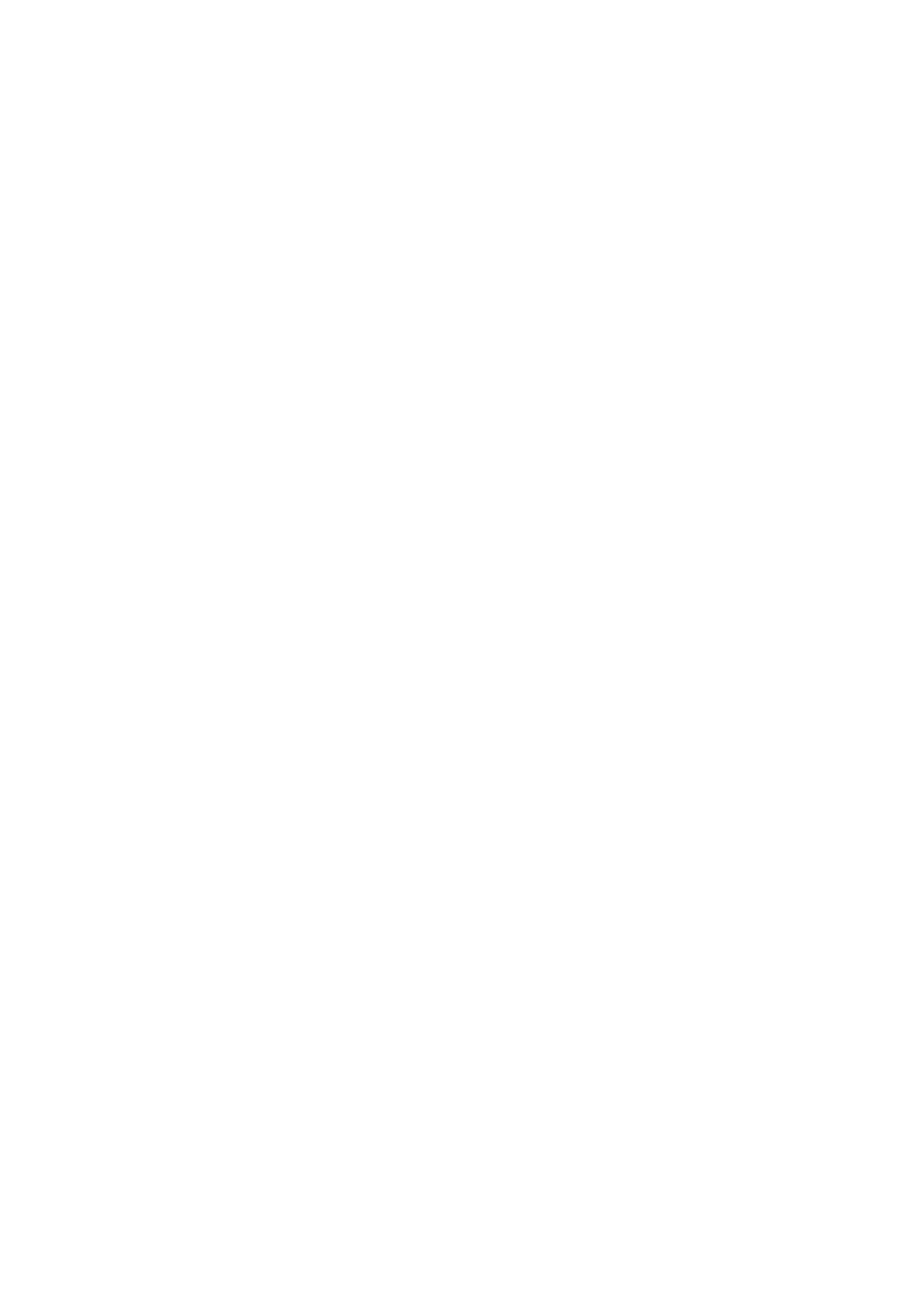




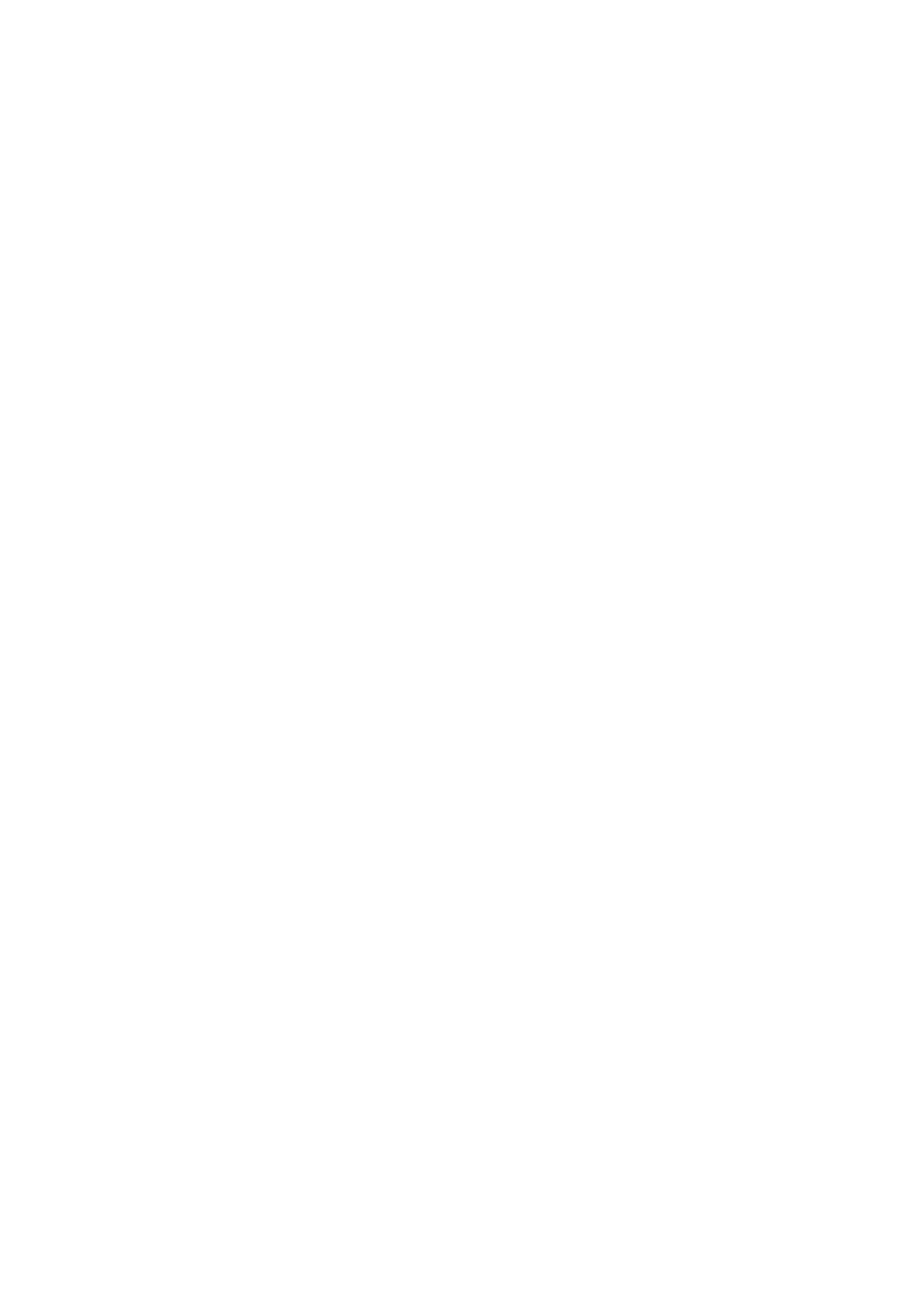




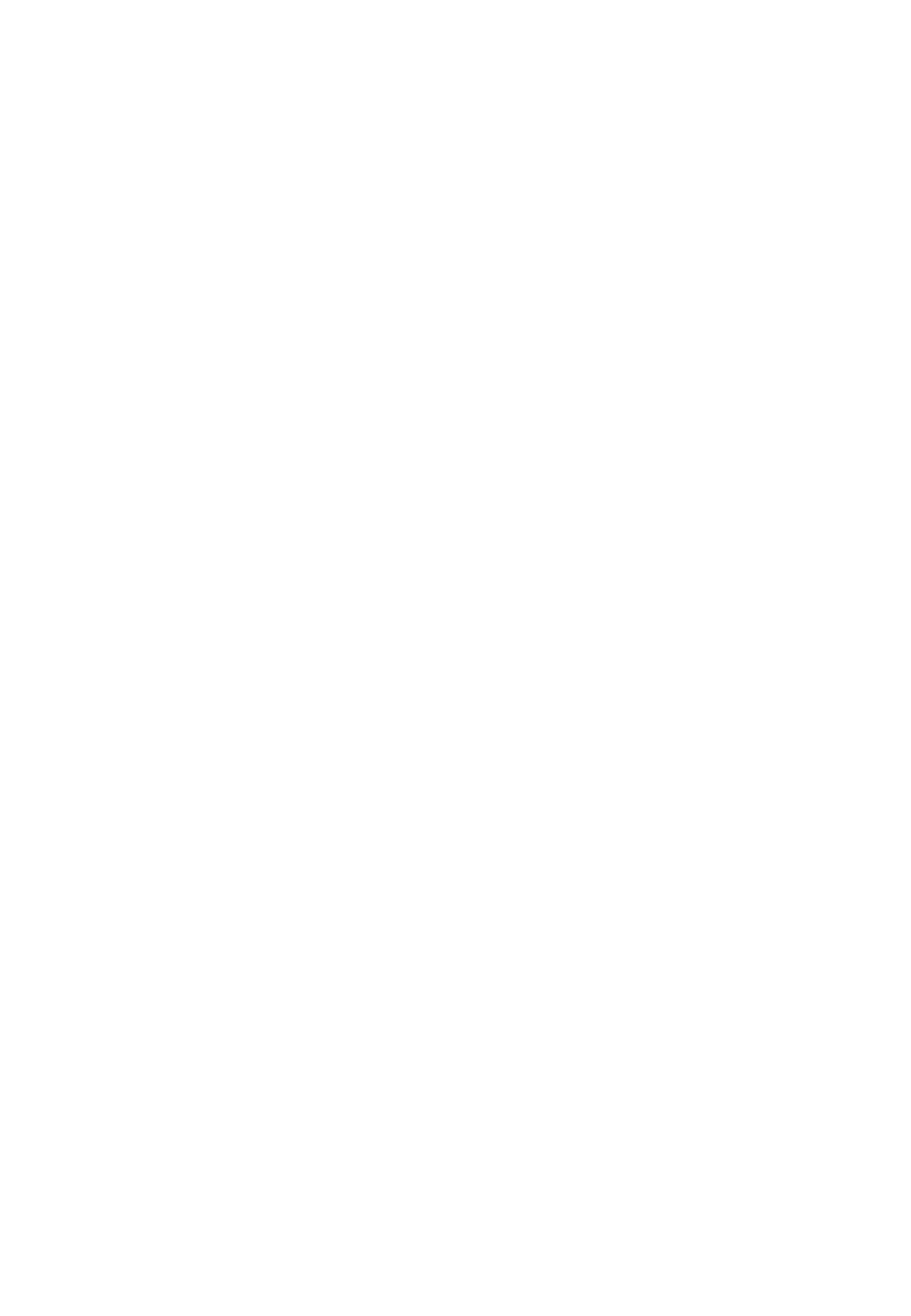




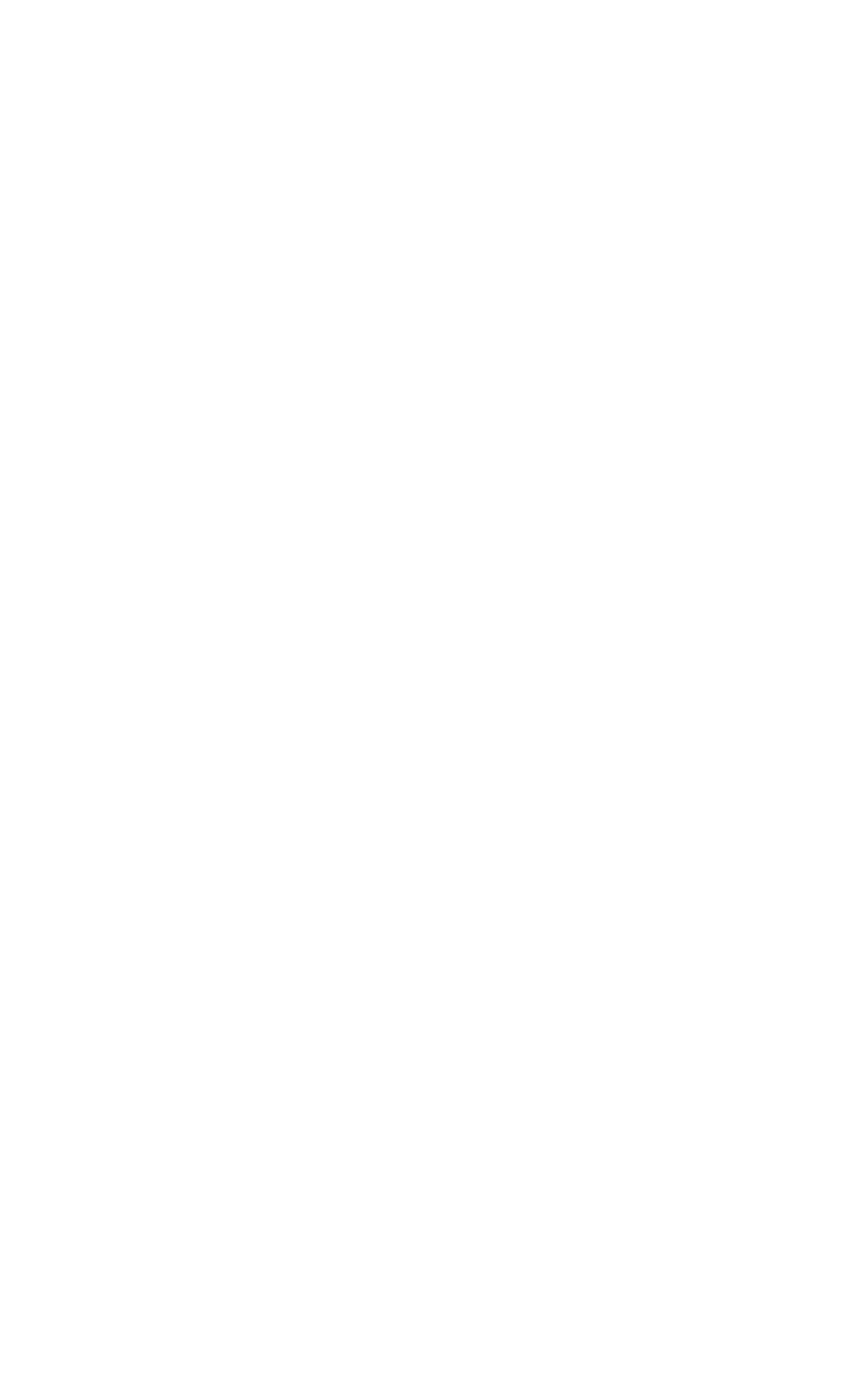




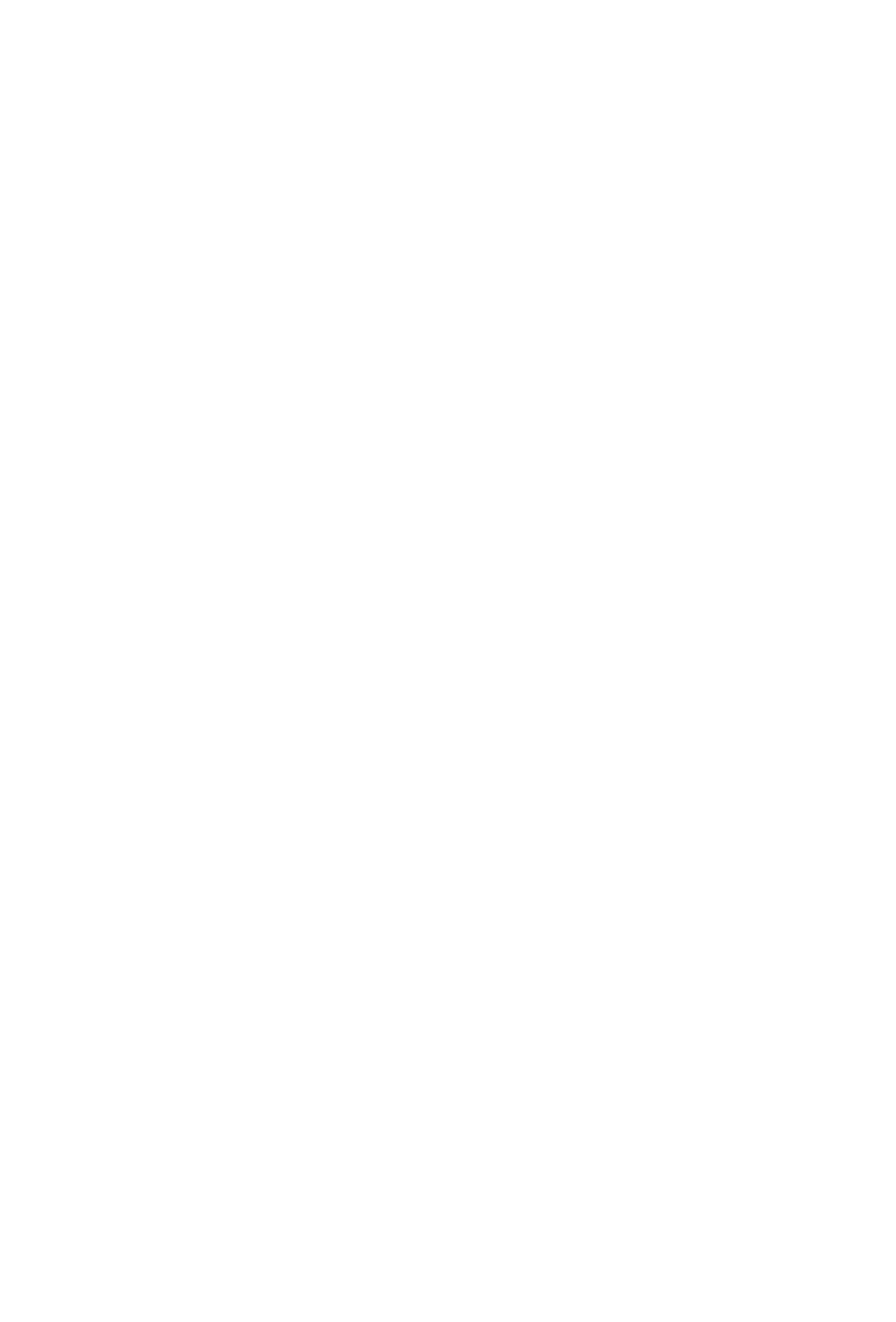




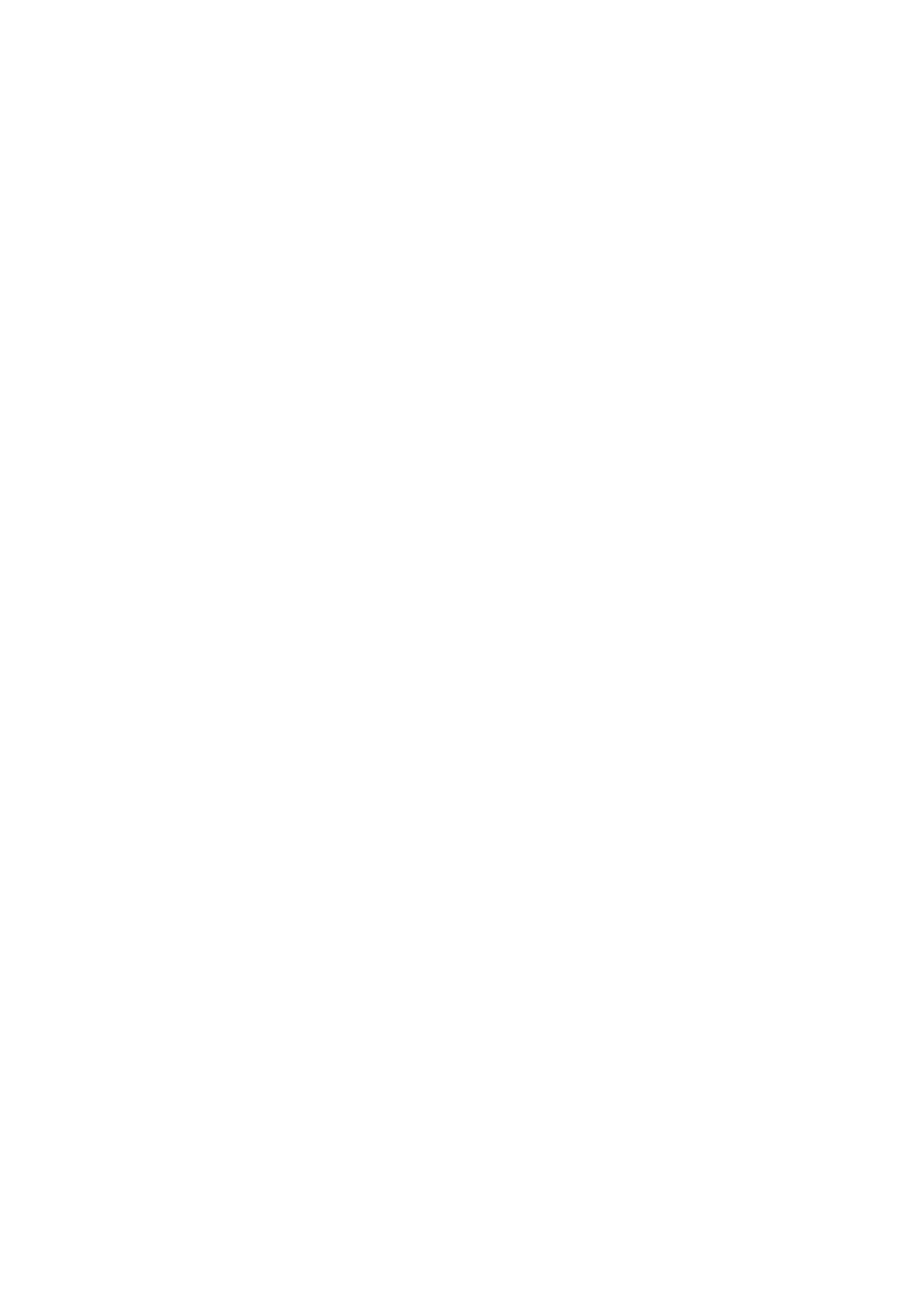




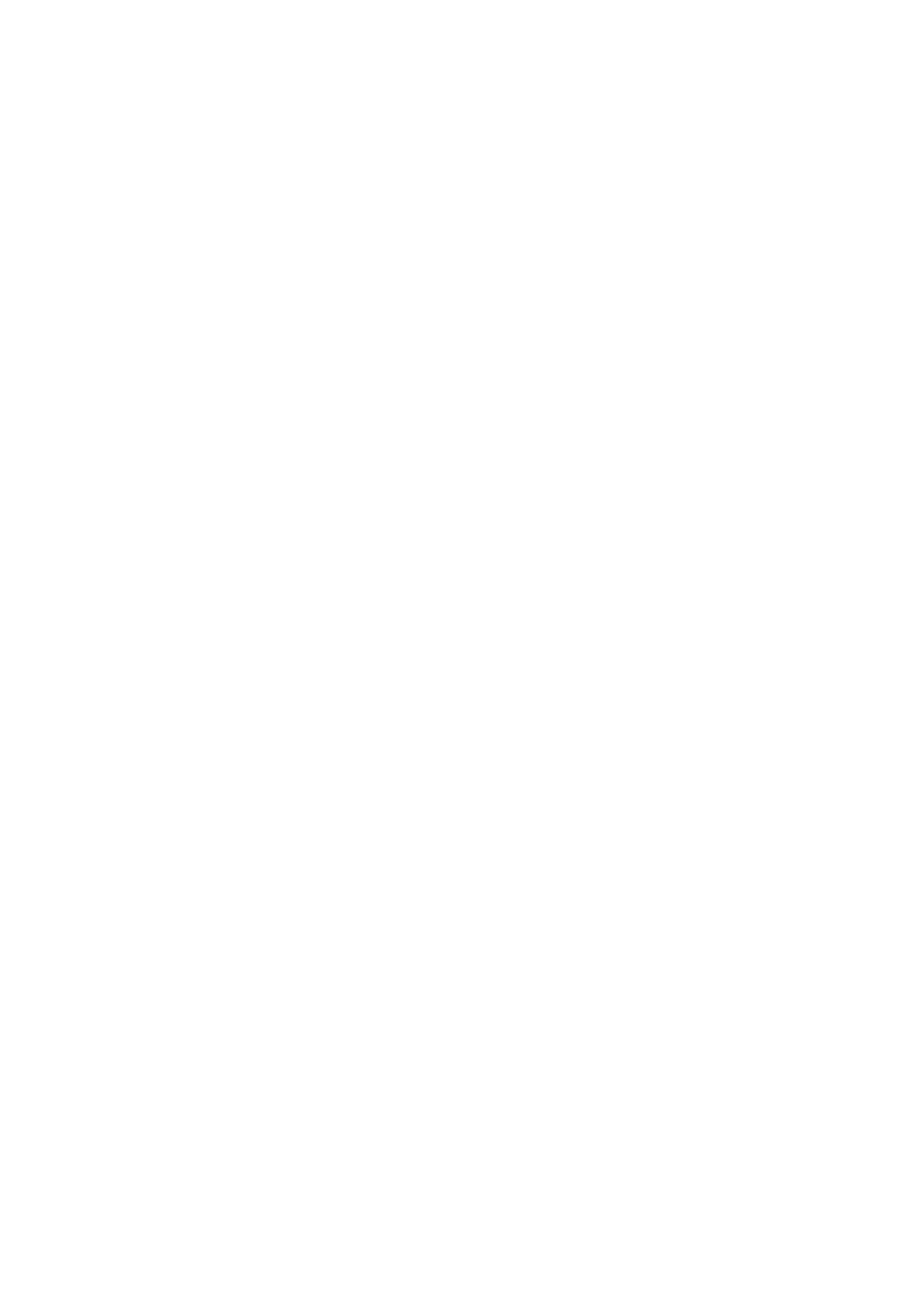




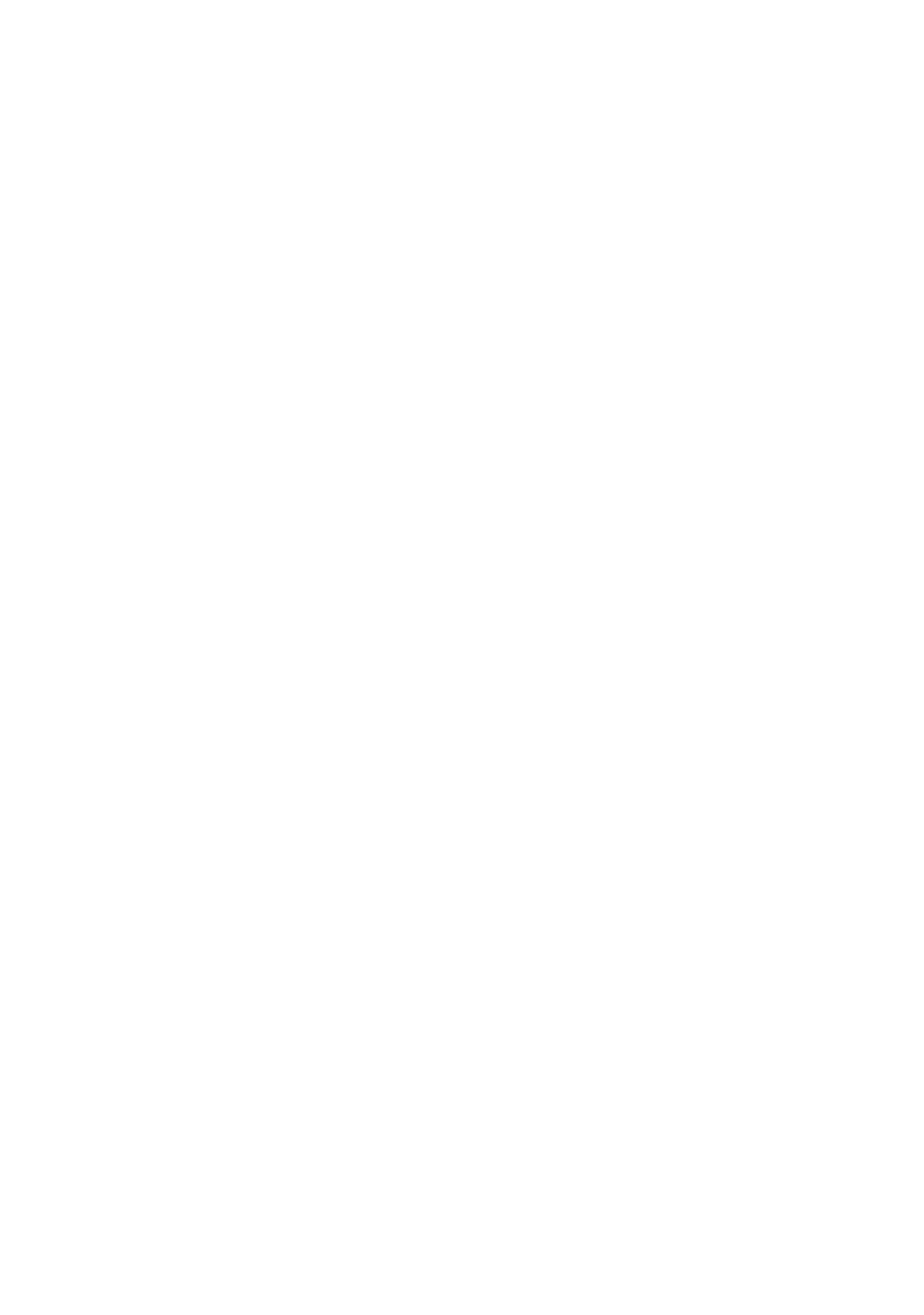




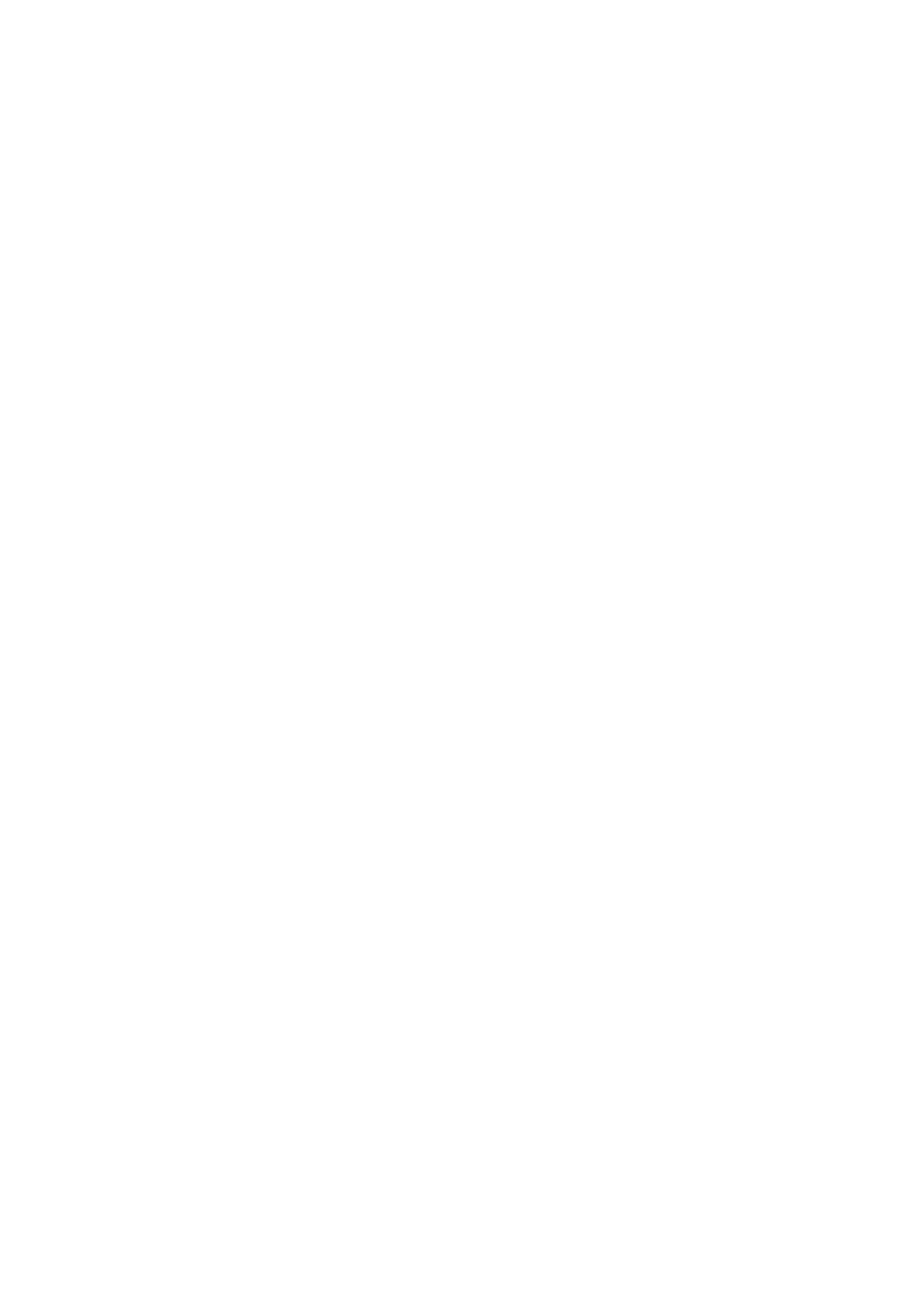




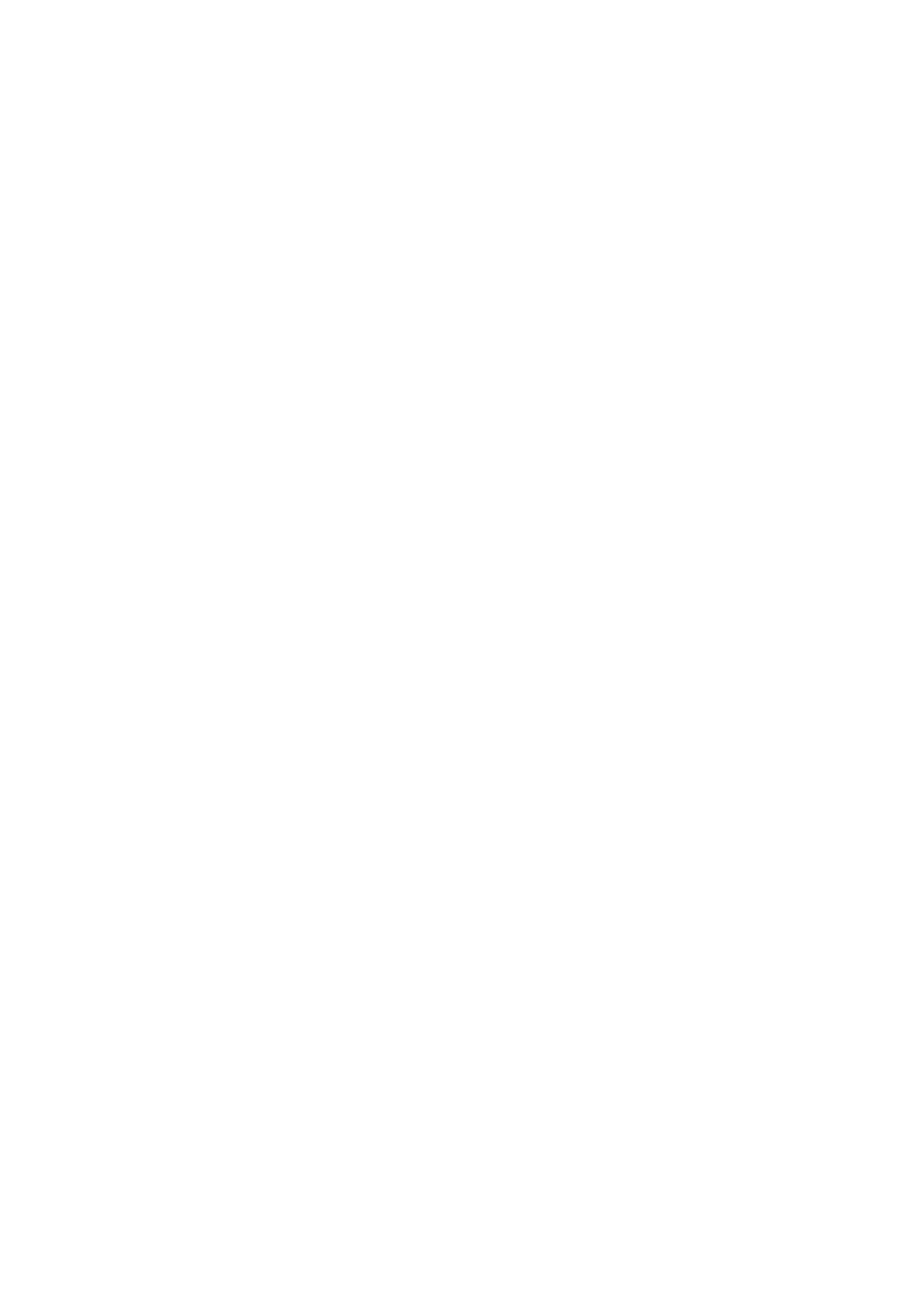




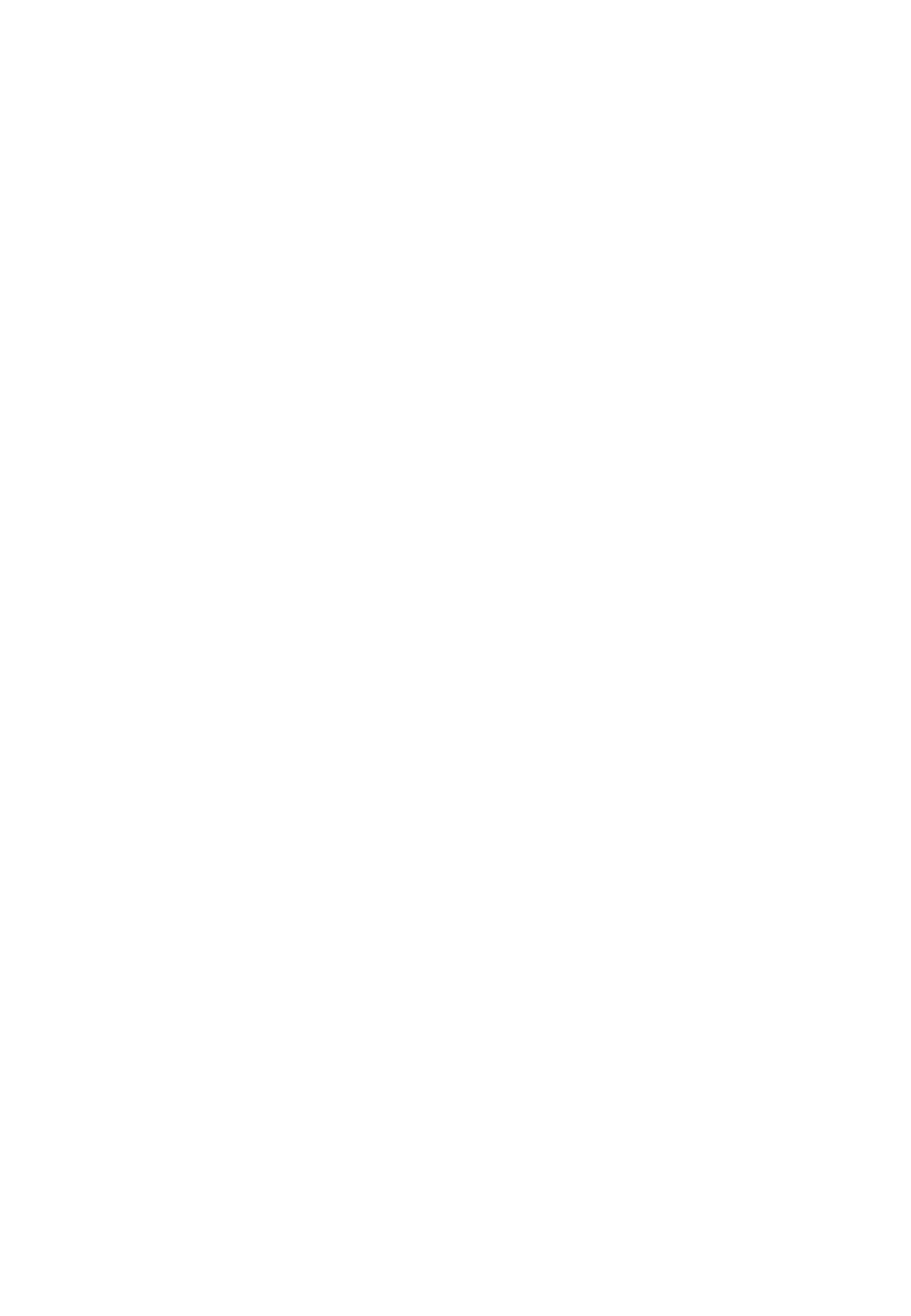




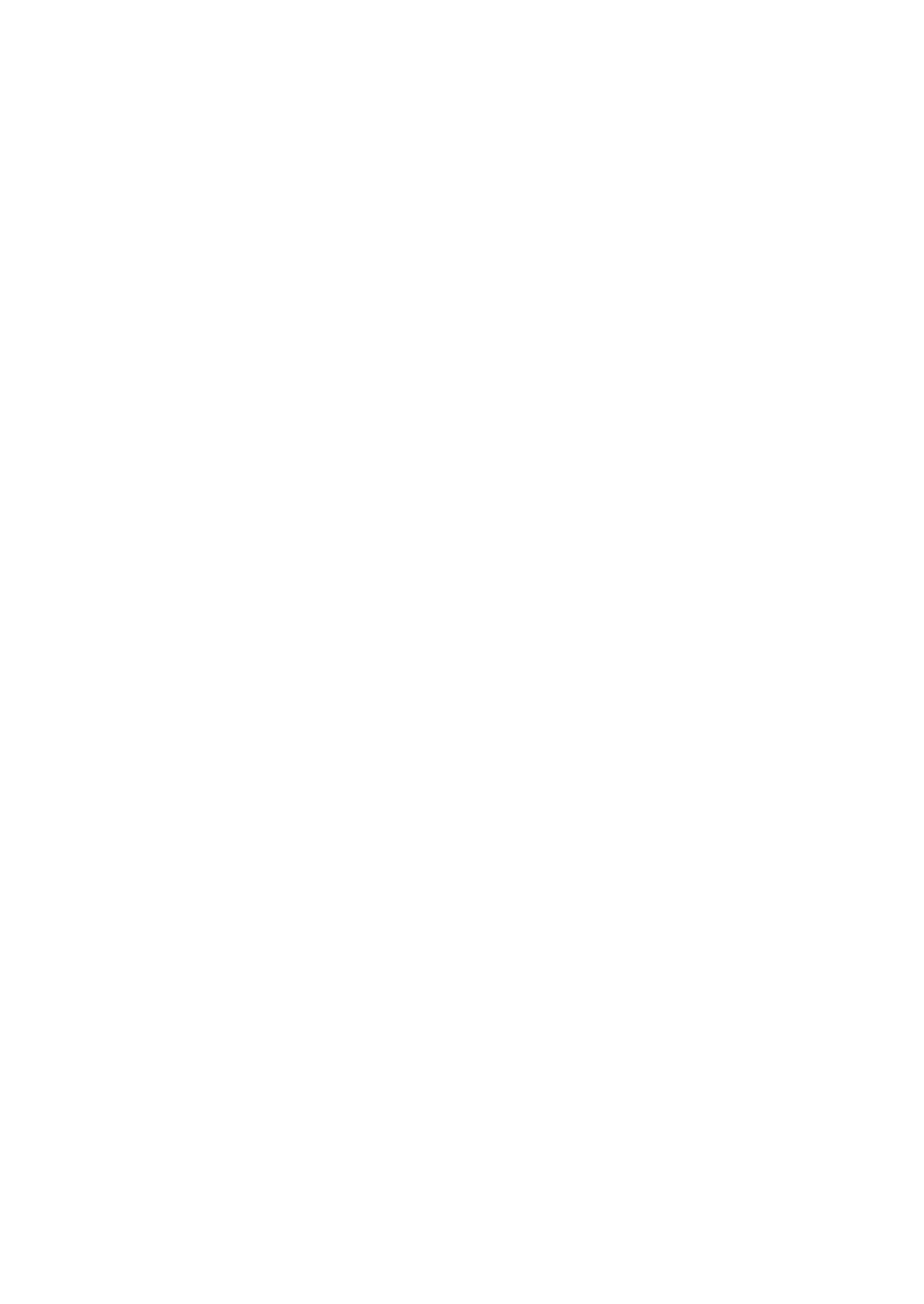




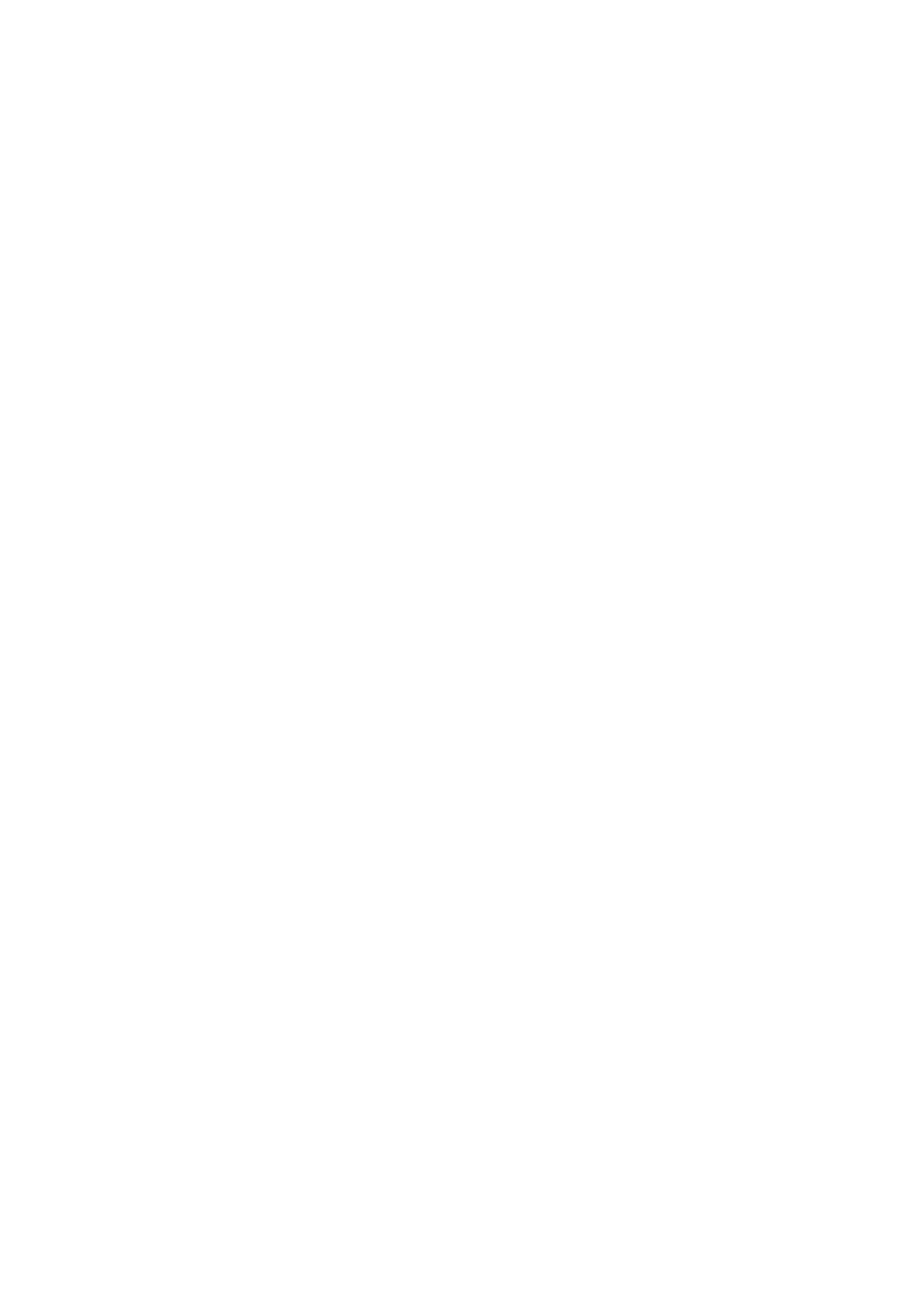




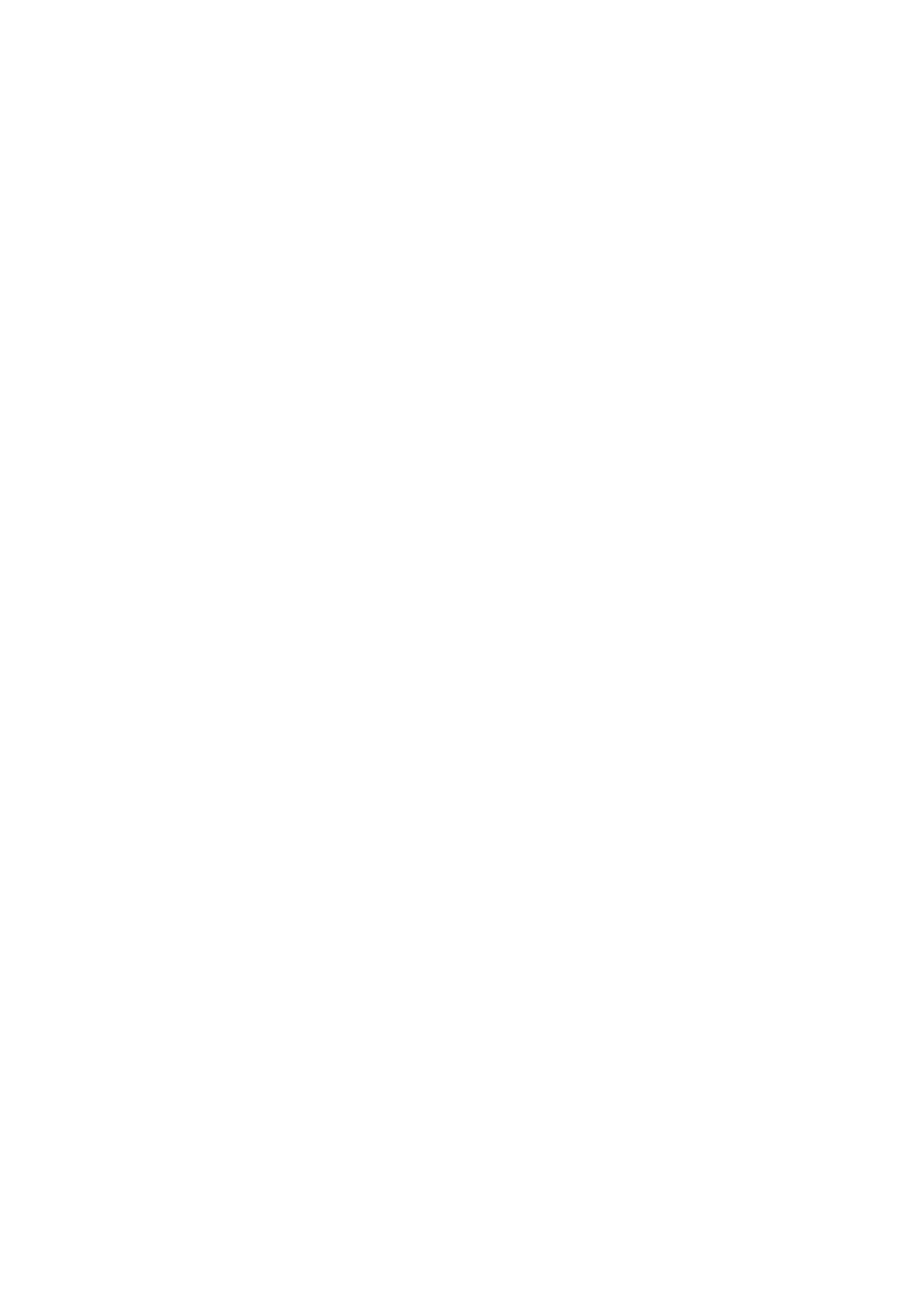




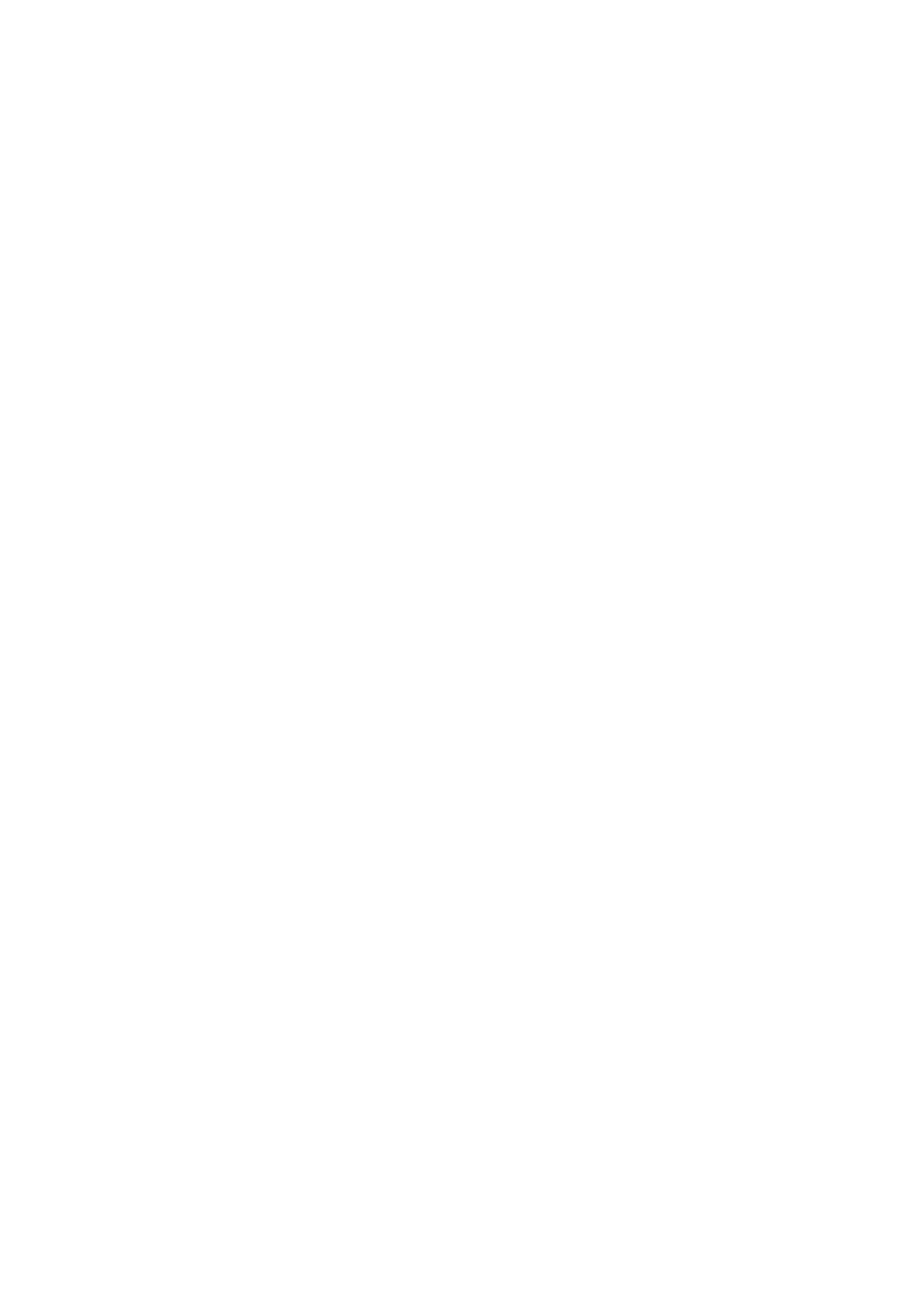




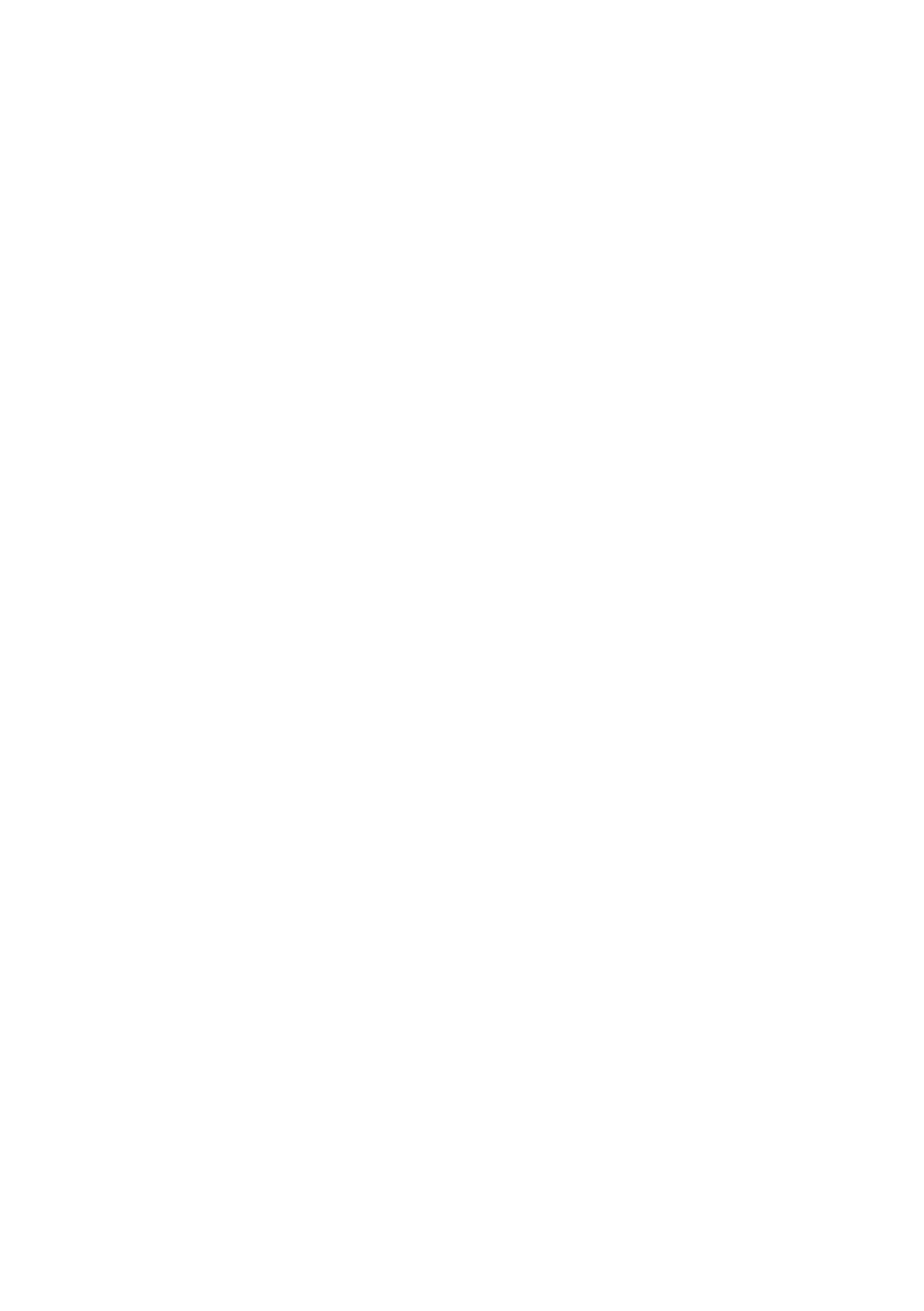




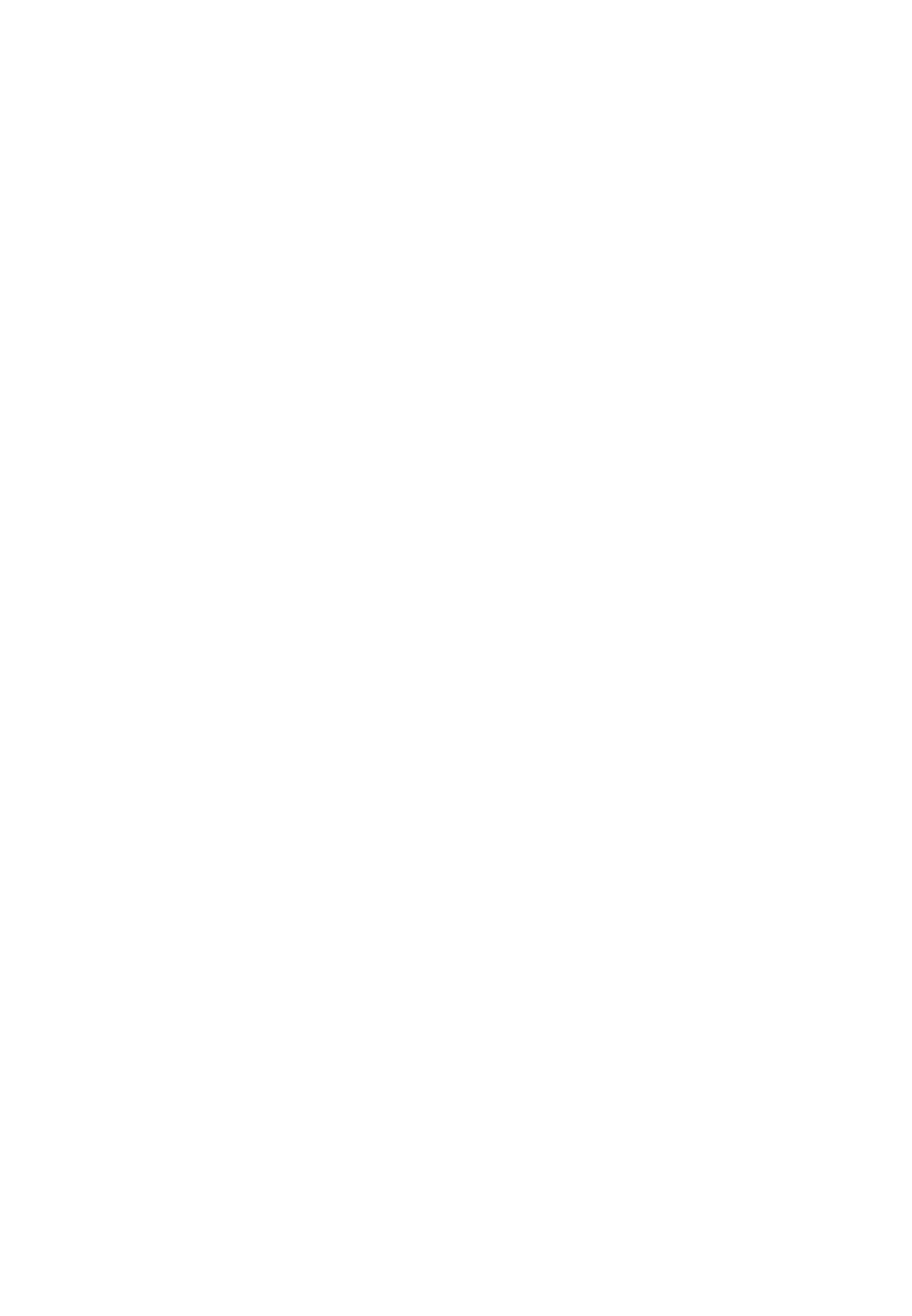




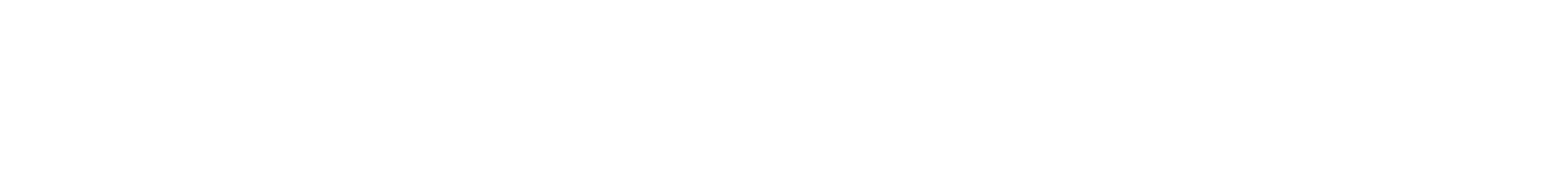

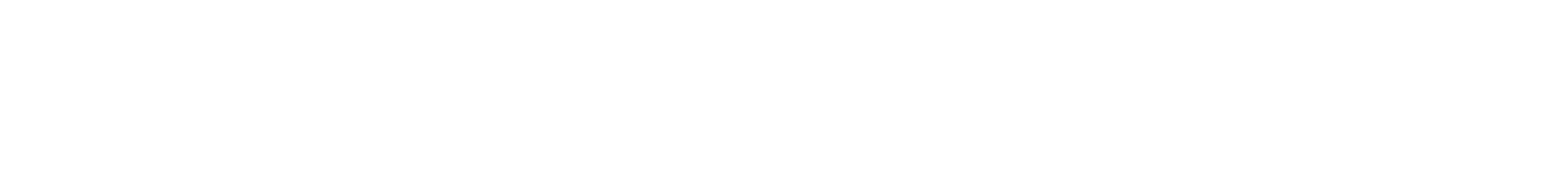

客

蕶

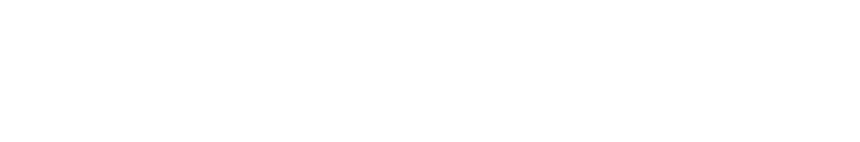

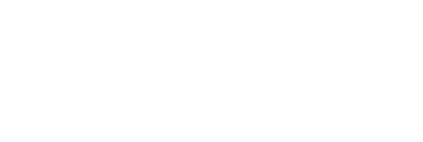

莎

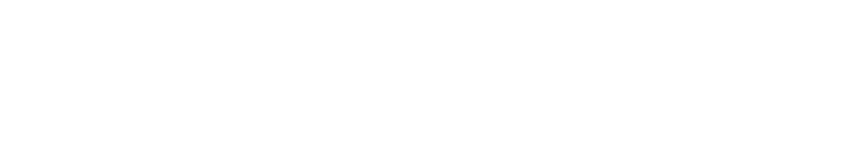

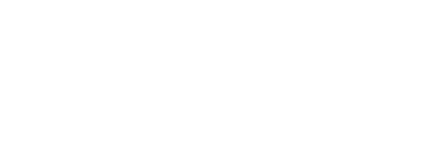

$\begin{array}{lll} & & \\ 0 & 0 & 0 \\ 0 & i\end{array}$

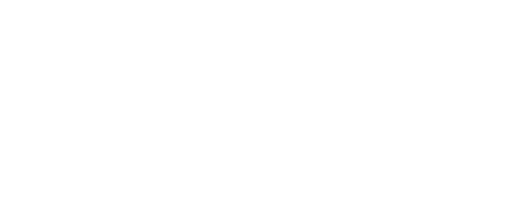

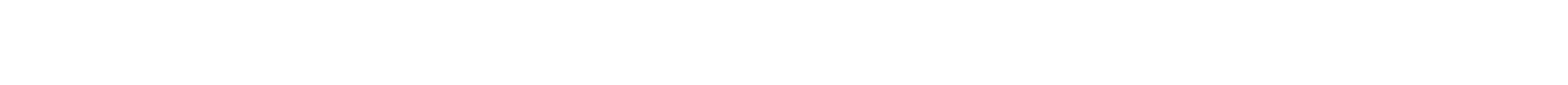

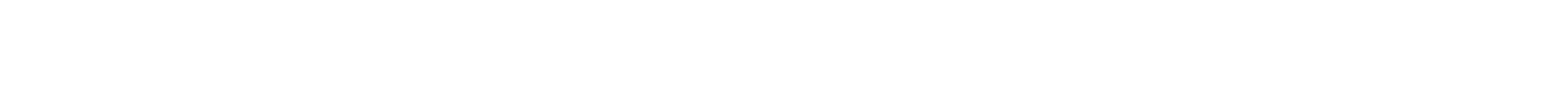

原

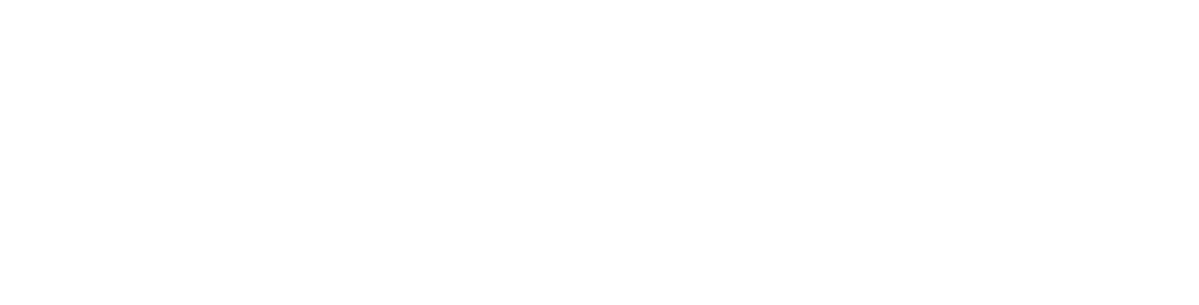
衰蒌 


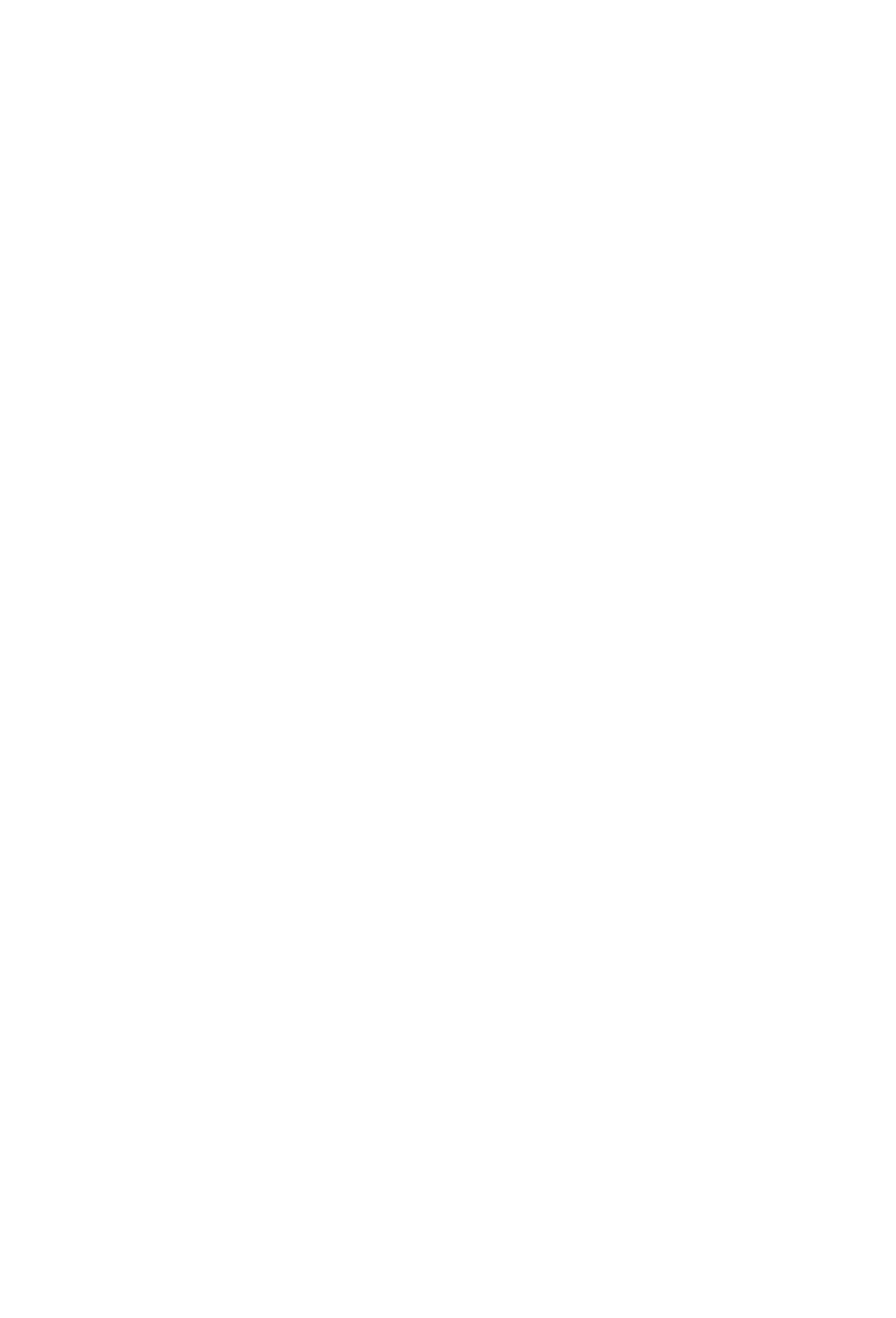




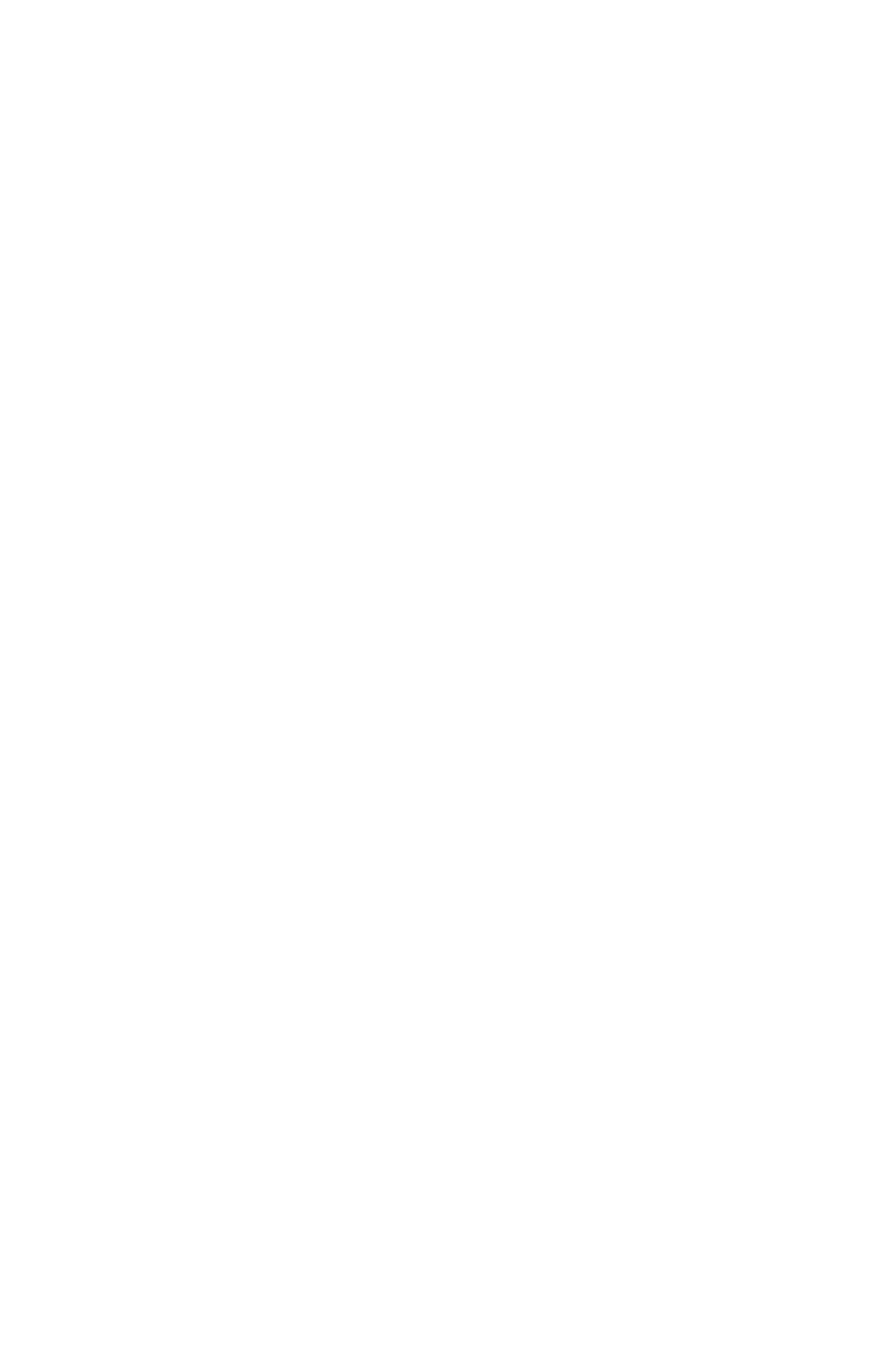

Tables 237 


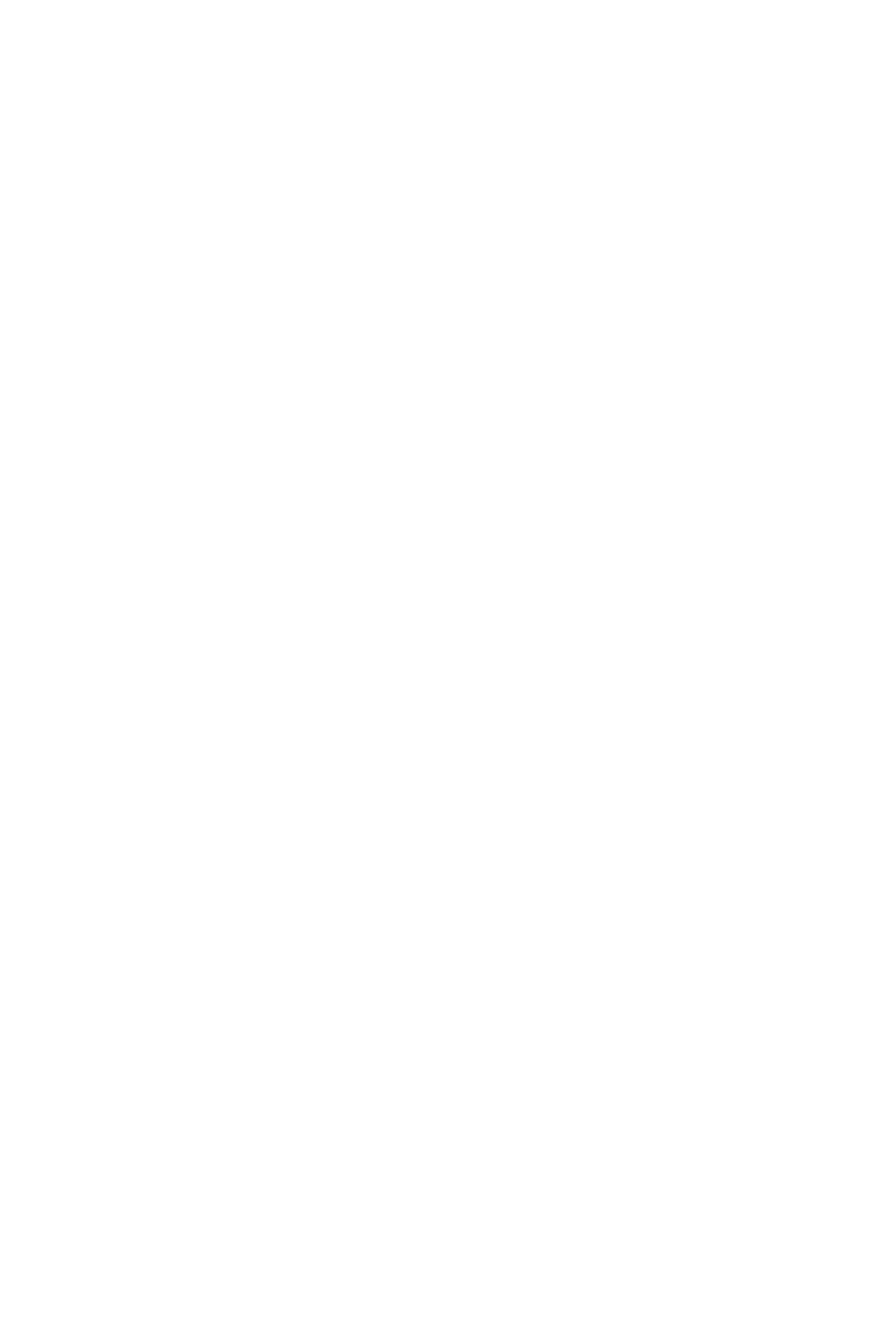




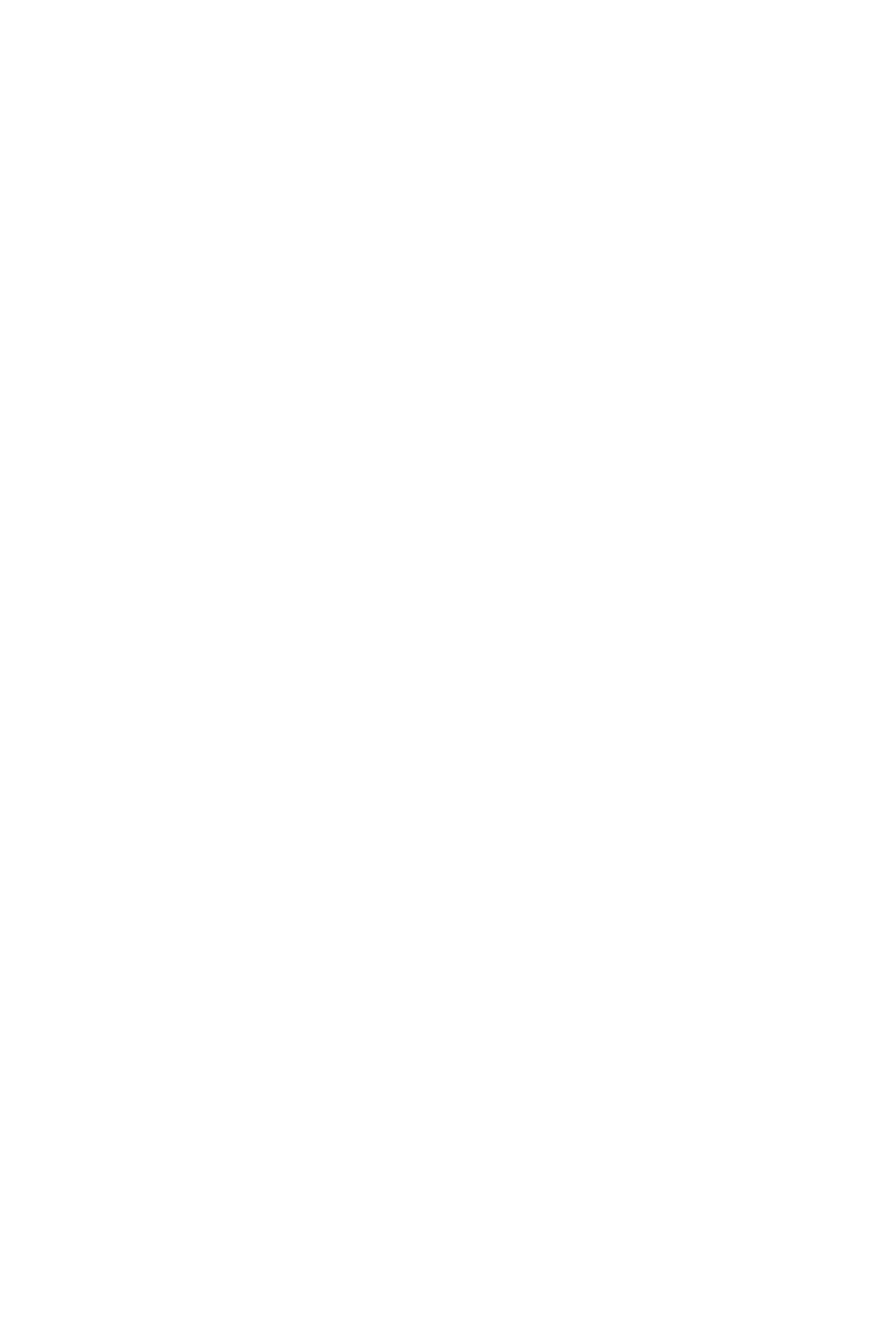




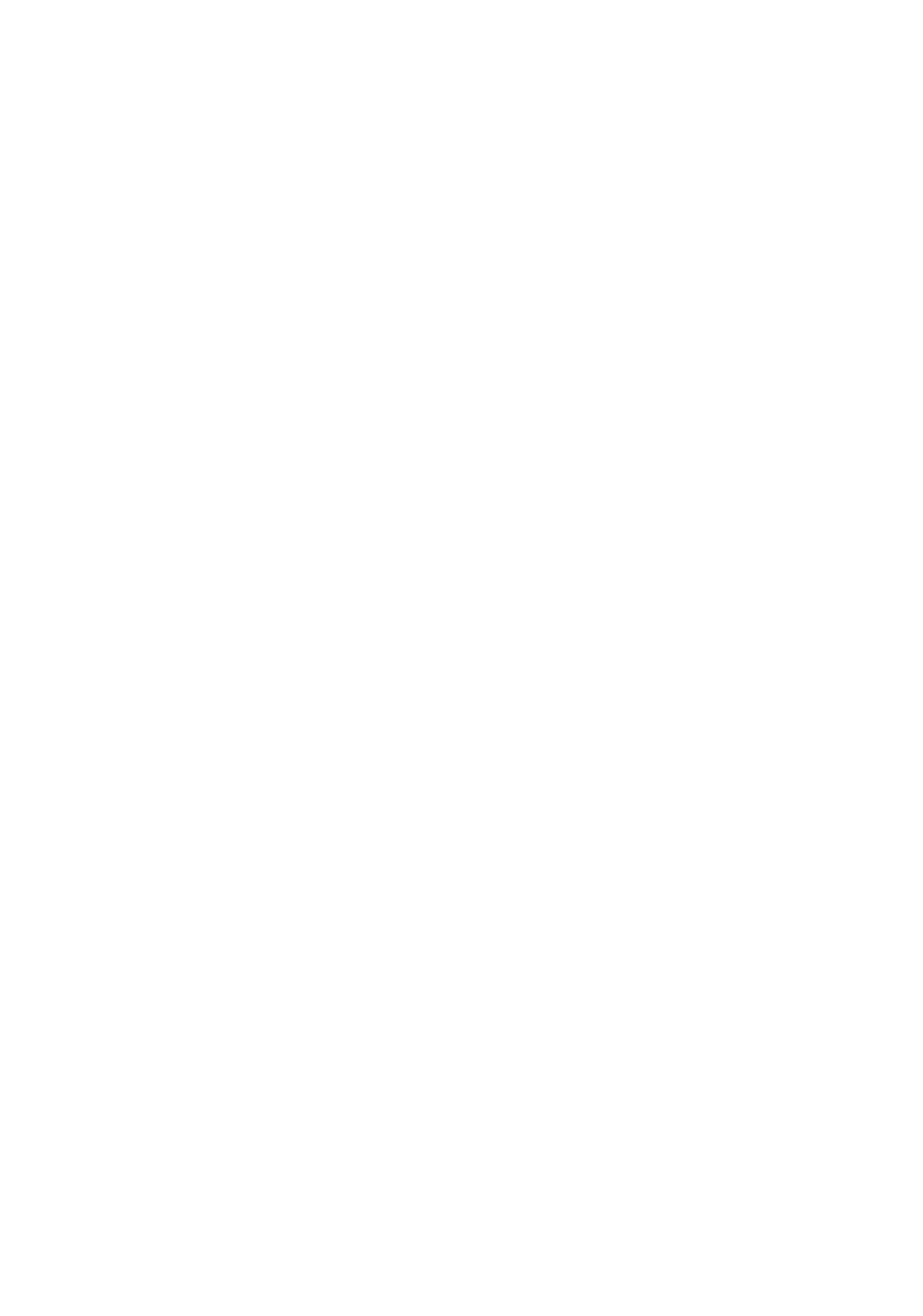




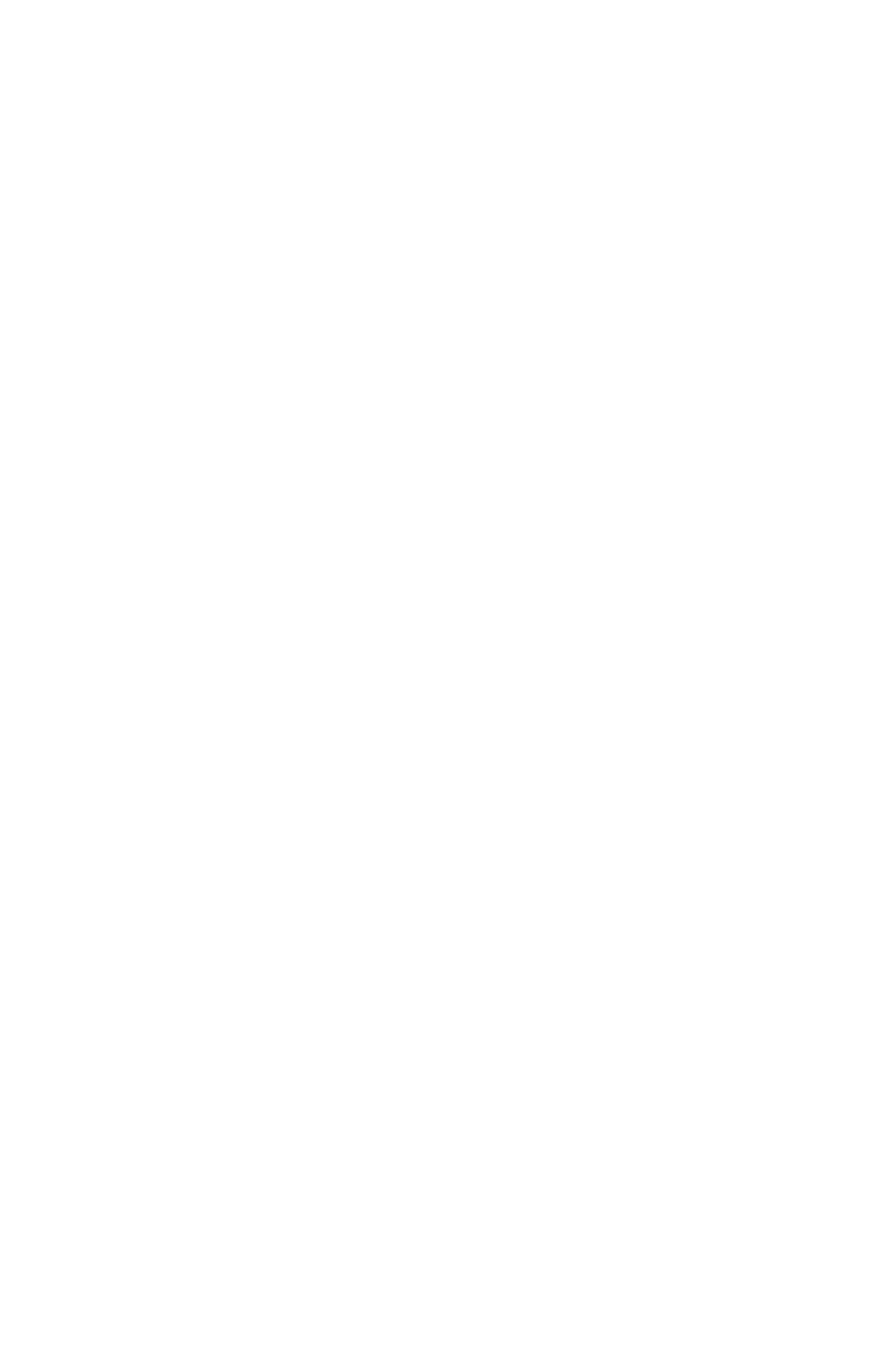




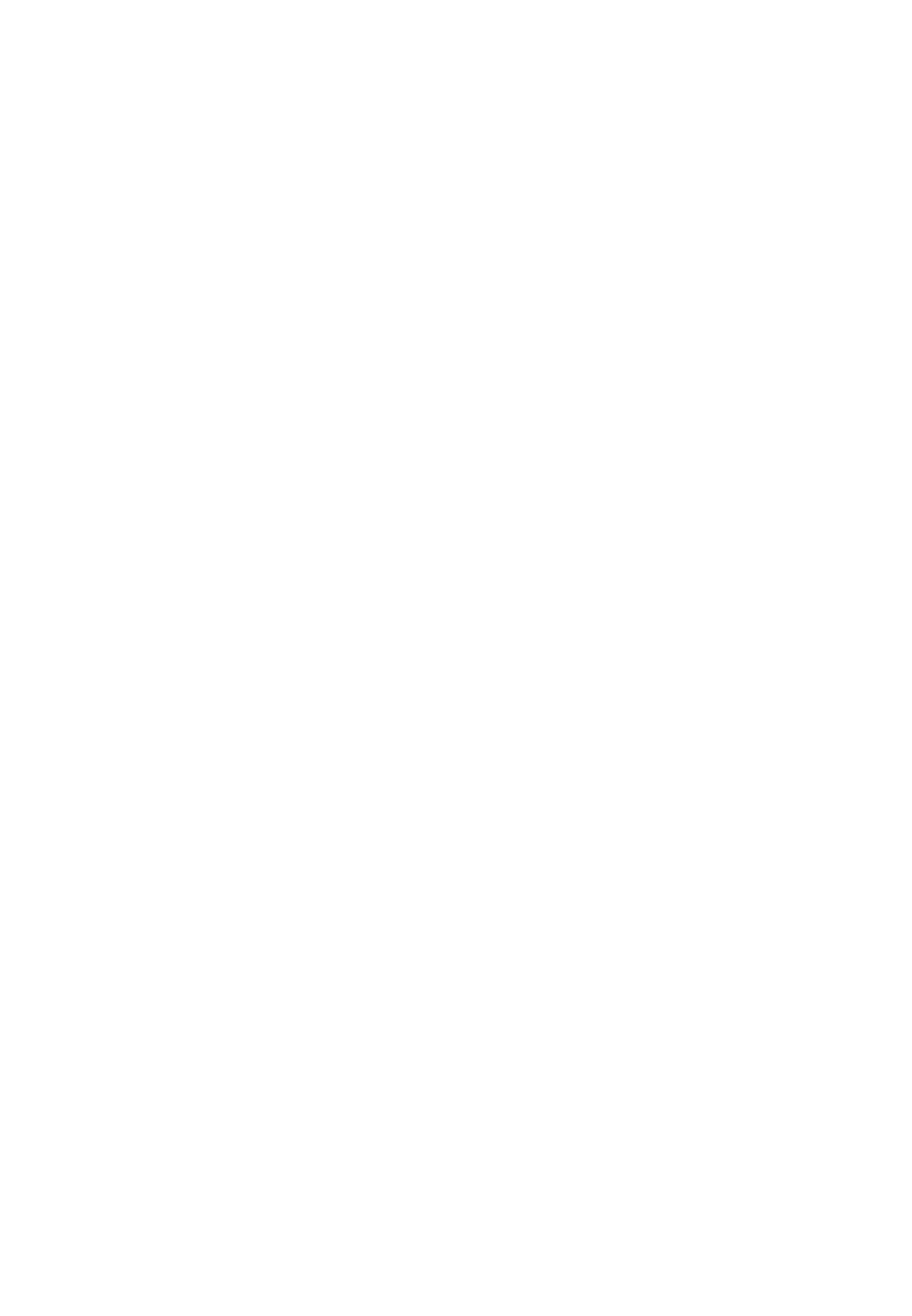




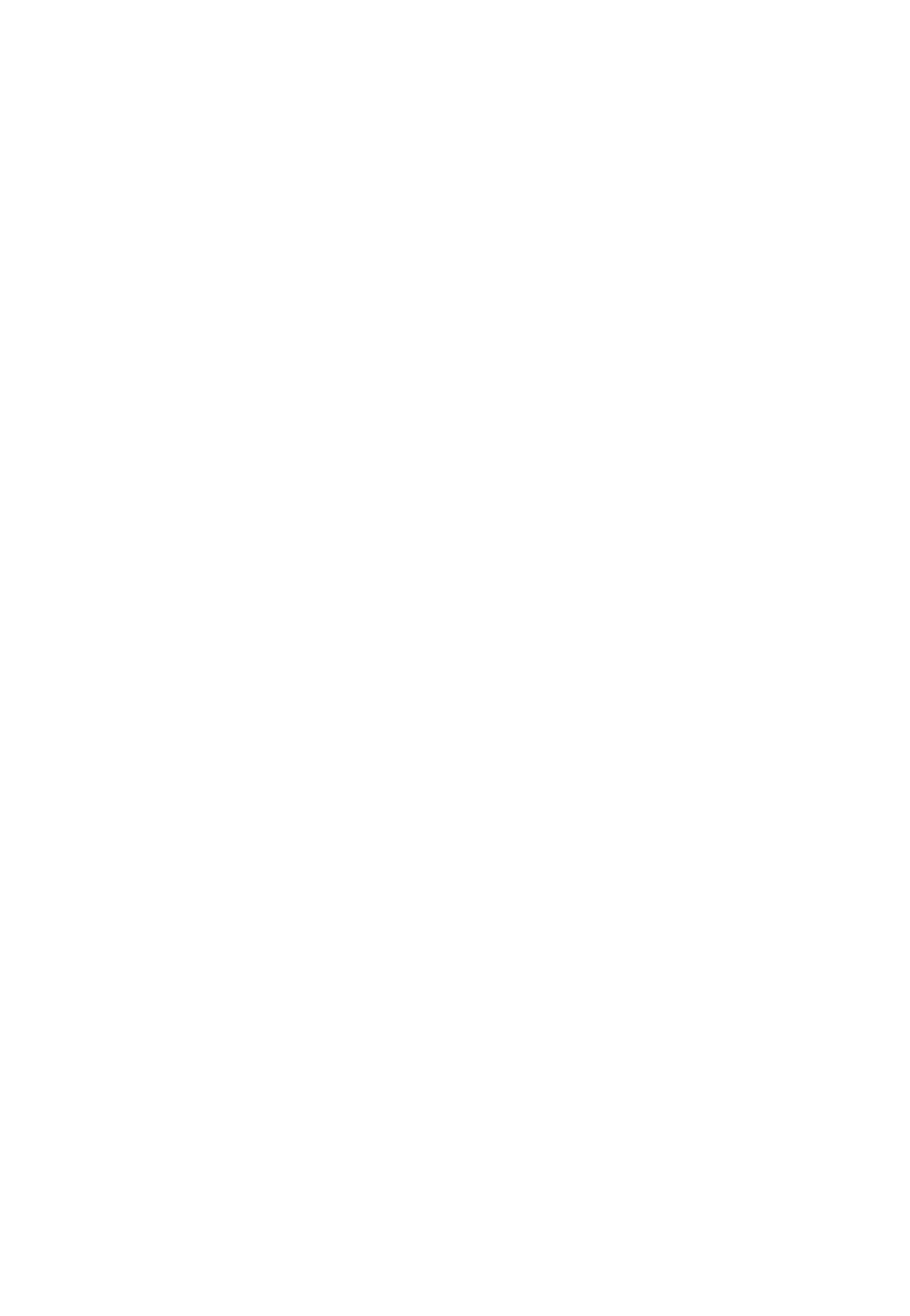




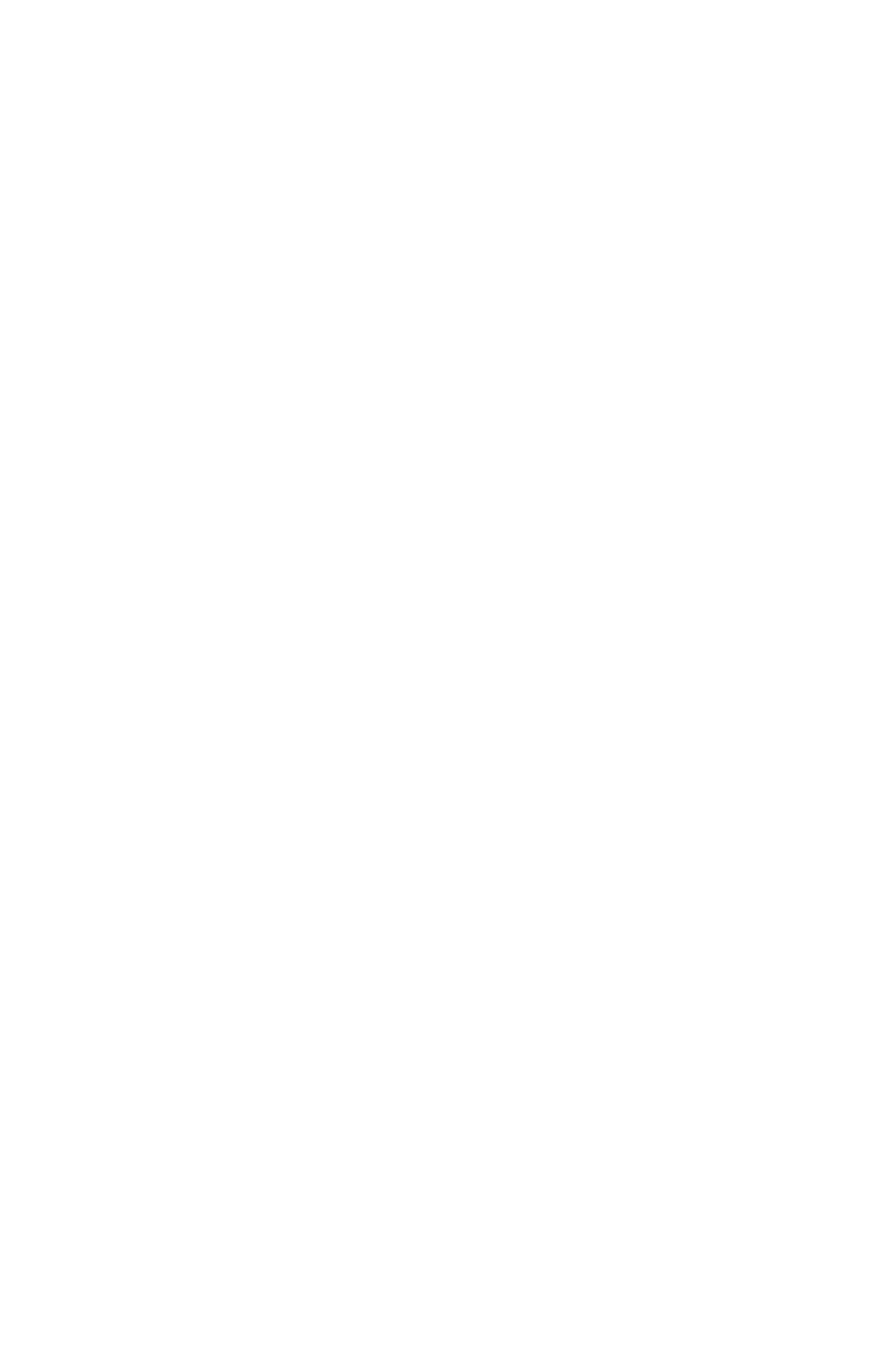




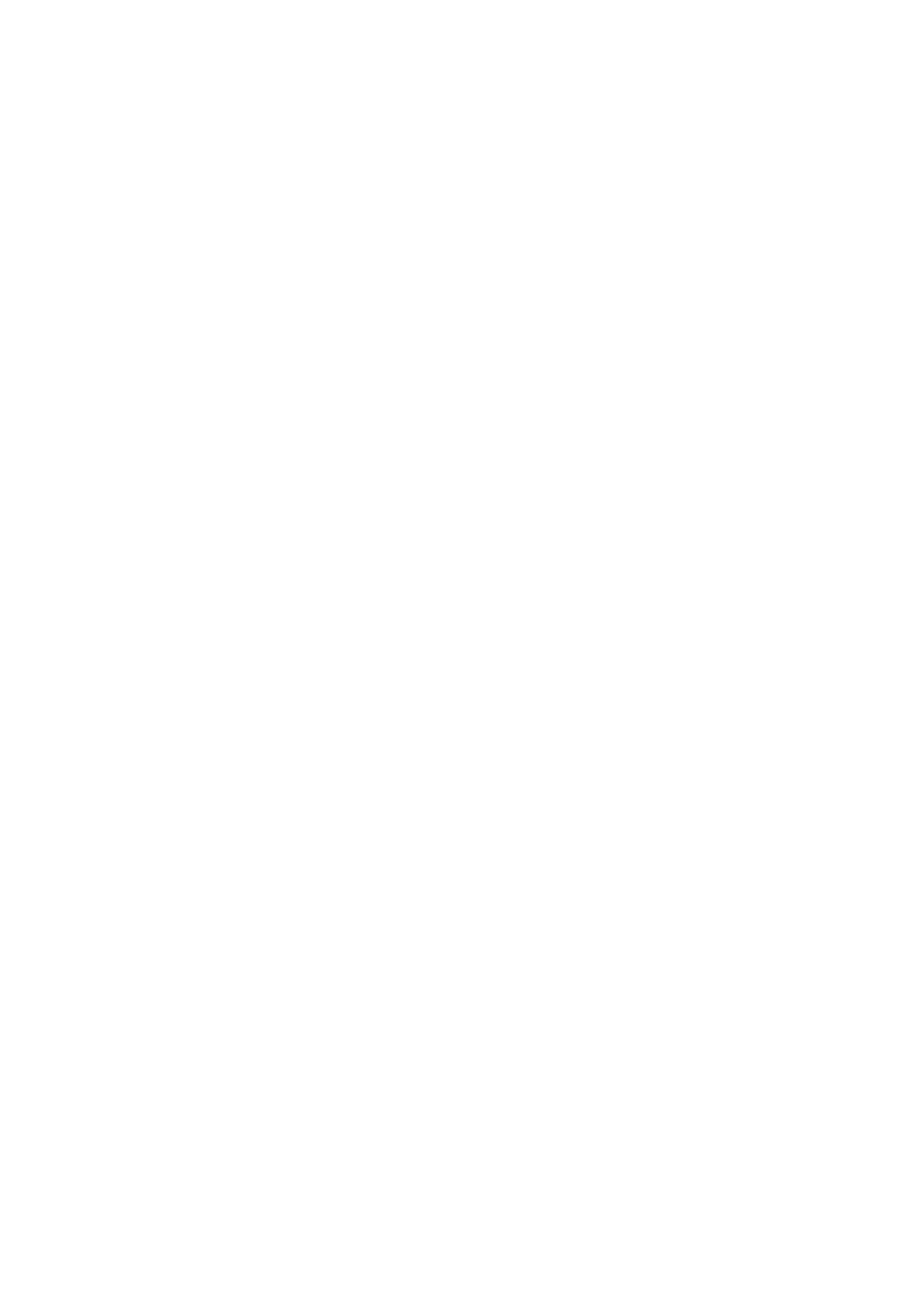




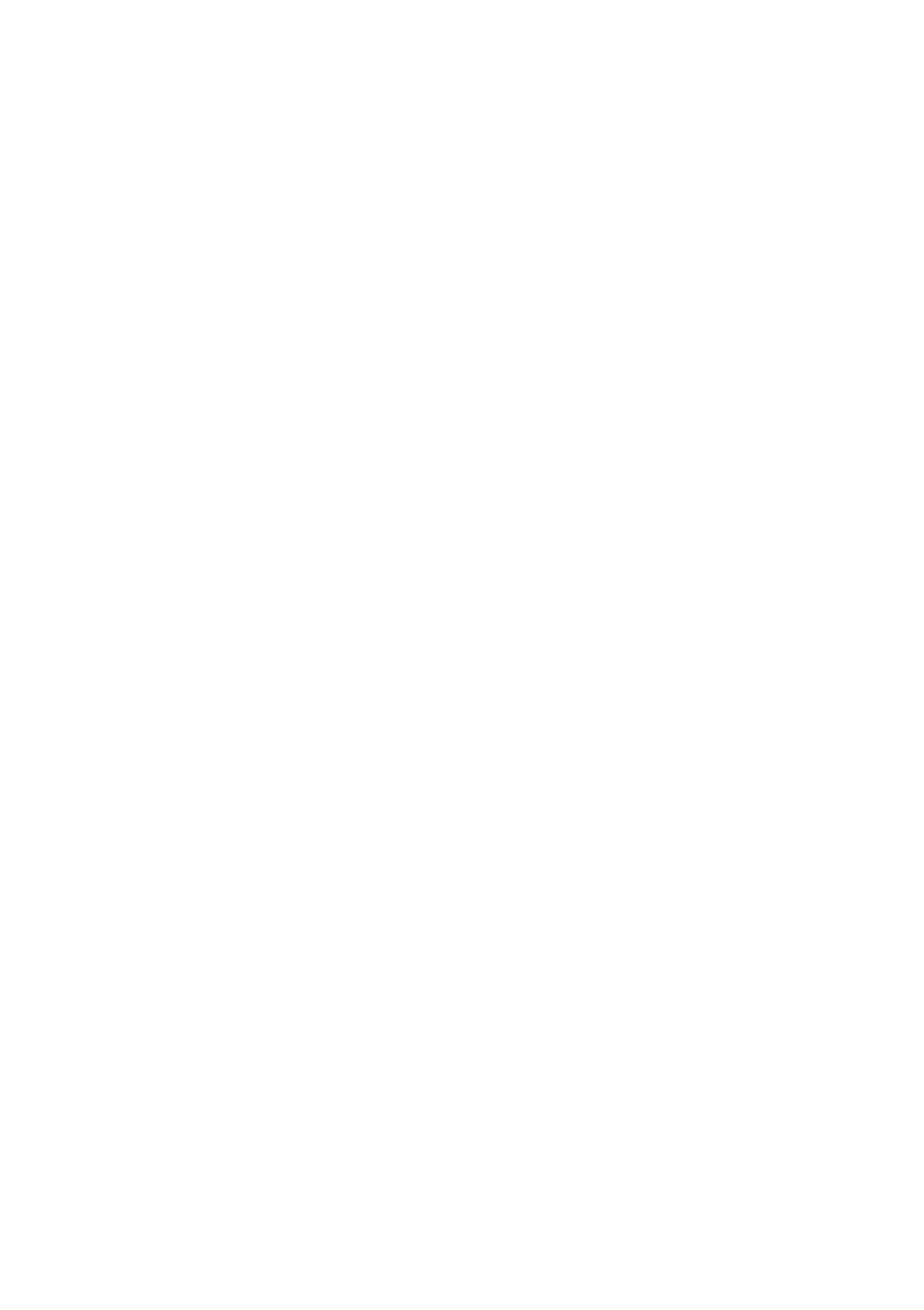




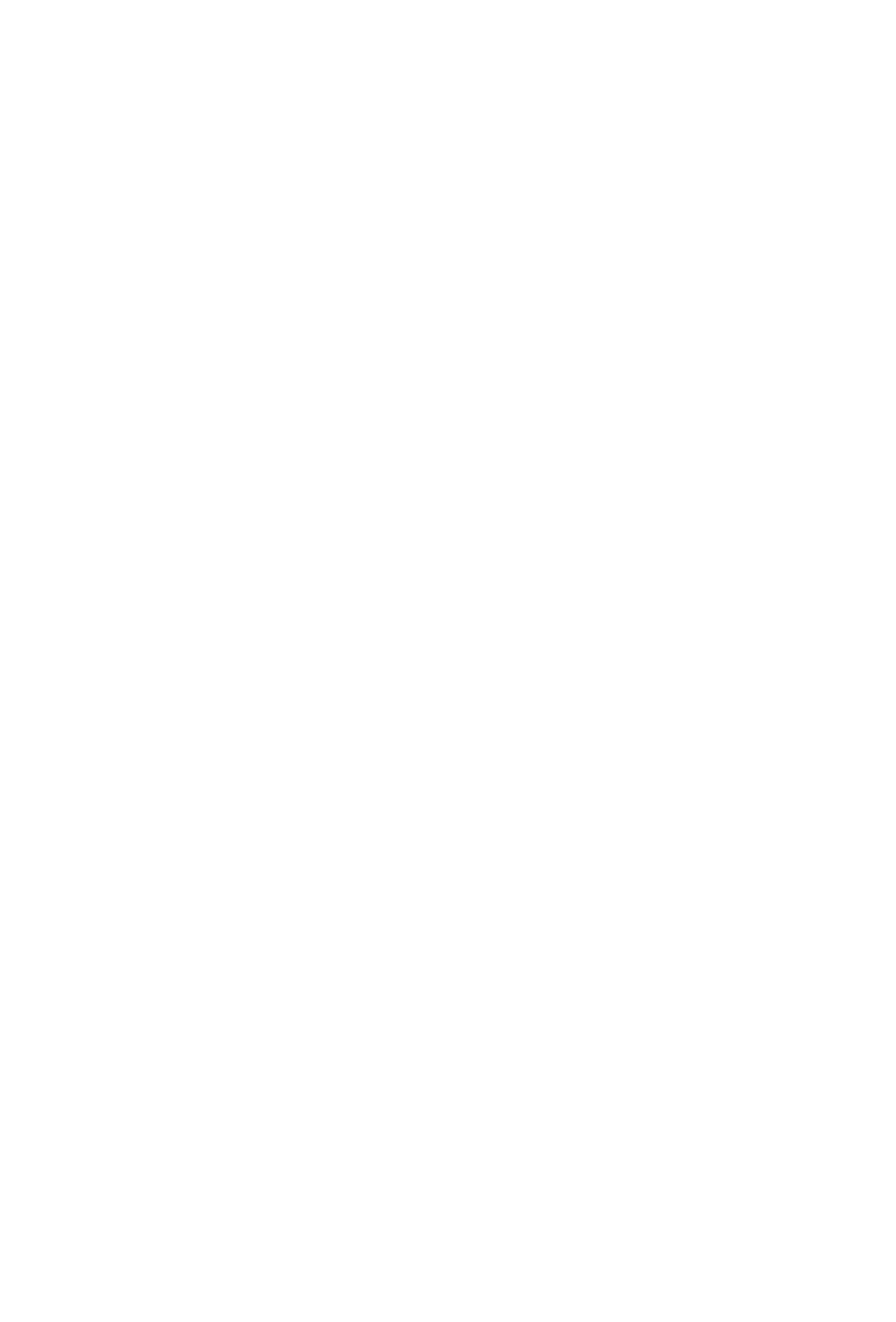




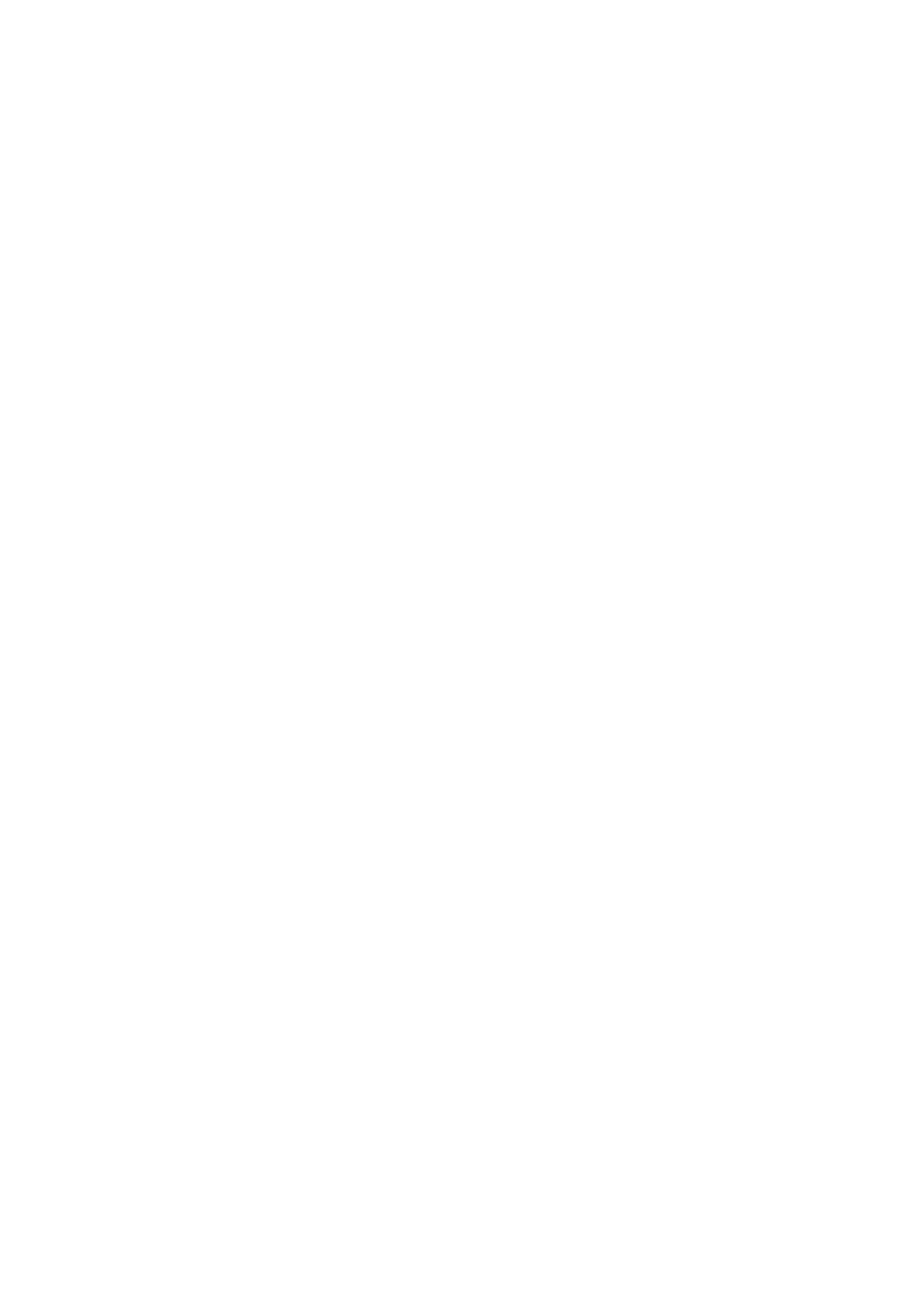




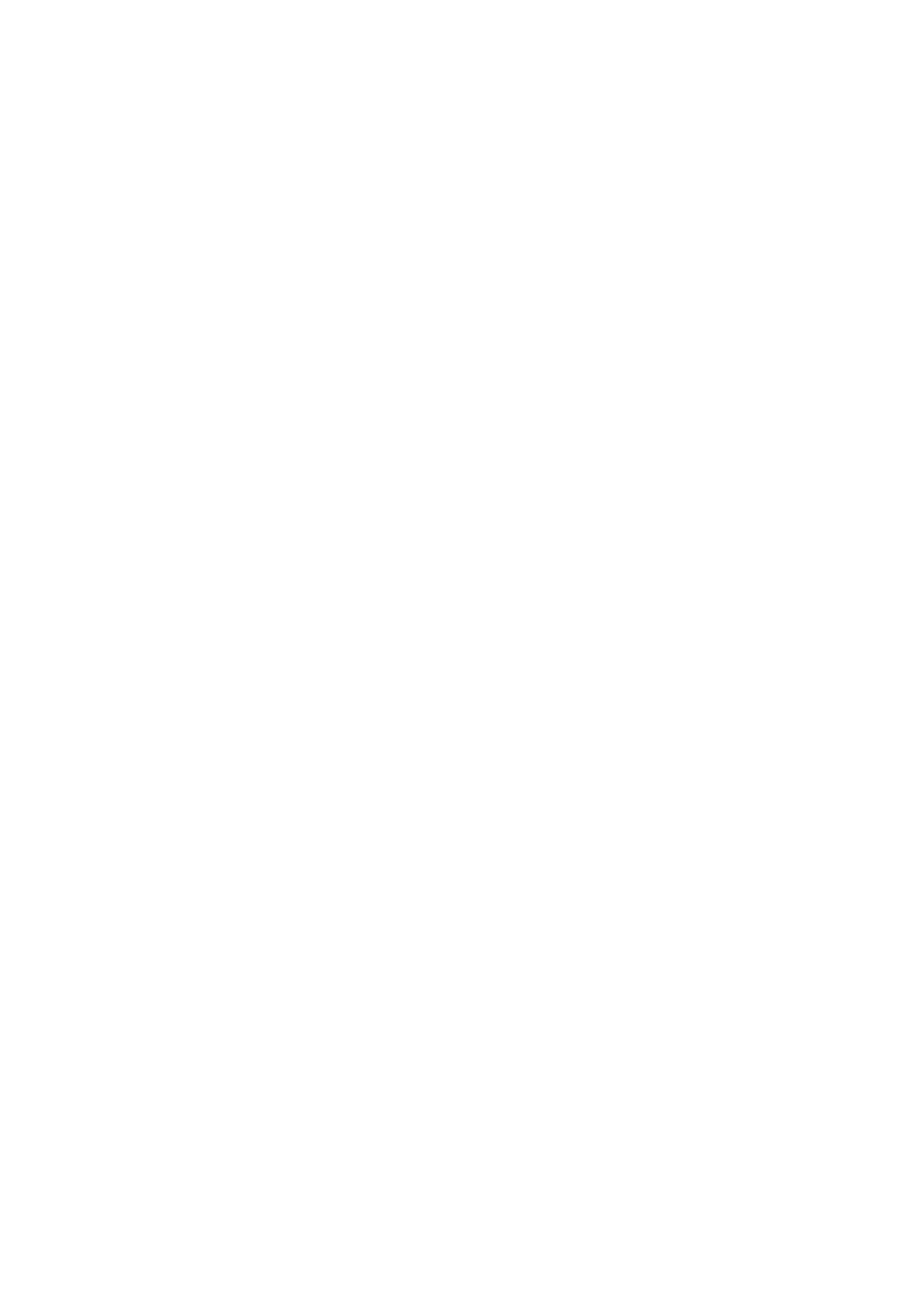




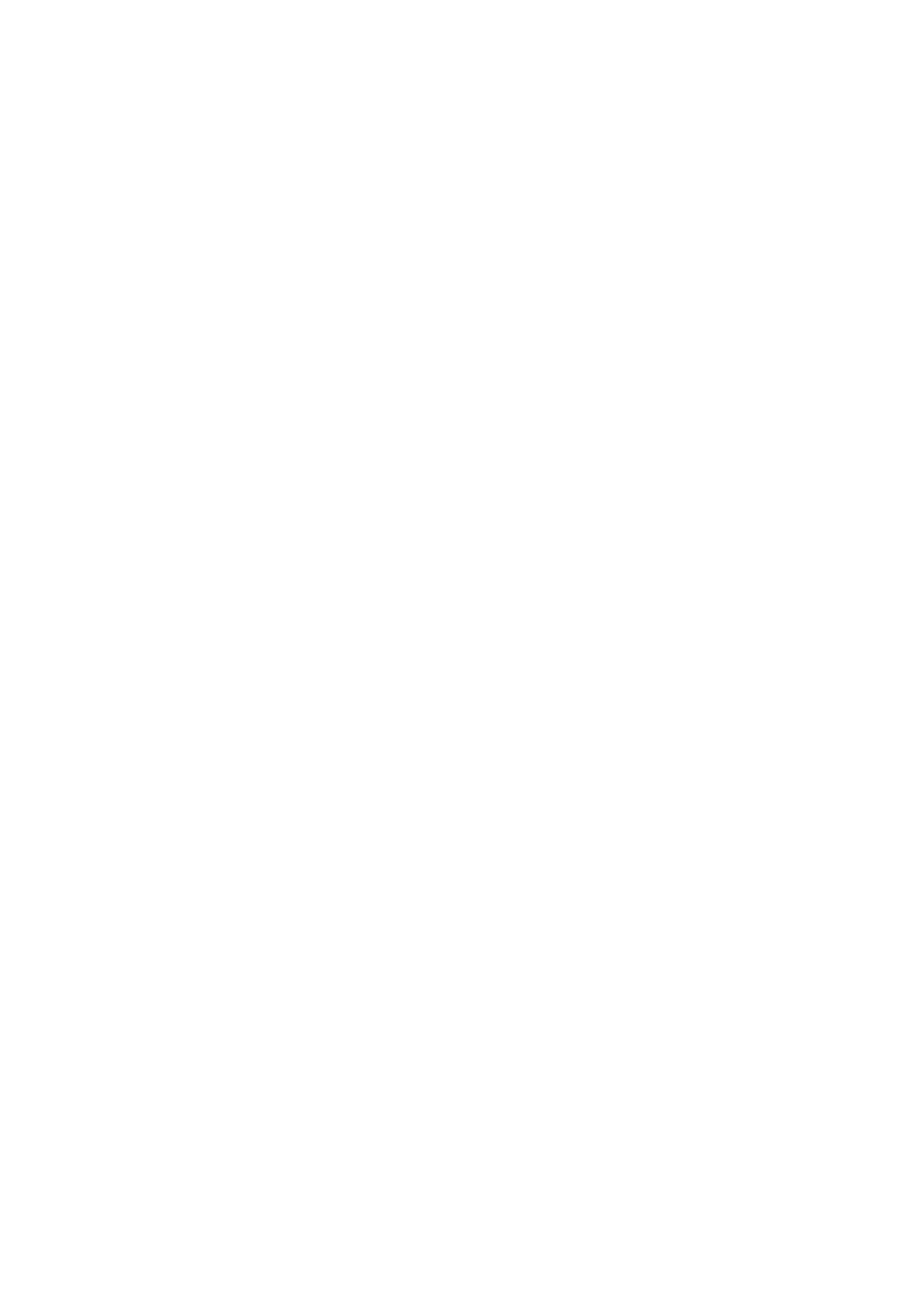




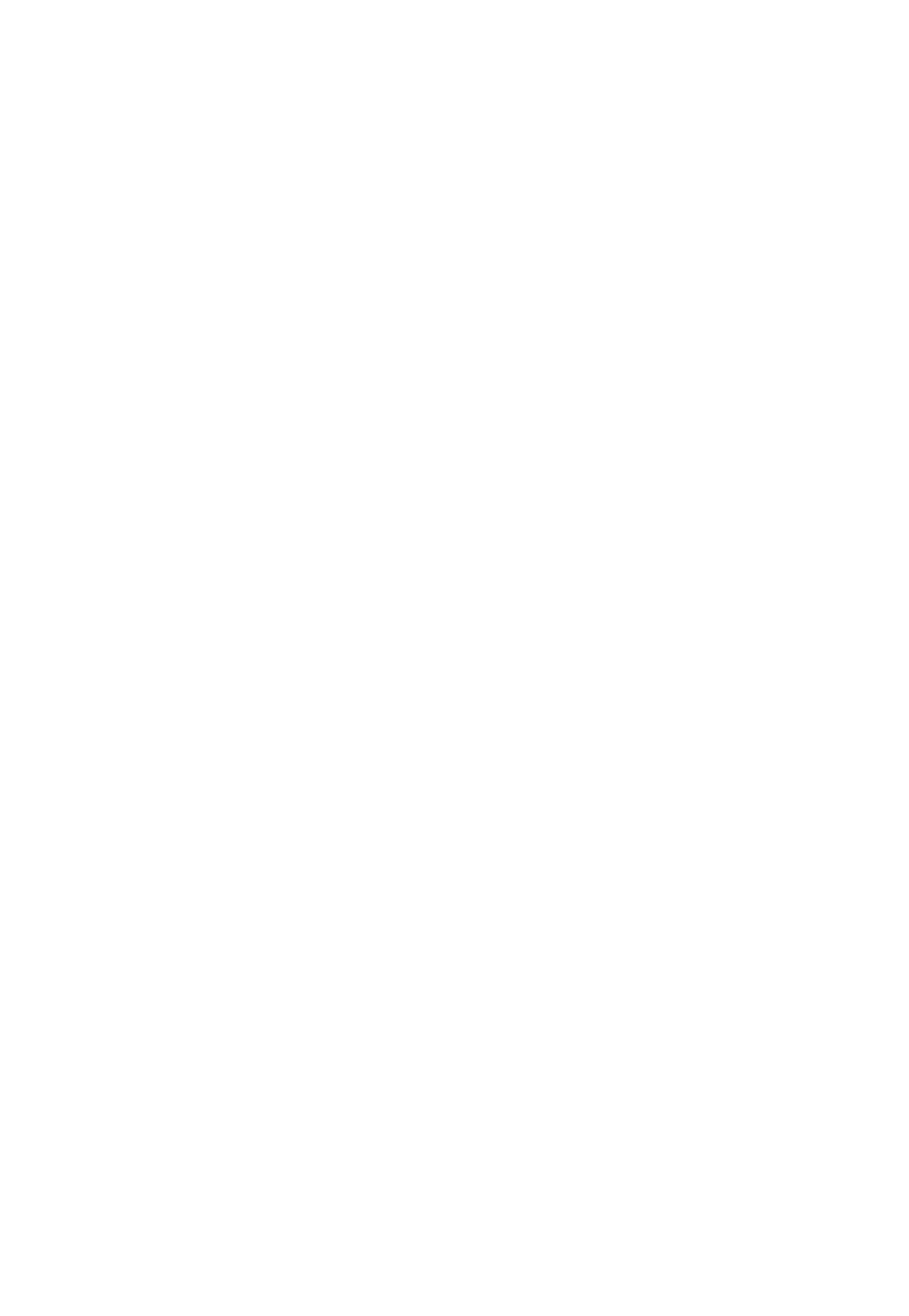




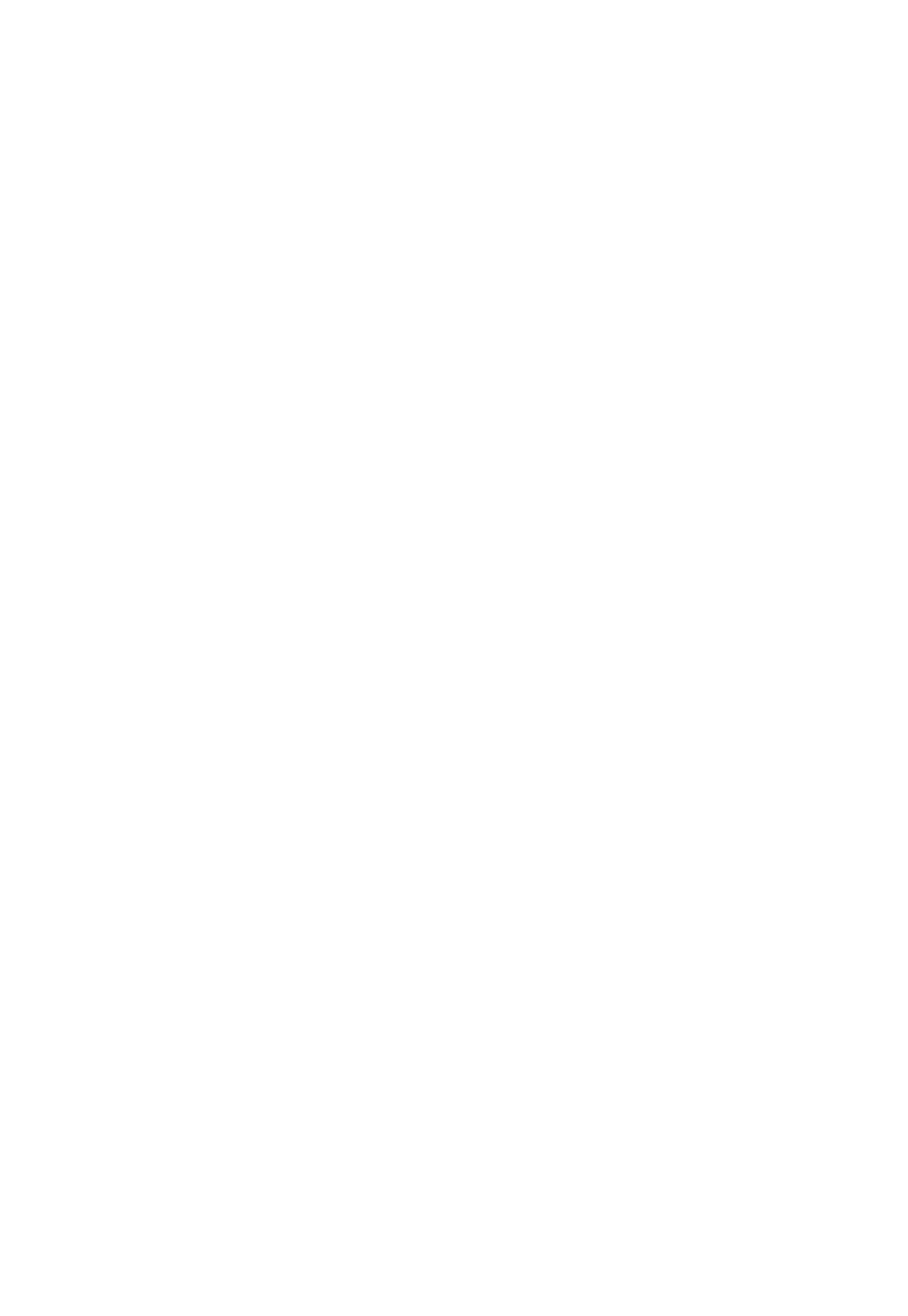




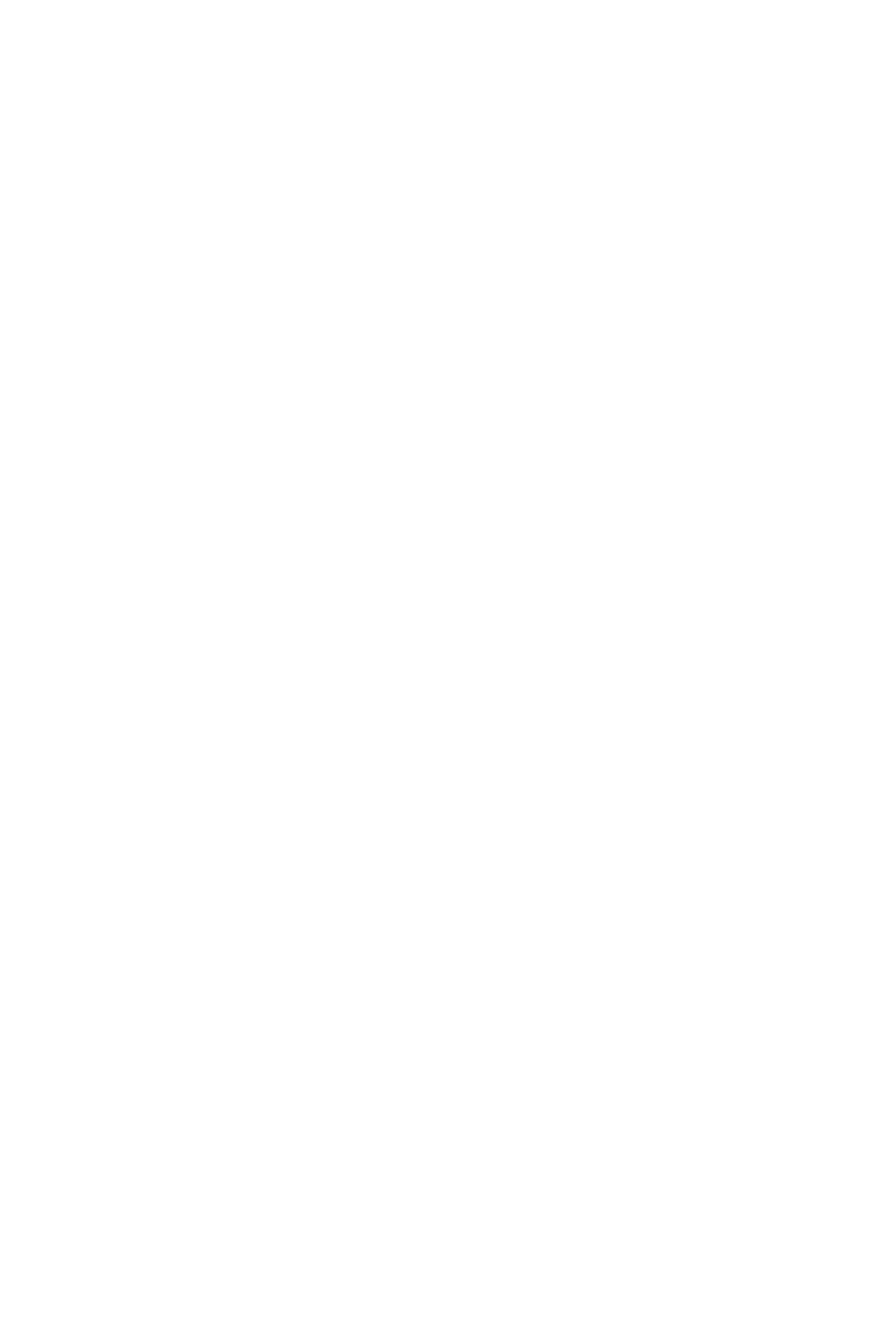




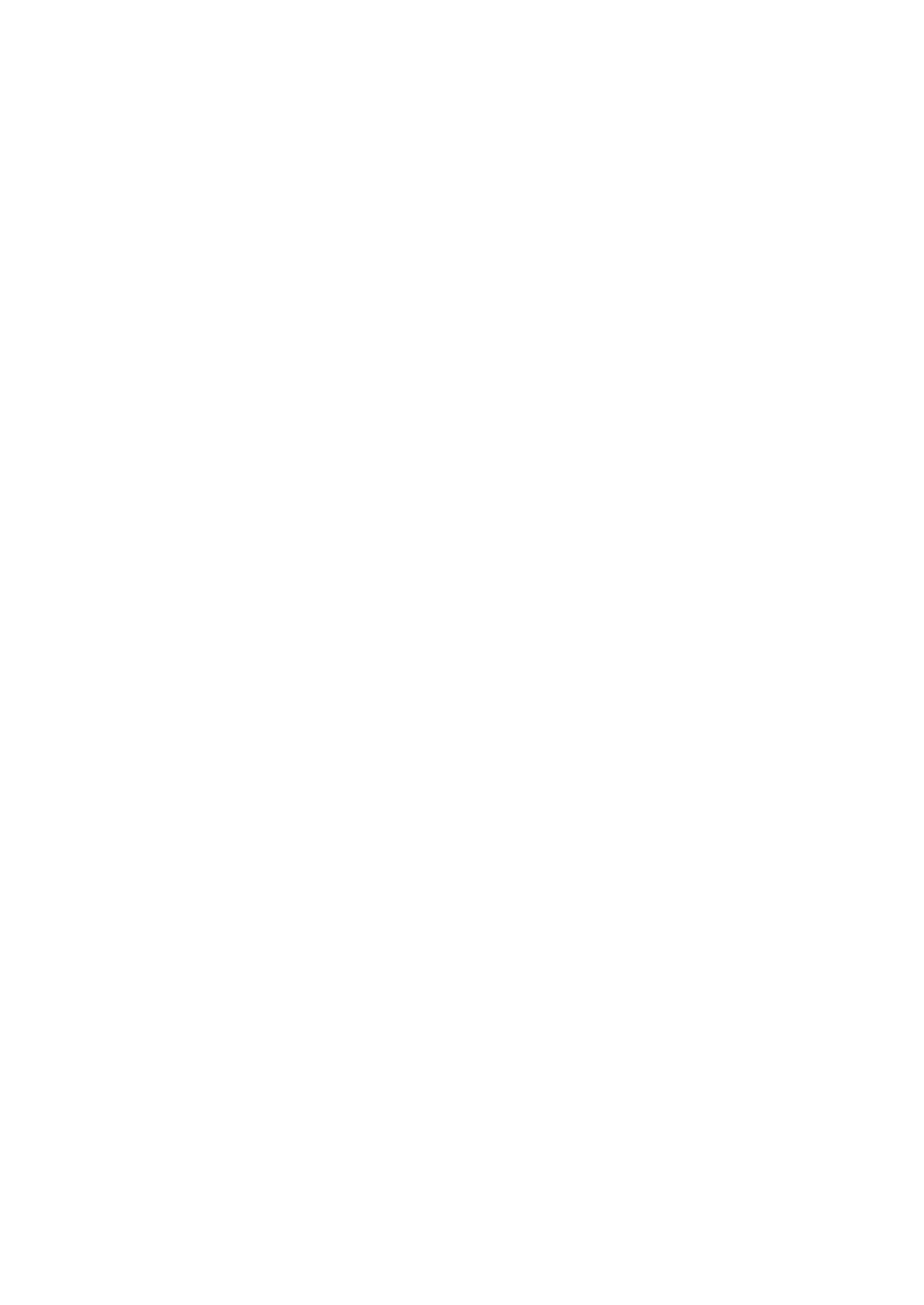




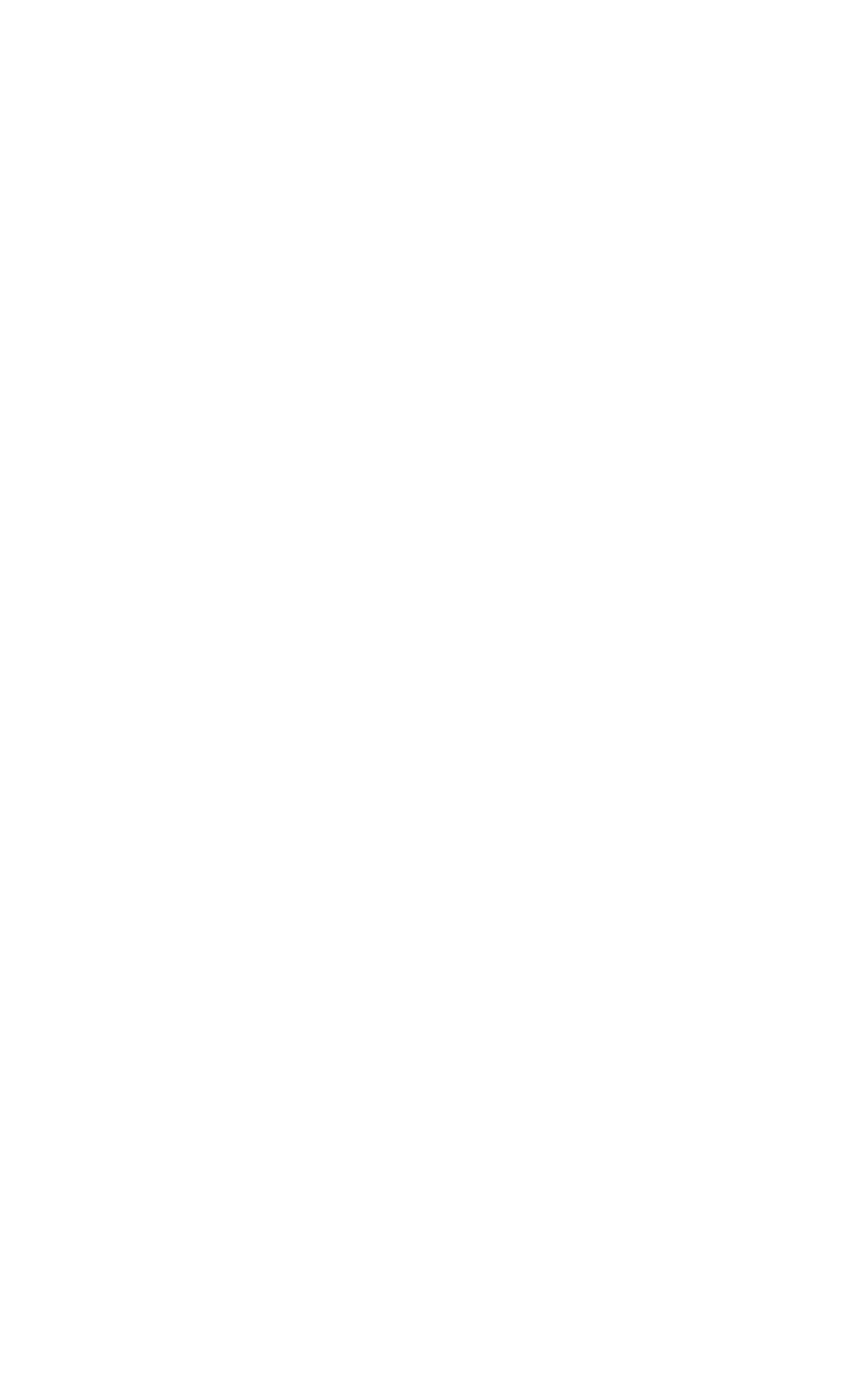




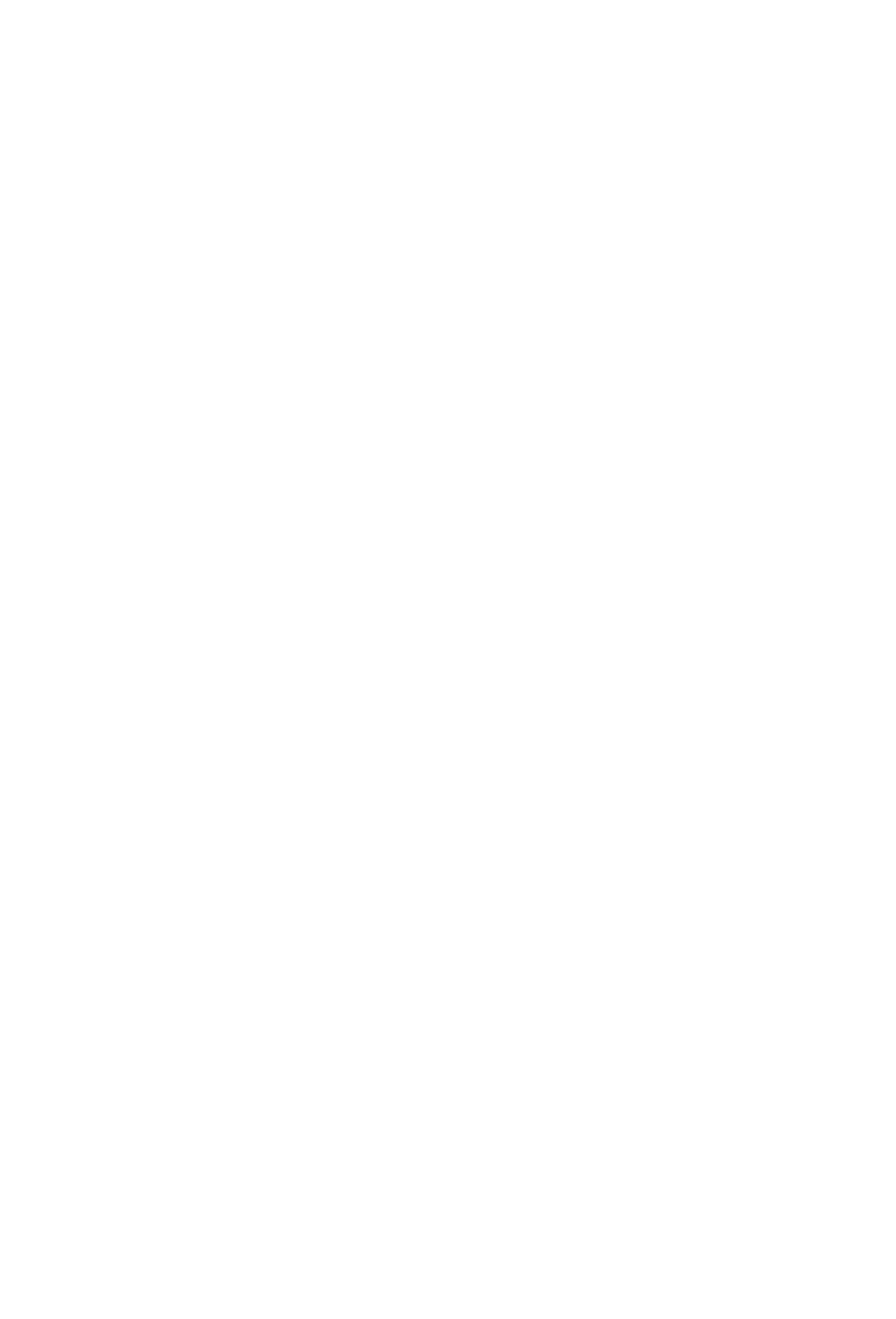




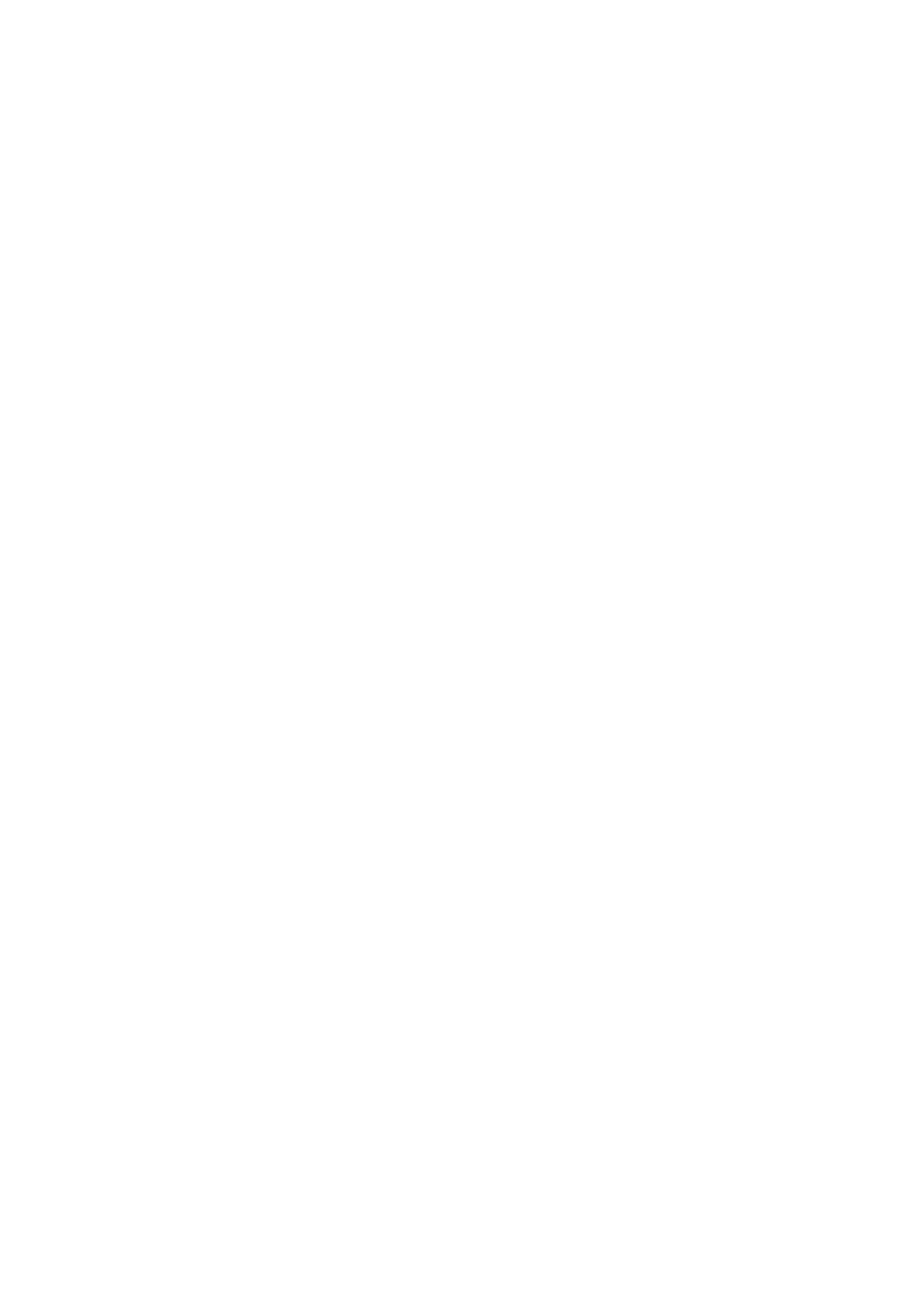




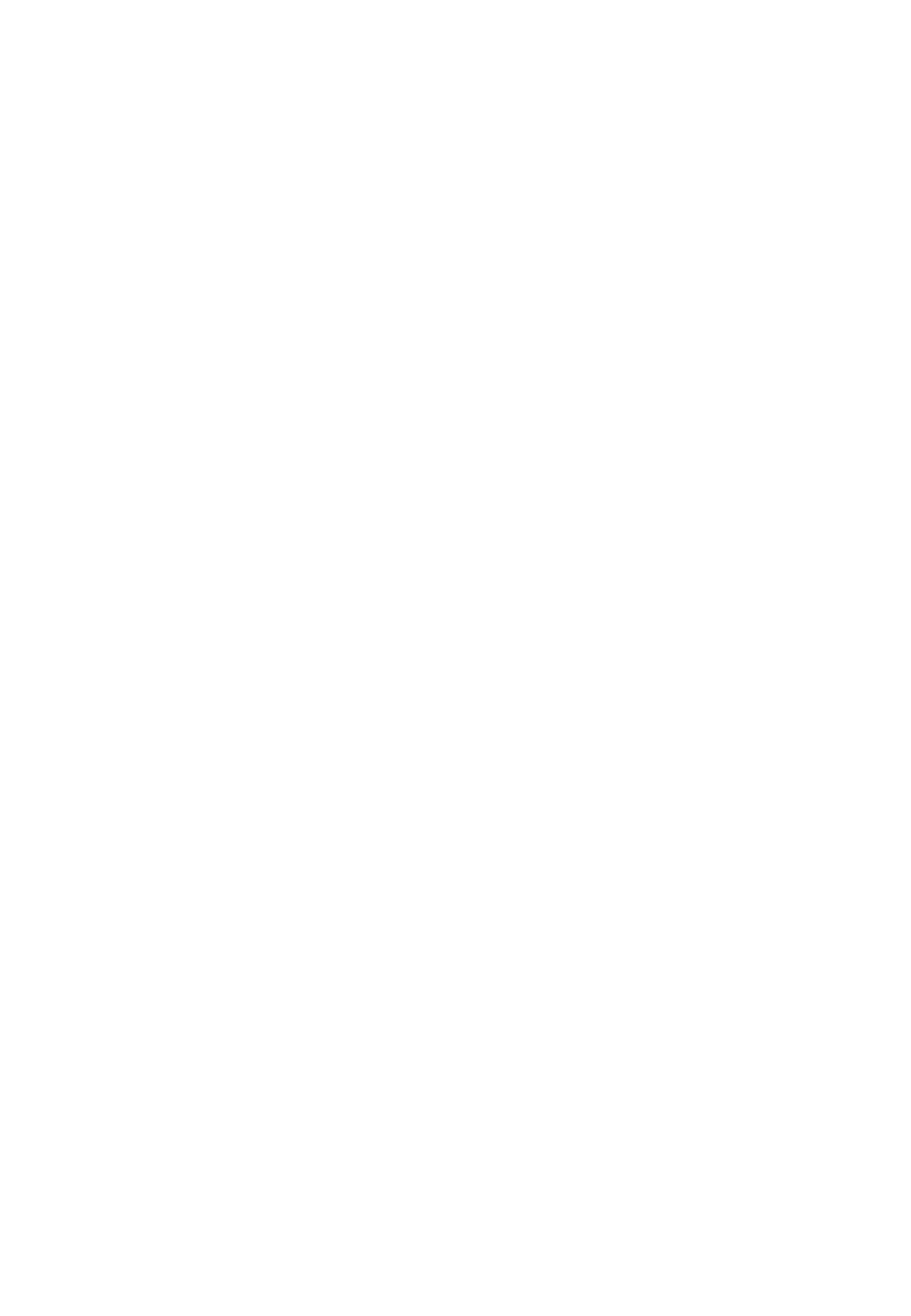




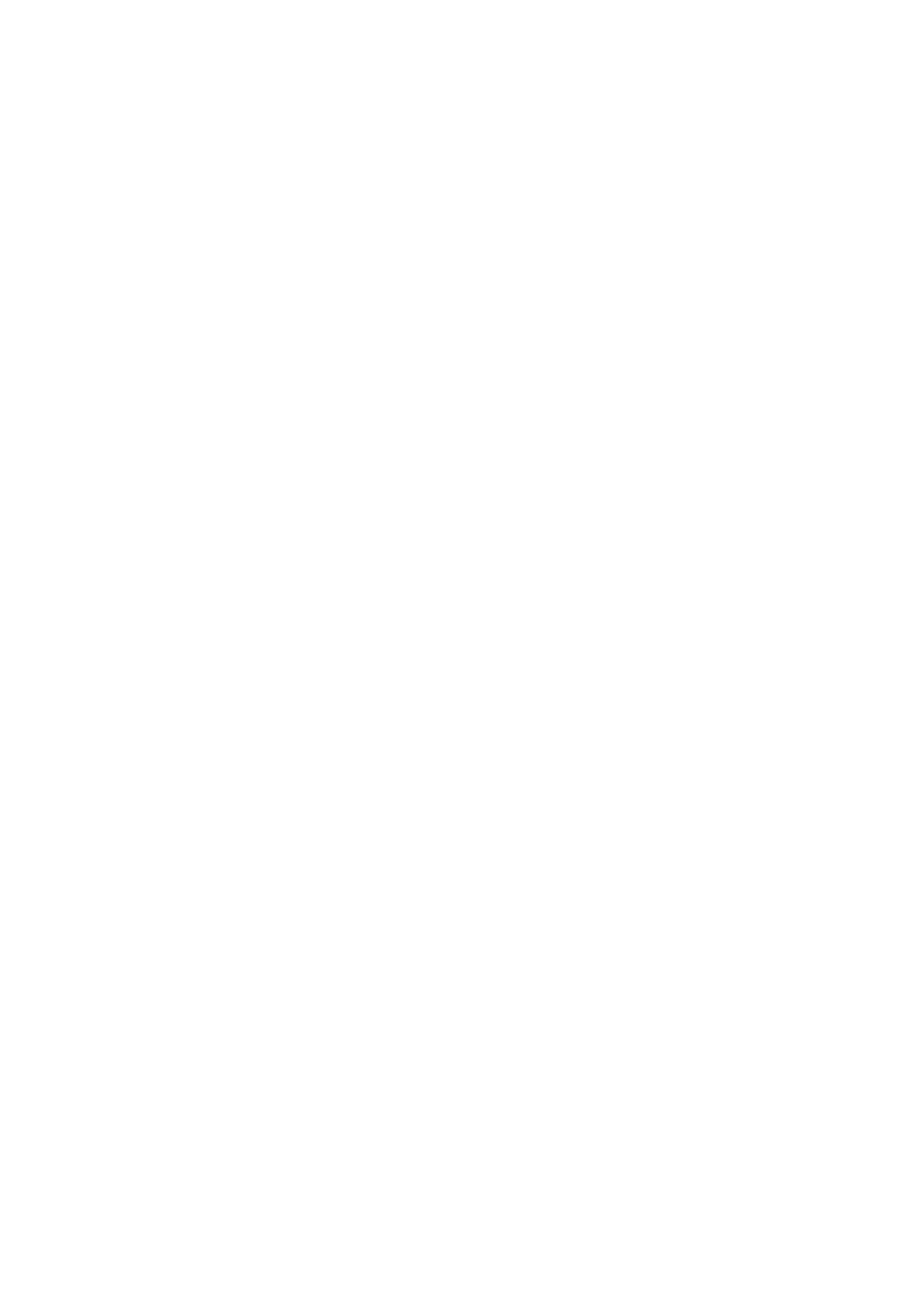




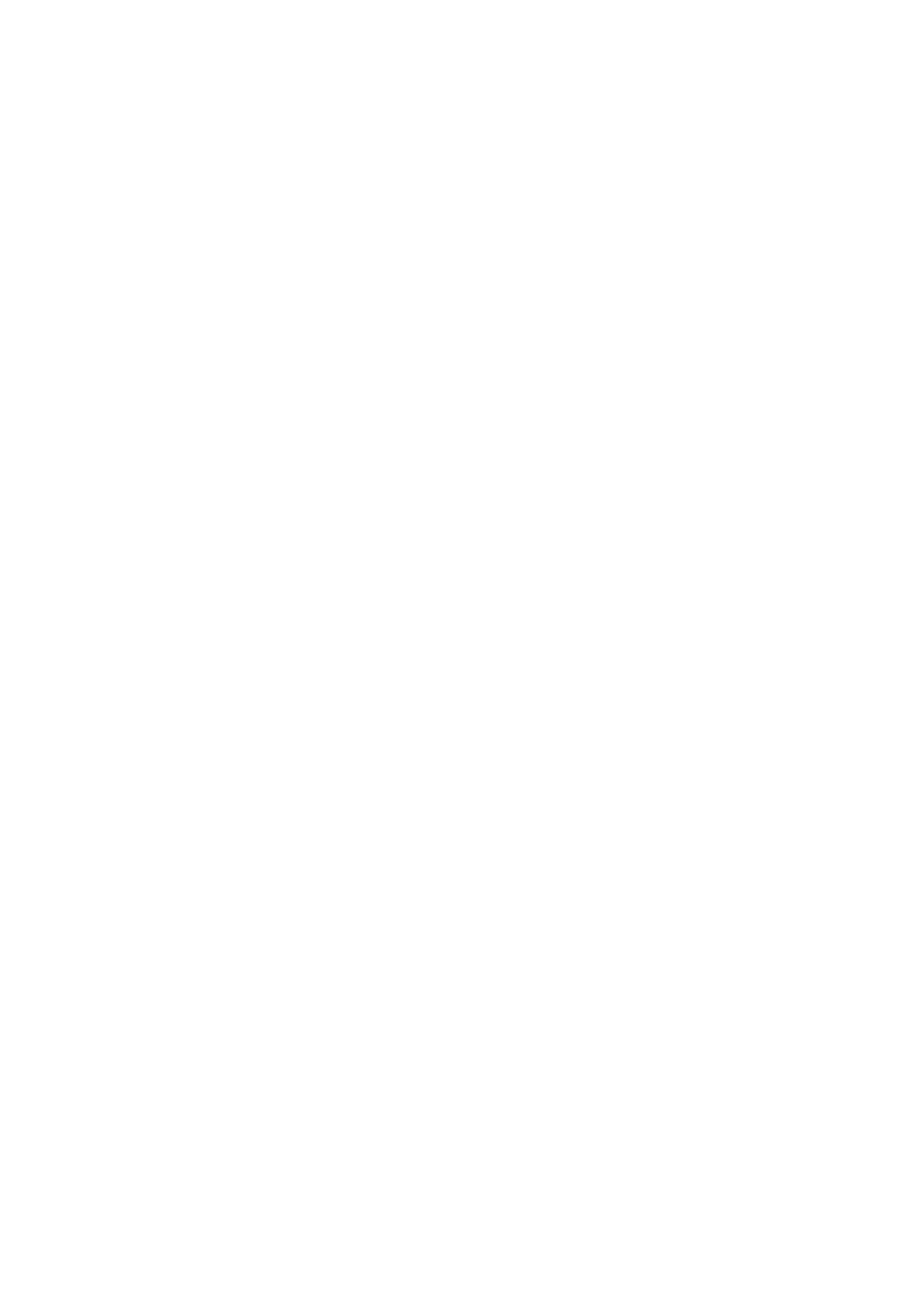




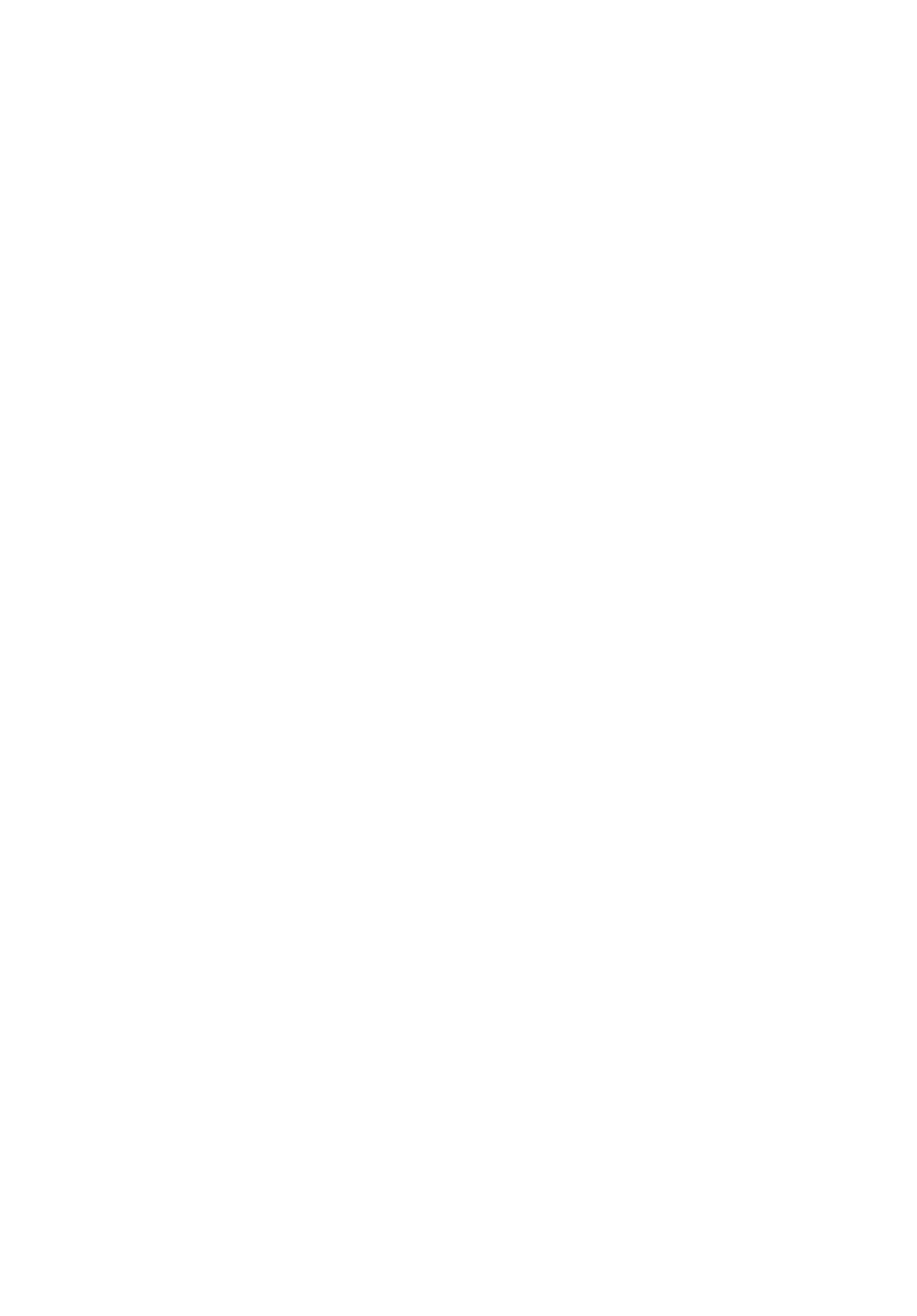




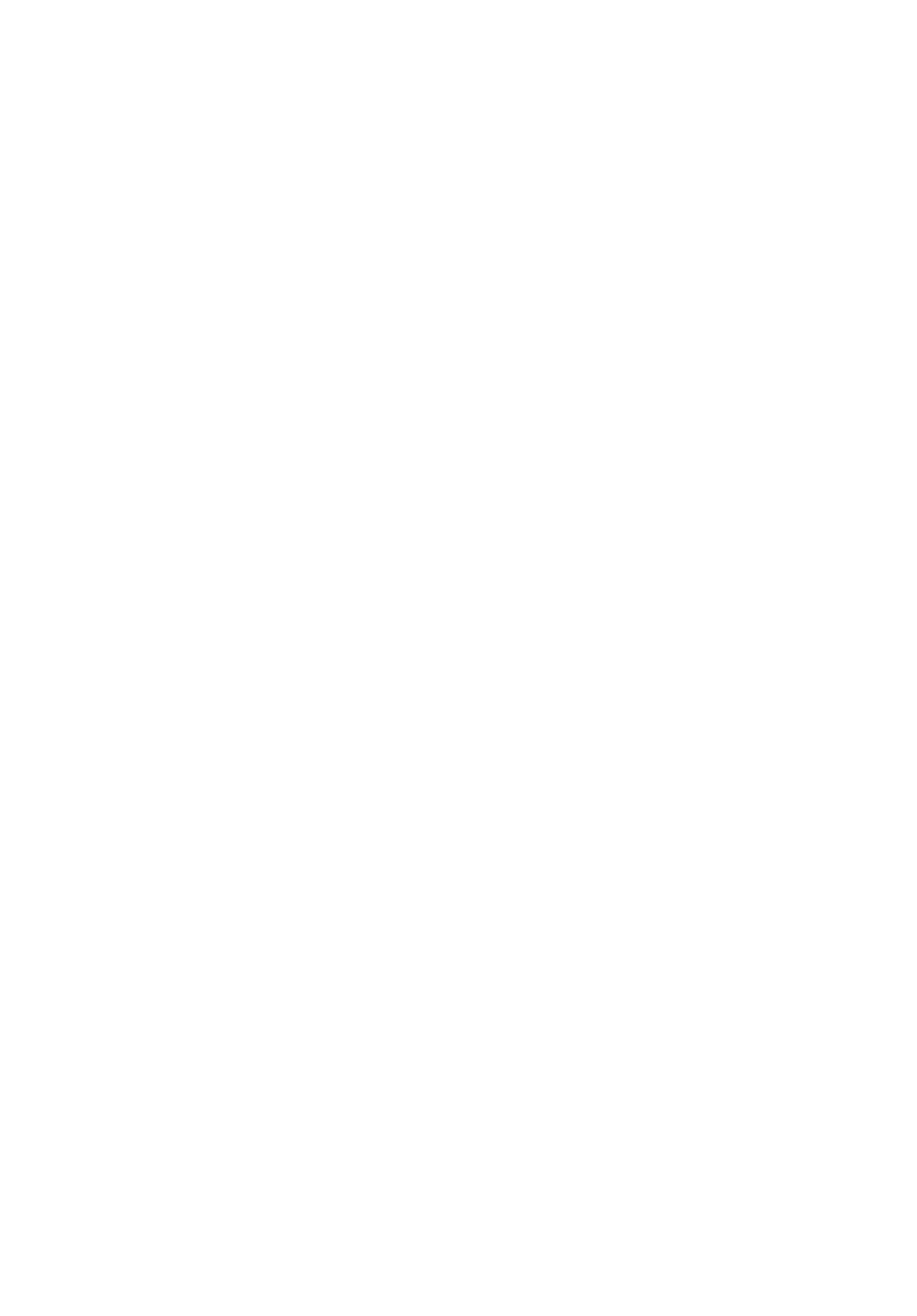




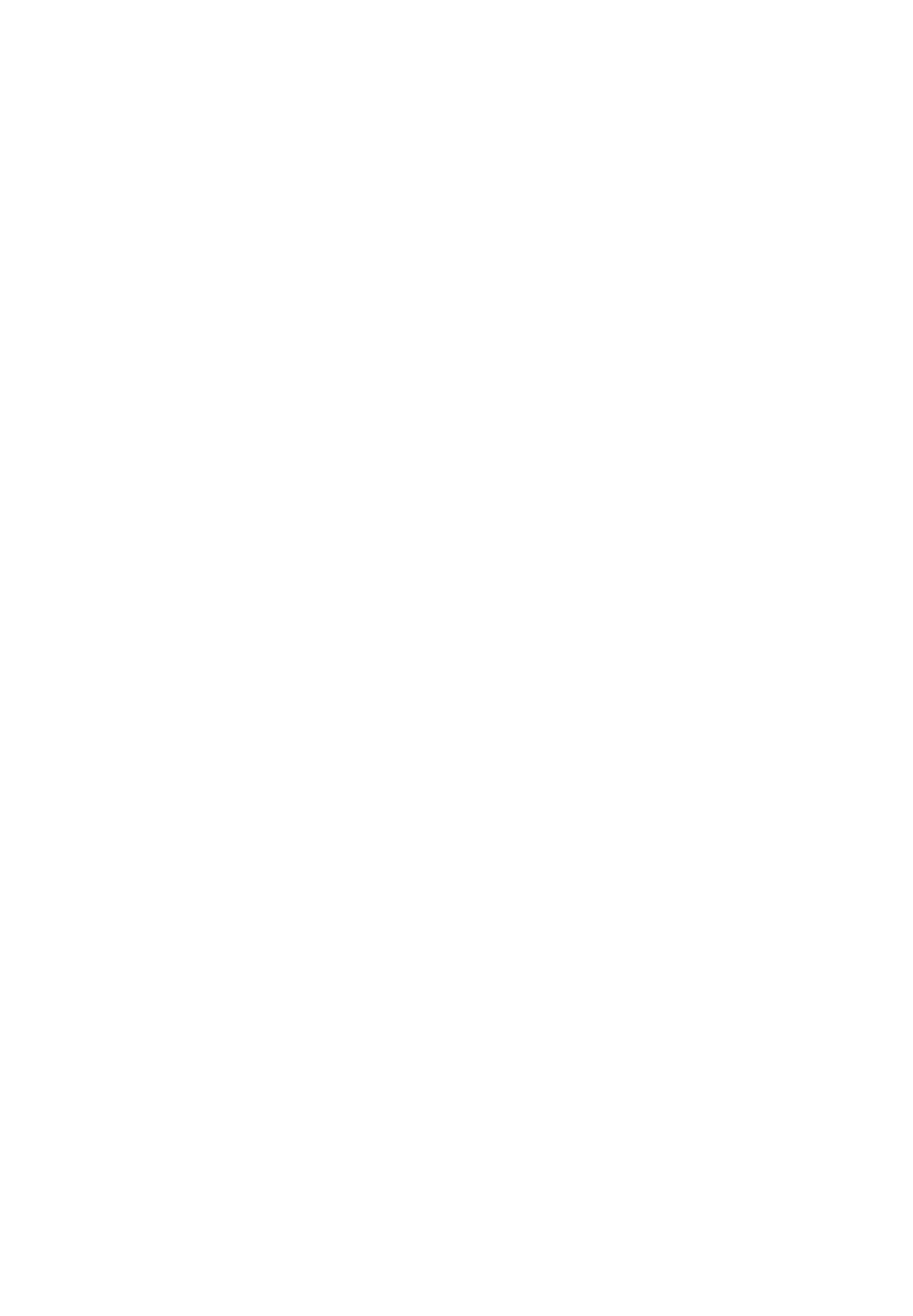




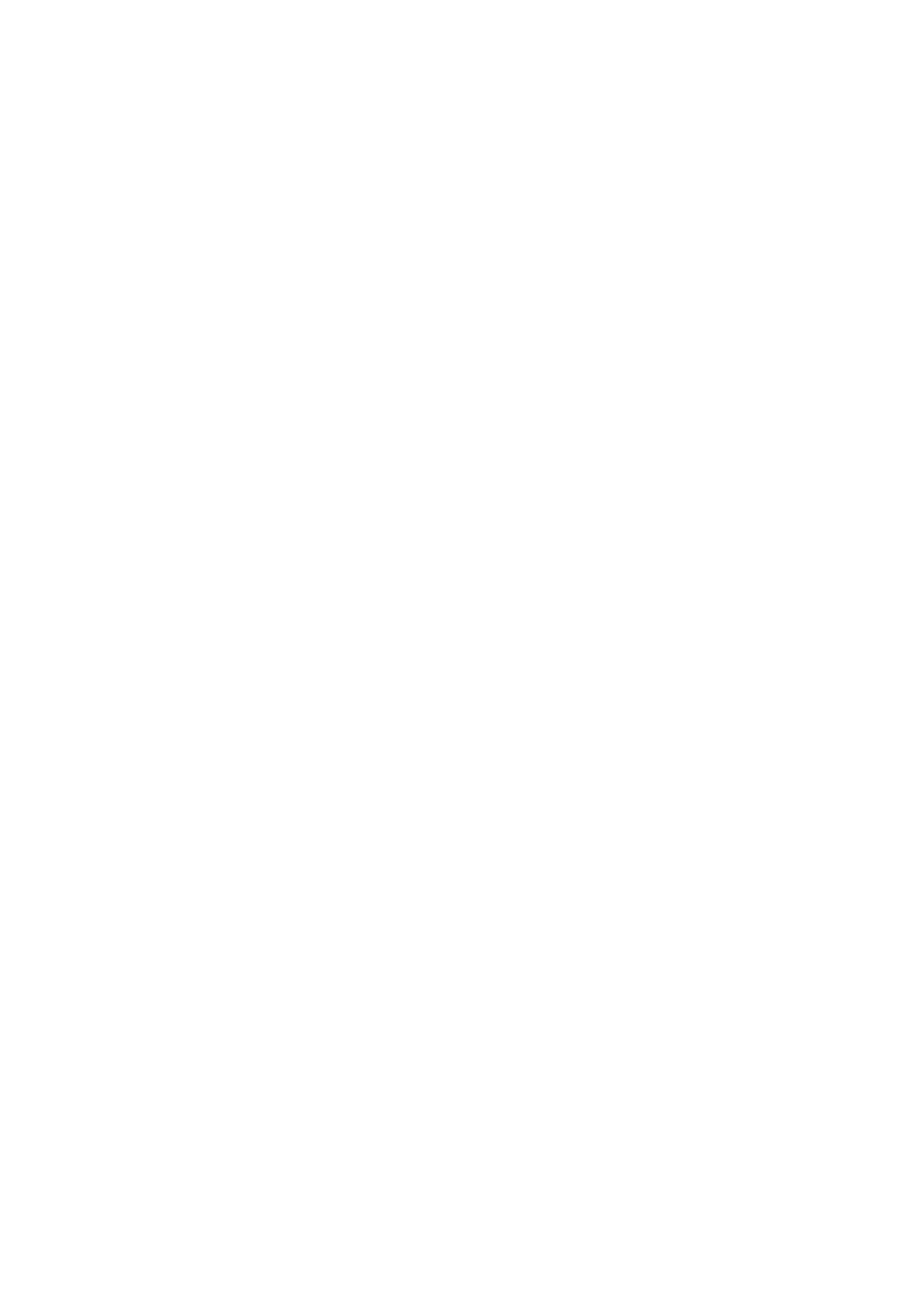




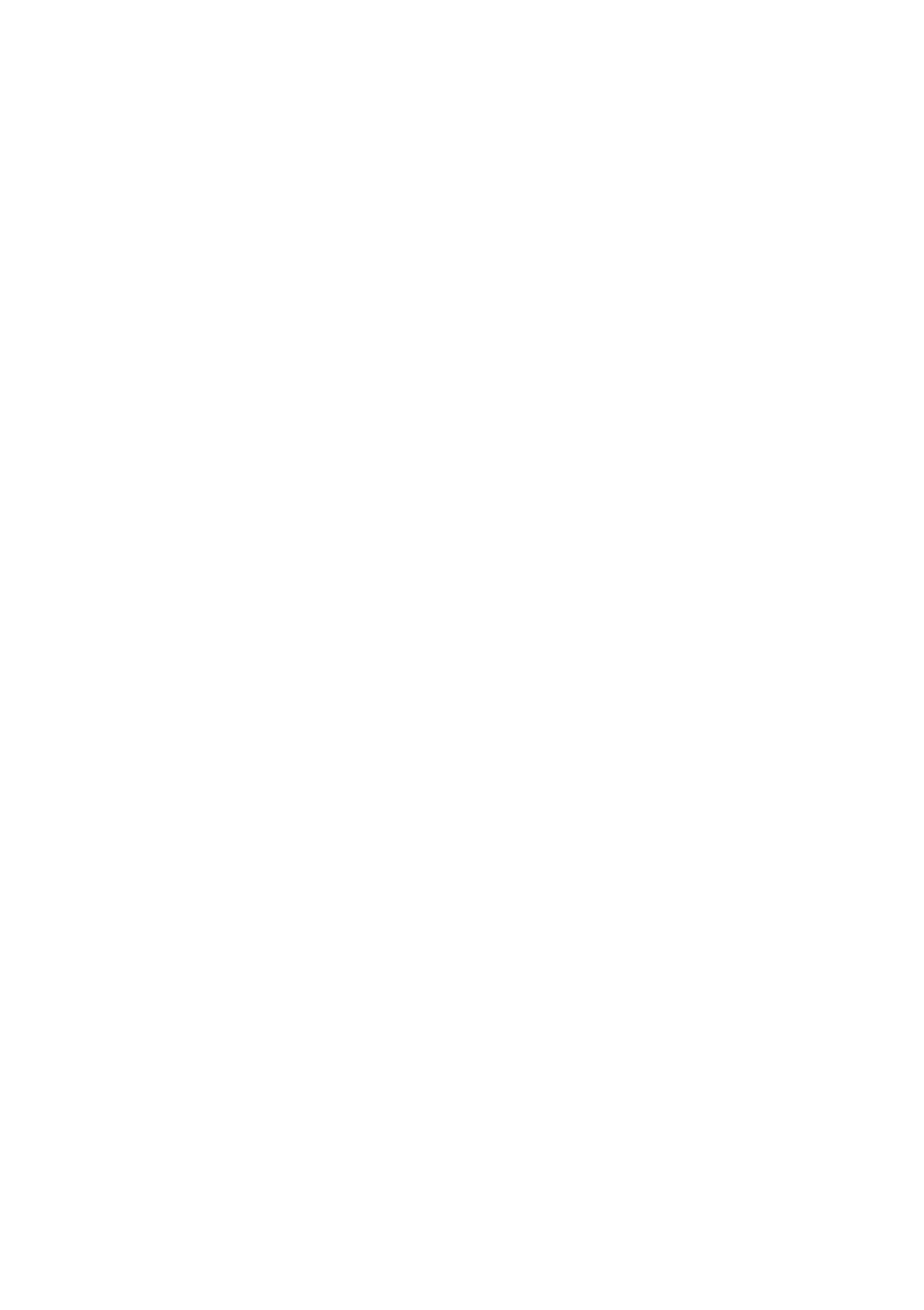




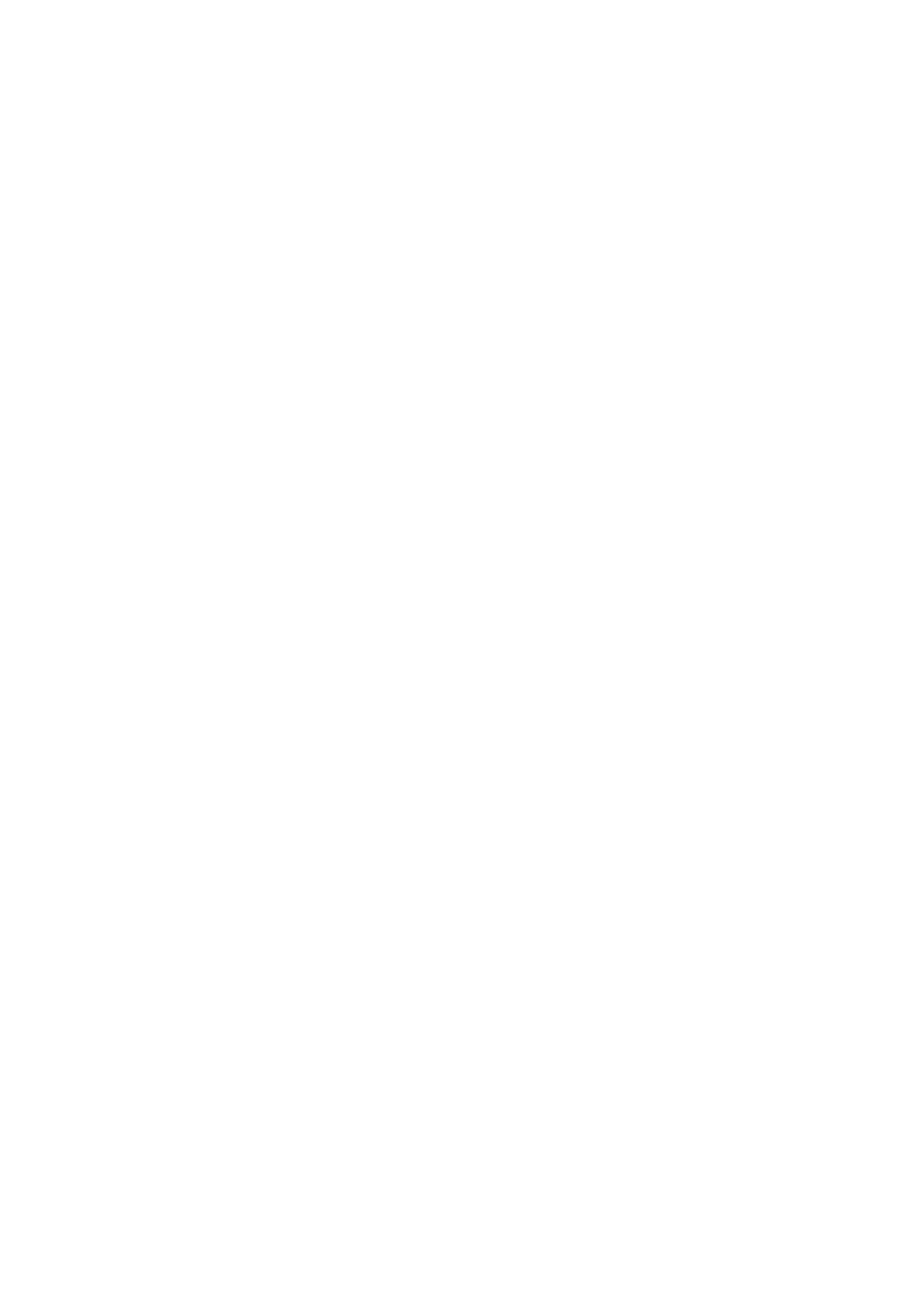




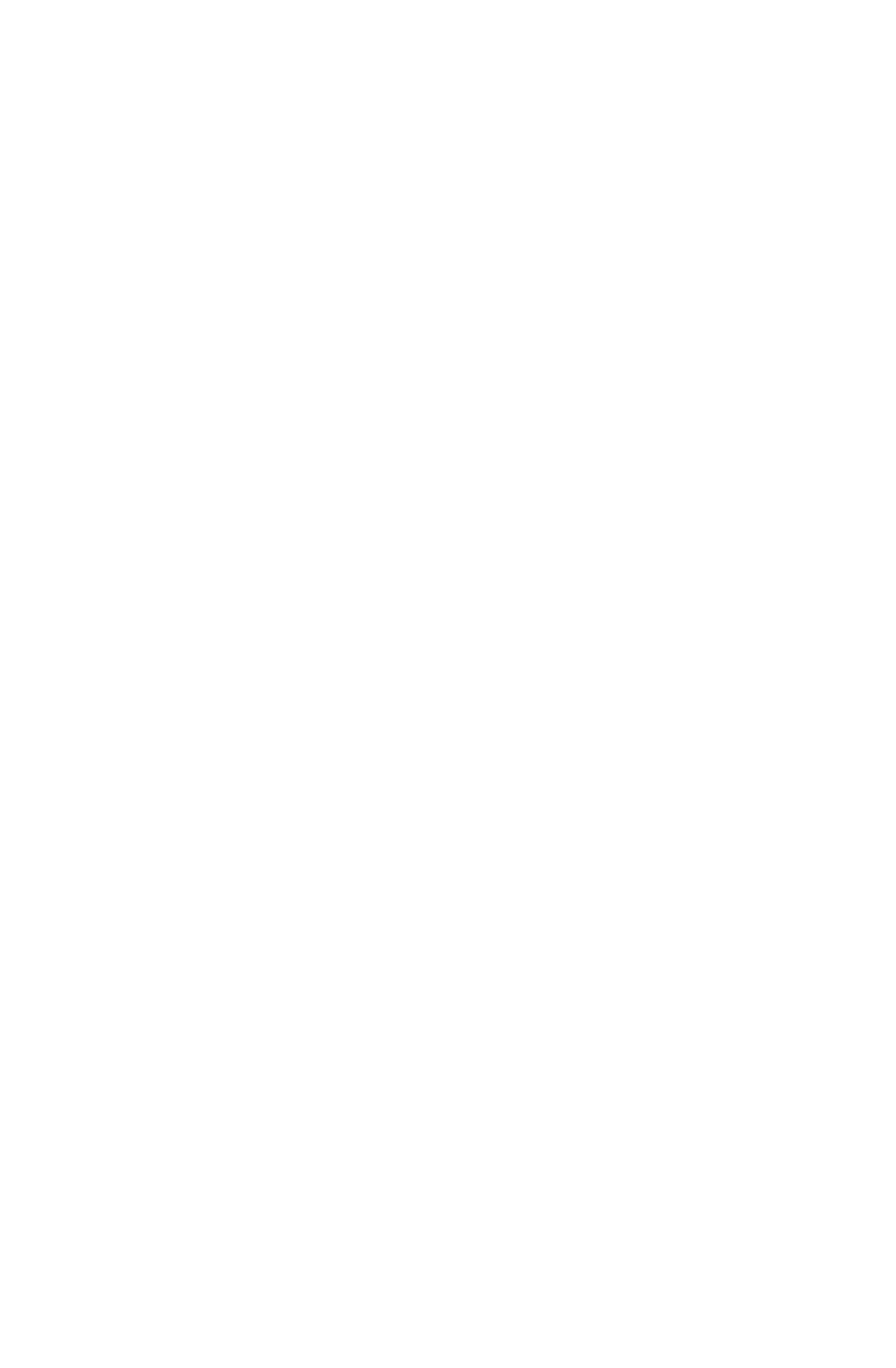




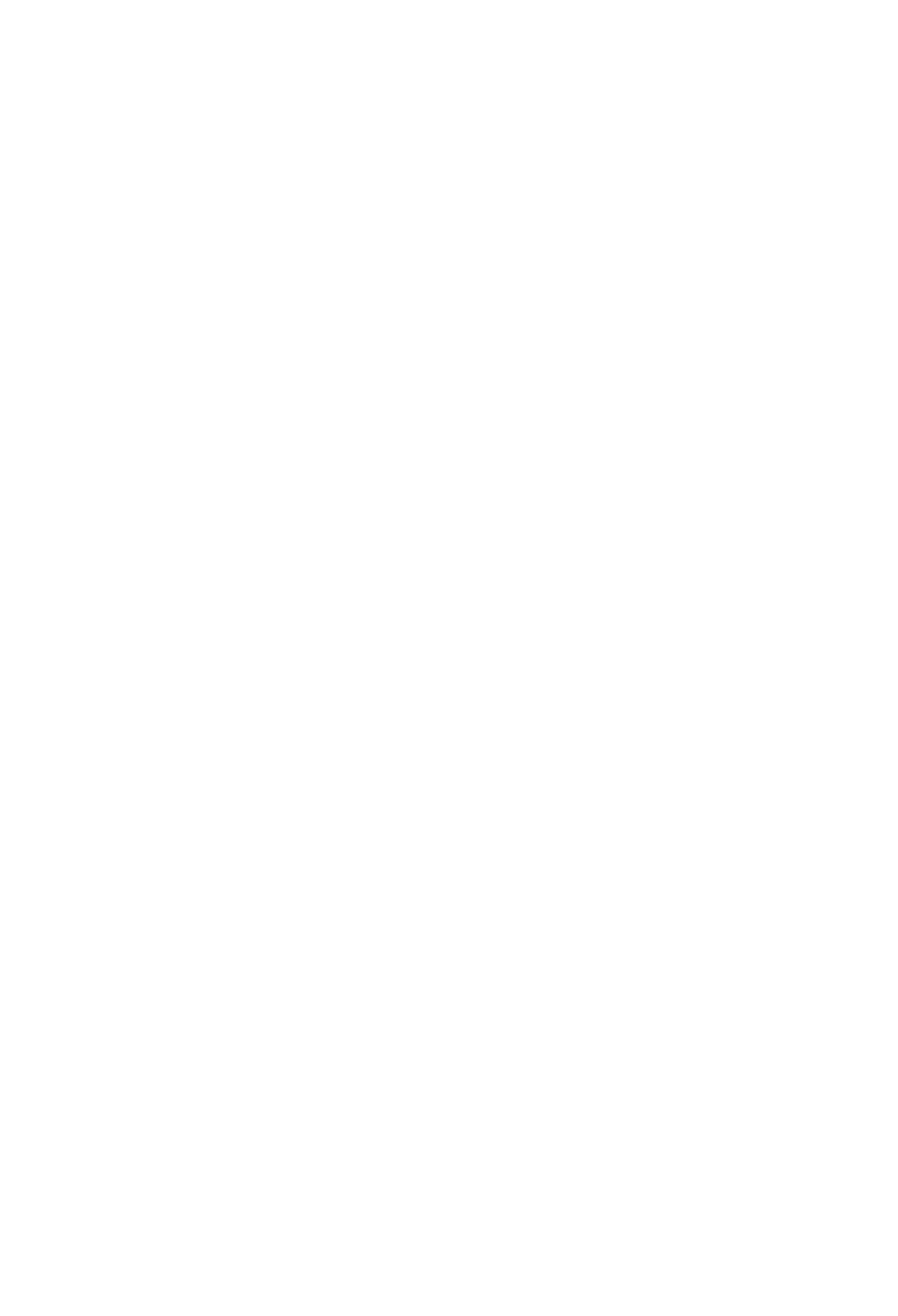




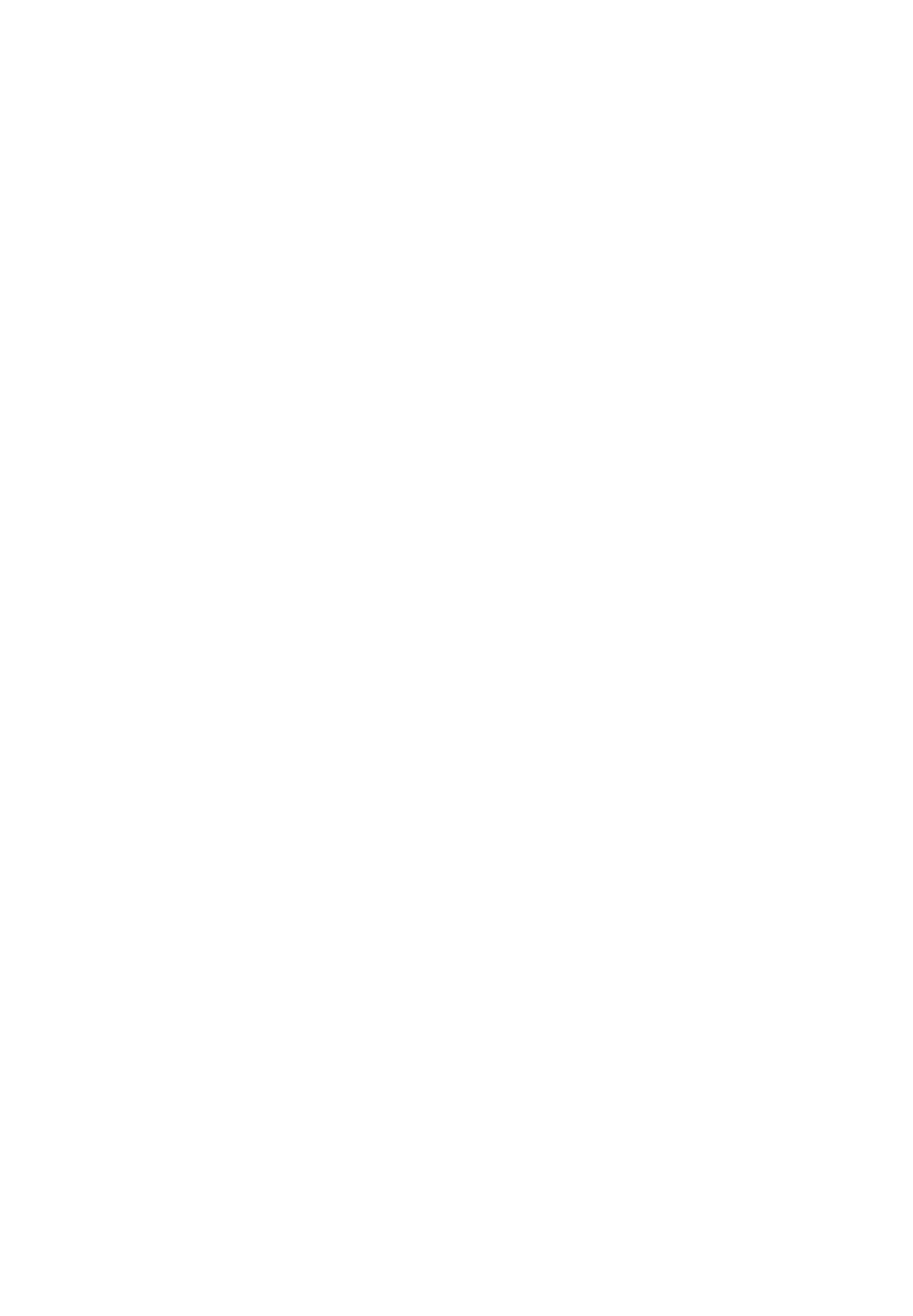




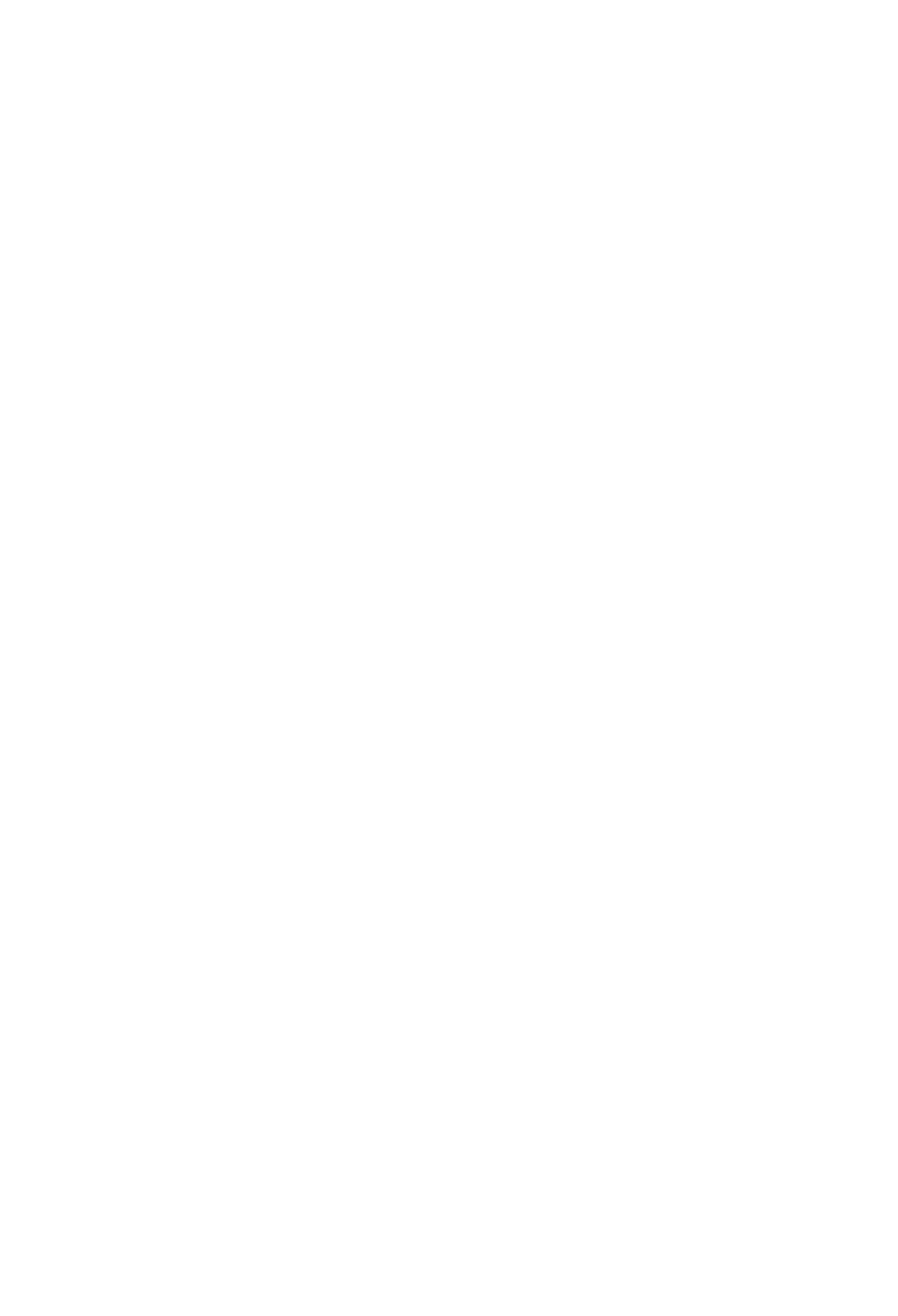




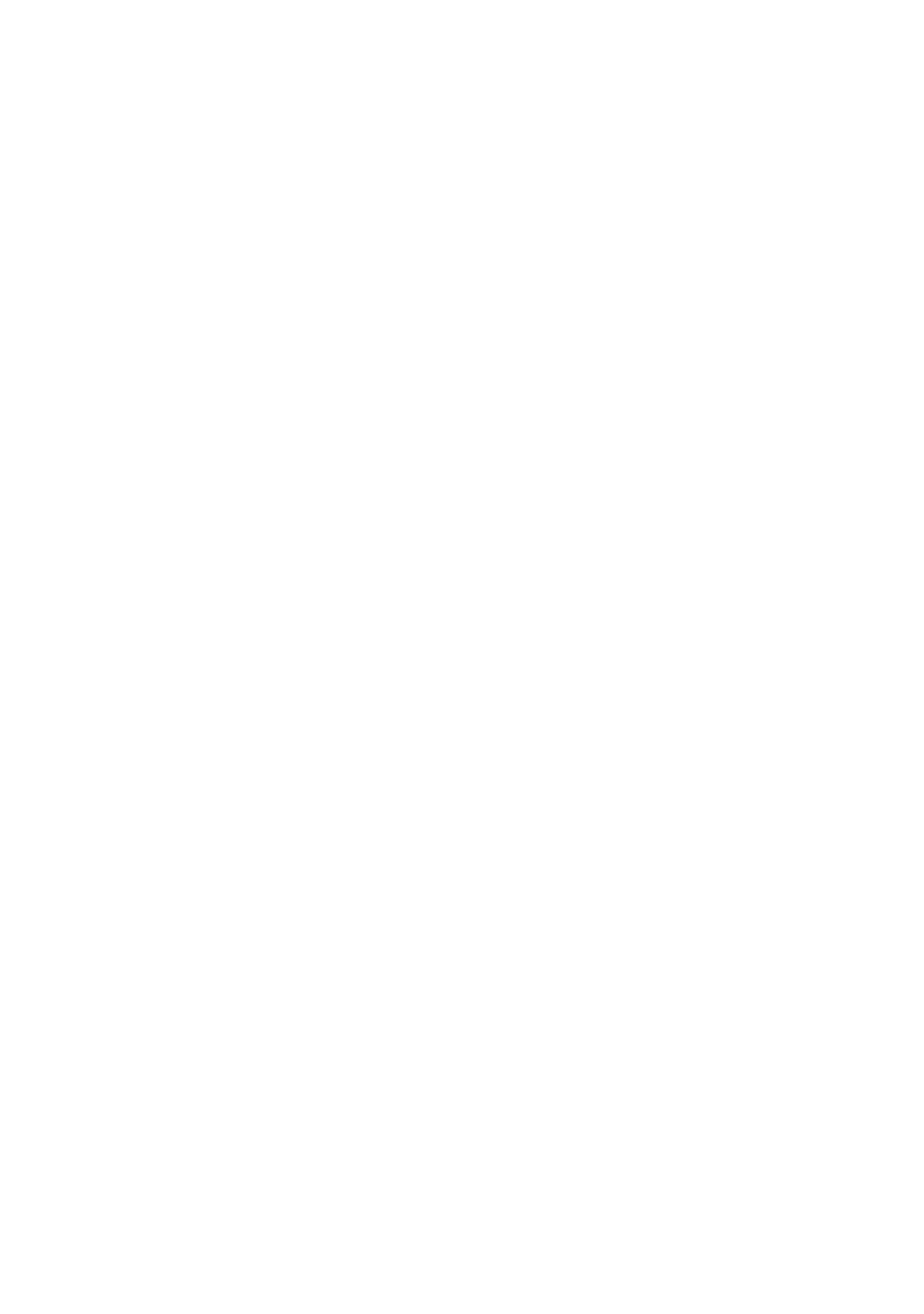




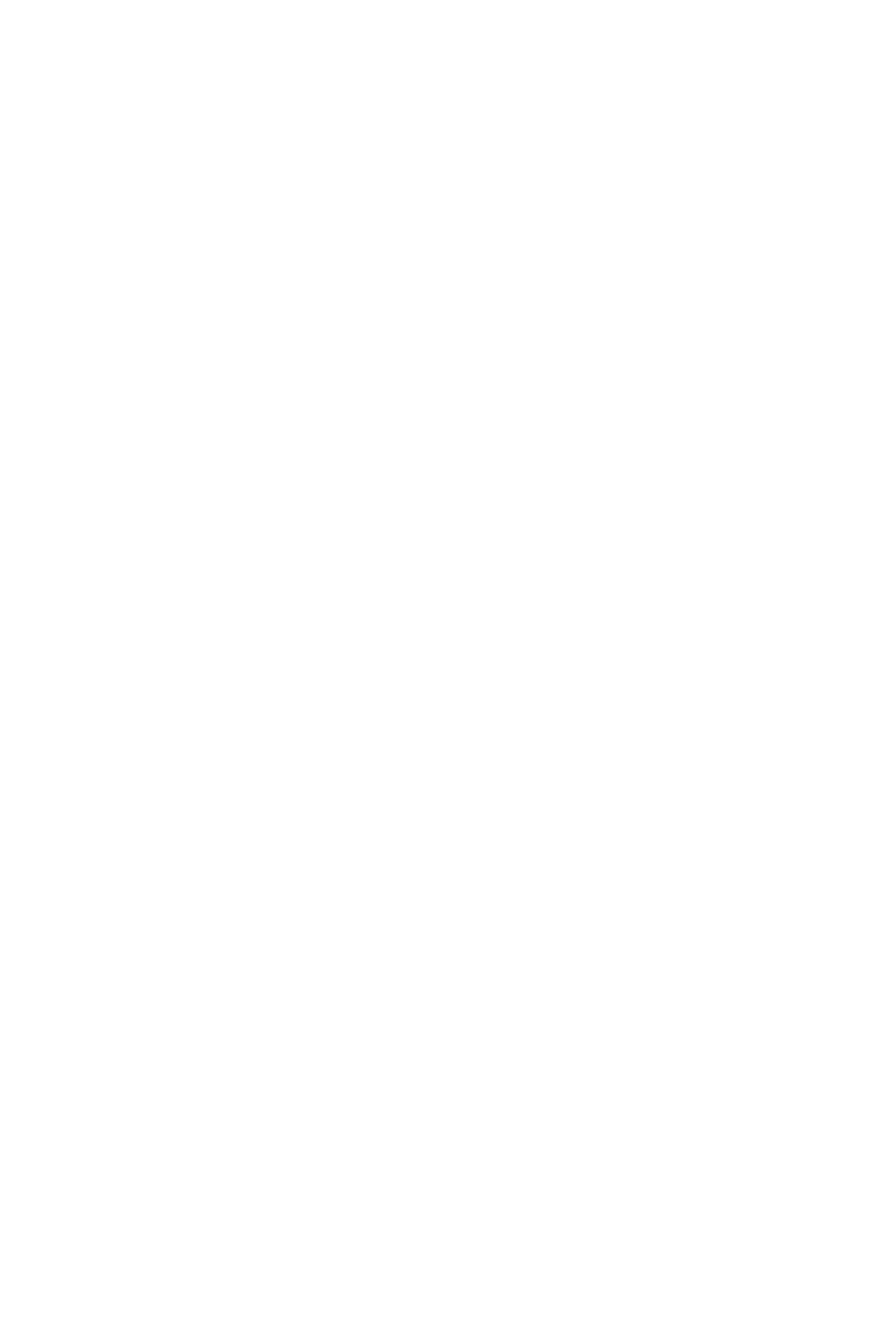




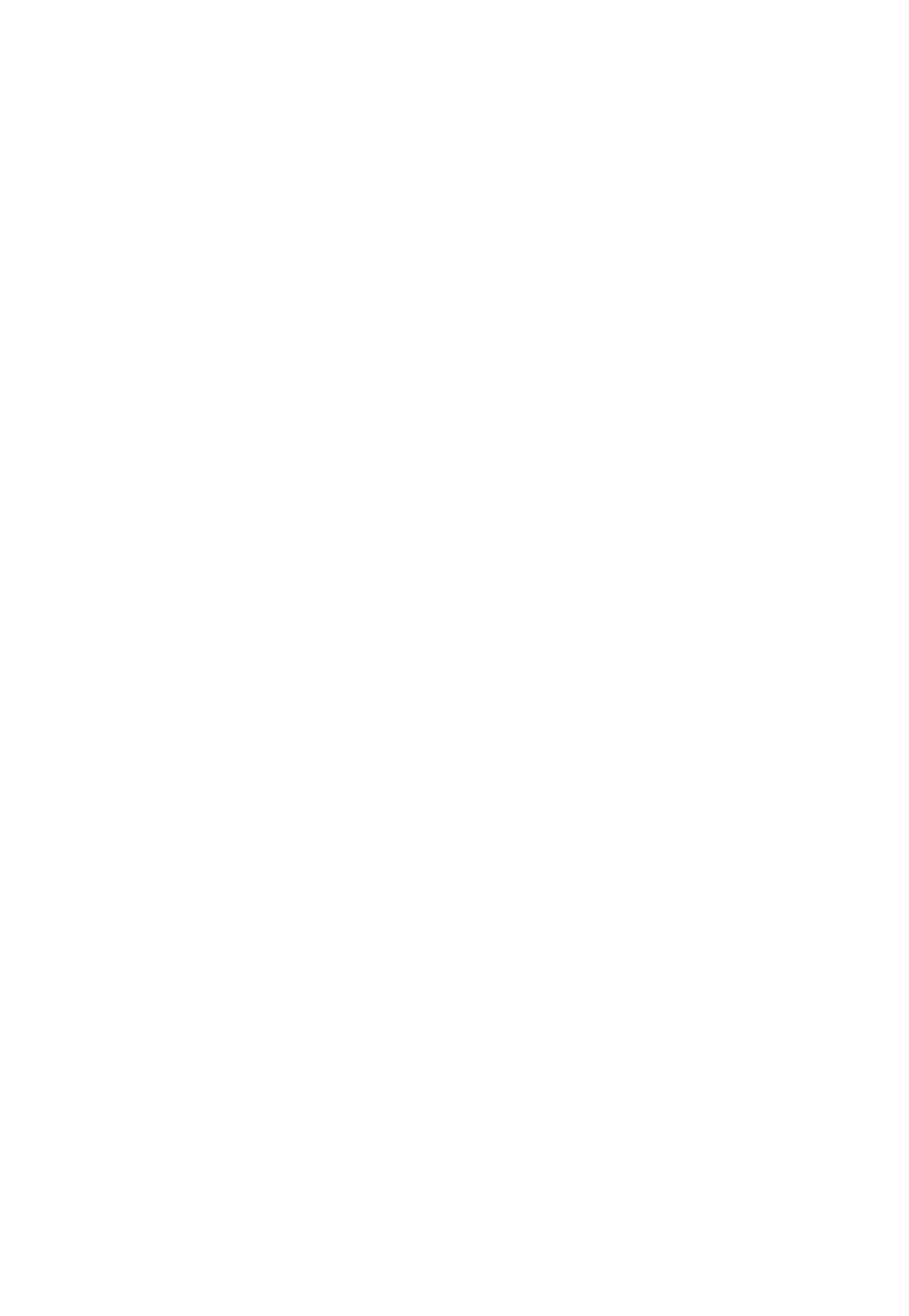




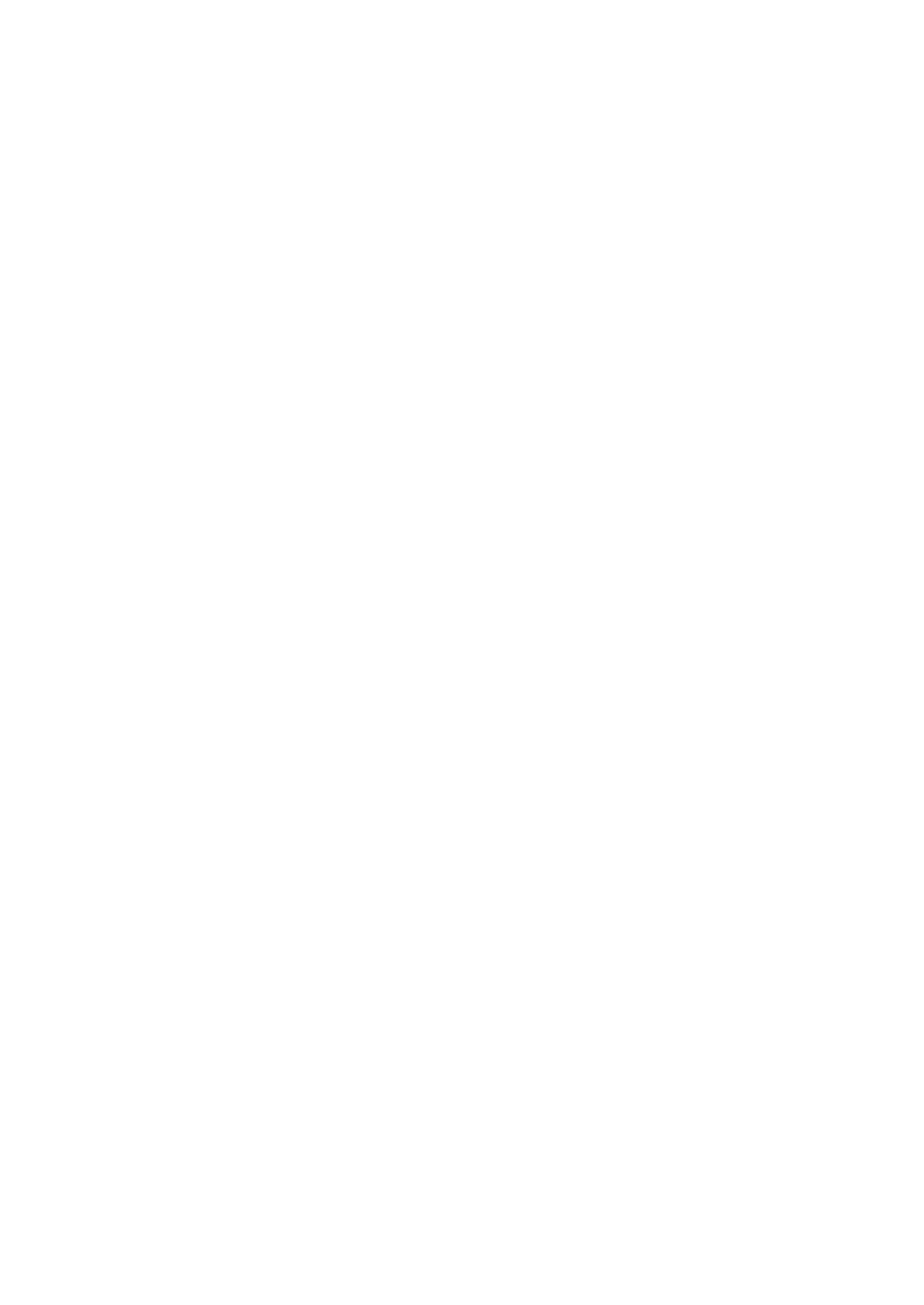




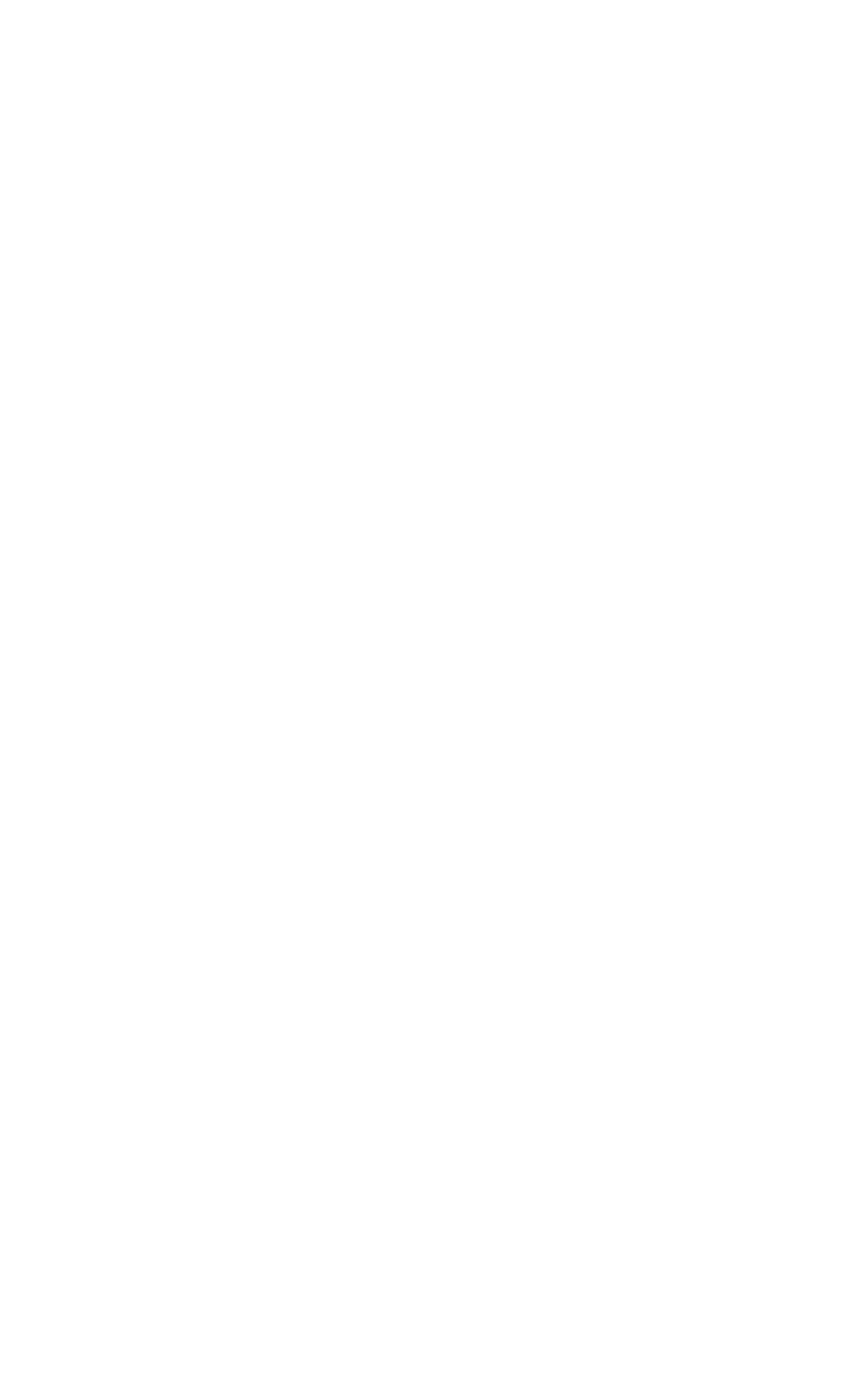




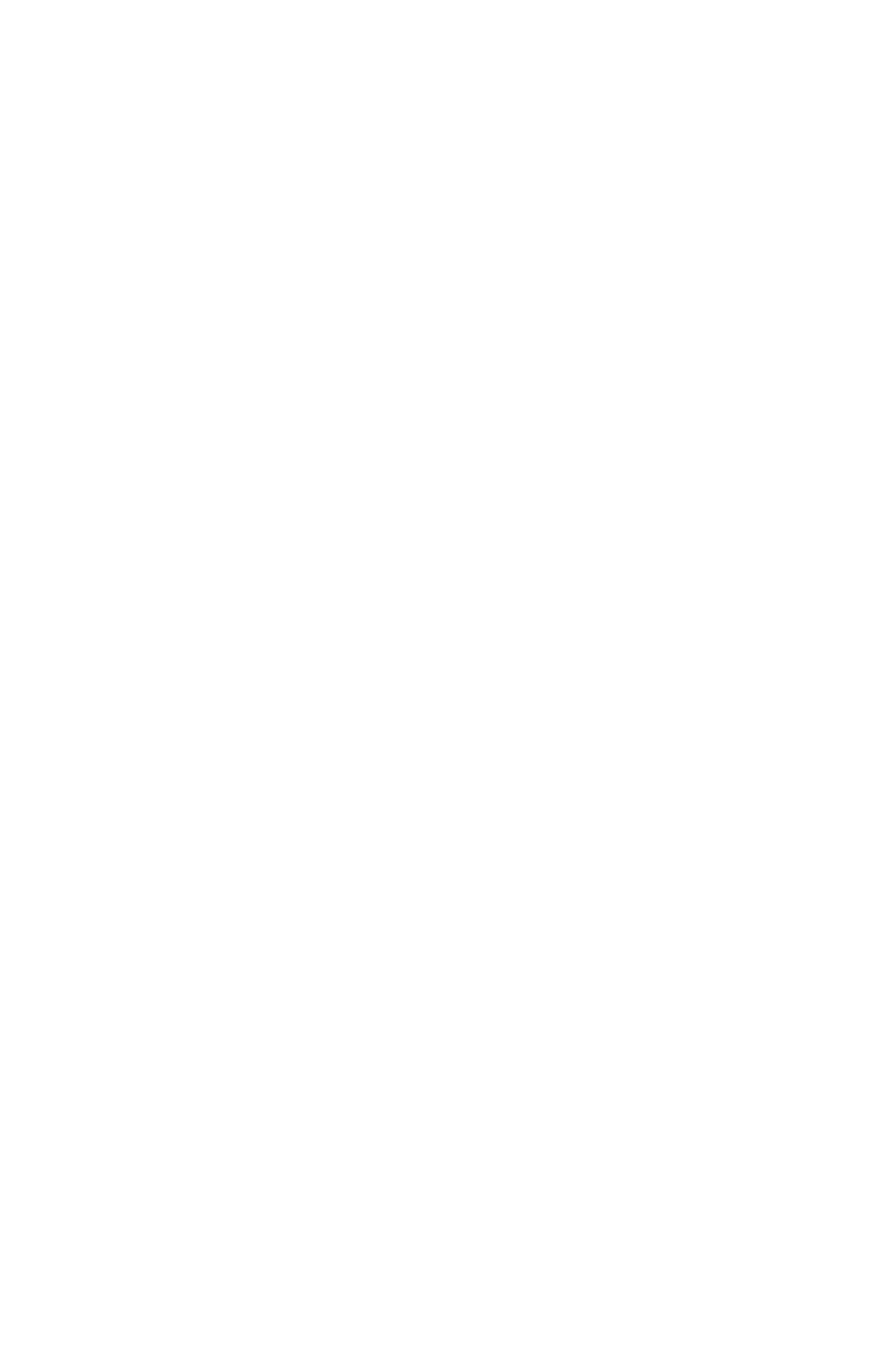




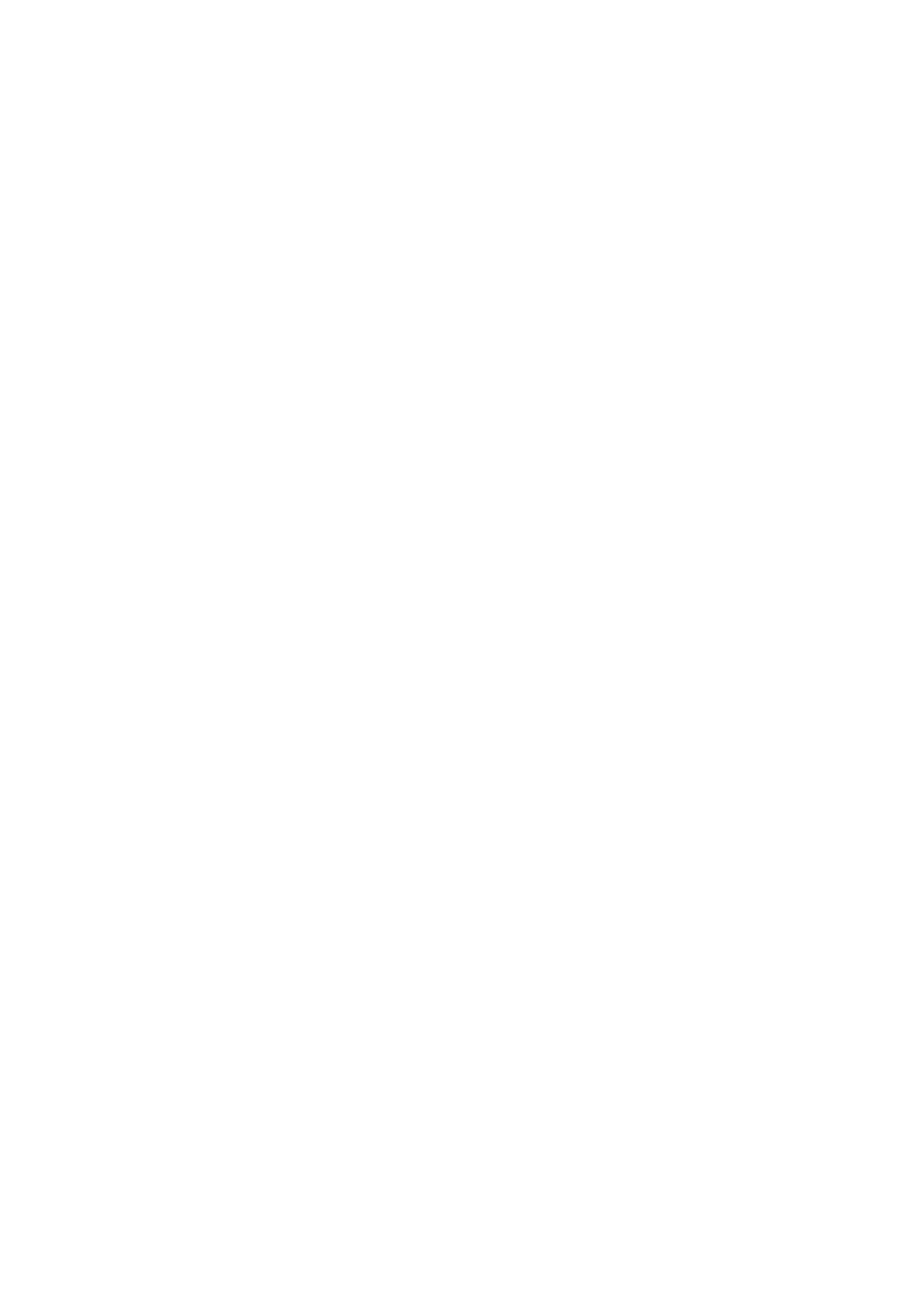




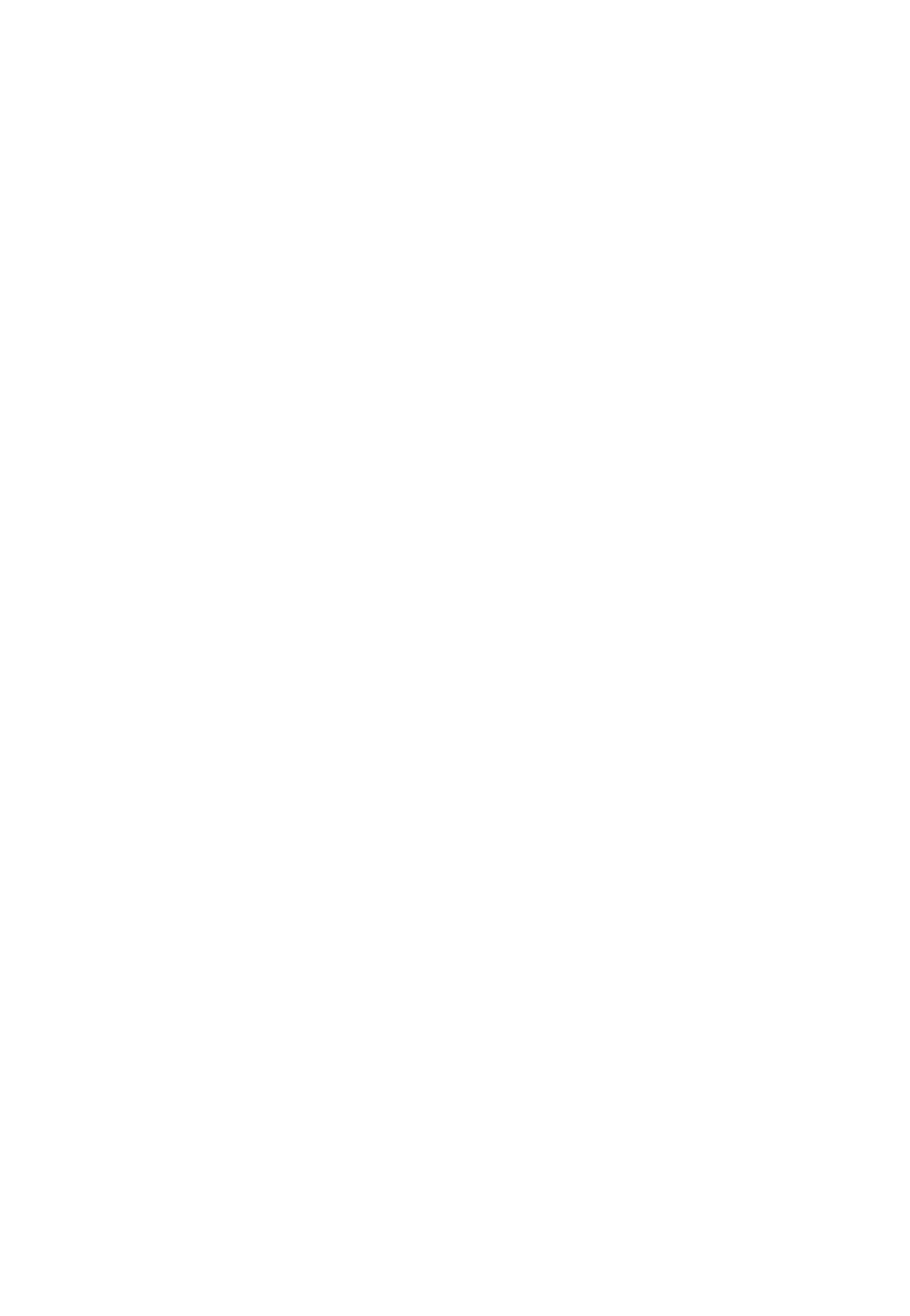




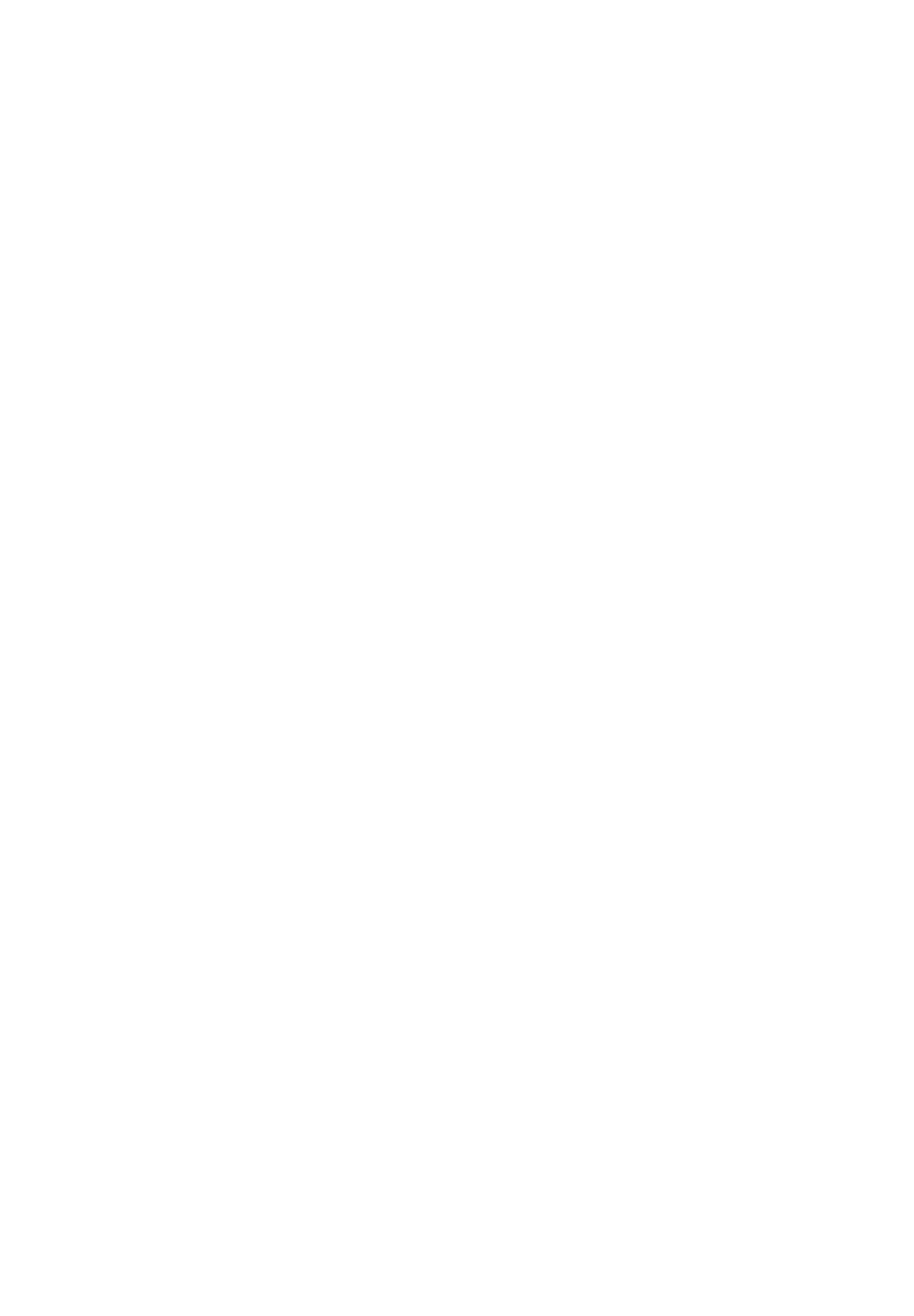




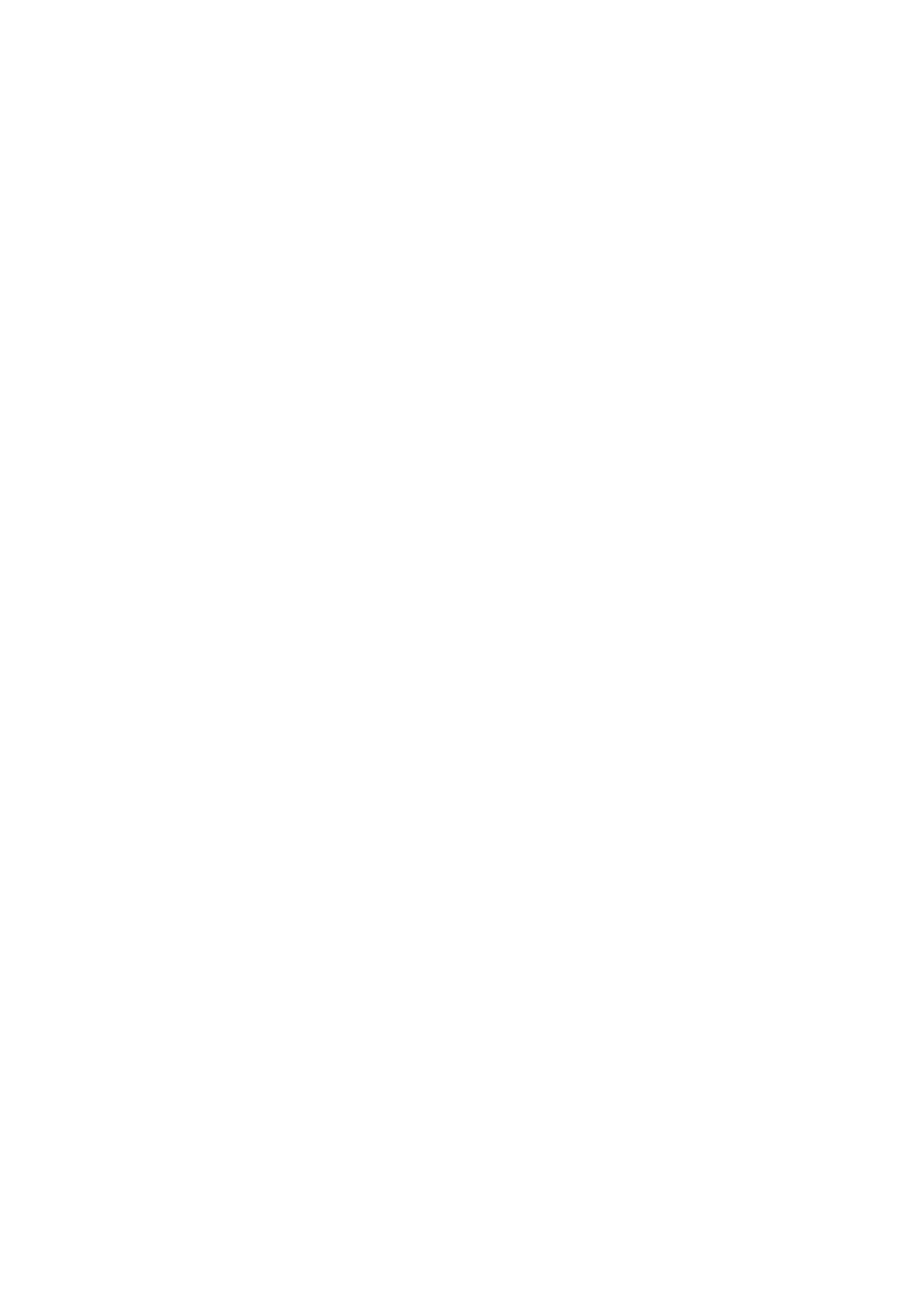




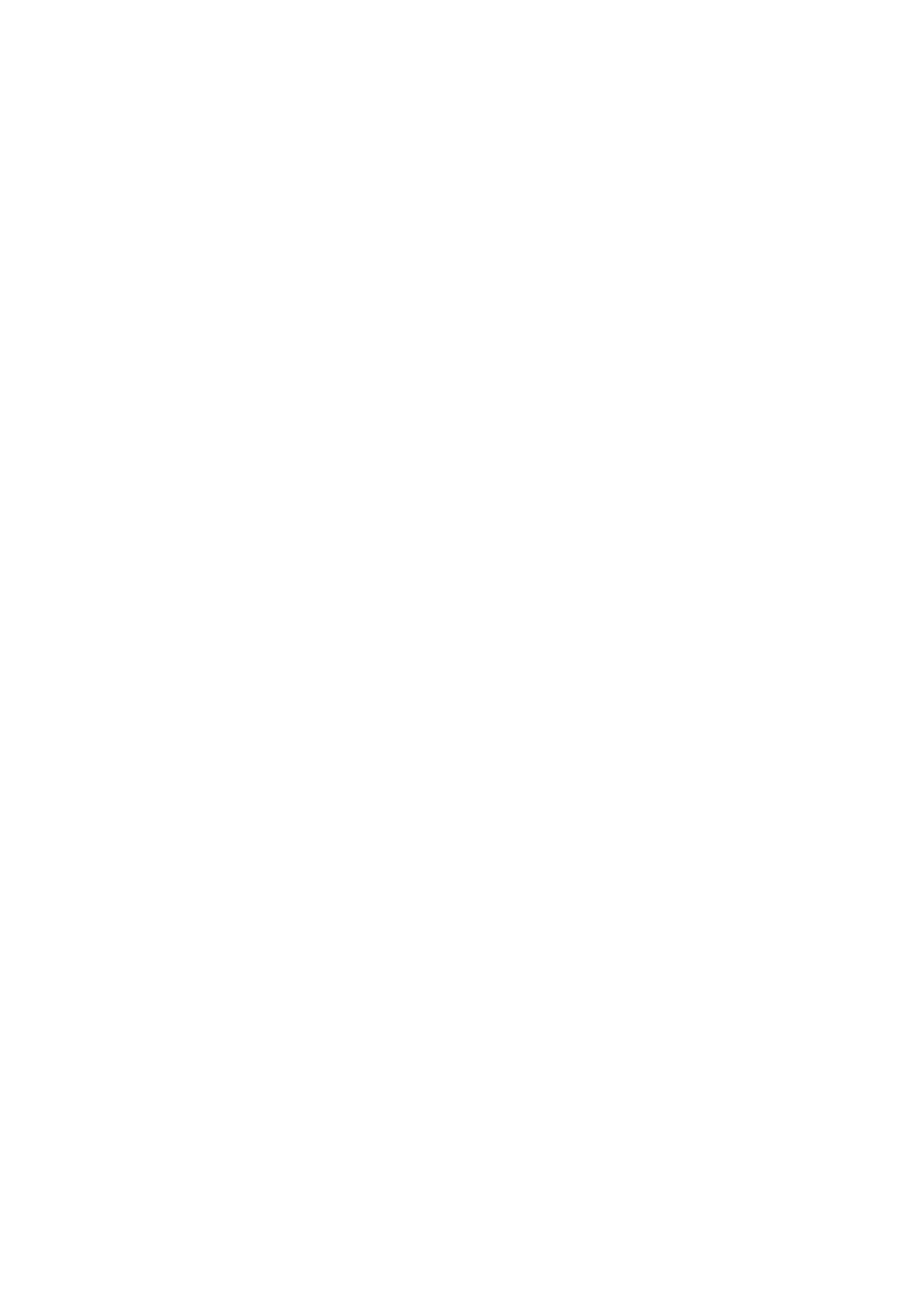




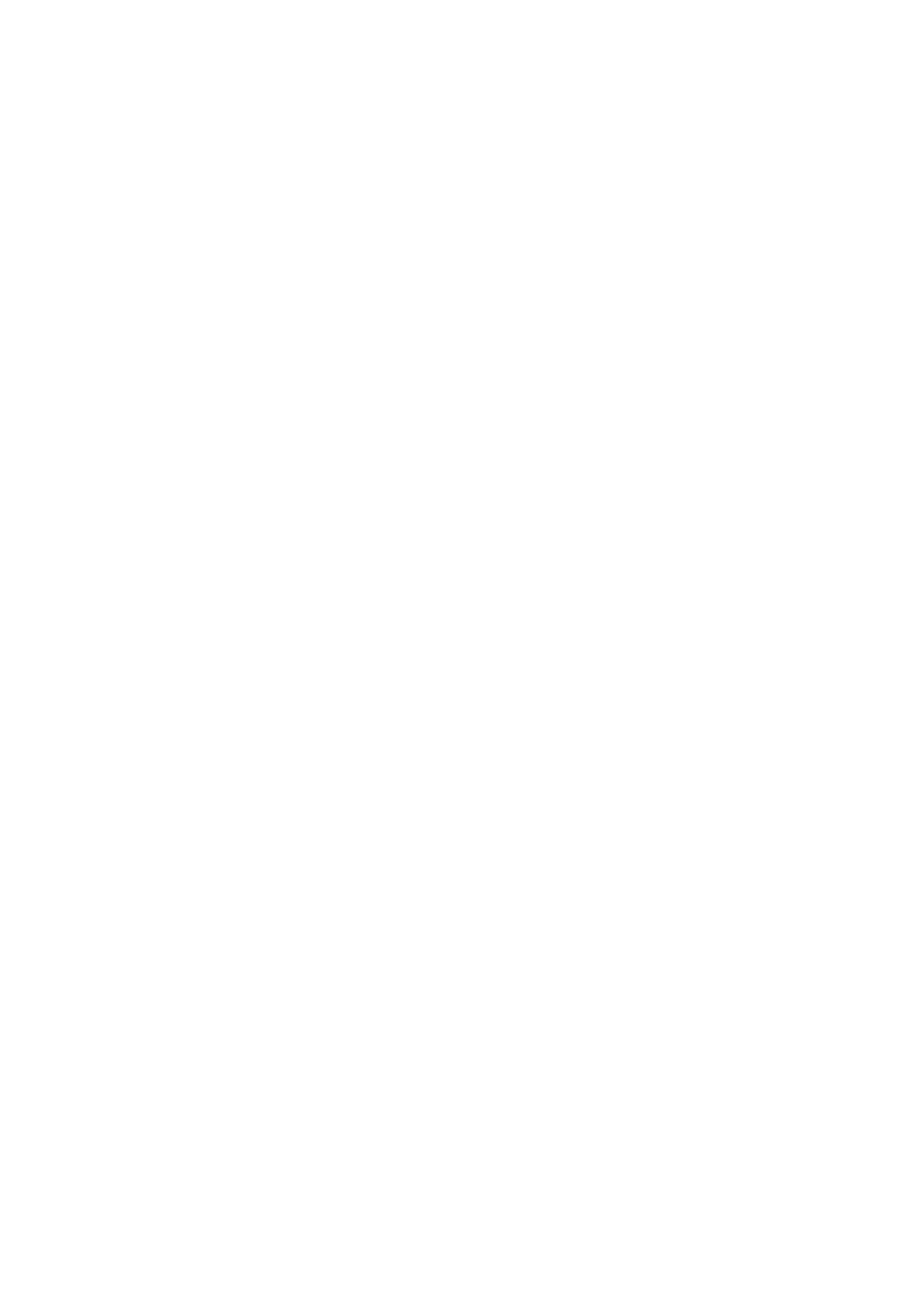




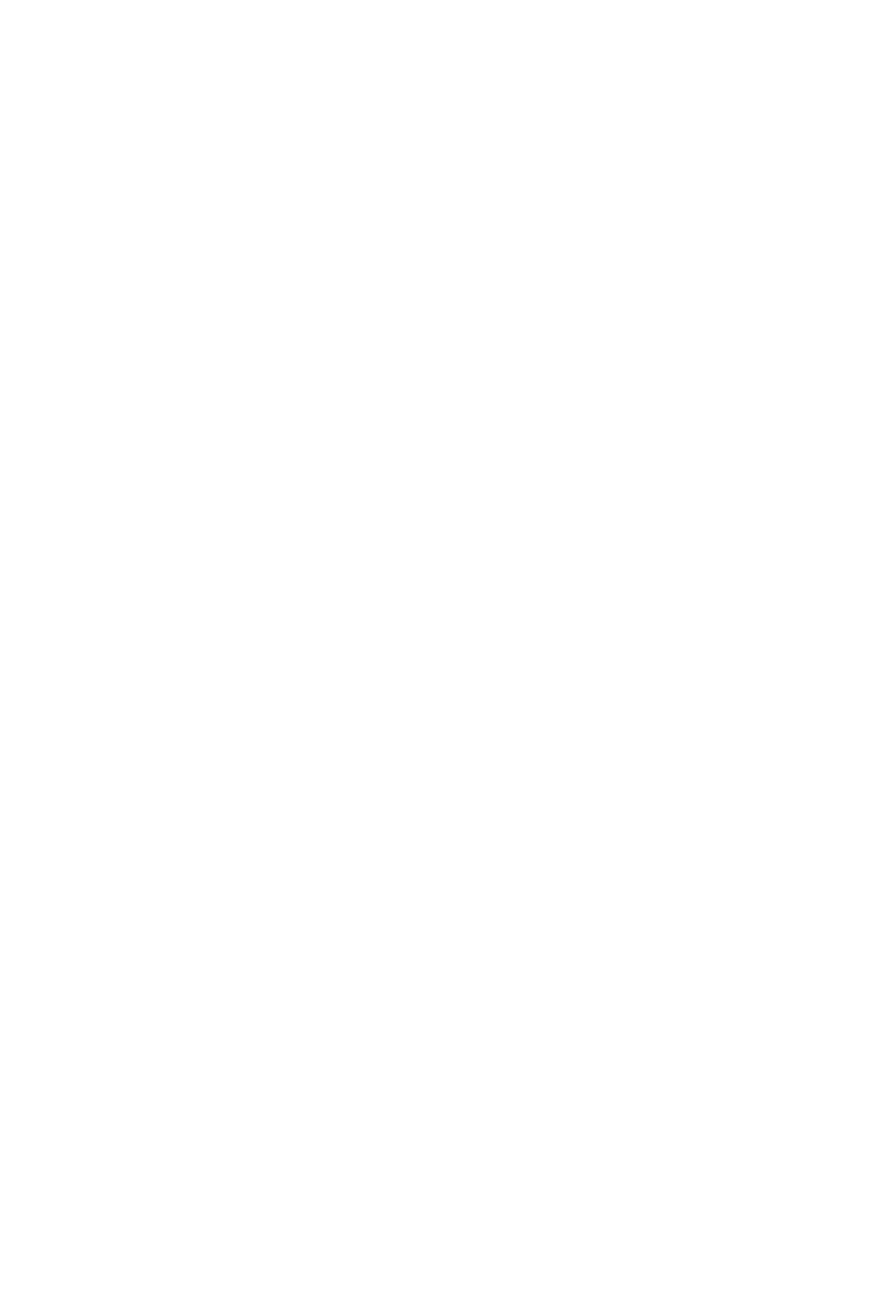




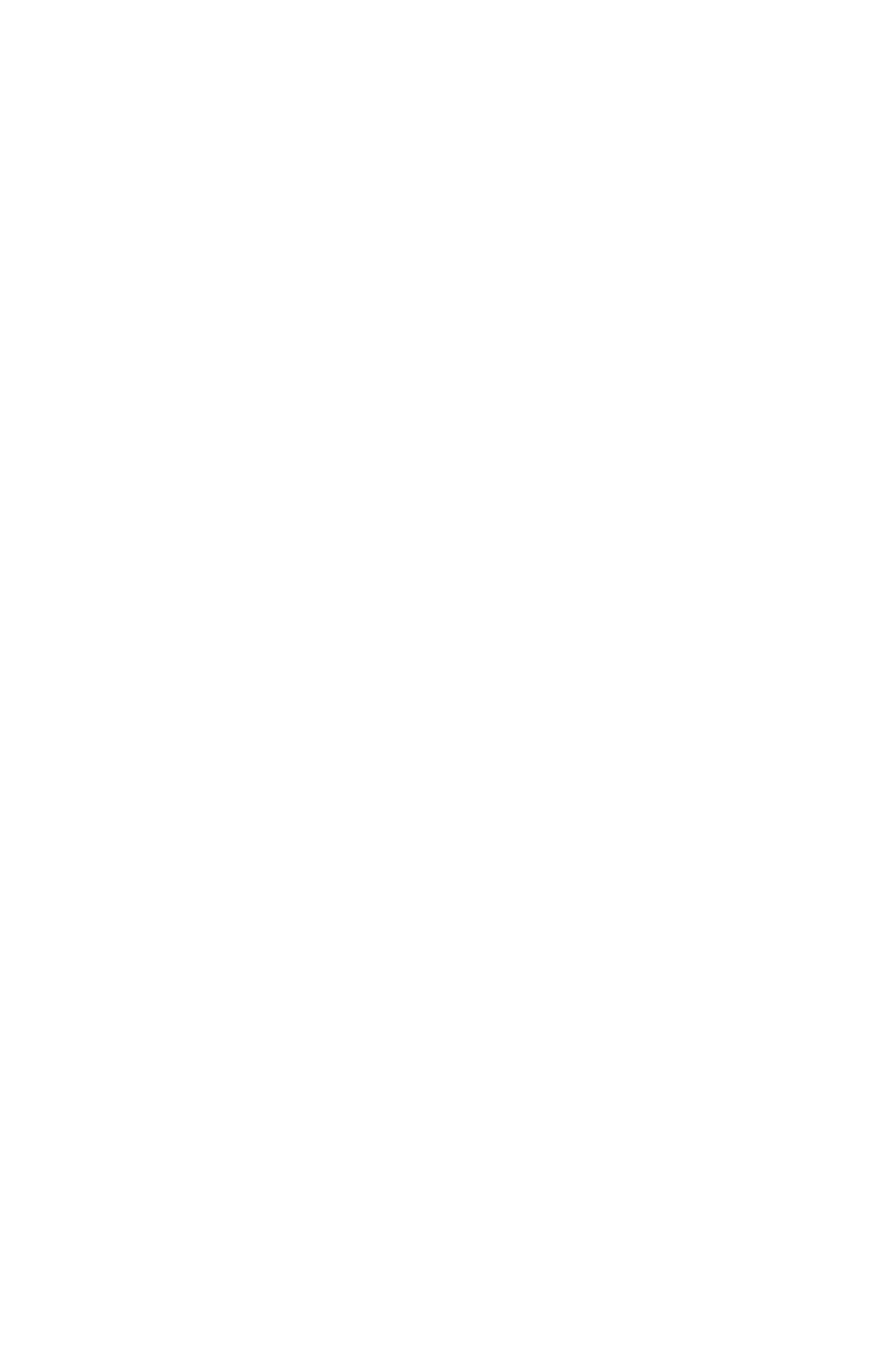




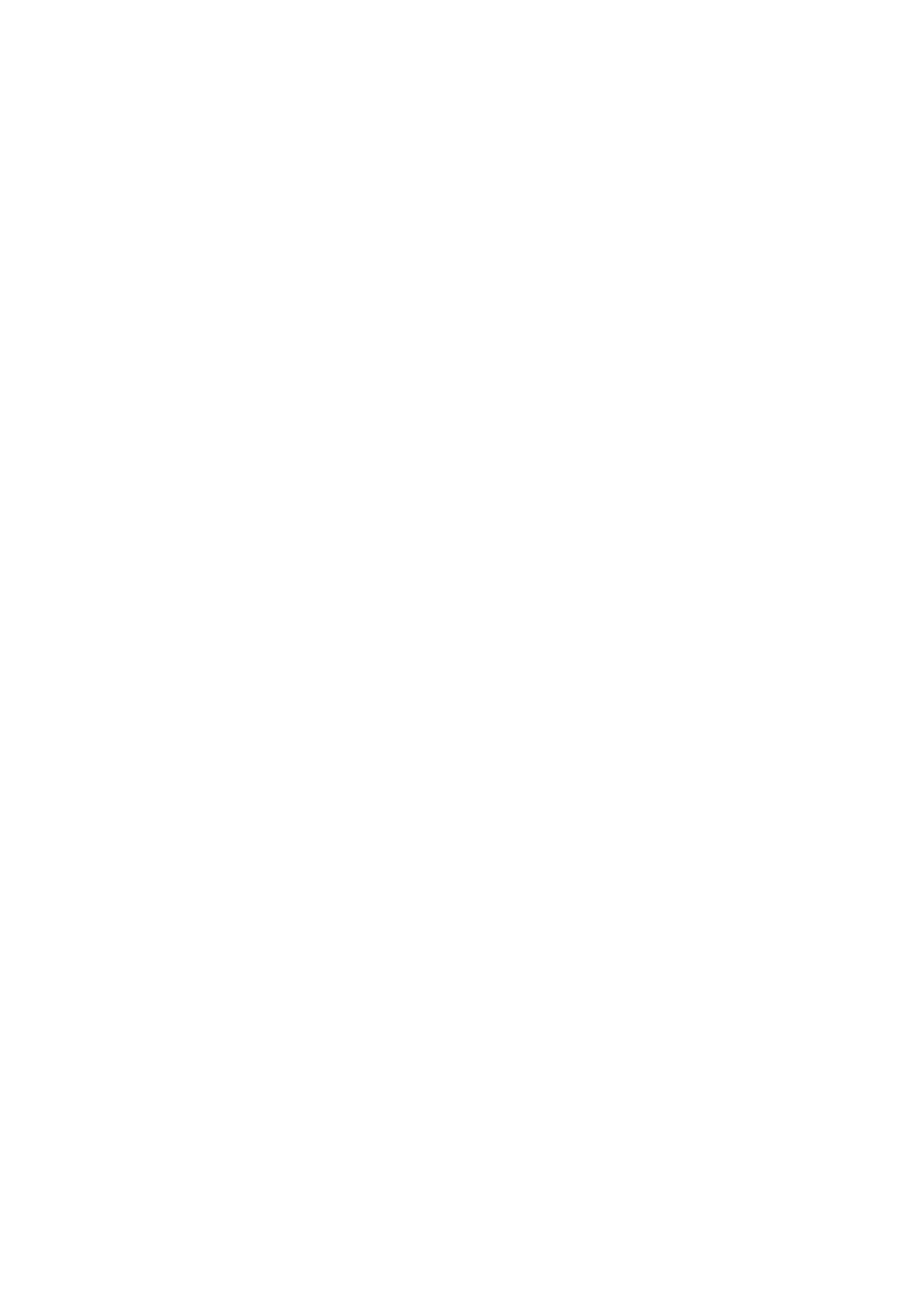




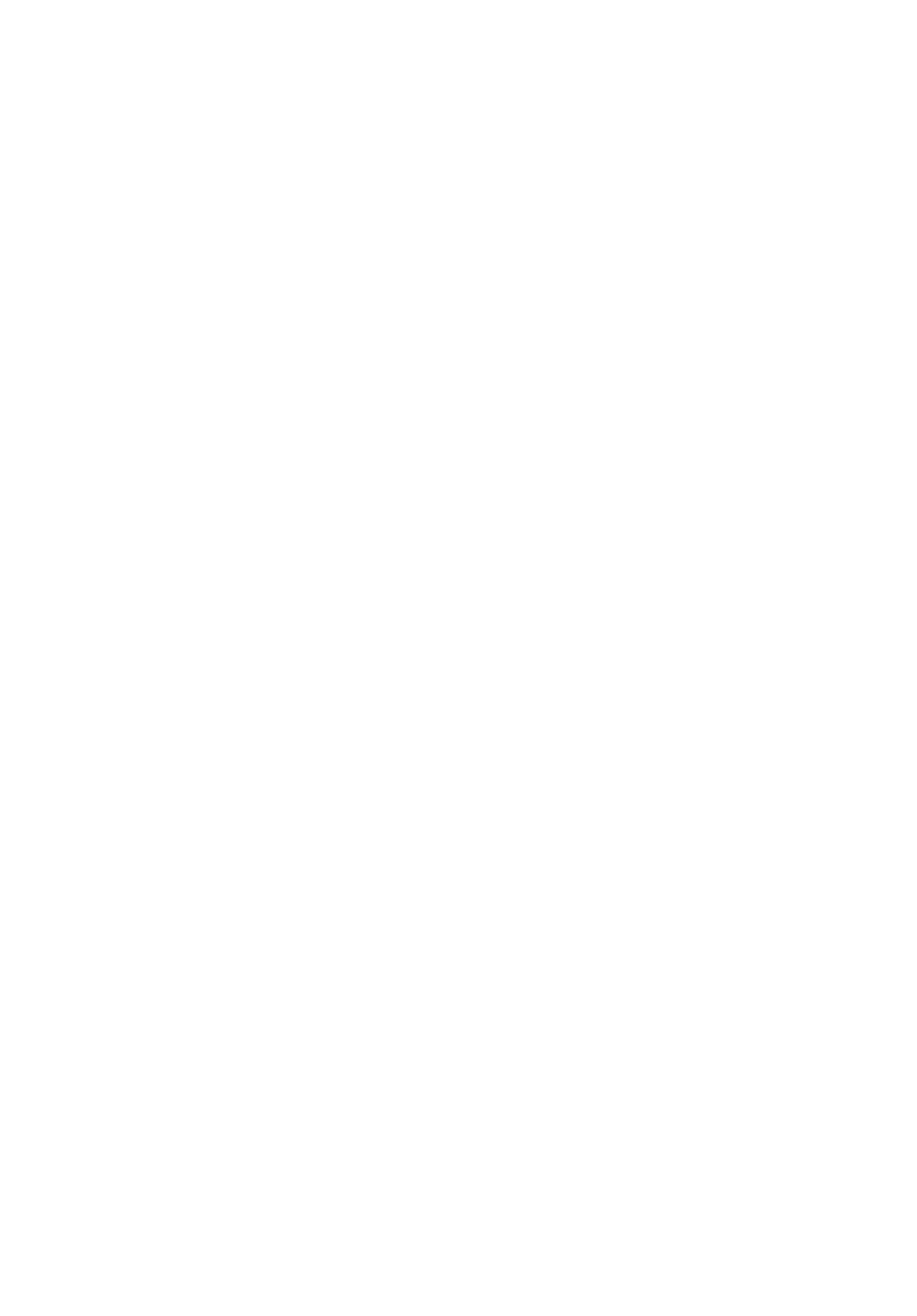




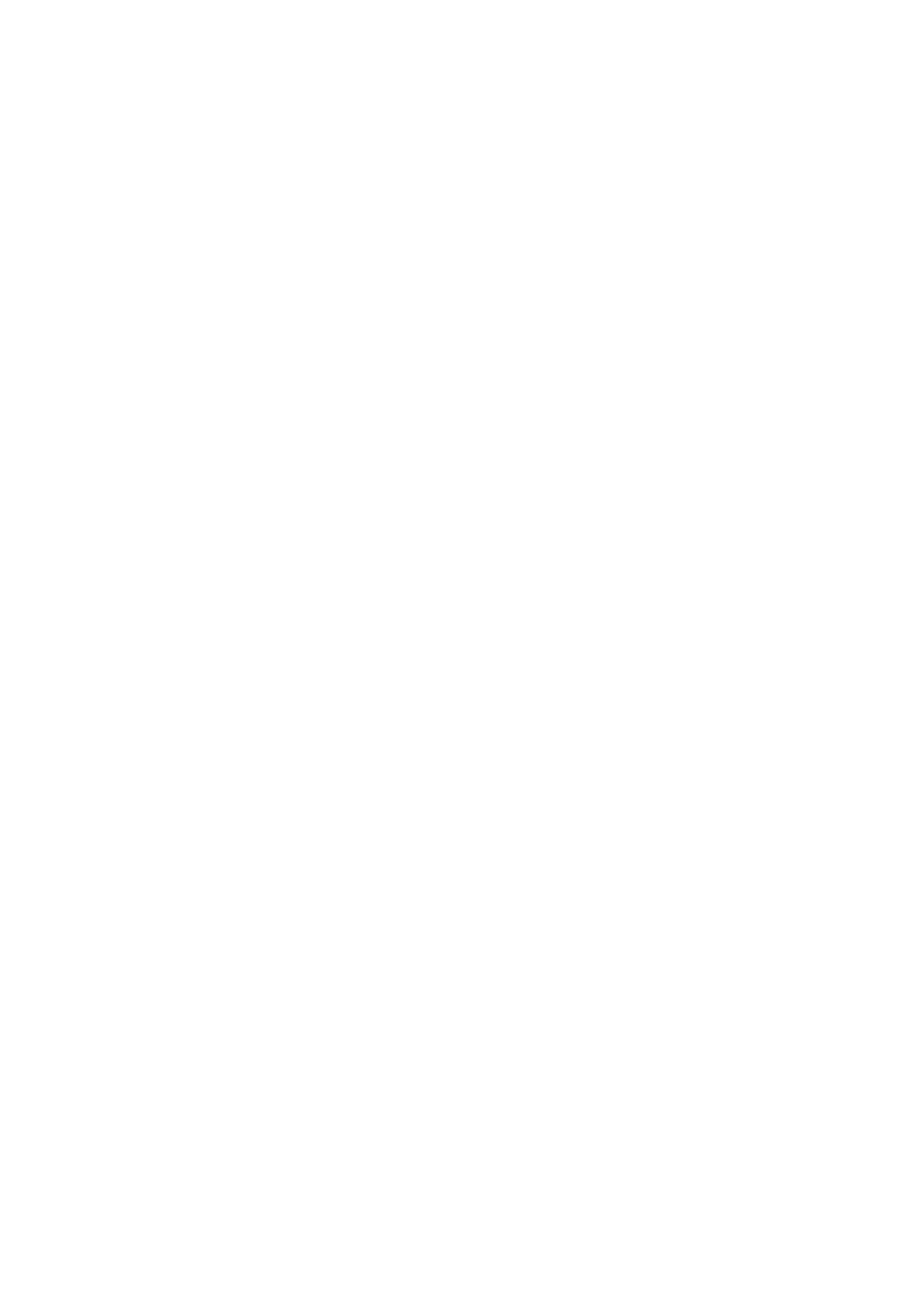




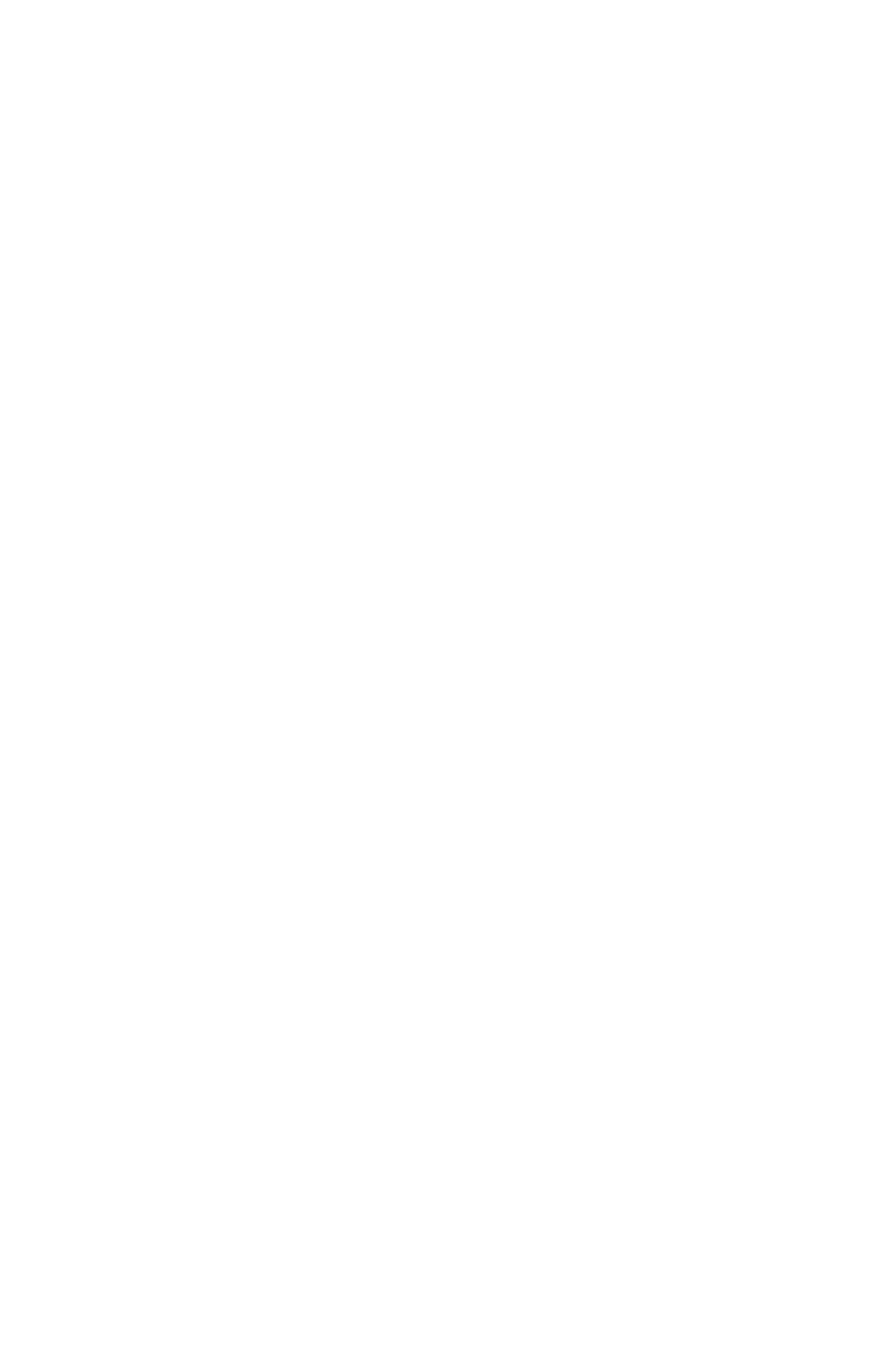




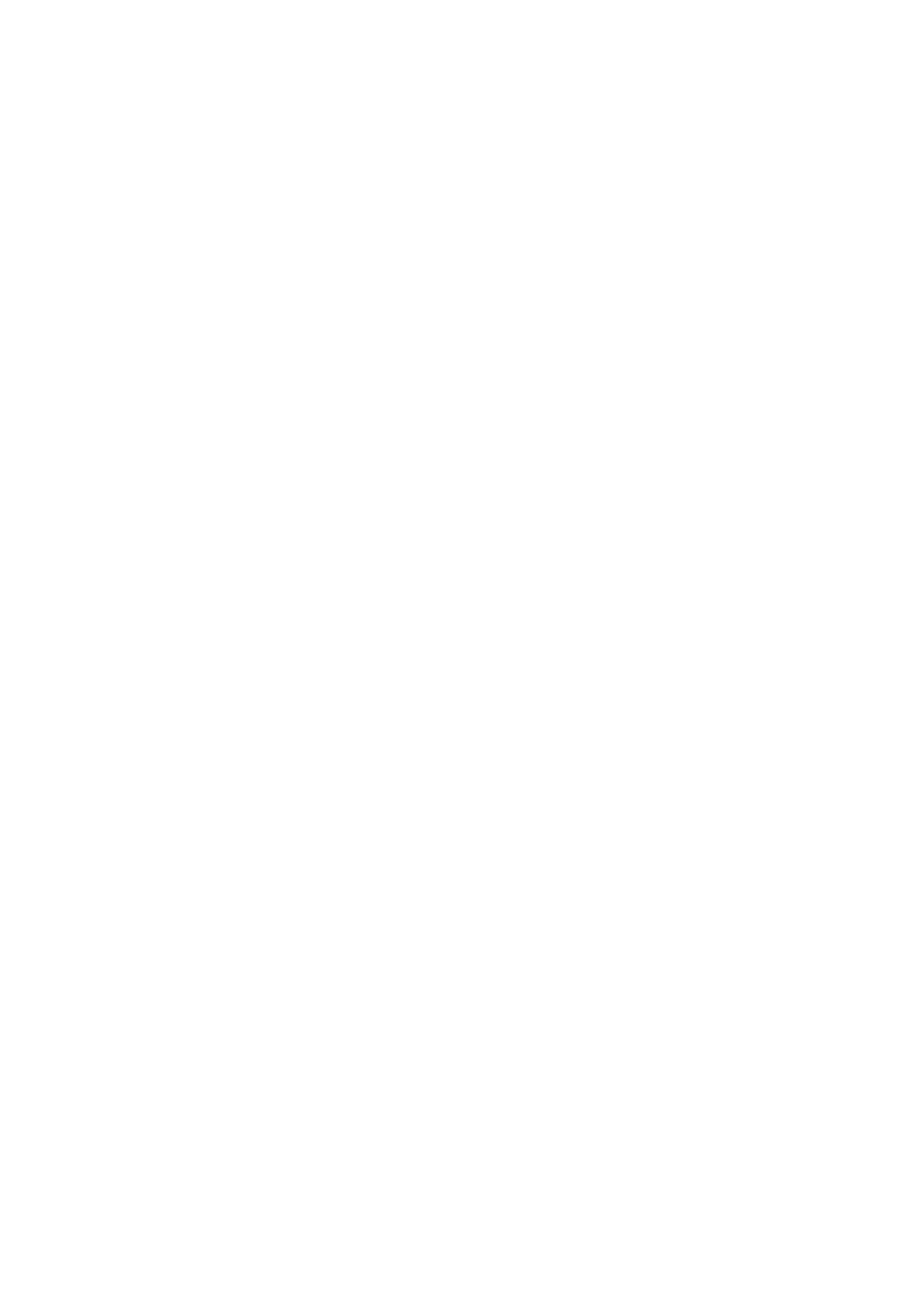




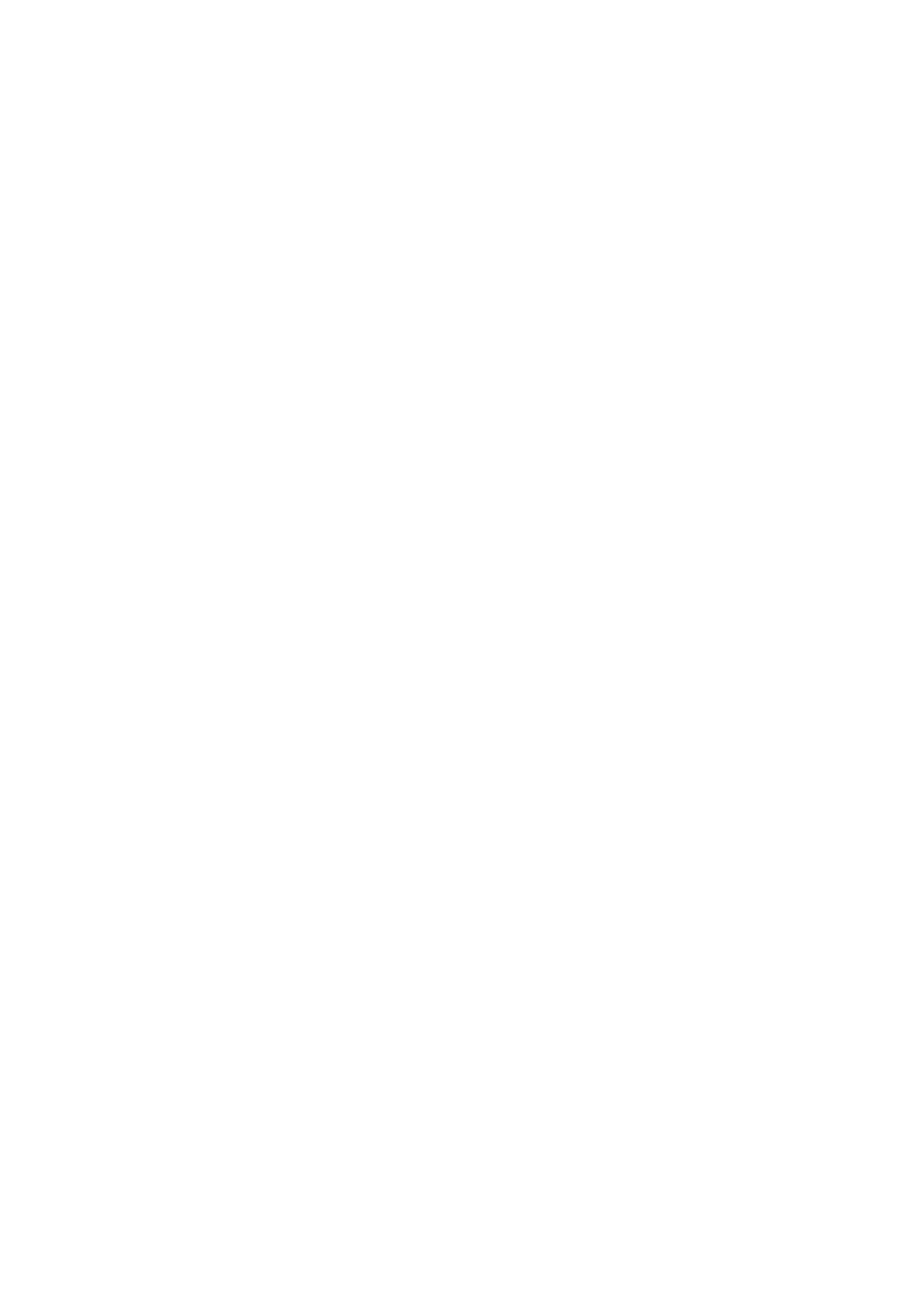




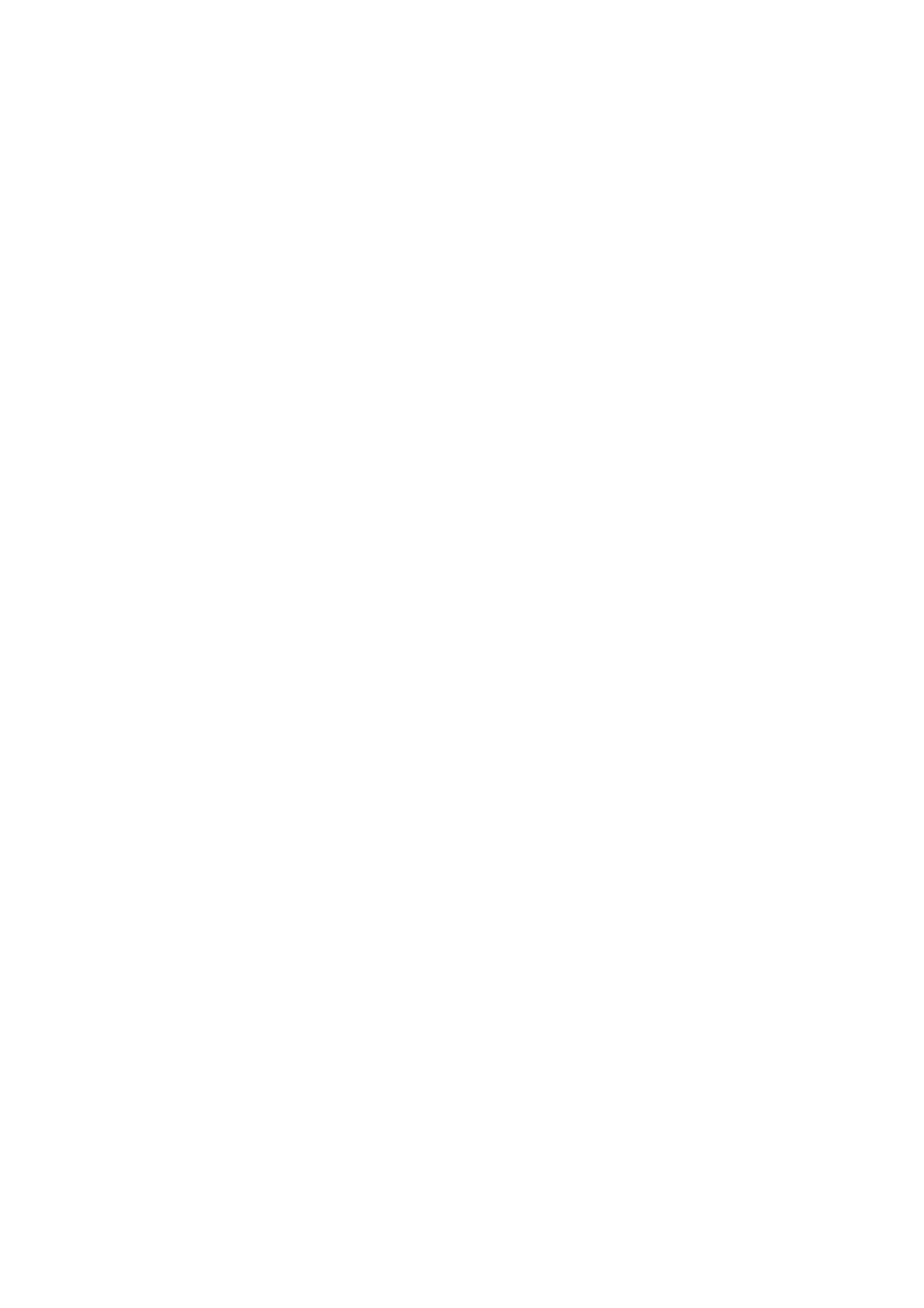




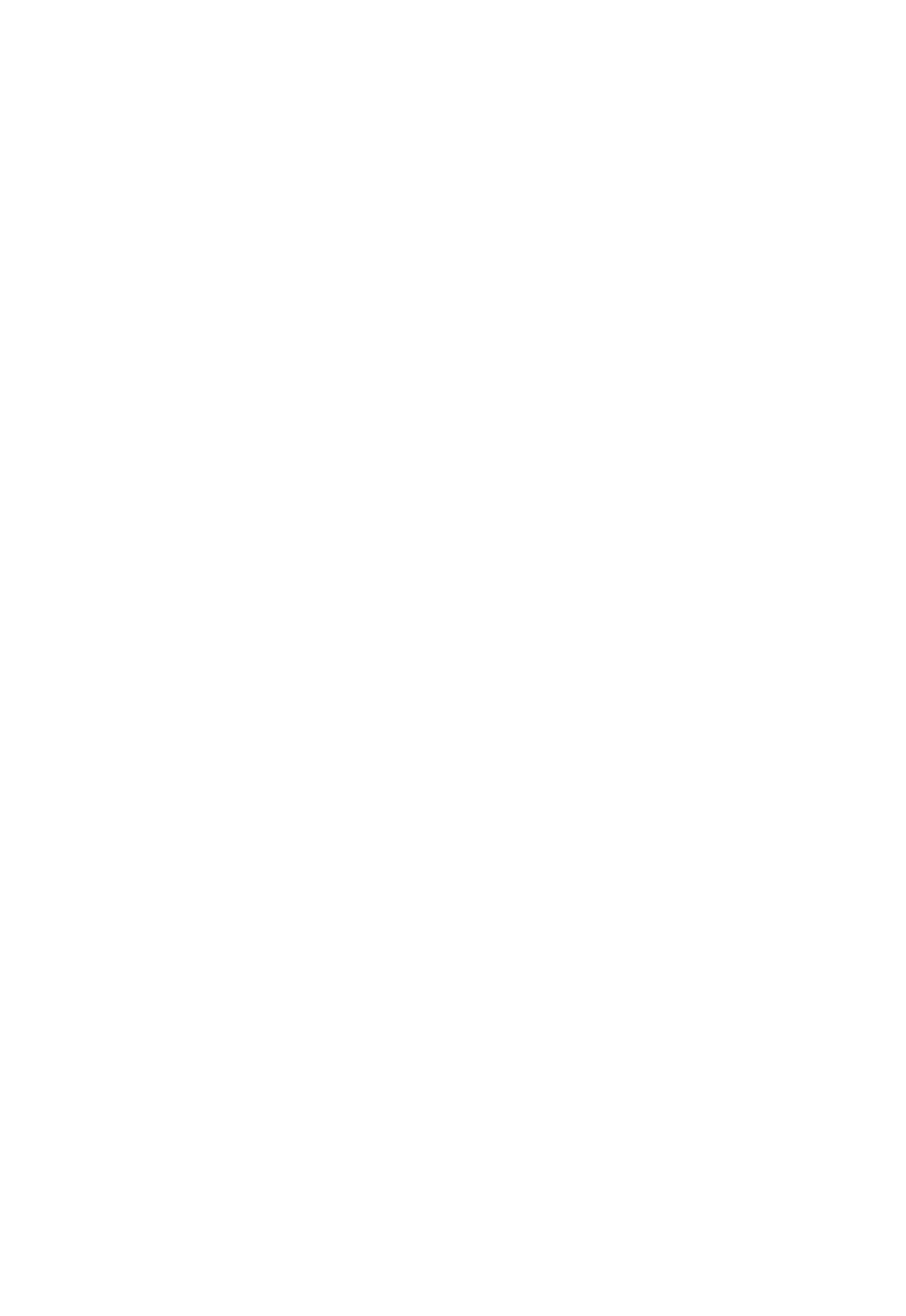




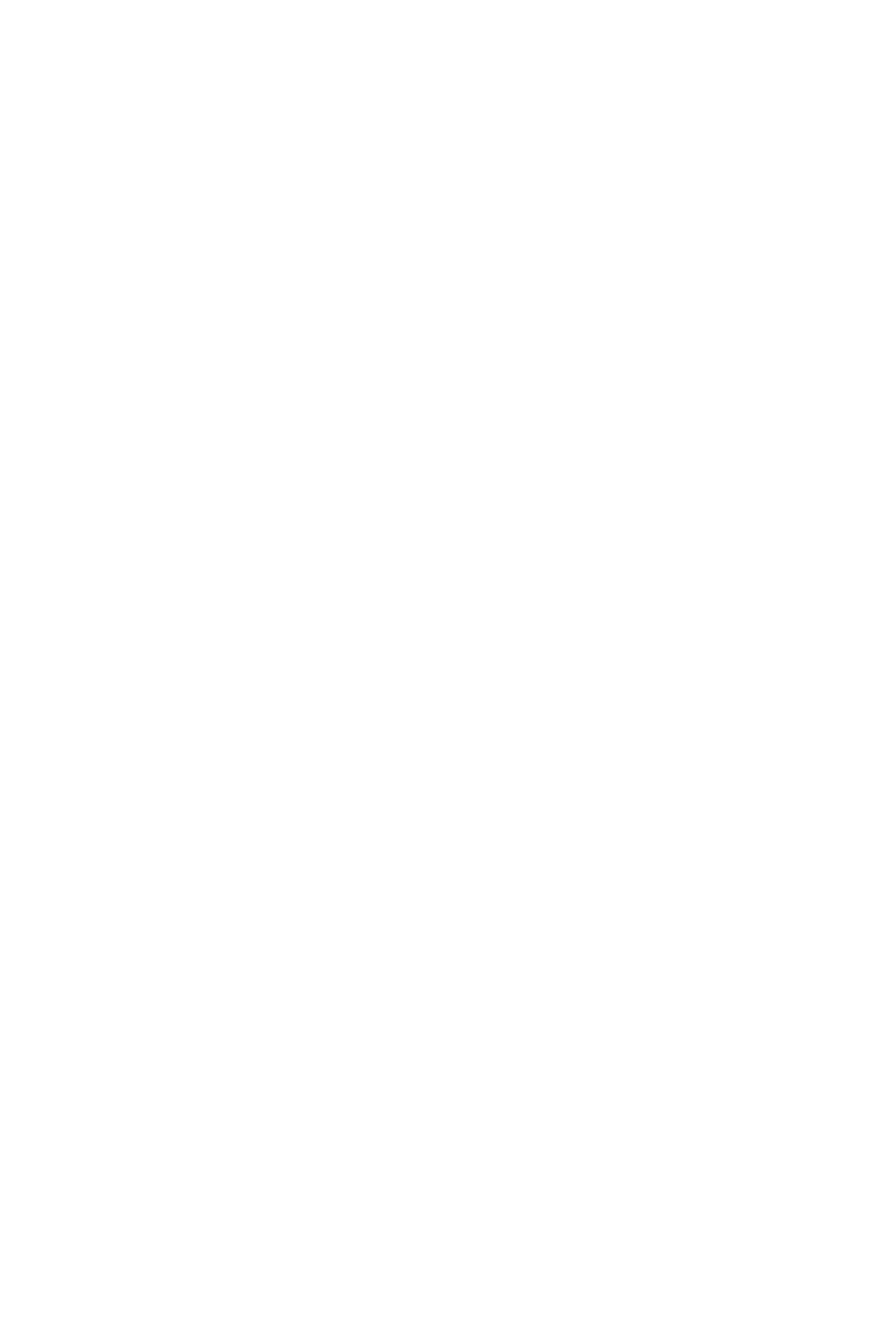




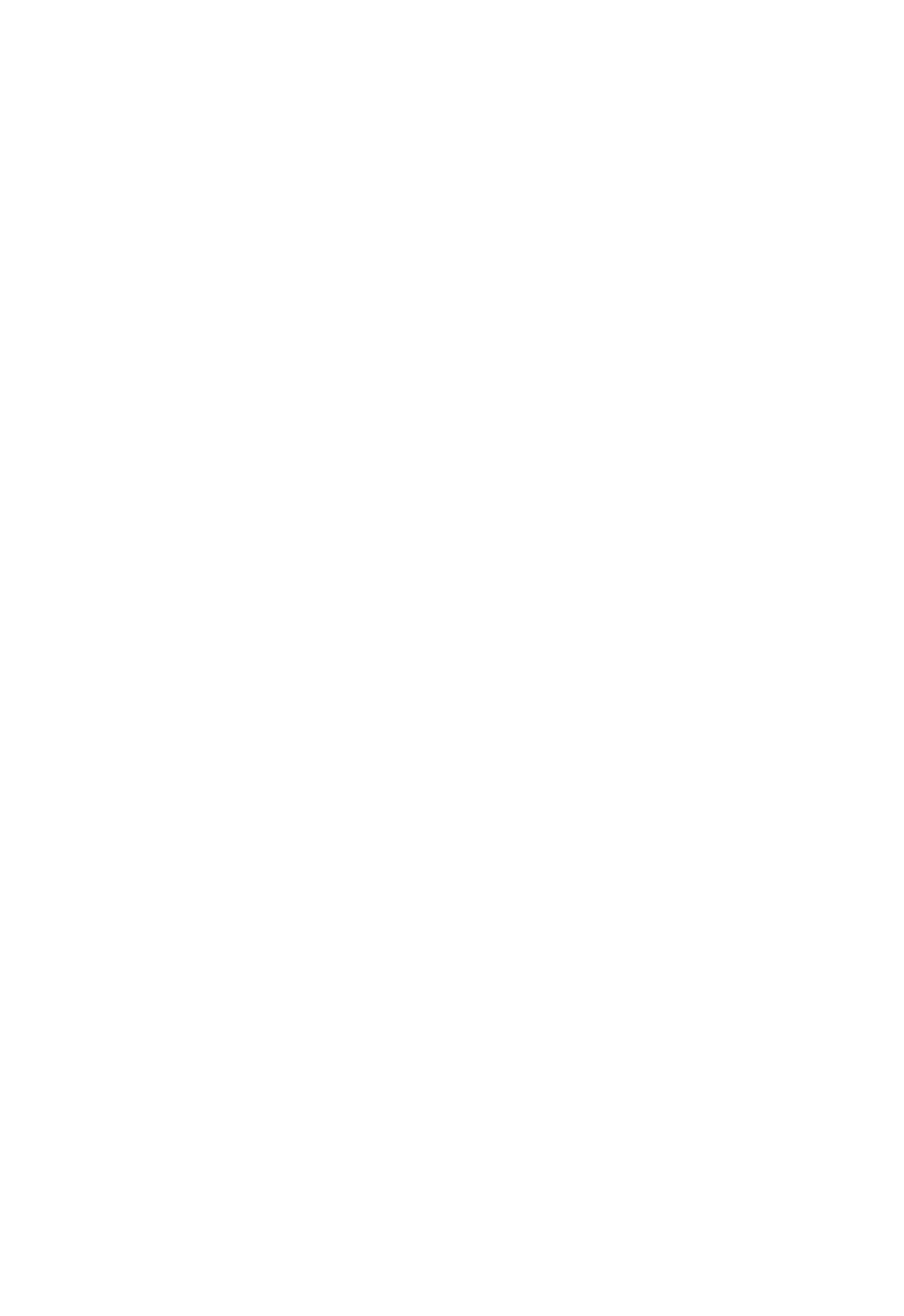




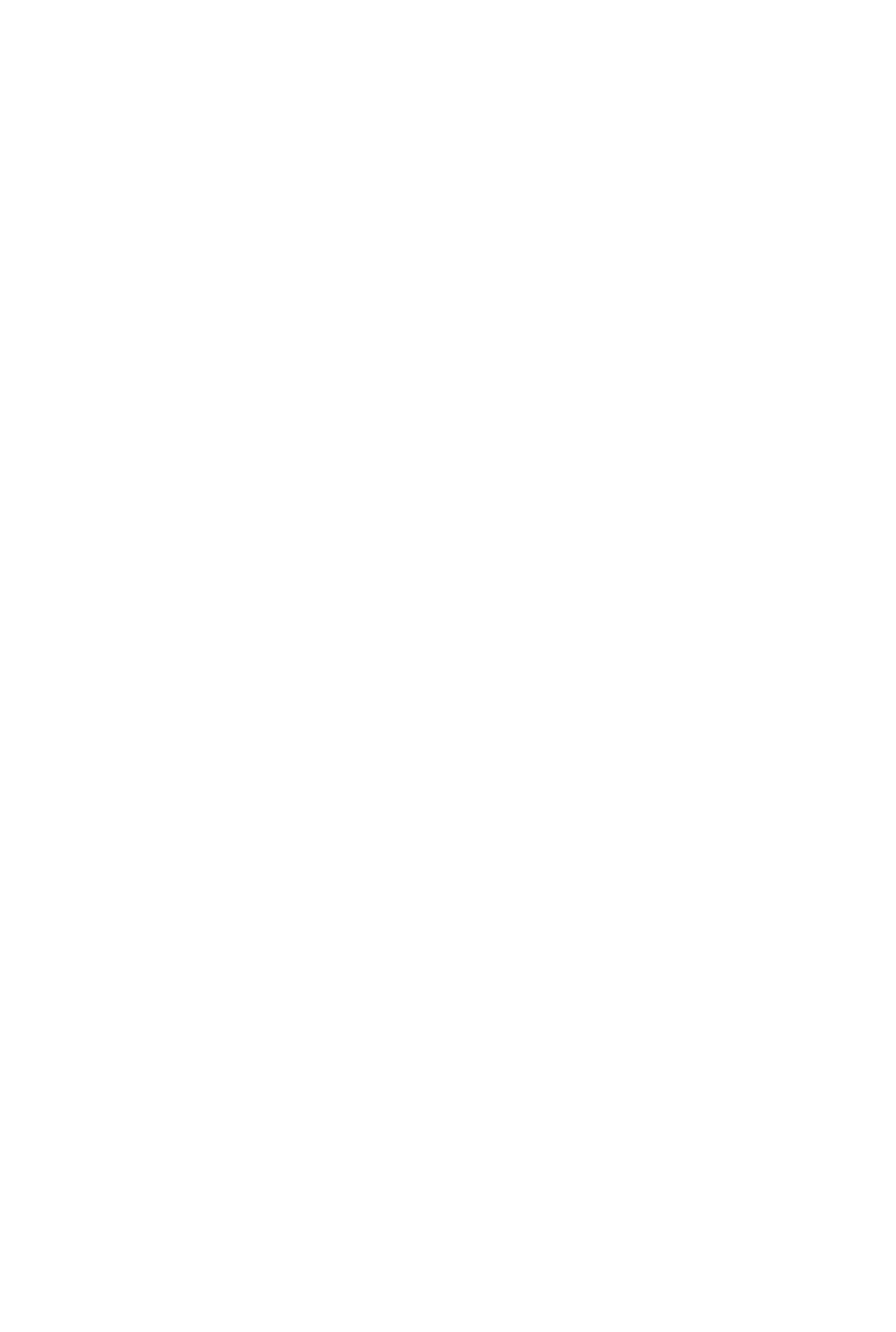




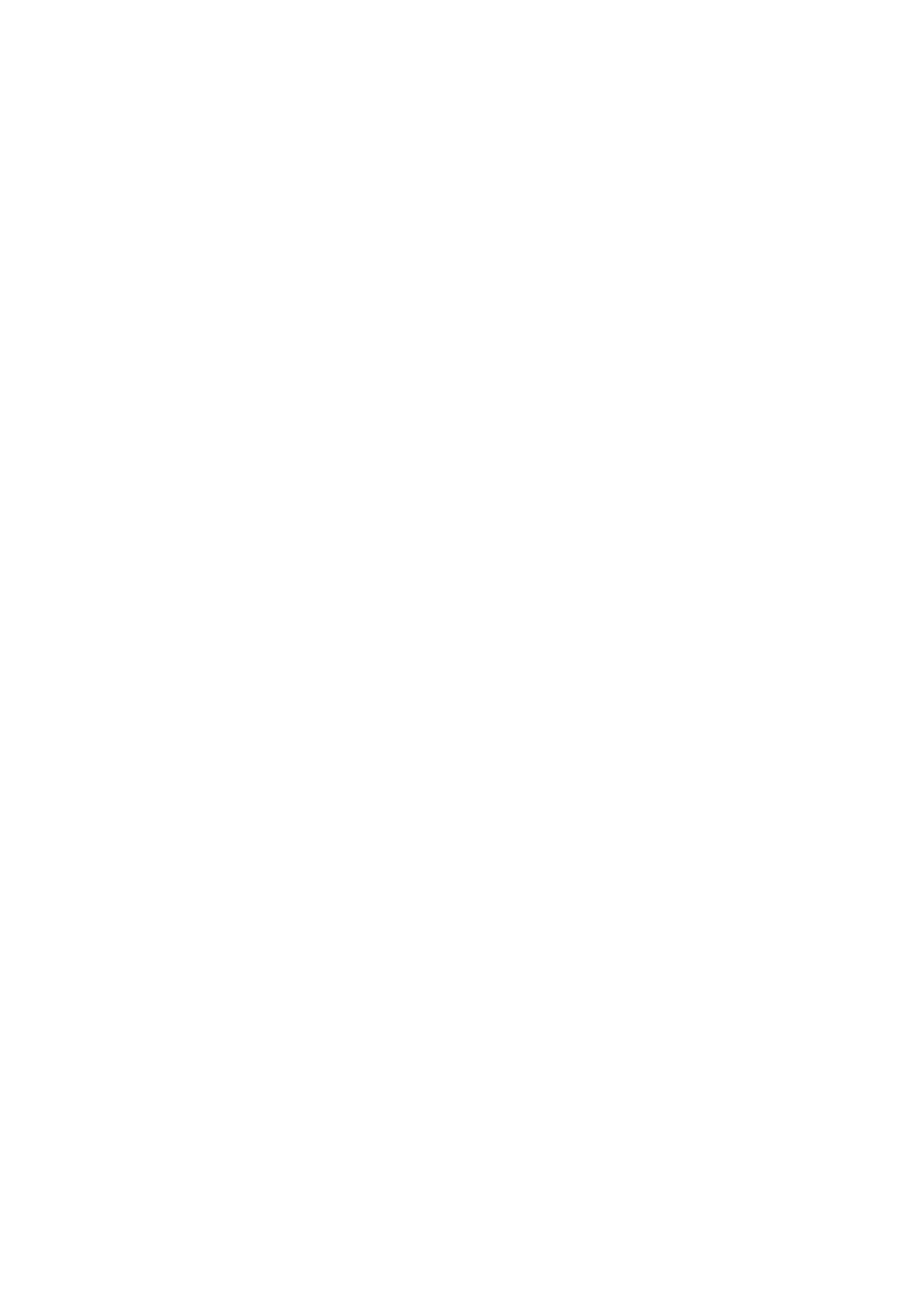




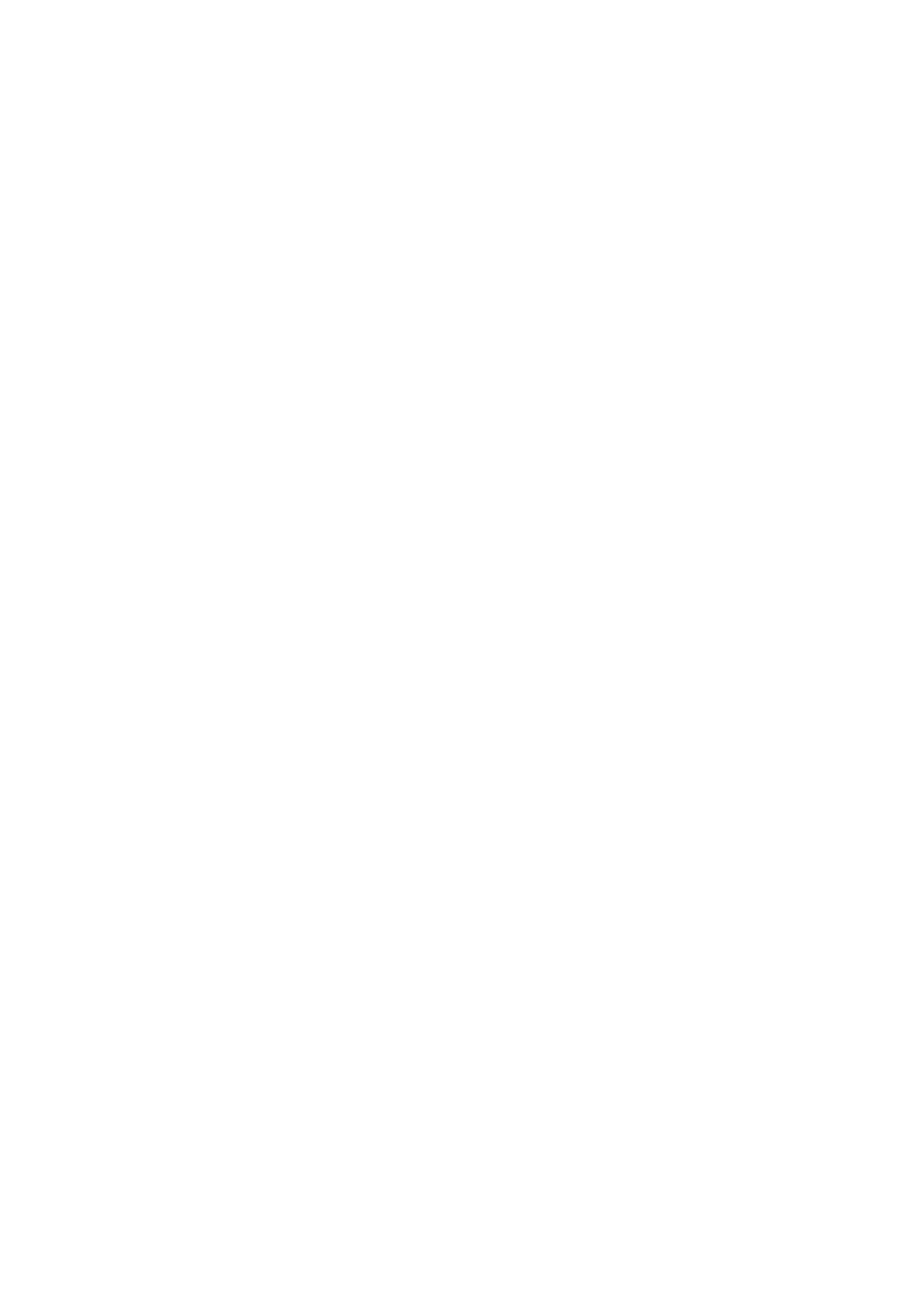




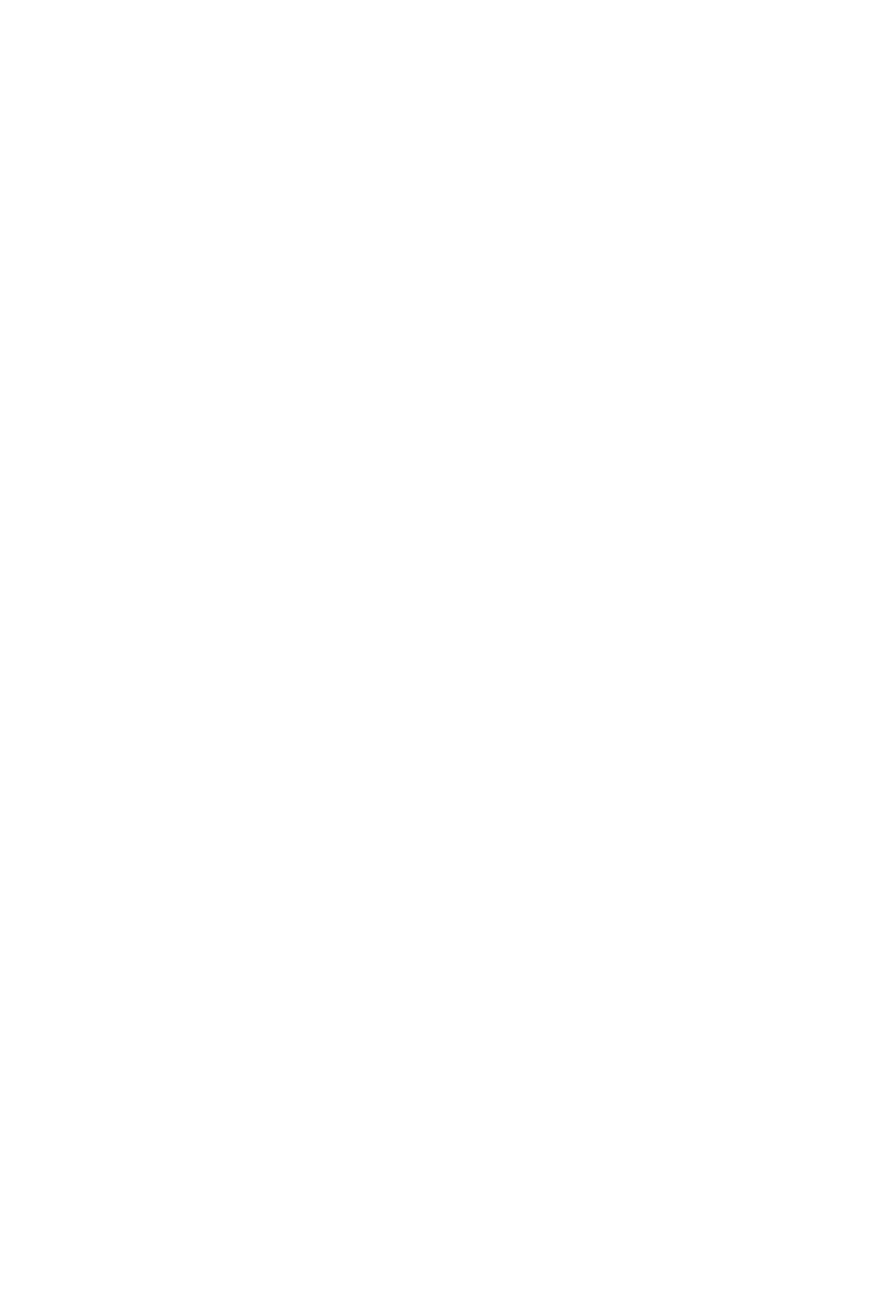


\|\|\|\|\|\|$\|1\|$

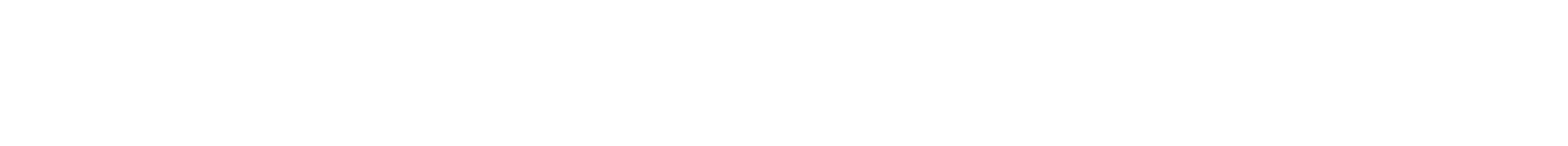

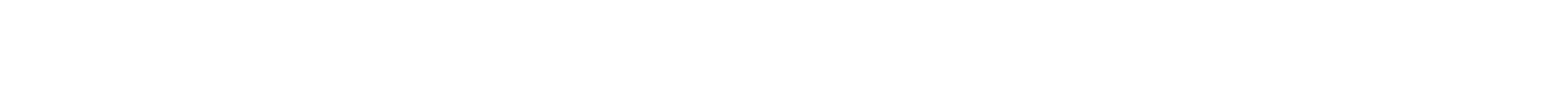

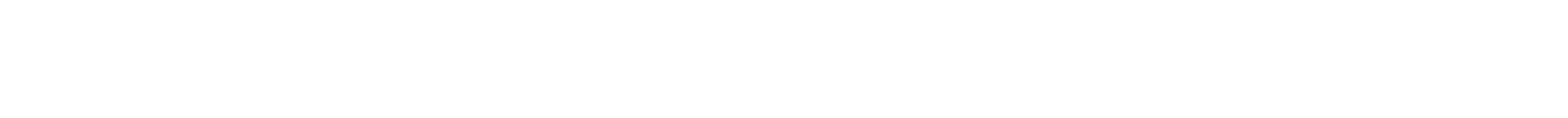

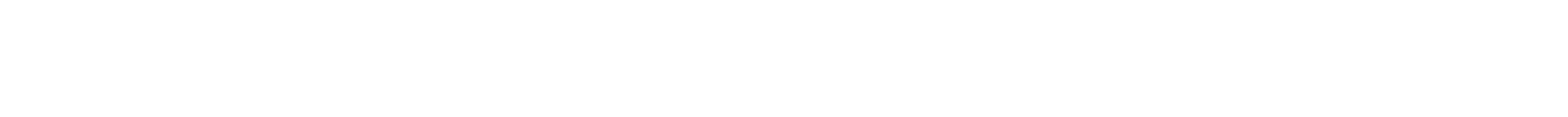

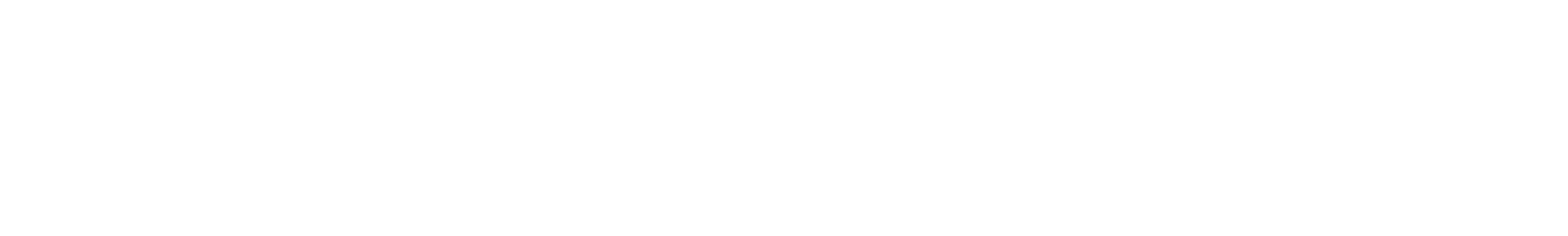

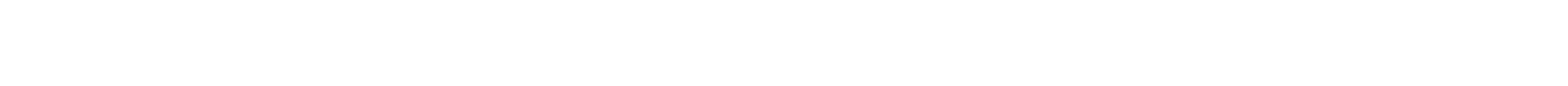

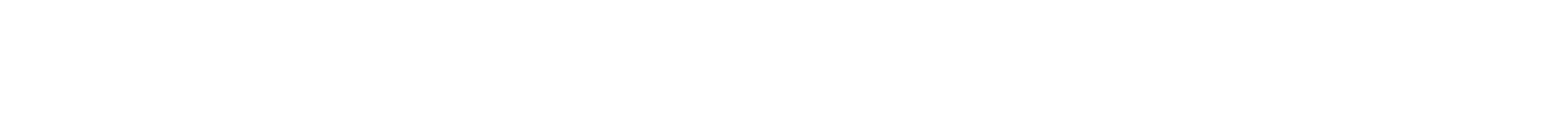

点

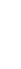

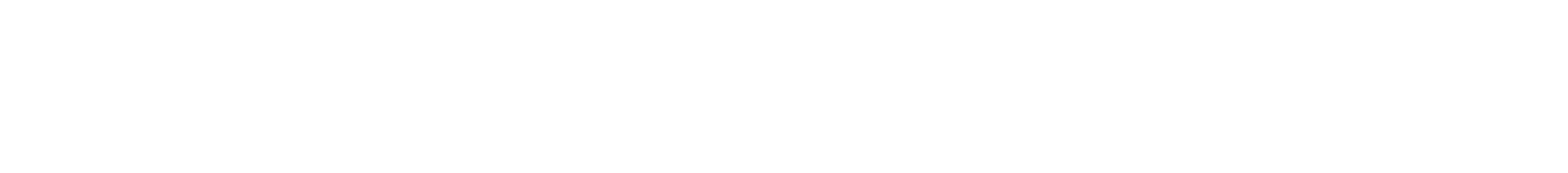

.

要

3

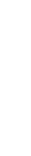

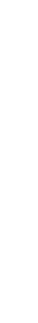

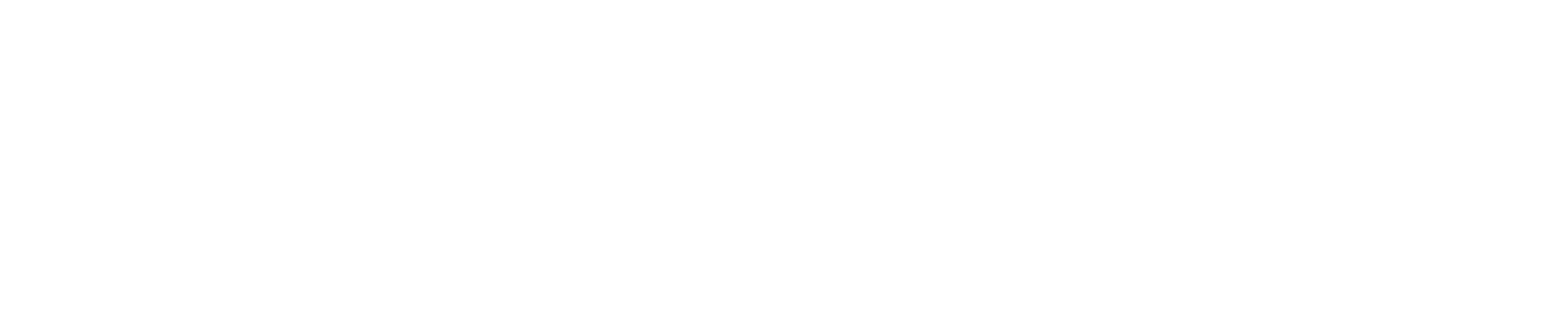

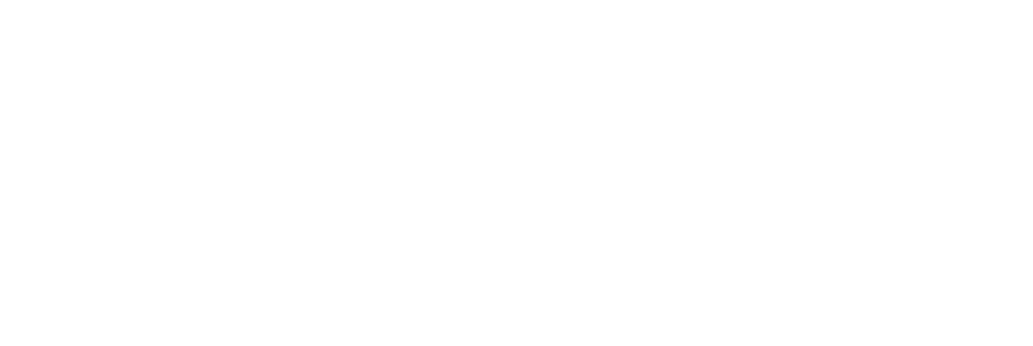

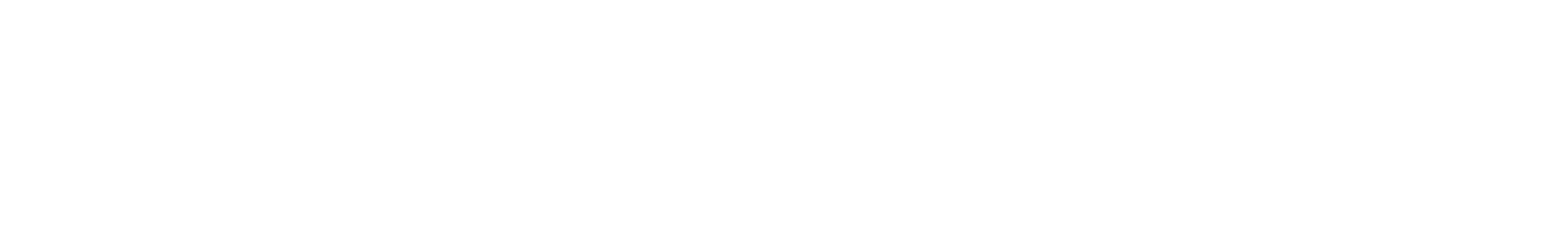

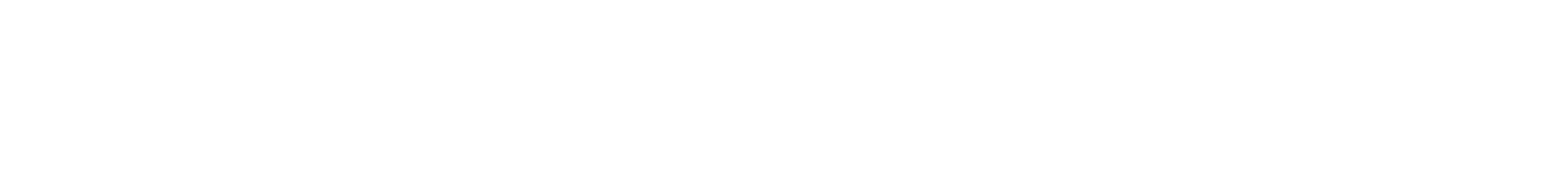

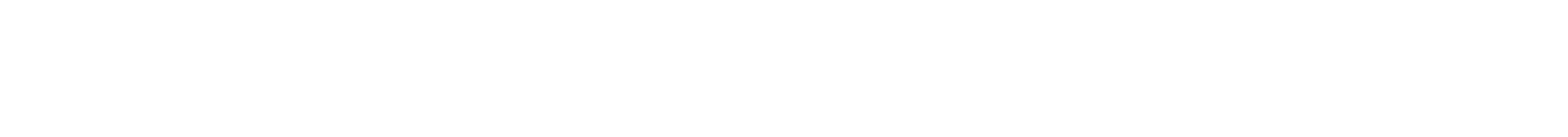




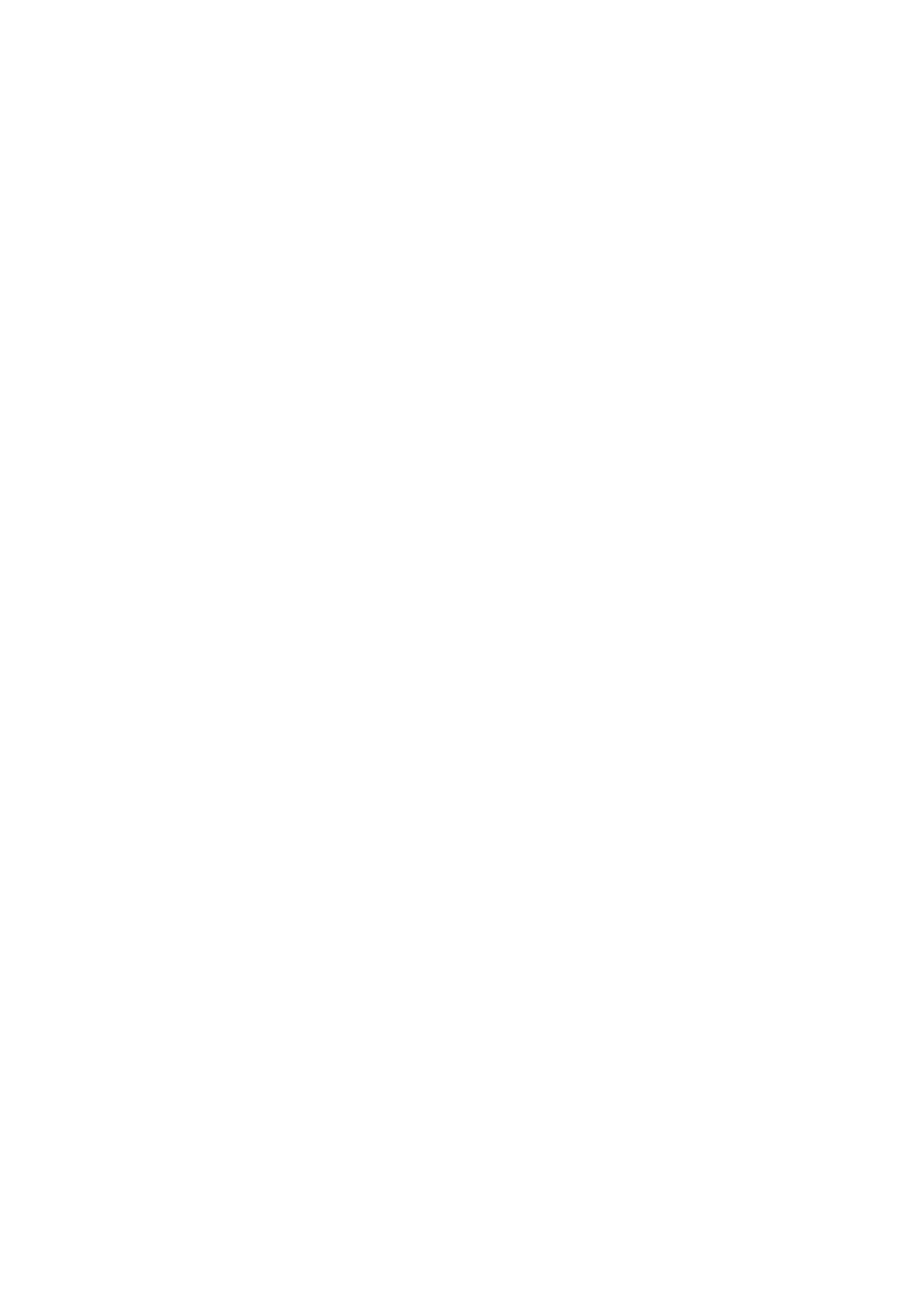




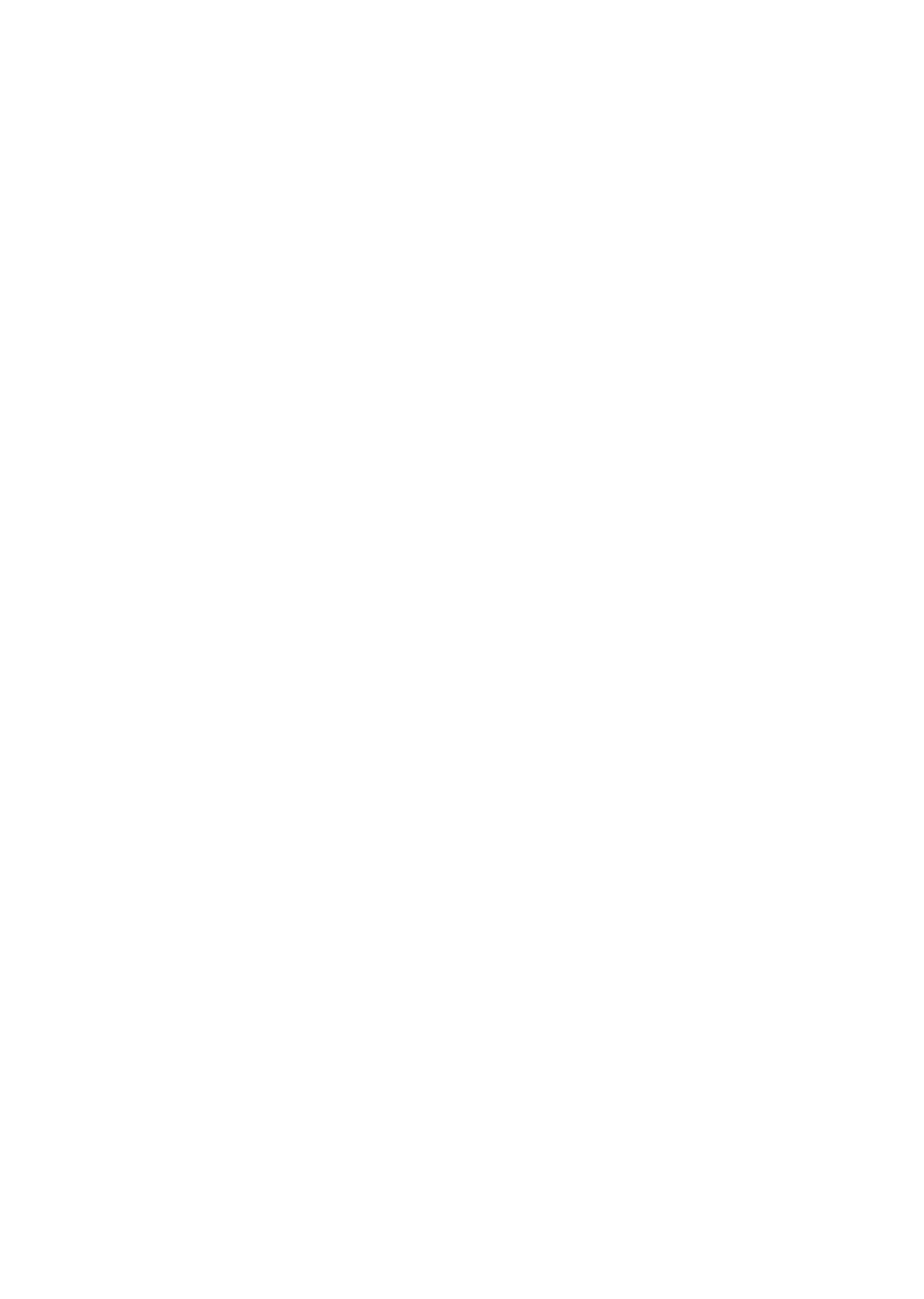




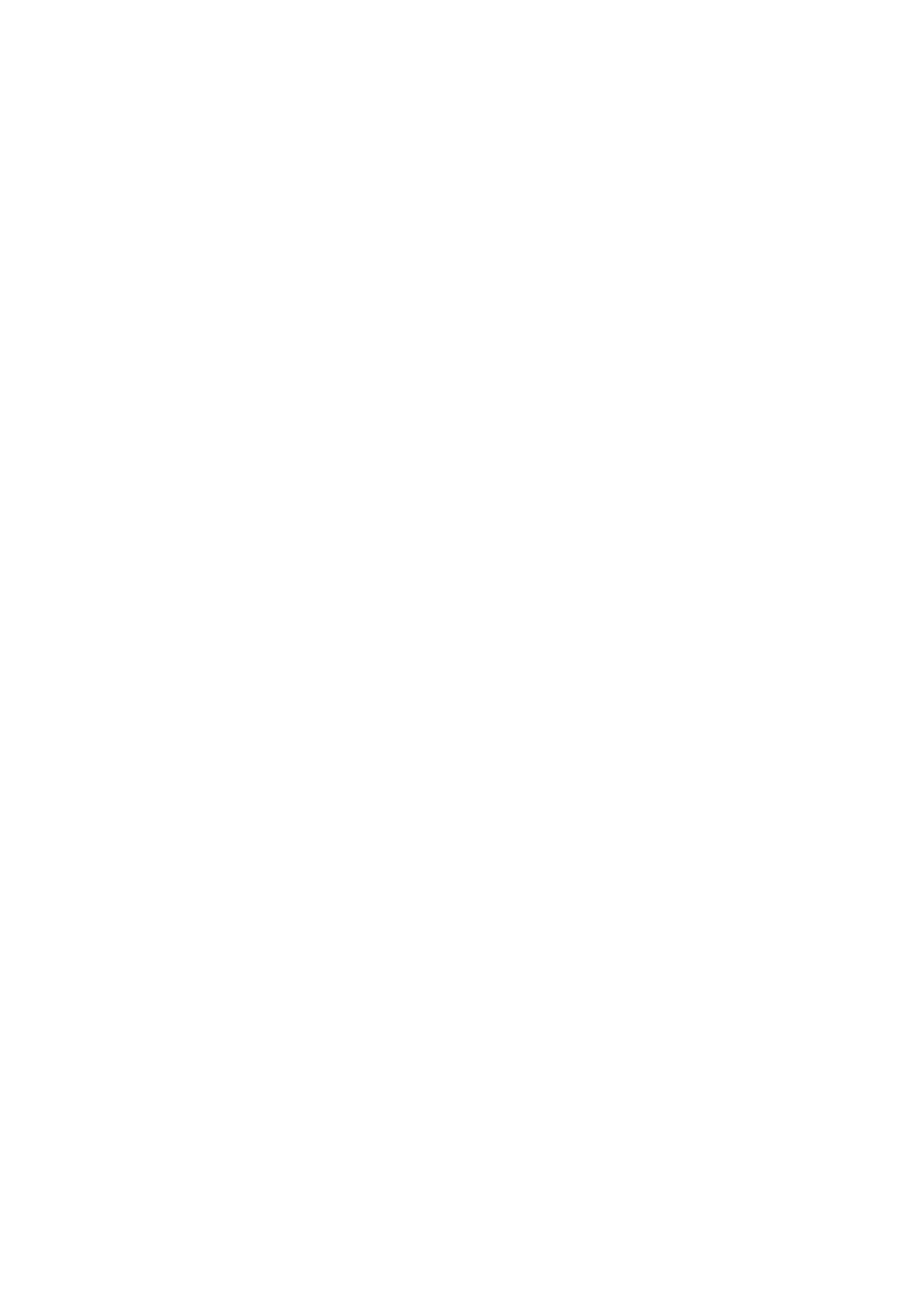




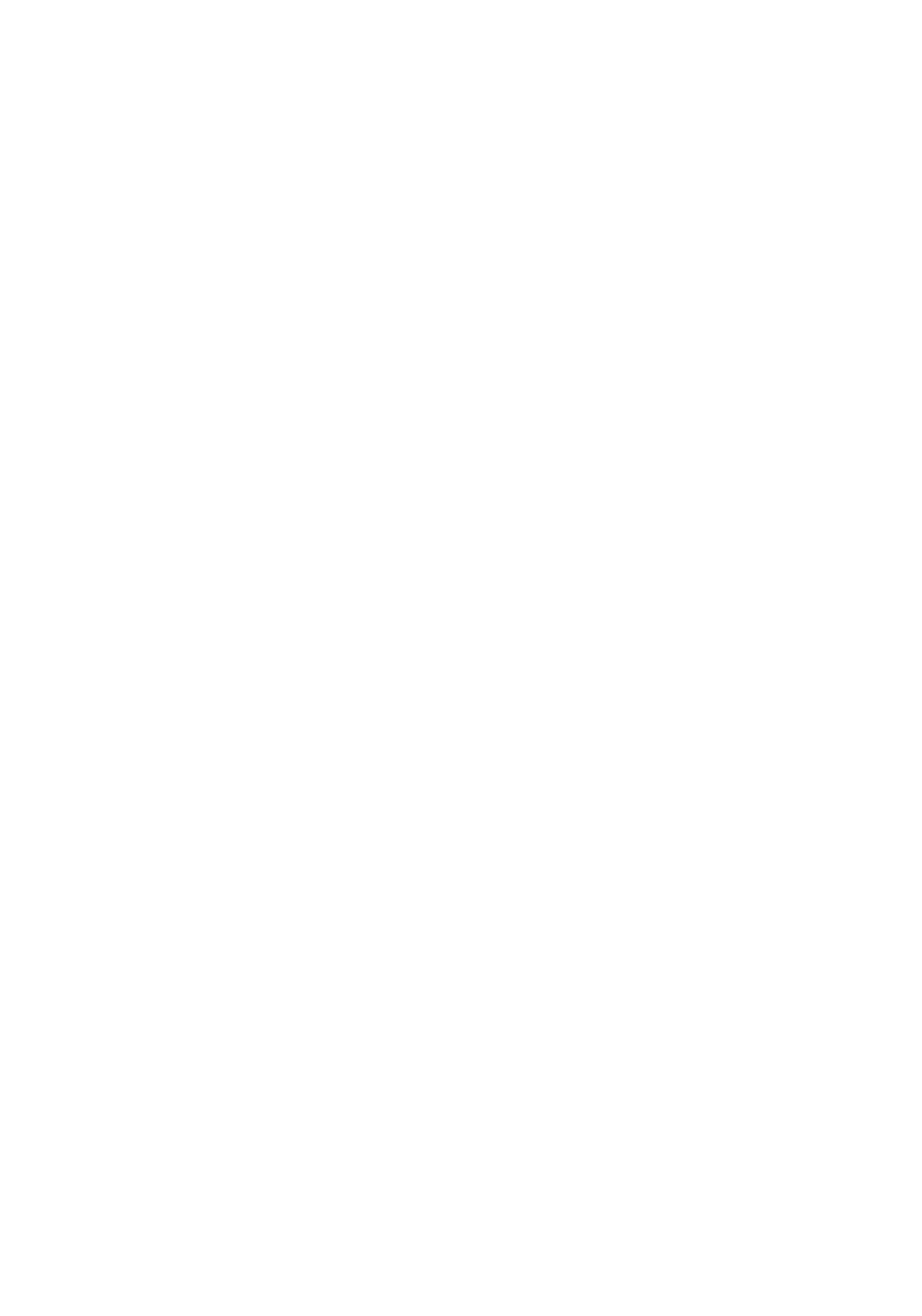




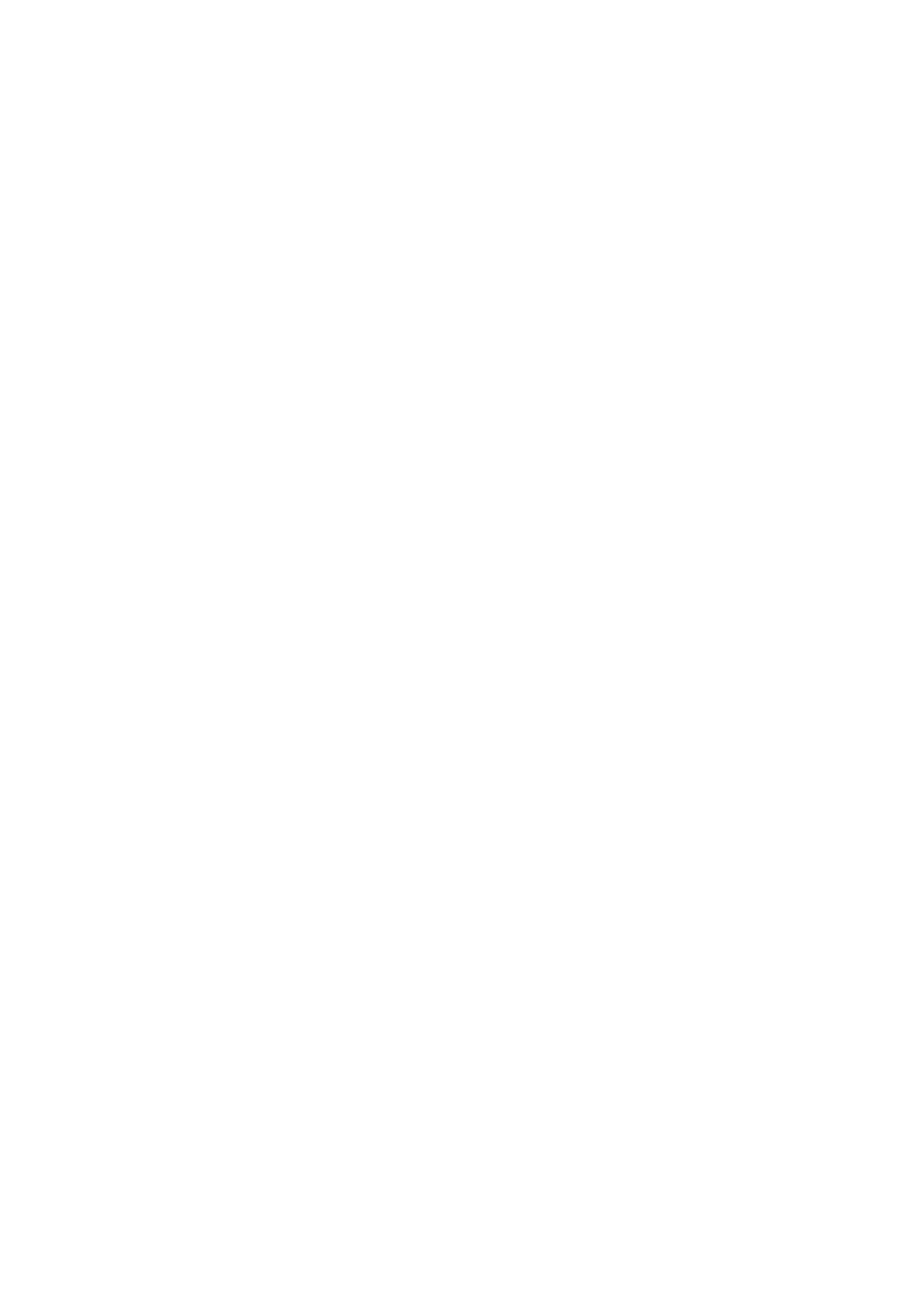




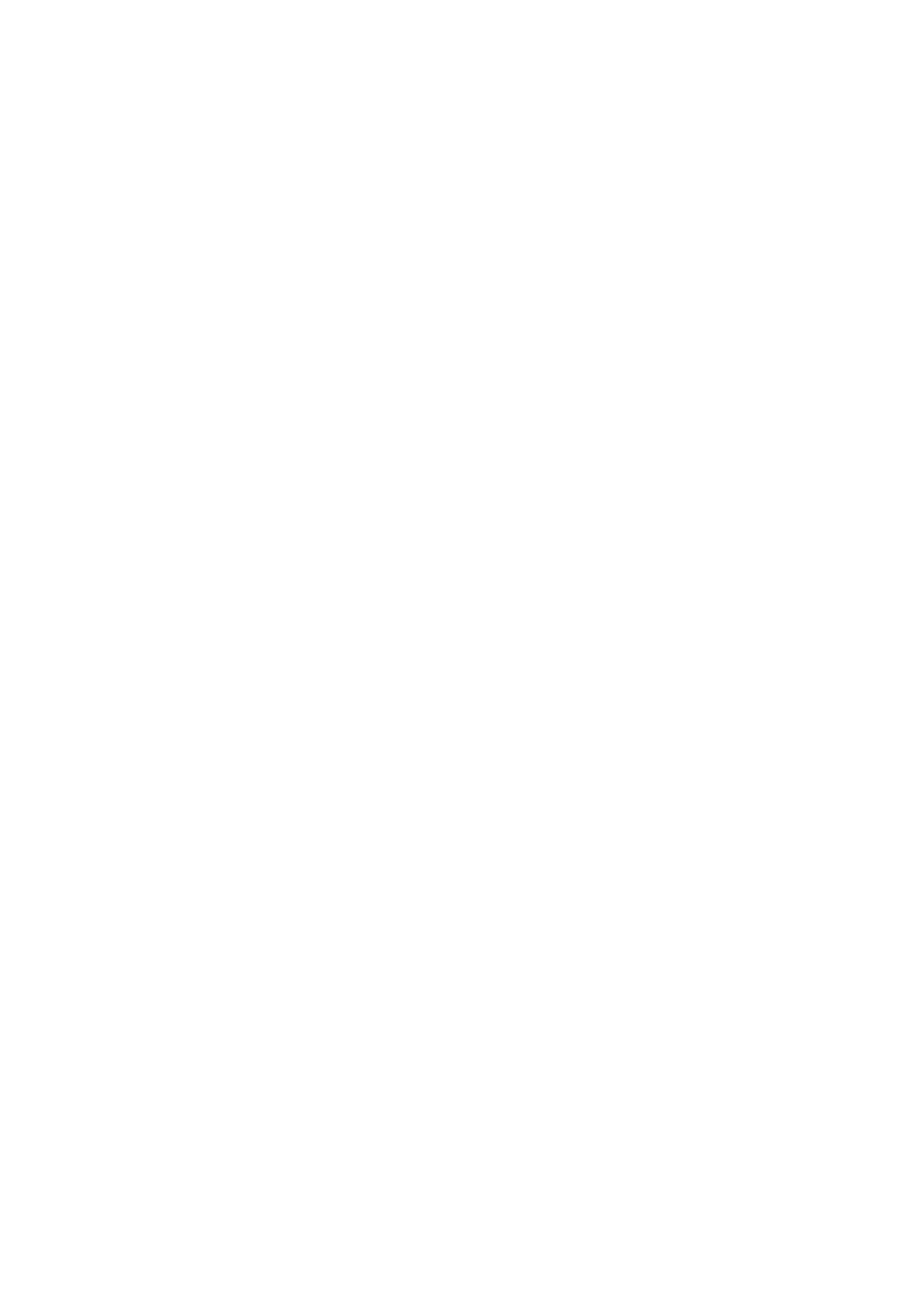




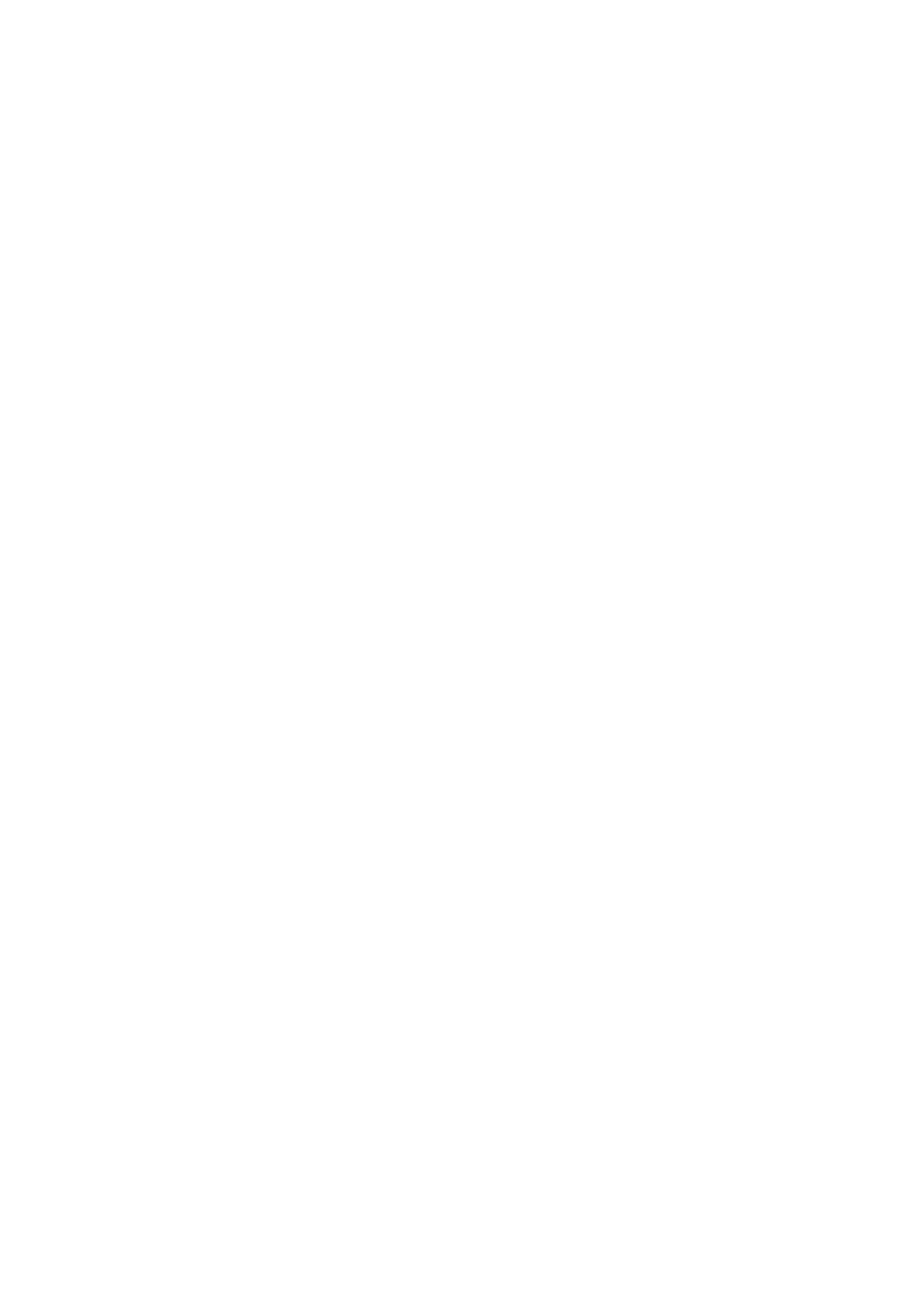




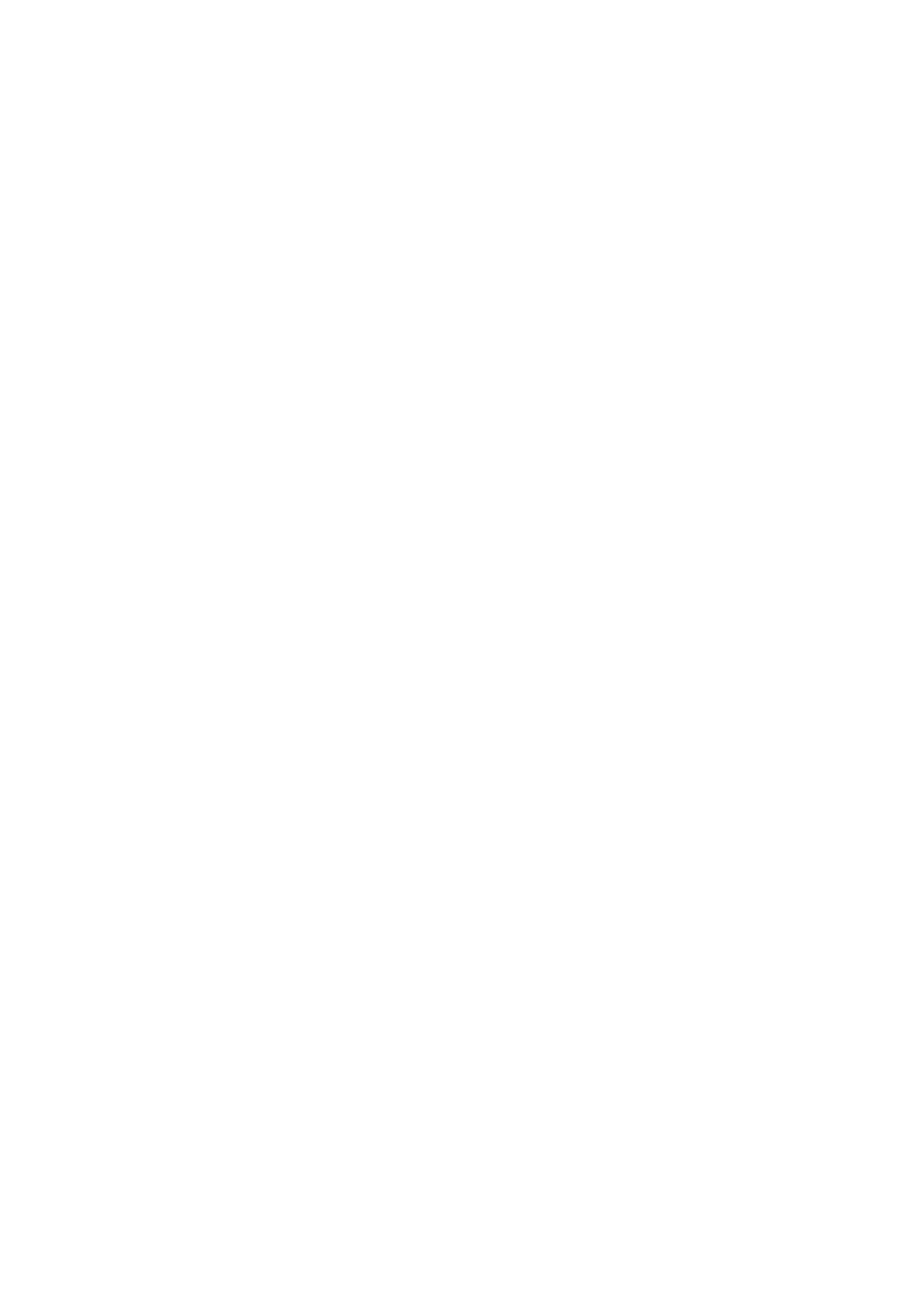




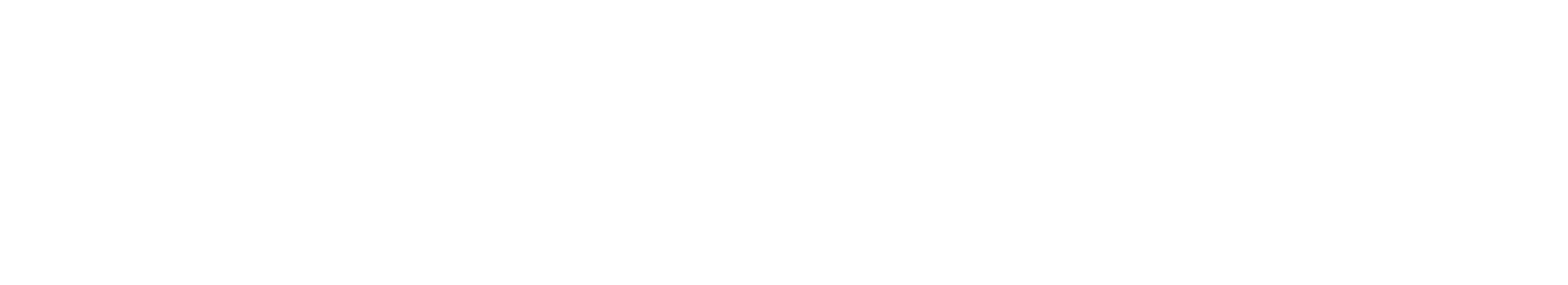

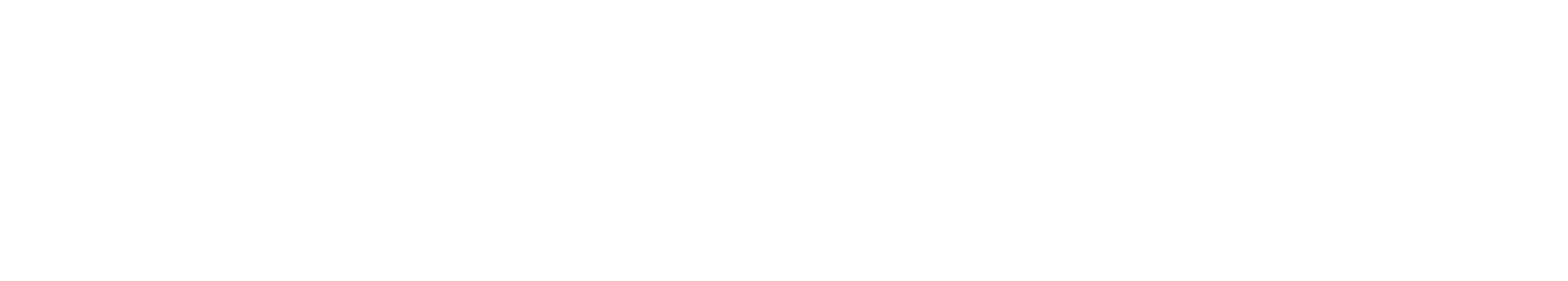

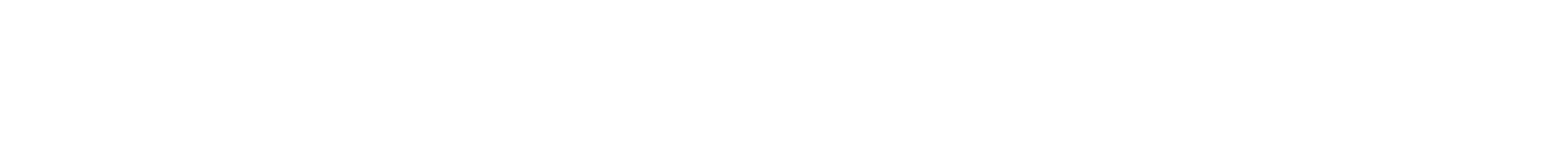

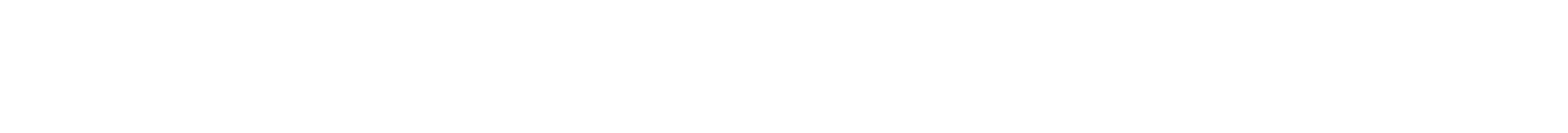




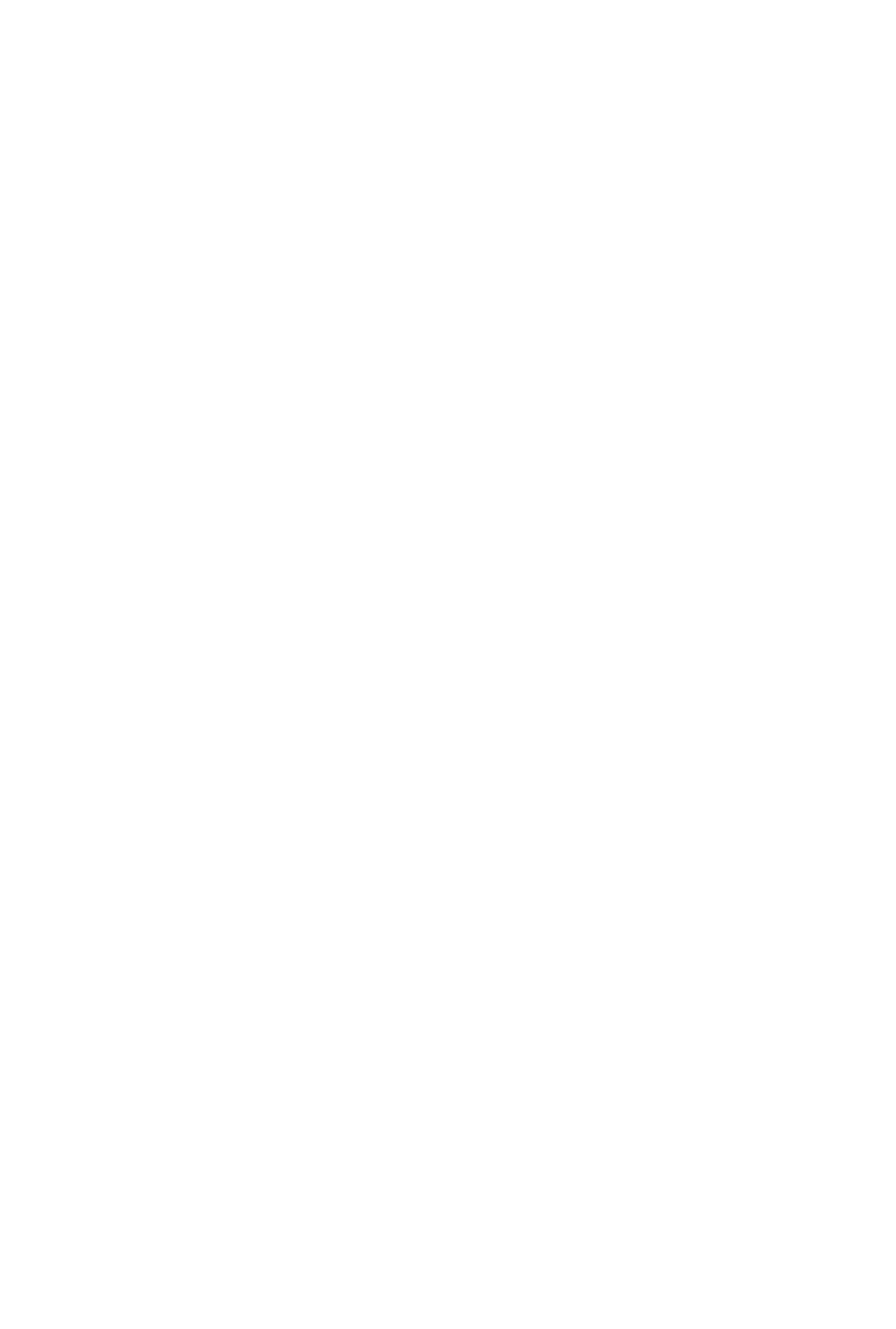




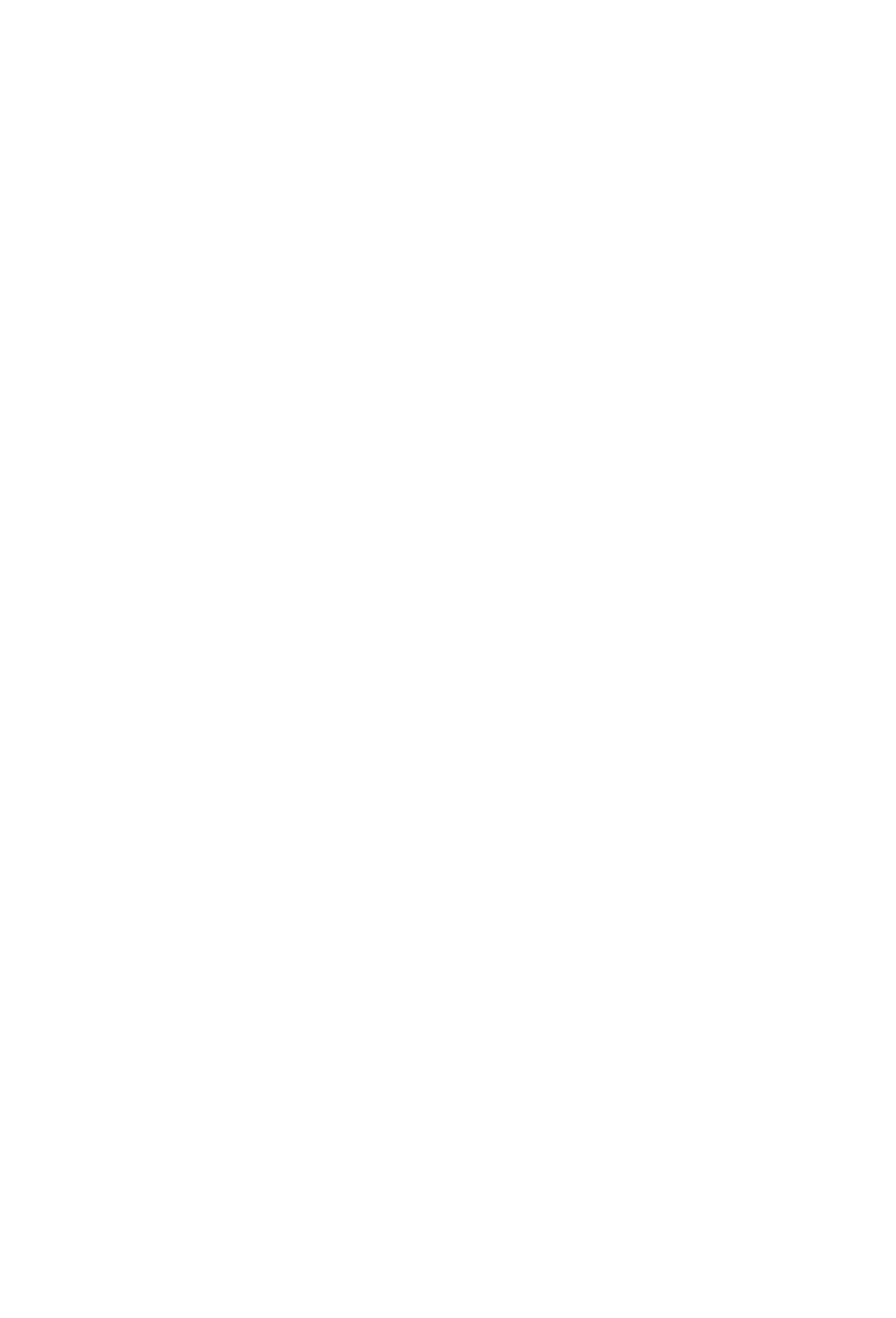




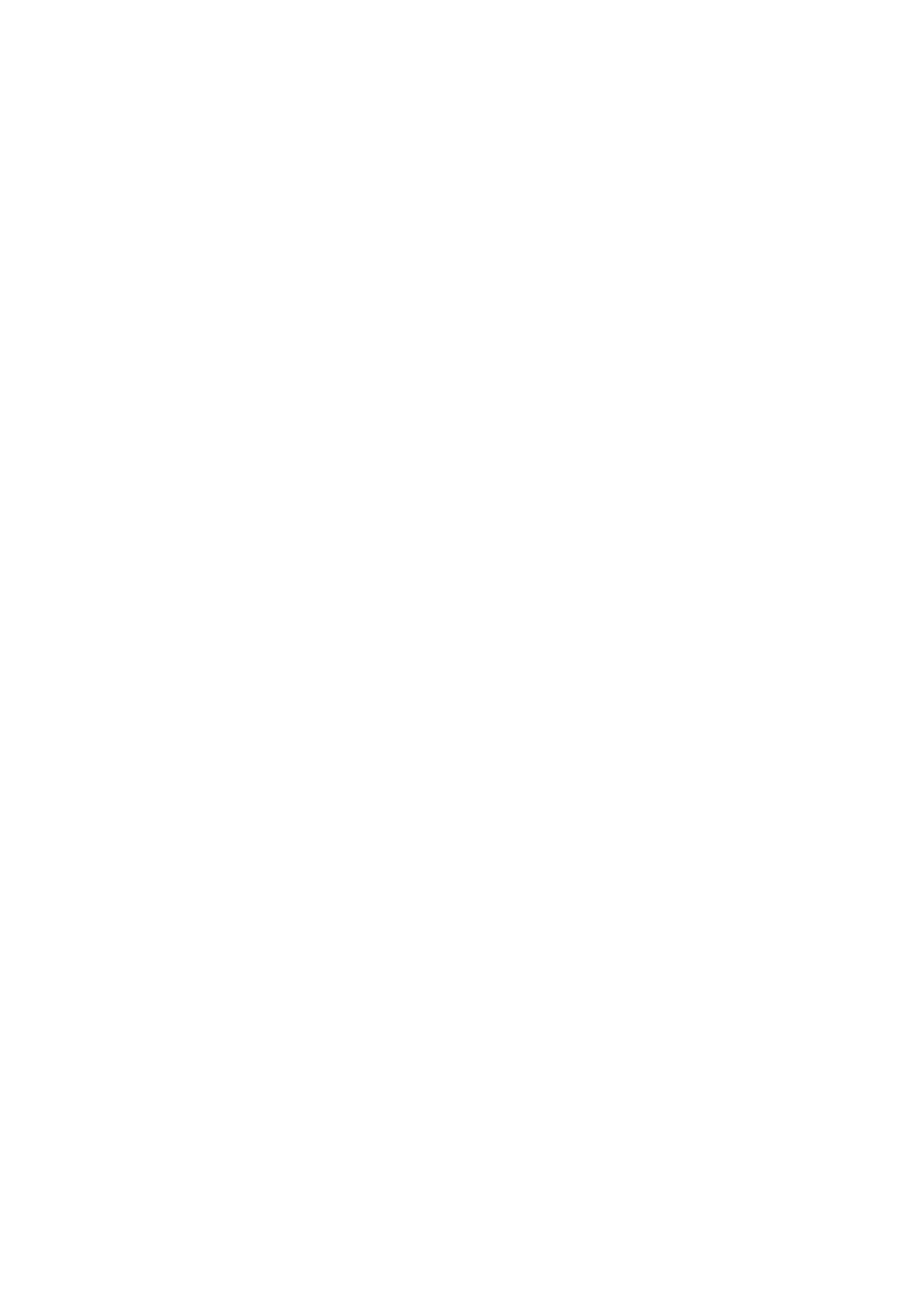




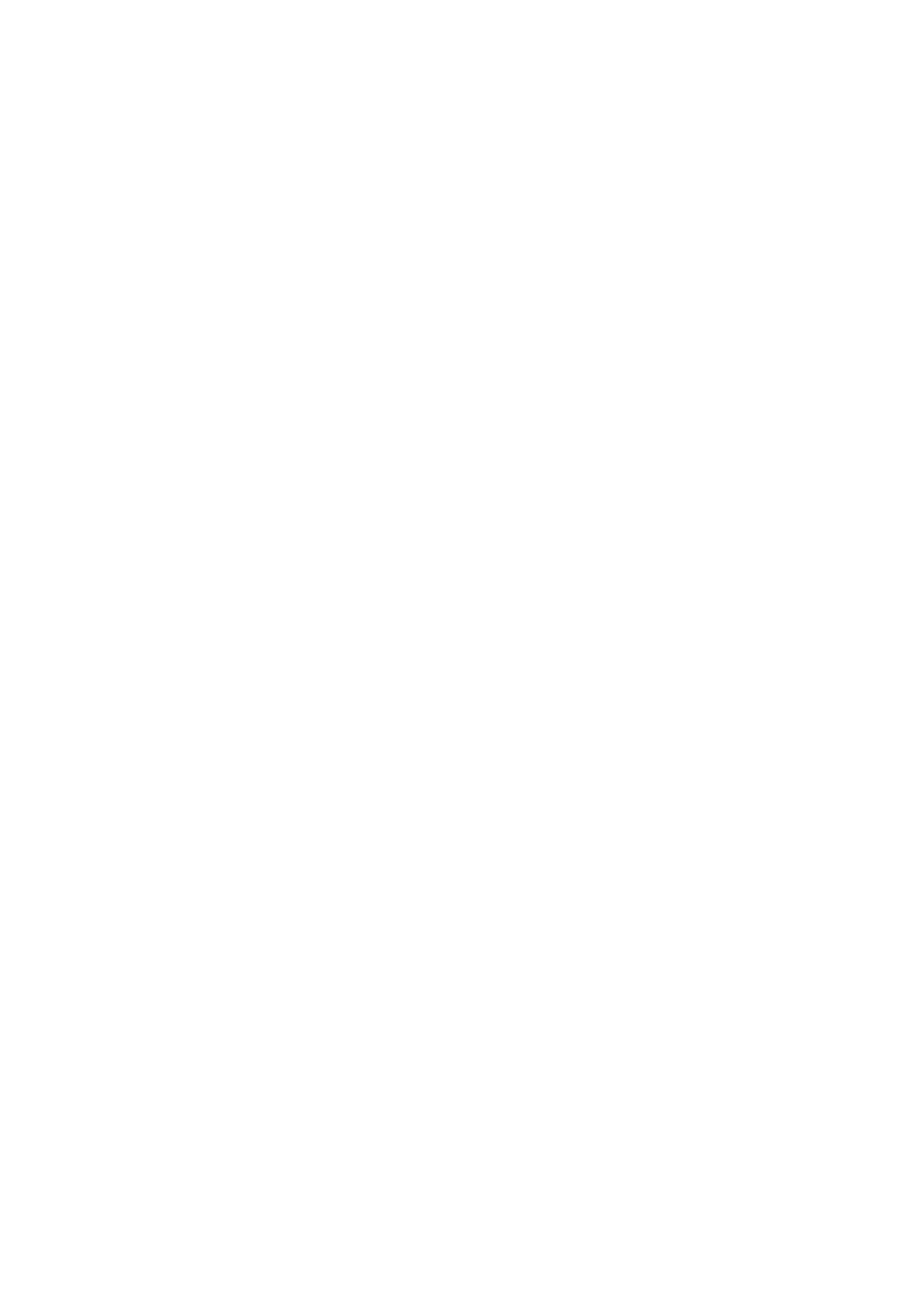




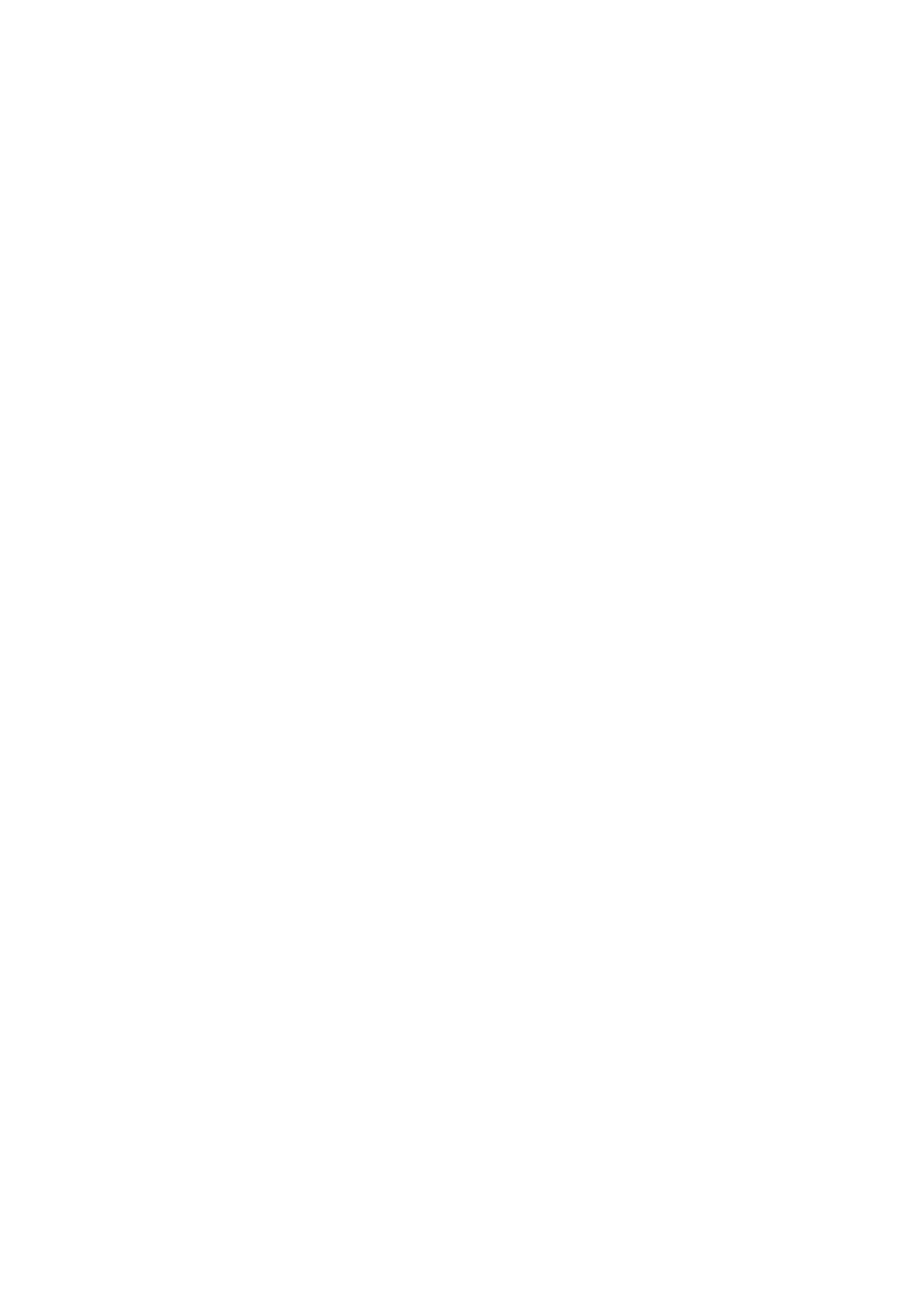




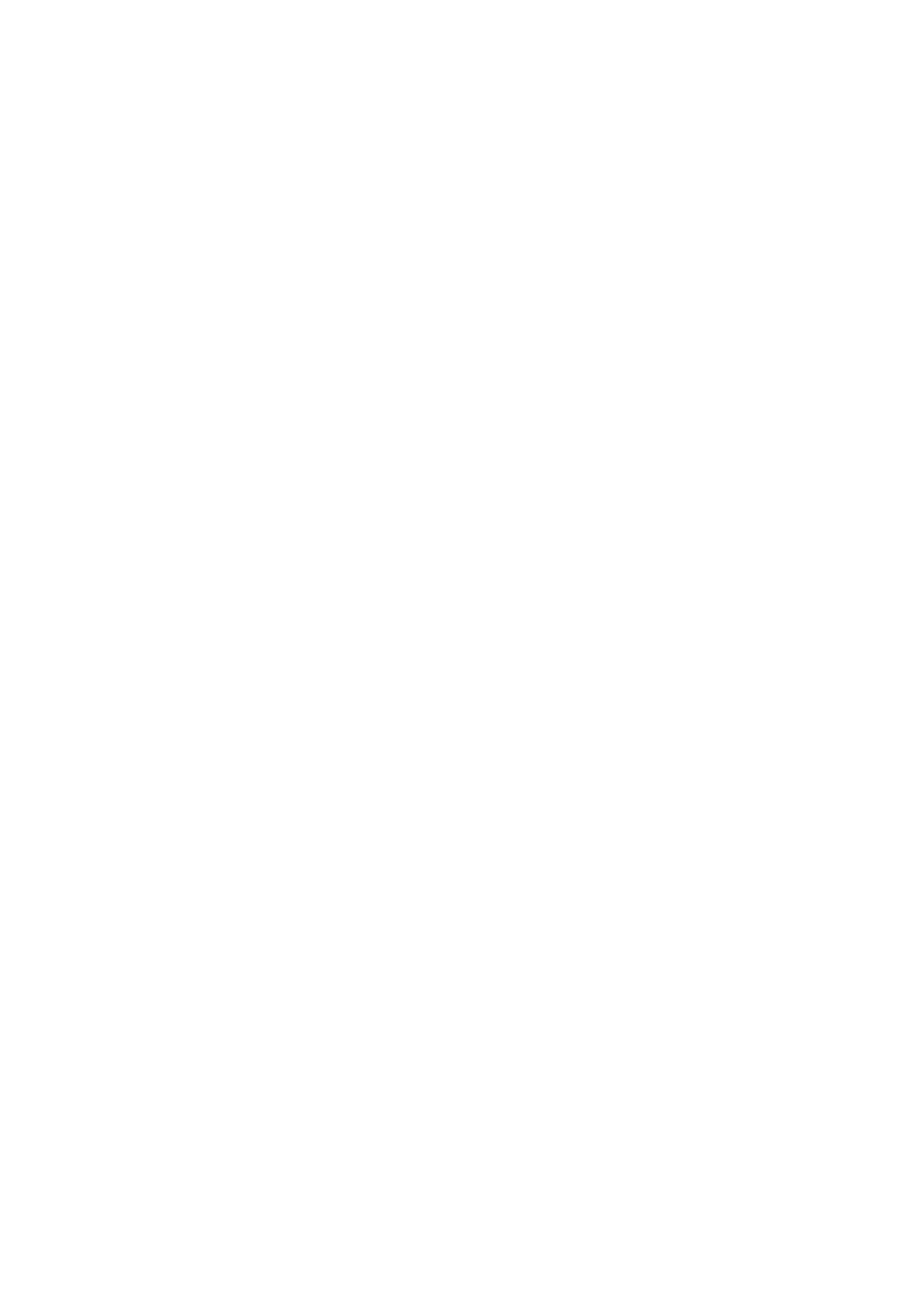




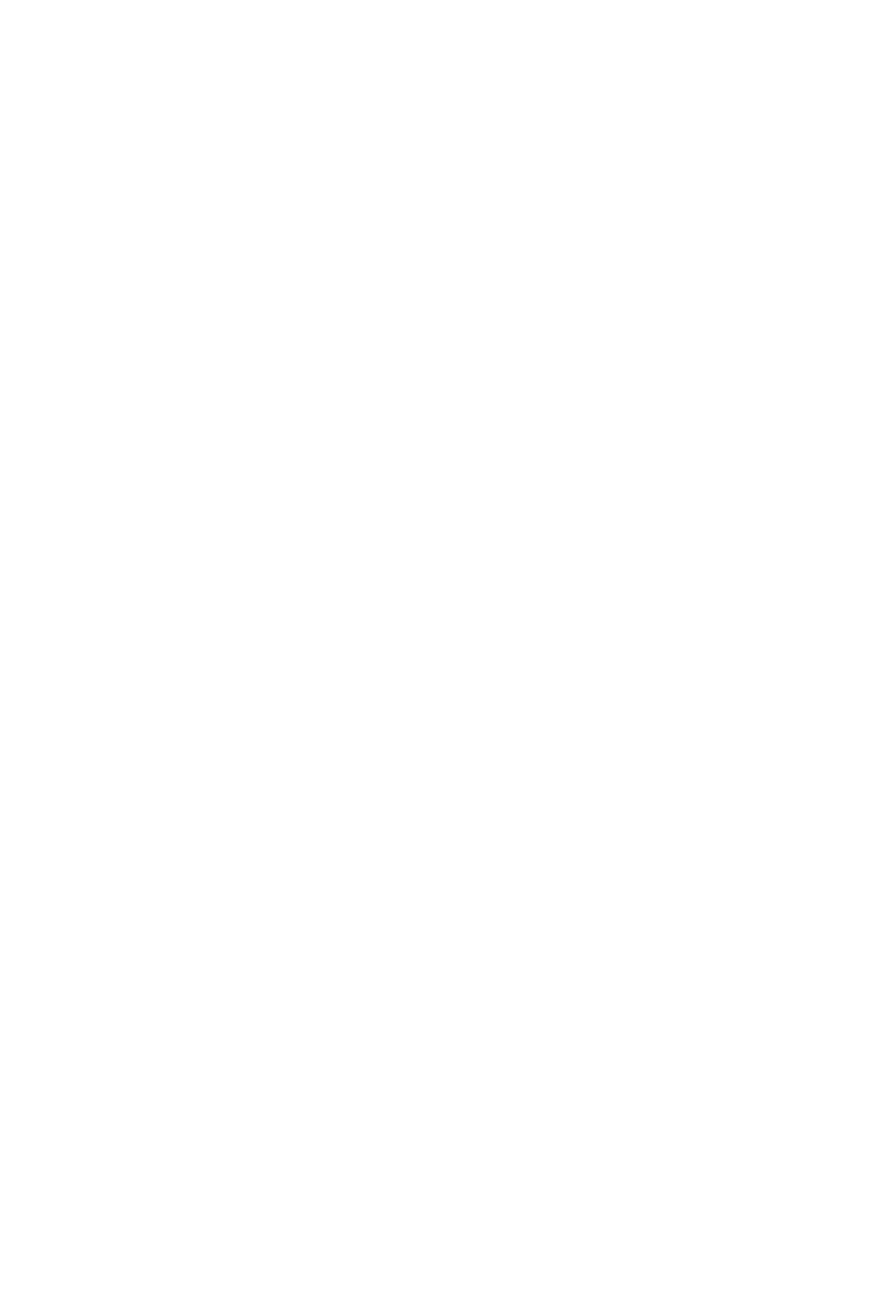




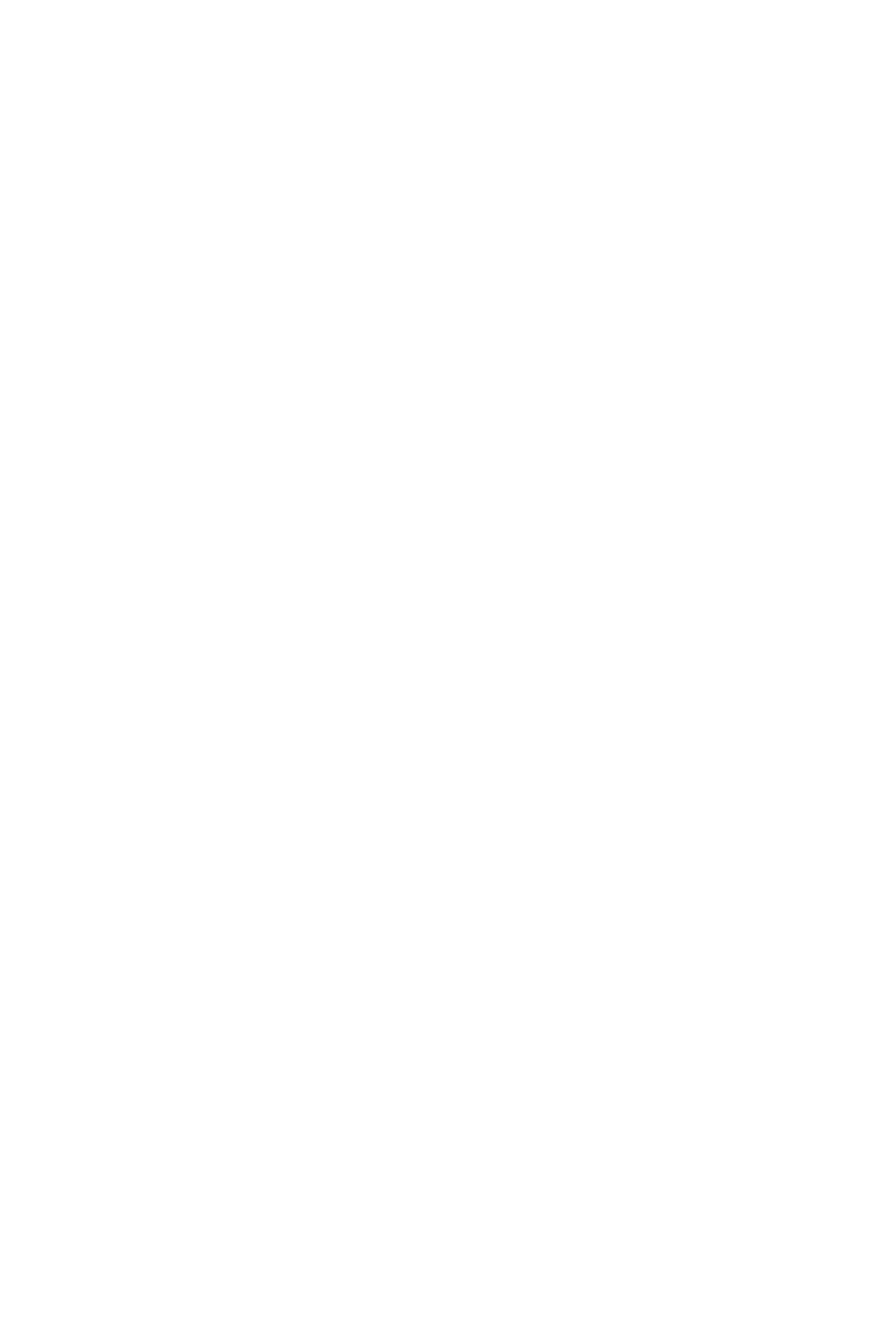




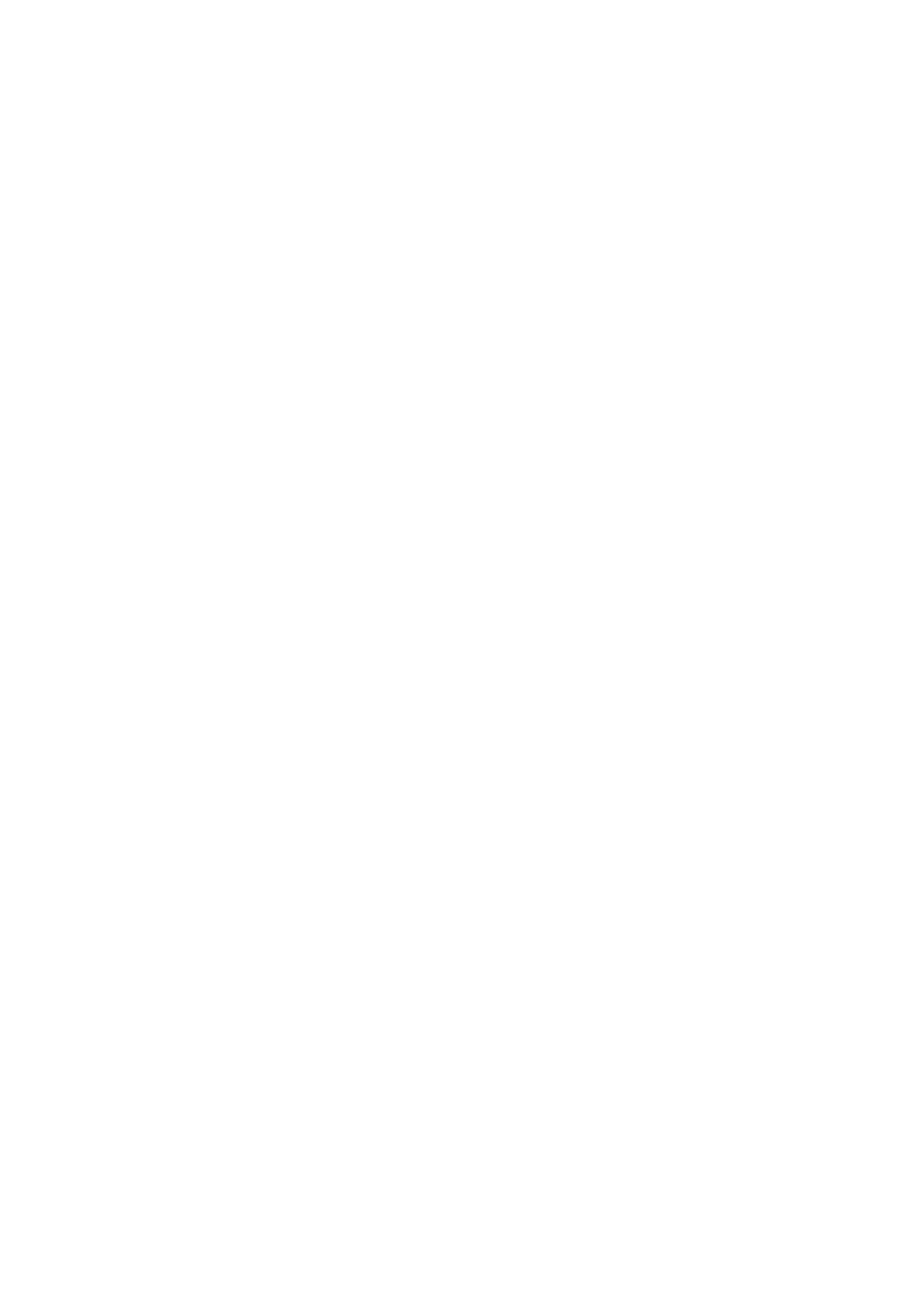




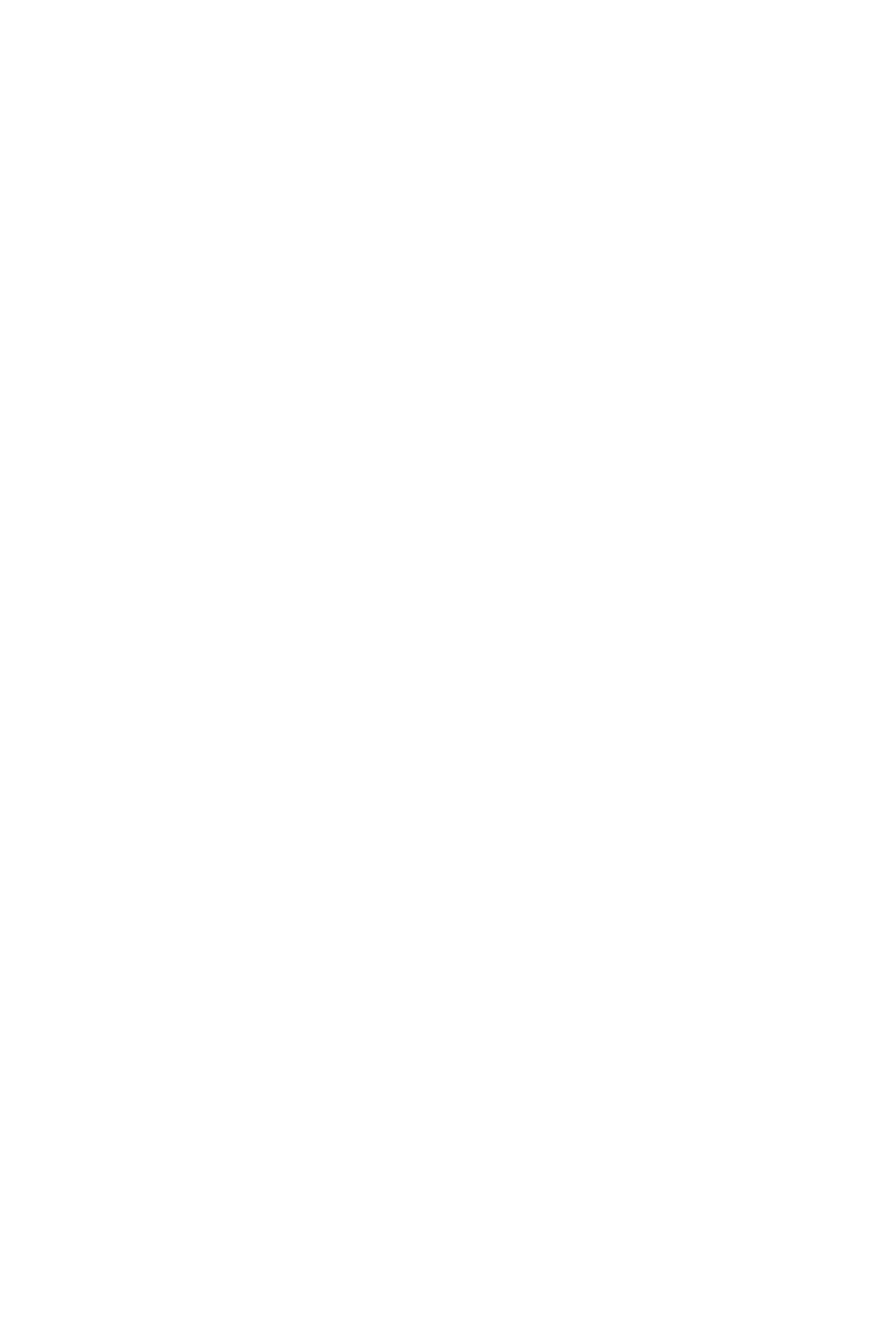


||⿴囗十)

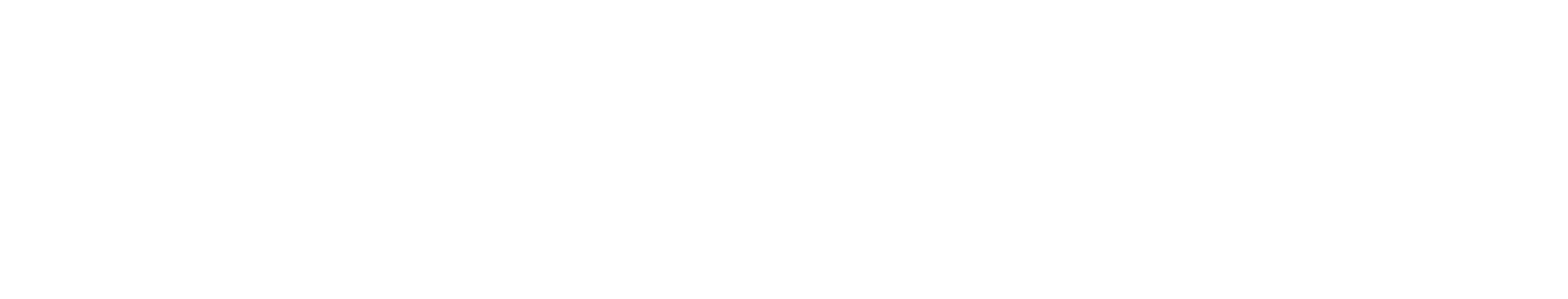

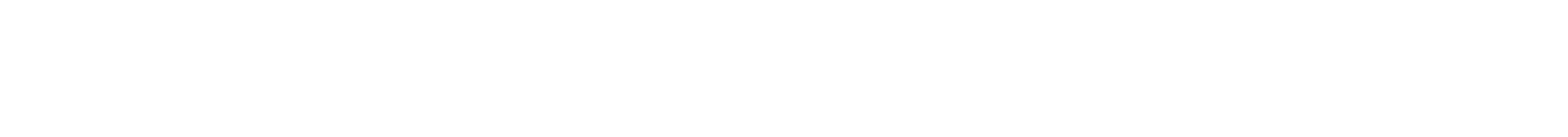

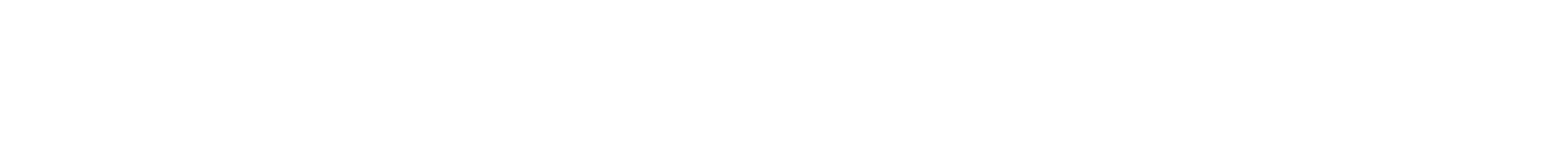

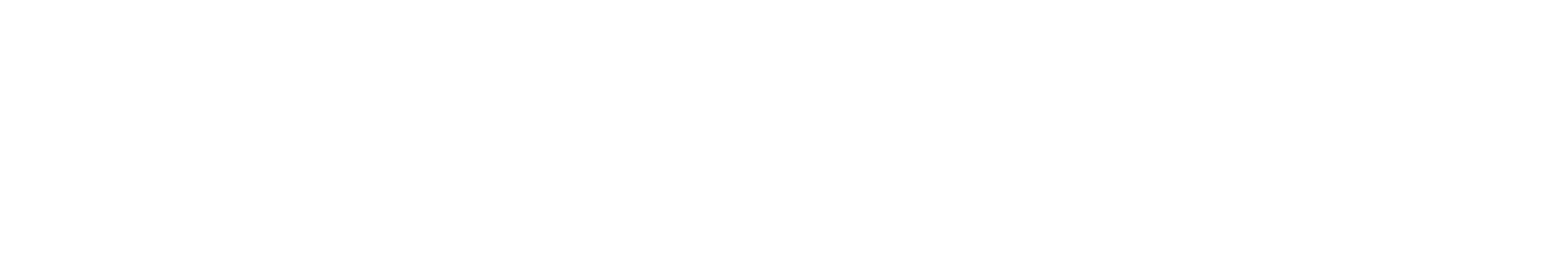

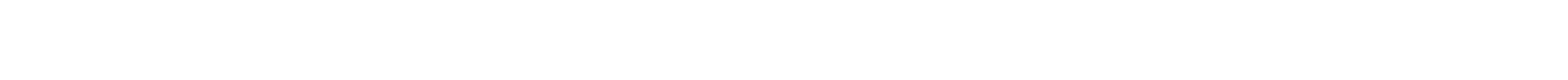

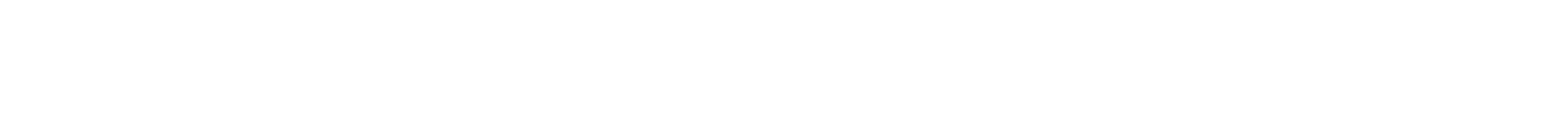
总 疍

$$
\underset{\substack{\infty \\ \stackrel{\infty}{N}}}{\infty}
$$$$
8
$$

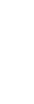

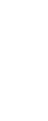

.

留

$\stackrel{\text { ำ }}{\text { ำ }}$

$\begin{array}{lll}\bumpeq & \infty & \infty \\ \stackrel{0}{*} & \infty & \dot{q}\end{array}$

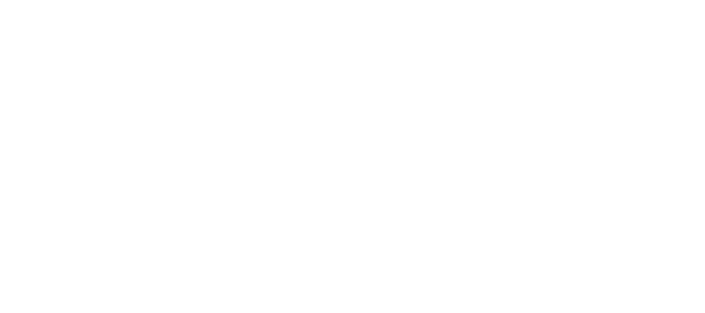

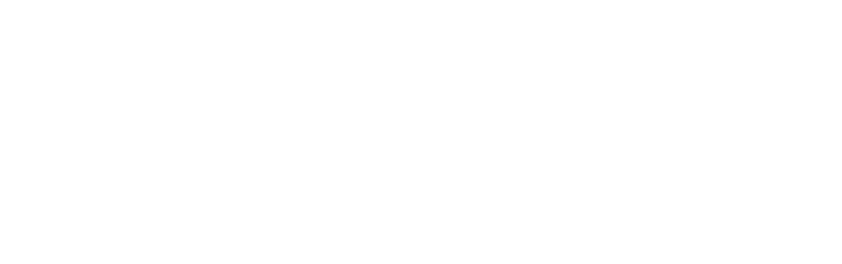

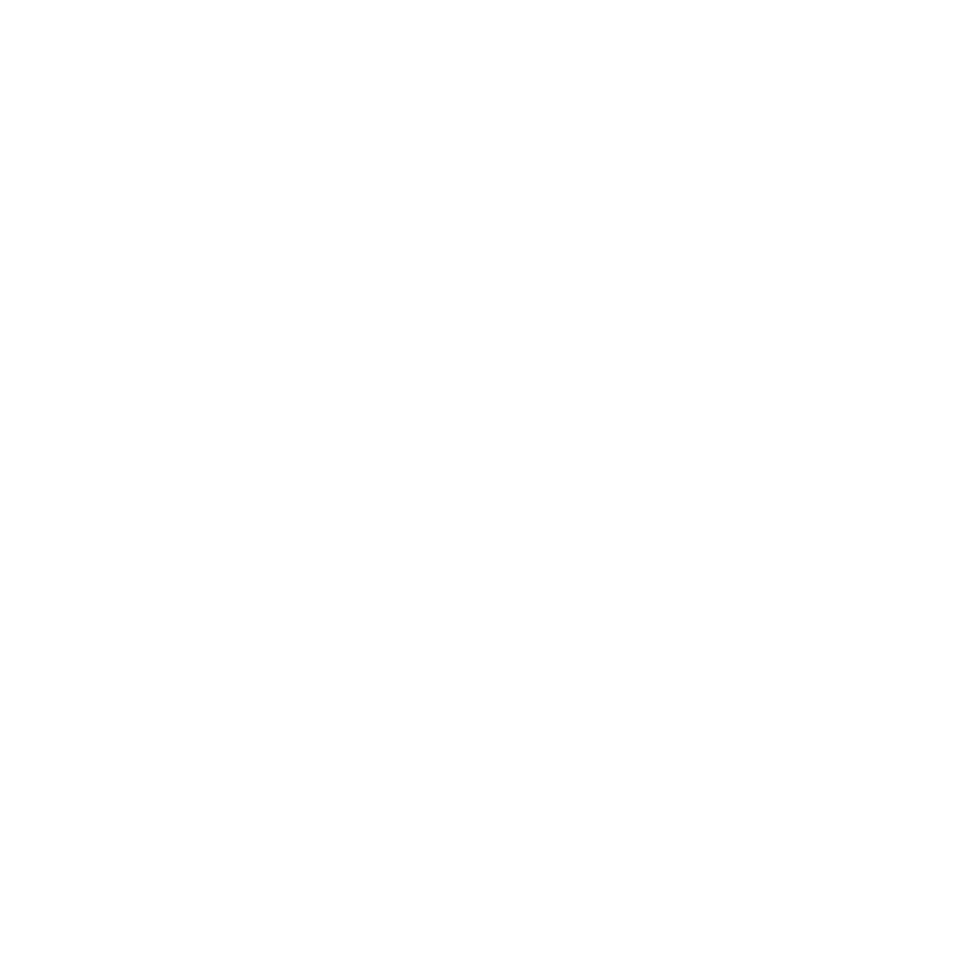




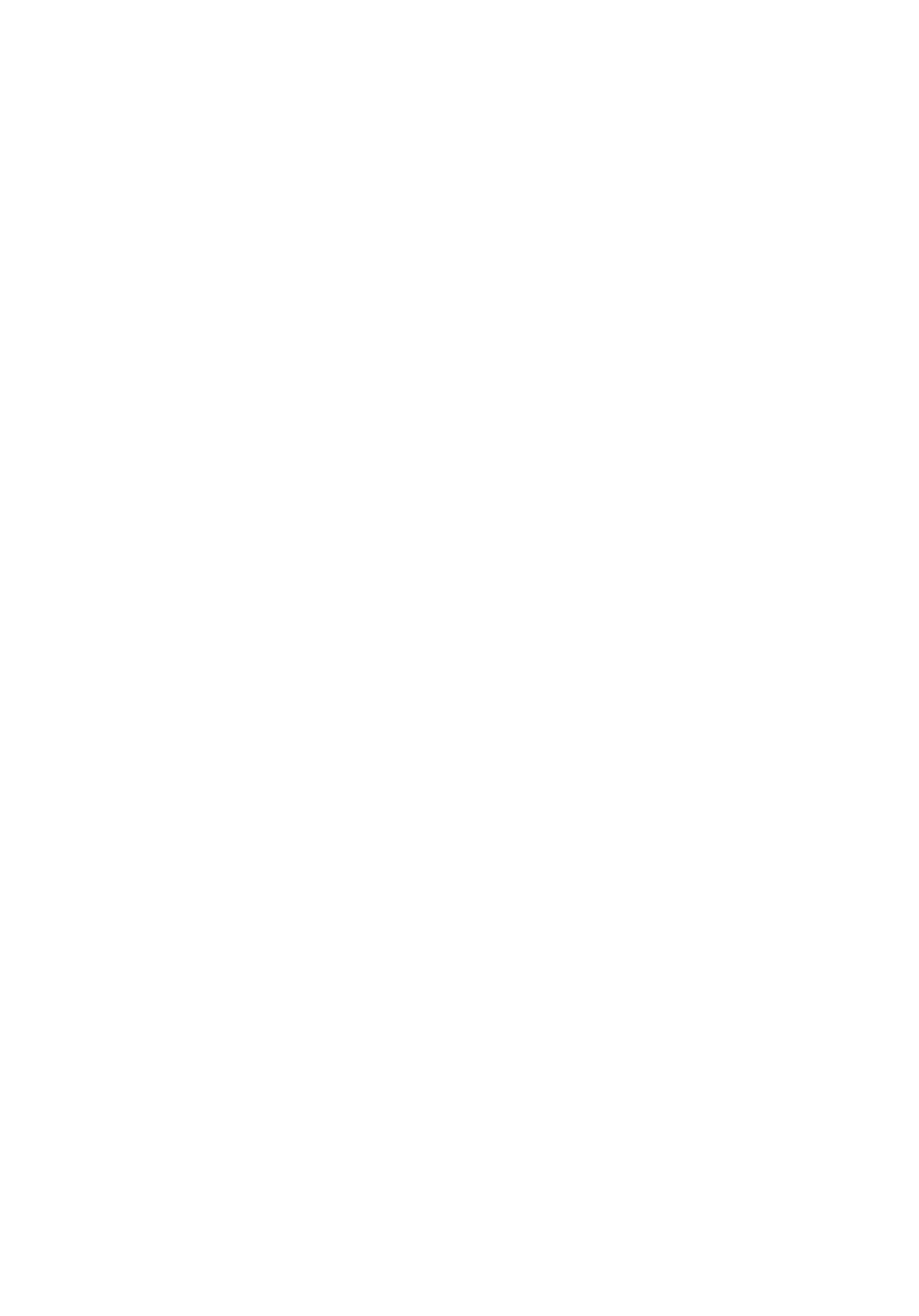




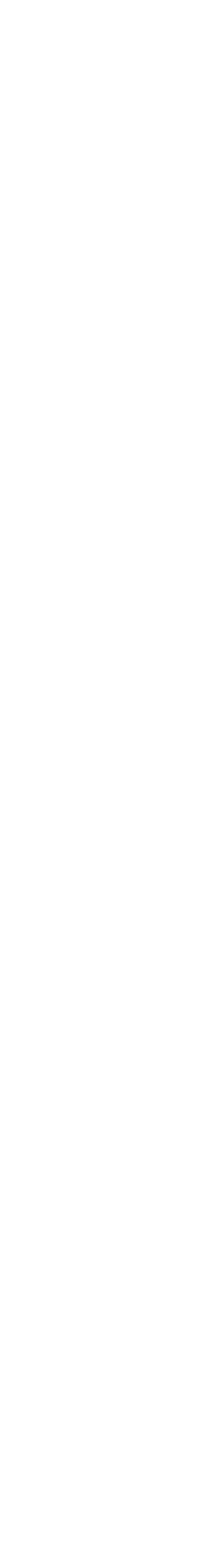

Tables 321 


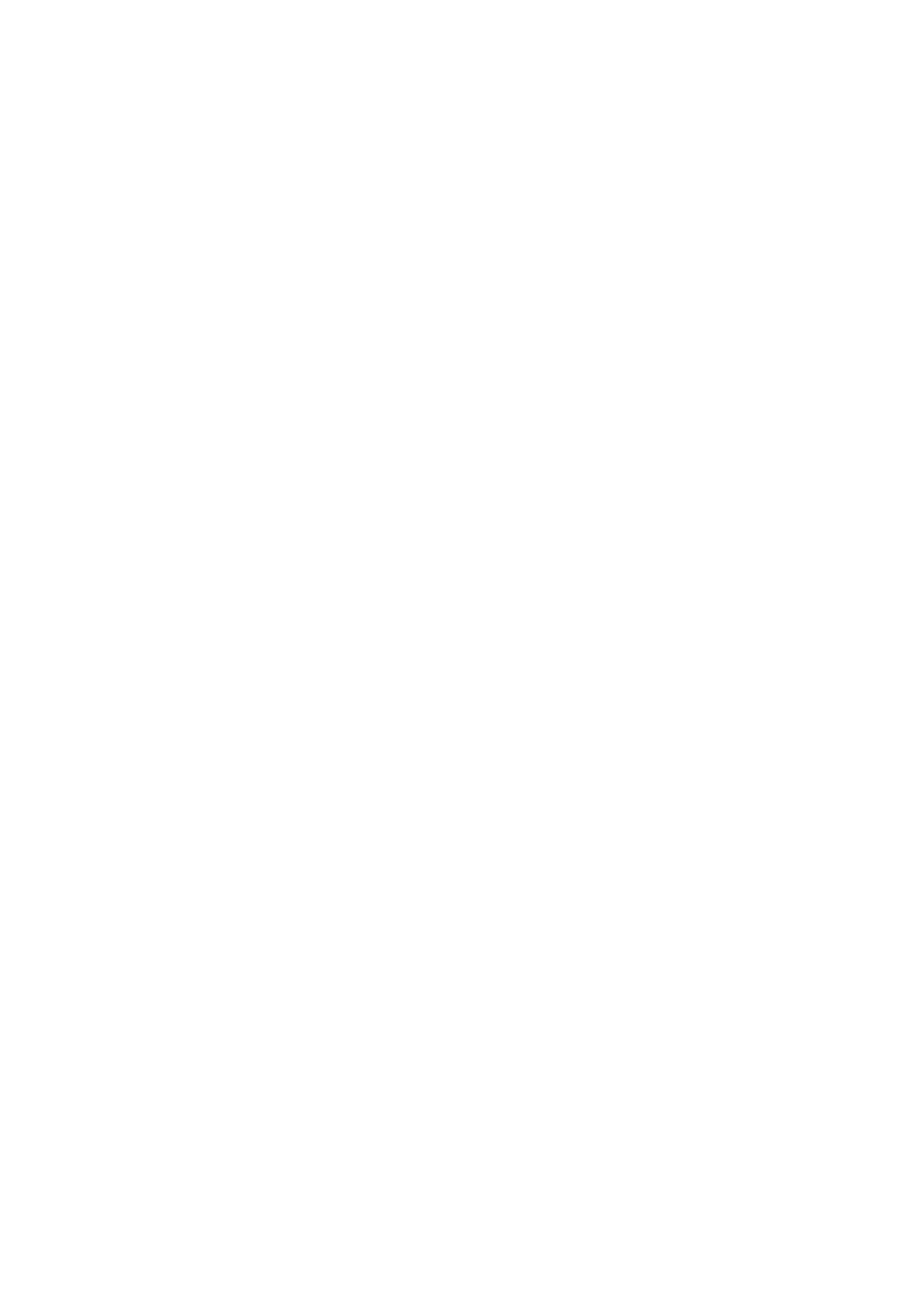




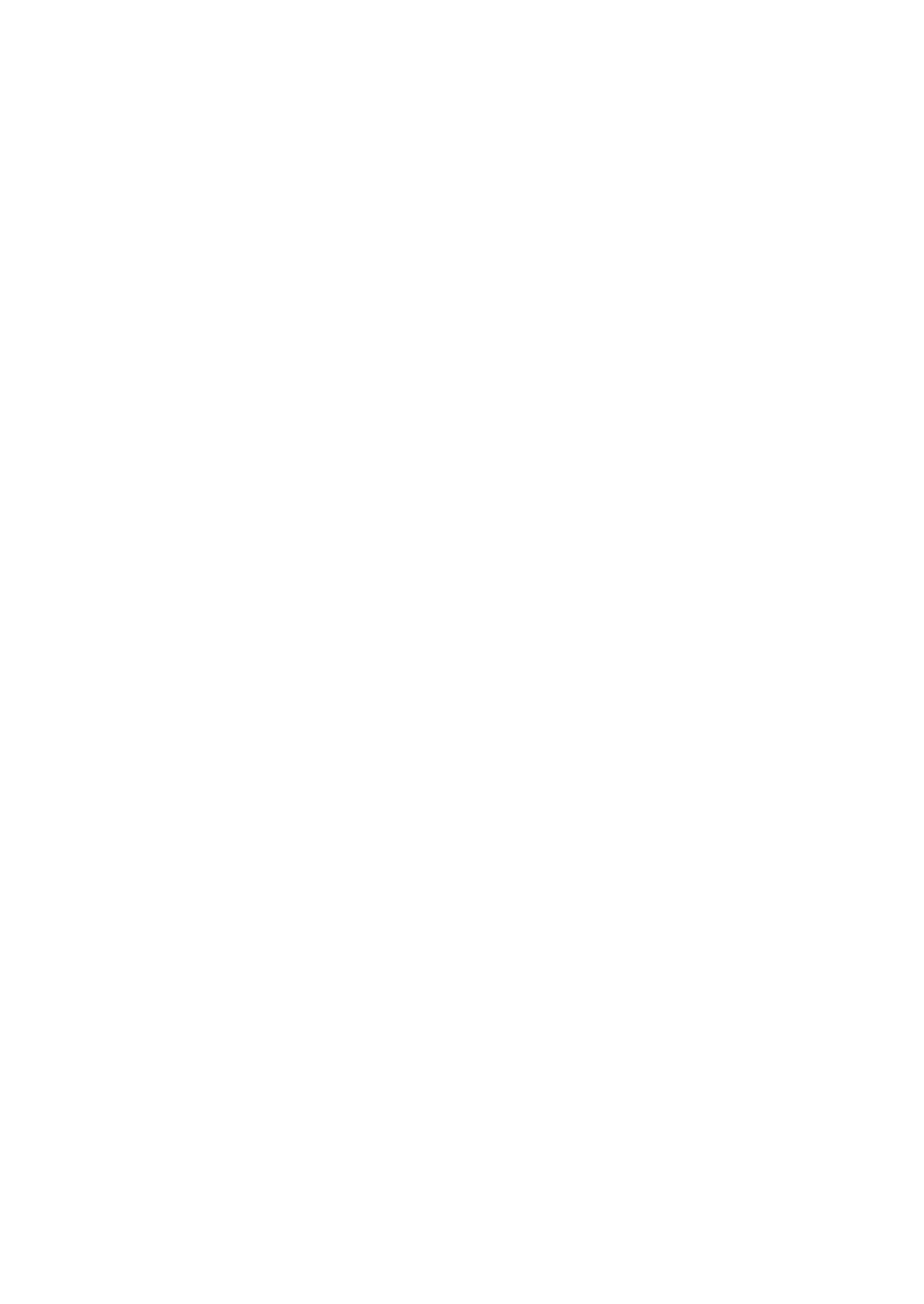




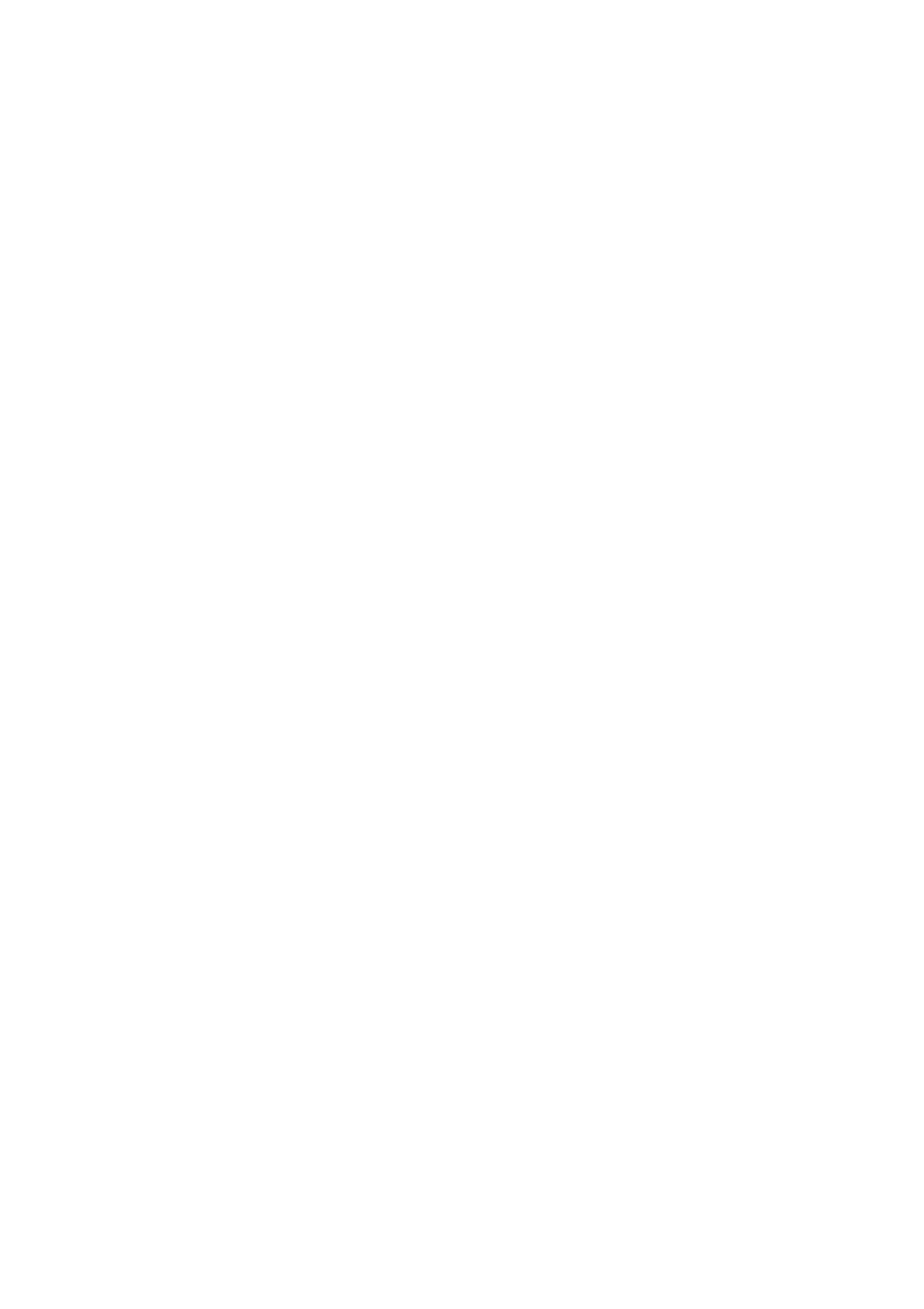




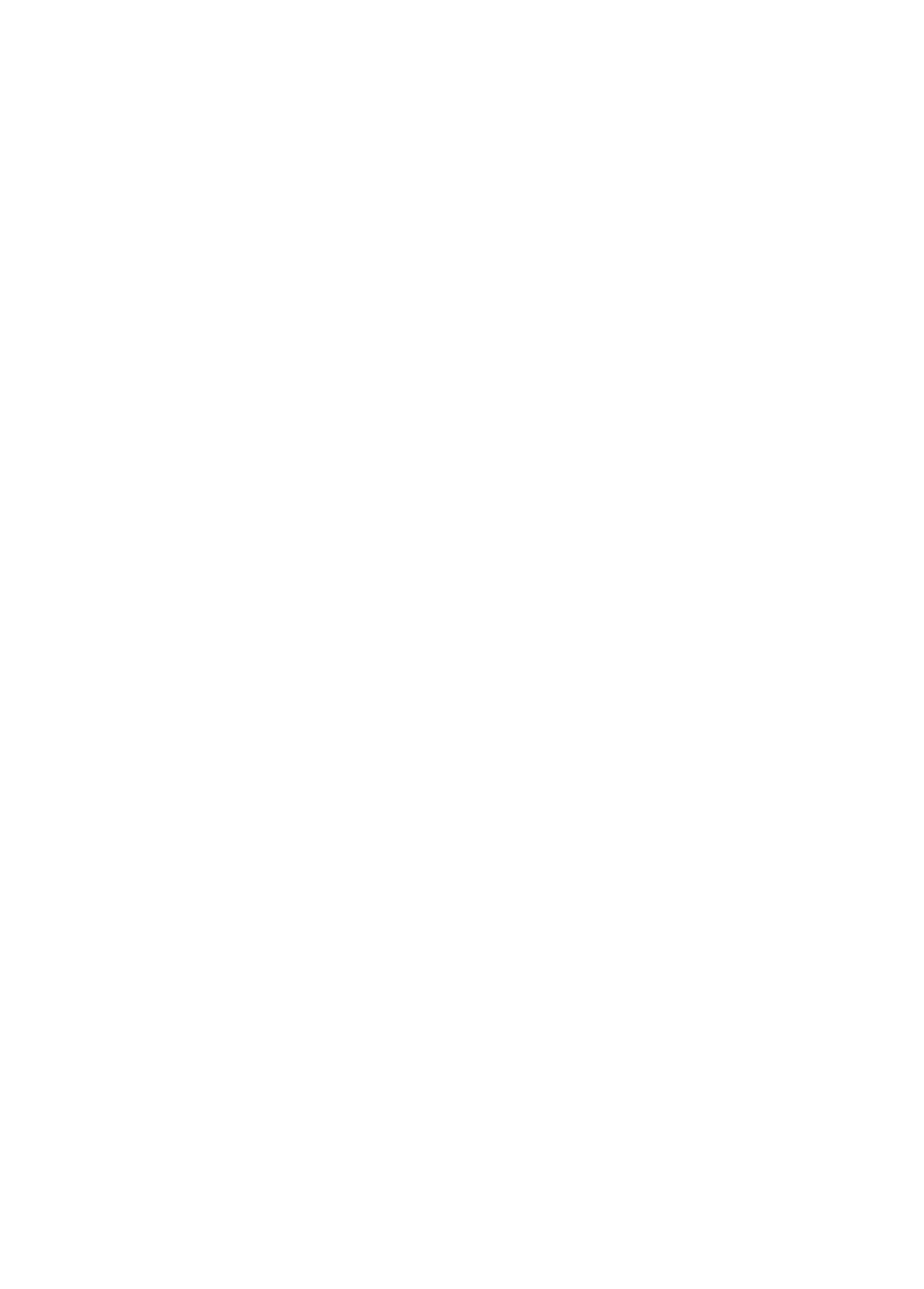




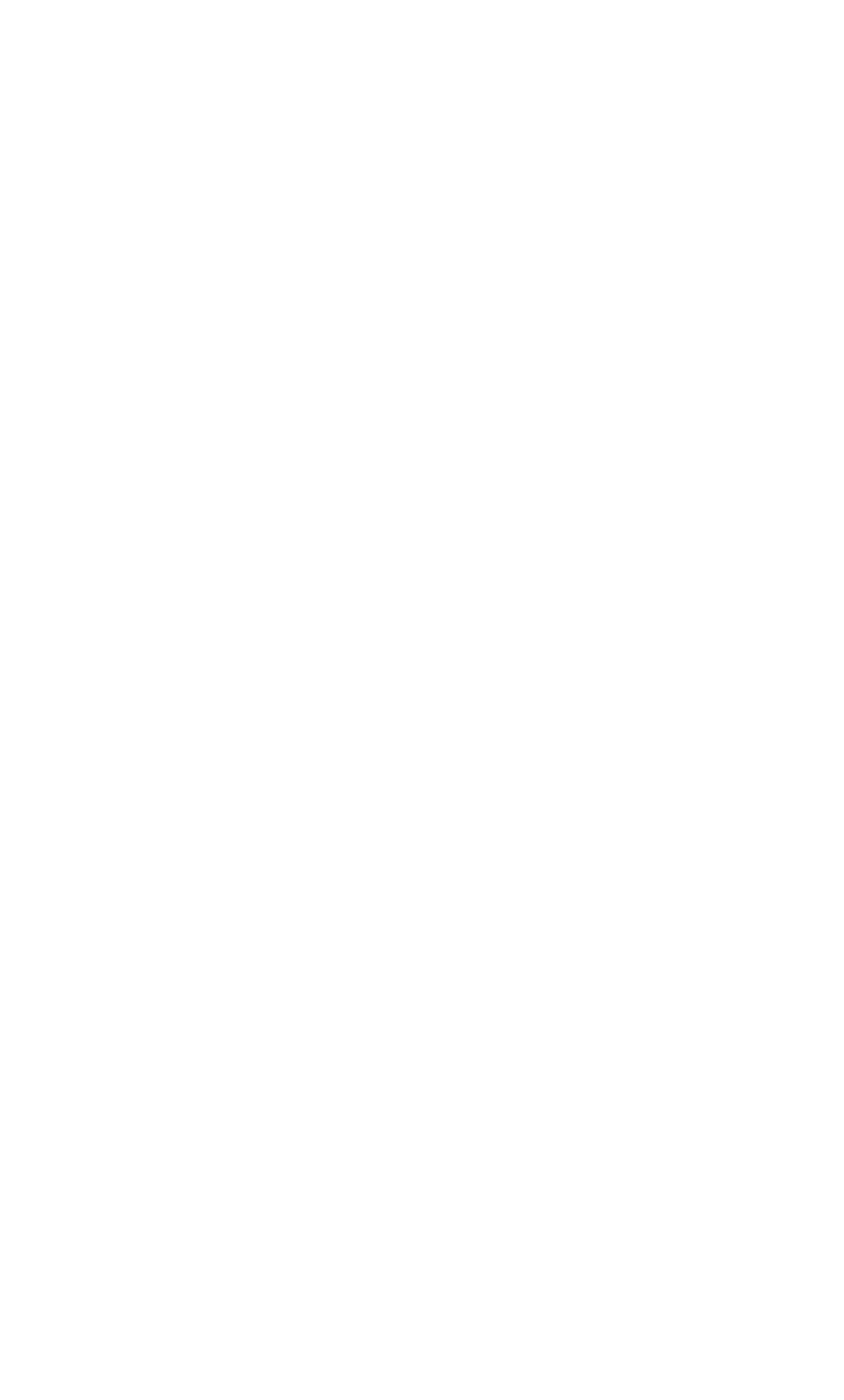




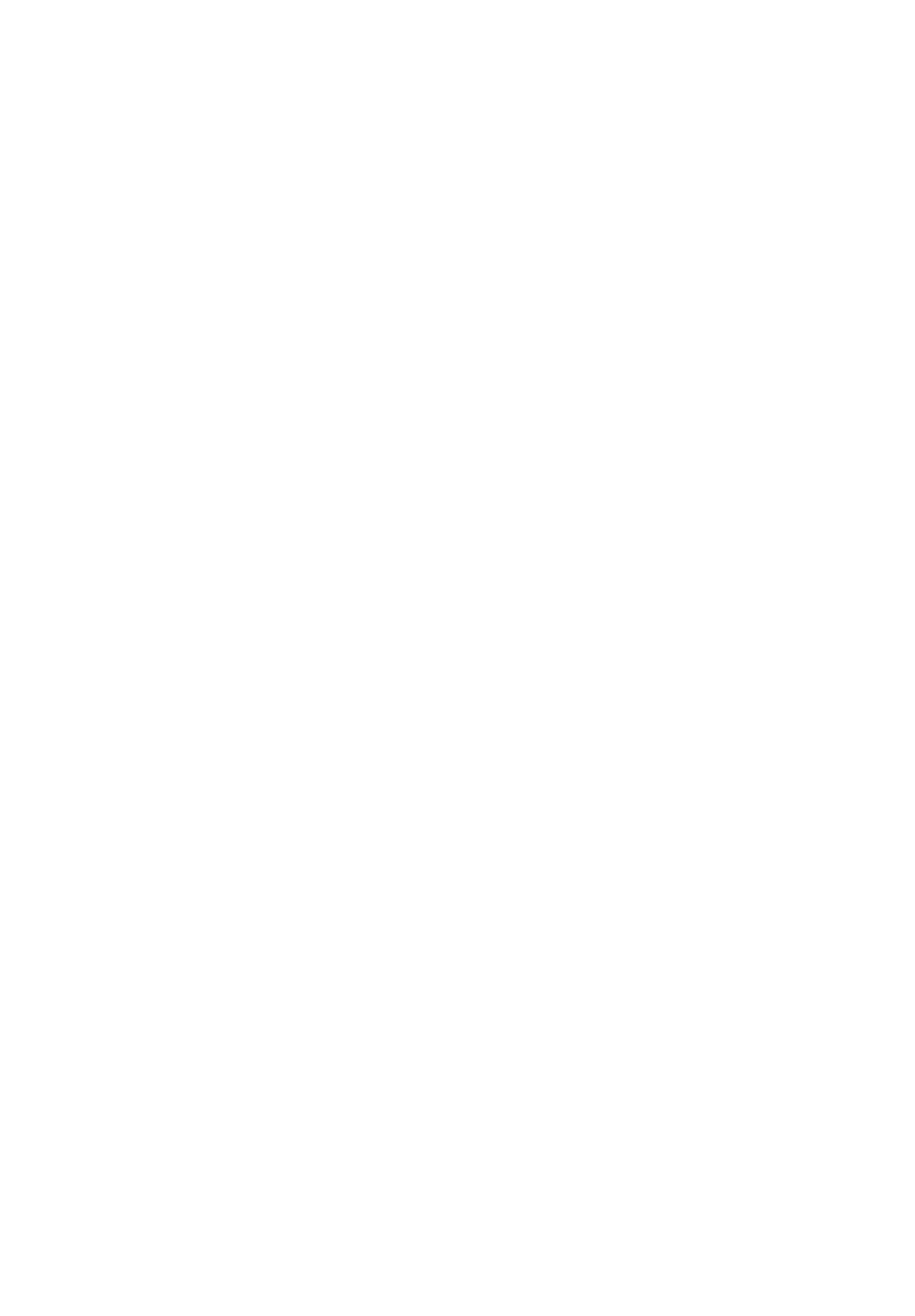




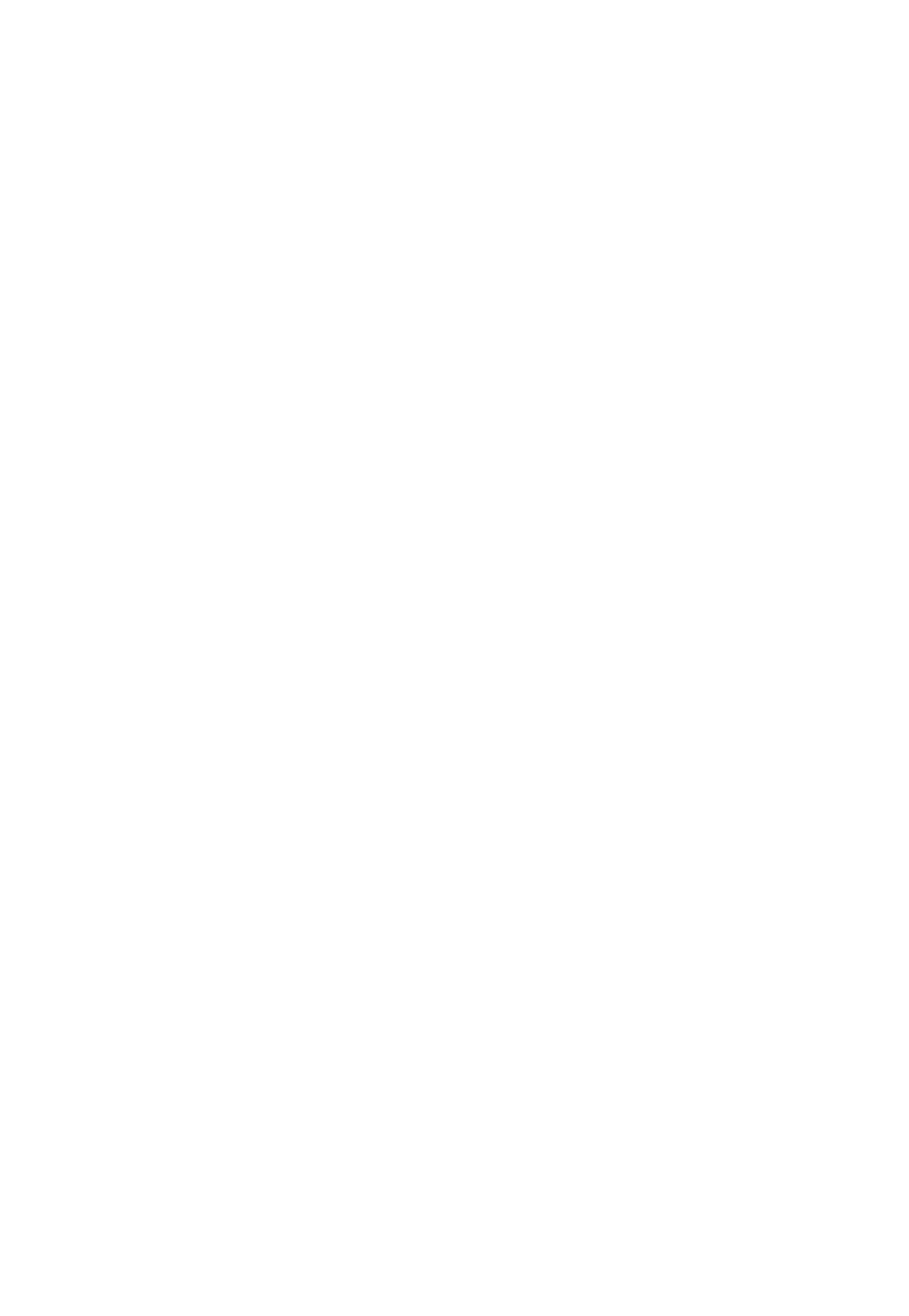




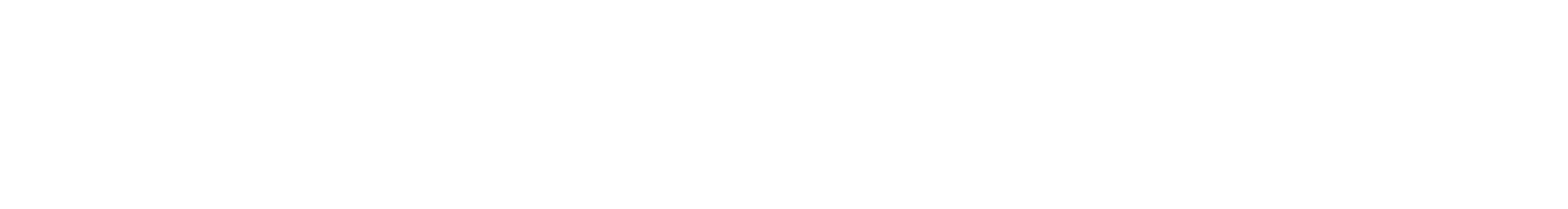

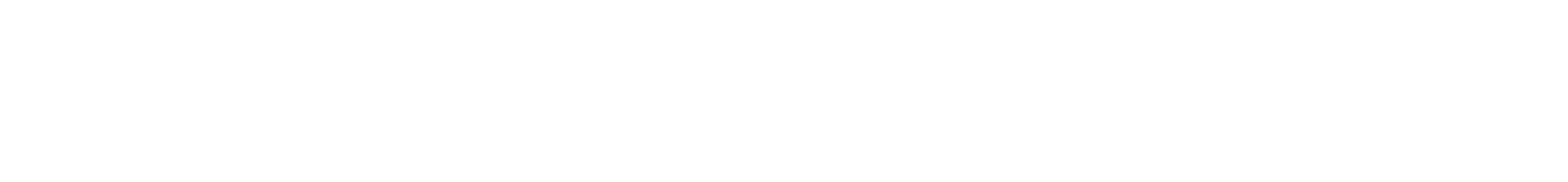

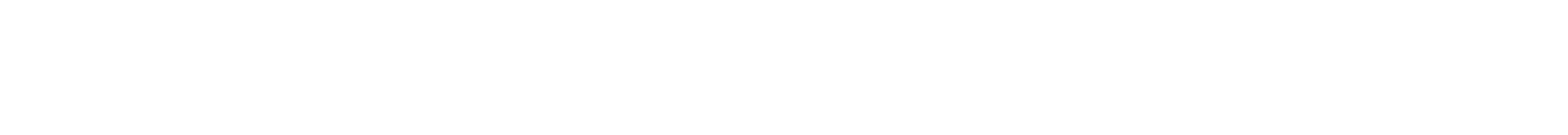

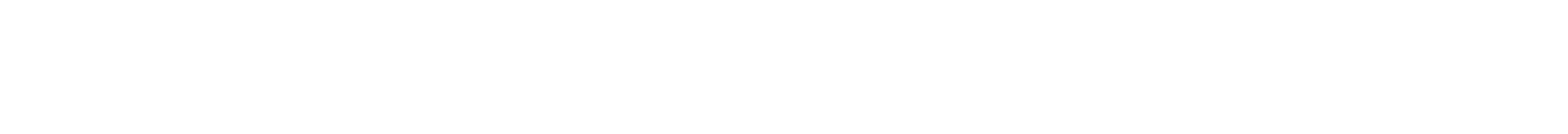

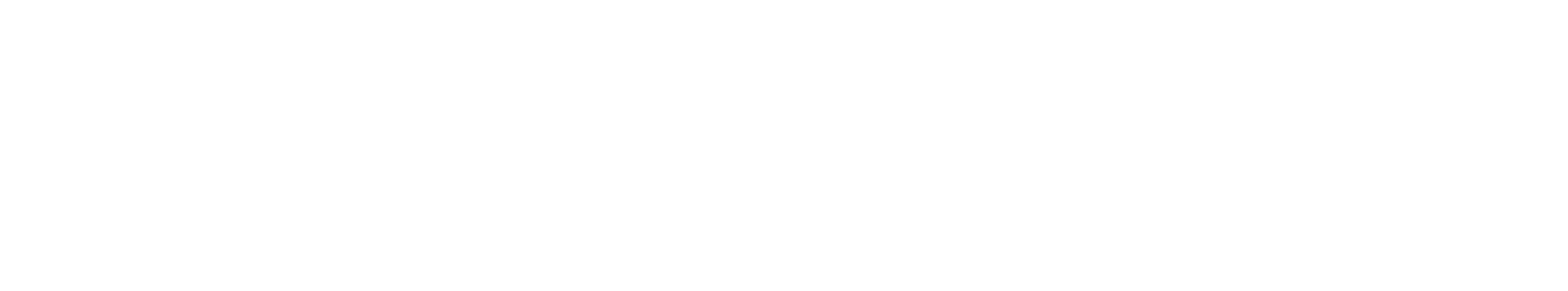

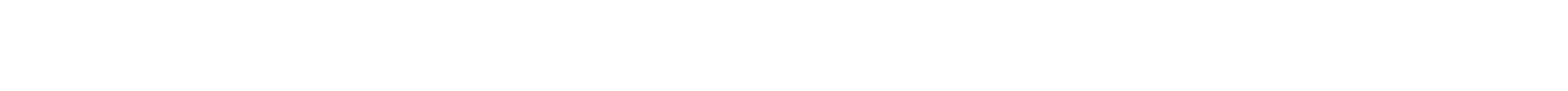

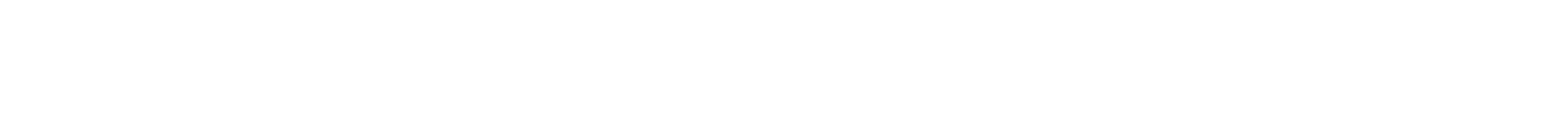

突

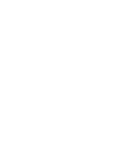

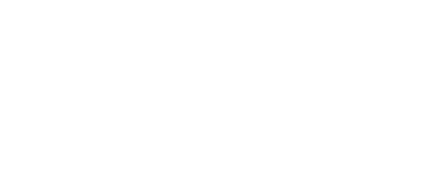

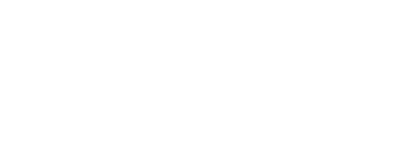




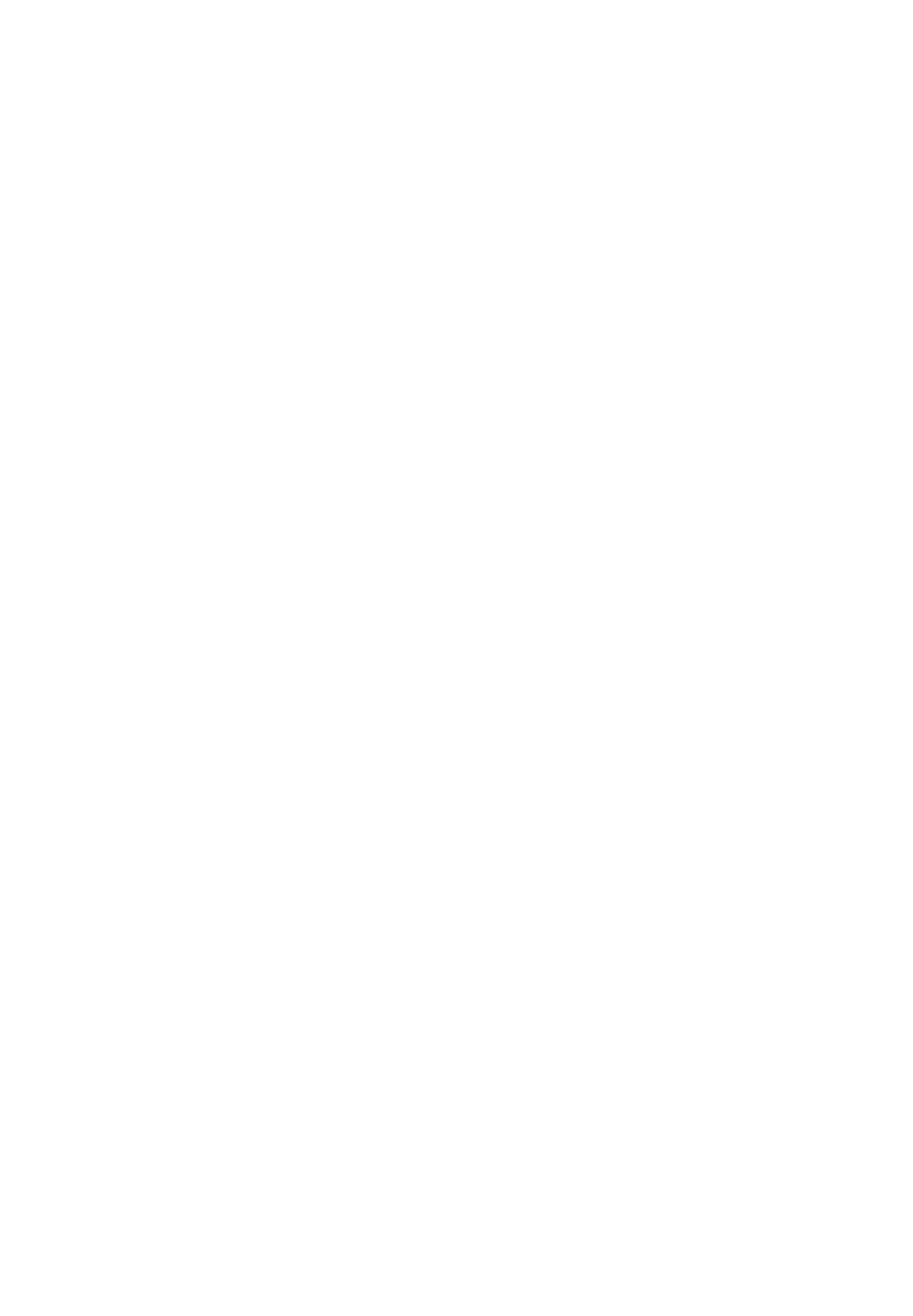




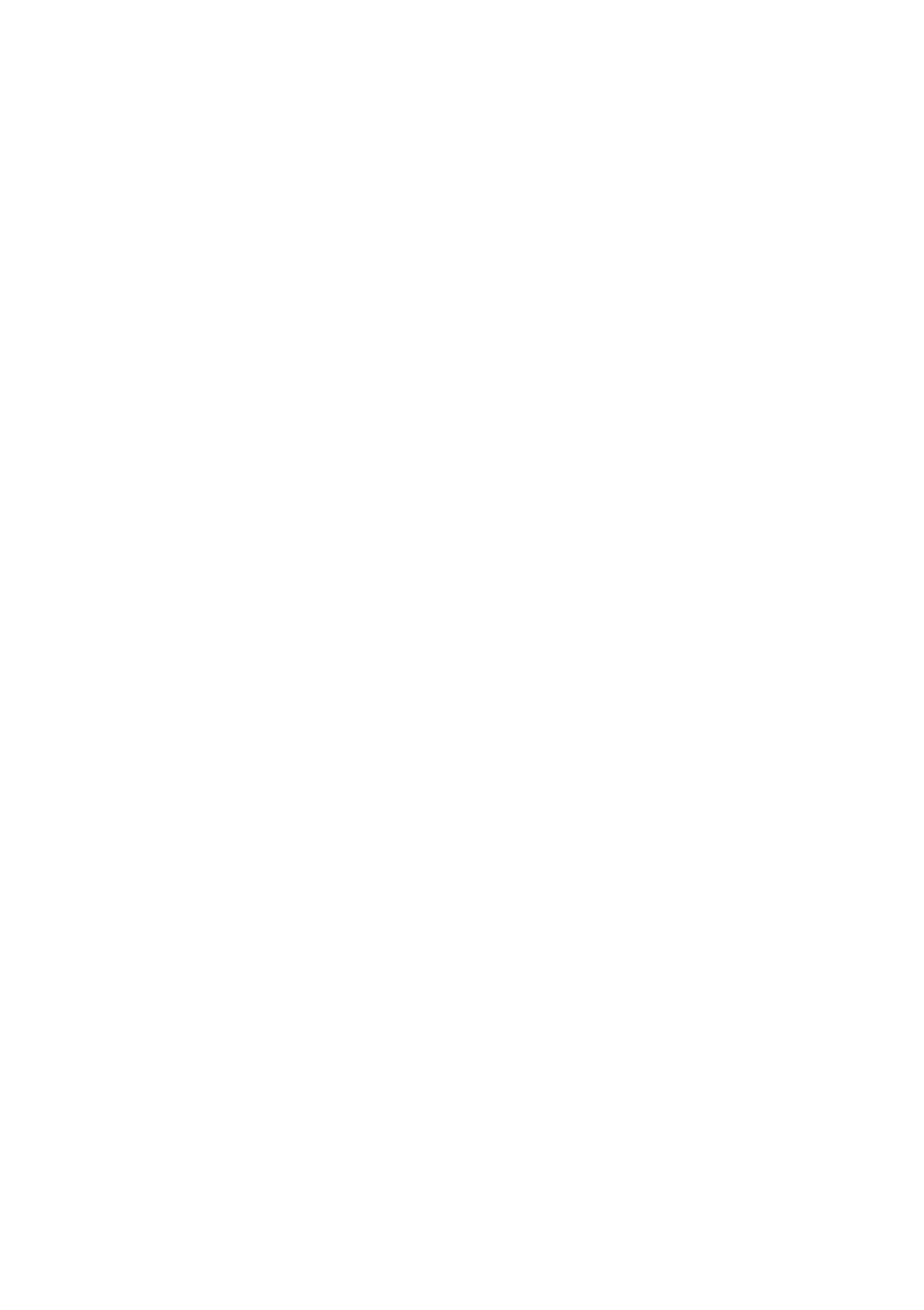




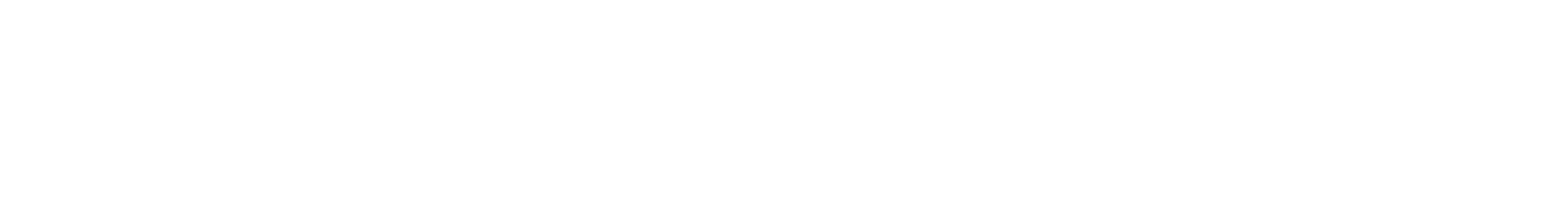

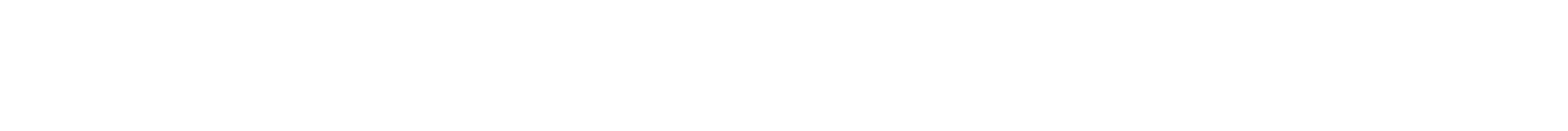

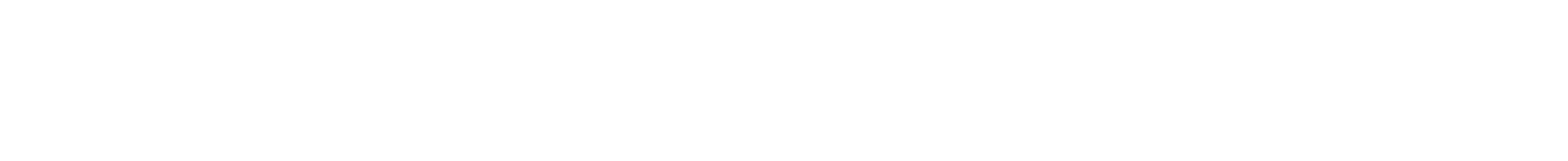

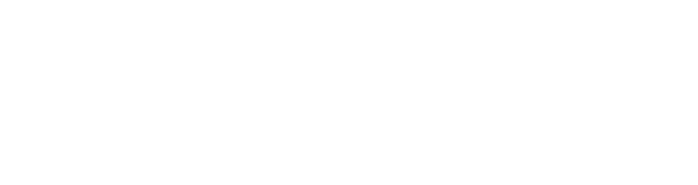

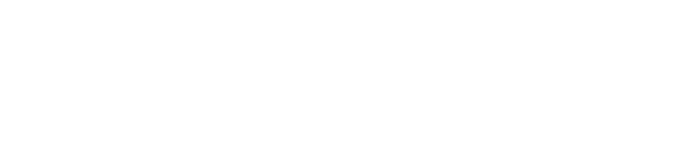

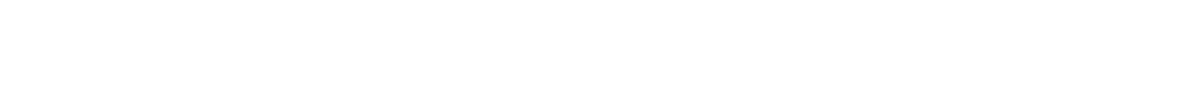

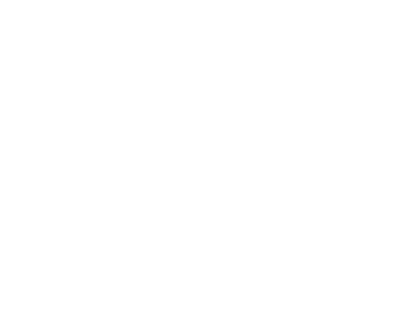

$\frac{\vec{\infty}}{\infty}$

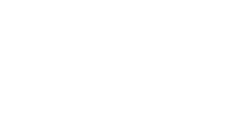

\section{兽}

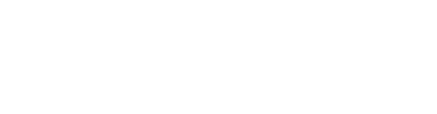

窈

商

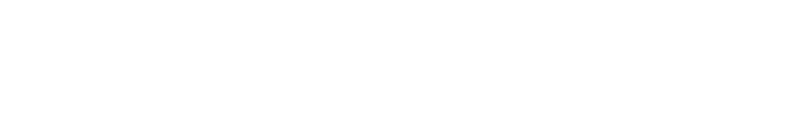

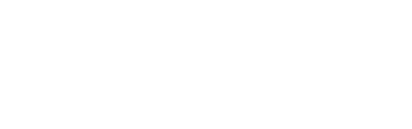

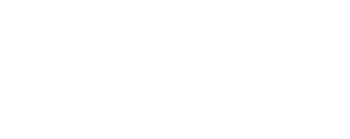

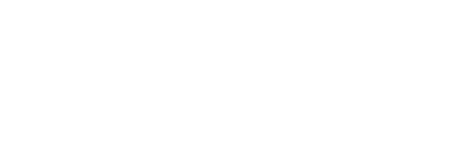

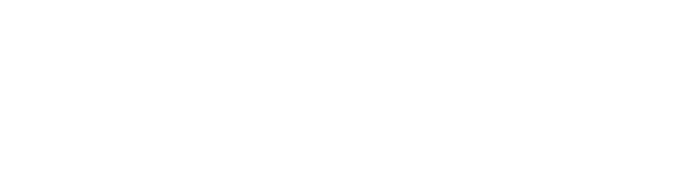

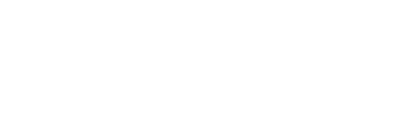

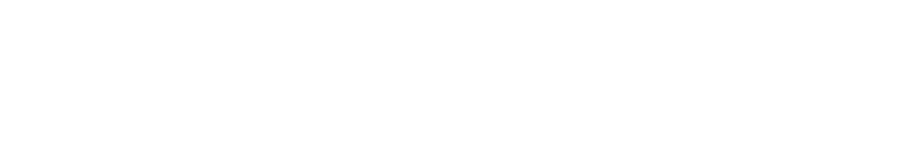

营

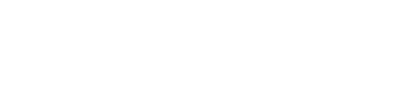

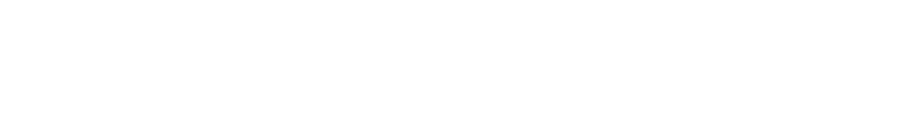

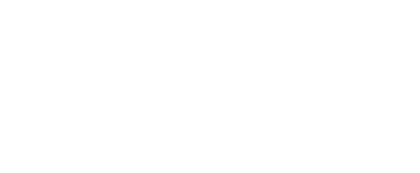

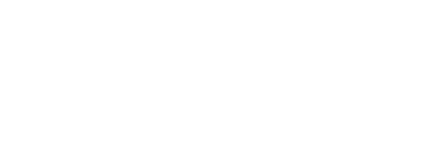

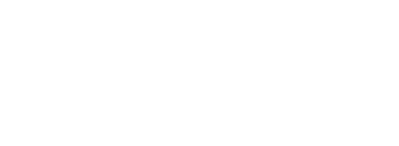

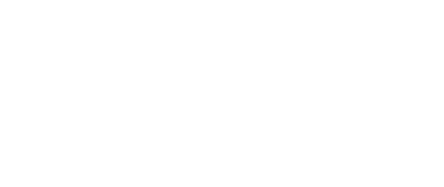




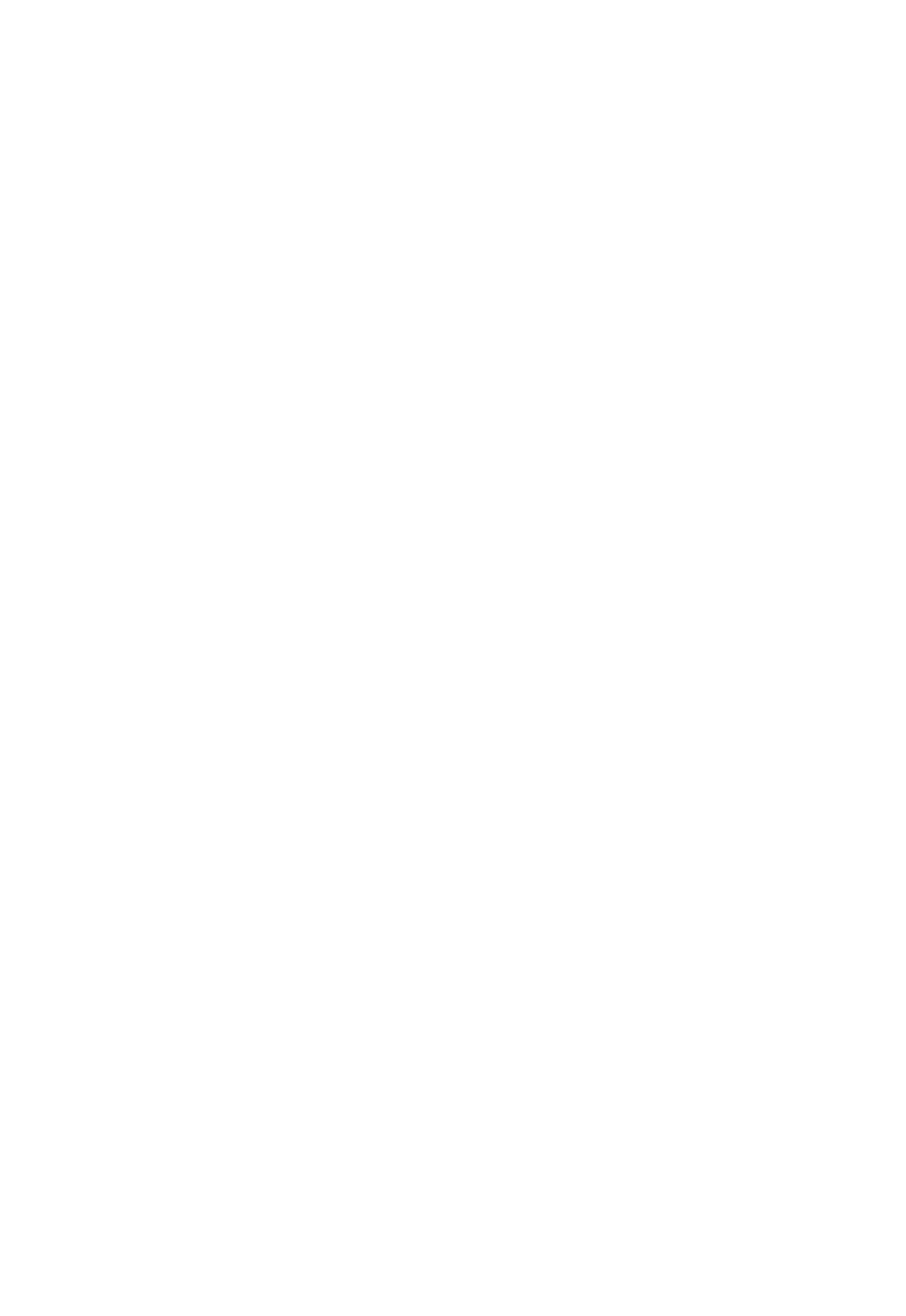




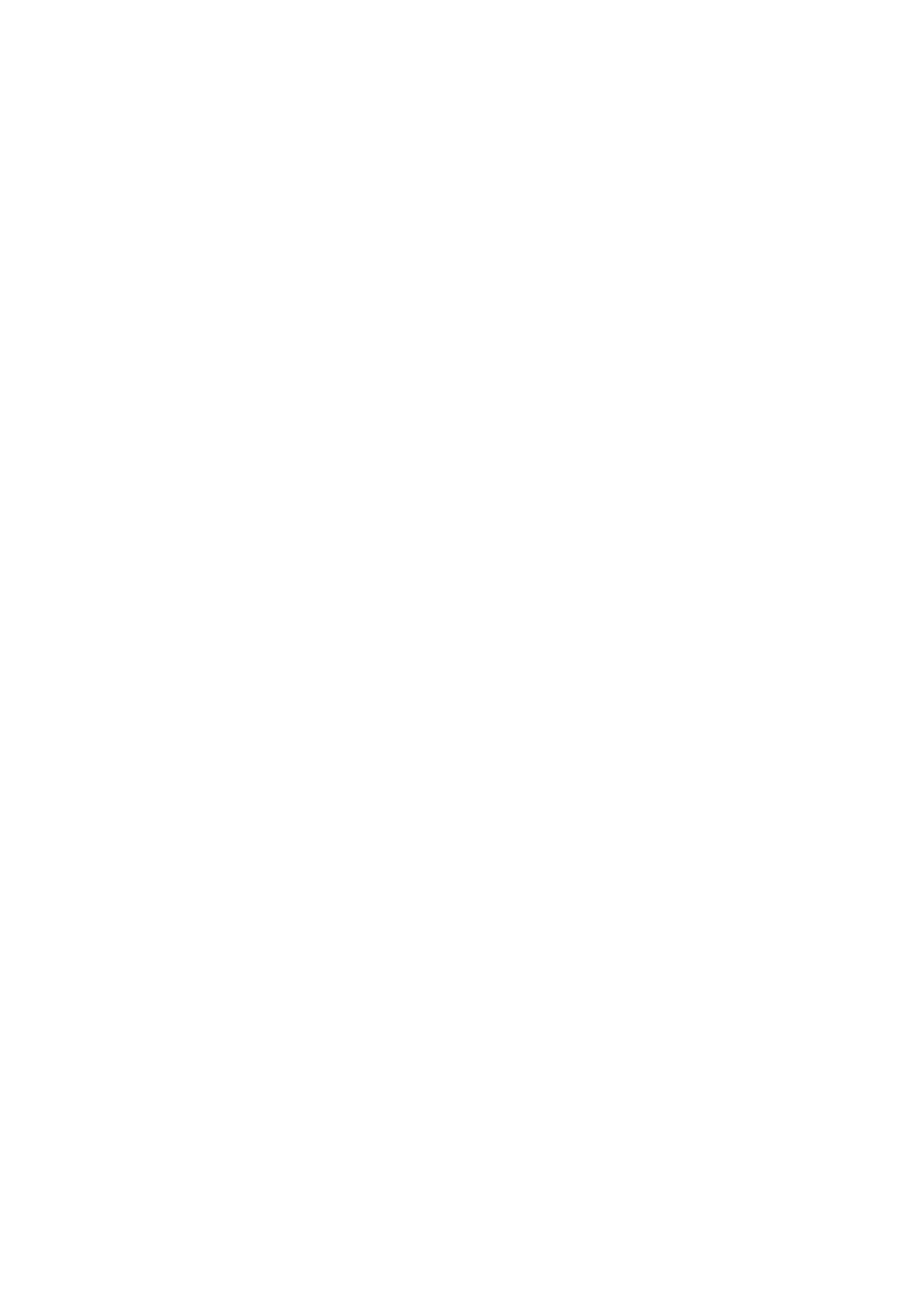




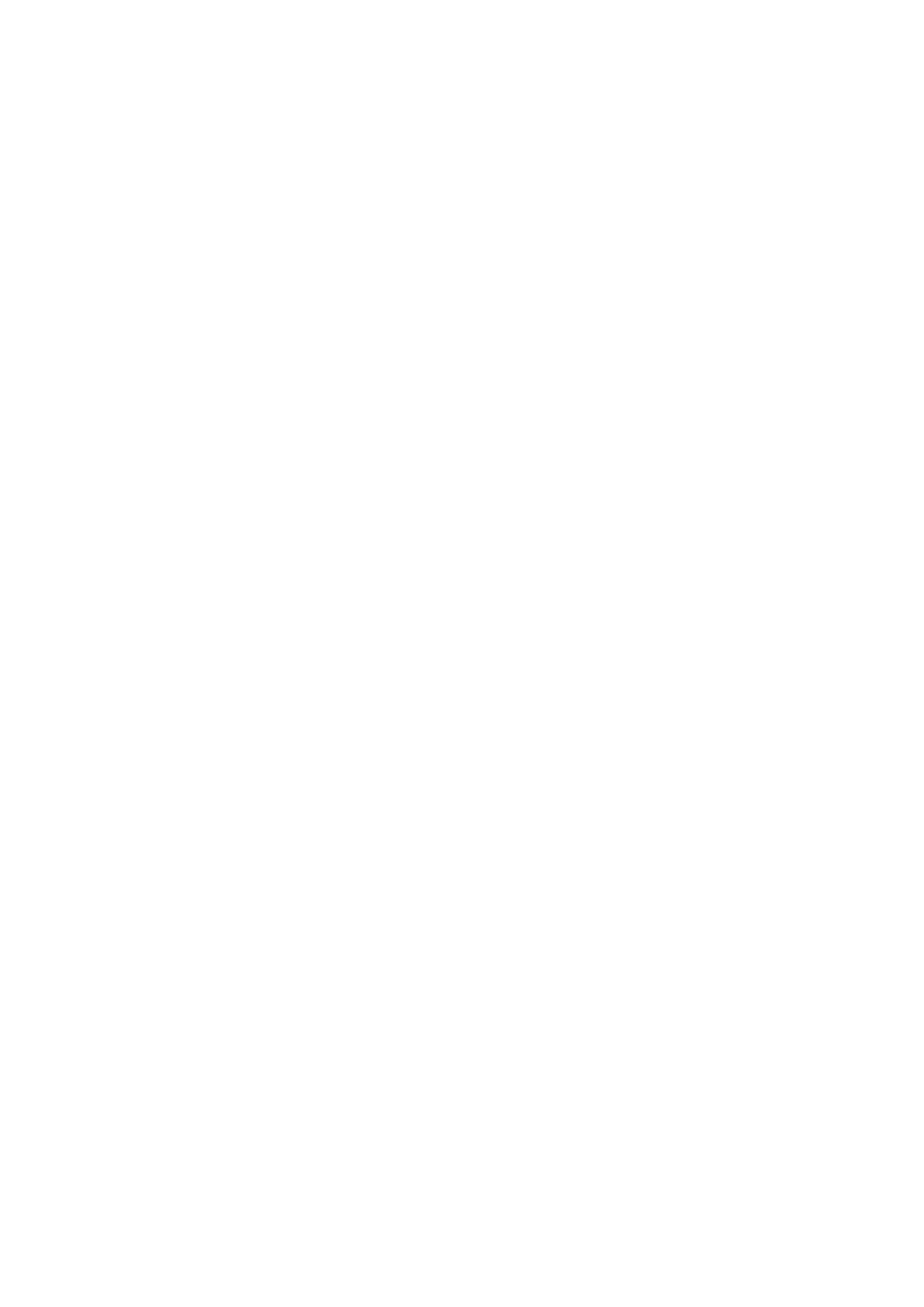




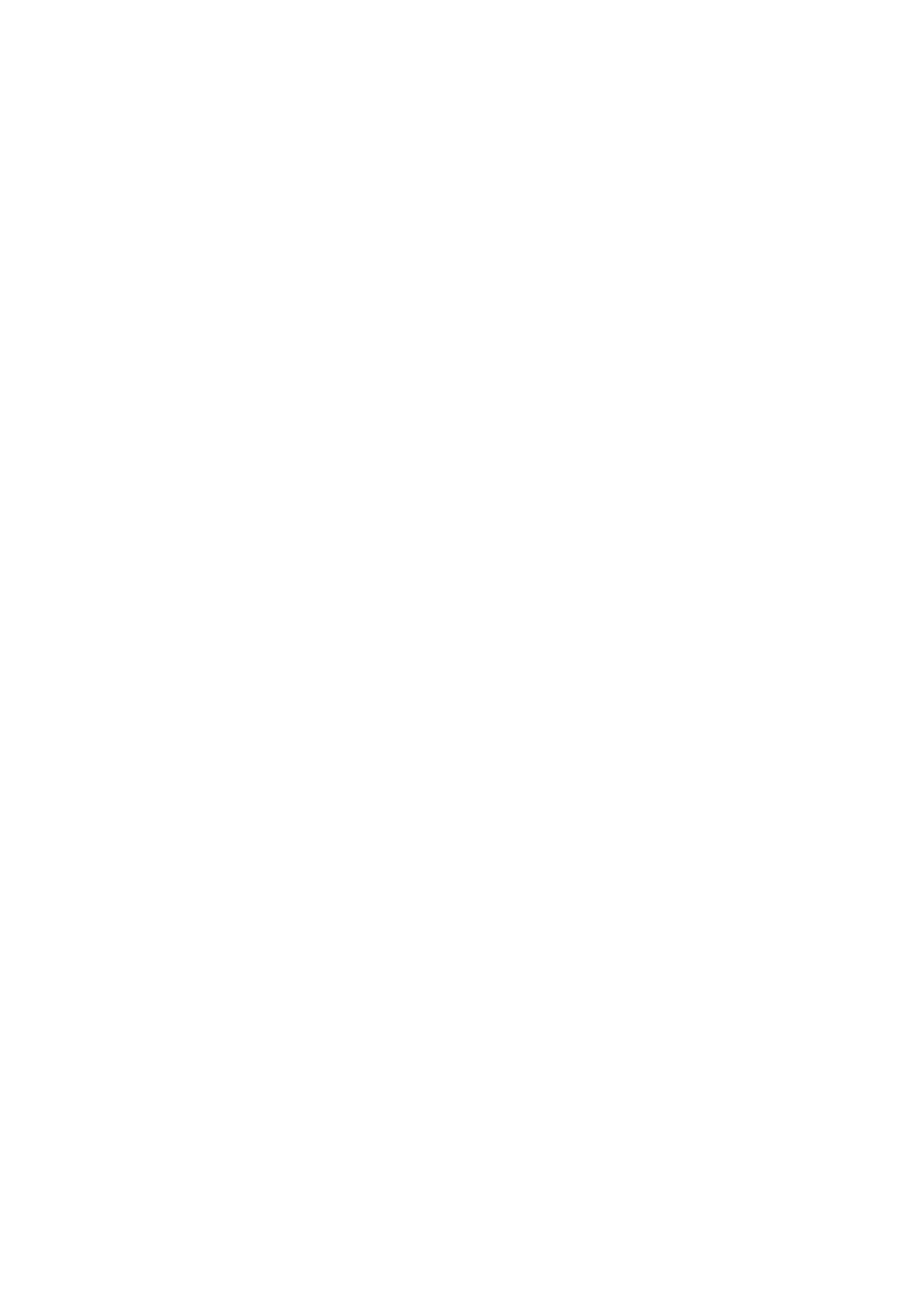




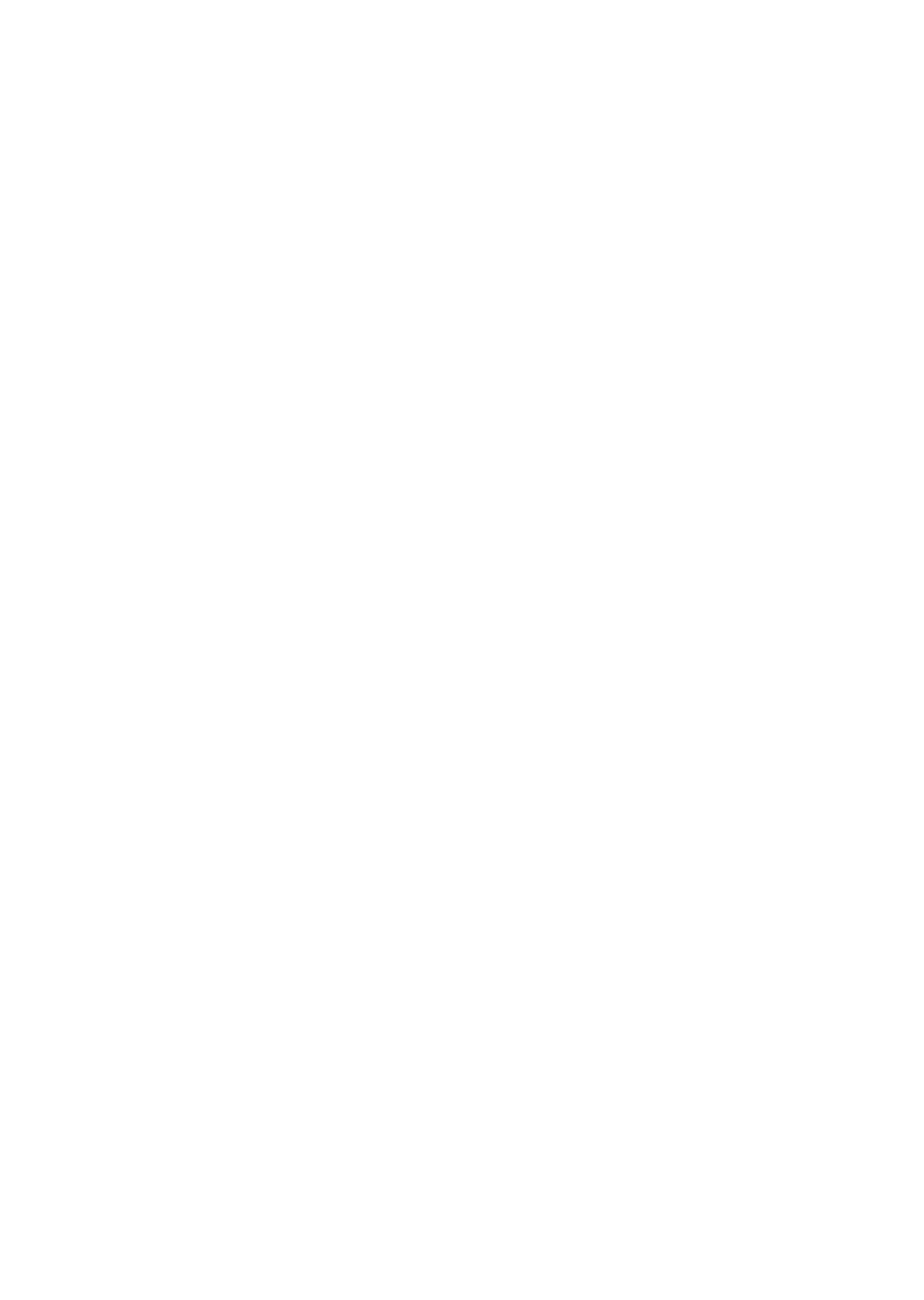




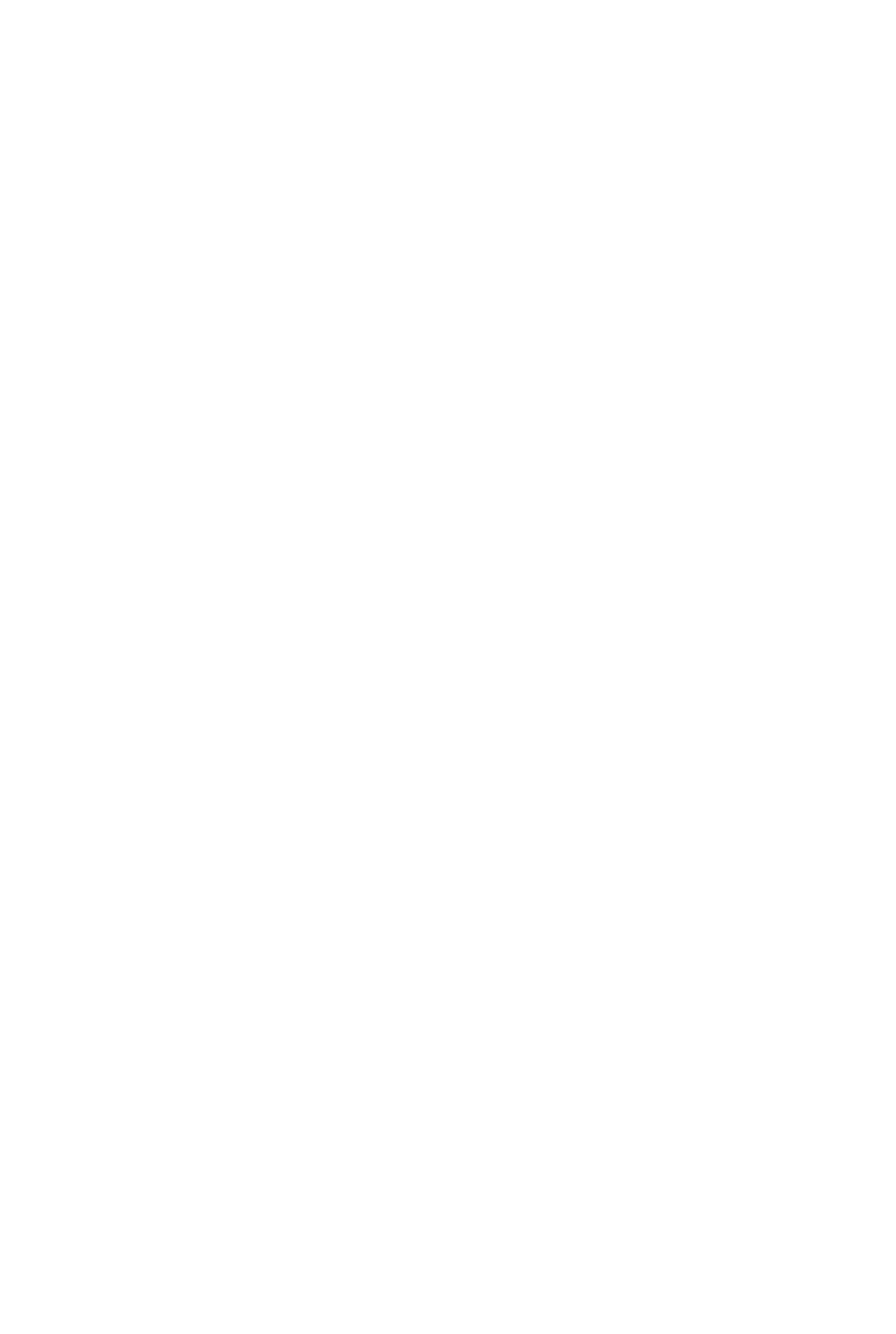




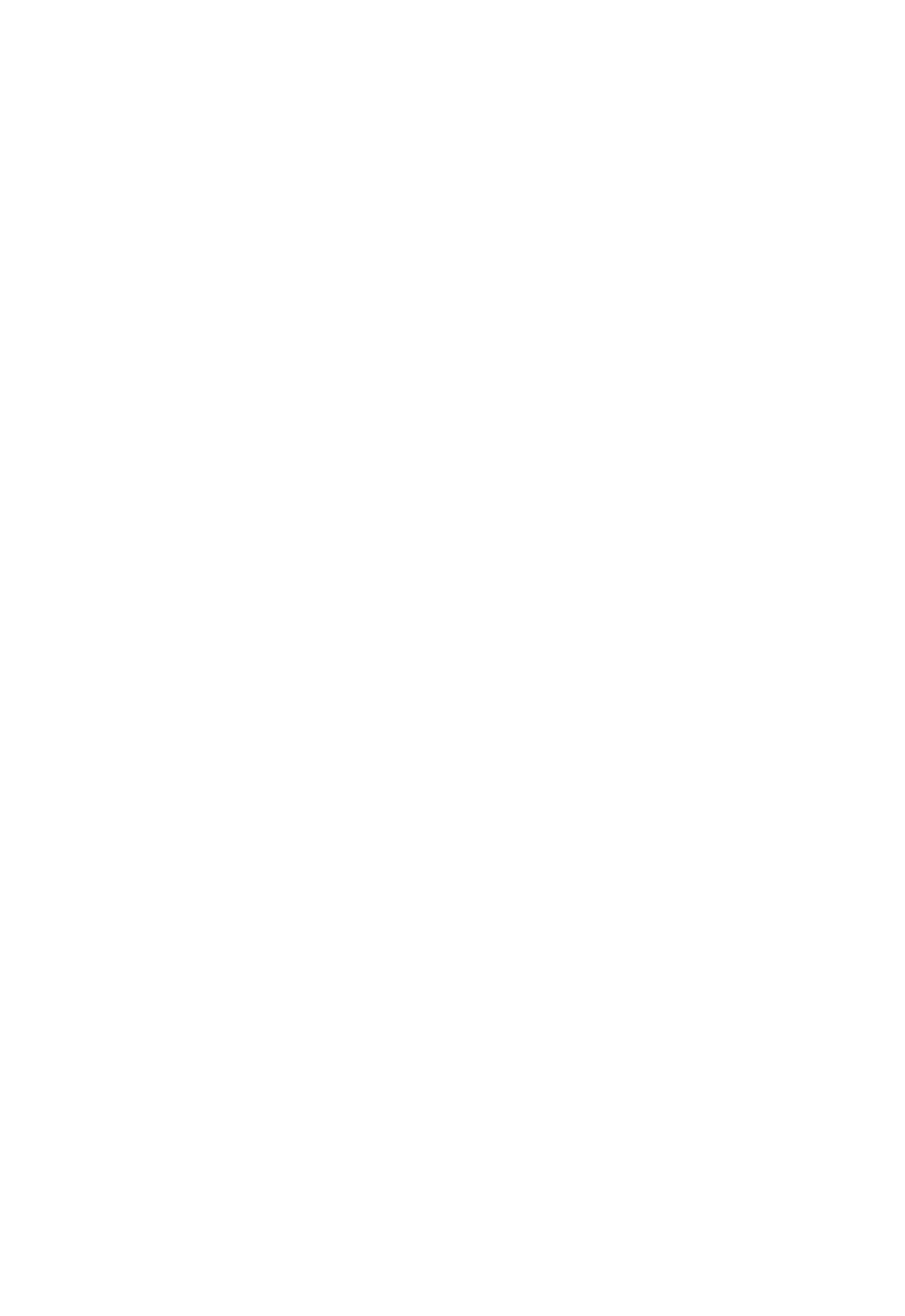




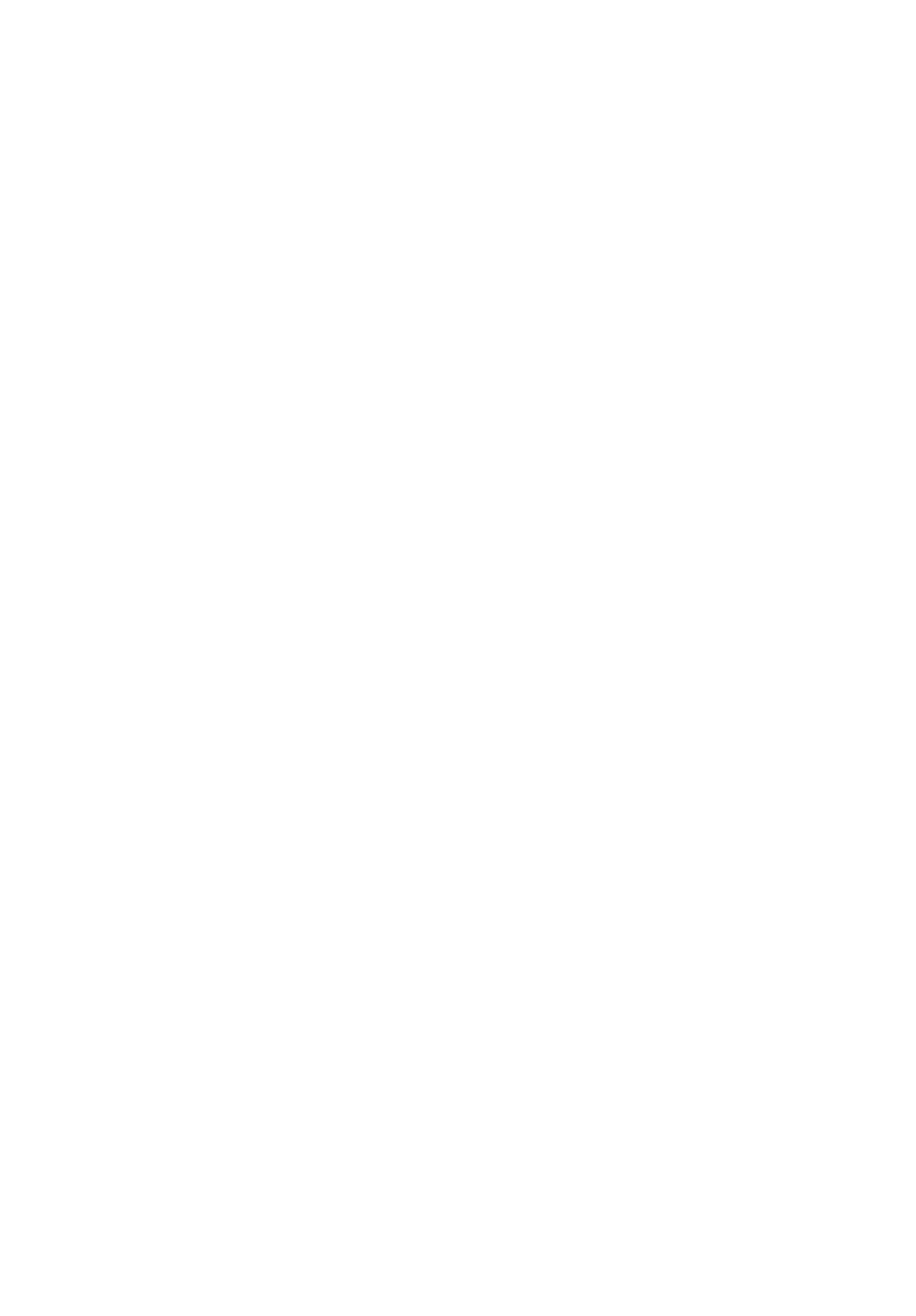




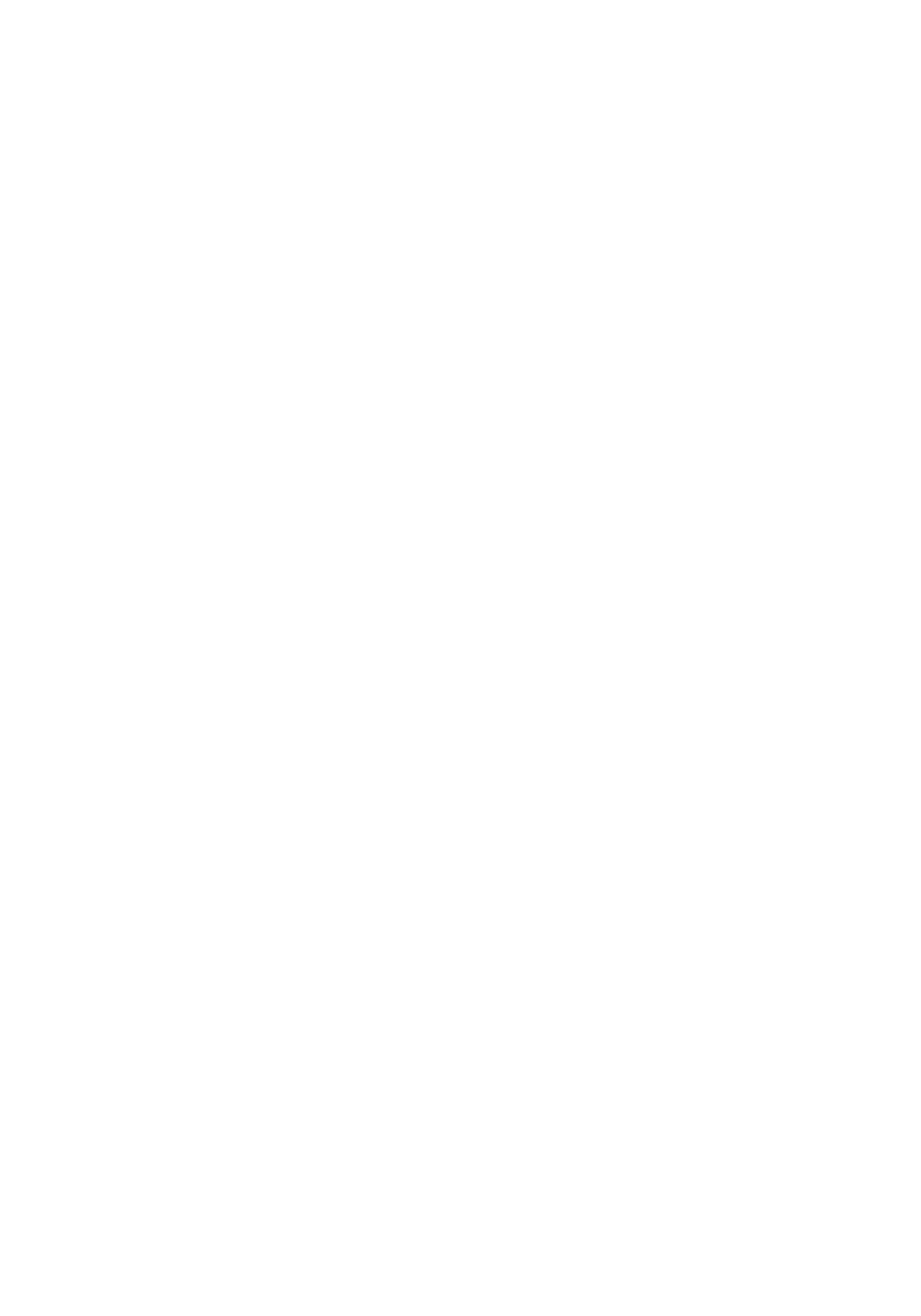




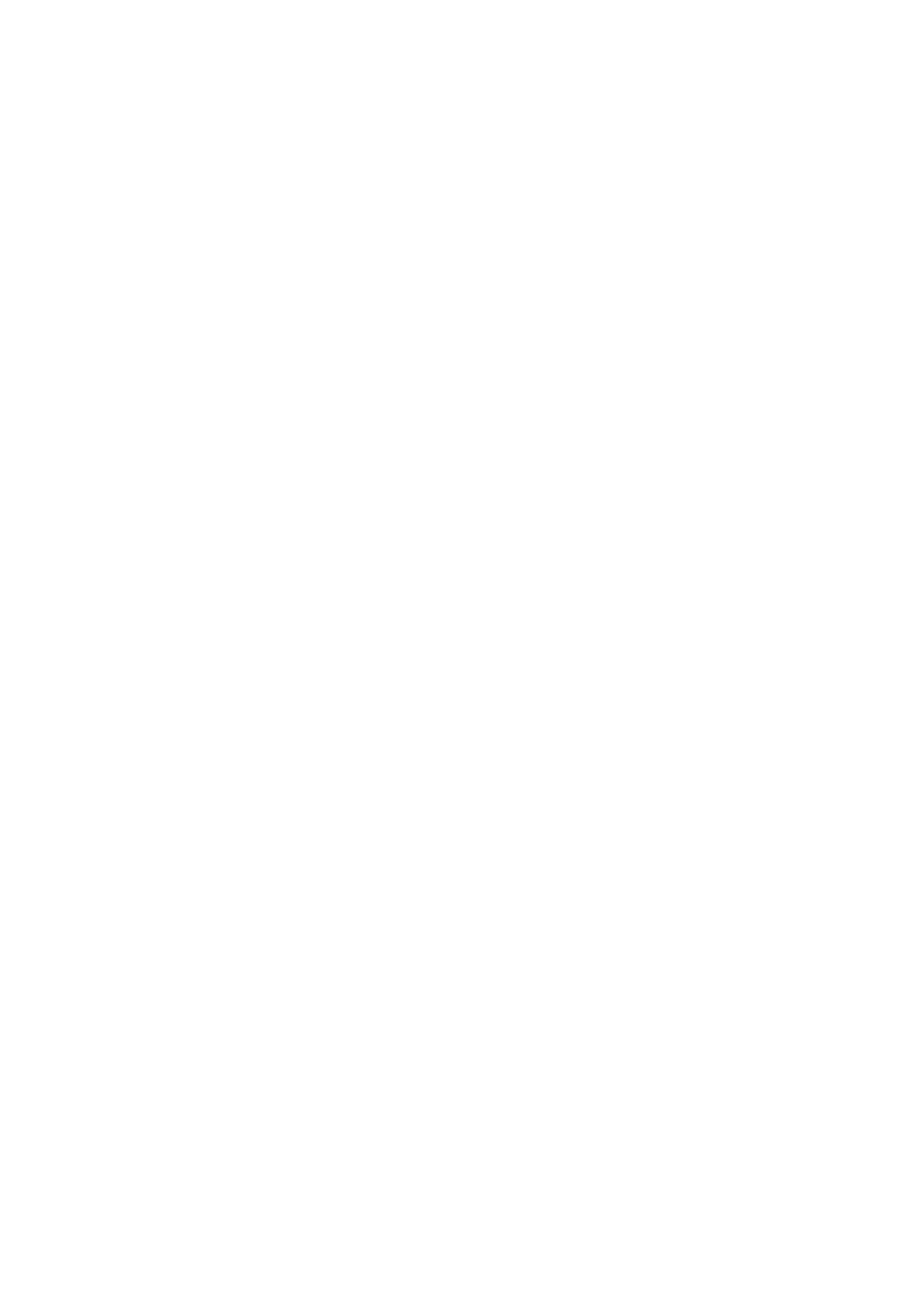




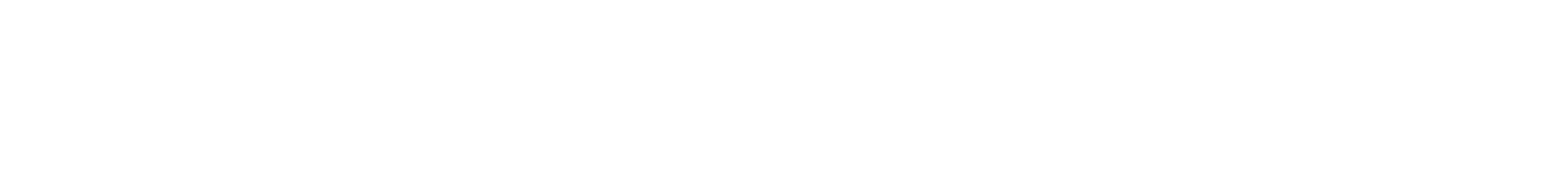

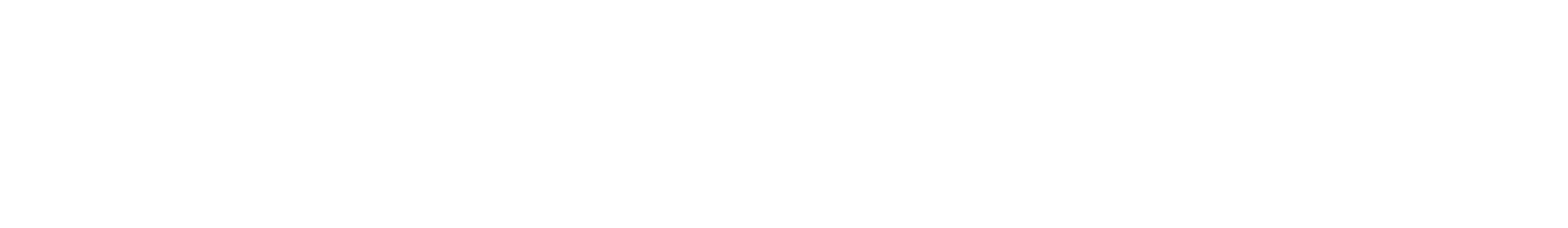

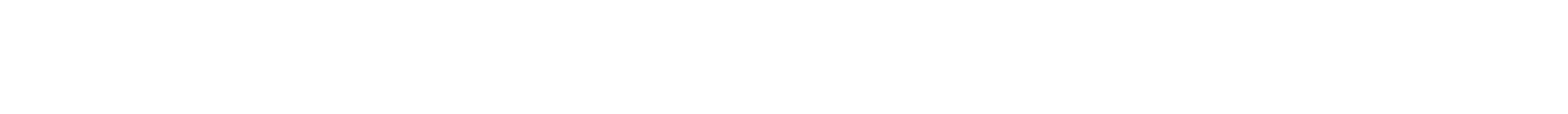

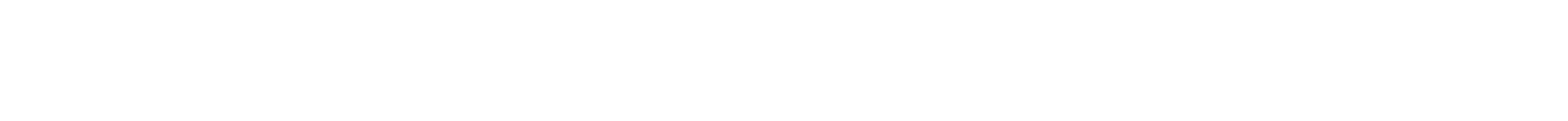

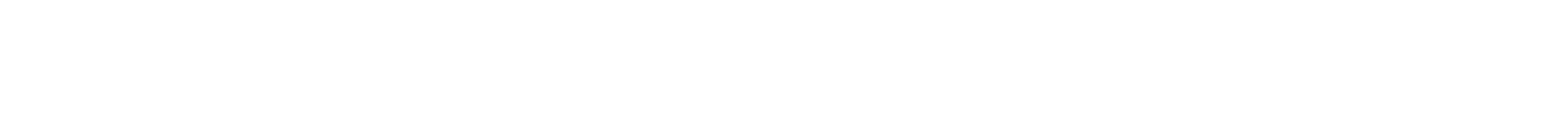

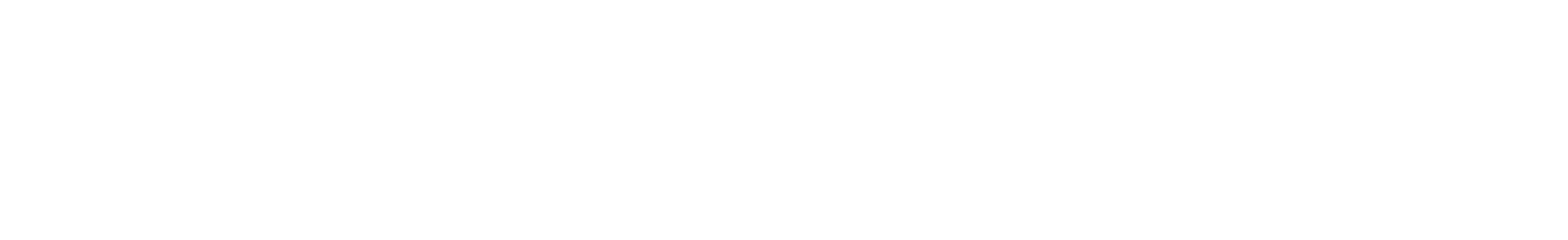

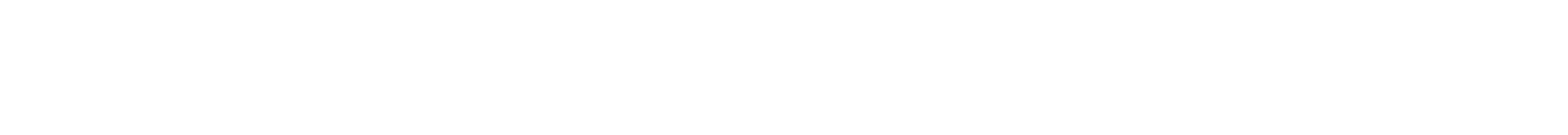

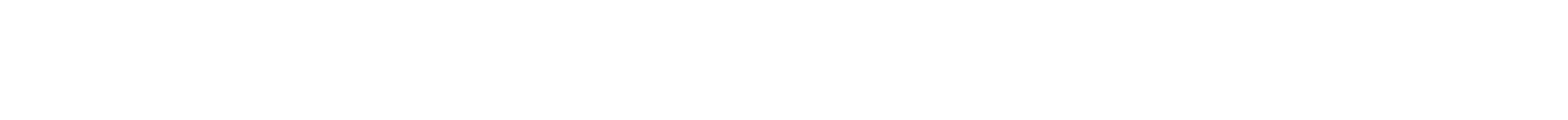

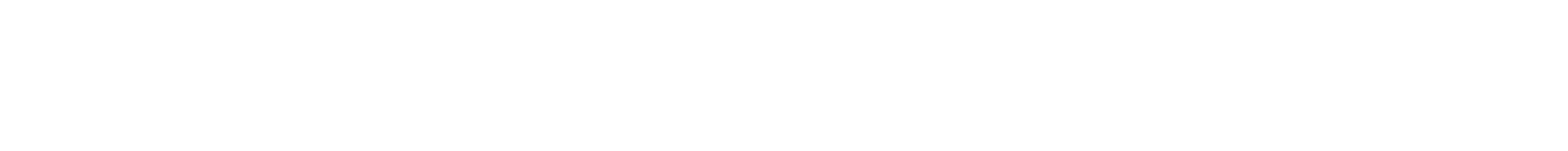




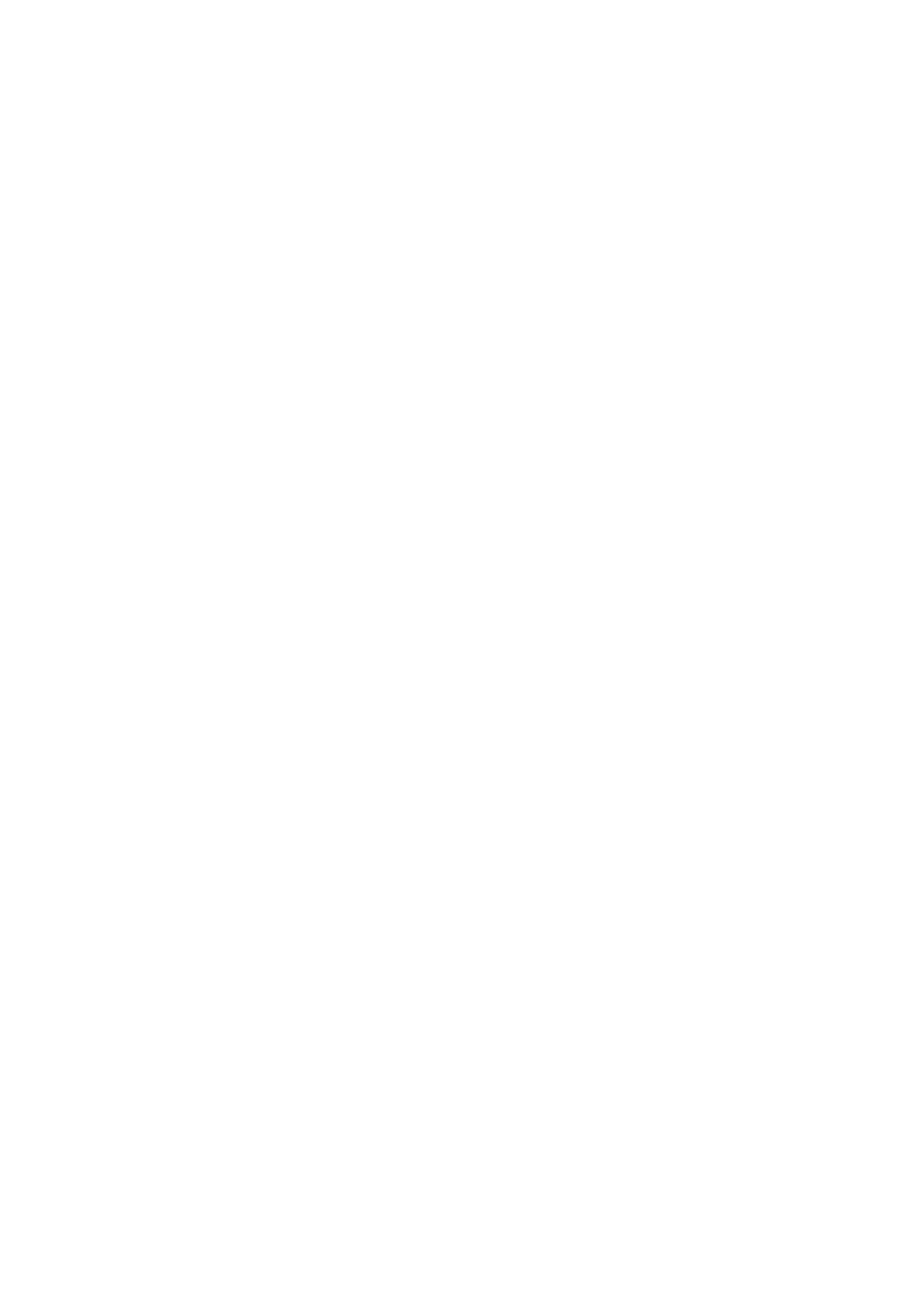




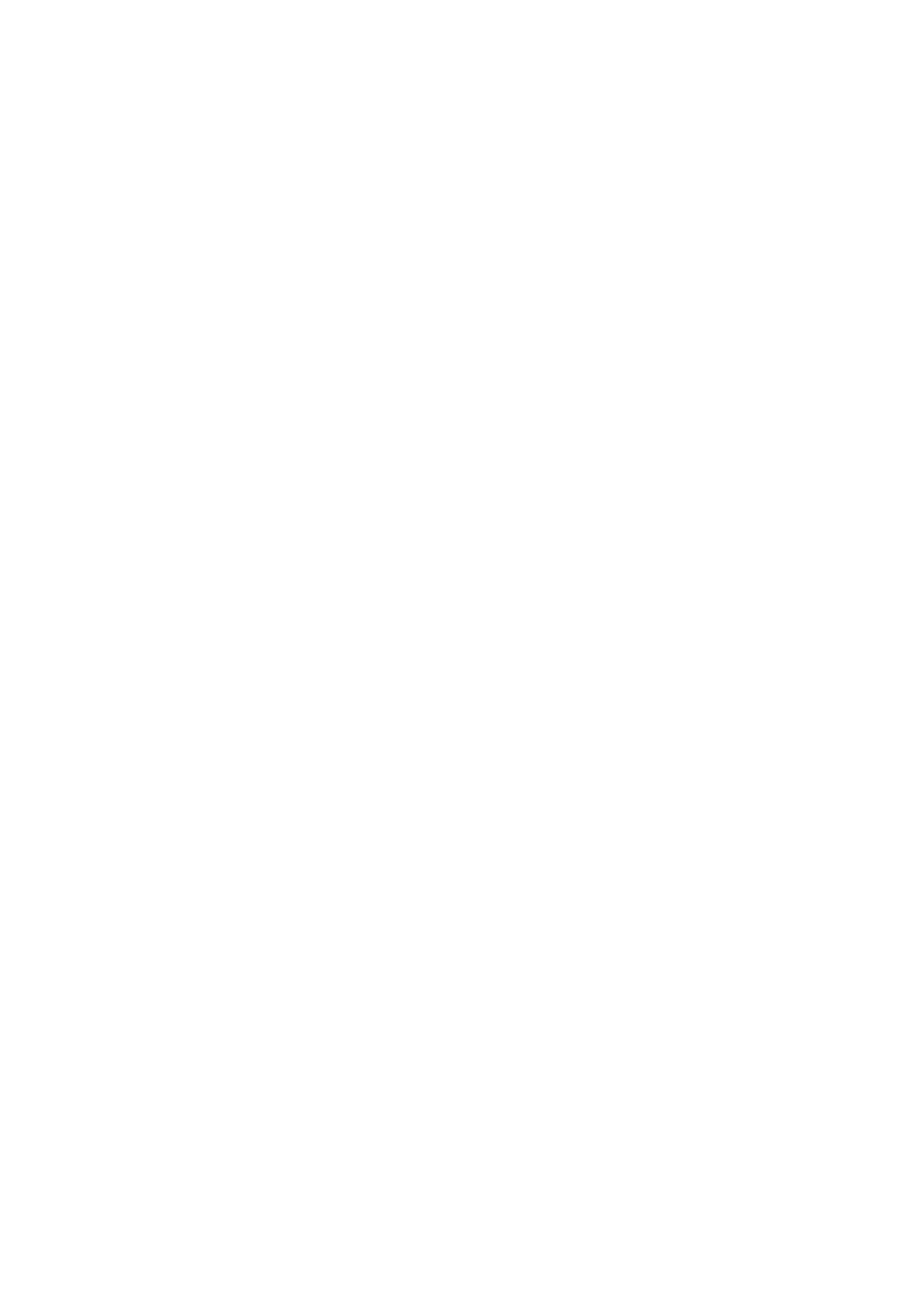




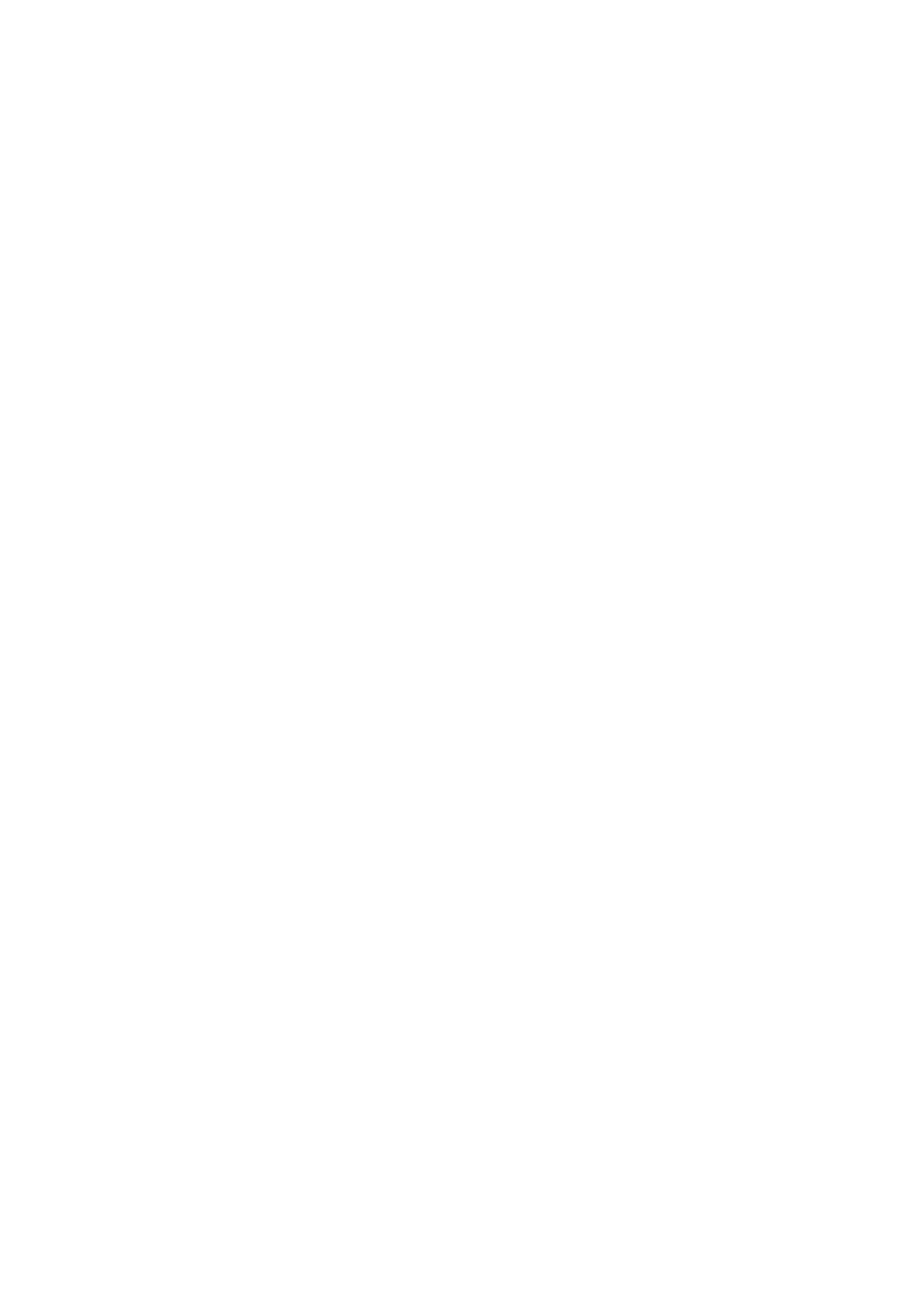




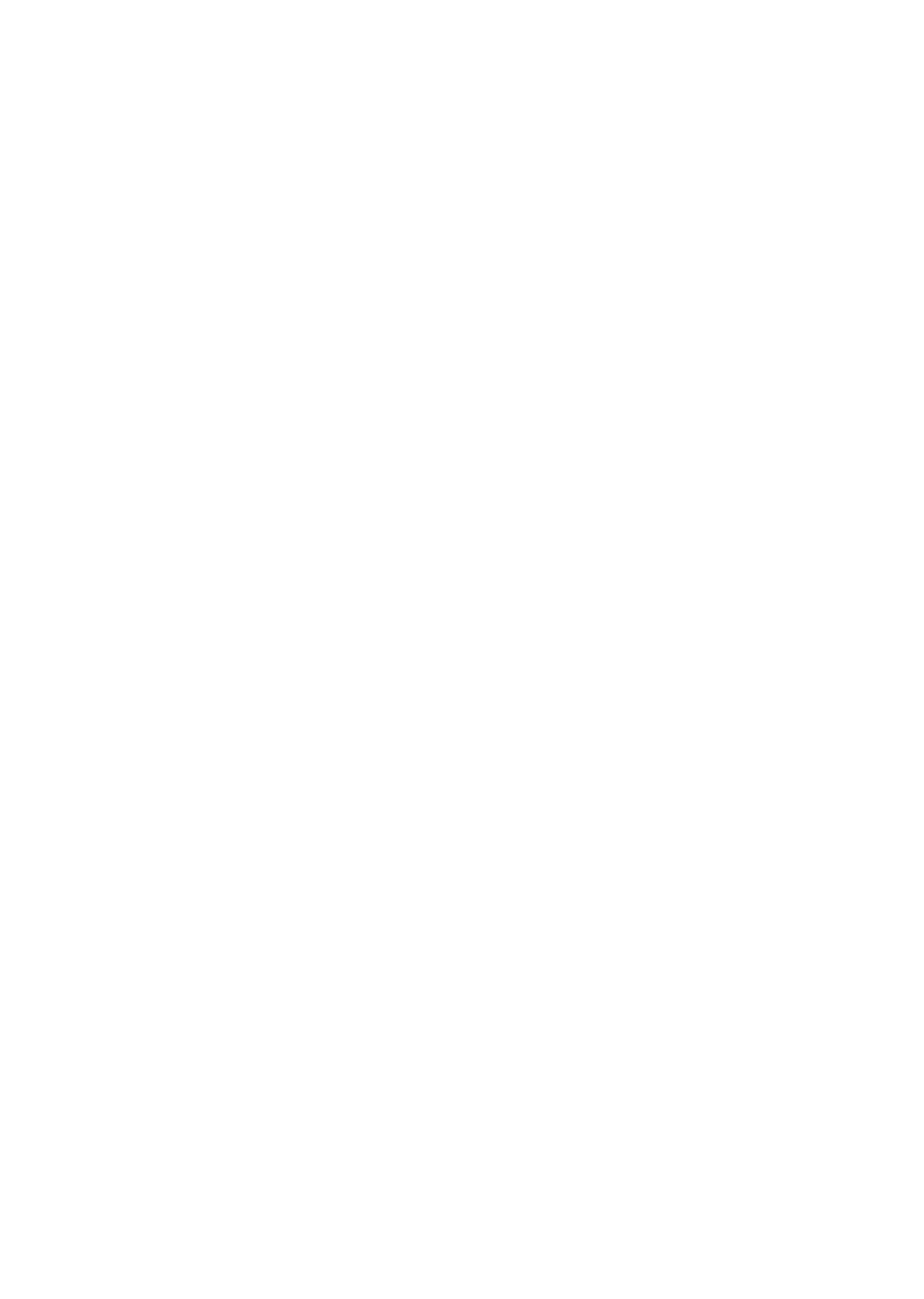




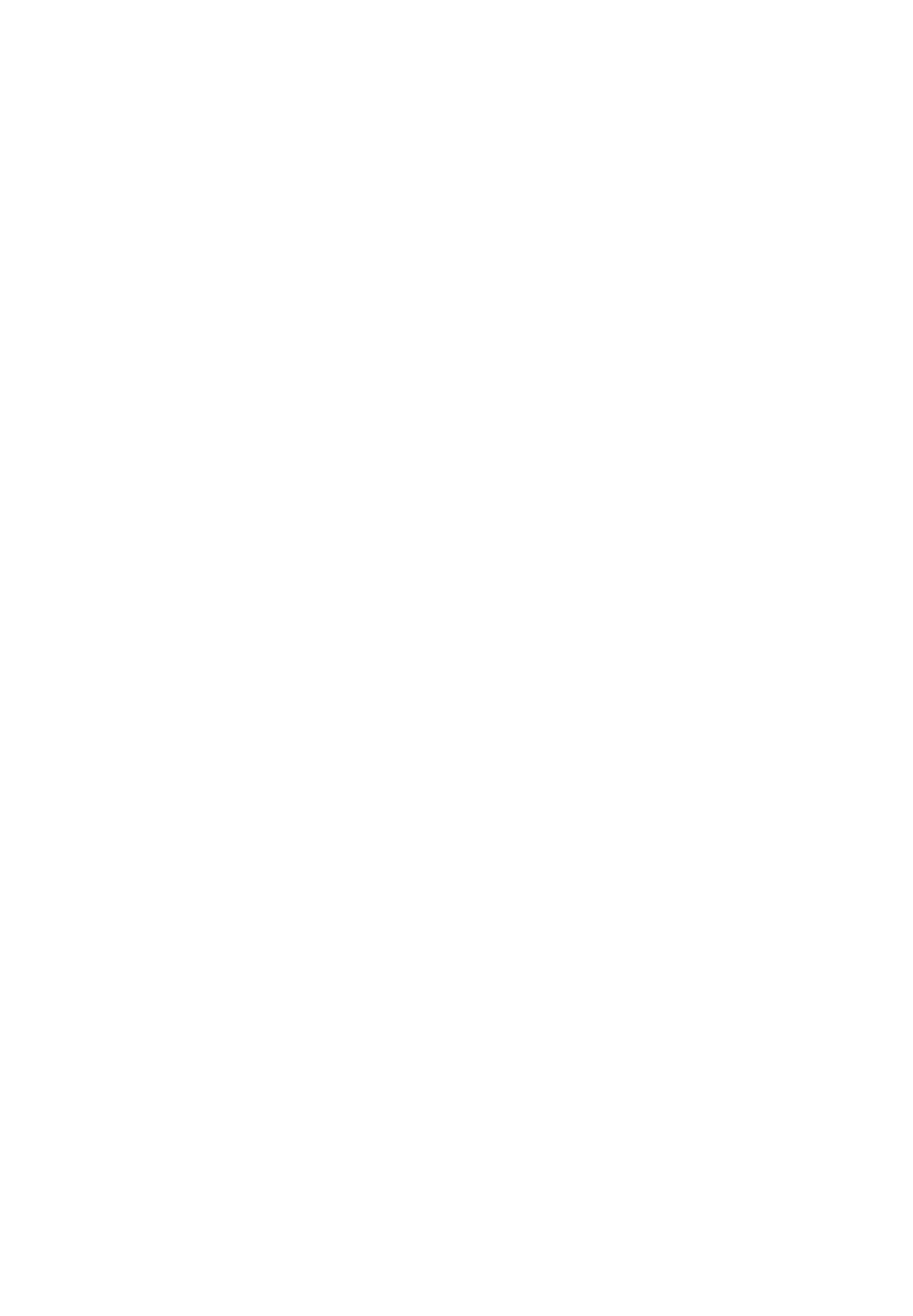




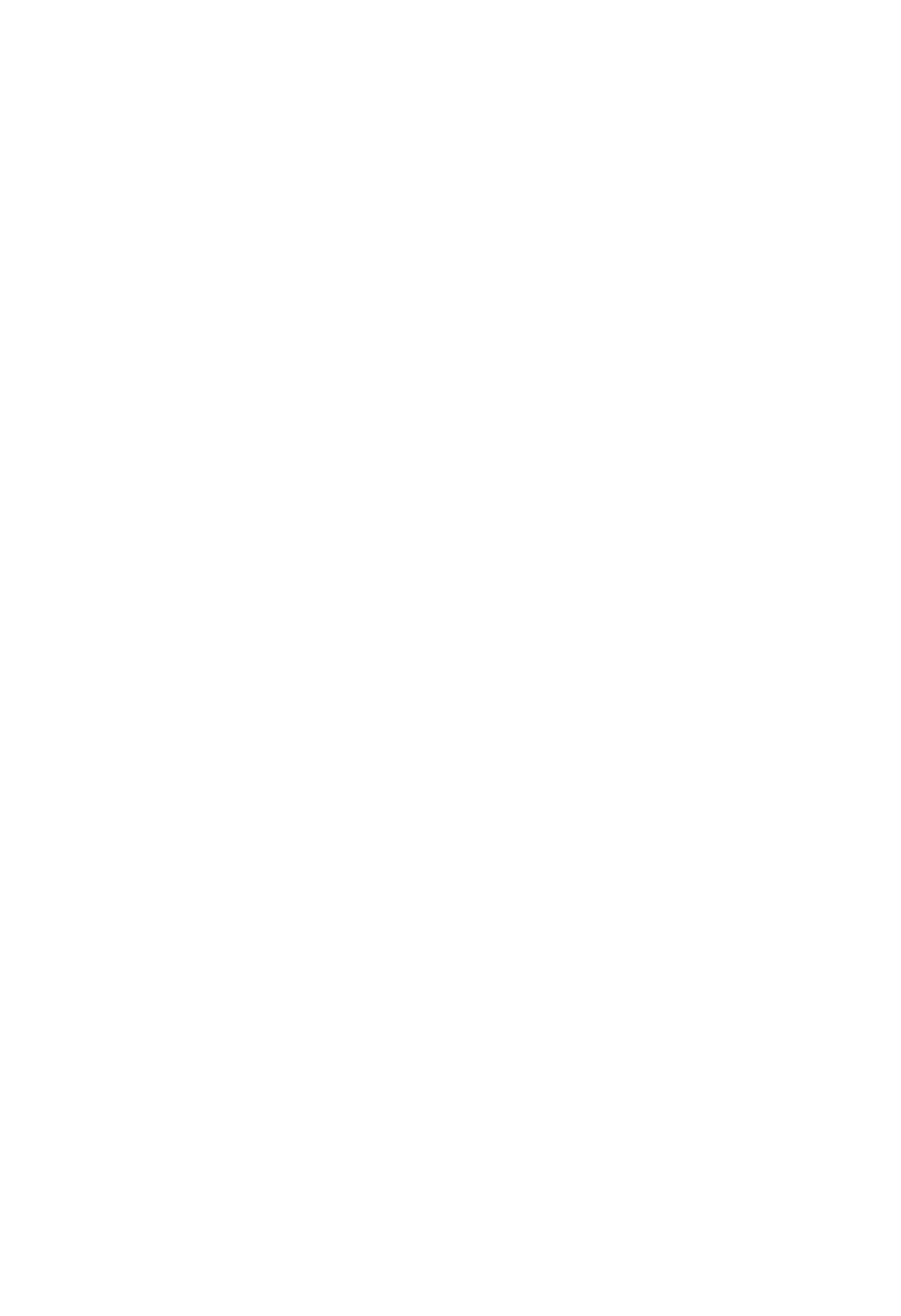




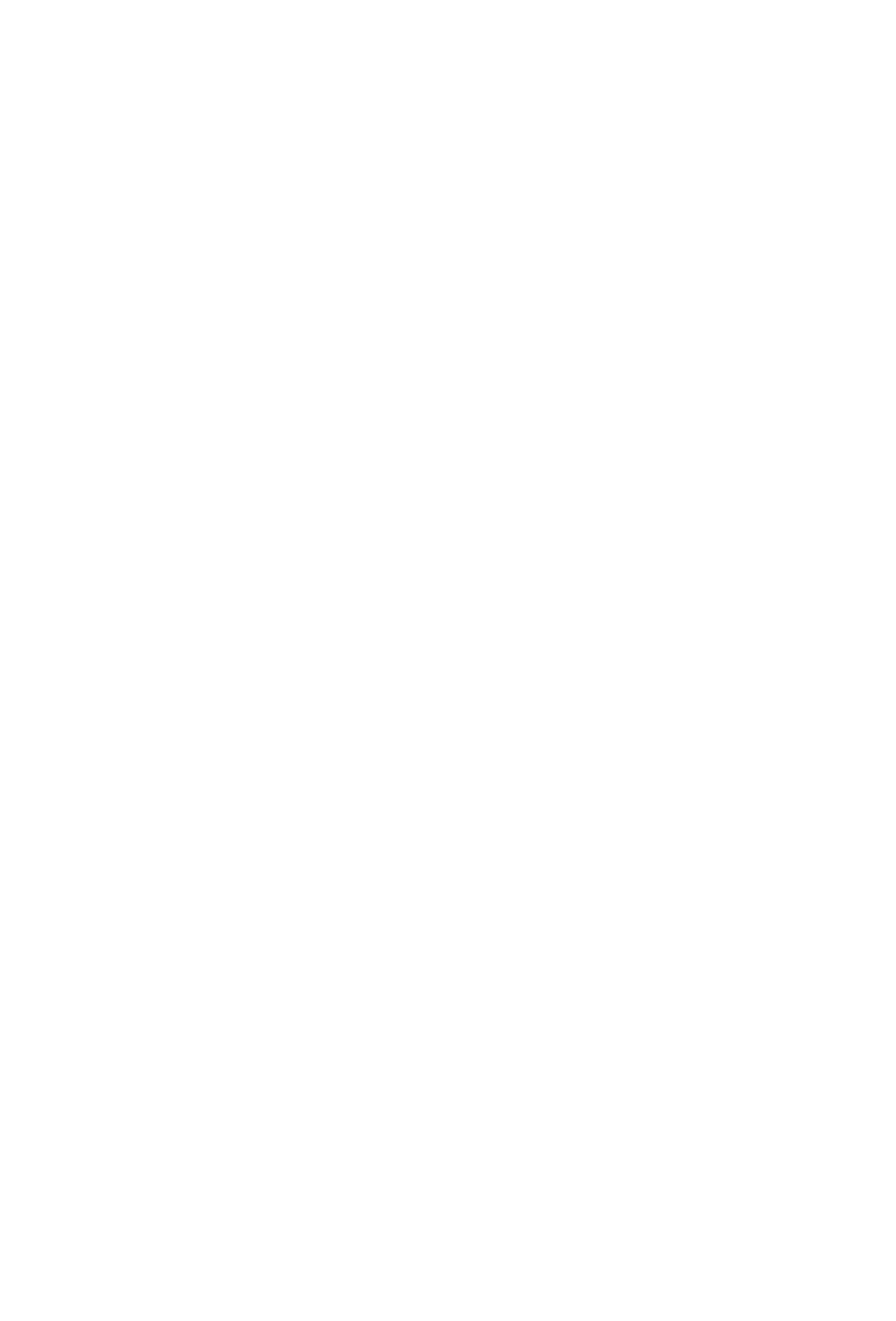




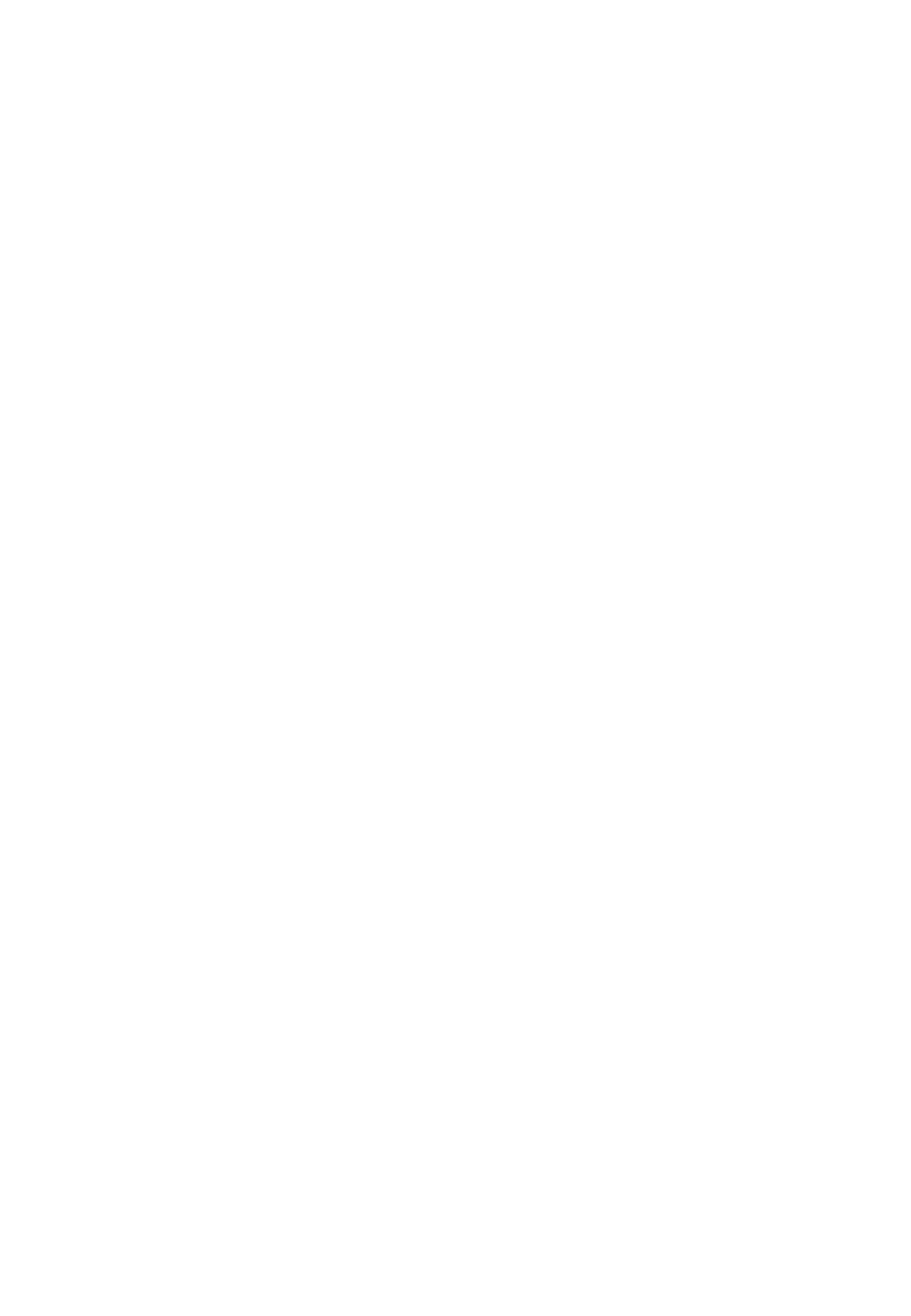




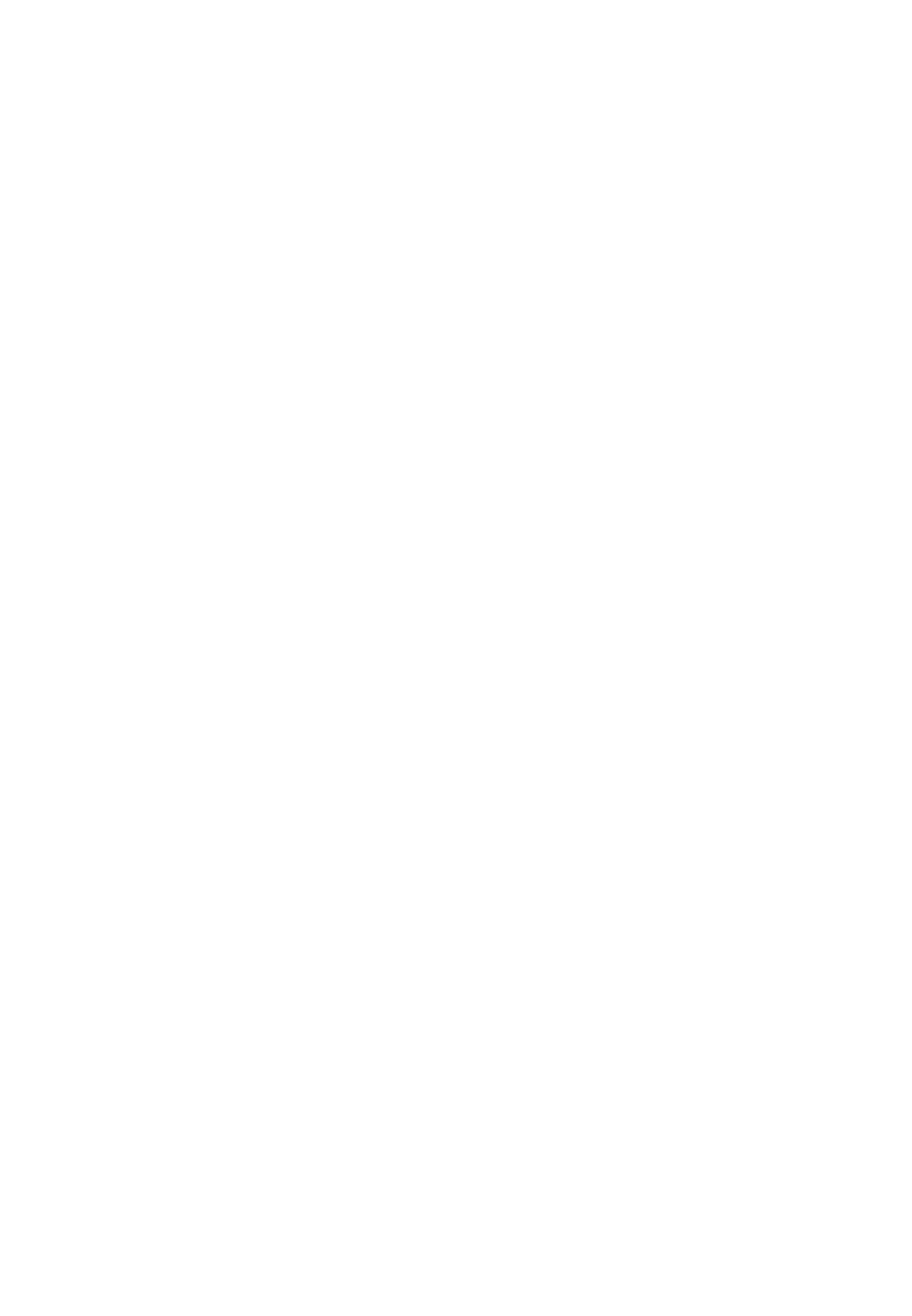




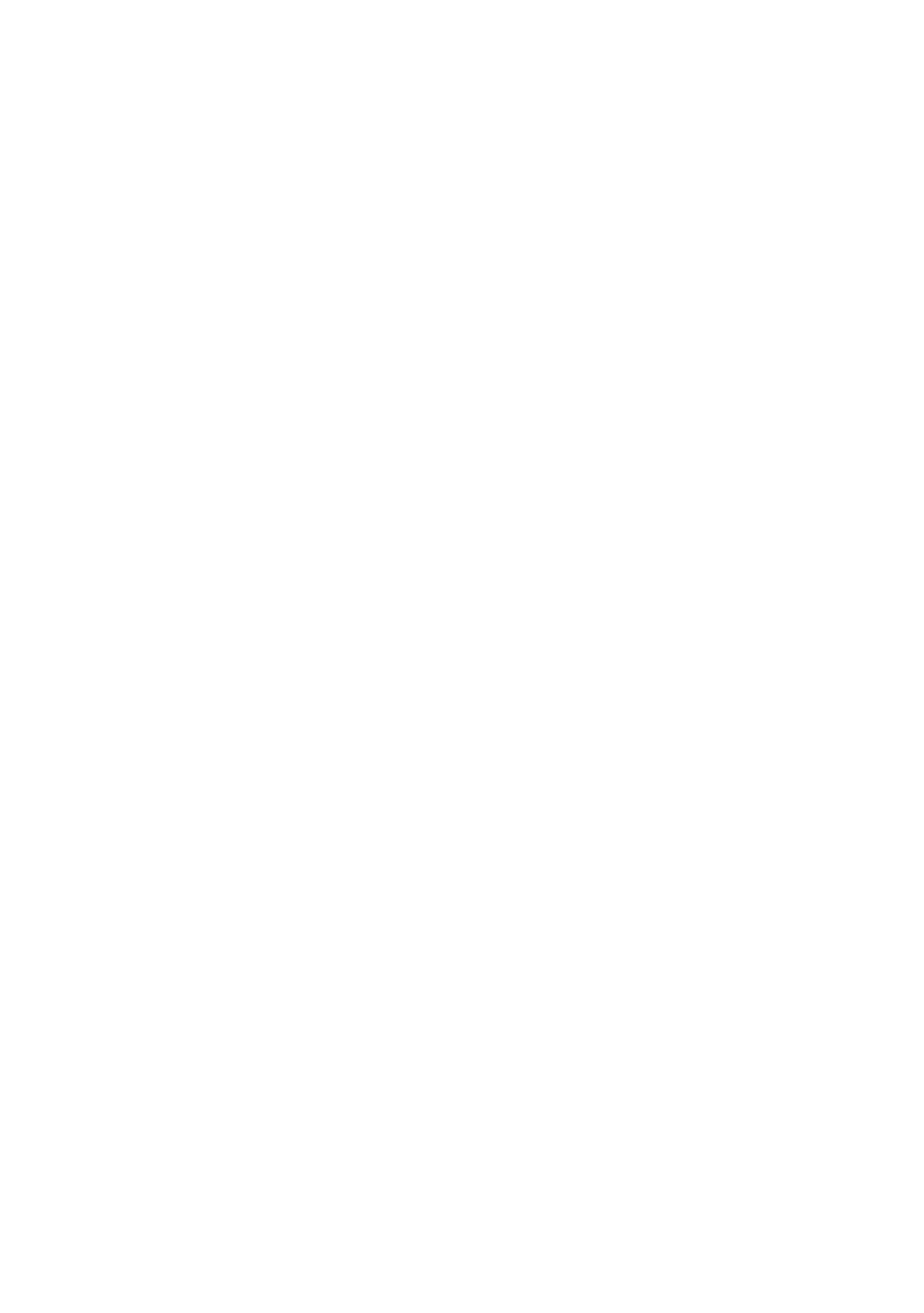




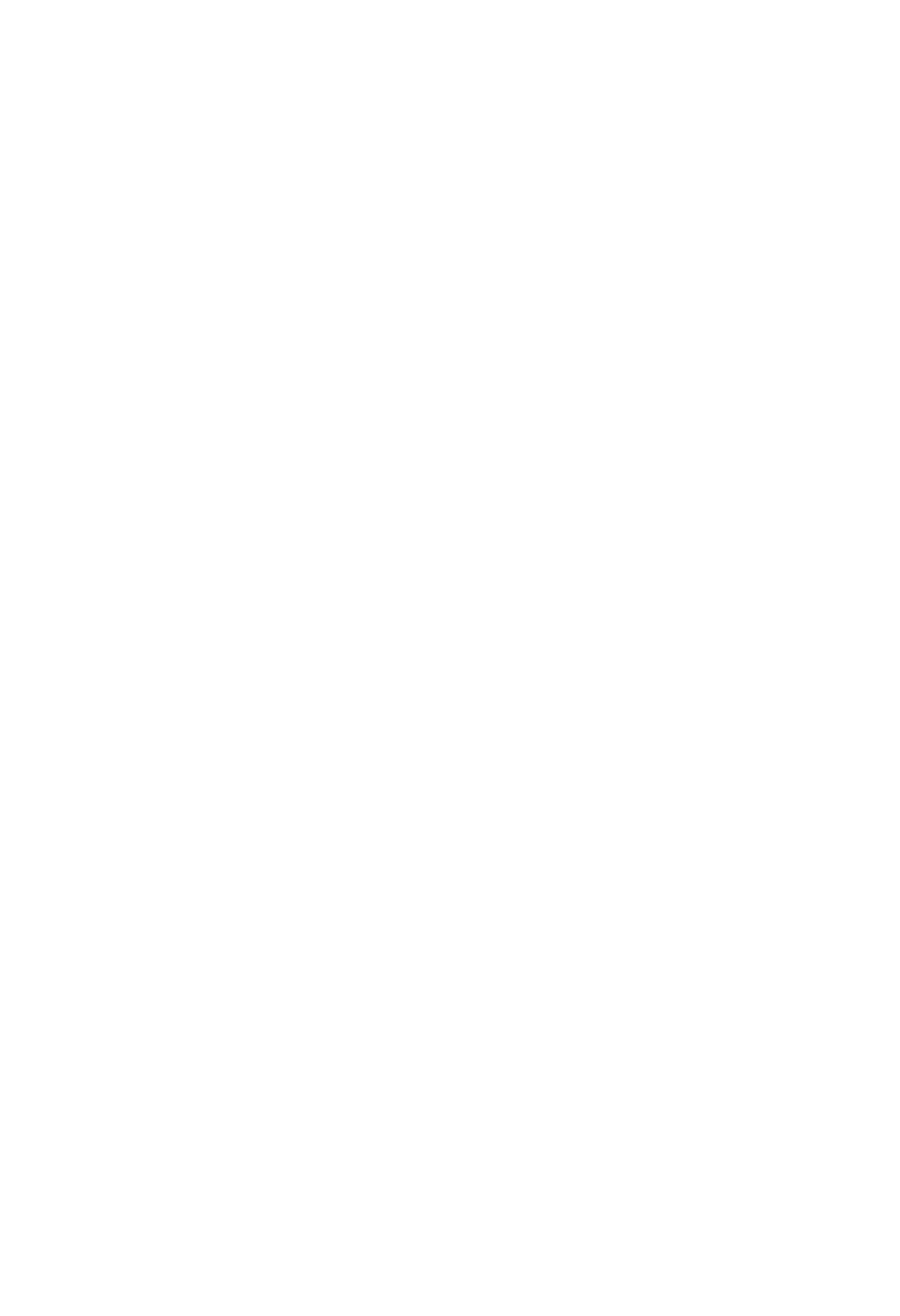




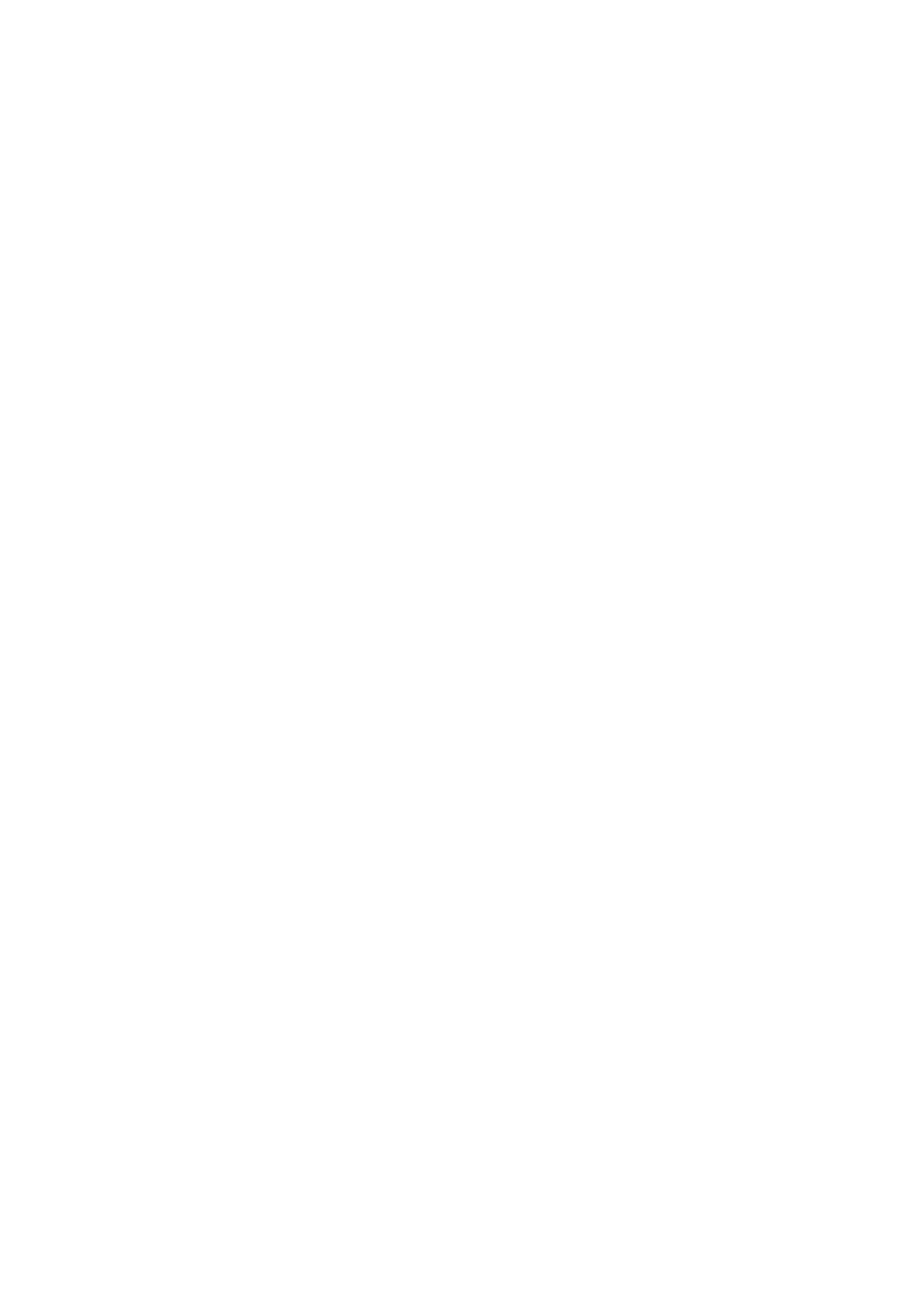




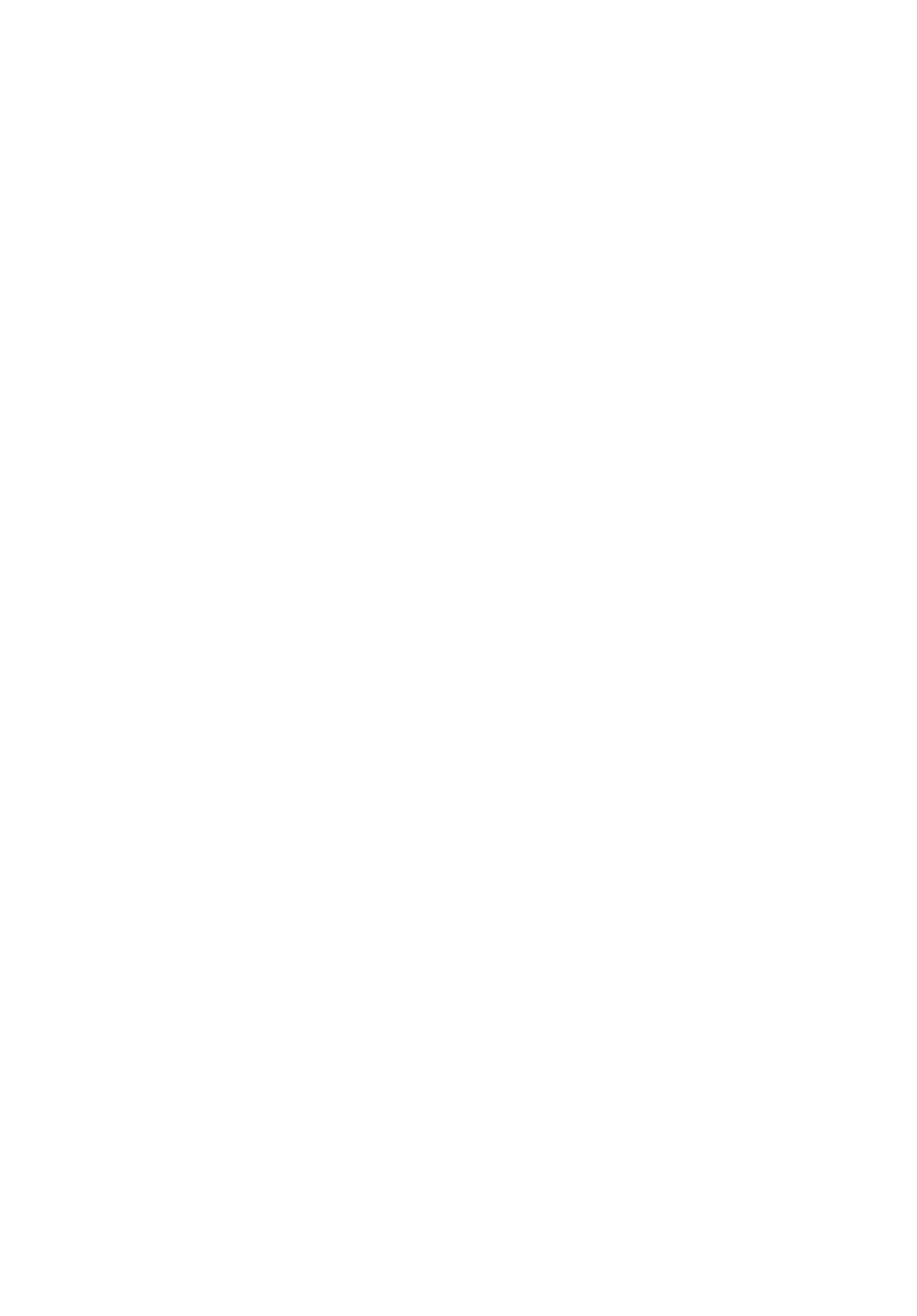




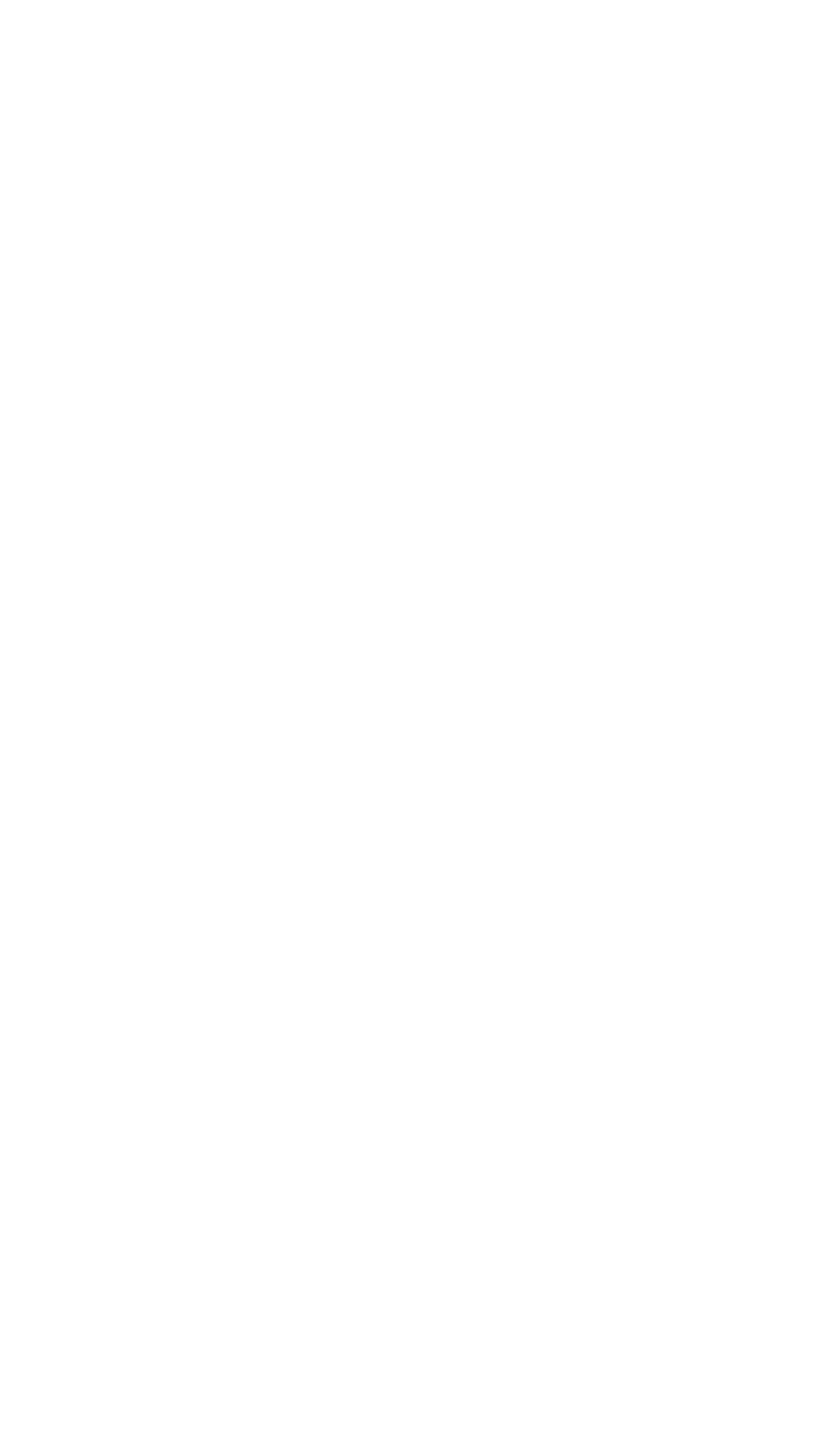




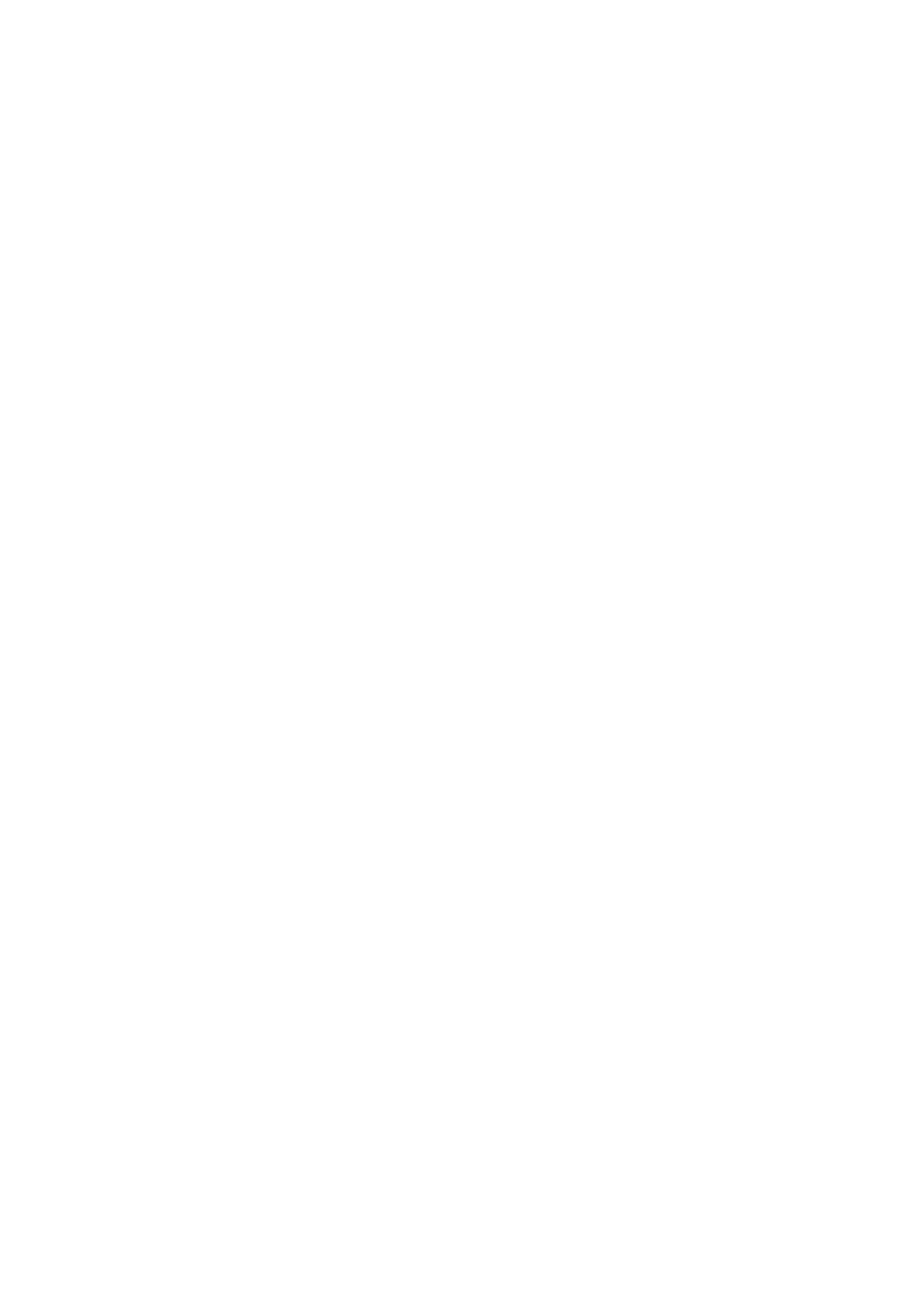




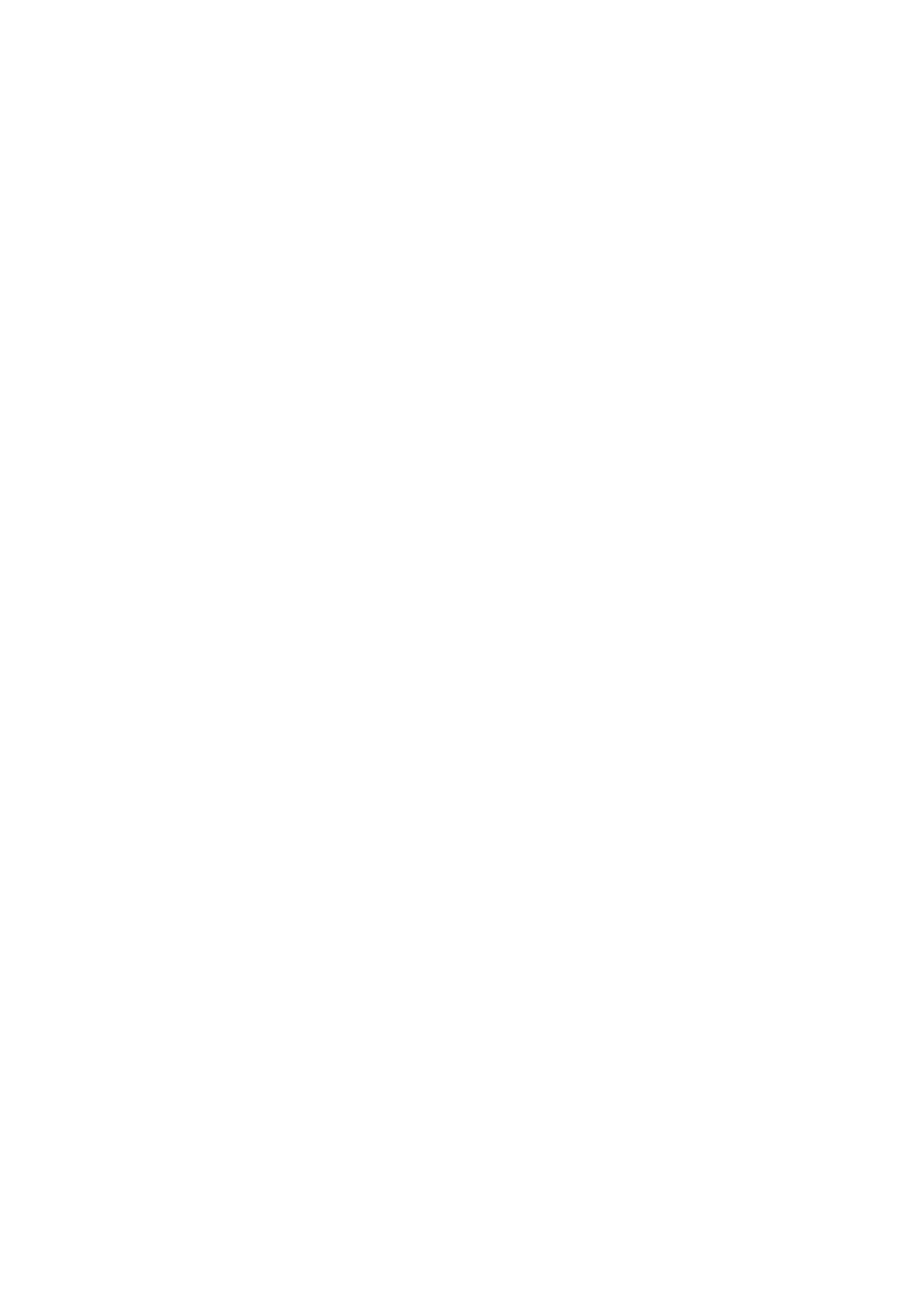




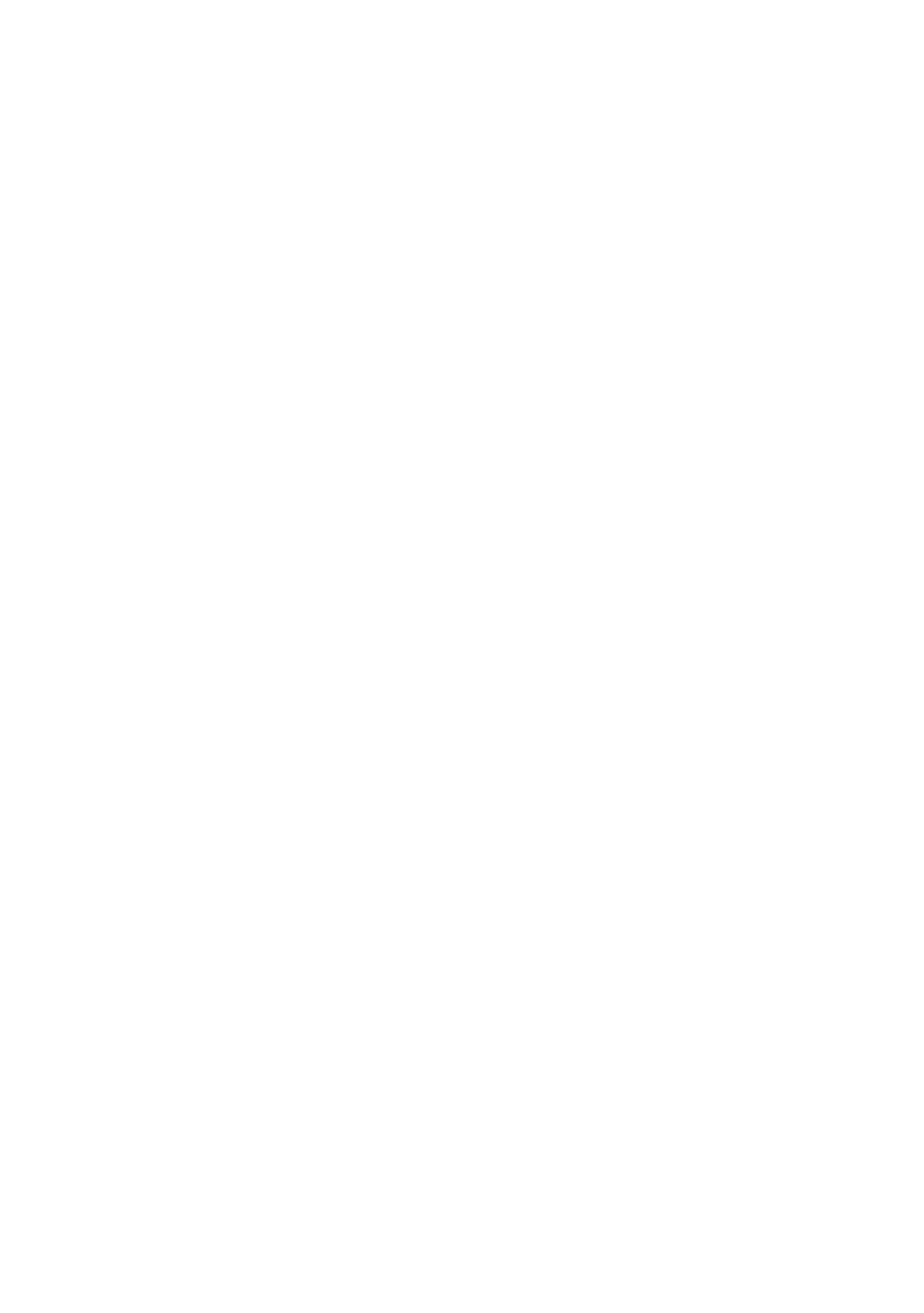




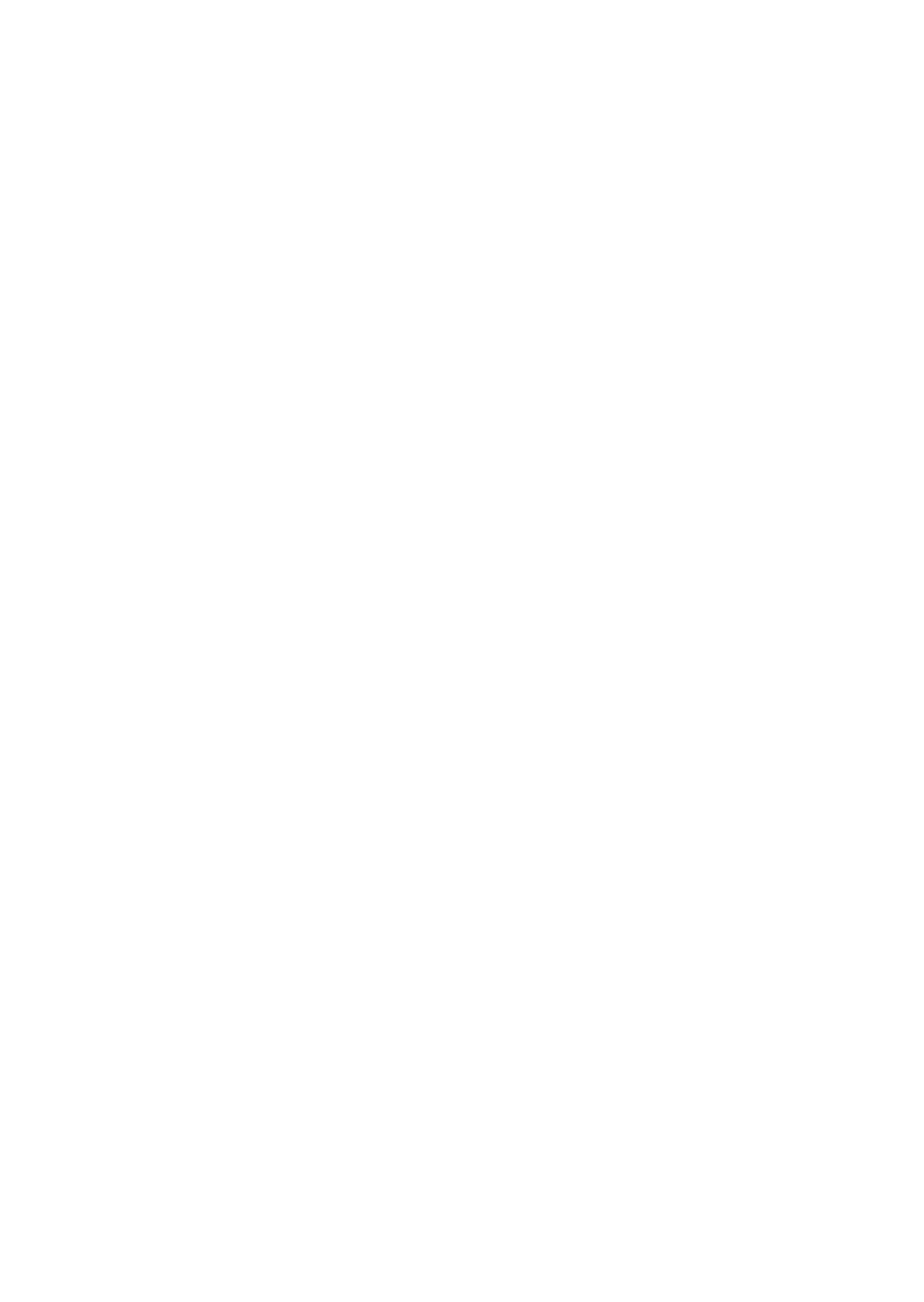




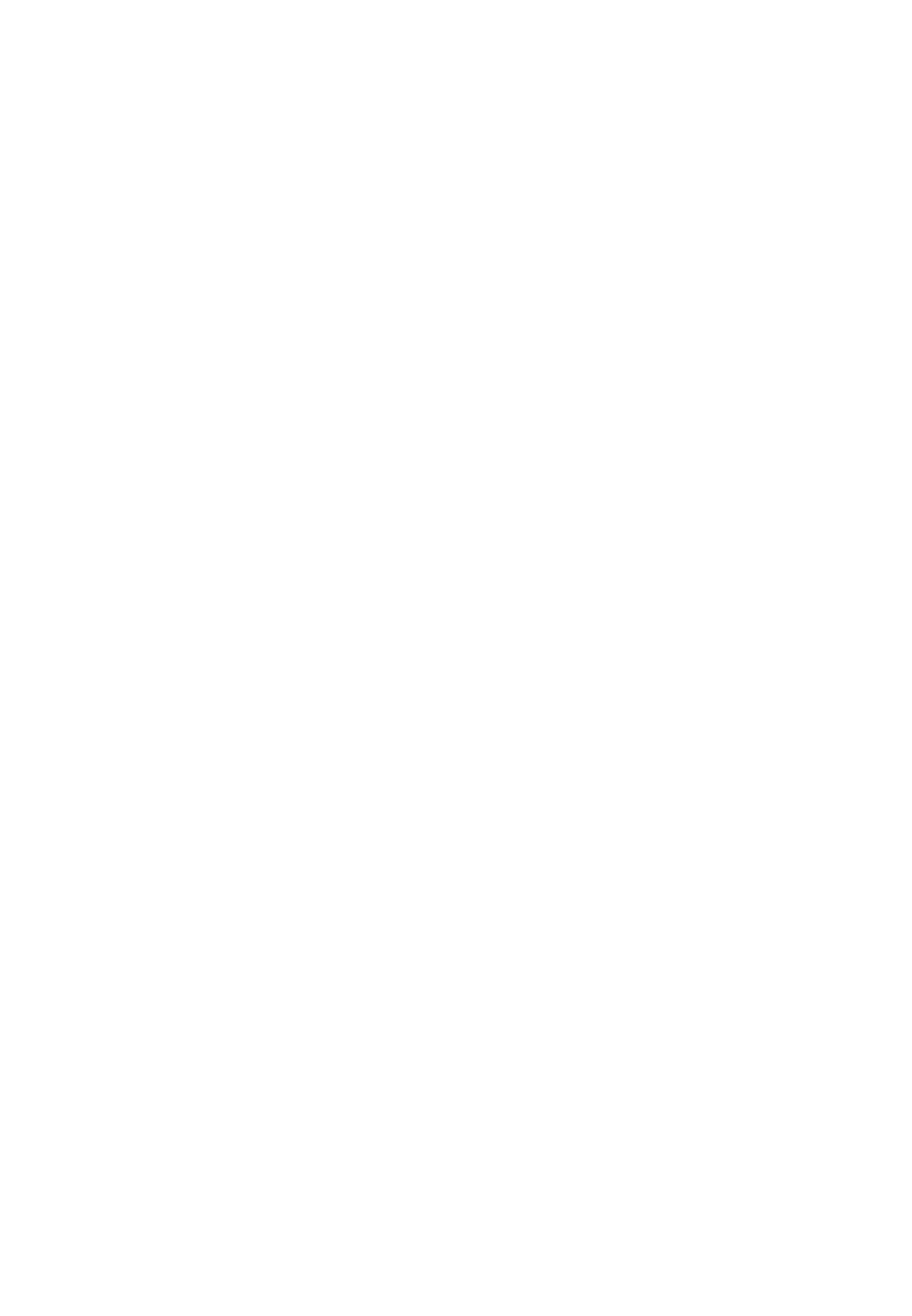




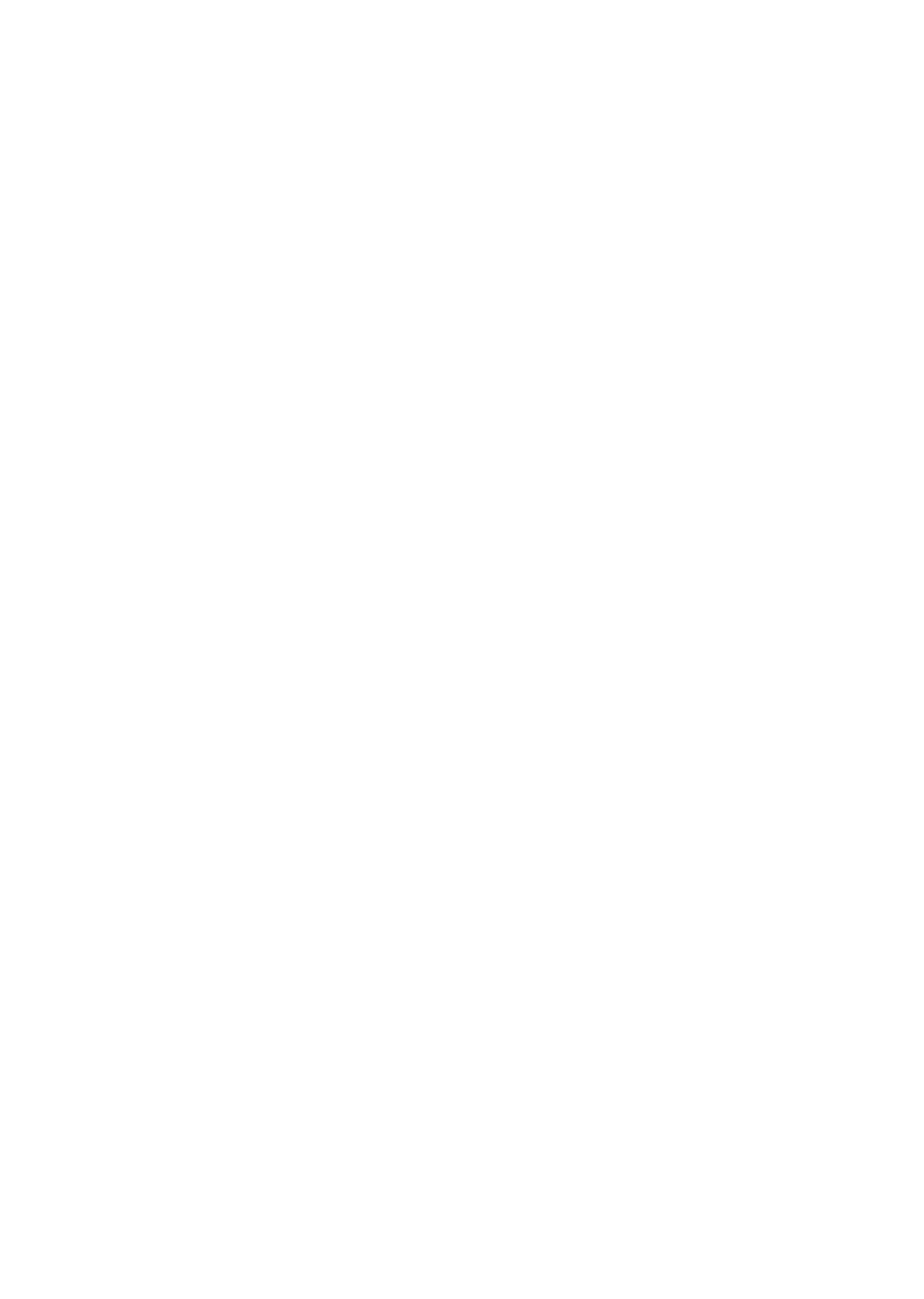




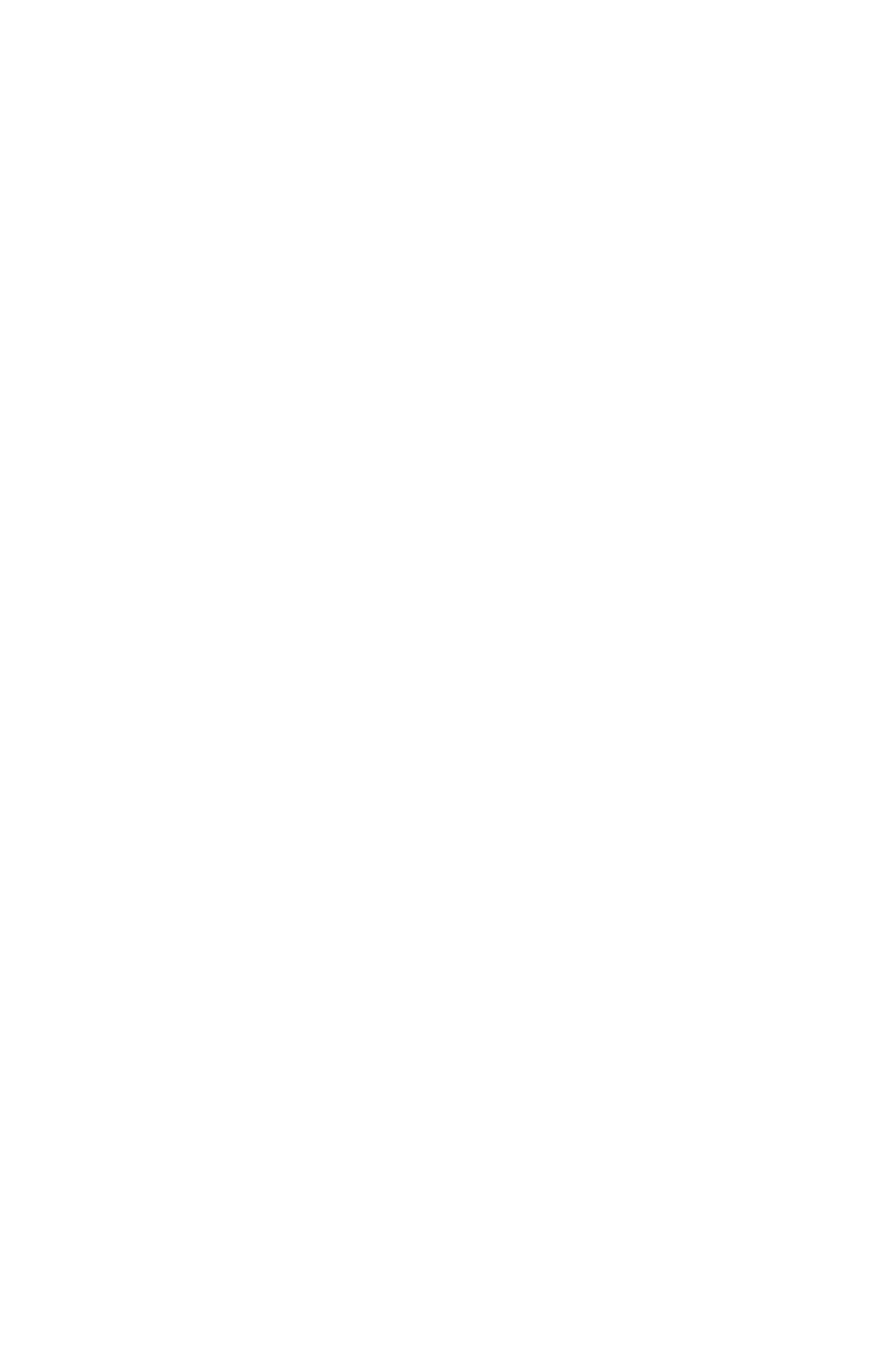




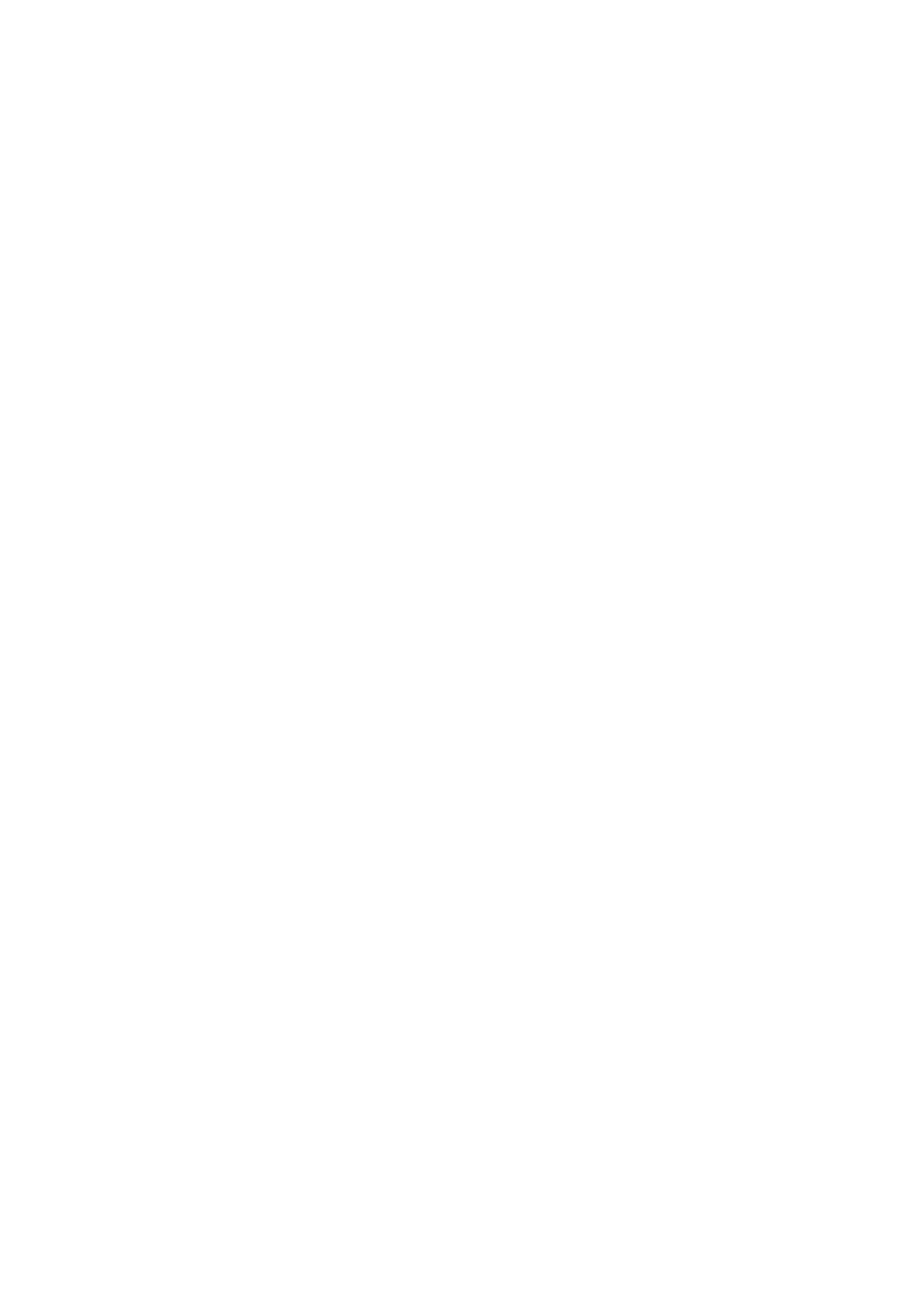




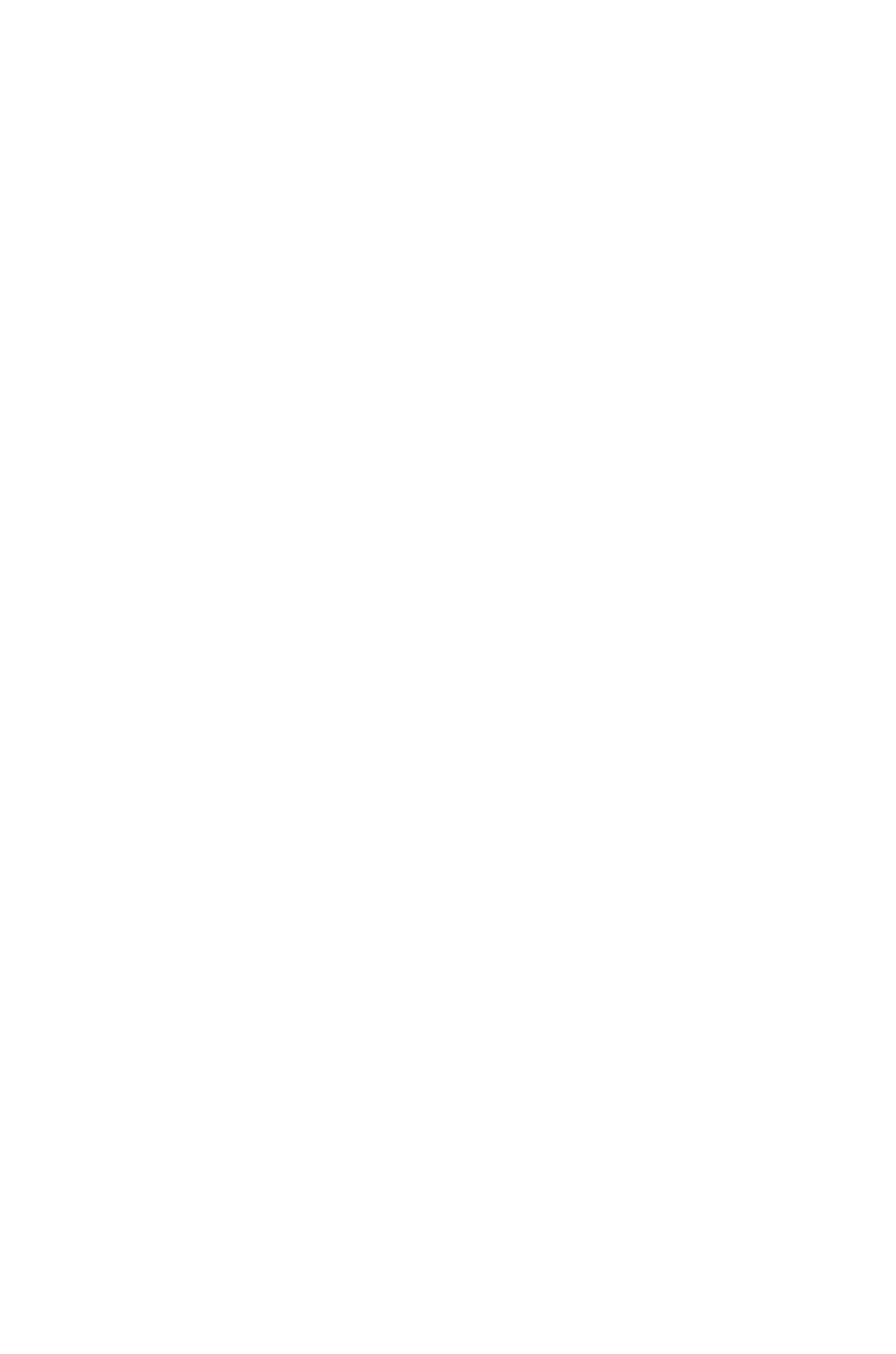




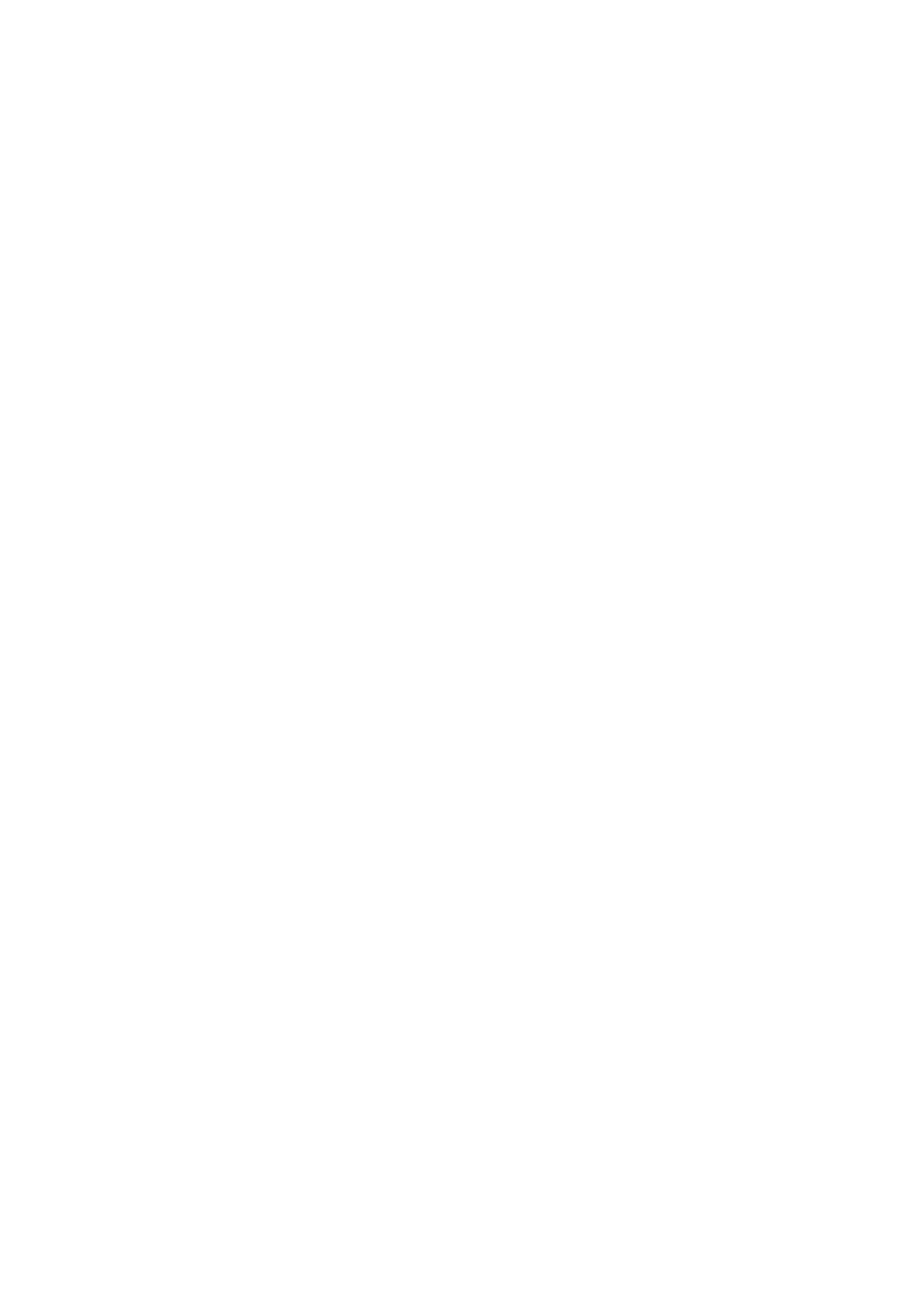




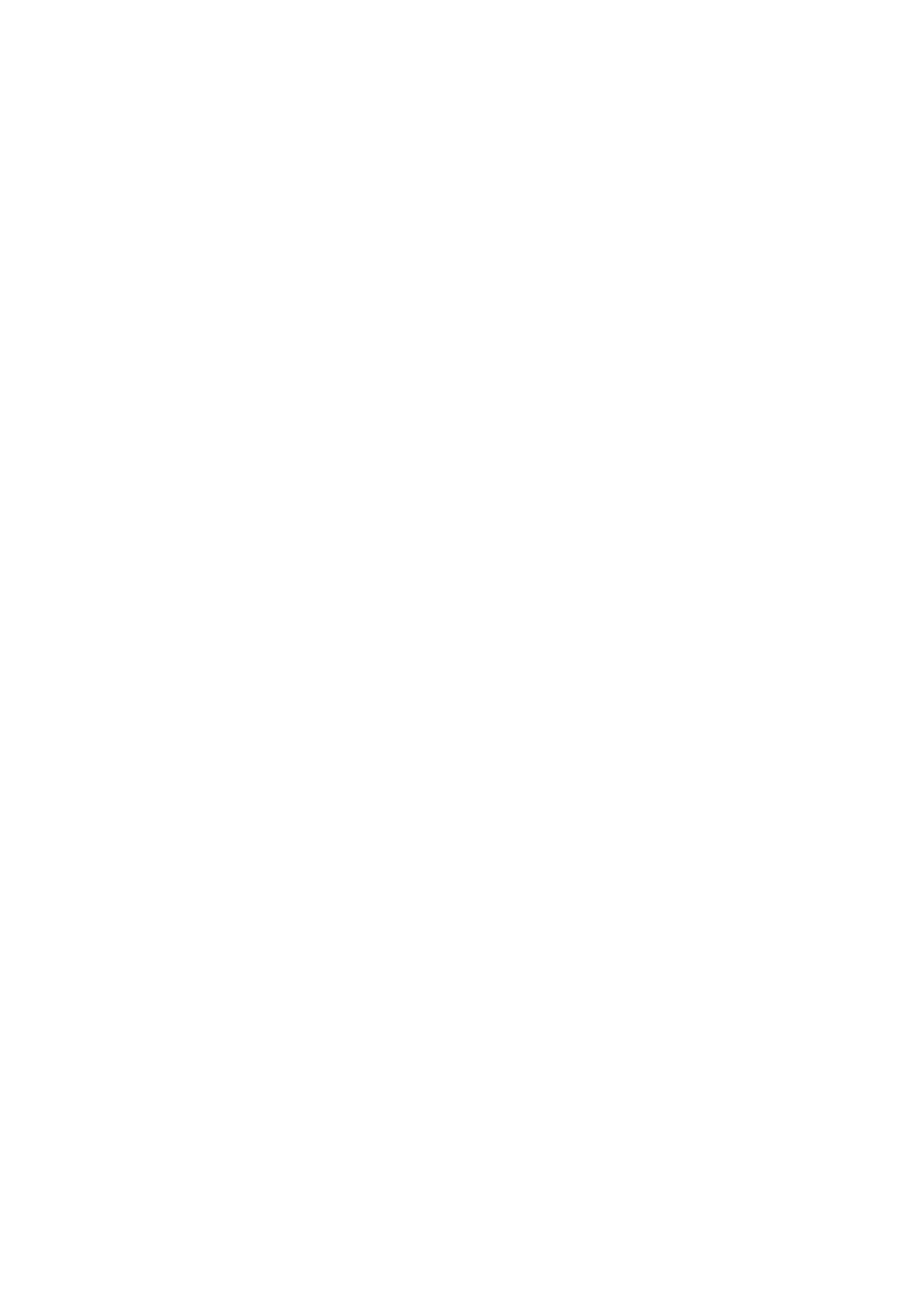




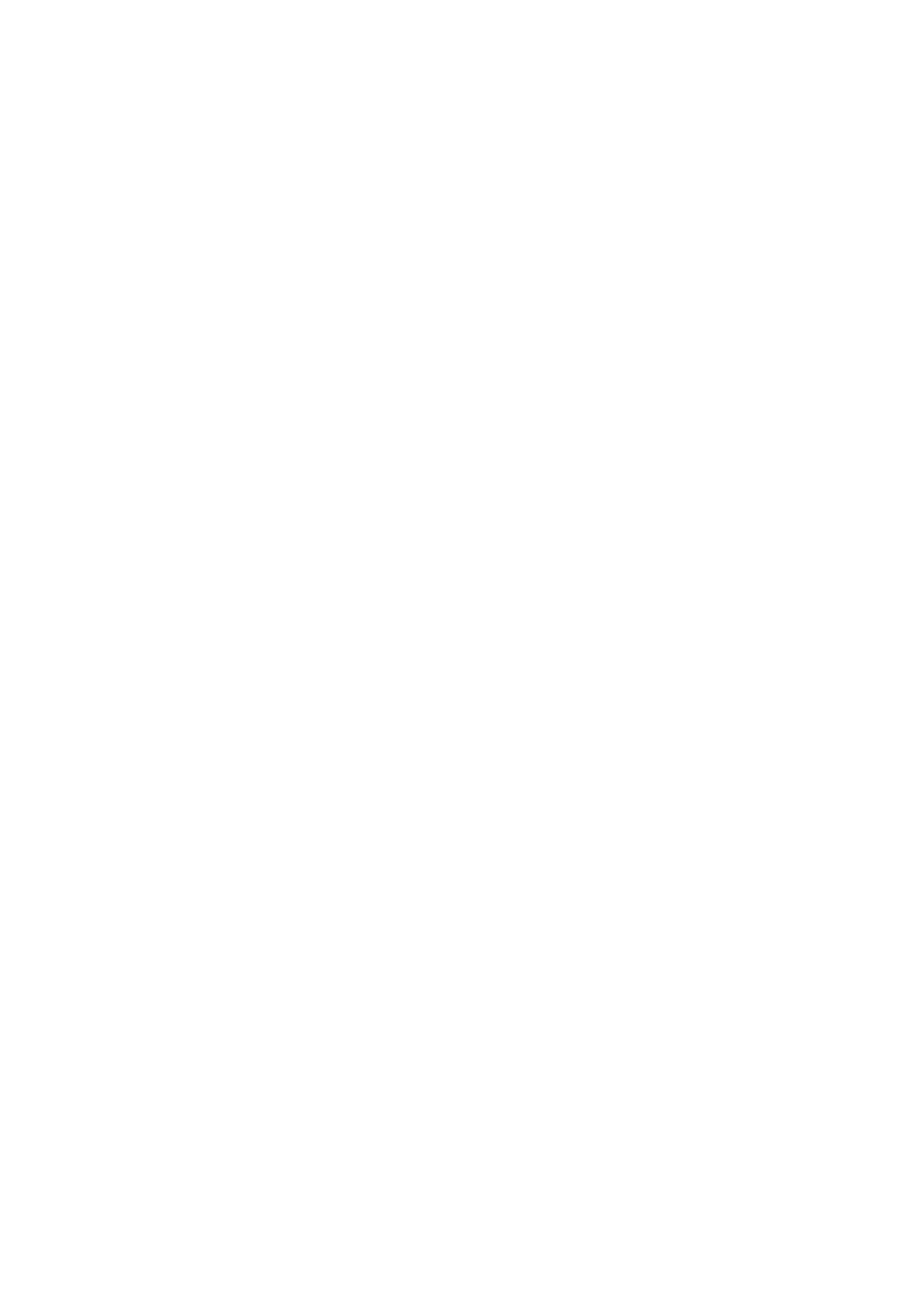




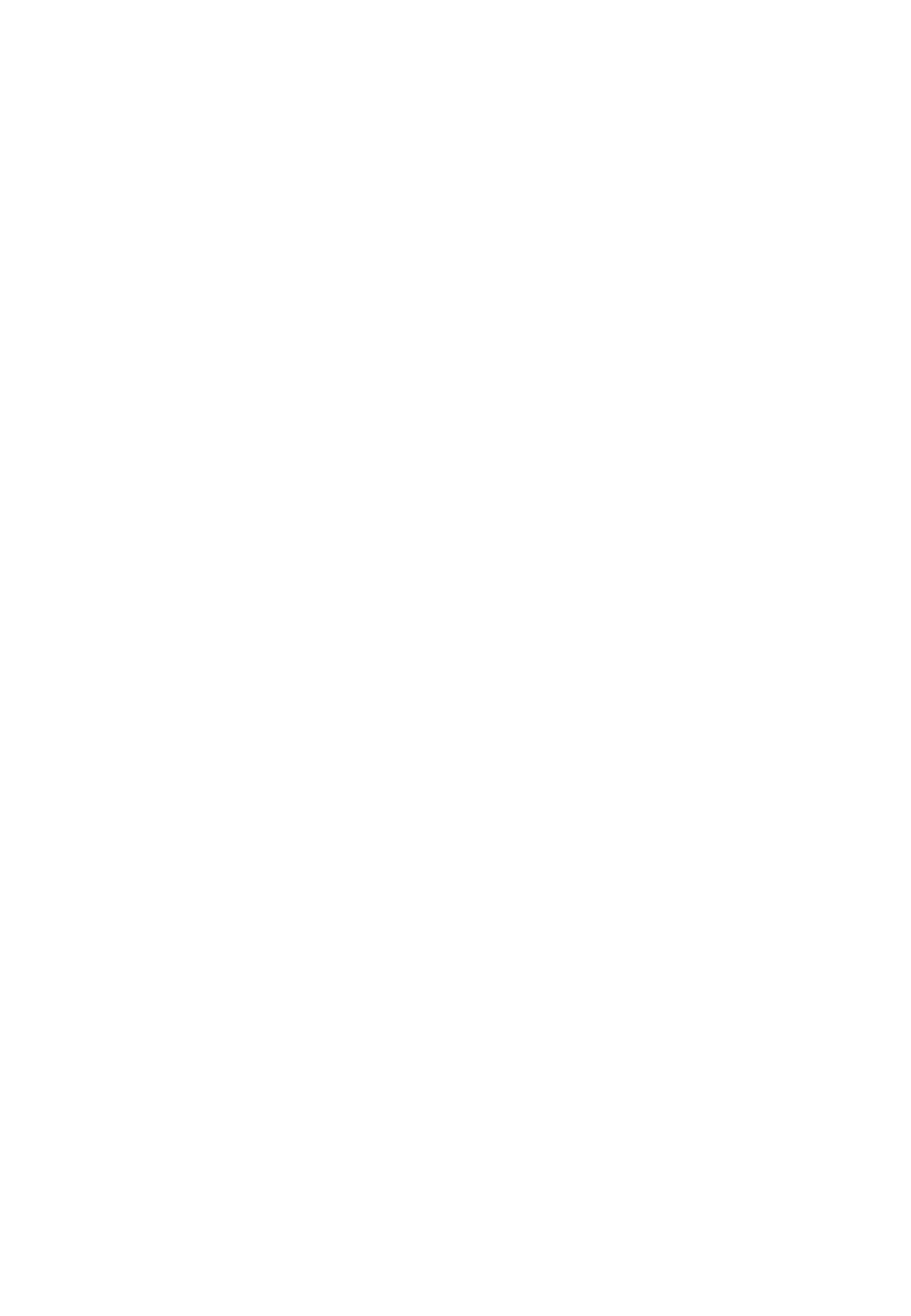




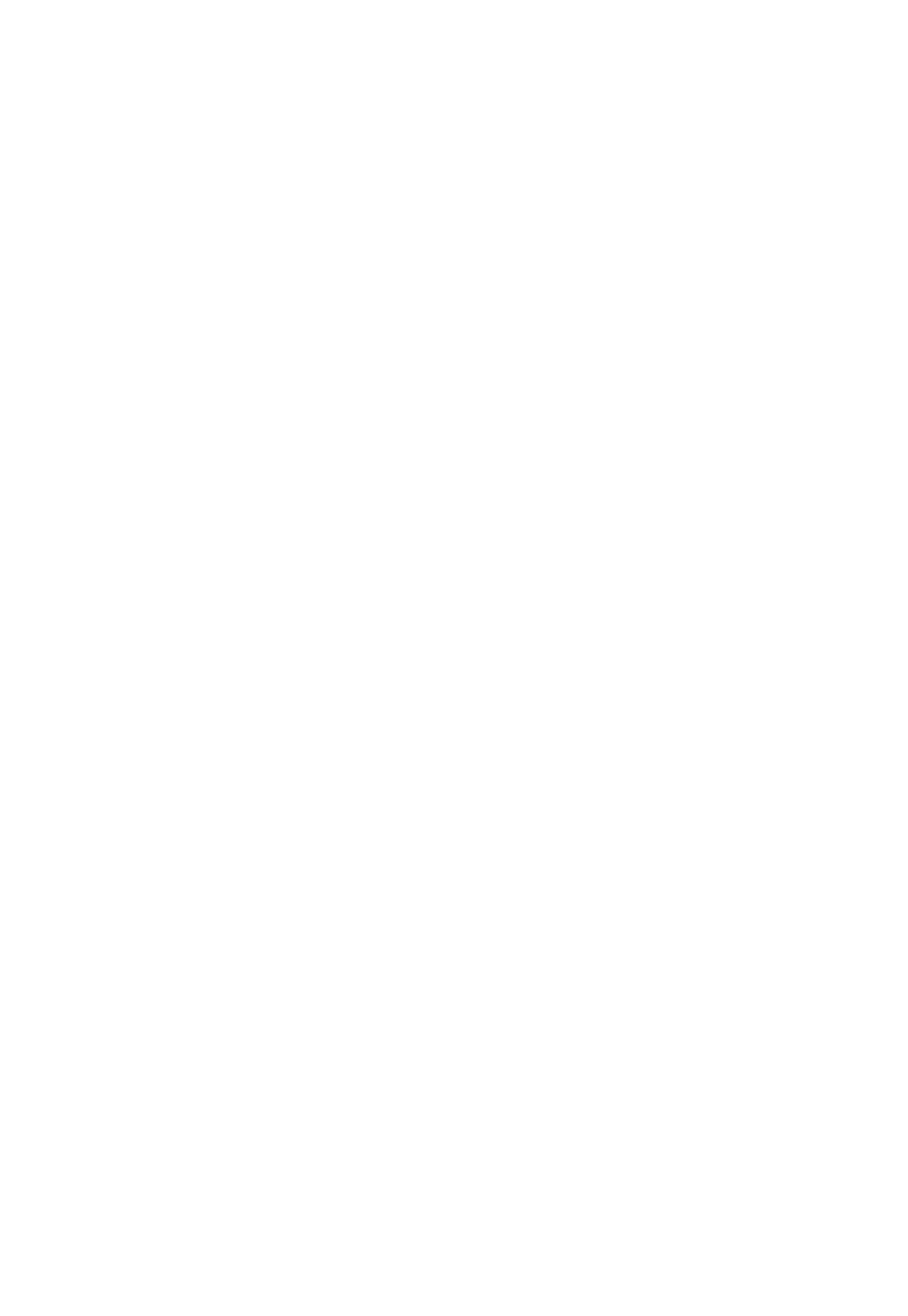




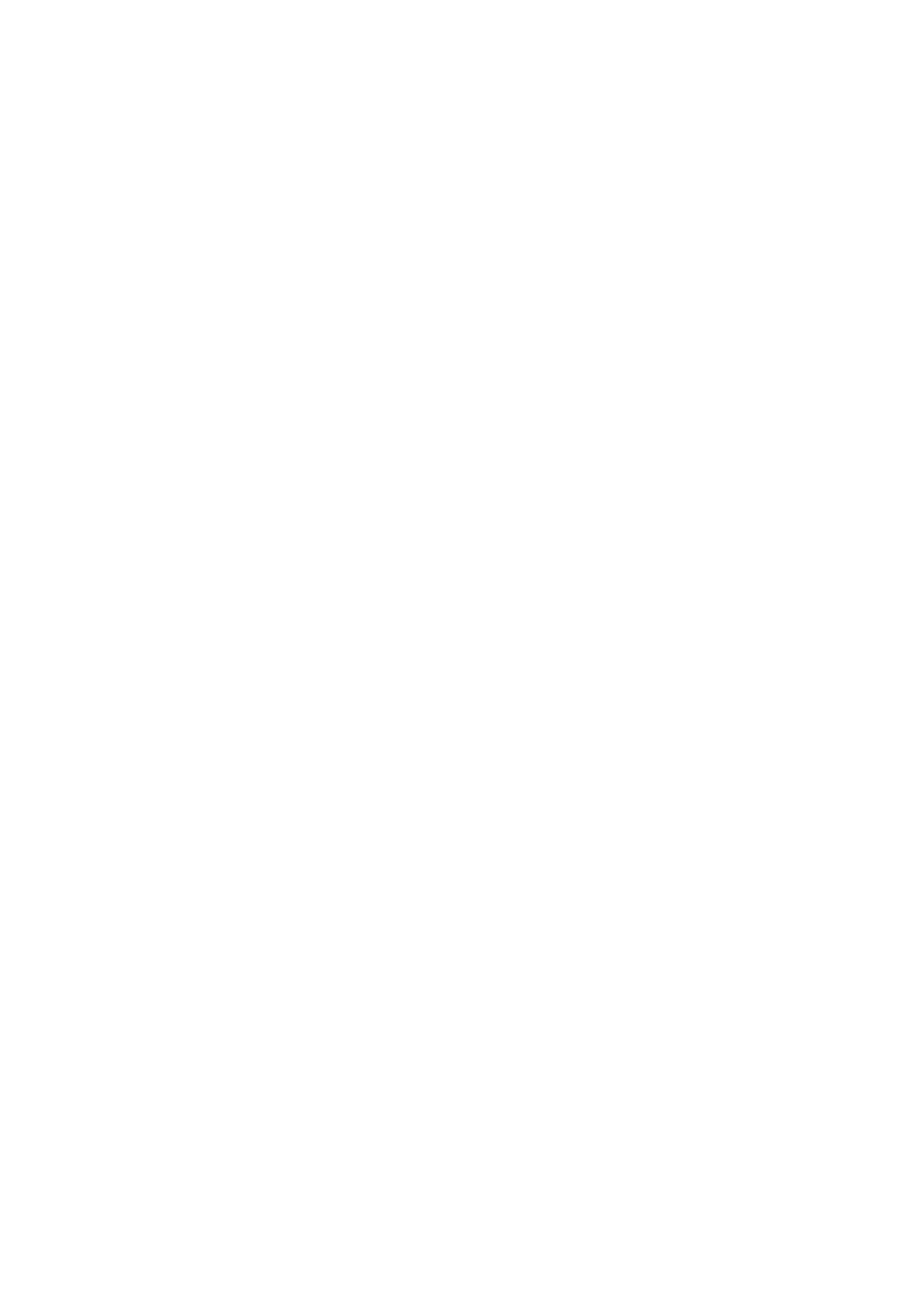




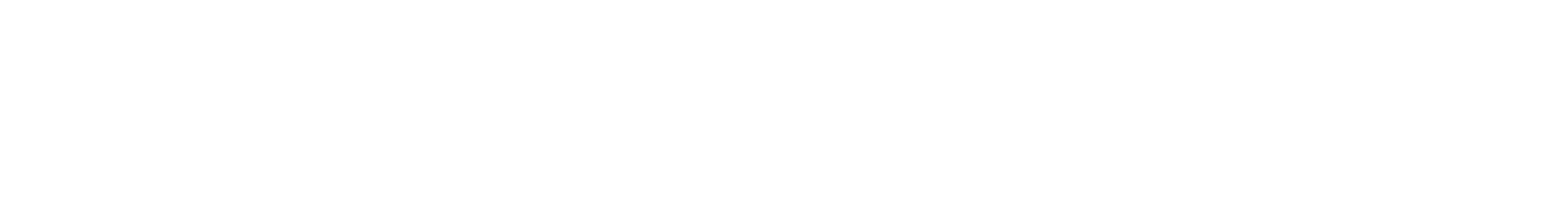

(n)

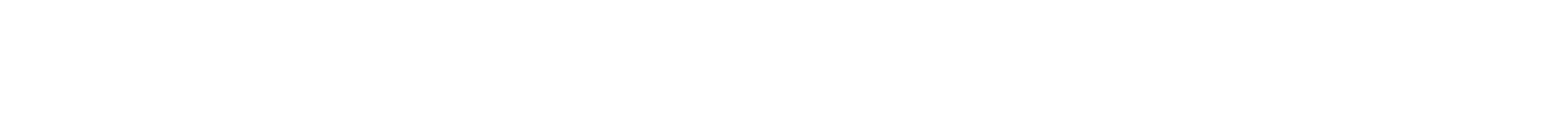

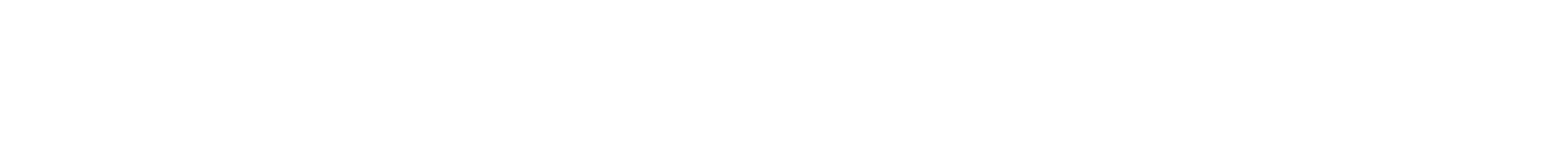

II)

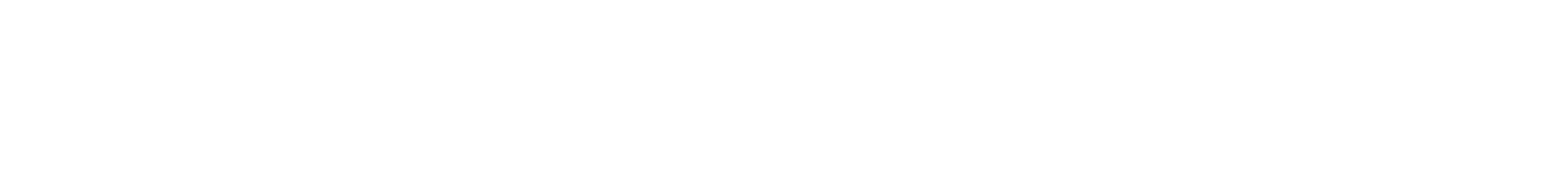

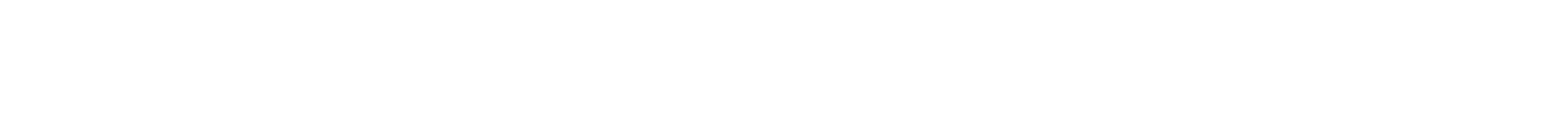

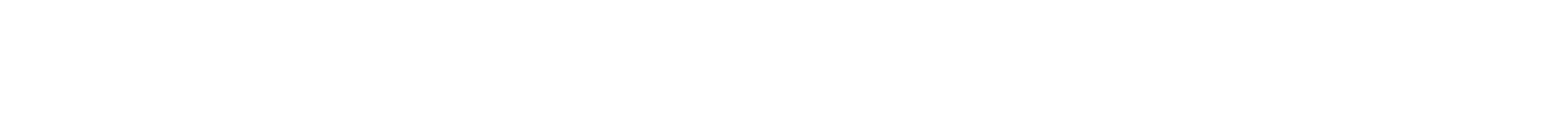

疍

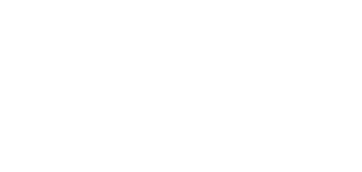

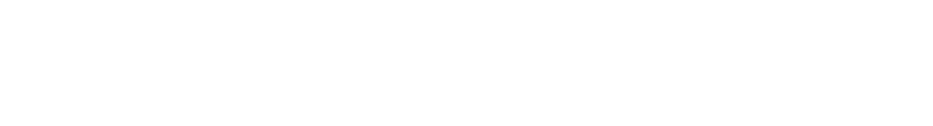

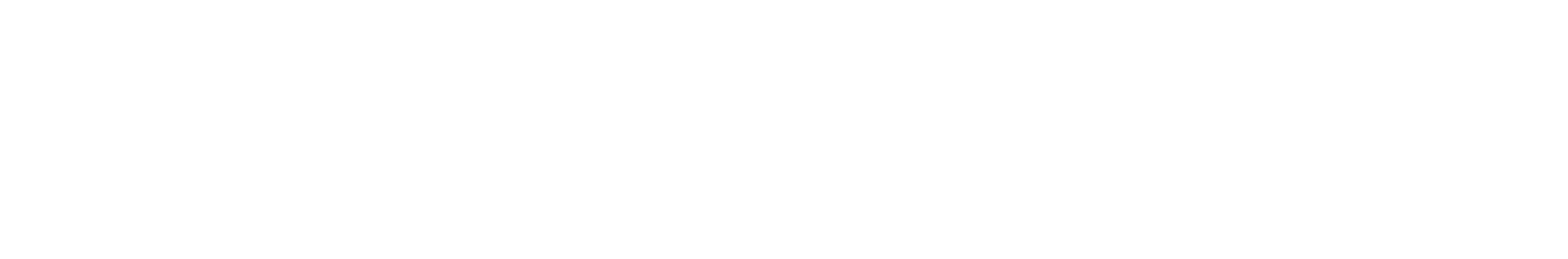

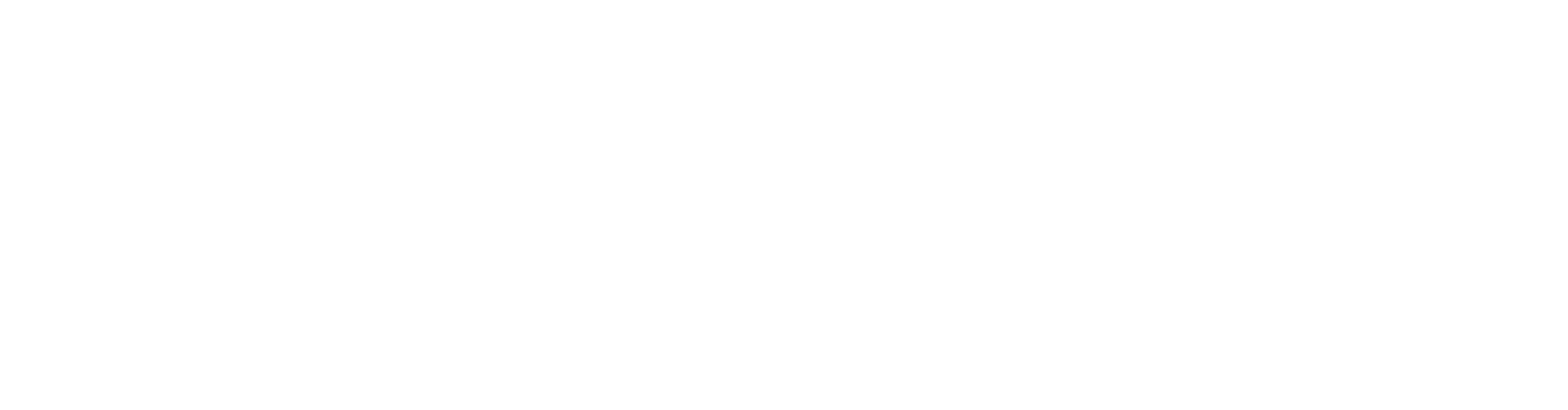

吉

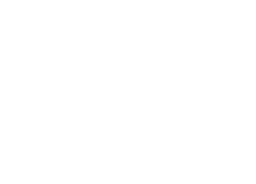

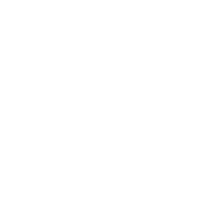

㠃

竞 


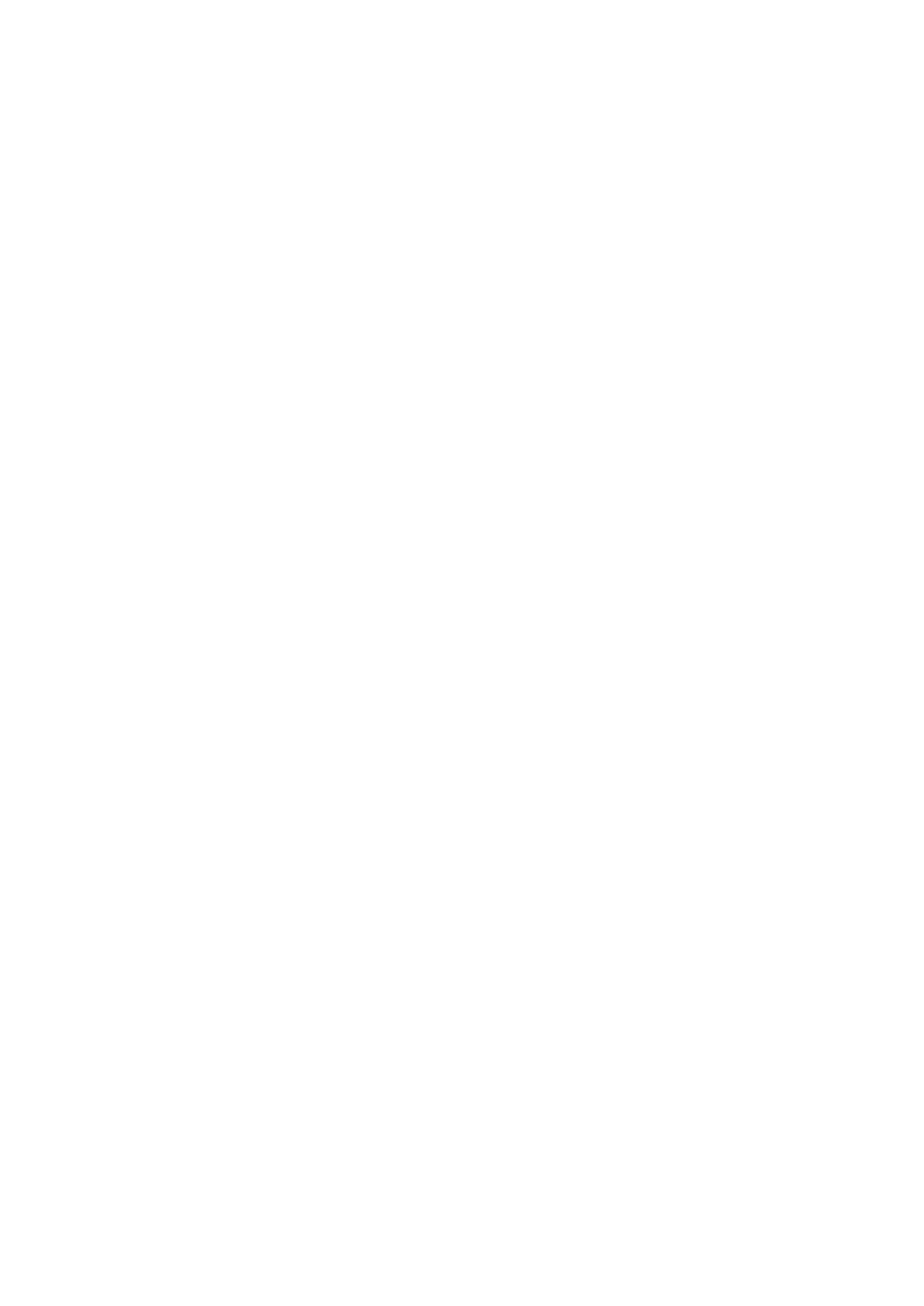




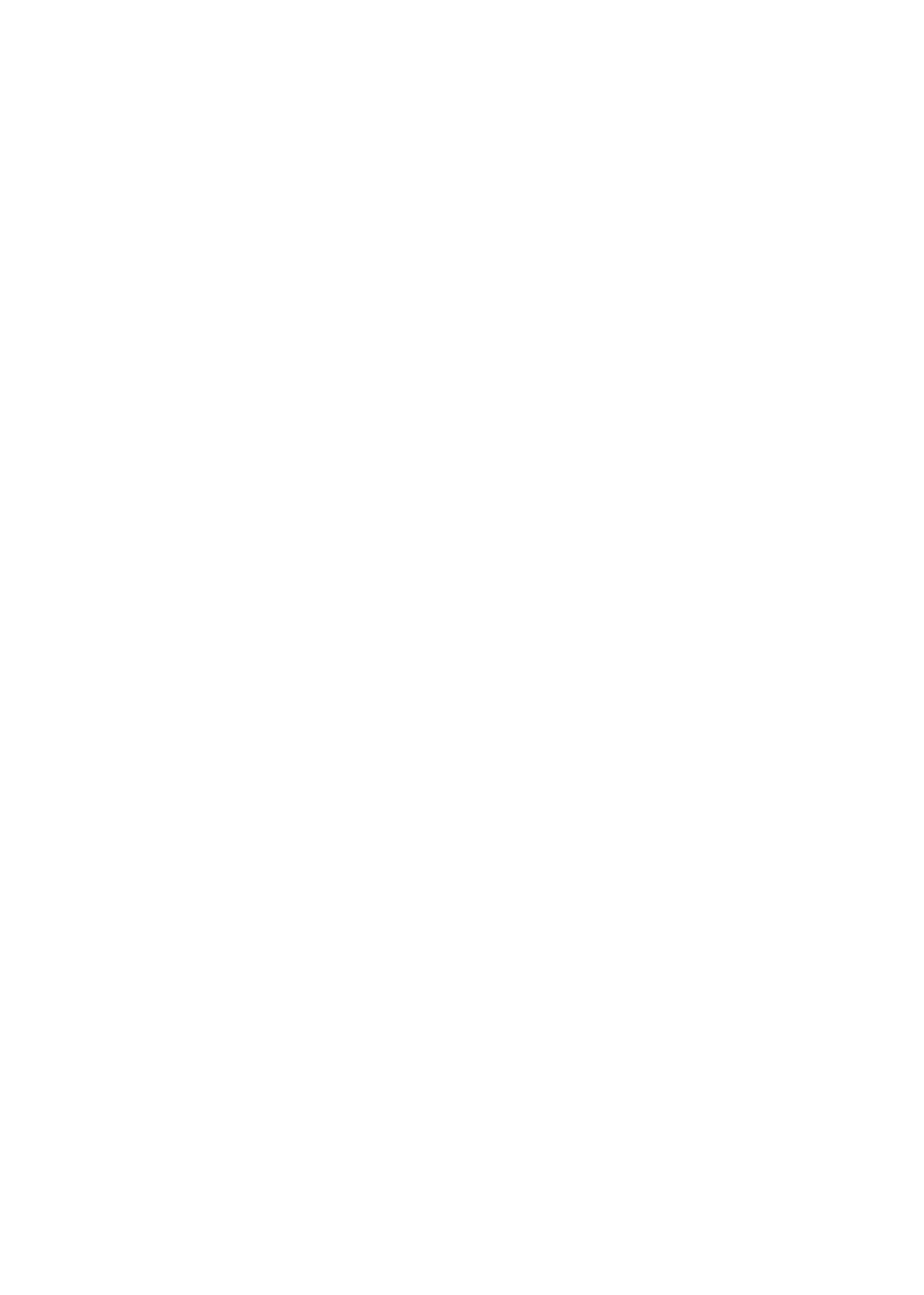




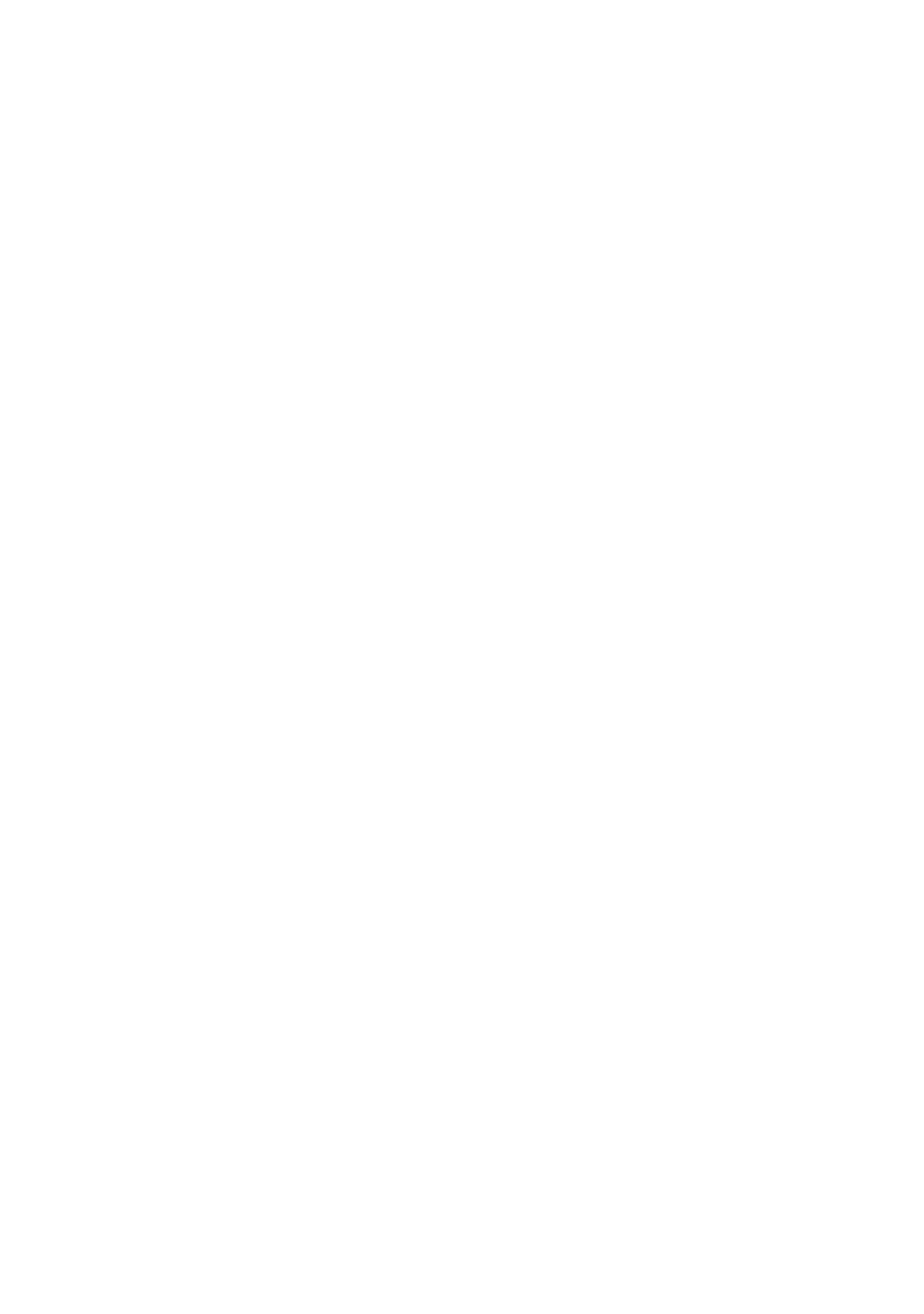




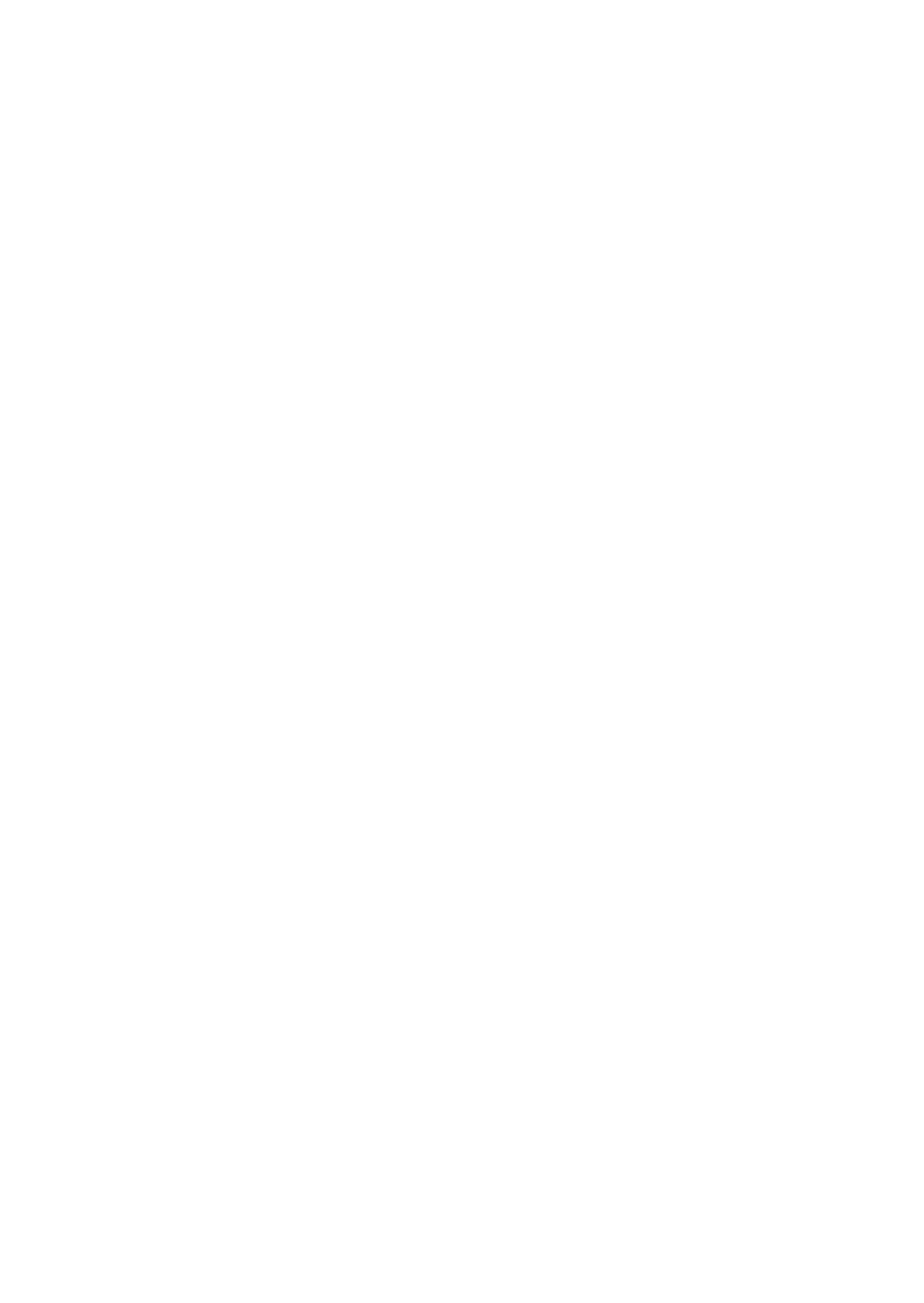




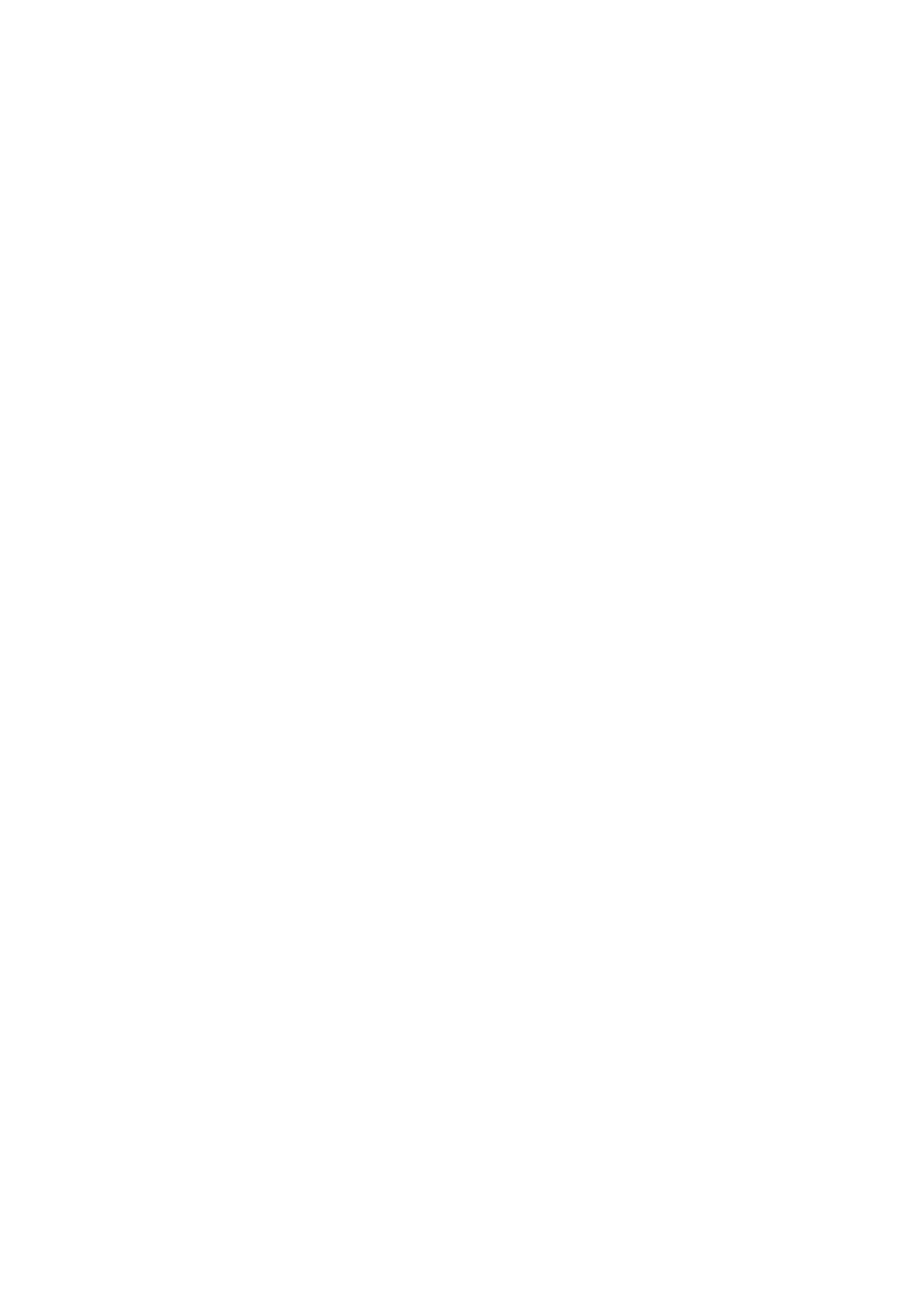




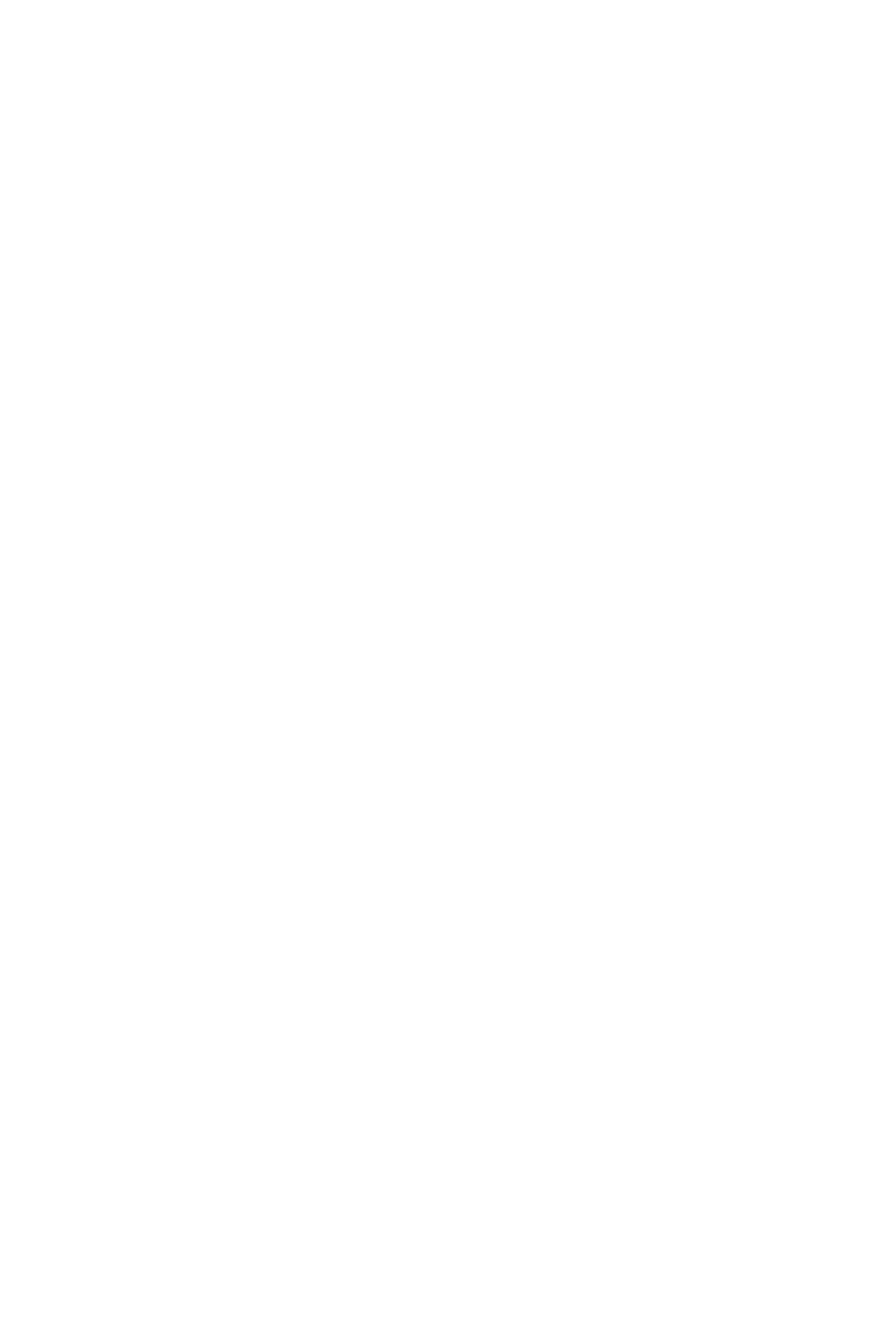




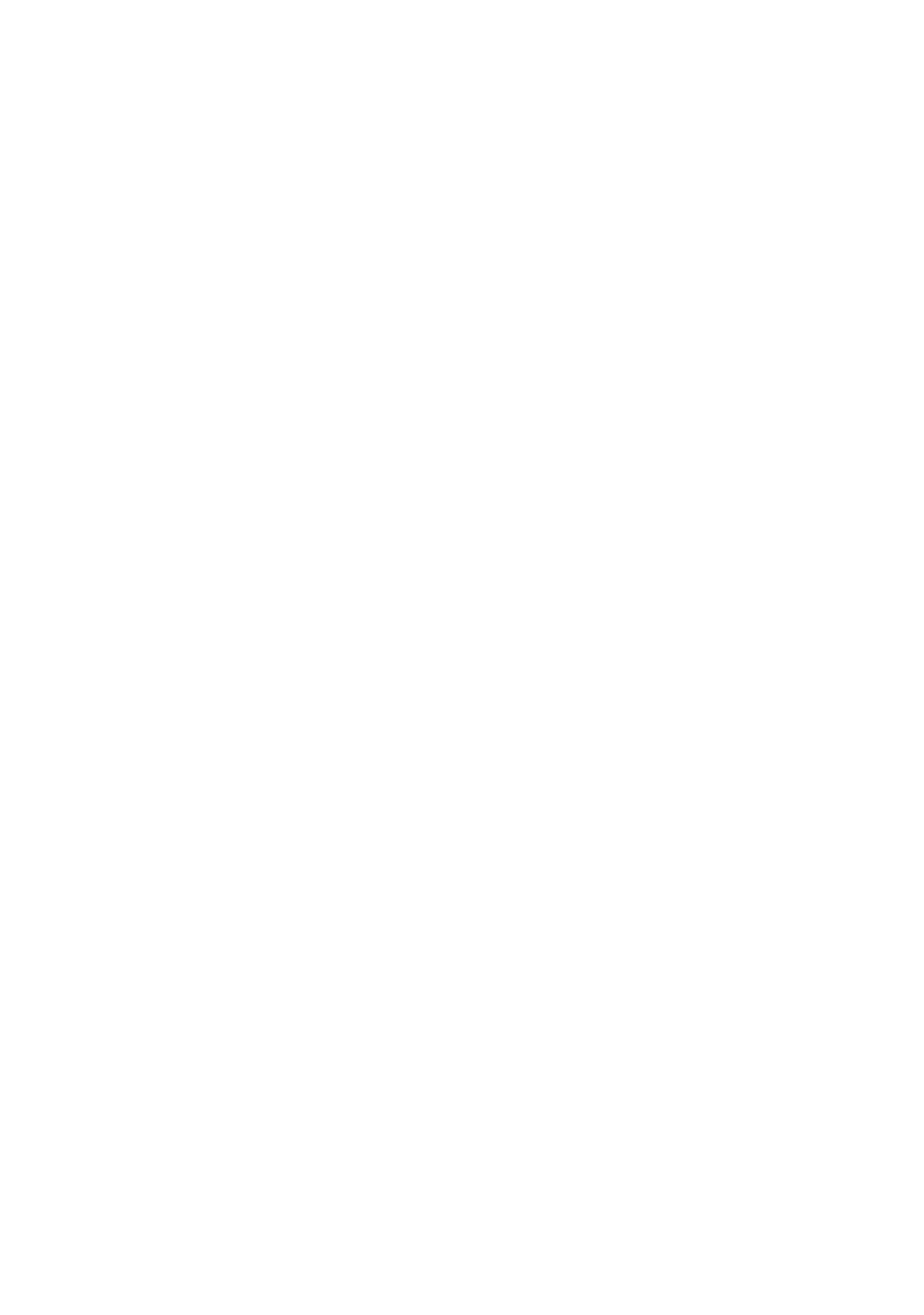




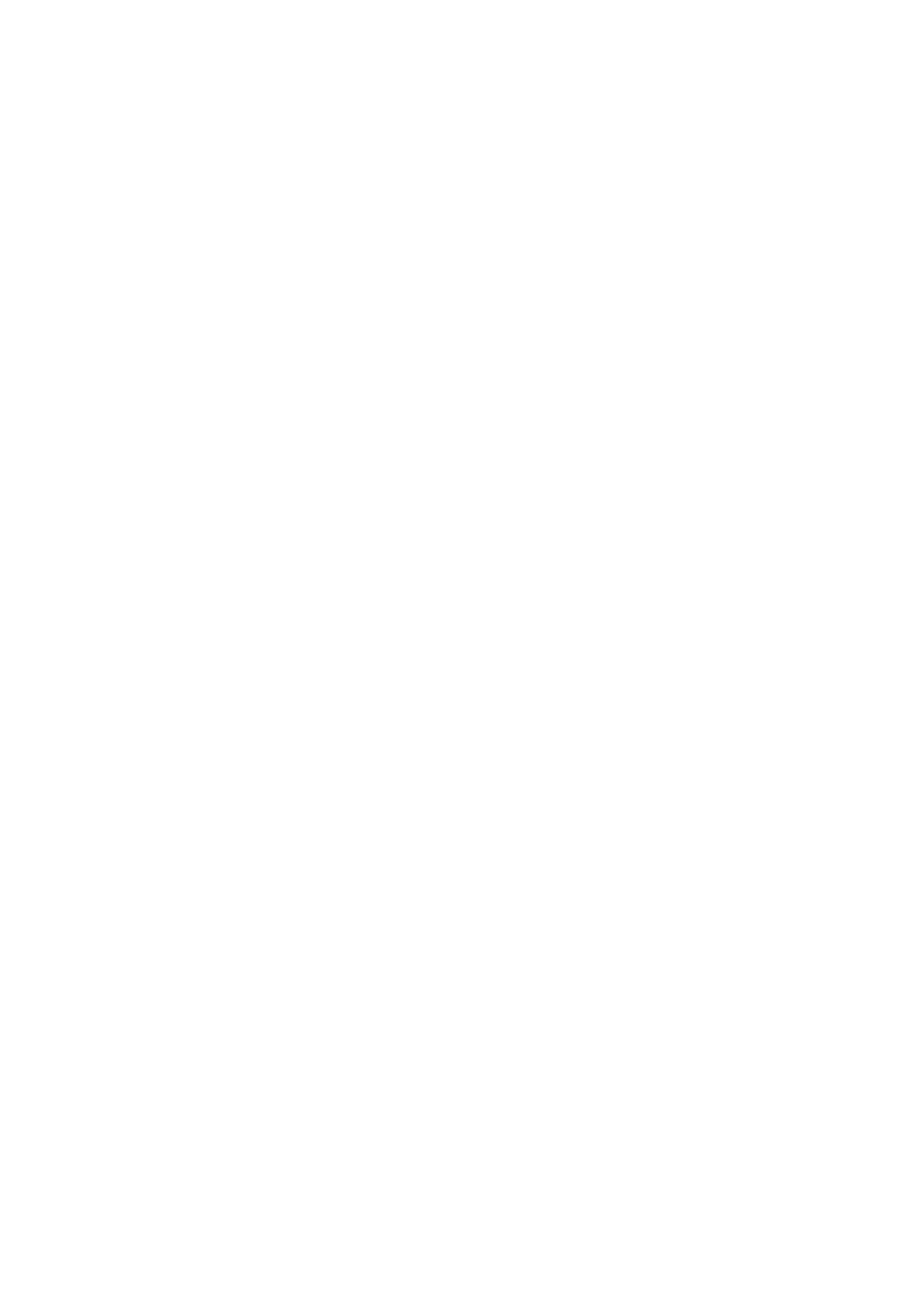




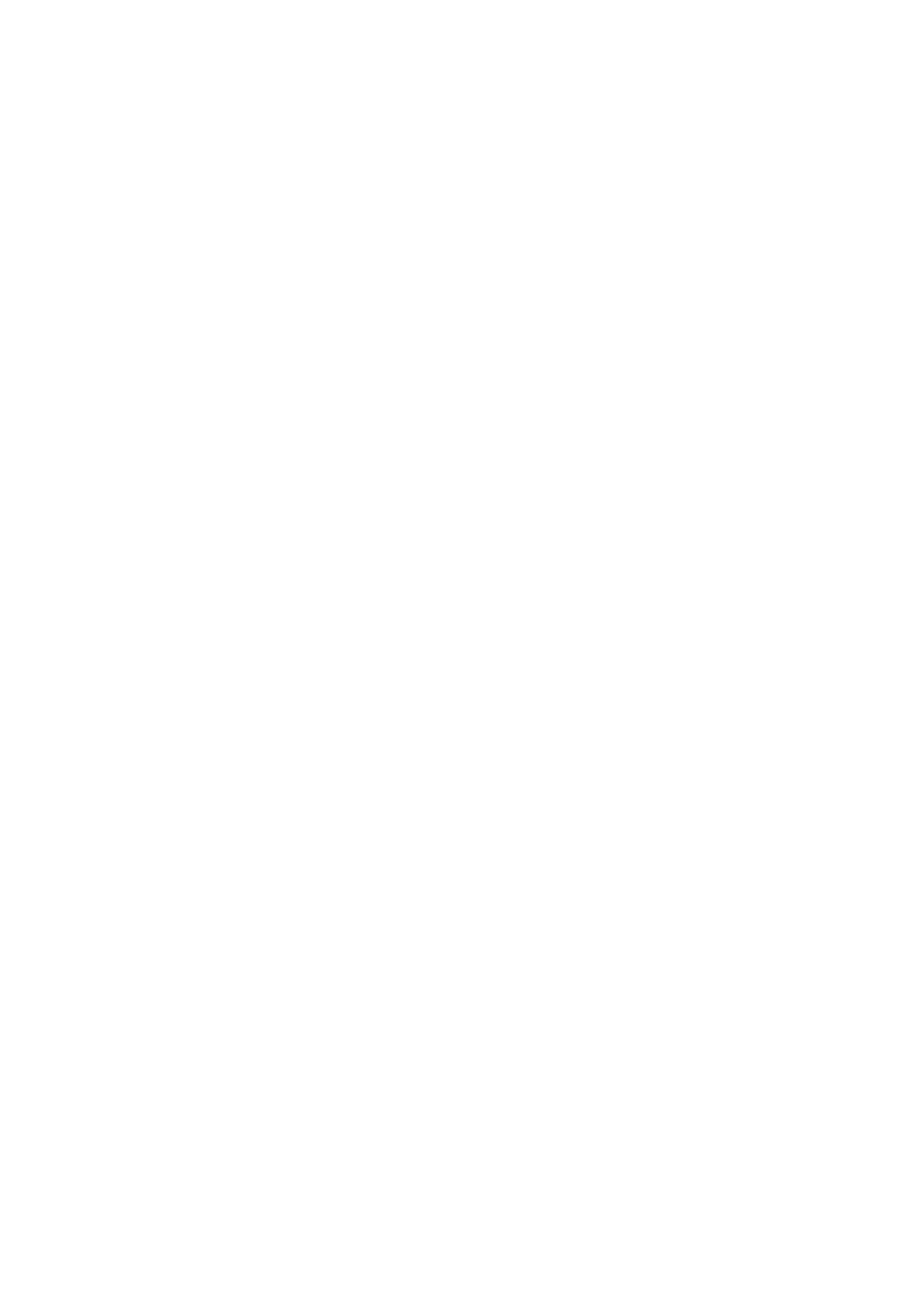




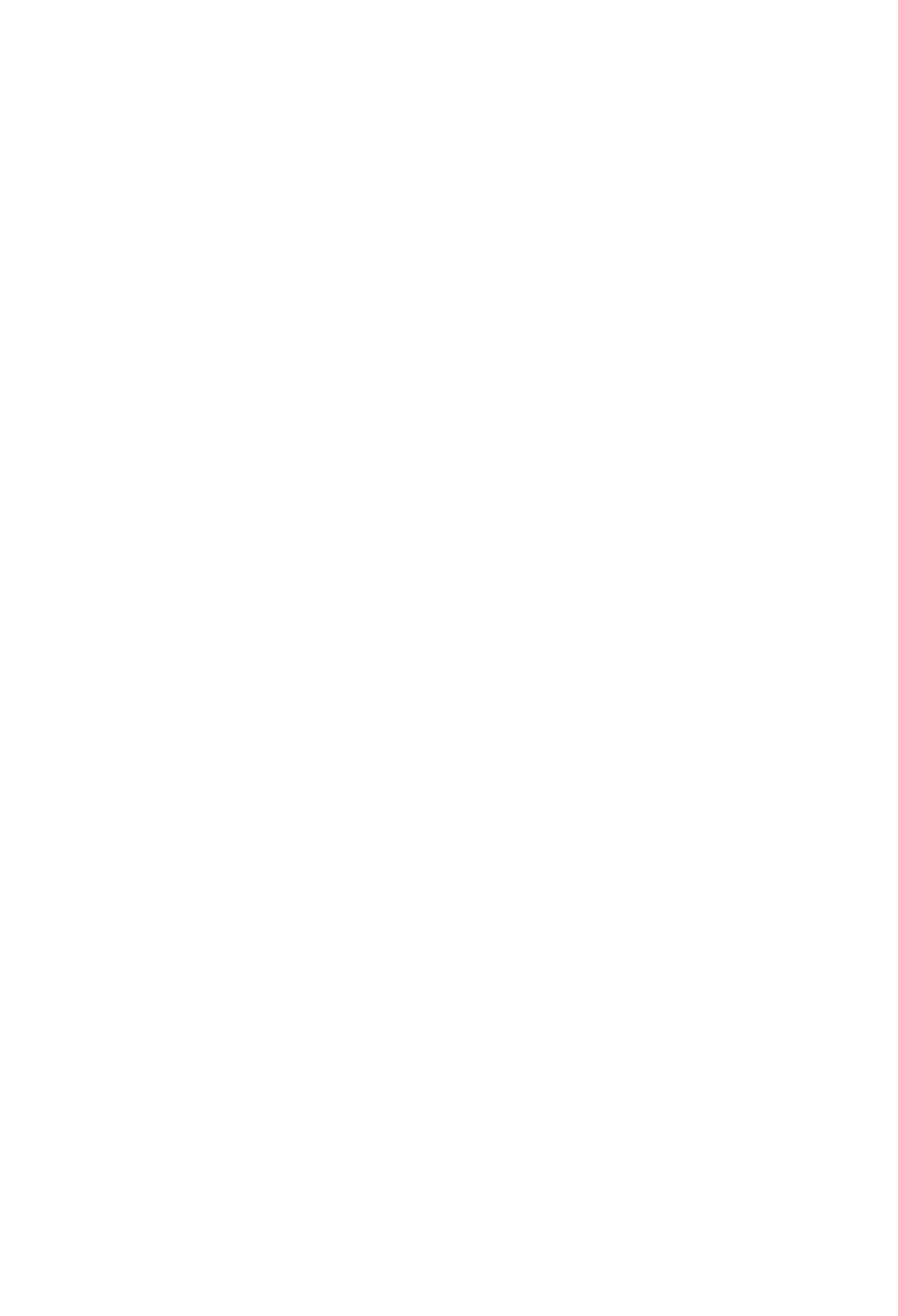




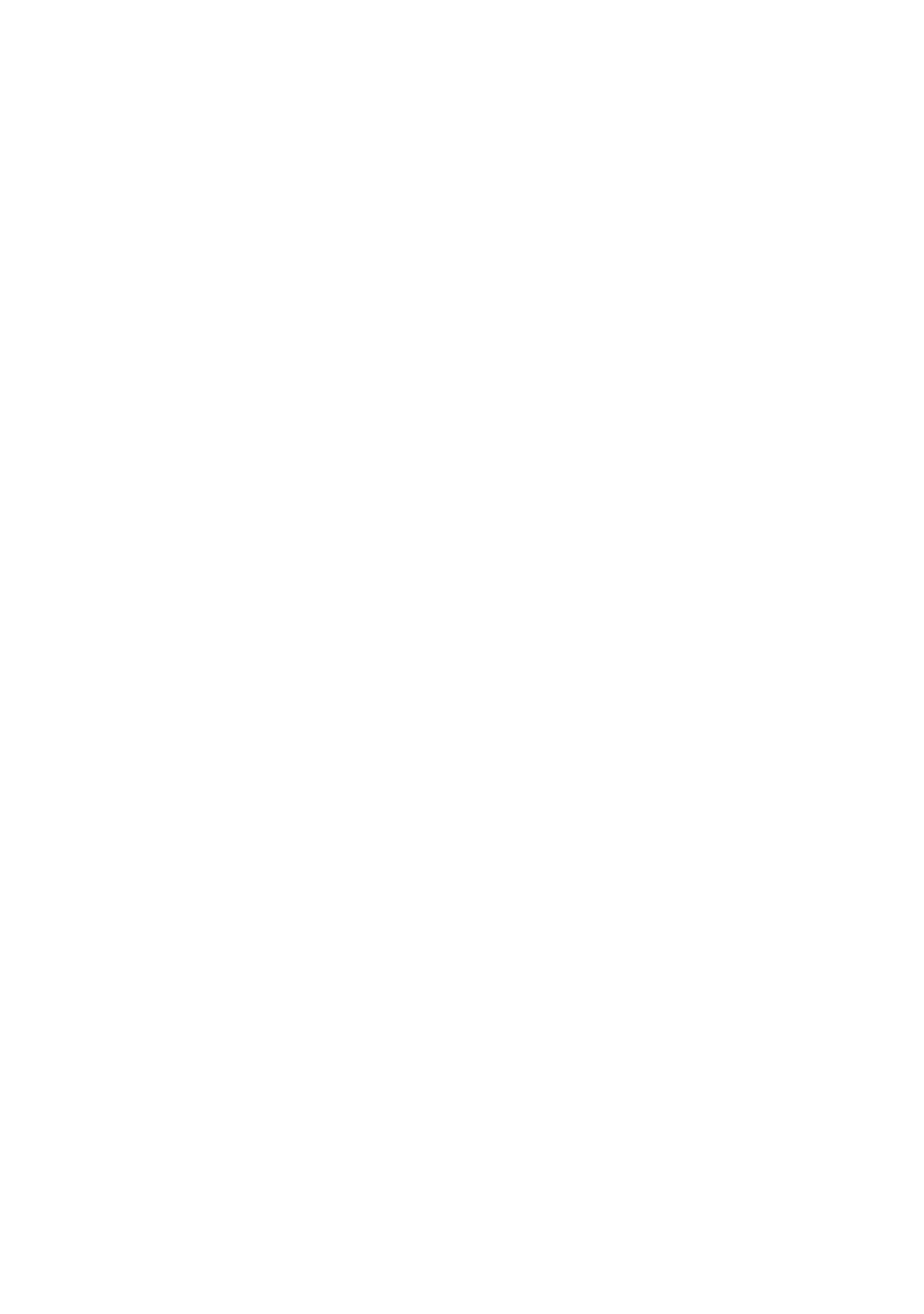




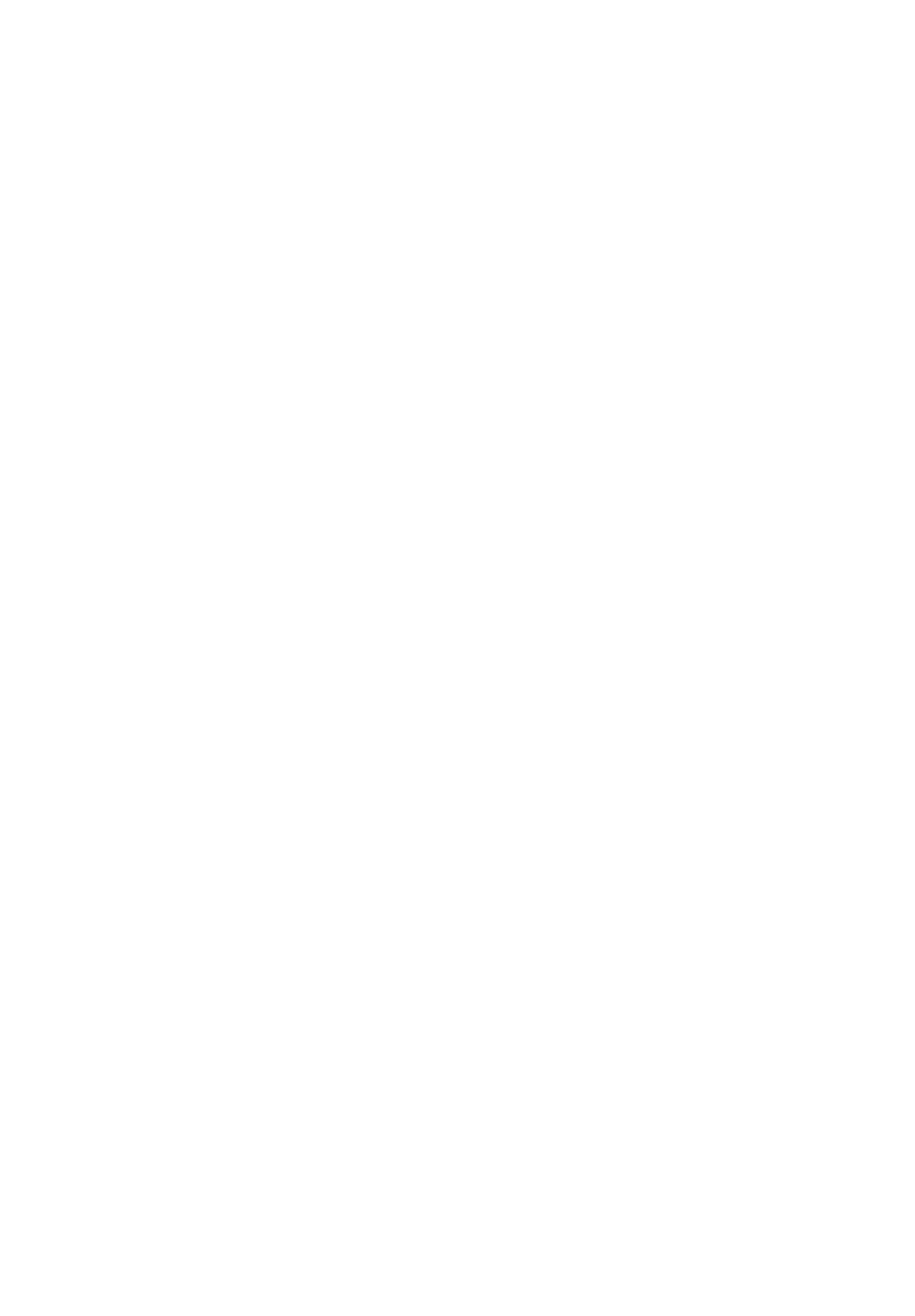




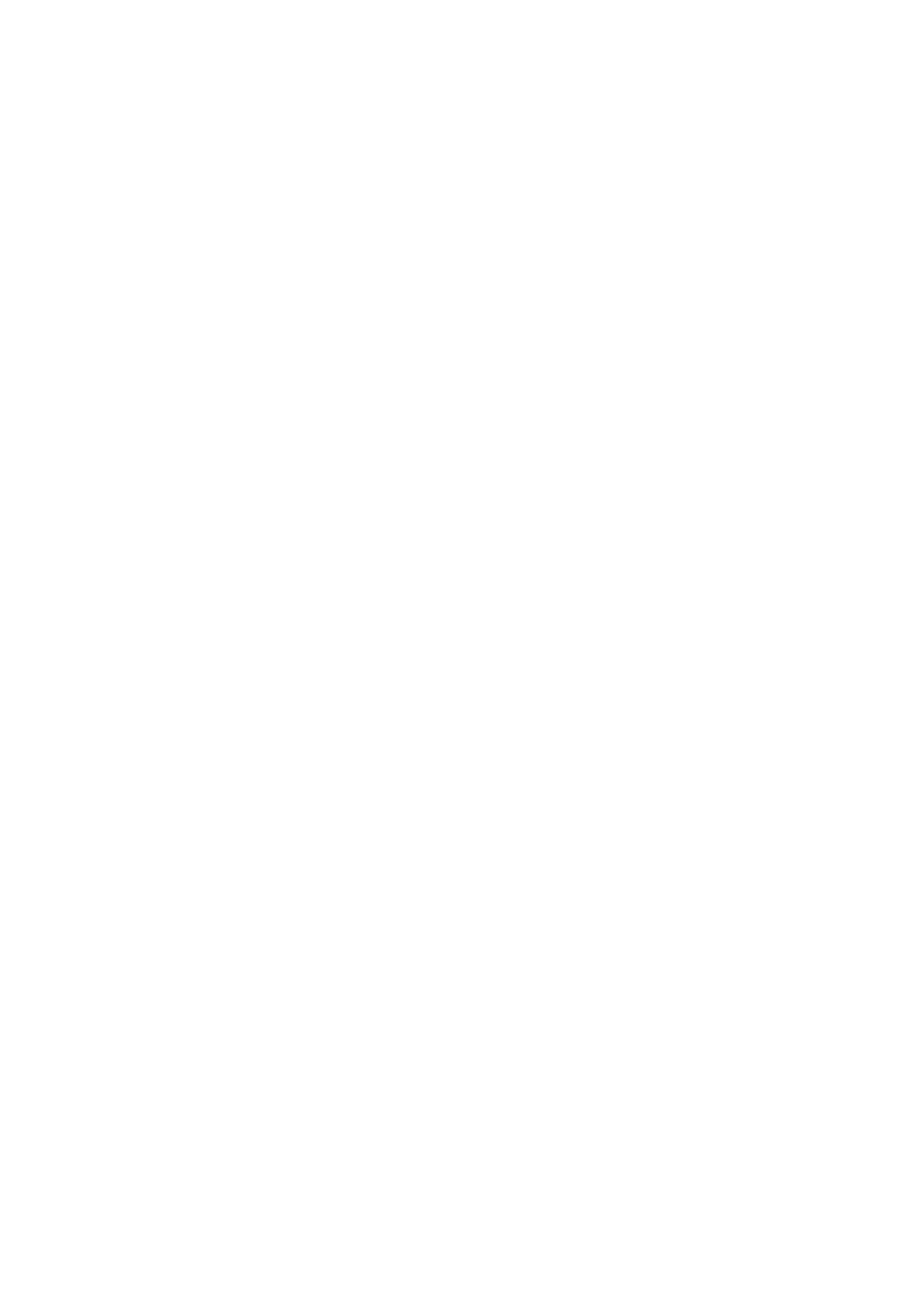




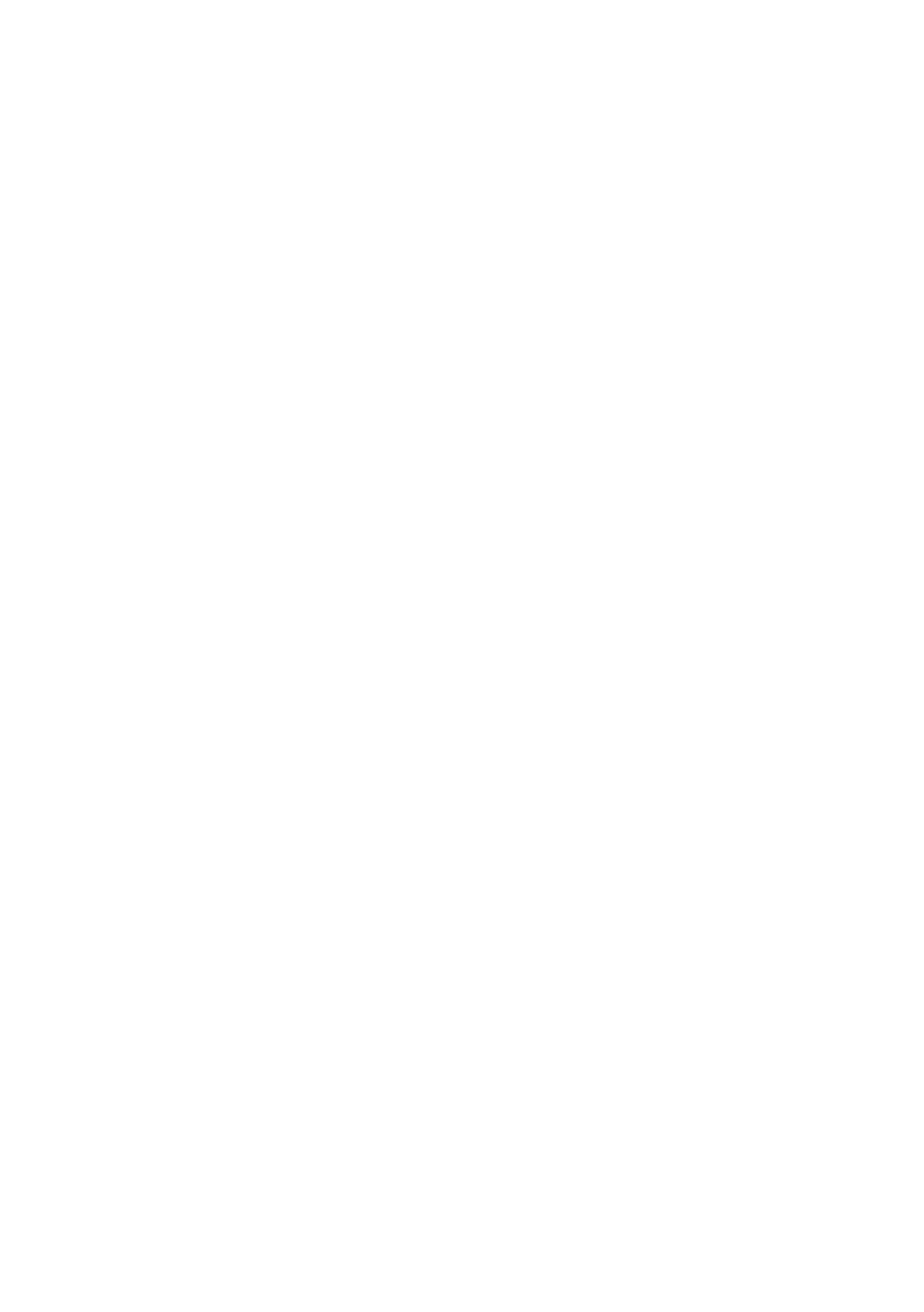




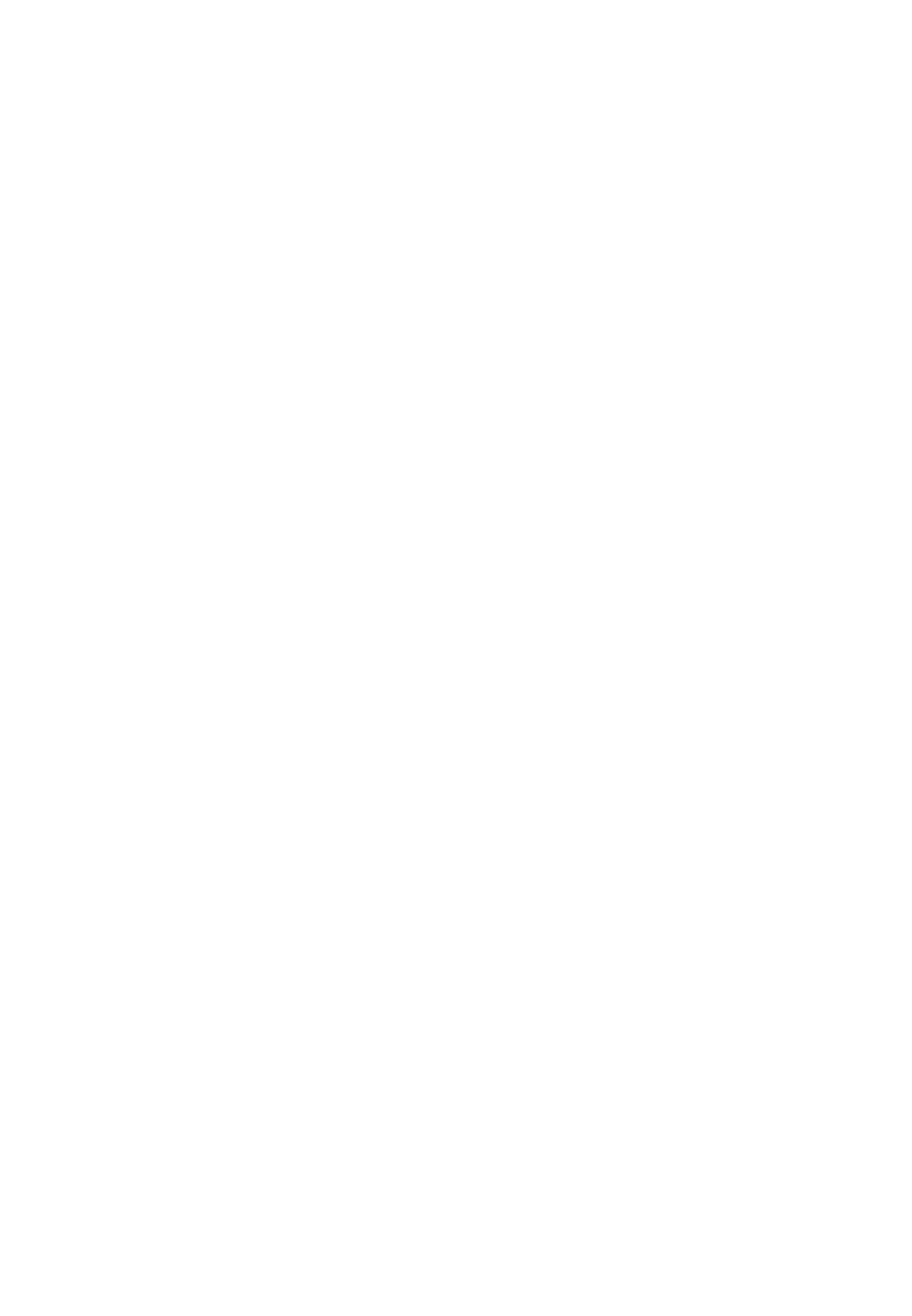




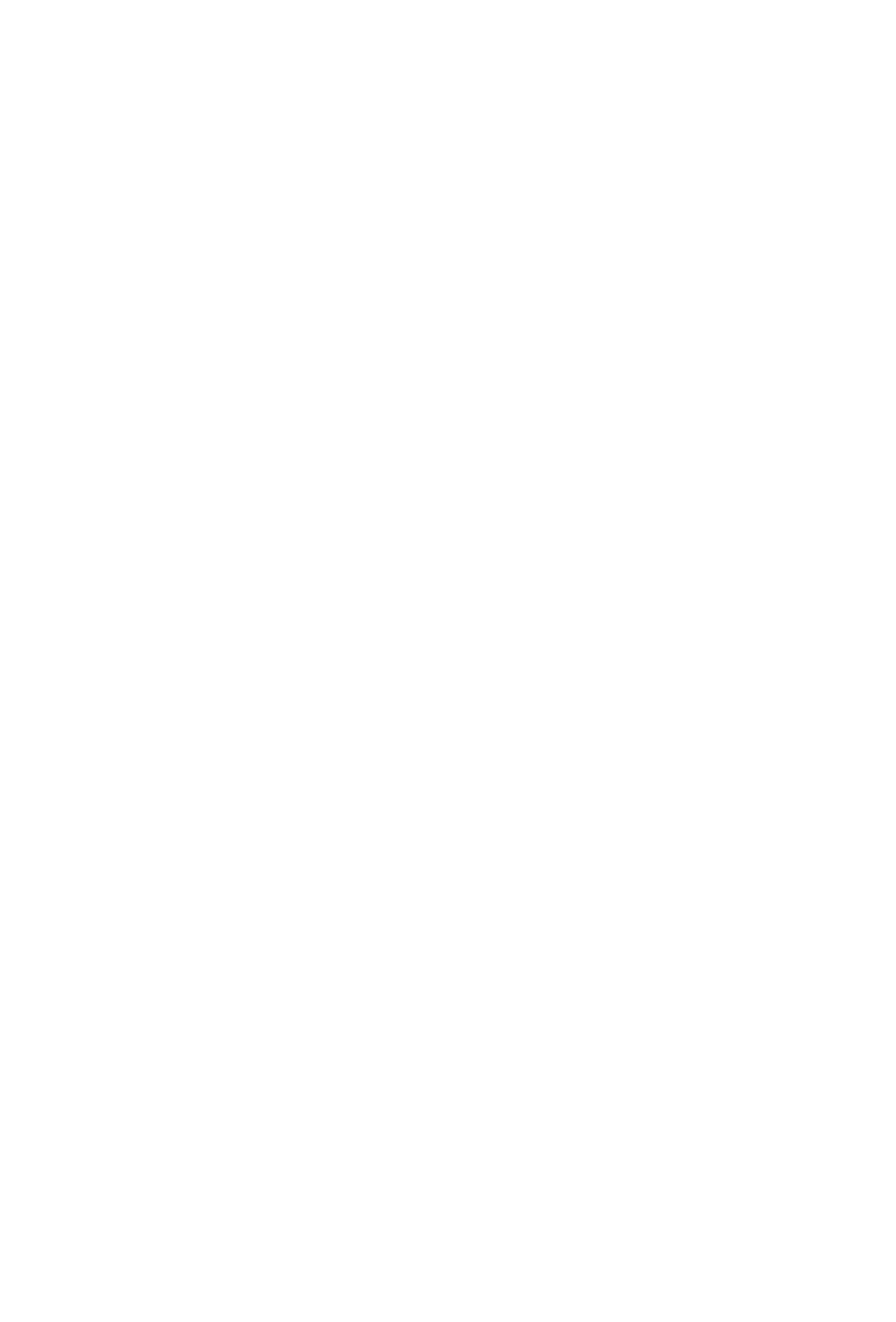




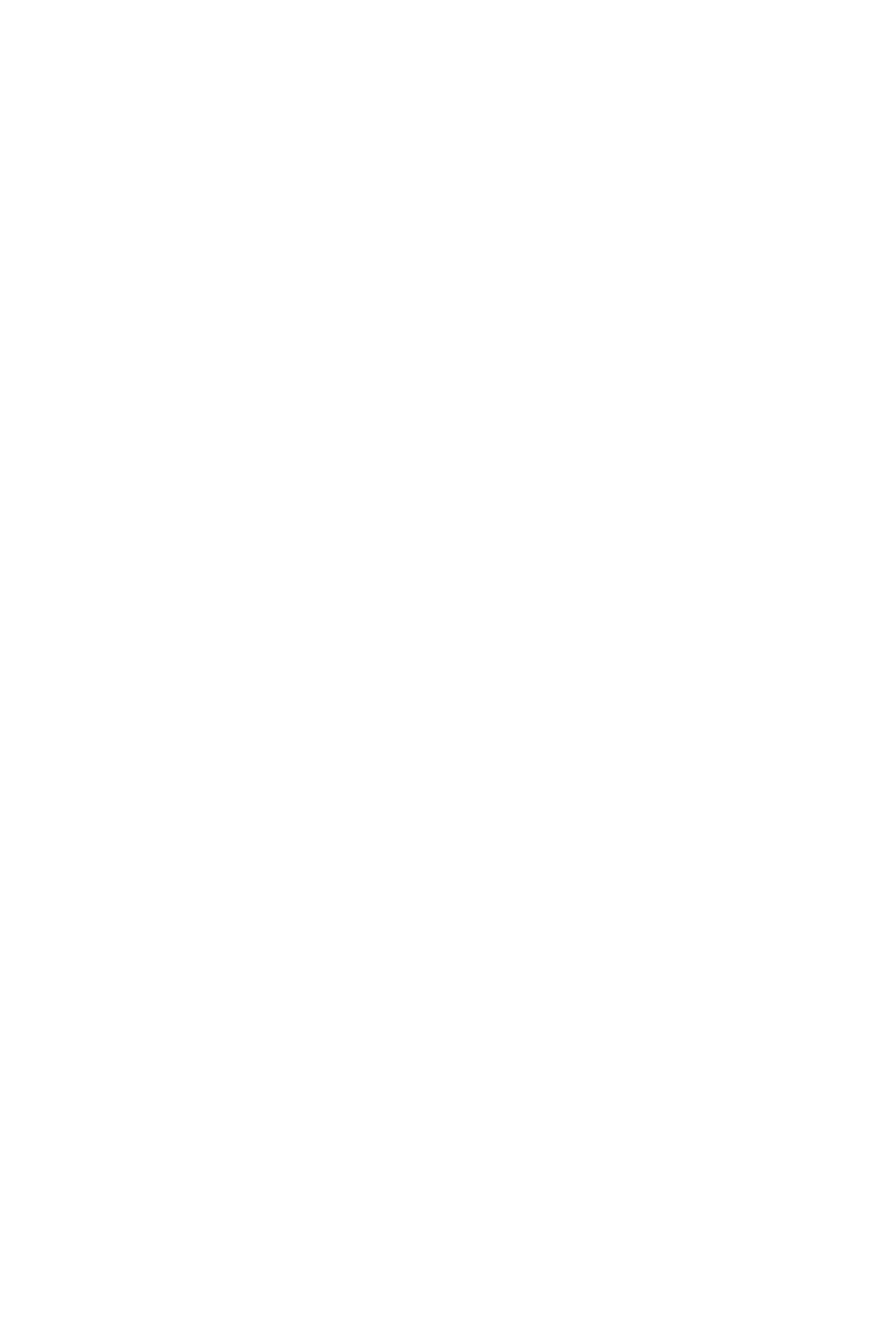




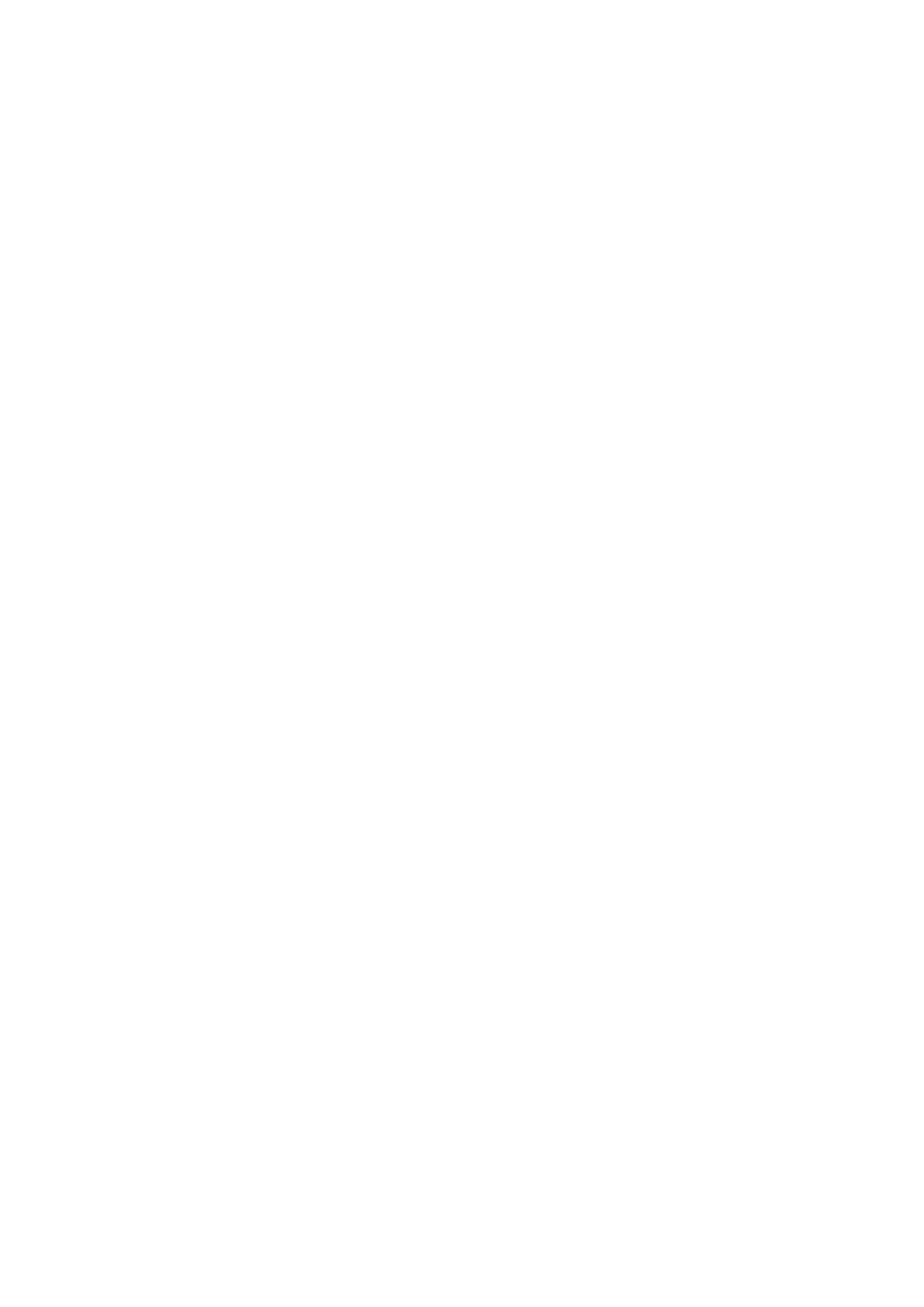




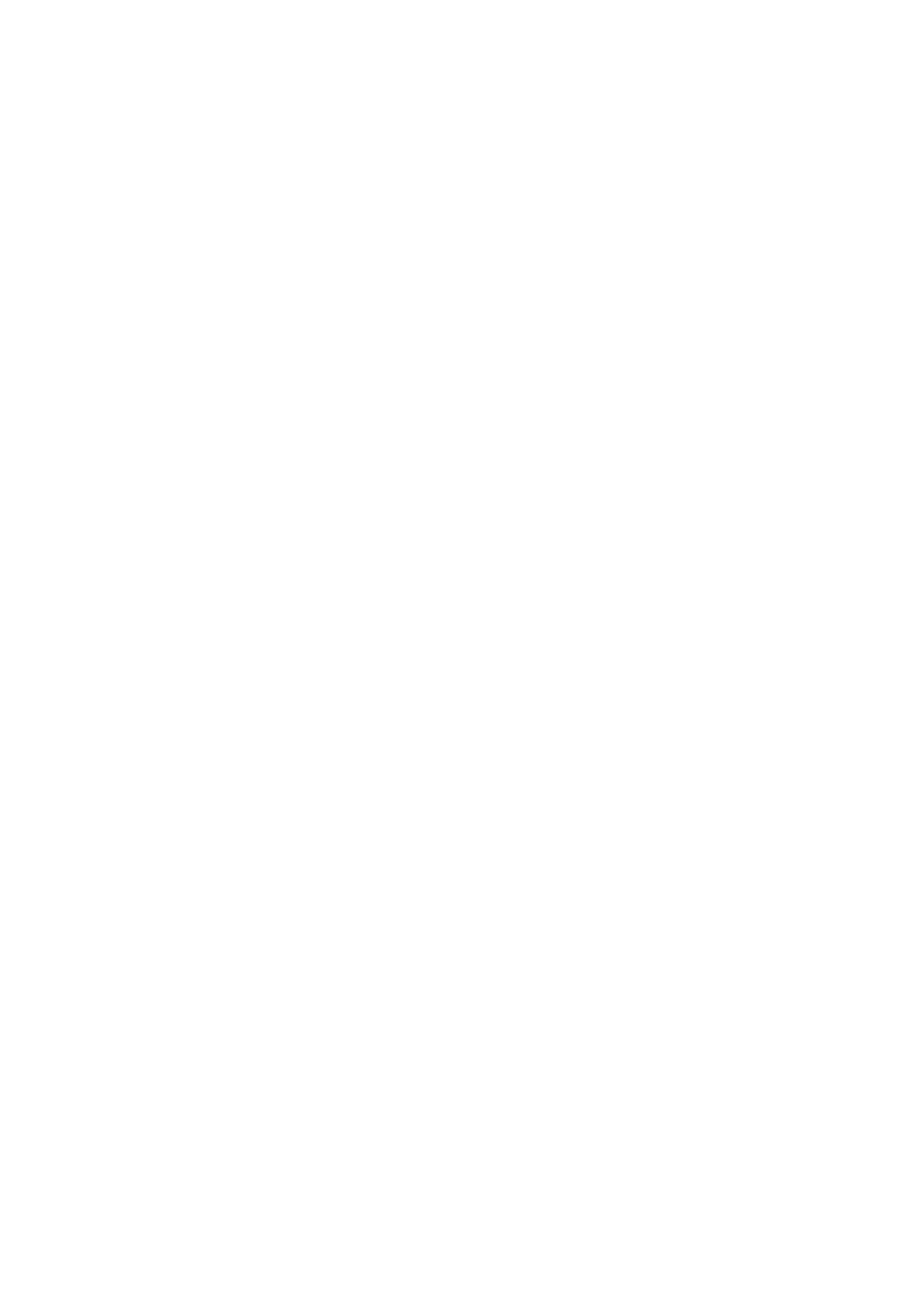




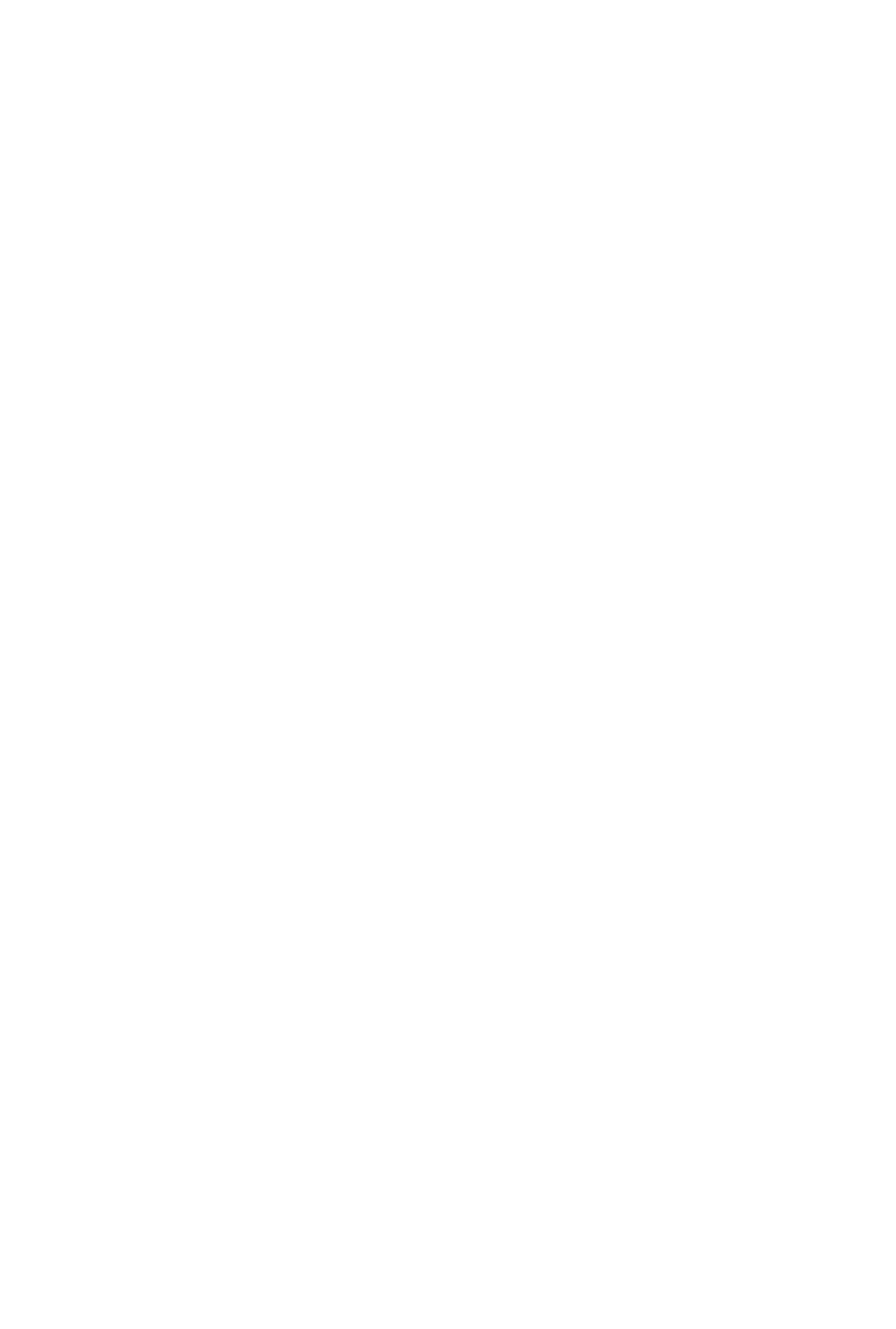




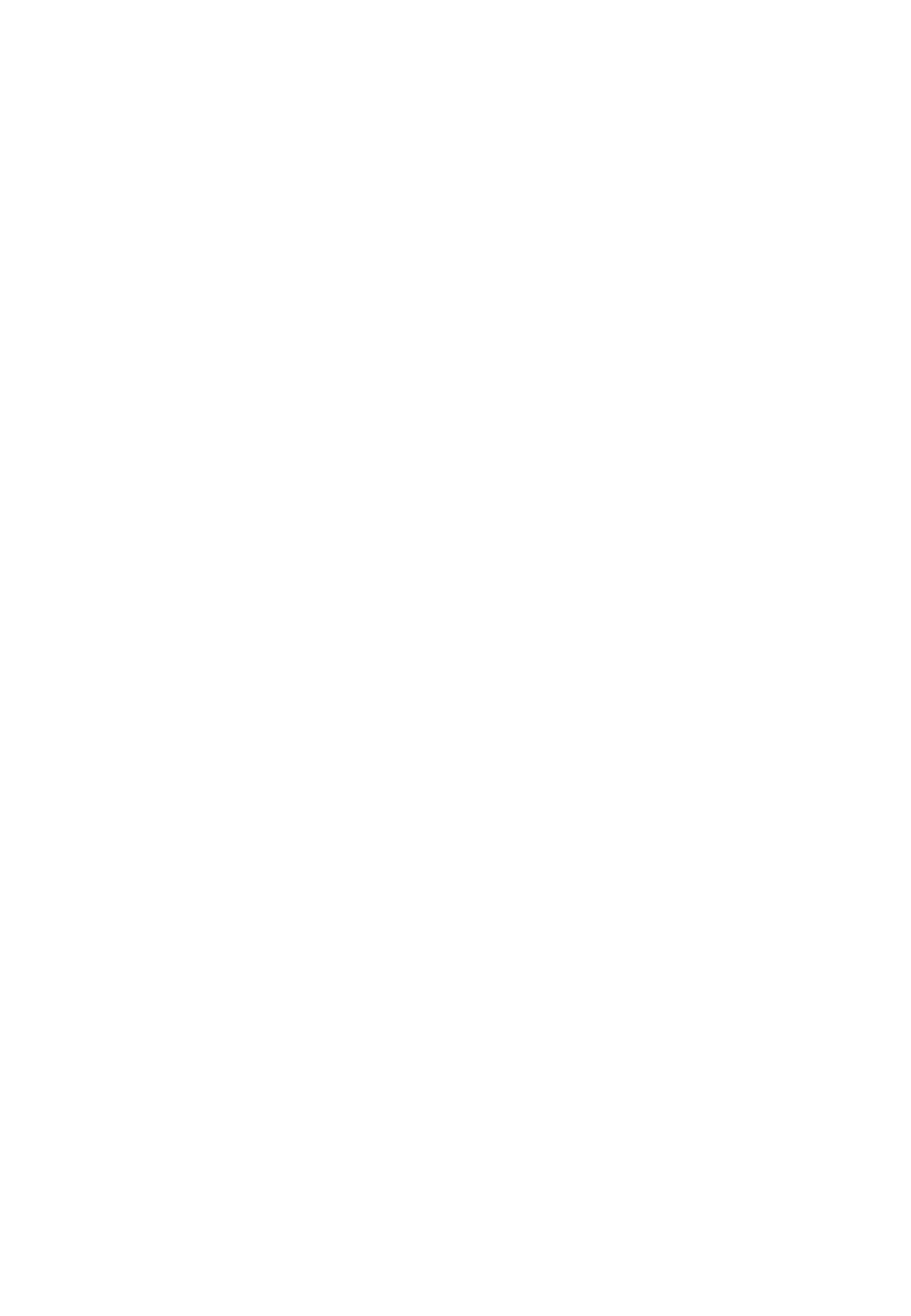




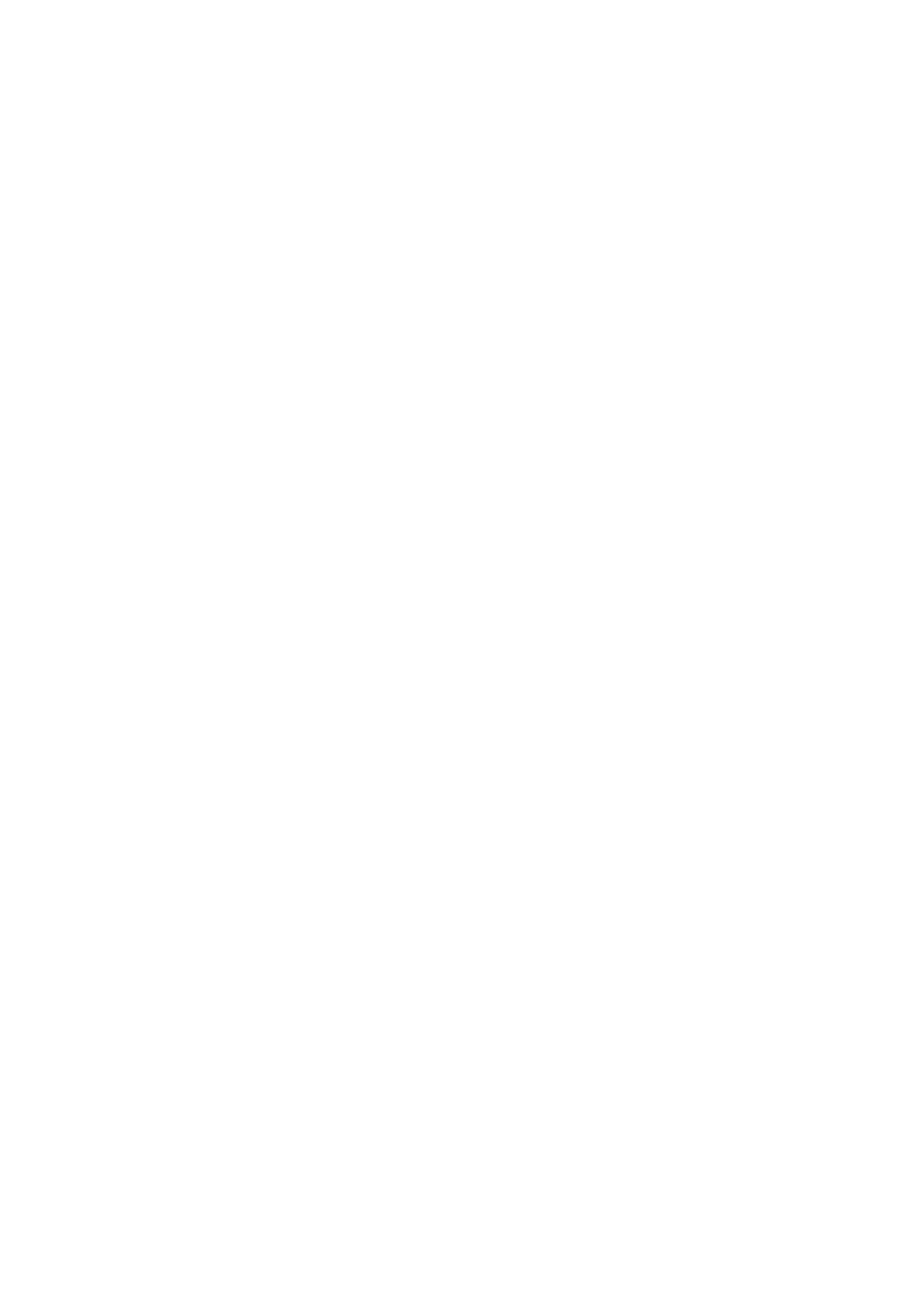




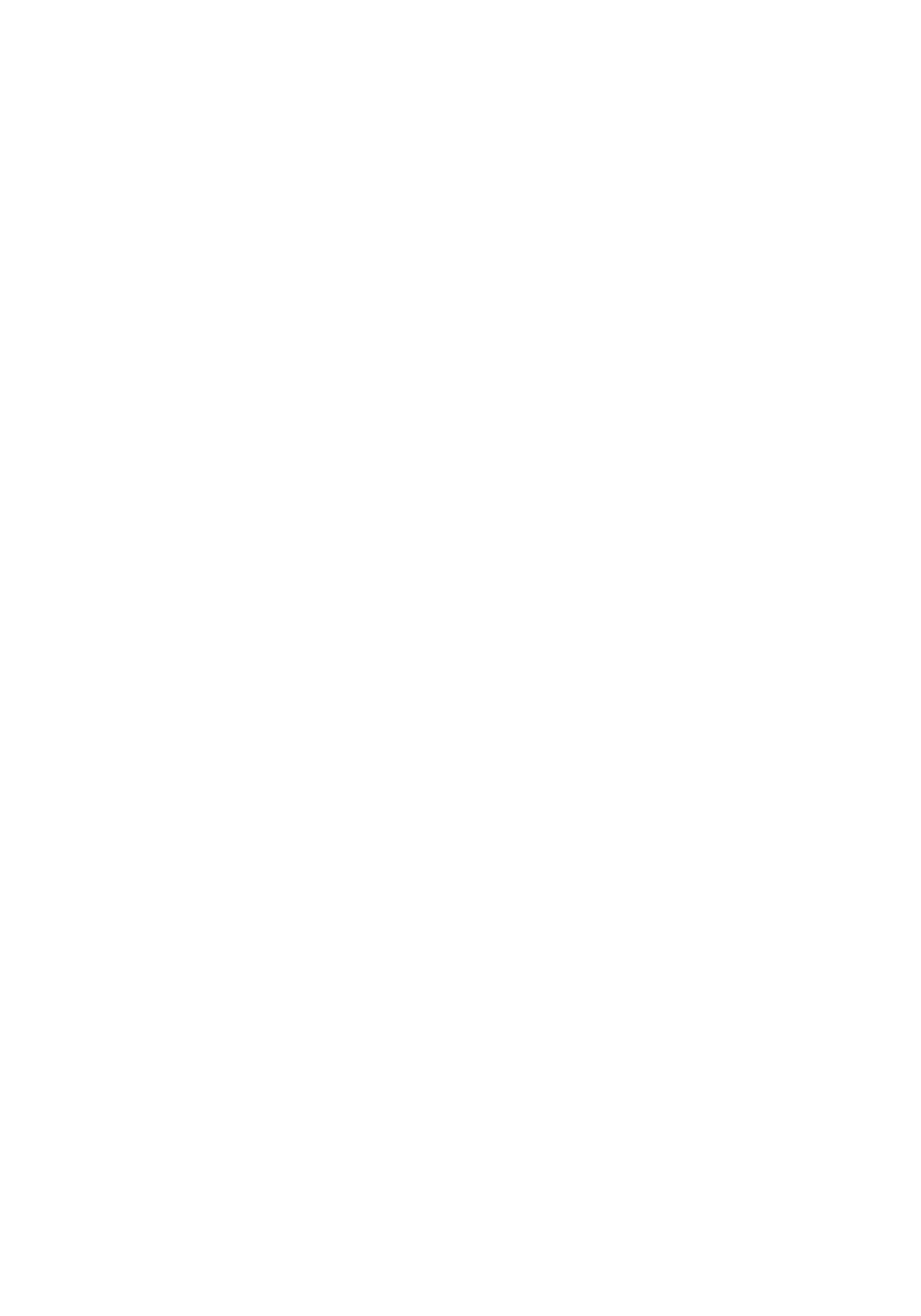




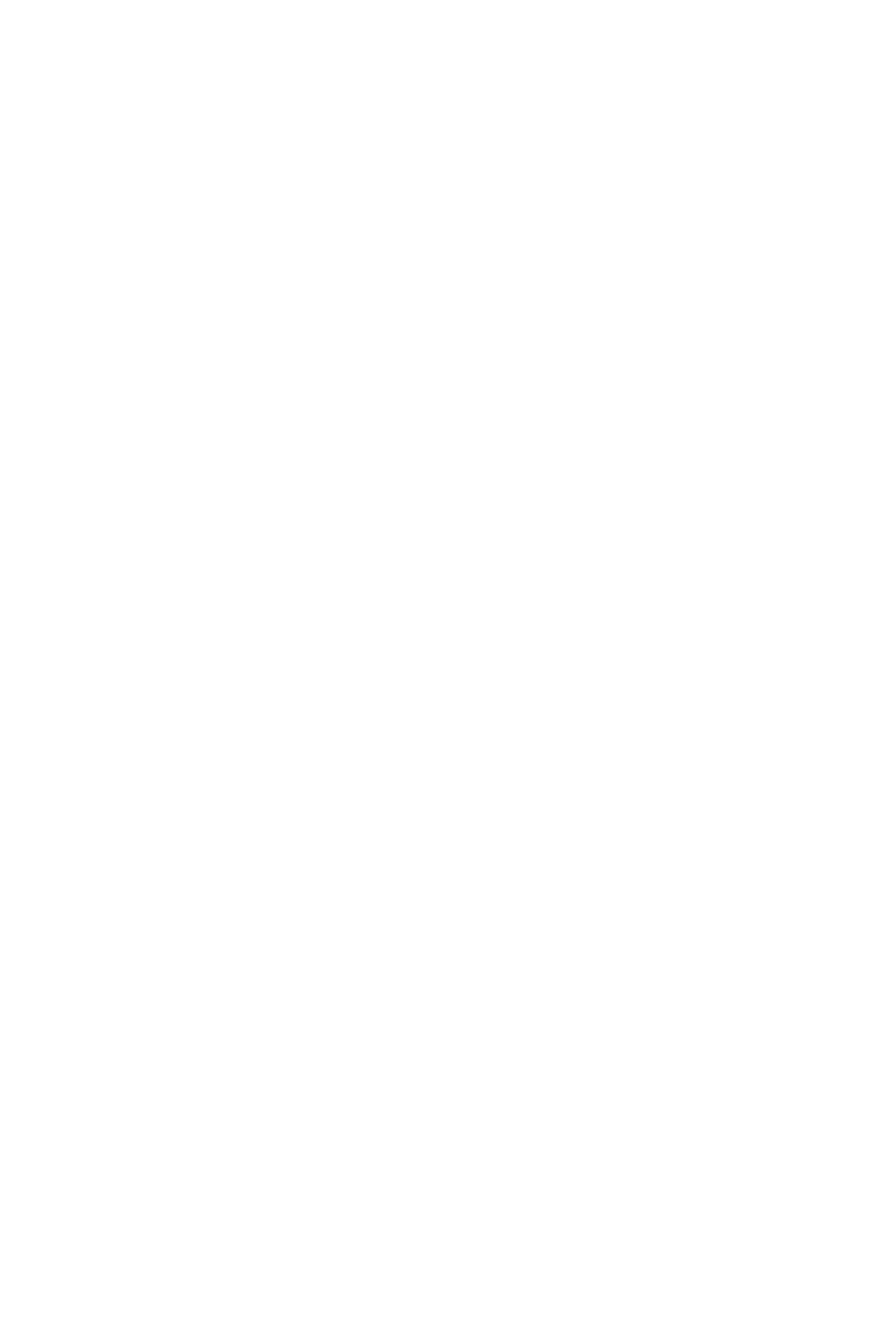




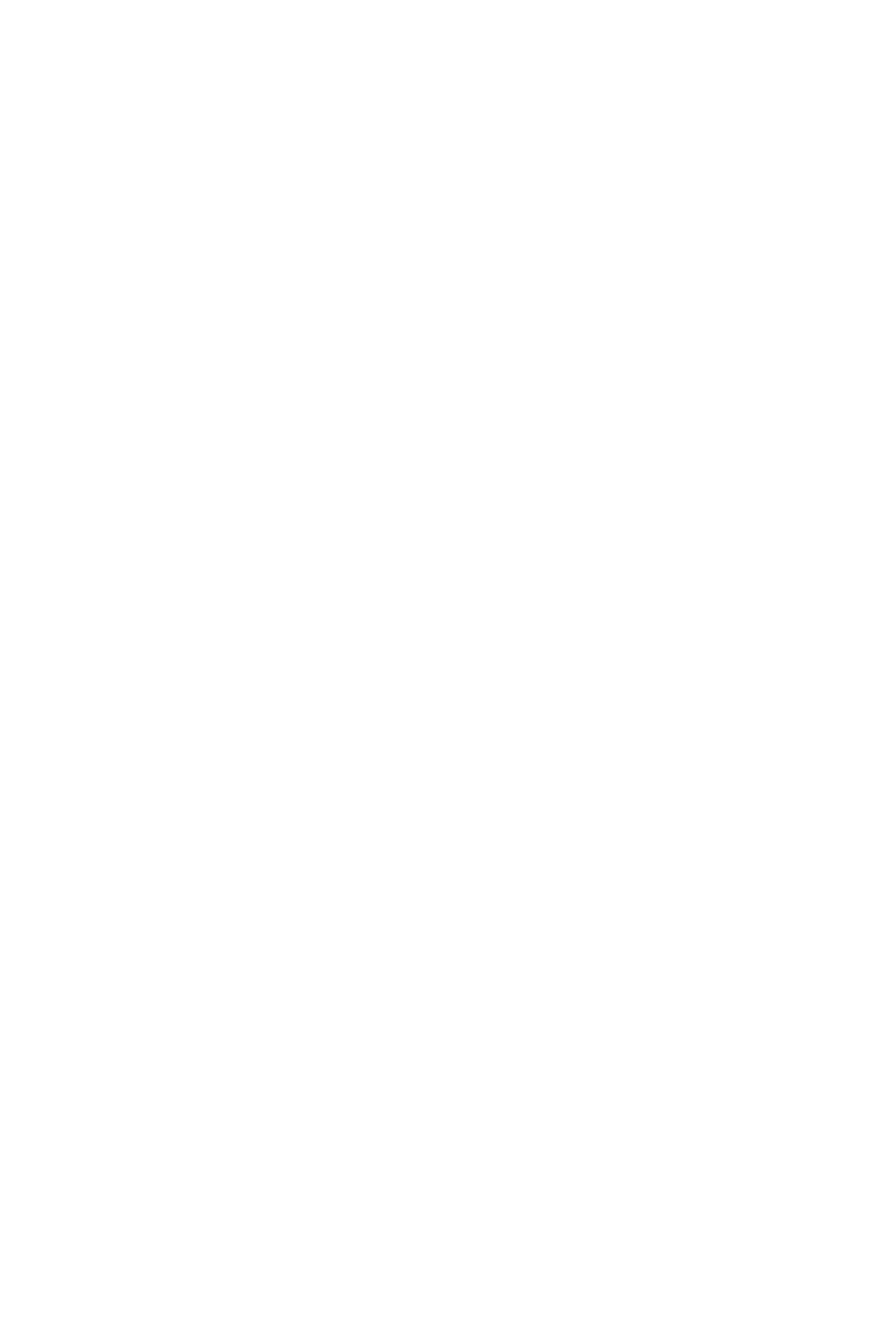




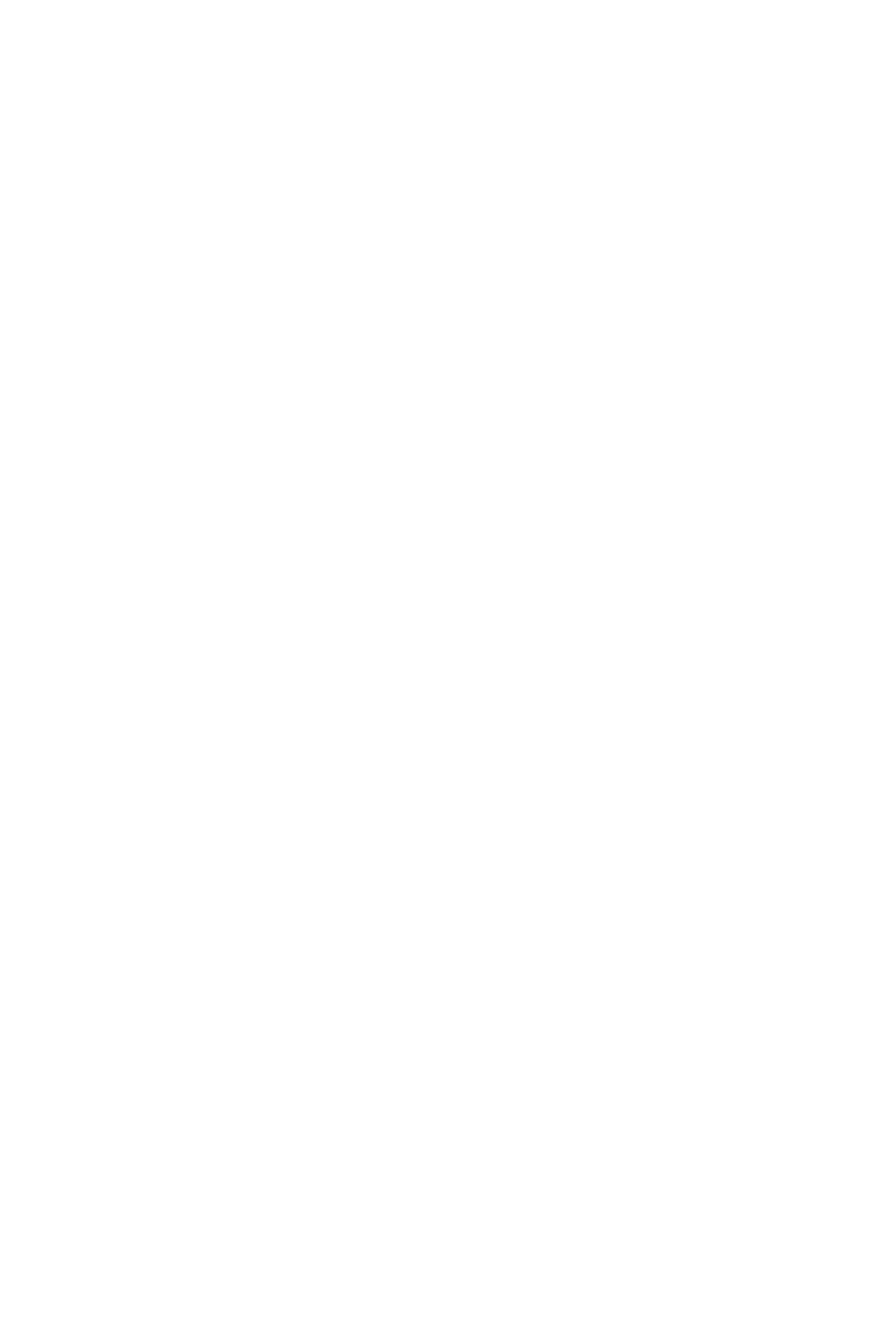




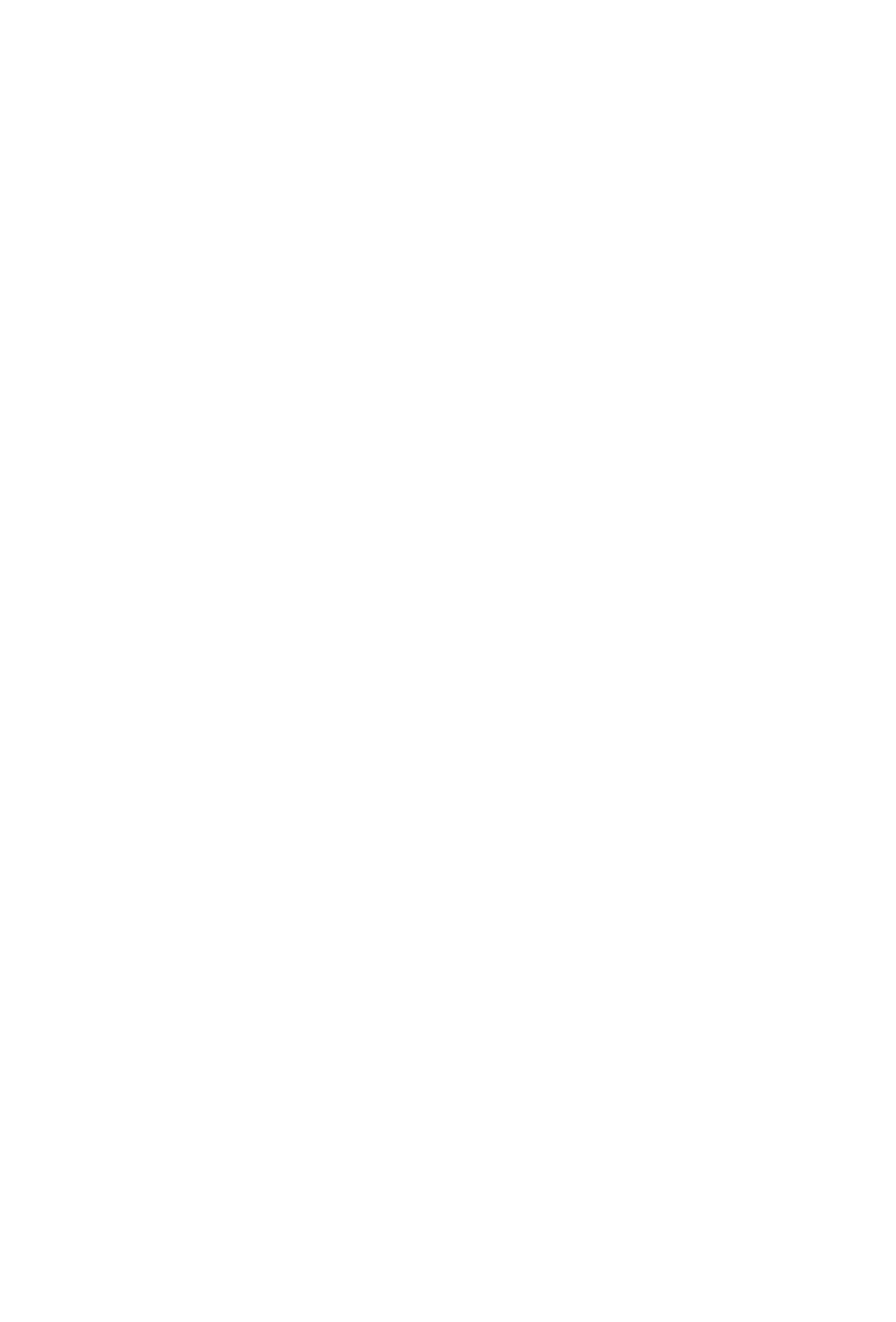




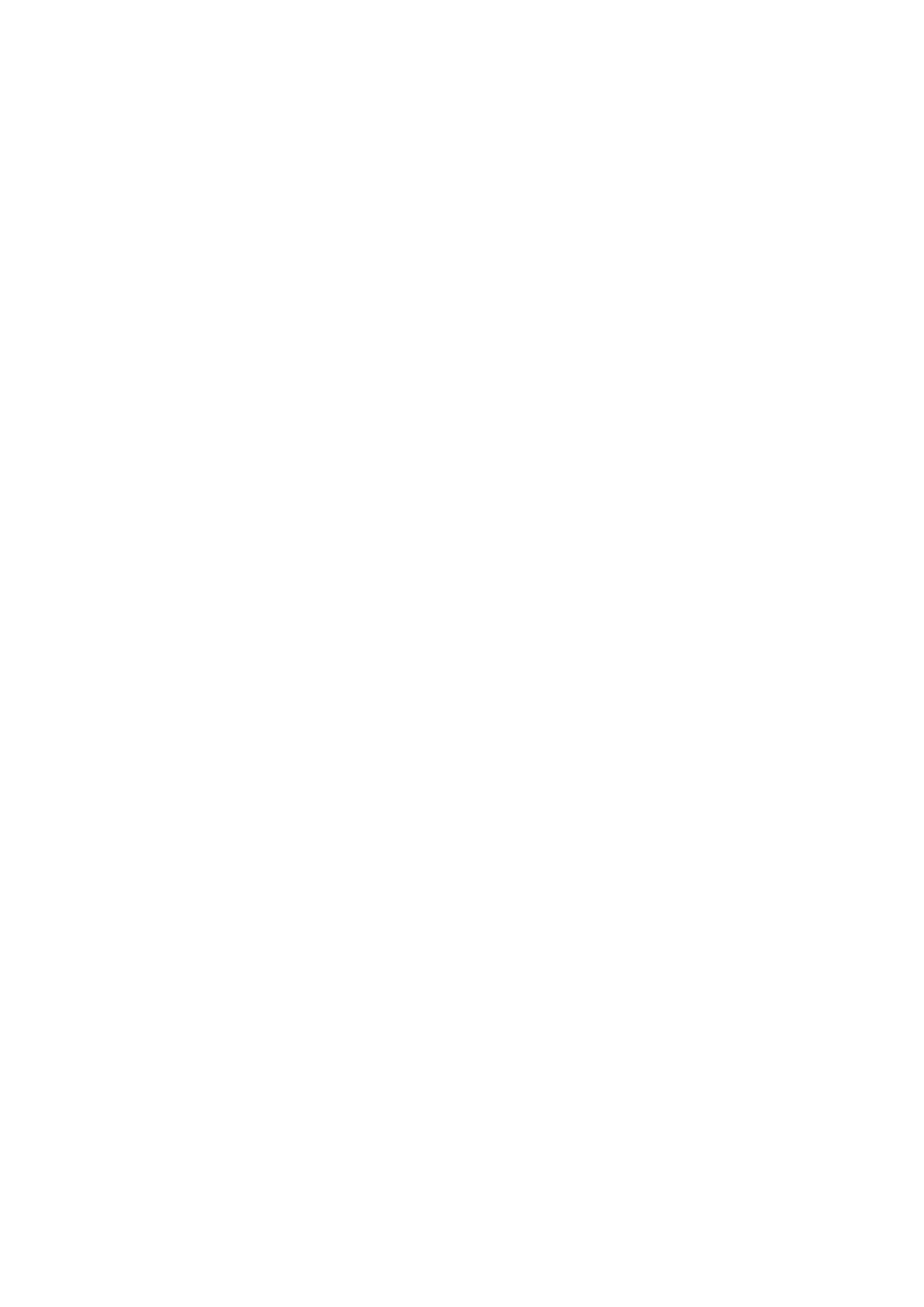




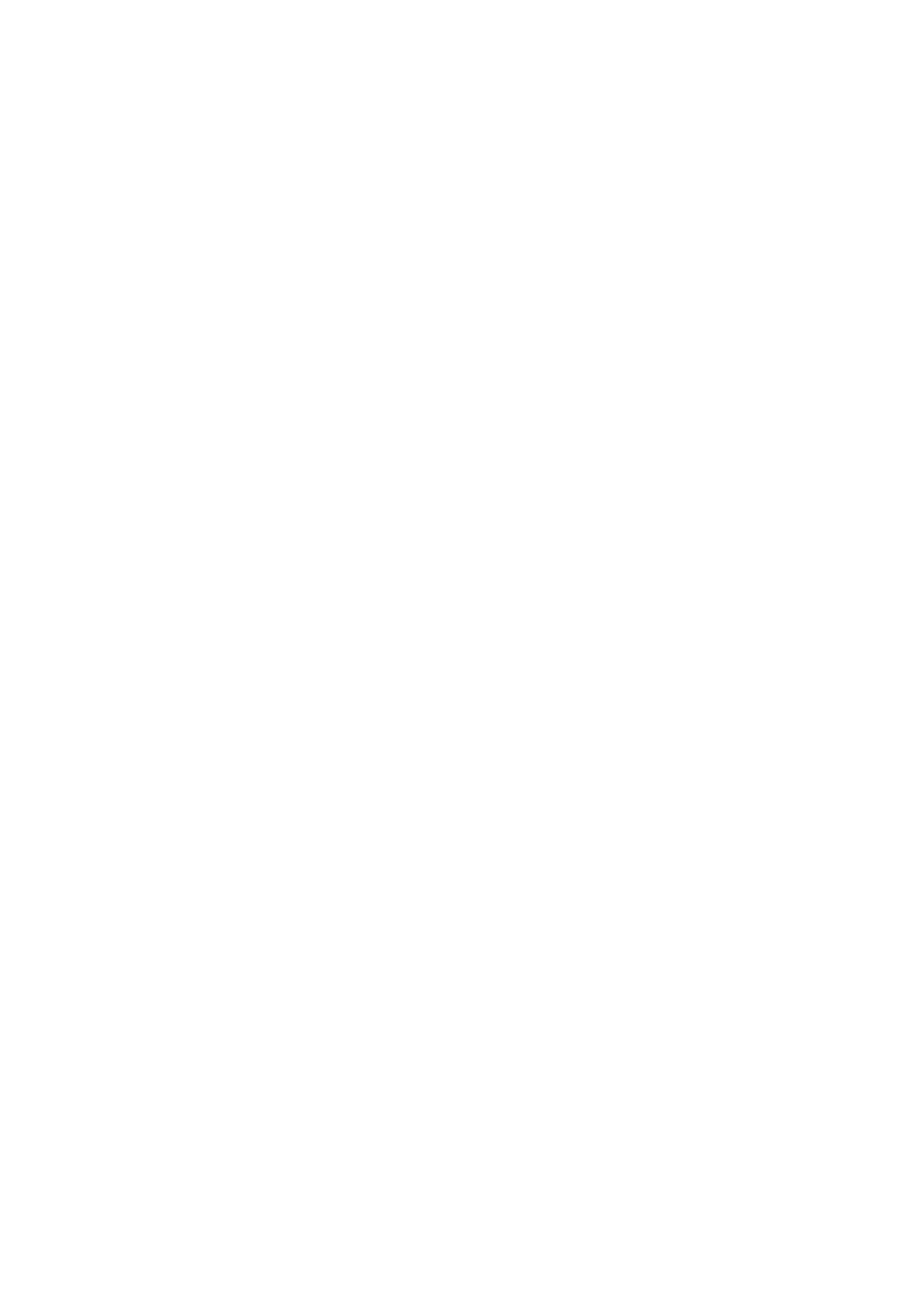




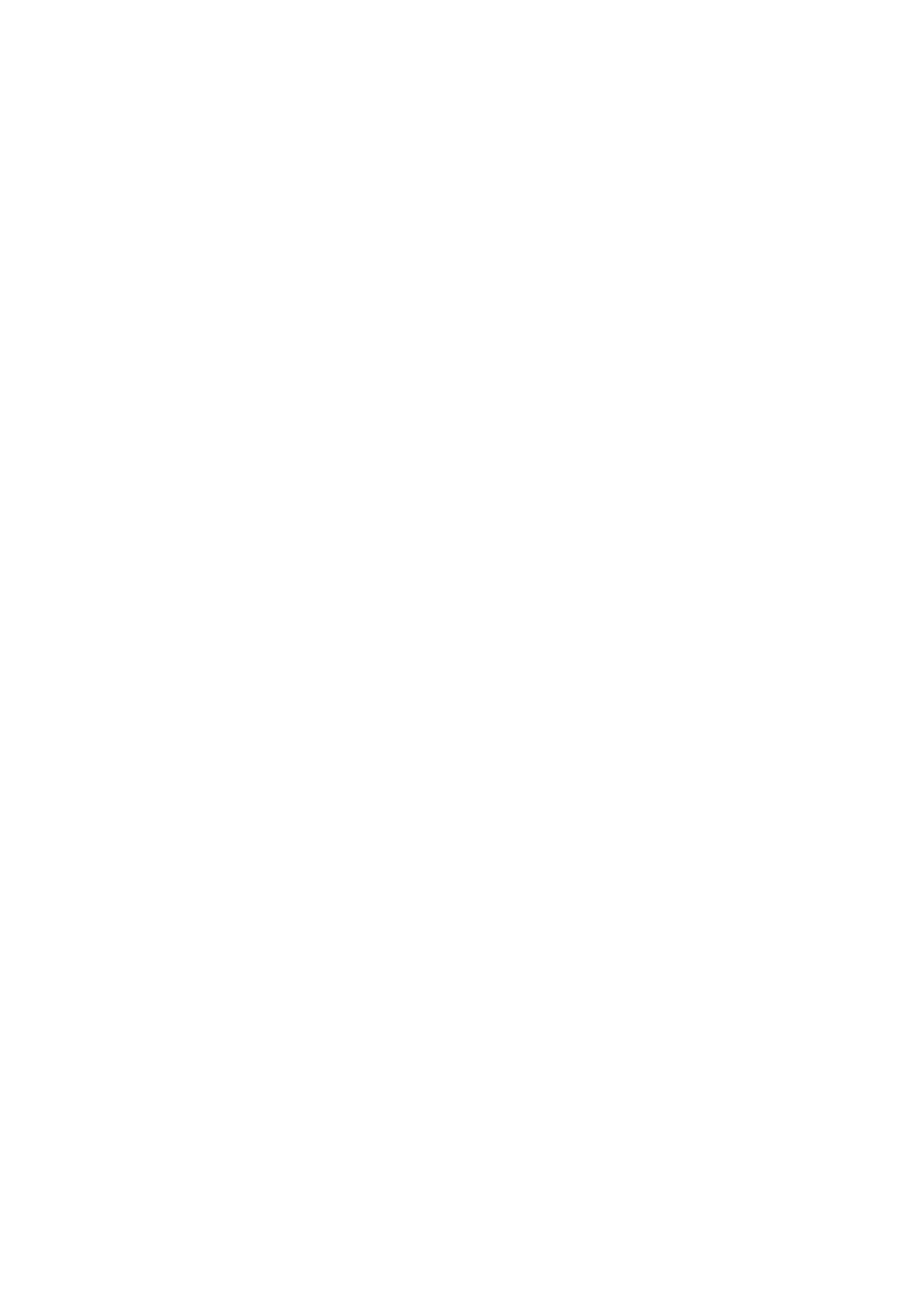




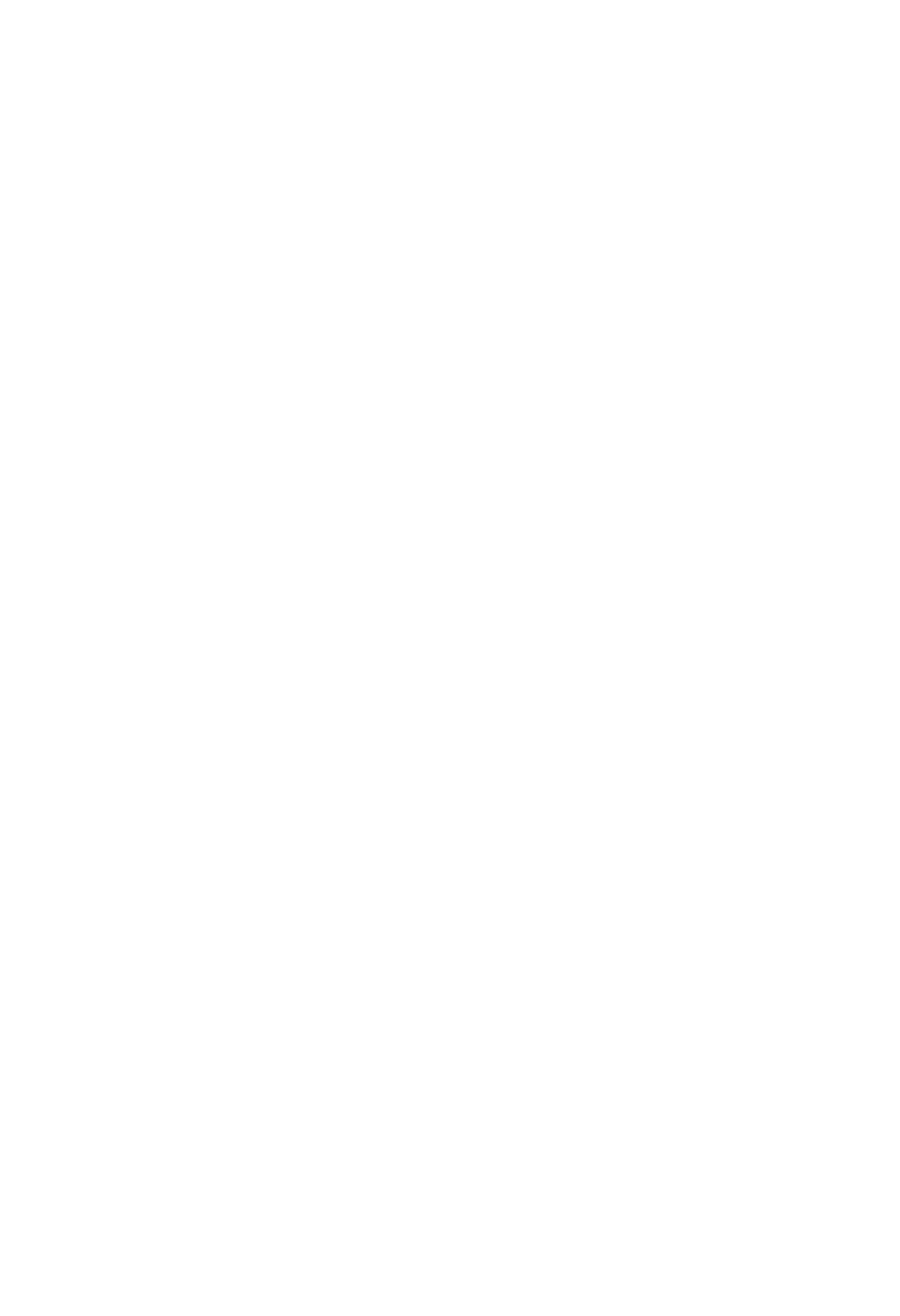




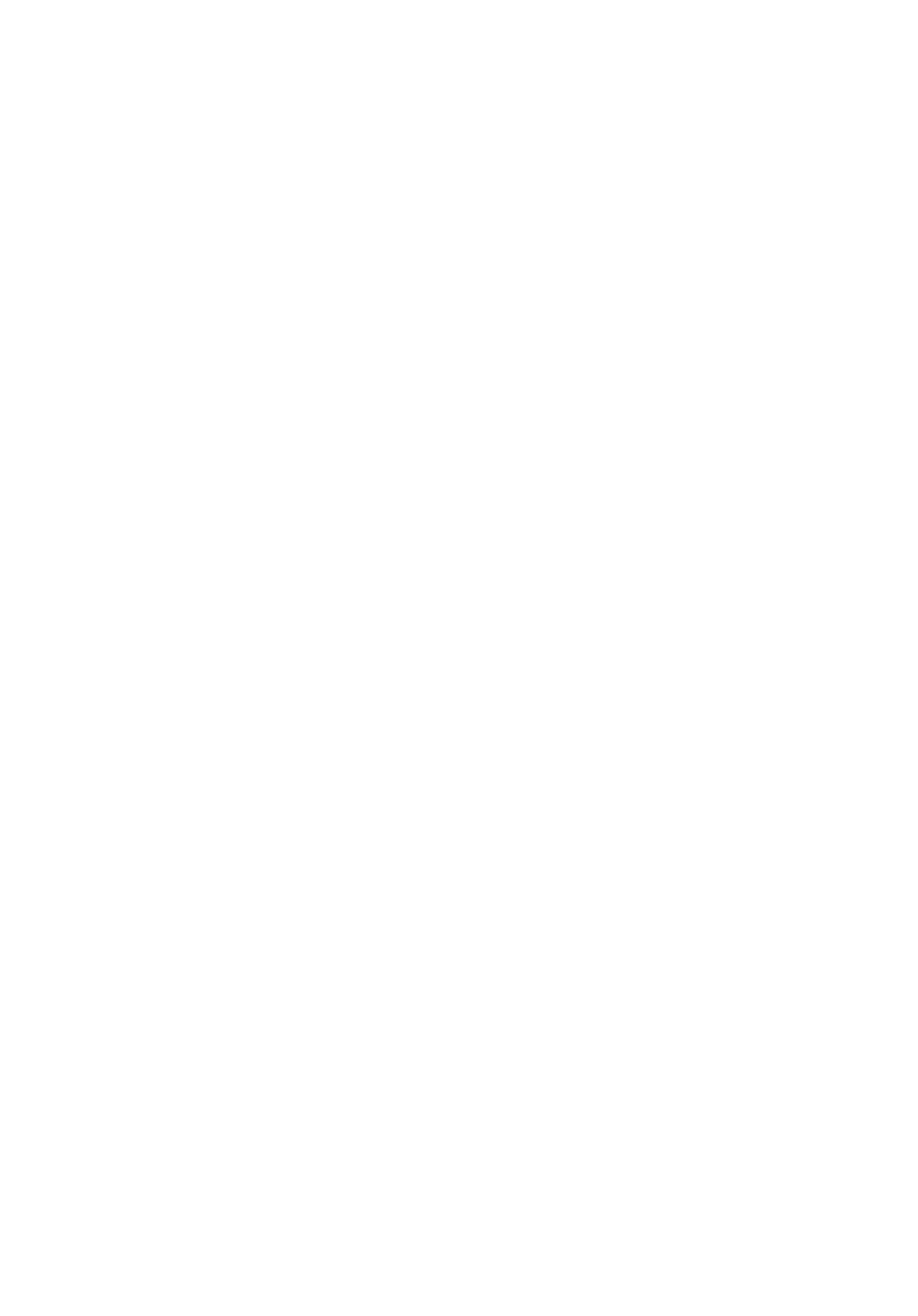




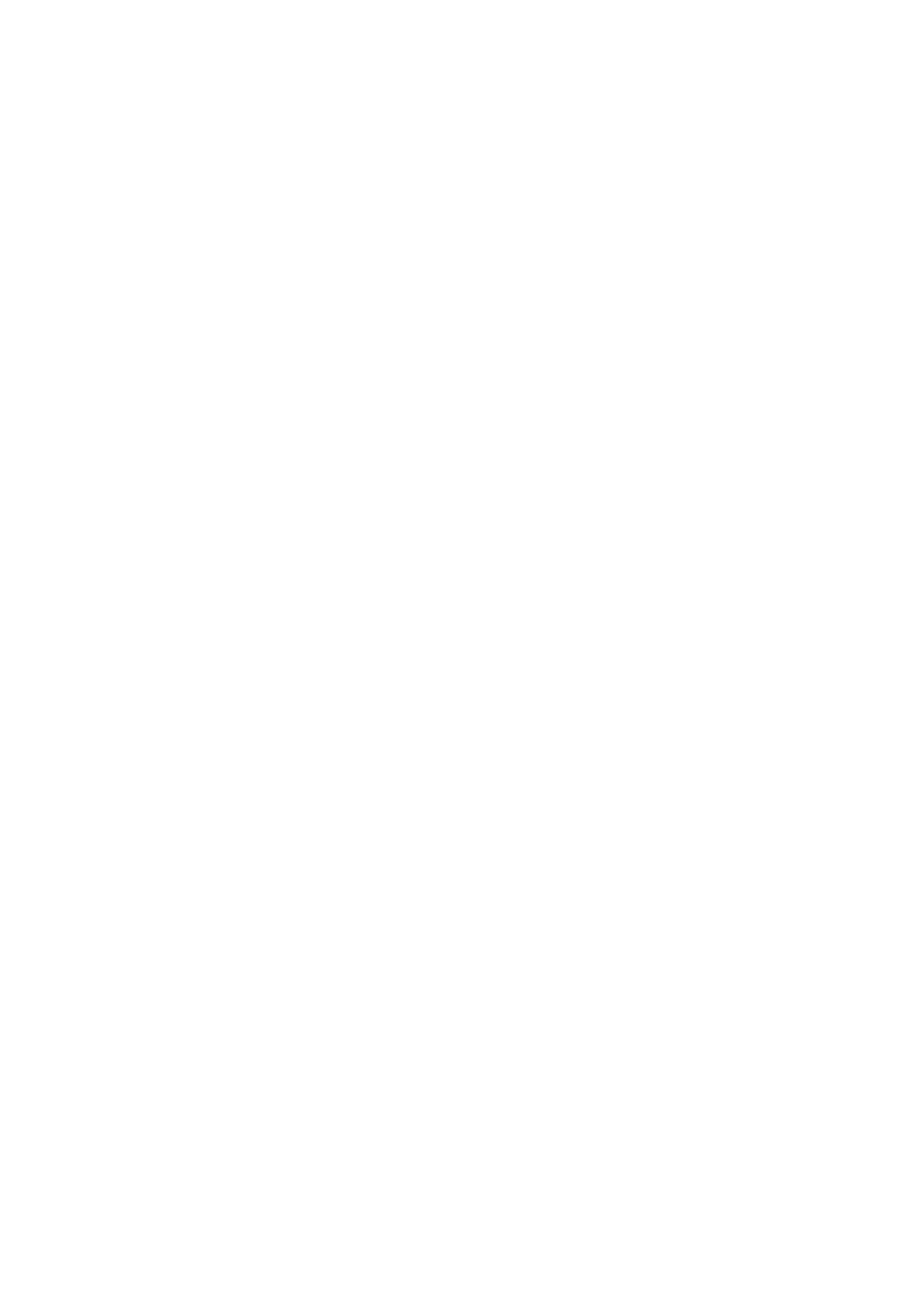




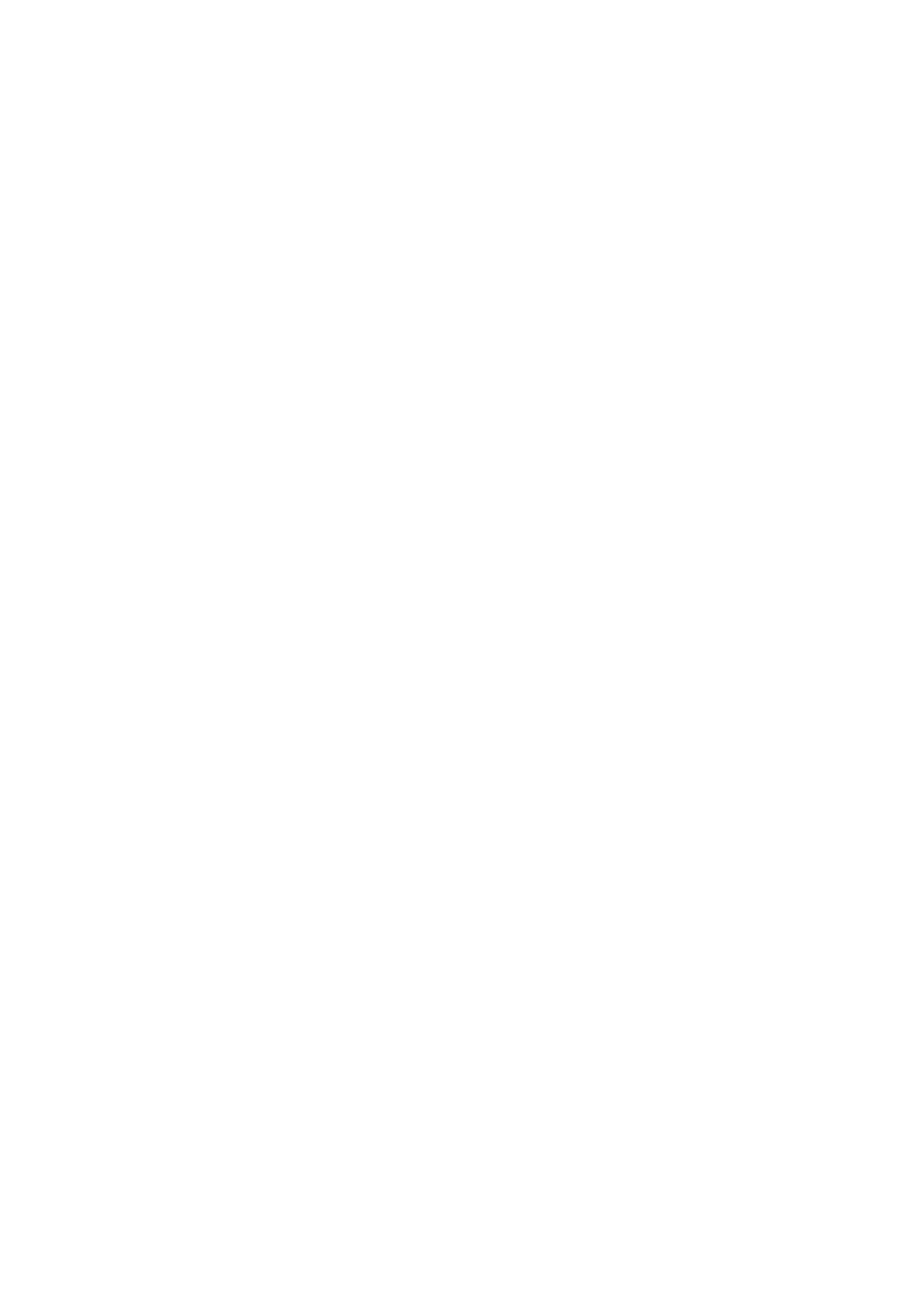




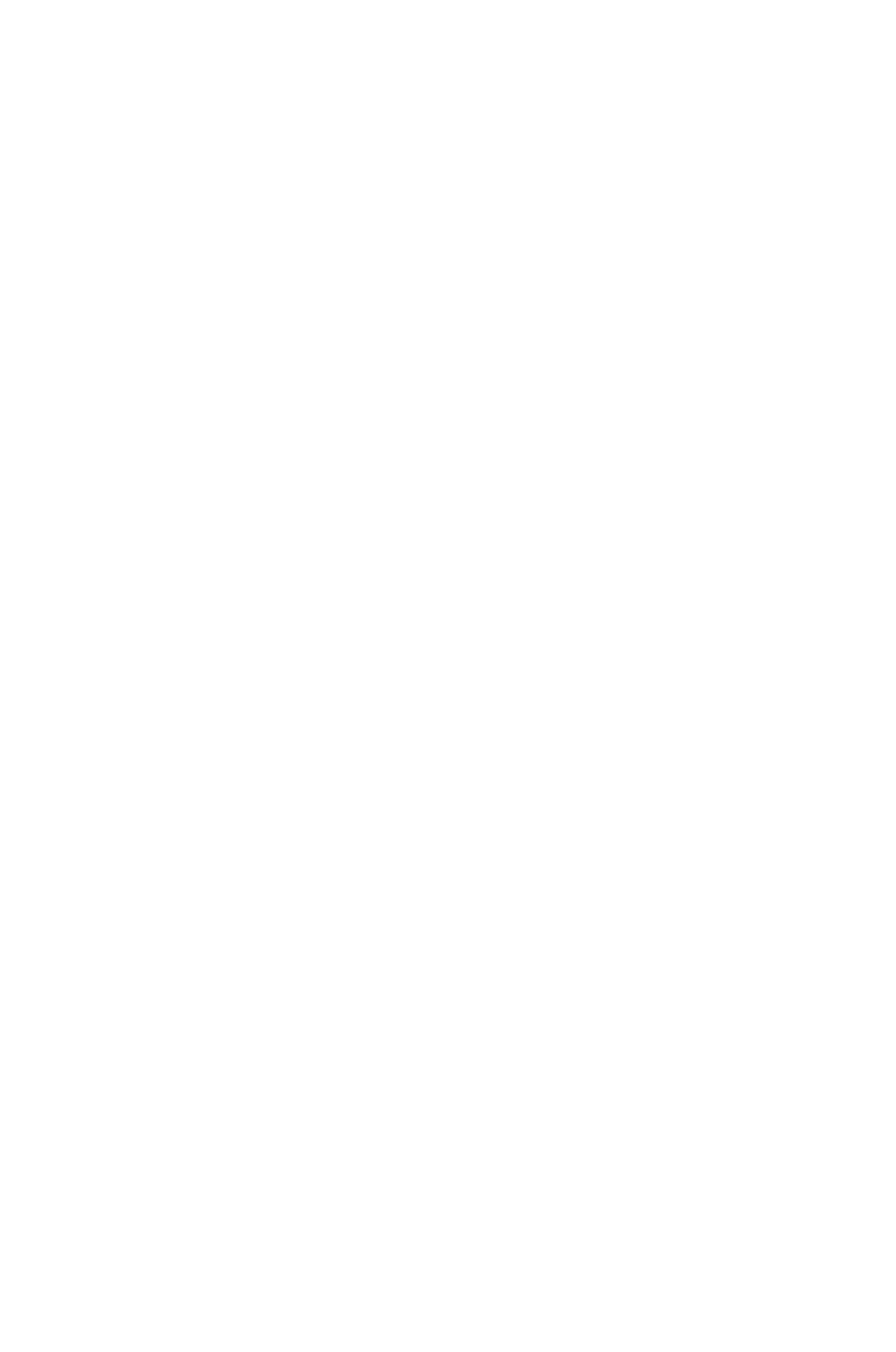




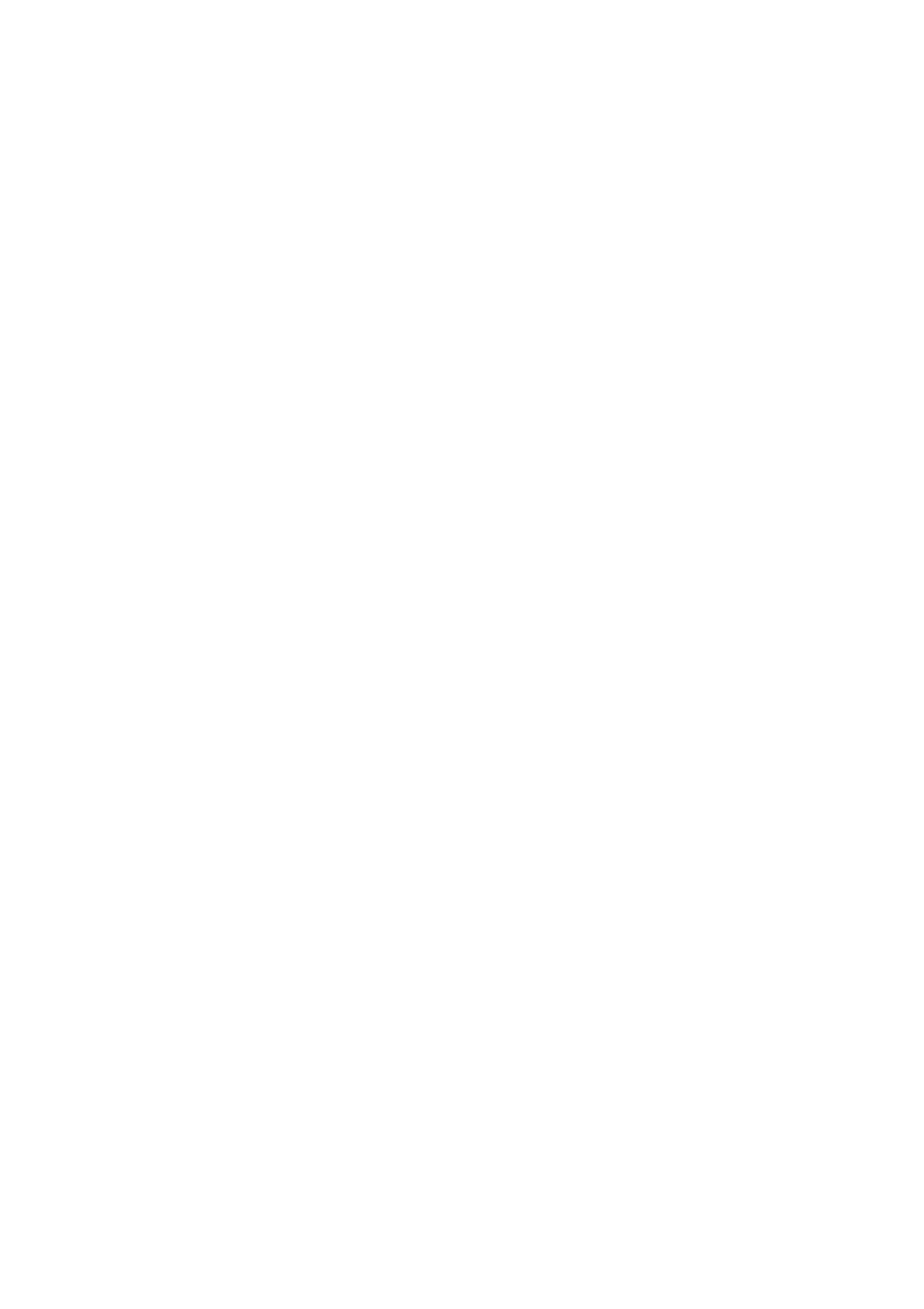




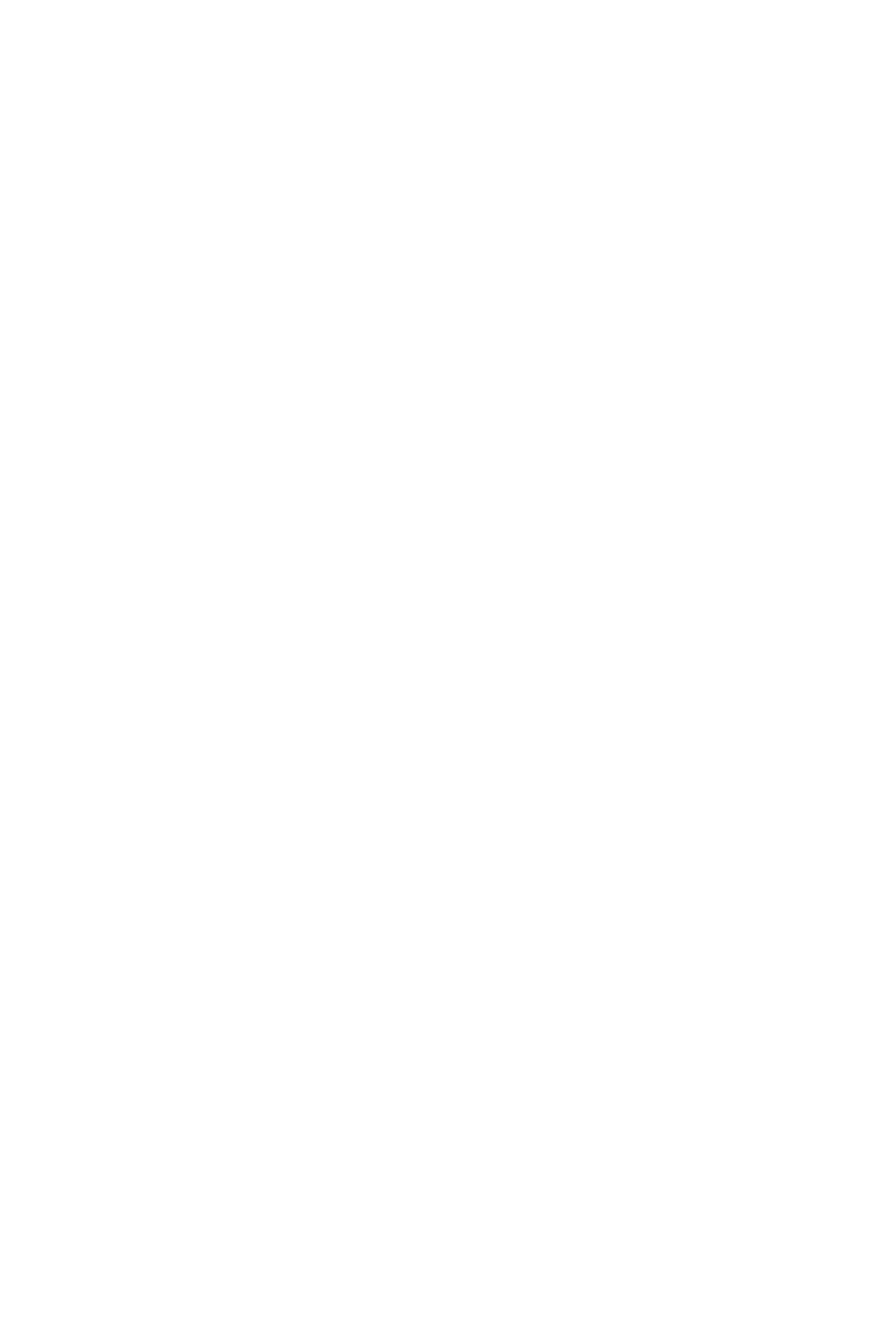




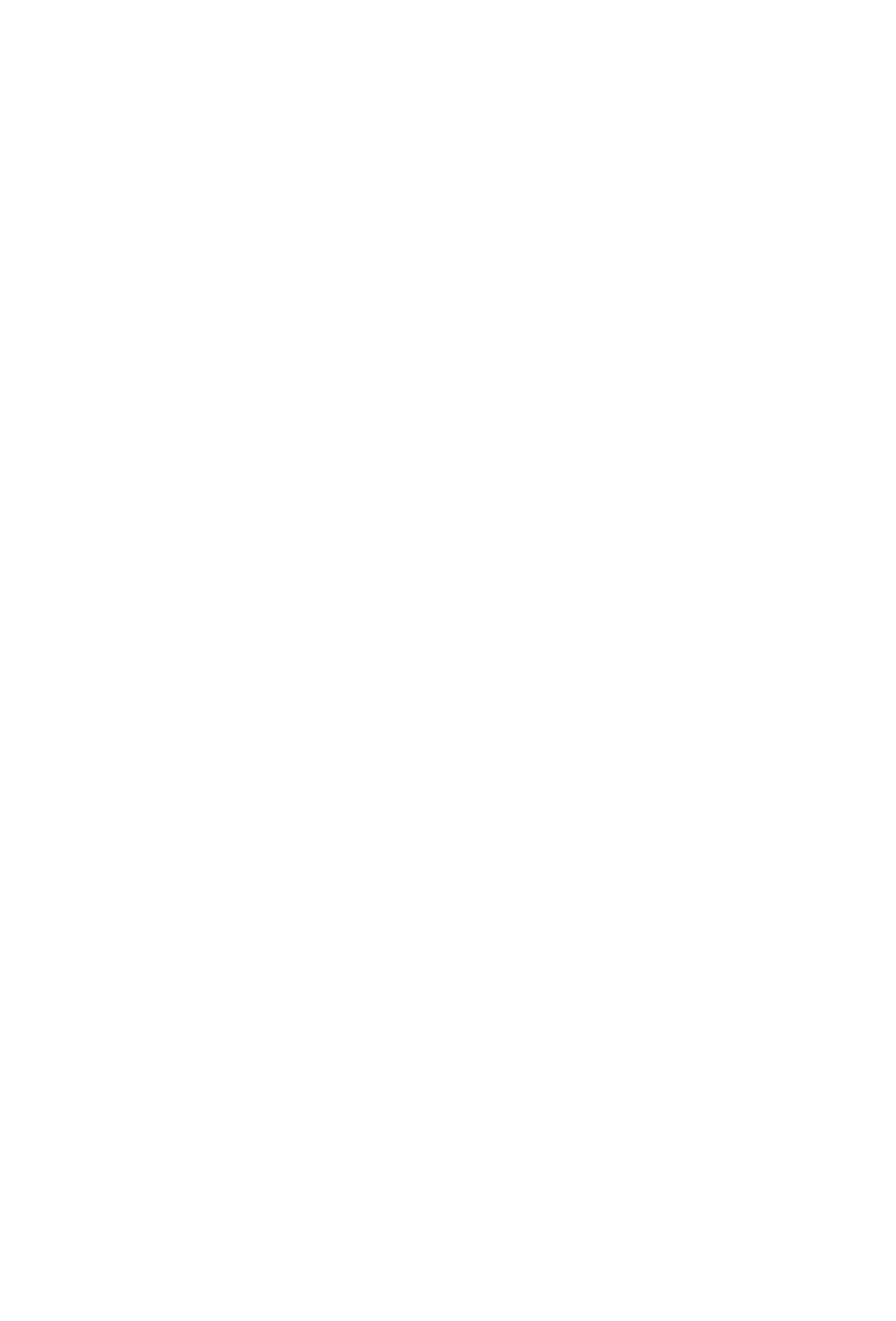




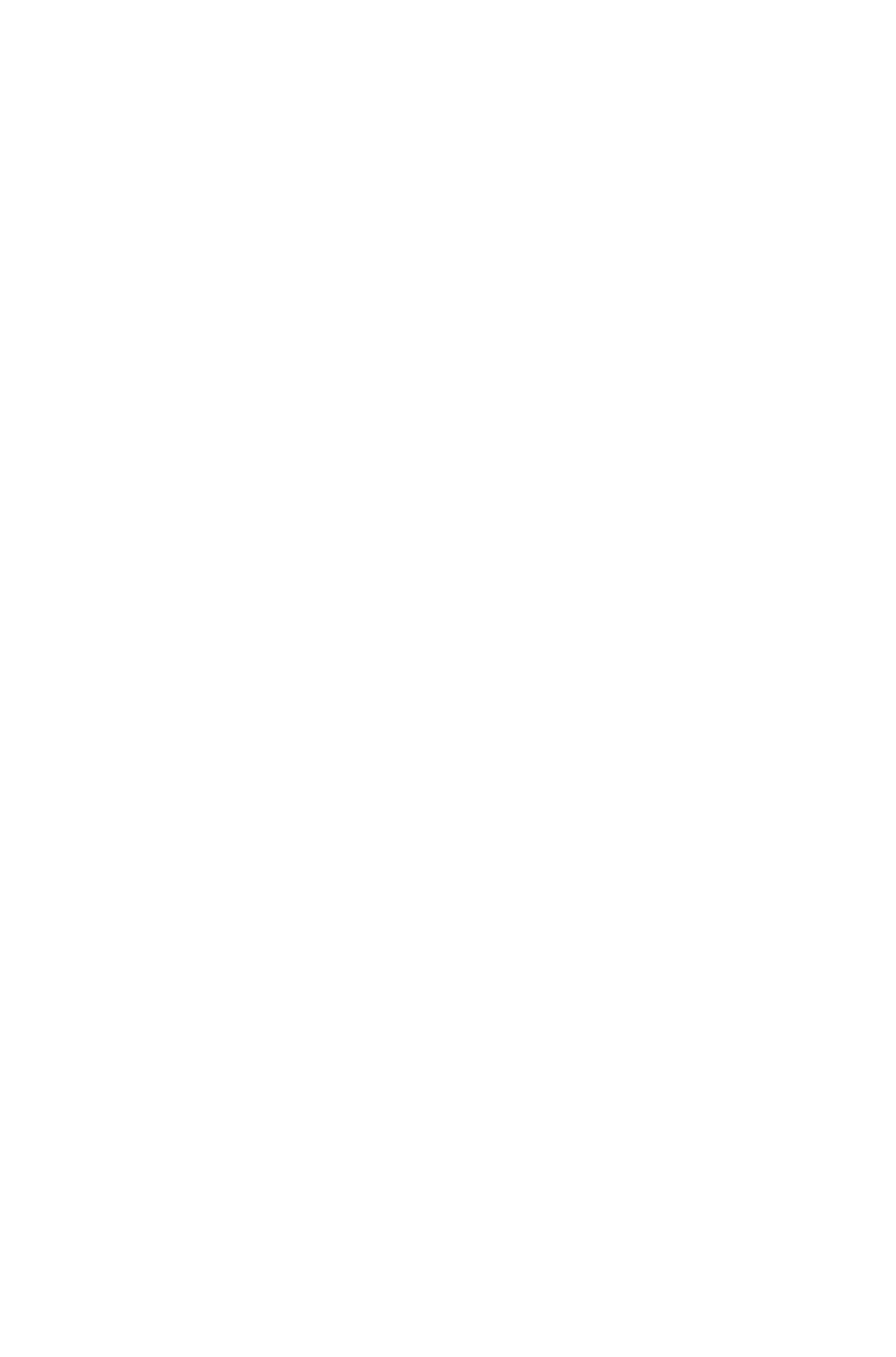




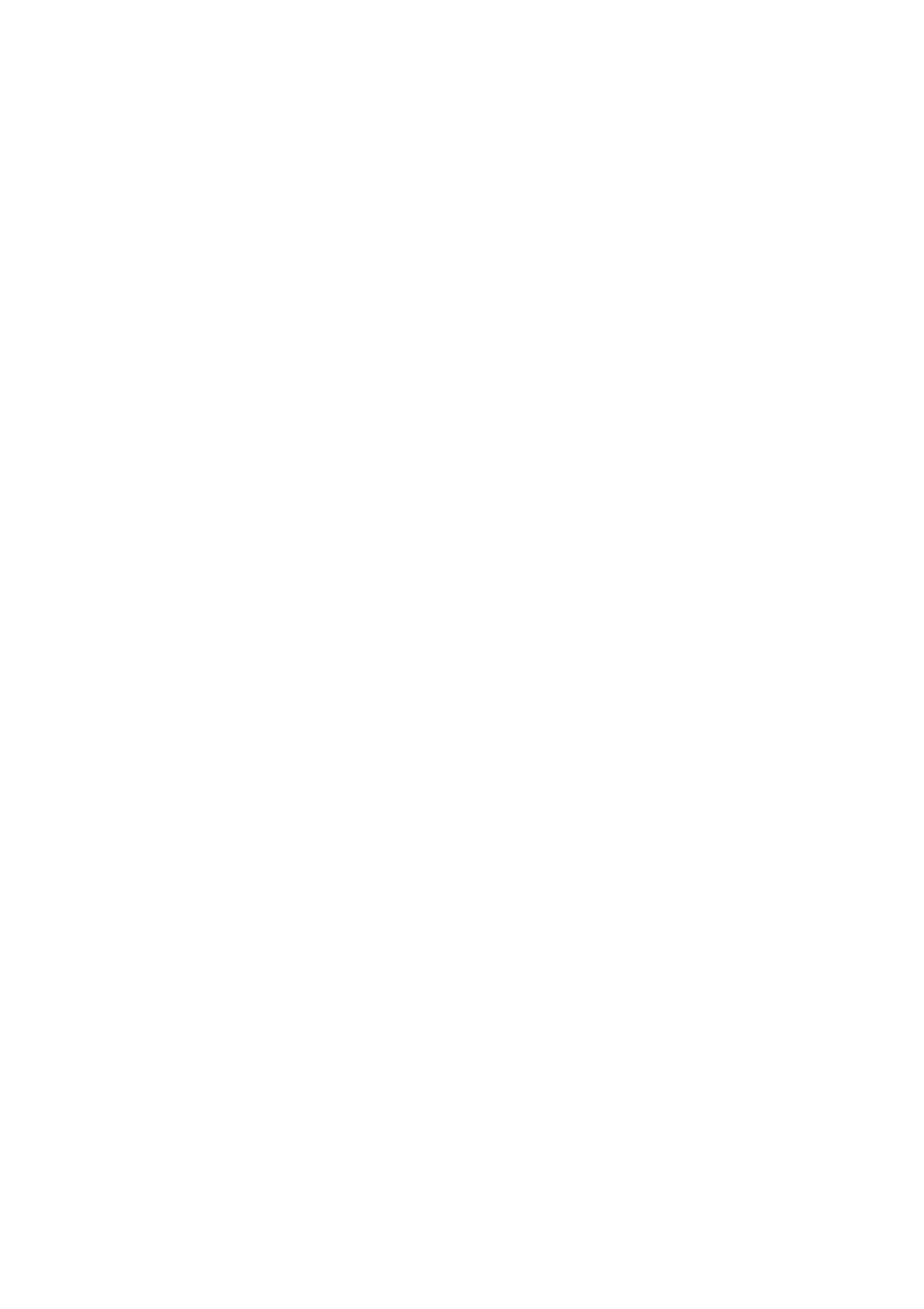




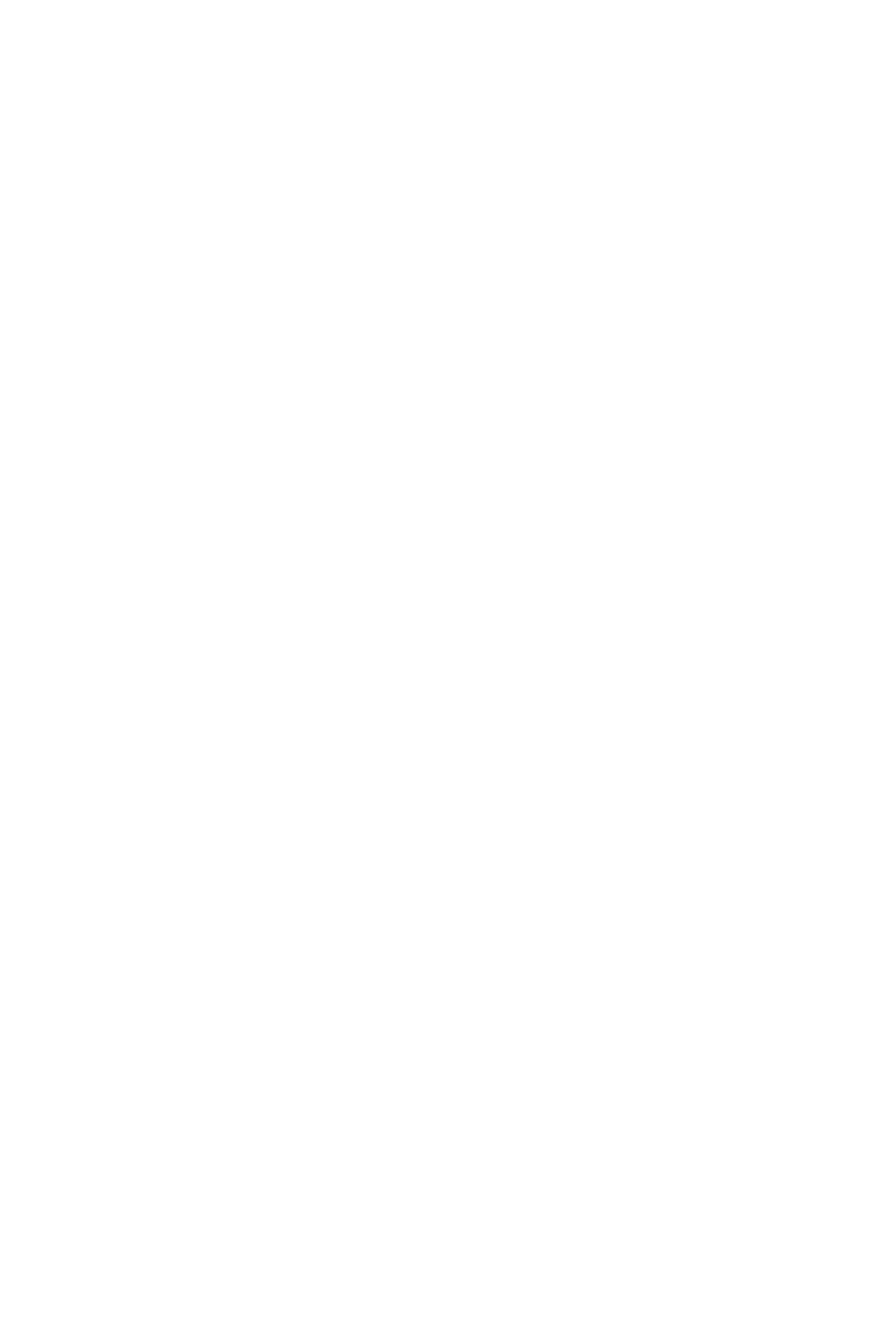




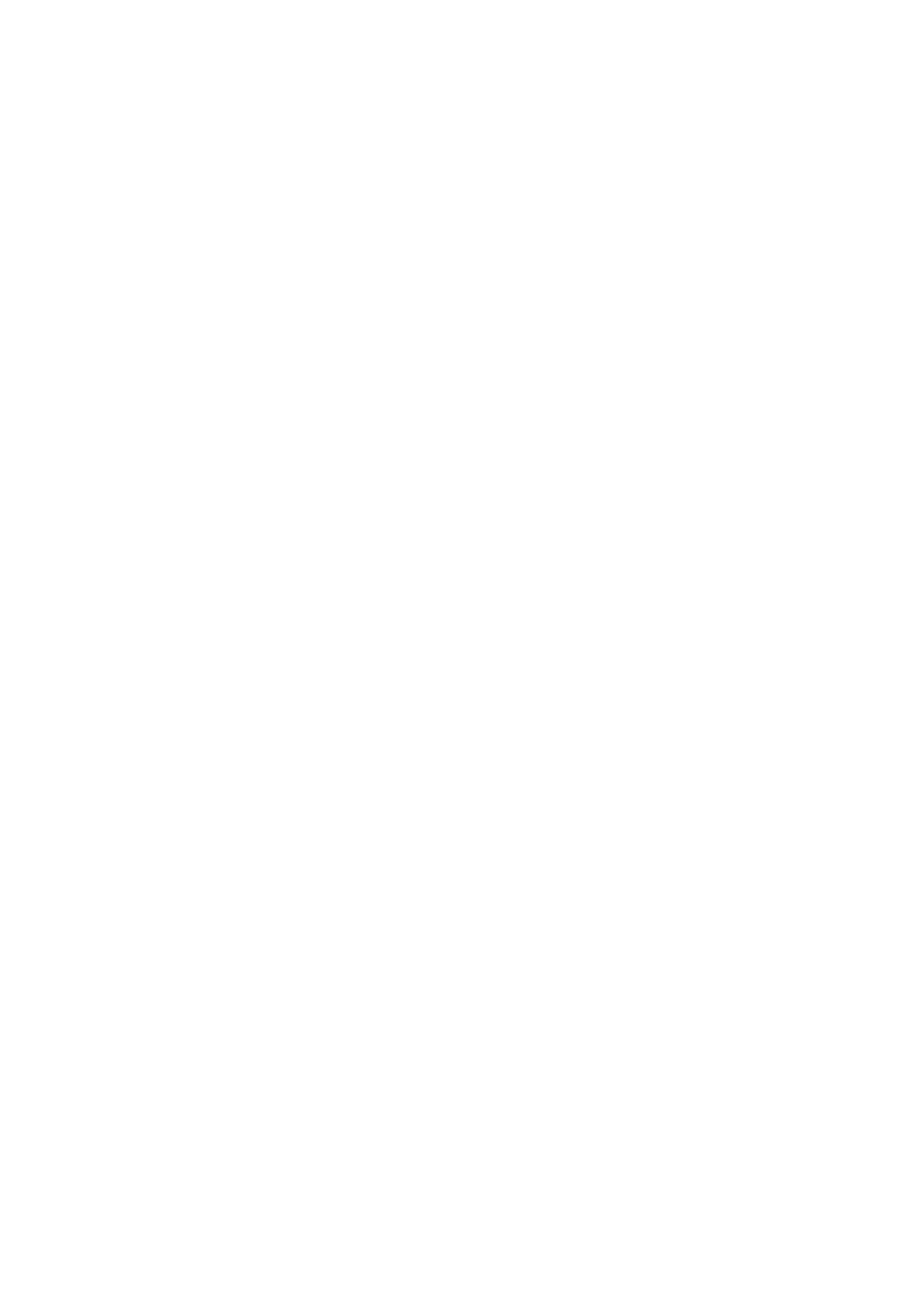




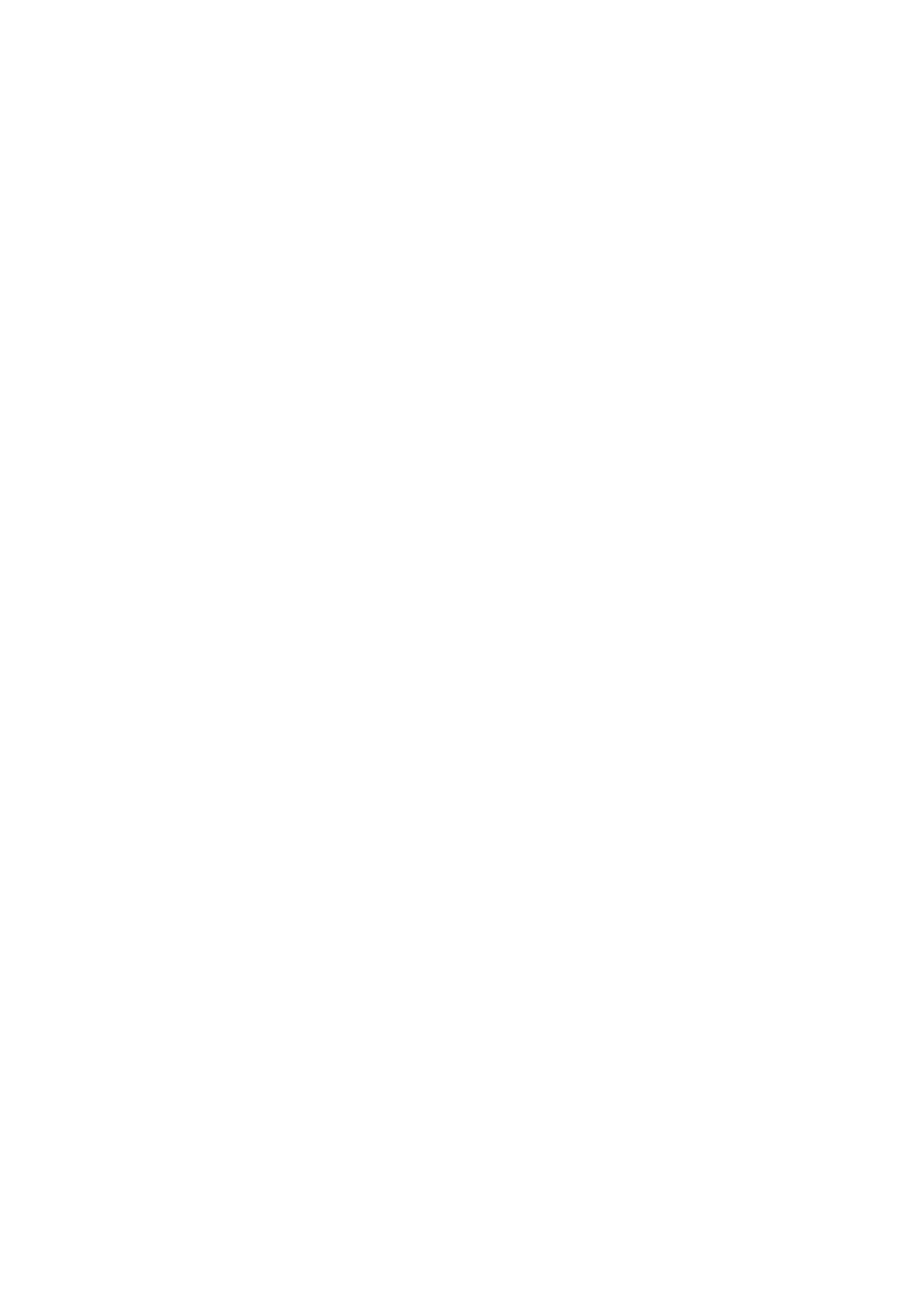




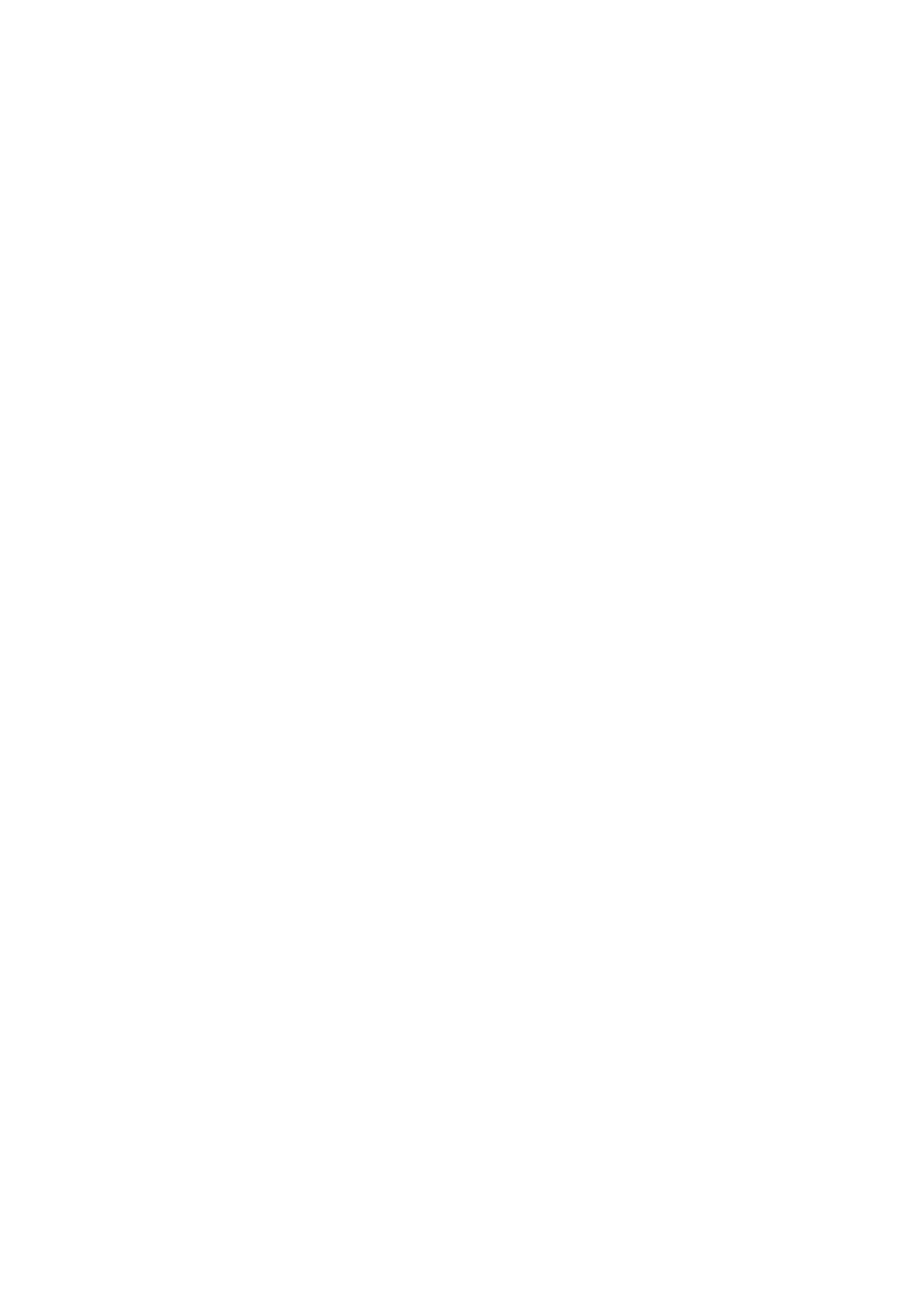




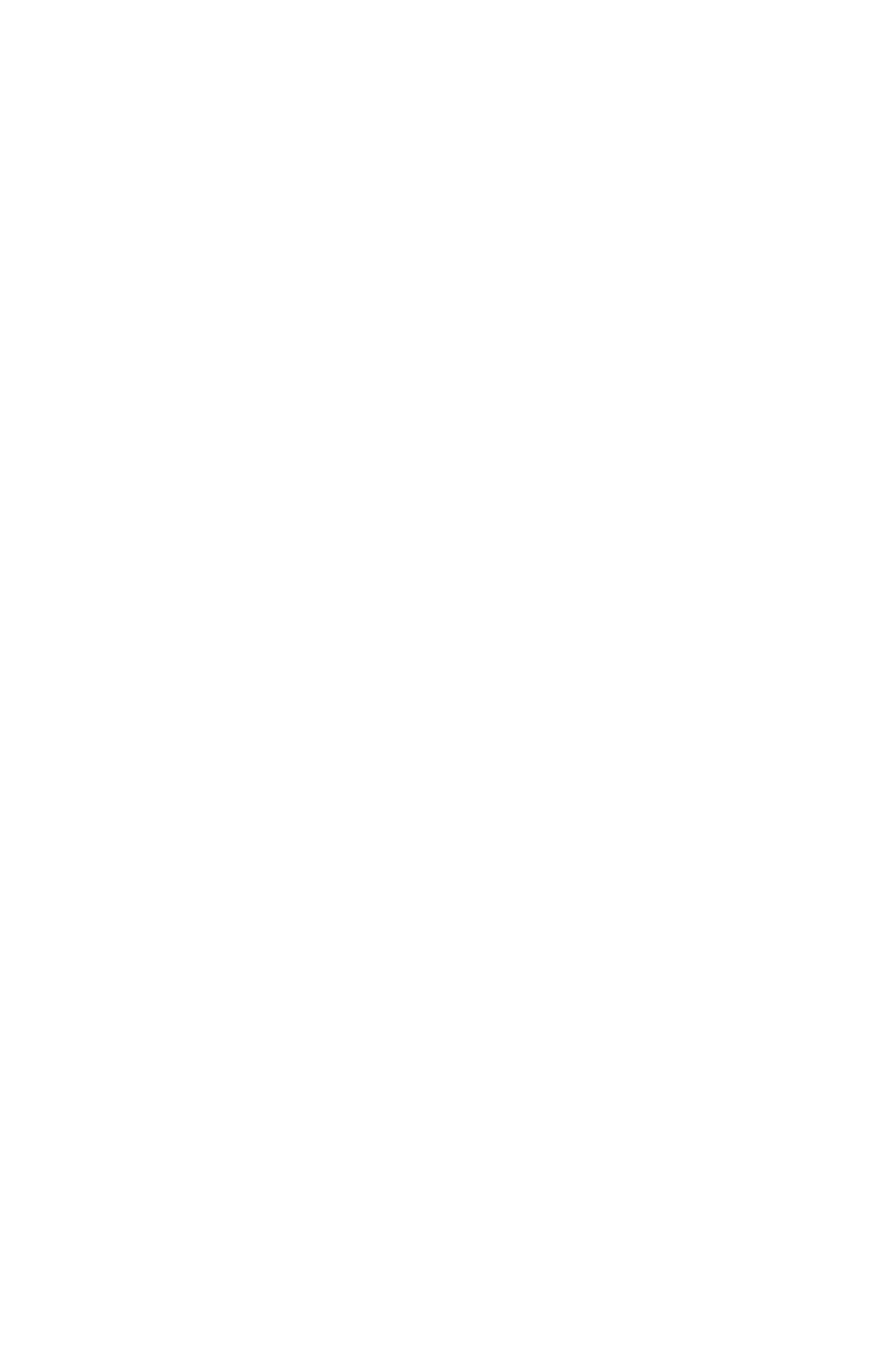




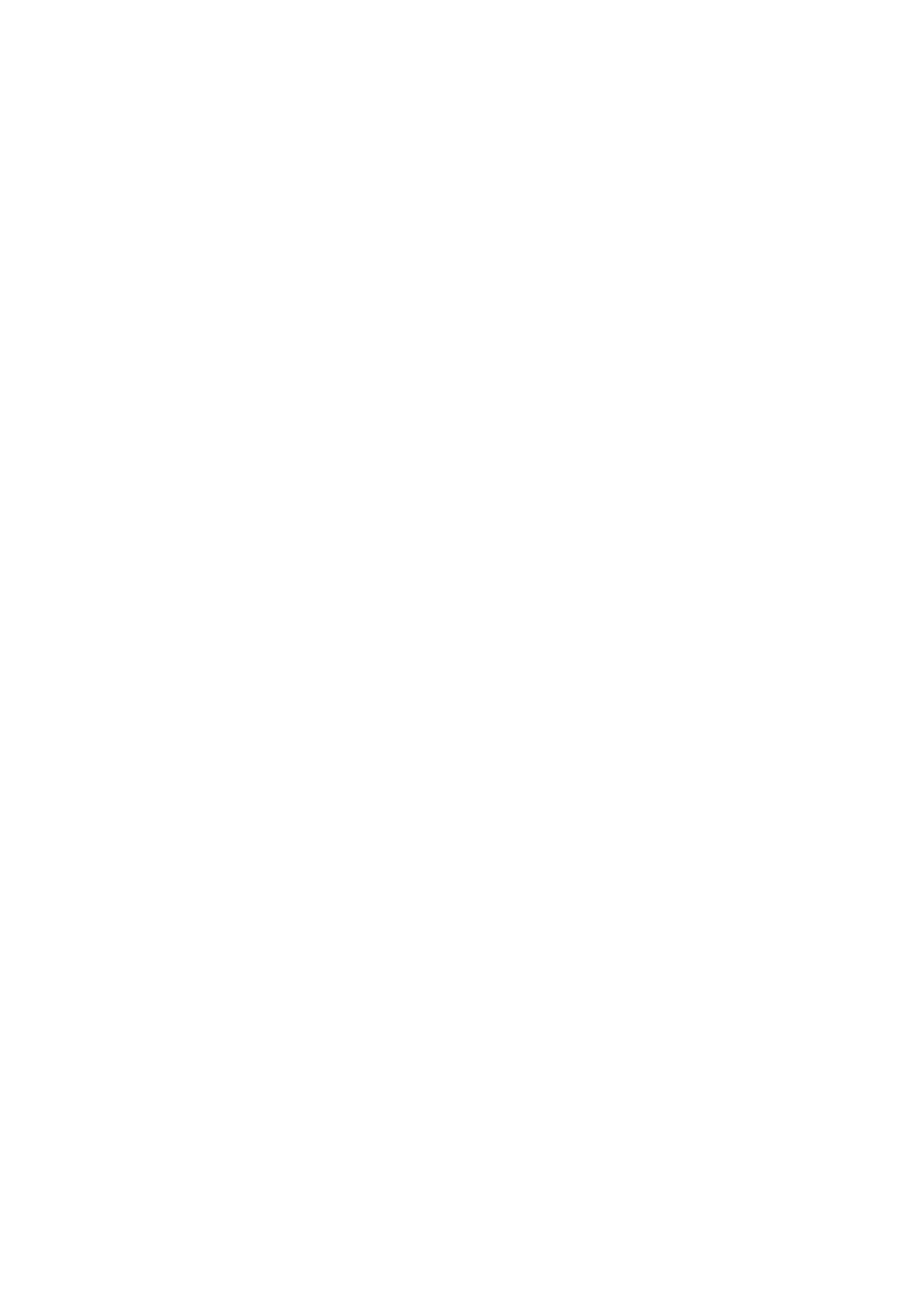




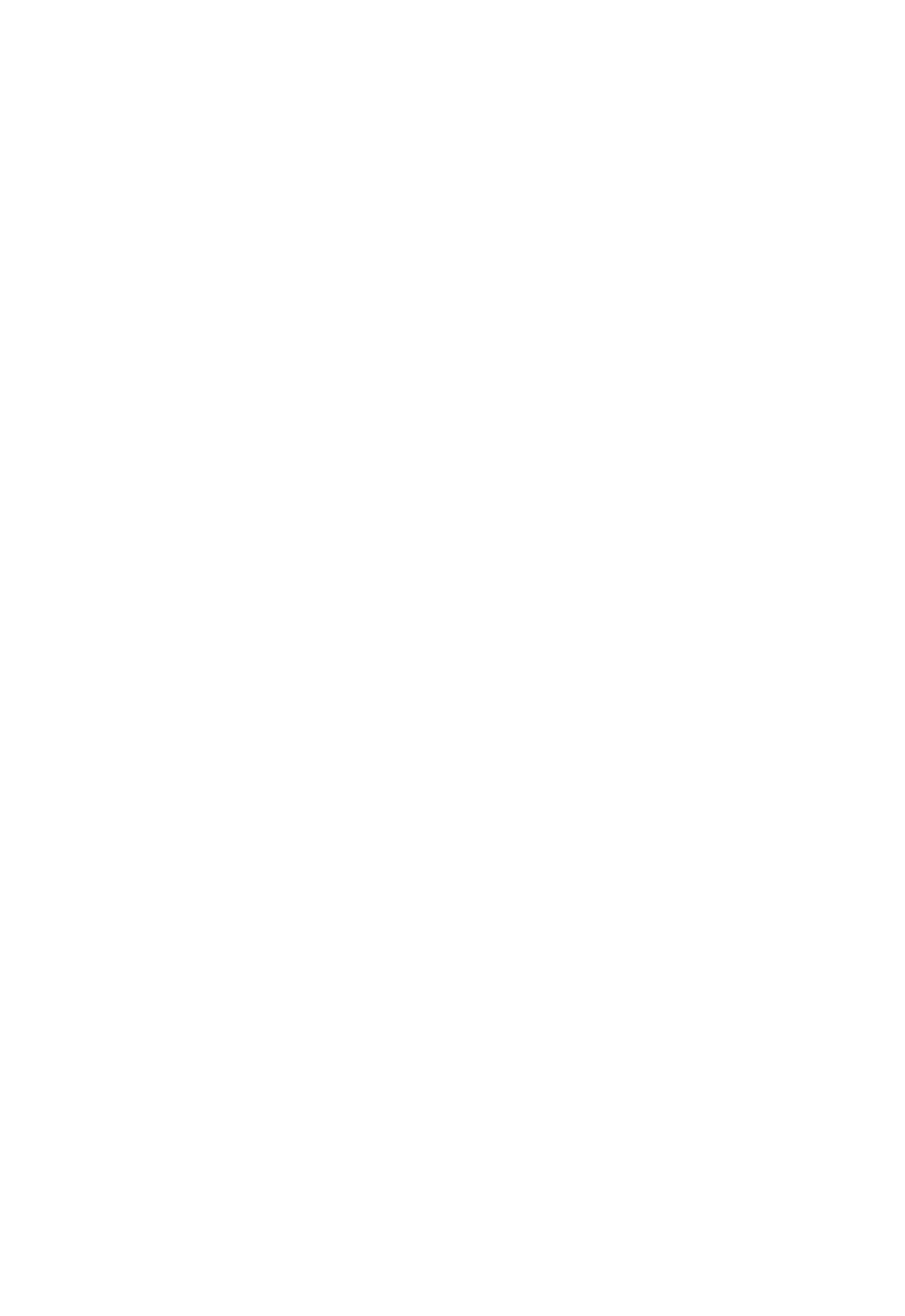




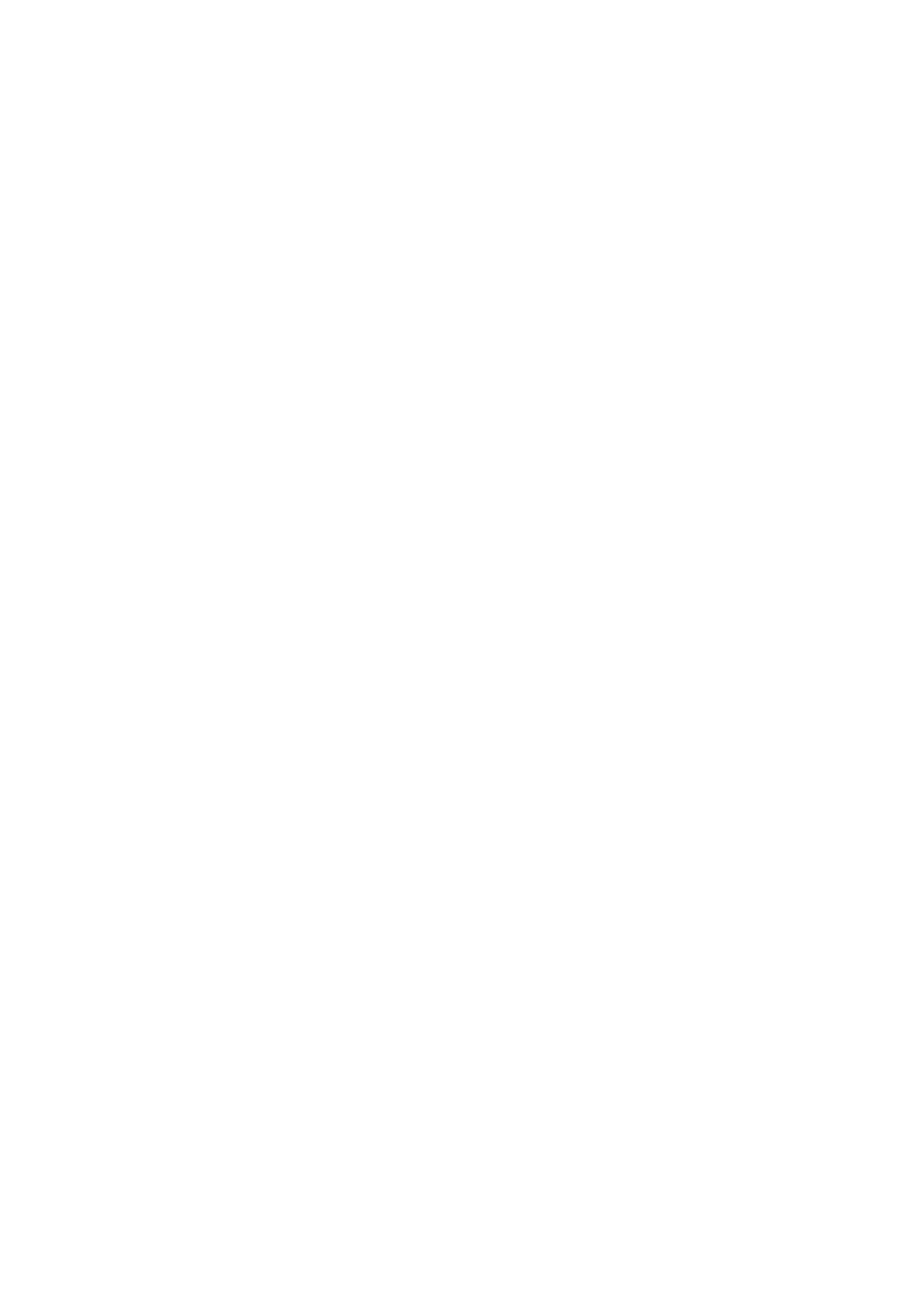




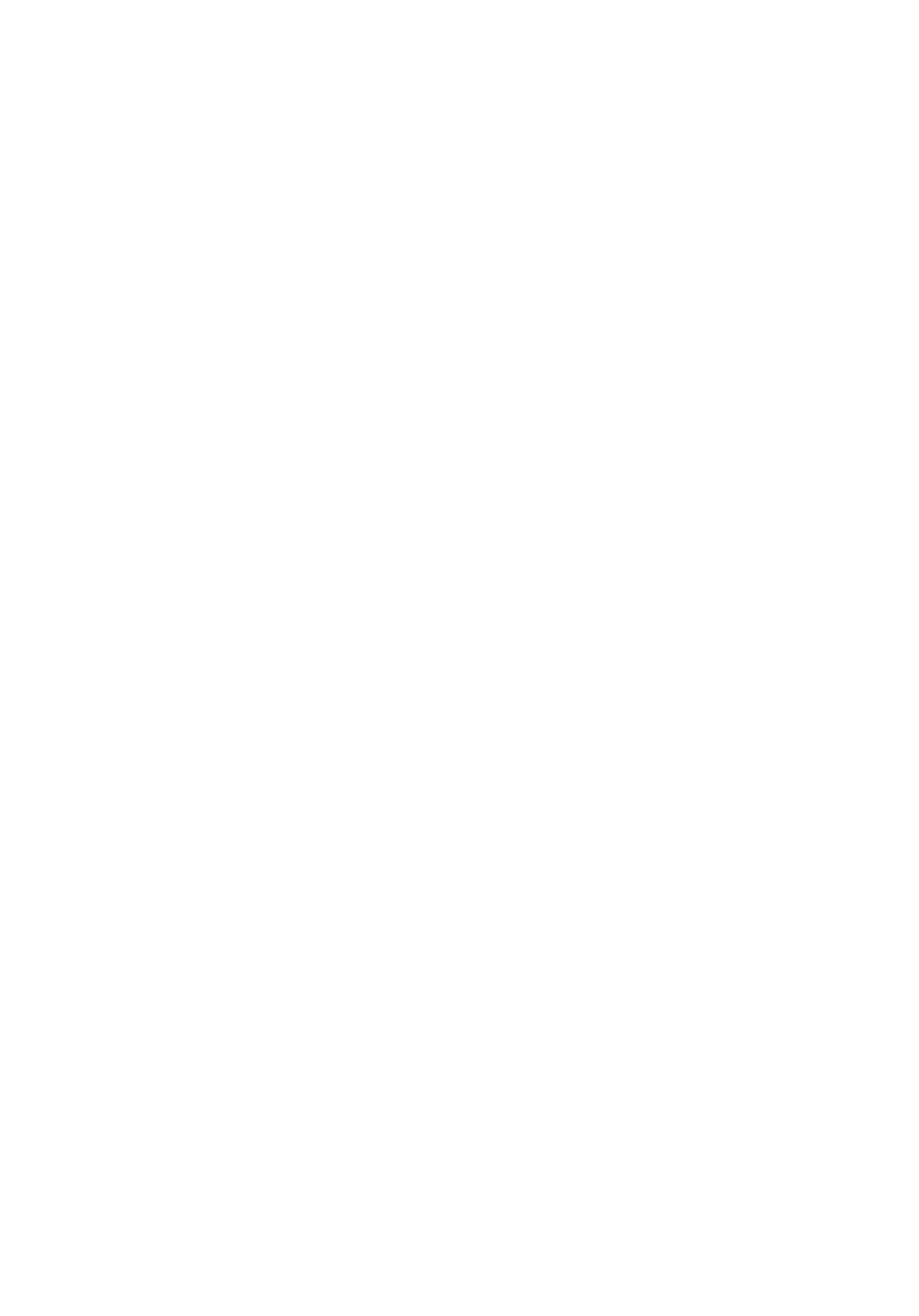




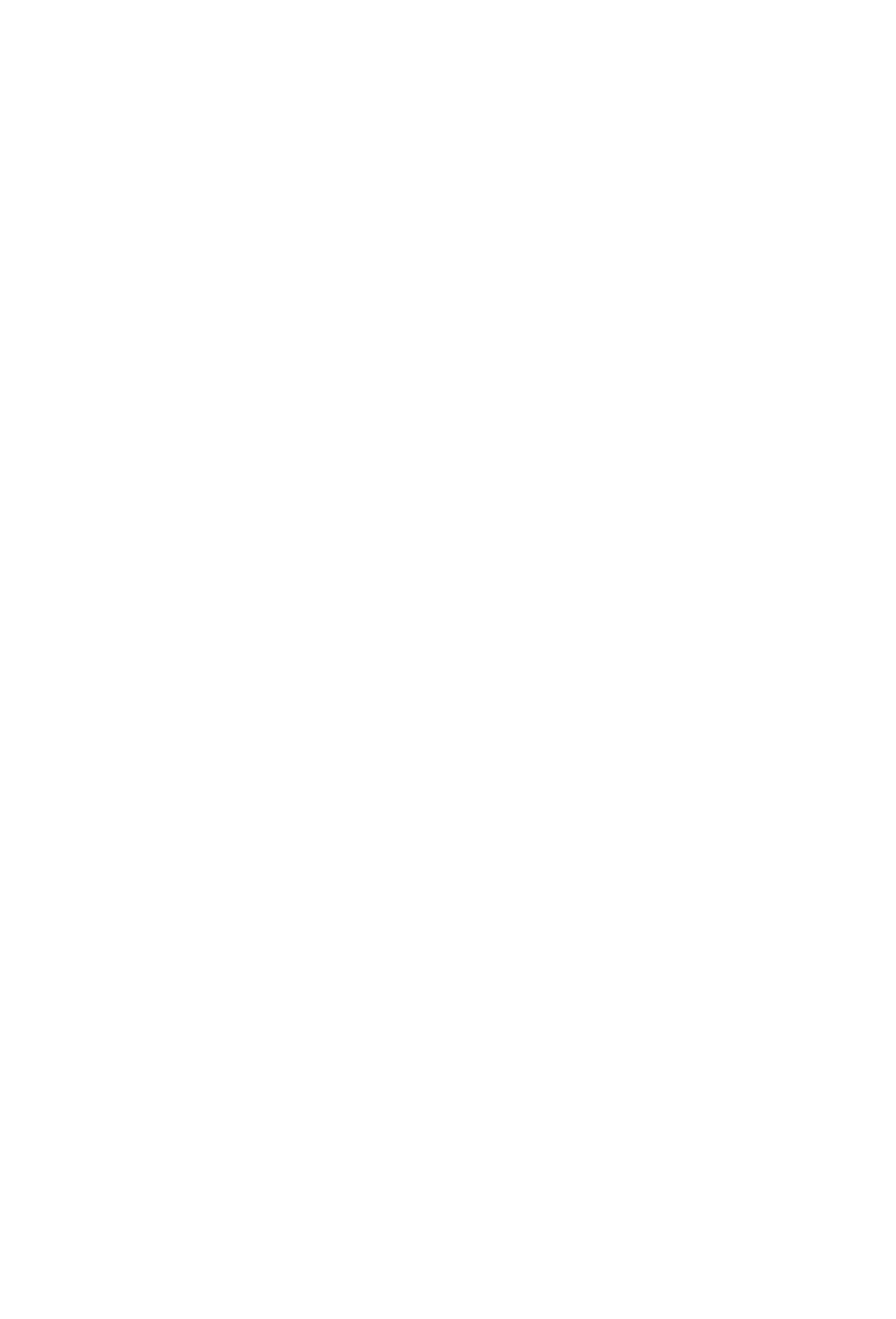




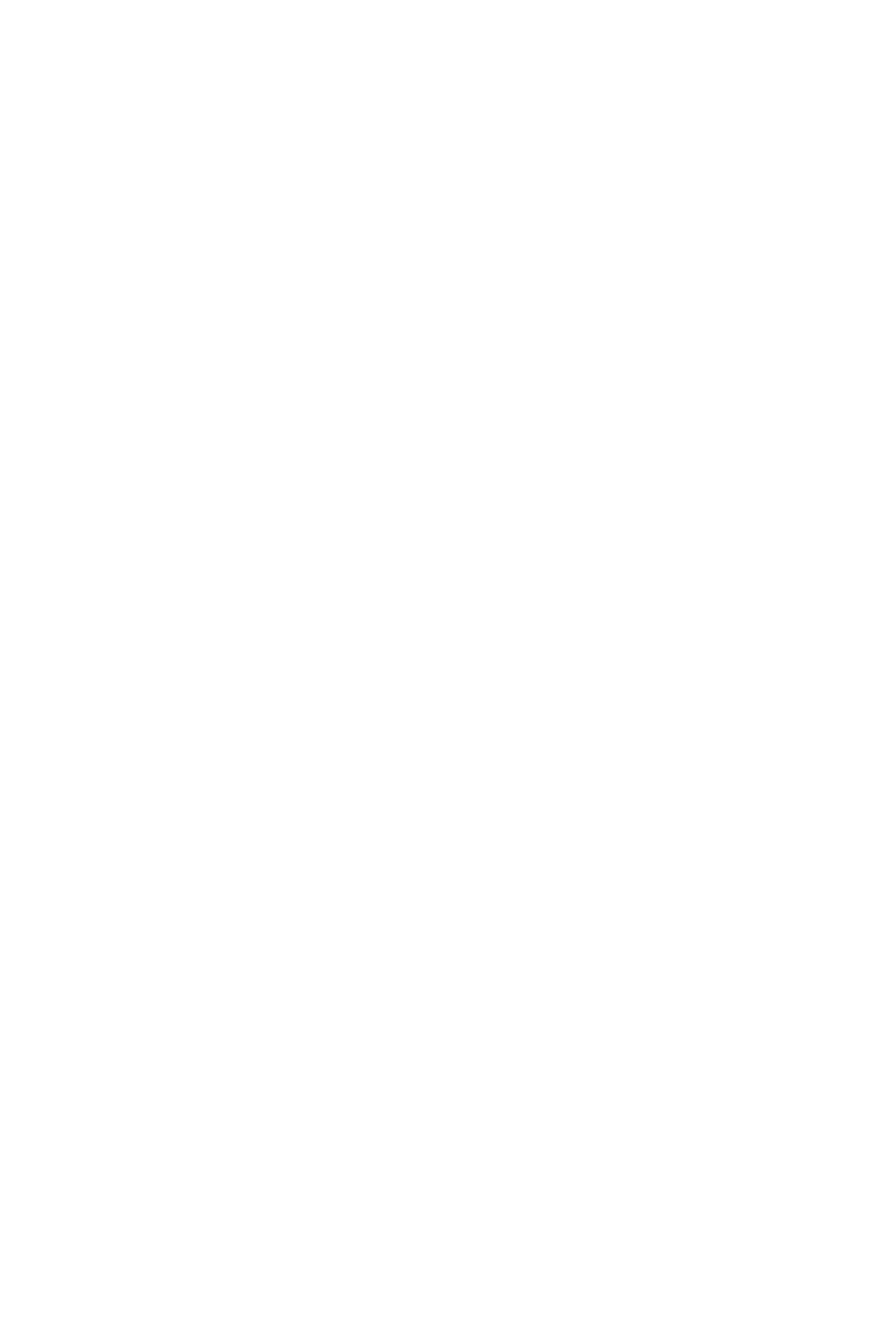




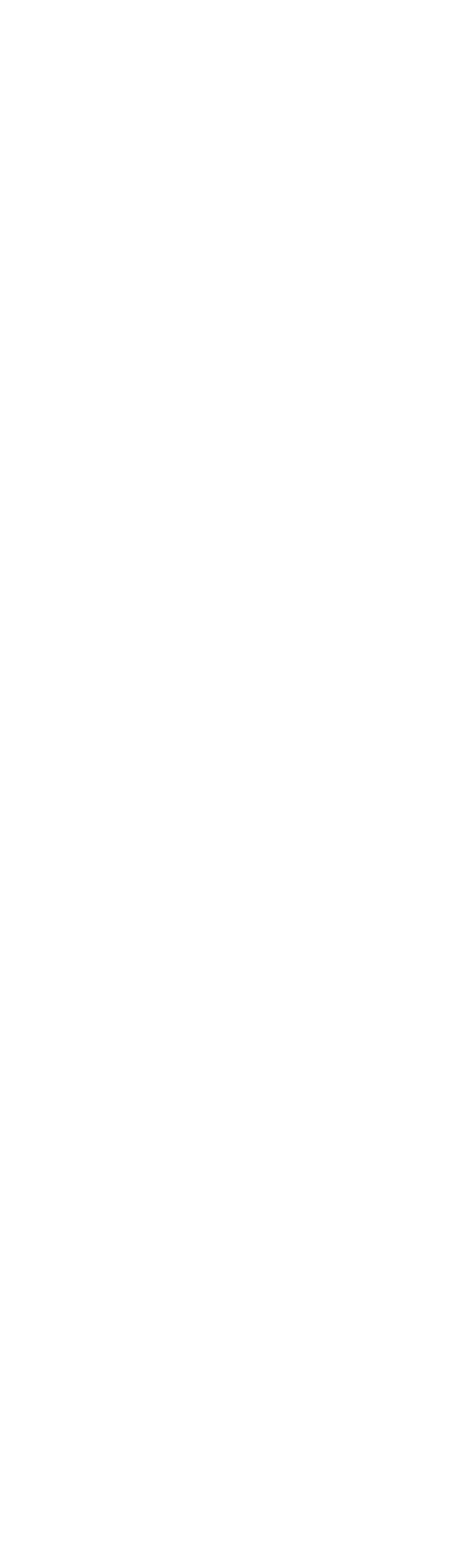




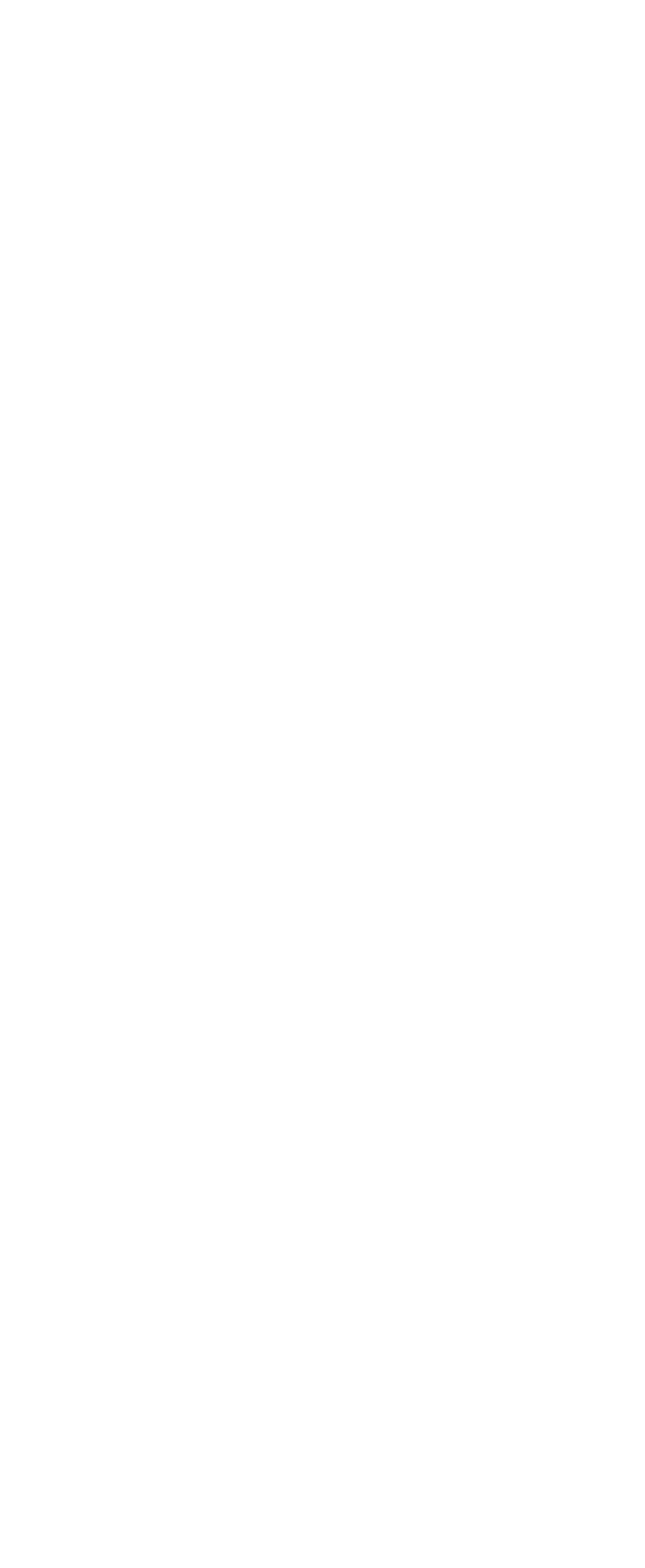




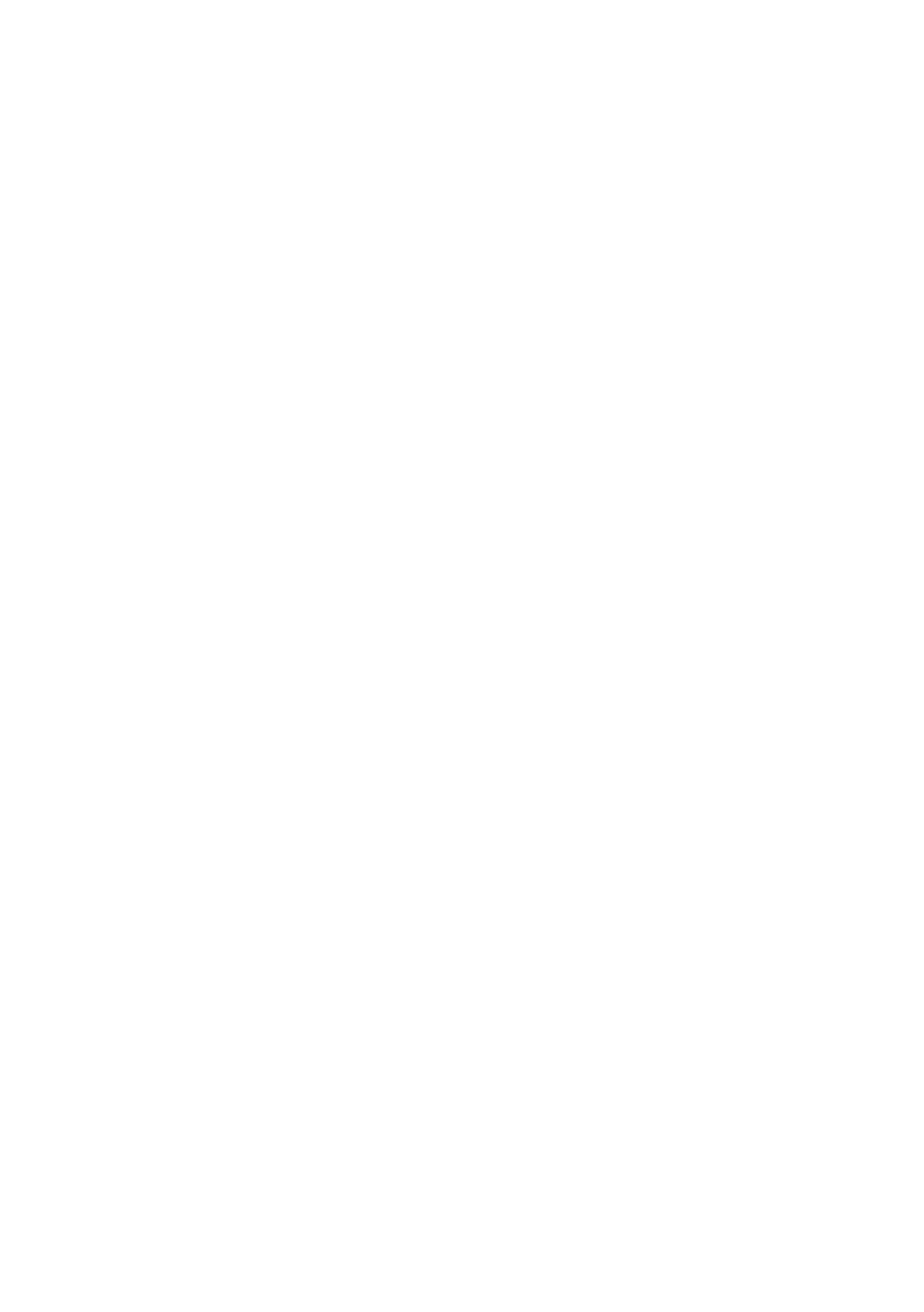




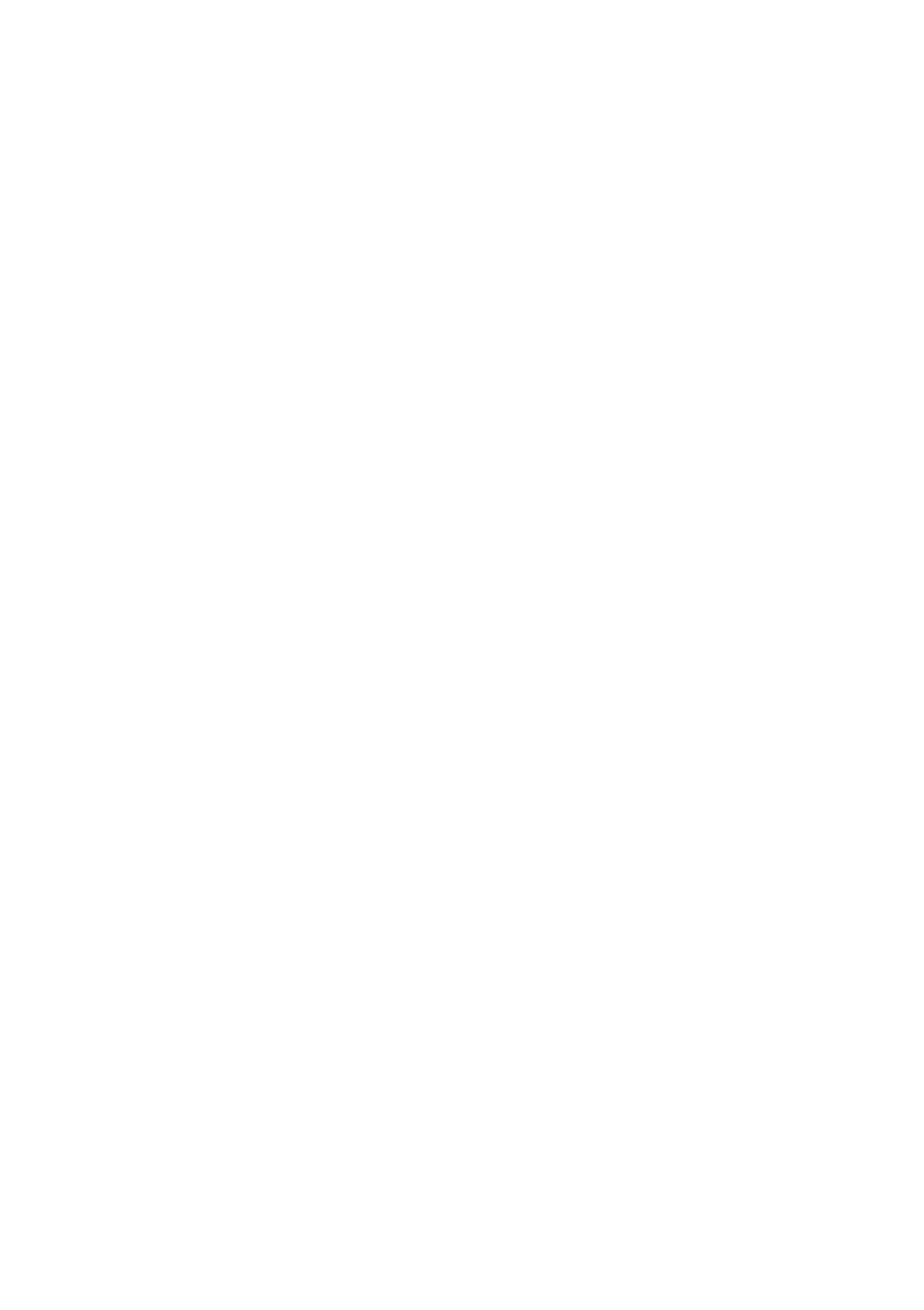




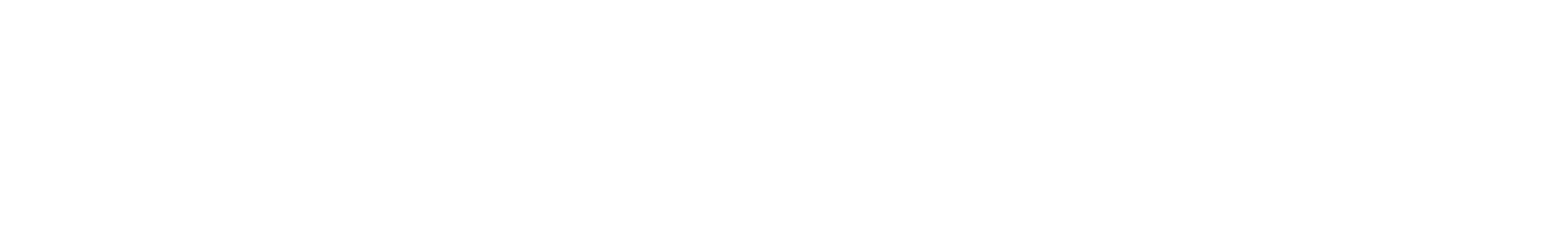

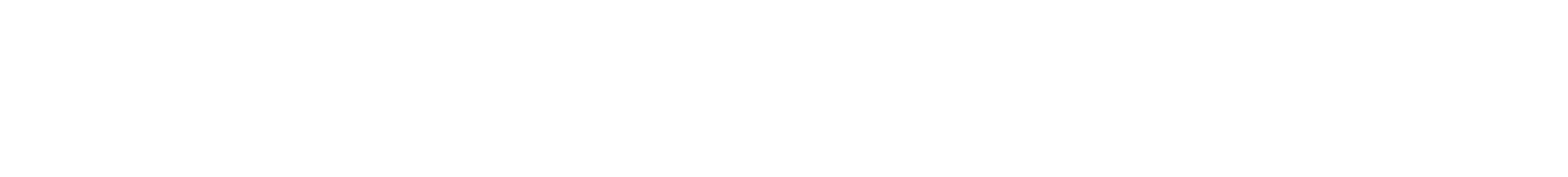

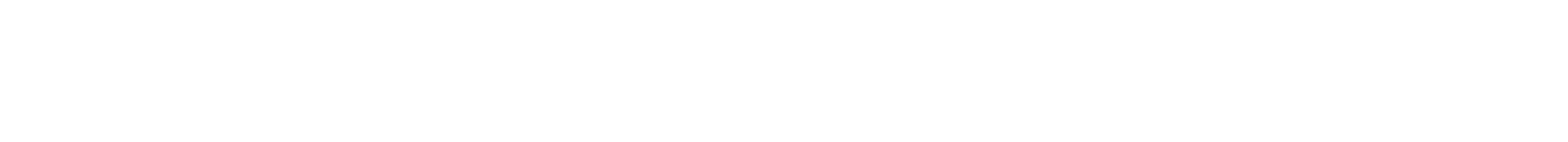

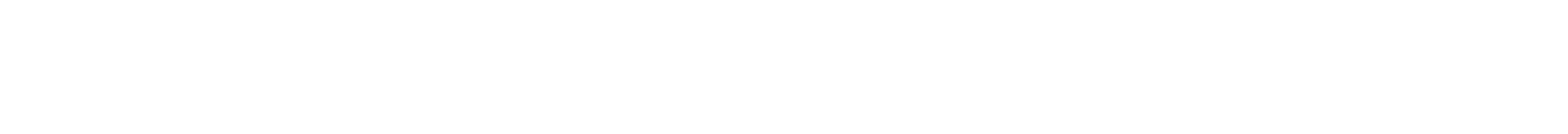

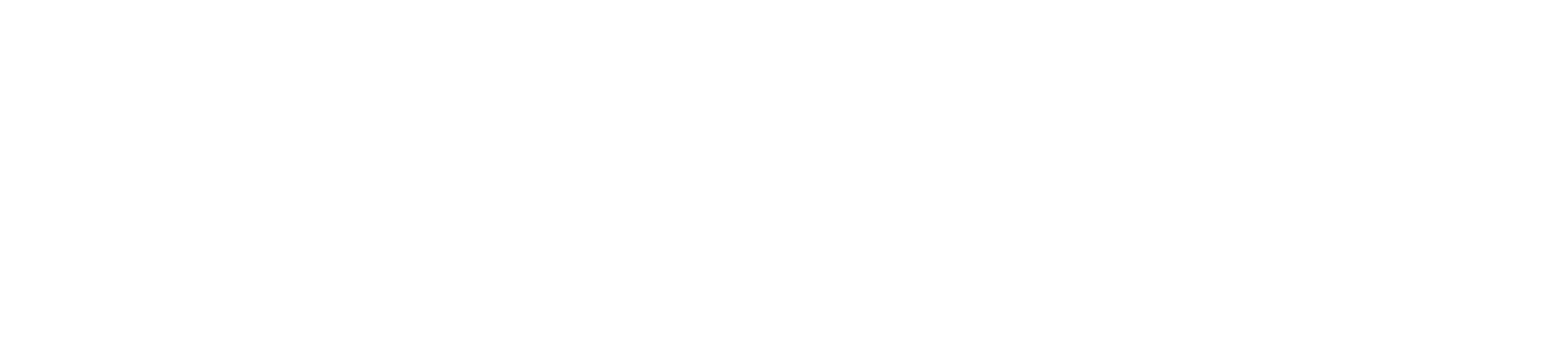

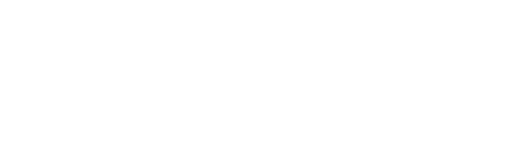

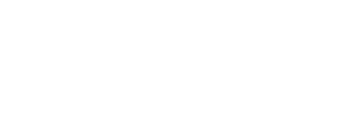

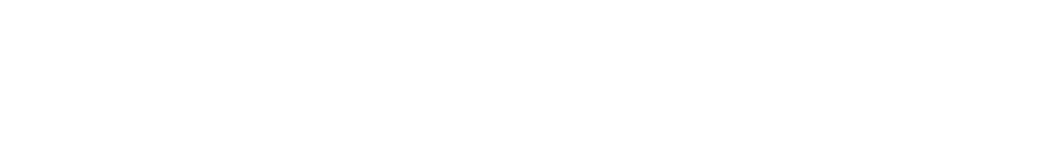

递

悹

落

.

(1)

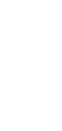

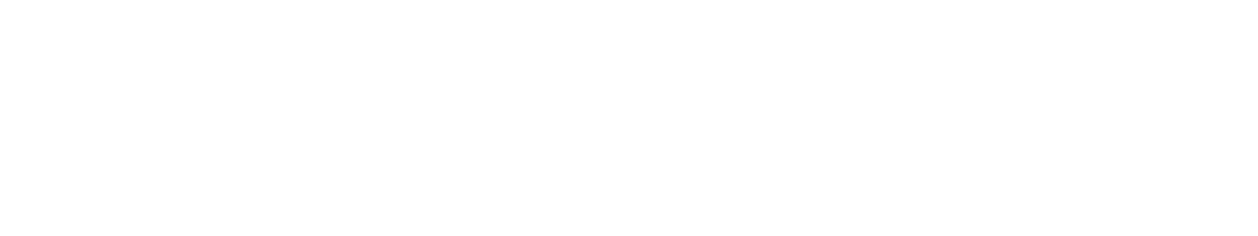

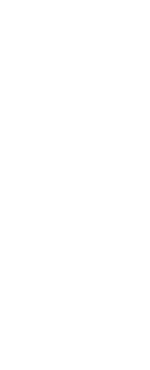

(1)

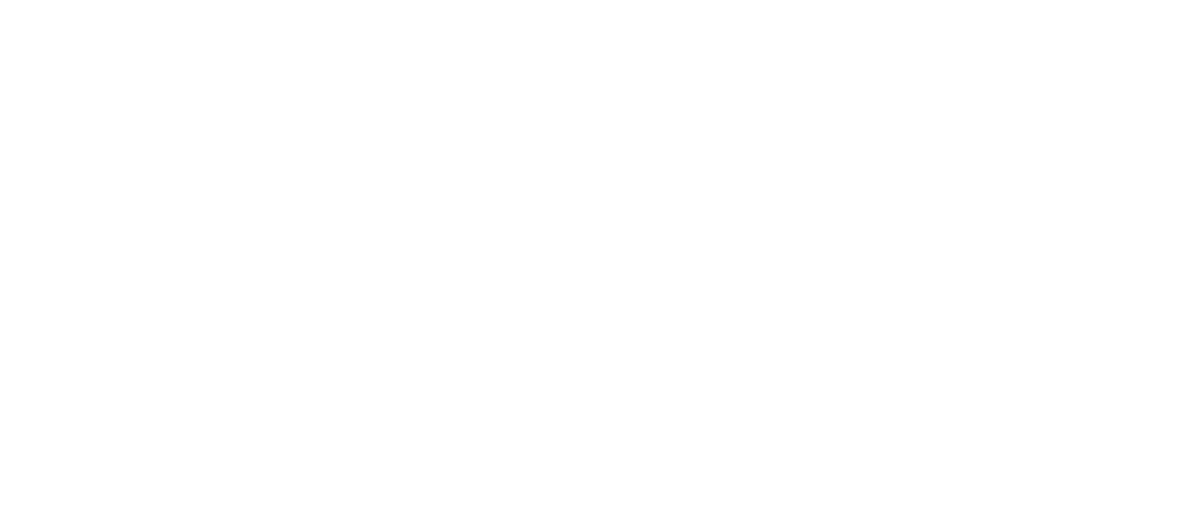

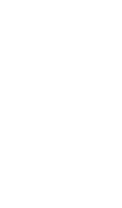

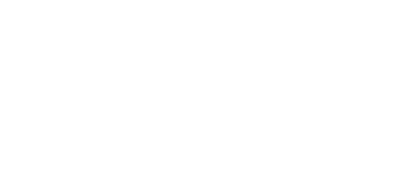

$n$
0
0

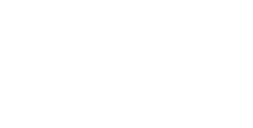

粦藏

产要

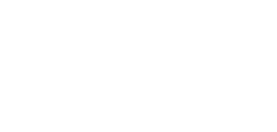

当点当吉

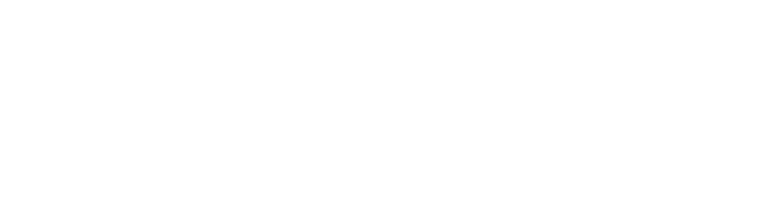

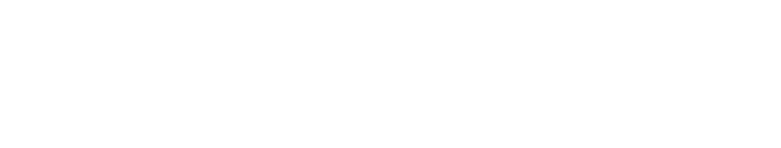

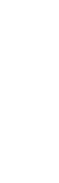




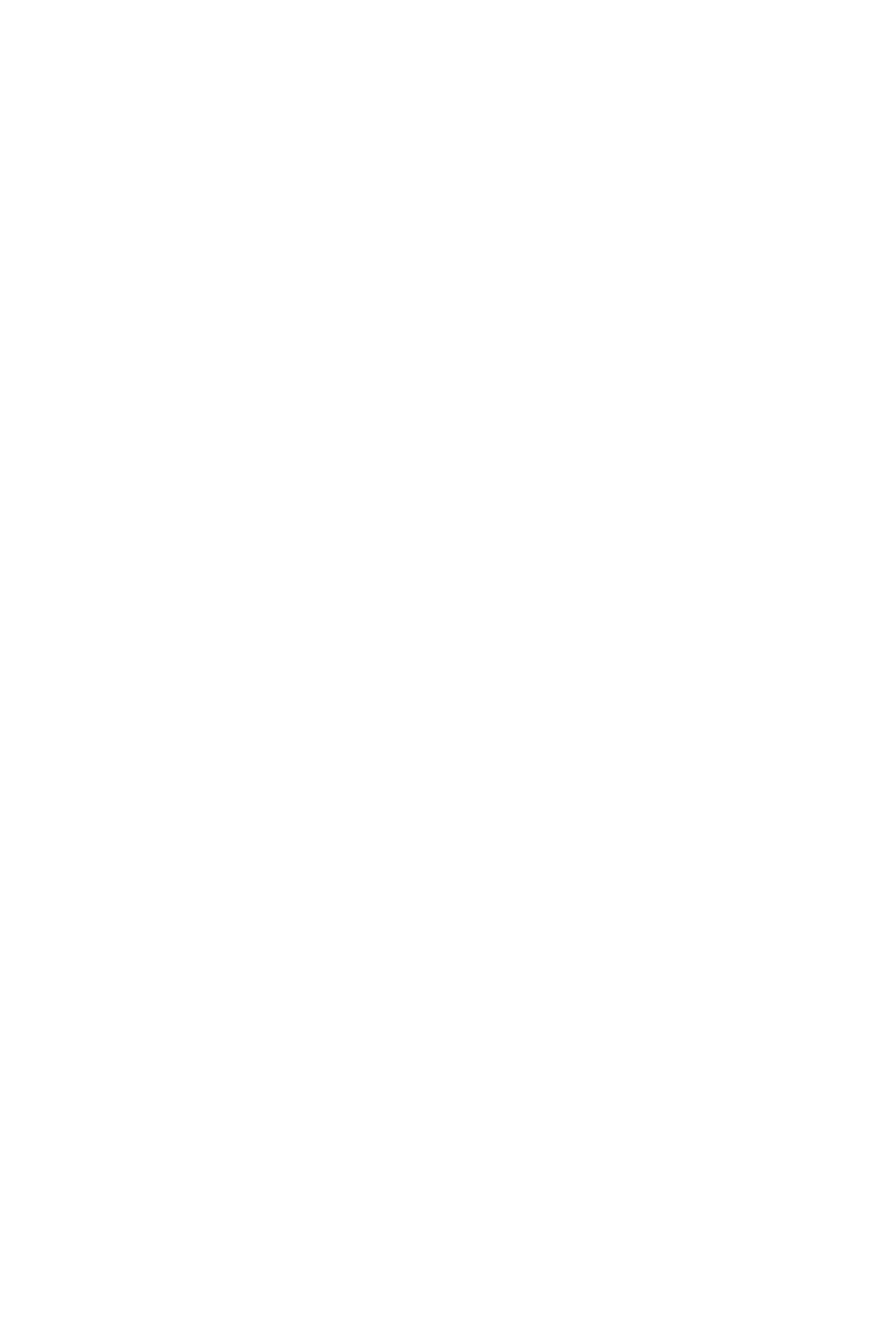




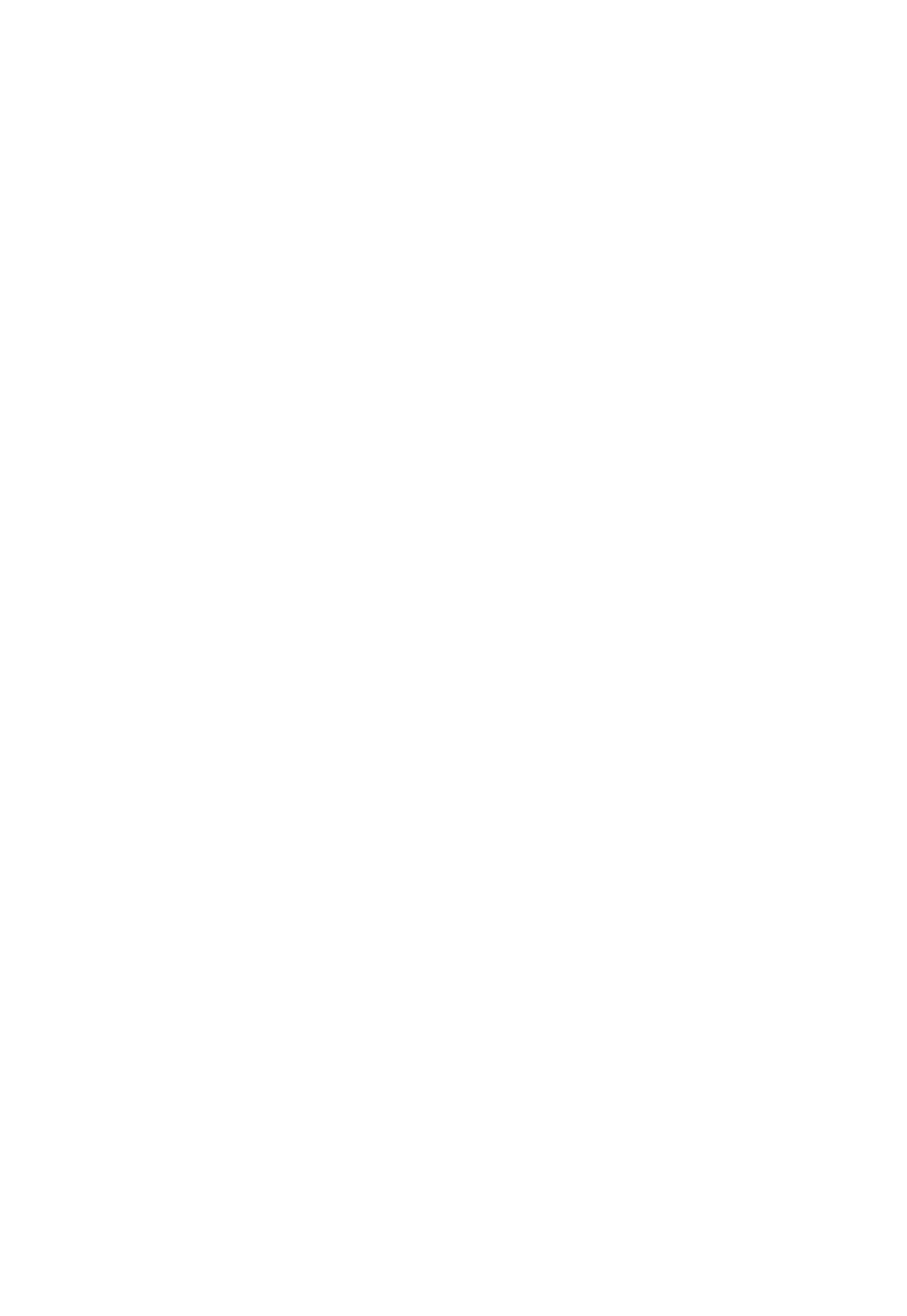




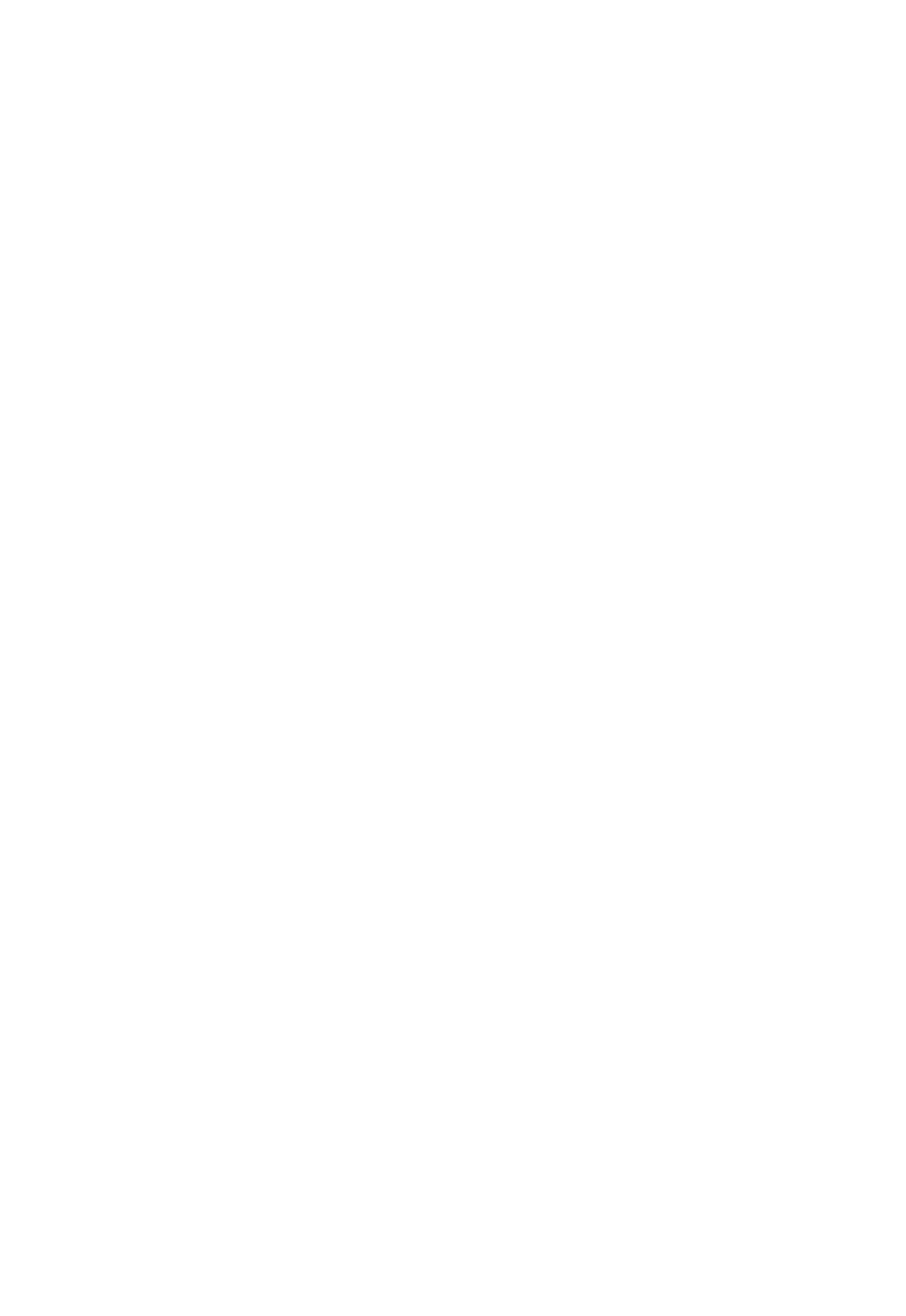




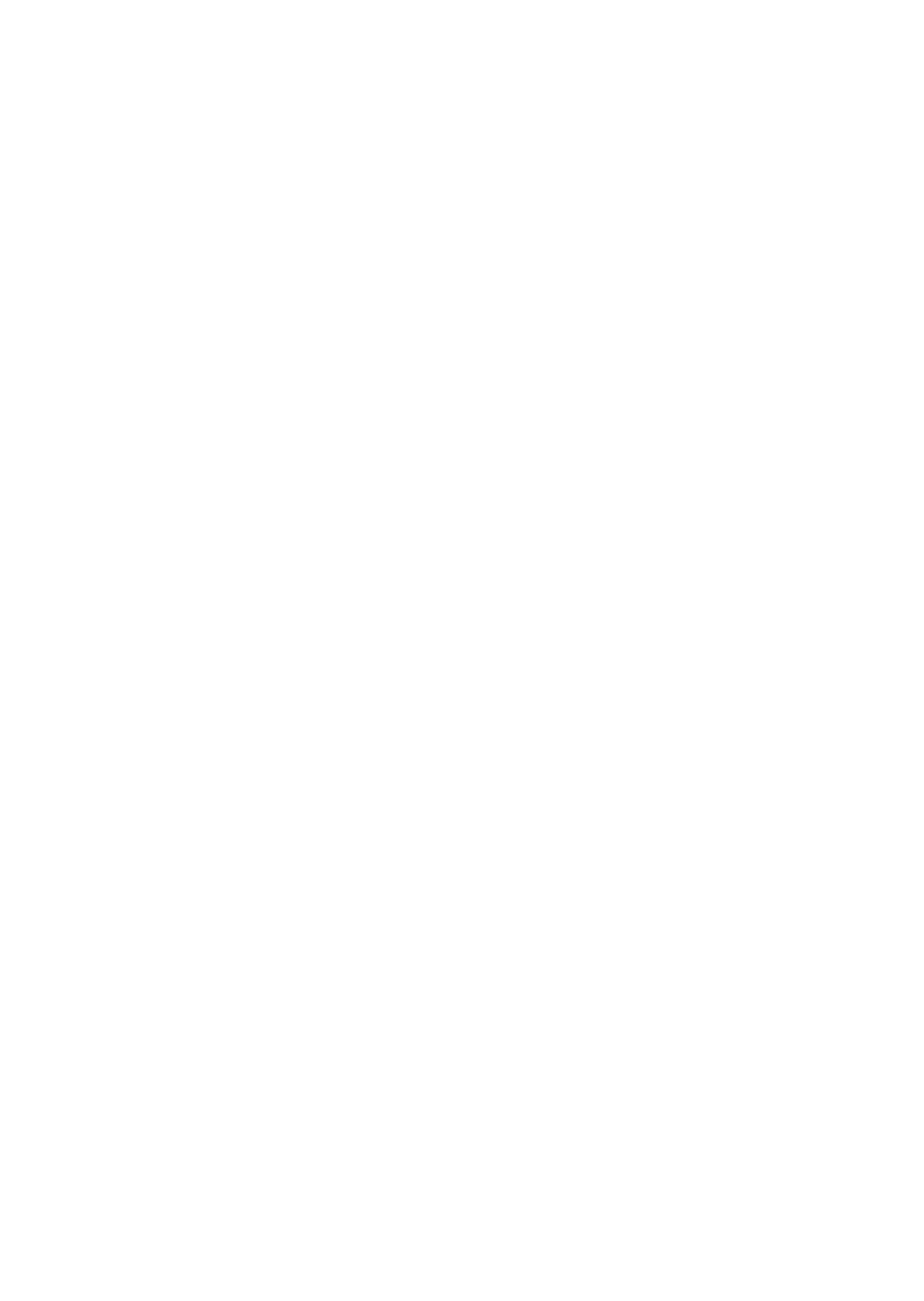




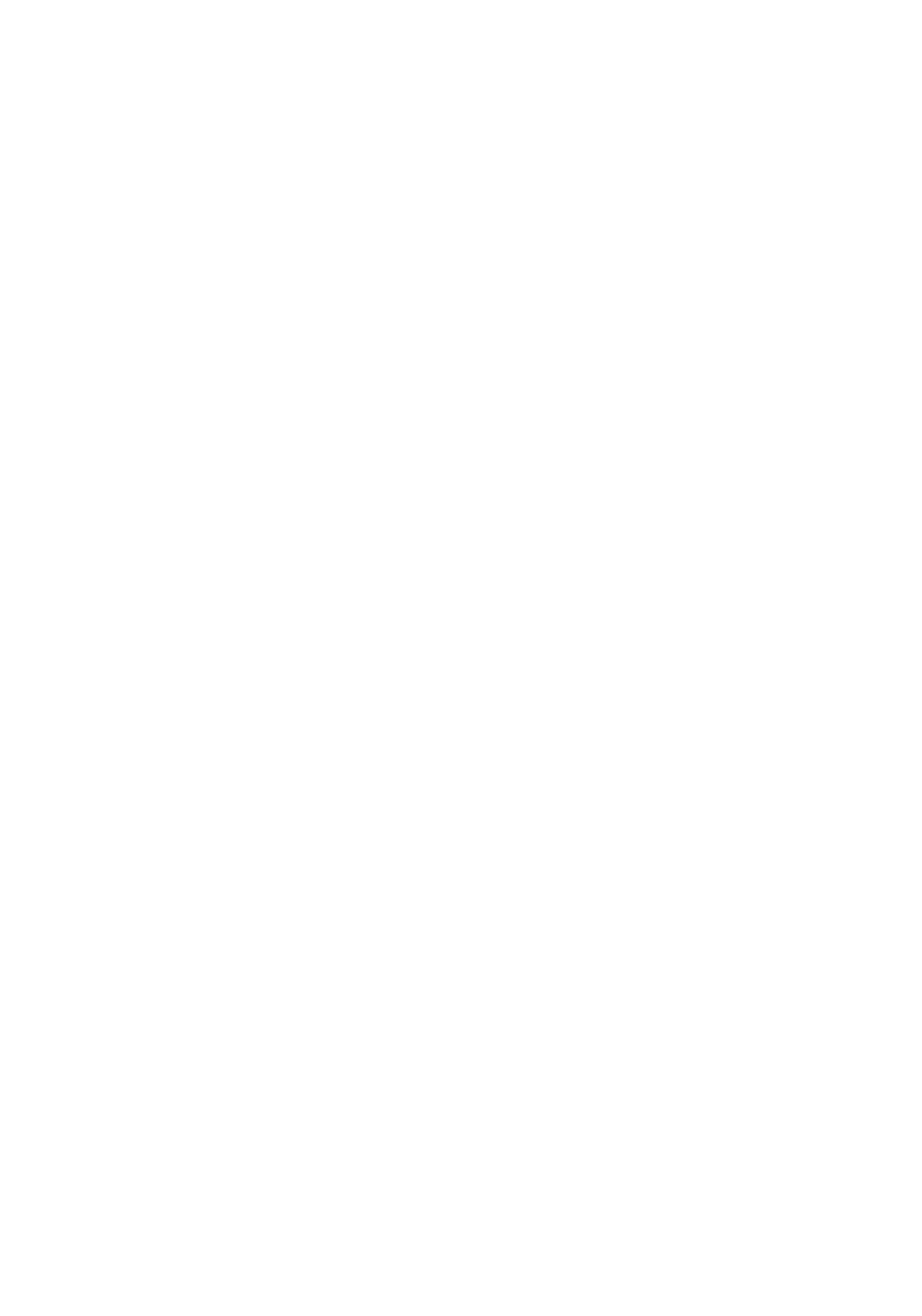




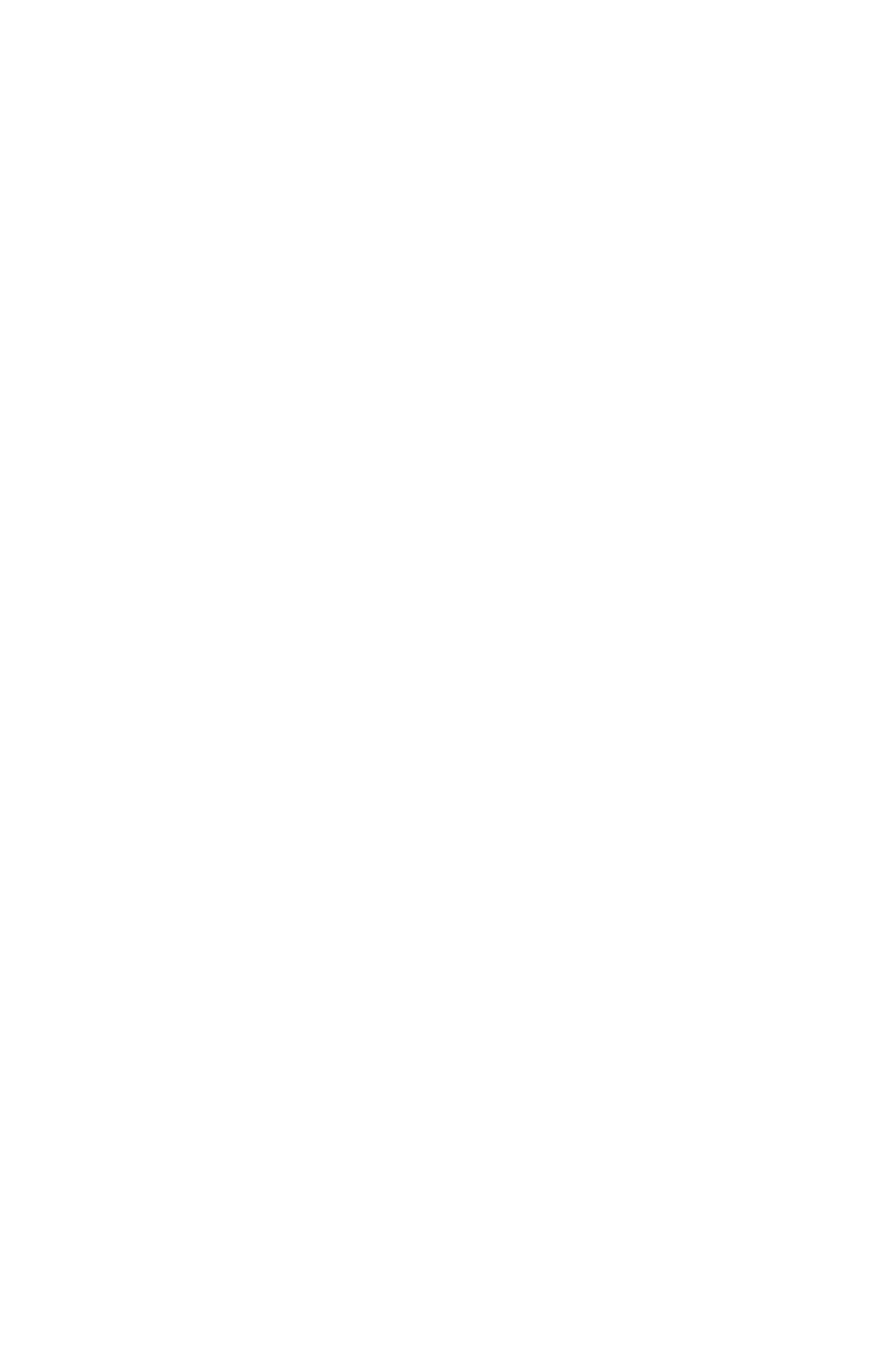




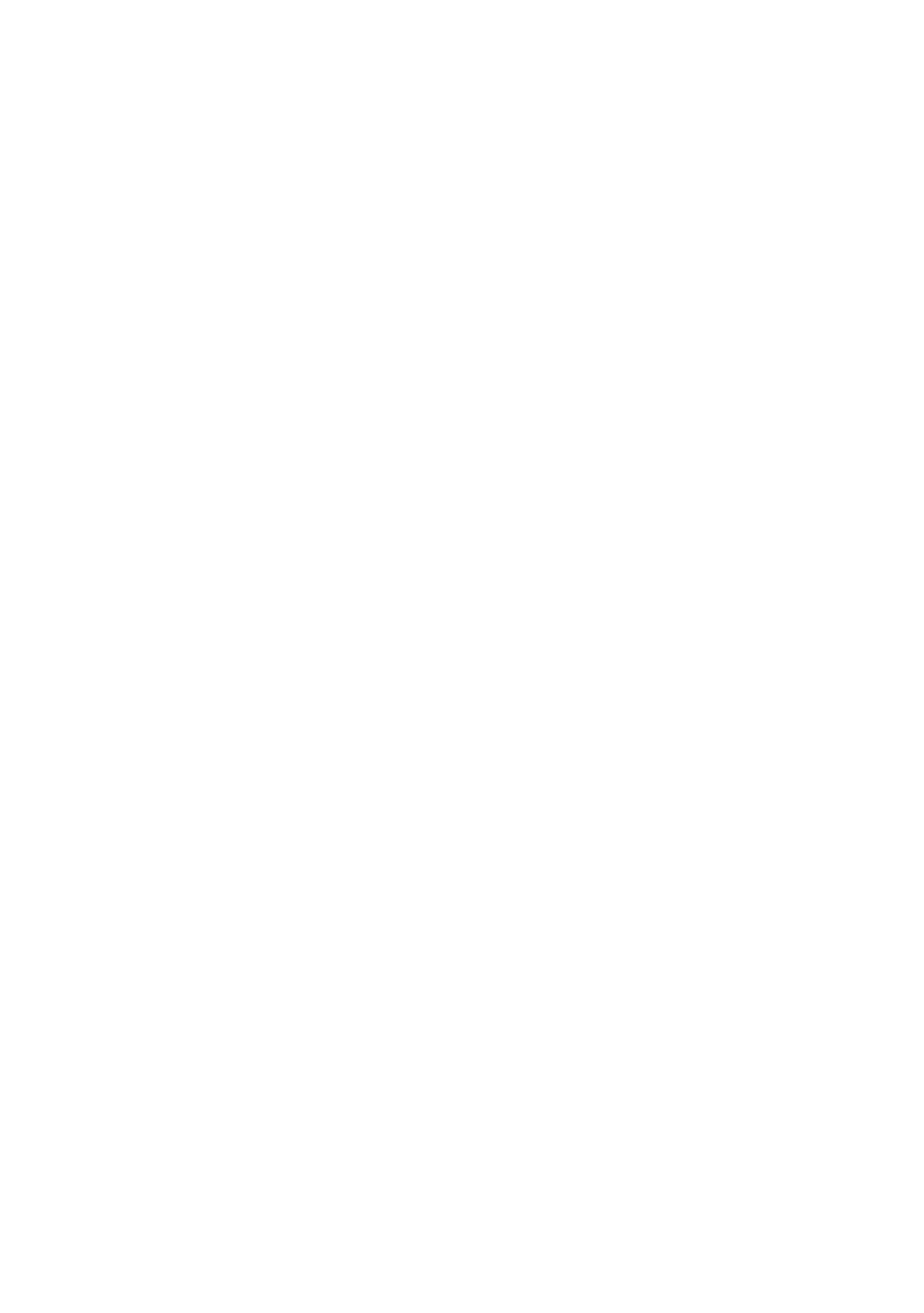




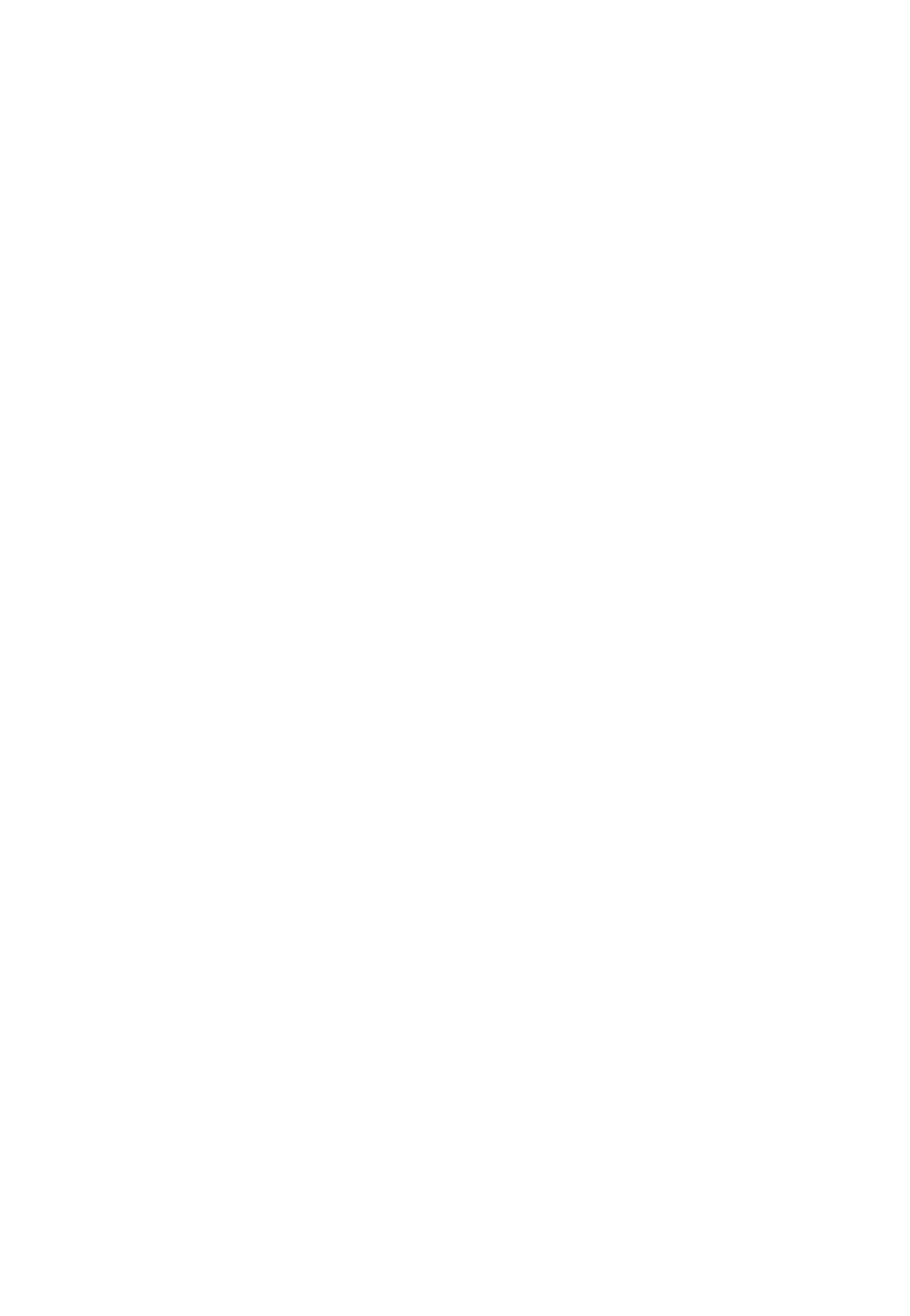




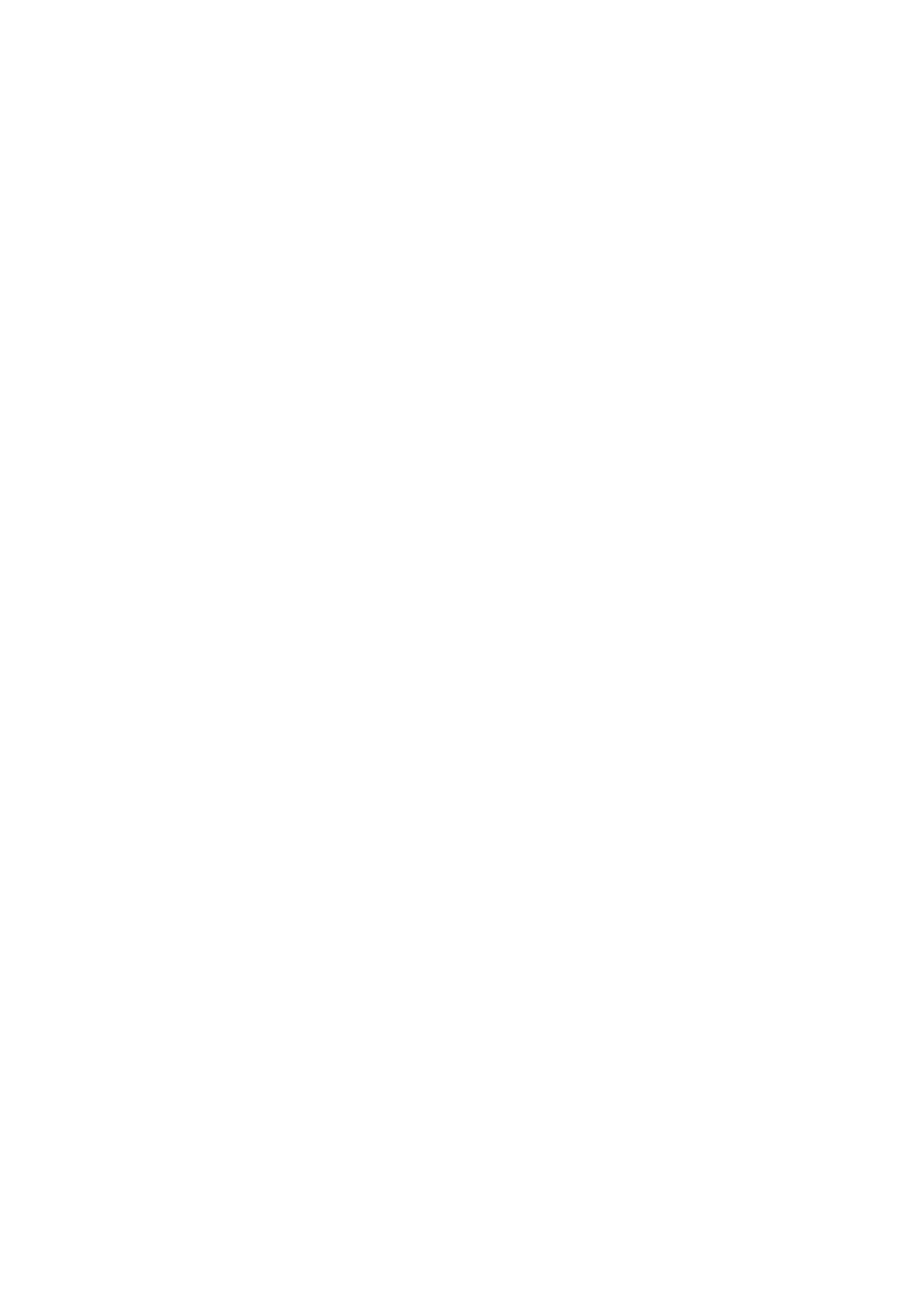




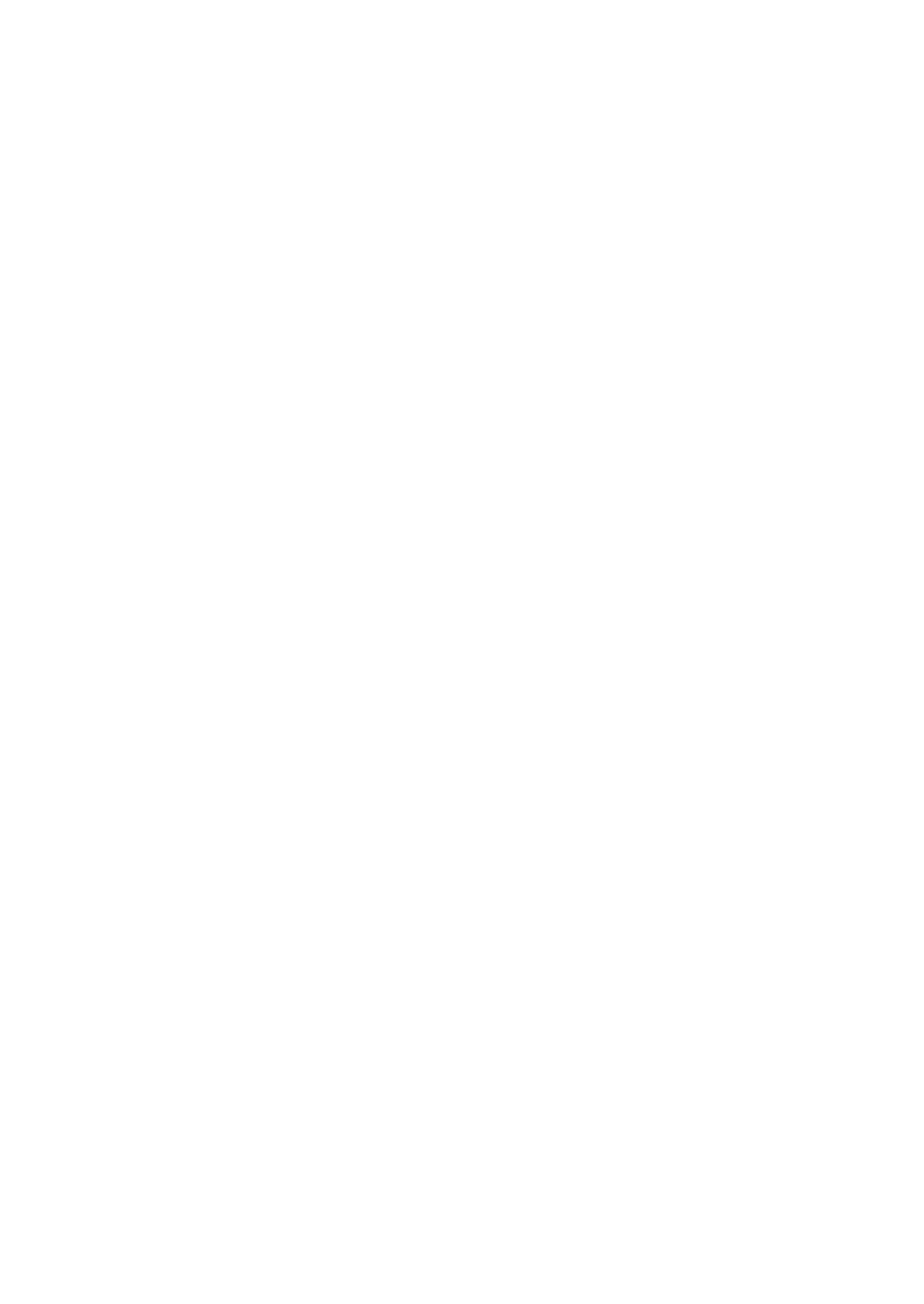




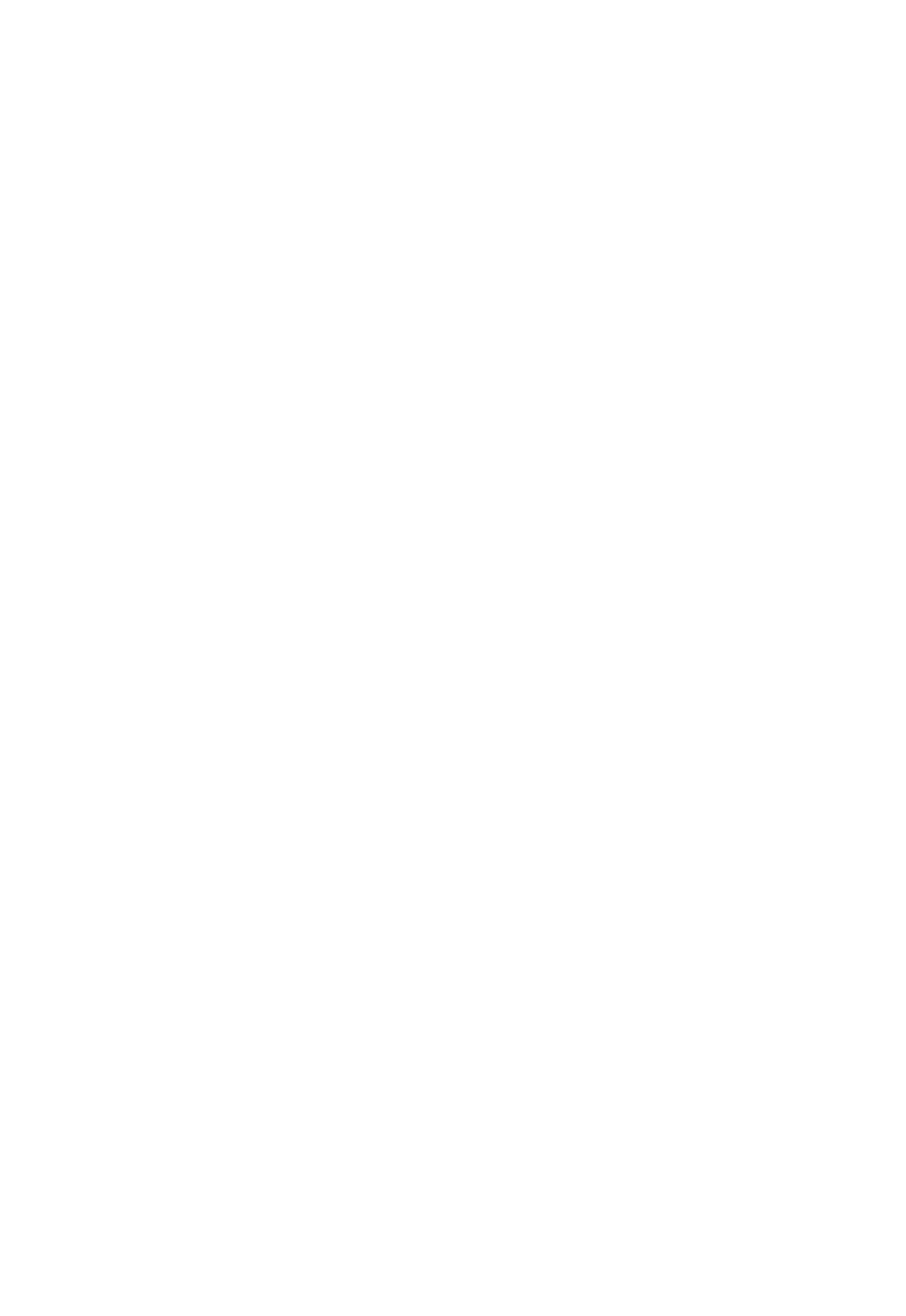




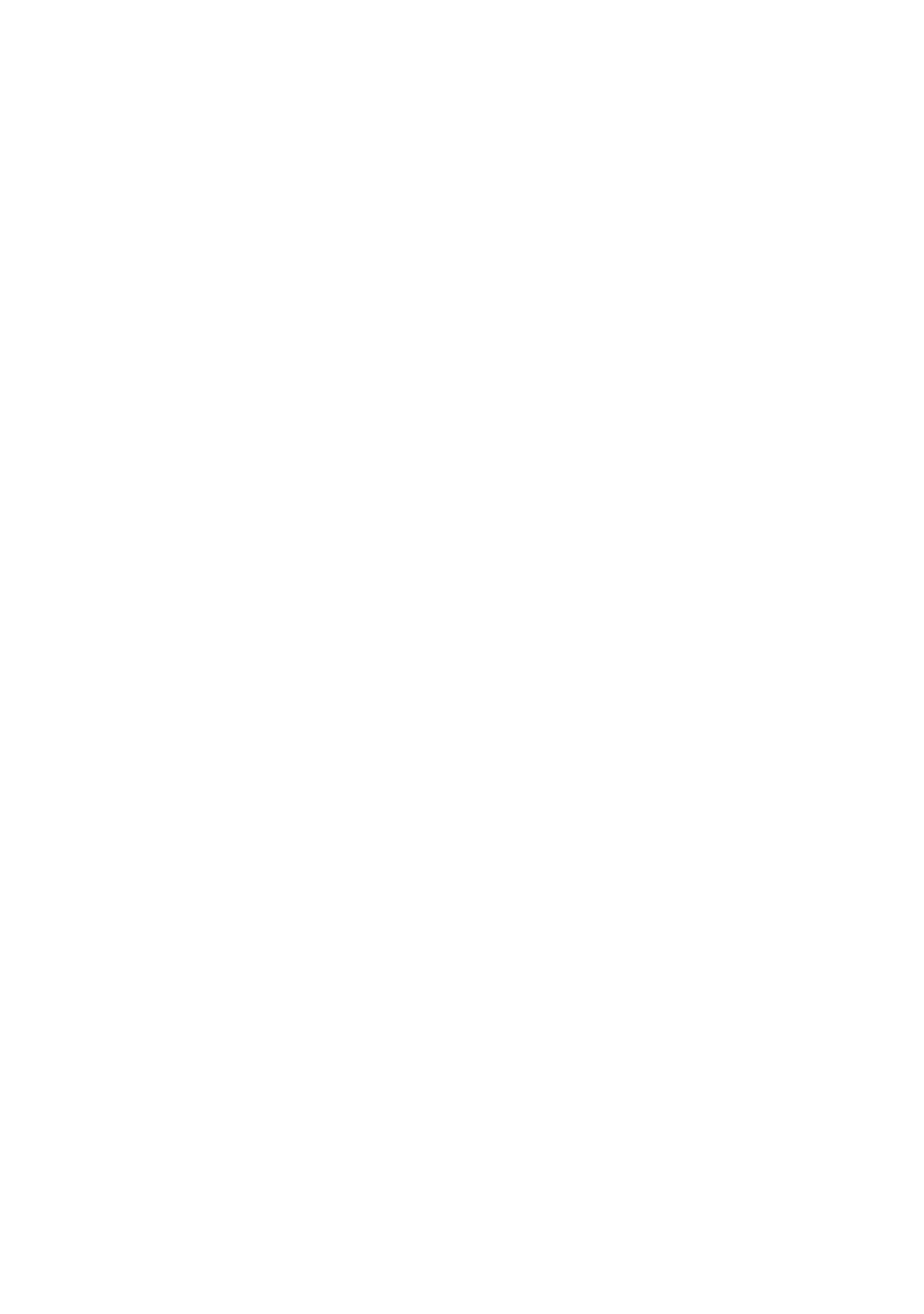




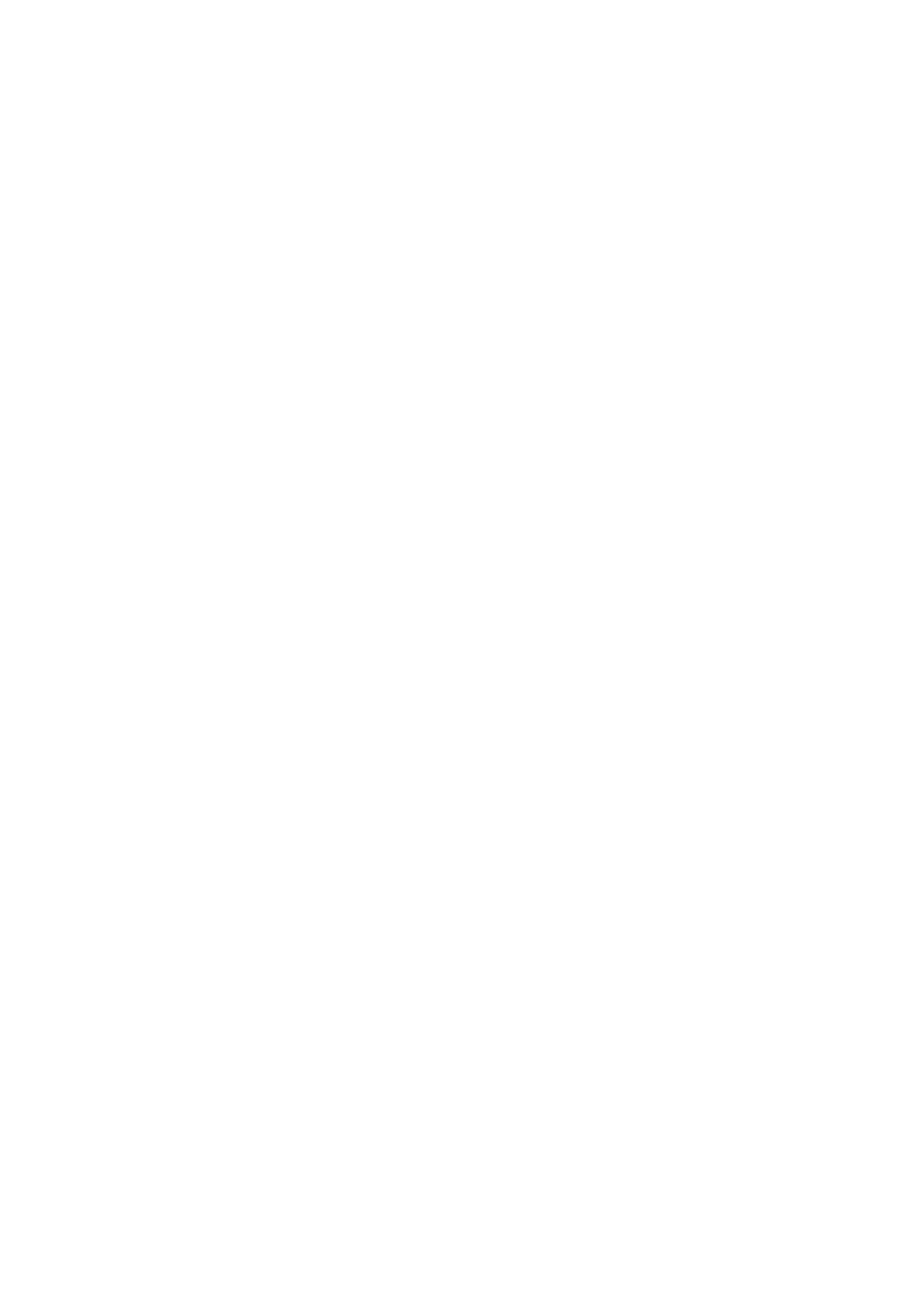




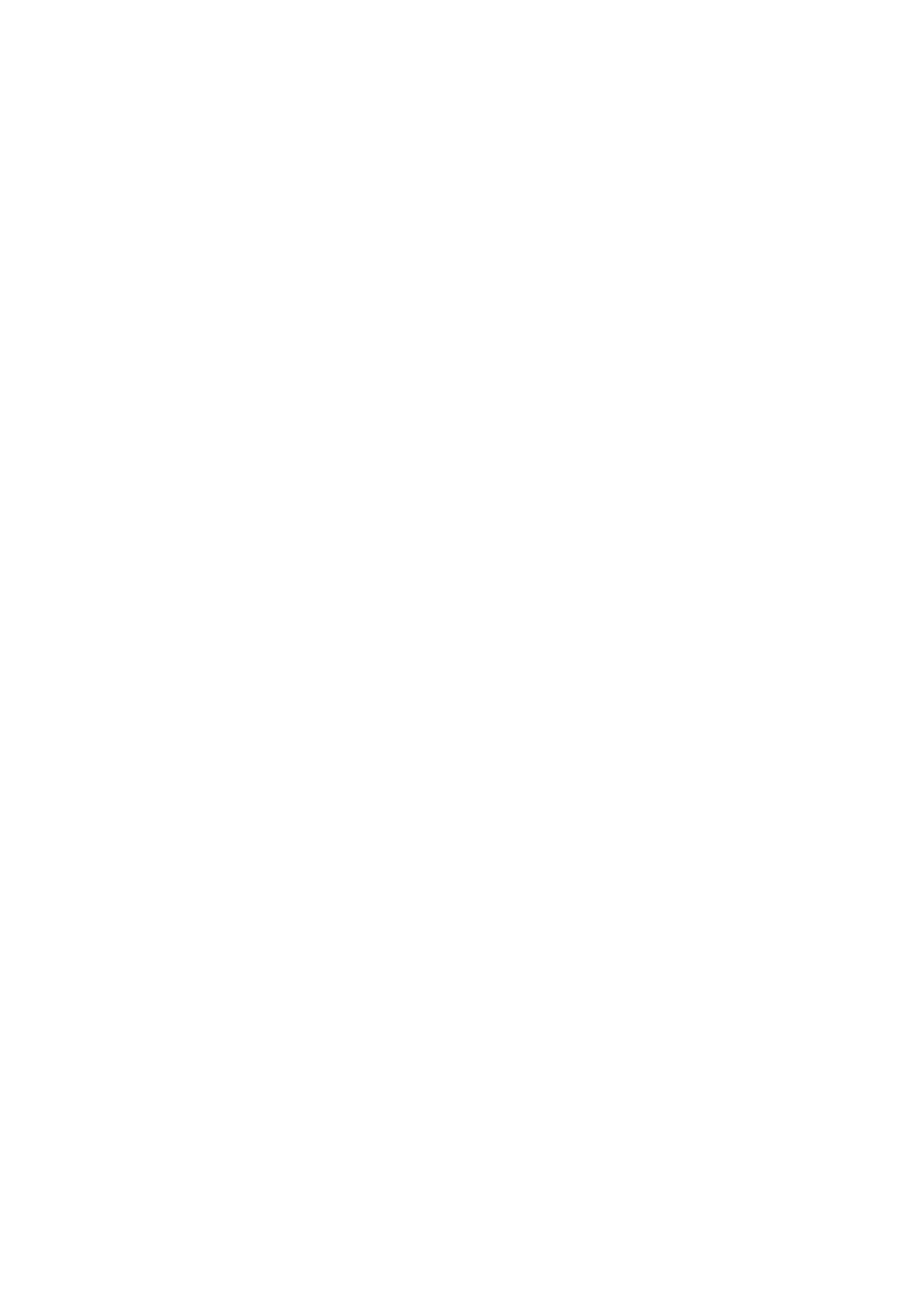




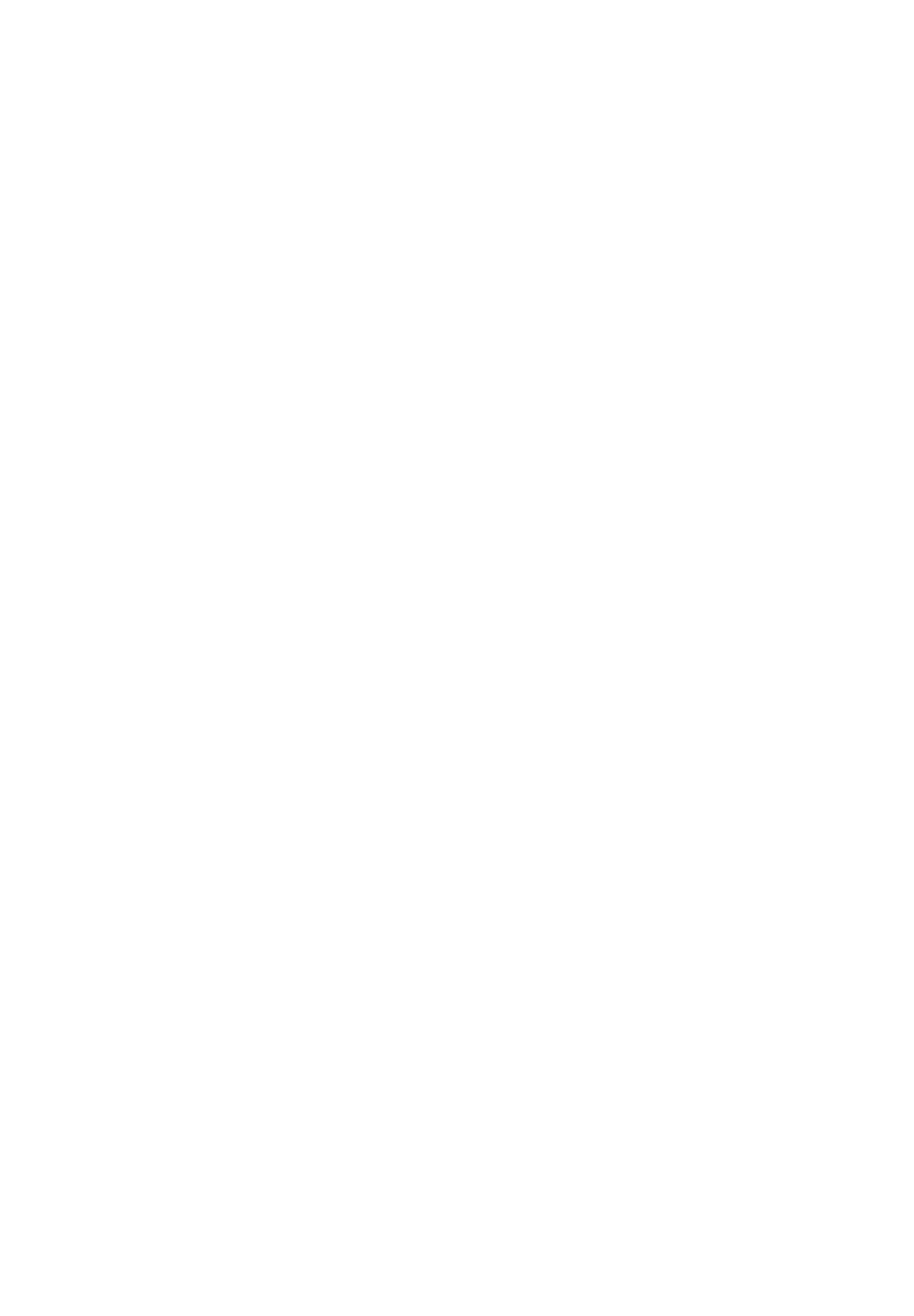




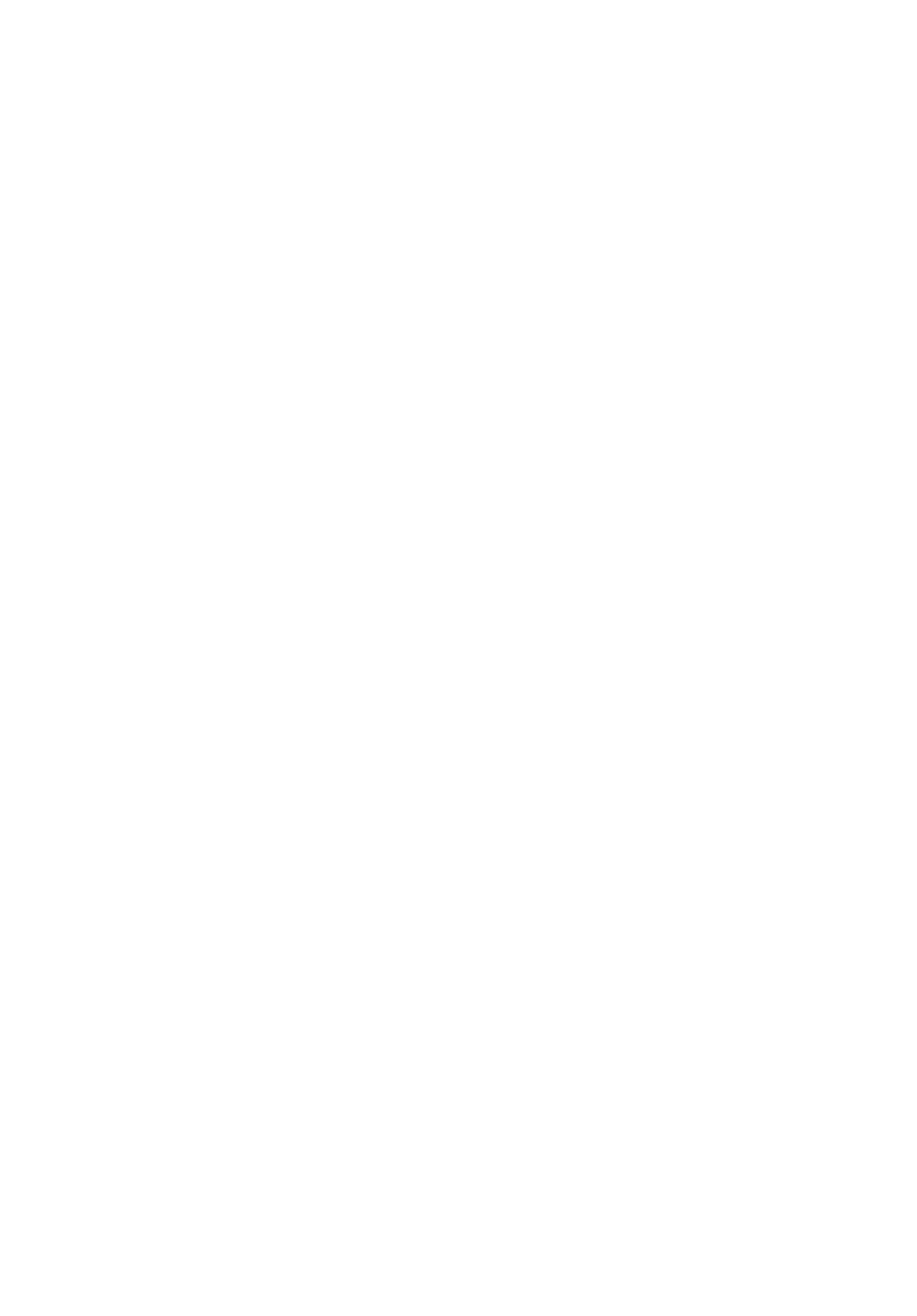




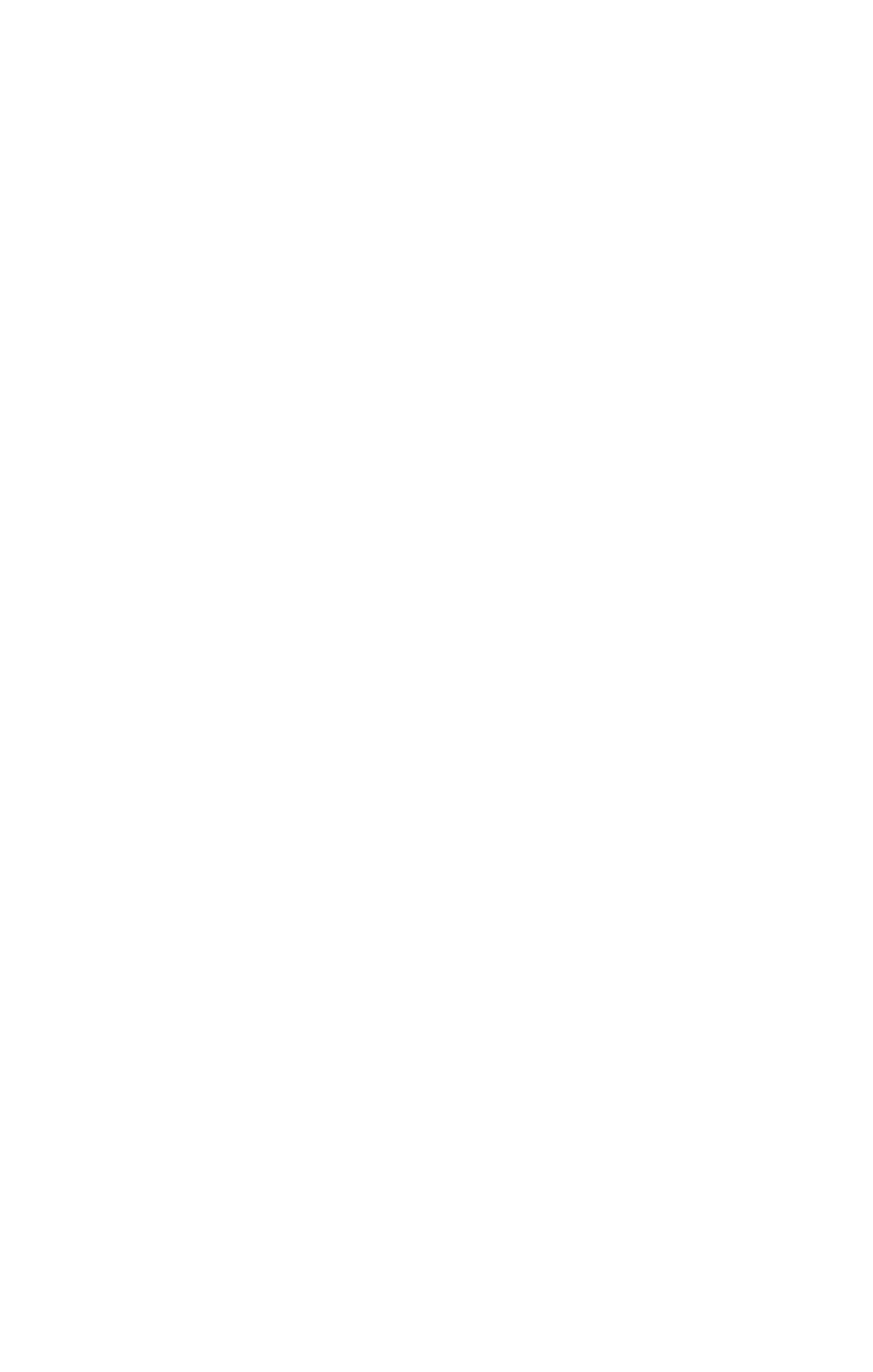




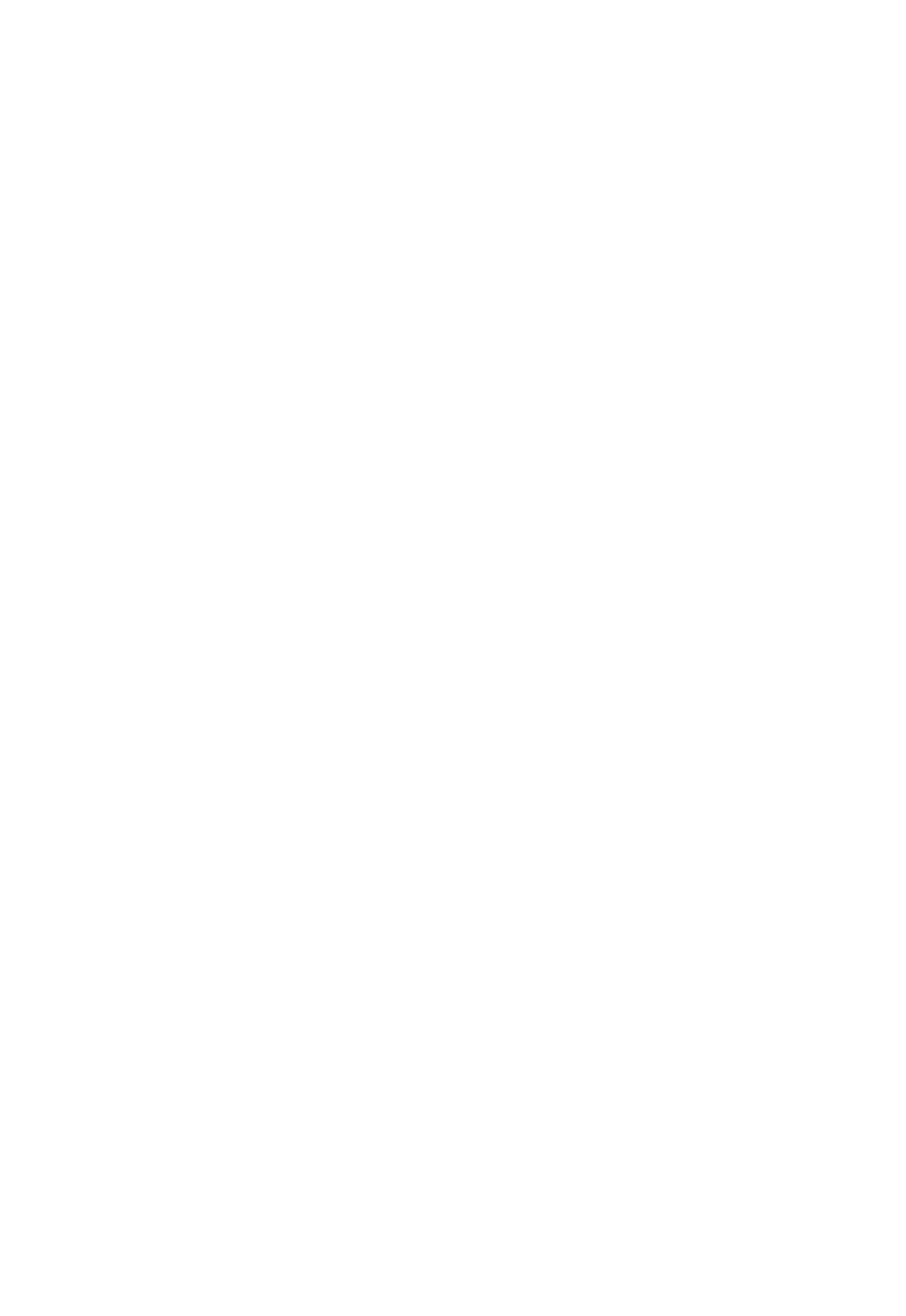




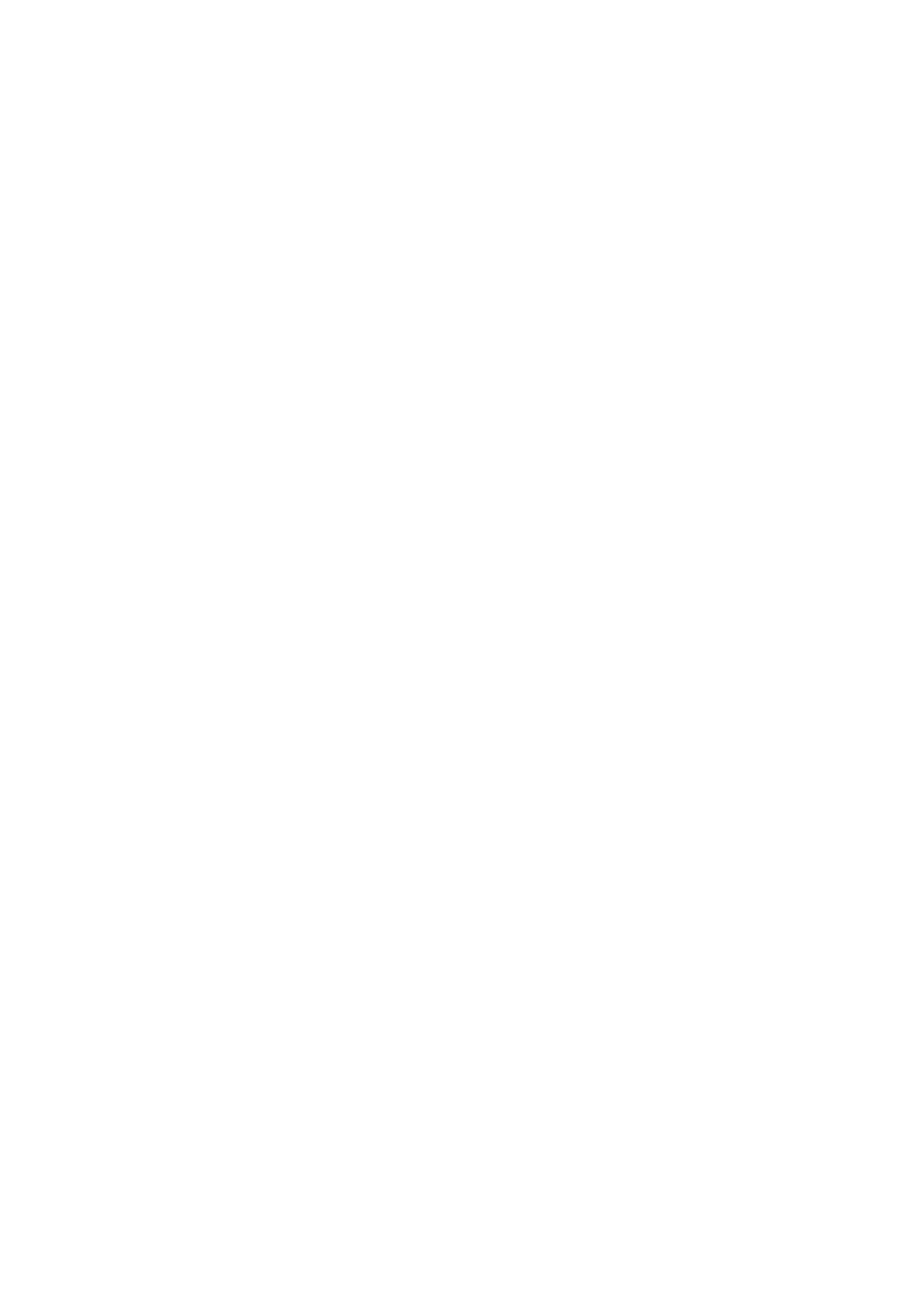




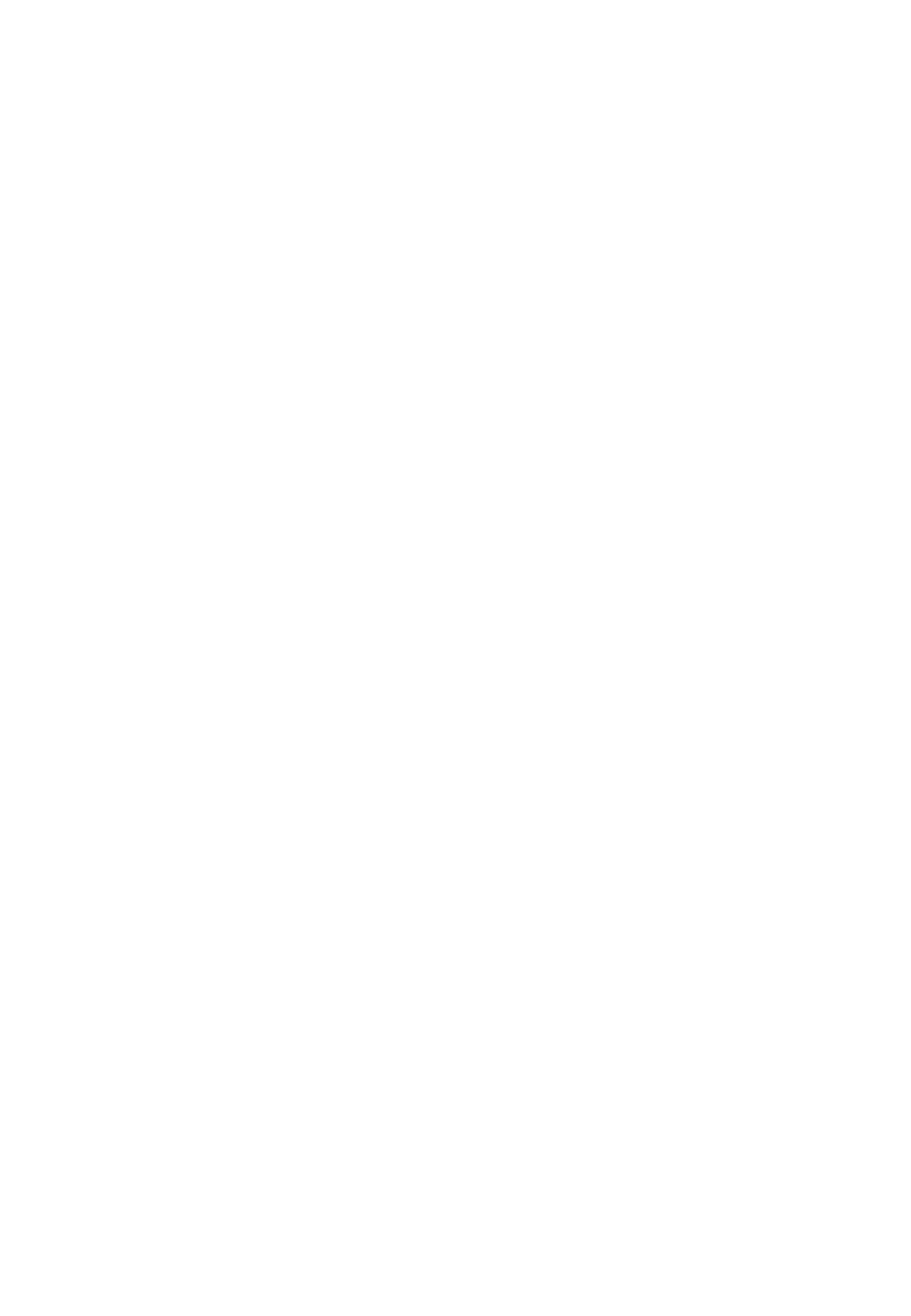




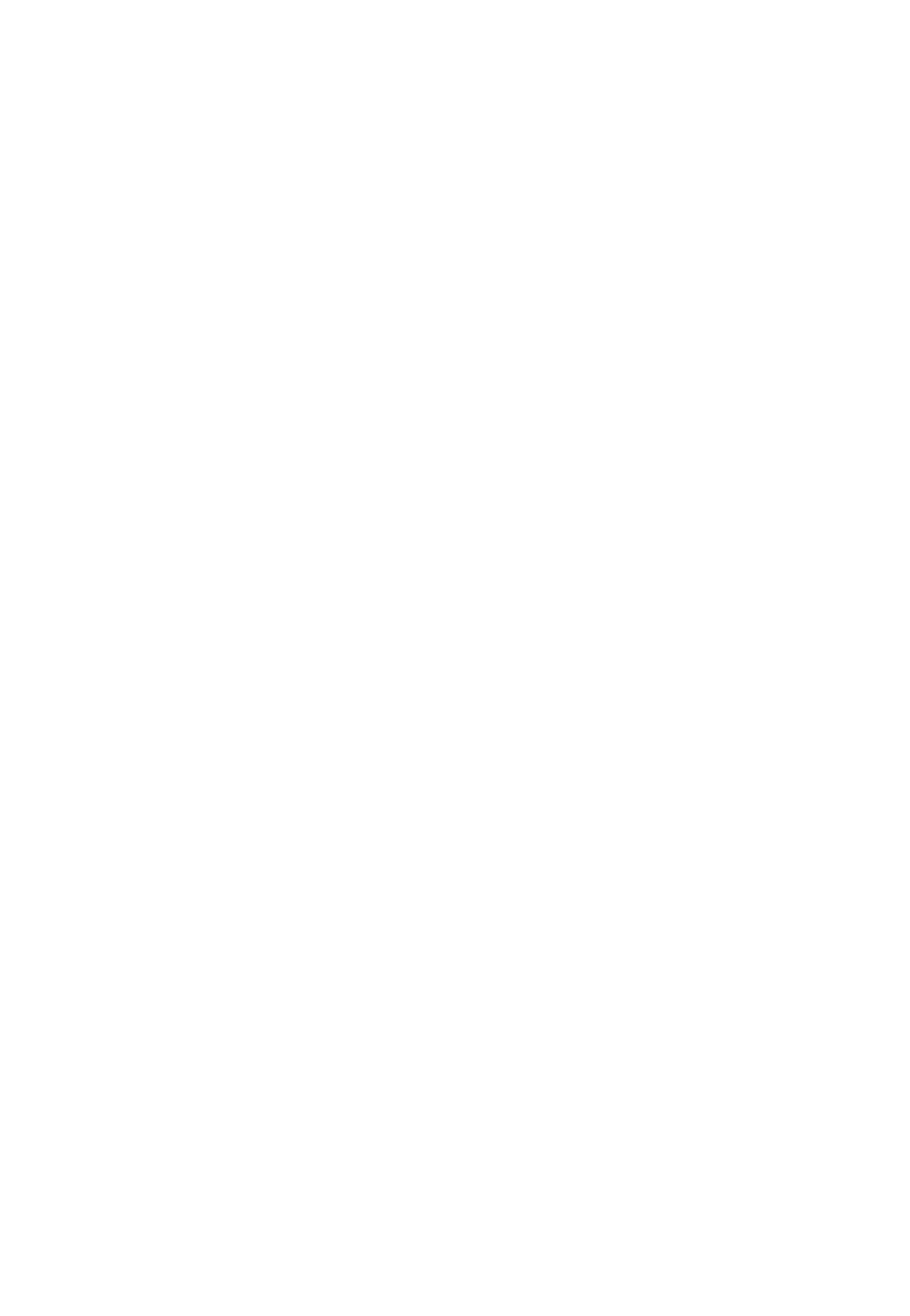




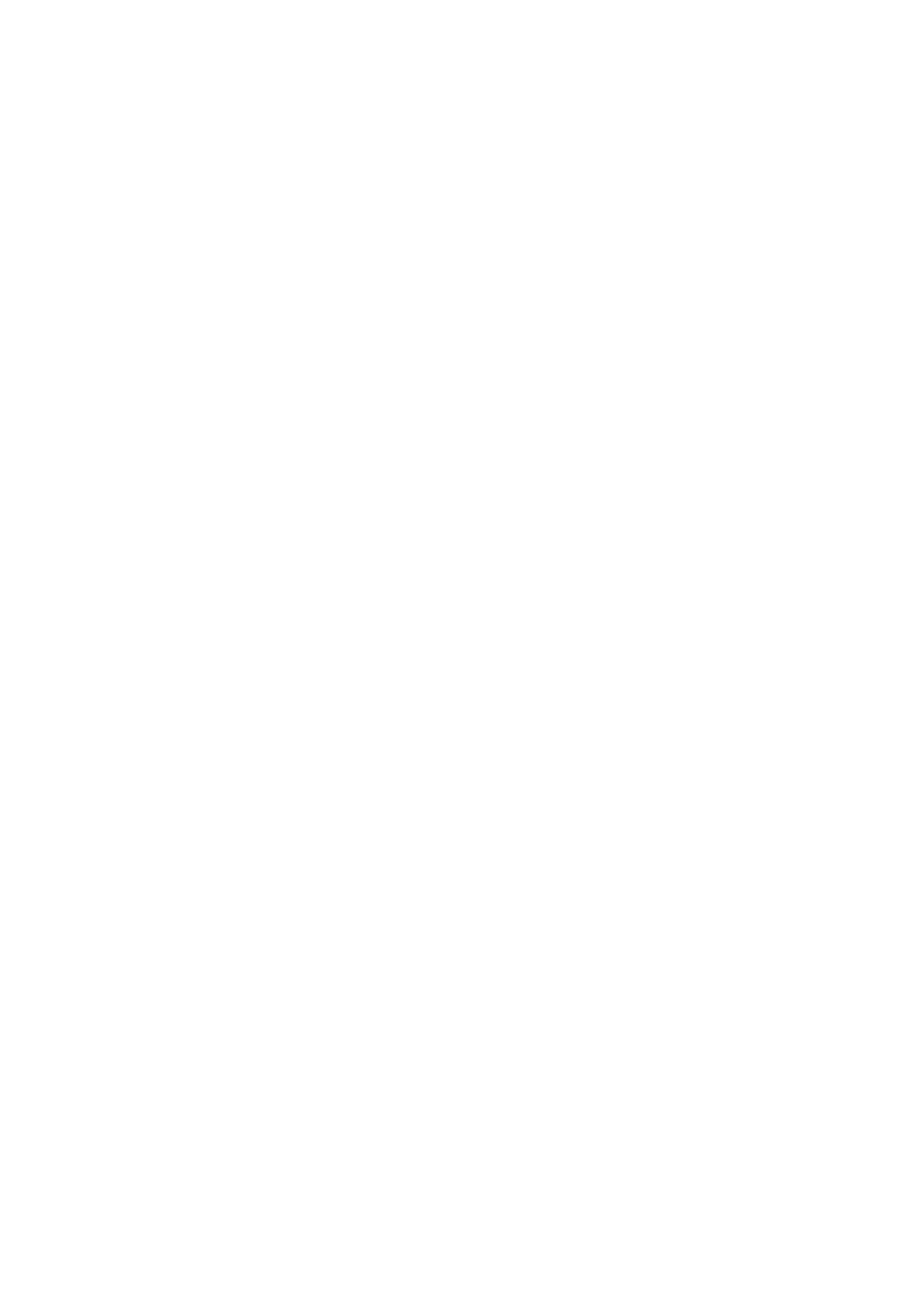




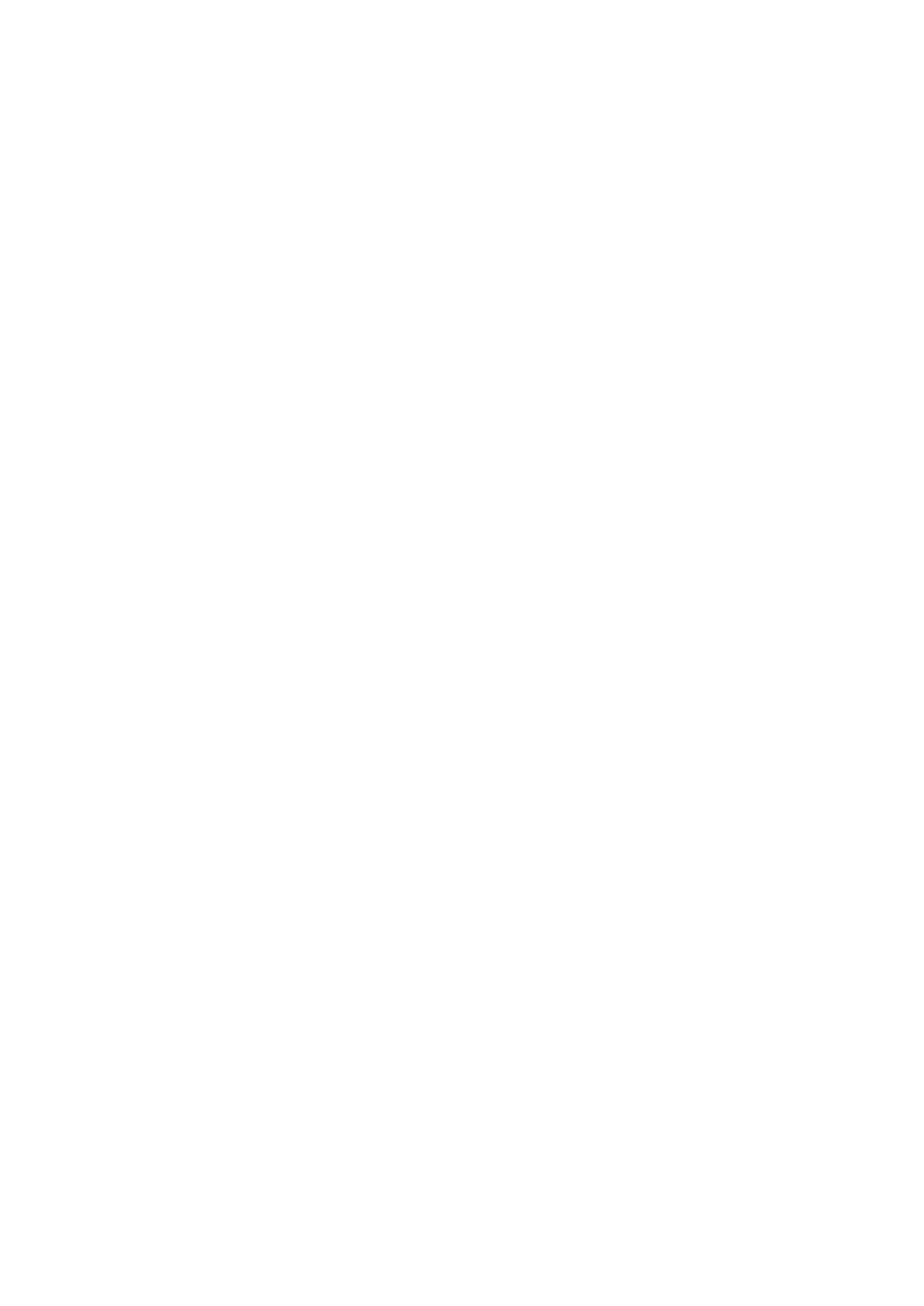




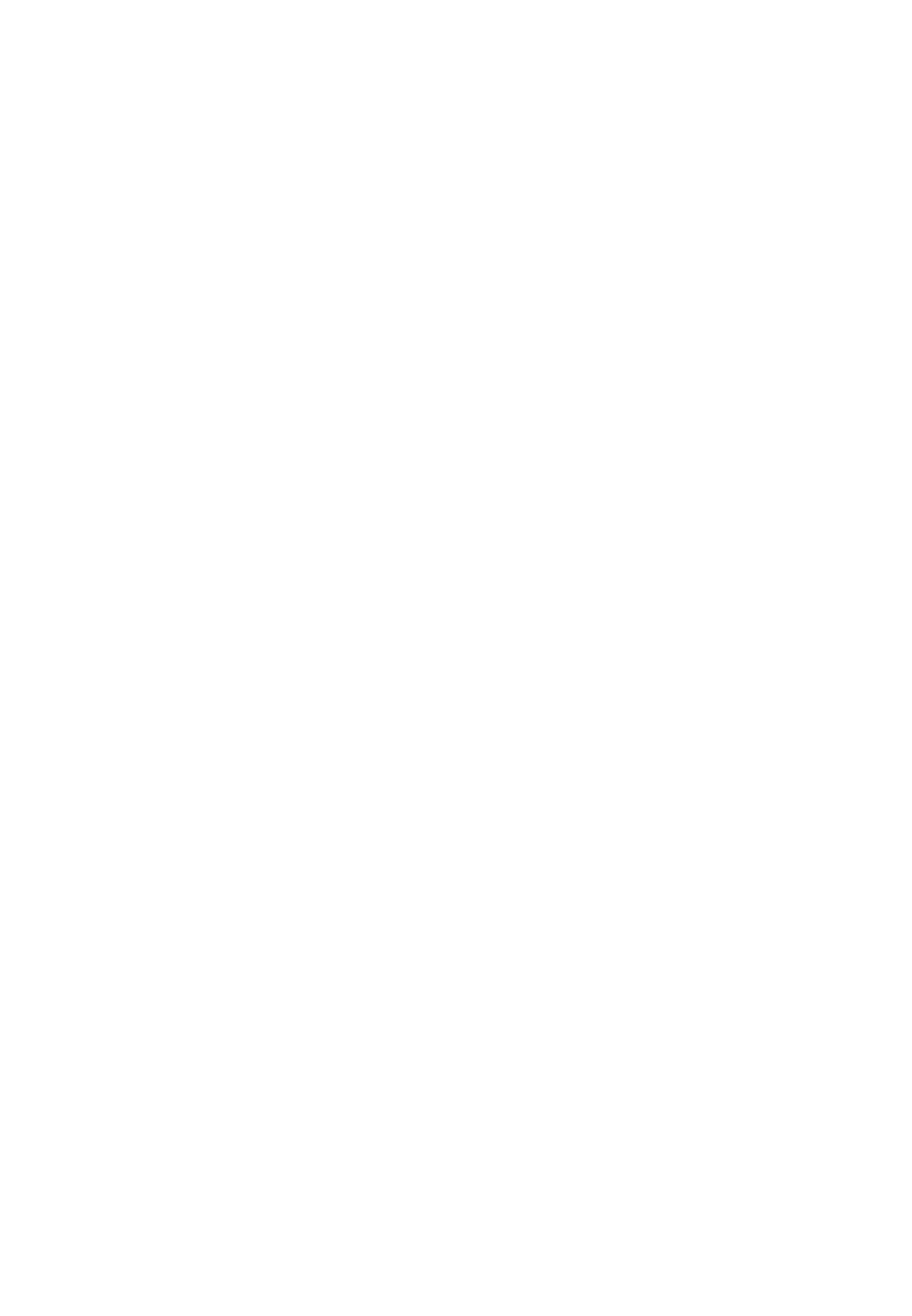




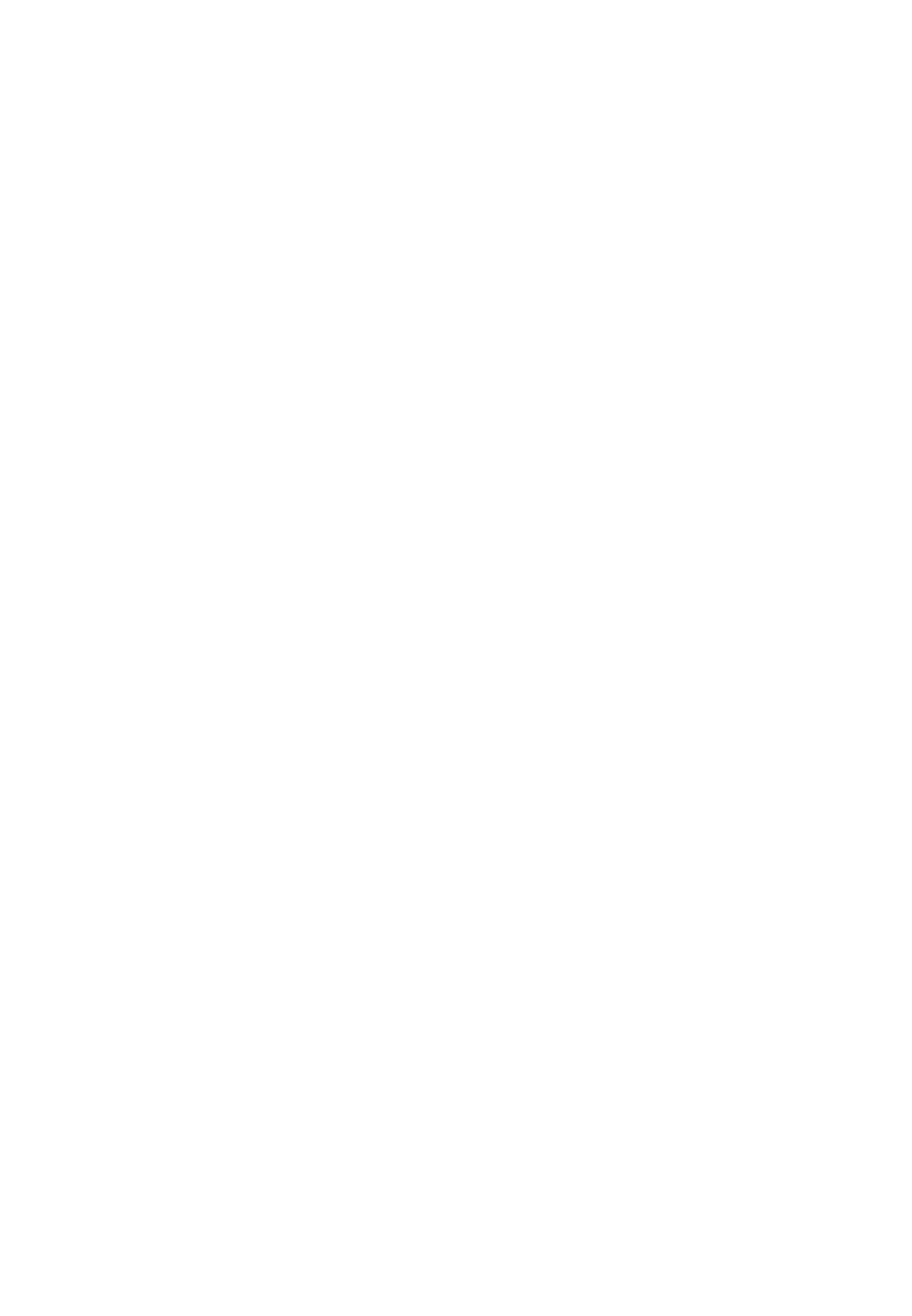




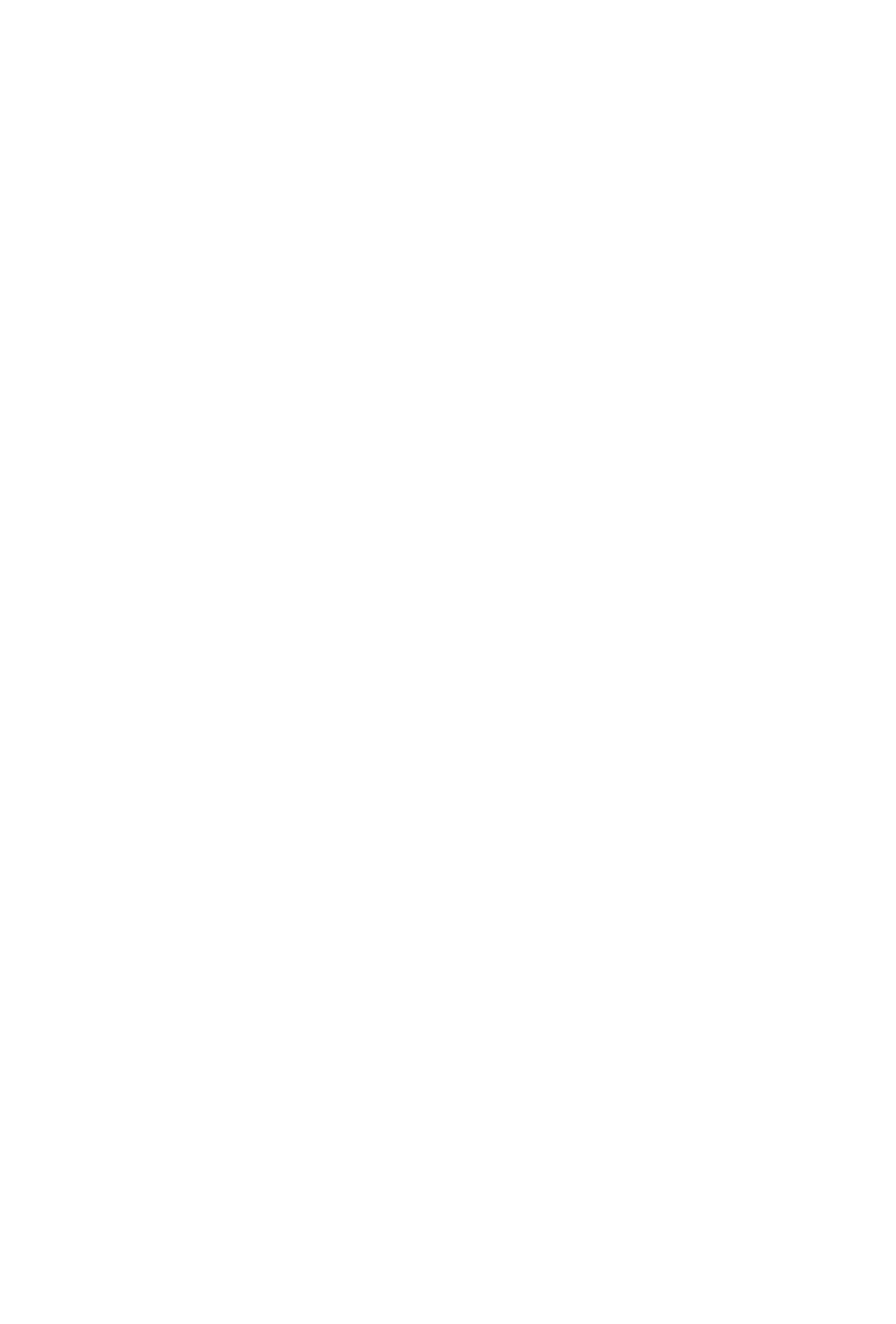




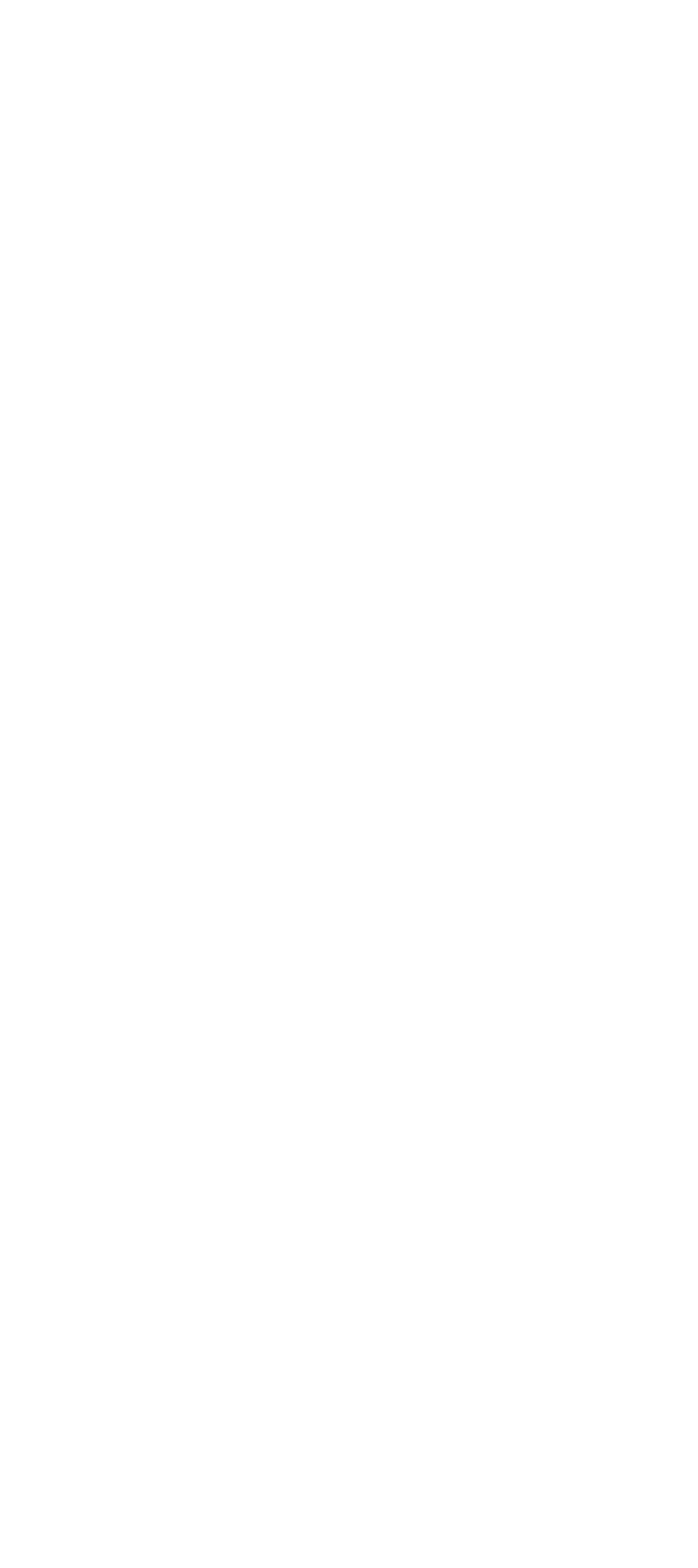




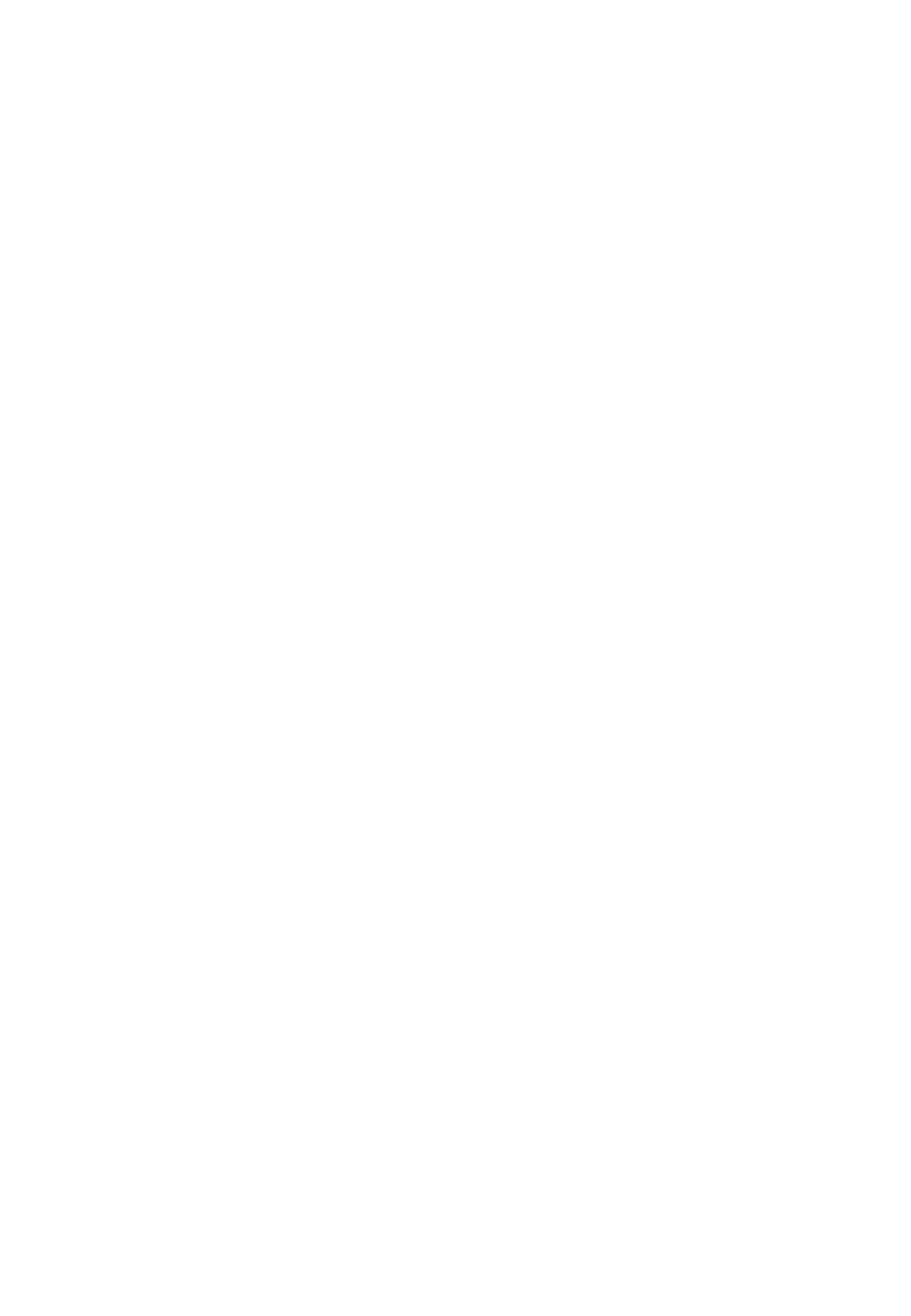




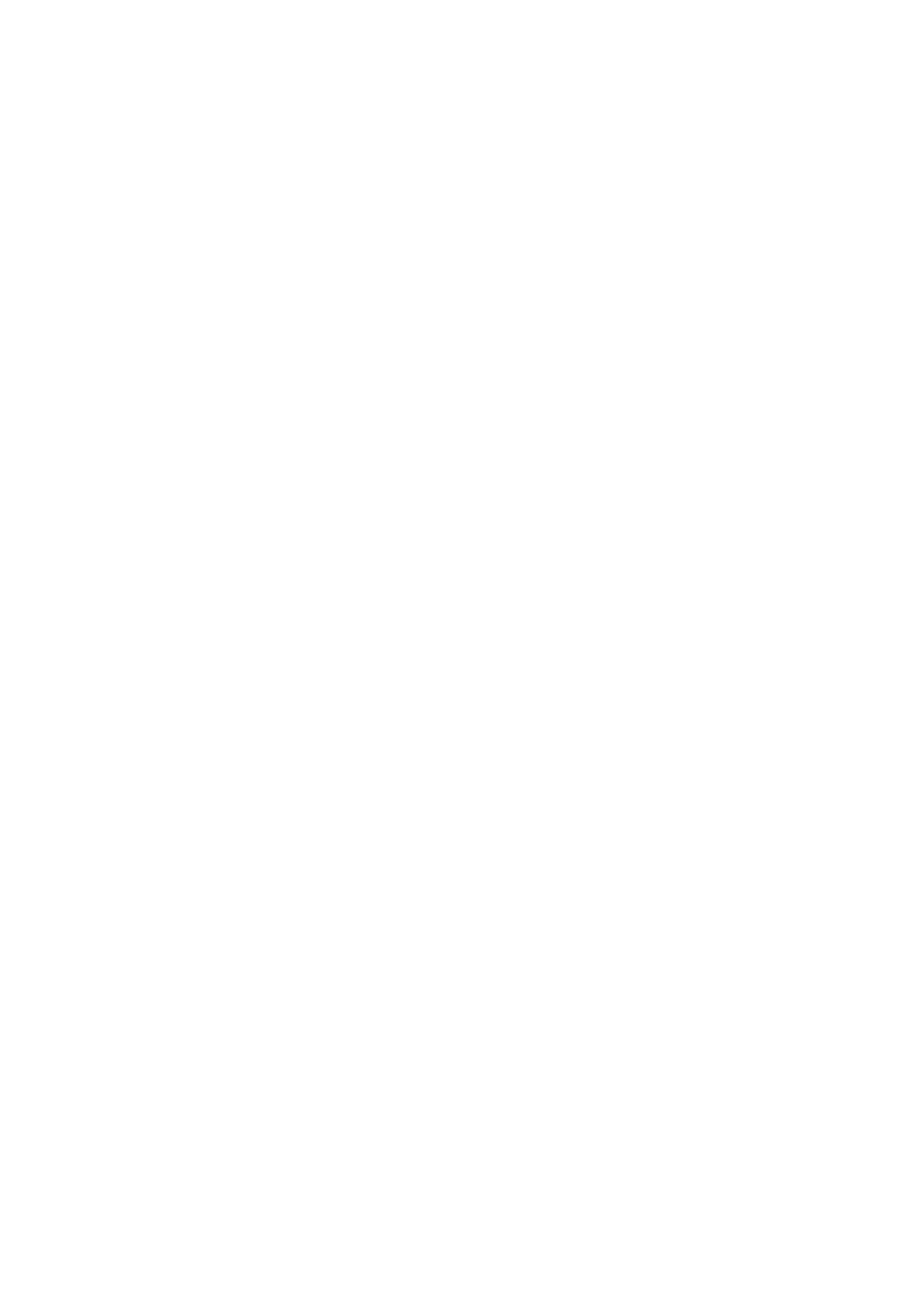




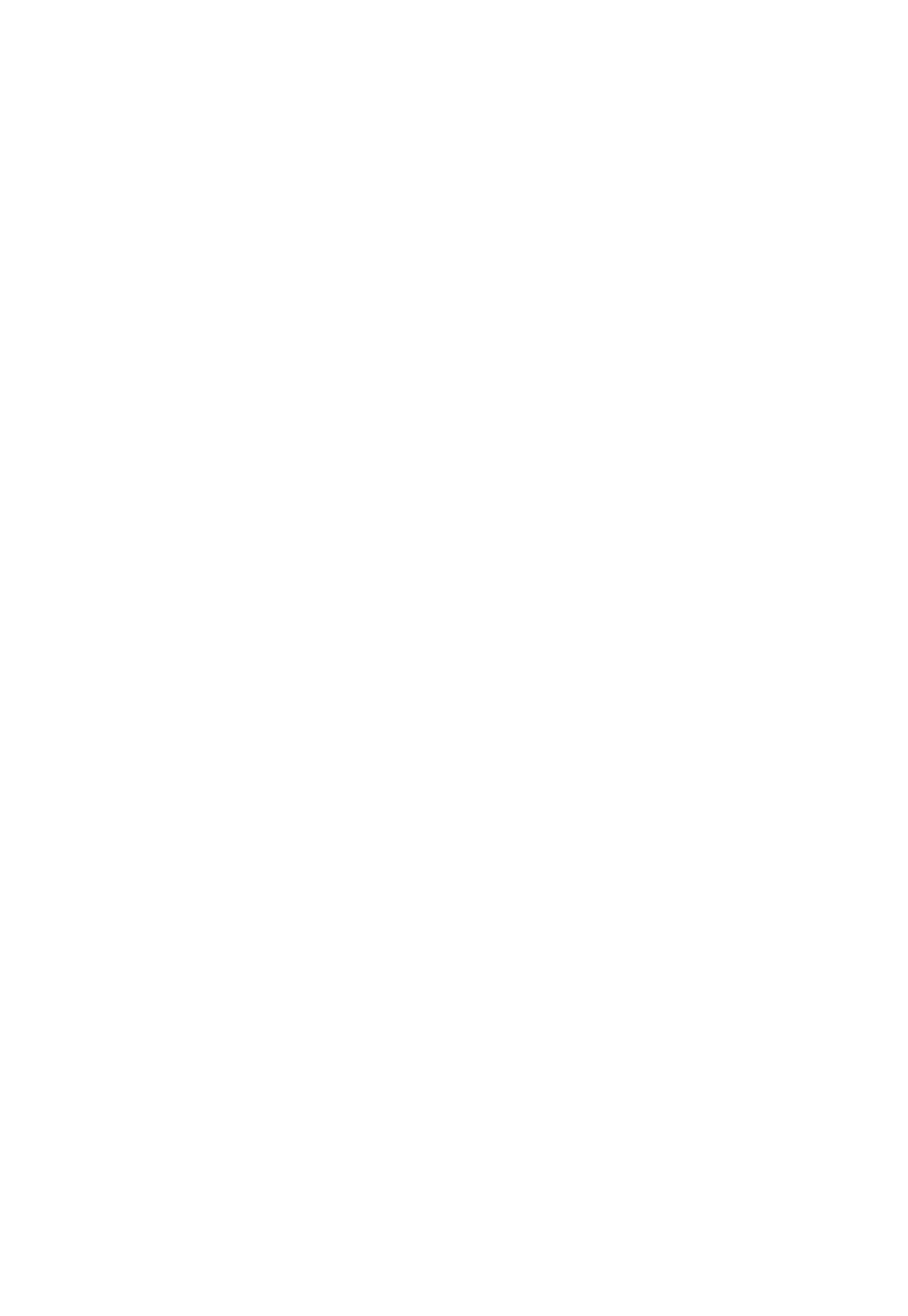




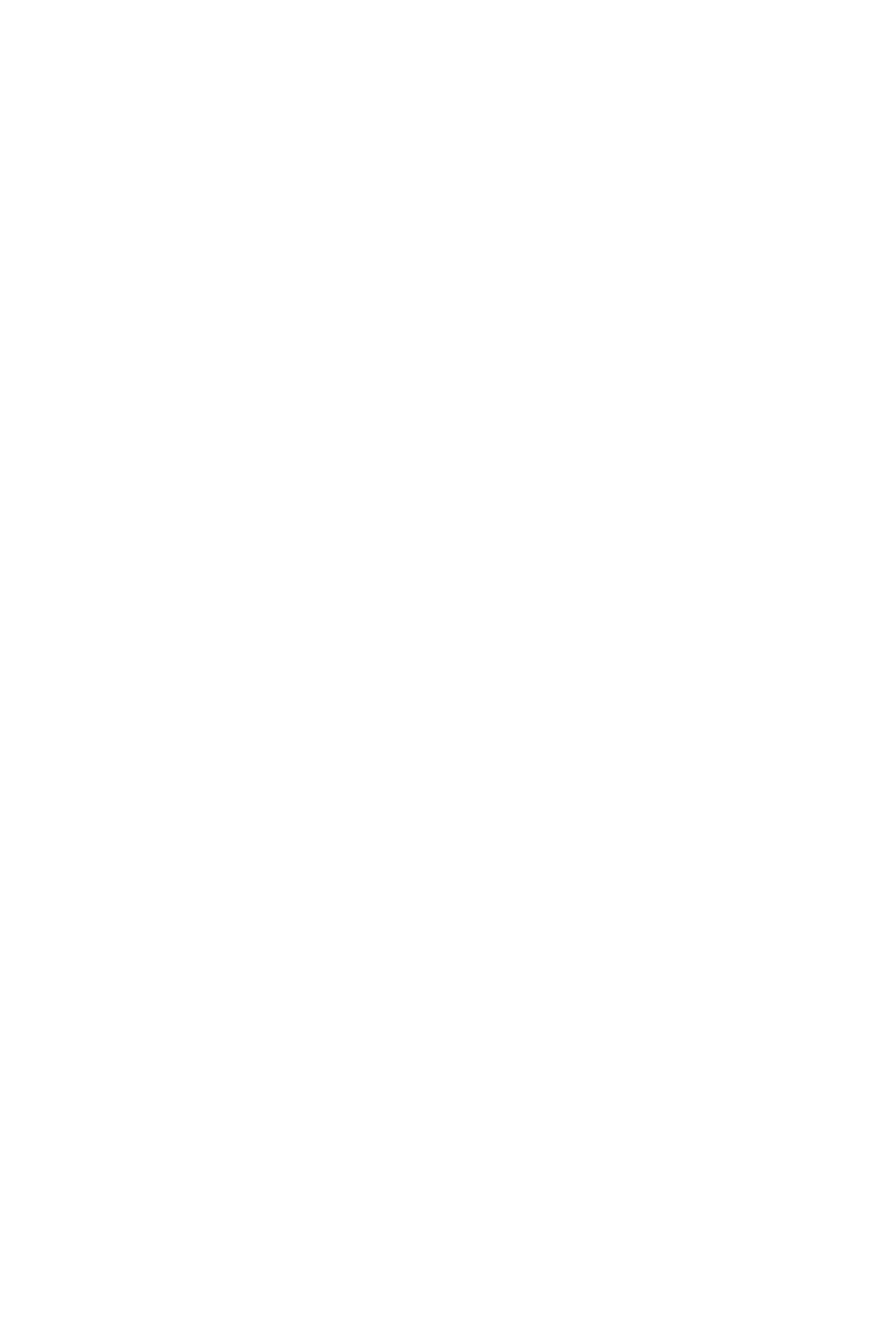




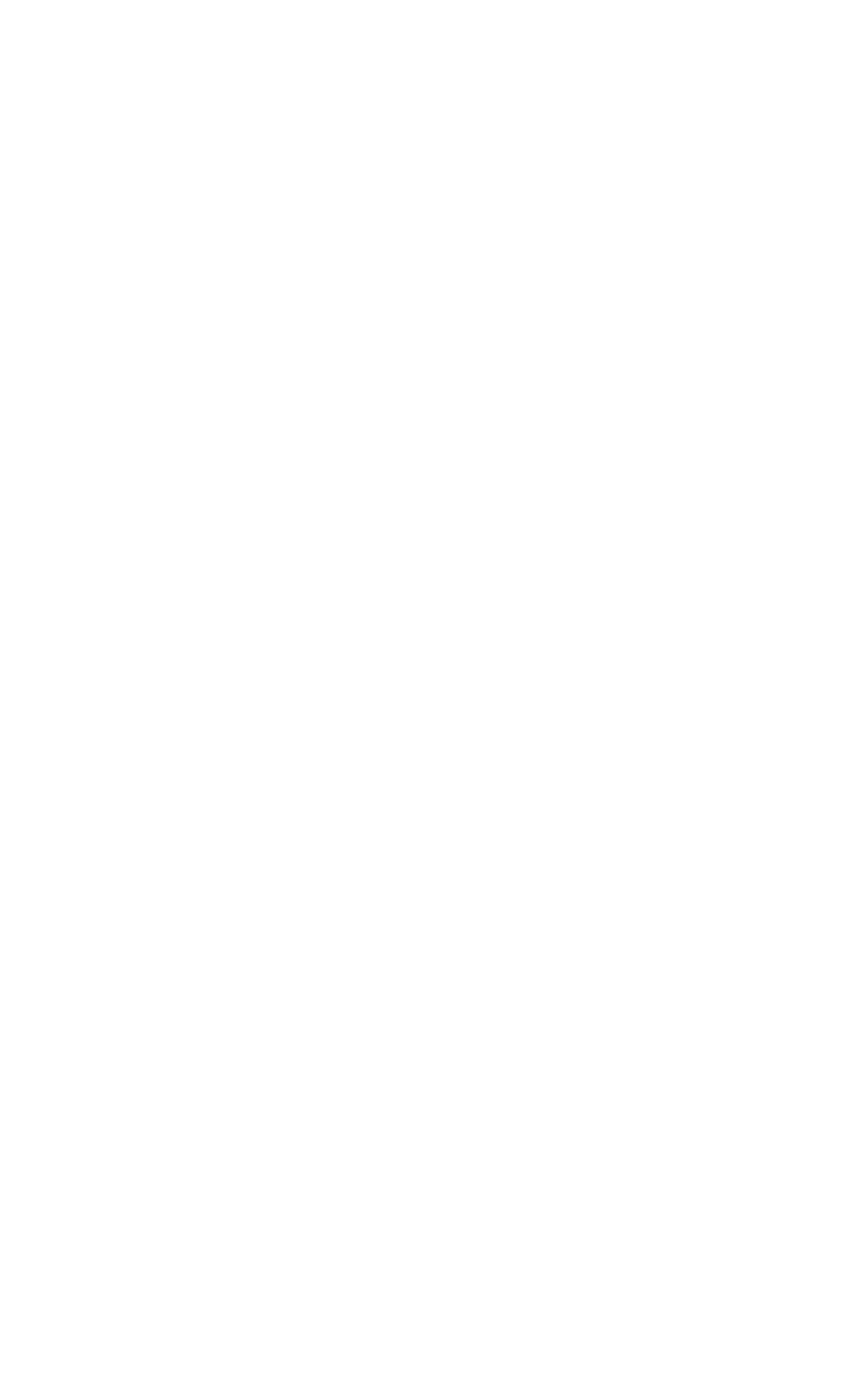




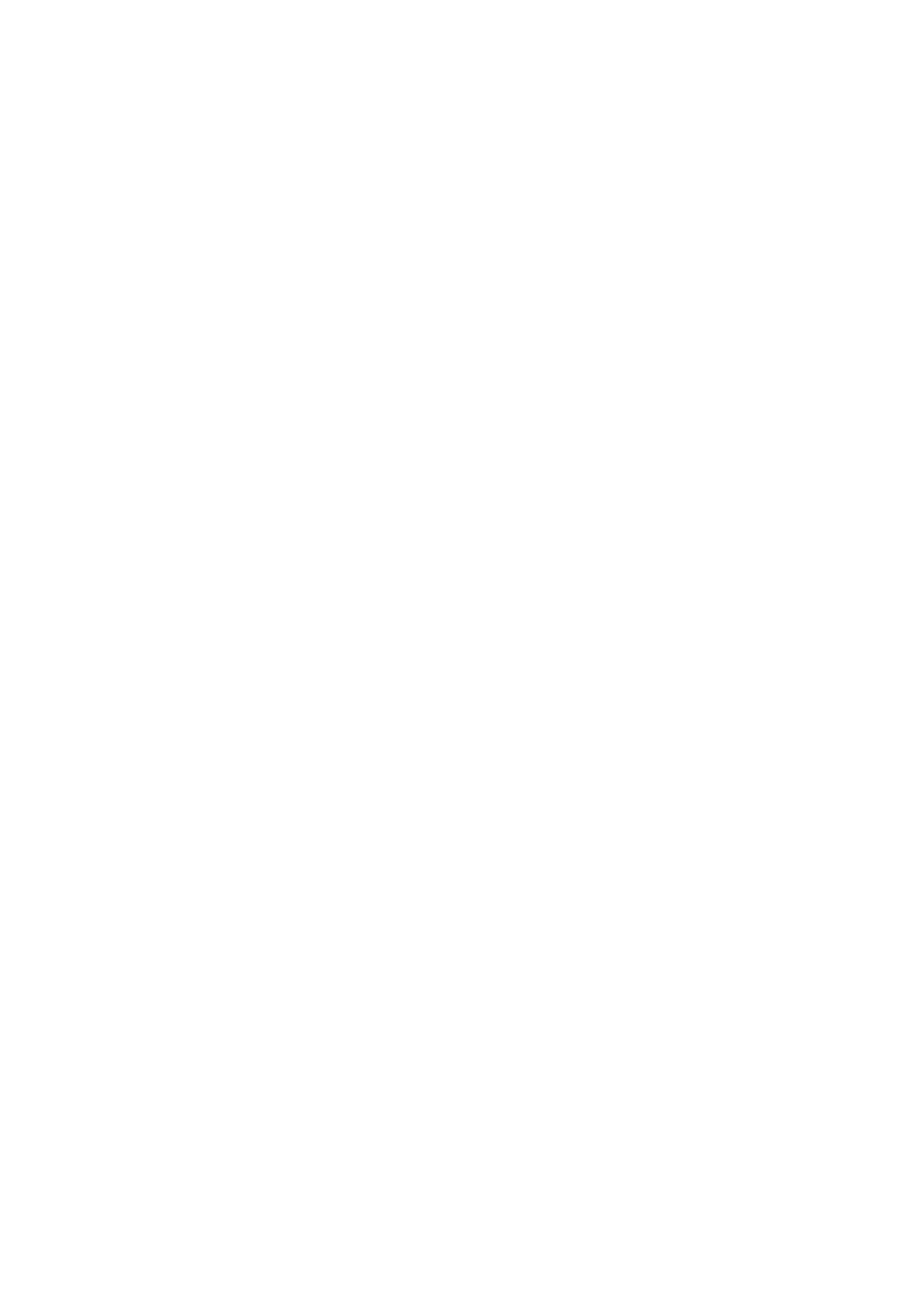




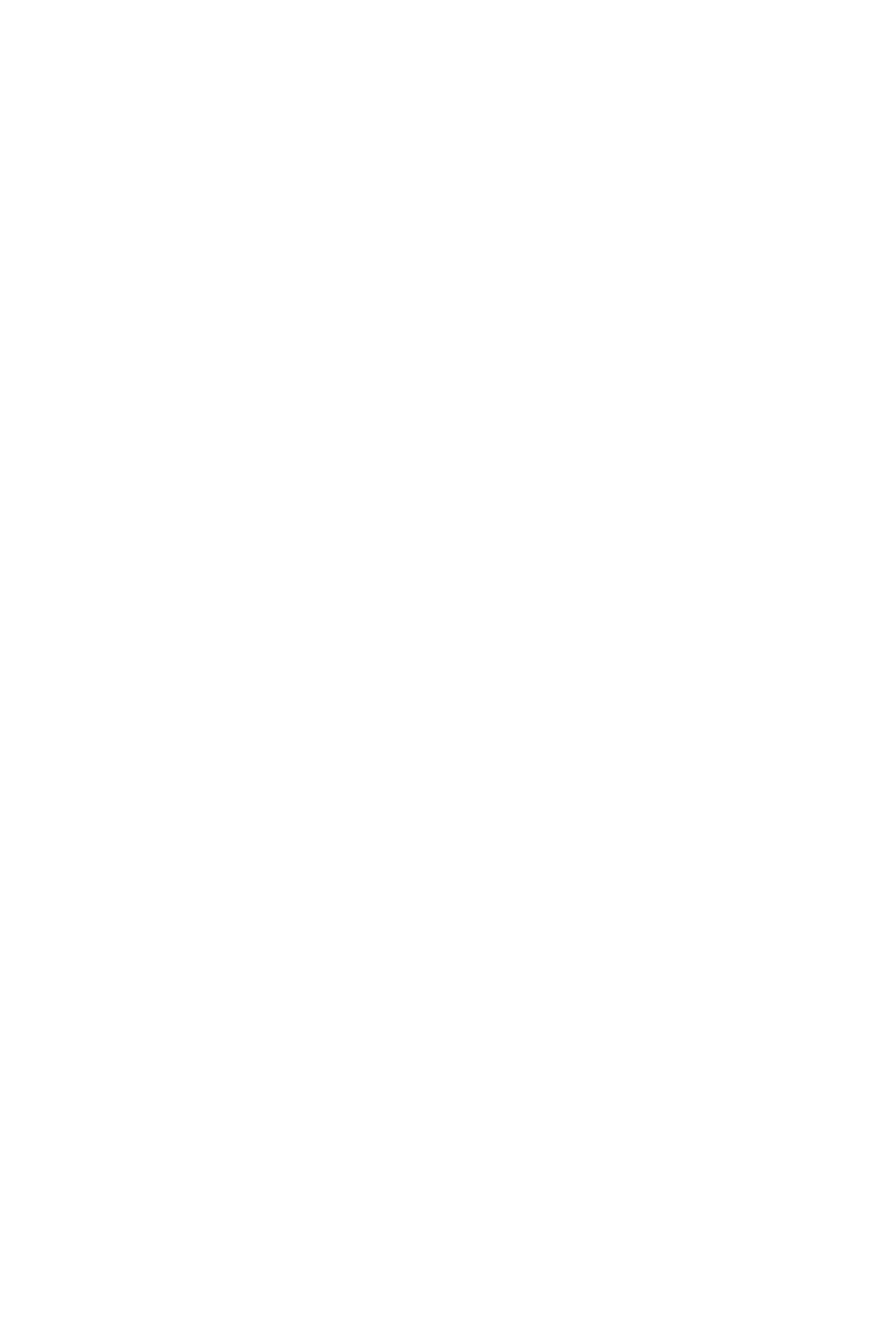




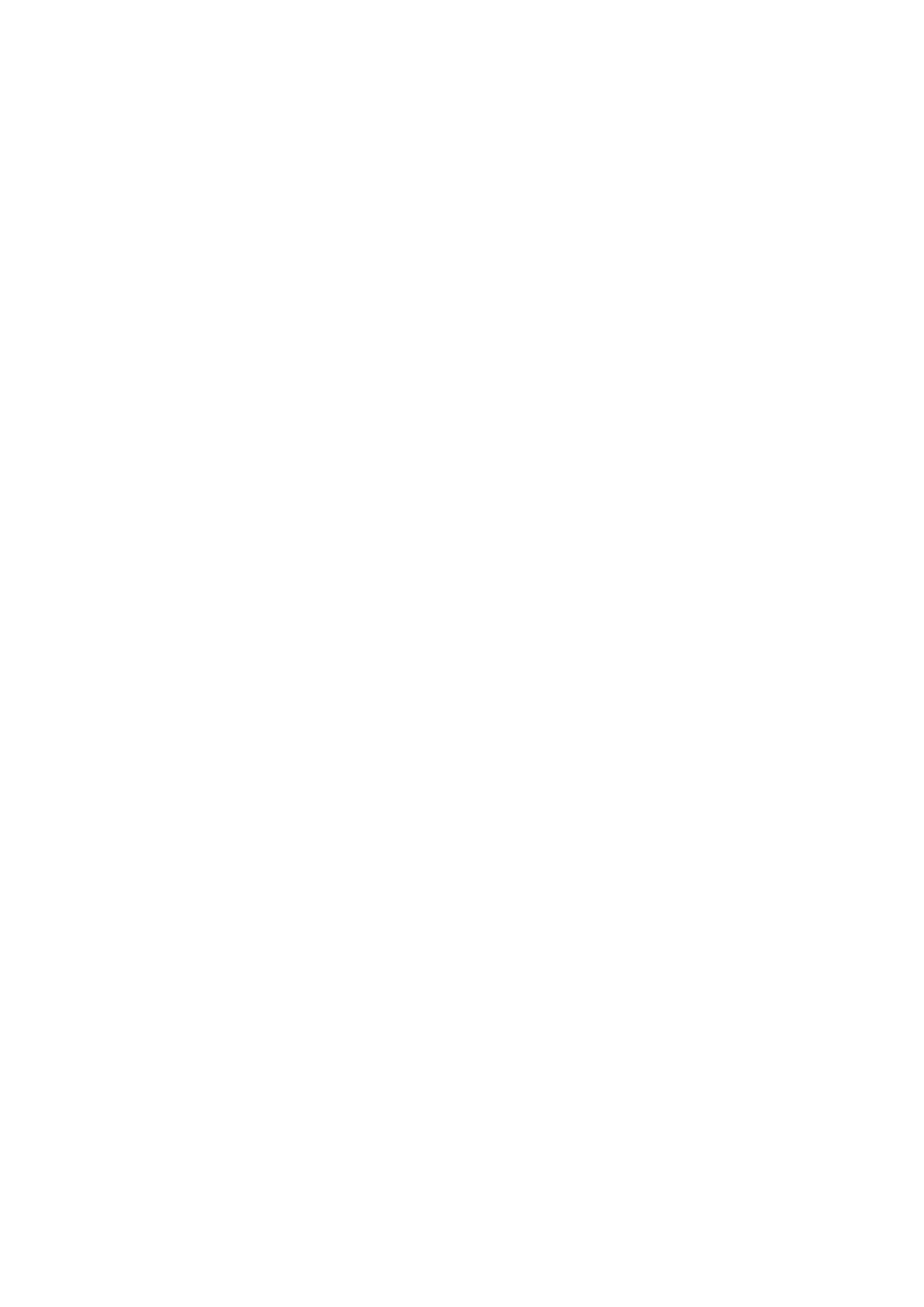




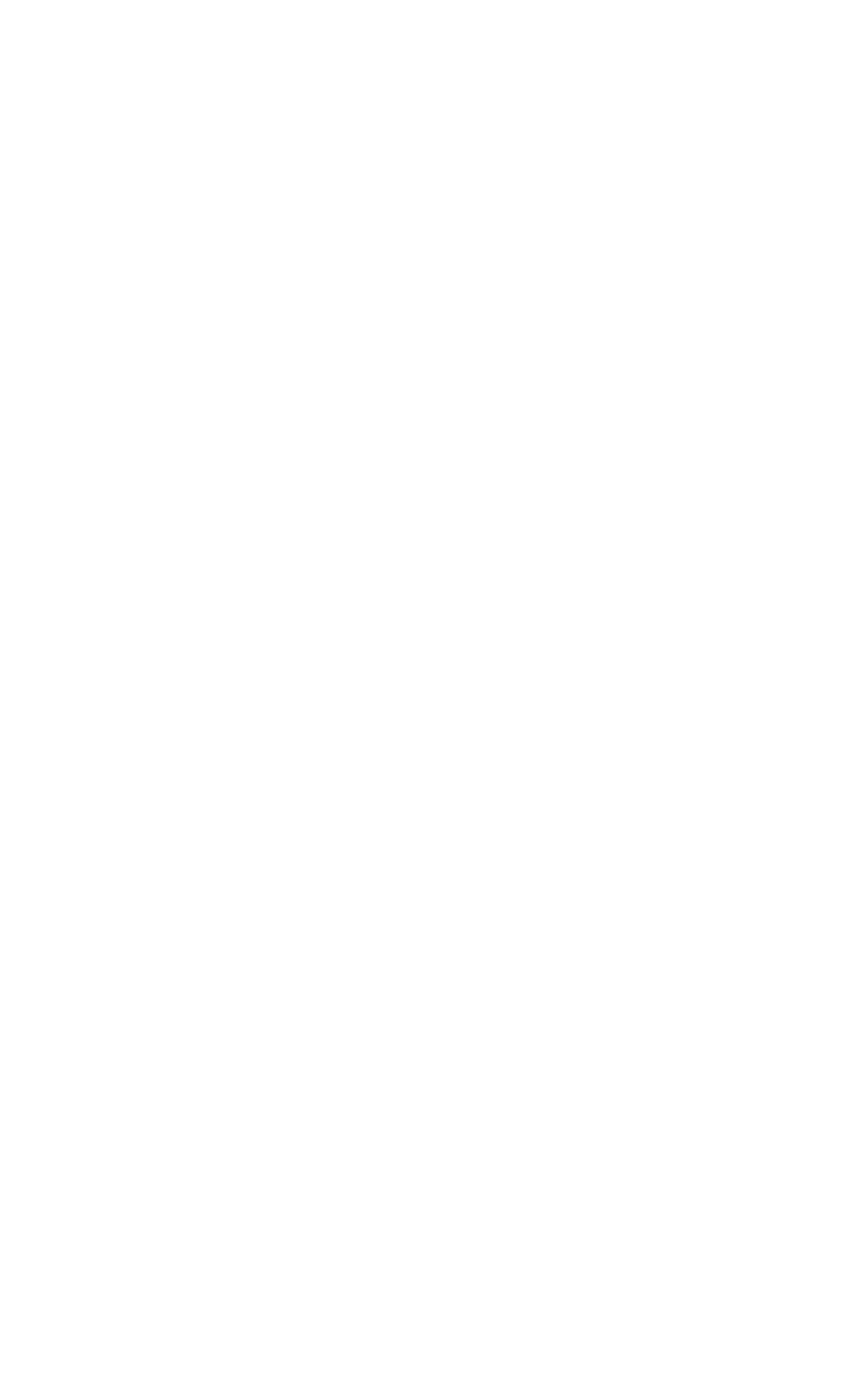




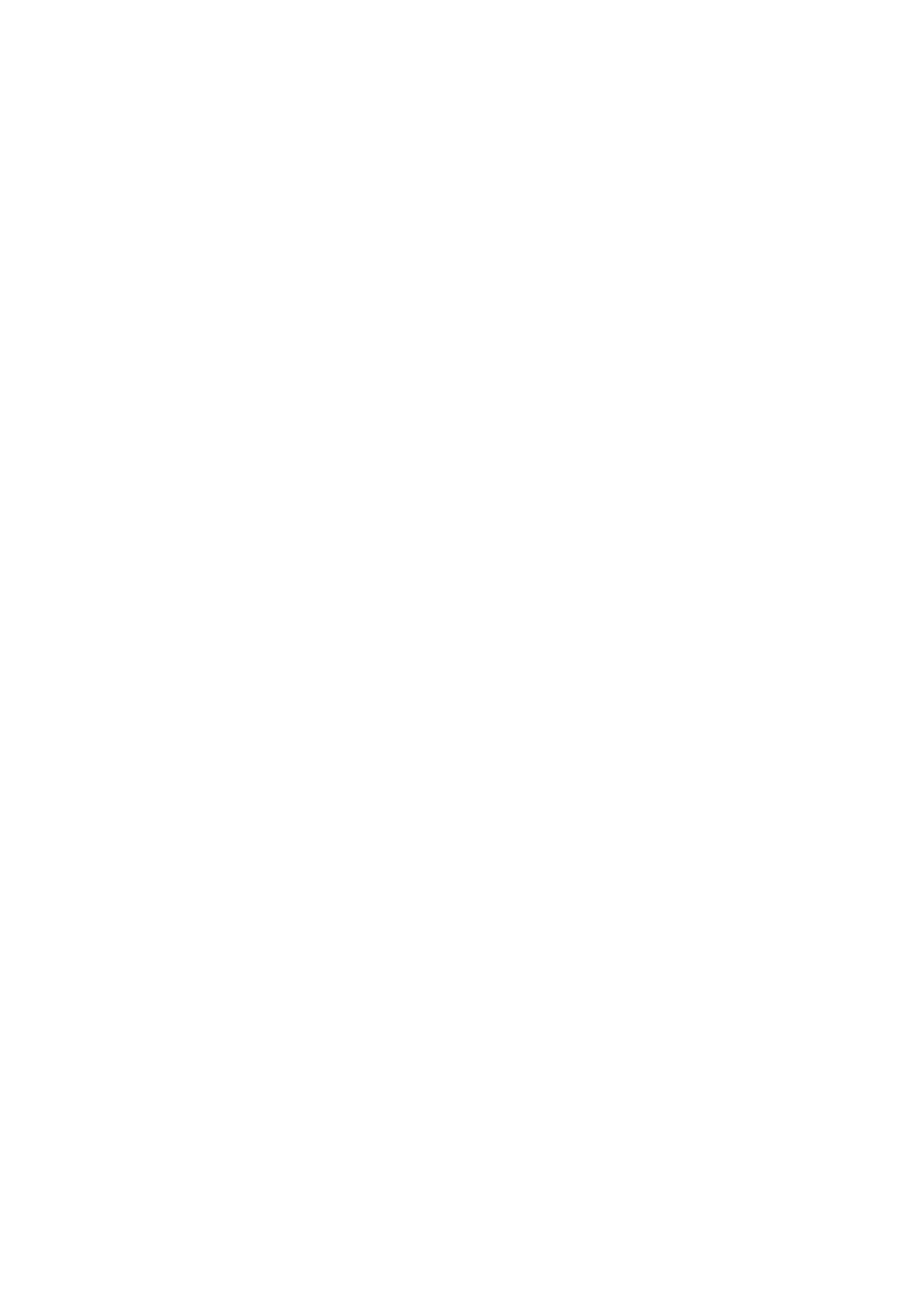




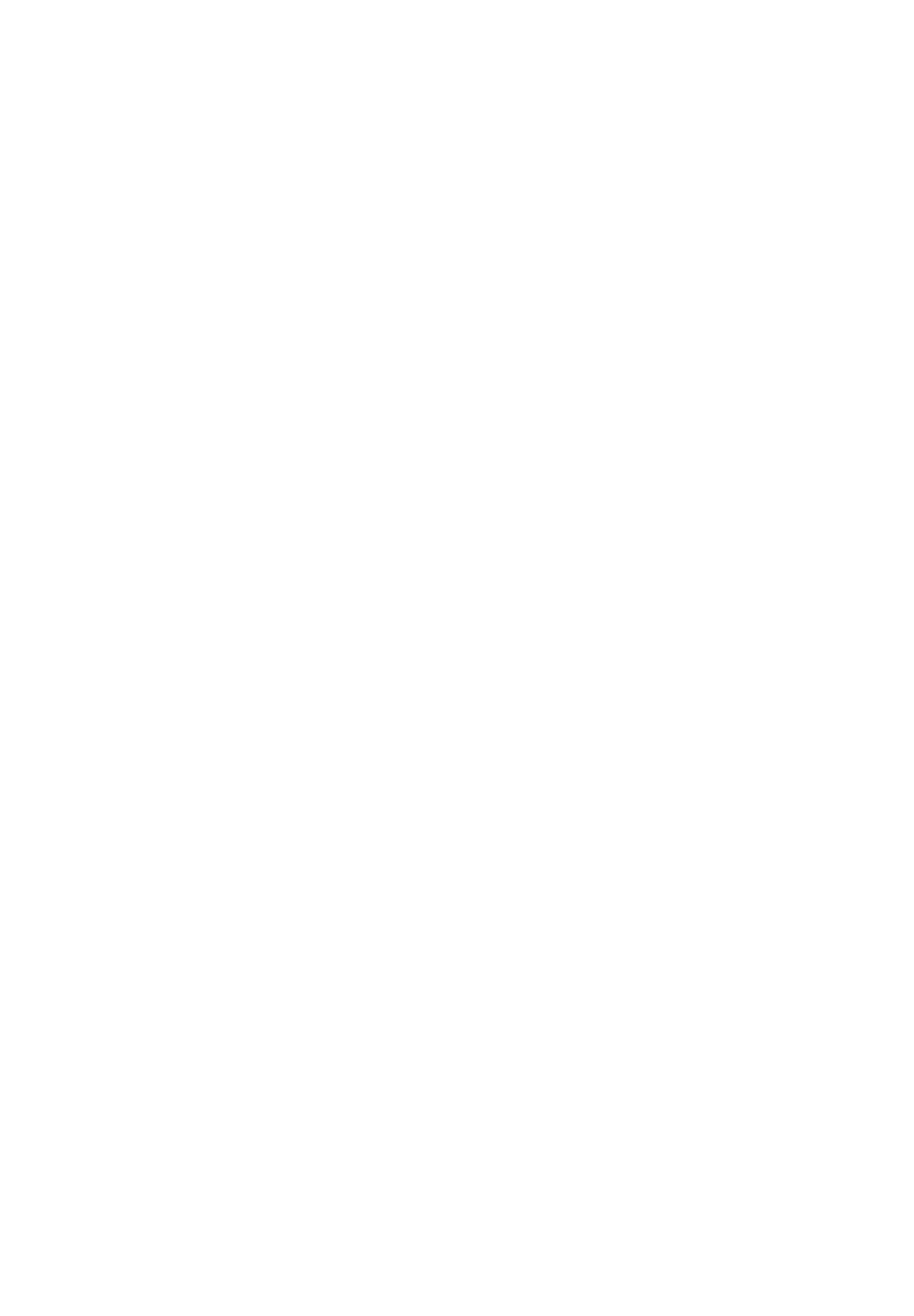




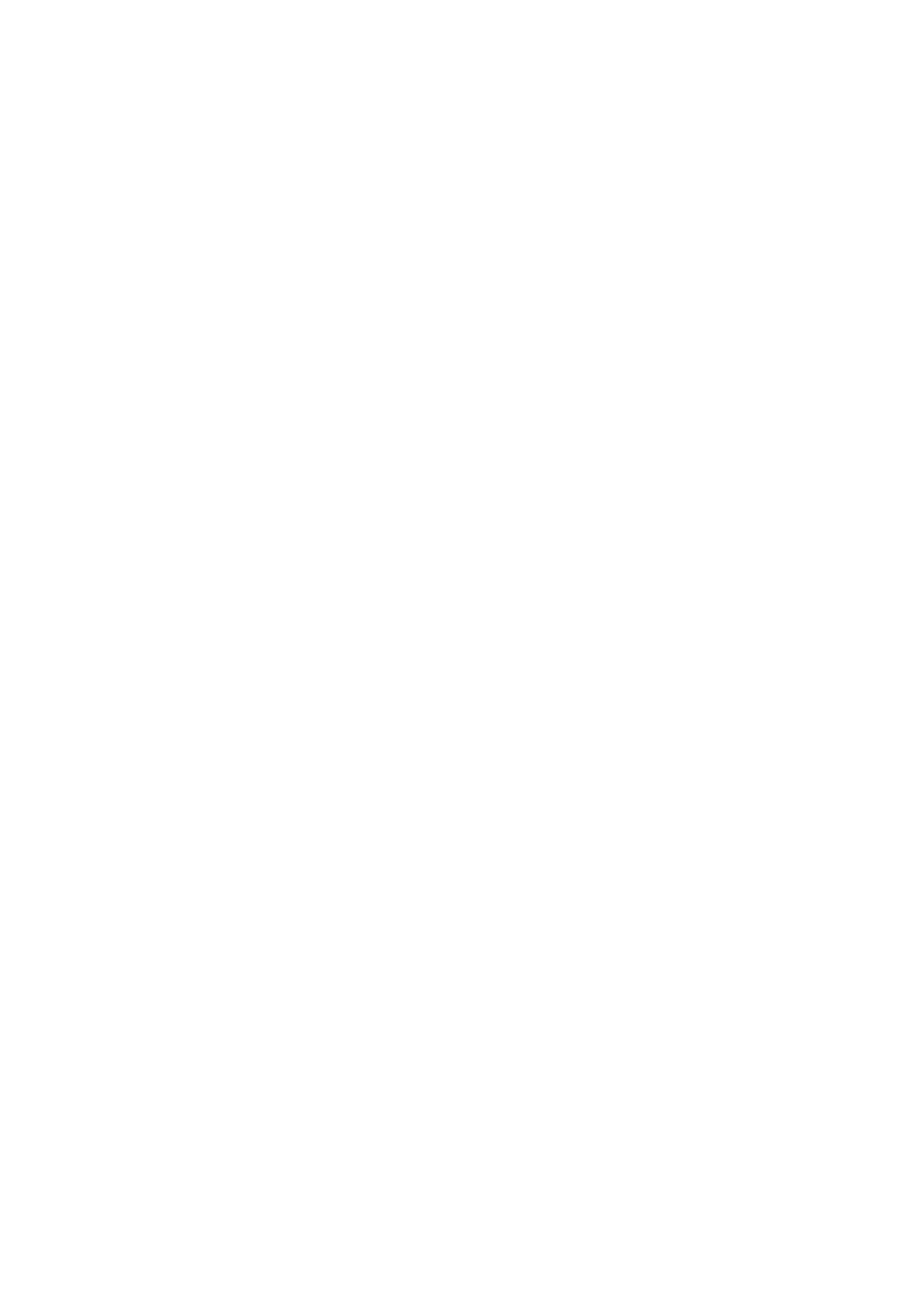




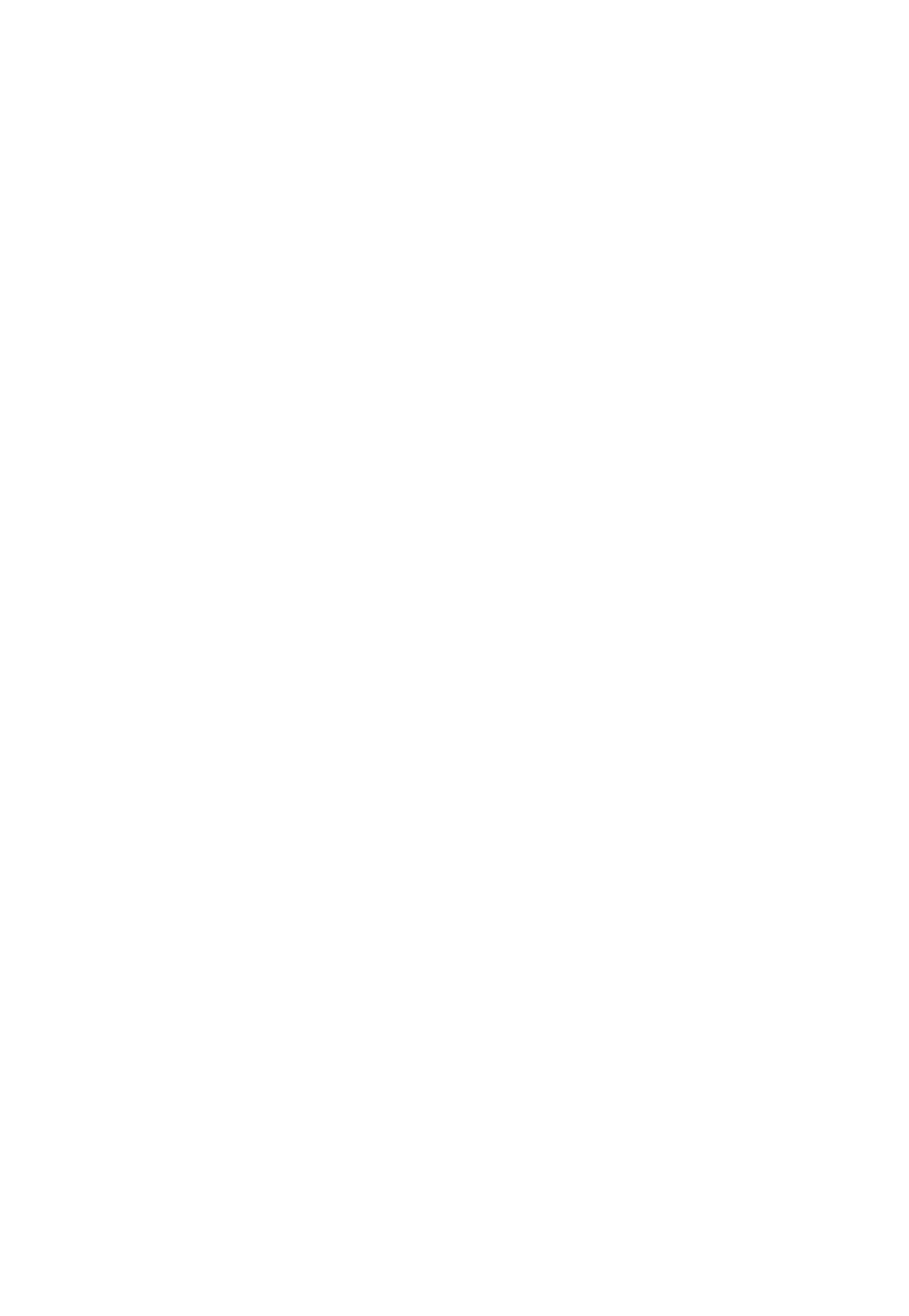




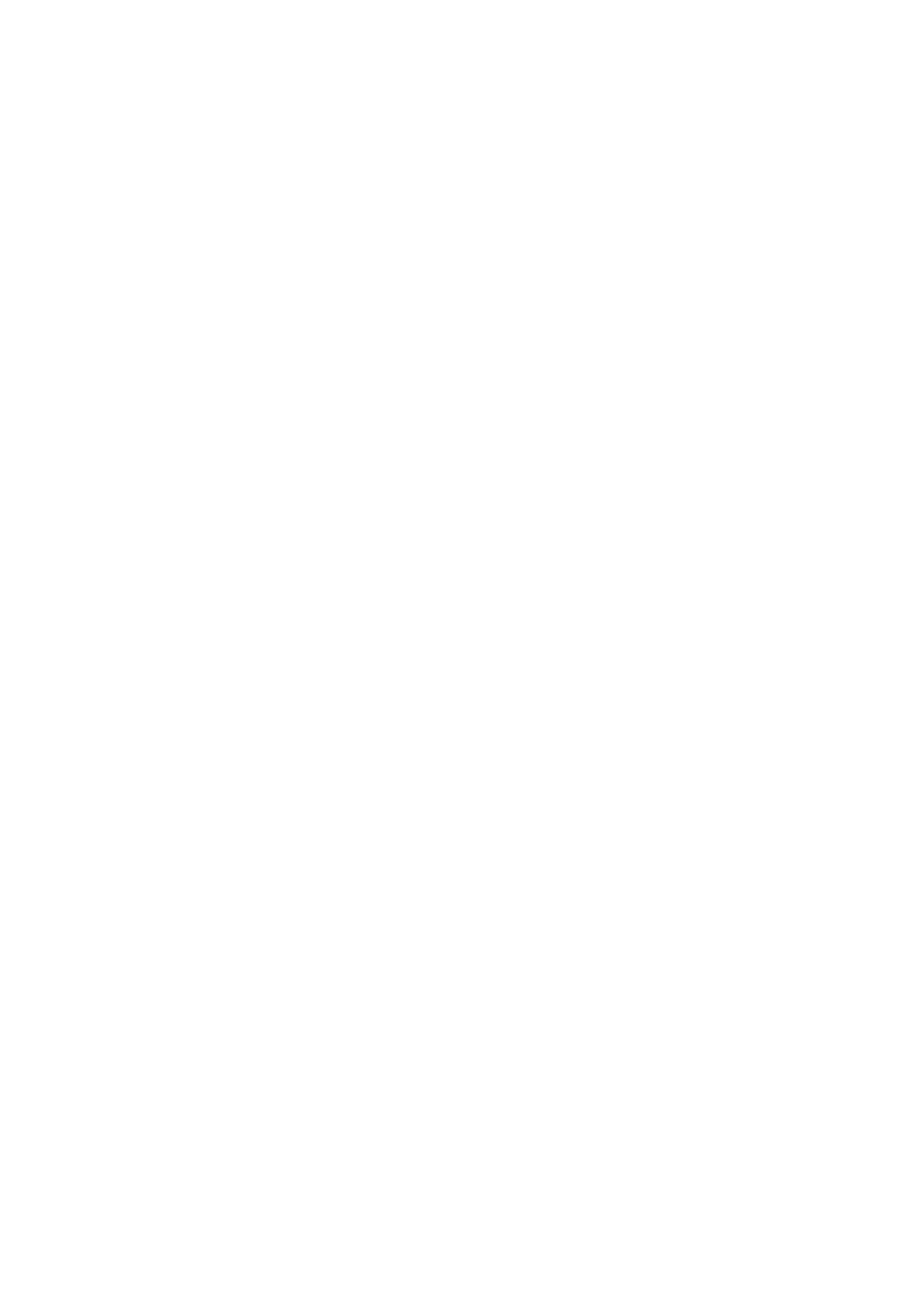




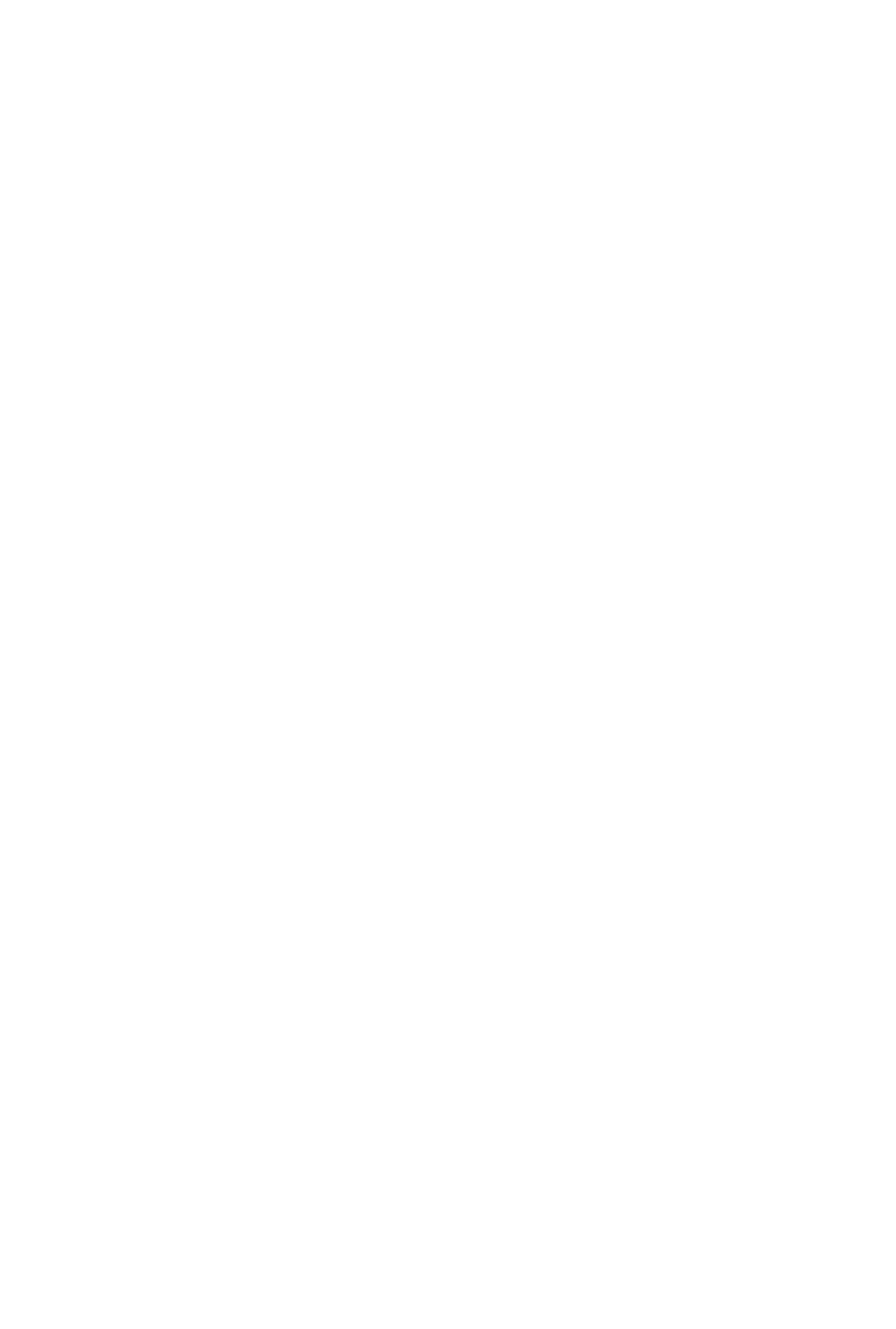




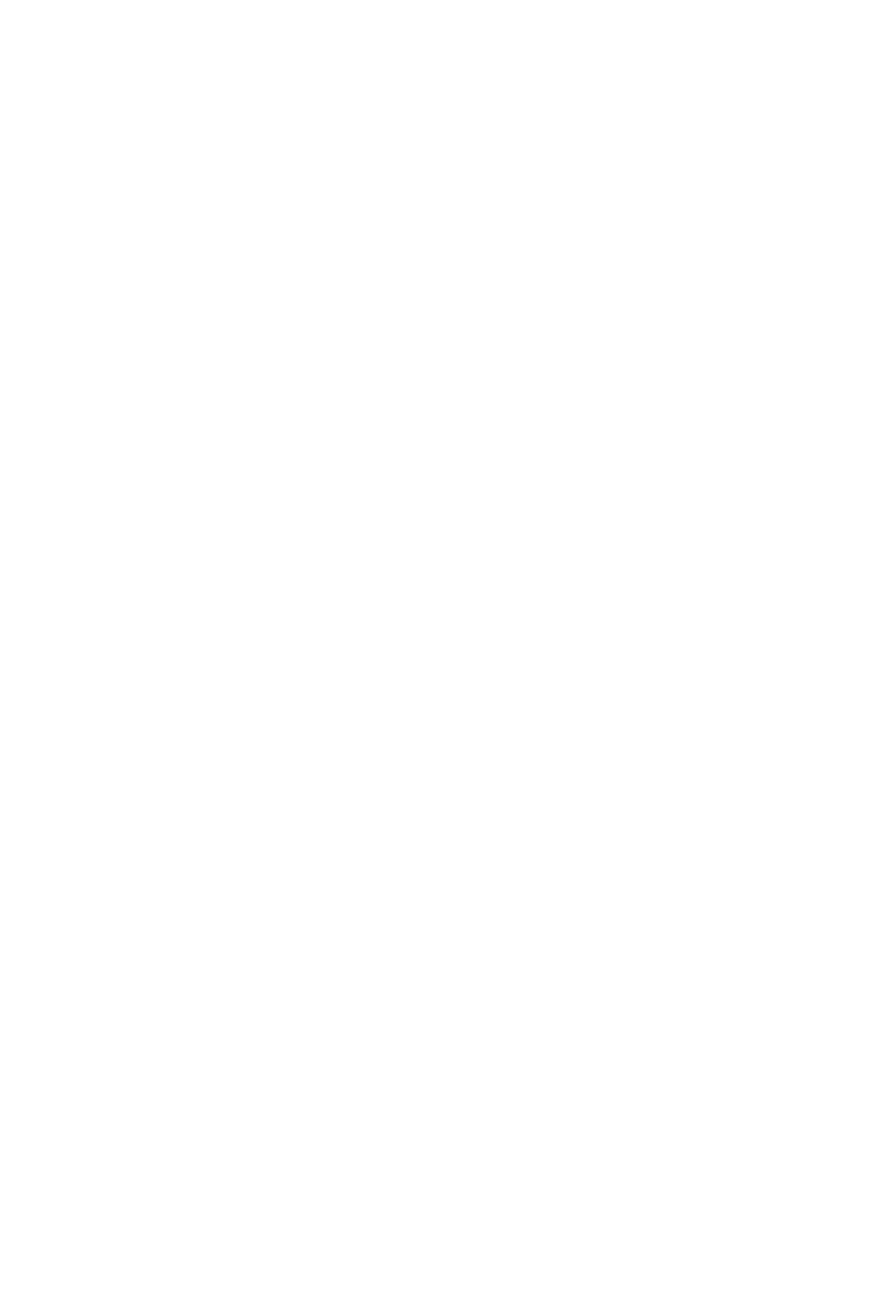




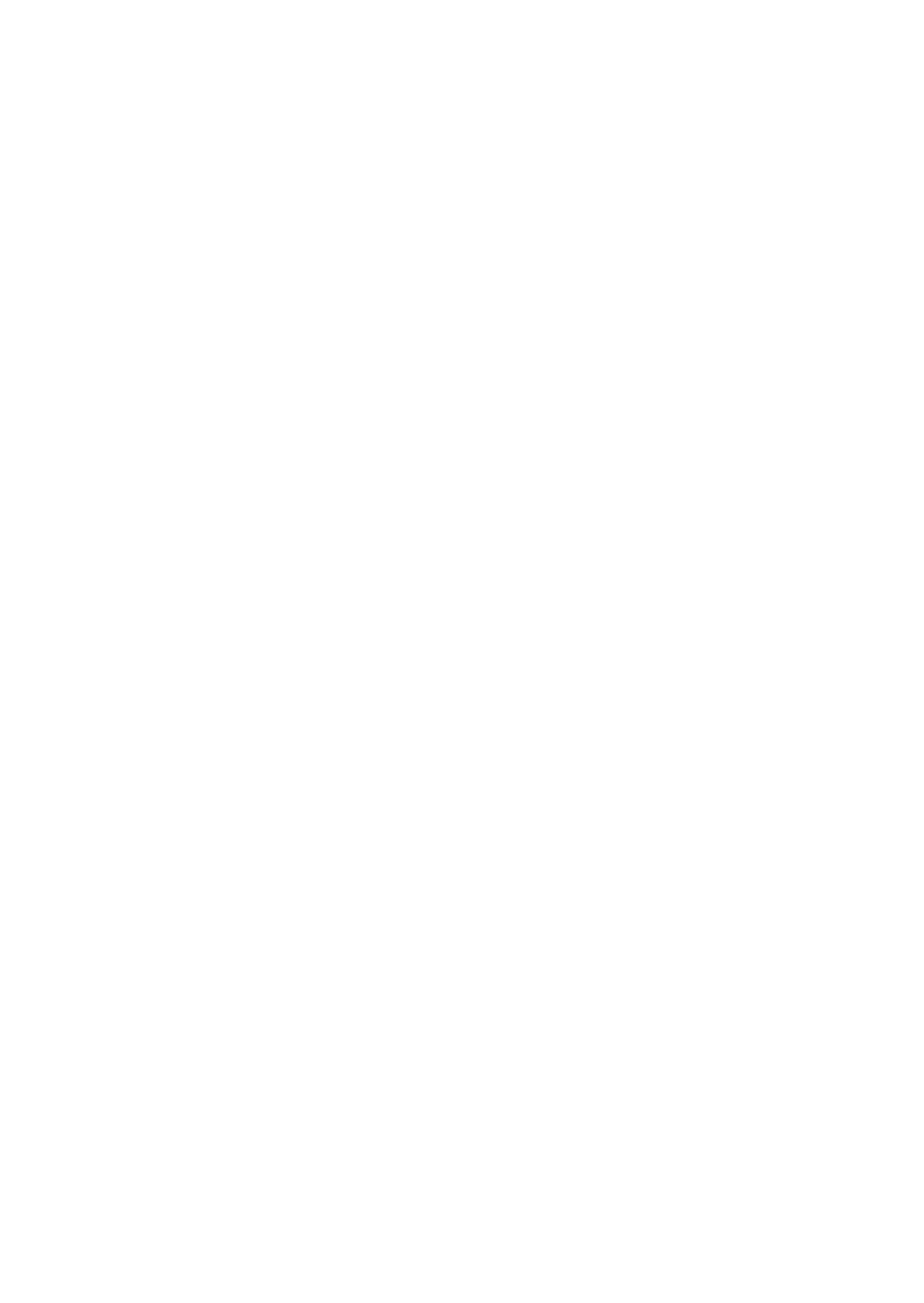




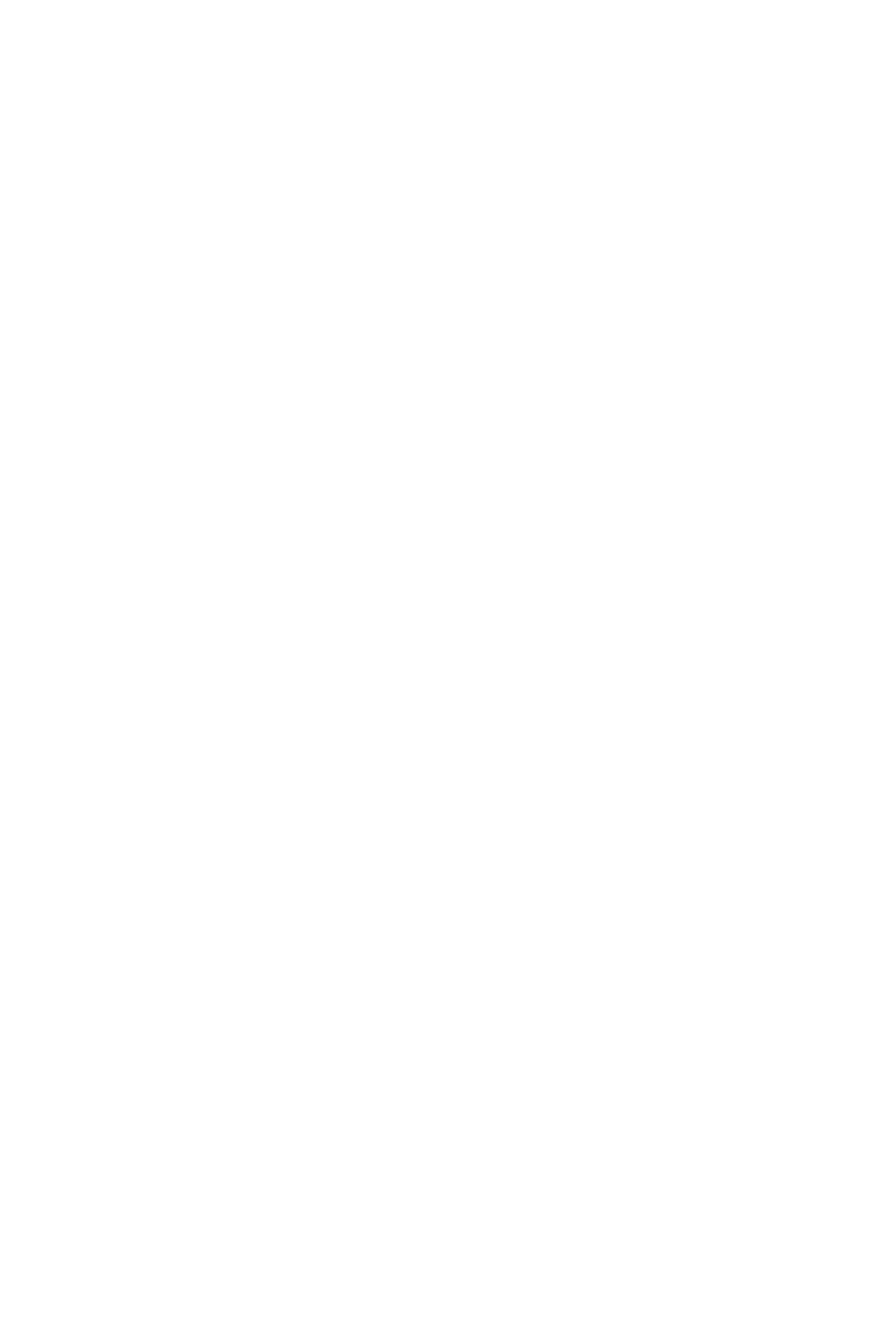




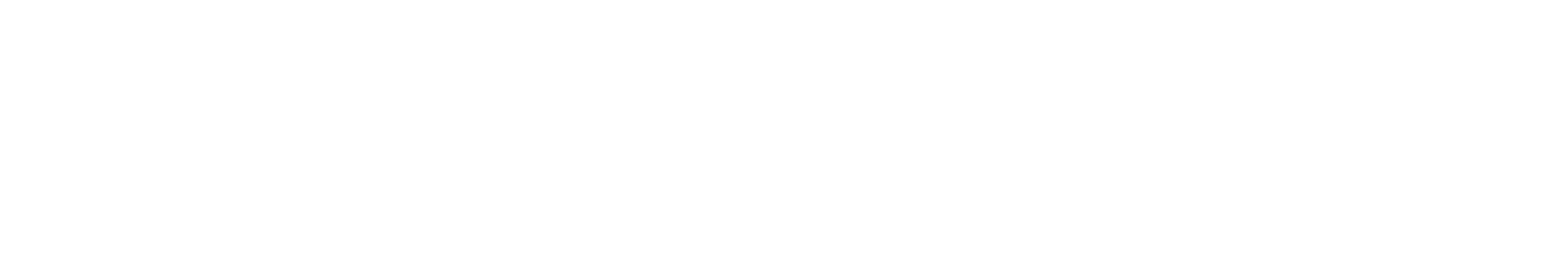

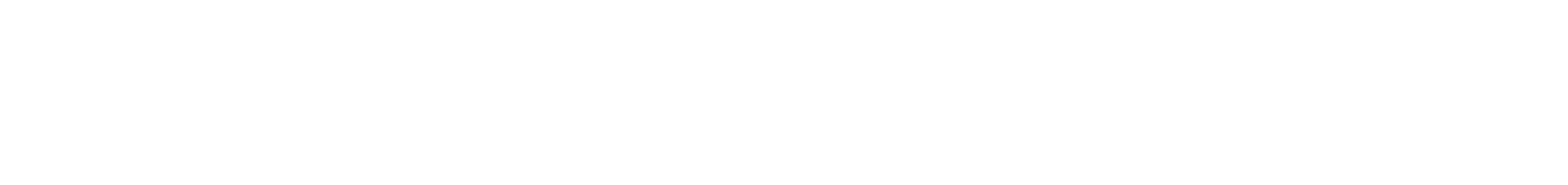

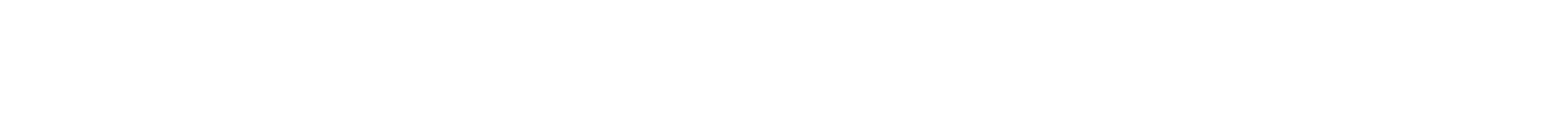

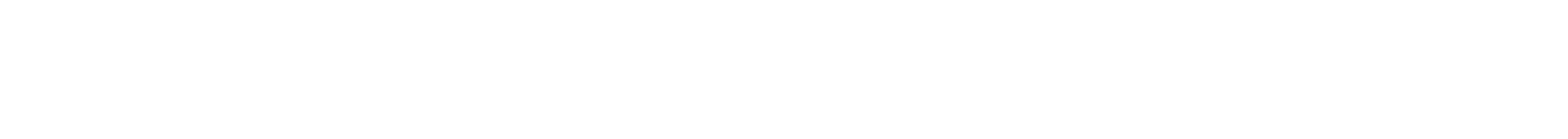

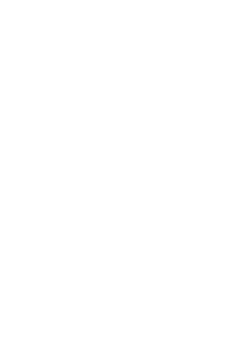

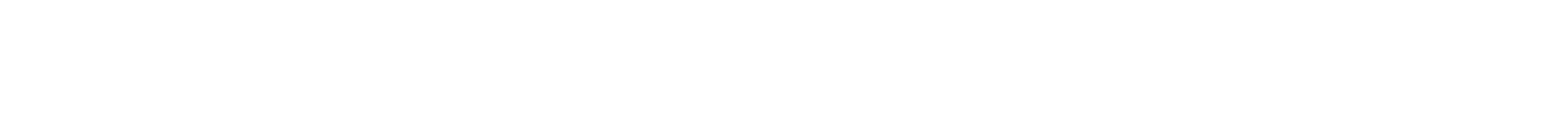

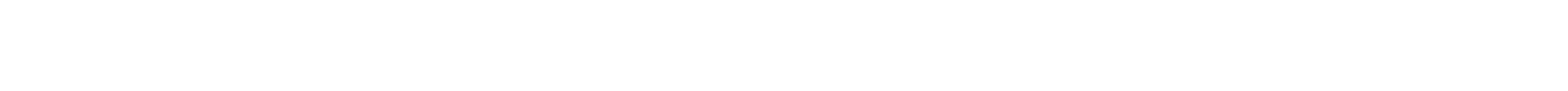

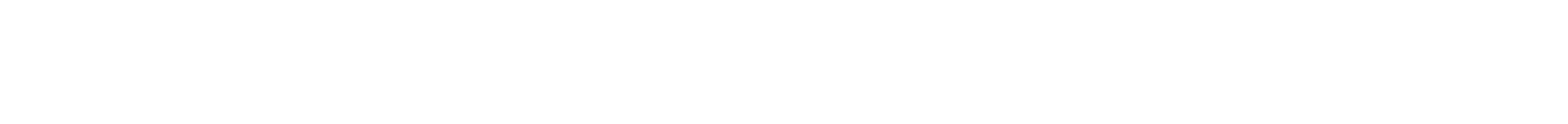

$$
\begin{aligned}
& \underset{\Xi}{\underline{g}} \\
& \text { 荡 }
\end{aligned}
$$

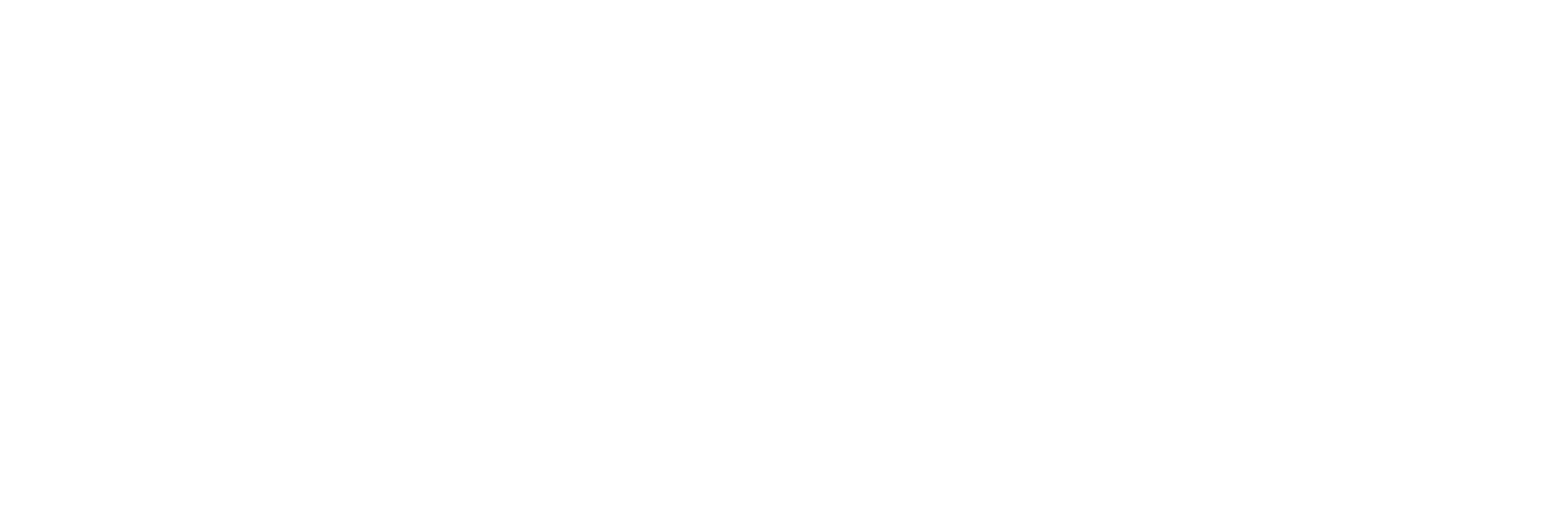

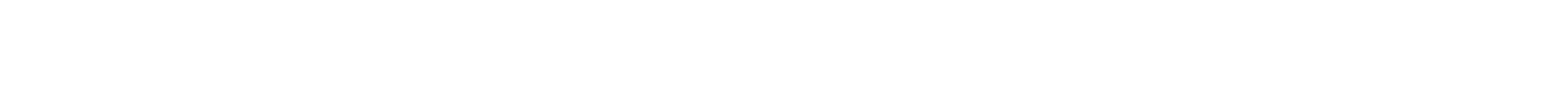

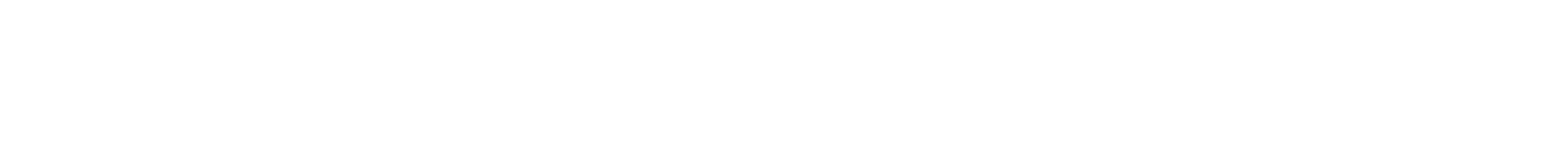




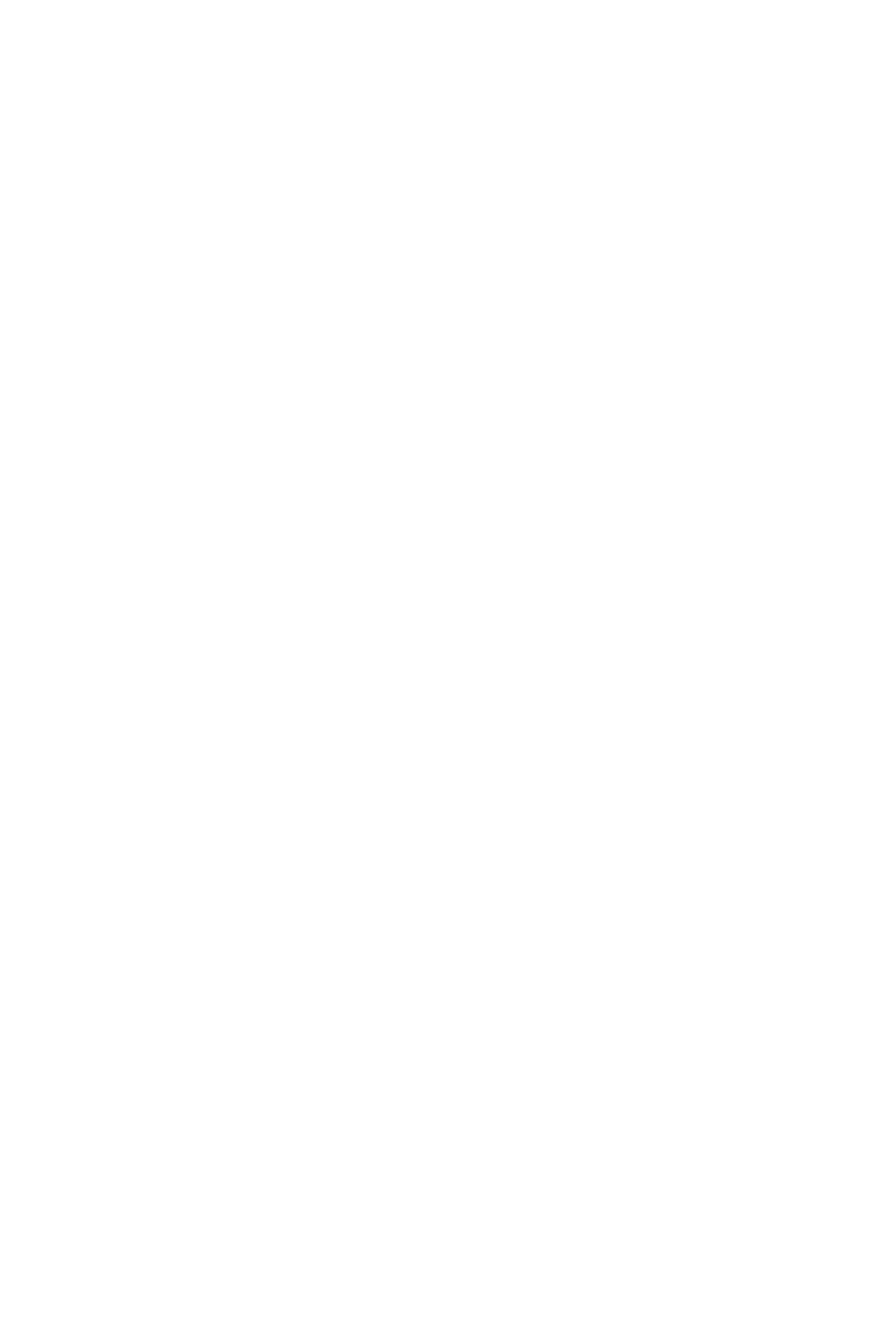




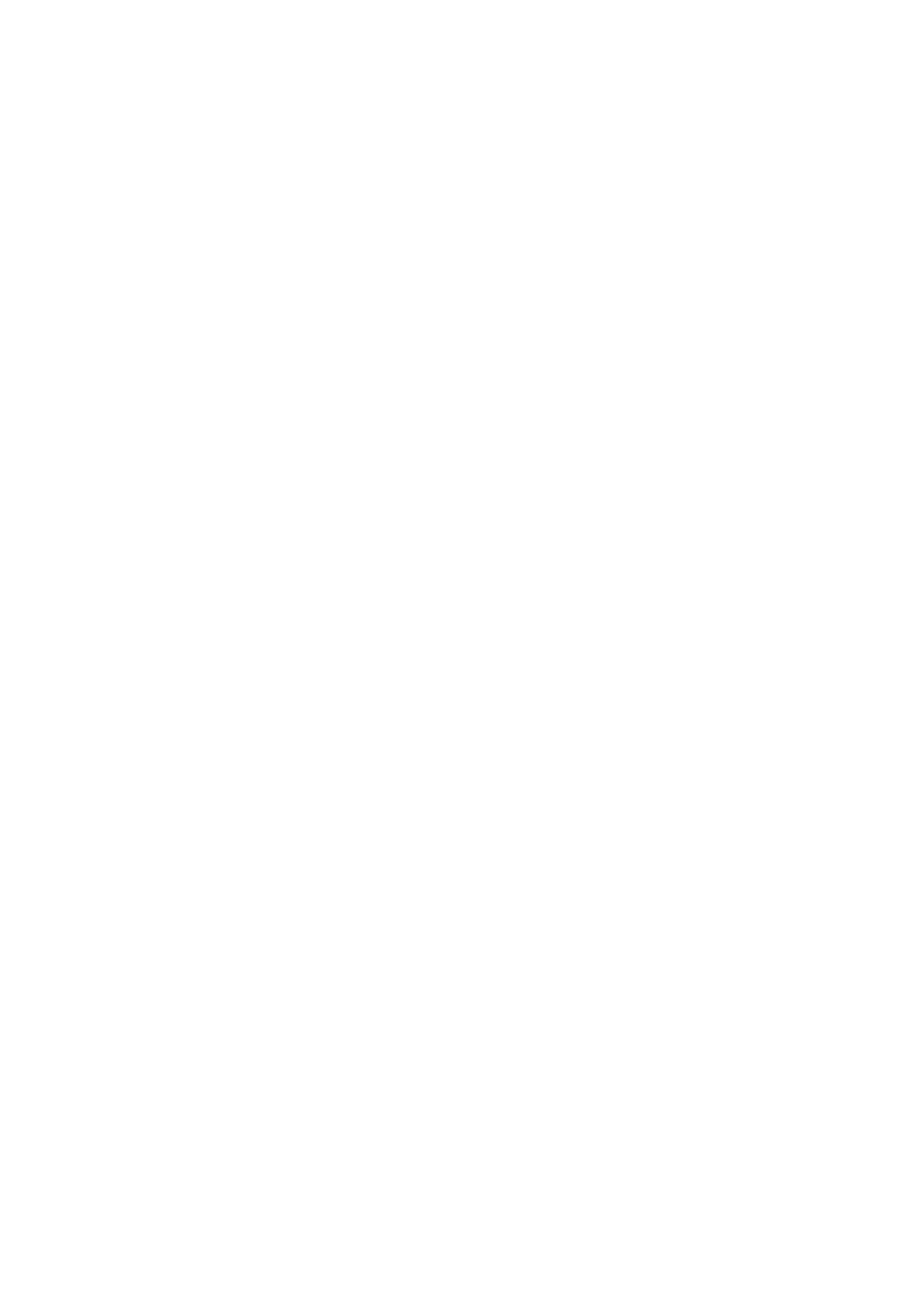




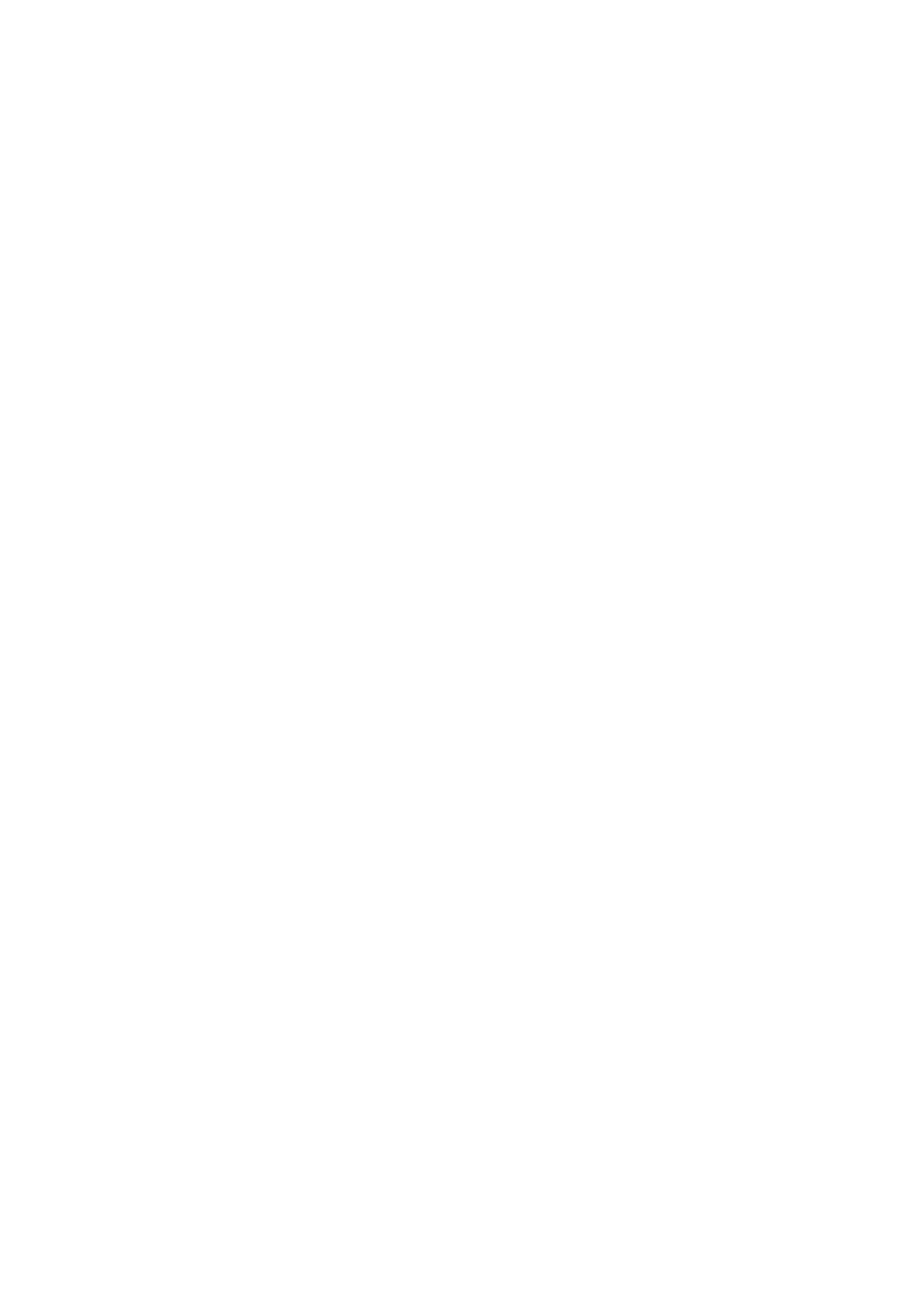




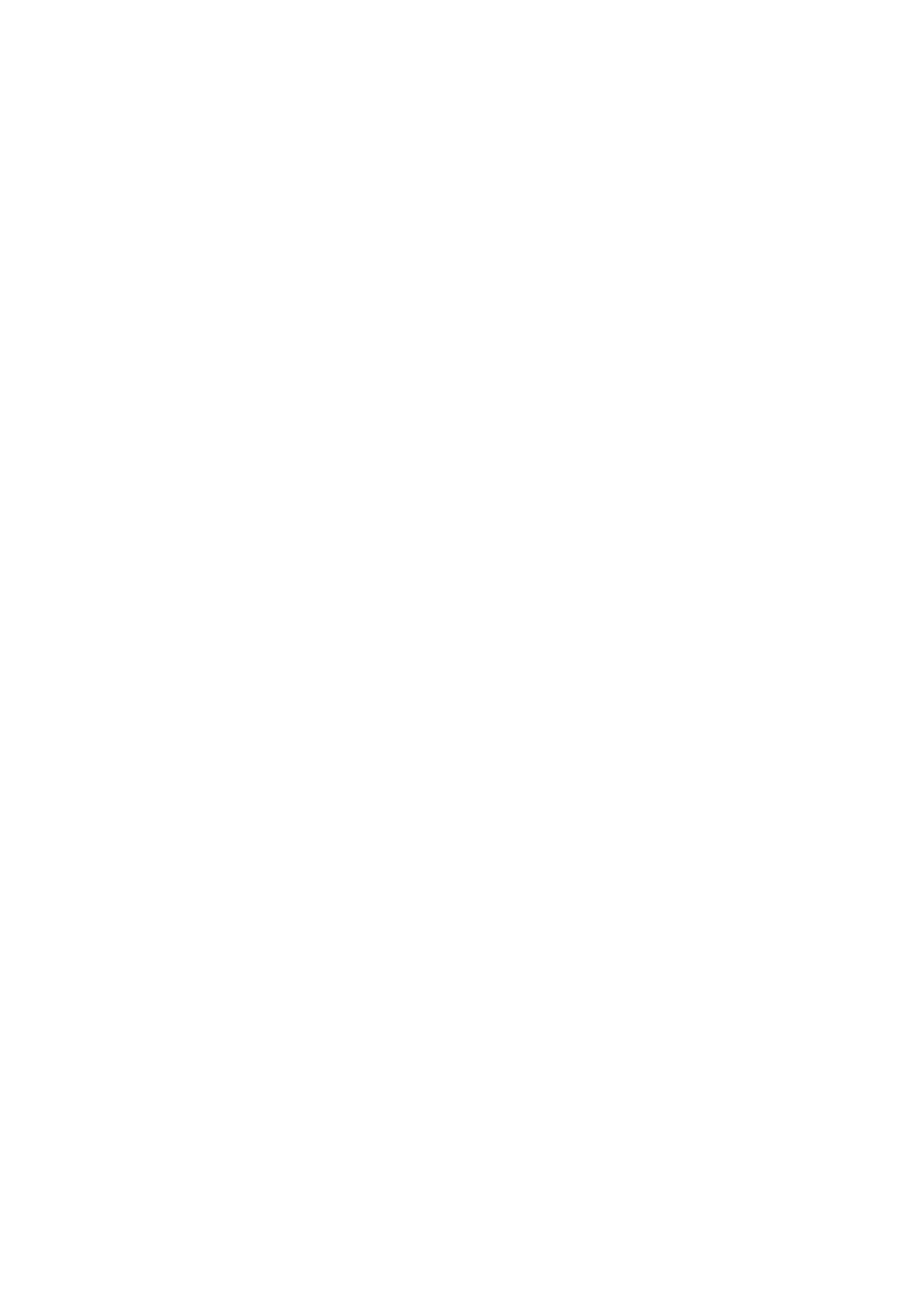




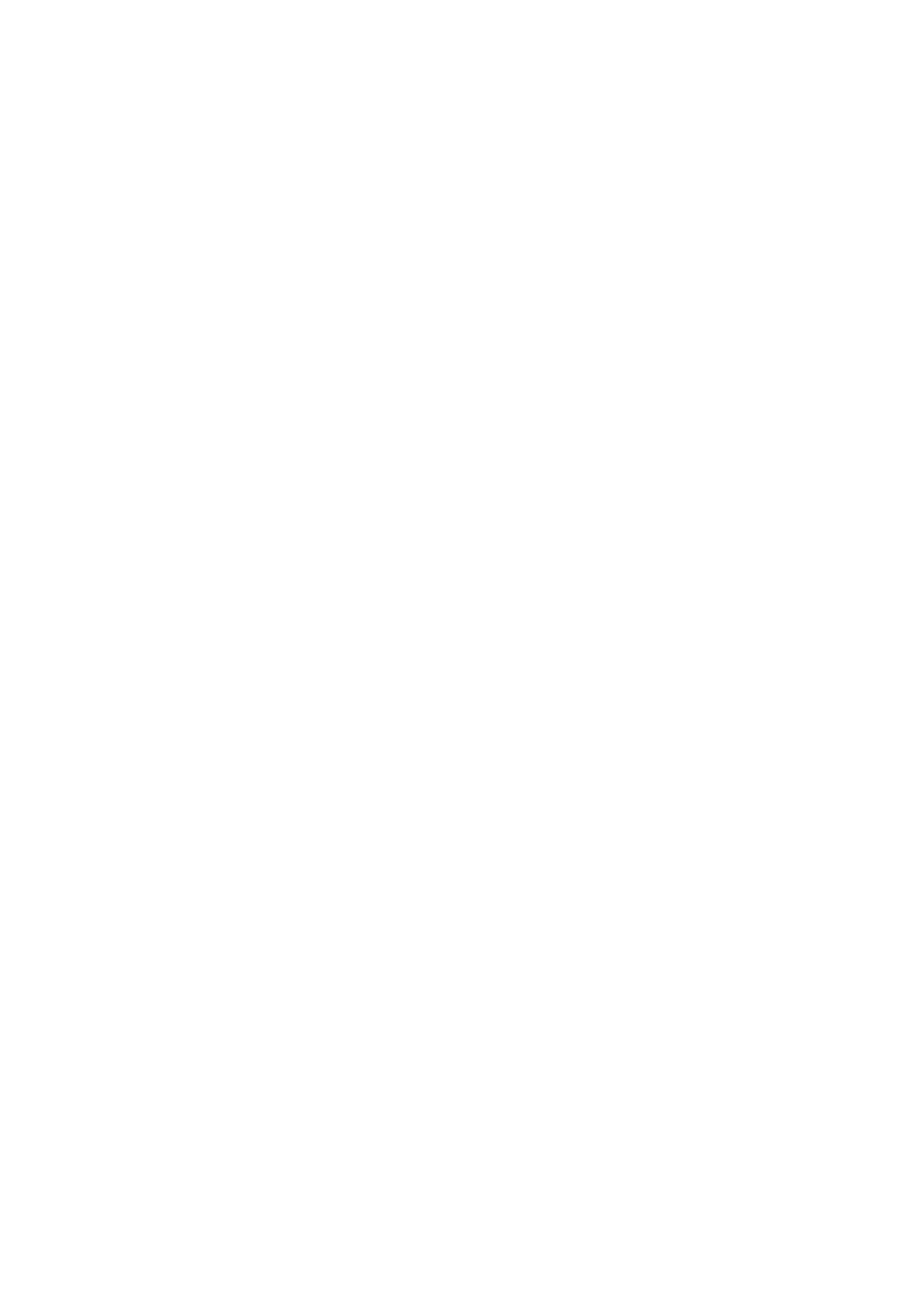




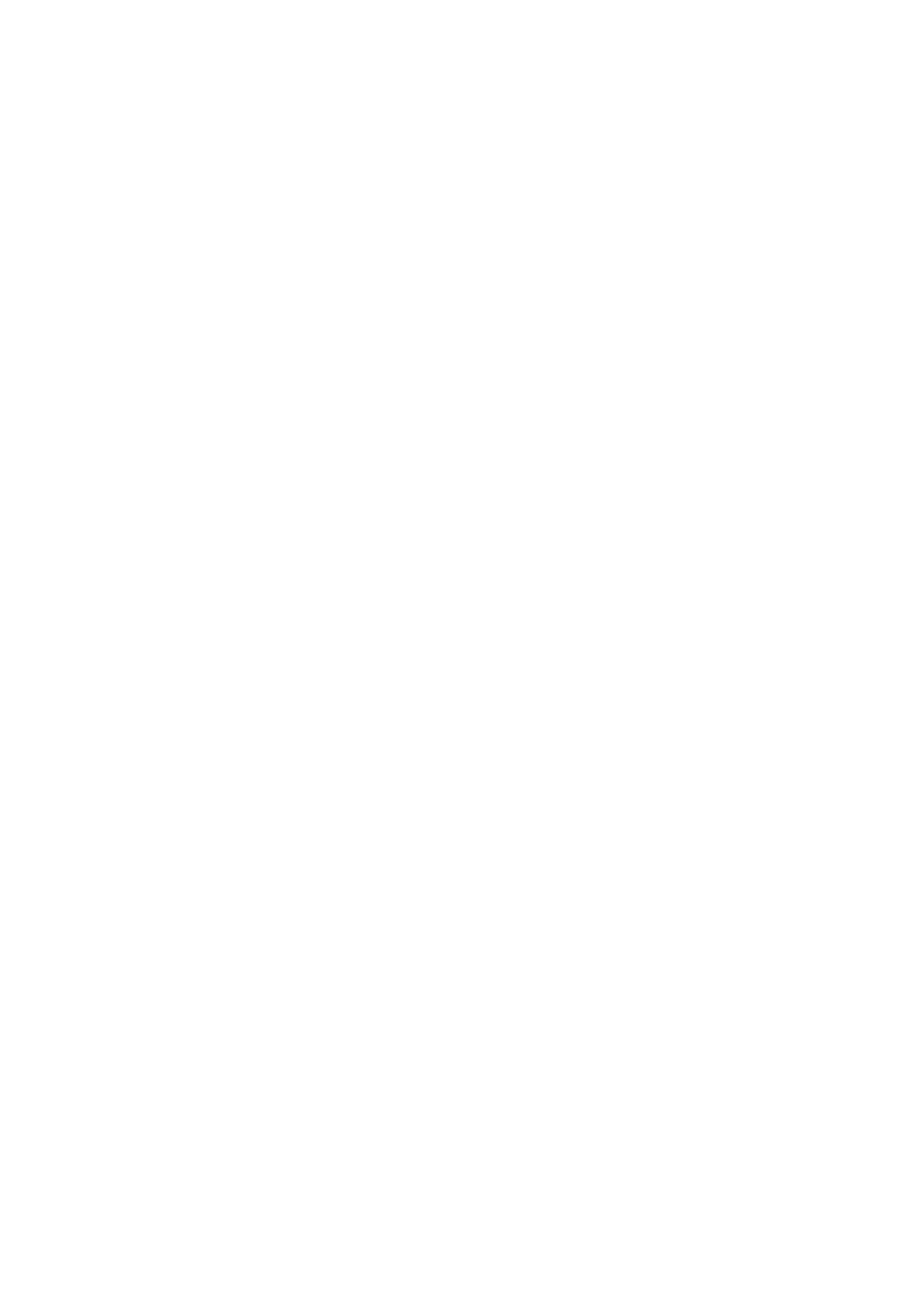




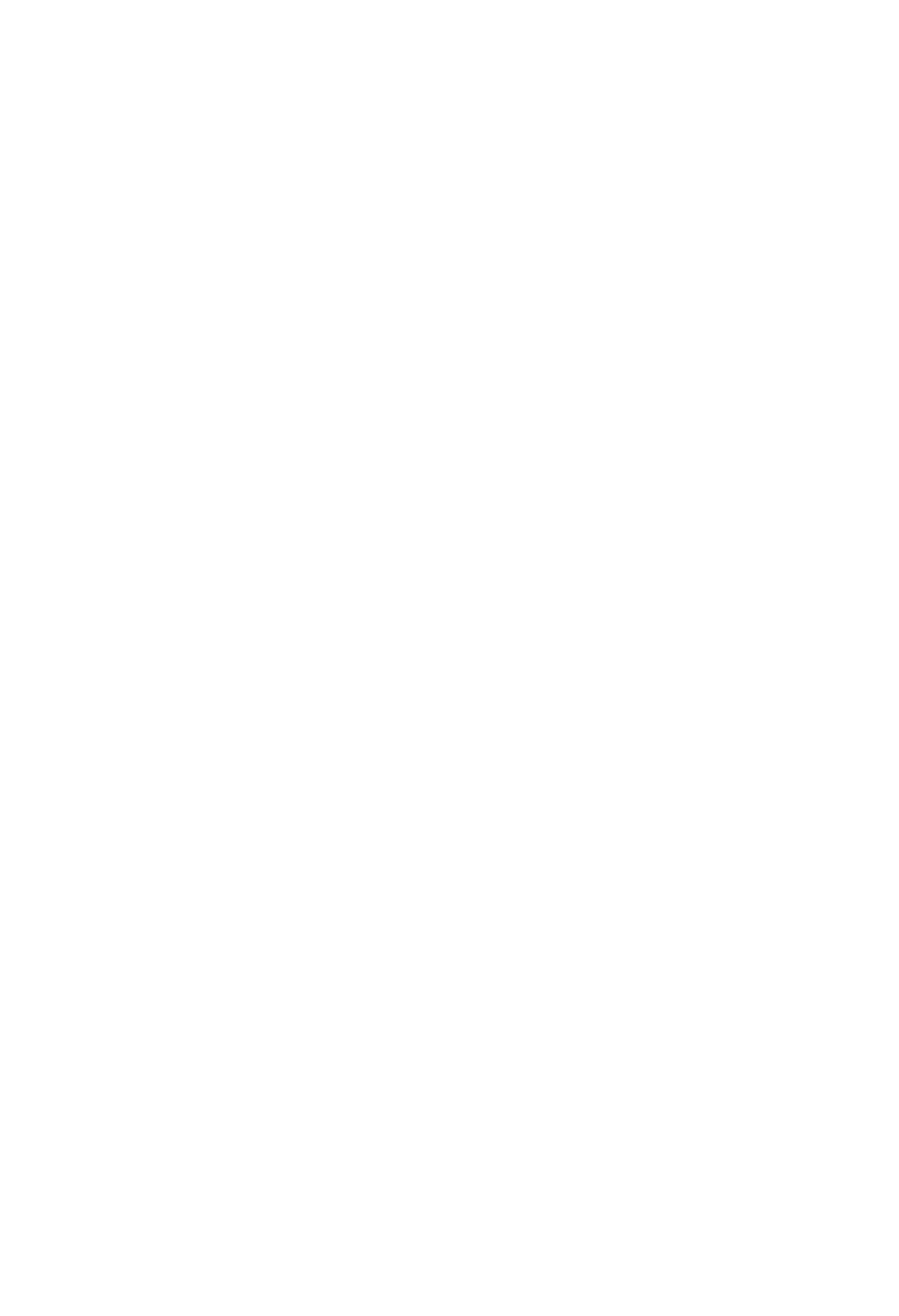




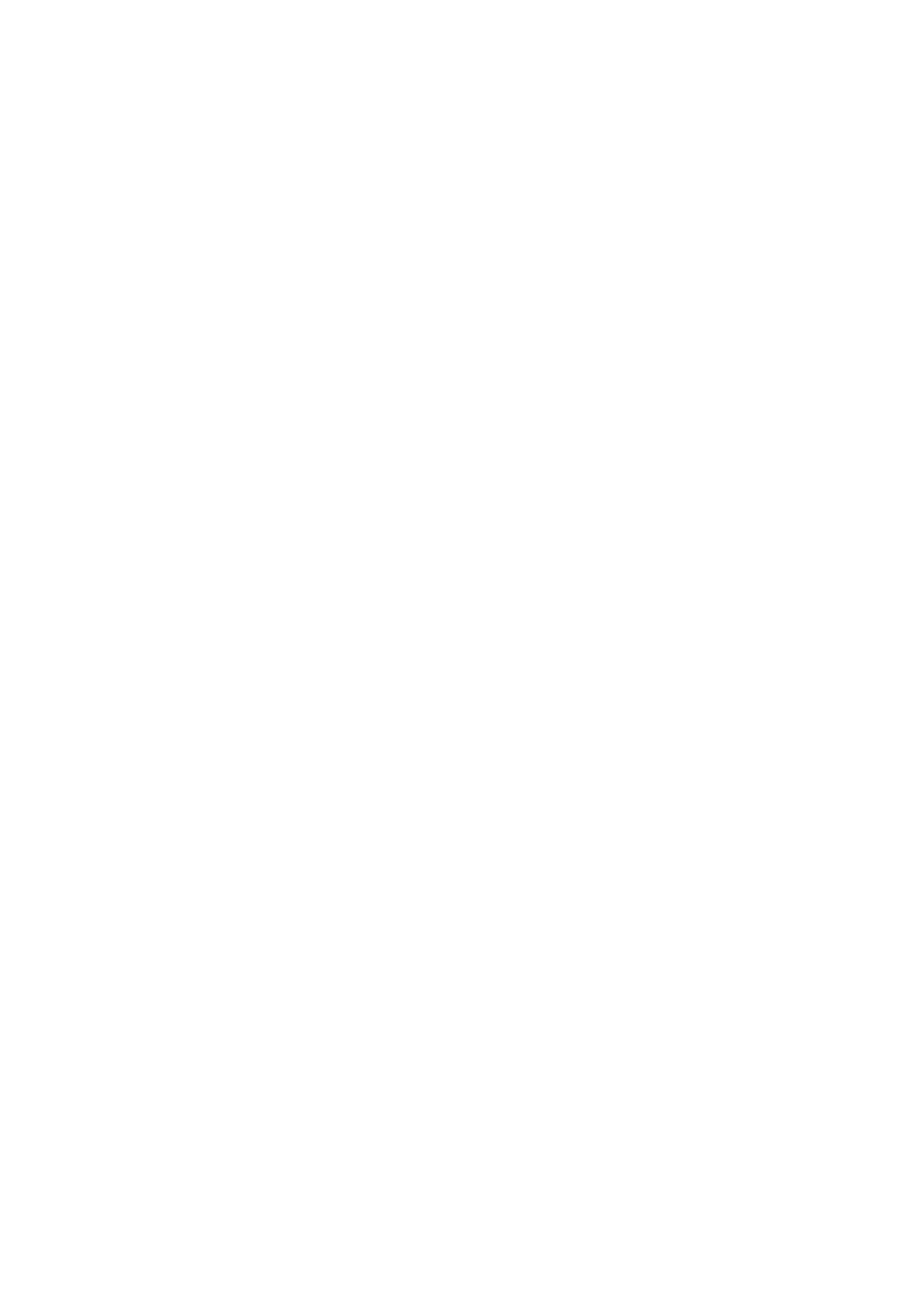




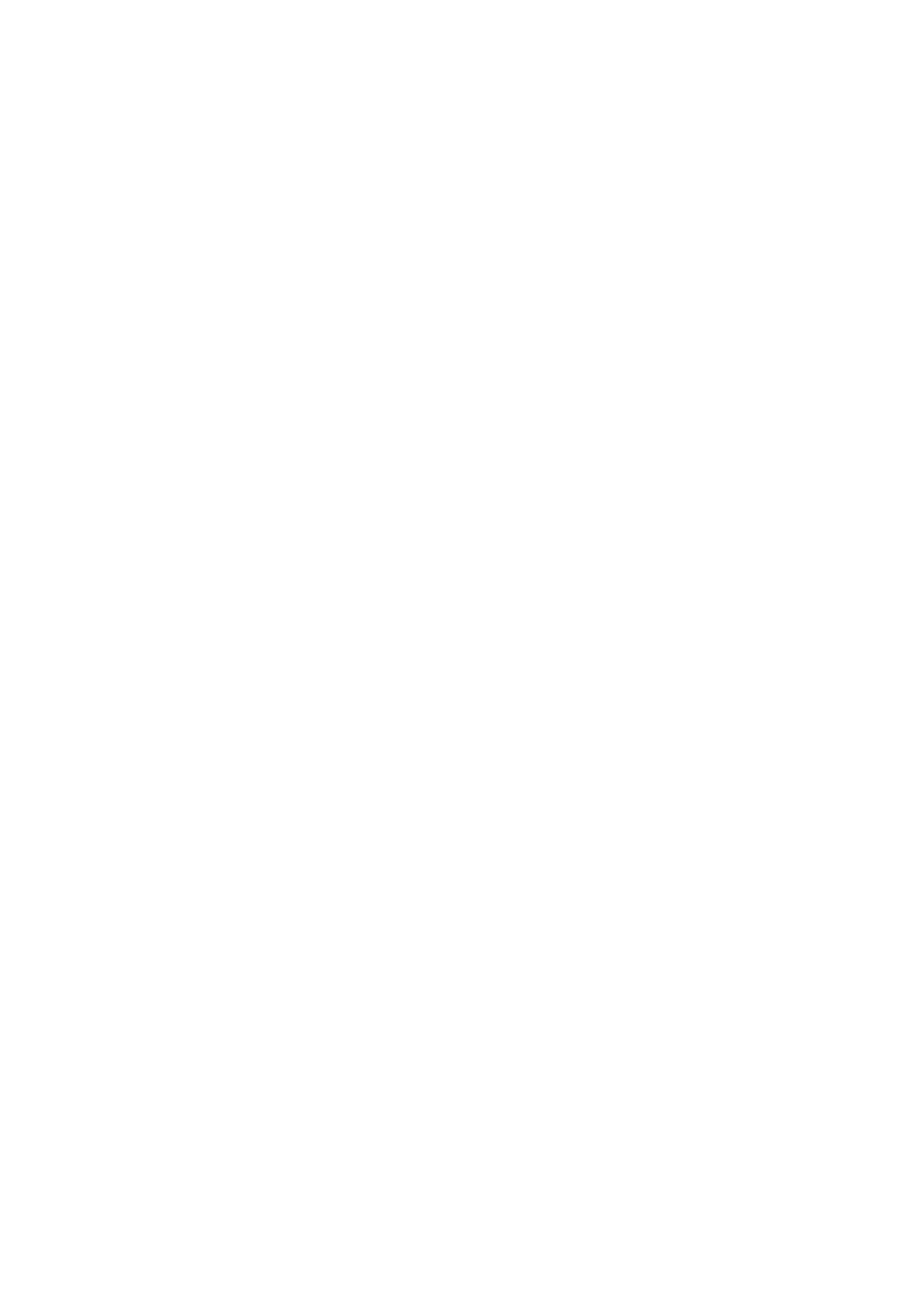




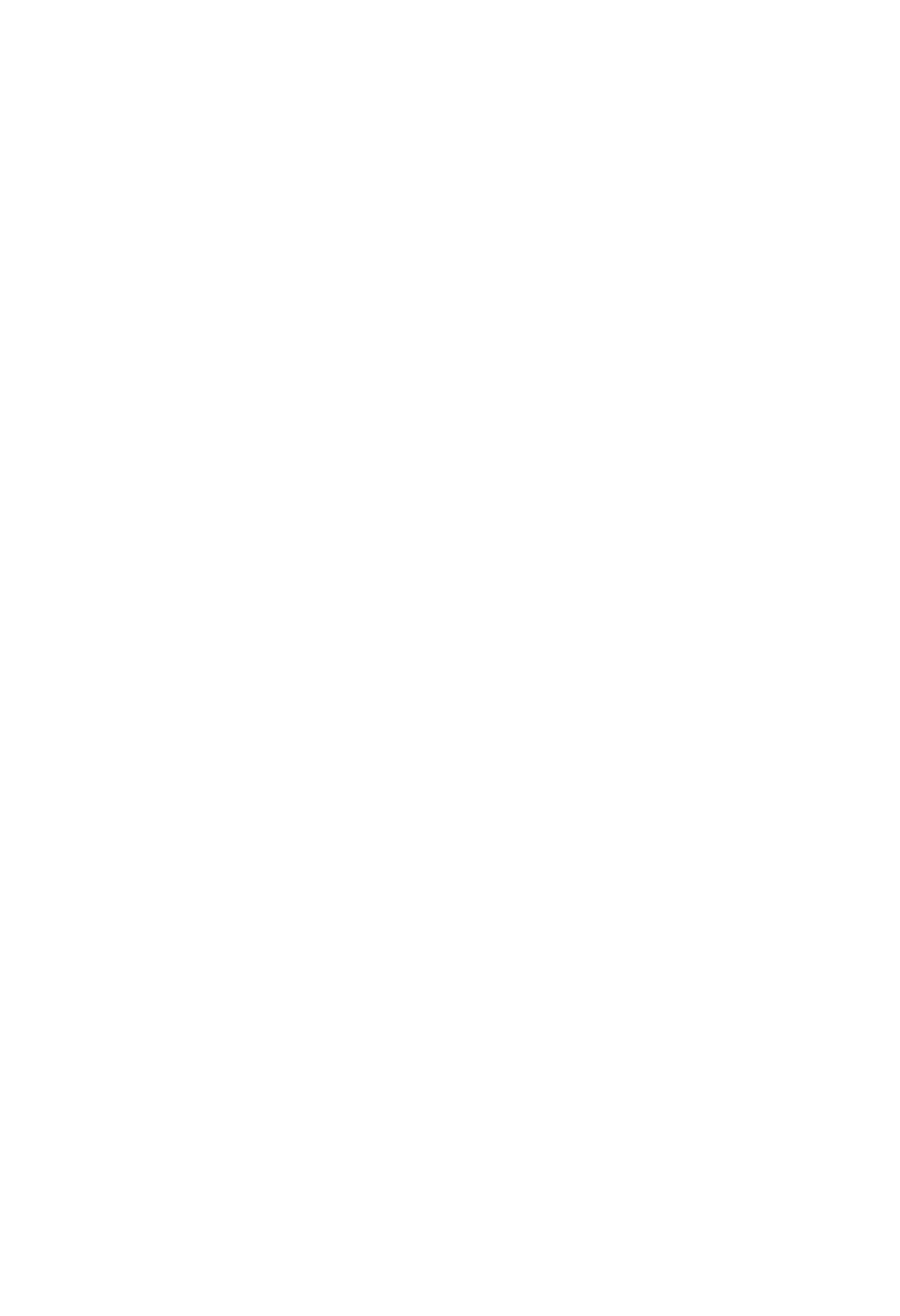




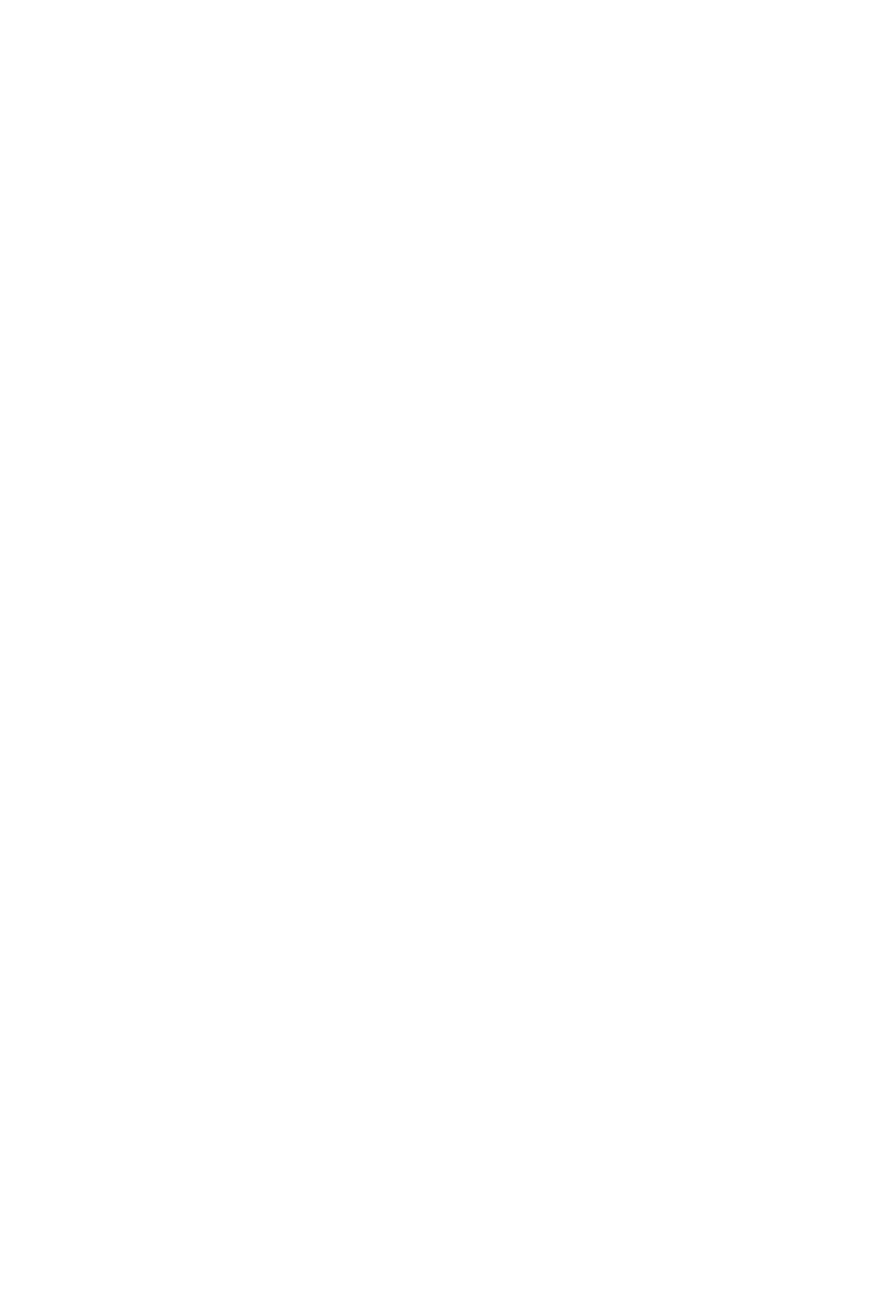




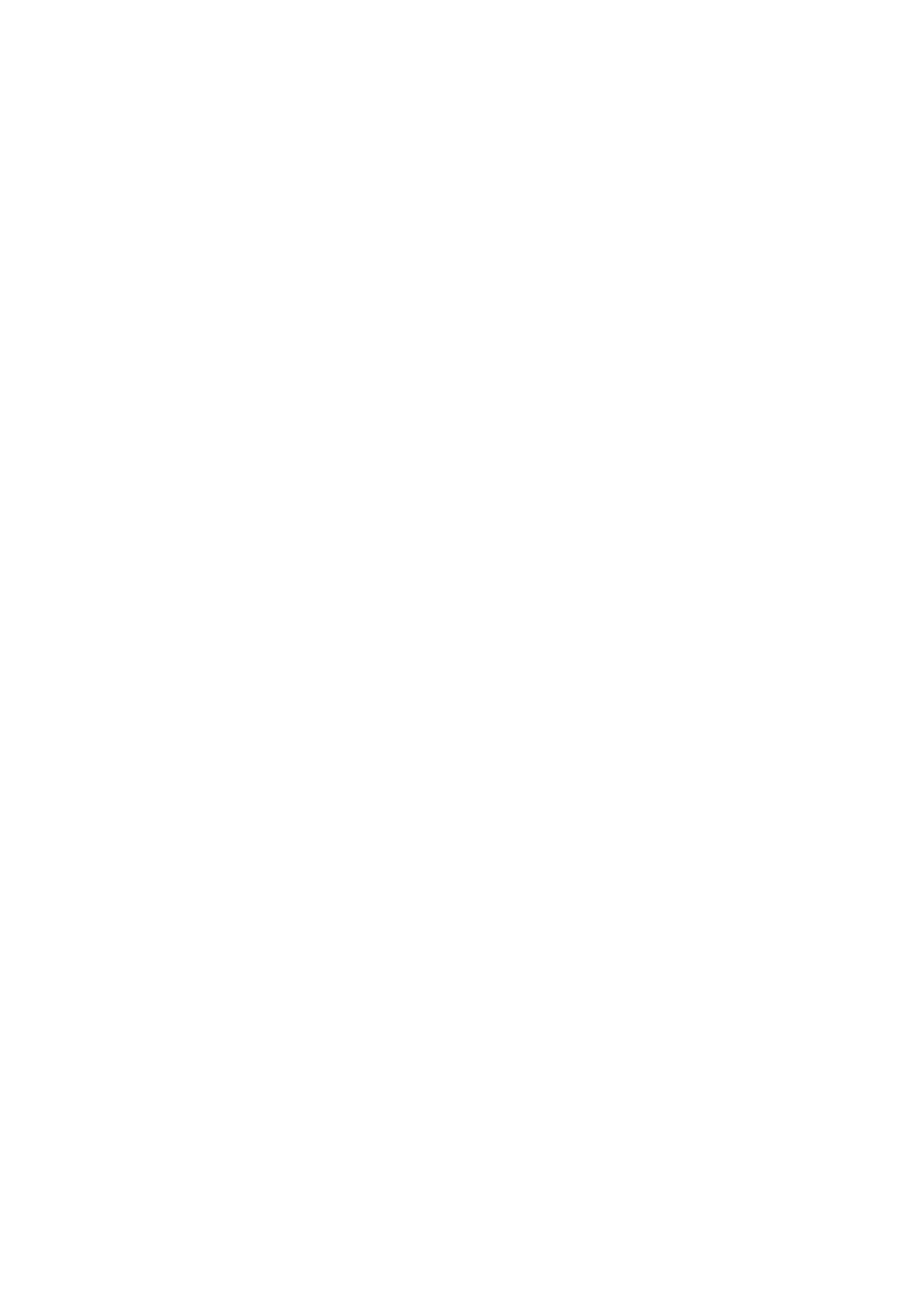




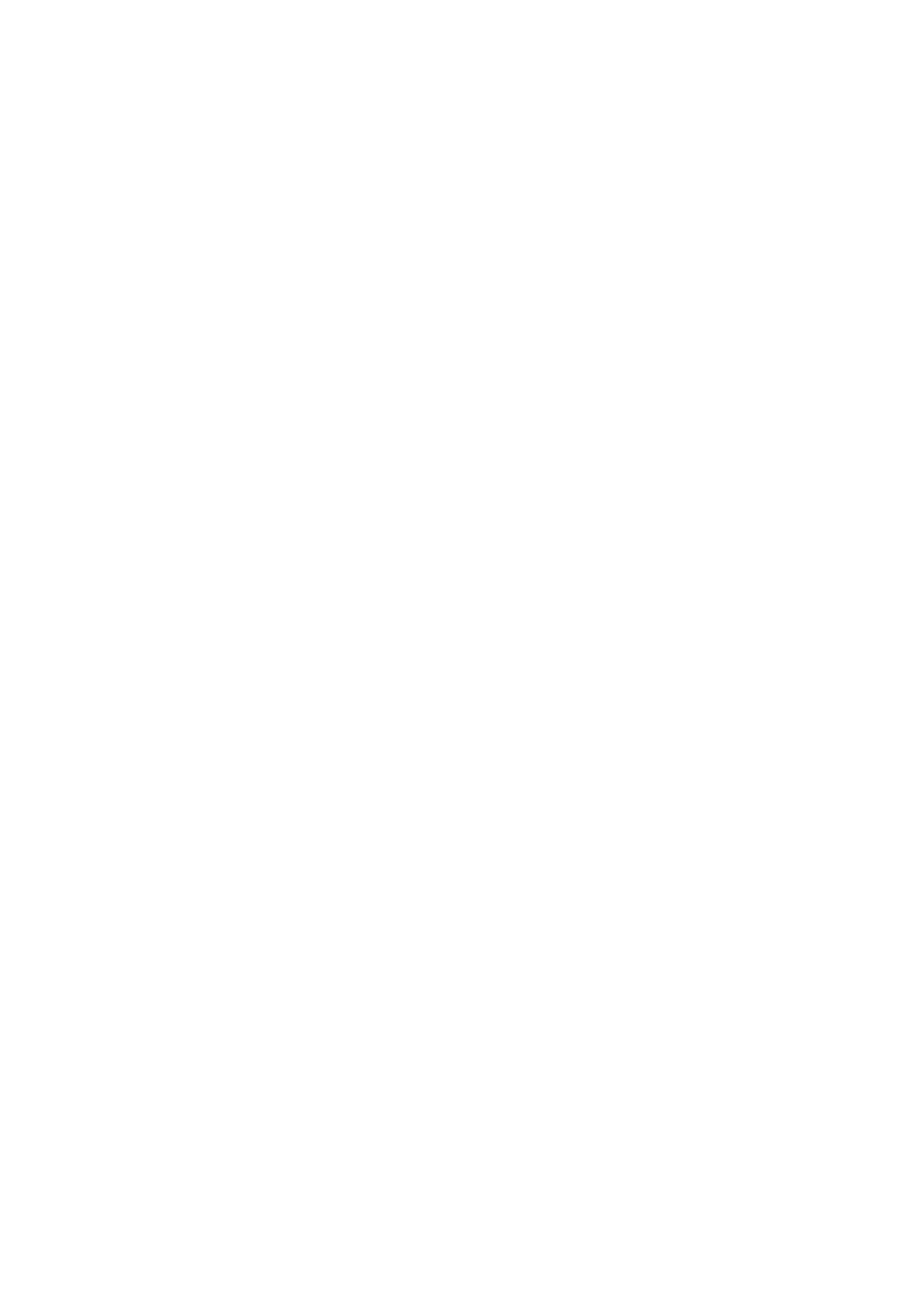




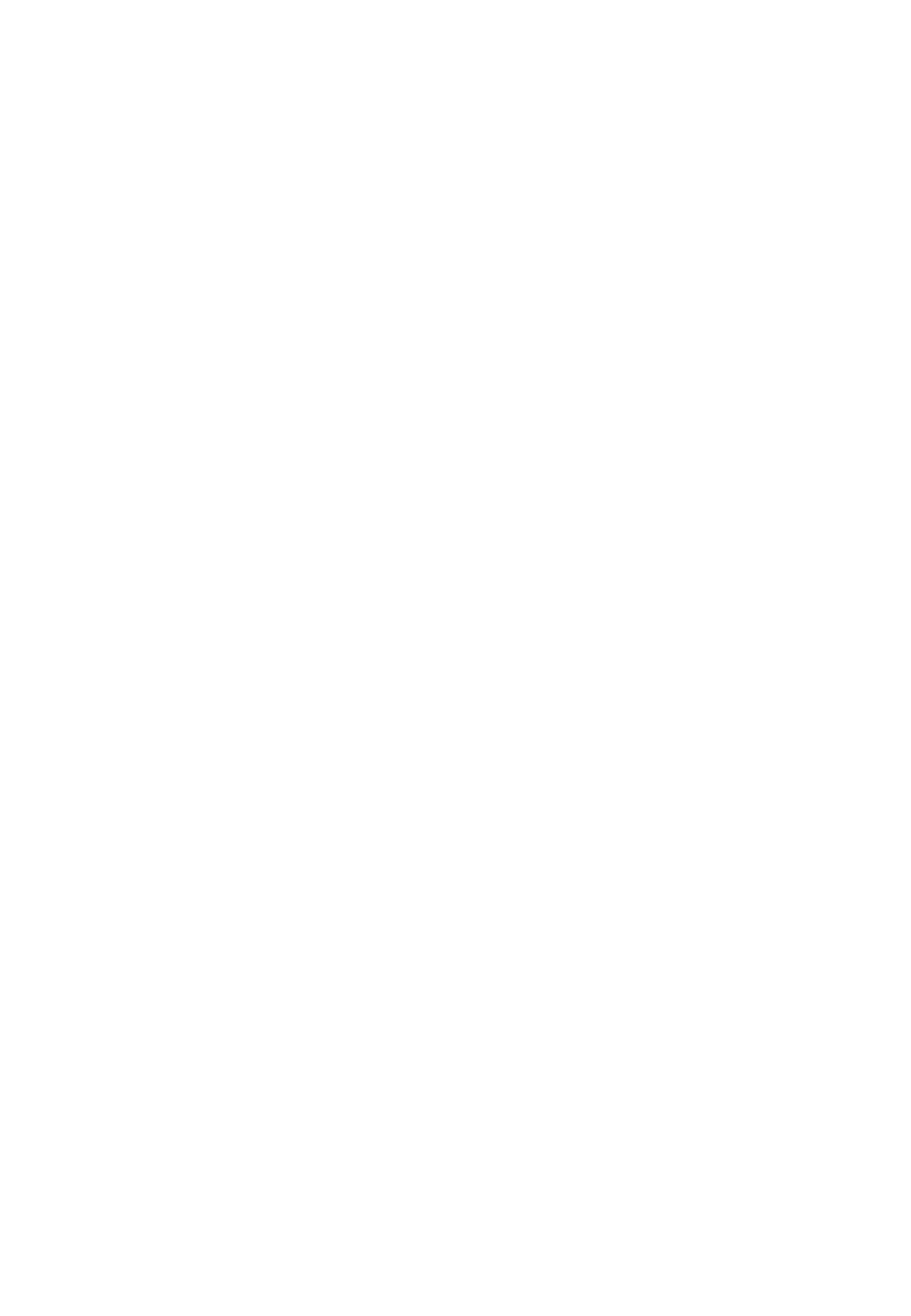




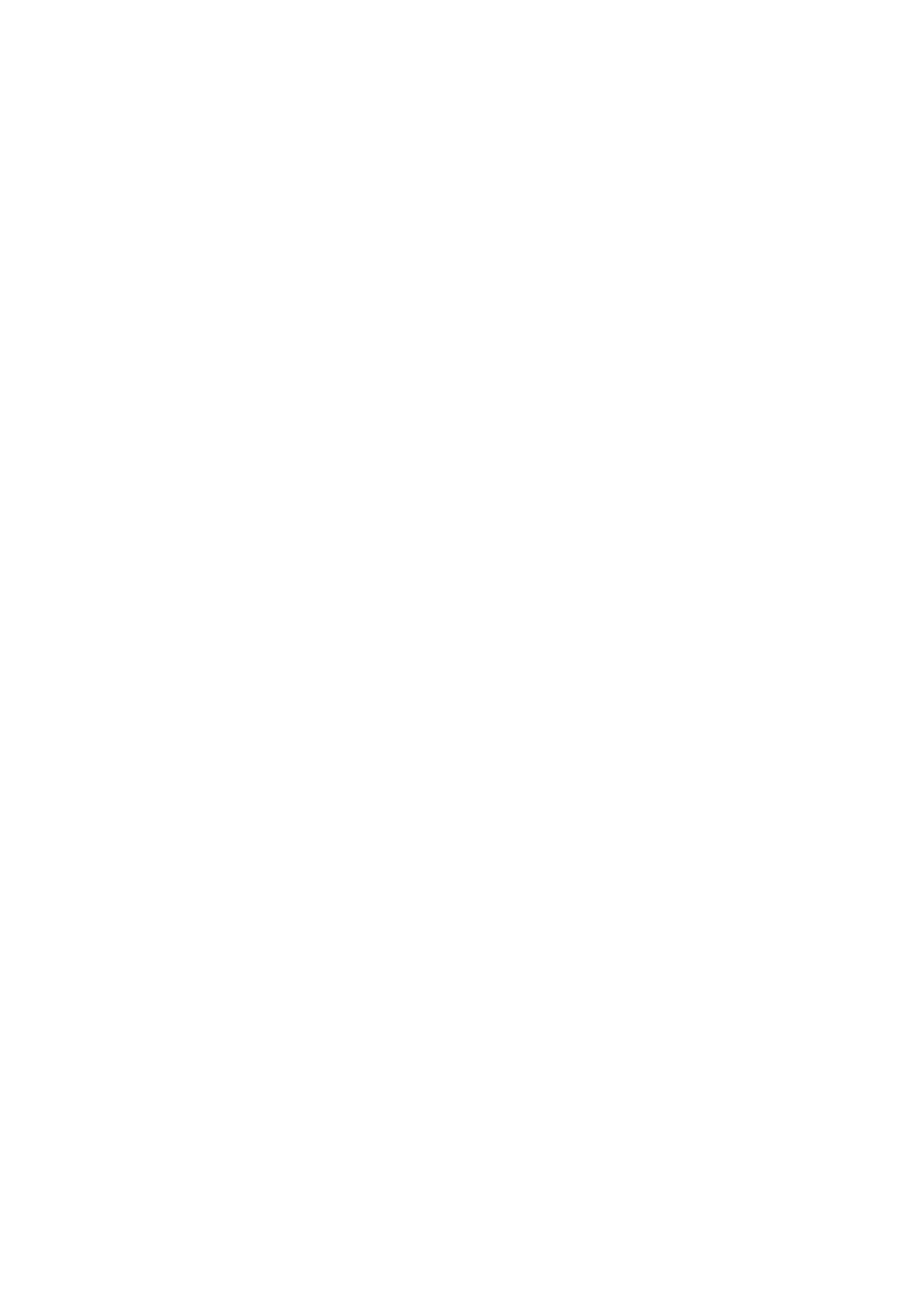




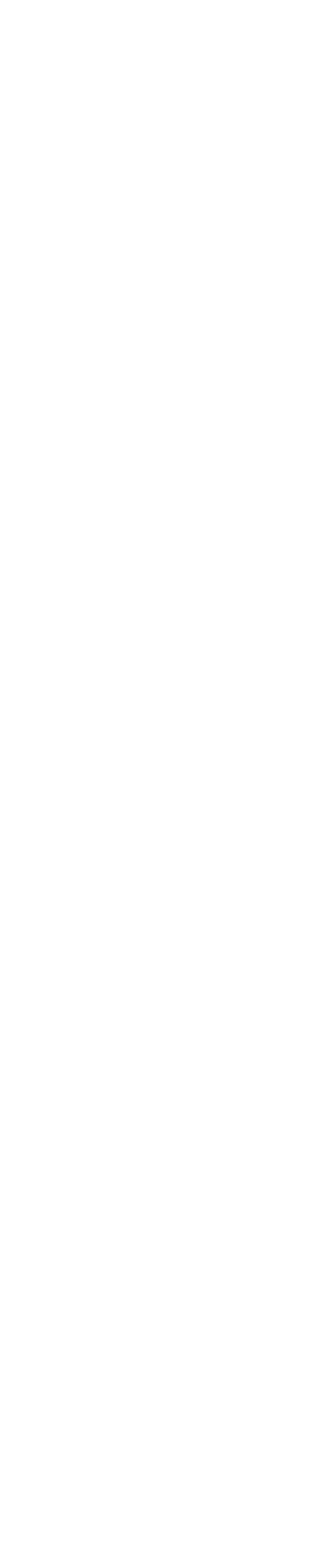




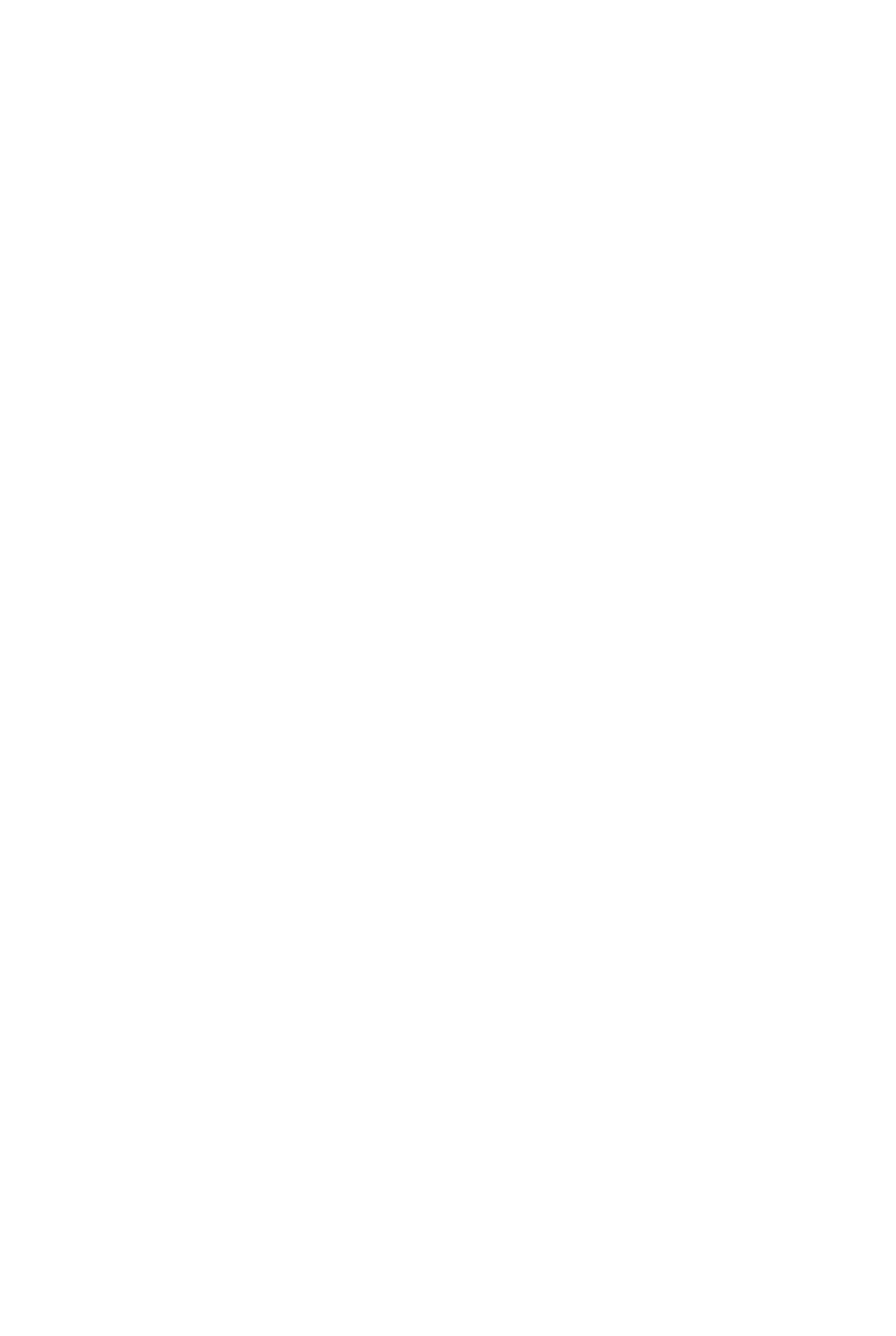




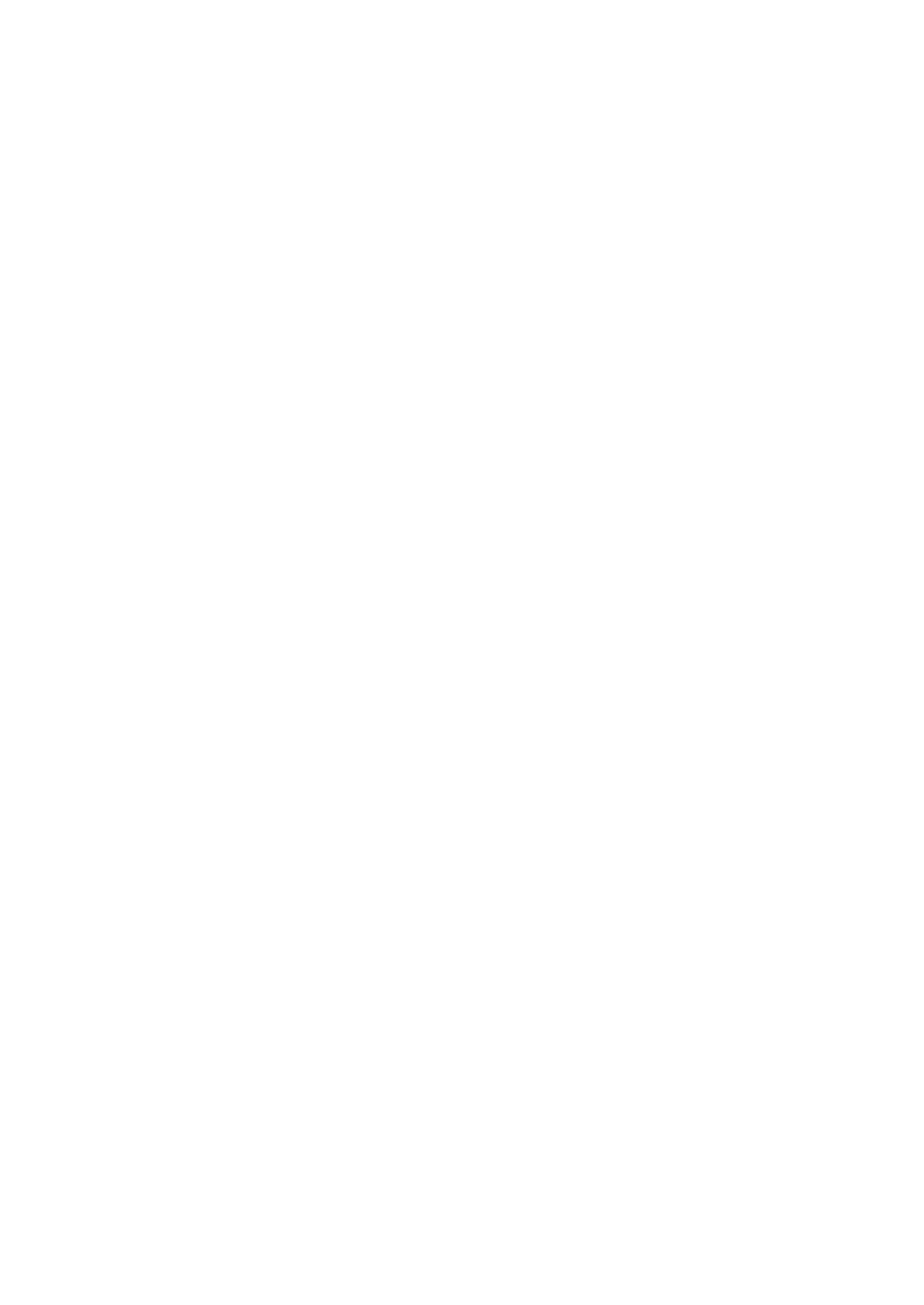




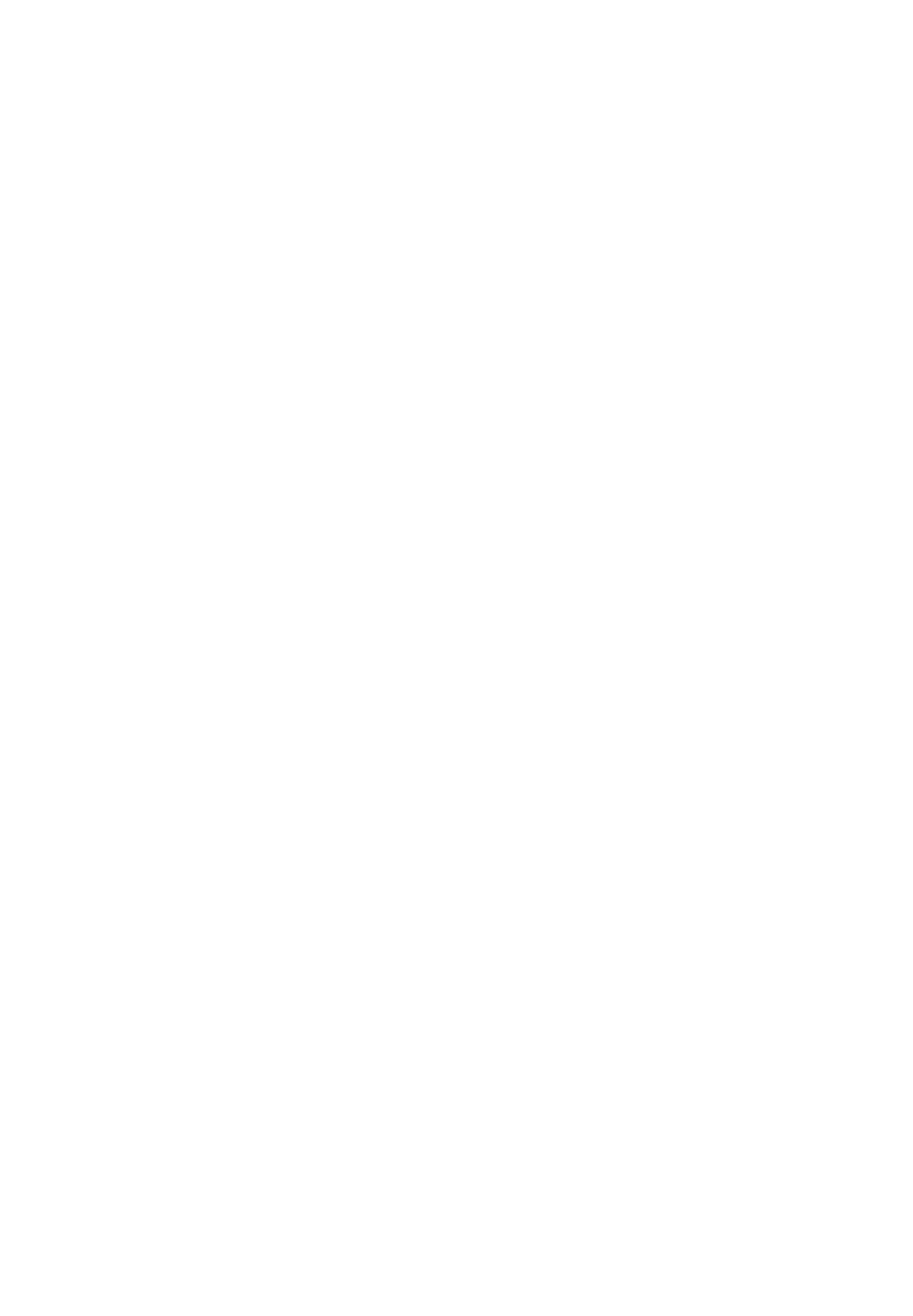




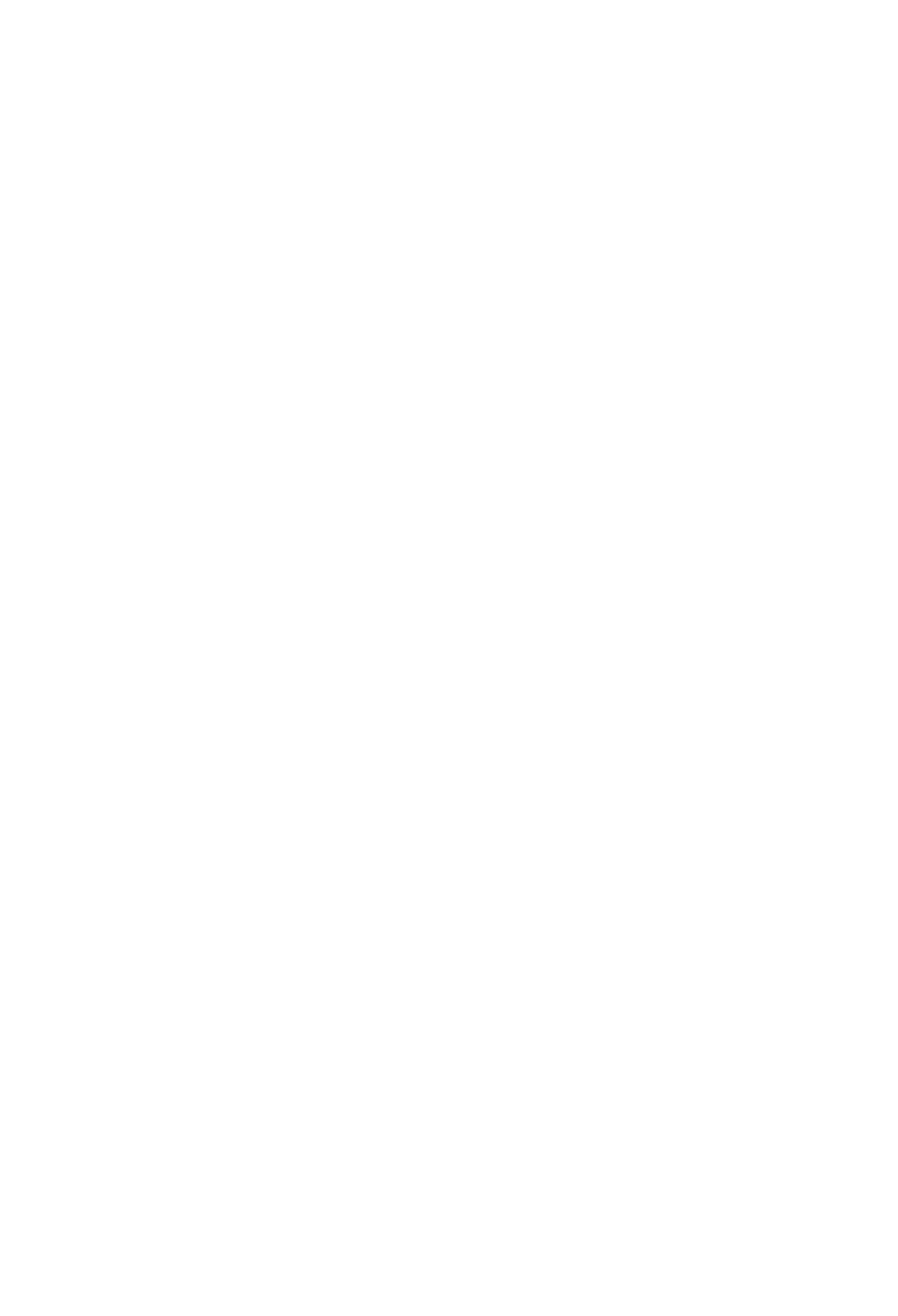




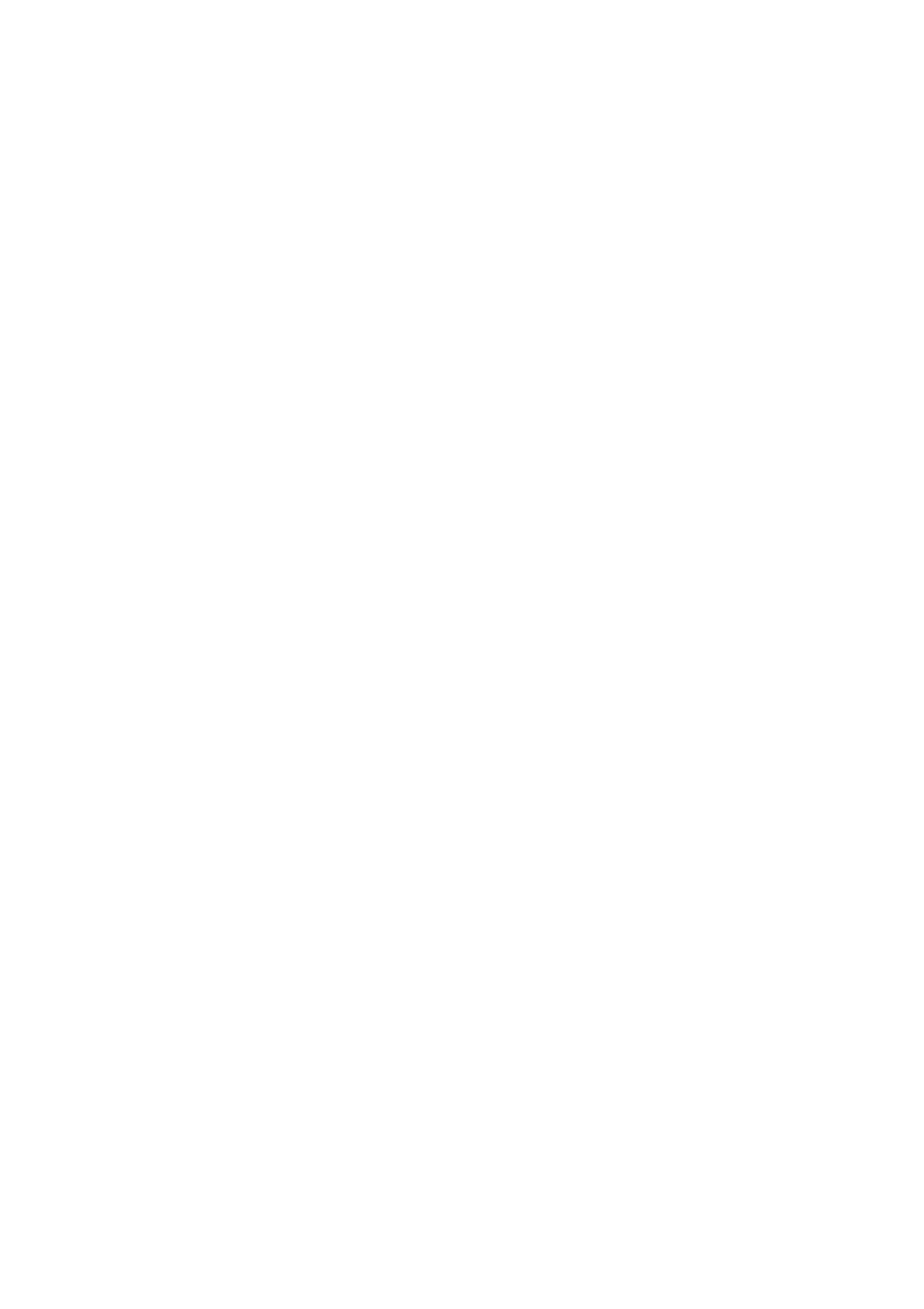




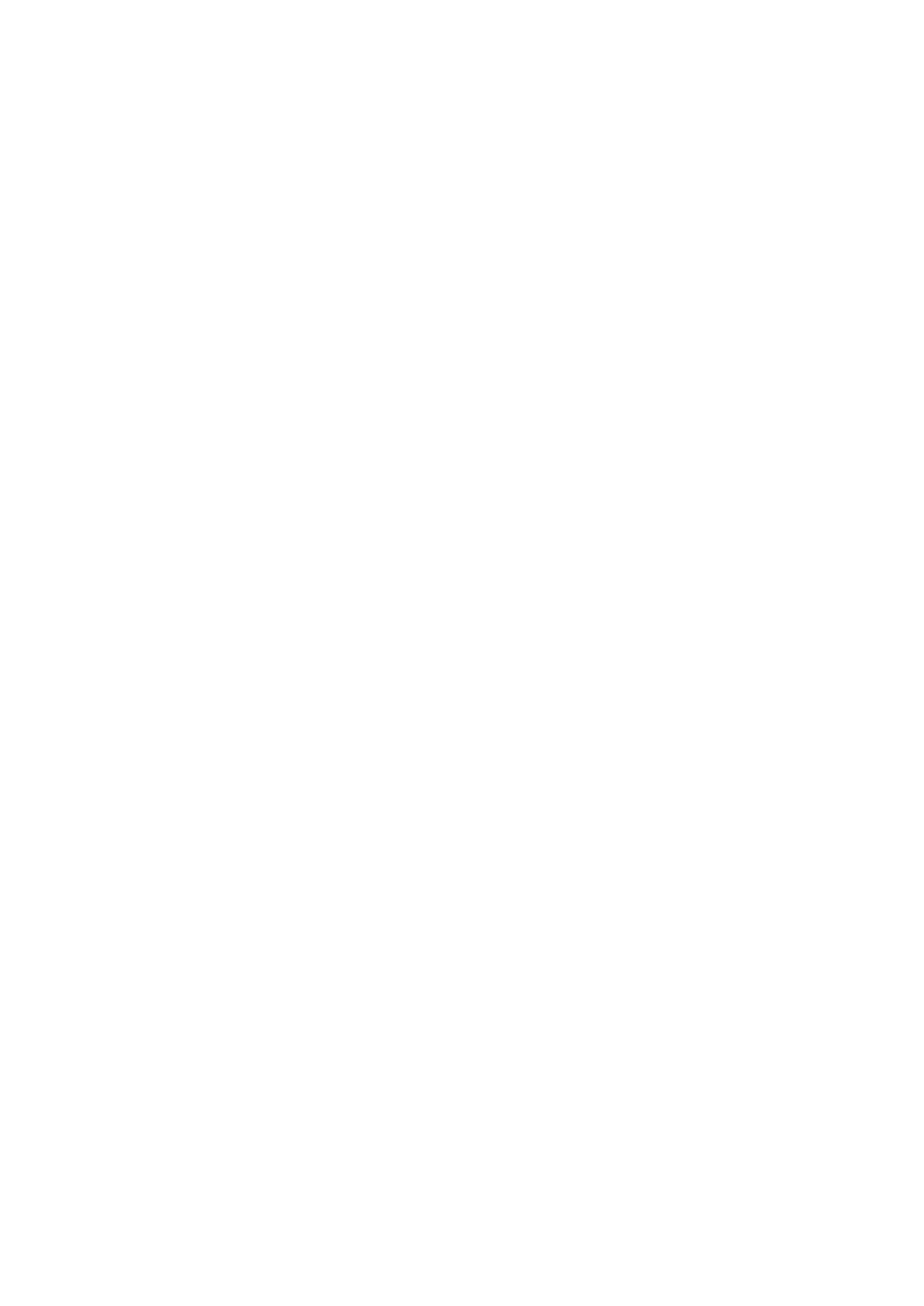




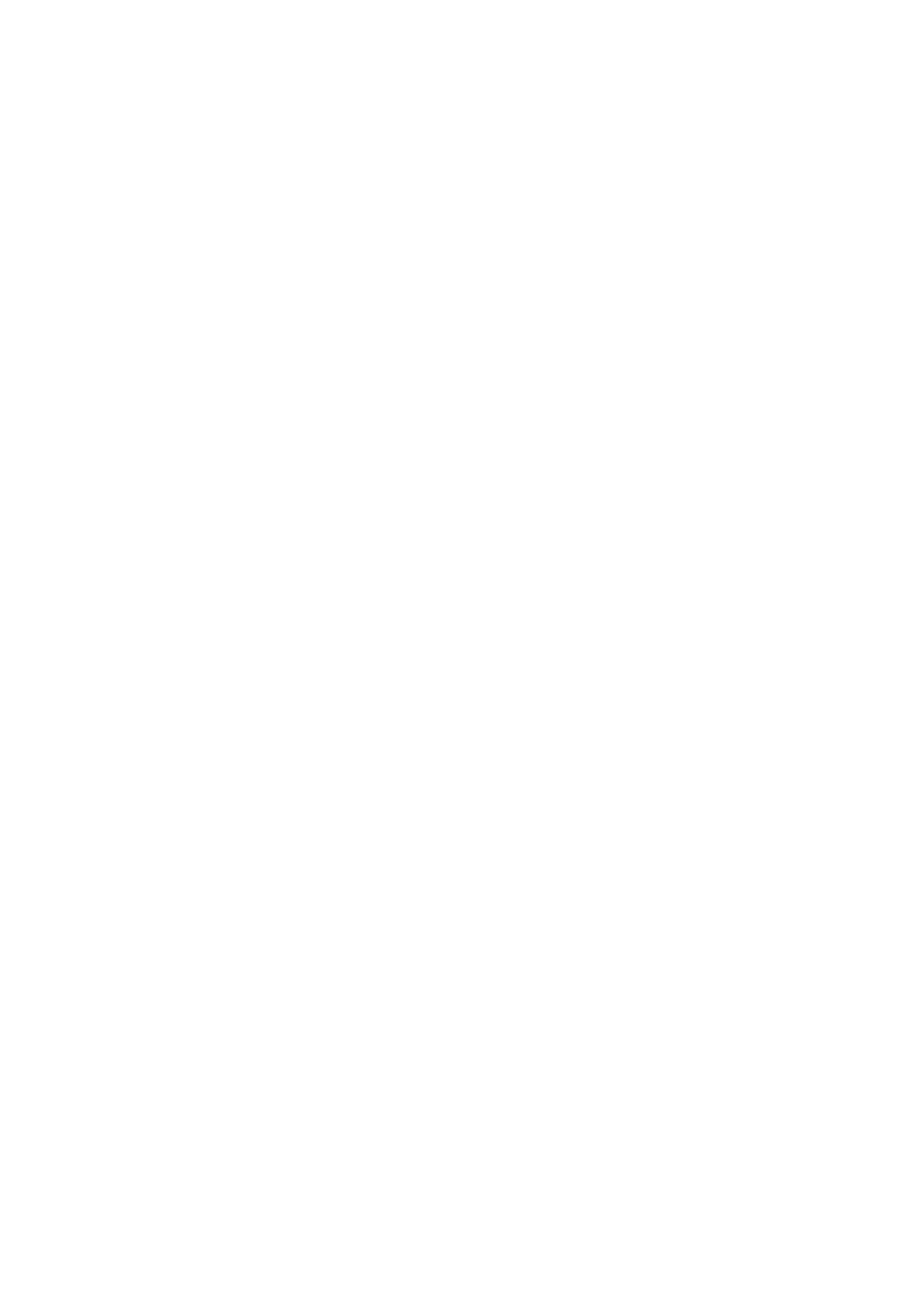




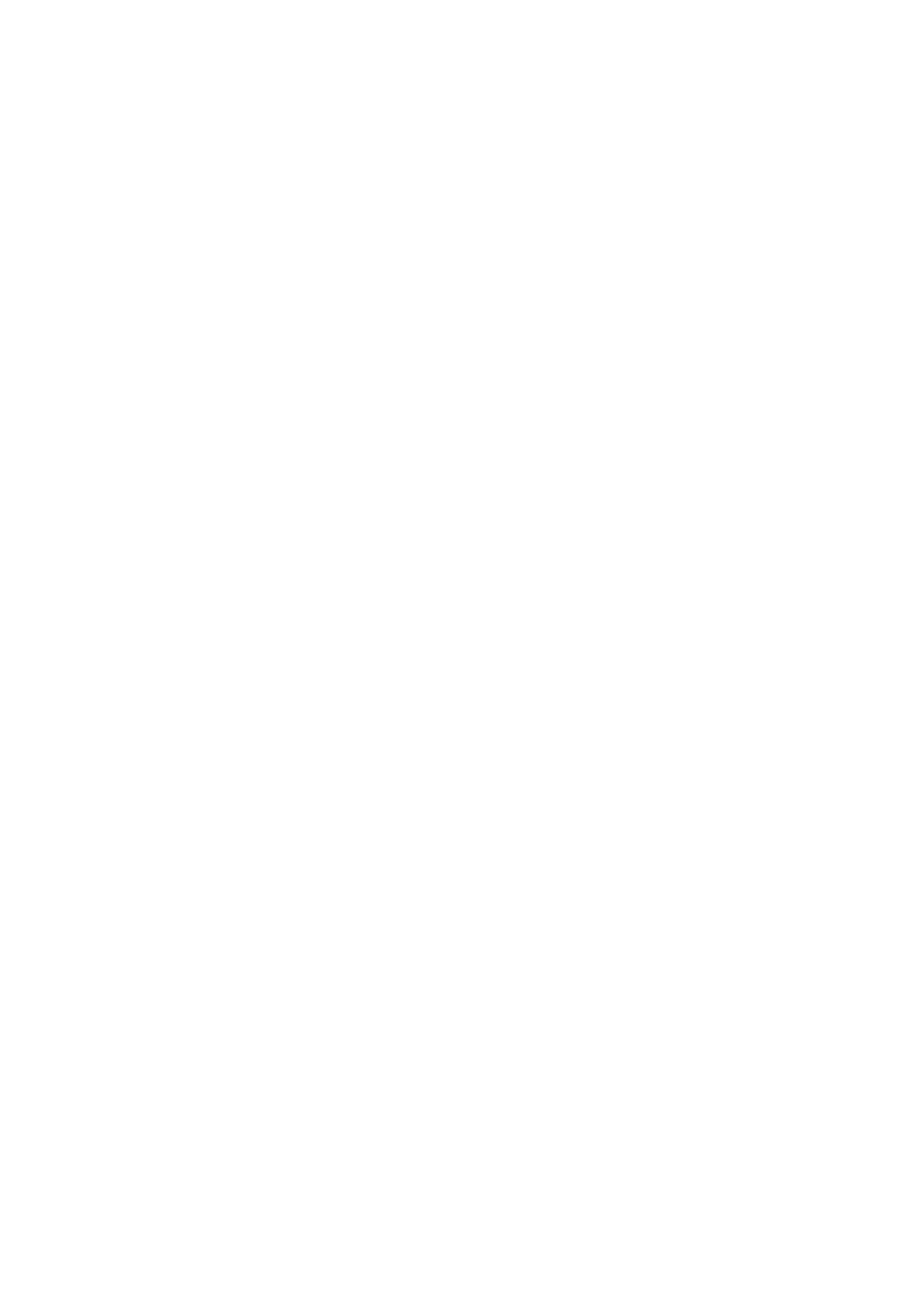




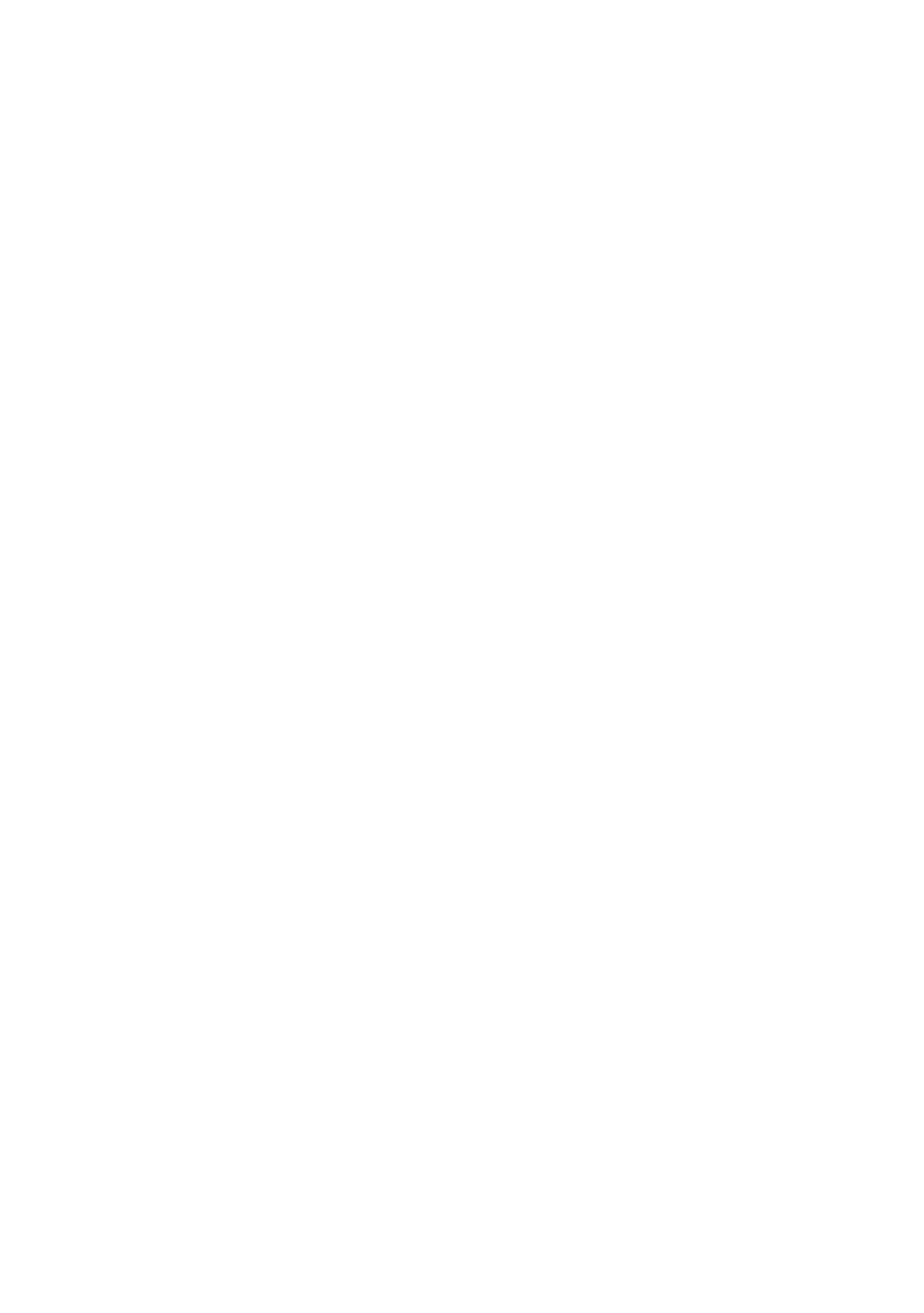




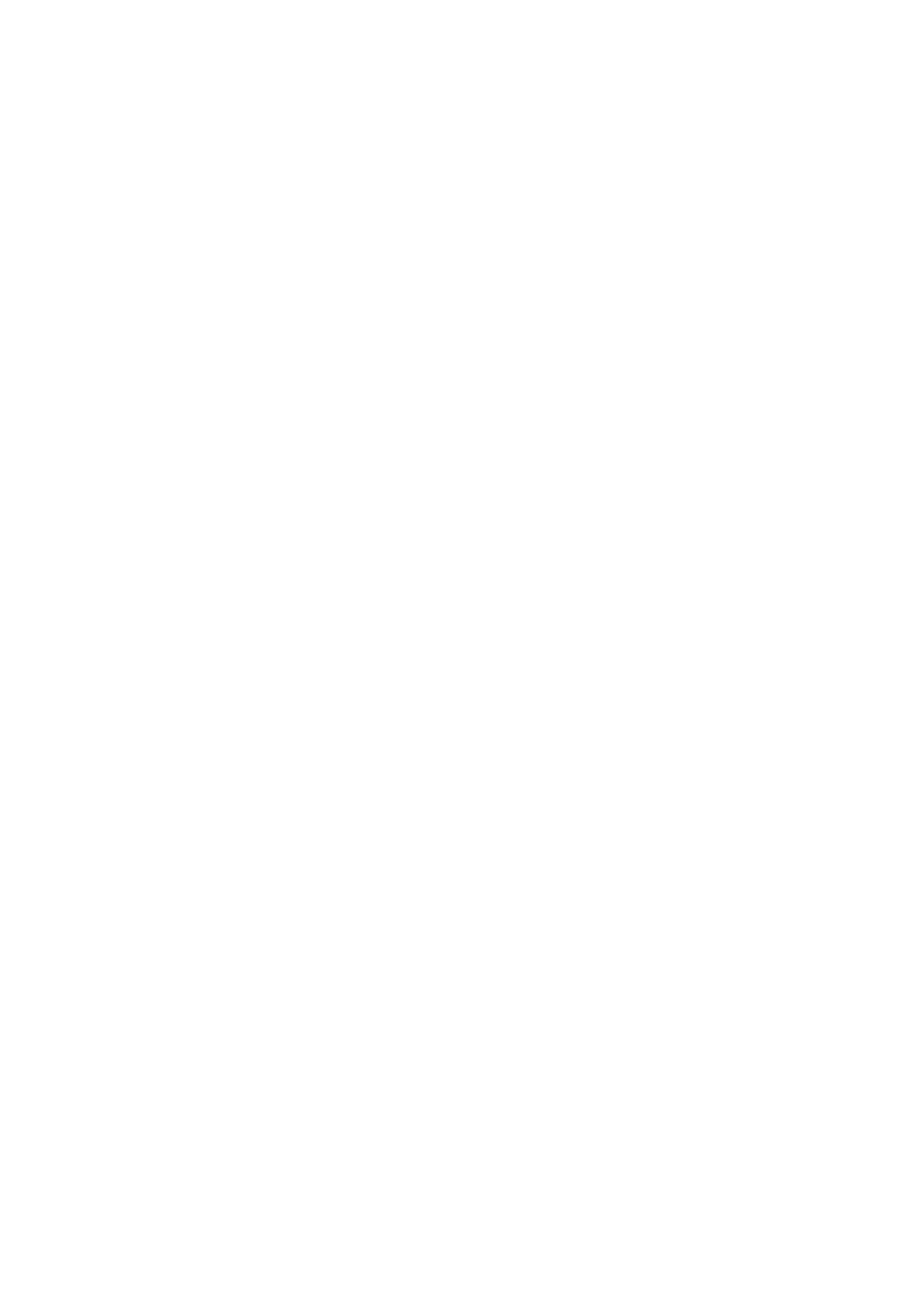




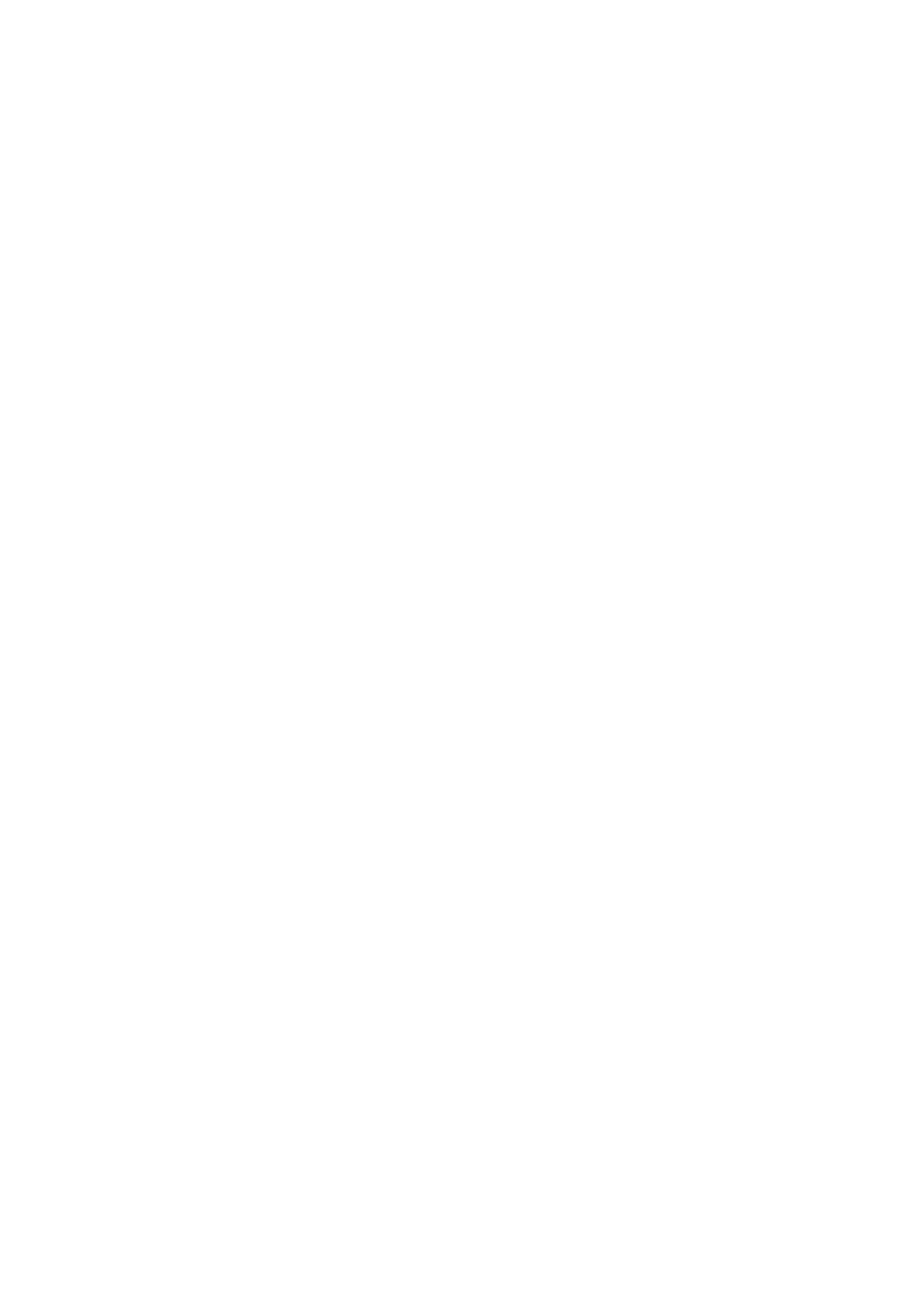




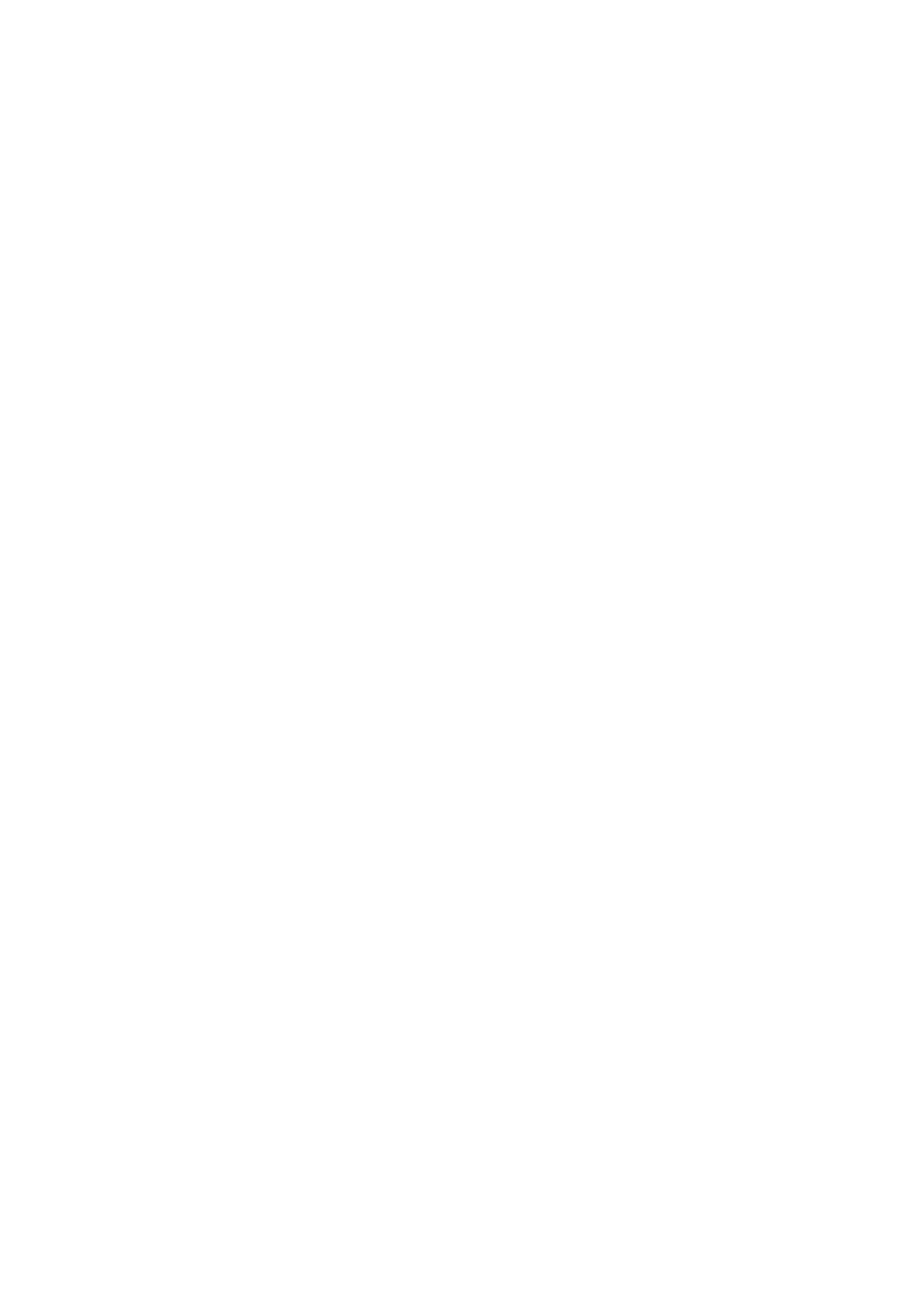




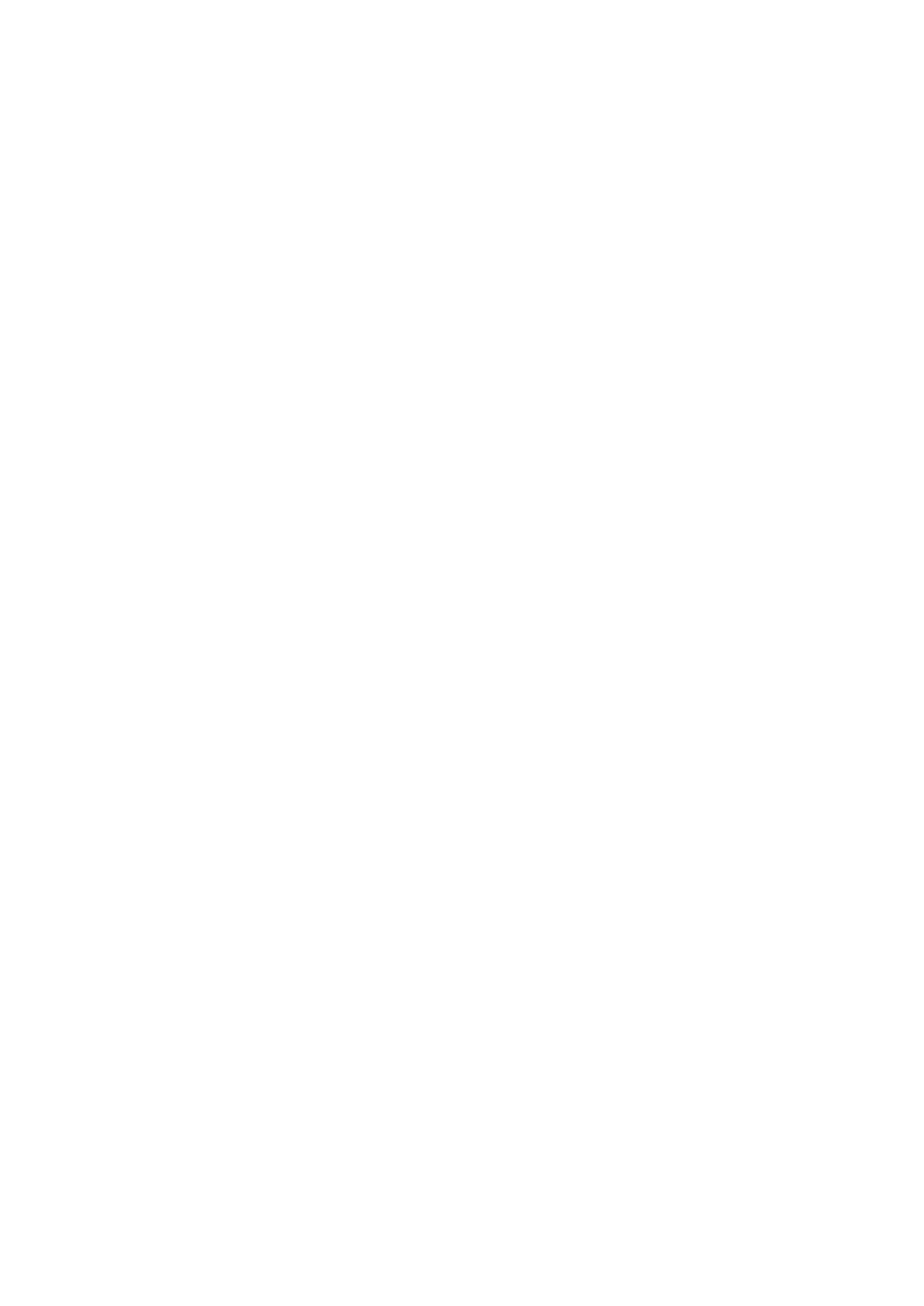




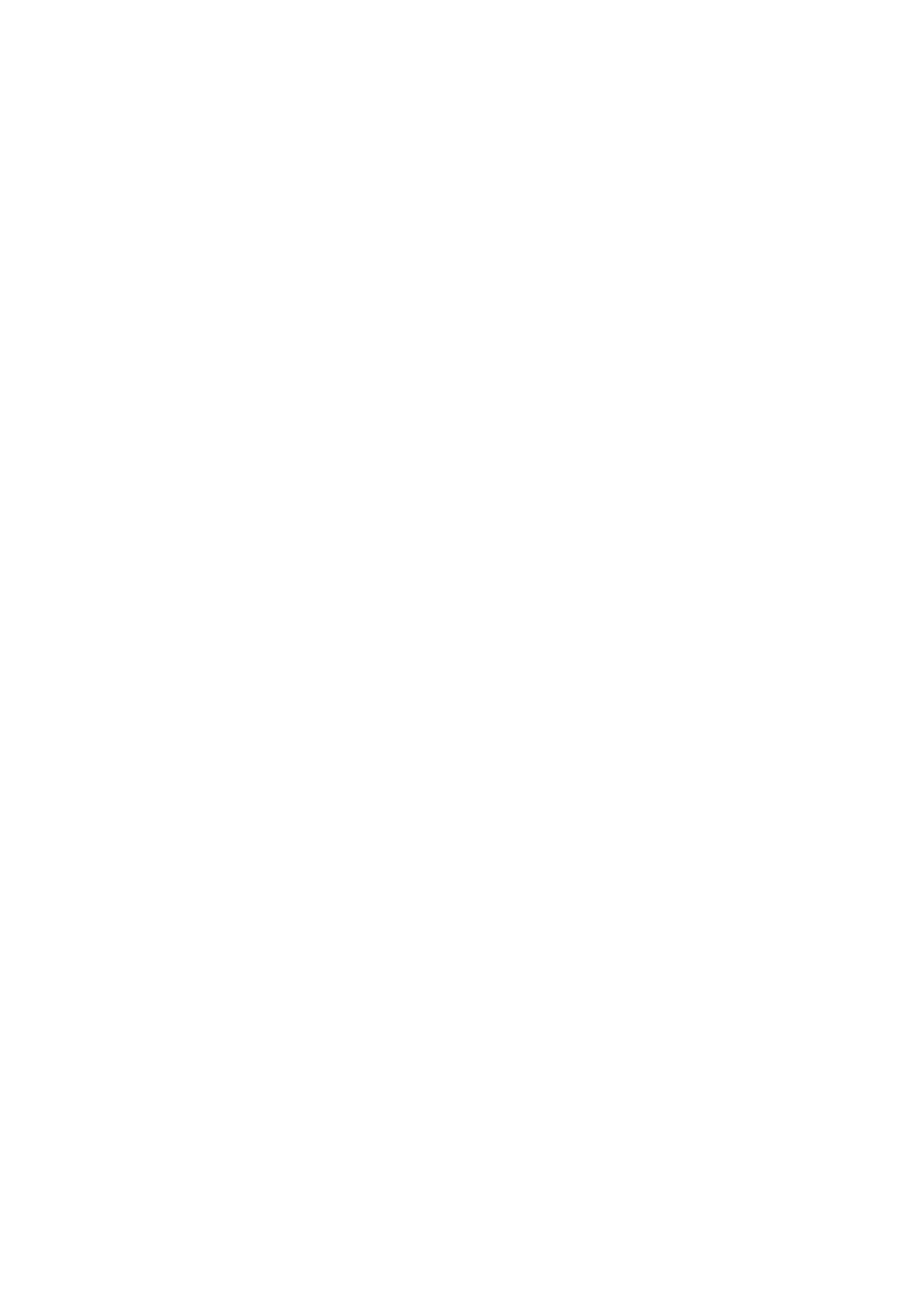




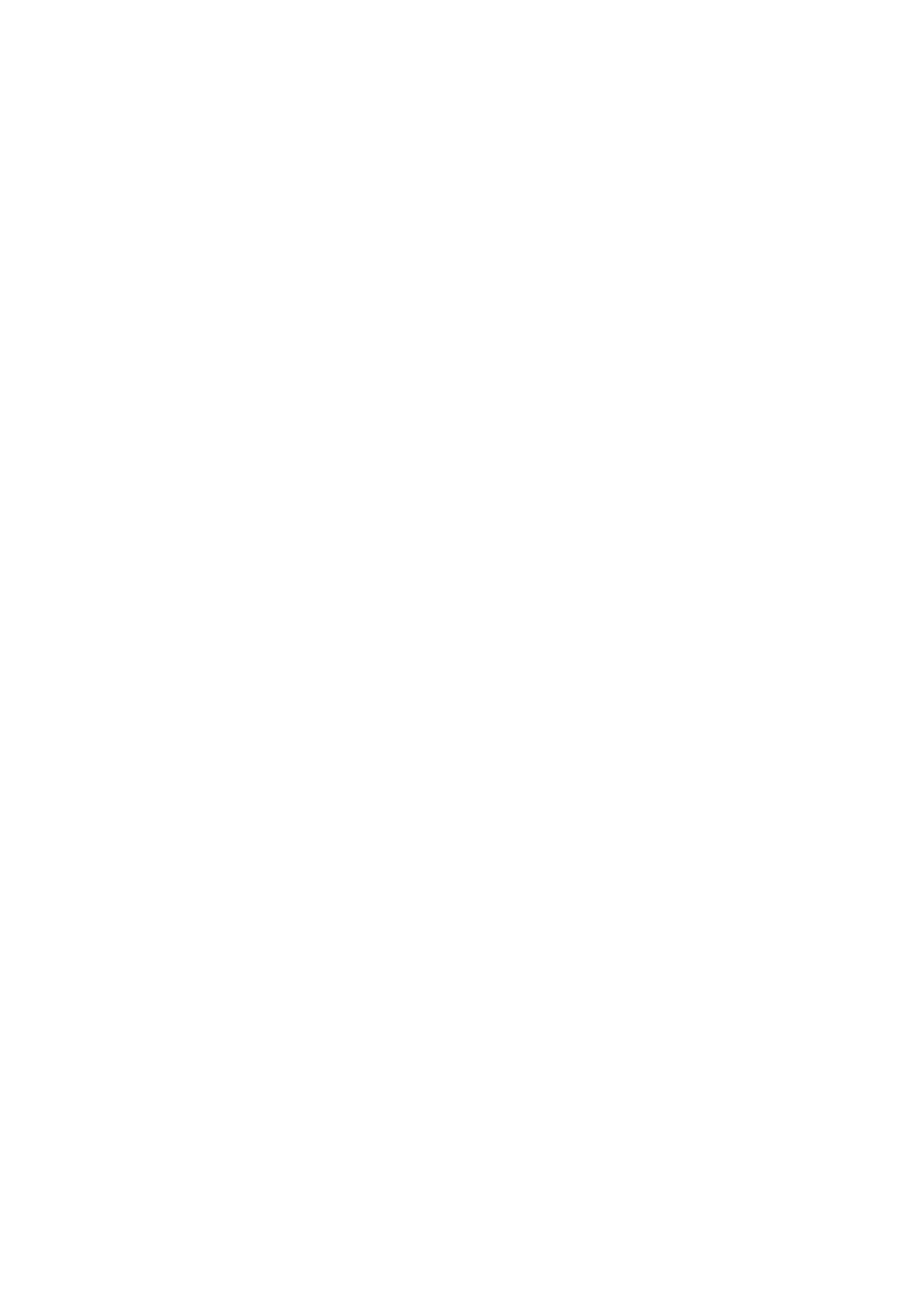




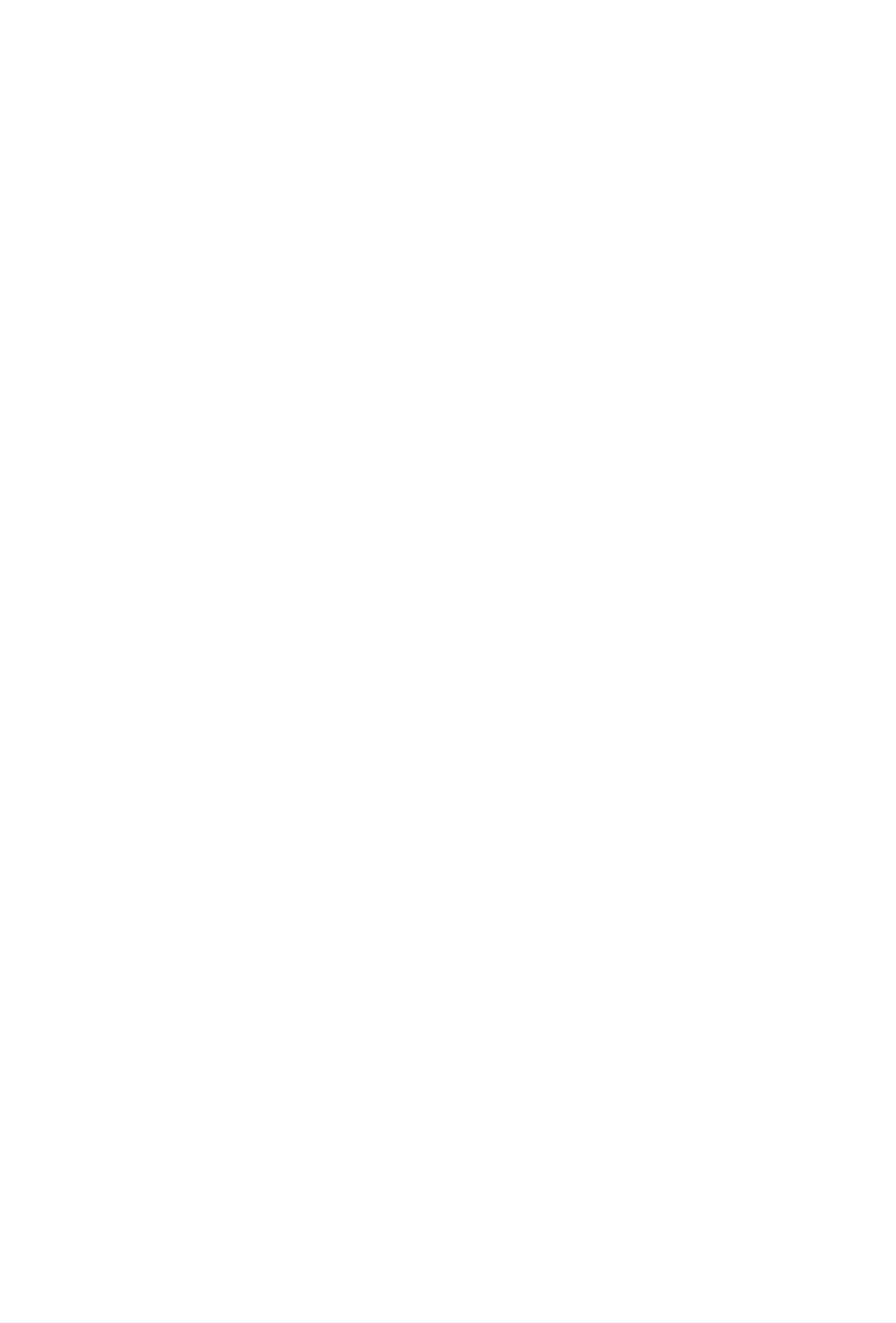




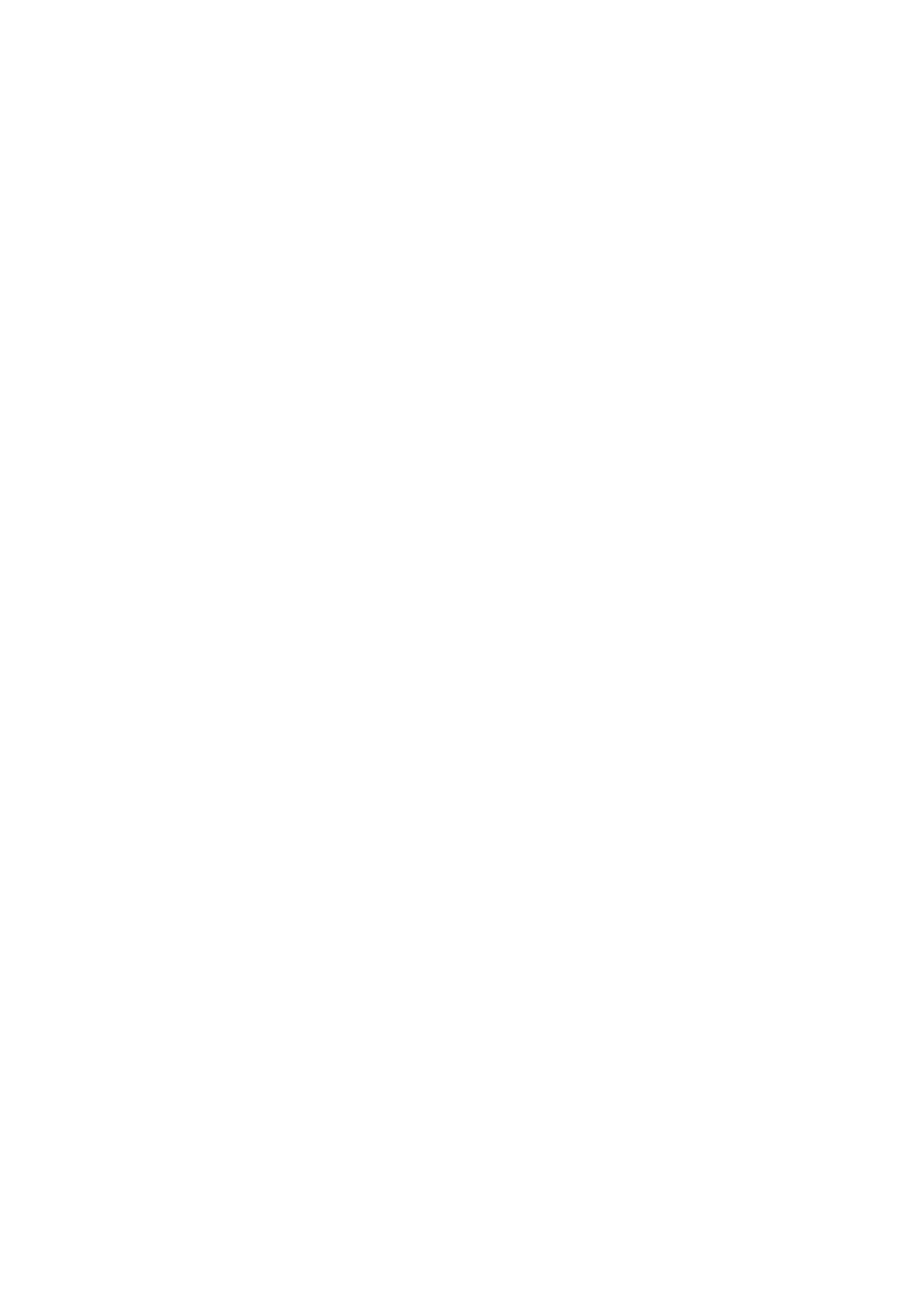




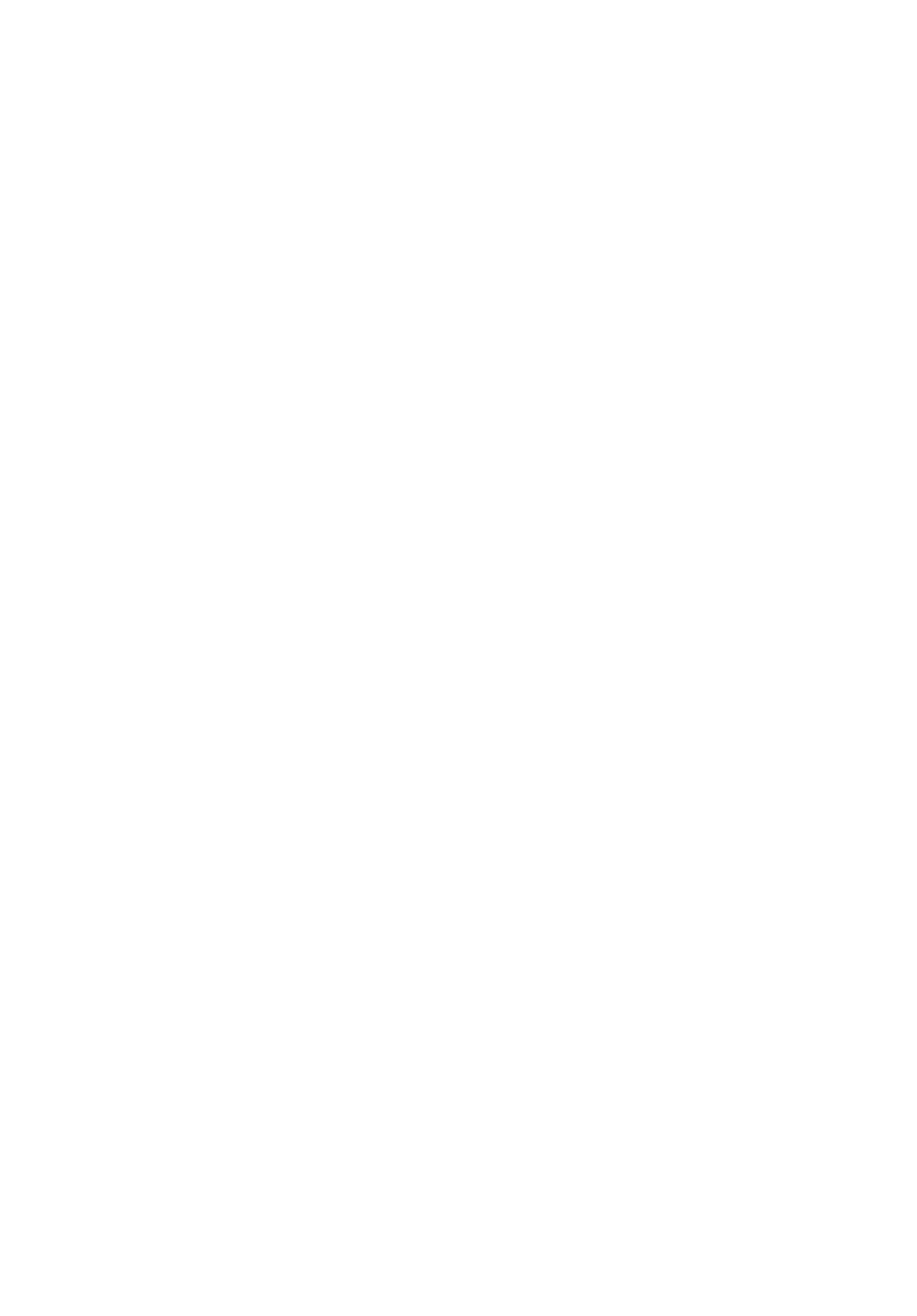




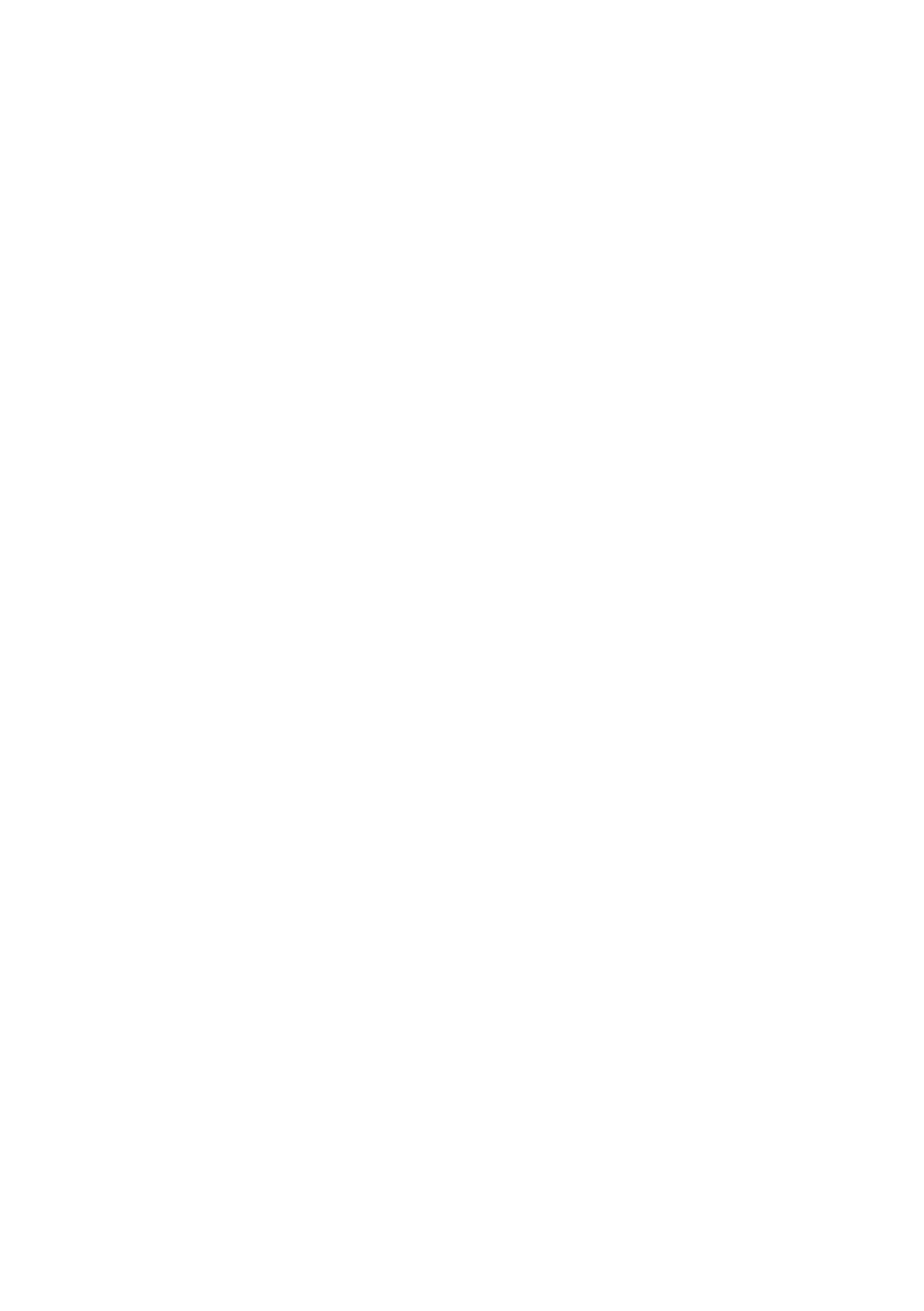




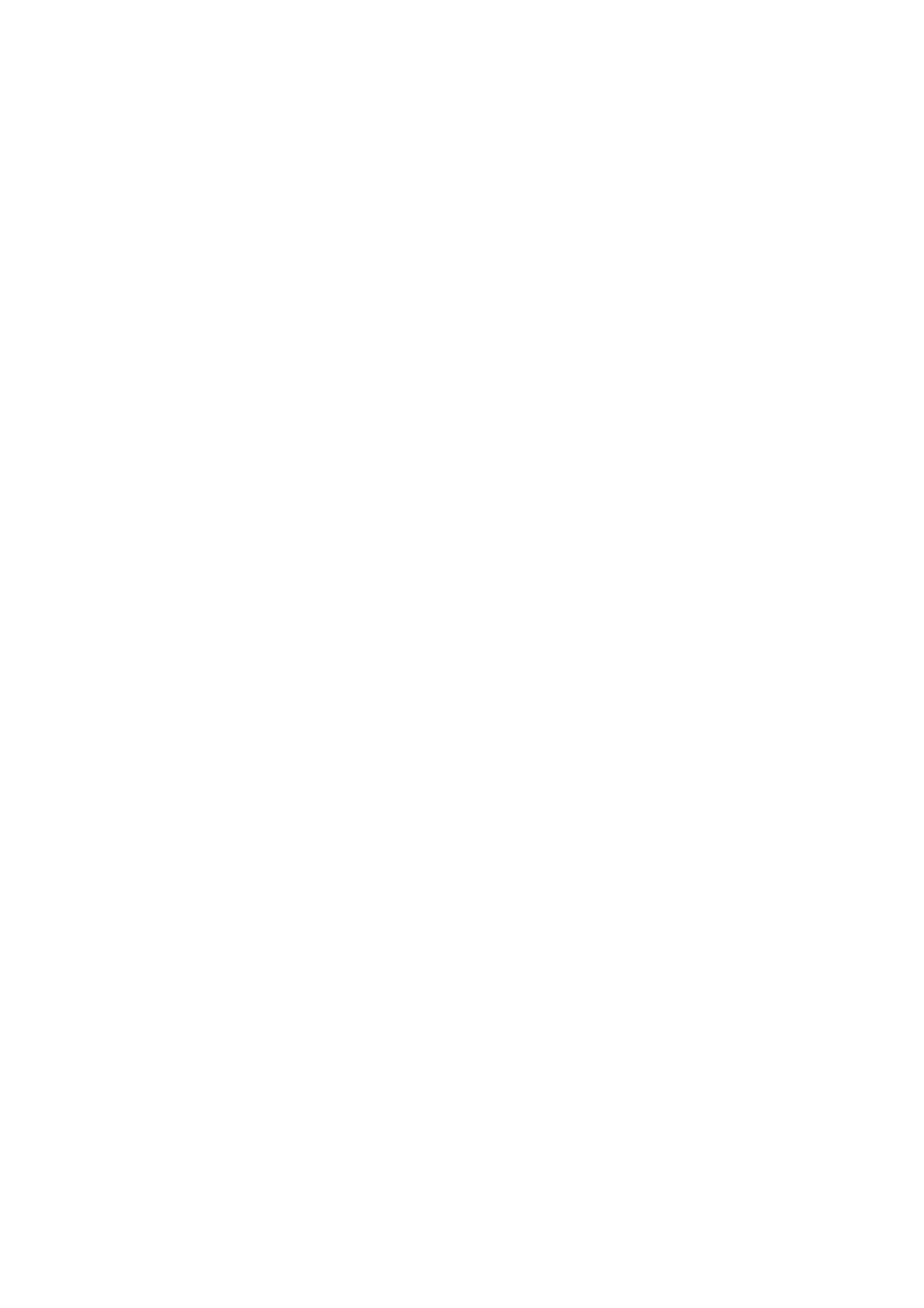




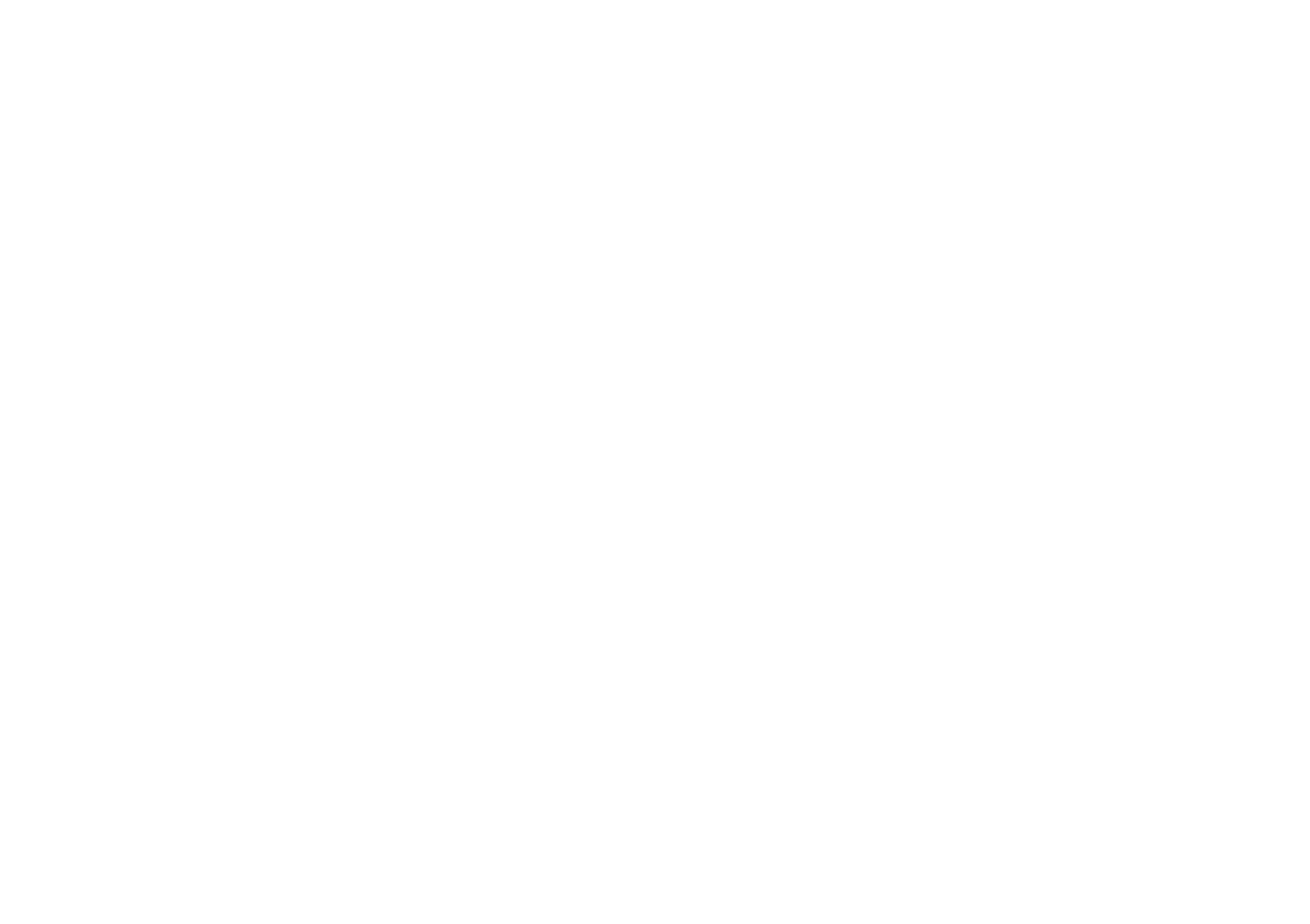

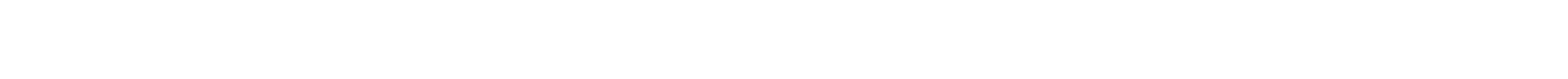

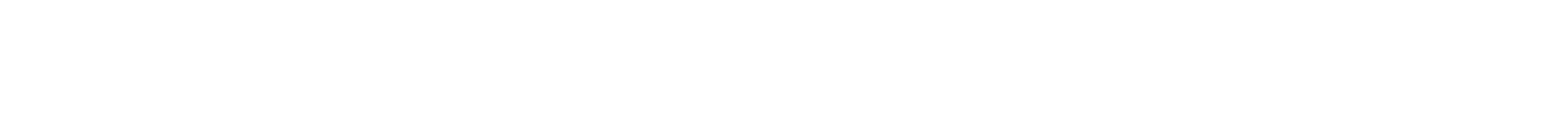

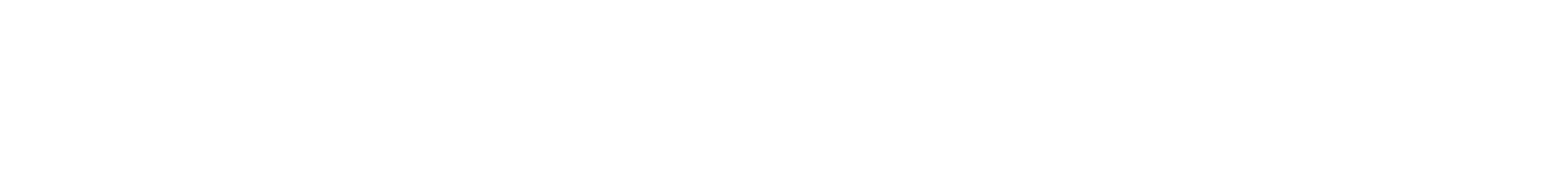

$$
\begin{aligned}
& \text { 产兽 }
\end{aligned}
$$

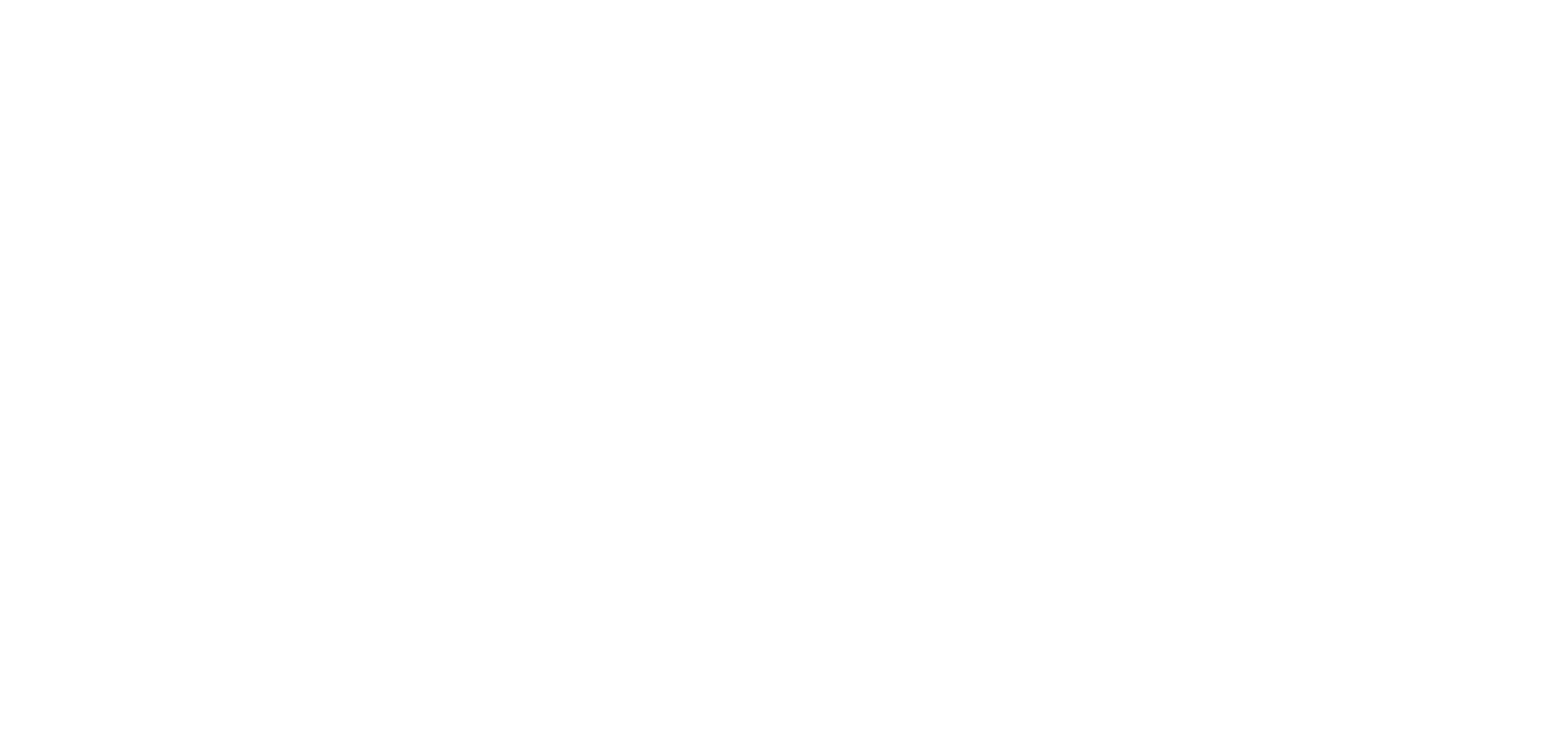




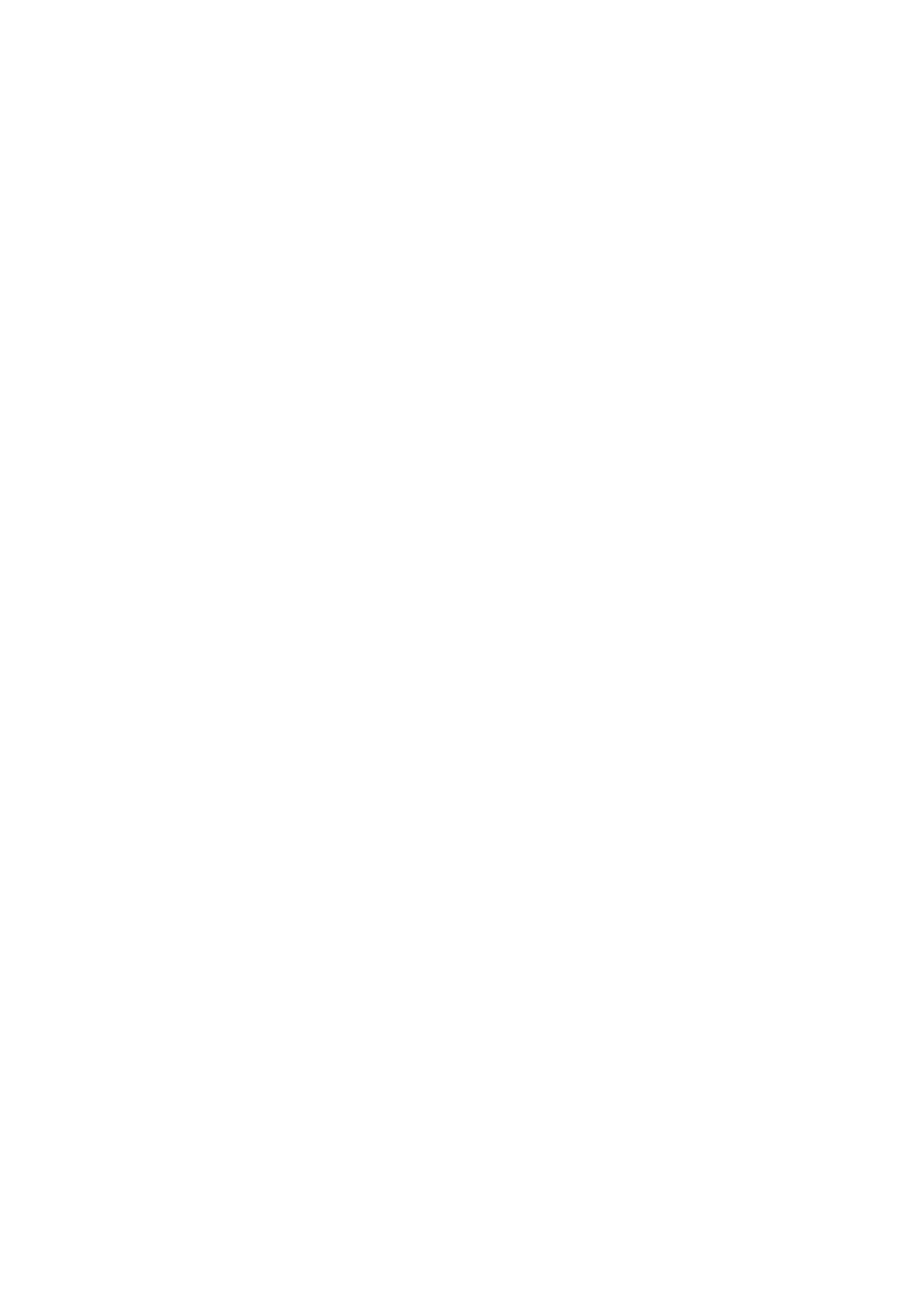




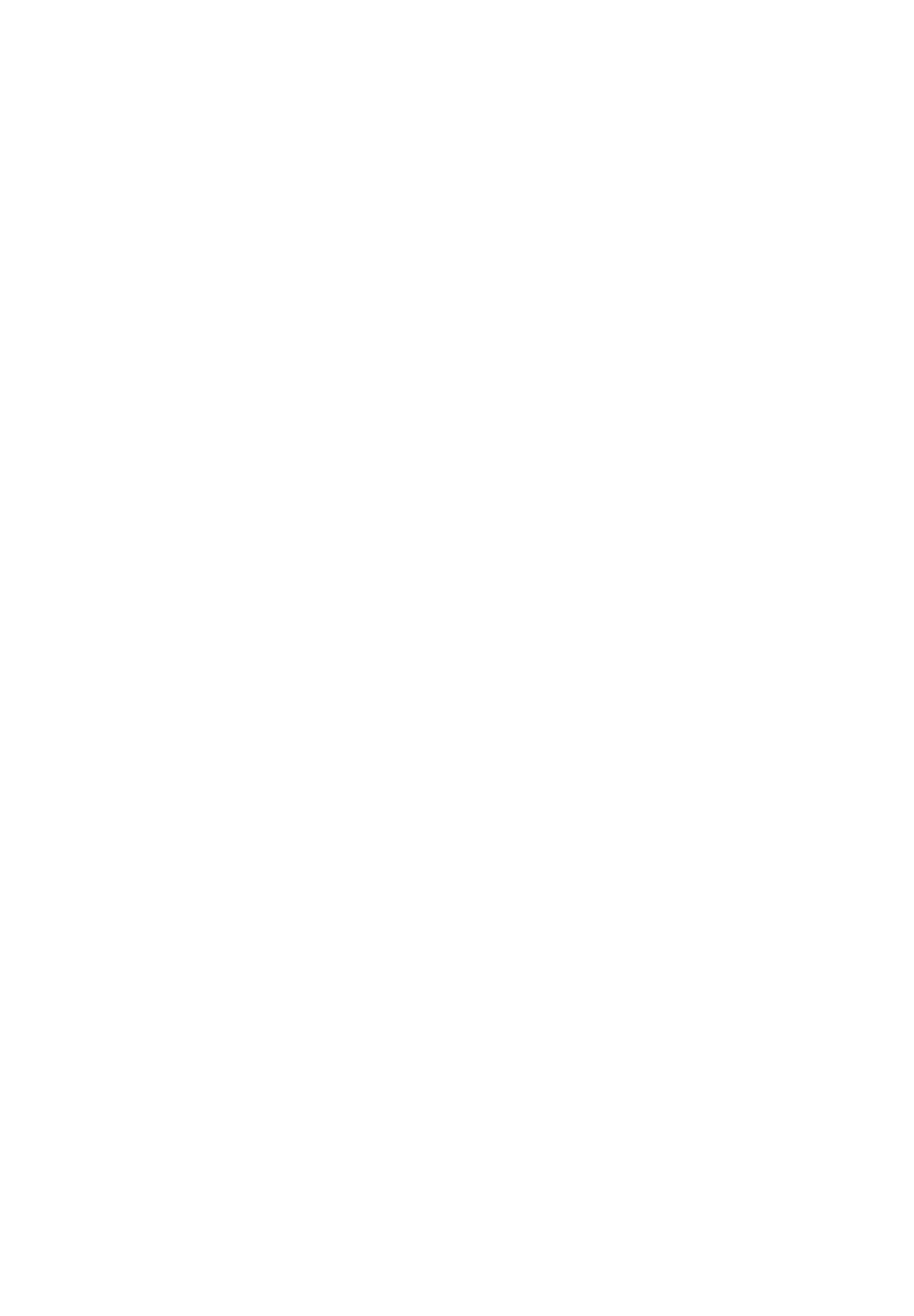




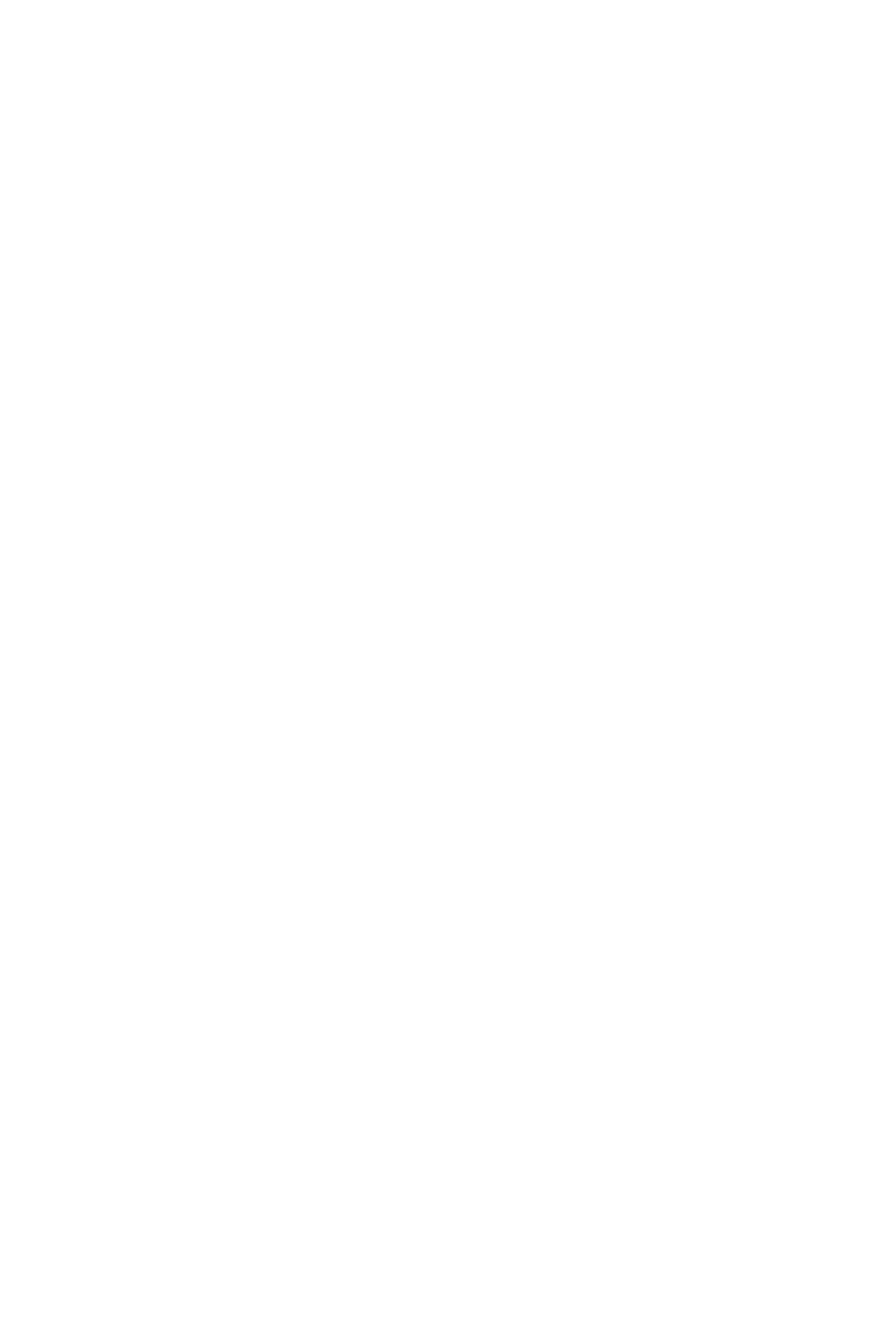




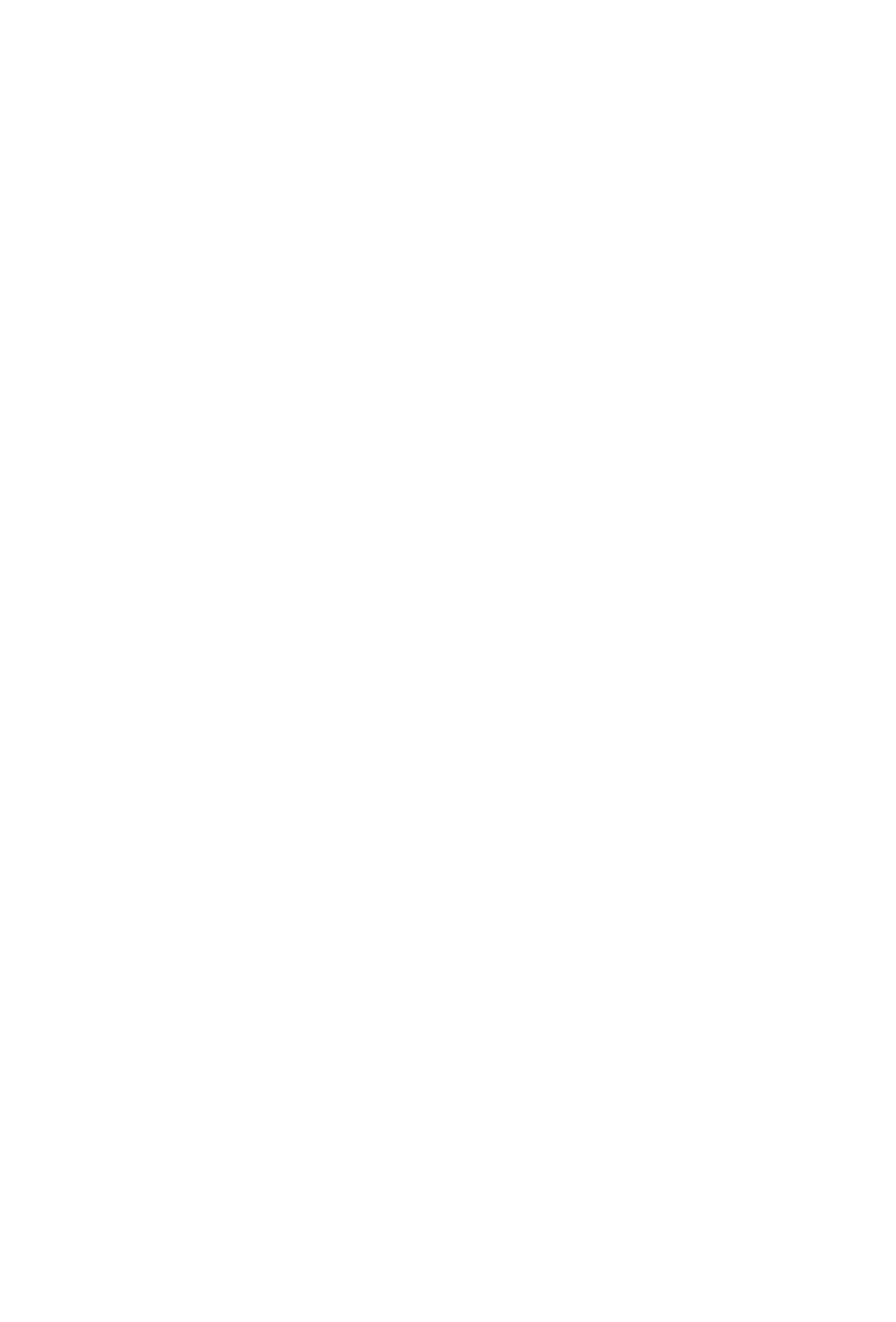




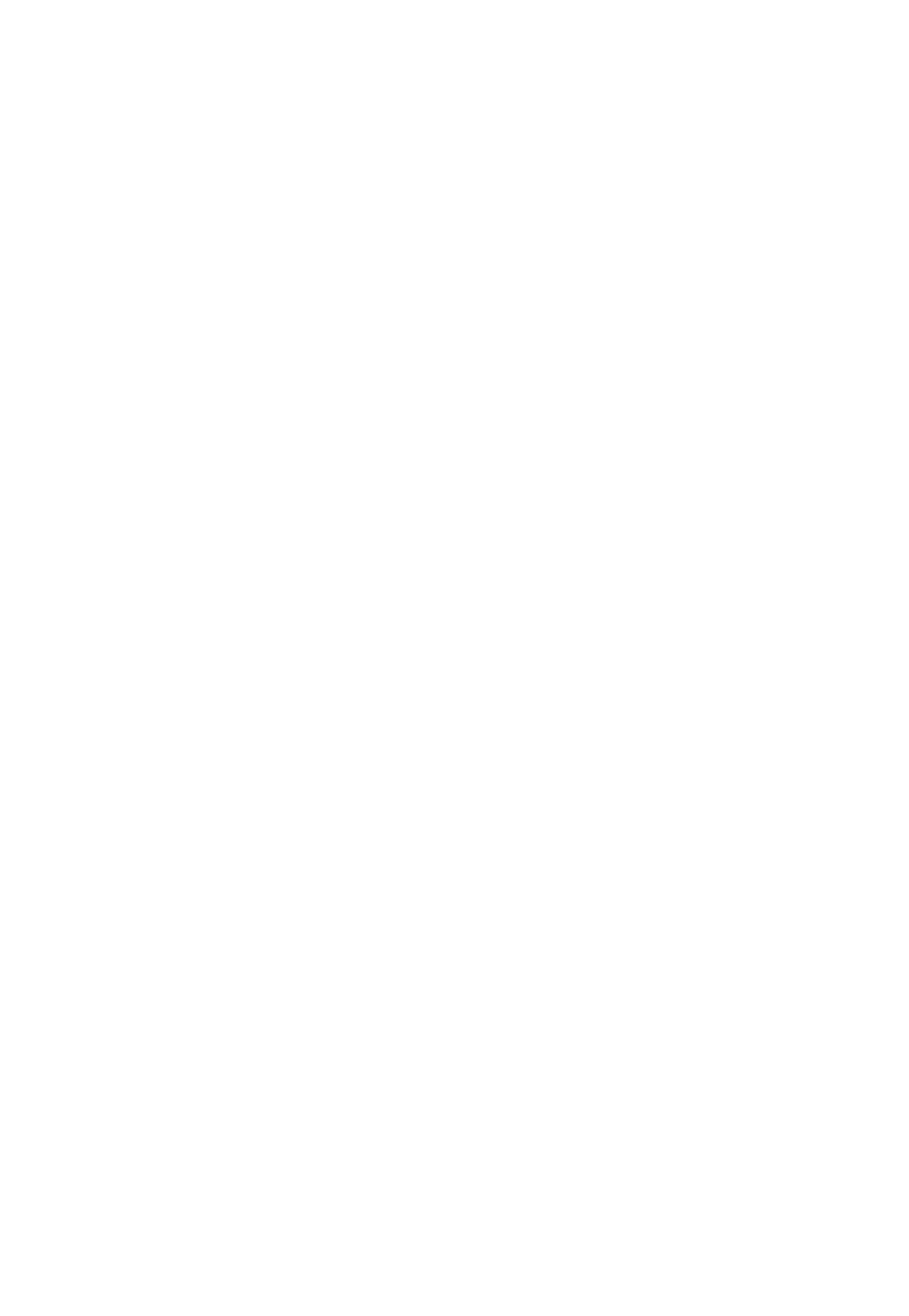




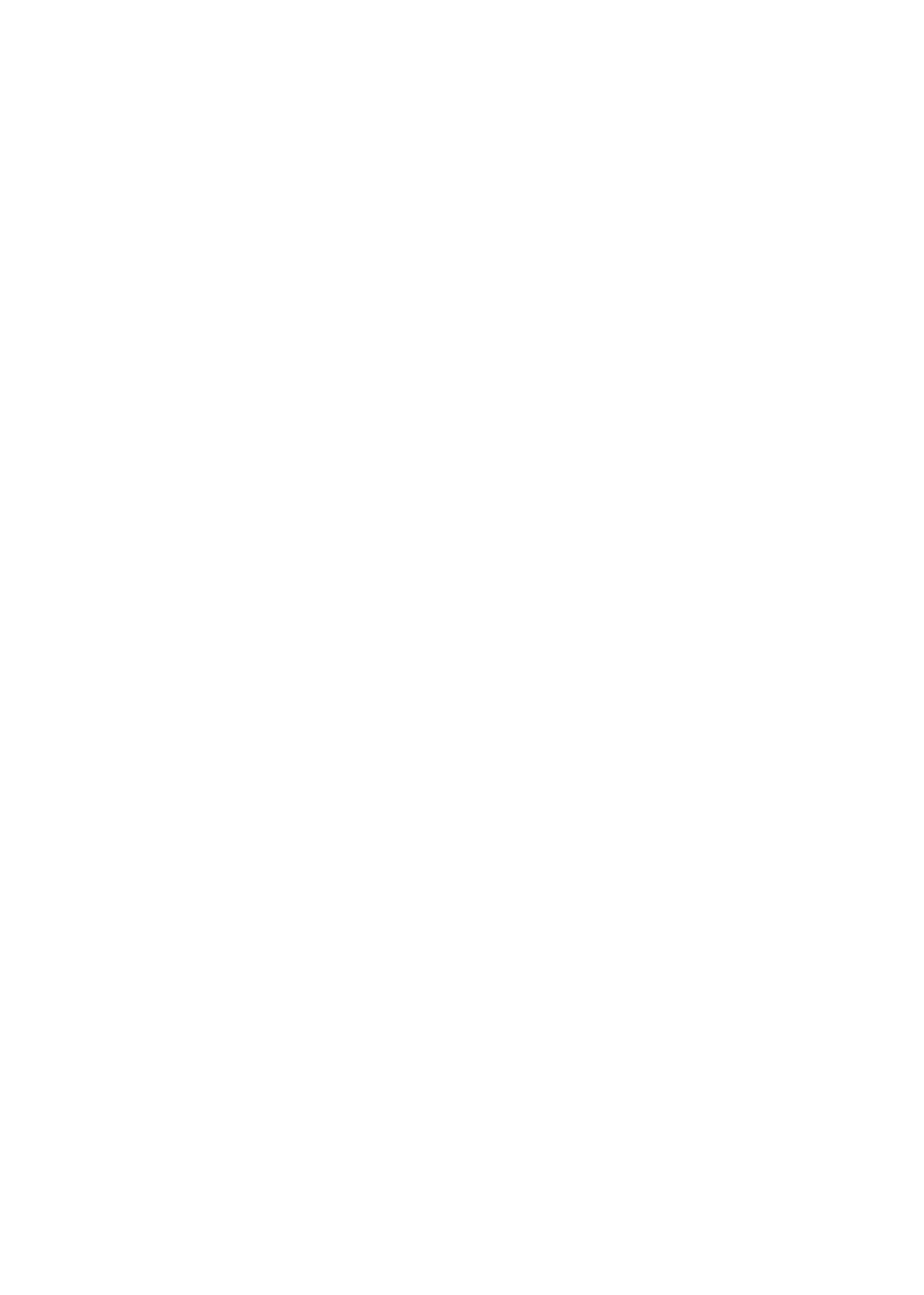




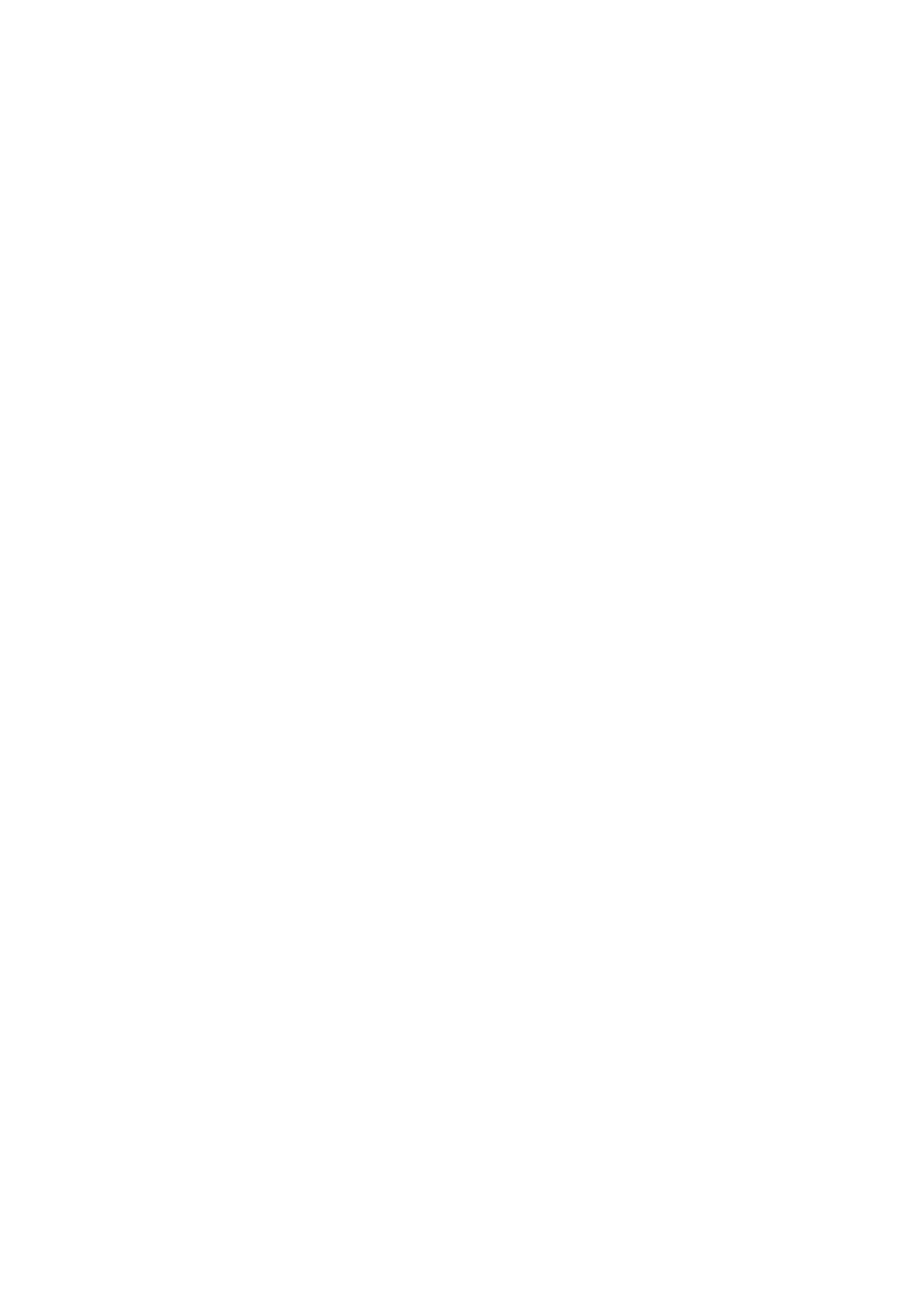




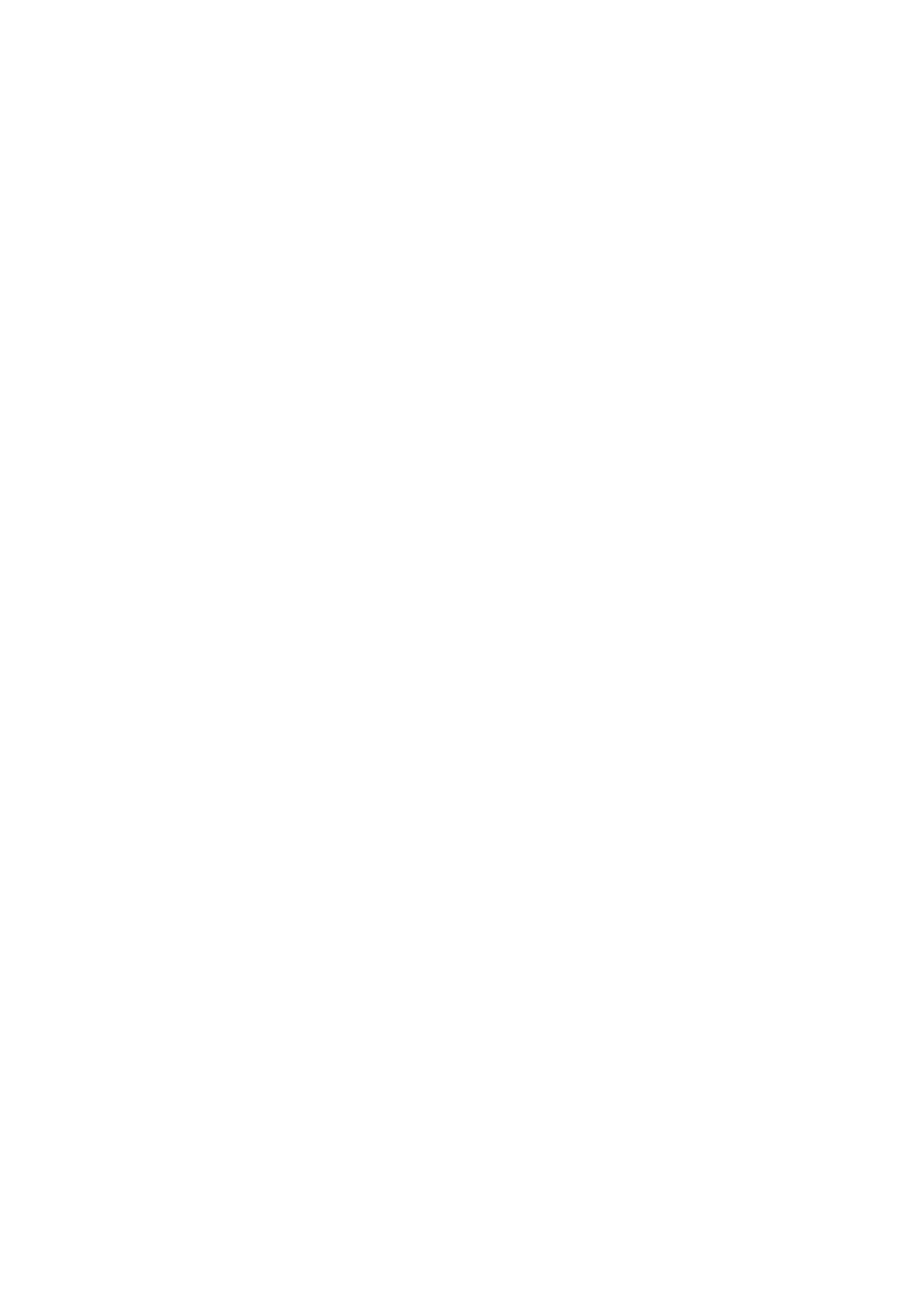




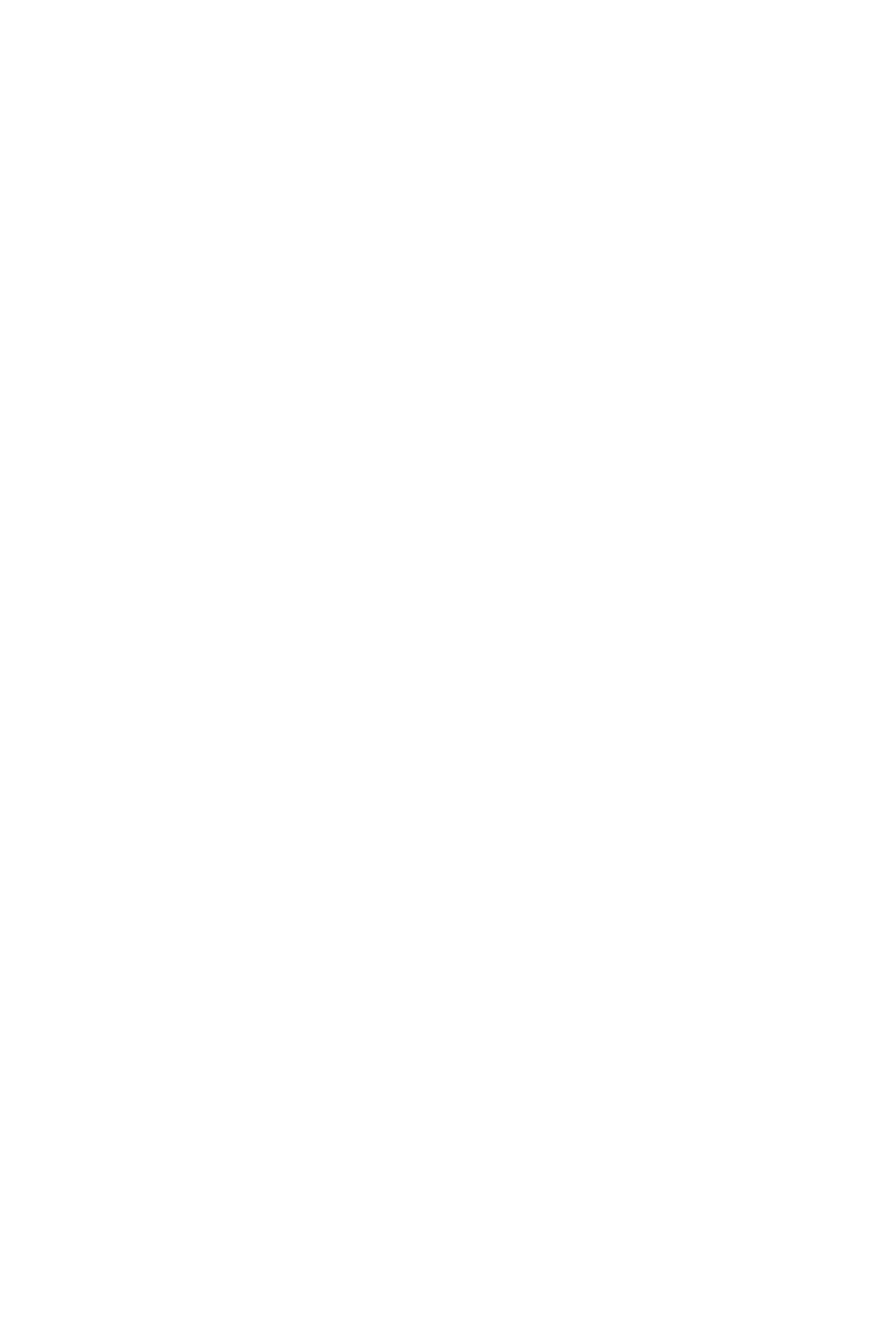




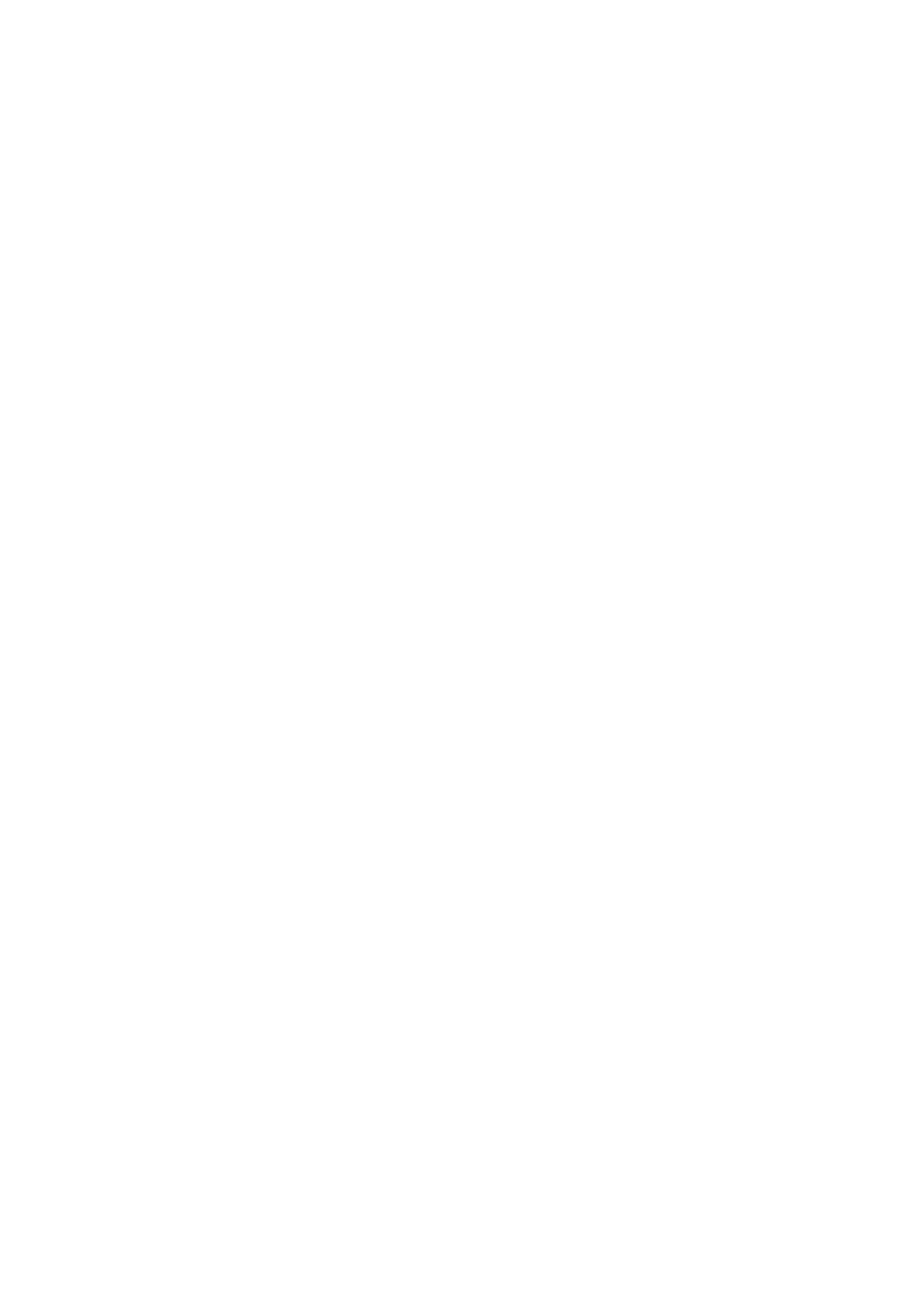




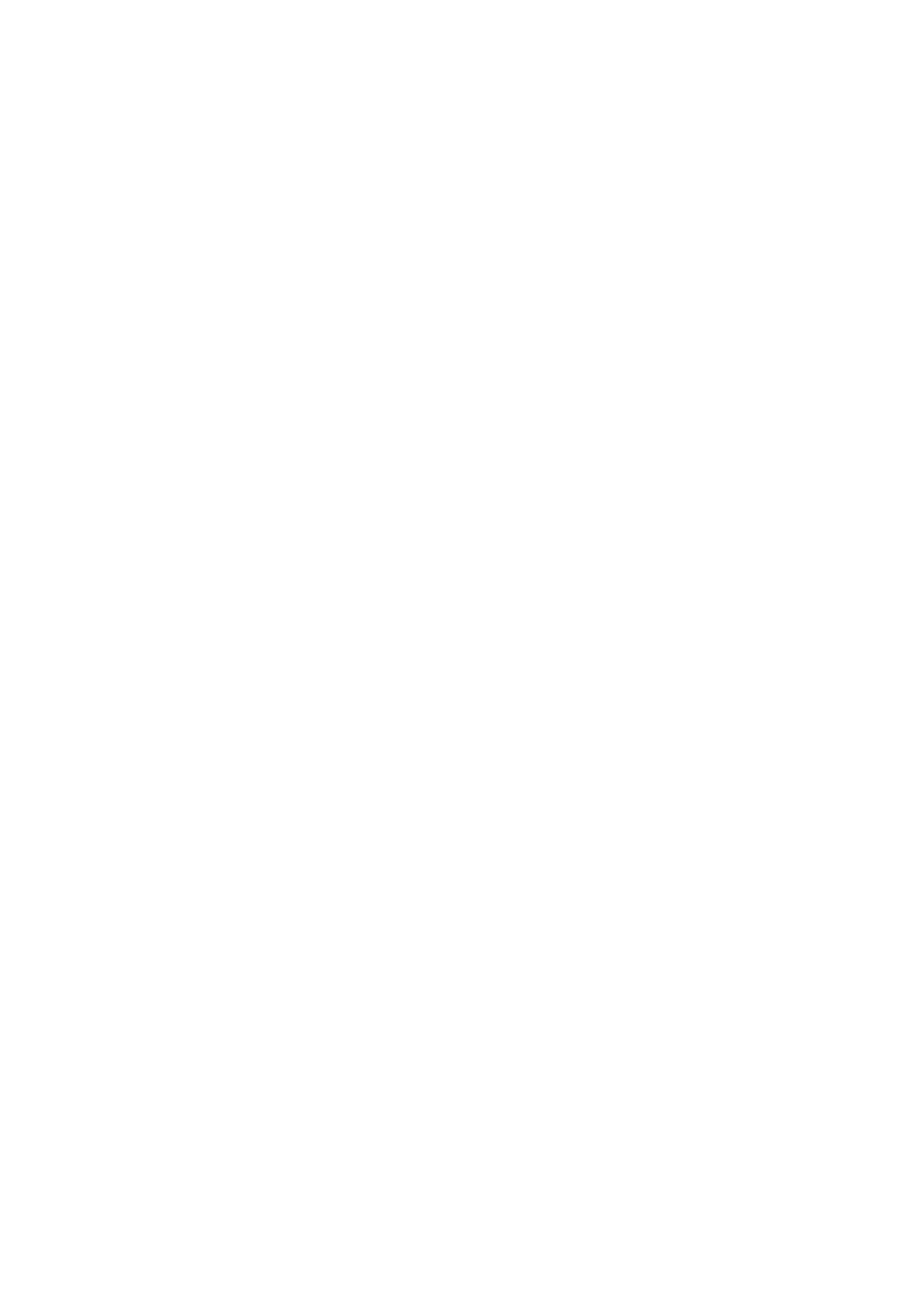




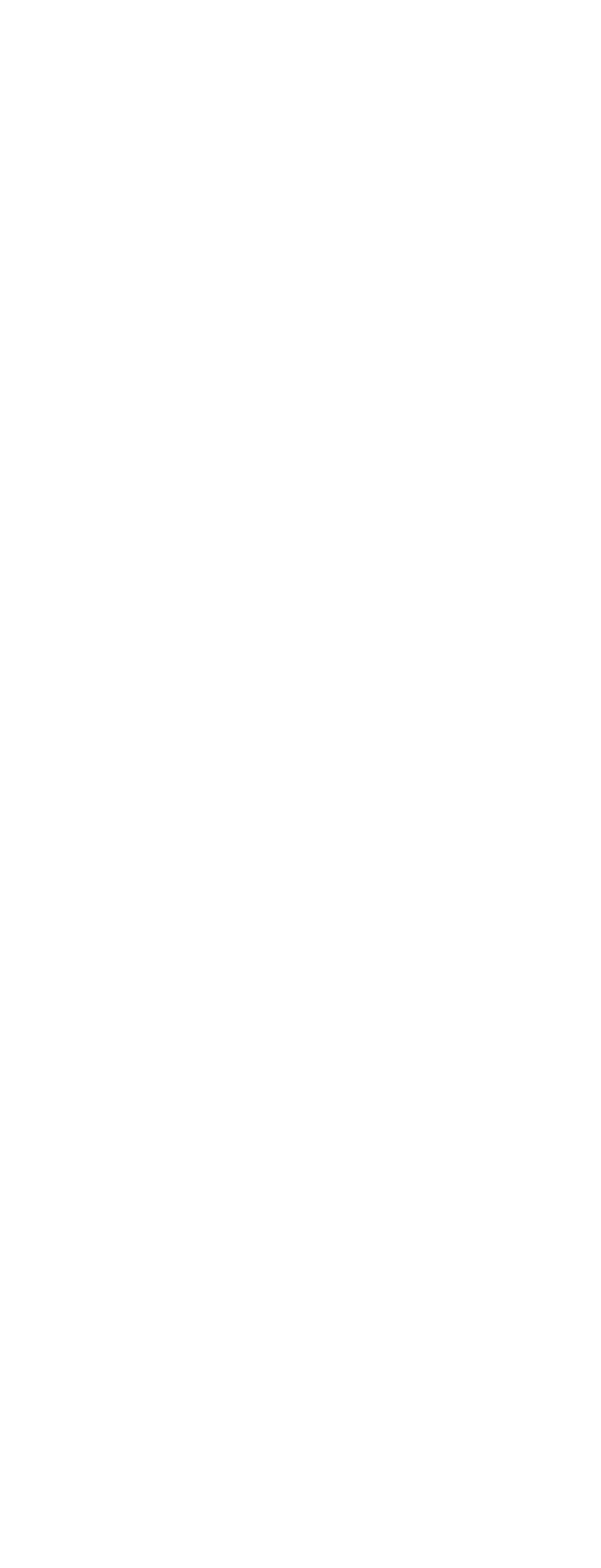




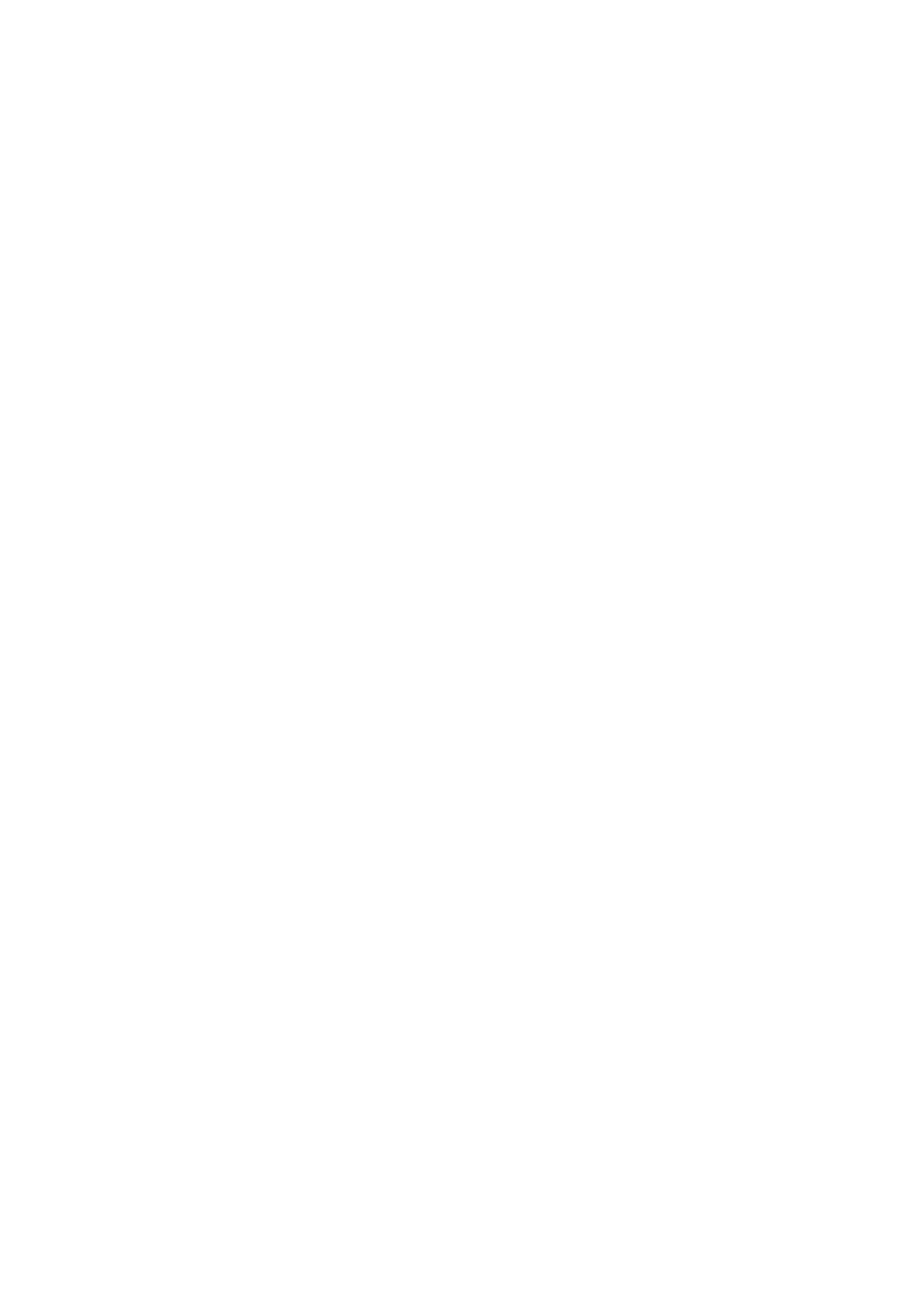




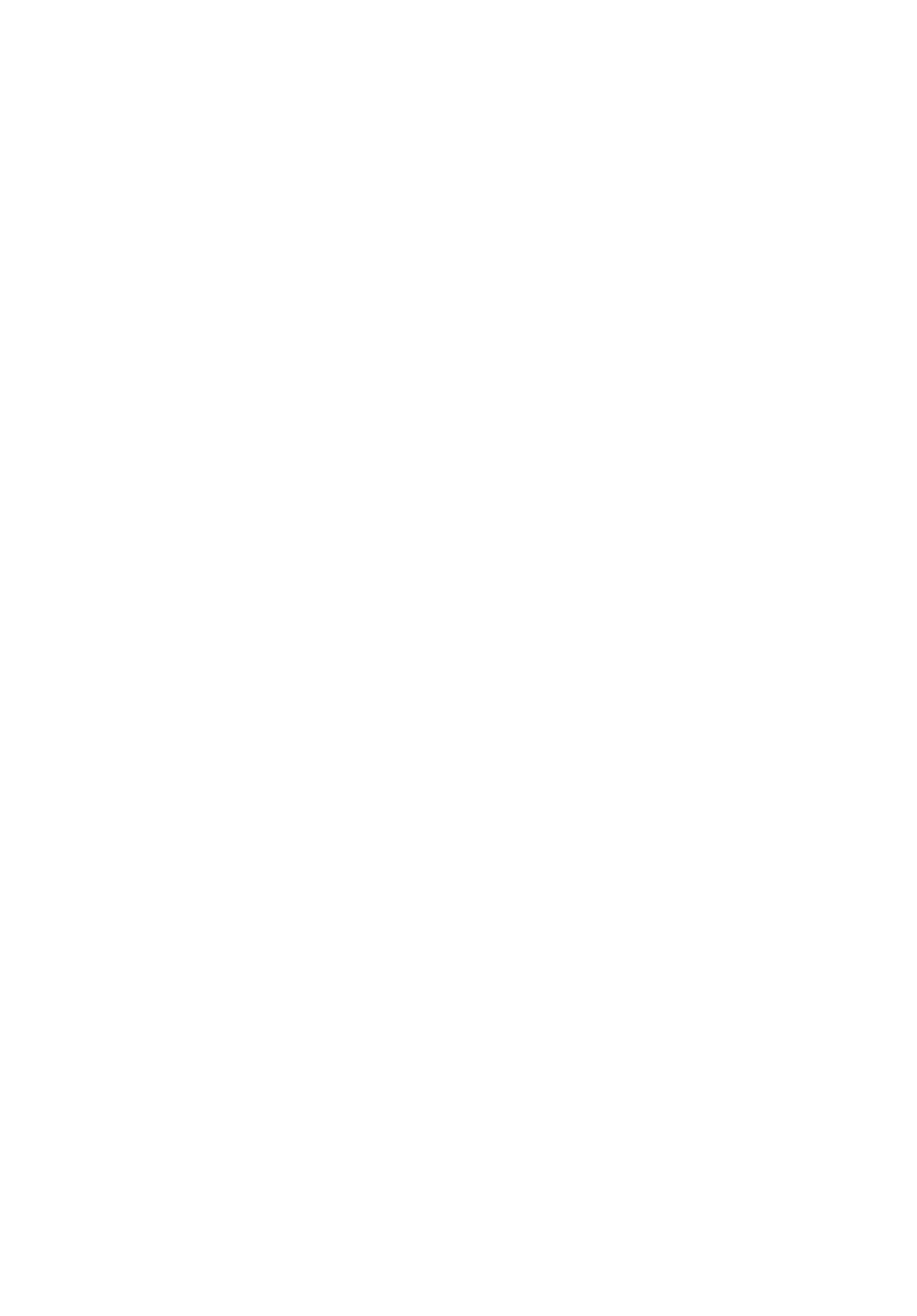




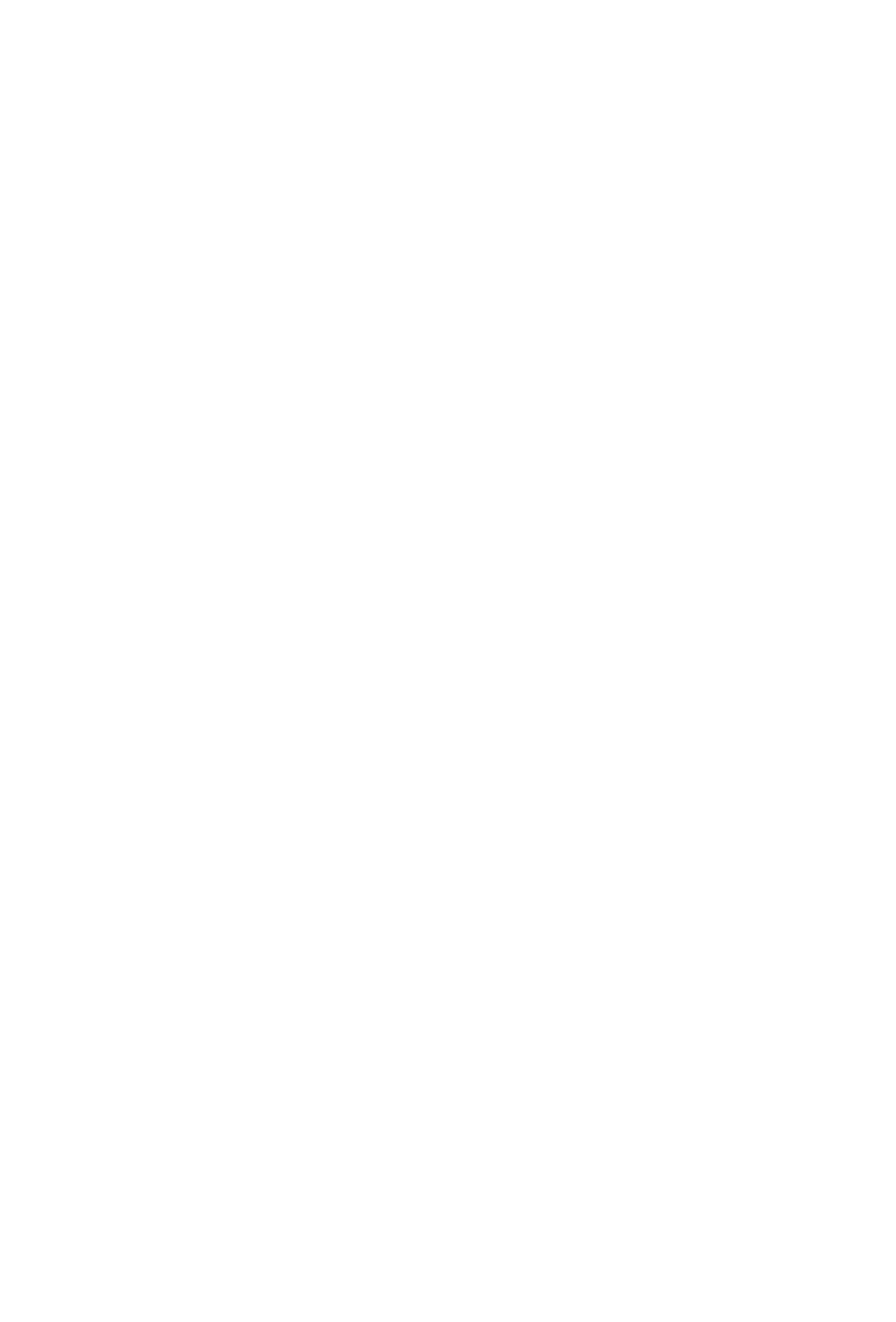




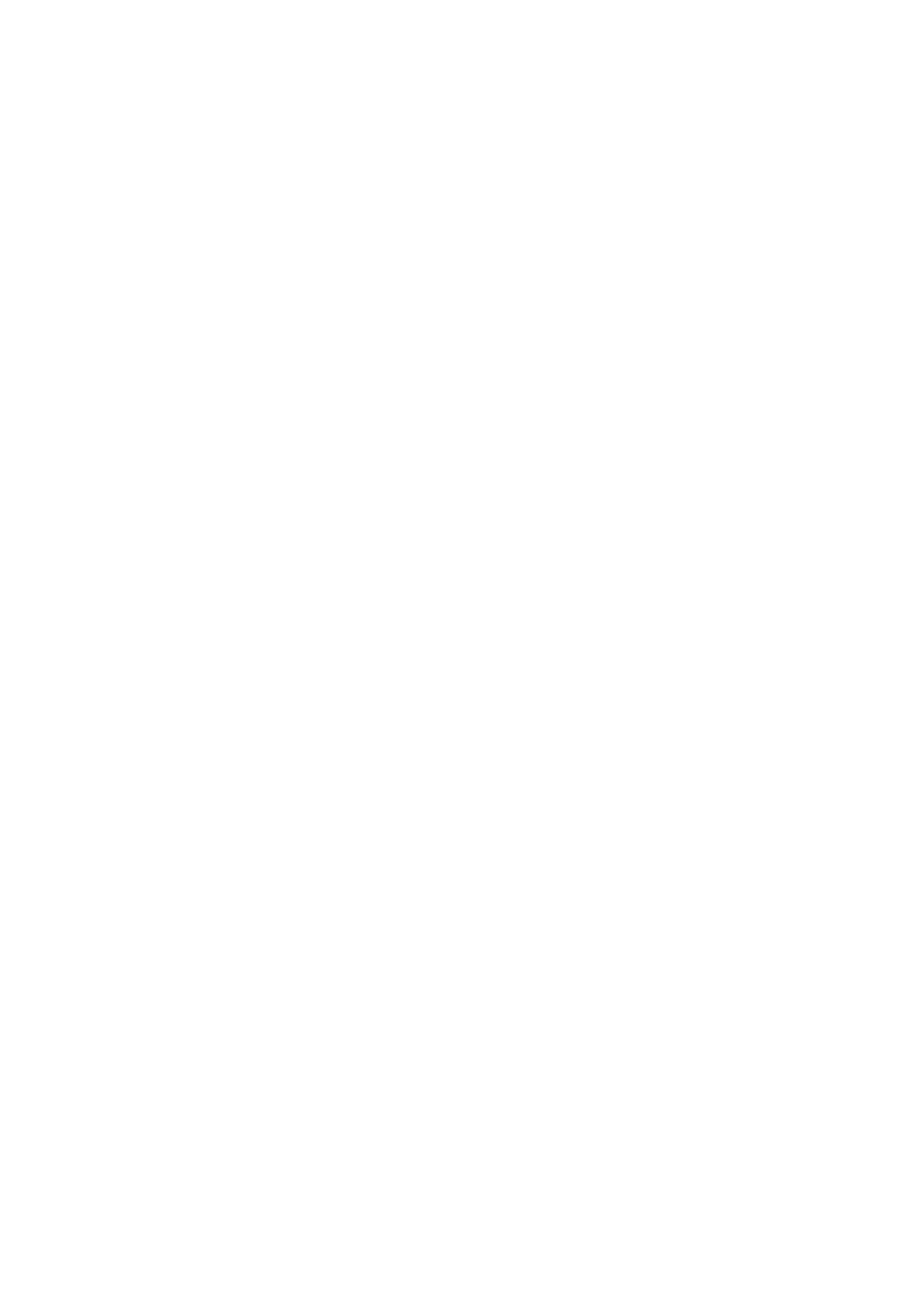




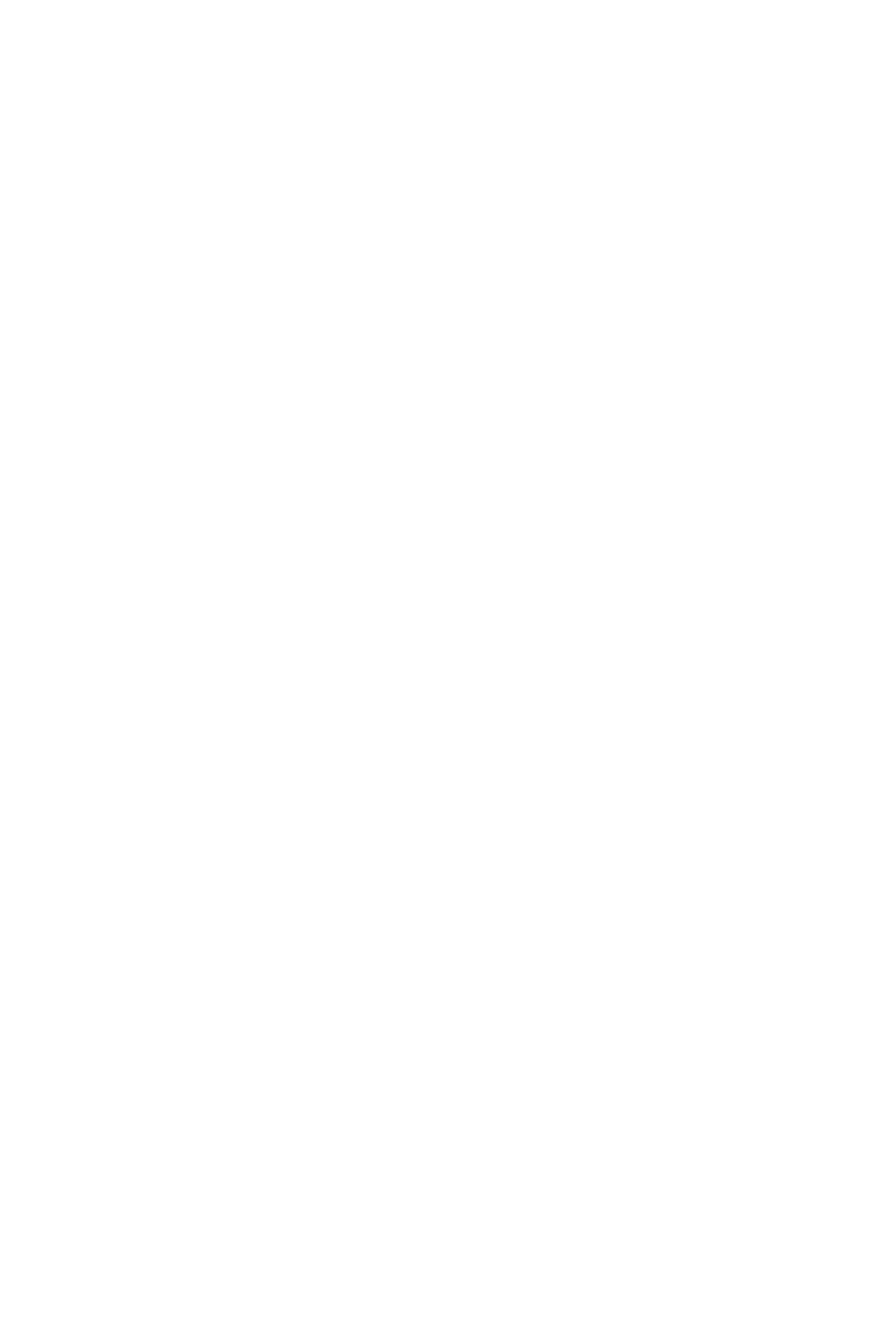




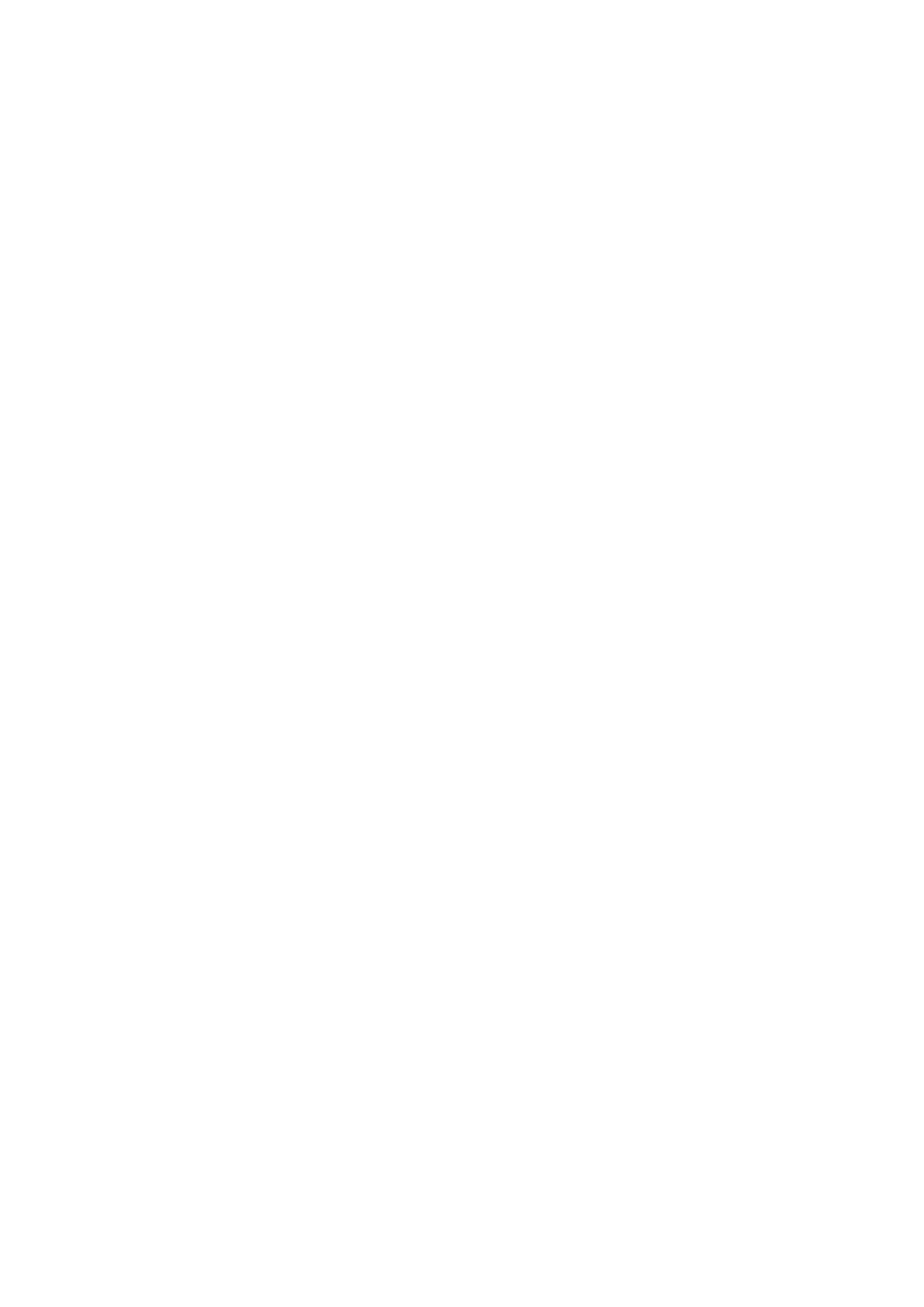




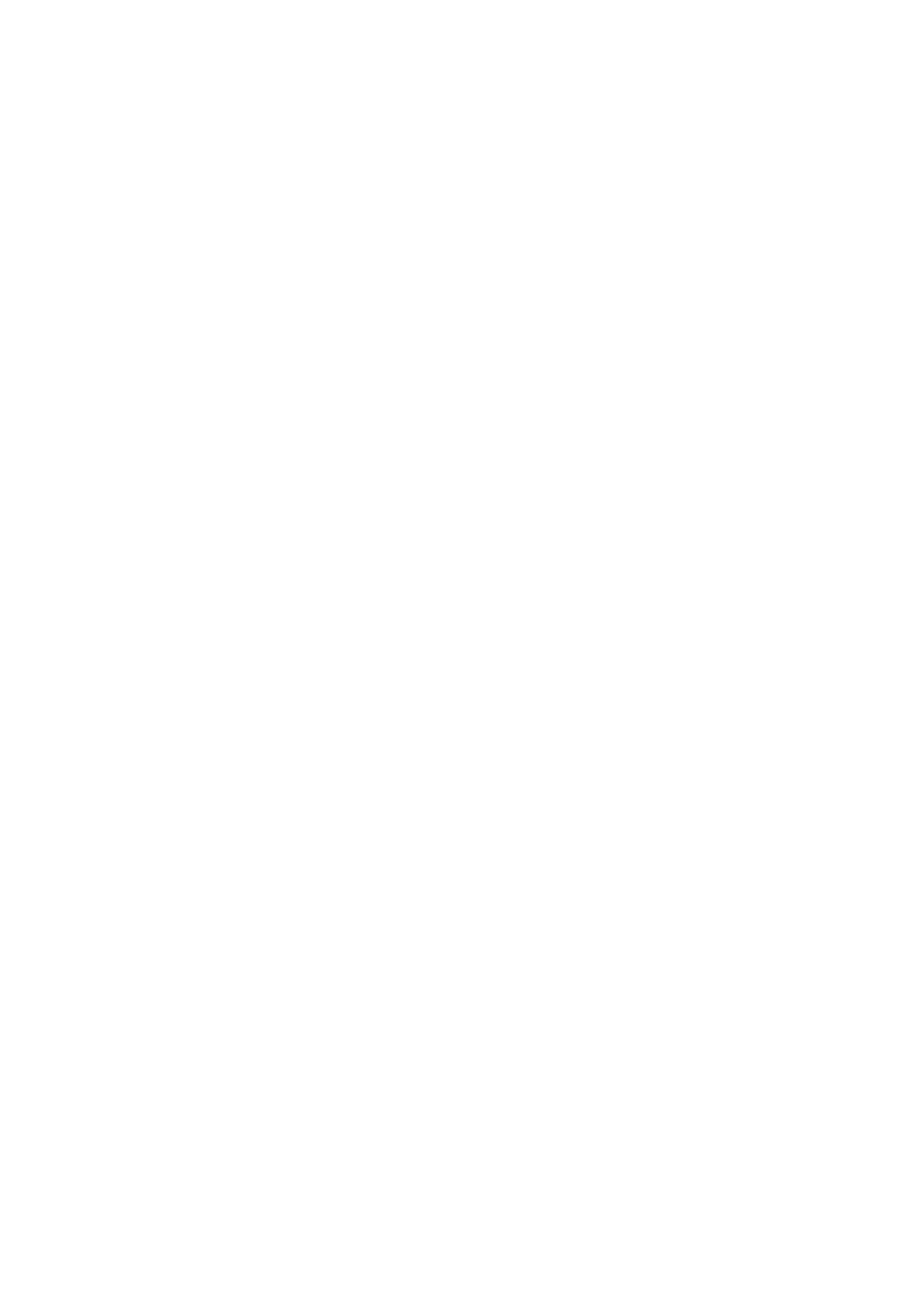




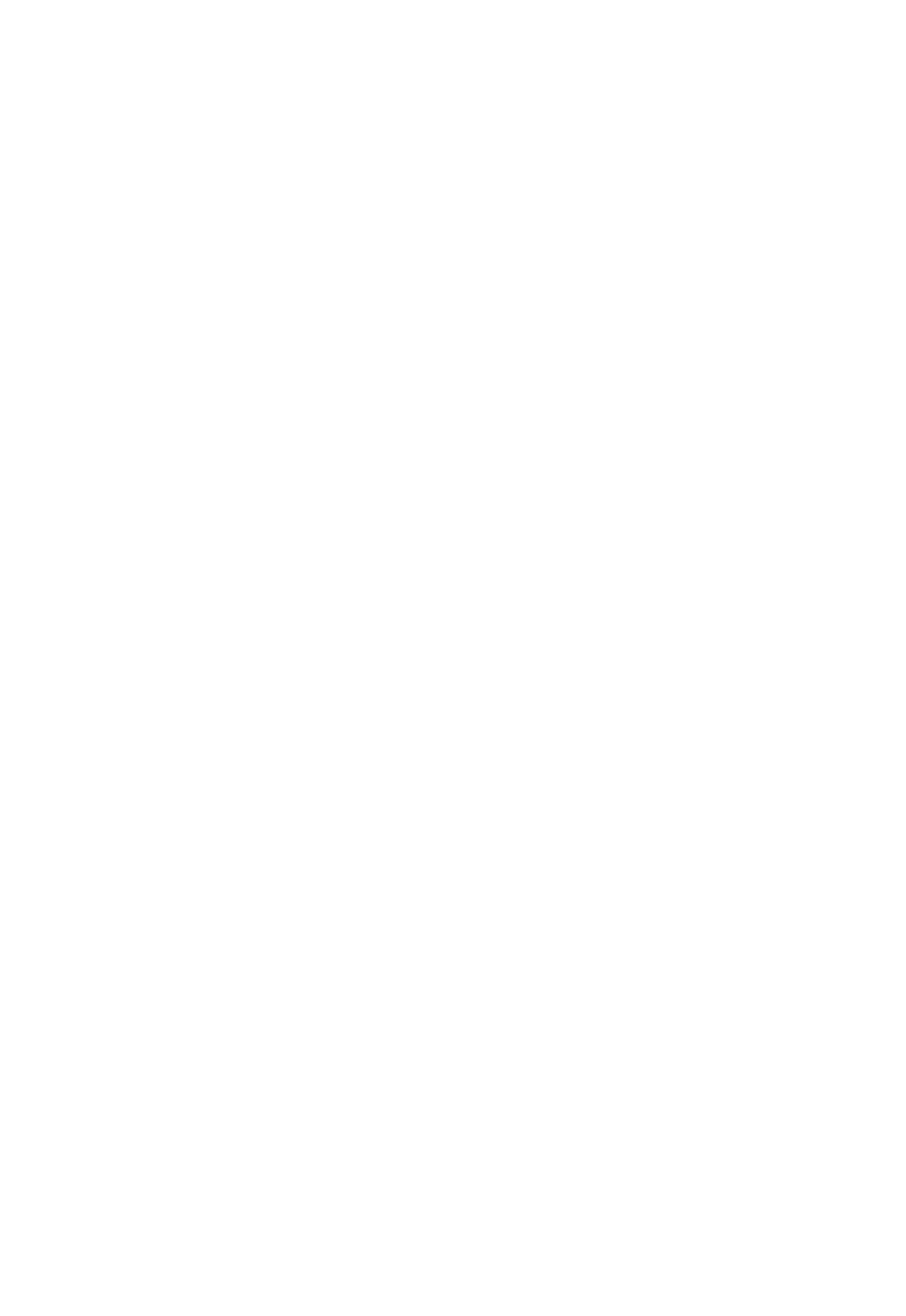




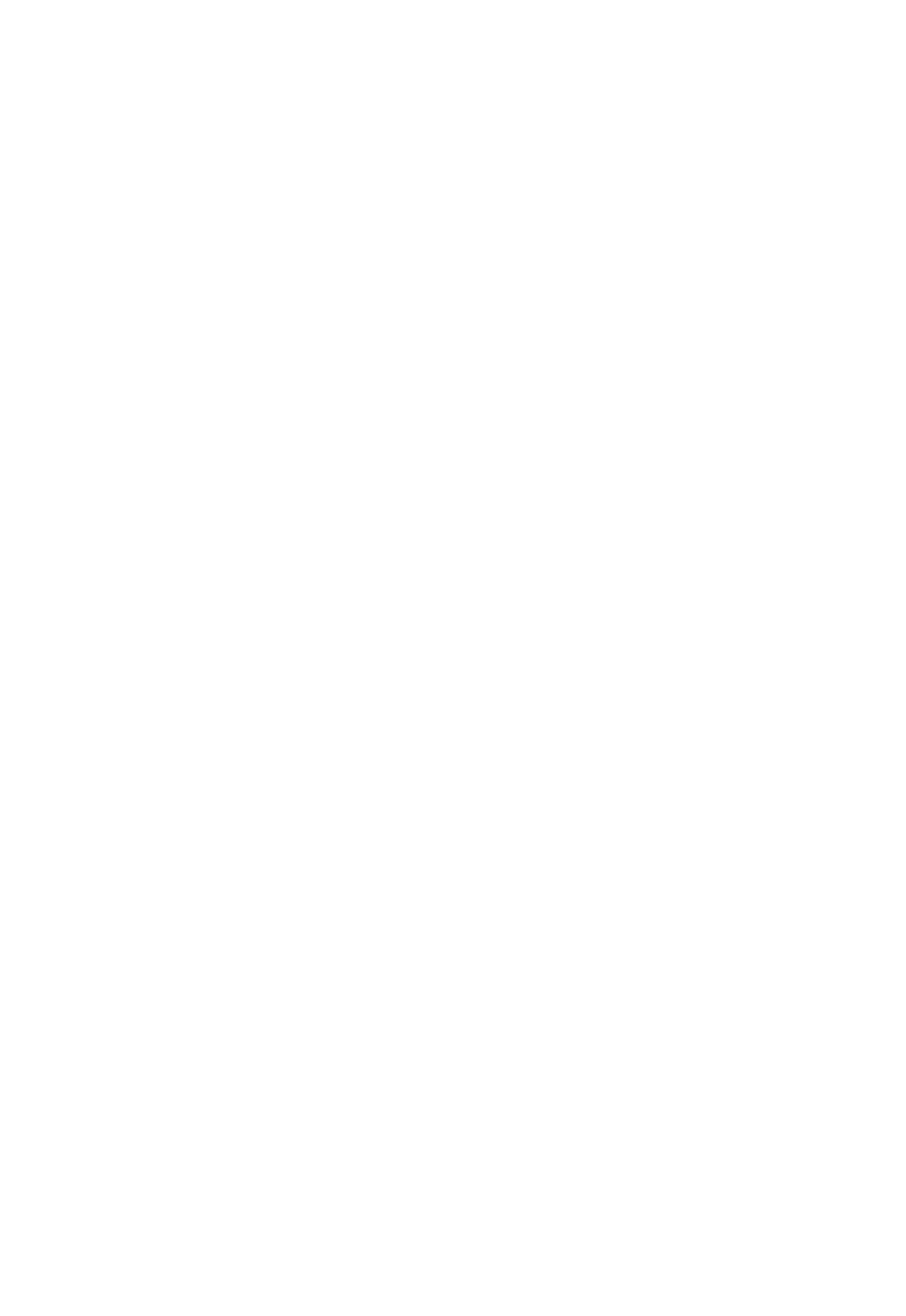




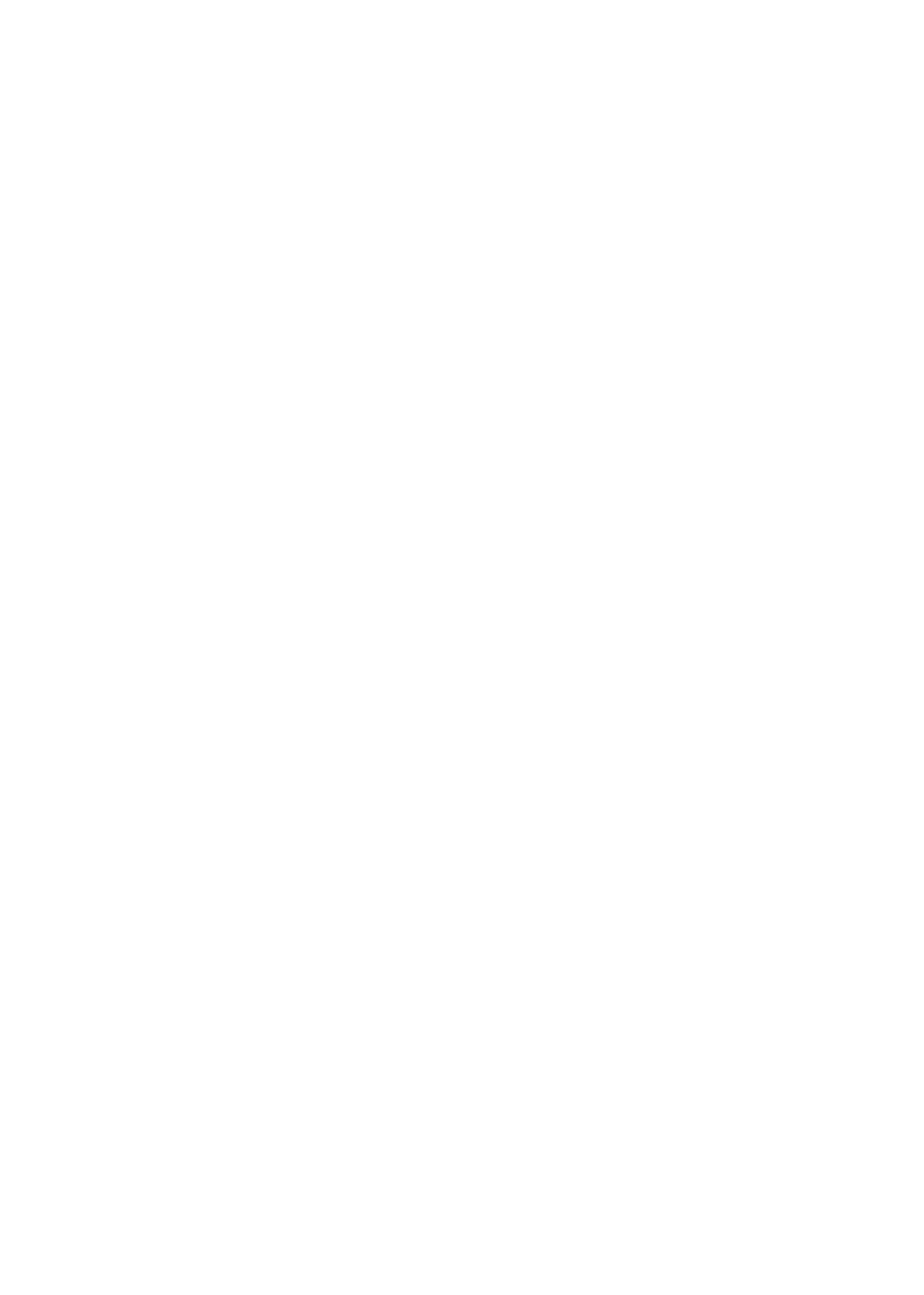




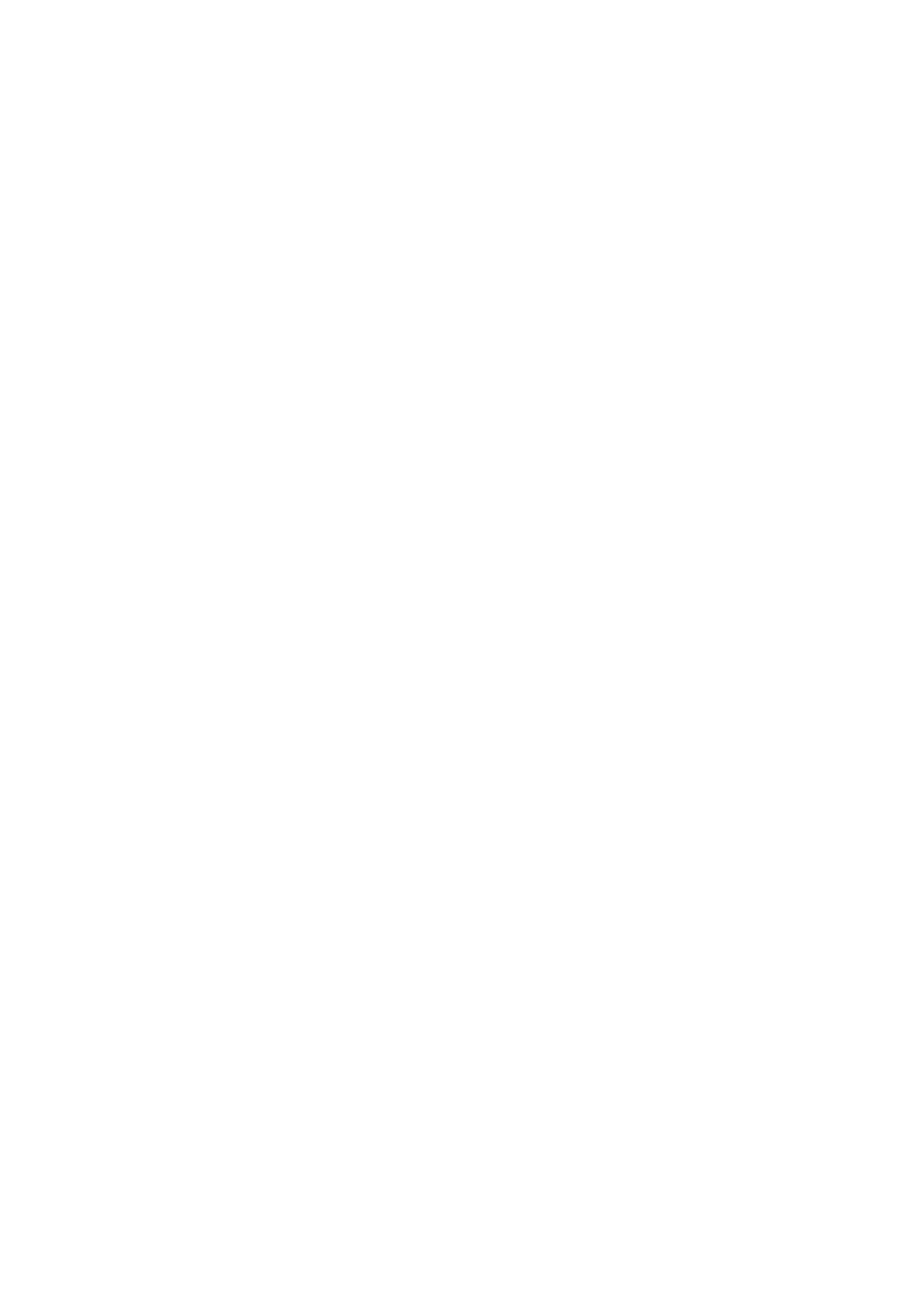




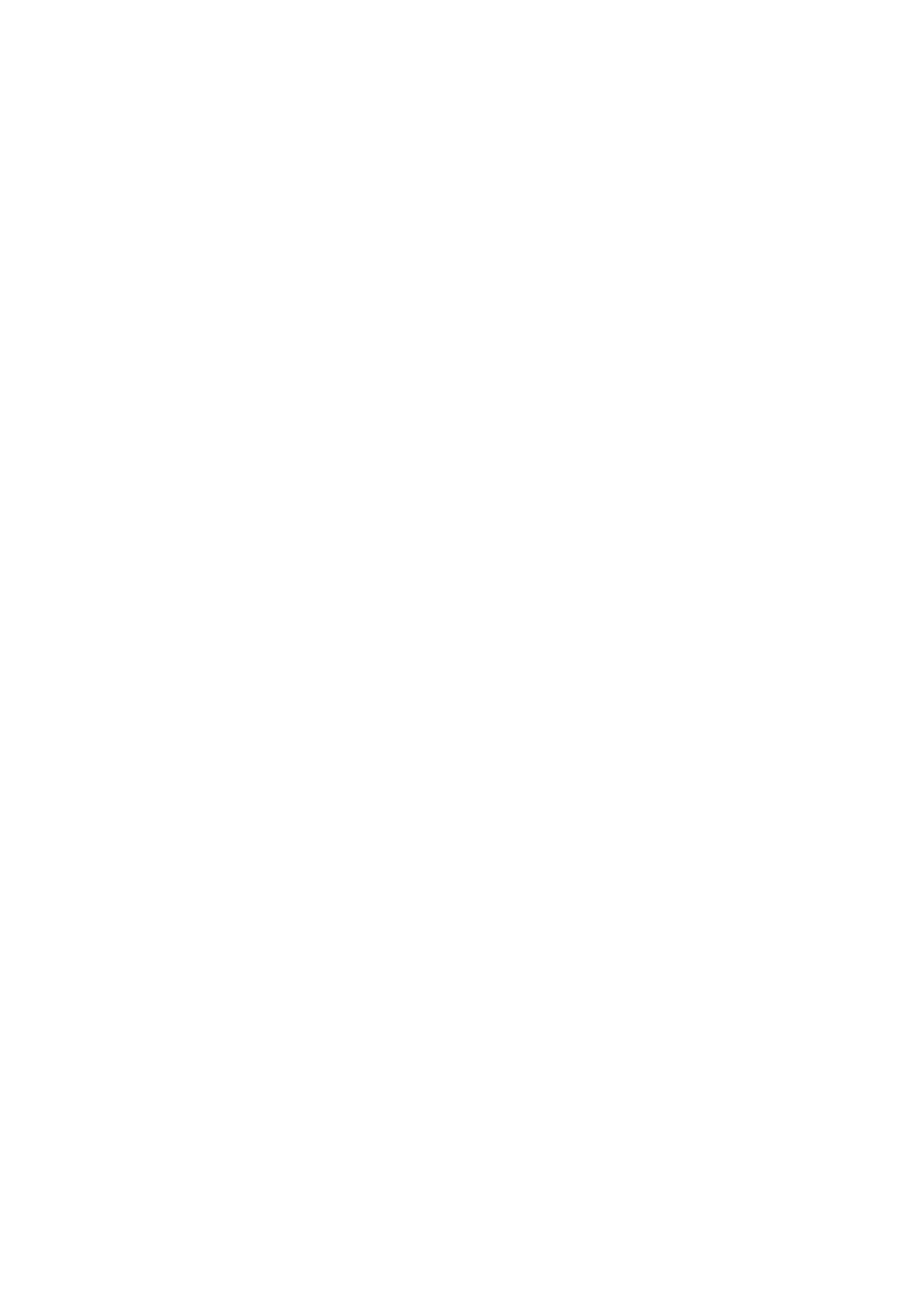




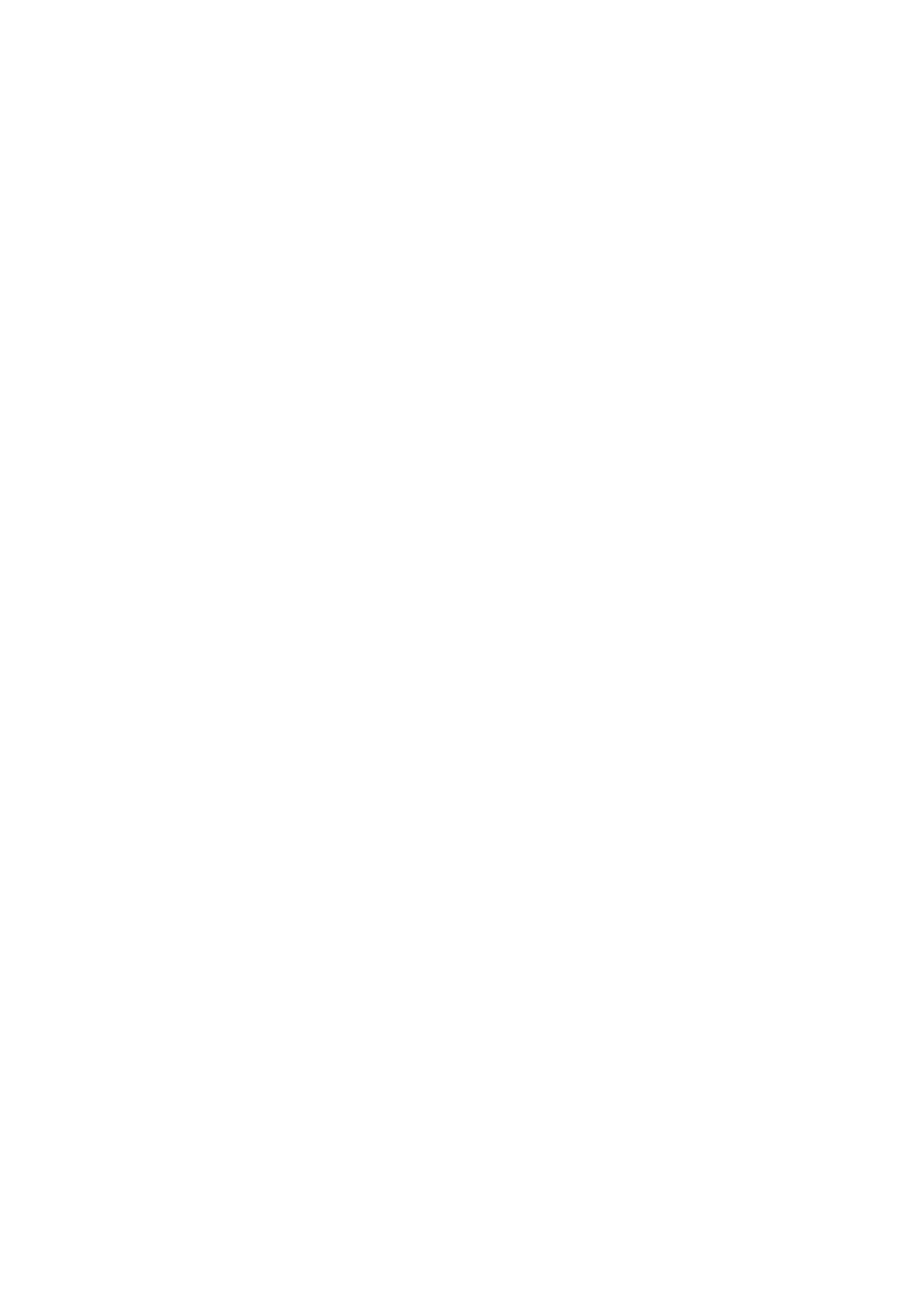




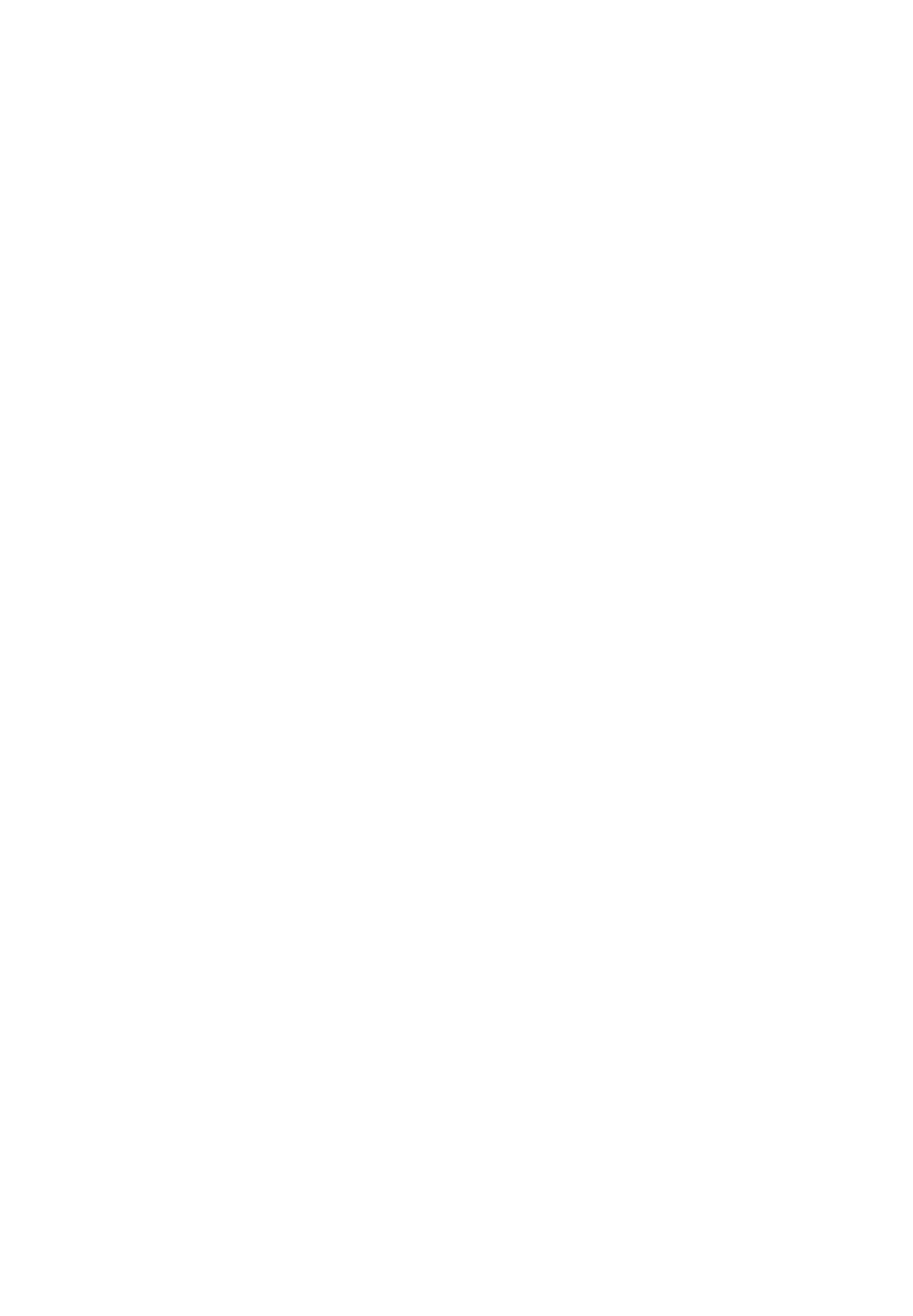




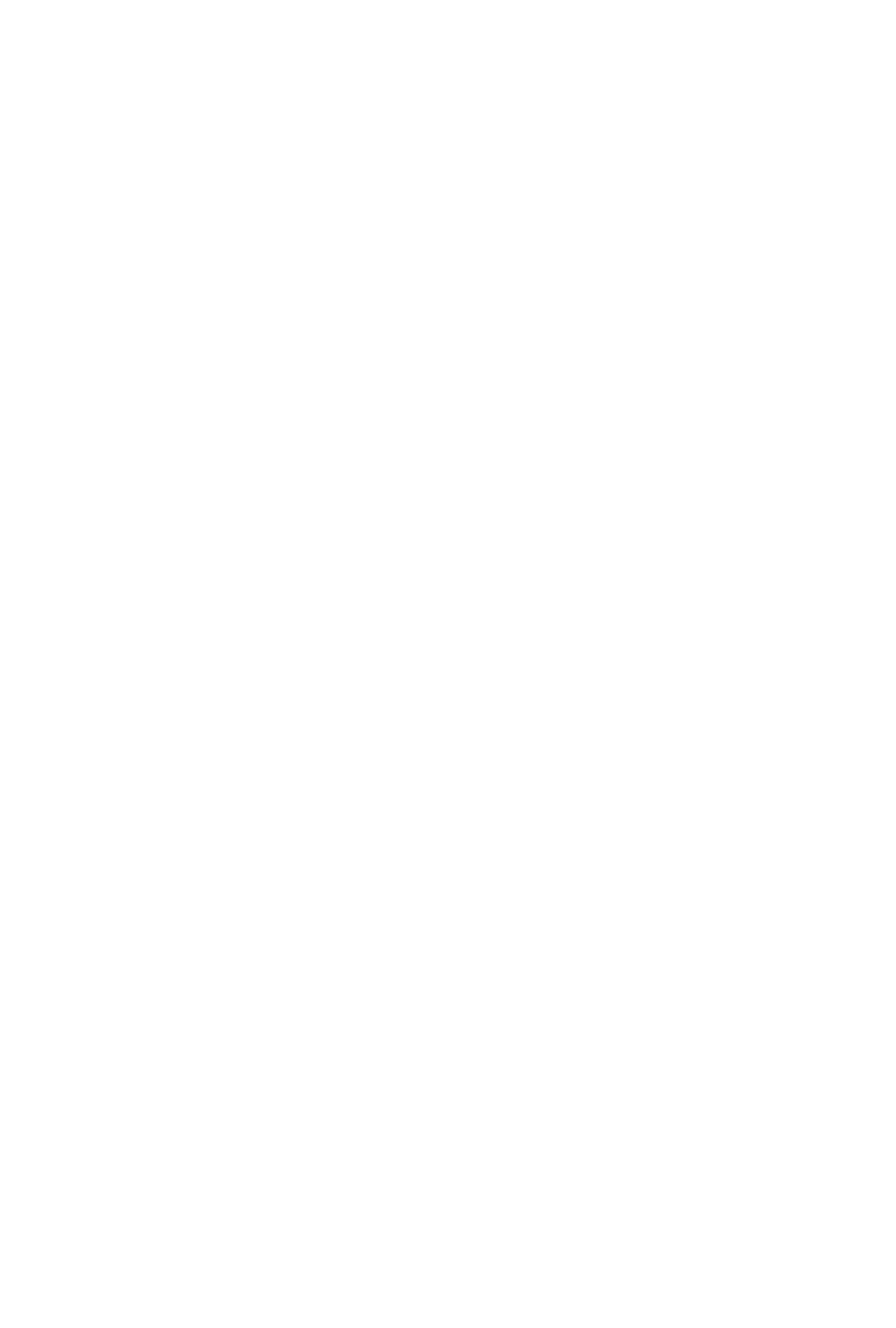




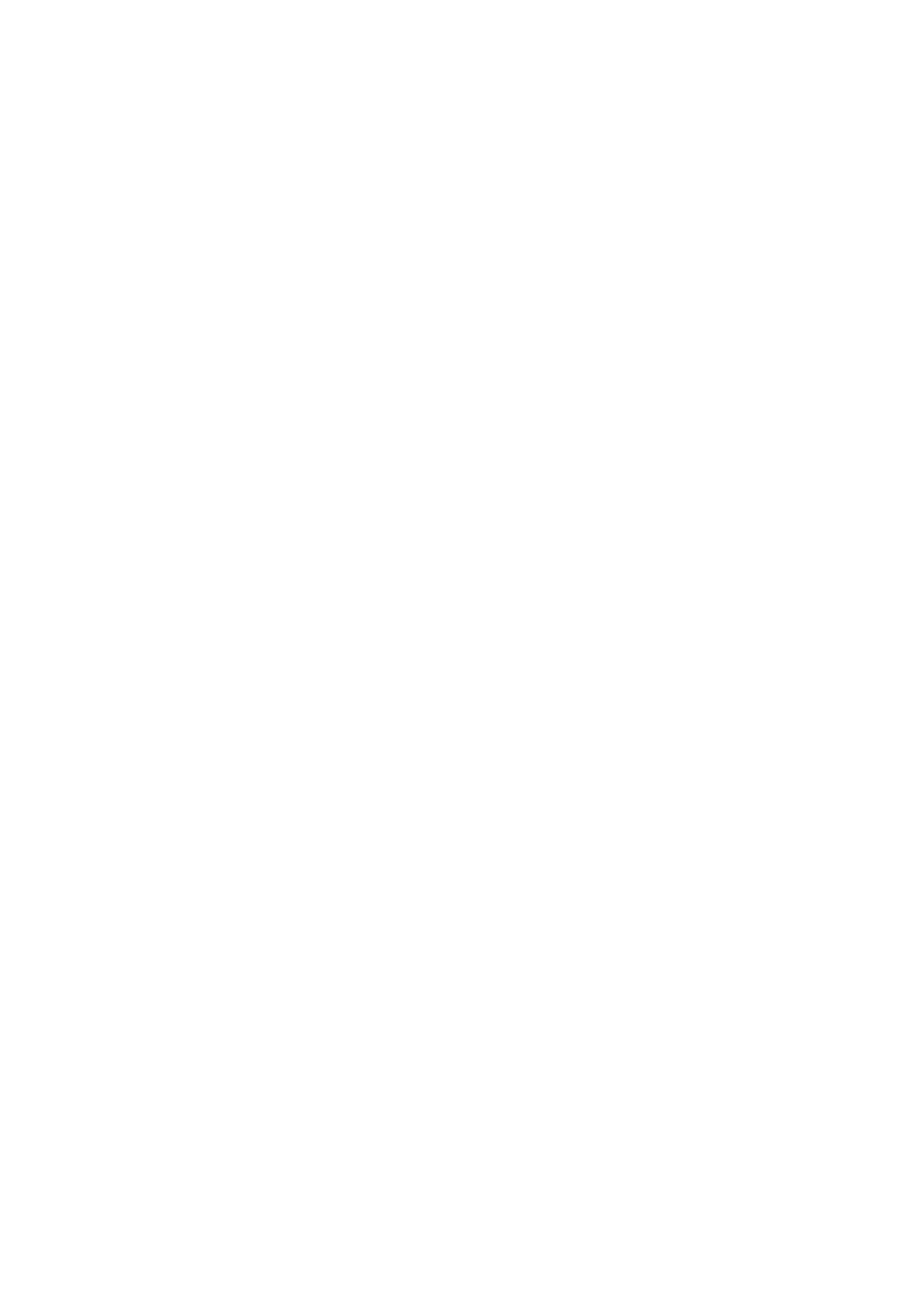




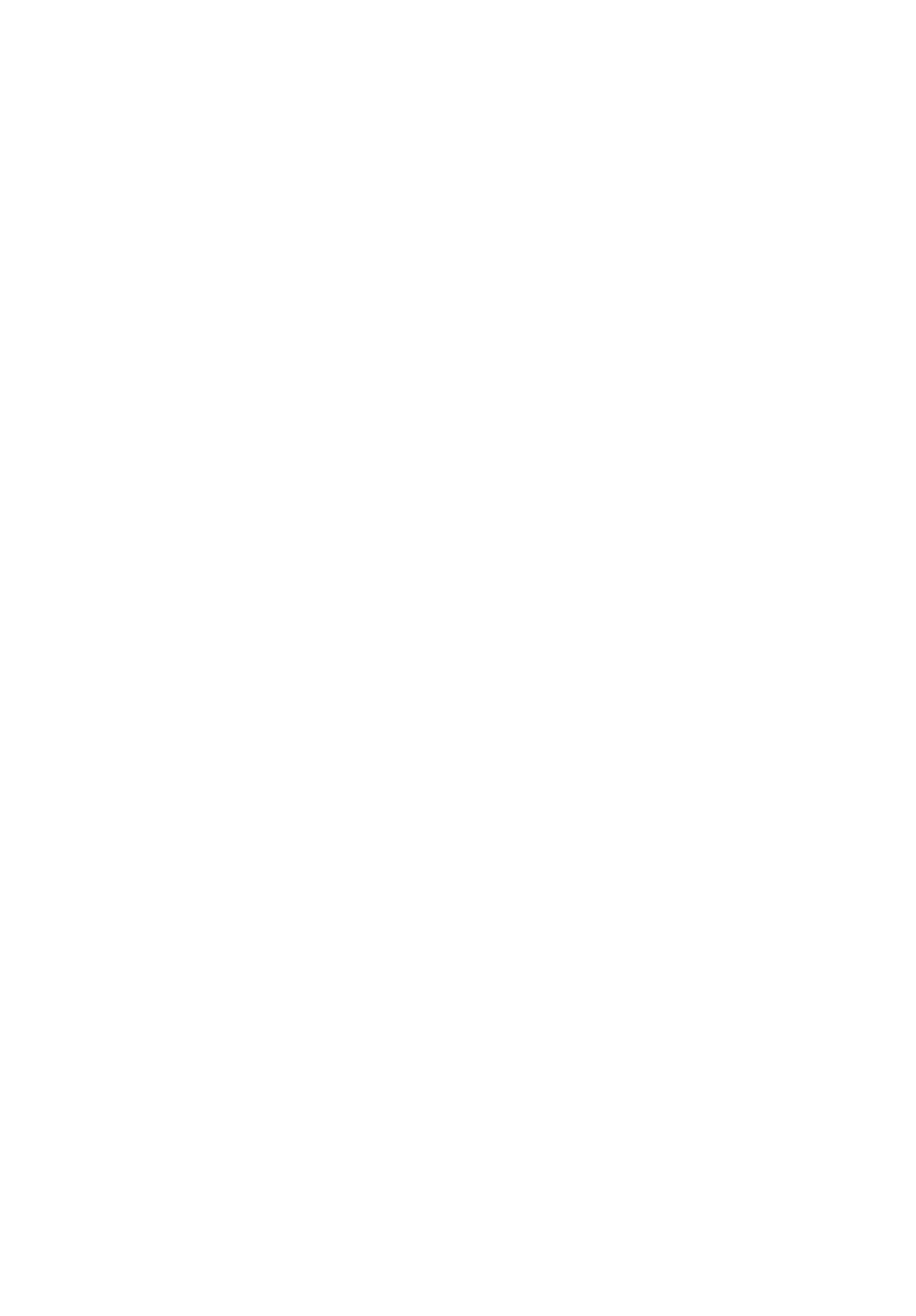




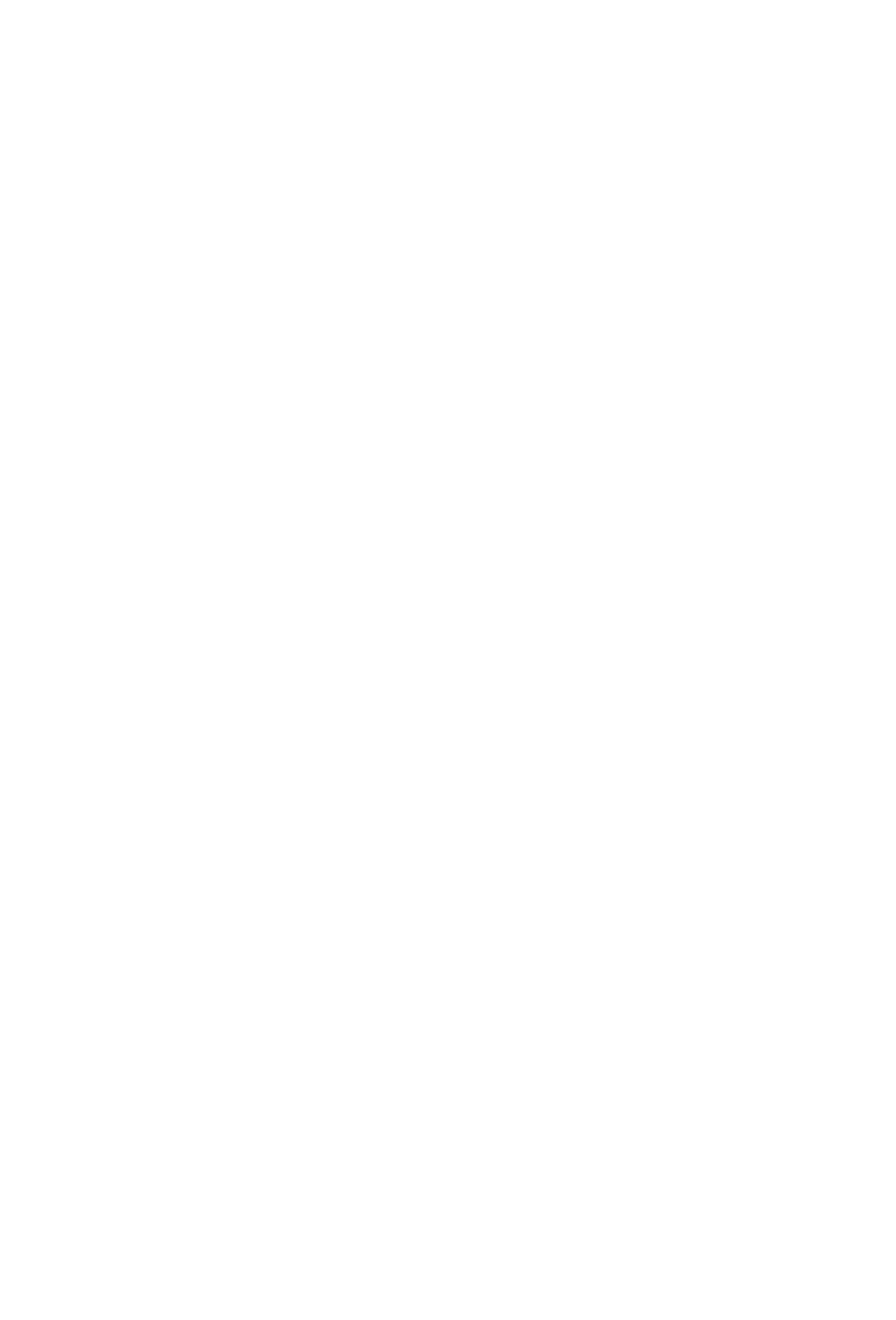




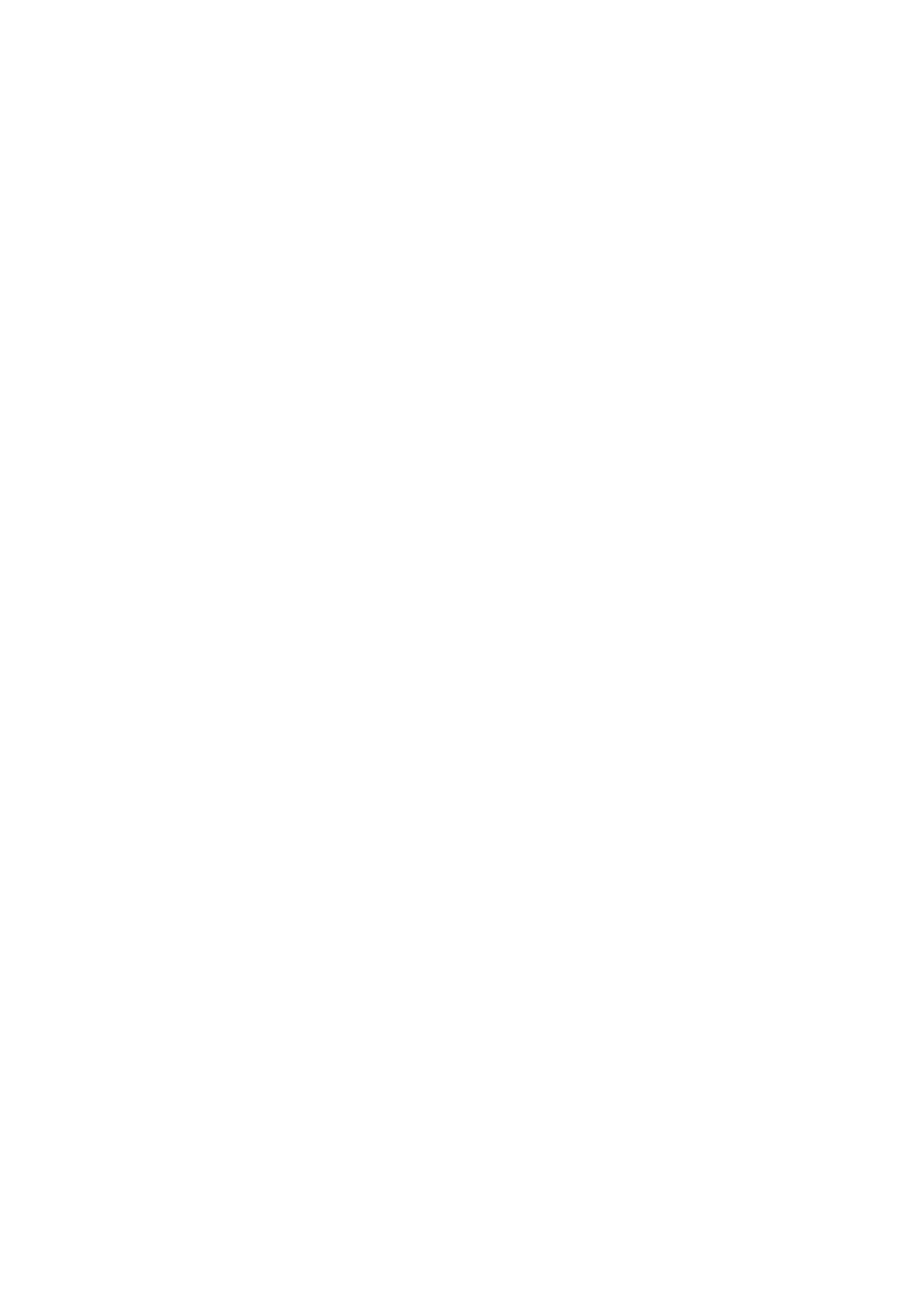




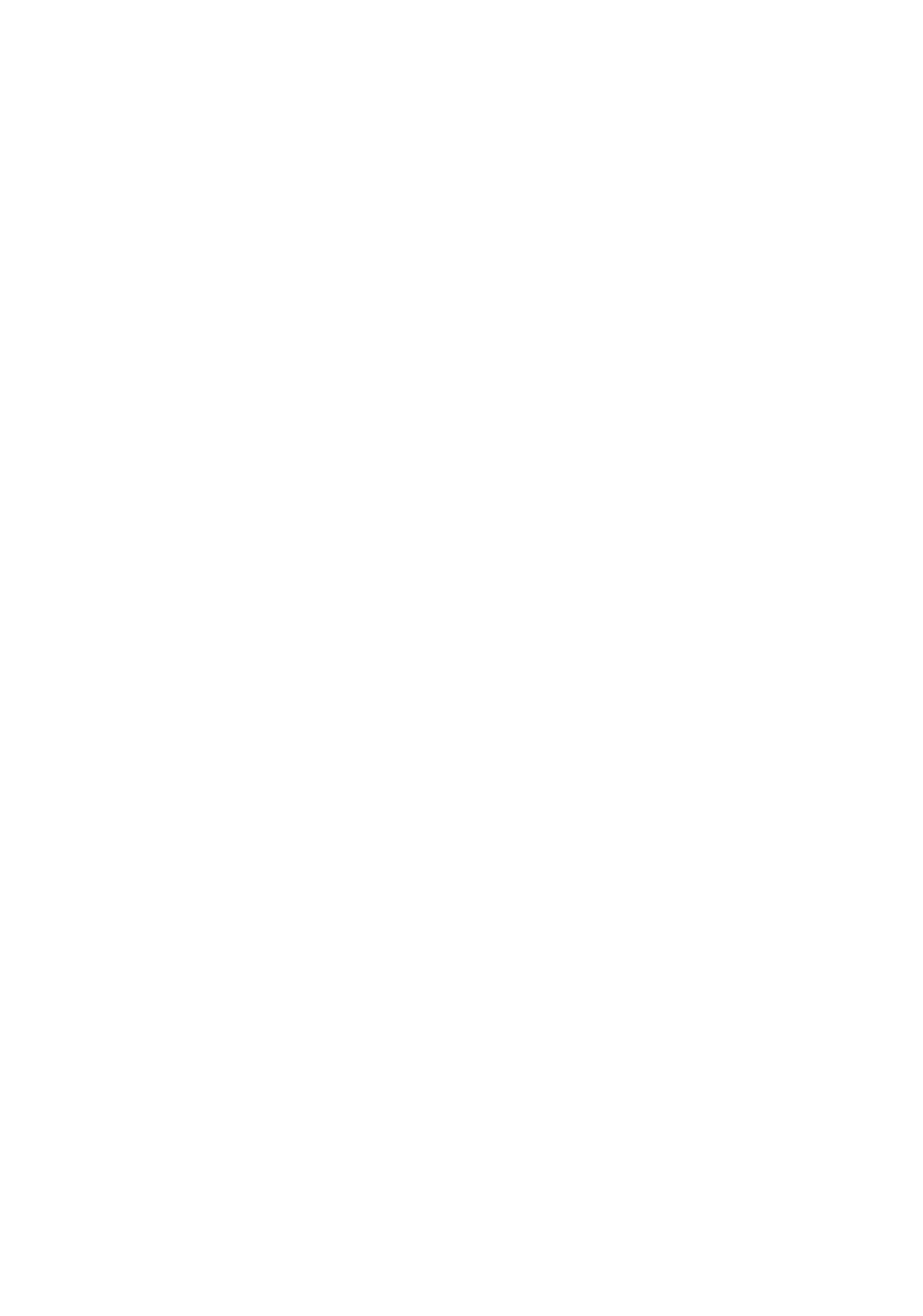




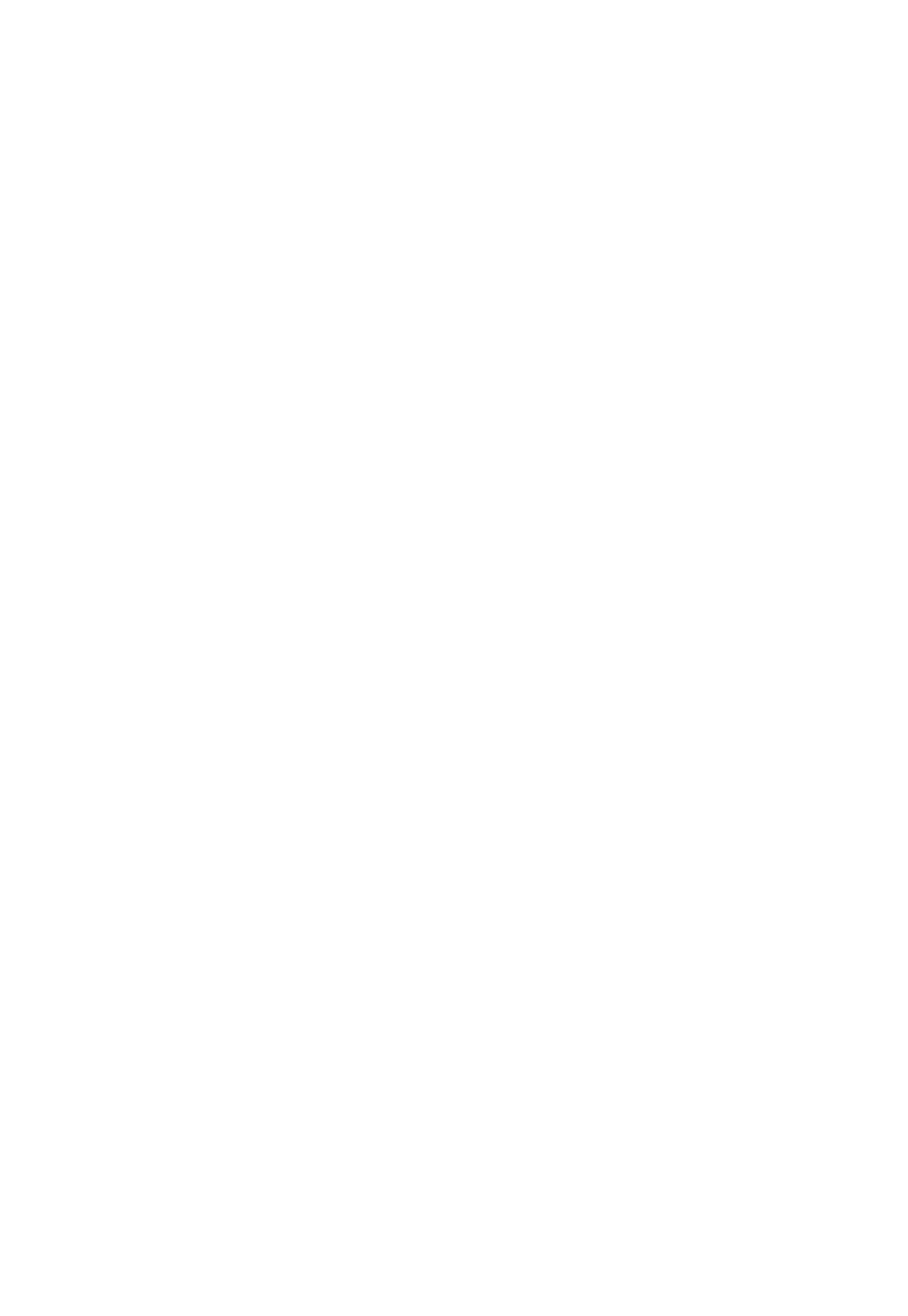




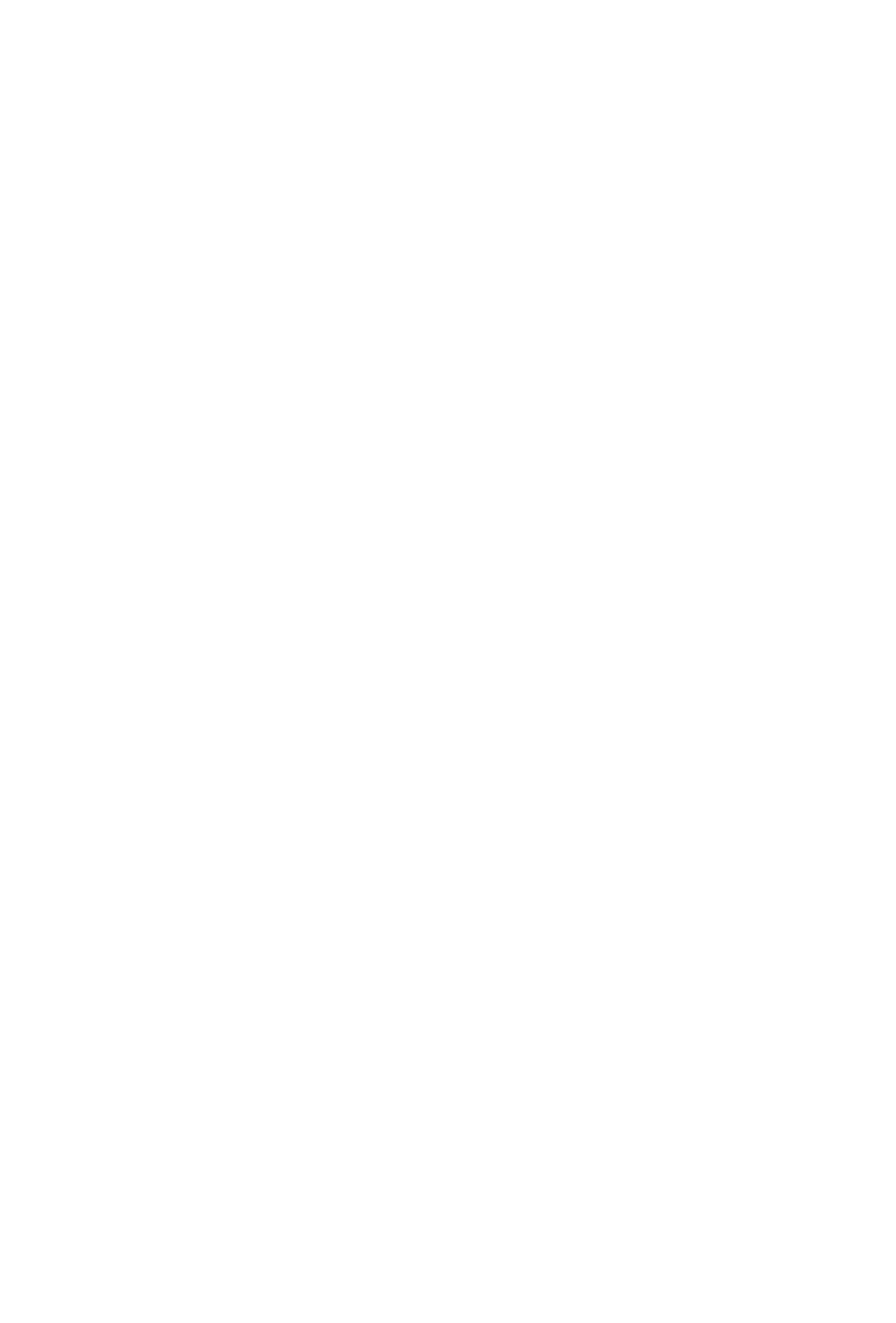




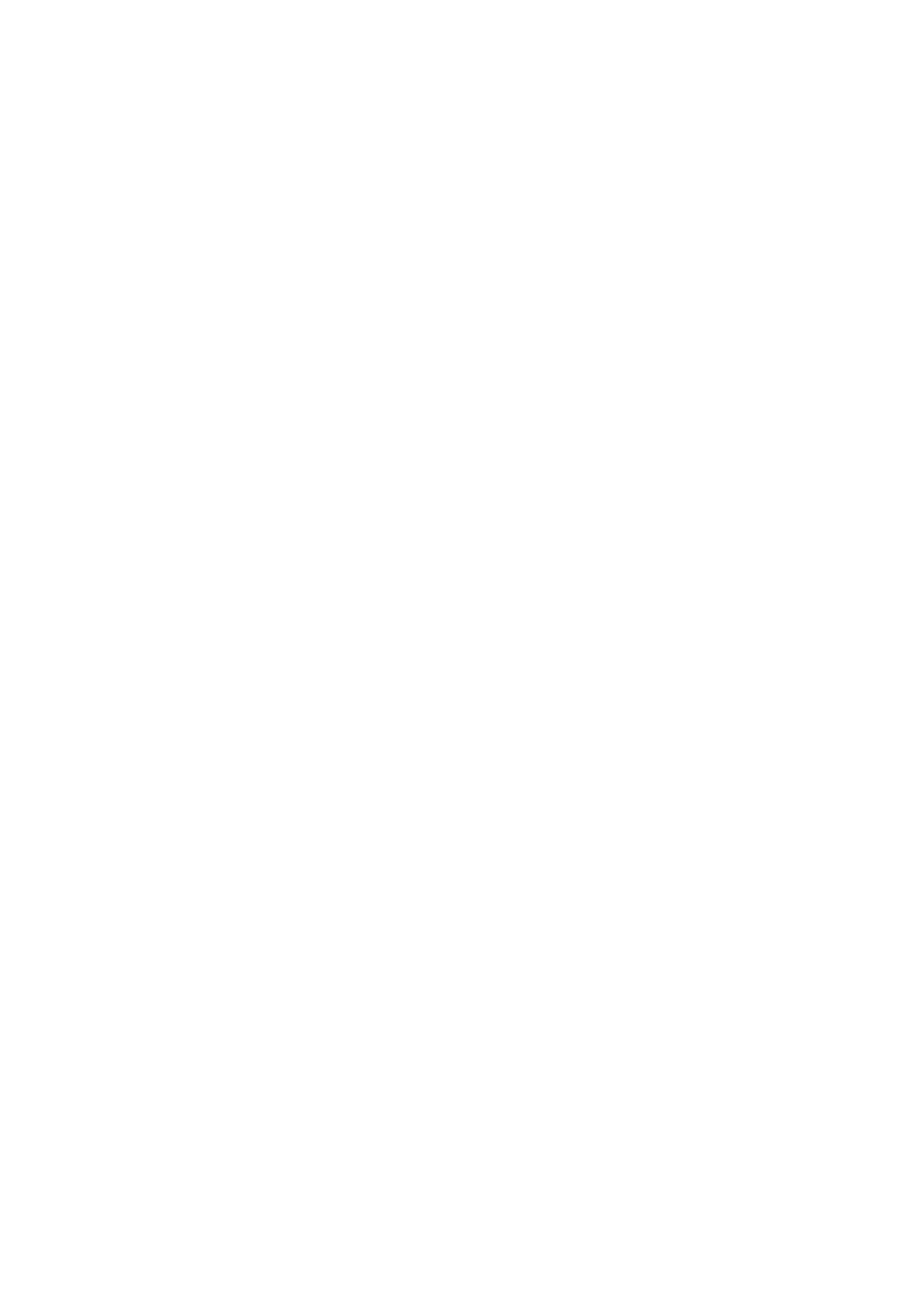




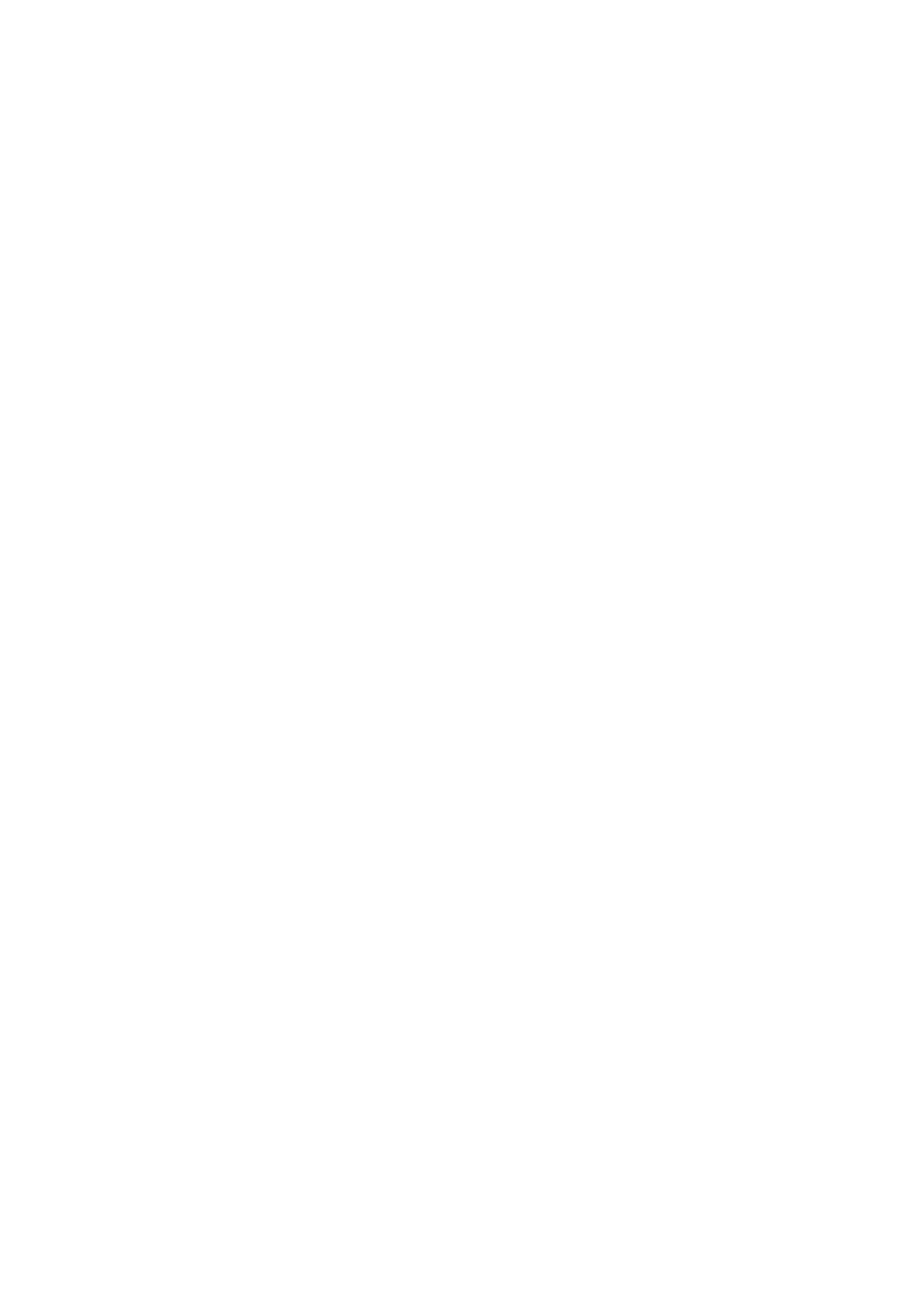




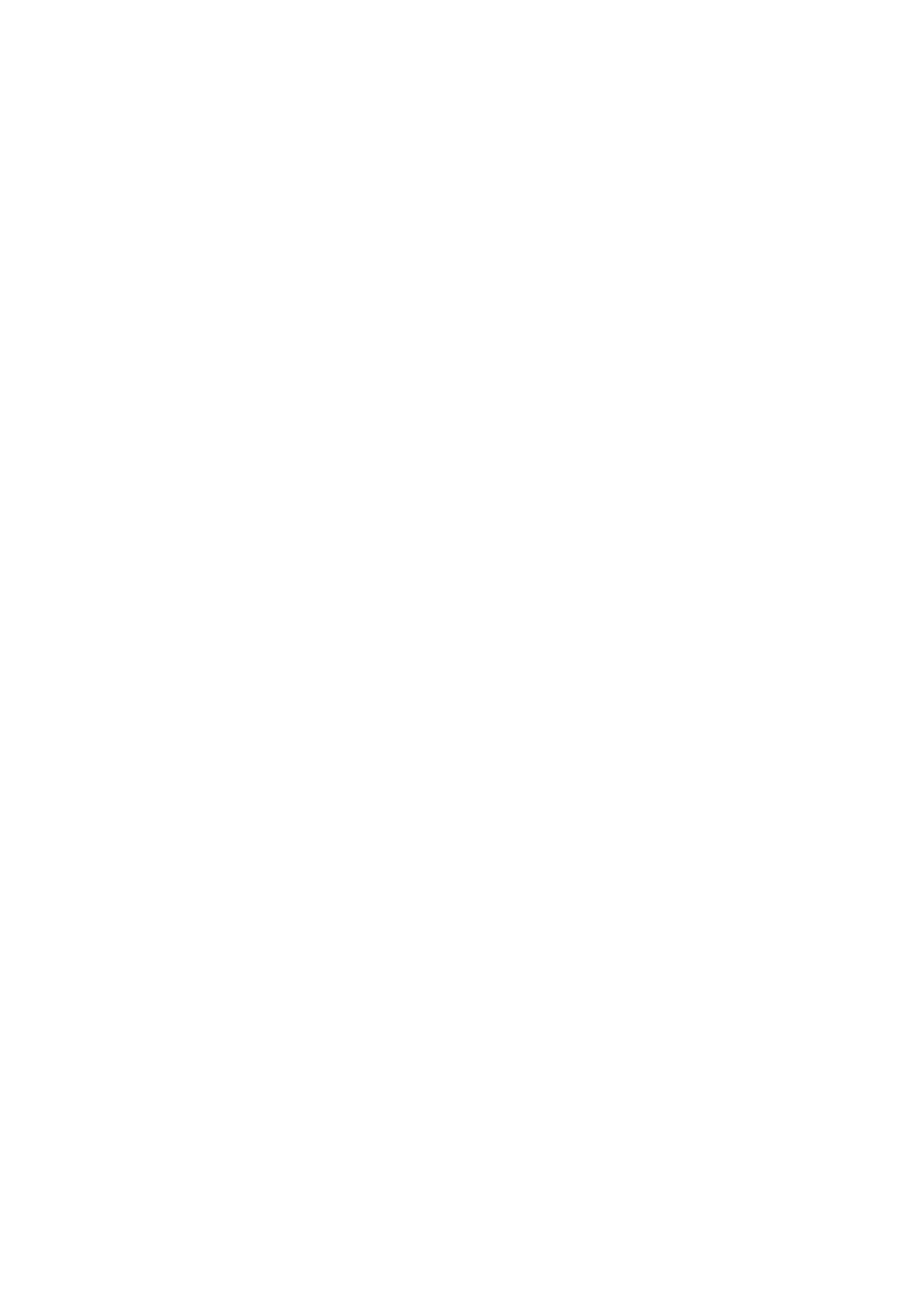




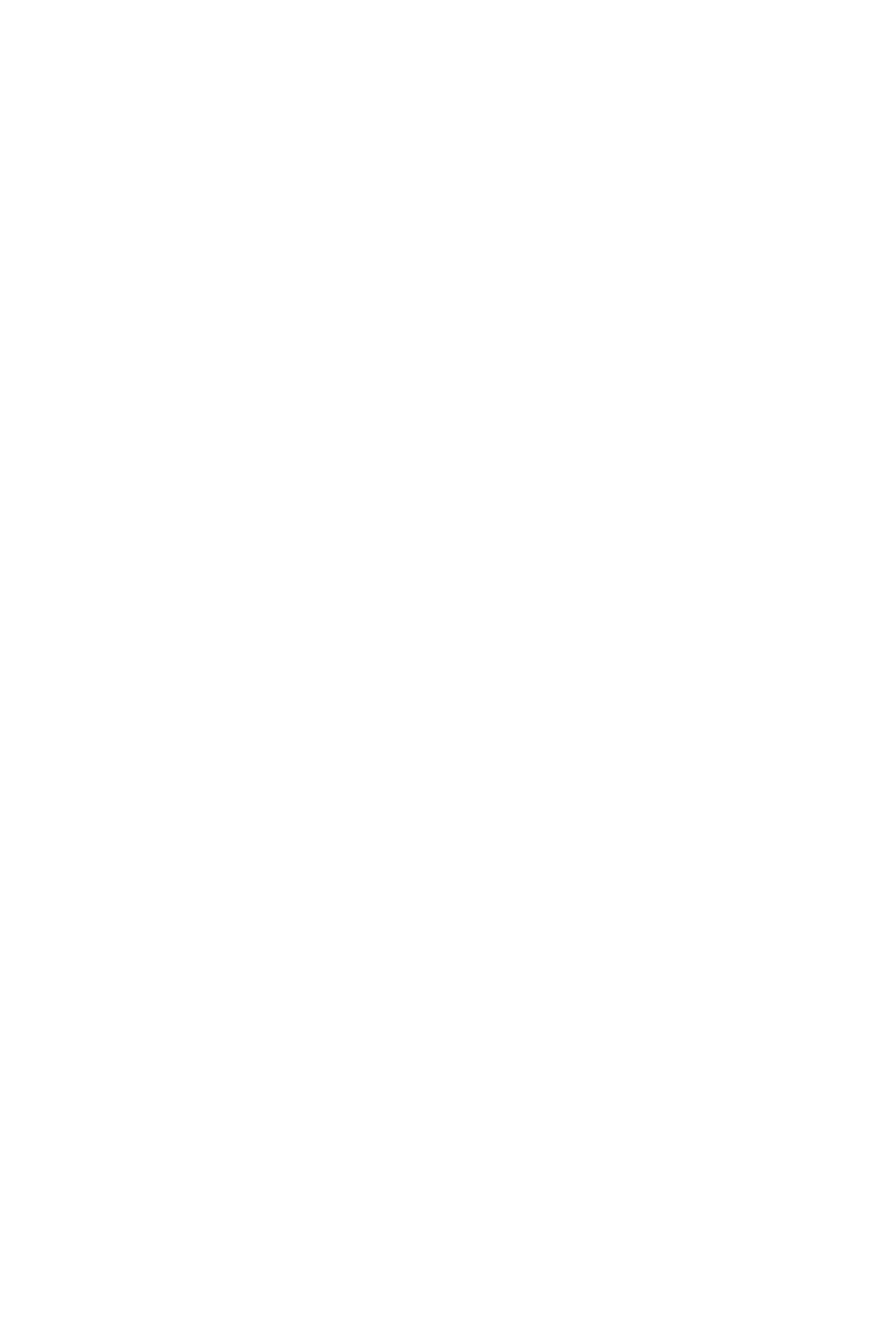




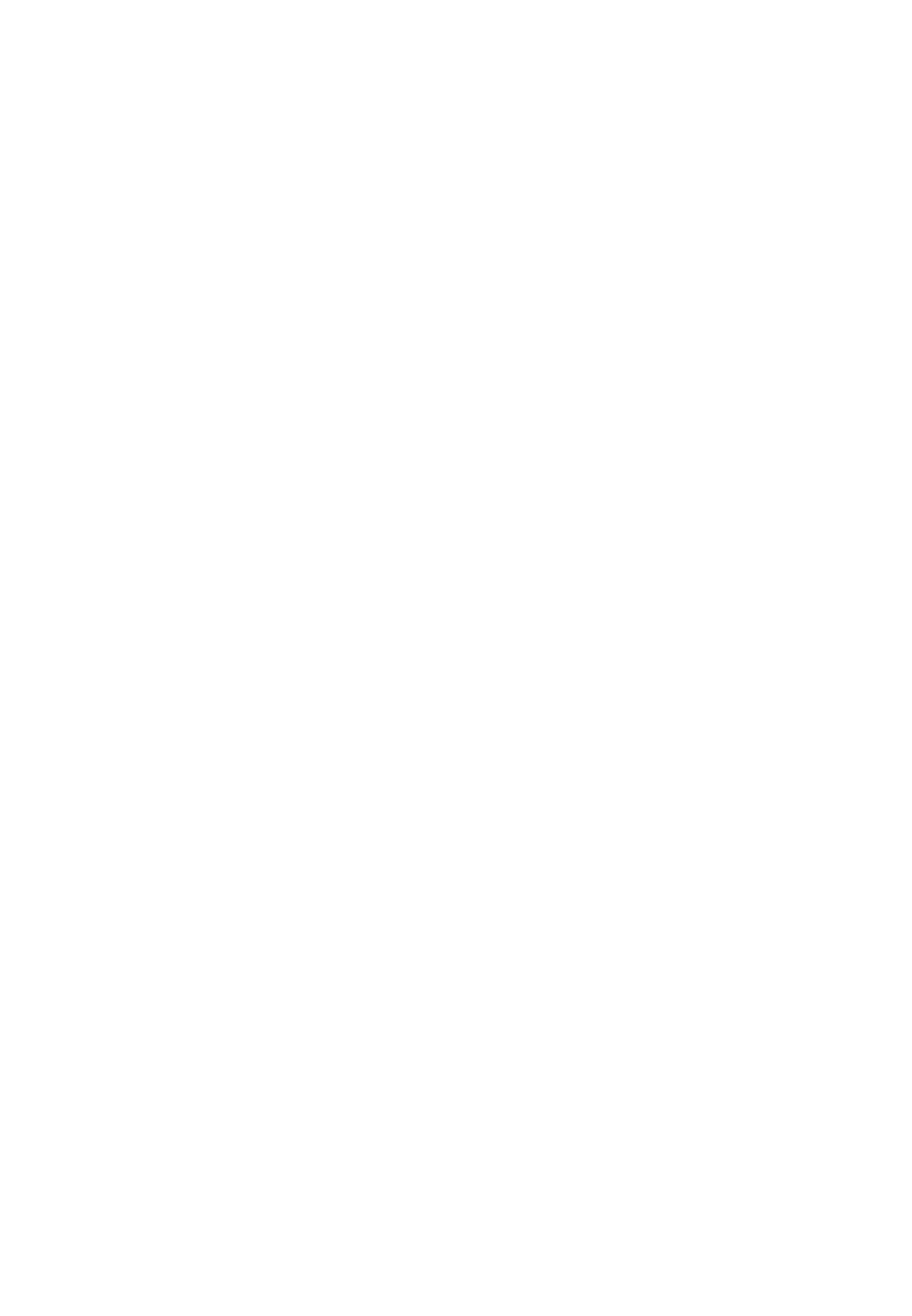




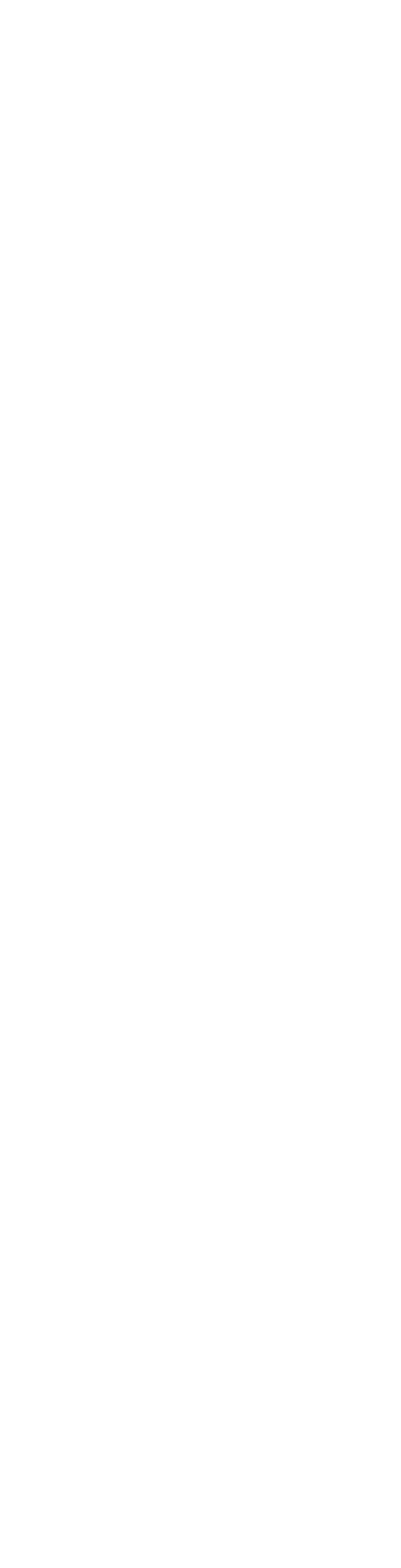




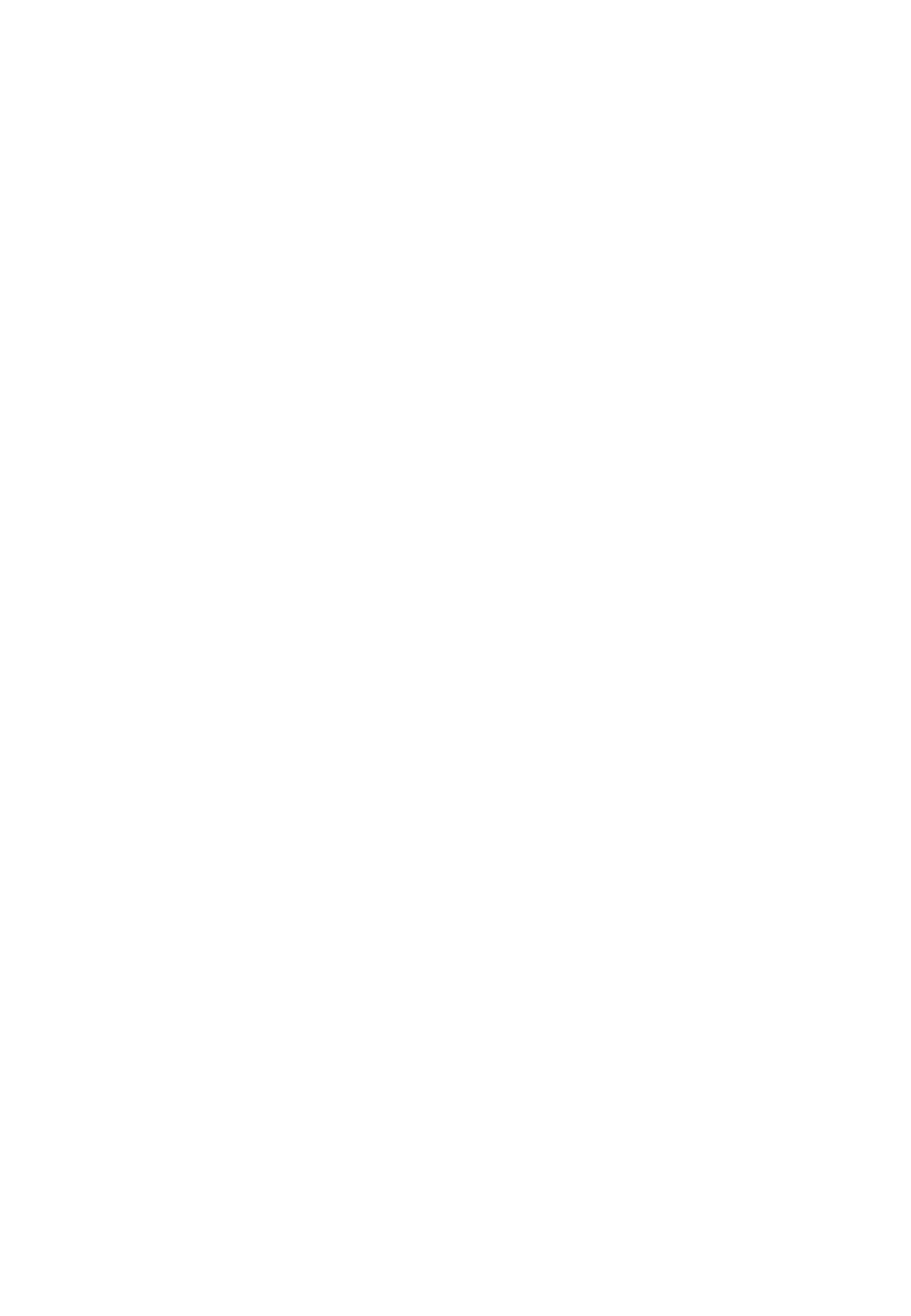




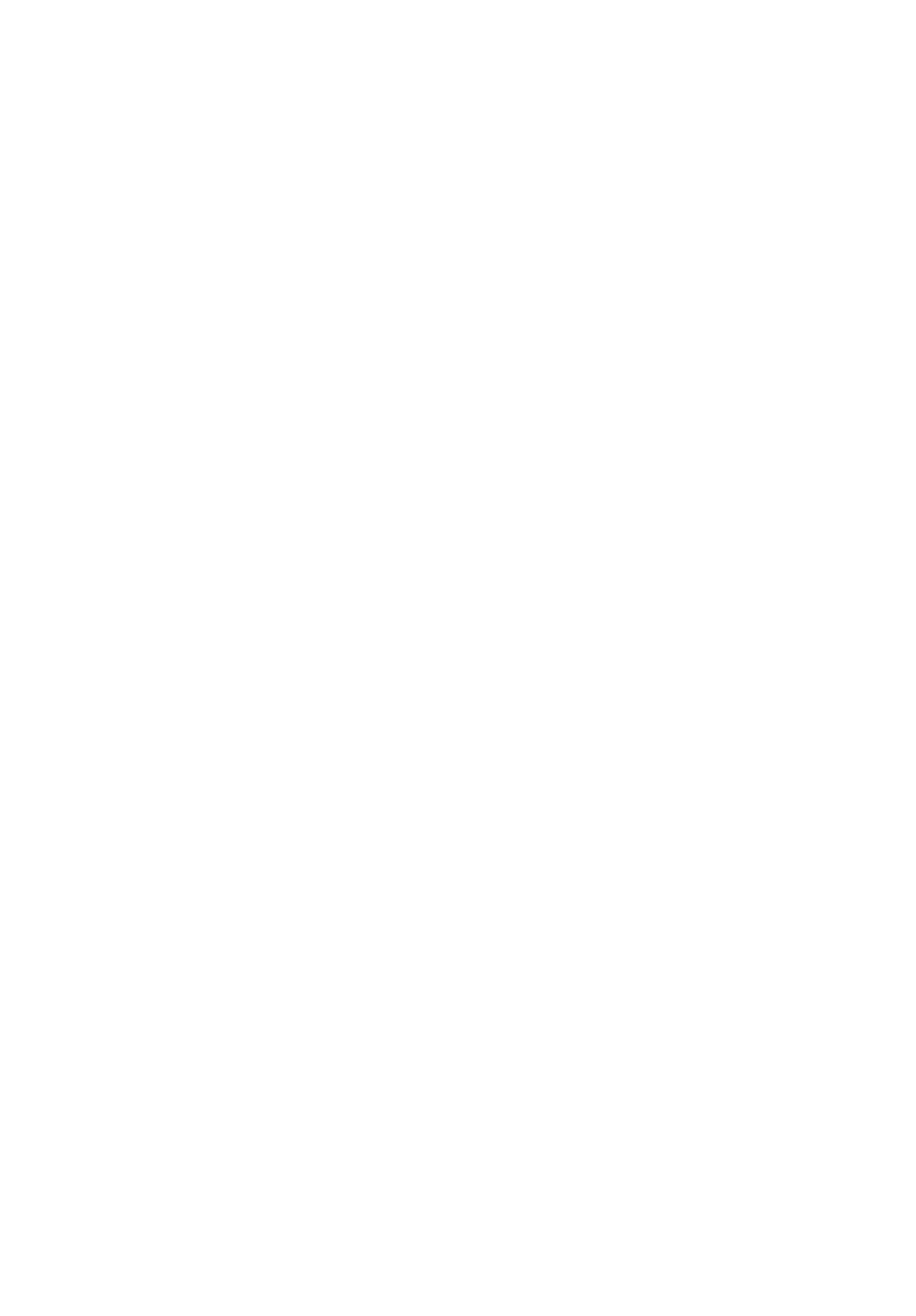




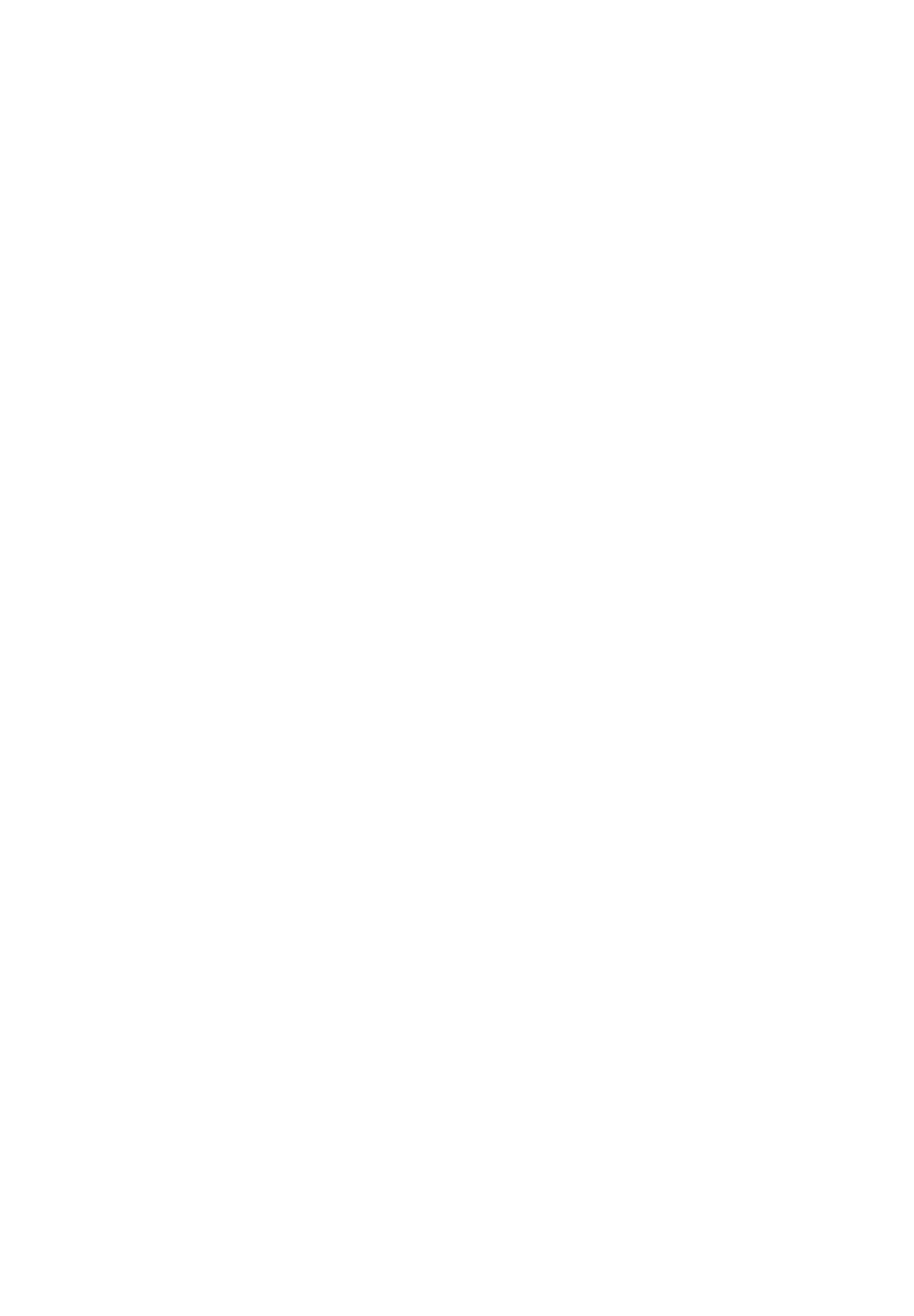




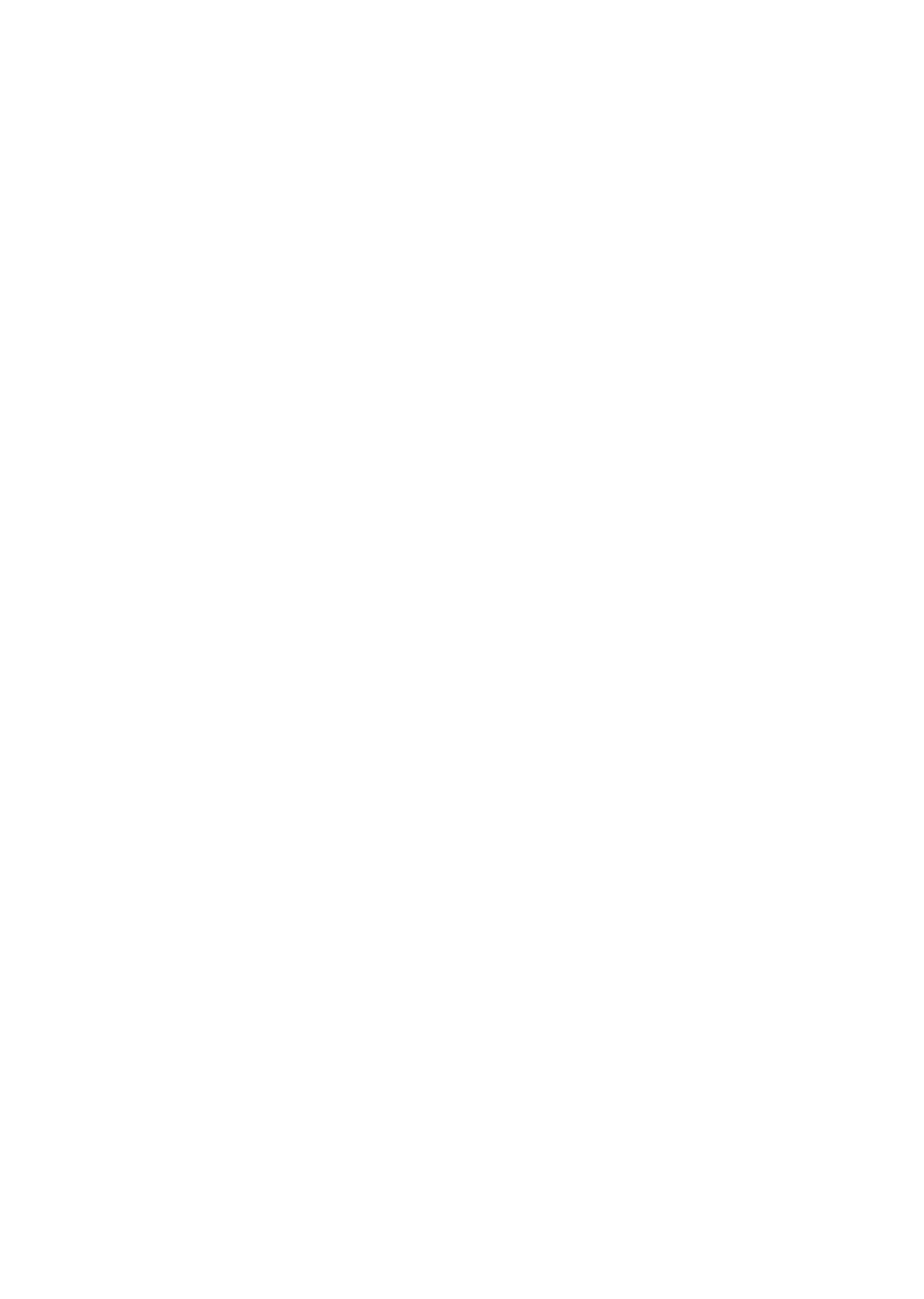




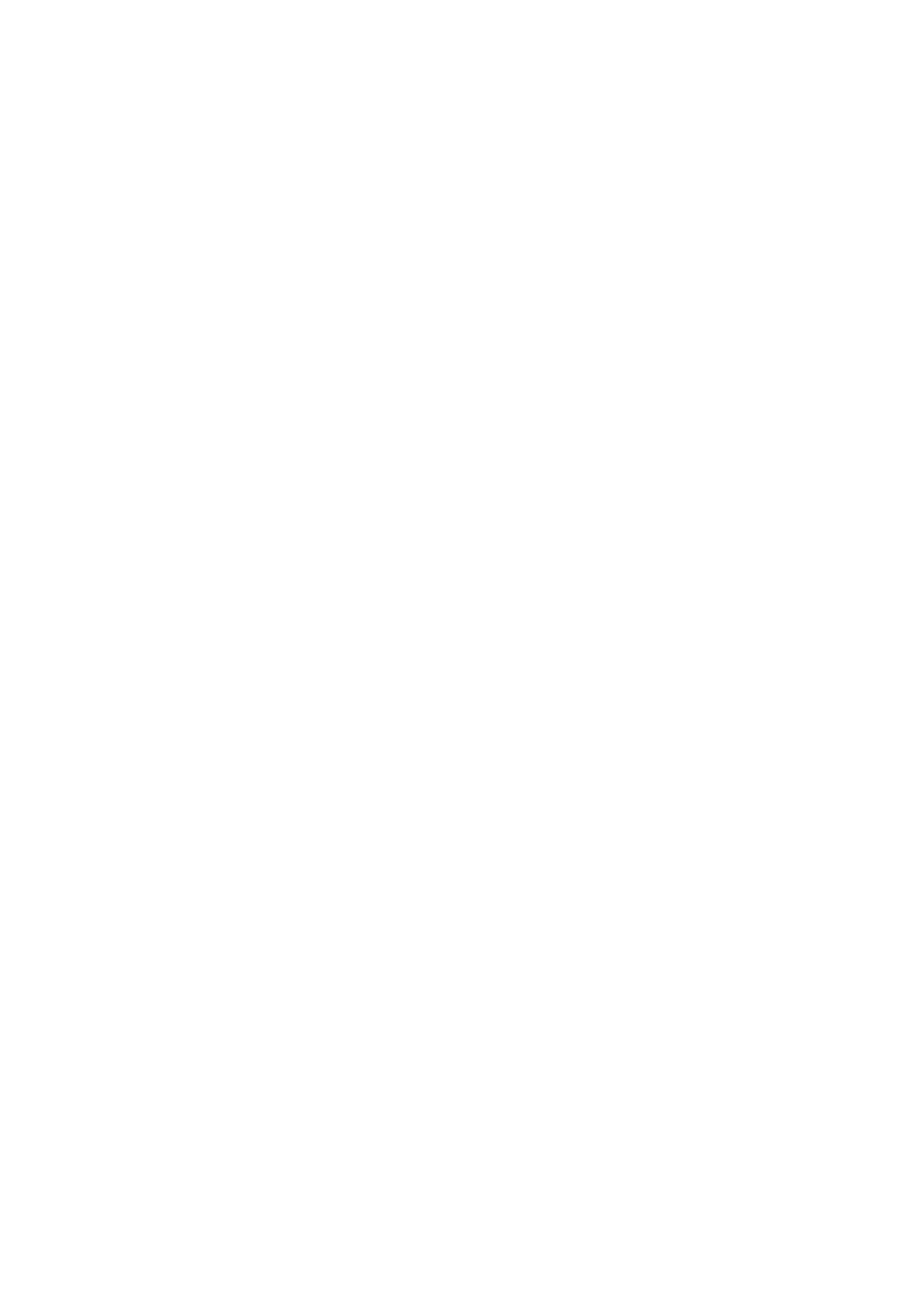




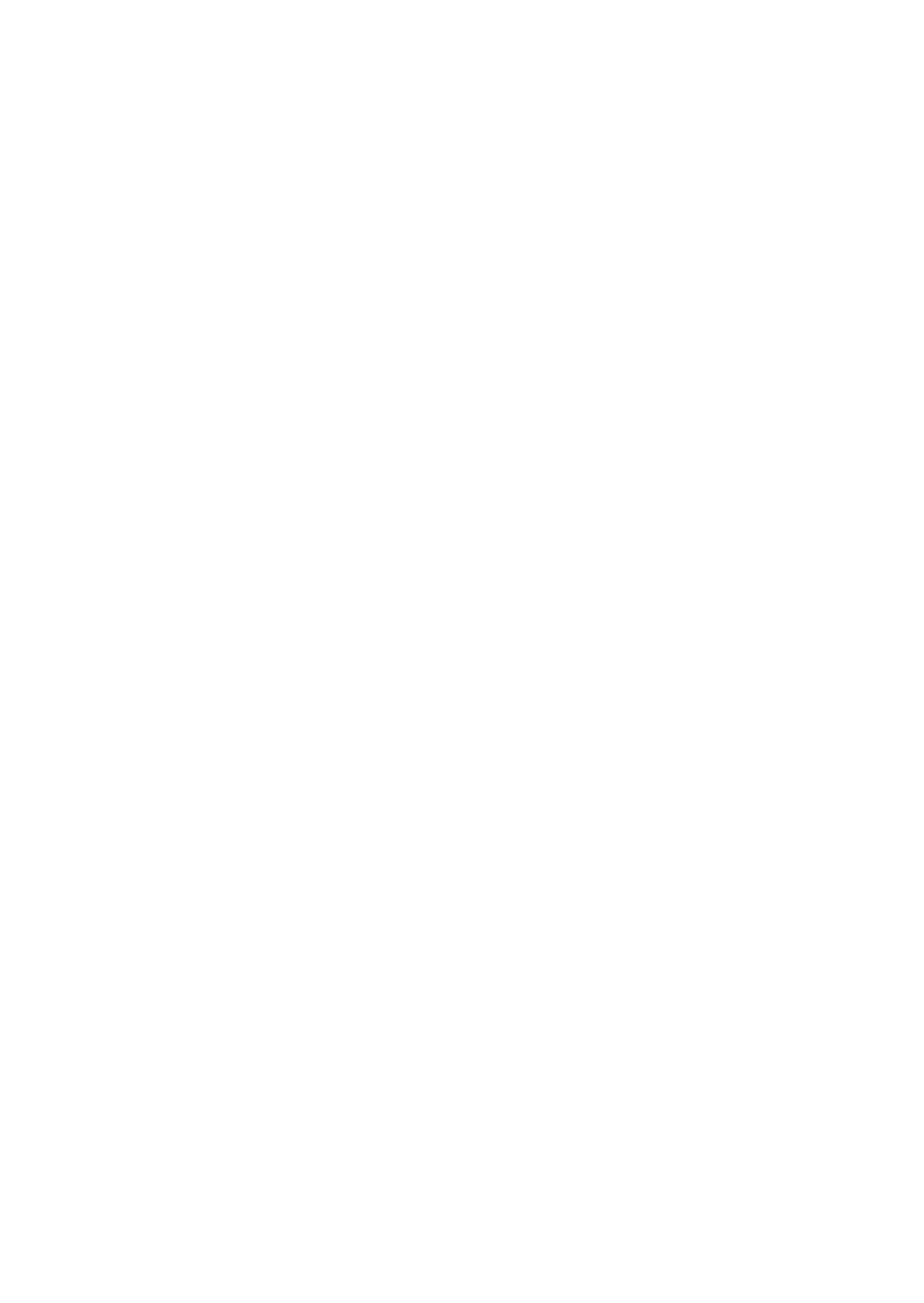




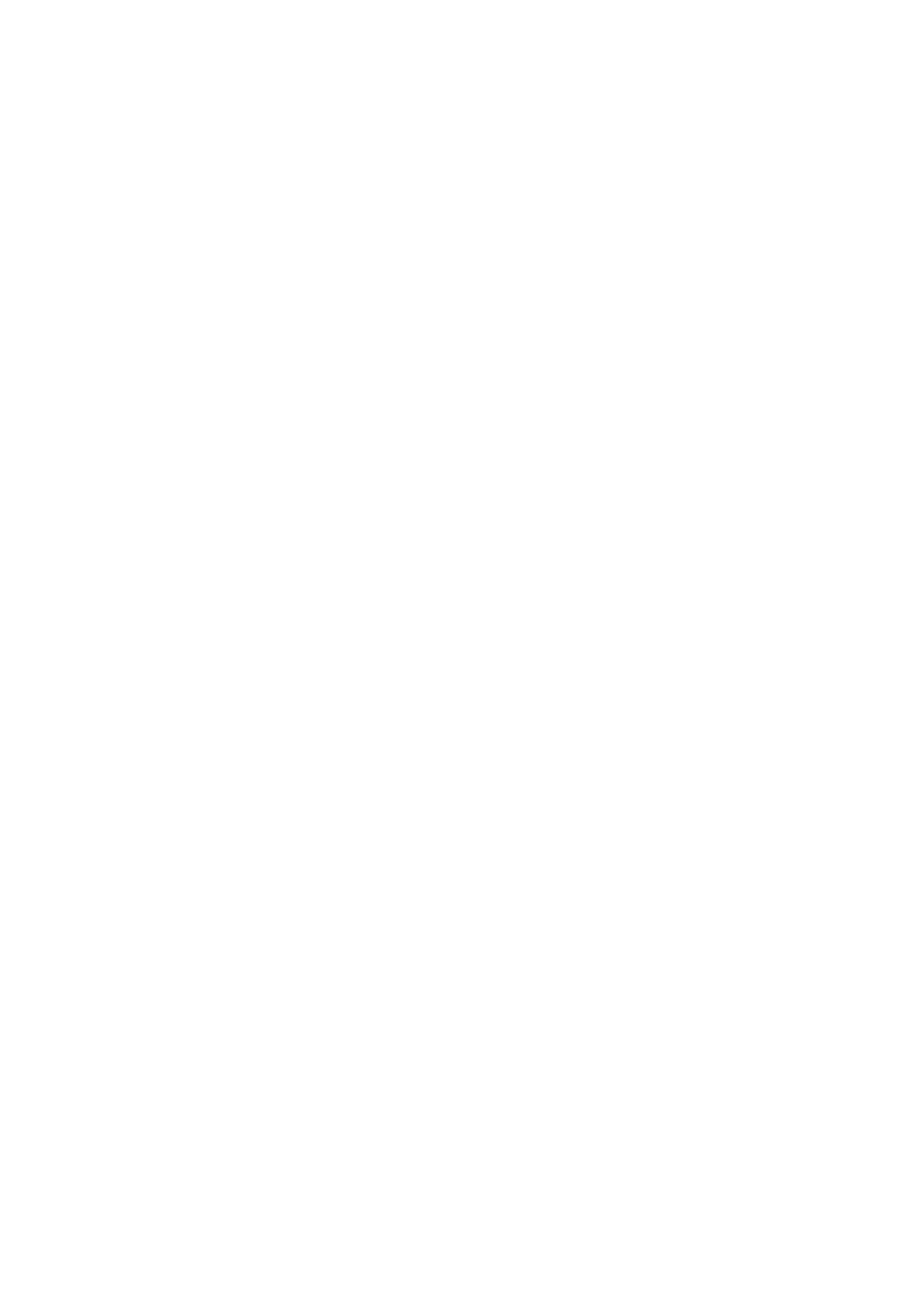




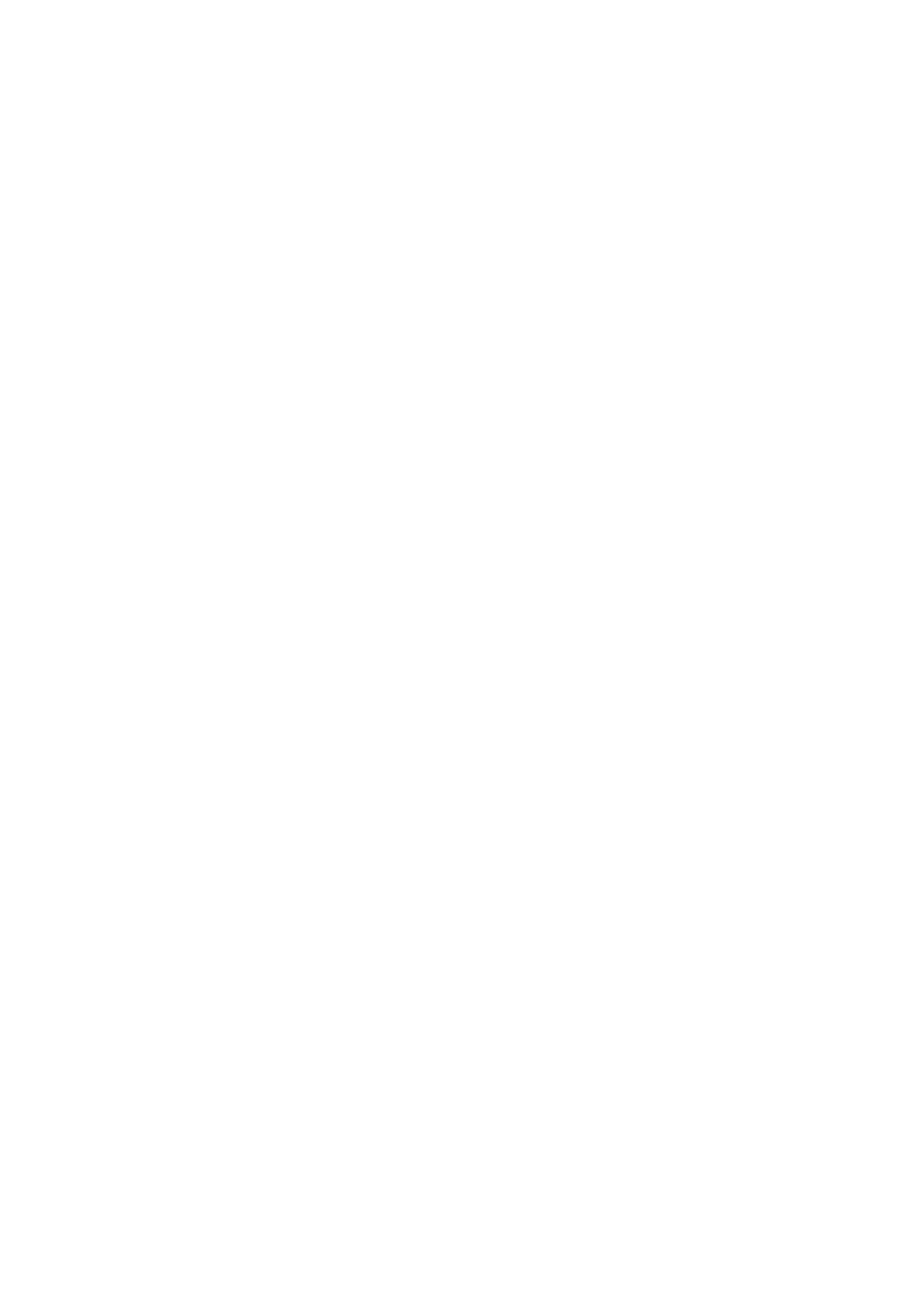




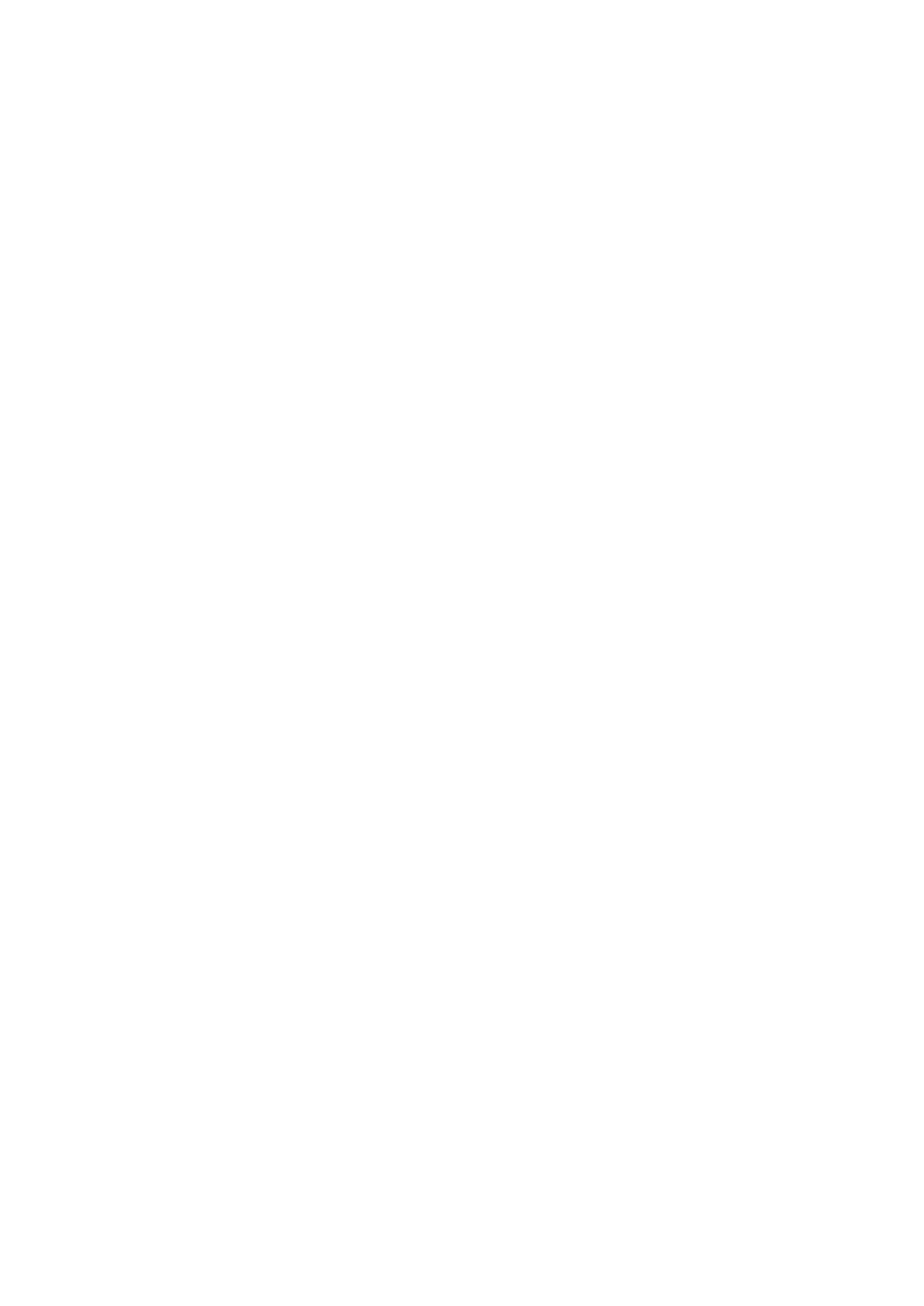




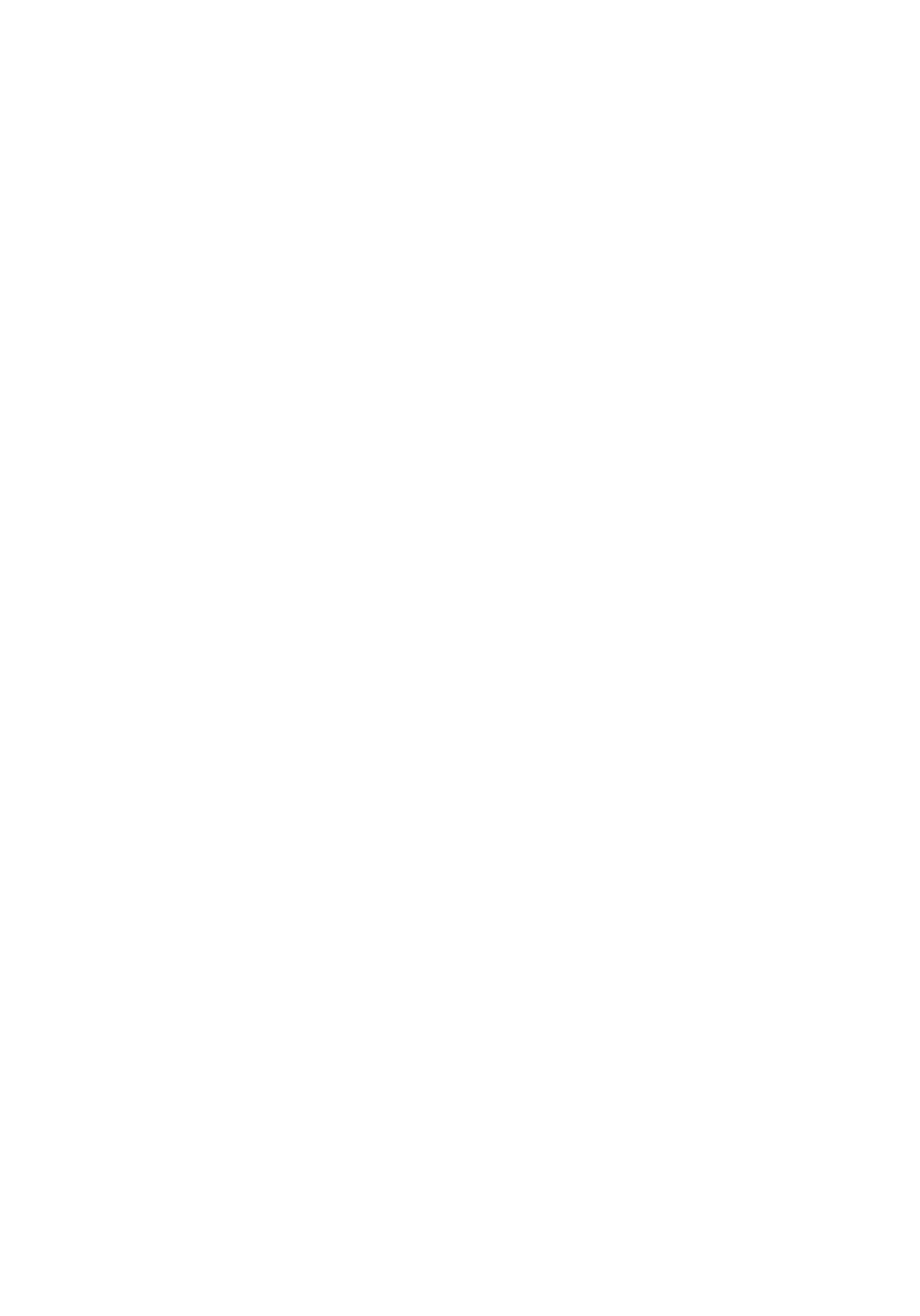




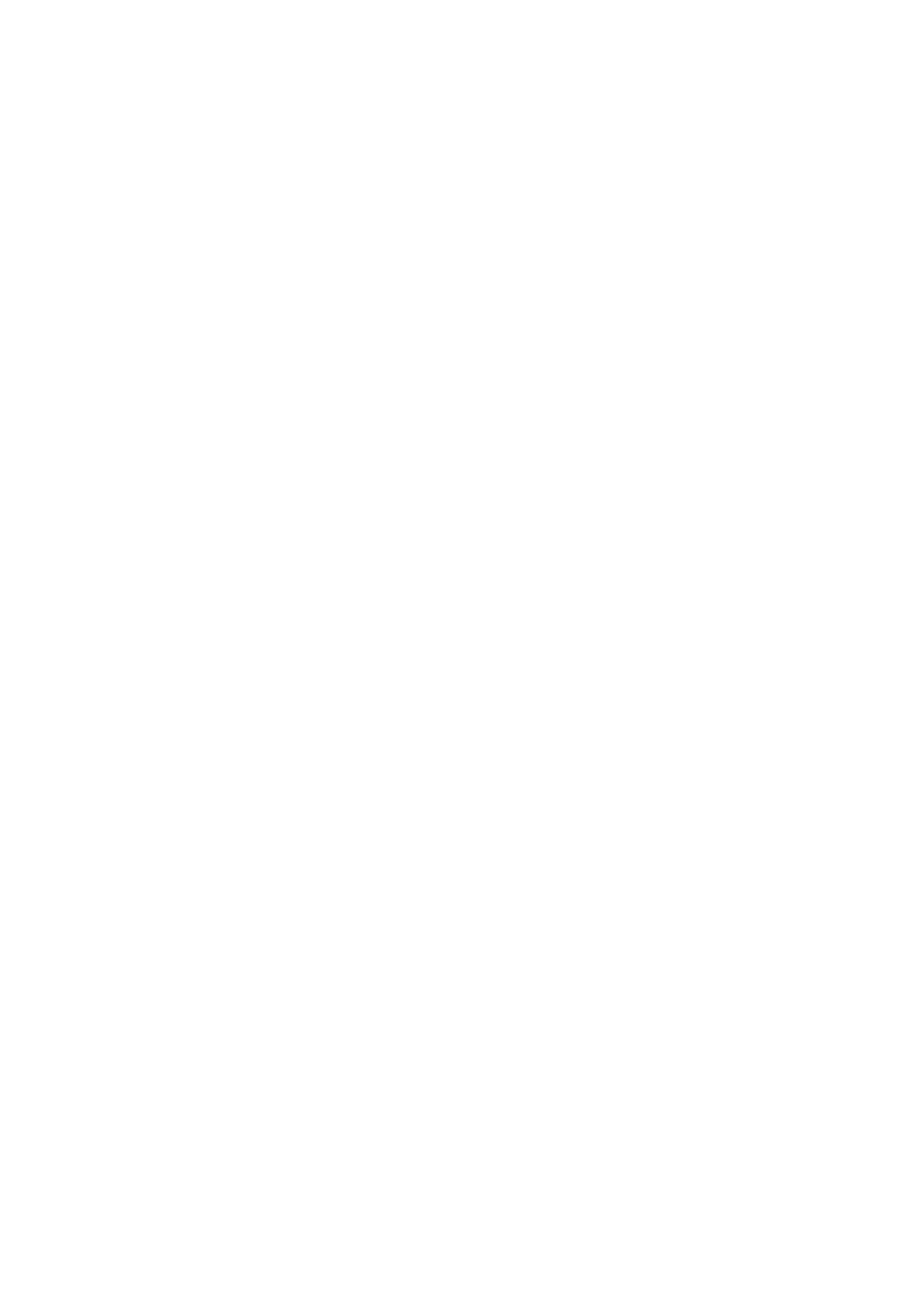




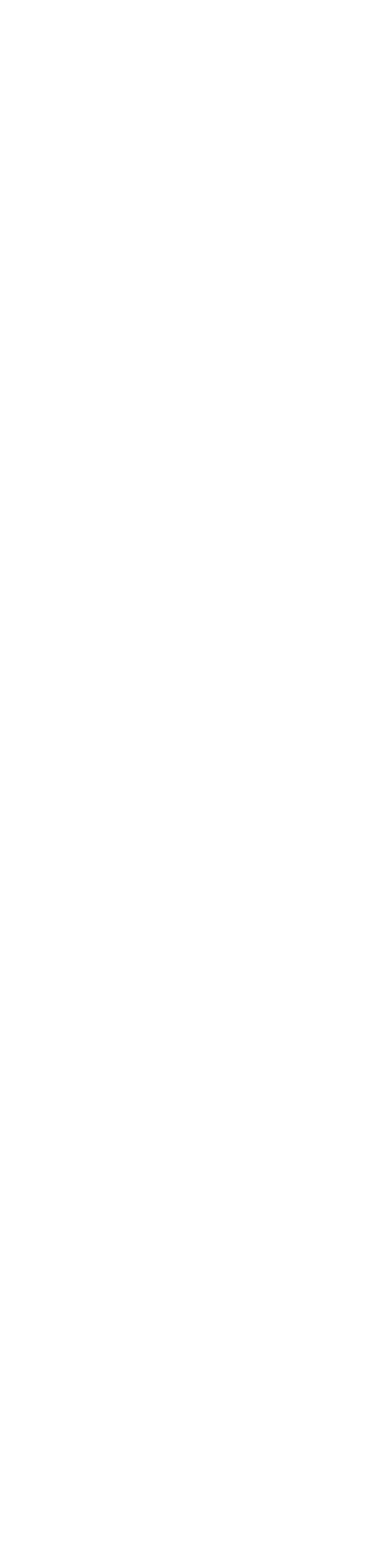




\title{
INDEX
}

Abbreviated basin names appear at the end of the site name. Abbreviations are as follows:

Eastern Shore (EASTERN); Potomac to Shenandoah (POT-SHEN); Shenandoah (SHEN); Potomac (POTOMAC);

Potomac to Rappahannock (POT-RAPP); Rappahannock (RAPP); Rappahannock to York (RAPP-YORK); YOrK (YORK)

York to James (YORK-JAMES); James (JAMES); James to Chowan (JAMES-CHOWAN); Chowan (CHOWAN); Roanoke (ROANOKE);

Yadkin (YADKIN); New (NEW); Big Sandy (BIG SANDY); Holston (HOLSTON); Clinch (CLINCH); Powel1 (POWELL)

Page

Aaron Creek at mouth nr Forksville...... (CHOWAN) 351

Aarons Creek above mouth nr Buffalo Springs.

Aarons Creek at Rt $604 \mathrm{nr}$ Nelson

Aarons Creek, N.F., at mouth at Midway. (ROANOKE)

Aberdeen Creek at mouth at Clay Bank...... (YORK)

Able Creek at mouth nr Dixie.............. (JAMES)

Abner Branch above Left Fork

nr Murphy................ (BIG SANDY)

Abrer Branch at mouth nr Murphy......... (BIG SANDY) 472

Abners Fork at mouth nr Kelsa........ (BIG SANDY) 490

Abrams Creek above Rt 659

nr Winchester.............. (POT-SHEN)

Abrams Creek at B\&O $R R$ at winchester. (POT-SHEN)

Abrams Creek at Rt $656 \mathrm{nr}$ Winchester.. (POT-SHEN)

Abrams Creek at Rt 657 at Winchester.. (POT-SHEN)

Abrams Creek at Rt $659 \mathrm{nr}$ Winchester.. (POT-SHEN)

Abrams Creek at Rt 7 nr Winchester.... (POT-SHEN)

Abrams Creek at U.S. Bwy 11 at Winchester.

(POT-SHEN)

Abrams Creek at U.S. HWy 523

at Winchester................ (POT-SHEN)

Abrams Creek at mouth nr Mendota........ (HOLSTON)

Abrams Creek at mouth nr Winchester... (POT-SHEN)

Abrams Creek below Rouss Spring at Winchester.............. (POT-SHEN)

Abrams Creek below Rt 656

nr Winchester.

Abrams Creek below Rt 657 at ST

at Winchester............... (POT-SHEN)

Abrams Creek below U.S. HWy ii

at Winchester.

(POT-SHEN)

Abrams Creek below U.S. Hwy 523 at Winchester.............. (POT-SHEN)

Academy Creek at mouth nr Studley.......... (YORK)

Accokeek Creek at Rt 508 at Brooke...... (POTOMAC)

Accokeek Creek at Rt $609 \mathrm{nr}$ Brooke...... (POTOMAC)

Accokeek Creek at mouth at Indian Foint nr Passapatanzy.

Accotink Creek above Rt 620

nr Annandale................ (POTOMAC)

(POTOMAC) 109

Accotink Creek at Army Engineer Rd nr Accotink Station...

Accotink Creek at Barkley $D_{r}$

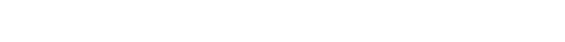

(POTOMAC)

(POTOMAC)

Accotink Creek at Davidson Airfield

at Accotink...........

nr Springfield.

( POTOMAC)

( POTOMAC)

Accotink Creek at Keene Miii Rd

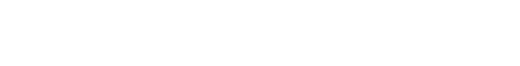

( POTOMAC)

ne Annandale. ................ (POTOMAC)

Accotink Creek at Pickett St

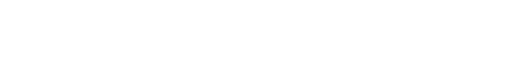

nr Fairfax.

(POTOMAC)

(POTOMAC)

Accotink Creek at RF\& $R$

nr Newington................. (POTOMAC)

Accotink Creek at Shirley Bwy ne Lorton.

(POTOMAC)

nr Creek at Southern $R R$ below

Lake Accotink at Springfield.... (POTOMAC)

Accotink Creek at Telegraph Rd

nr Accotink

(POTOMAC)

Accotink Creek at U.S. Hiwy i

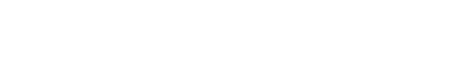

nr Annandale.... (POTOMAC)

Accotink Creek at mouth nr Accotink.... (POTOMAC)

Accotink Creek below Braddock Rd

nI Annandale.

( POTOMAC)

Accotink Creek below Field Lake

Branch at Newington............. (POTOMAC)
416

416

416

199

23

23

23

Accotink Creek below Mason Run nr accotink. Accotink Creek nr Essex Ave at Spring field.

Accotink Creek nr Lake Bivd n Annandale.

Accotink Creek nr Littie River

Turnpike nr Annandale.

Accotink Creek trib at Arlington Blvd

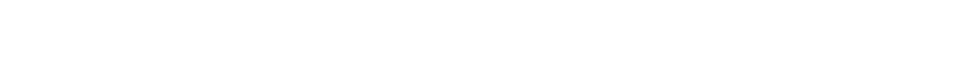

( POTOMAC)

Acquinton Creek at Rt $629 \mathrm{nr}$ King William. (YORK)

Acquinton Creek at Rt 632 at Palls........ (YORK)

Acquinton Creek at mouth nr Tunstail....... (YORK)

Adair Run at mouth at Glen Iyn........... (NEW)

Adams Branch at mouth $n r$ Dugspur.......... (NEW)

Adams Creek at mouth nr Signpine.......... (YORK)

Adams Swamp at $\mathrm{Va}$. - N.C. Stato line nr Lake Drummond........ (JAMES-CHOWAN)

Airfield Pond trib at Rt 622 nr Wakefield................

Albemarle \& Chesapeake Canal at Great Bridge....... nr Mount Pleasant ..... trib at Ethendge Rd

nr Great Bridge........
Albemarle \& Chesapeake Canai

\author{
(........... (CHOWAN)
}

..... (JAMES-CHOWAN)

..... (JAMES-CBOWAN)

317
at Rt 604 nr Great Bridge... (JAMES-CHOWAN)

Albemarle \& Chesapeake Canal at Southern RR nr Great Bridge. (JAMES-CHOWAN) 317

Alcotti Run at mouth $n=$ Goldvoin........ (RAPP)

Alder Cabin Branch at mouth nr Ceres... (HOLSTON)

Allen Creek at Gladstone................ (JAMES)

Allen Creek at Rt 4 nr Norvelio........ (ROANOKE)

Allen Creek at Rt $40 \mathrm{nr}$ Mount Airy..... (ROANOKE)

Allen Creek at Rt $615 \mathrm{nr}$ Norvello....... (ROANOXE)

Allen Creek at U.S. Hwy 58 nr Boydton.. (ROANOKE)

Allen Creek at mouth nr Lawrencevilie... (CHOWAN)

Allen Creek at mouth $\mathrm{nr}$ Mount Airy..... (ROANOKE)

Allen Creek at mouth nr Phillis........ (ROANOKE)

Allen Creek below Coleman Creek nr The Ridge.................. (ROANOKE)

Allens Branch at mouth nr Glen Allen.... (JAMES)

Allens Creek at Rt 151 nr Piney River.... (JAMES)

Alleys Creek at mouth nr Duncan Gap.. (BIG SANDY)

Almond Creek at Rt 5 at Richmond......... (JAMES)

Altoona Branch at mouth nr Pulasici......... (NEW)

Alum Creek below Rockbr $\downarrow d g e$ Alum Springs nr Millboro.

(JAMES)

Alvy Creek at mouth nr Artrip..........(CLINCE)

Amos Branch at mouth nr Hiddleston..... (ROANOKE)

Amos Branch at mouth nr Nickelsvilie.... (CLINCE)

Anderson Branch at Rt 40 at Sissex....... (CHOWAN)

Anderson Branch at Rt $634 \mathrm{nr}$ Sussex...... (CBOWAN)

Anderson Branch at mouth ar Sussex...... (CHOWAN)

Anderson Branch at mouth nr Weber City. (BOLSTON) Anderson Branch trib at Rt 542 nr Sussex........................................... 332

Anderson Creek at mouth $\mathrm{nr}$ By las........ (JAMES) 263 Anderson-Cox Spring at Sugar Grove...... (BOLSTON) 492 Andy Branch at mouth nr Council....... (BIG SANDY) 464

Andy Trent Branch \& tributaries above $\mathrm{Va}$. Ky. State line nr Hurley... (BIG SANDY) 488 Angelico Creek at Rt 652 nr Capron.......(CHOWAN) 335 Angelico Creek at mouth nr Capron........(CBOWAN) 335 Anglin Branch at U.S. Bwy 58 nr Stuart. (ROANOKE) 395 Anglin Branch at mouth nr Nettlertdge.. (ROANOKE) 395 Angola Creek at Rt $664 \mathrm{nr}$ Angola.........(JAMES) 274 Angola Creek at mouth nr AnBola............ (JAMES) 275 Angola Creek trib at Rt 664 nr Angoia..... (JAMES) 275 Antioch Swamp at mouth nr Zuni.... (CHOWAN) 343 Antipoison Creek at mouth nI Foxweilis.(POT-RAPP) 116 
Abbreviated basin names appear at the end of the site name. Abbreviations are as follows Eastern Shore (EASTERN); Potomac to Shenandoah (POT-SHEN); Shenandoah (SHEN); Potomac (POTOMAC); Potomac to Rappahannock (POT-RAPP); Rappahannock (RAPP); Rappahannock to York (RAPP-YORK); York (YORK); York to James (YORK-JAMES); James (JAMES); James to Chowan (JAMES-CHOWAN); Chowan (CHOWAN); Roanoke (ROANOKE); Yadkin (YADKIN); New (NEW); Big Sandy (BIG SANDY); Holston (HOLSTON); Clinch (CLINCR); Powell (POWELL)]

Applewhite Swamp at Rt 612 nr Drewryville. Applewhite Swamp at mouth nr Drewryville.

(CHOWAN) ttox River (Lake Chesdin) at (CHOWAN) 334

\section{Appomattox River (Lake Chesdin) at
Leonards Cave nr Sutherland.} $\ldots$ (JAMES) 282

Whipponock Creek nr Sutherland.
Appomattox River (North Branch Appomattox) at Rt $24 \mathrm{nr}$ Appomattox. (JAMES) 271 Appomattox River (North Branch Appomattox) at Rt $616 \mathrm{nr}$ Hixburg...(JAMES) 271

Appomattox River (North Channel) at HaLl Island nr Petersburg....... (JAMES) 283

Appomattox River (South Channel) at Hall Island nr Petersburg....... (JAMES) 283

Appomattox River Canal at Rt 600 at Matoaca.................. (JAMES) 282

Appomattox River above Lake Chesdin nr Winterpock.................. (JAMES) 280

Appomattox River above Namozine Creex nr Winterpock................. nr Winterpock.................. (JAMES) 280

Appomattox River above dam at safety wire nr Suther land....... (JAMES) 282

Appomattox River at Cat Is land

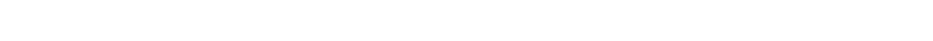

Appomat tox River at Hopewe L L........... (JAMES) 288

Appomattox River at I-95 at Petersburg... (JAMES) 283

Appomattox River at Rt 10 at Hopewell.... (JAMES) 288

Appomattox River at Rt 36 at Petersburg.. (JAMES) 283

Appomattox River at Rt 45 at Farmville... (JAMES) 273

Appomattox River at Rt 600 at Matoaca.... (JAMES) 282

Appomattox River at Rt 602 nr Mannboro... (JAMES) 277

Appomattox River at Rt 609

at Beazley Ford nr Prospect........ (JAMES) 272

Appomattox River at Rt $609 \mathrm{nr}$ Macon....... (JAMES) 275

Appomattox River at Rt 612 nt New Store.. (JAMES) 272

Apponattox River at Rt 621 nr Sunny Side.(JAMES) 275

Appomattox River at SCL RR at Petersburg

(JAMES) 283

Appomattox River at SCL RR bridge at Hopewell.

Apponattox River at Southern $R R$

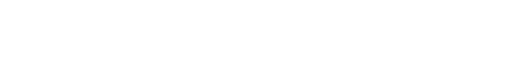

Appomattox River at U.S. Hwy 15

Appomattox River at U.S. Hwy 360 nr Amelia

(JAMES) 277

Apponattox River at bouy 14 nr Hopeweil... (JAMES) 284

Apponattox River at buoy $16 \mathrm{nr}$ Hopewel... (JAMES) 284

Appomattox River at buoy $9 \mathrm{nr}$ Hopewe 11... (JAMES) 288

Appomattox River below Lake Chesdin nr Petersburb........ (JAMES) 282

Appomattox River below

Namozine Creek nr Winterpock....... (JAMES)

281

Appomattox River below Cattle Creek nr Matoaca.................. (JAMES)

Appomattox River below N\&W RR at $F$ armville

Appomattox River ar Petersburg............ (JAMES) 282

Appomattox River, S.F., at Rt 627 at mouth ni Everisreen.

(JAMES) Creek at $R F \& P R$ nr Widewater Beach.

(POTOMAC)

Aquia Creex at Rt 610 nr Garrisonvilie. (POTOMAC)

Aquia Creek at Rt 641 at Garrisonville. (POTOMAC)

Aqui a Creek at U $S$ Ewy 1 at Aquia.... (POTOMAC)

Aquia Creek at buoy 10 at Widewater Beach............ (POTOMAC) 108

Aquia Creek at mouth

nr Widewater Beach. (POTOMAC) 108

Ararat River at Rt $749 \mathrm{nr}$ Ararat........... (YADKIN) 426

Ararat River at Va. $-N$.C. State line nr Ararat

(YADKIN) 426

Archer Creek at mouth nr Lynchburg........ (JAMES) 235

Archies Creek at mouth nr Claudvilie... (ROANOKE) 394
Armistead Creek at mouth nr Clarkton,.,(ROANOKE) 387

Arnold Spring at Atkins...............(HOLSTON) 499

Arnolds Creek at mouth nr Lake Anna Dam... (YORK) 172

Arthur Swamp at mouth nr Reams......... (CHOWAN) 329

Ash Camp Creek $0.4 \mathrm{mi}$ below Rt 59 at Keysville.............

Ash Camp Creek $1.0 \mathrm{mi}$ below Rt 59 nr Keysvilie.

(ROANOKE) 390

Ash Camp Creek at mouth nr Eureka....... (ROANOKE) 390

Ash Camp Creek below sewage pond at Keysville..............

.. (ROANOKE)

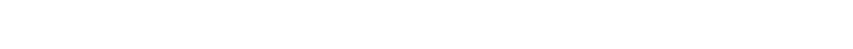

Ash Camp Creek trib No. 1 above mouth ne Keysuille.

Ash Hollow Run at mouth nr Winchester. (POT-SREN) 23

Ashcake Creek at mouth nr Clover.......(ROANOKE) 393

Ashton Creek at Rt 616 at Ashton.......... (JAMES) 287

Ashton Creak at Rt 620 nr Ashton.......... (JAMES) 288

Ashton Creek at Rt 746 nr Hopeweli........ (JAMES) 288

Ashton Creek at U.S. Ewys 1/301 ne Ashton.......................................... 287

Ashton Creex at mouth nr Hopewel1........ (JAMES) 288

Ashton Creex trib ne Colonial Heights..... (JAMES) 288

Ashville Bridge Creek at mouth ne Sigma. (JAMES-CHOWAN) 316

Assamoosick Swamp at Rt 40 ne Homeville. (CHOWAN) 336

Assamoosick Swanp at Rt 604

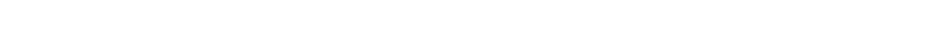

Assamoosick Swamp at $\mathrm{Rt} 607 \mathrm{nr}$ Dory........(CHOWAN) 336

Assamoosick Swamp at Rt 622 nr Littleton.... 33 ick nr Homeville........................ (CHOWAN) 336

Assamoosick Swamp at mouth nr Courtland. (CHOWAN) 337

Assamoosick Swamp trib No. 1 at $\mathrm{Rt} 40 \mathrm{nr}$ Homevilie.............(CHOWAN) 336

Assamoosick Swamp trib No. 1 tributary

at Rt 40 nr Homeville.........(CHOWAN) 336

Assamoosick Swamp trib No. 2 at Rt $622 \mathrm{nr}$ Littleton...........(CHOWAN) 336

Assamoosick Swamp trib No. 3 at R. 607 ne Dory.

Assamoosick Swamp trib No. 4 at Rt 606 nr Dory.

Assamoosick Swamp trib at Rt 35 nr Sebrell.

Assawoman Creek at Assawoman Iniet nr Modest Town.

Assawoman Creeix at Rt 679 nr Temperanceville

Assawoman Creex at R. 695 nr Temperanceville.

Assawoman Creek at Rt 730 nr Temperanceville.

Assawoman Creek trib at Rt 679 nr Temperanceville.

(EASTERN)

Augusta Spring at Augusta Springs. Austin Run at mouth nr Stafford.

Aylett Creek at U.S. Hwy 360 at Aylett.... (YORK)

Aylett Creek at mouth nr Aylett.......... (YORK)

Babbs Run at mouth at De Haven....... (POT-SHEN)

Back Bay at Va. - N.C. State line nr Back Bay.............. (JAMES-CHOWAN)

Back Bay between Cédar Is íand and $F$ alse Cape nr Back Bay.. (JAMES-CHOWAN) 316

Back Bay between Ragged Island and Wash Elats nr Back Bay..(JAMES-CHOWAN) 316 Back Bay off Long Island nr Back Bay................ (JAMES-CHOWAN) Back Branch at mouth nr Kentuck........ (ROANOKE)
316

\section{6}


Abbreviated basin names appear at the end of the site name. Abbreviations are as follows:

Eastern Shore (EASTERN); Potomac to Shenandoah (POT-SHEN): Shenandoah (SHEN); Potomac (POTOMAC)

Potomac to Rappahannock (POT-RAPP): Rappahannock (RAPP): Rappahannock to York (RAPP-YORK); York (YORK);

York to James (YORK-JAMES); James (JAMES); James to Chowan (JAMES-CHOWAN); Chowan (CHOWAN); Roanoke (ROANOKE);

Yadkin (YADKIN): New (NEW); Bis Sandy (BIG SANDY); Holston (HOLSTON); Clinch (CLINCH); POwe11 (POWELL)]

Page

Back Creek above Rt 600 nr Sunrise

Back Creek above Rt 617 nr Hardy.

(JAMES) 207

Creak along Rt 39 r Mountain Grove. (JAMES) 207

Back Creek at Rt 39 nr Mountain Grove... (JAMES) 207

Back Creek at Rt 600 at Lightnez Cemetary

(JAMES) 207

Back Creek at Rt 600 at Parrott.

(NEW)

Back Creek at Rt 600 at Sunrise....... (JAMES) 207

Back Creek at Rt 600 nr Sunrise............ (JAMES) 207

Back Creek at Rt $603 \mathrm{nr}$ Mill Gap......... (JAMES) 206

Back Creek at Rt 608 nr De Haven.......(POT-SHEN) 21

Back Creek at Rt 613 at Starkey........ (ROANOKE) 367

Back Creek at Rt 624 at Lyndhurst......... (SHEN) 39

Back Creek at Rt 632 at Gore..........(POT-SHEN) 20

Back Creek at Rt 636 at Lithia.......... (JAMES) 221

Back Creek at Rt 637 nr Highland............ (NEW) 449

Back Creek at Rt 640 at Spec nr Lithia... (JAMES) 220

Back Creek at Rt 640 nr Lithia........... (JAMES) 221

Back Creek at Rt 660 nr Dundee......... (ROANOKE) 367

Back Creek at Rt 664 nr Sherando........... (SHEN) 39

Back Creek at Rt $666 \mathrm{nr}$ Roanoke........... (ROANOKE) 367

Back Creek at Rt $671 \mathrm{nr}$ Va. - W.Va

State Iine nr De Haven.......... (POT-SHEN)

Back Creek at Rt 740 at De Haven...... (POT-SHEN)

$\begin{array}{lll}\text { Back Creek at U.S. Ewy } 220 \text { nr Roanoke...(ROANOKE) } & 367 \\ \text { Back Creek at VEPCO dam nr Sunrise....... (JAMES) } & 207\end{array}$

Back Creek at Va, $-W$. Va. State Line

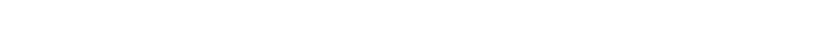

Back Creek at mouth at Leesvilie........ (ROANOKE)

Back Creek at mouth at Parrott............ (NEW)

Back Creek at mouth nr Bacova Junction... (JAMES)

Back Creek at mouth or Hardy........... (ROANOKE)

Back Creek at mouth nr Hebron nr Swoope... (SHEN)

Back Creek at mouth nr Lyndhurst......... (SEEN)

Back Creek at mouth nr New Castle........ (JAMES)

Back Creek at mouth nr Seaford...... (YORK-JAMES )

Back Creek at mouth nr Ware Neck...... (RAPP-YORK)

Back Creek at old U.S. HWy 522

at Gainesboro.....................

( POT-SHEN)

Back Creek below Babbs Rur

at De Haven................ (POT-SHEN)

Back Creek dam powerplant outfail

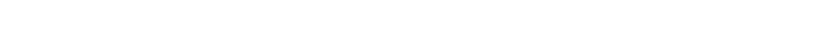

Back Creek nr Bacova Junction............ (JAMES)

Back Creek nr Parrott................. (NEW)

Back Creek on Rt 600 nr Mountain Grove... (JAMES)

Back Fork at mouth nr Murrayfield...... (HOLSTON)

Back River at Northend Point nr Fox Hill.............. (YORK-JAMES)

Back River off Northend Point

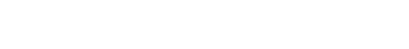

Back River off Stony Point nI Poquoson ..........

Backlick Run at Braddock Rd nr Annandale............

Backlick Run at Bren Mar Park at Alexandria....

Backlick Run at Leesv
at Springfield.

(YORK-JAMES)

(YORK-JAMES)

( POTOMAC)

Backlick Run at mouth at Alexandria

Backlick Run below Shirley Hwy nr Springfield.

( POTOMAC)

( POTOMAC)

( POTOMAC

(POTOMAC)

Backlick Run below South Van Dorn St at Alexandria.

( POTOMAC)

Bacon Hill Branch at Rt 600 at Exmore.. (EASTERN)

Bad Branch at mouth nr McClure....... (BIG SANDY)

Bad Creek along U.S. Hwy 23 at Pound. (BIG SANDY)

Bad Creek at mouth at Flat Gap........ (BIG SANDY)

Bad Creek at mouth nr Pound.

Bad Creek trib at U.S. Hwy 23

(BIG SANDY) at Pound.

(BIG SANDY)

Bailey Branch at mouth nr Burrowsilile... (JAMES)

Bailey Branch trib at Rt 10 nr Spring Grove.

(JAMES) nr Hopewell.

(JAMES)

Bailey Creek at Fort Lee ...................... (JAMES)
Bailey Creek at Rt $10 \mathrm{nr}$ Hopeweil......
Bailey Creek at Rt 156 at Hopewe 11.
Bailey Creek at Rt 630 at Fort Lee.

Bailey Creek at mouth nr Bermuda Hundred.

Bailey Creek at mouth nr Hopewell
Bailey Creek below Cattail Creek nr Hopewe 11 .

Bailey Creek trib No. 1 tributary at Rt $337 \mathrm{nr}$ Boone.

Bailey Creek trib No. 2 tributary at Rt 337 nr Boone

Bailey Creek trib at Rt 337 nr Boone.

Balley Swamp at mouth nr Montross

Baileys Trace at Bonny Blue.

Baileys Trace at Rt 636 at St Chan....(POWELL) 558

Baker Branch at mouth or Chatham Hill.. (HOLSTON) 513

Baker Branch at mouth or Eill...........(CLINCH) 547

Baker Spring at Waynesboro................................. 40

Bakers Creek at mouth nr Hockley..........(YORK) 198

Balds Run at mouth at Culpeper......................... 129

Ball Creek above Grissom Creek nr Council

(BIG SANDY) 464

Ball Creek above Nance White Branch nr Council...................... SIG SANDY) 464

Bal1 Creek along Rt 620 ir Councii...(BIG SANDY) 465

Ball Creek at mouth at Council.......(BIG SANDY) 465

Ball Creek below Barton Fork nr Council

(BIG SANDY) 465

Ballinger Creek at $\dot{R} t \dot{6}$ at Esmont.......... (JAMES) 242

Ballinger Creak at Rt 613 nr Palmyra...... (JAMES) 256

Ballinger Creek at mouth at Warren....... (JAMES) 242

Balliager Creek at mouth ar Palmyra...... (JAMES) 256

Ballous Creek at mouth nr Danripple.... (ROANOKE) 409

Balls Branch at mouth nr Litwalton.........(RAPP) 155

Balls Branch trib above Balls Millpond ne I i twalton.

(RAPP) 155

Bal1s Creek at mouth nr Mila.......... (POT-RAPP) 114

Balls Creek at mouth nr warsaw............ (RAPP) 153

Banister River at Rt 614 nI Halifax.... (ROANOKE) 415

Banister River at Rt 640 nr Mount Airy. (ROANOKE) 413

Banister River at Rt 642 nI Halifax.... (ROANOKE) 414

Banister River at Rt $832 \mathrm{nr}$ Chatham..... (ROANOKE) 412

Banister River at U.S. Hwy 29 ne Chatham.

(ROANOKE) 411

Banister River at U.S. Hwy 360 (Business) at Halifax.

Banister River at U.S. Hwy $360^{\circ}$ nr Five Forks

(ROANOKE)

(ROANOKE)

Banister River at mouth nr Wolf Irap... (ROANOKE)
Bar Branch at mouth nr Ebenezer....... (ROANOKE)

Bar Swamp Creek at mouth nr Baltimore Corner.

(CHOWAN) 327

Barbour Run at mouth nr Gordonsvilie......(RAPP) 134

Barbours Creek along Rt 611 nr New Castle.

(JAMES) 218

Barbours Creek at Rt 617 nr New Castle... (JAMES) 218

Barbours Creek at mouth nr New Castle.... (JAMES) 219

Bargers Branch at Rt 646 at Spring Milis.

(ROANOKE) 385

Bark Camp Branch at Rt 704 nr Tacoma.... (CLINCE) 544

Bark Camp Branch at mouth nr Mack Creek Viliage............. (NEW) 442

Bark Camp Branch at mouth ir Norton.......(CLINCH) 544

Barkcanp Branch at mouth

at Stony Battery.

Barkc amp

Barker Creek at mouth nr Sutherlin...... (ROANOKE)

Barkhouse Branch at Chula.

Barnes Swamp at mouth nr Walkers......... (JAMES) 299

277

Barnhardt Creek at mouth at Roanoke..... (ROANOKE) 363

Barr Creek at mouth nr Oak Leve1....... (ROANOKE) 373

Barrett Creek at mouth nr Mila........(POT-RAPP) 114

Barrows Creek at mouth nr walkers.......... (JAMES) 298

Barrows Run at mouth nr Warrenton........... (RAPP) 119

Barterbrook Branch at mouth nr Staunton... (SEEN) 36

Bartley Branch at Flannagan Reservoir nr Clintwood.

Barton Branch at mouth at Quebec........ (EOLSTON) 
Abbreviated basin names appear at the end of the site name. Abbreviations are as follows

Eastern Shore (EASTERN); Potomac to Shenandoah (POT-SHEN); Shenandoah (SHEN); Potomac (POTOMAC)

Potomac to Rappahannock (POT-RAPP); Rappahannock (RAPP); Rappahannock to York (RAPP-YORK); York (YORK)

York to James (YORK-JAMES); James (JAMES): James to Chowan (JAMES-CHOWAN); Chowan (CHOWAN); ROanoke (ROANOKE):

Yadkin (YADKIN); New (NEW); Big Sandy (BIG SANDY); Holston (HOLSTON); Clinch (CLINCH); POWell (POWELL)]

Page

Barton Fork above Coon Flat Branch

Barton Fork above Jackson Fork ne Council.

(BIG SANDY) 465 Fork below Jackson Fork

(BIG SANDY) 465

COUncil... (BIG SANDY)

\section{Barton Fork below}

(BIG SANDY) 465

(BIG SANDY) 465

Bartons Crek (POTOMAC) 71

Barts Iick Creek above Little Lick Creek nr Haysi.

(BIG SANDY) 480

Barts Lick Creek at Rt 611 at Bartilck.

(BIG SANDY)

Barts Lick Creek at mouth at Bartick.

(BIG SANDY)

Bassett Branch at mouth ir Fieldale.... (ROANOKE)

Batie Creek along Rt 662 nr Jonesville.. (POWELL)

Battle Run at Rt 618 nr Laure 1 Mt 11 s...... (RAPP)

Battle Run at Rt $633 \mathrm{nr}$ Laurel Mt lls....... (RAPP)

Battle Run at Rt 729 nr Laurel Milis....... (RAPP)

Battle Run at U.S. Hwys 211/522 ne Washington.

(RAPP) 125

Battle Run at mouth ir Laurel Milis........ (RAPP) 126

Battle Run trib No. 1 at Rt 622 nr Laurel Mills.

Battle Run trib No. 2 along Rt 627 nr Laurel Milis................ RAPP) 125

Battle Run trib No. 2 at Rt $6 \dot{3} \dot{3}$ nr Laurel Mills ............

Battle Run trib No. 2 trihutary
at Rt 627 nr Laurel Mills. at Rt $627 \mathrm{nr}$ Laurel Mills.......... (RAPP)

Bawley Branch at mouth nx Swansonville................. (ROANOKE) 405

Baylor Spring nr Churchvilie........................... 34

Baylors Creek at mouth nr Loretto............. (RAPP) 149

Beagle Gap Run nr Waynesboro............. (SHEN) 40

Beales Mill Run at mouth nr Neenah..... (POTOMAC) 111

Bear Branch at Aslington Blvd nr Vienna.

(POTOMAC) 86

Bear Branch at mouth at Biackwood......... (POWELL)

Bear Branch at mouth at Cedar Bluff.... (HOLSTON)

Bear Branch at mouth at Wilson Chapel nr Norton.

(POWELL) 553

Beax Branch at mouth ix Mouth of Wilson.... (NEW) 427

Bear Creek above Yellow Creek nr Wise... (CLINCH) 540

Bear Creek above trib No. 2 at Wise..... (CLINCH) 540

Bear Creek at Bear Creek Lake Recreation Area nr Trents Mil1.....(JAMES) 258

Bear Creek at Bear Creek Lake Dam nr Trents Mill................ (JAMES) 258

Bear Creek at Interstate RR nr Norton... (CLINCH) 540

Bear Creek at Rt 622 nr Marion............ (HOLSTON) 500

Bear Creek at Wise..................(CLINCE) 540

Bear Creek at headwaters of

Bear Creek Lake nr Trents Mill.... (JAMES) 258

Bear Creek at mouth nr Atkins.......... (HOLSTON) 500

Bear Creek at mouth nr Mike............................. 385

Bear Creek at mouth nr Red House......... (ROANOKE) 388

Bear Creek at mouth nr Trents Miii........ (JAMES) 258

Bear Creek below Yellow Creek nr Wise... (CLINCE) 540

Bear Creek below sewage lagoon nr Wise..(CLINCH) 540

Bear Creek trib No. I nz Wise...........(CLINCH) 540

Bear Creek trib No. 2 at Wise................ (CLINCE) 540

Bear Garden Creek at Rt 672 nr Arvonia... (JAMES) 246

Bear Garden Creek at mouth at New Canton. (JAMES) 246

Bear Garden Run at Rt 522 nr Va. $-W$. Va

State line nz Shockeysvilie..... (POT-SHEN)

Bear Lithia Spring nr Elkton............ (SHEN)

Bear Spring Branch at mouth at Berton....... (NEW)

Beazds Creek at mouth nr Endicott...... (ROANOKE)

Bearpen Branch at mouth at Imboden...... (POWELL)

Bearpen Creek at mouth at Isom........ (BIG SANDY)

Bearpen Creek at mouth nr Pound....... (BIG SANDY)

Bearpen Creek, Left Fork, at Rt 630 nf Pound................. (BIG SANDY)

Bearpen Creek, Right Fork, at Rt 630 ne Pound.................... (BIG SANDY)
Bears Element Creek at mouth ne North View.

Bearskin Creek at Rt 612 nr Chatham... (ROANOKE) 41

Bearskin Creek at mouth $n r$ Chatham..... (ROANOKE) 411

Beartown Branch at mouth

nx Chatham Hill.............. HOLSTON) 512

Beautiful Run at Rt 231 nr Pratts......... (RAPP) 135

Beautiful Run at Rt 621 nx Rochelle... (RAPP) 135

Beautiful Run at mouth nx Madison Milis... (RAPP) 135

Beautiful Run nx Rt 616 nr Madison Mills.. (RAPP) 135

Beautiful Run trib at Rt 231 nr Pratts... (RAPP) 135

Beaver Branch at mouth ne Adsit........(CHOWAN) 325

Beaver Branch at mouth nr Aylett..........(YORK) 194

Beaver Branch at mouth nr Carters Bridge. (JAMES) 243

Beaver Creek above mouth nr Loutsa........ (YORK) 178

Beaver Creek at Colonial Heights........(HOLSTON) 510

Beaver Creek at Goodson St at Bristol.. (HOLSTON) 510

Beaver Creek at Randall St at Bristol.. (HOLSTON) 510

Beaver Creek at Rt 108 nr Martinsville. (ROANOKE) 402

Beaver Creek at Rt $\$ 405$ at (nr) Bristol................ (HOLSTON) 510

Beaver Creek at Rt $638 \mathrm{nr}$ Daniei...........(YORK) 166

Beaver Creek at Rt 658 at Bristol...... (HOLSTON) 510

Beaver Creek at Rt 660 nr Bocock......... (JAMES) 235

Beaver Creek at Rt 680 nr Crozet............. (JAMES) 248

Beaver Creek at Rt 810 nr Crozet............ (JAMES) 248

Beaver Creek at State and 7 th Sts at Bristol.

(HOLSTON) 510

Beaver Creek at U.S. Hwy 501

Be Rustburg. . Hwys ii/ig

at Bristol.

(JAMES)

235

Beaver Creek at $\mathrm{Va},-$ Tenn. State line at Bristol.

(HOLSTON)

510

Beaver Creek at Vailey $\dot{D} r$ above Bristol.

(HOLSTON) 511

Beaver Creek at jeep trail nr Loulsa......(YORK) 178

Beaver Creek at mouth at Martinsvilie... (ROANOKE) 402

Beaver Creek at mouth at North Holston. (HOLSTON) 514

Beaver Creek at mouth nr Ashland.........(YORK) 181

Beaver Creek at mouth ni Crozet........... (JAMES) 248

Beaver Creek at mouth nx Danie1............ (YORK) 166

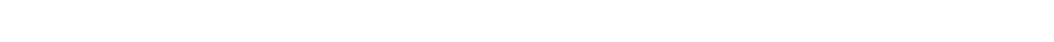

Beaver Creek at mouth nr Galax............... (NEW) 430

Beaver Creek at mouth nr Howardsville....(JAMES) 242

Beaver Creek at mouth nr Louisa........... (YORK) 178

Beaver Creek at mouth nr Lynchburg........ (JAMES) 235

Beaver Creek below Beaver Creek Lake nr Wallace................ (HOLSTON) 510

Beaver Creek nr Hilander Fark............. (HOLSTON) 510

Beaver Creek nr Martinsville............ (ROANOKE) 402

Beaver Creek off U.S. Hwy 11 nx Bristol.................. HOLSTON)

Beaver Creek trib above U.S. Hwy 33 nr Louisa.

Beaver Creek trib at mouth ne North Holston.

... (HOLSTON

Beaver Pond Creek at Rt 612 nr Rawlings. (CHOWAN)

Beaver Pond Creek at mouth nr Cherry till.

(CHOWAN)

Beaver Fond Creek at mouth nr Forksvilie.

(CHOWAN)

Beaver Pond Creek at mout nr Clarksville.

(ROANOKE)

Beaver Pond Creek at mouth nr Rawiings. . (CHOWAN)

Beaver Pond Swamp at mouth nr Stony Creek.

(CHOWAN)

(RAPP)

Beaver Run at mouth nr Madison.

(RAPP)

Beaver Run at mouth nr Somerset.

Beaverdam Creek above Courthouse Creek nr Crozier.

( JAMES )

(HOLSTON) at Damascus

Beaverdam Creek along Rt $75 j$ nz Goodview. 
Abbreviated basin names appear at the end of the site name. Abbreviations are as follows:

Eastern Sbore (EASTERN); Potomac to Shenandoah (POT-SHEN); Shenandoah (SHEN); Potomac (

Potomac to Rappahannock (POT-RAPP); Rappahannock (RAPP); Rappahannock to York (RAPP-YORK); York (YORK)

York to James (YORK-JAMES): James (JAMES); James to Chowan (JAMES-CHOWAN); Chowan (CHOWAN); Roanoke (ROANOKE);

Yadkin (YADKIN); New (NEW); Big Sandy (BIG SANDY); Holston (HOLSTON); Clinch (CLINCH); Powell (POWELL))

Beaverdam Creek at Rt 1009 at Hillsville... (NEW) 441 Beaverdan Creek at Rt 156 at Mechanicsville.

Beaverdam Creek at Rt 632 nr Barhamsville. ( JAMES)

Creek at Rt 639 at State Farm. (JAMES) 262

年 (JAMES) 262

Beaverdam Creek at Rt 668 nr Factory Hill nr Cleopus........ (CHOWAN) 347

Beaverdan Creek at Rt $715 \mathrm{nr}$ Beaverdam.... (YORK) 174

Beaverdam Creek at Rt 734 nr Mountville.............. (POTOMAC) 70

Beaverdam Creek at Rt $738 \mathrm{nr}$ Beaverdam....(YORK) 174

Beaverdam Creek at Rt $757 \mathrm{nr}$ Hardy..... (ROANOKE) 368

Beaverdam Creek at Rt 886 at Hillsville....(NEW) 441

Beaverdam Creek at U.S. HWy 221

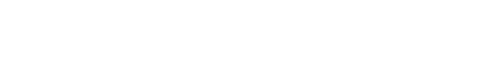

Beaverdam Creek at U.S. Hwy 58 at Hillsville U. H. HWy 58

Beaverdam Creek at U.S. Hwy 58 at Damascus................ (HOLSTON) 497

Beaverdan Creek at Va.-Tenn. State line nr Damascus.......................

Beaverdam Creek at former mouth
nr Richmond. ................
Beaverdam Creek at former mouth

(HOLSTON) nr Walkers.

(JAMES)

Beaverdam Creek at mouth at East Stone Gap.

Beaverdam Creek at mouth at Damascus... (HOLSTON)

Beaverdam Creek at mouth at Hillsville.....(NEW)

Beaverdam Creek at mouth at Max Meadow..... (NEW)

Beaverdam Creek at mouth nr Boyd Tavern.. (JAMES)

Beaverdam Creek at mouth nr Earlysville.. (JAMES)

Beaverdam Creek at mouth nr Goodview... (ROANOKE)

Beaverdan Creek at mouth nr Hewlett....... (YORK)

Beaverdam Creek at mouth nr Independence... (NEW)

Beaverdan Creek at mouth $\mathrm{nr}$ Jefferson... (JAMES)

Beaverdam Creek at mouth nr Kings Store... (NEW)

Beaverdam Creek at mouth nr Leesburg... (goTOMAC)

Beaverdam Creek at mouth nr Oatlands... (POTOMAC)

Beaverdam Creek at mouth nr Sperryvilie... (RAPP)

Beaverdam Creek at mouth nr Woodlawn....... (NEW)

Beaverdam Creak below N\&W RR at Damascus.

(HOLSTON) 497

Beaverdam Creek nr Yorktown.............. (JAMES) 303

Beaverdam Creek nr mouth nr Mountville. (POTOMAC) 70

Beaverdam Creek trib above Rt 645

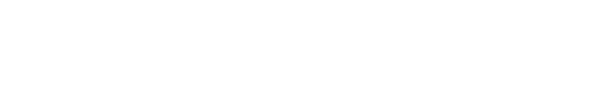

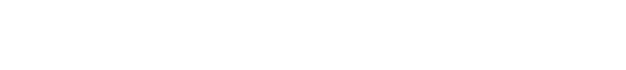

nr Phi lomont...........................
Beaverdam Creek, West Fork, at mouth

$n x$ Hardy ....................... (ROANOKE)
Beaverdam Run above Russeij Branch nr Ashburn................. (POTOMAC) 74

Beaverdam Run at Marine Rd 2 nr Garrisonville............... (POTOMAC) 108

Beaverdam Run at Rt $607 \mathrm{nr}$ Ashburn..... (POTOMAC) 74

Beaverdam Run at mouth nr Garrisonville.

Beaverdam Run at mouth nr Jeffersonto... (POTOMAC)

Beaverdam Run $n r$ mouth at Lake Kilby..... (JAMES)

Beaverdam Swamp above Rt 606 nr Ark. (RAPP-YORK)

Beaverdam Swamp at Rt 616 at Gloucester.

(RAPP-YORK)

Beaverdam Swamp at mouth nr Franki in... (CHOWAN)

Beaverdam Swamp below Cow Creek nr Ware Neck. rdam Swamp trib No. 1 at mouth

Br Ark.................................

(RAPP-YORK)

164

Beaverdam Swamp trib No. 2 at Rt 606 at Ark.

(RAPP-YORK)

164

Beaverdam Swamp trib No. 2 at mouth nr Gloucester...................

Beaverdam Swamp trib No. 3 at mouth

(RAPP-YORK)

164

164 (RAPP-YORK)

68

429

444

72

24

32

06

4
Beaverdam Swamp trib No. 4 at Rt 616 at Gloucester.

Beaverpond Branch at mouth nr Red House....... 648

Beaverpond Creek at Rt 648

nr Scotts Fork.

(ROANOKE)

Beaverpond Creek at mouth nr Dahlia .... (JAMES)

Beaverpond Creek at mouth nr Scotts Fork. (JAMES)

Beck Creek at mouth nr Lynchburg......... (JAMES)

Beckner Branch at U.S. Hwy 11 nr Eincastle.

(JAMES)

(CHOWAN)

Becky Branch at mouth $n r$ Alberta.

Beckys Creek at mouth nr Scruggs. ....... (ROANOKE)
Beddingfield Creek at mouth nr Barley... (CHOWAN)

Bee Branch at mouth nr Gibson Station... (POWELL)

Beech Creek at mouth $\mathrm{n} r$ Ashland........... (YORK)

Beech Creek at mouth nr Lodi.

Beech Fork at Rt 624 at $\mathrm{Va}$. -W. Va. State line at Amonate.

(HOLSTON)

IG SANDY

Beech Grove Branch at mouth nr Dona..... (CLINCH)

Beech Swamp at mouth $n=$ Ark......... (RAPP-YORK)

Beechtree Creek at mouth nr Level Run.. (ROANOKE)

Beggars Bridge Creek nx Dawley Corners.......... (JAMES-CHOWAN)

Beggars Bridge Creek at Dawley Rd nr Pleasant Ridge.

(JAMES-CHOWAN)

Beggars Bridge Creek trib at Gum Bridge Rd nr Pleasant Ridga. (JAMES-CHOWAN)

Belcher Branch at mouth at Harman.... (BIG SANDY)

Belfield Creek at mouth nr Montross...... (RAPP)

Bell Creek along Rt 612 nr Staunton....... (SHEN)

Bell Creek at Rt 732 at Franks Mill $n=$ Staunton.

Bell Creek at St. Pauls Chapel

nr Staunton..................

Bell Creek at mouth nr Staunton.
Belle Cove Branch at U.S. Hwy 50 nr Glasgow.

(SHEN)

Bellyache Swamp at mouth nr Adams Grove. (CHOWAN) Bellyache Swamp trib at mouth nr Adams Grove.

Belmont Bay at Sandy Point nr Woodbridge................. (POTOMAC)

Belmont Bay at buoy $6 \mathrm{nr}$ Woodbridge... (POTOMAC) Belwood Swamp above McMahon Swamp nr Lancaster.................... (RAPP)

Belwood Swamp at Rt 201 nr Lancaster..... (RAPP)

Belwood Swamp at mouth nr Lancaster........ (RAPP) Benges Branch above Norton Reservoir nr Norton.

(POWELL)

Benges Branch at mouth at Norton........ (PCWELL)

Benges Creek at mouth nr Dungannon....... (CLINCH)

Bennett Creek at Rt 337 nr Driver........ (JAMES)

Bennett Creek at U.S. Hwy $17 \mathrm{nr}$ Driver... (JAMES)

Bennett Creek at mouth nr Crittendon.... (JAMES)

Bennett Creek at mouth nr Poquoson. (YORK-JAMES)

Bennett Run at mouth $n r$ Bergton.......... (SHEN)

Bens Branch at Rt $616 \mathrm{nr}$ Jordan Mines... (JAMES)

Bent Creek at Rt 26 at Bent Creek...... (JAMES)

Bentin Chaffin Spring nr Tramel...... (BIG SANDY)

Bentley Branch at mouth nr Pulaski........ (NEW)

Bentleys Creek at mouth nr Drakes Branch.

Bergen Branch at U.S. Hwy 421 nr Stone Creek.

(ROANOKE)

Berles Creek at mouth i.............

(POWELL)

(ROANOKE)

Bernards Creek at Rt 711 nr Manakin.

(JAMES)

Bernards Creek at mouth nr Tuckahoe Village.

(JAMES)

Berry Creek at mouth $n r$ Watauga........ (HOLSTON)

Berry Hollow trib off Rt $600 \mathrm{nr}$ Nethers... (RAPP)

Berry Run at Rt 629 at Lahore............ (YORK)

Berrys Creek at mouth $n r$ Indian valiey..... (NEW)

Bethany Creek at mouth nr Glenford.....(HOLSTON

Bethel Branch at Rt $687 \mathrm{nr}$ Bloxom...... (EASTERN)

Bethel Branch at mouth nr Bloxom........ (EASTERN

Betsey Branch at mouth nr Whitewood... (BIG SANDY)
386

279

356

279

221

353

369

563

181

495

488

551

164
383

316

316

316

462

151

34

34

34
34

34

229

158

357

357

102

102

157

157

157

553

553

544
308

308

308

203

52

211

236
477

442

391

559

392

254

264

507

168

439

518

17

17
458 
Abbreviated basin names appear at tbe end of the site name. Abbreviations are as follows:

Eastern Shore (EASTERN); Potomac to Shenandoah (POT-SHEN); Shenandoah (SHEN); POtOmac (POTOMAC);

Potomac to Rappahannock (POT-RAPP); Rappahannock (RAPP); Rappahannock to York (RAPP-YORK); YorK (YORK);

York to James (YORK-JAMES); James (JAMES); James to Chowan (JANES-CHOWAN); Chowan (CHOWAN); Roanoke (ROANOKE);

Yadkin (YADKIN); New (NEW); Big Sandy (BIG SANDY); Holston (HOLSTON); Clinch (CLINCH); Powell (POWELL)]

Page

Betts Mill Creek at mouth $\mathrm{nr}$ Mila....(POT-RAPP) 114

gettys Creek at mouth $n r$ Scrug8s........(ROANOKE) 369

Beverly Run at Rt 618 below

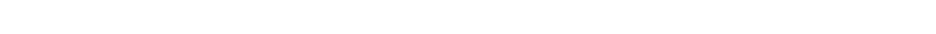

Beverly Run at Rt 630 nr Alps .............. (YORK) 193

Beverly Run at Rt $721 \mathrm{nr}$ Alps............. (YORK) 194

Beverly Run at Terrys Run Channel

in Lake Anna........... (YORK)

Beverly Run at mouth nr Beulahyille....... (YORK)

Bis Bluewing Creek at mouth nr Cluster Springs.

(ROANOKE) 416

Big Branch at $R t 63$ at Fremont........ (BIG SANDY)

Big Branch at Rt $80 \mathrm{nr}$ Murphy.

Bis Branch at U.S. Hwys $211 / 522$ at Washington.

471

Bis Branch at mouth $n=$ Wharncliffe, $W . V a \ldots . . . .$. (BIG SANDY)

Big Branch at mouth at Fremont......... (BIG SANDY)

Big Branch at mouth at Snowflake......... (HOLSTON)

Big Branch at mouth at St. Charles...... (POWELL)

Big Branch at mouth $n r$ Ceres.......... (HOLSTON)

Big Branch at mouth nr Claudviile....... (ROANOKE)

Bis Branch at mouth nr Clintwood..... (BIG SANDY)

Bis Branch at mouth nr Colonial Heights.. (JAMES)

Big Branch at mouth nr Copper Valley....... (NEW)

Big Branch at mouth nr Georges Fork.. (Bïg SANDY)

Big Branch at routh nr Hitesburg....... (ROANOKE)

Bis Branch at wouth nr Ivanhoe.

Bis Branch at mouth nr Konnarock. (NEW)

Big Branch at mouth nr Longshoal.

Bis Branch at wouth nr Martinsville.... (ROANOKE)

Bi Branch at mouth $n r$ Poweliton..........(CHOWAN)

Big Branch at mouth nr Rawlings........... (CHOWAN)

$\mathrm{Big}$ Branch at mouth $n r$ Washington.......... (RAPP)

Bis Branch below Rt 672 nr Council... (BIG SANDY)

Big Branch trib at mouth nr Council.. (BIG SANDY)

Big Cedar (Cedar) Creek above U.S. Hwy 19 at Lebanon

Bis Cedar Branch at Rt 627 nr Vansant.................. (BIG SANDY)

(CLINCH)

B \& Cedar Creek at mouth nr Coulwood... (CLINCH)

Bis Cedar Creek below Little Cedar Creek nr Lebanon.

(CLINCH)

Bis Cherry Creek at mouth nr Meadows of Dan.............. (ROANOKE)

Big Chestnut Creek at mouth nr Dickinson.

Big Cranberry Creek at U.S. Hwys $58 / 221$

Bis Creek at Allegheny st at Richlands....... (NINCH)

Big Creek at Rt $759 \mathrm{nr}$ Jollett........... (SHEN)

Big Creek at mouth nr Blackweli........... (HOLSTON)

Big Creek at mouth nr New Kent........... (YORK)

Big Creek below West Fork at Richlands... (CLINCH)

Bis Cub Creek at R't 701 nr Madisonville.

Big Cub Creek at mouth nr Madisonville.

(ROANOKE)

ROANOKE

Big Entry Ditch below Portsmouth Ditch nr Deep Creek..... (JAMES) 309

Bis Entry Ditch nr Deep Creek........... (JAMES)

Big Guinea Creek at Rt 600 at Stony Point Mills

(JAMES)

Bis Guinea Creek at mouth at Stony Point Mills

(JAMES)

Big Hounds Creek at mouth nr Biackstone. (CHOWAN)

Big Hounds Creek nr Kenbridge.......... (CHOWAN)

Big Indian Creek at mouth nr Copper Valley. (NEW)

$B 1 B$ Indian Creek trib at mouth nr Indian Valley.........

(NEW)

Big Indian Run at

(RAPP) 117

Bis Indian Run at wouth nr Fint Hili..... (RAPP) 117

Big Juniper Creek at mouth nr Lunenburg. (CBOWAN) 348

B18 Laurel Creek above Little

Laurel Creek nr Konnarock.........(HOLSTON)

432
528

516

187

528

388

388
Bis Laurel Creek at mouth

nr Bent Mountain............(ROANOKE) 358

is Laurel Creek at mouth nr Copper Valley. (NEW) 446

Bis Laurel Creek trib at mouth

nr Konnarock.................... HOLSTON) 496

Bis Lick Creek above Pine Creek nr Dye...(CLINCH) 529

Bis Lickinghole Creek above Little Lickinghole Creek nr Crozier........ (JAMES) 260

Bis Lickinghole Creek at CEO RR at Irwin. (JAMES) 261

Big Lickinghole Creek at Rt 6 nr Goochland.

(JAMES) 260

Bis Lickinghole Creek at Rt 600

nI Goochl and .......................... 261

Bis Lickinghole Creek at Rt 613 nr Goochland................. (JAMES) 260

Big Lickinghole Creek at Rt 673 nr Othma. (JAMES) 260

Big Lickinghole Creek trib at U.S. Hwy $250 \mathrm{nr}$ Ferncliff....... (JAMES)

Big Macks Creek above mouth nr Hiwassee.... (NEW) 442

B18 Macks Creek at mouth nr Hiwassee.......(NEW) 442

Bis Moccasin Creek above Little Moccasin Creek at Gate City......(HOLSTON) 522

Big Moccasin Creek at Rt 612 at Collinwood nr Hansonville.... (HOLSTON) 522

Big Moccasin Creek at Rt 614 nr Weber City.............. (HOLSTON) (HOLSTON) 523

Big Moccasin Creek at Rt 619

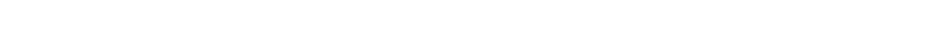

Big Moccasin Creek at U.S. Hwy 58 nr Gate City....................... HOLSTON) 523

Big Moccasin Creek at U. nr Gate City.................... (HOLSTON)

522

ccasin Creek at mouth

nI Weber City............... (HOLSTON)

Bis Moccasin Creek below Gate City...... (HOLSTON)

Bis Moccasin Creek trib at mouth

nr Gate City................... (HOLSTON)

523

Bis Otter River (Otter River) at Rt 682 nr Evington....

(ROANOKE) 382 ter River (Otter River) at

Bis Otter River above Tardy Branch nr Altavista.

(ROANOKE) 380

(ROANOKE) 382

Aiver at U.S. Havy 29

nr Altavista...

(ROANOKE)

382

Bis Otter River at mouth

nr Lynch Station.

Big Prater Creek along $\dot{R} t$ 620 nr Vansant.

(ROANOKE) 382

Bis Prater Creek at Rt 620 at Vansant.

(BIG SANDY)

460

is Prater Creek at mouth at Vansant. (BIG SANDY)

Bis Reed Island Creek at U.S. Hwy 221

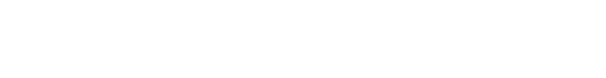
nr Allisonia.

Bis Reed Island Creek below Rt 693 nr Allisonia ........ $\ldots$ Ri

Big Reed Island Creek off Rt 693

nr Allisonia ..... $\ldots \ldots \ldots \ldots \ldots$ nr Laurel Fork..... nr Centreville. ciky Run at U.S. Hwys 29/211 nr Centreville............. (POTOMAC)

B18 Rocky Run at mouth ni Centrevilie.. (POTOMAC) Big Run at U.S. Hwy 211 nr Luray.......... (SHEN)

Bis Run at mouth nr Hamburg ............ (SHEN)

BIg Run at mouth ne Kings Store............... (NEW)

Big Run at mouth nr Rocky Bar................ (SHEN) 43

Big Smith Spring at Natural Bridge ........ (JAMES) 223

Bis Spraddle Branch at mouth nr McClure. . . . . . . . .

Bis Spring Branch at mouth

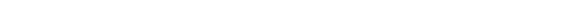


Abbreviated basin names appear at the end of the site name. Abbreviations are as follows:

Eastern Shore (EASTERN); Potomac to Shenandoah (POT-SHEN); Shenandoah (SHEN); Potomac (POTOMAC);

Potomac to Rappahannock (POT-RAPP); Rappahannock (RAPP); Rappahannock to York (RAPP-YORK); YOrk (YORK);

York to James (YORK-JAMES); James (JAMES); James to Chowan (JAMES-CHOWAN); ChOWan (CHOWAN); ROanoke (ROANOKE);

Yadkin (YADKIN); New (NEW); BiB Sandy (BIG SANDY); Holston (HOLSTON); Clinch (CLINCH); POWe11 (POWELL)]

Page

Big Spring at Liberty Furnace.

(SHEN)

( JAMES) (SHEN)

Bis Spring at Mill Gap.

Big Spring at U.S. Hwy 50 nr Leesburg. (POTOMAC)

Big Spring nr Castlowood.

Big Spring nr Poplar Hill.

Big Springs at Elliston.

Bis Spruce Pine Branch at mouth nr Duty

(ROANOKE)

is Swamp at mouth nr Providence Forge... (JAMES)

$$
\text { nr Murphy. }
$$

Bill Burleson Spring nr ípps.

BIG SANDY) (CLINCH)

Biliups Creek at mouth nr Redart...... (RAPP-YORK)

Birch Creak at Rt 659 nr Paces........ (ROANOKE)

Birch Creok at Rt $729 \mathrm{nr}$ Birch......... (ROANOKE)

Birch Creok at mouth nr Paces.......... (ROANOKE)

Birchfield Creak at Rt 636

$$
\text { nr Duncan Gap. . }
$$

(BIG SANDY)

Birchfield Creok at mouth

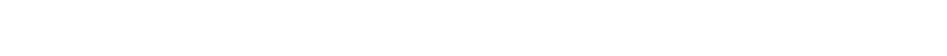

Birchin Creak at mouth nr Darvills..... (CHOWAN)

Birchwood Run at mouth nr Passapatanzy.... (RAPP)

Birchwood Run trib No. 1 at mouth nI Passapatanzy.

(RAPP)

irchwood Run trib No. 2 at

former mouth nr Passapatanzy.

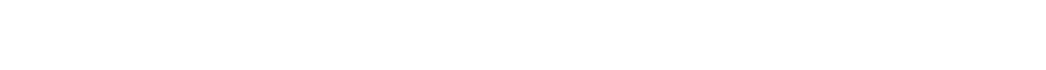

Bird Swamp (former mouth) nr Toano......... (YORK) 198

Birds Branch at mouth ne Charlotte Court House..... (ROANOKE) 390

Biscuit Run at mouth at Charlottesvilie.. (JAMES) 254

Biscuit Run nr Red Hill................ (JAMES) 254

Bishop Branch at mouth at Riverside..... (HOLSTON) 494

Bishop Branch at mouth

at Sugar Grove.......................... (HOLSTON) 492

Bishop Creok nr Lynch Station.............(ROANOKE) 379

Black Branch Swamp at mouth nr Stony Creak.........

Black Branch above trib No. 1

(CHOWAN) 331 nr Watson ........... Hwy nr Haymarket...........

( $P O T O M A C)$

(POTOMAC) 96

Black Branch at mouth nr Lenah........... (POTOMAC) 9

Black Branch at mouth nr Stony creek..... (CHOWAN) 328

Black Branch below Rt $860 \mathrm{nr}$ Watson.... (POTOMAC) 72

Black Branch below trib No, 1 $\mathrm{n}$ r Watson.

(POTOMAC) 72

Black Branch trib No. i nr Watson....... (POTOMAC)

Black Branch trib No. 2 nr Watson........ (POTOMAC)

Black Creek at Rt $635 \mathrm{nr}$ Burdetto........ (CHOWAN)

Black Creek at mouth at Burdette......... (CHOWAN)

Black Creek at mouth nr Norton............ (POWELL)

Black Creek at mouth nr Shiny Rock...... (ROANOKE)

Black Creek at mouth nr Tunstall..........(YORK)

Black Creek at mouth nr Turbevilie...... (ROANOKE)

Black Creek nr Colleen ................ (JAMES)

Black Creek nr Norton. . . . . .

(POWELL) 553 nr Berlin.....

(CHOWAN) 345 nr Sedley.

(CHOWAN) 345

Black Creek trib at mouth nr Quinton.... (YORK)

Black Haw Branch at mouth nr Glen Alien... (JAMES) 29

Black Oak Branch at mouth nr Marcem..... (CLINCH) 549

Black Rock Run at mouth nr Brokenburs..... (YORK) 190

Black Run at mouth at Rawley Springs....... (SEEN) 27

Black Run at mouth nr Orange........... (YORK)

Black Spring nr Rapps Mill nr Natural Bridge.

(JAMES) 230

Black Swamp above Kenna Swamp nr Montross. (RAPP) 151

Black Swamp at mouth nr Newville.......(CHOWAN) 335

Black Wainut Creok at mouth at Randolph

(ROANOKE) 389

Black Walnut Run at Rt 602

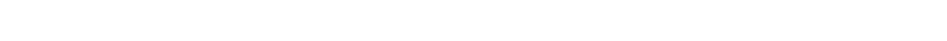

Black Walnut Run at mouth at Burr Hiii....(RAPP) 140
Black Walnut Run trib No. 1 at mouth nr Rhoadesville.

Black Walnut Run trib No. 2

at mouth nr Rhoadesvi11e........(RAPP) 140

Black Walnut Run trib No. 3 at mouth nr Rhoadesvillo

Black Walnut Run trib No. 4

at mouth nr Rhoadesville.

(RAPP) 140

Black Water Swamp at mouth nr Loretito...... (RAPP) 150

Blackberry Creek at mouth at Bassett... (ROANOKE) 401

Blackey Fork at mouth at Wolford..... (BIG SANDY) 489

Blacklog Branch at mouth nr Bartlick. (BIG SANDY) 487

Blackman Creek at Rt $667 \mathrm{nr}$ Hallsboro.... (JAMES) 284

Blacks Creek at Rt $40 \mathrm{nr}$ Mount Airy.... (ROANOKE) 413

Blacks Run above mouth nr Mt. Crawford.... (SHEN) 31

Blacks Run at Harrisonburg.............. (SHEN) 30

Blacks Run at $I-81$ at Harrisonbur. .......... (SHEN) 30

Blacks Run at Purcell Park bridge at Harrisonburg........... (SHEN)

Blacks Run at Rt 679 nr Harrisonburg...... (SHEN)

Blacks Run at Rt $704 \mathrm{nr}$ Harrisonburg...... (SHEN)

Blacks Run at Rt 726 at Harrisonburg....... (SHEN)

Blacks Run at Rt $988 \mathrm{nr}$ Harri sonburg...... (SHEN)

Blacks Run at mouth nr Mt. Crawford........ (SHEN)

Blacks Run below landfill at Harrisonburg. (SHEN)

Blacks Run trib No. 1 at U.S. Hwy 11 n Harrisonburg........................ (SHEN)

Blacks Run trib No. 2 at Rt 42 at Harrisonbur8 ............... (SHEN)

Blackstone Creek at mouth nr Scotts Crossroad.............. (CHOWAN)

Blackwater Creek along Rt 604 at Blackwater................. (CLINCH)

Blackwater Creek at Lynchburg............... (JAMES)

Blackwater Creek at Rt 190 at Blackwater.... (JAMES-CHOWAN) 318

Blackwater Creek at Rt 615 nr Castleton... (RAPP) 122

Blackwater Creek at U.S. Hwy 460 at Lynchburs...............

Blackwater Creek at U.S. Hwy 501 at Lynchburs...........

Blackwater Creek at Va.-Tenn. State line nr Black

nr Cardinal................ (RAPP-YORK)

Blackwater Creok at mouth at Ciarkton.. (ROANOKE) 387

Blackwater Creok at mouth nr Castleton.... (RAPP) 122

Blackwater Creok, East Fork, at mouth nr Blackwater.................. (CLINCH)

Blackwater Creok, Northeast Fork, nr Blackwater............... (CLINCH)

Blackwater River above Poplar Camp Creek nr Union Hall.. (ROANOKE) 371

Blackwater River above Standiford Creek nr Uni on Hall... (ROANOKE) 371

Blackwater River above Union Camp outfall nr Franklin. .

Blackwater River above mouth nr Riverdale.

Blackwater River at Cherry Grove nr Franklin................

Blackwater River at Goorges Bend nr Franklin...... Ri

Blackwater River at nr Rocky Mount................... (ROANOKE)

Blackwater River at Rt 189 nr Franki $i n .$. (CHOWAN) 346

Blackwater River at Rt 31 nr Dendron.... (CHOWAN) 341

Blackwater River at Rt $40 \mathrm{nr}$ Waverly.... (CHOWAN) 340

B lackwater River at Rt $602 \mathrm{nr}$ Barham..... (CHOWAN) 340

Blackwater River at Rt $603 \mathrm{nr}$ Burdette... (CHOWAN) 344

Blackwater River at Rt $611 \mathrm{nr}$ Franklin.. (CHOWAN) 345

Blackwater River at Rt $617 \mathrm{nr}$ Dendron... (CHOWAN) 341

Blackwater River at Rt $620 \mathrm{nr}$ Zuni...... (CHOWAN) 342

Blackwater River at Rt $621 \mathrm{nr}$ Raynor...... (CHOWAN) 341

Blackwater River at Rt 671 nr Crossroads

Blackwater River at Rt 919 nr Rocky Mount.

(ROANOKE)

370

(ROANOKE)

370 
Abbreviated basin names appear at the end of the site name. Abbreviations are as follows: Eastern Shore (EASTERN); Potomac to Shenandoah (POT-SHEN); Shenandoah (SHEN); Potomac (POTOMAC);

Potomac to Rappahannock (POT-RAPP); Rappahannock (RAPP); Rappahannock to York (RAPP-YORK); York (YORK);

York to James (YORK - JAMES); James (JAMES); James to Chowan (JAMES-CHOWAN); Chowan (CHOWAN); Roanoke (ROANOKE);

Yadkin (YADKIN); New (NEW); Big Sandy (BIG SANDY); Holston (HOLSTON); Clinch (CLINCH); Powell (POWELI)]

Blackwater River at U.S. Hwy 220 n.r Rocky Mount.

Blackwater River at U.S. Hwy 460 at Zuni.

(ROANOKE) 370

(CHOWAN) 342

Blackweter River at U.S. Hwys $58 / 258$ at Franklin.

Blackwater River at Va.-N.C. State line nr Riverdale..........(CHOWAN) 346

Blackwater River at mouth nr Penhook.... (ROANOKE) 372

Blackwater River at old U.S. Hwy 58 at rranklin.

(CHOWAN) 346

Blackwater River nr Dudley School nI Scruggs.

(ROANOKE) 371

BLackwater River nr Erankiin............(CHOWAN) 345

Blackwater River nr Union Hall (now in Smith Mountain Lake)..... (ROANOKE) 371

Blackwater River nr mouth nI Penhook... (ROANOKE) 371

Blackwater River trib No. 1 at Rt $189 \mathrm{nr}$ Holland.

(CHOWAN) 346

Blackwater River trib No. 2 at U.S. Hwy 258 nr Riverdale........ (CHOWAN) 346

Blackwater River trib No. 3 at

U.S. HWy 258 nr Riverdale. (CHOWAN) 346

Blackwater River trib nr Union Hail.... (ROANOKE) 371

Blackwater River, N.F., at mouth

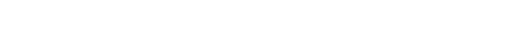

Blackwater River, S.F., at mouth

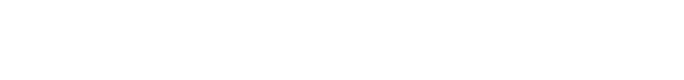

(ROANOKE) 369 nI Disputanta. $\cdots i j$ nI Prince George.

(ROANOKE) 369

Blackwat water Swamp at Rt 618 nI Disputanta.

(CHOWAN) 339

(CHOWAN) 339

Blackwater Swamp at $\mathrm{R} t 635$ nI Disputanta.

(CHOWAN) 339

Blackwater Swamp below N. F. Blackwater Swamp nI Disputanta.

Blackwater Swamp trib No. 1 at Rt 613

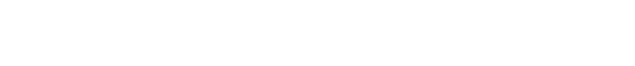
at Disputanta.

Blackwater Swamp, N.F., at Rt 616 nr Prince George. . . . . . . . .

Blackwell Branch above Double Spring Branch at Blackwel1. . . Mi ............

(CHOWAN) 339

(CHOWAN) 339

(CHOWAN) 339

(CHOWAN) 339

(CHOWAN) 339

(HOLSTON) 516

(POT-RAPQ) 114

$\begin{array}{ll}\text { Blairs Creek at mouth at Smithfieid...... (JAMES) } & 304 \\ \text { Bland Creek at Rt } 510 \text { nr Spainville...... (JAMES) } & 278 \\ \text { Bland Creek at mouth nr Denaro........... (JAMES) } & 278\end{array}$

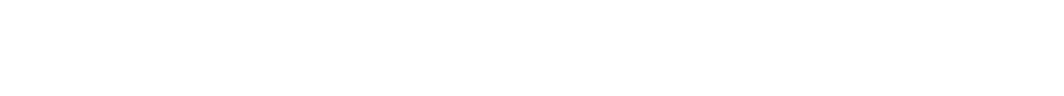

Bland Creek at mouth nr Denaro............ (JAMES) 278

Blue Creek at mouth at Clarksvilie....... (ROANOKE) 419

Blue Hole Spring at Mt. Solon....................... 27

Blue Run at Rt 231 nr Somerset................................ 135

Blue Run at Rt 641 nr Somerset........................... 135

Blue Run at Rt 678 at Barboursviile........ (RAPP) 134

Blue Run at mouth nI Gordonsville............. (RAPP) 135

Blue Run at mouth nr Stanardsville........ (JAMES) 253

Blue Spring Branch nr Burkes Garden.........(NEW) 453

Blue Spring Creek at Rt 612 at Sumit........(NEW) 433

Blue Spring Creek at Rt 514 at Sumit........(NEW) 433

Blue Spring Creek at Rt 675 nr Cedar Springs.... nr Cedar springs................NEW) 434

Blue Spring Run at Rt $6 i \dot{6}$ nI Jordan Mines.

(JAMES) 211

Blue Spring Run at mouth nI Jordan Mines.

(JAMES) 211

Blue Spring nr Rich Patch.

(JAMES) 211

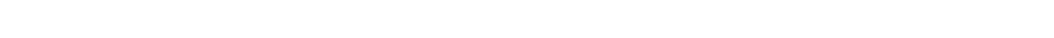

Blue Spring nr Summit................. (NEW) 434

Blue Springs Branch at mouth ni Bruno... (HoLsToN) 521

Bluestone Creek above Rt 640 nr Orgainville (Laconia).........(ROANOKE) 417

Bluestone Creek at Rt 640 nI Orgainville.............. (ROANOKE)
Bluestone Creek at Rt 699 nI Orgainvilie (Laconia)

Bluestone Creek at U.S. HWy 15 nI Jeffress.......... Bluestone River above Va. $-W . V a$ State line at Yards.............. NEW) 456

Bluestone River above water plant at Bluefield.

(NEW) 455

Bluestone River at $\mathrm{Rt} 7 i \overline{7}$ at Falis Milis.... (NEW) 456

Bluestone River at Rt 720 at Bluefield.....(NEW) 455

Bluestone River at U.S. HWy 460 at Bluefield........ at Bramwell, W.Va. .

Bluestone River at Ve. $-W . V a$. State line nr Falls Mills..........(NEW) 456

Bluestone River at mouth nr Summers, W.Va.. (NEW) 456

Bluestone River below water plant at Bluefield

(NEW) 455

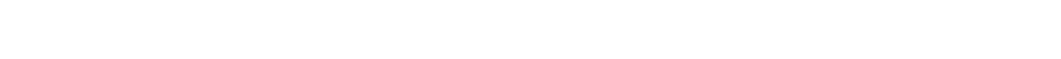

Bluff Run at mouth nr Spotsylvania.......... (YORK) 190

Boar Swamp above Meadow Rd nr White Oak Swamp.

Boathouse Creek at mouth nI Seaford.................. (YORK-JAMES)

Boatswain Creek at former mouth nI Richmond...................... (JAMES)

Bob Cummins Spring nr Abingdon.......... (HOLSTON)

Body Camp Creek at mouth at Stone Mountain............. (ROANOKE)

Boiler Run at mouth nr Beulahvilie......... (YORK)

Boiling Spring at Grahams Forge........... (NEW)

Bolar Run at Rt 607 at Bolar.............. (JAMES)

Bolar Run at mouth nr Burnsviile......... (JAMES)

Bolar spring at Bolar............... (JAMES

Bold Branch at mouth at Stone Mountain. (ROANOKE)

Bold Branch at mouth nr Forksville...... (CHOWAN)

Bold Camp Creek at mouth at Pound.... (BIG SANDY)

Bolin Branch at mouth rI Chatham....... (ROANOKE)

Bolton Branch at Rt 631 nI Flint Hiii..... (RAPP)

Bonbrook Creek at Rt 624 nr Whiteville... (JAMES)

Bond Branch at Rt 612 nI Culpeper......... (RAPP)

Bonnie Brook at mouth nr McGaheysviile... (SHEN)

Bonum Creek at mouth nr coles Point.... (POTOMAC)

Bonys Run at mouth at Shawsville....... (ROANOKE)

Bookers Mill Stream at mouth nr Farnham... (RAPP)

Boom Swamp at mouth nr Port Royal......... (RAPP)

Boone Run at mouth nI Eliton.............. (SHEN)

Boot Swamp at mouth nr Beulahville....... (YORK)

Bootens Run at mouth nr Stanardsville..... (RAPP)

Booth Branch at mouth nr Grundy...... (BIG SANDY)

Boothe Creek at mouth nr Kings Store....... (NEW)

Boozy Creek at Va.-Tenn. State line nr Maces Spring............... (HOLSTON)

Borden Marsh Run at Rt 624 nr Boyce....... (SHEN)

Borden Marsh Run at mouth nr Milidaie..... (SHEN)

Bore Auger Creek at mouth nr Chamblissburg.............. (ROANOKE)

Boston Creek at mouth nr Nahor........... (JAMES) Bottom Creek at Rt 637 nf Crockett Spring............... (ROANOKE)

Bottom Creek at mouth nI Simpsons....... (ROANOKE)

Bourdon Creek at mouth nr Rawlings...... (CHOWAN)

Bowen Swamp at mouth ni Montross.......... (RAPP)

Bowens Creek above mouth Tr West Bassett.

Bowler Creek at Rt 660 nr Lindsay........... (YORK)

Bowler Creek at mouth nr Gordonsviile..... (YORK)

Bowman Branch at mouth nr Watauga...... (HOLSTON)

Bowman Branch nr Watauga.............. (HOLSTON) Boyd Branch above mouth ir Davenport. (BIG SANDY) Boyd Spring nr Radford.................. (NEW) Bradley Creek at mouth nr Meadville.... (ROANOKE) Bradiey Run at mouth nr Roxbury........... (JAMES)
202

295

508
439

378

194

437

205

205

378

351

482

411
117

258

129

44
112

359

154

149

193

133

461

444

511

64
64

377

255

358

358

325
151

400

400

175
175

507

507

468
447

414
296 
Abbreviated basin names appear at the end of the site name. Abbreviations are as follows: Eastern Shore (EASTERN); Potomac to Shenandoah (POT-SHEN): Shenandoah (SHEN); Potomac (POTOMAC); Potomac to Rappahannock (POT-RAPP); Rappahannock (RAPP); Rappahannock to York (RAPP-YORK); York (YORK); York to James (YORK-JAMES); James (JAMES); James to Chowan (JAMES-CHOWAN); ChOWan (CHOWAN); Roanoke (ROANOKE); Yadkin (YADKIN); New (NEW); Big Sandy (BIG SANDY); Holston (HOLSTON); Clinch (CLINCH); Powell (POWELL)]

Page

Bradshaw Creek at Rt 629 nI Ironto.....(ROANOKE) 361 Bradshaw Creek at mouth nr Ironto.......(ROANOKE) 362

Brake Branch at U.S. Hwy 11

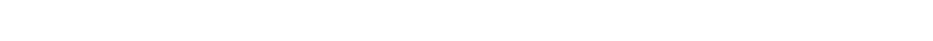

Brake Branch at mouth at Eiliston........ (ROANOKE) 359 Branch Croek at mouth nI Fine Creek Mil1s.

(JAMES) 262

Brandon Creek at U.S. Hwy 58 n Turbev Tur

(ROANOKE) 408

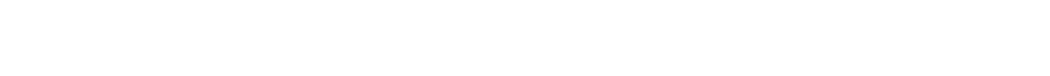

Brandy Creek at mouth nr Ant.......... (CHOWAN) 354

Branham Mill Swamp at mouth nr Haynesville.

(RAPP) 154

Brannon Branch at mouth nr Dugspur..........(NEW) 439

Brantley Swamp at mouth ne Ivor...

Brattons Run at Rt 39 nr Goshen............ (JAMES) 225

Brattons Run below Locher Silica Mine nr Goshen

(JAMES) 225

Brattons Run trib at Rt 180 nr Goshen.... (JAMES)
224
Braudy Branch at mouth nr Lindell..... (HOLSTON) 517

Breeden Branch at mouth nr Rowe....... (BIG SANDY) 457

Breezers Branch at mouth nr Coulwood....(CLINCH) 534

Breezers Branch below Independence Church nr Coulwood.............. (CLINCH)

Bremo Creek at mouth nr Bremo Biuff........ (JAMES)

Brewers Creek at mouth at Hobson......... (JAMES)

Brick Hill Creek at mouth nr Loretto......(RAPP)

Brick Kiln Creek at Rt 134 nr Poquos on..............

Brick Kiln Creek at Rt 172

ni Poquoson............... (YORK-JAMES)

Brick Kiln Creek at mouth

nr Poquoson................ (YORK-JAMES)

Brick Kiln Creok trib at Rt 134

nr Tabh.................. (YORK-JAMES

Bridge Creek at mouth nr Champlain....... (RAPP)

Bridle Creek at U.S. Hwy 58 nr Fox.......... (NEW)

Bridle Creek at mouth nr Bridle Creok....... (NEW)

Briery Branch above Beaver Creek nr Spring Creek. .

(SHEN)

Briery Branch at mouth nr Brodnax......... (CHOWAN)

Briery Branch at mouth nr Spring Creok.... (SHEN)

Briery Branch nr Briery Branch............ (SHEN)

Briery Branch nr Spring Creek............... (SHEN)

Briery Branch trib at Rt 257 nr Spring Creek.

Briery Creek (Run) at mouth nI Scottsville................ (JAMES)

Briery Creek at Rt $628 \mathrm{nr}$ Farmilie...... (JAMES)

Briery Creek at U.S. Hwy 15 nr Hampden Sydney...

Briery Creek at U.S. Hwy 460 (Business) nI Rice.

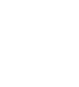

(JAMES)

Briery Creak at mouth nr Rice........... (JAMES)

Briery Swamp at mouth nr Church Viow. (RAPP-YORK)

Bristo1 Mine Run at mouth nr Port Royal... (RAPP) Brittain Spring nr Holston Mill nr Marion............

(HOLSTON)

Broad Bay at Ocean Park........... (JAMES-CHOWAN)

Broad Bay at buoy 16 nr Ocean Park............. (JAMES-CHOWAN)

Broad Branch at mouth nr Bishops Corner. (CHOWAN)

Broad Branch at mouth nr Manakin......... (JAMES)

Broad Creak at N\&W RR at mouth at Norfolk.

(JAMES) 310

Broad Creak at $R t 610$ nr Glasgow.......... (JAMES)

Broad Croek at mouth nr Deltaville........ (RAPP)

Broad Creak at mouth nr Glasgow........... (JAMES)

Broad Hollow Creek at mouth nr Pearisburg.. (NEW)

Broad Run at Rt 28 nr Bristow.......... (POTOMAC)

Broad Run at Rt 619 nr Bristow........ (POTOMAC)

Broad Run at Rt 675 nr Gainesvilie...... (POTOMAC)

Broad Run at Rt 692 at Brentsville...... (POTOMAC)

Broad Run at Rt 7 nr Leesburg.......... (POTOMAC)

Broad Run at Southern RR at Bristow.... (POTOMAC)

Broad Run at U.S. Hwy 17 nr Warrenton.. (POTOMAC)

Broad Run at U.S. Hwy 29 at Buckland... (POTOMAC)

534

245

203

203

203

203

150

428

428

26

351

26

26
26

26

244

274

273

274

274

160

149

493

315

315

350

263

310
230

159

231

452
95

95

94

96
74

95

95

94
Broad Run at mouth at Brentsville.

(POTOMAC)

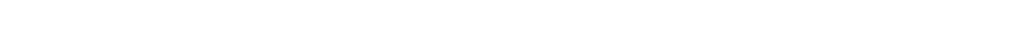

(SHEN) 37

Broad Run trib No. 1 at U.S. Hwy 29 at Buckland.

Broad Run trib No. 2 off Rt 234

at Manassas................... (POTOMAC) 95

Broad Run trib No. 3 at Rt 619 at Bristow..................

Broad Run trib No. 4 at Rt 619 at Bristow. . $\cdots$ at Rt $2 \ddot{i j}$ nr Bristow.

(JAMES)

(POTOMAC)

( POTOMAC)

(POTOMAC)

( POTOMAC)

Run, East Fork, trib No. tributafy at Rt $215 \mathrm{nr}$ Bristow.. (POTOMAC)

Broad Run, N.F., at U.S. Hwys $29 / 211$ nr Haymarket.

POTOMAC) 94

Broad Run, N.F. at mouth

(POTOMAC)

Broad Run, S.F., at Rt 621 at Arcola... (POTOMAC)

Broad Run, S.F., at U.S. Hwy 50 nr Arcola . …… tributary at Rt $215 \mathrm{nr}$ Bristow... (POTOMAC)

Broadhead Creek at mouth at Greenvilie....,(SHEN)

Broadhead Spring Nos. 1 and 2 ni Greenville...... nr Chancellorsvillo ............. (YORK)

Brock Run above Chancellorsvillo.

Brockenbrough Creek at mouth nr Leedstown..............

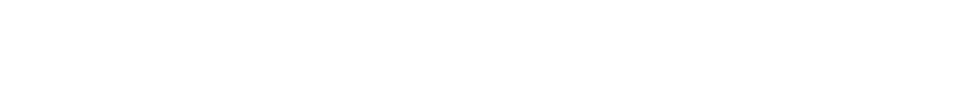

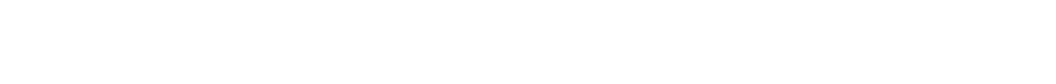

(RAPP) 121

Brokenback Run at elev $1360 \mathrm{nr}$ Nethers.... (RAPP) 121

Brokenback Run at elev 1740 nI Nethers.... (RAPP) 121

Brokenback Run at elev 2000 nI Nethers..... (RAPP) 121

Brokenback Run at elev 2490 nr Nethers.... (RAPP) 121

Brokenback Run at mouth nr Nethers......... (RAPP) 121

Brokenback Run, S.F., nr Nethers......................... 121

Brook Run at Rt 647 nI Lignum............................ 140

Brook Run at mouth nr Culpeper.............................. 140

Brook Run trib No. 1 at mouth nr Culpeper. (RAPP) 139

Brook Run trib No. 2 at mouth nr Culpeper. (RAPP) 139

Brooks Creek at mouth nr King and Queen Court House...... (YORK)

Brown Lick Branch at mouth nr Max Meadows...(NEW) 437

Browns Branch at Rt $612 \mathrm{nr}$ Adams Grove.. (CHOWAN) 333

Browns Branch at Rt $615 \mathrm{nr}$ Adams Grove. (CHOWAN) 334

Browns Branch at mouth at Adams Grove... (CHOWAN) 334

Browns Creek at mouth nr Ki Imarnock........ (RAPP) 158

Browns Creok trib at mouth ar Kilmarnock. (RAPP) 158

Browns Dan River at mouth nr Claudville.

Browns Run at U S Hory i

Browns Run at mouth nr Remington...... (RAPP) 128

Browns Run off Rt $644 \mathrm{nr}$ Elk Run...................... 127

Browns Run trib at Rt $644 \mathrm{nt}$ Bealeton........ (RAPP) 128

Browns Spring Nos. 1 and 2 nr Lyndhurst... (SHEN) 39

Brumley Creek at Rt 611 at Brumley Gap...............(HOLSTON) 518

Brumley Creek at mouth nr Brumiey Gap... (HOLSTON) 518

Brumley Creek nr Hansonville..........(HOLSTON) 518

Brumley Creek trib at mouth at Brunley Gap.

(HOLSTON) 518

Brush Creek at Flannagan Reservoir at Isom.

(BIG SANDY) 484

Brush Creek at Rt 615 at Terrys Fork.......(NEW) 445

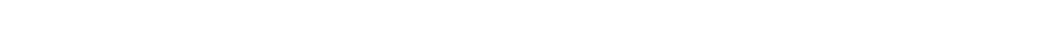

Brush Creek at Rt $94 \mathrm{nr}$ Ivanhoe................... 432

Brush Creek at Rts $693 / 600$ nr Whitacre.

(POT-SHEN) 21

Brush Creek at mouth nr De Haven......(POT-SHEN) 21

Brush Creek at mouth nr Fries.................. 432 
Abbreviated basin names appear at the end of the site name. Abbreviations are as follows Eastern Shore (EASTERN); Potomac to Shenandoah (POT-SHEN); Shenandoah (SHEN); Potomac (POTOMAC); Fotomac to Rappahannock (POT-RAPP); Rappahannock (RAPP); Rappahannock to York (RARP-YORK); York (YORK); York to James (YORK-JAMES); James (JAMES); James to Chowan (JAMES-CHOWAN); ChOWan (CHOWAN); ROanoke (ROANOKE); Yadkin (YADKIN); New (NEW); Big Sandy (BIG SANDY); Holston (HOLSTON); Clinch (CLINCH); Rowell (POWELL)]

Page

Brush Creek at mouth nr Independence...... (NEW) 428

Brush Creek at mouth nr Leda........... (ROANOKE) 414 Brush Creek at mouth nr Murrayfieid..... (HOLSTON) 495

Brush Creek at mouth nr Riner.................W 445

Brushy Fork above Va. $-W$. Va. State Line nr Palo Alto.................... (POT-SHEN) 20

Brushy Fork at mouth $\mathrm{nr}$ Mayo............(ROANOKE) 395

Bubbling Spring (Lick Run) at Rt 630 nr Millboro Springs................. JAMES) 215

Buck Creek at U.S. Hwy 29 nr Covesviile.. (JAMES) 241

Buck Creek at mouth $n r$ Aspen...........(ROANOKE) 387

Buck Is land Creek at Rt $53 \mathrm{nr}$ Simeon..... (JAMES) 254

Buck Is land Creek at mouth nr Boyd Tavern................. (JAMES) 255

Buck Island Creek below Rt 729 below Houchins Creek nr Simeon........... (JAMES) 254

Buck Mountain Creek at Rt 665 nr Free Union............... (JAMES)

Buck Mountain Creek at mouth

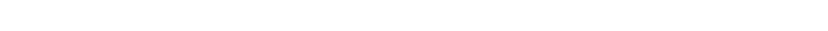

Buck Run at Rt $635 \mathrm{nr}$ Flint Hi11.......... (RAPP)

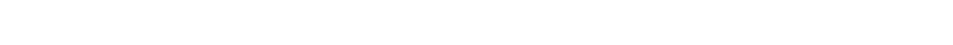

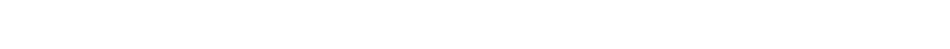

Buck Run at mouth nr Culpeper............. (RAPP)

Buck Run at mouth nr Flint Hill.

138

Buck Run at mouth nr Wirtz........ (ROANOKE)

Buckeye Branch at mouth nr Big Rock... (BIG SANDY)

Buckeye Branch at mouth nr Dunbar....... (POWELI)

.

Buckhorn Branch at mouth nr Worlds. (NEW)

Buckhorn Creak at mouth nr Longshoal (ROANOKE) (NEW

Buckhorn Creek at mouth nr North View... (CHOWAN)

Buckhorn Creek nr Como N.C. (CHOWAN)

Buckhorn Swamp at Rt 651 nr Sebreil...... (CHOWAN)

Buckhorn Swamp at Rt 652 nr Capron....... (CHOWAN)

Buckhorn Swamp at mouth nr Branchvilie.. (CHOWAN)

Buckhorn Swamp at mouth nr Sebrell....... (CHOWAN) 335

Buckner Run at mouth nr Ruckersvili........ (RAPP) 134

Bucks Branch at mouth nr Lodi......... (HOLSTON) 495

Buckskin Creek above mouth nr Cherry Hill.

(CHOWAN) 326

Buckskin Creek at Rt 692 nr McKenney ..... (CHOWAN) 326

Buckskin Creek at mouth nr Cherry Hili.. (CHOWAN) 326

Buckskin Creek at mouth nr Crossroads.. (ROANOKE) 387

Buckskin Creek trib at U.S. Hwy 1 at Mckenney.

(CHOWAN) 326

Buckyard Branch at mouth nr Aylett......... (YORK

Buddle Branch above STP at Austinvi11e..... (NEW)

Buddle Branch along Rt 636 at Austinville.. (NEW)

Buddle Branch at mouth at Austinville...... (NEW)

Buffalo Branch along Rt 42 nr Christian... (SHEN)

Buffalo Branch at Rt 254 nr Buffalo Gap... (SHEN)

Buffalo Branch at Rt 720 nr Churchville... (SHEN)

Buffalo Branch at mouth nr Churchvillo.... (SHEN)

Buffalo Branch at mouth nr Laurel Fork...... (NEW)

Buffalo Branch at mouth nr Leesville... (ROANOKE)

Buffalo Branch trib No, 1 at Rt 42

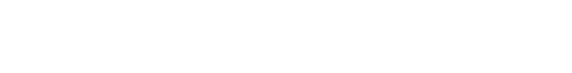
nr Christian.

(SHEN)

Buffalo Branch trib No. 2 at Rt 42

Buffalo Creek above Bluestone Creek nr Buffalo Springs.............

Buffalo Creek above Tanyard Branch at Buffalo Springs........

Buffalo Creek above U.S. Hwy is at Farmuille $\ldots \ldots \ldots$ Murat

Buffalo Creek at Rt 25

$$
\text { Murat }
$$

Buffalo Creek at Rt 608 nr Glasgow.

Buffalo Creek at Rt $610 \mathrm{nr}$ Glasgow.

Buffalo Creek at Rt 63 nr Nora..

Buffalo Creek at Rt 658 nr Hampden Sydney

Buffalo Creek at Rt 665 ir Hampton Sydney.

Buffalo Creek at U.S. Hwy ii at Troutvillo

(ROANOKE)

(JAMES)

(JAMES)

(JAMES)

( $\dot{B} \dot{I G}$ SANDY)

( JAMES )

(ROANOKE

Buffalo Creek at U.S. Hwy il nr Giassow. (JAMES)
326
195

434

434

435

33
33

33

33

438

378

33
Buffalo Creek at U.S. HWy 15 at Farmville.

Buffalo Creek at U.S. Hwy 220 nr Daleville.

Buffalo Creek at U.S. Hwy 460 at New London.........

Buffalo Creek at U.S. Hwy at Buffalo Springs.

.... (JAMES) 273

Buffalo Creek at mouth nr Clover......... (ROANOKE) 392

Buffalo Creek at mouth nr Dalevilie..... (ROANOKE) 365

Buffalo Creek at mouth nr Evington..... (ROANOKE) 381

Buffalo Creek at mouth nr Glas gow....... (JAMES) 231

Buffalo Creak at mouth ar Melrose........ (ROANOKE) 383

Buffalo Creek at mouth nr Nora......... (BIG SANDY) 478

Buffalo Creek at mouth nr Whitevilie..... (JAMES) 258

Buffalo Fork at mouth nr Hurley.... (BIG SANDY) 490

Buffalo Marsh Run at Rt 527 nr Middletown

(SHEN) 61

Buffalo Marsh Run at mouth nr Middietown. (SHEN) 61

Buffalo River at Rt 610 at Forks of Buffalo.

Buffalo River at Rt 610 above

Buppy Creek at Sandidges.......... (JAMES) 238

Buffalo River at Rt 657 nI Tye River...... (JAMES) 240

Buffalo River at Rt 778 at Henleys Store. (JAMES) 239

Buffalo River at U.S. Hwy 29 nr Amherst. (JAMES) 239

Buffalo River at mouth nr Tye River...... (JAMES) 240

Buffalo River trib at U.S. Hwy 60 nr Amberst.

(JAMES) 239

Buffalo River, $N$. $\mathbf{F}$ at Forks of Buffalo.

Buffalo River, S.F. (hest Fork) at Rt 635 at Forks of Buffalo..... (JAMES)

238

Buford Branch at mouth nr Lawrencevilie.

Bull Creek at mouth nr Perth.

(CHOWAN) 354

Bull Creek nr Harman Junction.

ROANOKE) 383

Bull Mountain Fork at mouth nr Mayo.... (ROANOKE) 395

Bull Neck Creek above Jones Millpond nr Tappahannock.

(RAPP)

Bull Run (Occoquan Reservoir)

at Rt 612 nr Clifton.

.... (POTOMAC) 101

Bull Run at Rt 659 nr Catharpin............ (POTOMAC) 97

Bull Run at Rt $705 \mathrm{nr}$ Catharpin.........(POTOMAC) 97

Bull Run at U.S. Hwy $58 \mathrm{nr}$ St. Paul..... (ClINCH) 538

Bull Run at U.S. Hwys $29 / 211$ at Bull Run

(POTOMAC) 97

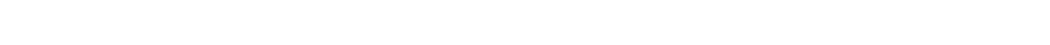

Bul1 Run at mouth nr Doswell................. (YORK) 173

Bull Run at mouth nr Penhook.............................. 371

Bull Run at mouth nr spencer............... (ROANOKE) 396

Bul1 Run below Rt 616 at Manassas Park..................(POTOMAC) 100

Bull Run nr Manassas..................... (POTOMAC) 99

Bull Run trib No. 2 at Lake St at Manassas................... (POTOMAC) 100

Bul1 Run trib No. 3 at Lake St at Manassas..................... (POTOMAC) 100

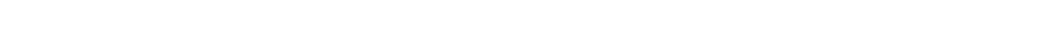

Bull Run trib at mouth at Manassas Park.

Bull Yearling Run at mouth nr Stanardsuille.

(YORK) 196

(RAPE) 133

Bullhill Run at Hopewell................. (JAMES) 288

Bullpasture River $1.0 \mathrm{mi}$ above Cowpasture River at Williamsville...(JAMES) 214

Bullpasture River $1.75 \mathrm{ml}$ above Cowpasture Rivar or Will1amsvil1e.. (JAMES) 214

Bullpasture River $2.5 \mathrm{mi}$ above Cowpasture River nr Williamsville..(JAMES) 214

Bullpasture River above Cowpasture River at Williansville.. (JAMES) 
Abbreviated basin names appear at the end of the site name. Abbreviations are as follows:

Eastern Shore (EASTERN); Potomac to Shenandoah (POT-SHEN); Shenandoah (SHEN); POtomac (POTOMAC);

Potomac to Rappahannock (POT-RAPP); Rappahannock (RAPP): Rappahannock to York (RAPP-YORK); York (YORK);

York to James (YORK-JAMES); James (JAMES); James to Chowan (JAMES-CHOWAN); ChOWan (CHOWAN); Roanoke (ROANOKE);

Yadkin (YADKIN); New (NEW); Big Sandy (BIG SANDY); Holston (HOLSTON); Clinch (CLINCH); POwell (POWELL)!

Page

Bullpasture River along Rt 654 above McDowe11...............(JAMES) 214

Bullpasture River at Rt 612 nr Flood..... (JAMES) 214

Bullpasture River at Rt 614 at Williamsville...............JAMES) 214

Bullpasture River at Rt 618 ne Doe Hill.

(JAMES) 214

Bullpasture River at U.S. Hwy 250 at McDowe $11 \ldots \ldots \ldots \ldots \ldots \ldots \ldots \ldots$ (JAMES) 214

Bulls Creek at mouth $n=$ Cttoman........................... 156

Bumgardner Branch at mouth nr Watauga... (HoLSTON) 507

Bunch (Hudson) Creek at U.S. Hwy 15 nr Boswells Tavern............... (YORK) 176

Bunch (Hudson) Creek off Rt 640 nr Thelma.

Bunch Creek at mouth nr Boswe11s Tavern... (YORK) 176

Bundy Creek at mouth at Bundy........... (POWELL) 557

Burgess Creek at mouth nr Lebanon........... (CLINCH) 533

Burgess Creek at mouth nr Ridgeway..... (ROANOKE) 403

Burke Mill Stream at mouth

nr James Store.............. (RAPP-YORK)

Burkes Garden Creek above Iittle Creek nr Shawver Mill...................... (NEW)

Burks Fork at mouth nr Hiilsviiie........... (NEW)

Burks Run at mouth at Graysontown.......... (NEW)

Burnett Creek at mouth nr Champlain......... (RAPP)

Burnley Branch at mouth nr Barboursvilie. (JAMES)

Burns Creek at mouth at Tacoma..........(CLINCH)

Burnt Cabin Branch at mouth at Gate city................. (HOLSTON)

Burnt Mill Creek at $R t 14$ at Shacklefords. (YORK)

Burnt Mi11 Creek at mouth nr West Point... (YORK)

Burnt Mill Run at mouth nI Middleburg.. (POTOMAC)

Burnt Mill Swamp at mouth nr Zuni....... (CHOWAN)

Burnt Reeds Swamp at mouth $n z$ Boykins... (CHOWAN)

Burton Branch at mouth nr Boydton...... (ROANOKE)

Burton Creek at Lynchburg............. (JAMES)

Burton Creek trib at U.S. Hwy 29 at Lynchburs.

(JAMES)

Burton Spring nr Gratton...... (CLINCH)

Burtons Branch at mouth nr Amon......... (JAMES)

Bush Mi11 Stream at Rt 601 nI Heathsville................ (POT-RAPP) 114

Bush Mill Stream at mouth nI Howland.. (POT-RAPP) 114

Bush Mountain Stream at mouth nI Stanardsuille.

(RAPP)

Bush Park Creek at former mouth nr Deltavil1e.

(RAPP)

Bush River at Rt $630 \mathrm{nr}$ Worsham............... (JAMES)

Bush River at U.S. Hwy 460 nr Rice....... (JAMES)

Bush River at mouth nI Rice............ (JAMES)

Bush Run at mouth nr Callaway.

ROANOKE)

Bushy Fork at Va.-N.C. State line

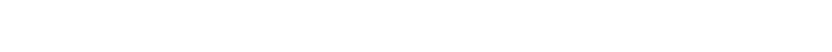

Butcher Creek above Kerr Reservoir noydton. (ROANOKE)

Butcher Creek at $\mathrm{Rt} 756$ ni Boydton..... (ROANOKE)

Butcher Creek nr former mouth in Kerr Reservoir nr Boydton...... (ROANOKE)

Butcher Fork at $R t 683$ at East Stone Gap.

( POWELL)

Butcher Fork at mouth at East Stone Gap. (POWELL)

Butchers Branch at mouth at Airmont.... (POTOMAC)

Butler Creak at mouth ne Scotts Fork..... (JAMES)

Buttermilk Creek at mouth nr otter Hi11.

(ROANOKE)

Buttermilk Run at mouth nr Hinton........... (SHEN)

Butterwood Branch at mouth nf Thornton Gap.

(RAPP)

Butterwood Creek at Rt 603 nr Genito..... (JAMES) Butterwood Creek at Rt 613 nr Darvilis... (CHOWAN) Butterwood Creek at Rt 646 or Baltimore Corner Butterwood Creek at mouth or DeWitt..... (CHOWAN) Butterwood Creek at mouth nr Red House. (ROANOKE) Button Creek at Rt 24 nr Rustburg...... (ROANOKE) Button Creek at mouth nI Sherwi11....... (ROANOKE)
Button Creek trib at Rt 24 nr Rustburg. (ROANOKE)

Buzzard Den Branch at mouth nr Murrayfield............... (HOLSTON)

Bye Creek at mouth nr Meadville....... (ROANOKE)

Byers Branch at mouth nr Mt. Sidney........ (SHEN)

Byers Creek at Rt $735 \mathrm{nr}$ Glade Spring.. (HOLSTON)

Byers Creek at mouth nr Glade Spring... (HOLSTON)

Byrd Creek at Rt 6 nr Elk Hill......... (JAMES)

Byrd Creek at Rt $659 \mathrm{nr}$ Wilmington........ (JAMES)

Byrd Creek at mouth nr Elk Hill......... (JAMES)

Byrd Park Spring at Richmond........... (JAMES)

Byrds Branch at mouth nr Turbeville.... (ROANOKE)

385

495

414

32
505

505

257

257

265

408

C. E. Lefel Spring nr Looney........... (JAMES) 217

C. H. Hambrie Spring nr Snowvilie............. (NEW) 446

Cabin Branch at mouth

at Tuckahoe Village...... (JAMES) 263

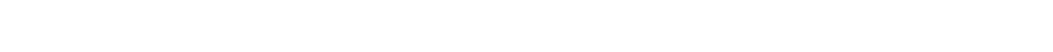

Cabin Branch at mouth nr Culpeper........................... 138

Cabin Branch at mouth nr Sterling........ (POTOMAC) 74

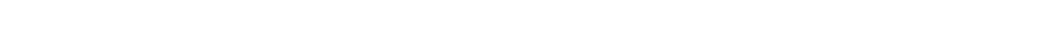

Cabin Creek at mouth nr Brumley Gap.... (HOLSTON) $\$ 18$

Cabin Fork at mouth nr Nora......... (BIG SANDY) 476

Cabin Point Swamp at Rt 641 nI Stony Creek. .

(CHOWAN) 330

Cabin Point Swamp at mouth

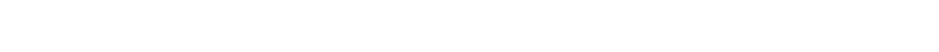

Cabin Run at mouth at Front Royai............ (SHEN) 5

Cady Creek at mouth nr Hanover...........(YORK) 183

Cain Branch at U.S. Hwy 50 nr Chantiliy..................... POTOMAC) 98

Cain Branch at mouth nz Chanti11y......(POTOMAC) 98

Calamo Branch (Creok) trib at Tanager St at Springfield.....(POTOMAC) 88

Caldwells Creek (East Fork Falling River) at Rt $719 \mathrm{nr}$ Appomattox... (ROANOKE) 384

Calfpasture River Spring nz Deerfield.... (JAMES) 224

Calfpasture River at $R t 42$ above Mi11 Creek at Goshen.

(JAMES) 224

Calfpasture River at $\mathrm{Rt} 687$ nr Craigsville.

(JAMES) 224

Calfpastuze River at $R t 888$ above

Hodges Draft nr West Augusta...... (JAMES) 224

Calfpasture River at mouth nr Goshen..... (JAMES) 225

Calfpasture River below Mill Creek at Goshen...................... (JAMES) 224

Calfpasture River nr Deerfieid............ (JAMES) 224

Calfpasture River nr Goshen............ (JAMES) 224

Calfpasture River nr U.S. Hwy 250

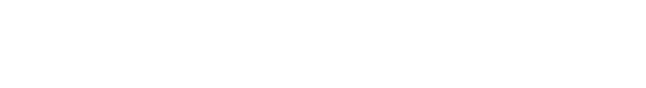

(JAMES) 223

Callahan Creek at Rt 78 at Appalachia... (POWELL) 555

Callahan Creek at $\mathrm{Rt} 78 \mathrm{nr}$ Stonega...... (POWELL) 554

Callahan Creek at mouth at Appalachia... (FOWELL) 555

Callahan Creek below Preacher Creek

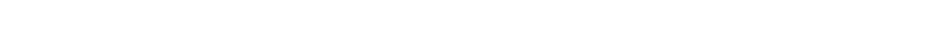

Canden Spring nr Glasgow............... (JAMES) 231

Cameron Run above Hooff Creek at Alexandria..................(POTOMAC) 84

Cameron Run above South Quaker Lane at Alexandria............... (POTOMAC)

Cameron Run at South Quaker Lane at Alexandria ............... (POTOMAC)

Cameron Run at Telegraph Rd at Alexandria.

(POTOMAC)

Cameron Run below Southern RR

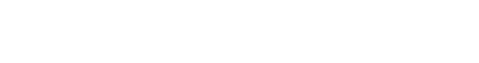

( POTOMAC)

Cameron Run below Telegraph Rd at Alexandria......

Camp Branch Creek at mouth
nr Breaks..........

(POTOMAC)

(BIG SANDY) 487

Camp Branch at mouth nr Figsboro....... (ROANOKE) 401

Camp Branch at mouth ne Indian Valley...... (NEW) 439

Camp Branch at mouth nr Martinsville... (ROANOKE) 403 
Abbreviated basin names appear at the end of the site name. Abbreviations are as follows

Eastern Shore (EASTERN); Potomac to Shenandoah (POT-SHEN); Shenandoah (SHEN); Potomac (POTOMAC)

Potomac to Rappahannock (POT-RAPP); Rappahannock (RAPP); Rappahannock to York (RAPP-YORK); York (YORK);

York to James (YORK-JAMES); James (JAMES); James to Chowan (JAMES-CHOWAN); Chowan (CHOWAN); Roanoke (ROANOKE);

Yadkin (YADKIN); New (NEW); Big Sandy (BIG SANDY); Holston (HOLSTON); Clinch (CLINCH); Powell (POWELL)]

Camp Creek above Wheeler Creek nr Boswells Tavern.

Camp Creek at Rt 640 at Poindexter

Camp Creek at mouth at Haysi.

Camp Creek at mouth or Clintwood

Camp Creek at mouth nr Copper Hili.................

Camp Creek at mouth nr Dryden.

Camp Creek at mouth nr Floyd.

Campbel1 Branch at mouth nr Lebanon..... (CLINCH)

Campbel1 Creek at mouth nr Hanover........ (YORK)

Campbel1 Creek at mouth nr Woodford....... (YORK)

Camps Prong above Norris Prong nr Kilmarnock.

(RAPP) 158

Canal Swamp at mouth at Eiko

(JAMES) 296

Cane Branch at mouth nr Bartlick.... (BIG SANDY)

Cane Creek above Tiller Fork nr Duty. (BIG SANDY)

Cane Creek above mouth nr Ringsold..... (ROANOKE)

Cane Creek above trib No. 2 nr Duty.. (BIG SANDY)

Cane Creek along Rt 601 at Duty.......(BIG SANDY)

Cane Creek along Rt 611 nr Blowing Rock.

Cane Creek at Flannagan Reservoir nr Blowing Rock................. BIG SANDY) 484

Cane Creek at Rt 643 above Pennington Gap.................. (POWELL) 560

Cane Creek at Rt 647 at Ben Hur......... (POWELL) 560

Cane Creek at mouth at Duty.......... (BIG SANDY) 471

Cane Creek at mouth below Pennington Gap.

(POWELL) 560

Cane Creek nr Duty.

(BंG SANDY) 470

Cane Creek nr Smith Gap nr Duty....... (BIG SANDY) 470

Cane Creek trib No. 1 at mouth nr Duty...........................

Cane Creek trib No. 2 at mouth Creek trib No, 3 at $\mathrm{Rt} 6 \dot{6} \dot{1}$

Canepatch Creek at mouth ni Dunbar

(BIG SANDY) 470

(BIG SANDY) 470

Caney Branch at mouth nr Emporia.

Caney Creek at mouth at McClure

(BIG SANDY) 471

(POWELL) 554

(CHOWAN) 355

Caney Swamp at mouth nr Claresvilie.

Cannon Branch trib No. 1 tributary at Rt 661 at Manassas.

(BIG SANDY) 478

(CHOWAN) 356

(POTOMAC) 95

Cannon Branch trib No. 2 at Rt 661 at Manassas

( POTOMAC)

(POTOMAC) or Bristow.

Cannon Creek at mouth in Garrisonviiie

Canoe Branch at mouth nr Holston....... (HOLSTON)

Canton Creek at mouth nr Oak Leve1..... (ROANOKE)

Cape Charles Harbor at Cape Charles.... (EASTERN)

Cape Charles Harbor at mouth at Cape Charles.

(EASTERN)

Cape Charles Spring Branch at mouth nr ititleton.

Capon (Pewee) Run at mouth nr Bergton...... (SHEN)

Captain Hickory Run at Rt 681 nr Great Falls.

(POTOMAC)

Captain Hickory Run at mouth nr Great Falls.

(POTOMAC)

(JAMES)

Carbell Swamp ar mouth at Lake Prince

Carding Machine Branch at mouth at Josephine.

Cargills Creek at mouth nr Dryburg

(POWELL)

(ROANOKE)

(HOLSTON) 504

Carlock Creek at Rt 774 at Chilhowie... (HOLSTON)

Carlock Creek trib at mouth ar Chilhowie.

$\begin{array}{ll}\text { (HOLSTON) } & 504 \\ \text { (ROANOKE) } & 409\end{array}$

Carlton Creek at mouth nr Eimo.

Carper Branch at mouth nr Highland.

Carr Creek at mouth nr Bolton.

Carter Creek at buoy 6 above mouth ar Irvington.

(NEW) 449

(HOLSTON) 522

(RAPP) 159

(YORK) 199

$\begin{array}{ll}\text { Carter Creek at mouth nr Clay Bank......... (YORK) } & 199 \\ \text { Carter Creek at mouth nr Irvington........ (RAPP) } & 159\end{array}$

Carter Creek at mouth nr White Marsh....... (YORK) 199
Carter Creek below Church Prong at Irvington.

Carter Creek, Eastern Branch. above mouth at Irvington.

(RAPP) 158

Carter Creek, Eastern Branch. at mouth at Irvington.

(RAPP) 158

Carter Hall Springs at Millwood.

(RAPP) 159

Carter Mill. Creek at mouth nr Huddleston.

(SHEN) 65

Carter Run above Carter Run

trib No. I nr Marshal1.

(ROANOKE) 378

Carter Run at Rt 688 nr Jeffersonton...

Carter Run at mouth or Jeffersonton.......... (RAPP) 119

Carter Run off Rt 691 nr Marsha11.............. (RAPP) 119

Carter Run trib No. 1 at $k$ t 719 at Marshall.

Carter Run trib No. 2 at Rt 721 nr Morgantown

(RAPP) 118

Carter Spring nr Saltville............(HOLSTON) 514

Carver Branch at Rt 600 nr Davenport. (BIG SANDY) 468

Carvers Branch at mouth nr Winterpock.... (JAMES) 277

Carvers Creek at mouth nr Saluda.....(RAPP-YORK) 160

Carvin Cove Reservoir nr Roanoke........ (ROANOKE) 365

Carvin Creek at Rt 115 at Hollins.......(ROANOKE) 365

Carvin Creek at Rt 1814 nr Cloverdale... (ROANOKE) 365

Carvin Creek at mouth nr Hollins....... (ROANOKE) 365

Carys Creek at mouth nr Crewe..........(CHOWAN) 322

Carys Creek at mouth $n \mathbf{r}$ Dixie............ (JAMES) 256

Cascade Creek above mouth nr Cascade... (ROANOKE) 405

Cascade Creek at Rt 855 at Cascade..... (ROANOKE) 404

Cascade Creek at Rt $860 \mathrm{nr}$ Cascade...... (ROANOKE) 404

Cascades Creek at Rt 687 at Callison..... (JAMES) 209

Cascades Spring at Healing Springs........ (JAMES) 208

Castle Run at mouth nr St. Paul.......... (CLINCH) 538

Castle Spring nr Churchuille................ SHEN) 34

Cat Point Creek at mouth nr Tappahannock. (RAPP) 152

Cat Point Creek below Rt 637 nI Montross.. (RAPP) 151

Catawba Creek at Catawba............... (JAMES) 220

Catawba Creek at Rt 600 nr Catawba.......... (JAMES) 220

Catawba Creek at Rt 606 nr Fincastle..... (JAMES) 220

Catawba Creek at Rt 626 at Clarkton.... (ROANOKE) 387

Catawba Creek at Rt 635 nr Fincastle...... (JAMES) 220

Catawba Creek at U.S. Hwy 220 n $F$ incastle.

(JAMES) 220

Catawba Creek at mouth at Clarkton..... (ROANOKE) 387

Catawba Creek at mouth at Salisbury....... (JAMES) 220

Catawba Creek nz Fincastle............ (JAMES) 220

Cate Branch above Rt 713 nr Yuma........(HOLSTON) 524

Cate Branch at mouth nr Yuma...........(BOLSTON) 524

Cate Branch trib at mouth nr Yuma........ (HOLSTON) 524

Catharpin Creek at U.S. Hwy 15 nr Haymarket.

Catharpin Creek at mouth nr Gainesville

(POTOMAC)

97

(YORK) 188

Catoctin Creek at Rt 663 at Taylortown.

Catoctin Creek at Rt $6 \overline{7} \dot{2}$

nr Point of Rocks Md ..... (POTOMAC)

Catoctin Creek at mouth nx Tay lorstown. (POTOMAC)

Catoctin Creek, N.F., at Rt 287 nr Hillsboro. nr Waterford. . (POTOMAC)

Catoctin Creek, N.F., at Rt $\dot{g}$

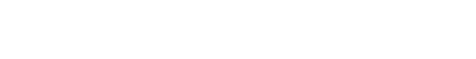

Catoctin Creek, N.F., at mouth

nr Waterford.......... at Purcellvilie..............

Catoctin Creek, S.F., at Rt 690 at Purcellville....

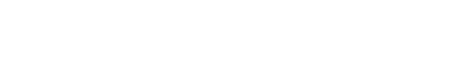

Catoctin Creek, S.F., at Rt 9 nr Hamilion................ (POTOMAC)

5


Abbreviated basin names appear at the end of the site name. Abbreviations are as follows: Eastern Shore (EASTERN); Potomac to Shenandoah (POT-SHEN); Shenandoah (SHEN); Potomac (POTOMAC): Potomac to Rappahannock (POT-RAPP); Rappahannock (RAPP); Rappahannock to York (RAPP-YORK); York (YORK) York to James (YORK-JAMES); James (JAMES); James to Chowan (JAMES-CHOWAN); Chowan (CHOWAN); Roanoke (ROANOKE); Yadkin (YADKIN); New (NEW); Big Sandy (BIG SANDY); Holston (HOLSTON); CIinch (CLINCH); POWel1 (POWELL)]

Catoctin Creek, S.F., at mouth nr Waterford. (FOTOMAC)

Cattail Branch at mouth nr Chancellorsville.

(YORK)

Cattail Branch at mouth nr Leesburg.... (POTOMAC)

Cattai 1 Creek above mouth nr Disputanta. (CHOWAN)

Cattail Creek at Hopewell............. (JAMES)

Cattail Creek at mouth nr Apple Grove..... (YORK)

Cattail Creek at mouth nr Dahlia........ (CHOWAN)

Cattail Creek at mouth nr Disputanta.... (CHOWAN)

Cattail Creek at mouth nr Montpelier...... (YORK)

Cattail Creek at mouth nr Purdy.......... (CHOWAN)

Cattail Creek at mouth nr Sanford.

Cattail Run above U.S. Bwy $1 / 460$

at Petersburg................ (JAMES)

Cattail Run at U.S. Hwy $220 \mathrm{nr}$ Bolar..... (JAMES)

Cattail Run at mouth at PetersburB...... (JAMES)

Cattail Swamp at mouth at Burdette...... (CHOWAN)

Cattall Swamp at mouth nr Quinton.

Cattail Swamp trib No. 1 at Rt 635 nr Burdette.

(YORK)

Cattail Swamp trib No, 2 at Rt 635 nr Burdette..........

(CHOWAN)

(CHOWAN)

Cattail Swamp trib No. 3 at Rt 635

(CHOWAN)

Cattle Creek at Rt 657 nr Beach.

(JAMES) 281

Cattle Creek at former mouth at Lake Chesdin.

(JAMES) 281

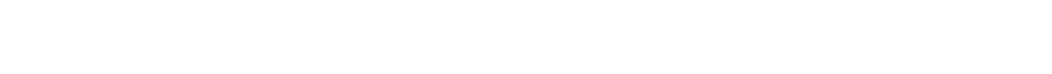

Cavitts Creek at Rt 16 at Tazewel1...... (CLINCH) 526

Cavitts Creek at mouth at Tazewe11...... (CLINCR) 526

Caynor lake above dam nr Culpeper.......... (RAPP) 128

Caynor lake at dam nr Culpeper............ (RAPP) 128

Caynor lake trib No. 2 nr Norman.......... (RAPP) 128

Caynor lake trib No. 2 tributary nr Norman.

(RAPP) 128

(RAPP) 128

(NEW) 452

Cecil Branch at mouth at Bane.

Cedar Bluff Creek at old U.S. Hwy ii nr Buchanan.

(JAMES) 222

Cedar Branch at mouth at Saltville..... (gOLSTON) 515

Cedar Branch at mouth nr Kelsa..... (BIG SANDY) 490

Cedar Creek above Rt 628 nr Winchester.... (SHEN) 61

Cedar Creek at Bath-Alleghany county line ni Natural We11........ (JAMES) 209

Cedar Creek at Gilmore Mills nr Natural Bridge............... (JAMES)

(JAMES) 223

Cedar Creek at Eoquoson............ (YORK-JAMES) 203

Cedar Creek at Red Mills Rd nI Natural Bridge................ (JAMES) 223

Cedar Creek at Rt $600 \mathrm{nr}$ Mt. Oijive......... (SHEN) 60

Cedar Creek at Rt 605 at Cailison.......... (JAMES) 209

Cedar Creek at Rt 610 nr Natural Bridge.. (JAMES) 223

Cedar Creeix at Rt 623 nr Marlboro......... (SHEN) 60

Cedar Craek at Rt 628 at Mar1boro........... (SHEN) 61

Cedar Creek at Rt $635 \mathrm{nr}$ Strasburg......... (SHEN) 61

Cedar Creek at Rt 706 nr Cedarville.... (8OLSTON) 506

Cedar Creek at U.S. Hwy 11 nr Meadowvilie................ (Holston)

Cedar Creek at U.S. Hwy ii nr Middi etown. (SHEN)

Cedar Creek at mouth nr Ashland......... (YORK)

Cedar Creek at mouth nr Blackstone....... (ChOWAN)

Cedar Creek at mouth nr Cedarville..... (HOLSTON)

Cedar Creek at mouth nr Center Cross....... (RARP)

Cedar Creek at mouth nI Natural We11.... (JAMES)

Cedar Creek at mouth nr Strasburg........ (SHEN)

Cedar Creek at mouth nI Toshes.......... (ROANOKE)

Cedar Creek nr Lebanon Church.

Cedar Creek, East Fork, at mouth at Cedarville.

(SHEN)

(HOLSTON)

Cedar Creek, West Fork, at mouth at Cedarville................. (GOLSTON)

Cedar Grove Branch at Rt 39

nr Rockbridse Baths.

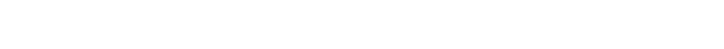

Cedar Run above Rt $678 \mathrm{nr}$ Warrenton.

Cedar Run at Auburn. .

(JAMES)

(RAPP)

(POTOMAC)

( POTOMAC)

506

506

209

61
Cedar Run at Forest Trail nr Syria.....

Cedar Run at Rt 603 nr Blacksburg...

Cedar Run at Rt 603 nr Catlett.

Cedar Run at Rt 611 nr Aden.

Cedar Run at Rt 619 at Brentsville.

Cedar Run at Rt 646 nr Aden...

Cedar Run at Rt $647 \mathrm{nr}$ Culpeper...

Cedar Run at Rt $672 \mathrm{nr}$ Warrenton.

Cedar Run at Rt 806 nI Catlett.

Cedar Run at U.S. Hwy 522 nI Culpeper.

Cedar Run at mouth at Brentsville...

Codar Run at mouth at Ellett. . .

Cedar Run at mouth nr Culpeper.

Cedar Run at mouth nr Grahans Forge.

Cedar Run at mouth nI Syria..

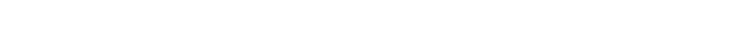

Cedar Run nr mouth nr Culpeper........... (RAPP)

Cedar Run trib No. 1 at Rt 645 nr Aden.

(POTOMAC)

Cedar Run trib No. i tributary at Rt $645 \mathrm{nr}$ Aden. .

(RAPP) 136

361

(POTOMAC) 92

(POTOMAC) 93

(POTOMAC) 93

(RAPP) 139

(POTOMAC)

(RAPP) 139

(POTOMAC) 93

(ROANOKE) 361

(RAPP) 139

(NEW) 438

136

93
139

92

Codar Run trib No 2 at $\mathrm{Rt} 645 \mathrm{nr}$ Aden. (POTOMAC)

Cedar Run trib No. 3 tributary at Rt $645 \mathrm{nr}$ Aden........... Run trib No. 3 tribi

(POTOMAC)

Codar Run trib No. 3 tributary

(POTOMAC)

Cedar Run trib No. 4 at Rt 611 nr Aden. (POTOMAC)

Cedar Run trib No. 5 at Rt 611 nr Aden. (POTOMAC)

Codar Run trib at U.S. Hwy 522 nr Culpeper

(RAPP) 138

Cedarbush Creek at mouth nr Ordinary...... (YORK)

Cedarville Spring at Cedarvilie........ (HOLSTON)

Cedarville Spring at Cedarville (SHEN)

Cellar Creek at Rt $610 \mathrm{nr}$ Spainville..... (JAMES)

Central Branch at mouth nr Zion Crossroads.

( $Y O R K)$

278

Chamberlains Bed Creek at mouth nr Dinwiddie.

(CHOWAN) 327

Chamblin Branch at Rt 605 nr Mount Weather.

(SHEN) 65

Champ Branch at mouth nr Hilton..... (HOLSTON) 522

Champion Swamp at mouth nI Smithfieid.... (JAMES) 304

Chances Branch at mouth at Ewing........ (POWELL) 563

Chandlers Mill Run above The Bis Swamp nr Montross.

(RAPP) 151

Chaney Creek above mouth ne South Clinchfield ...........(CLINCH)

Chaney Croek at Rt 615 nr South Clinchfield.

(CLINCA)

536

Chaney Creek at Rt 616 nr South Clinchfield.

(CLINCH)

536

Chaney Creek at mouth nr Carbo.

(CLINCH)

Chaney Croek at mouth nr Louisa.

Chaney Creek trib No. 1 at mouth nr South Clinchfield.

(YORK)

536

167

Chaney Creek trib No. 2 at mouth nr South Clinchfield

536

CIINCA

(YORK)

Chape 1 Creek at mouth nr Blakes........ (RAPP-YORK)

Chapel Swamp at ACL RR nI Somerton...... (CHOWAN)

Chapel Swamp at Rt 759 nr Somerton......(CHOWAN)

Chapel Swamp at mouth ni Somerton.

Chapel Swamp trib No. 1 at Rt 664 nr Somerton.

(CHOWAN)

Chapel Swamp trib No. 2 at Rt 664 nr Somerton.

(CHOWAN)

(CHOWAN)

Chappel1 Creek at mouth nr Hopewe $11 . .$. . (JAMES)

Chatman Branch at Rt 612 nr Drewryville. (CHOWAN)

Chatman Branch at mouth nr Drewryville.. (CHOWAN)

Cheatham Pond at outlet nI Williansburg... (YORK)

Cheese Creek at Rt 644 at Boonsboro...... (JAMES)

Cheese Creek at mouth nr Hodges......... (ROANOKE)

Cheneys Creek at mouth at Irwin.

Cherry Orchard Branch at mouth nr Templetan.

(CHOWAN)

. 63 .

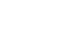

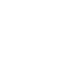

\section{6}

7

65
. 
Abbreviated basin names appear at the end of the site name. Abbreviations are as follows:

Eastern Shore (EASTERN); Potomac to Shenandoah (POT-SHEN); Shenandoah (SHEN); Potomac (POTOMAC);

Potomac to Rappahannock (POT-RAPP); Rappahannock (RAPP); Rappahannock to York (RAPP-YORK); York (YORK)

York to James (YORK-JAMES); James (JAMES); James to Chowan (JAMES-CHOWAN); ChOwan (CHOWAN); ROAnoke (ROANOKE);

Yadkin (YADKIN); New (NEW); Big Sandy (BIG SANDY); Holston (HOLSTON); Clinch (CLINCB); POwell (POWELI)]

Page

Cherrystone Creek above Tanyard Branch nr Chatham.

Cherrystone Creek above water intake

at Chatham. ..................... (ROANOKE)

(ROANOKE)

412

Cherrystone Creek at Rt $802 \mathrm{nr}$ Chatham. (ROANOKE)

Cherrystone Creek at Rt $964 \mathrm{nr}$ Chatham. (ROANOKE)

Cherrystone Creek at U.S. Hwy 29 at Chatham

(ROANOKE)

stone Creek at mouth nr Spring Garden.

(ROANOKE)

(ROANOKE) Chatham.

Cherrystone Creek below Tanyard Branch nr Chatham.........

(ROANOKE)

nr Cape Charles.

(EASTERN)

(EASTERN)

Cherrystone Inlet nr Cape Charles.

Cherrytree Branch at mouth nr Axton.... (ROANOKE)

Chesapeake Bay at Little Creek Channel nr Norfolk.

(JAMES-CHOWAN) 314

Chesconessex Creok at mouth at Chesconessex.

(EASTERN) 16

Chestrut Branch nr Forest at Goode...... (ROANOKE)

Chestrut Camp Branch at mouth $\mathrm{nr} \mathrm{Ka} . \ldots$ (CLINCH)

Chestrut Creek above Rt 89 at Galax........(NEW)

Chestnut Creek at Rt $602 \mathrm{nr}$ Fries........... (NEW)

Chestnut Creek at Rt $721 \mathrm{nr}$ Fries........... (NEW)

Chestrnut Creek at U.S. Hwy 221 at Galax.... (NEW)

Chestnut Creek at mouth nr Fries.......... (NEW)

Chestnut Creek nr Hickory Flat at Galax..... (NEW)

Chestnut Creek trib at mouth nr Galax....... (NEW)

Chestnut Iick at Rt $701 \mathrm{nr}$ Catharpin... (POTOMAC)

Chestnut Lick at mouth nr Catharpin.... (POTOMAC)

Chestnut Lick trib at Rt 701 nr Haymarket.

(

Chetocric Swamp at mouth nr Jarratt..... (CHOWAN)

Chickahominy River above Walkers Dam at Walkers.................. (JAMES) 29

Chickahominy River at I-295 nr Atiee..... (JAMES) 293

Chickahominy River at I-64 nr White Oak Swamp.

Chickahominy River at Rt 155 nr Providence Forge......

Chickahominy River at Rt 156 $n x$ Seven Pines............. (JAMES) 295

Chickahominy Rivar at Rt $609 \mathrm{nr}$ Roxbury. (JAMES) 296 Chickahominy River at Rt 615 at Highland Springs.

Chickahominy River at Rt 618

nr Providence Forge.
Chickahominy River at Rt 624 ne Farrington.

(JAMES) 295

Chickahominy River at Rt 625 $n=$ Glen Allen................ (JAMES) 292

Chickahominy River at Rt $626 \mathrm{nr}$ Eimont... (JAMES) 292

Chickahominy River at Rt 627 nr Richmond. (JAMES) 293

Chickahominy River at Telegraph Rd

Chickahominy River at U.S. Hwy $30 i$ nr At leo.

(JAMES) 292 ahominy River at u.s. Hwy 33

(JAMES) 293 nr Glen Allen............. 350

(JAMES) 292

Chickahominy River at U.S. Hwy 350 nr Mechanicsville........... nr White Oak Swamp............... (JAMES) 296

Chickahominy River at buoy io nx Centerville............... (JAMES) 300

Chickahominy River at mouth nr claremont. (JAMES) 300

Chickahominy River below Walkers Dam nr Walkars. .

(JAMES) 298

Chickahominy River nr Walkers............ (JAMES) 298

Chickahominy River trib No. 4 at Telegraph Rd nr Greenwood....... (JAMES) 293

Chickahominy River trib No. 4

at Greenwood................. (JAMES)
Chickahominy River trib No. 5

at Telegraph Rd nr Greenwood........ (JAMES) 293

Chickahominy River trib from I-95

At lee Rd interchange nr Greenwood. (JAMES) 292

Chickahominy River trib no. 1 at mouth $\mathrm{nr}$ Richmond.

Chickahominy River trib no. 2 at C\&O RR at Providence Forge..... (JAMES)

Chickahominy River trib no. 3 at Windsor Shades nr Walkers....... (JAMES)

Chickhominy River at Barretts Ferry Bridge (Rt 5) nr Claremont.

Childress Branch at mouth nr Isom.... (BIG SANDY)

Childrey Creek at mouth at Clarkton.... (ROANOKE) Chimey Branch at mouth nr Mack Craek Village.

Chimney Branch nr Vesuvius............. (JAINCR)

Chimney Rock Fork nr Rt 657 nr Ka....... (CLINCH)

Chincoteague Bay trib nr Horntown....... (EASTERN)

Chinquapin Swamp at mouth ne Waverly..... (CHOWAN)

Chisel Run at mouth nr Lightfoot......... (JAMES)

Chisholn Creek at mouth nr Laurel Fork..... (NEW)

Chisman Crook at mouth nr Poquoson. (YORK-JAMES)

Chisman Crook nr Seaford.

Chopawamsic Creek at U.S. Hwy 1 nr Quantico

(POTOMAC)

Chopawamsic Creek at mouth nr Quantico. (POTOMAC)

Chopawamsic Creek, Middle Fork, above Marine Rd nr Garrisonville.......

(POTOMAC)

Chopawamsic Creek, North Branch, above Marine Rd 1 nr Joplin........... (POTOMAC)

Chopawamsic Creek, South Branch

at mouth nr Joplin............. (POTOMAC)

Chopawamsic Creek, South Branch, bolow

Marine Rd 1 nr Garrisonville.... . (POTOMAC)

Chowan River above Buckhorn Creek nr Riddicksville, N.C........... (CHOWAN)

Christians Creek at Rt 254 nr Laurel tit Rt.

(SHEN)

(SHEN)

Christians Creak at Rt $612 \mathrm{nr}$ Verona....... (SHEN)

Christians Creek at Rt 794 nr Fishersville. ians Creek at U.S. Hwy ii nr Groenville.

Christians Creek at U.S. Hwy 250 nr Staunton............ $36{ }^{2}$ nr Stuarts Draft.

Christians Creek at mouth nr New Hope.............

Christians Cropk . New thope

Christopher Creek at Rt 613

nr Wares Crossroads.............. (YORK)

Christopher Creek at mouth nr Belmont..... (YORK)

Chub Run at mouth nr Stanley ............ (SHEN

Chub Run nr Stanley.................. (SHEN)

Chuckatuck Creek (Brewers Creek)

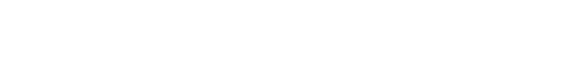
at Hobson.................... (JAMES)

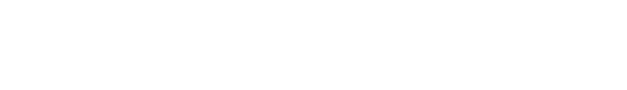
at Crittenden.

(JAMES )

Chuckatuck Creak at mouth nr Crittenden. (JAMES)

Chuckatuck Creek off Kings Point nr Crittenden.

( JAMES ) tuck Creek off Pike Point

at Crittenden.

Church Branch at mouth at Colonial Heights.

(JAMES)

Church Creek at mouth nr Silver Beach. . (EASTERN)

Church Rock Branch at mouth $\mathrm{nr} \mathrm{Ka} \ldots . .$. (CLINCH)

Church Run above Tomahawk Creek nr Orange. (YORK)

Church Run at Rt $631 \mathrm{nr}$ Orange........... (YORK)

Church Run at mouth nr somerset............ (RAPP)
Page

295 
Abbreviated basin names appear at the end of the site name. Abbreviations are as follows:

Eastern Shore (EASTERN): Potomac to Shenandoah (POT-SHEN): Shenandoah (SHEN); Potomac (POTOMAC):

Potomac to Rappahannock (POT-RAPP); Rappahannock (RAPP); Rappahannock to York (RAPP-YORK); York (YORK)

York to James (YORK-JAMES); James (JAMES); James to Chowan (JAMES-CHOWAN); Chowan (CHOWAN); ROanoke (ROANOKE);

Yadkin (YADKIN); New (NEW); Bis Sandy (BIG SANDY); Holston (HOLSTON); Clinch (CLINCH); Powell (POWELL)]

Church Swamp at mouth nI Church Viow. (RAPP-YORK) 160

Church Swamp at mouth nr Tappahannock..... (RAPP) 152

Clairborne Run at Rt 3 at Fredericksburg. (RAPP) 145

Clairborne Run at Rt 627 nr Fredericksburg................(RAPP) 145

Clairborne Run at U.S. Hwy 1 nI Eredericksburg................RAPP) 145

Clairborne Run at mouth at Fredericksburs .................(RAPP) 145

Clardie Creek at mouth nr Buffalo Springs

Clark Swamp at mouth nr Waikerton

Clarks Creek at mouth nr Ararat.

(ROANOKE) 415

(YORK) 195

Mr Ararat.......... (YADKIN) 426

Claxton Creok at mouth nr Seaford... (YoRk

Clay Branch at mouth or Pittsville.....(ROANOKE) 372

Claypool Branch above mouth nr Coulwood. (CLINCH) 534

Claypool Branch at Rt 647 nr Flatwoods.. (CLINCH) 534

Claypool Branch at mouth nr Coulwood.... (CLINCH) 534

Claytor Dam outfall (APCO) nr Radford...... (NEW) 444

Claytor Lake trib at Rt 611 nr Dublin....... (NEW) 444

Claytor Reservoir at Claytor Dam nr Radford........................................ 444

Clear Creek above Berry Run at Lahore....... (YORK) 168

Clear Creek at Rt 629 at Lahore........... (YORK) 168

Clear Creek at mouth at Bristol.........(HOLSTON) 510

Clear Creek at mouth at Norton........(CLINCH) 539

Clear Creek below Clear Creek Lake

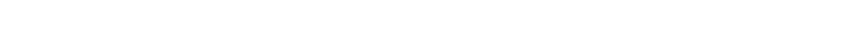

539

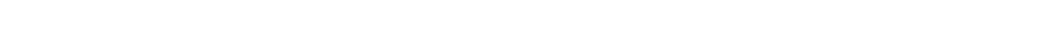

Clear Fork at mouth nI Galax.................(NEW) 430

Clear Spring Branch at mouth nx Dryden.. (POWELL) 557

Clearbrook Run at Rt 749 nI Stephenson............... (POT-SHEN) 24

Cleeks Mill Spring nz Bolar.

(JAMES) 205

Cleghorn Valley Creek at mouth

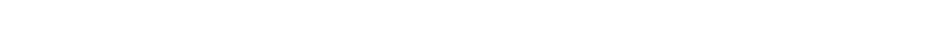

Clems Branch at mouth nr Flat Ridge........(NEW) 428

Clendennin Creek at mouth at Pearisburs.... (NEW) 453

Clifton Fork at mouth nr Keen Mountain.

Clinch River above Big Creok at Richlands. (CIINCH) 528

(BIs SANDY) 457

Clinch River above Bull Run nI St. Paul. (CLINCH) 538

Clinch River above Cedar Creek nr Coulwood.

Clinch River above Copper Creek

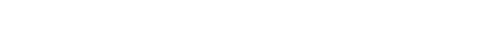

Clinch River above Guest River nr St. Paul.

Clinch River above Lincolnshire Branch at Tazewell. . itile River

(CIINCH) 532

(CLINCH) 548

CLINCH) 538 ni Honaker.

(CLINCH) 525

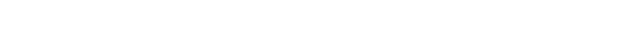
at Doran. (CLINCB) 529

Clinch River above Bium creek ir Tazewell.

(CLINCA) 526

Clinch River above Pounding Mill....... (CLINCH)

Clinch River above Pucketts Branch Ar Barnett.

(CLINCH) 532

Clinch River above Rt 84 ñ Cedar Biuff. (CLINCH) 527

Clinch River above Rts $661 / 664$ at Cleveland.................. (CINCH) 53

Clinch River above Town Hili Creek

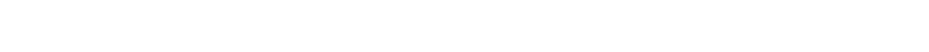

Clinch River along Rt 707 at Richlands.. (CLINCH) 528

Clinch River at Burtons Ford ne St. Paul.

(CLINCH) 538

Clinch River at Cinchport.

(CLINCH) 548

Clinch River at Daw nr Raven.......................... 529

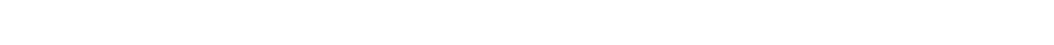

Clinch River at Nash Ford nr Artrip.......(CLINCH) 534

Clinch River at Rt 16 (Alternate) at Tazewe 11 .

(CLINCH) 526

Clinch River at Rt 253 nr St. Paul........ (CIINCH) 538

Clinch River at Rt 259 above Castlewood. (CLINCH) 537

Clinch River at Rt 263 below Carterton.. (CLINCH) 537

Clinch River at $\mathrm{Rt} 61$ at Tazewell.......(CLINCH) 525
Clinch River at Rt 619

at Fort Blackmore.

Clinch River at Rt 637 at Maxwell........ (CLINCH) 528

Clinch River at Rt 637

at Pounding Mil1................(CLINCH)

River at Rt 723 at Raven........(CLINCH) 529

Clinch River at Rt 80 at Blackford...... (CLINCH) 531

Clinch River at $\operatorname{STP}$ at Tazewell..........(CLINCH) 526

Clinch River at Speers Ferry Mil1 Dam above Speers Ferry.......(CIINCH) 549

Clinch River at Starnes Tunnel nr Hili.. (CLINCH) 547

Clinch River at U.S. Ewy 460 at Cedar Bluff...... (Alternate) at $\mathrm{St}$. Paul.......... (ClINCH) 538

Clinch River at Va.-Tenn. state line nr Fairview..........(CLINCE) 550

Clinch River at wittens Fort nr Tazewell.

(CLINCE) 526

Clinch River below Benges Creek nr Dungannon................ (CIINCE)

Clinch River below Benges Creek ar Wood. (CIINCE) 544

Clinch River below Lick Creek at Kerns. (CLINCH) 546

Clinch River below Mill Creek nr Raven.. (CLINCH) 529

Clinch River below Plum Creek na Tazewe 11 .

(CLINCE) 526

Clinch River below Rt 84 nr Cedar Bluff (CLINCB) 527

Clinch River below STP at Tazewell......(CLINCB) 526

Clinch Rivez below St. Paul............. (CLINCE) 538

Clinch River below U.S. Hwy 58 at Speers Ferry.....................

Clinch River below Weaver Creek at Artrip.......................

Clinch River below Wittens Fort nr Maxwell.......... Hij nr Tazewell.

(CLINCE) 549

$\ldots \ldots(\mathrm{CLINCH})$

535

Clinch River nr Hubbard Hill

526

Clinch River nr Bounding Mill. (CL INCH)

526

Ciinch River nI Rourkes Gap nr Maxwell. (CLINCB) 526

Clinch River nr Tazewell, Tenn.........(CIINCH) 552

Clinch River nr Wittens Fort ni Maxweil. (CLINCB)

Clinch River trib at Nash Ford (CLINCB)

Clinch River, N.F., above Dry Creek nI Pattonsville...............(CLINCB)

Clinch River, N.F., above trailer park STP at Pattonsville......... (CIINCE)

Clinch River, N.F., at Rt 61 at Tazewell

(CLINCH)

526

534

551

551

Clinch River, N.F., at Rt 621 nr Dona... (CLINCA)

Clinch River, N.F., at Rt 624 nI Pattonsville.... 638 I Pattonsville.

Clinch River, N.F., at U.S. Hwy 23 nI Duffield... . U.S. Hwys $58 / 42 i$ at Duffield.................... (CL INCB)

clinch River, N.F. at Va. -Tenn. State line at Dona............. (CLINCB)

Clinch River, N.F., at Wittens Milis nr Tazewel1.

Clinch River, N.F below Duffield........(CLINCE) 525

Clinch River, N.F.' trib No. 1 at mouth nr Tazewe11..

Clinch River, N.F., trib No. i at mouth nI Fairview.

Clinch River, N.F. , trib No, 2 above mouth in Pattonsville.......(CLINCg)

Clinch River, N.F., trib No. 2 at mouth nr Tazewell.

Clinch River, N.F., trib No. 3 at mouth ir Tazewell.

Clinch River, N.F. trib No. 4 at mouth or Tazewel1............(CLINCH) 
Abbreviated basin names appear at the end of the site name. Abbreviations are as follows:

Eastern Shore (EASTERN); Potomac to Shenandoah (POT-SHEN); Shenandoah (SHEN); Potomac (POTOMAC):

Potomac to Rappahannock (POT-RAPP); Rappahannock (RAPP); Rappahannock to York (RAPP-YORK); York (YORK);

York to James (YORK-JAMES); James (JAMES); James to Chowan (JAMES-CHOWAN); ChOwan (CHOWAN); Roanoke (ROANOKE);

Yadkin (YADKIN); New (NEW); Big Sandy (BIG SANDY); Holston (HOLSTON); Clinch (CLINCH); Powell (POWELL)]

Clinch River, N.F., trib No. 5 at mouth ar Tazewell.

525

Clinch River, N.F., trib No. 6 at mouth at Tazewell..........(CLINCH) 525

Clinch River, S.F., at Rt 61 at Tazewell

Clinch River, S.F., at U.S. Hwy is at Tazewe $11 \ldots \ldots \ldots \ldots$. . . . . . . . . . . 525

Clopton Swamp at mouth nr Quinton........... (YORK) 186

Clorence Dudding Spring nr Looney......... (JAMES) 217

Clover Creek at mouth nr Clover.........(ROANOKE) 392

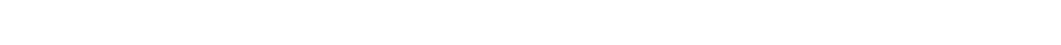

Coal Creek at mouth nr Galax....................... 431

Coal Run above Stony Run nr Stokesville... (SHEN) 25

Coalpit Branch above Rt. 657 nr Ka....... (CLINCH) 544

Coalpit Branch at mouth nr Ka............(CLINCH) 544

Coan Mill Stream nr Rowes Landing nI Heathville.

(POTOMAC)

113

Coan River at Walnut Point nI Lewisetta................... (POTOMAC) 113

Coan River at buoy is nr Bundick.........(POTOMAC) 113

Coan River at buoy $19 \mathrm{nr}$ Bundick.......(POTOMAC) 113

Coan River at buoy 21 at Bundick.........(POTOMAC) 113

Coan River at buoy $8 \mathrm{nr}$ Lewisetta....... (POTOMAC) 113

Coan River at mouth at buoy 6 at Lewisetta............... (POTOMAC) 113

Coards Branch at Rt 763 nr Parksley...(EASTERN) 17

Coards Branch at mouth nr Lee Mont...... (EASTERN) 17

Cobb Branch at mouth nr Drewryvilio......(CHOWAN) 334

Cobb Mill Creek at mouth at Oyster.....(EASTERN) 13

Cobbin Creek at mouth nr Beulahville..... (YORK) 193

Cobbs Creek at mouth nr Martinsvilie... (ROANOKE) 404

Cobbs Creek at mouth nr Wilton.......(RAPR-YORK) 161

Cochran Spring nr Middlebrook........... (SHEN)

Cockrell Creek above mouth nr Reedville.................. (POT-RAPP) 115

Cockrell Creek at end of Main st at Reedville..... (POT-RAPP) 114

Cockrell Creek at mouth at Fieeton..... (POT-RAPP) 115

Cockrell Creek off Cockrell Point

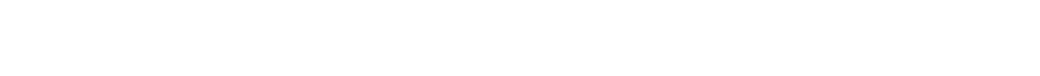

Cohoon Creek above spillway of Lake Cohoon nr Suffolk........... (JAMES) 306

Cohoon Creek nr mouth at Lake Cohoon...... (JAMES) 306

Coiner Spring No. 1 nr Waynesboro.......... (SHEN) 39

Coiner Spring No 2 nr Waynesboro.......... (SHEN) 39

Coiner Spring nr Waynesboro............. (SHEN)

Cold Spring Branch above Lake Gaston Gasburg.

(ROANOKE) 425

Cold Spring Branch nr Gasburg........... (ROANOKE) 424

Coldkall Creek at mouth nr Horntown..... (EASTERN) 11

Coldwater Creek at mouth nr Powellton... (CHOWAN) 354

Coleman Creek $0.2 \mathrm{mi}$ below U.S. Hwy 58 at Boydton

(ROANOKE)

421

Coleman Creek $0.4 \mathrm{mi}$ below U.S. Hwy 58 at Boydton................... at NFED RR nr Boydton...... (ROANOKE)

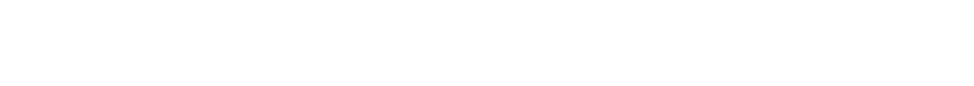

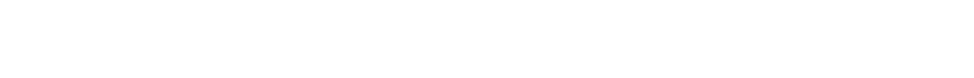

(ROANOKE)

421 421 (

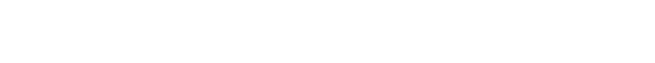

(ROANOKE) at The Ridge.

(ROANOKE)

421

Coleman Creek above NF\&D RR nir Boydton. (ROANOKE) 421

Coleman Creek at mouth nr Mayo .......... (ROANOKE)

Coleman Creek at mouth nx The Ridge.... (ROANOKE)

Coles Creek at mouth nr Retreat........ (ROANOKE)

Coles Run at mouth nr Drewrys Bluff...... (JAMES)

Coles Run nr Stuarts Draft............. (SHEN)

College Creek at Colonial Fkwy nr Williamsburg.

(JAMES) 301 College Creek at mouth nr Bacons Castle.. (JAMES) 301 College Run at mouth nr Bacons Castle.... (JAMES) 301 Collier Branch at mouth nr Dahlia.......(CHOWAN) 356 Colliers Creek at Rt 251 nr Collierstown. (JAMES) 230 Colliers Creek at Rt 644 at Collierstown. (JAMES) 230
Colliers Creek at R.t 770 at Collierstown. (JAMES) Colliers Creek at mouth nr Collierstown. (JAMES) Collins Run above Rt 614 nr Providence Forge............ (JAMES)

Collins Run at R.t 155 nr Providence Forge.

Collins Run trib at Rt 155 nr Providence Forge

(JAMES )

(JAMES )

Colvin Creek at mouth nr Barboursvilie.... (RAPP)

Colvin Run at Hunter Mill Rd

at Reston (nr Herndon)......... (POTOMAC)

Colvin Run at mouth nr Great Falis...... (POTOMAC)

Colvin Run trib below Wiehle Ave at Reston............ (POTOMAC)

Comers Branch at mouth at McCready...... (HOLSTON)

Comers Creek at mouth at Quebec......... (HOLSTON)

Comers Rock Branch at mouth nr Elk Creek... (NEW)

Conaway Creek at Rt 610 at Conaway,... (BIG SANDY)

Conaway Creek at mouth nr Bis Rock... (BIG SANDY)

Congers Creek at mouth at Goods Mili...... (SHEN)

Conley Swamp at mouth nr Morattico........ (RAPP)

Connellys Run at mouth at Radford............ (NEW)

Conners Creek at mouth at Woolwine..... (ROANOKE)

Contrary Creek (arm of Lake Anna)

above Freshwater Creek nr Mineral...(YORK) 170

Contrary Creek (arm of Lake Anna)

nr Mineral...............................

Contrary Creek $1.1 \mathrm{mi}$ below

U.S. Hwy 522 nr Mineral. ..........(YORK)

Contrary Creek $1.4 \mathrm{mi}$ above

U.S. Hwy $522 \mathrm{nr}$ Mineral............. (YORK)

Contrary Creek $2.0 \mathrm{mi}$ above

U.S. Hwy 522 nr Mineral...........(YORK)

Contrary Creek $2.1 \mathrm{mi}$ above

U.S Hwy 522 nr Mineral........... (YORK)

Contrary Creek $2.4 \mathrm{mi}$ above

U.S. Hwy 522 nr Mineral..........(YORK)

Contrary Creek $2.45 \mathrm{mi}$ above

U.S. Hwy 522 nr Mineral.

Contrary Creek $2.5 \mathrm{mi}$ above U.S. Hwy 522 nr Mineral.

Contrary Creek above Lake Anne nr Mineral.

Contrary Creek above unnamed trib at U.S. Hwy 522 nr Mineral.

Contrary Creek at North Anna River

Channel in Lake Anna........... (YORK)

Contrary Creek at Rt 652 nr Mineral........ (YORK)

Contrary Creei at Rt 680

nr Keen Mountain.......... (BIG SANDY)

Contrary Creek at U.S. Hwy 522 nr Mineral.

Contrary Creek at mouth nr Keen Mountain.

Contrary Creok below U.S. Hwy 522 nr Mineral.

(BIG SANDY)

Contrary Creek trib nr Minerai.

(YORK)

Contrary Swamp at mouth nr Upright... (RAPP-YORK)

Conway River at Rt $230 \mathrm{nr}$ Stanardsville... (RAPP)

Conway River at Rt $667 \mathrm{nr}$ Kinderhook....... (RAPP)

Conway River at Rt $667 \mathrm{nr}$ Stanardsvilie... (RAPP)

Conway River at mouth nr stanardsville.... (RAPP)

Conway River trib at Rt $667 \mathrm{nr}$ Kinderhook. (RAPP)

Cook Creek at mouth at Bonsack.

(ROANOKE)

Cook Fork above Boyd Fork nr Davenport.

(BIG SANDY)

Cooks Branch at mouth nr Darvi11s.....(CHOWAN)

Cooks Branch at mouth nr Smoky Ordinary. (CHOWAN)

Cooks Creek at Rt 257 at Mt. Crawford..... (SHEN)

Cooks Creek at Rt 701 at Dayton................. (SHEN)

Cooks Creek at Rt 701 nr Dayton........... (SHEN)

Cooks Creek at Rt 704 nr Dayton............ (SHEN)

Cooks Creek at Rt 732 at Dayton............. (SHEN)

Cooks Creok at Rt 867 at Mt. Crawford...... (SHEN)

Cooks Creek at U.S. Hwy 11 nr Mt. Crawford................... (SHEN)

Cooks Creek at mouth nr Mt. Crawford...... (SHEN)

Cooks Creek at mouth nr Orange............ (YORK)
230

230

298

297

298

134

77

77

77

514

493

463

37

155

448

397

171

170

170

170

170

171

171

457

170

457

170

170

133

133

133

133

133

366

467

327

333
31

30

30

30

30
31

30

31
166 
Abbreviated basin names appear at the end of the site name. Abbreviations are as follows:

Eastern Shore (EASTERN); Potomac to Shenandoah (POT-SHEN); Shenandoah (SHEN): Potomac (POTOMAC);

Potomac to Rappahannock (POT-RAPP); Rappahannock (RAPP); Rappahannock to York (RAPP-YORK); York' (YORK);

York to James (YORK-JAMES); James (JAMES); James to Chowan (JAMES-CHOWAN); Chowan (CHOWAN); Roanoke (ROANOKE);

Yadkin (YADKIN); New (NEW); Big Sandy (BIG SANDY); Holston (HOLSTON); Clinch (CLINCH); POWell (POWELL)]

Page

Cool Branch at mouth nr Penhook......... (ROANOKE)

Cool Spring Creek at mouth nr Chancellorsville.

Cooley Camp Branch at mouth nr Hayters Gap.

(YORK)

371

188

Coon Eranch at mouth nr Asberrys........ (HOLSTON)

Coon Branch at mouth nr Hinesvilie...... (ROANOKE)

Coon Branch at mouth nI Nora..........(BIG SANDY)

Coon Branch at mouth nr Wolford..... (BIG SANDY)

Coon Flat Branch nr Council........... (BIG SANDY)

Coppahaunk Swamp at Rt 615 nr Waveriy... (CHOWAN)

Coppahaunk Swamp nI Dendron........... (CHOWAN)

Copper Creek at Rt $619 \mathrm{nr}$ Gate City.

(CLINCH) 549

Copper Creek at Rt $627 \mathrm{nr}$ Speers Ferry.. (CLINCH)

Copper Creek at Rt 71 nr Nickelsville... (CLINCH)

Copper Creek at mouth nr speers Ferry... (CLINCH)

Copper Creek trib No. 1 at U.S. Hwy 58 (AIternate) nr Dickensonville..... (CLINCH)

Copper Creok trib No. 2 at mouth at Dickensonville.

(CLINCH)

Copperhead Branch at Rt 602 nr Council.

(BIG SANDY)

Corbin Creek at mouth nr West Point........ (YORK) nr Dungannon.

(CLINCH) 543

Corder Branch at mouth nr Coeburn...........(CLINCH) 543

Cormack Run at mouth nr Mine Run...........(RAPP) 140

Cornelius Creek at mouth nr Drewrys Bluff.

(JAMES) 268

Cornett Spring nr Atkins

Corrotoman River at mouth nr Irvington.... (RAPP)

Corrotoman River off Corrotoman Point nr Irvington

Corrotoman River, Eastern Branch

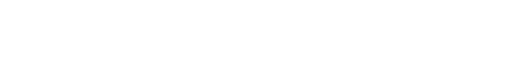
off Moran Wharf nr Irvington.......(RAPP) 158

Corrotoman River, Western Branch, at Rt 600 at Lancaster.....

Corrotoman River, Western Branch, at buoy 9 ir Irvington............ (RAPP) at buoy 9 nr Irvington.... off Bar Point nr Irvington.

Corrotoman River, Western Branch, trib at mouth nr Lancaster.

(RAPP)

Corrowaugh Swamp at mouth nr Waiters.... (CHOWAN)

Corrowaugh Swamp trib at Walters ........ (CHOWAN)

Coscorie Branch at Rt $35 \mathrm{nr}$ Courtland... (CHOWAN)

Cotton Creek at Rt 710 nr Palmer Springs............... (ROANOKE)

Cotton Creek at former mouth nr Bracey. (ROANOKE)

Couches Creek at Rt 667 at Victoria.....(CHOWAN)

Couches Creek at mouth nr Lunenburg..... (CHOWAN)

Count Branch at mouth

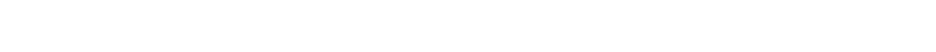

Coursey Spring nr Williansville.........(JAMES) 215

Courthouse Branch at mouth nr Amelia Court House............ (JAMES) 276

Courthouse Creek above Beaverdam Creek nr Goochland.......(JAMES) 261

Courthouse Creek above Glebe Creek at Charles City................ (JAMES) 290

Courthouse Creek at Rt 5 at Charles City. (JAMES) 290

Courthouse Creek at Rt 632 at Goochland. (JAMES) 261

Courthouse Creek at Rt 634 at Goochland. (JAMES) 261

Courthouse Creek at mouth at Charles City.

Courthouse Creek at mouth

nr King and Queen Court House.......(YORK) 196

Cove Branch at mouth nr Asberrys........ (HOLSTON) 513

Cove Creek above Duncan Branch

nr Stanleytown............... (CLINCH)

Cove Creek along Rt $722 \mathrm{nr}$ Stanieytown. (CLINCH)

Cove Creek at Earlehurst................ (JAMES)

Cove Creek at Rt 6 at Faber............... (JAMES)

Cove Creek at Rt 632 at $F$ aber............ (JAMES)
Cove Creek at Rt $65 \mathrm{nr}$ Stanleytown..... (CLINCH)

Cove Creek at Rt $803 \mathrm{nr}$ Hilton.........(HOLSTON) 520

Cove Creek at U.S. Hwy 29 nr Covesvilie.. (JAMES) 242

Cove Creek at U.S. Hwy 58 nr Muddy Gap nr Shelleys... (HOLSTON) 520

Cove Creek at U.S. HWy 58 nr Sheileys... (HOLSTON) 520

Cove Creek at mouth at Rockfish.......... (JAMES) 242

Cove Creek at mouth nr Maces Spring.... (HOLSTON) 521

Cove Creek at mouth nr Max Meadows.......... (NEW) 437

Cove Creek at mouth nr Shawver Mili........... (NEW) 454

Cove Creek nr Bristol................ (HOLSTON) 520

Cove Creek, West Fork, below Oneida Branch nr Bluefield...........(NEW) 454

Cove Run at Callaghan................... (JAMES) 210

Cove Run at mouth nr Craigsviije............. (JAMES) 225

Covington River at U.S. Hwys $211 / 522$ ne Spertrorille.

(RAPP) 125

Covington River at mouth ni Washingtion.... (RAPP) 125

Cow Branch at mouth nI Cascade......... (ROANOKE) 405

Cow Creek at mouth nr Republican Grove. (ROANOKE) 387

Cow Creek at mouth nr Ware Neck....... (RAPP-YORK) 164

Cow Fork at Va. -Ky. State line nr Breaks

(BIG SANDY) 487

Cowan Branch at mouth nr Wininger....... (HOLSTON)

Cowan Rose Creek at mouth nr Nora.... (BIG SANDY) 478

Cowan Rose Creek trib nr Nora........ (BIG SANDY) 478

Cowardin Run at mouth nr Bacova........... (JAMES) 208

Cowpasture River above

Jackson River at Iron Gate......... (JAMES) 216

Cowpasture River above Bullpasture River nr Williamsville........... ture River above nr McDowe 11

Cowpasture River along Rt 614 ar Flood...

Cowpasture River at Rt 39 nr Millboro Springs.

Cowpasture River at Rt 42

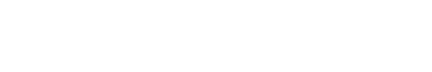

(JAMES)

214 below Liberty nr Williansville..... (JAMES) 214

Cowpasture River at Rt 614 above Stuart Spring nr Head Waters...... (JAMES)

Cowpasture River at Rt 616 below Shaws Fork nI McDowel1............ (JAMES) 213

Cowpasture River at Rt 625 nI Burnsville. (JAMES) 215

Cowpasture River at Rt 644 nr Nimrod Hall.

(JAMES) 216

Cowpasture River at Rt 655 nr Nimrod Hall . .

Cowpasture River at Rt 678 nr Green Valley..................JAMEs) 215

Cowpasture River at U.S. Hwy $2 \dot{5} \dot{0}$ nr Head Waters.

Cowpasture River below Bullpasture River at Williansville. (JAMES) 215

Cowpasture River below Rt 633 nr Clifton Forge.

(JAMES) 216

Cox Branch above Tazeweil Reservoir nr Gratton.

(NEW) 454

Cox Branch at mouth at Nebo........................... 512

Cox Branch at mouth nI Fairview.........(CLINCH) 551

Cox Creek at Rt 669 at Baskervilie...... (ROANOKE) 422

Cox Creek at mouth nr Bundy............... (PONELL) 557

Cox Creek at mouth nr Phillis................ (ROANOKE) 422

Cox Mill (Mill) Creek at Rt 664 nr Green Spring.

Cox Mill Creek at mouth ne Green Spring.

Crab Creek at U.S. Hwy 11 at Christiansburg.

Crab Creek at U.S. Hwy 460

at Christiansburg.

(NEW)

(NEW)

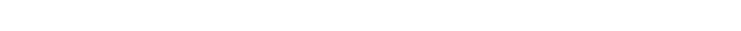

Crab Creek at mouth nr Snow Creek.........(ROANOKE) 374

Crab Creek trib at U.S. Hwy 11

nr Christiansburs

(NEW) 448

Crab Orchard Branch at mouth nr Coeburn. (CIINCH) 542 
Abbreviated basin names appear at the end of the site name. Abbreviations are as follows Eastern Shore (EASTERN); Potomac to Shenandoah (POT-SHEN); Shenandoah (SEEN); Potomac (POTOMAC); Potomac to Rappahannock (POT-RAPP); Rappahannock (RAPP); Rappahannock to York (RAPP-YORK); York (YORK); York to James (YORK-JAMES); James (JAMES); James to Chowan (JAMES-CHOWAN); Chowan (CHOWAN); Roanoke (ROANOKE); Yadkin (YADKIN); New (NEW); Big Sandy (BIG SANDY); Holston (BOLSTON); Clinch (CLINCH); POWell (POWELL)]

Crab Orchard Creek along Rt 605 nI Bland........................... 450

Crab Orchard Creek at U.S. Hwy 21 at Biand. (NEW) 450 Crab Orchard Creek at mouth at Huddlest on.

(ROANOKE) 378

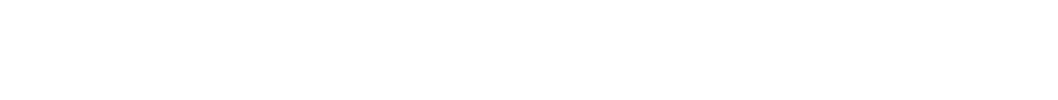

Crab Orchard Creek at mouth nr Bland........(NEW) 450
Crab Orchard Creek trib at Bland......... (NEW) 450
Crab Run along U.S. Hwy 250 nr McDoweii... (JAMES) 214

Crab Run along U.S. Hwy 250 nr MeDowe

Crab Rus at mouth at Bergton.

Crabbe Mill Stream at mouth at Feathsvilie..

(POT-RAPP) 114

Craborchard Creek at mouth in Keokee....(POWELL) 557

Crabtree Creek at mouth nr Nash.......(JAMES) 236

Craddock Branch at mouth nI Buffalo Junction............. (ROANOKE) 416

Craddock Creek at mouth

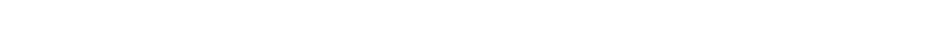

Craddock Creek at mouth nr Penhook...... (ROANOKE) 372

Craig Branch at mouth nr Ironto......... (ROANOKE) 361

Craig Creek above Muddy Branch nI McDoralds Mill.

. 311 n Abbott................ (JAMES) 217

Craig Creek at Rt 616 at New Castie....... (JAMES) 218

Craig Creek at Rt 685 at Eagle Rock........ (JAMES) 219

Craig Creek at Rt 705 at Oriskany...... (JAMES) 219

Craig Creek at mouth nr Eagle Rock........ (JAMES) 219

Craig Creek trib at Rt 606 nr New Castle.

(JAMES) 219

Craig Run at mouth nr Millwood............ (SHEN) 65

Craig Run at mouth nr Remington............(RAPP) 127

Cranberry Creek at mouth nr Hilisvilie.......(NEW) 440

Cranberry Cre日k at mouth nr Woodlawn........ (NEW) 432

Cranes Creek at mouth at Sandy Point.. (POT-RAPP) 114

Cranes Nest River $2.0 \mathrm{mi}$ above mouth nr Tarpon.

(BIG SANDY) 486

Cranes Nest River above Lick Fork

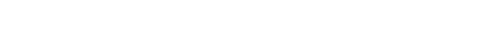

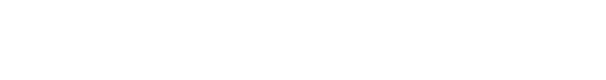

(BIG SANDY)

485

(BIG SANDY)

486

River at Flannagan

Reservoir at Tarpon.

(BIG SANDY) 486

nr Duncan Gap........

Cranes Nest River at Rt 83

nr Clintwood.

(BIG SANDY) 485

(BIG SANDY)

486

Nest River below
Clinchfield RR nr Clintwood.... (BIG SANDY)

Crany Creek at mouth nr Gloucester... (RAPP-YORK)

Crawford Creek at mouth nr Snow Creek...(ROANOKE)

Creasy Mill Creek at mouth at Stone Mountain. .

(ROANOKE) 378

(HOLSTON) 492

Cressy Creek trib at mouth

at Sugar Grove

(HOLSTON) 492

(JAMES) 270

$\begin{array}{ll}\text { Crewey Branch at mouth nr Broadford...... (BOLSTON) } & 513 \\ \text { Criddlin Swamp at mouth nr Tappahannock... (RAPP) } & 152\end{array}$

Crigger Creeik (Horns Branch) at mouth nr Cedar Springs.

(NEW) 434

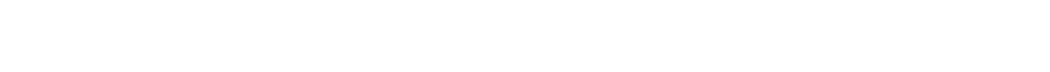

Cripple Creek at Rt $94 \mathrm{nr}$ Ivanhoe............(NEW) 434

Cripple Creek at mouth nr Ivanhoe...............WW) 434

Cripple Creek nr Cedar Springs............. (NEW) 433

Cripple Creek trib at Rt 749 at Cedar Springs.

(NEW) 433

Critical Fork at mouth ni i ipps

cromwells Run at Rt $715 \mathrm{nr}$ Rectortown... (POTCMAC) 69

is Run at mouth nr Middleburs.

Crook Branch at Morningside $D_{I}$ nI Fairfax

(POTCMAC)

Crook Branch at Prosperity Ave nr Fairfax.

(POTOMAC)

(POTOMAC)

(POTOMAC)
Crooked Branch above Lester Branch nI Vansant. .................... SIG SANDY)

Crooked Branch at mouth at Birchieaf. (BIG SANDY) 476

Crooked Branch at mouth nr Centralia..... (JAMES) 269

Crooked Branch at mouth nr Osceola.... (HOLSTON) 506

Crooked Creek at U.S. Hwy 58 at Woodlawn... (NEW) 432

Crooked Creek at mouth nr Blackstone.... (CHOWAN) 323

Crooked Creek at mouth nr Fries........... (NEW) 432

Crooked Creek at mouth nr North View.... (CHOWAN) 350

Crooked Creek at mouth nr Penns Store..(ROANOKE) 396

Crooked Creek at mouth nr South Hil1.... (CHOWAN) 350

Crooked Run above mouth nr Front Royai.... (SHEN) 64

Crooked Run at Quarry Rd at Riverton....... (SHEN) 64

Crooked Run at Rt $263 \mathrm{nr}$ Mt. Jackson.......(SHEN) 57

Crooked Run at Rt 618 nI Culpeper...........RAPP) 137

Crooked Run at Rt 639 at Nineveh (n) Reliance)

Crooked Run at U.S. Hwys $340 / 522$ at Riverton.

63

Crooked Run at mouth at Delapiane.

Crooked Run at mouth nr Musevilie........ (ROANOKE)

Crooked Run at mouth nr Rapidan..............(RAFP)

Crooked Run at mouth or Sandy River.... (ROANOKE)

Crooked Run nr Nineveh............... (SHEN)

Crooked Run trib at Rt 42 nr Conicvilie... (SHEN)

Cross Canal Ditch below Rt 1332 nr Holiy Grove, N.C........ (JAMES-CHOWAN)

Crow Run at Rt 159 nr tematite.......... (JAMES)

Croxton Stream above Jones Millpond nr Tappahannock.

(RAPP)

Crump Creek at Rt $605 \mathrm{nr}$ Crosses Corner... (YORK)

Crump Creek at mouth nr Crosses Corner.... (YORK)

Crump Creek trib No. 1 at mouth nr Crosses Corner............

Creek trib No. 2 at mouth nr Crosses Corner.......
swamp above U.S. Hwy 60

Crumps Swamp above

JAMES )

(CHOWAN)

Crupper Run at mouth nI Rehoboth.

Crystal Lake at Virginia Beach.

Cub Creek at Rt 40 at Phenix.

Cub Creek at Rt 615 nr Madisonville.... (ROANOKE)

Cub Creek at mouth $n$ r Crossroads......... (ROANOKE)

Cub Creek at mouth nr Dungannon.......... (CLINCH)

Cub Creek at mouth nr Bolly Grove........... (YORK)

Cub Run along U.S. Hwy 340 nr Grove Hiii.. (SHEN)

Cub Run at Braddock Rd nr Chantilly.... (POTOMAC)

Cub Run at Rt 658 ar Bull Run......... (POTOMAC)

Cub Run at U.S. Hwy so nr Chantiily.... (POTOMAC)

Cub Run at U.S. Hwys $29 / 211$ nr Centreville................. (POTOMAC)

Cub Run at mouth at Manas sas Park...... (POTOMAC)

Cub Run at mouth at Rocky Bar........... (SEEN)

Cub Run at mouth nr Grove Hi1i.............. (SHEN)

Cub Run nr mouth nr Rocky Bar............ (SHEN)

Cub Run trib at Rt 658 at Bul1 Rum.... (POTOMAC)

Cub Run trib at U.S. Hwy 33 at Montevideo. (SHEN)

Culbertson Branch at mouth n Nickelsville.

Cunningham Creek at Rt 660 nr Palmyra.... (JAMES)

Cunningham Creek at mouth at Palmyra..... (JAMES)

Cunningham Creek, M.F., above N.F Cunningham Creek nr Cunningham..... (JAMES)

Cunningham Creek, N.F., above M.F. Cunningham Creek nr Cunningham.... (JAMES)

Cunningham Creek, S.F., above M.F.

Cunningham Creek nr Cunningham..... (JAMES)

Curratuck Creek at mouth nr Craddocksville.

Curvin Harris Spring nr Councii.......(BIG SANDY)

Custis Creek at mouth nr Locustville... (EASTERN)

Cutter Creek at mouth ni Georges Fork.

ni Benns Church.. (JAMES) 304

Cypress Creek nr mouth at Smithfield..... (JAMES) 304 
Abbreviated basin names appear at the end of the site name. Abbreviations are as follows:

Eastern Shore (EASTERN); Potomac to Shenandoah (POT-SHEN): Shenandoah (SHEN); Potomac (POTOMAC);

Potomac to Rappahannock (POT-RAPP); Rappahannock (RAPP); Rappahannock to York (RAPP-YORK); York (YORK);

York to James (YORK-JAMES); Janes (JAMES); James to Chowan (JAMES-CHOWAN); Chowan (CHOWAN); Roanoke (ROANOKE)

Yadkin (YADKIN); New (NEW); Big Sandy (BIG SANDY); Holston (HOLSTON): Clinch (CLINCH); Powell (POWELL)]

Cypress Swamp at Rt 32

at Cypress Chapel.

Cypress Swanp at Rt 604

nr Cypress Chapei.

( JAMES-CHOWAN)

319

Cypress Swamp at Rt 616 nr E1beron.

Cypress Swanp at Rt 630 nr Elberon.

Cypress Swamp at Rt $635 \mathrm{nr}$ Burdette.

JAMES-CHOWAN )

(CHOWAN)

341

(CHOWAN) 345

(CHOWAN) 341

Cypress Swamp at mouth nr Dendron.

Cypress Swamp nr Cypress Chape1... (JAMES-CHOWAN)

Cypress Swamp trib No. 1 at White

Marsh Rd nr Cypress Chapel. (JAMES-CHOWAN) 319

Cypress Swamp trib No. 2 at

Desert Rd at Cypress Chapei. (JAMES-CHOWAN) 319

Cypress Swamp trib No. 3 at

Desert Rd at Cypress ChapeI. (JAMES-CHOWAN)

319

D. A. Fuffman Spring ne Kuffman.

(NEW)

450

D. J. Walker Spring nr Bastian.

(NEW)

453

Dalton Branch at Va.-W.Va. State line at Bishop.

(BIG SANDY)

488 Canal at Dan River Milis

(ROANOKE)

407

Dan River above Hyco. River

nr Buffalo Springs............. (ROANOKE) 415

Dan River above Sandy River

at U.S. Hwy 29 nr Danville.

(ROANOKE)

405

Dan River above mouth of Hyco River nr Buffalo Springs.

(ROANOKE) 415

Dan River at $N \& W R$ at South Boston.

(ROANOKE) 410

Dan River at Pinnacles of Dan gorge nr Kibler................... (ROANOKE) 394

Dan River at Reedy Isiand at Danvilie.. (ROANOKE) 407 Dan River at Rt 176 ne Mayfield N C.

Dan River at Rt 62 at Milto.............. (ROANOKE) 405

Dan River at Rt 658 at Paces.......... (ROANOKE) 409

Dan River at Rt 704

nr Francisco $N$.

(ROANOKE) 394

Dan River at Rt $745 \mathrm{nr}$ Meadows of Dan... (ROANOKE) 393

Dan River at Rt 804 at South Boston... (ROANOKE) 410

Dan River at STP nr Danvilie.......... (ROANOKE) 407

Dan River at Southern RR at Clarksvilia............... (ROANOKE) 418

Dan River at Southern $R R$ at Danvilie... (ROANOKE) 407

Dan River at Staunton River State Park nr Buffalo Springs

Dan River at U.S. Hwy 29 below

Dan River Canal at Danville...... (ROANOKE) 407

Dan River at U.S. Hwy 501

at South Boston............ (ROANOKE) 410

Dan River at U.S. Hwy $58 \mathrm{nr}$ Delila..... (ROANOKE) 408

Dan River at Va.-N.C. State inne nI Danvilie.

(ROANOKE) 408

Dan River below Fail Creek at Danville. (ROANOKE)

Dancing Creek at mouth nr Dutton..... (RAPP-YORK)

Daniel Branch at mouth nr Oak Grove........ (NEW)

(NEW) 432

Daniels Creek at mouth at Fieldale...... (ROANOKE) 401

Daniels Run at mouth at Caliaway........ (ROANOKE) 369

Daniels Run at mouth at Fairfax......... (POTOMAC) 86

Darden Mill Run at mouth nr Sunbeam...... (CHOWAN) 338

Darden Mi II Run trib No. 1 nr Sunbeam... (CHOWAN) 338

Darden Mill Run trib No. 2 nr Sunbeam... (CHOWAN) 338

Dark Run at mouth at Shawsvilie........ (ROANOKE) 359

Dark Run at mouth nr Madison............... (RAPP) 137

Dark Swamp at mouth nr Elberon............ (CHOWAN) 341

Dark Swamp at mouth ne Surfy....

Dave Branch at mouth at Grundy........ (BIG SANDY) 461

(JAMES) 301

Daves Branch at mouth nr Konnarock..... (HOLSTON) 496

David Creek at Bent Creek................ (JAMES) 236

Davis Creek at U.S. HWy $29 \mathrm{nr}$ Lovingston. (JAMES) 241

Davis Creek at Woods Mili nr Lovingston. (JAMES) 241

Davis Creek at mouth nr Cartersvilie.... (JAMES) 259

Davis Creek at mouth nr Mollusk........... (RAPP) 157

Davis Creek at mouth nr New Point..... (RAPP-YORK) 162
Davis Millpond at dam nr Lancaster.

Davy Land Branch at Forest Rd 700

nr Dungannon................. (CLINCH) 543

(RAPP) $\quad 157$

Dawkins Branch above mouth nr Bristow. (POTOMAC) 95

DeBusk Branch at mouth

nr East Stone Gap.

Dead Run at Churchill Rd at McLean...... (POTOMAC) 78

Dead Run at Old Dominion Dr at McLean.. (POTOMAC) 78

Dead Run at Old Georgetown Pike nr McLean.

(POTOMAC)

Dead Run at mouth $n \mathrm{r}$ Chantiliy......... (POLOMAC)

Dean Branch at mouth $n r$ Ivanhoe............ (NEW)

Deanes Branch at Rt 626 nr Driver......... (JAMES)

Deans Branch at mouth at Thomas Bridge. (HOLSTON)

Deep Branch at mouth $\mathrm{nr}$ Dory........... (CHOWAN)

Deep Creek above Rt $153 \mathrm{nr}$ Mannbaro...... (JAMES)

Deep Creek above Swift Creek Reservoir ar Hall sboro.

Deep Creek at Proyost ..........

Deep Creek at Rt $612 \mathrm{nr}$ Mannboro............ (JAMES)

Deep Creek at Rt $614 \mathrm{nr}$ Spainvilie........ (JAMES)

Deep Creek at Rt $619 \mathrm{nr}$ Crewe........... (JAMES)

Deep Creek at Rt $629 n=\mathrm{Irenholm} . . . \ldots \ldots$ (JAMES)

Deep Creek at Rt $630 \mathrm{nr}$ Crewe............ (JAMES)

Deep Creek at Rt $640 \mathrm{nr}$ Apple Grove........ (YORK)

Deep Creek at Rt 684 (Rt 27) nr Provost. (JAMES)

Deep Creek at VEPCO plant nr Ches apeake.. (JAMES)

Deep Creek at former mouth nr Hallsboro. (JAMES)

Deep Creek at mouth at Deep Creek...... (EASTERN)

Deep Creek at mouth at Newport News...... (JAMES)

Deep Creek at mouth $n x$ Apple Grove........ (YORK)

Deep Creek at mouth nr Mannboro.......... (JAMES)

Deep Creek at mouth nr Morattico............. (RAPP)

Deep Creek at mouth $n r$ Provost........... (JAMES)

Deep Creek trib No. 1 at Deep Creek...... (JAMES)

Deep Creek trib No. 2 at Deep Creek...... (JAMES)

Deep Run $0.5 \mathrm{mi}$ above Rt $708 \mathrm{nr}$ Grottoes.. (SHEN)

Deep Run at Rt $615 \mathrm{nr}$ Goldvein.......... (RAPP)

Deep Run at Rt 638 nr Brightwood.......... (RAPP)

Deep Run at Tuckahoe Village............ (JAMES)

Deep Run at U.S. Hwy $17 \mathrm{nr}$ Goldvein......... (RAPP)

Deep Run at mouth nr Fredericksburg......... (RAPP)

Deep Run at mouth nr Goldvein........... (RAPP)

Deep Run at mouth nr Lynnwood............ (SHEN)

Deep Run at mouth nr Madison.............. (RAPP)

Deep Run at mouth nr white Oak Swamp.... (JAMES)

Deepwater Creek at mouth nr Longshoal...... (NEW)

Deer Branch at mouth at Hollins........ (ROANOKE)

Deerlick Branch at mouth nr Richmond Heights.

Delaney Creek at mouth

nr Drakes Branch.

Den Creek at mouth at Eilett........... (ROANOKE)

Denton Valiey Creek at mouth nr Green Spring.

(HOLSTON)

Deskin Creek at mouth at Maxwe11........(CLINCH)

Desper Creek nr mouth nr Mineral.......... (YORK)

Devil Fork nr Rt 619 above mouth nr Ka.. (CLINCH)

Devils Branch at mouth $\mathrm{nr}$ Kelsa...... (BIG SANDY)

Devils Branch at mouth nr Wylliesburg.. (ROANOKE)

Devils Ditch at mouth nr Stanardsvilie.... (RAPP)

Devils Run at U.S. Hwy 522

$$
\text { nr Griffinsburg. }
$$

(RAPP) 122

Devils Run at mouth ne Griffinsburg.

Diascund Creek Reservoir above Rt 627 nr Walkers.

Diascund Creek Reservoir at spiliway

(JAMES)

122

Diascund Creek Reservoir off Beaverdan Creek nr Walk

Diascund Creek Reservoir of Timber Swamp $n r$ Walkers.......... (JAMES)

(JAMES)

Diascund Creek Reservoir off pump station nr Walkers.

(JAMES)

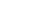

78

58

434

308

493

279

284

260

279
278

278

260

178

260

309

16

303

178

279
156

260

309

308
42

131

263

131

145

43

137
296

439

365

270

391

508

526

178
545

490

417

133 
Abbreviated basin names appear at the end of the site name. Abbreviations are as follows

Eastern Shore (EASTERN); Potomac to Shenandoah (POT-SHEN); Shenandoah (SHEN); Potomac (POTOMAC);

Potonac to Rappahannock (POT-RAPP); Rappahannock (RAPP); Rappahannock to York (RAPP-YORK); York (YORK)

York to James (YORK-JAMES); James (JAMES); James to Chowan (JAMES-CHOWAN); ChOwan (CHOWAN); Roanoke (ROANOKE);

Yadkin (YADKIN); New (NEW); Big Sandy (BIG SANDY); Holston (HOLSTON); Clinch (CLINCH); POWell (POWELL)]

Page

Diascund Creek at Forest Rd nr Walkers.. (JAMES) 298

Diascund Creek at Rt $627 \mathrm{nr}$ Walkers...... (JAMES) 298

Diascund Creek at Rt $628 \mathrm{nr}$ New Kent..... (JAMES) 298

Diascund Creek at mouth $n r$ Walkers........ (JAMES) 299

Dices Spring nr Burketown................ (SHEN)

Dick Branch above Fox Creek nr Murphy.

(BIG SANDY) 473

Dick Branch nr Murphy.

(BIG SANDY) 473

Dickens Craek at mouth ne. Holly Grove..... (YORK) 180

Dickerson Swamp at mouth ne Tunstall... (YORK) 186

Dickey Creek at Rt 16 at Sugar Grove... (HOLSTON) 492

Dickey Creek at mouth at Sugar Grove... (HOLSTON) 492

Dickeys Swamp above Dogwood Fork nr Millers Tavern.

(YORK) 196

Dickeys Swamp at Rt 14 nr St. Stephens Church.

(YORK) 196

Dickeys Swamp at Rt 620 nr Stevensvilie...(YORK) 196

Dicks Branch at mouth nr Disputanta..... (CHOWAN) 339

Dicks Creek at mouth at Maggie...........(JAMES) 218

Difficult Creak at Rt $7 \mathrm{nr}$ Reston...... (POTOMAC) 77

Difficult Creek at U.S. Hwy 360 nr Scottsburg.

(ROANOKE)

392

Difficult Creek at mouth nr Stone Mountain.

Difficult Creek at mouth nr Dryburg...

Difflcult Run at Rt 665 nr Fairfax. .

Difficult Run at Vale. Rd nr Vienna.

(ROANOKE) 378

(ROANOKE) 393

(POTOMAC) 76

(POTOMAC) 70

(POTOMAC) 76

Difficult Run at mouth nr Great Falls. . (POTOMAC)

Difficult Run below Rt 193 nr Great Falis................. (POTOMAC)

Dillard Creek at mouth nr Shipman........ (JAMES)

Dillons Mill Branch at mouth nr Burnt Chimey.

(ROANOKE)

Dilly Branch at mouth nr Barnett........ (CLINCH)
Ding Creek at mouth nr Holly Brook..... (NEW)
Dingus Branch at mouth nr Wood.

Dilly Branch at mouth nr Barnett........ (CLINCH)
Ding Creek at mouth nr Holly Brook..... (NEW)
Dingus Branch at mouth nr Wood.

Dingus Branch at mouth $\mathrm{nr}$ Wood.

Dinner Creek at mouth nr Penhook.

(ROANOKE)

Dismal Creek above Mi11 Branch nr Oakwood.

(BIG SANDY)

Dismal Creek at Rt 638 at Whitewood.. (BIG SANDY)

Dismal Creek at Rt 666 nr Oakwood... (BIG SANDY)

Dismal Creek at mouth nr Holly Brook....... (NEW)

Dismal Creek at mouth nr Oakwood..... (BIG SANDY)

Dismal Swamp Canal at Va.-N.C.

State line nr Lake Drummond. (JAMES-CHOWAN)

Dismal Swamp Canal trib No. 10 nr Deep Creek.

(JAMES)

Dismal Swamp Canal trib No. is nr Deep Creek............. (JAMES-CHOWAN)

Dismal Swamp Canal trib No. 3 nr Deep Creak.

Dismal Swamp Canal trib No. nr Deep Creek..............

Dismal Swamp Canal trib No. 6 nr Deep Creek. . W No. nr Deep Creek. ........ nr Deop Creok..........
Swamp Canal trib no. Desert Rd nr Cypress Chapel. (JAMES-CHOWAN)

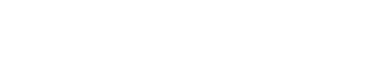

(JAMES) 309

\section{Dismal Swamp Canal trib no
nr Deep Creek......
Dismal Swamp trib No. I at}

Dismal Swamp trib No. 2 at Desert Rd at Cypress Chape 1. (JAMES-CHOWAN)

Dismal Swamp trib No. 3 at Desert Rd nr Cypress Chape1. (JAMES-CHOWAN)

Dismal Swamp trib No. 4 at Desert Rd nI Cypress Chape 1. (JAMES-CHOWAN)

Dismal Swamp trib No. 5 at Desert Rd nr Cypress Chapel. (JAMES-CHOWAN)

Dismal Swamp trib No. 6 at

Desert Rd nr Cypress Chape1. (JAMES-CHOWAN)

District Home Spring at Waynesboro........ (SHEN)

Ditch Creek at mouth nr Stuart.......... (ROANOKE)

Ditto Branch at mouth $n r$ Sago.......... (ROANOKE)

Dividing Branch at Rt $632 \mathrm{nr}$ Yale....... (CHOWAN)

532

544

320
Dividing Branch at mouth nr Red House. (ROANOKE) Dividing Creek at mouth $\mathrm{nr}$ Ditchley... (POT-RAPP) Dixon Creek at mouth nr West Point........ (YORK) Dobbins Creek at mouth nr Eloyd........... (NEW)

Dobie Swamp (Dicks Branch) at mouth nr Newville................ (CHOWAN)

Dockery Creek nr Smiths Crossroads..... (ROANOKE) Dockman Swamp above Rt 614 nr Providence Eorge.

(JAMES) 298

Dodd Cren at 8th St at Arlington...... (POTOMAC)

Dodd Creek at Rt $8 \mathrm{nr}$ Floyd.............. (NEW)

Dodd Creok trib at Rt 8 nr Floyd............ (NEW)

Dodge Spring Run nr Stuarts Draft.......... (SHEN)

Dodge Spring nr Stuarts Draft........... (SHEN)

Dodson Branch at mouth $\mathrm{nr}$ Boydton...... (ROANOKE)

Doe Creek at mouth at Pembroke........... (NEW)

Doo Creek at mouth nr Hopkins ........... (EASTERN)

Doe Run at mouth $n=$ Sontag........... (ROANOKE)

Dog Branch at mouth $n r$ Philomont....... (POTOMAC)

Dog Creek at mouth nr Brookneal......... (ROANOKE)

Dog Run above STP nr Berryville........... (SHEN)

Dog Run at Rt $608 \mathrm{nr}$ Berryvilio.......... (SHEN)

Dog Run at Rt $621 \mathrm{nr}$ Berryvilio............. (SHEN)

Dog Run at STP nr Berryville........... (SHEN)

Dog Run at mouth nr Berryvilio........... (SHEN)

Dog Run at mouth nr Reston.

Dogue Creek East trib at Patton Blvd nr Accotink.

(POTOMAC)

( POTOMAC)

Dogue Creek East trib at Pole Rd nr Gum Springs

Dogue Creek East trib at U.S. Hwy 1 nr Accotink.

(POTOMAC)

Dogue Creek West trib at Telegraph Rd nI Accotink.

(POTOMAC)

(PotOMAC)

Dogue Creek at Rt $623 \mathrm{nr}$ Accotink....... (POTOMAC)

Dogue Creek at Telegraph Rd nI Franconia................. (POTOMAC)

Dogue Creek at U.S. Hiwy 1 nr Accotink. (POTOMAC)

Dogue Creek at mouth nr Accotink....... (POTOMAC)

Dogue Run above Keys Run nr Port Royal... . (RAPP)

Dogwood Fork at mouth nr Millers Tavern. . (YORK)

Dollins Creek at Rt $635 \mathrm{nr}$ Crozet........ (JAMES)

Donald Branch at mouth nr Flat Gap... (BIG SANDY) Donaldson Run at Military Rd at Arlington................ (POTOMAC)

Dorrell Creek at mouth nr Beulahville..... (YORK)

Dorrells (Darrels) Run at mouth nr Aden.

Dorton Hollow trib at Rt 600 nr South Clinchfiold.

Dotson Creek at mouth nI Duncan Gap.. (BIG SANDY)

Double Branch at mouth at Clays Mi11... (ROANOKE)

Double Branch at mouth nI Cherry Hili.. (CHOWAN)

Double Creek at mouth nr Sutherlin..... (ROANOKE)

Double Spring Branch above

Blackwell Branch at Blackwe11.... (HOLSTON)

Douglas Creek at North Anna River Channel in Lake Anna.

(YORK)

Douglas Run at mouth nr Emporia .......... (CHOWAN)

Douthat Lake nr Clifton Forge........... (JAMES)

Dove Fork at mouth nr Boswelis Tavern..... (YORK)

Dover Creek above Little River at Sabot.

(JAMES)

Dover Creek at Rt 6 at Sabot.

(JAMES)

Dowel1 Branch at mouth nr Hilton....... (HOLSTON)

Doyles River at Rt 629 at Browns Cove.... (JAMES)

Doyles River at Rt $810 \mathrm{nr}$ White Hall..... (JAMES)

Doyles River at mouth nr white gall...... (JAMES)

Drag Creek at mouth nr Spray, N.C...... (ROANOKE)

Dragon Run at mouth $n r$ Upright....... (RAPP - YORK)

Dragon Swamp at Rt 602

nr Church View.
Page

388

115

197
445

331

422

98

80
445

445

445

38
38

420

450

16
373

70

386

65
65

65

65

65
77

86

86

86

85

85

86

85

86

86
148

196

247

481

194

535

485

485

482
392

$32 B$

408

516

171

355

175

262

262

521

250
250

250

404
160

160 
Abbreviated basin names appear at the end of the site name. Abbreviations are as follows:

Eastern Shore (EASTERN); Potomac to Shenandoah (POT-SHEN); Shenandoah (SHEN); Potomac (POTOMAC);

Potomac to Rappahannock (POT-RAPP): Rappahannock (RAPP); Rappahannock to York (RAPP-YORK); York (YORK) :

York to James (YORK-JAMES); James (JAMES); James to Chowan (JAMES-CHOWAN); Chowan (CHOWAN); Roanoke (ROANOKE);

Yadkin (YADKIN); Now (NEW); Big Sandy (BIG SANDY); Holston (HOLSTON); Clinch (CLINCH); Powall (POWELL)]

Dragon Swamp at Rt 603 at Mascot..... (RAPP-YORK)

Dragon Swamp at U.S. Hwy 17

$$
\text { nr Saluda. }
$$

(RAPP-YORK) 160

Drakes Branch at mouth nr Ėairviow........(CLINCH) 551

Draper Mill Creek at mouth

$$
\text { nr Dickinson. }
$$

(ROANOKE) 373

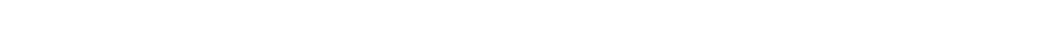

Drinking Swamp at mouth nr Haymesvilie.....(RAPP) 154

Drum Point Creek at Boone............... (JAMES) 311

Drum Point Creek trib No. 1 at Boone...... (JAMES) 312

Drum Point Creek trib No. 2 nr Boone...... (JAMES) 312

Drum Point Croek trib No. 2 tributary nr Boone

Dry Branch at U.S. Hwy 23 nr Duffield... (CLINCH) 550

Dry Branch at mouth nr Saint Clair Bottom............ (HOLSTON) 494

Dry Branch at mouth at ELk Garden....... (CLINCH) 532

Dry Branch at mouth at Nebo............ (HOLSTON) 512

Dry Branch at mouth at Pennington Gap... (POWELL) 560

Dry Branch at mouth at Sheva...........(ROANOKE) 412

Dry Branch at mouth nr Allisonia........... (NEW) 440

Dry Branch at motth nr Atkins........... (HOLSTON) 500

Dry Branch at mouth nr Caylor..............(POWELL) 563

Dry Branch at mouth nr Criglersville......(RAPP) 136

Dry Branch at mouth nr Duffield.........(CLINCH) 550

Dry Branch at mouth nr Duncanvilie...... (HOLSTON) 517

Dry Branch at mouth nr Glenvar.......... (ROANOKE) 362

Dry Eranch at mouth nr Maces Spring.... (HOLSTON) 521

Dry Branch at mouth $\mathrm{nr}$ McCoy ................ (NEW) 449

Dry Branch at mouth nr Murrayfield....... (HOLSTON) 494

Dry Branch at mouth nr Mustoo.............. (JAMES) 205

Dry Eranch at mouth nr Rose Hili.......... (EOWELL) 563

Dry Branch at mouth nr Sonans........... (ROANOKE) 413

Dry Branch at mouth nr Tumbling Creek... (HOLSTON) 516

Dry Creek (Pattonsvilie Branch) nr Pattonsville..............(CLINCH)

Dry Creek above U.S. Hwy 360 ne Winterpock.

(JAMES) 285

Dry Creek above mouth nr Hailisboro.......... (JAMES) 286

Dry Creek above mouth nr Smiley......... (POWELL) 562

Dry Creek at Rt 635 nr Farmvilie............. (JAMES) 272

Dry Creek at former mouth in

Swift Creek Reservoir nr Hallsboro. (JAMES) 286

Dry Creek at mouth at Dungannon..........(CIINCH) 543

Dry Creek at mouth at Stanleytown......... (CLINCH) 546

Dry Creek at mouth at Stickleyvilie...... (POWELL) 561

Dry Creek at mouth nr Burkeville......... (CHOWAN) 322

Dry Creek at mouth nr Codar Springs......... (NEW) 434

Dry Creek at mouth nr Mayo.............. (ROANOKE) 416

Dry Creek at mouth nr Pattonsviile.........(CLINCH) 551

Dry Creek below Kinzer Hollow nr Smiley. (POWELL) 562

Dry Creek below U.S. Hwy 360 nr Hallsboro...................... JAMES)

Dry Croek below West Branch nr Hailisboro. (JAMES)

Dry Creek nr Clover Hill High School ne Hallsboro.

(JAMES) 285

Dry Croek ne Rt 602 ni Stanieytown........ (CLINCH)

Dry Creek trib No. 1 (Ashbrook Creek) nr Winterpock

(JAMES) 285

ry Fork along Rt 627 nr Vansant.... (BIG SANDY) 450

Dry Fork at Rt 627 at Vansant.

Dry Fork at Rt 637 at Va. $-\mathrm{W}$. Va State line nr Amonate.

Dry Fork at Rt 653 nr Mabe (BIG SANDY) 460

Dry Fork at Rt 806 nr Lacey

Dry Fork at Rt 866 above mouth nr Mount Hermon.

Dry Fork at mouth at Lacey Spring

Dry Fork at mouth at North Gap..

Dry Fork at mouth at Vansant.

Dry Fork at mouth nr Chatham.

(BIG SANDY)

(BIG SANDY)

(CLINCH) 547

(SHEN) 56

Dry Fork at mouth in Mabe.

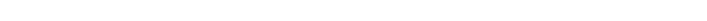

Dry Mili Branch along Rt. 699 nr Leesburg.

Dry MiIl Branch at mouth at Leesburs.
(ROANOKE) 406

(SHEN) 56

(NEW) 454

(BIG SANDY) 450

(ROANOKE) 411

(POT-SHEN) 24

( POTOMAC)

(POTOMAC)
Dry Mountain Creek at mouth at Long Island.

(ROANOKE) 383

Dry River $0.9 \mathrm{mi}$ below Harrisonburg Reservoir nr Rawley Springs.

Dry River above Harzisonburg Reservoir n. R Rawley Springs

Dry River at Rt 257 at Bridgewater.............. (SHEN)

Dry River at Rt 613 nr Rawley Springs..... (SHEN) 27

Dry River at Rt 847 at Rawley Springs..... (SHEN)

Dry River at mouth at Bridgewater......... (SHEN)

Dry River off U.S. HWy 33 nr Rawley Springs.

( $S H E N$ )

ry Run at Rt $624 \mathrm{nr}$ McClung................... (JAMES)

Dry Run at Rt $625 \mathrm{nr}$ McClung................. (JAMES)

Dry Run at mouth at Compton.............. (SHEN)

Dry Run at mouth nr Elkton.............. (SHEN)

Dry Run at mouth nr Green Spring........ (HOLSTON)

Dry Run at mouth nr Luray................ (SHEN)

Dry Run at mouth nr MCCluns............. (JAMES)

Dry Run at mouth nr Speedwe $11 \ldots \ldots \ldots \ldots$ (NEW)

Dry Run nr Burnsville.

(JAMES)

Dry Run nr Groseclose.................. (HOLSTON)

Dry Run trib at mouth nr Groseclose... (HOLSTON)

Dry Run, N.F., at Rt 669 nr Thornton Gap.. (SHEN)

Dry Run, S.F. at Rt 696 nr Fairview..... (SHEN)

Duck Run at mouth at Goods Mill........... (SHEN)

Duck Run at mouth nr Mountain Eaiis.......... (SHEN)

Ducker Creek at mouth nr Prospect........ (JAMES)

Duckinghoe Creek at Rt 613 nr Wares Crossroads.

Duckinghoe Creek at mouth nr Beimont........ (YORK)

Ducks Swamp at mouth nr Walters........ (CHOWAN)

Duffy Branch at mouth nr Sago...

(ROANOKE)

Dukes Branch at mouth nr Edgerton.

(CHOWAN)

(RAPP)

Dumplin Branch at mouth nr Ammon......... (JAMES)

Dumps Creek at $\mathrm{NSW}$ RR at Carbo.......... (CLINCE)

Dumps Creek at Rt 500 nr South Clinchfield............ (CLINCH)

Dumps Creek at mouth at Carbo.......... (CIINCH)

Dumps Creek below Laurel Branch nI South Clinchfield.

(CL INCH) Creek trib No. 1 at mouth nr South Clinehfield.

(CLI NCH)

(CLINCE) nr South Clinchfield.

(CLINCH) Creek trib No. 3 at it 600 nr South Clinchfield.

Duncan Branch at Duncan Mil1 nI Stanleytown

(CLINCE)

Dunlap Creek at $R$ t 159 nr Hematite........ (JAMES)

Dunlap Creek at U.S. HWy 60 at Covington

Dunlap Creek at U.S. Hwy 60 nr Callaghan........

(JAMES )

(JAMES) 210 nr Covington.

(JAMES )

Dunlap Creek at mouth at Covingtor.

Dunnavant Creek (Snoppersons Creek) at mouth nr Eureka.

Dunns Spring at Mitchelltown

(ROANOKE) 389

Dutch Creek at mouth at Rockfish.

(JAMES) 206

Dutch Hollow Branch at Rt 724 nr Brownsburg

(JAMES) 242 ans Creeic at $\mathrm{Rt} \quad \dot{674}$ nr Lovettsuilie.

(JAMES) 226

Dutchmans Creek at mouth nr Lovettsville.

(POTOMAC)

Duty Creok at mouth nr Fine Creek Mills.. (JAMES)

Dyer Creek at mouth nr New Point..... (RAPP-YORK)

Dymer Creek above mouth nr Ki lmarnock.

(POT-RAPE)

Dymer Creek at Rt 200 nr Kilmarnock... (POT-RAPP)

Dymer Creek at mouth nr Eoxwells...... (POT-RAPP)

Dymer Creok below Rt 200 nr Ki Imarnock. 
Abbreviated basin names appear at the end of the site name. Abbreviations are as follows:

Eastern Shore (EASTERN); Potomac to Shenandoah (POT-SHEN); Shenandoah (SHEN); POtomac (POTOMAC)

Potomac to Rappahannock (POT-RAPP); Rappahannock (RAPP); Rappahannock to York (RAPP-YORK); York' (YORK)

York to James (YORK-JAMES); James (JAMES); James to Chowan (JAMES-CHOWAN); Chowan (CHOWAN); Roanoke (ROANOKE);

Yadkin (YADKIN); New (NEW); Big Sandy (BIG SANDY); Holston (HOLSTON); CIinch (CLINCH); Poweli (POWELL)]

Page

Eagle Botton Creek at mouth at Fries....... (NEW) 430

Early Run nr mouth at Lake Kilby.......... (JAMES) 306

East Back Creek along Rt 84 nr Mustoe.... (JAMES) 206

East Back Creek at mouth nr Mustoe........ (JAMES) 206

East Branch at mouth nr Cascade........ (ROANOKE) 404

East Branch at mouth nr Wilmington........ (JAMES) 257

East Dry 8ranch at mouth nr Churchvilie... (SHEN) 33

East Flume of Dunlop Mills at Richmond... (JAMES) 266

East Fork above confluence with West Fork nr Galax.

(NEW) 431

East Fork at mouth nI Atkins.

East Fork at mouth nr Hillsville. (HOLSTON) 500 (NEW) 440

(HOLSTON)

East Fork at mouth nr Woodlawn............ (NEW)

East Little Seneca Creek at mouth n Gladys

(ROANOKE)

East Prong (Branch) at mouth nr Midway. (ROANOKE)

East Prong above West Prong nr Floyd....... (NEW)

East River above mouth at Glen Lyn.......... (NEW)

East River at buoy 12 nr Mathews...... (RAPP-YORK)

East River at buoy 5 nr Mobjack...... (RAPP-YORK)

East River at buoy $7 \mathrm{nr}$ Mobjack........ (RAPP-YORK)

East River at buoy $9 \mathrm{nr}$ Mathews....... (RAPP-YORK)

East River at mouth at Glen Lyn............ (NEW)

East River at mouth at Mobjack....... (RAPP-YORK)

East River off Williams Wharf

East Run at Rt 609 at Barnotts.......... (JAMES)

East Run at mouth at barnetts........... (JAMES)

East Sappony Cre日k at mouth

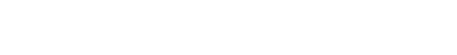

East Wilderness Creek at mouth nr Holly Brook .................. (NEW)

Easter Creek at mouth nr Copper $\mathrm{Valiey} \ldots \ldots$ (NEW)

Eastland Creek at mouth nr Boydton..... (ROANOKE)

Eckels Branch at mouth at Pilot.......... (NEW)

Eddington Branch at mouth nr Hayters Gap.

(HOLSTON

Edwards Creek at mouth nr Ankum........... (CHOWAN)

Edwards Creek at mouth nr New Design... (ROANOKE)

Eidson Creek at Rt 254 nr Churchville.....(SHEN)

Eidson Creek at Rt 703 at Hebron nr Swoope.

Eidson Creek at mouth nr West vi ew........ (SHEN)

Elder Swamp at mouth nr Seven Pines...... (JAMES)

Elizabeth River at Army base STP

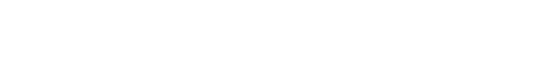

Elizabeth River at Craney Isiand

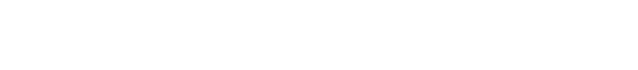

(JAMES )

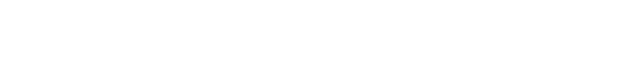

Elizabeth River at Pinner Point ST nr Portsmouth.........

\section{STP}

Elizabeth Rever at
Degausing Station at West Norfolk.

Elizabeth River at Western Branch STP at West Norfolk................ (JAMEs) 312

Elizabeth River at confluence with Scott Creok at Portsmouth..... (JAMES) 311

Elizabeth River at confluence of Southern 8ranch at Norfolk........ (JAMEs) 311

Elizabeth River at confluence with Western Branch nr West Norfolk..... (JAMES) 312

Elizabeth River at mouth nr Norfolk....... (JAMES) 313

Elizabeth River, Eastern Branch, at Norfolk. ................

Elizabeth River, Eastern Branch, a Berkley Bridge at Norfolk.... Ford Park at Norfolk.

$\begin{array}{ll}\ldots \ldots \ldots \text { (JAMES) } & 311 \\ \ldots \ldots \text { (JAMES) } & 311\end{array}$ Ford Park at Norfolk...........

Elizabeth River, Eastern Branch, at N\&W RR at Norfolk.

(JAMES) 311

Elizabeth River, Eastern Branch, at Rt 165 at Virginia Beach..........(JAMES) 310
Elizabeth River, Eastern Branch, at U.S. Hwy 13 at Norfolk. Elizabeth River, Eastern Branch, at U.S. Hwy 460 at Norfolk.

Elizabeth River, Eastern Branch, at VEPCO plant at Norfolk.......

Elizabeth River, Eastern Branch, at mouth of Broad Creek at Norfolk.... (JAMES) 310

Elizabeth River, Southern Branch, at Rt 104 nr Deep Creek...........

Elizabeth River, Southern Branch, at Lumber' RR nr Deep Creok ...... (JAMES) 308

Elizabeth River, Southern Branch, above Paradise Creek at Chesapeake

Elizabeth River, Southern Branch, above U.S. Coast Guard Station at Portsmouth

(JAMES) 310 at Portsmouth................ Belt Line RR at Chesapoake....

Elizabeth River, Southern Branch, at Gilmerton Bridge at Chesapeake..... (JAMES) 309

Elizabeth River, Southern Branch, at Jordan Bridge at Chesapeake......... (JAMES) 310

Elizabeth River, Southern Branch, at Paradise Creok at Ches apeake.

Elizabeth River, Southern Branch, at

Elizabeth River Southern Branch ake. U.S. Navai Shipyard at Chesapeake.. (JAMES) 310

Ellzabeth River, Southern Branch, at downtown tunnel at Portsmouth...... (JAMES) 310

Elizabeth River, Southern Branch, at mouth at Norfolis.

Elizabeth River, Southern Branch, below Jones Creek at Ciesapeake.......... (JAMEs) 310

Elizabeth River, Western Branch, at $A C L R R$ at Portsmouth. .

Elizabeth River, Western Branch, at Lovett Point nr West Norfolk.... (JAMES) 312

Elizabeth River, Western Branch, nr Lovett Point at Portsmouth...... (JAMES)

Elizabeth River, Western Branch, at Bailey Creek at Ches apeake...

Elizabeth River, Western Branch, at Churchland Bridge nr Portsmouth.... (JAMES)

Churchland Bridge nr Portsmouth
Elizabeth River, Western Branch, at
Rt 337 at Portsmouth........

Elizabeth River, Western 8ranch, at
Rt 337 at Portsmouth........

Elizabeth River, Western Branch, at West Norfolk Bridge nr West Norfolk..... (JAMES) 312

Elk Creek at Mt. Carmel Church nI Galax.... (NEW) 430 Elk Creek at North Anna River Channel in Lake Anna..............(YORK) 171

ELk Creek at Rt 652 at Lake Anna.......... (YORK) 171

ELk Creek at Rt $690 \mathrm{nr}$ Lake Anna............ (YORK) 171

ELk Creek at U.S. Hwy 221 (U.S. Hwy 460 ) nr Forest.

ELk Creek at Va.-N.C. State ine nr stuart.................. (ROANOKE) 394

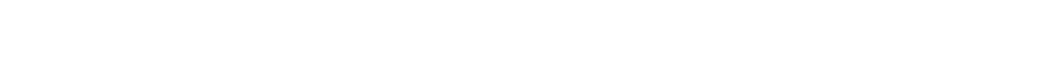

Elk Creek at mouth nr Goode................. (RÖANOKE) 380

Elk Creek at mouth nr Natural 8ridge...... (JAMES) 223

Elk Creak at mouth nr Twin Oaks, N.C........(NEW) 428

ELk Creek, East Fork, at Belfast Trail nr Natural Bridgo......

Elk Creek, East Fork, at Rt 759

nr Natural Bridge....
Elk Creek, Lower, at Va. -Ky.
State line nr Argo, Ky

(JAMES) 223 seek Middle, at Va.-Ky. State line nr Argo, Ky.........(BIG SANDY) 491

ELk Creek, North Branch, above confiuence with South Branch nr Elk Creek........(NEW) 429

Elk Creek, Right Fork Lower, at $\mathrm{Va}$. -Ky. State line nr Argo, Ky. (BIG SANDY) 491

Elk Creek, South Branch, above confiuence with North Branch $n r$ Elk Creek........ (NEW)

\section{.}


Abbreviated basin names appear at the end of the site name. Abbreviations are as follows Eastern Shore (EASTERN); Potomac to Shenandoah (POT-SHEN); Shenandoah (SHEN); Potomac (POTOMAC);

Potomac to Rappahannock (POT-RAPP); Rappahannock (RAPP); Rappahannock to York (RAPP-YORK); York (YORK)

York to James (YORK-JAMES); James (JAMES); James to Chowan (JAMES-CHOWAN); Chowan (CHOWAN); Roanoke (ROANOKE);

Yadkin (YADKIN); New (NEW); Big Sandy (BIG SANDY); Holston (HOLSTON); Clinch (CLINCH); Poweli (POWELL)]

Page

Elk Creek, Upper, at Rt 711

nT Argo Ky $\mathrm{KY}$ (BIG SANDY)

490

Elk Creek, Upper, at Va. -Ky State line nr Argo, Ky.........(BIG SANDY) 490

Elk Garden Creek above Loop Creek nr Elk Garden. 532

Elk Run at Rt 806 at Elk Run.........(POTOMAC) 92

ELk Run at Rt 806 nx Calverton............ (POTOMAC) 92

Elk Run at U.S. Hwy 340 at Elkton.......... (SHEN) 44

Elk Run at mouth at Elkton........................ 44

Elk Run at mouth nr Calverton.......... (POTOMAC) 93

Elk Run at mouth nr Parnassus............................... 35

Elk Run at mouth nr Ruckersvilie.................................. 134

Elk Run below NoW RR at Elikton........... (SHEN)

Elik Run trib No. 1 at Rt 806 nr Elk Run................ (POTOMAC)

Elk Run trib No. 2 at Rt 806 nr Elik Run.

( POTOMAC)

Elikhorn Branch at mouth at North Holston................ (HOLSTON)

Elkhorn Creek at Rt $67 \dot{\mathrm{nr}}$ Ricevilie... (ROANOKE)

Elkhorn Creek at mouth nr Leda.......... (ROANOKE)

Elikhorn Creek at mouth nr Wood lawn.

Elkins Branch at mouth nr Grundy.

Elklick Run at Rt 609 nr Chantiliy...... (POTOMAC)

Elklick Run at mouth nr Chantilly.

Elliott Creok at Rt 639 nr Alleghany Spring.

Elliott Creek at mouth

at Alleghany Spring..... (ROANOKE) 359

Elliotts Creek at mouth nr Cheapside...(EASTERN) 13

Eldis Creek at mouth $n r$ Crossroads...... (ROANOKE) 387

Elmwood Creek at mouth nr Loretto............(RAPP) 149

Elwood Swamp at Rt 616 nr Elberon....... (CHOWAN) 341

Elwood Swamp at mouth nr Elberon........(CHOWAN) 341

Ely Creex at mouth nr Stone Creex.......... (POWELL) 559

England Run at mouth ns Fredericksburg....(RAPP) 144

Ennis Pond (Ennis Mill Run) nr mouth at Lake Prince.

Enochs Branch at mouth nr Grundy

(JAMES) 307

Entry Creek at mouth nr Mike...

Entry Run at mouth nr Stanardsville....... (RAPP)

Eppes Creeic at mouth nr Carters Bridge... (JAMES)

Evans Creek at Rt 623 nr Brodnax........ (CHOWAN)

Evans Creek at mouth nr Brodinax.

Exol Swamp at mouth nr Center Cross...(RAPP-YORK) 160

Eyrehall Creek at mouth nr Cheriton.... (EASTERN)

Eyreville Creek at mouth nr Cheriton.:. (EASTERN)

Ezeld Branch at mouth nr Brunswick....... (CHOWAN)

Fall Creek above mouth nr Price, N.C... (ROANOKE)

Fall Creek at Rt 719 nr Danville...... (ROANOKE)

Fall Creek at mouth at Danville........ (ROANOKE)

Fall Creex at mouth at Dungannon.......... (CLINCH)

Fall Creek at mouth nr Carters Mili... (ROANOKE)

Fall Creek at mouth nr Irisburg........ (ROANOKE)

Fall Quarry Run at mouth nr Fredericksburg.

Fall Run above Furnace Ruin

(RAPP) or Mountain Falls.

(SHEN)

Fal1 Run above Rt 606 at Mountain Fails... (SHEN)

Fall Run at Rt 600 nr Mountain Falls...... (SHEN)

Falling 8 ranch at mouth nr Crockett Spring.

(ROANOKE) 359

Falling Creek $0.5 \mathrm{mi}$ above mouth nir Richmond.

(JAMES) g Creek at Hopkins Road nr Drewrys Bluff.

(JAMES)

Creek at Old Buckingham Rd

(JAMES) 267 (Rt 677) at Midlothian.

Falling Creek at Rt $10 \mathrm{nr}$ Drewrys Bluff. (JAMES)

Falling Creek at Rt 651 nr Chesterfieid. (JAMES)

Falling Creek at Rt 653 nr Midlothian.... (JAMES)
397

407

507

394

404

144

60

60

60

268

268

267
267

182

267
267

Falling Creek at U.S. Hwy 1

nr Drewrys Bluff.................. (JAMES) 268

Falling Creek at U.S. Hwy 1 nr Ashland....(YORK) 182

Falling Creek at U.S. Hwy 360 nr Richmond.

(JAMES) 267

Falling Creek at mouth nr Ashland..... (YORK) 182

Falling Creek at mouth nr Drewrys Bluff.. (JAMES) 268

Falling Creek at mouth nr Hampder. Sydney.

(JAMES) 273

Falling Creek at mouth nr Hardy..... (ROANOKE) 368

Falling Creek at mouth nr Otter Hill... (ROANOKE) 381

Falling Creek at old Rt 24 nr Stewartsville.

Falling Creek below Rt 619 ar Stewartsville.

(ROANOKE) 368

Falling Creek nr Rt 619 nr Stewartsville.............(ROANOKE) 368

Falling Creek trib No. $i$ at Rt 24 nr Stewartsville. . . $\ddot{k} \ddot{2} \ddot{2}$ nr Stewartsvilie..............(ROANOKE) 367

Falling Creek trib No. 3 at Rt 24 nr Stewartsville............ (ROANOKE)

Falling River (East Fork Faliing River) above Rt 646 at Spring Mills..... (ROANOKE) 385

Falling River (East Fork of

N.F. Falling River) above

S.F. Falling River nr Mike.

Falling River above Caldwells Creek nr Appomat tox

(ROANOKE)

385

... (ROANOKE) 384

Falling River at Rt $643 \mathrm{nr}$ Naruna...... (ROANOKE) 386 Falling River at Rt 645 nr Spout Spring.

Falling River at Rt 647 nr Spout Spring.

Falling River at Rt 650 nr Spring Mil1s.

Falling River at Kts $679 / 648$ nr Spring Mills...

(ROANOKE) 384

Falling River at mouth ni Brookneal..... (ROANOKE) 387

Falling River below Hat Creek nr Brookneal.

Falling River trib No. 1 above mouth at Appomattox...........

Falling River trib No. 2 at Rt 691

(ROANOKE) 384

Falling River, S.F., at Rt $\ddot{6} \dot{6} \dot{\sigma}$ nr Rustburg...............

Falling River, S.F., at Rt 648 nr Spring Mills................ (ROANOKE) 385

Falling River, S.F., at mouth nr Mike... (ROANOKE) 385

Falling Run at mouth at Emporia........(CHOWAN) 355

Falling Spring Creek at Rt 687 at Falling Spring

Falling Spring Creek at U.S. Hwy 220 nr Falling Spring.

(JAMES) 209

Falling Spring nr Falling Spring............ (JAMES) 209

Falls Creek at mouth nr Victoria........(CHOWAN) 322

Falls Creek trib at Rt 49 nr Victoria... (CHOWAN) 322

Falls Hill Creek at mouth

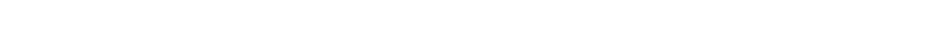

Falls Run at mouth at Fredericksburg......(RAPP) 145

Falls Run at mouth at Jerome............. (SHEN) 57

Farmers Branch at mouth nr Saxe........... (ROANOKE) 391

Farmers hall Creek at Rt 631 nr Champlain. (RAPP) 150

Farmers Hall Creek at U.S. Hwy 17 nr Champlain.............................. 150

Farmers Hald Creek at mouth nr Champiain.. (RAPP) 150

Farnham Creek at mouth nr Morattico......(RAPP) 155

Farnham Creek trib at mouth nr Morattico..(RAPP) 155

Farrier Branch at mouth nr Sinking Creek... (NEW) 450

Fawcett Run at Rt 622 at Marlboro.........(SHEN) 61

Fawcett Run at mouth at Marlboro............ (SHEN) 61

Feathercamp Branch at mouth nr Laureldale................. HOLSTON) 497

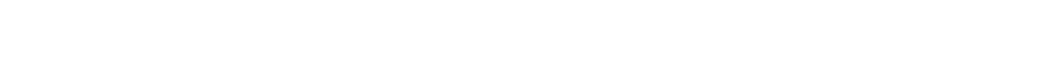


Abbreviated basin names appear at the end of the site name. Abbreviations are as follows:

Eastern Shore (EASTERN); Potomac to Shenandoah ( POT-SHEN): Shenandoah (SHEN); Potomac (POTOMAC);

Eotomac to Rappahannock (POT-RAPE); Rappahannock (RAPP); Rappahannock to York (RAPP-YORK); York (YORK)

York to James (YORK-JAMES); James (JAMES); James to Chowan (JAMES-CHOWAN); ChOWan (CHOWAN); ROanoke (ROANOKE);

Yadkin (YAOKIN); New (NEW); Big Sandy (BIG SANDY); Holston (HOLSTON); Clinch (CLINCH); Powell (POWEII)]

Page

Feeder Ditch above Dismal Swamp Canal at Arbuckle Landing nr Deep Creek.

Feeder Ditch at mouth at Arbucki Landing ni Deep Creek.

( JAMES-CHOWAN)

320

(JAMES-CHOWAN)

320

Feeder Ditch below Lake Drummond thake Drumono.

(JAMES-CHOWAN) 320

Felgates Creek at Colonial Parkway nr Yorktown

Felgates Creek at U.S. Naval Station nr Yorktown.

(YORK)

Fellowbed Branch at mouth nr Church Road. (JAMES)

Felts Branch at mouth nr Sebrell........ (CHOWAN)

Ferry Creek at mouth nr Dutton........ (RAPP-YORK

Fielding Creek nr Boswells Tavern.........(YORK)

Fields Run at mouth nr Culpeper.......... (RAPP)

Fiery Run at Rt 635 nr Flint Hiil......... (RAPP)

Fiery Run at mouth nr Flint Hill......... (RAPP)

Fifteenmile Creek at Rt 676 nr Green Spring.

Fifteenmile Creek at mouth nr Green Spring.

(HOLSTON)

$$
\cdots
$$

Fighting Creek at mouth nr Genito ....... (JAMES)

Fine Creek at Rt 711 at Fine Creek Mills. (JAMES)

Fine Creek at mouth nr Fine Creek Mills.. (JAMES)

Finley Creek at mouth nr Glenford...... (HOLSTON)

Finney Branch at mouth nr Sago......... (ROANOKE)

Finney Creek at mouth nr Wachapreague.. (EASTERN)

Finneywood Creek at mouth nr Chase City. (CHOWAN)

Firestone Creek at U.S. Hwy 11 nr Fincastle.

First Branch at mouth nr Beach............... (JAMES)

First Fork at mouth at Sago.............. (ROANOKE)

Fishing Fork at mouth nr Leatherwood... (ROANOKE)

Fishing Run at mouth nr Chancellorsville..(RAPP)

Fishpond Creek at Rt 617 nr Hixburg...... (JAMES)

Fishpond Creek at mouth nr Hixburg....... (JAMES)

Fivemile Ditch nr Deep Creek............ (JAMES)

Flas Run at Rt $650 \mathrm{nr}$ Story............ (CHOWAN)

Flag Run at mouth nr Courtland........ (CHOWAN)

Flag Run trib at Rt 611 at Courtiand... (CHOWAN)

Flanigan Branch at mouth nr Irisburg... (ROANOKE)

Flannigan Branch at mouth nr Proffit..... (JAMES)

Flat Branch at Rt 1530 at Manassas Park................ (POTOMAC)

Flat Branch at Rt $234 \mathrm{nr}$ Manassas....... (POTOMAC)

F lat Branch at mouth at Manassas Park.. (POTOMAC)

Flat Branch at mouth at Tuckahoe Village. (JAMES)

Flat Branch at mouth nr Lawrenceville... (CHOWAN)

Flat Branch off Rt 1501 at Manassas Park.................. (POTOMAC)

Flat Creek above STP at South Hill..... (ROANOKE)

Flat Creek at $R t 24$ nr Evington......... (ROANOKE)

Flat Creek at Rt 604 (Rt 148) nr Chula... (JAMES)

Flat Creek at Rt 609 ne Chula........... (JAMES)

Flat Creek at Rt 630

nr Smiths Crossroads............. (ROANOKE) 423

Flat Creek at Rt 631

nr Smiths Crossroads .......... (ROANOKE)

Flat Creek at Rt $632 \mathrm{nr}$ Chula......... (JAMES)

Flat Creek at Rt 637 nr Beechwood......... (ROANOKE)

Flat Creek at Rt 642 nr Jetersvilie....... (JAMES)

Flat Creek at Rt 642 nr South Hill..... (ROANOKE)

F lat Creek at Rt 681 nr Ame1ia.......... (JAMES)

Flat Creek at mouth nr Chula............... (JAMES)

Flat Creek at mouth nr Otter River....... (ROANOKE)

Flat Creek below Rocky Branch

$$
\text { nr South Hill................ (ROANOKE) }
$$

Flat Creek below STP at South Hiil..... (ROANOKE)

Flat Creek nr Smiths Crossroads......... (ROANOKE)

Flat Rock Branch at mouth nr Buffalo Springs.............. (ROANOKE)

Flat Rock Creek at Rt 647 nr Kenbridge.. (CHOWAN)

Flat Rock Creek at mouth nr Forksville.. (CHOWAN)

Flat Run at Rt 3 nr Flat Run........... (RAPP)

Flat Run at mouth nr Culpeper............ (RAPP)

Flat Run at mouth nr Richardsvi11e....... (RAPP)
Flat Run at mouth nr Simpsons ........ (ROANOKE)

200

280

161

176

142

117

507

507

275

262

262
518

374

12

349

221

286

375

403

143

271

309

337

337

337
404

253

98

98

98

263
352

98

422

382

277

276

422

277

423
276

422

276

277
382

422

422

423

417

350

351
142

142
130

142

358
Flat Run at mouth nr Stokesville.

Page

lat Run trib at mouth nr Culpeper.

(SHEN)

(RAPP) 130

Flat Run trib at mouth nr locust Grove.

Flat Swamp at mouth nr Boykins........(CHOWAN) 357

Fiat Swamp trib at Rt 659 nr Branchville.

(CHOWAN)

Flat Swamp trib at mouth nr Branchville.

Flatlick Branch at Braddock Rd nI Chantil1y

Flatlick Branch at Sully Rd

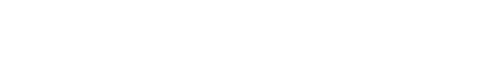

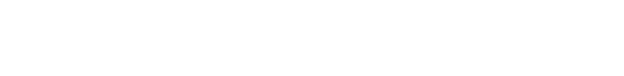

(POTOMAC)

latlick Branch at mouth or Chantilly.

Flatrock Branch at mouth nr Smoky Ordinary.

.

Flatwoods Branch at mouth nr Ironto.... (ROANOKE) 361

Fleenor Branch at U.S. HWy 58 nr Bristol.

(HOLSTON) 520

Fleenor Brarch at mouth nr Ketron......(HOLSTON) 520

Flint Run at Rt 622 at Limeton............. SHEN) 51

Flint Run at mouth nr Karo.............. (SHEN)

Flintstone Creek at mouth nr Castle Craig...

Flippen Creek at Richmond.

Flippins Creek at mouth nr Grady.......... (JOANOKE)

Flower Branch at mouth nr Gate City...... (CLINCH)

Flowerdew Hundred Creek at mouth nr Westover.

(JAMES)

Flyblow Creek at mouth at Mount Airy.... (ROANOKE)

Folly Creek at mouth nr Accomac........ (EASTERN)

Folly Creek at mouth nr Holly Grove.

(YORK) 179

Folly Lick Branch at Third St at Herndon.

( $P O T O M A C$ )

Folly Mills Creek at U.S. Hwy ii nr Staunton.

(SHEN)

Folly Mi11s Creek at mouth nr Stuarts Draft.

Foltz Creek at mouth at Jerome.

(SHEN)

Fonticello Spring at Richmond.

Forbes Creek nr New Store.

Foremost Run at Terrys Run Channel in Lake Anna.

(SHEN)

(J AMES )

(JAMES )

(YORK)

Fork Bridge Creek at mouth nr Beulahvilie. (YORK)

Fork Creek at mouth nr Apple Grove........ (YORK)

Fort Run at mouth at Timberville......... (SHEN)

Fosters Creek at U.S. Hwy 250 nr Ferncliff.

(YORK)

Fosters creek at mouth nr Ferncliff.

(YORK)

Foul Ground Creek at mouth nr Burnt Chimmey

Fountains (Fontaine) Creek at Rt $603 \mathrm{nr}$ Brink.

Fountains (Fontaine) Creek at Rt $639 \mathrm{nr}$ Emporia.

Fountains Creek at U.S. Hwy 301 nr Pleasant Hill, N.

Fountains Creek at mouth nr Branchuille.

(ROANOKE)

(CHOWAN)

(CHOWAN)

(CHOWAN)

(CHOWAN)

Fourmile Creek at Doran Rd nr Richmond Heights.

Fourmile Creek at Va.-Tenn. State iine nr Ewing.

( JAMES )

(

( JAMES )

le Creek at mouth

nr Bermuda Hundred.

Fourmile Run at Arlington Ridge Rd at Alexandria.

Fourmile Run at Arlington STP at Alexandria.

Fourmile Run at East Giebe Rd at Alexandria.

Fourmile Run at George Washington Memorial Parkway at Al

Fourmile Run at Old Glehe Rd at Alexandria.

( POTOMAC)

(POTOMAC)

(POTOMAC)

(POTOMAC)

(POTOMAC)
382

294

549

291

413
12

75

36

36

57
256

266
271

169

195

178

177

177

371

355

356

356

356

270

563

270

80

80

80 
Abbreviated basin names appear at the end of the site name. Abbreviations are as follows:

Eastern Shore (EASTERN); Potomac to Shenandoah (POT-SHEN); Shenandoah (SHEN); Potomac (POTOMAC);

Potomac to Rappahannock (POT-RAPP); Rappahannock (RAPP); Rappahannock to York (RAPP-YORK); York (YORK);

York to James (YORK-JAMES); James (JAMES); James to Chowan (JAMES-CHOWAN); Chowan (CHOWAN); Roanoke (ROANOKE);

Yadkin (YADKIN); New (NEW); Big Sandy (BIG SANDY); Holston (HOLSTON); CIinch (CLINCH); Powell (POWELI)]

Pase

Fourmile Run at Shirlington Rd

Fourmi le Run (

80

Fourmile Run below Columbia Pike at Arlington.

( POTOMAC)

( FOTOMAC) below WEOD RR

Alexandria.

80

Fowler Branch at mouth ne Hiiton......... (HOLSTON) 521

Fox Branch at mouth nr Carson........... (CHOWAN) 330

Fox Branch at mouth nr Drewryviile....... (CHOWAN) 334

Fox Branch at mouth nr Louisa............ (YORK) 166

Fox Creek above Dick Branch nr Murphy

(BIG. SANDY) ceok above Jackson Branch

Fox Creek Murphy .................... (BIG SANDY)

Fox Creek Murphy................... (BIG SANDY)

473

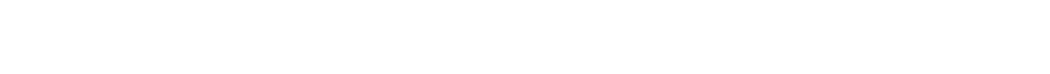

Fox Creek at mouth at Capahosic...........(YORK) 199

Fox Creek at mouth nr Colley..........(BIG SANDY) 473

Fox Creek at mouth nr Fox.............. (NEW) 428

Fox Creek below Dick Branch ne Murphy

(BIG SANDY)

Fox Creek below Jackson Branch

(BIG SANDY) ne Murphy.

( POTOMAC)

wamp at Rt

Fox Hall Swamp at Rt 639

nr Potomac Mills.

(POTOMAC) 111

Fox Mill Run $200 \mathrm{ft}$ above old U.S. Hwy 17 at Gloucester.

Fox Mili Run above old U.S. Hwy i7 at Gloucester.

(RAPP-YORK)

164

Fox Mill Rus at mouth nr ware Neck... (RAPP-YORK) 164

Fox Mill Run below old U.S. Hwy 17 at Gloucester.

(RAPP-YORK) 164

Foxes Creek at mouth nr Harcum......... (RAPP-YORK) 161

Fraley Branch at Fraleytown nr Duffield.(CLINCH) 550

France Swamp at Rt 606 nr Toano........... (YORK) 198

France Swamp at mouth nr Toano............ (YORK) 198

France Swamp below STP at Toano............. (YORK) 198

Francis Mill Creek at mouth at Cripple Creek................... (NEW) 434

Francis Spring nr Bane............................ (NE) 452

Frank Slusser Spring at Rt $i 14$ nr Blacksbuy

(ROANOKE) 360

Frank Lin Branch at mouth nr Gate City.. (HOLSTON) 522

Franks Branch at Rt 626 at Colonial Heights.

(JAMES) 287

Franks Bzanch at Rt 631

at Colonial Heights.............. (JAMES)

Franks Branch at mouth at Colonial Heights.

(JAMES) 287

Franks Branch at mouth nr Adams Grove... (CHOWAN) 357

Eranks Branch at mouth nr Imboden....... (POWELL) 555

Free Creek at Rt $608 \mathrm{nr}$ Buena Vista...... (JAMES) 229

Freemason Run at Rt 747 nf Mt. Solon....... (SHEN) 25

Freemason Run at mouth nr Mt. Solon....... (SHEN) 26

French Creek at mouth nr Harcum...... (RAPP-YORK) 161

Freshwater Creek above STP at Mineral.....(YORK) 170

Freshwater Creek at mouth nr Mineral.......(YORK) 171

Freshwater Creek trib at mouth

nr Mineral...................... (YORK)

Fridley Spring at Hooks Mili nI Rich Patch.

JAMES) 219

Frisby Branch at Rt $24 \mathrm{nr}$ Buckingham.... (JAMES) 245

Froman Run at Rt 623 nf Marlboro........... (SHEN) 60

Froman Run at mouth nr Marlboro.............. (SHEN) 60

Frying Pan Branch at Centreville Rd if Herndon.

Frying Pan Branch at mouth ne Herndon.

Fyingpan Creek above Lick Branch nI Duty.

( POTOMAC)

pan Creek at mouth

nI Birchleaf.

(BIG SANDY)

(BIG SANDY)

Fryingpan Creek at mouth nr Toshes.
376
Fryingpan Creek below Tiny nr Colley. (BIG SANDY)

Page

Fryingpan Creek trib No. 1 at mouth

$$
\text { nr Duty. }
$$

Fryingpan Creek trib No. 2 at mouth $\mathrm{nr}$ Colley

Fryingpan Creek trib No. 3 at mouth nr Colley.

Fryingpan Creek trib No. 4 at mouth nr Colley.

(BIG SANDY)

475

(BIG SANDY) 475

(BIG SANDY) 475

Fuller Branch at mouth nf hayters Gap. (HOLSTON) 51

Furnace Creek above Rush Fork nr F Loyd..... (NEW)

Furnace Creek at mouth at Rocky Mount. (ROANOKE)

Furnace Run at mouth nf Marlboro......... (SEEN)

464

444

373
60

G. W. Wright Spring nr Bennetts Mill

nI Blacksburg................ (ROANOKE)

Gabe Branch at mouth nr Dunbar.......... (POWELL)

Gaddes Creek at mouth nr Provost.......... (JAMES)

Galena Creek at U.S. Hwy 52 nr Austinville. (NEW)

Galena Creek at mouth nr Austinville....... (NEW)

Gallaman Swamp at mouth nr Harcum.... (RAPP-YORK)

Galley Swamp at mouth nr Stony Creek... (CHOWAN)

Gambo Creek at Bagby Rd at Dahlgren.... (POTOMAC)

Gambo Creek at Blandy Blvd nr Dahlgren. (POTOMAC)

Gambo Creek at Rt $635 \mathrm{nr}$ Dahlsren...... (POTOMAC)

Gambo Creek at Tisdale Rd at DahIBren.. (POTOMAC)

Gambo Creek at U.S. HWy 301 nr Dahlgren.

(POTOMAC)

Gambo Creek at mouth nr Dahisren........ (POTOMAC)

Gap Creek at Rt $730 \mathrm{nr}$ Mt. Jackson......... (SHEN)

Gap Run at mouth $n r$ Elkton............ (SHEN)

Gap Run at mouth nI Rectortown.

(POTOMAC)

Garden Creok at Rt 632 at Mount Heron.

(BIG SANDY)

Garden Creek at Rt 559 at Oakwood.... (BIG SANDY)

Garden Creek at mouth at Oakwood..... (BIG SANDY)

Gardner Creek at mouth nr Coles Point.. (POTOMAC)

Gargathy Creek at Gargathy Inlet

$$
\text { nI Modest Town............... (EASTERN) }
$$

Garlands Creek at mouth $\mathrm{nr}$ Montross.... (RAPP)

Garlands Millpond at mouth nr Haynesviile. (RAPP)

Garlands Millpond trib nr Haynesville.... (RAPP)

Garnand Branch at mouth at Roanoke..... (ROANOKE)

Garnetts Creek at mouth nI Stevensville... (YORK)

Garrett Branch at mouth nI Grady....... (ROANOKE)

Garrett Creek at mouth at Holston...... (HOLSTON)

Garth Run at mouth nr Wolftown........... (RAPP)

Gaspard Creek at mouth at Craigs Mill.. (HOLSTON)

Genito Creek at Rt 6 nr Crozier.......... (JAMES)

Genito Creek at mouth

nf Fine Creek Mills.

(JAMES)

Genito Creek at mouth nf Lawrenceville.

(CHOWAN) 351

Gent Branch at Rt 619 nr Vansant...... (BIG SANDY)

Georges Branch at mouth

$$
\text { at Tuckahoe Viliage. }
$$

(JAMES)

Georges Branch at mouth nr Church Road.. (JAMES)

Georges Creek at Rt 40 nr Gretna....... (ROANOKE)

Georges Creek at U.S. Hwy 29

(Business) at Gretna.

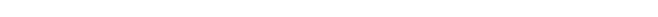

(ROANOKE)

Georges Fork at Rt 621 nr Isom....... (BIG SANDY)

Georges Fork at Rt 83

$$
\text { at Georges Fork. }
$$

Georges Fork below Laurel Creek at Georges Fork.

(BIG SANDY)

(BIG SANDY)

Georges Run at mouth

at Alleghany Spring ........ (ROANOKE)

Georges Swamp at mouth nf Aylett........... (YORK)

Georgia Branch at mouth nr Axton.

German River above Spring River

$$
\text { nr Criders }
$$

Cerman Swamp at Rt 606 ne Littleton...

German Swamp at mouth nr Littleton....... (CHOWAN) 
Abbreviated basin names appear at the end of the site name. Abbreviations are as follows: Eastern Shore (EASTERN); Potomac to Shenandoah (POT-SHEN); Shenandoah (SHEN); Potomac (POTOMAC);

Potomac to Rappahannock (POT-RAPP); Rappahannock (RAPP); Rappahannock to York (RAPP-YORK); York (YORK)

York to James (YORK-JAMES); James (JAMES); James to Chowan (JAMES-CHOWAN); ChOWan (CHOWAN); ROanoke (ROANOKE);

Yadkin (YADKIN); New (NEW); Bis Sandy (BIG SANDY); Holston (HOLSTON); Clinch (CLINCH); POWeli (POWELL)]

Page

Germy Creek at mouth nr Brookland...... (ROANOKE)

Gibson Croek at mouth nr Wolf Irap..... (ROANOKE)

Gilbert Fork at mouth ar Davenport... (BIG SANDY)

Giles Creek at mouth nr Keysville....... (CHOWAN)

Giles Run at U.S. Hwy $1 \mathrm{nr}$ Woodbridge.. (POTOMAC)

Gillenwater Branch at mouth nr Gate City....................................

Gillie Creek at Government Rd

(CLINCH) at Richmond.

(JAMES)

Gillie Creek at Rt 5 at Richmond.

(JAMES)

Gillie Creek at Williamsburs Ave at Richmond.

(JAMES)

(JAMES)

Gilije Creak at mouth at Richmond. .

Gills Creek at Rt 122 nr Burnt Chimney. (ROANOKE)

Gills Creek at Rt $668 \mathrm{nI}$ Dudiey School. (ROANOKE)

Gills Creek at Rt $834 \mathrm{nr}$ Burnt Chimney. (ROANOKE)

Gills Creek at mouth nr Scruggs.

(ROANOKE)

Gills Creek trib nr Clearbrook....... (ROANOKE)

Gills Creek, N.F.. at mouth nr Hardy... (ROANOKE)

Gilmez Springs nr Gate City........... (BOLSTON)

Gilmore Run at mouth nr Ruckersville...... (RAPP)

Gilpin Springs nr Mount Weather........... (SHEN)

Gimiet Branch at mouth at Delmar........ (BOLSTON)

Gin Creek above Turners Siding $n=$ St Charles.

(POWELI)

Gin Creek at mouth $\mathrm{nr}$ St. Charles...... (POWELL)

Gingoteague Run at Rt $625 \mathrm{nr}$ Port Royal... (RAPP)

Gingoteague Run at mouth $n x$ Port Royal.... (RAPP)

Giuliani Springs ne Ashby Gap.

Glade Creek above Wise.

149

(Rode Creek above mouth at Vinton....... (ROANOKE)

Glade Creek at Rt 629 at Grahams Forge..... (NEW)

Glade Creek at Wise.................. (CIINCH)

Glade Creek at mouth at Grahams Forge......(NEW)

Glade Creek at mouth at Wise...........(CLINCH)

Glade Creek at mouth nr Dickinson...... (ROANOKE)

Glade Creek at mouth nr Woodlawn.......... (NEW)

Glade Creek below Wise.

(CLINCH)

lade Creek trib at Rt 636 at Wise......(CLINCH)

Glade Creek trib at mouth at Webster... (ROANOKE)

Glader Branch at mouth at Huddleston... (ROANOKE)

Glady Fork at mouth nr Dewey.......... (BIG SANDY)

Glady Fork at mouth $\mathrm{nr}$ Galax.............. (NEW)

Glady Fork at mouth nr $\mathrm{Ka}, \ldots \ldots \ldots \ldots$ (CLINCH)

Glady Fork at mouth nr Sandy River..... (ROANOKE)

Glebe Creek at Charles City............. (JAMES)

Glebe Creek ne Coles Point ............. (POTOMAC)

Glebe Creek off Rt $726 \mathrm{nr}$ Lottsburg... (POTOMAC)

Glebe Creek trib at Rt 155 nr Charles City

(JAMES)

Glebe Run at mouth nr 8rokenburg......... (YORK)

Globe Swamp at Rt $608 \mathrm{nr}$ Shack lefords..... (YORK)

Glebe Swamp at mouth nr Shacklefords...... (YORK)

Goalders Creek at mouth nr West Point..... (YORK)

Gobble Branch at mouth nr Duncanville.. (HOLSTON)

Goblintown Creek at Fairy Stone

Lake Dam nr Bassett............. (ROANOKE) 400

Goblintown Creek at Rabbit Is iand ni Bassett.

town Creek at Stuarts Knob nI Bassett.................. (ROANOKE)

Goblintown Creek at former mouth nr Bassett. ................ (ROANOKE)

Goblintown Creek at mouth nr Bassett... (ROANOKE)

Goblintown Creek below Green Branch ni Bassett.

Mine Creek at Rt 613 in Louisa.

(ROANOKE)

(YORK)

Gold Mine Creek at Rt $628 \mathrm{nr}$ Louisa.......(YORK) 167

Gold Mine Creek at mouth nr Belmont.......(YORK) 167

Gold Mine Creek trib at Rt 659 at Louisa.. (YORK) 167

Gold Mine Creok trib at mouth nr Louisa... (YORK) 167

Gold Mine Creek trib tributary No. 1 above STP at Louisa............. (YORK)

Gold Mine Creek trib tributary No. I at Rt 669 at Louisa.............. (YORK)
400
Gold Mine Creek trib tributary No. 1

tributary at Louisa..............
Gold Mine Creek trib tributary No. 2 nz Louisa.

(YORK)

Colden Branch at mouth nr Ringgold......

Goldenvale Creek at Rt 616 $n z$ Rappahannock Academy

Goldenvale Creek at Rt 617 nI Rappahannock Academy

Goldenvale Creek at U.S. Hwy 17
ne Port Royal................

. (RAPP) 148

(RAPE) 148

Goldmine Creek at mouth or Rockvillo a ... (RAPP) 148

Golin Run at mouth nr Fredericksburg........ (RAPP) 144

Goode Creek at mouth nt Chula............. (JAMES) 277

Goodell Creek at Rt $49 \mathrm{nz}$ Jeffress....... (ROANOKE) 418

Goodell Creek nr Jeffress.............. (ROANOKE) 418

Goodzich Branch at mouth nr Lawrenceville.

(CHOWAN) 352

Gooney Run at Rts $622 / 649 \mathrm{nr}$ Gien Echo.... (SHEN) 51

Gooney Run at U.S. Hwy 340 at Karo........ (SHEN) 51

Gooney Run at mouth at Karo............. (SHEN) 51

Goose Creek above Rt 621 nr Leesburg... (POTOMAC) 72

Goose Creek above Rt 630 at Leesville... (ROANOKE) 378

Goose Creek above Rt 732 nr Huddleston.....................

(ROANOKE) 378

Goose Creek above Sycolin Creek

nr Leesburs. ................... nr Leesburg

(BOTOMAC) 72

Goose Creek at Rt $122 \mathrm{nr}$ Bedford..........(ROANOKE) 377

Goose Creek at Rt $55 \mathrm{nz}$ Markham......(POTOMAC) 68

Goose Creek at Rt $611 \mathrm{nr}$ Middleburg....(POTOMAC) 69

Goose Creek at Rt $621 \mathrm{nr}$ Leesburg....... (POTOMAC) 72

Goose Creek at Rt 525 at Huddleston.... (ROANOKE) 378

Goose Creek at Rt $626 \mathrm{nr}$ Middleburg.... (POTOMAC) 69

Goose Creek at Rt 653 nI Crockett Spring

(ROANOKE) 358

Goose Creek at Rt $7 \mathrm{nr}$ Ashburn.......... (POTOMAC) 73

Goose Creek at Rt $710 \mathrm{nr}$ Rectortown.... (POTOMAC) 69

Goose Creek at Rt $734 \mathrm{nr}$ Mountville... (POTOMAC) 70

Goose Creek at U.S. Hwy 15 at Oatlands. (POTOMAC) 71

Goose Creek at U.S. Hwy 17

Goose Creek at U.S. Hwy so

69 Cr Middleburg.

Goose Creek at mouth at Bristol.......... (HOLSTON) 510

Goose Creek at mouth at Leesville...... (ROANOKE) 378

Goose Creek at mouth nr Leesburg........ (POTOMAC) 73

Goose Creek at mouth nr MCAdam...............(NEW) 443

Goose Creek at mouth nr Mt. Sidney.............(SHEN) 32

Goose Creek at mouth nr Seaford..... (YORK-JAMES) 202

Goose Creek at mouth nr Simpsons........ (ROANOKE) 358

Goose Creek at mouth nr Staunton...........(SHEN) 36

Goose Creek below Cattail Branch nI Leesburs .......... nr Leesville................. (ROANOKE) 378

Goose Creek trib at Rt iii nr Oatiands. (POTOMAC) 71

Goose Creek, N.F., at R. 722 $\mathrm{n}=\mathrm{Lincoln} . \ldots \ldots \ldots$

Goose Creak, It F. at Rt 729

C) 70 nr Lincoln.................. (POTOMAC) 70

Goose Creek, N.F., at Rt 782 nr Lincoln................... (POTOMAC)

Goose Creek, N.F., at U.S. Hwy 460 nI Montvale (Thaxton).

Goose Creek, N.F., at mouth nI Oatlands.

(ROANOKE) 377

(POTOMAC) 71

Goose Creek, S.F., at Rt 607 at Montvale................. (ROANOKE) 377

Goose Creek, S.F., at mouth nr Irving. (ROANOKE) 377 Gordon Creek below Jolly Pond at Rt $633 \mathrm{nI}$ Lighfoot.

Gose tollow trib at Rt 628 at St. Paul...(CIINCH) 537 
Abbreviated basin names appear at the end of the site name. Abbreviations are as follows:

Eastern Shore (EASTERN); Potomac to Shenandoah (POT-SEEN); Shenandoah (SEEN); Potomac (POTOMAC);

Potomac to Rappahannock (POT-RAPP); Rappahannock (RAPP); Rappahannock to York (RAPP-YORK); York' (YORK);

York to James (YORK-JAMES); James (JAMES); James to Chowan (JAMES-CHOWAN): Chowan (CHOWAN); ROanoke (ROANOKE);

Yadkin (YADKIN); New (NEW); Big Sandy (BIG SANDY); Holston (HOLSTON); Clinch (CLINCH); Powel1 (POWELL)]

Gosee Swamp at mouth $\mathrm{nr}$ Stony Creek.....(CBOWAN) 330 Gouldman Branch at mouth

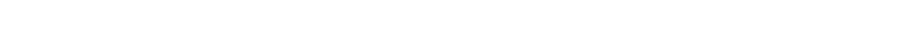

Gourd Creek at mouth nr Sago...........(ROANOKE) 375

Governor Creek above Webb Creek ni Central Garage.

(YORK) 186

Grable Branch at mouth nr Green Spring. (HOLSTON) 508

Graham Creek at mouth nr Elon............. (JAMES) 234

Graham Creek at mouth nr Monroe........... (JAMES) 234

Grapevine Branch at mouth nr Patterson.

(BIG SANDY) 459

Grass Creek at mouth

nr King and Queen Court House.

Grassy Branch at Rt 721 nr Sanville.

Grassy Branch at mouth nr Konnarock.

Grassy Branch at mouth nr Sanville.

Grassy Creek at Rt 624 nr Drill.

(YORK) 196

(ROANOKE) 396

(HOLSTON) 496

(ROANOKE) 396

(CLINCI) 531

Grassy Creek at Rt 80 at Breaks...... (BIG SANDY)

Grassy Creek at Rt 80 nr Breaks...... (BIG SANDY)

Grassy Creek at U.S. Hwy 15 nr Cozy Cabin.

Grassy Creek at U.S. Jwy 460 at Grims leyvilie.

(ROANOKE)

(BIG SANDY)

Grassy Creek at mouth nr Grims leyville.............. (BIG SANDY)

Grassy Creek at mouth at Martinsvilie.. (ROANOKE)

Grassy Creek at mouth nr Breaks......(BIG SANDY)

Grassy Creek at mouth nr Clarksville... (ROANOKE)

Grassy Creek at mouth nr Collinwood..... (CLINCH)

Grassy Creek at mouth nr Gladesboro......... (NEW)

Grassy Creek at mouth nr Omega.......... (ROANOKE)

Grassy Creek nr Fieldale.............. (ROANOKE)

Grassy Fork at mouth nr Irisburg....... (ROANOKE)

Grassy Fork at mouth nr Oak Level........ (ROANOKE)

Grassy Fork at mouth nr Snow Creek...... (ROANOKE)

Grassy Swamp Creek at mouth n r Glen Allen.

(JAMES) 292

Grave 1 Lick Creek at mouth at Hamiin..... (CLINCH) 537

Gravel Run at mouth nr Beulahville........(YORK) 194

Gravelly Run at mouth nr Reams.............. (CEOWAN) 329

Grave11y Run nr Dinwiddie...................WOWAN) 329

Grays Branch at mouth nr wardeii...........(CLINCH) 531

Grays Creek at Rt $618 \mathrm{nr}$ Surry.......... (JAMES) 301

Grays Creek at mouth nr Surry........... (JAMES) 301

Grays Fork at mouth at Stella.......... (ROANOKE) 396

Grease Creek at mouth nr Buckingham....... (JAMES) 245

Greasy Creek at Rt 612 at Harman.......... (CLINCH) 527

Greasy Creek at mouth nr Longshoal............ (NEW) 440

Greasy Creek at mouth nr Museville..... (ROANOKE) 375

Greasy Run along Rt 631 nr Browntown....... (SEEN) 51

Greasy Spring Branch nr Alhambra.......... (JAMES) 237

Great Branch at mouth nr Centralia....... (JAMES) 269

Great Branch at mouth nr Rawlings........ (CEOWAN) 325

Great Creek above Hagood Creek

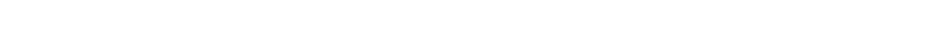

Great Creek at Lawrencevilie ............(CHOWAN) 353

Great Creek at Rt $46 /$ U.S. HWy 58 at Lawrenceville.

Great Creek at Rt 617 nr Bracey.

Great Creek at Rt $618 \mathrm{nr}$ Cochran.

Great Creek at Rt $620 \mathrm{nr}$ Marengo.

Great Creek at Rt $620 \mathrm{nr}$ Marengo........ (ROANOKE)

Great Creek at mouth nr McKenney.......... (CHOWAN)

Great Neck Creek at U.S. Hwy 58 nr Virginia Beach.......... (JAMES-CHOWAN)

Great Neck Creek trib

at Ocean Blvd at Oceana..... (JAMES-CHOWAN) 315

Great Run at Rt $607 \mathrm{nr}$ Turnbul1.............(RAPP) 120

Great Run at Rt 637 at Yorktown............... (JAMES) 303

Great Run at U.S. Hwy $15 \mathrm{nr}$ Madison Mi1is. (RAPP) 138

Great Run at U.S. Hwy 211 nr Warrenton....(RAPP) 119

Great Run at mouth nr Opal................RAPP) 120

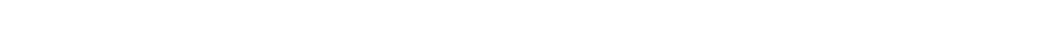

Great Run trib at Rt 802 nr Warrenton........ (RAPP) 120

Great Run trib at U.S. Ewy 211
Great Run trib tributary above STP at Warrenton.

Great Wicomico River at Glebe Point or Mila.

( RAPP)

Great Wicomico River at Rt 604 nr Eorse Head.

Great Wicomico River at buoy 11 nr Mila.

Great Wicomico River at buoy 9 nr Mila.

( POT -RAPP)

114

Wicomico River at mouth

nr Fleeton.

(POT-RAPP)

114

(POT-RAPP)

Green Branch at mouth nr Goldvein.......... (RAPP)

Green Cove Creek at mouth nr Konnarock. (HOLSTON)

Green Creek at mouth nr CaIlaway....... (ROANOKE)

Green Creek at mouth nr Penns Store.... (ROANOKE)

Green Creek at mouth nr Schuyler......... (JAMES)

Green Rock Branch at mouth at Chatham... (ROANOKE)

Greenbriar Creek at Rt 83 at Vicey...(BIG SANDY)

Greenbriar Creek at mouth at Vicey... (BIG SANDY)

Greenbrier Branch at mouth at Newport...... (NEW)

Greenbrier Creek above Rough Branch nr Vicey.

(BIG SANDY)

Greenbrier Creek at mouth nr Wharncliffe, W.Va.......... (BIG SANDY)

Greendale Creek at mouth at Holston... (HOLSTON)

Greenfield Creek at mouth or Brokenburg... (YORK)

Greens Creek nr Nassawadox. ........ (EASTERN)

Greensville Creek at mouth nr Emporia... (CHOWAN)

Greentown Branch at mouth or Powellton.. (CHOWAN)

Greenvale Creek at mouth nr water View.... (RAPP)

Greenway (Hogthief) Creek along Rt 694 nr Cedarville................ (HOLSTON)

Greenway Creek at Rt 694 nr Abingdon.... (HOLSTON)

Greenway Creek at mouth nr Cedarville... (HOLSTON)

Greever Branch at mouth at Chilhowie... (HOLSTON)

Gressitt Pond outlet nr Hockley........... (YORK)

Grimes Creek at mouth nr Goodview........ (ROANOKE)

Grindall Creek at DuPont Flant or Drewrys Bluff.

(JAMES) 268

Grindall Creek at Rt 150 at Chesterfield. (JAMES)

Grindall Creek at Walmsley Blvd at Richmond.

( JAMES )

Grindall Creek at mouth at Chesterfield. (JAMES)

Grindall Creek at mouth or Drewrys Bluff. (JAMES)

Grindstone Branch at mouth nr Shelleys. (HOLSTON)

Grissom Creek above Venia nr Council. (BIG SANDY)

Grissom Creek at Rt 626 nr Council... (BIG SANDY)

Grissom Creek at Venia nr Council.... (BIG SANDY)

Grissom Creek nr Fletcher Ridge or Council.

(BIG SANDY)

Grissom Creek trib nr Council.

(BIG SANDY)

Grosses Creek at mouth nr Murrayfield.. (HOLSTON)

Grove Creek at mouth nr Newport News..... (JAMES)

Guess Fork at N\&W RR nr Jurley....... (BIG SANDY)

Guest River above Bear Creek at Norton. (CLINCH)

Guest River above Esserville........... (CLINCH)

Guest River above Lick Log Branch nr St. Paul.

(CLINCE) River above Machine Creek nr Tacoma.

Guest River above Rt 72 at Coeburn....... (CLINCH) 542
Guest River above Toms Creek at Coeburn. (CLINCH) 541

Guest River above sewage plant outfall at Norton.

Guest River along N\&W RR nr Tacoma....... (CLINCH)

Guest River along U.S. Hwy 58 (Alternate) below Norton.

Guest River at Interstate RR

at Esserville.............. (CIINCH)

(CLINCE)

Guest River at Interstate RR nr Norton. (CLINCH)

Guest River at $R t 11$ at Coeburn Airport nr Coeburn.

Guest River at Rt 14 below Tacoma....... (CLINCH)

Guest River at Rt 626 at Lipps.........(CLINCH)
496

369

396

411

477

450

488

519
188

13

354
354

156

506

506
506

504

198

368

268

268

268

268
520

464

465

464

464

464

302

489

539

542

541

541

541

539

541

542

541

541
539

539 
Abbreviated basin names appear at the end of the site name. Abbreviations are as follows:

Eastern Shore (EASTERN); Potomac to Shenandoah (POT-SHEN); Shenandoah (SHEN): Potomac (POTOMAC):

Potomac to Rappahannock (POT-RAPP); Rappahannock (RAPP); Rappahannock to York (RAPP-YORK); York (YORX) :

York to James (YORX-JAMES); James (JAMES); James to Chowan (JAMES-CHOWAN); Chowan (CHOWAN); ROanOke (ROANOKE);

Yadkin (YADKIN); New (NEW); Bis Sandy (BIG SANDY); Holston (HOLSTON); Clinch (CLINCH); Powel1 (POWELL)]

Guest River at Rt 658 nI Coeburn........ (CLINCH)

Guest River at Rt 706 at Tacoma............. (CLINCH)

Guest River at Rt 72 at Coeburn............. (CLINCH)

Guest River at U.S. Hwy 58 (Alternate) at Norto

(CLINCH)

541

541 River at U.S. Hwy 58 (Alternate)

Guest River at mouth nr St. Paul.

(CLINCH)

(CLINCH) 543

Guest River below Bad Branch ar Coeburn. (CLINCH)

Guest River below Bear Creek at Norton. (CLINCH)

Guest River below Lost Creek at Norton. (CLINCH)

Guffey Creek at mouth nI Trout Dale.

(NEW)

Guilford Church Branch at mouth

$$
\text { at Guilford. }
$$

Gullford Creek at mouth nr Guilford... (EASTERN)

Gum Branch at former mouth nr Haliwood. (EASTERN)

Gum Branch at mouth nr Cochran......... (CHOWAN)

Gum Run at mouth at Rawley Springs......... (SHEN)

Gum Spring Branch at mouth nr Roanoke.. (ROANOKE)

Gunns Run at Rt 5 ar Charles City........ (JAMES)

Gunns Run at mouth nr Charles City.

(JAMES) 291

Gunston Cove (Pohick Creek) nr Lorton... (POTOMAC)

Gunther Branch at mouth nr Birch....... (ROANOKE)

Gupton Run at mouth nr Catlett.

( POTOMAC)

Guthrie Creek at mouth ar Gressitt.......... (YORK)

Guthrie Creek at mouth nr Snow Creek.... (ROANOKE)

Guy Creek at Rt 606 ir Nas sawadox....... (EASTERN)

Guys Run at mouth nr Goshen.............. (JAMEs)
H. L. Atkins Spring ar Atkins

(HOLSTON)

H. S. Kinser Spring nr Shawver Miii........ (NEW)

Hackett Creek at mouth nI Ladysmith....... (YORK)

Hackney Creek at Va,-Ky, State Iine nI Big Rock.

(BIG SANDY)

Haddox Branch at mouth nr Addington..... (CLINCH)

Hairston Branch at mouth at Martinsville.

(ROANOKE)

Hale Branch at Rt 714 nr Marvin....... (BIG SANDY)

Hale Creek at mouth nr Bassett......... (ROANOKE)

Hale Creek at mouth nr Patterson.....(BIG SANDY)

Hales Creek at mouth nr Hendricks Store............ (ROANOKE)

Halfway Creek at mouth

nr Cluster Springs.......... (ROANOKE) 416

Halfway Creek at mouth nr Bacons Castie..(JAMES) 301

Halifax Reservoir (Banister Lake) at $\mathrm{Hal}$ if $a x \ldots \ldots$ (ROANOKE)

Ha11 Creek above Tattle Branch nr Glade Spring............. (HOLSTON)

Hall Creek at U.S. HWy il nr Glade Spring............... (HOLston) 505

Hall Creek or Emory................................ 505

Hall Creek ar Glade Spring.............. (HOLSTON)

Hal1 Creek, East Fork, at mouth or Giade Spring.

(HOLSTON)

Halls Spring nr Buena Vista............ (JAMES)

Hamblin Branch at mouth ne Rose Hiii... (POWELL)

Hamilton Branch at Rt 629 above Hugart Run

amilton Branch at mouth nr Deerfield.

Hampton Hal1 Branch at Kinsale........... (POTOMAC) 11

Hampton River at Hampton............... (JAMES) 313

Hampton River at Rt 143 at Hampton........ (JAMES) 313

Hampton River at $R t 351$ at Hampton........ (JAMES) 313

Hampton River at U.S. Hwy 258 at Hampton. (JAMES) 313

Hampton River at mouth at Hampton........ (JAMES) 313

Hancock Branch at mouth nr Oak Hall.... (EASTERN) 19

Handpole Creek at mouth nr Loretto.........(RAPP) 150

Handy Creek at mouth at Poplar Camp........... (NEW) 435

Haneytown Creek at Rt 810

nr stanardsville............... (JAMES)
Haneytown Creek at mouth nI Stanardsville.

Hanks Branch at mouth $n r$ Lambsburg........ (SHEN) 43

Hannah Run at mouth nI Nethers........... (RAPP) 120

Happy Creek (Harmony Hollow Creek) ir Front Royal.

(SHEN) 63

Happy Creek at Kerfoot Ave at Front Royal. (SHEN) 63

Happy Creek at Riverton Junction ir Front Royal.

(SHEN)

Happy Creek at Rt 55 at Front Royal........ (SHEN) 63

Happy Creek at mouth at Front Roya $1 \ldots . . .$. (SHEN) 63

Happy Creek in Lake Gordonsville nr Gordonsville.................. (YORK) 175

Happy Creek trib at Rt 604 ar Gien Echo... (SHEN) 63

Hardware River at Rt 20

at Carters Bridge.............. (JAMES) 244

Hardware River at Rt 618 ir Scottsvilie.. (JAMES) 244

Hardware River at Rt 637 below

Briery Creek (Run) ar Scottsvil1e. (JAMES) 245

Hardware River at mouth at Hardware...... (JAMES) 245

Hardware River, Middle Branch of N.F... at mouth at Red Hill....

Hardware River ne Carters Bridge. (JAMES) 244

Hardware River, N.F., above South Branch at Red Hill.

Hardware River, N.F, at U.S. Hwy 29 at Red Hill.

Hardware River, N.F., below South Branch at Red Hill.

Hardware River, S. $\vec{F}$, above $\dot{N} . \dot{F}$

Hardware River nr Carters Bridge... (JAMES) 243

Hardware River, S.F., at Rt 712 nI Alberene...........

Hardware River, S.F. a

r Carters Bridge ............. (JAMES)

(JAMES) 243

Hardware River, South Branch of $\mathbb{N} . \dot{F}$. at U.S. Hwy $29 \mathrm{nr}$ North Garden..... (JAMES)

Hardware River, South Branch of N.F.

at mouth at Red Hil1............. (JAMES)

244

Hardwood Creek at mouth nr Purdy............ (NEWW

Hardy Creek at Rt 660 ar Smiley........... (POWELL)

Hardy Creek at Rt 661 nr Smiley......... (POWELL)

Hardy Creek at mouth nr Smiley.......... (POWELL)

Hardy Creek trib at mouth at Hagan........ (POWELL)

Hardy Spring Branch at mouth ir Gasburs.

Harkrader Spring nI Grahams Forge............ (NEW)

Harmon Branch at mouth ni Nebo........ (HOLSTON)

Harnsberger Creek at Luray. ............. (SHEN)

Harnsberger Spring No. 3 at Luray.......... (SHEN)

Harnsberger Spring Nos. 1 \& 2 at Luray.... (SHEN)

Harpen Creek at mouth at Sandy Level... (ROANOKE)

Harper Creek at mouth nr Harcum.... (RAPP-YORK)

Harper Creek at mouth nr Oakwood...... (BIG SANDY)

Harpers Run at U.S. Hwy 17 nr Morrisville. (RAPP)

Harpers Run at mouth nI Remington........ (RAPP)

Harris Creek at Lynchburg............... (JAMES)

Harris Creek at Rt $130 \mathrm{nr}$ Monroe.......... (JAMES)

Harris Creek at Rt $20 \mathrm{nr}$ Keene............ (JAMES)

Harrds Creek at Rt $208 \mathrm{nr}$ Louisa............. (YORK)

Harris Creek at Rt 632 nr Trevilians..... (YORK)

Harris Creek at Rt 636 nr Monroe......... (JAMES)

Harris Creek at Rt 675 nr Monroe........... (JAMES)

Harris Creek at mouth nr Lake Anna.......... (YORK)

Harris Creek at mouth nr Louisa........... (YORK)

Harris Creek at mouth nr Prospect......... (JAMES)

Harris Creek below Southern RR at Monroe. (JAMES)

Harris Creek trib nr Monroe............. (JAMES)

Harris River at mouth nr Fox Hill... (YORK-JAMES)

Harris Swamp at mouth nr Jarratt........ (CHOWAN)

Harrison Branch at Colonial Heights...... (JAMES)

Harrison Creek at Petersburg............ (JAMES)

harrison Creek at mouth nr Tunstal1.......(YORK)
244

450

326

562

562

561

424

406

437
512

48

48

48

376

161

459

128

234

234

244
177

177

233

233

171

177

272
233

234

204

326

284

283
187 
Abbreviated basin names appear at the end of the site name. Abbreviations are as follows: Eastern Shore (EASTERN); Potomac to Shenandoah (POT-SHEN): Shenandoah (SHEN); POtOmac (POTOMAC); Potomac to Rappahannock (POT-RAPP); Rappahannock (RAPP); Rappahannock to York (RAPP-YORK); YorK (YORK); York to James (YORK-JAMES); James (JAMES); James to Chowan (JAMES-CHOWAN); Chowan (CHOWAN); Roanoke (ROANOKE) Yadkin (YADKIN); New (NEW); Big Sandy (BIG SANDY); Holston (HOLSTON); Clinch (CLINCH); Powell (BOWELL))

Harry Branch at mouth ar Whitewood... (BIG SANDY) Harry George Creek at mouth ir Water View. (RAPP) Harry Taylor Spring nr McClung........... (JAMES) Hart Creek at mouth nr Coulwood............. (CINCH) Hartmans Spring at Lyndhurst. (SHEN) Harvelis Branch at mouth ni Carson. Harvey Creek at mouth nr Moneta. Harveys Creek at mouth ni Fleeton. CHOWAN (ROANOKE) Hat Creek at Roseland. POT-RAPP (JAMES)

Hat Creek at mouth nr Brookneal..... (ROANOKE)

Hatcher Creek at Rt $667 \mathrm{nr}$ Trents Mi11... (JAMES)

Hatcher Creek at Trents Mi11............ (JAMES)

Hatcher Creek at mouth nr Penhook........ (ROANOKE)

Hatcher Run at Rt 613 nr Reams.......... (CHOWAN)

Hatcher Run at Rt $631 \mathrm{nr}$ Sutherland..... (CHOWAN)

Hatcher Run at mouth nr Reams.......... (CHOWAN)

Hatcher Run trib No, 1 at Rt 670 nI Reams.

Hatcher Run trib No. 2 at Rt 670

(CHOWAN) nr Reams.

(CHOWAN)

Hatcher Run trib No. 2 tributary at Rt 670 n Reams.

CHOWAN )

Hatchet Branch at Rt 655 or Nora.... (BIG SANDY)

Hatchet Creek at mouth nr Waldsboro.... (ROANOKE)

Hatter Run at mouth nr Madison............. (RAPP)

Hawes Millrace at mouth nr Studley........ (YORK)

Hawkins Creek at mouth nr Buckner........ (YORK)

Hawkins Creek at mouth nr Hewlett.......... (YORK)

Hawkins Run at mouth or Dinwiddie.......(CHOWAN)

Hawks Branch at mouth nr Denaro........... (JAMES)

Hawksbill Creek above Dry Run nr Luray.... (SHEN)

HawksbiIl Creek above Rt 675 at Luray..... (SHEN)

Hawksbill Creek above U.S. Hwy 211

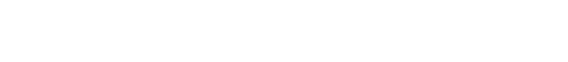

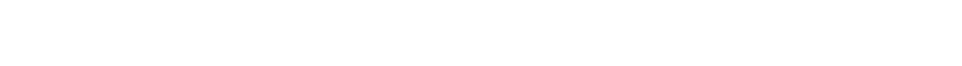

Hawksbill Creek aiong $\mathrm{Rt}$ 654 nr Luray....... (SHEN)

Hawksbill Creek along U.S. Hwy 340

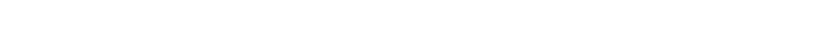

Hawksbill Creek along U.S. Hwy 340 nI Luray.

( SHEN)

Hawksbill Creek at Linden Ave at Luray..... (SHEN)

Hawksbill Creek at Rt 642 at Luray......... (SHEN)

Hawksbill Creek at $R t 548$ at Springeieid.. (SHEN)

Hawksbill Creek at Rt 654 nr Springfield.. (SHEN)

Hawksbill Creek at Rt 675 at Luray......... (SHEN)

Hawksbill Creek at Rt 689 nr Stanley...... (SHEN)

Hawksbill Creek at mouth nr Elkton......... (SHEN)

Hawksbill Creek at mouth nr Springfield... (SHEN)

Hawksbill Creek below STP at Luray......... (SHEN)

Hawksbill Creek below U.S. Hwy 211 (Bypass) at Luray............... (SHEN)

Hawksbill Creek off Rt 648 nr Springfield. (SHEN)

Hawksbill Creek trib at Rt 626 nr Swift Run.

Hawksbill Creek, East, along Rt $62 \dot{s}$ at Ida.

(SHEN)

Hawksbil1 Creek, East, at Rt 642 ni Luray. (SHEN)

Hawksbi11 Creek, East, at mouth at Luray.. (SHEN)

Hay Run at mouth ni Rock Mountain...... (ROANOKE)

Hays Creek at Rt 39 at Rockbridge Baths.. (JAMES)

Hays Creek at Rt 602 nr Rockbridge Baths. (JAMES)

Hays Creek at Rt 724 n Brownsburg....... (JAMES)

Hays Creek at mouth nr Covington......... (JAMES)

Hays Creek at mouth nr Lawrenceville.... (CHOWAN)

Hays Creek nr Rts $602 / 712$

nr Rockbridge Baths............... (JAMES)

Hazel River along Hazel River Trail nI Nethers

459

156

215

534

330

377

115

237

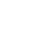

258

372

329

329

330

329

329

329

478

372
137

185

173

172

328
278

49

48

48

48

47

48
48

48

RAPP) 120

Hazel River at Rt 229 at Rixeyviile............ (RAPP) 126

Hazel River at Rt 600 nr Nethers.......... (RAPP)

Hazel River at Rt 604 at Slate Mills nr Woodville.

(RAPP) 120

Hazel River at Rt 618 ir Woodviile............. (RAPP)

Hazel River at Rt 625 nr Rixeyville.

Hazel River at Rt 631 nr Woodville.

(RAPP)

Hazel River at Rt 640 nr Rixeyville.

127

Hazel River at Rt 729 nr Castleton.

(RAPP)

(RAPP)
Hazel River at U.S. Hwy 522 nr Boston.

(RAPP) 122

Hazel River at mouth nr Remington.

Hazel River trib No. 1 at mouth Ir Nethers.

(RAPP) 127

Hazel River trib No. 2 at Rt $23 i$ nr Woodville.

Hazel River trib No. 3 at Rt 231 nr Woodville....

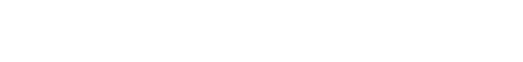

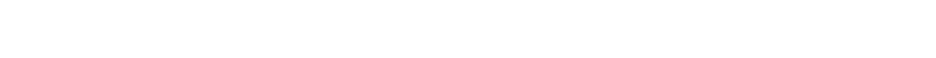

Hazel River trib at Rt 615 nr Castieton... (RAPP) 123

Hazel Run at U.S. Hwy 17 bridge nr Fredericksburg.

(RAPP)

Hazel Run at mouth nr Chanceliorsvilie......(RAPP) 143

Hazel Run at mouth nr Fredericksburg...... (RAPP) 145

Head River Branch at mouth r.r Howland. (POT-RAPP) 114

Health Meadows Branch at mouth nr Carson.

(CHOWAN) 330

Healy Creek at mouth in Wilton......... (RAPP-YORK) 151

Healys Pord trib at Rt 620

ne Harmony Village.......... (RAPP-YORK)

Heartquake Creek at mouth or Truhart......(YORK) 197

Hell Point Creek at Rt 629

nr Sigma............. nr Sigma. . . . . . . . . Whitetop.

Helton Creek at Va. -N.C. State line nr Rugby

Helton Creek, N.F. above $\ddot{S} . \dot{F}$ Helton Creek nr Piney Creek, N.C..... (NEW)

Helveys Mill Creek at mouth at Point Pleasant. .....

Helveys Mill Creak trib No. 1
at Rt 42 at goint Eleasant

Helveys Mill Creak trib No. 2 at Rt 42 at Point Pleasant.

(NEW)

Hemp Fork at mouth nr Chathar

(ROANOKE) 410

Hickory Hollow Branch at Saltpetre Cave.. (JAMES)

Higgins Swamp above Southern RR
47
49

49

48

47

44
50

48

48

49

44

47

48

48

369

227
226

226

211

352.

226

nr Gardonsville.

(RAPP)

Henderson Creek at Rt 729 nr Shadweil.... (JAMES)

Heninger Branch at mouth nr Ceres...... (HOLSTON)

Henry Widener Branch at mouth nr Lodi.. (HOLSTON)

Henshaw Run at mouth nr Stanardsville.... (RAPP)

Hensley Spring nr Elkton............... (SHEN)

Herrick Creok at mouth nr west Point....... (YORK)

Gerring Creek at Rt 600 nr Aylett......... (YORK)

Herring Creek at Rt 609 nr Aylett.........(YORK)

Herring Creek at Westover.............. (JAMES)

Herring creek at mouth nr Aylett.......... (YORK)

Herring Creek trib at mouth

$$
\text { nr Beulahville. }
$$

Hess Creek at Rt 622 at Dye

Heywood Creek at mouth nr Achilies... (RAPP-YORK

Hickaneck Swamp at Rt 616 nr Ivor....... (CHOWAN)

Hickaneck Swamp at mouth nr Raynor....... (CHOWAN)

Hickerson Branch at mouth nr Wood....... (CI INCH)

Hickman Run at Rt 647 at Flint Hiil........ (RAPP)

Hickman Run at mouth nr Flint Hi11......... (RAPP)

Hickory Creek at Rt 669 below

Lake Louisa nr Louisa.

(YORK) 166

Hickory Creok at Southern $R R$ at Faber..... (JAMES) 242

Hickory Creek at U.S. Hwy 29

$$
\text { nr Covesville. }
$$

(JAMES)

Hickory Creek at mouth nr Brookneai.... (ROANOKE)

Hickory Creek at mouth nr Louisa.......... (YORK)

Hickory Creek, N.F., at mouth ne Louisa... (YORK)

Hickory Creek, S.F., at mouth nz Louisa... (YORK)

Gickory Run at mouth nr Rawlings........ (CHOWAN)

Hickory Swamp at mouth nr Jarratt.

Hickory Swamp at mouth nr Jarratt....... (CHOWAN) 333

Hidens Branch at mouth at Culpeper....... (RAPP) ns White Oak Swamp.

( JAMES )

135

512

495

133
44

187

(9)

290

195

530

165
342

342

544

17

17

242

242
386

386
166

166

166

220

129

123
123 
Abbreviated basin names appear at the end of the site name. Abbreviations are as follows:

Eastern Shore (EASTERN); Potomac to Shenandoah (POT-SHEN); Shenandoah (SHEN): Potomac (POTOMAC);

Potomac to Rappahannock (POT-RAPP); Rappahannock (RAPR); Rappahannock to York (RAPP-YORK); York (YORK)

York to James (YORK-JAMES); James (JAMES); James to Chowan (JAMES-CHOWAN); Chowan (CHOWAN); Roanoke (ROANOKE);

Yadkin (YADKIN); New (NEW); Big Sandy (BIG SANDY); Holston (HOLSTON); Clinch (CLINCH); POWell (POWELL)]

Page

Hi 11 Creek at mouth at Long Is land..... (ROANOKE) Hills Creek at mouth nr Hodges.......... (ROANOKE)

Hills Creek at mouth nr Irvington.......... (RAPR)

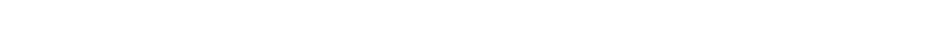
Hilton Creek at mouth at Hiltion.......... (HOLSTON) Hites (Heights) Spring nr Luray............ (SHEN) Hittles Mill Stream at U.S. Hwy 522 at Flint Hill.

(RAPP)

Hittles Mill Stream at nouth nr Flint Hill.

(RAPP)

Hobbs Branch at mouth $\mathrm{nr}$ Grundy....... (BIG SANDY)

Hobby Swamp at mouth nr Paige........... (YORK)

Hockley Creek at mouth nr Hockley......... (YORK)

Hodges Cove at Fish Neck (YORK-JAMES) Hog Neck Creek at mouth nr Modest Town:

(EASTERN) 11

Hogan Branch at mouth at Bulaski........... (NEW) 442

Hogan Creek at mouth nr Dryburg........ (ROANOKE) 393

Hog camp Branch at mouth nr Syria........... (RAPP) 136

Hogue Creek at Rt 614 nr Hayfield..... (POT-SHEN) 21

Hogue Creek at Rt $679 \mathrm{nr}$ Hayfield.....(POT-SEEN) 21

Hosue Creek at U.S. Hwy 50 nr Hayfield....... Hiwy

Hogue Creek at U.S. Hwy 522 nr Gainesboro.

$\ldots \ldots \ldots$ (POT - SHEN)

21

Hogue Creek at mouth nr Cedar Grove.. (POT-SHEN)

Hogwallow Branch at mouth nr Repass..... (CLINCH)

Holdens Creek above mouth nr Sanford... (EASTERN)

Holdens Creek at Rt 701 nr Makemie Park. . (EASTERN)

Holdens Creek at mouth ir Sanford...... (EASTERN)

Holdens Creek below Rt 701 nr Makemis Park.

(EASTERH)

Holiday Creek (Cemetery Creek)

at 4-H Camp nr New Store.......... (JAMES)

Holiday Creek (Holiday Lake)

at Holiday Lake Dam nr New Store... (JAMES)

Holiday Creek (Holiday Lake)

below Forbes Creek nr New Store.... (JAMES)

Holiday Creek above Forbes Creek nr New store.

(JAMES)

Holiday Creek above Rt 614

nr Andersonville ............... (JAMES)

Holiday Creek at mouth nr New Store...... (JAMES)

Holiday Creek nr Toga.................. (JAMES)

Holladay Branch at mouth nr Glen Allen... (JAMES)

Holland Run nr mouth at Lake Kilby....... (JAMIS)

Hollies Church Branch at mouth nr Pungoteague.

Hollowing $C r e e k$ at mouth nr Beaverdam..... (YORK)

Holiy Creek above Rock Branch at Clintwood.

(BIG SANDY)

Holly Creek at Clintwood..................... (BIG SANDY)

Holly Creek at Rt 607 at Clintwood... (BIG SANDY)

Holly Creek at Rt 672 at Clintwood... (BIG SANDY)

Holly Creek at mouth nr Clintwood.... (BIG SANDY)

Holly Grove Cove at mouth ar Franktown. (EASTERN)

Hollywood Dam powerplant outfall at Richmond................. (JAMES)

Holmans Creek at Rt $\dot{6} \dot{g} 8$ at Quicksburg...... (SHEN)

Holmans Creek at mouth nr Quicksburg...... (SHEN)

Holmes Run above Lake Barcroft nr Annandale................. (POTOMAC)

Holmes Run above Rt 236 at Alexandria. (POTOMAC)

Holmes Run at Annandale Rd Ir Annandale.

(POTOMAC)

Holmes Run at Holmes Run Acres nr Annandale................. (POTOMAC)

Holmes Run at North Chambiis st at Alexandria.

( POTOMAC)

Holmes Run at Rose Lane nr Annandale... (POTOMAC)

Holmes Run at Shirley Hwy at Alexandria.

(POTOMAC)

Holmes Run at Shreve Rd at Merrifield.. (POTOMAC)

Holmes Run at Sleepy Hollow Rd nr Annandale.

( POTOMAC)
21

21
21
531

531
19

19

19

19

271

272

271

271

271

272
271

292

306

15

173

486

486

486

486

486

15

266
55

55
55

81

82

81

81

82

81

82

81

81
383

382

521

521
49

117

117

01

191
198

202

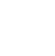

3

Holmes Run at U.S. Hwy 50 at Merrifieid.

Holmes Run at mouth at Alexandria.......... (POTOMAC)

Holmes Run below Lake Barcroft nr Alexandria.............. (POTOMAC)

Holmes Spring nr Goshen...............JAMES) 226

Holmes Swamp at mouth nr Center Cross.

Holston River. Middle Fork. above Marion. ............

(RAPP-YORK) 160

Holston River, Middie Fork, at Rt 762 at Chilhowie......... (HOLSTON) 504

Holston River, Middle Fork, below Marion................ (HOLSTON) 501

Holston River, Middle Fork, above

Bear Creek or Marion............ (HOLSTON)

Holston River, Middle Fork, above Ś $\dot{T}$ at Marion.................. (HoLston) 501

Holston River, Middle Fork, at

U.S. Hwy II nr Groseclose.........(HOLSTON) 499

Holston River, Middle Fork, at

U.S. Hwy 11 nr Marion............ (HOLSTON) 500

Holston River, Middle Fork, at

U.S. Hwy 11 at Seven Mile Ford... (HOLSTON) 503

Holston River, Middle Fork, at U.S. Hwy $58 \mathrm{nr}$ Osceola.......... (HOLSTON)

Holston River, Middle Fork, at at U.S. Hwy 11 at Marion...... (HOLSTON)

Holston River, Middle Fork, at Rt $6 \dot{59}$ above Laurel Springs Creok nr Marion................

(HOLSTON) 502

Holston River, Middle Fork, at Rt 679

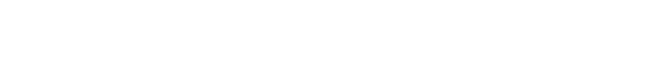

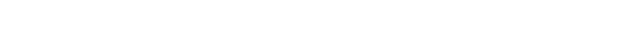

Holston River, Middie Fork, at $\mathrm{Rt} i i_{4}$ nr Glade Spring........

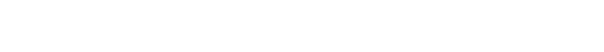

Holston River, Middle Fork, at mouth nr Watauga. 'jid Fork, bejow Bear Creek at Atkins............(HOLSTON) 500

Holston River, Middle Fork, off Rt 608 above Greever Branch nr Chilhowie.

(HOLSTON) 499

(HOLSTON) 500

(HOLSTON) 505

(HOLSTON) 506

(HOLSTON) 507 on River, Middle Fork, trib No. 1 at mouth nr Groseclose........ at mouth nr Seven Mile Ford...... (HOLSTON) 503

Holston River. Middle Fork, trib No. il at mouth at Seven Mile Ford...... (BOLSTON)

Holston River, Middle Fork, trib No. 12 at mouth at Seven Mile Ford....... (HOLSTON)

503

Holston River. Middle Fork, trib No. is at mouth at Chilhowie........... (HOLSTON)

Holston River, Middle Fork, trib No. 14 at mouth at Chilhowie........... (HOLSTON)

504

Holston River, Middle Fork, trib No. is at mouth nr Chilhowie........... (HOLSTON)

Holston River. Middle Fork, trib No, 16 at mouth $n r$ Glade Spring......... (HOLSTON)

Holston River, Middle Fork, trib No. 17 at mouth nr Glade Spring......... (HOLSTON)

Holston River, Middle Fork, trib No, 18 at mouth $\mathrm{nr}$ Meadowview.......... (HOLSTON) 506 Holston River, Middle Fork, trib No. 19 at mouth nr Osceola.............. (HOLSTON)

Holston River. Middle Fork, trib No. 2 at mouth at Groseclose.......... (HOLSTON)

499

Holston River, Middle Fork, trib No. 3 at mouth nr Atkins............(HOLSTON)

Holston River, Middle Fork, trib No, 4 at mouth $\mathrm{nr}$ Atkins............. (HOLSTON)

Holston River, Middle Fork, trib No. 5

at mouth nr Atkins............. at mouth ne Marion................ HOLSTON) 
Abbreviated basin names appear at the end of the site name. Abbreviations are as follows

Eastern Shore (EASTERN); Potomac to Shenandoah (POT-SHEN): Shenandoah (SHEN); POtomac (POTOMAC)

Potomac to Rappahannock (POT-RAPP); Rappahannock (RAPP); Rappahannock to York (RAPP-YORK); York (YORK)

York to James (YORK-JAMES); James (JAMES); James to Chowan (JAMES-CHOWAN); ChOWan (CHOWAN): ROanoke (ROANOKE);

Yadkin (YADKIN); New (NEW); Big Sandy (BIG SANDY); Holston (HOLSTON); Clinch (CLINCH); Powell (POWELL))

Holston River, Middle Fork, trib No. 7 at mouth nr Marion.............

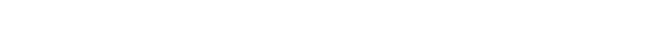

Holston River, Middle Fork, trib No. 9 at mouth nr Seven Mile Ford...... (HOLSTON) 503 Holston River, N.F., abovo Moccasin Creek nr Weber City.....(HOLSTON) 521

Holstor River, N.F., above Turkey Run Creek at McCready.....(HOLSTON) 514 Holston River, N.F., along Rt 42 nr Broadford...........

Holston River, N.F along Rt 611 below Saltville........ nir Saltville.

HOLSTON) 502

HOLSTON) 502

Barker Mill Dam at Mendota.......(HOLSTON) 520

Holston River, N.F., at Nebo............ (HOLSTON) 512

Holston River, N.F., at Rt $6 i 1$ nr Plasterco........ Ri $6 \dot{6}$ ij at Saltvilie...............(HOLSTON) 515

Holston River, N.F. at Rt $6 i \dot{s}$ at Mendota................... (HoLsTon)

Holston River, N.F. at Rt 633 above Beaver Creek ni North Holston....(HOLSTON) 514

Holston River, N.F.' at Rt 91 below Cedar Branch at Saltville........(HOLSTON) 515

Holston River, N.E., at Southern RR nr Mendota.................(HOLSTON) 519

Holston River, N,. , at U.S. Hwy is at Holston........................ 519

Holston River, N.F., at U.S. Hwy 23 nr Gate City................. HOLSTON) 523

Holston River, N.E. at Va. Tenn. State line nr' Weber City.........(HOLSTON) 524

Holston River. N.F. bolow Locust Cove Ćreek nr Broadford... (HOLSTON) 513

Holston River, N.F., nr Craigs Mill.... (HOLSTON) 519

Holston River, N.F. nr Henrytown

Holston River, N.F., off Rt $61 i$ above Stonemill Creek nI Plasterco.....(HOLSTON) 515

Holston River, N.F., off Rt 611 below Mchenry Creek nr Plasterco.......(HOLSTON) 515

Holston River, N.F., trib No. 1 at mouth at Ceres........................

Holston River, N.F., trib No. 2 at mouth nr Ceres....... at mouth $\mathrm{nr}$ Nebo.................

Holston River, N.F., trib No. at mouth nr Plasterco....
on River. N.F. trib No. at mouth at Pine Grove...

Holston River, N.F., trib No. at mouth at Mendota........

Holston River, N.F. trib No. 7 at mouth nr Maces Spring.

at mouth ar Hilton........... (HOLSTON)

(HOLSTON) 520

Holston River, N.F. trib No. 8 tributary nr Hilton...... at mouth $\mathrm{nr}$ Weber City........... (HOLSTON)

(HOLSTON) 521

Holston River. N.F trib No.

Holston River, S.F., (South Holston Lake) above Mays Branch nr Watauga..... (HoLsToN) 507

Holston River, S.F. (South Holston Lake) above Fifteenmile Creek nr Green Spring.................(HOLSTON) 507

Holston River, S.F., (South Holston Lake) above Wolf Creok nr Green Spring. (HOLSTON) 508

Golston River, S.F., (South Holston Lake) off Cox Mill (Mill) Croek

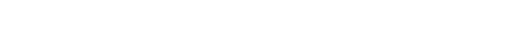

(HOLSTON) 507

Holston River, S.F. I.I mi above Laurel Creek ir Damascus......... (HOLSTON)
Holston River, $S, F$, above

U.S. Hwy 58 nir Damascus

Holston River, S.F., above Grosses

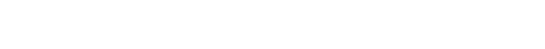

Holston River, S.F., above Laurel Creek nr Damascus................ (HOLSTON) 496

Holston River, S.F., above Middle Fork Holston River' nr Alvarado........(HOLSTON) 498

Holston River, S.F., above Rt 645 at Riverside nr Chilhowie.

Holston River, S.F., along Rt 675 at Sugar Grove...............

Holston River, S.F., at Rt 600 at Saint Clair Bottom, at Toas.............................

Holston River, S.F., at Rt 670 at Roberts Mill nr Sugar Grove...... (HOLSTON) 492

Holston River, S.F., at Rt 710 above Louse Creek at Alvarado...........(HOLSTON) 498

Holston River, S.F., at Rt 712 at Delmar nr Damascus...........(HOLSTON) 498

Holston River, S.F., at Sequoya Camp nr Green Spring.............

Holston River, S.F., at U.S. Hwy 58 nr Damascus ....................... (HOLSTON) 498

Holston River, S.F. , at Va. Tenn. State line below Taylor Knob nr Green Spring............

Holston River, S.F., at Va. -Tenn. State line nr Groen Spring.......(BOLSTON)

Holston River, S.F. below Grosses Creek nr Murrayfield.

Holston River, S.F., below Middle Fork Holston River'nr Watauga.........

Holston River, S.F. below Va.-Tenn. State line nr Green Spring.

Holstor River, S.F., trib No. 1

Holston River, S.F. trib No. 10 n Iodi.

$\ldots \ldots$ (HOLSTON) HOLSTON) 509

(HOLSTON) 495

(HOLSTON) 507

(HOLSTON) 509 River, S.F, trib No. 11 at mouth nr Drowning Ford.

Holston River, S.F., trib No. 12 at mouth nr Deimar......

(HOLSTON)

Holston River, S.F., trib No. 2
Holston River, S.F., trib No. 3 nr Quebec........ at mouth at Riverside....

Holston River. S.F. trib No. 5

at mouth at Riverside.......... (HOLSTON)
Holston River, S.F. trib No. 6 (HOLSTN) at mouth nr Saint Clair Bottom...(HOLSTON) 494 Holston River, S.F., trib No. 7 at mouth nr Saint Clair Bottom...(HOLSTON) 494

Holston River, S.F., trib No. 8 nr Lodi ................... (HOLSTON) Holston River, S. F. , trib No. 9 nr Lodi .................... (HOLSTON)

Holt Creek at mouth nr Machipongo....... (EASTERN)

Gome Creek at Rt $700 \mathrm{nr}$ Big Rock..... (BIG SANDY)

Home Creek at mouth nr Aiken Sunmit.... (ROANOKE)

Gome Creek at mouth nr Bis Rock...... (BIG SANDY)

Home Creek, Left Fork, at mouth nr Big Rock. .

(BIG SANDY) 463

Hone Quarry Run at mouth in Briery Branch. (SHEN) 26

Hone Quarry Run nr Briery Branch.......... (SEEN) 26

Boney Branch at mouth at Morefield....... (CLINCH)

Honey Branch at mouth nr Wakenva..... (BIG SANDY)

Honey Run at Rt 42 at Timbervilie.......... (SHEN)

Honey Run at Southern RR at Timbervilie... (SHEN)

Honey Run at mouth nr Alma........... (SHEN)

Hooes Run above Rt 641 nI Occoquan...... (POTOMAC)

Hooes Run at mouth nr Occoquan......... (POTOMAC)

Hookers Creak at mouth nr Claudville... (ROANOKE)

Hooks Branch at mouth at Marion........(HOLSTON)

498

94

96

494

94

2

8

98

9

7


Abbreviated basin names appear at the end of the site name. Abbreviations are as follows:

Eastern Shore (EASTERN); Potomac to Shenandoah (POT-SHEN): Shenandoah (SHEN); POtomac (POTOMAC);

Potomac to Rappahannock (POT-RAPE); Rappahannock (RAPP); Rappahannock to York (RAPP-YORK); York (YORK)

York to James (YORK-JAMES); James (JAMES); James to Chowan (JAMES-CHOWAN); Chowan (CHOWAN); Roanoke (ROANOKE);

Yadkin (YADKIN); New (NDW); Big Sandy (BIG SANDY); holston (HOLSTON); Clinch (CLINCH); Powel1 (POWELL)]

Hopkins Branch at mouth nr Thomas Bridge.

Forn Harbor at Mill Point nr New Point.

(HOLSTON)

493

162

Horner Run at Rt 691 nir Marshaij

(RAPP-YORK)

(RAPP)

(RAPP)

Horner Run at mouth nr Marshall.

(ROANOKE)

(JAMES)

Horners Run at mouth at Richmond.

(CHOWAN)

Hornet Swamp at Rt $655 \mathrm{nr}$ Joyner.

Hornet Swamp at mouth nr Joyner......... (CHOWAN)
Hornet Swamp trib at Rt $608 \mathrm{nr}$ Joyner... (CHOWAN)

Hornquarter Creek at mouth nr Hanover...... (YORK)

Horse Mountain Creek above

Covington Reservoir nr Covington... (JAMES) 212

Horse Mountain Run nr Covington......... (JAMES)

Horse Pasture Creek at mouth r Spencer.

(ROANOKE) 397

Horse Swamp Creek at C\&O RR at Richmond. (JAMES) 294

Horse Swamp at mouth nr Zuni.......... (CHOWAN) 344

Horsepen Branch at Rt 626 nr Dory.......... (CHOWAN) 343

Horsepen Branch at U.S. Hwy 250 at Richmond. . . . . . . . . .

Horsepen Branch at former mouth nr Mannboro. . . . . .

Horsepen Branch at mouth

nr Fredericks Hall.

(YORK)

Horsepen Branch at mouth at Richmond....... (JAMES)

Horsepen Branch at mouth nr Cherry Hiii. (CHOWAN)

Horsepen Branch at mouth nr Chula........ (JAMES)

Horsepen Branch at mouth nr Vicksvilie.. (CHOWAN)

Horsepen Branch trib at Rt $628 \mathrm{nr}$ Dory. (CHOWAN)

Horsepen Creok at Rt 16 at Va. $-W$. Va State line at Bishop....... (BIG SANDY)

Horsepen Creok at Rt $667 \mathrm{nr}$ Hallsboro.... (JAMES)

Horsepen Creek at mouth at Buckingham.... (JAMES)

Horsepen Creak at mouth at Randolph.... (ROANOKE)

Horsepen Creok at mouth nr hallsboro..... (JAMES)

Horsepen Creak nr Blackstone.

Horsepen Run at Dulles Access Rd

nr herndon...

(CHOWAN)

( POTOMAC)

(POTOMAC)

Horsepen Run at Sully Rd $n r$ Herndon.... (POTOMAC)

Horsepen Run at West Ox Rd nr Floris... (POTOMAC)

Horsepen Run at mouth nr Fivemile Fork.... (RAPP)

Horsepen Run at mouth nr Sterling....... (POTOMAC)

Eorsepen kun below Frying Pan Branch nr Herndon.

Horsepen Springs nì Birigss.

(POTOMAC)

(SHEN)

Horseshoe Branch at mouth nr Hardy...... (ROANOKE)

Hors ley Creek at mouth nI Big Island..... (JAMES)

Horton Branch at mouth nr Clinchport.... (CLINCH)

Hoskins Creek at Rt 618 nI Tappahannock... (RAPP)

Hoskins Creek at Rt $659 \mathrm{nr}$ Tappahannock... (RAPP)

Hoskins Creek at Rt 717 nr Tappahannock... (RAPP)

Eoskins Creok at U.S. Hiwy 360 nI T appahannock.

(RAPP) 153

Hoskins Creok at mouth ar Tappahannock..... (RAPP) 153

Hot Springs Run at Bacova Junction...... (JAMES) 208

Hot Springs Run at Rt 687 at Callison..... (JAMES) 208

Hot Springs Run at mouth nr Callison...... (JAMES) 208

Hot Springs Run nr Bacova Junction....... (JAMES) 208

Houchins Creek at Rt 729 nr Simeon....... (JAMES) 254

Houff Spring nr Lyndhurst............... (SHEN)

Houndshell Branch at mouth

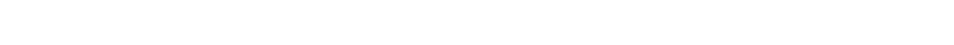

Houses Creek at mouth $\mathrm{nr}$ Ankum..... (CHOWAN) 355

Howell Branch above Morton Foods

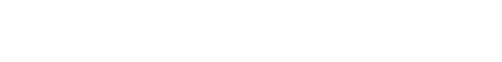

(JAMES) 247

Howe 11 Branch above confluence with Lickinghole Creek nr Crozet... (JAMES) 248

Howell Branch at Morton Foods Plant nr Crozet.

(JAMES) 247

Howell Branch at mouth nr Georges For

Howel 1 Branch at mouth nr Floyd.

Howell Branch below Morton effluent

(NEW) 445 Br crozet.

(JAMES) 248

Howell Branch nr Crozet.
Howell Creek at mouth nr Pittsylvania.. (ROANOKE)

376

Howsers Branch at private road nr Oat 1 ands

Euckleberry Branch at mouth

ne Edgerton.

(POTOMAC)

71

Huckleberry Creek at mouth nr Floyd.......(NEW) 445

Huddle Branch at mouth nr Rural Retreat.

Hudson Creek above Camp Creek nI Boswe 11s Tavern........ (YORK) 17

Huff Creek at U.S. Hwy 60 nr Amberst...... (JAMES) 239

Huff Creek at mouth nr Amberst............. (JAMES) 239

Huff Creek trib nr Amherst ............. (JAMES) 239

Hughes Creek at mouth nr Goochland....... (JAMES) 261

Hughes Creek at mouth nr Nettieridge.... (ROANOKE) 395

Hughes Draft at mouth nr Natural Weli....(JAMES) 208

Hughes River at Nicholson Hollow Trail nr Nethers. $\mathrm{River}$ at Rt $23 \dot{3}$ n Peola Milis

Hughes River at Rt 231 nr Peola Milis

Hughes River at Rt 601 at Peola Milis nr Etlan.

(RAPP)

121

River at Rt $604 \mathrm{nr}$ Griffinsbur8.... (RAPP)

Hughes River at Rt 605 nr Woodville........ (RAPP)

Hughes Run at mouth nr Fort Royal.

122

Humes Run at mouth nr Shenandoah.......... (SHEN)

Humphrey Creek at mouth nr Louisa.

Hundley Branch at mouth nr Grady...... (ROANOXF)

Hungars Creek at mouth nr Machipongo... (EASTERN)

Hungary Creek at mouth nr RIchmond........ (JAMES)

Hungry Mother Creek (Hungry Mother Lake)

nr Marion. ................... (HOLsTON)

Hungry Mother Creek above

Hungry Mother Lake nr Marion..... (HOLSTON)

Hungry Mother Creek above

campground STP nr Marion.......... (HOLSTON)

Hungry Mother Creek above mouth at Marion

(HOLSTON)

(HOLSTON)

Mother Creek along Rt 703

Mother Creek at Hungry Mother

State Fark Dam nr Marion.

(HOLSTON)

Hungry Mother Creek at Marion........... (HOLSTON)

Hungry Mother Creek at Rt 16 nr Marion. (HOLSTON)

Hungry Mother Creek trib at mouth nr Marion.

(HOLSTON)

Hungry Mother Creek trib nr Marion..... (HOLSTON)
Eungry Run at mouth at Aldie.......... (POTOMAC)

Eungry Run at mouth at Aldie.

Hungry Run below Merrimac Lake Dan nr Culpeper

(RAPP)

Hunnicut Creek at mouth nr Bacons Castle. (JAMES)

Hunters Branch at U.S. Hwy $15 \mathrm{nr}$ Palmyra. (JAMES)

Hunters Swamp at mouth nr Walters....... (CHOWAN)

Hunting Camp Creek at mouth nr Bastian..... (NEW)

Hunting Creek (Cameron Run) at

U.S. Hwy 1 at Alexandria.

Hunting Creek (Caneron Run) at mouth at Alexandria.

(POTOMAC)

(POTOMAC)

Hunting Creek above STP at

Rts $611 / 241$ at Alexandria........ (POTOMAC)

Hunting Creek across from Oaks Landing at Lee Mont

Hunting Creek at Alexandria STP at Alexandria............... (POTOMAC)

(EASTERN)

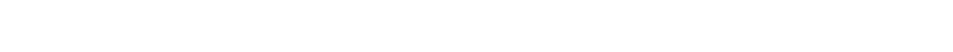

Hunting Creek at end of Rt 670 at Hopkins.

Hunting Creek at end of Rt 749 at hopkins.

(EASTERN)

(EASTERH)

Hunting Creek at mouth nr Mount Laure 1

(ROANOKE)

Hunting Creek at mouth nr Deltaville....... (RAPP)
Hunting Creek at mouth nr Hopkins......(EASTERN)

hunting Creek trib at Rt 763

nr Parksley.
121

122

147

113

167

14

294

502

502

502

502

501

502

502

502

502

502

502

129

302

256

344
454

84

85

84

17

84

232

17

17

389

159

17 
Abbreviated basin names appear at the end of the site name. Abbreviations are as follows:

Eastern Shore (EASTERN); Potomac to Shenandoah (POT-SHEN); Shenandoah (SHEN); Potomac (POTOMAC);

Potomac to Rappahannock (POT-RAPP); Rappahannock (RAPP); Rappahannock to York (RAPP-YORK); York (YORK)

York to James (YORK-JAMES); James (JAMES); James to Chowan (JAMES-CHOWAN); Chowan (CHOWAN); ROanoke (ROANOKE)

Yadkin (YADKIN); Now (NEW); Big Sandy (BIG SANDY); holston (HOLSTON); Clinch (CLINCH); Powell (POWELL)]

Page

Hunting Quarter Creek at Rt 632

nr Littleton.................

Hunting Quarter Creek at mouth
nr Littioton.................

Hunting Quarter Creek trib No.

at Rt $634 \mathrm{nr}$ Sussex.............. (CHOWAN)

Hunting Quarter Swamp at Rt 641 nr Sussex.............

Hunting Quarter Swamp at Rt 735

Bunting Quarter Swamp trib No. i

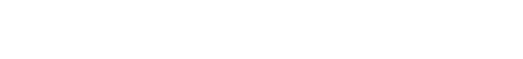

Hunting Quarter Swamp trib No. at Rt $735 \mathrm{nr}$ Sussex...

........ (CHOWAN)

(CHOWAN)

Hunting Run at mouth nr Chanceilorsviile. (RAPP)

hunts Creek at mouth nr Arvonia.......... (JAMES)

Hunts Creek at mouth nr Breaks........ (BIG SANDY)

Hunts Fork at mouth nr Kolsa.......

487

Hurricane Branch at Rt 40 at BLackstone

(BIG SANDY)

cane Branch at mouth nr Whit ewood.

(CHOWAN)

Hurricane Branch at mouth nr Biackstone. (CHOWAN)

Hurricane Branch nr Blackstone......... (CHOWAN)

Hurricane Branch trib at Blackstone .... (CHOWAN)

Hurricane Creek above Gilbert Fork nr Davenport............. Fork nr Davenport.

(BIG SANDY)

(BIG SANDY)

Hurricane Creek above Parett Fletcher Branch nr Davenport......

nr Davenport................. (BIG SANDY)

332

332

332

331

332

331

332

143

246

490

323

458

324

323

324

467

466

467

466 nI Davenport............... (BIG SANDY)

Hurricane Creek at $R t \quad 600$ above

Rockhouse Branch nr Davenport. (BIG SANDY)

467 cane Creek at Rt 80 at Davenport.............. (BIG SANDY)

Hurricane Creek at mouth at Davenport..................... SANDY)

468

Hurricane Creek at mouth nr Lunenburg... (CHOWAN) 348

Hurricane Creek at mouth nr Trout Dale. (HOLSTON) 493

Hurricane Creek below Gilbert Fork nI Davenport.............. (BIG SANDY)

Hurricane Creek below Pealog Branch nr Davenport............. (BIG SANDY)

467 ane Croek, Left Fork, above Boyd Branch nr Davenport....... (BIG SANDY) 468

Hurricane Creek, Left Fork, above Ivy Lick Creek nr Davenport.... (BIG SANDY) 468

Hurricane Creek, Left Fork, above Jakes Fork $n r$ Davenport........ (BIG SANDY) 468

Hurricane Creek, Left Fork, above New Camp Branch nr Davenport... (BIG SANDY) 467

hurricane Creek, Left Fork, above Ratcliff Fork nr Davenport..... (BIG SANDY)

Hurricane Creek, Left Fork, at Rt 600 nr Davenport... F. (BIG SANDY)

Hurricane Croek, Left Fork, at mouth nI Davenport.............. (BIG SANDY)

Hurricane Fork at $\dot{R} t{ }_{6} 0 \dot{0}$ nr South Clinchfield............ (CLINCE)

Hurricane Fork at mouth nr hurley..... (BIG SANDY)

Hutton Branch at mouth nr Marion....... (HoLsTON)

Hutton Creok at Huff Airport Rd nr Chilhowie.

Hutton Creek at U.S. Hwy ii

nr Chilhowi...... (HOLSTON)

Hutton Creek at mouth $\mathrm{n} r$ Chilhowie..... (HOLSTON)

Hutton Creek trib $n r$ Glade Spring...... (HOLSTON)

Byco River at Rt $738 \mathrm{nr}$ Omega.......... (ROANOKE)

Hyco River at U.S. Hwy 501

ne Denntston................ (ROANOKE)

Hyco River at U.S. Hwy 58 nr Ómega..... (ROANOKE)

Hyco Rtver at mouth $n r$ Midway.......... (ROANOKE)
Inch Branch at mouth nr Lyndhurst.

Indian Branch (Mili Run) at Rt 35 nr Sebrell.

Indian Branch (Mi $i i$ Run) at mouth ne Sebreit

Indian Branch trib at Rt 35 nr Sebrei... (CHOWAN)

Indian Creek above Copperhead Branch nr Counci2................. (BIG SANDY)

Indian Creek above Little Indian Creek ns Council............... (BIG SANDY)

Indian Creek above Puncheon Camp Branch nr Council............ (BIG SANDY)

Indian Creek above Sullivan Branch nr Duty.................... (BIG SANDY)

Indian Creek above Tank HoLlow Branch nr Stephens................. (BIG SANDY)

Indian Creek above Three Forks nr Duty.................. (BIG SANDY)

Indian Creek above U.S. Hwy 23 at Pound.................. (BIG SANDY)

Indian Creek above buoy 8

nr Kilmarnock............... (POT-RAPP)

Indian Creek along Rt 602 at Duty..... (BIG SANDY)

Indian Croek at Cedar Bluff............ (CIINCH)

Indian Creek at Indian Croek Rd nr Saint Brides........... (JAMES-CHOWAN)

Indian Creek at Kilmarnock Wharf at Kilmarnock............... (BOT-RAPP)

Indtan Creek at Lowesville............ (JAMES)

Indi an Creek at Nash Mill $\mathrm{nr}$ Wheelor.... (POWELL)

Indian Creek at Rt 602 at Duty....... (BIG SANDY)

Indian Creek at Rt 612 at harman..........(CLINCH)

Indi an Creak at Rt 724 at Ewtng....... (POWELL)

Indian Creek at U.S. Hwy 19 at Wardell.. (CLINCH)

Indian Creek at U.S. Hwy $58 \mathrm{nr}$ Caylor... (POWELL)

Indian Creek at Va. -Tenn. State line at Gibson Station............... (POWELL)

Indian Creek at buoy 11 at $\mathrm{K} i \mathrm{imarnock}$. (POT-RAPP)

Indian Creek at and of Rt 756 nr Kilmarnock. .

Indian Creek at mouth nr Hendricks Store............ (ROANOKE)

Indian Creek at mouth at Cedar Bluff... (CLINCH)

Indian Creek at mouth at Pound....... (BIG SANDY)

Indian Creek at mouth at Warde11........ (CLINCH)

Indian Creek at mouth nr Apple Grove....... (YORK)

Indian Creek at mouth nr Cherry Hill.... (CHOWAN)

Indian Creek at mouth nr Davenport... (BIG SANDY)

Indian Creek at mouth nr Kilmarnock... (POT-RAPP)

Indian Creek at mouth nr Stering...... (POTOMAC)

Indian Creek below Cane Creek at Duty.

Indian Creek trib No. I at mouth nr Duty................

Indian Croek trib No. 1 at mouth nr Gibson Station........ 602

Indian Creek trib No. 2 at Rt 602 nr Duty........ 2 at mouth

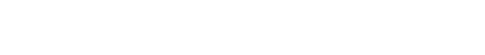

. . (BIG SANDY)

... (BIG SANDY)

Page

39

337

337

337

469

469

469

471

482

469

115

470

527

319

115

237

564

470
527

563

531

563

564

115

115

368

528

482

531

178

326
471

115

74

471

469

Indian Creek trib No. 3 bolow Cane Creek nr Duty............ (BIG SANDY)

Indian Creek trib No. 4 above Sullivan Branch nr Duty........ (BIG SANDY)

Indian Creek trib at Kilmarnock ........ (POT-RAPP)

Indian Creek, Left Fork, at mouth nr Warde $11 \ldots \ldots \ldots \ldots \ldots \ldots$ (CLINCH)

Indian Crook, North Branch, above South Branch Indian Creek nr Harman..... (CLINCE)

Indian Creek, South Branch, above North Branch Indian Creek nr Harman..... (CLINCH)

Indian Draft at mouth nr Falling Spring. . (JAMES)

Indian Field Creek at mouth nr Yorktown... (YORK)

Indian Gap Run trib at Buona Vista....... (JAMES)

Indian Grave Creek at mouth nr Pulaski.... (NEW)

Indian Run at Braddock Rd at Alexandria.

(POTOMAC) 
Abbreviated basin names appear at the end of the site name. Abbreviations are as follows

Eastern Shore (EASTERN); Potomac to Shenandoah (POT-SHEN); Shenandoah (SHEN); Potomac (POTOMAC);

Potomac to Rappahannock (POT-RAPP); Rappahannock (RAPP); Rappahannock to York (RAPP-YORK); YOrk (YORK);

York to Janes (YORK-JAMES); James (JAMES); James to Chowan (JAMES-CHOWAN); ChOWan (CHOWAN); ROanoke (ROANOKE);

Yadkin (YADKIN); New (NEW); Big Sandy (BIG SANDY); Holston (HOLSTON); Clinch (CLINCH); POWell (POWELL)]

Page

Indian Run at Cherokee St. at Alexandria.

(POTOMAC) 83

Indian Run at New Market at Lafayette.. (ROANOKE) 359

Indian Run at Rt 229 nr Rixeyville.......(RAPP) 126

Indian Run at mouth at Alexandria...... (PÓTOMAC) 83

Indian Run at mouth nr Glade Spring.... (HOLSTON) 505

Indian Run at mouth nr Rixeyville.........(RAFP) 127

Indiantown Creek at mouth nr Eastvilie.

(EASTERN) 13

Indigo Branch at Rt $633 \mathrm{nr}$ Dory......... (CHOWAN) 343

Indigo Branch at mouth nr Vicksville... (CHOWAN) 343

Ingram Bay at buoy $6 \mathrm{nr}$ Fleeton....... (POT-RAPP) 115

Irish Creek at Rt 608 at Cornwail......... (JAMES) 229

Isaac Run at Rt 522 nr Boyce..........(POT-SHEN) 22

Isaacs Creek at Rt $600 \mathrm{nr}$ Gainesboro.. (POT-SHEN) 21

Isaacs Creek at U.S. HWy 522 at Gainesboro............... (POT-SHEN)

Isaacs Creek at mouth nI Gainesboro... (POT-SHEN)

Is land Creek at mouth nr Clarksvilie... (ROANOKE)

Is land Creek at mouth nr Hillsville....... (NEW)

Is land Creek at mouth nr Otter H111.... (ROAONOKE)

Is land Swamp at mouth nI stony Creek.... (CAOWAN)

Ivy Branch at mouth at Stuart....... (ROANOKE)

Ivy Creek at Lynchburg................ (JAMES)

Ivy Creek at Rt 601 nr Boonesvilie....... (JAMES

Ivy Creek at Rt $601 \mathrm{nr}$ Charlottesville... (JAMES)

Ivy Creek at Rt 637 nr Mechums River..... (JAMES)

Ivy Creek at Rt $677 \mathrm{nr}$ Ivy nr Charlottesville.

Ivy Creek at Rt 743 at former mouth

mouth nr Charlottesville................ (JAMES) 251

Ivy Creek at Rt 800 at Schuyler............ (JAMES) 242

Ivy Creek at mouth nr Meadows of Dan... (ROANOKE) 393

Ivy Creek below Rt 335 at Schuyler.......(JAMES) 242

Ivy Creek below Rt 637 nr Mechums River.. (JAMES) 251

Ivy Creek trib nr Charlottesville ....... (JAMES) 251

Ivy Lick Creek at Rt 657

nI Davenpart................ (BIG SANDY)

J. A. Ayers Spring nr Rapps Mill

nr Natural Bridge............. (JAMES)

J. B. Keesing Spring at Cedar Springs . . ... (NEW)

J. L. Creger Spring nr Glade Spring.... (EOLSTON)

J. L. Vaughn Spring nr Shawsvilie ...... (ROANOKE)

J. N. Phelps Spring at Roanoke.......... (ROANOKE)

J. W. Slusser Spring on Rt 114

ar Blacksburs.

(ROANOKE)

J. W. Smith Spring at Webbs Mili

nr Abbott...................... (JAMES)

Jack Rock Branch at mouth nr Warfieid.... (CHONAN)

Jackpen Creek at mouth nr Menquín......... (YORK

Jacks Branch above C\&O RR nr Rugby nr Keswick................... (JAMES)

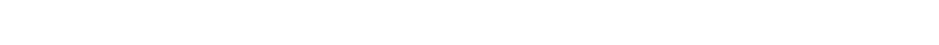

Jacks Creek at Big Rock. .

Jacks Creek at mouth at Big Rock..... (BIG SANDY)

Jacks Creek at moutb at Woolwine........ (ROANOKE)

Jacks Creek at mouth nr Dickinson...... (ROANOKT)

Jacks Creek at mouth nr Sparta........... (YORK)

Jecks Creek at mouth nr Tunstall......... (YORK)

Jacks Creek trib at Rt 630 at Sparta...... (YORK)

Jacks Run at mouth nr Lincoln.......... (POTOMAC)

Jacks Run trib at Rt 7 nr Purcelivilie. (POTOMAC)

Jacks Swamp at Pleasant Hil1, N.C ...... (CRONAN)

Jacks Swamp ni Pleasant Hill, N.C........ (CHOWAN)

Jackson Branch at mouth nr Penns Stör. (ROANOKE)

Jackson Branch nr Murphy............. (BIG SANDY)

Jackson Creek at mouth at Deltaville. (RAPP-YORK)

Jackson Creek at mouth nr Coles Point.. (POTOMAC)

Jackson Fork above Barton Fork ne Counctl....................... SANDY)

Jackson Fork at mouth nr Harman......... (CLINCA)

Jackson Fork at mouth nr Murphy........ (BIG SANDY)

Jackson River above Dunlap Creek

at Covington................... (JAMES)

230

433

504

359

366

360

217

325

186

255

323

463
397

374

193

187

193

70
70

356

396

473

160
112

465

527

472

209
Jackson River above Mackey Spring at Vanderpoo 1 .

Page

... (JAMES) 205

Jackson River at Rt 18 nr Covington.

Jackson River at Rt 39 nr Warm Springs... (JAMES) 206

Jackson River at Rt 600 nr Callison...... (JAMES) 208

Jackson River at Rt 506 nr Mustoe......... (JAMES) 205

Jackson River at Rt 607 nr Bolar.................... (JAMS) 205

Jackson River at Rt 623 nr Bolar............ (JAMES) 205

Jackson River at Rt 687

at Falling Spring ............... (JAMES) 209

Jackson River at Rt 727 at Iron Gate...... (JAMES) 213

Jackson River at Rt $84 \mathrm{nI}$ Vanderpoo1..... (JAMES) 205

Jackson River at Smith Creek at Clifton Forse.

Jackson River at U.S. Hwy 220

Jackson River at U.S. Hwy $22 \dot{0}$ at Clifton Forge................ (JAMES) 212

Jackson River at U.S. Hwy $220 \mathrm{nr}$ Bolar... (JAMES) 205

Jackson River at filtration plant at Covington................ (JAMES) 209

Jackson River t mouth nr Iron Gate.... (JAMES) 213

Jackson River below Back Creek ne Bacova Junction...............

(JAMES) 208

Jackson River below Dunlap Creek at Covington. . Bathright Dam

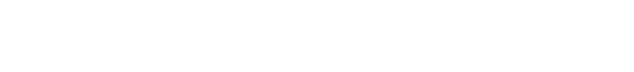

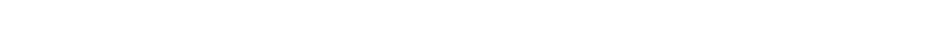

Jackson River nr Becova Junction............. (JAMES) 206

Jackson River, N.F. (East Fork), nr Vanderpool....................JAMES) 205

Jackson River, N.F. at mouth nr Mustoe. (JAMES) 205

Jacobs Creek at mouth nr Mike......... (ROANOKE) 386

Jacobs Fork at Va. $-W . V a$. State line

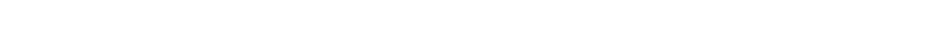

Jacobus Creek at mouth nr Johnstown.... (EASTERN) 14

Jakes Fork along Rt 503 at Davenport. (BIG SANDY) 468

Jakes Fork at mouth nr Davenport..... (BIG SANDY) 468

Jakes Fork trib above mouth

nr Davenport .... (BIG SANDY) 468

James Branch at mouth at Grady........... (ROANOKE) 375

James River (at Mayos Bridge)

at Richmond................... (JAMES) 266

James River (old channel) below

VEPCO powerplant at Dutch Gap......(JAMES) 269

James River (old channel) nI buoy 98 ni Westover.

(JAMES) 289

James River above Newport News

Shipbuilding at Newport News...... (JAMES)

305

James River above Pedlar River

at Holcomb(s) Rock........

James River above Rocky Row Run ni Snowden.

(JAMES)

232

James River above Rt 20 at Scottsvilie... (JAMES) 243

James River above U.S. Hary 17 at Newport News........

James River above U.S. Hwy 60 at Bent Creek.

(JAMES) 305

James River above Windmil1 Point nr Charles City

(JAMES) 236

James River and Kanawah Canal below Haxall nr Richmond.

(JAMES) 290

James River and Kanawha Canal above Rt 147 at Richmond.

(JAMES) 265

James River and Kanawhe Canal

above Albemarle nr Richmond........(JAMES) 265

James River and Kanawhe Canal

above Tredegar Plant at Richnond... (JAMES) 265

James River and Kanawha Canal

at Albemarle at Richmond.

(JAMES) 265

James River and Kanawha Canal

at Burnt Mili at Richmond........ (JAMES)

265

Janes River and Kanawha Canal

at Tredegar Plant at Richmond...... (JAMES) 
Abbreviated basin names appear at the end of the site name. Abbreviations are as follows:

Eastern Shore (EASTERN): Potomac to Shenandoah (POT-SHEN); Shenandoah (SHEN); POtomac (POTOMAC)

Potomac to Rappahannock (POT-RAPP); Rappahannock (RAPP); Rappahannock to York (RAPP-YORK); York' (YORK);

York to James (YORK-JAMES); James (JAMES); James to Chowan (JAMES-CHOWAN); Chowan (CHOWAN); Roanoke (ROANOKE);

Yadkin (YADKIN); New (NEW); B1g Sandy (BIG SANDY); Holston (BOLSTON); CIinch (CLINCE); POWel1 (POWELI)]

James River and Kanawha Canal

below headgates nr Richmond........ (JAMES) 264

James River and Kanawha Canal

powerplant outfall at Richmond..... (JAMES) 265

James River and Kanawha Canal at

city pumping plant at Richmond..... (JAMES) 265

James River and Kanawha Cana: at water

plant settling basin at Richmond... (JAMES) 265

$J$ ames River and Kanawha Canal below

city pumping plant at Richmond..... (JAMES) 265

James River at Balcony Falis............. (JAMES) 231

James River at Bedford Dam nr Major...... (JAMES) 231

James River at Blue Ridge Pkwy

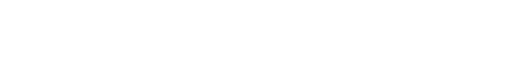

James River at Boulevard Bridge

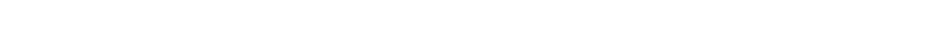

James River at DES Piers at Norfoik........ (JAMES) 313

James River at Ghost Fleet nr Fort Eustis.................. (JAMES) 303

James River at Hampton Bar at Hampton.... (JAMES) 308

James River at Hampton River at Hampton. (JAMES) 313

James River at Holcomb(s) Rock........... (JAMES) 233

James River at Hollywood Dam

at Richmond..................... (JAMES) 266

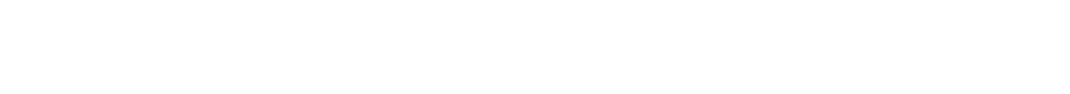

James River at Newport News

Middle Ground nr Hampton........... (JAMES) 308

James River at Newport News

Shipbuilding at Newport News....... (JAMES) 305

James River at Newport News Point

at Newport News................. (JAMES) 305

James River at Owens-Illinois

boat dock at Big Island.......... (JAMES) 232

James River at Rt $147 \mathrm{nr}$ Richmond......... (JAMES) 264

James River at Rt 156 nr Westover........ (JAMES) 289

James River at Rt 45 at Cartersville.... (JAMES) 259

James River at Rt 56 at Wingina.......... (JAMES) 240

James River at Rt 602 at Howardsville.... (JAMES) 242

James River at Rt 669 at Columbia........ (JAMES) 257

James River at Rt 759

at Natural Bridge Station........... (JAMES) 223

James River at Sabot......................... 262

James River at Scotland Ferry Pier at Scotland....................

(JAMES) 301

James River at Skimmer Creek

nr Big Is land................... (JAMES) 232

James River at State Farm............... (JAMES) 261

James River at Swanns Polnt at Jamestown. (JAMES) 300

James River at U.S. Hwy 11 at Buchanan... (JAMES) 222

James River at U.S. HWy 15

at Bremo Bluff.

James River at U.S. Hiw 220 below

Cowpasture River nr Iron Gate...... (JAMES) 216

James River at U.S. Bury 29

(Alternate) at Lynchburs .......... (JAMES) 234

James River at U.S. Bwy $501 \mathrm{nr}$ Snowden... (JAMES) 231

James River at U.S. Hwy 522 at Maidens... (JAMES) 261

James River at U.S. Hwy 60 at Bent Creek. (JAMES) 236

James River at VEPCO dam at Snowden...... (JAMES) 231

James River at Willi amsburg STP

nr Willi ambburg............... (JAMES) 302

James River at buoy $104 \mathrm{nr}$ Westover...... (JAMES) 289

James River at buoy $108 \mathrm{nr}$ Hopewe11...... (JAMES) 289

James River at buoy $112 \mathrm{nr}$ Hopewell....... (JAMES) 288

James River at buoy $114 \mathrm{nr}$ Hopewell........ (JAMES) 288

James River at buoy $116 \mathrm{nr}$ Hopewe11....... (JAMES) 288

James River at buoy $118 \mathrm{nr}$ Hopewel1...... (JAMES) 288

James River at buoy $12 \mathrm{nr}$ Newport News... (JAMES) 303

James River at buoy $124 \mathrm{nr}$ Hopewe11...... (JAMES) 270

James River at buoy $126 \mathrm{nr}$ Hopewel1....... (JAMES) 270

James River at buoy $137 \mathrm{nr}$ Hopewel1...... (JAMES) 270

James River at buoy 150 at Dutch Gap...... (JAMES) 269

James River at buoy $155 \mathrm{nr}$ Centralia...... (JAMES) 269

James River at buoy $157 \mathrm{nr}$ Centralia..... (JAMES) 269

James River at buoy $163 \mathrm{nr}$ Drewrys Bluff. (JAMES) 268

James River at buoy 166 at Richmond...... (JAMES) 267

James River at buoy 168 at Richmond........ (JAMES) 267
James River at buoy 175 at Richmond.

(JAMES) 267

James River at buoy $24 \mathrm{nr}$ Bacons Castie.. (JAMES) 303

James River at buoy $30 \mathrm{nr}$ Fort Eustis... (JAMES) 302

James River at buoy $36 \mathrm{nr}$ Willi amsburB... (JAMES) 302

James River at buoy $38 \mathrm{nr}$ Williamsburg... (JAMES) 302

James River at buoy $42 \mathrm{nr}$ Willi amsburB... (JAMES) 302

James River at buoy 55 at Jamestown...... (JAMES) 301

James River at buoy $69 \mathrm{nr}$ Claremont...... (JAMES) 291

James River at buoy $74 \mathrm{nr}$ Brandon........ (JAMES) 291

James River at buoy $74 \mathrm{~A} n r$ Brandon......... (JAMES) 291

James River at buoy 86 at

Windmill Point nr Charles City..... (JAMES) 290

James River at buoy $92 \mathrm{nr}$ Westover........ (JAMES) 290

James River at buoy $96 \mathrm{nr}$ Westover......... (JAMES) 289

James River at buoy 98 nr Westover........ (JAMES) 289

James River at city locks at Richmond.... (JAMES) 266

James River at mouth nr Phoebus........... (JAMES) 313

James River at mouth of Pagan River nr Newport News ........... Holcomb(s) Rock Dam nr Waugh...... (JAMES)

304

James River below Blackwater Creek at Lynchburg.

James River below goiman Creek

at Bremo Bluff.....................

233

Shipbuilding at Newport News....... (JAMES) 305

James River below Rt 20 at Scottsvilie... (JAMES) 243

James River below Skiffes Creek nr Fort Eustis ........

at Bremo Bluff................. (JAMES) 246

James River below U.S. Hiwy 220 at Lick Run

(JAMES ) River below Weyanoke Point

at buoy $77 \mathrm{nr}$ Garysvilile.......... (JAMES)

James Rtver diversion (cornmill tailrace) at Lynchburs ........... (JAMES )

James River diversion at

Reusens powerplant nr LymchburB.... (JAMES)

James River nr Dutch Gap.............. (JAMES)

James River nr U.S. Hwys $17 / 258$ bridge at Newport News............ (JAMES)

James River nr Willoughby Beach off Fort Wood at Norfolk........... (JAMES)

James River off Esso pier at Newport News.

River off Gravel Neck nr Bacons Castie..

James River off Sewolls Point at Norfolk.

(JAMES)

River powerplant diversion

at Bedford Dam nr Major.

James River powerplant diversion at Rousens Dam nr Lynchburs......... (JAMES)

James River powerplant outfall at VEPCO dam nr Snowden.

James River trib at Defense Generai Supply Center at Drewrys Bluff..... (JAMES)

James River trib at Rt 5 nr Five Forks... (JAMES)

James River trib at Rt $625 \mathrm{nr}$ Buchanan... (JAMES)

Jamison Branch at mouth nr Buffalo Junction........... (ROANOKE)

Jasper Creek at mouth nr Leesville..... (ROANOKE)

Jaybird Branch at mouth nr Coeburn...... (CLINCB)

Jeff Gillespie Spring at Liberty......... (CLINCH)

Jefferson Branch above mouth nr Dranesville.

Jefferson Branch at mouth nr Dranesville.

(РOTOMAC)

Jeffries Branch at mouth nr Upperville. (POTOMAC)

Jemima Branch at mouth nr Criglersville (RAPP)

Jennies Branch at mouth nr Newville..... (CHOWAN)

Jennings Branch at Rt 42 at Churchviiie... (SHEN)

Jennings Branch at Rt $801 \mathrm{nr}$ Churchville.. (SHEN)

Jennings Branch at U.S. Hwy 250

at Jennings Gap nr Churchville...... (SHEN)

Jennings Branch at mouth nr Churchvili.... (SHEN) 
Abbreviated basin names appear at the end of the site name. Abbreviations are as follows: Eastern Shore (EASTERN); Potomac to Shenandoah (POT-SHEN); Shenandoah (SHEN); POtOmac (POTOMAC); Potomac to Rappahannock (POT-RAPP); Rappahannock (RAPP); Rappahannock to York (RAPP YORK); York (YORK) York to James (YORK-JAMES); James (JAMES); James to Chowan (JAMES-CHOWAN); Chowan (CHOWAN); Roanoke (ROANOKE) Yadkin (YADKIN); New (NEW); Big Sandy (BIG SANDY); Holston (HOLSTON); Clinch (CLINCH); POWell (POWELL)]

Jennings Branch off U.S. Hwy 250

at Lone Fountain................... (SHEN)

Jennings Creek at Rt $614 \mathrm{nr}$ Arcadi .......... (JAMES)

Jennings Creek at mouth $\mathrm{nr}$ Indian Rock... (JAMES)

Jennings Creek at mouth nr Spencer...... (ROANOKE)

Jennys Creek nr Piney River ........... (JAMES)

Jeremys (Jeremiah) Run at N\&W $R$ R $^{\circ}$ nr Rileyville.

Jeremys Run $0.3 \mathrm{mi}$ above Rt 611

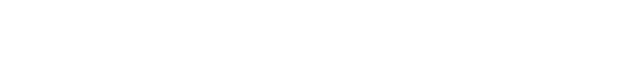
nr Rileyvilie.

Jeremys Run at Rt 662 at Rileyvilie....... (SHEN)

Jeremys Run at elev $1020 \mathrm{nr}$ Rileyvilie.... (SHEN)

Jeremys Run at elev $1140 \mathrm{nr}$ Thornton Gap.. (SHEN)

Jeremys Run at elev $1280 \mathrm{nr}$ Thornton Gap.. (SHEN)

Jeremys Run at elev $1490 \mathrm{nr}$ Rileyville.... (SEEN)

Jeremys Run at elev $1740 \mathrm{nr}$ Rileyville.... (SHEN)

Jeremys Run at elev $1870 \mathrm{nr}$ Rileyville.... (SHEN)

Jeremys Run at mouth at Rileyvilie....... (SHEN)

Jeremys Run below water wells

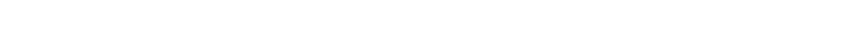

Jeremys Run trib nr Ri leyvilie.......... (SHEN)

Jericho Ditch nr N\&W RR at Suffolk........ (JAMES)

Jerimy Creek at mouth nr Danripple...... (ROANOKE)

Jerry Branch at Rt $42 \mathrm{nr}$ Clifton Forge... (JAMES)

Jerry Creek at mouth nr Flat Ridge......... (NEW)

Jerrys Branch at mouth nr Mike......... (ROANOKE)

Jerrys Creek at mouth nr Thomas Bridge. (HOLSTON)

Jerrys Run nr Hematite................ (JAMES)

Jesse Branch at mouth $n \dot{r}$ Nickelsvilie.. (CLINCK)

Jetts Creek at mouth nr Port Royal....... (RAPP)

Jetts Creek trib at mouth nr Port Royal... (RAPP)

Jill Creek at mouth at Woolwine........ (ROANOKE)

Jinkerson Branch at mouth nr Green Spring..................... (HOLSTON)

Joe Creek at Norwood.

509

Joel Branch at Forest $\ddot{R} \dot{7} \ddot{O} 0$ nr Dungannon.

(JAMES)

Creek at mouth nr Moliusk.

John 9 . Kerr Reservoir at dam

John $w$. Flannagan Reservoi

CLINCE)

. (RAPP) nr Eays $i$

(ROANOKE)

(BIG SANDY)

Johnchecohunk (Johnny Hawkins) Swamp

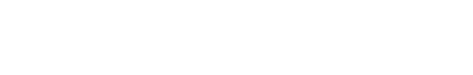

nr Elberon

(CEOWAN) 341

(CEOWAN)

Johnny Moore Creek at Rt $\mathbf{6} 58$ nr Clifton.

(POTOMaC) 100

Johns Creek RF\&P RR Shops it Richmond.... (JAMES) 294

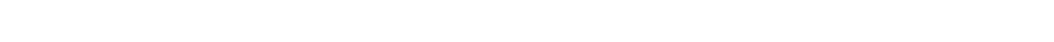

Johns Creek at Rt 297 at Bedford........... (ROANOKE) 381

Johns Creek at Rt 311 nr New Castie....... (JAMES) 218

Johns Creek at Rt 515 at New Castle....... (JAMES) 218

Johns Creok at Rt 632 nr Craig Springs... (JAMES) 218

Johns Creek at Rt 658 at Maggie.......... (JAMES) 218

Johns Creek at mouth at New Castie......... (JAMES) 218

Johns Creek at mouth nr Baywood............ (NEW) 429

Johns Creek at mouth nr Bedford.......... (ROANOKE) 381

Johns Creek nr Rt 718 nr Bedford......... (ROANOKE) 381

Johns Creek trib at Bedford Manor st at Bedford.

(ROANOKE) 380

Johns Creek trib at Rt 297 at Bedford.. (ROANOKE) 380

Johns Creek trib at Rt 311 nr New Castie.

(JAMES) 218

Johns Fork at mouth nr Duty............. (BIG SANDY) 469

Johns Fork nr Cane Gap nr Duty........ (BIG SANDY) 469

Johns Fork nr Duty......................... BIG SANDY) 469

Johns Fork trib at mouth nr Duty....... (BIG SANDY) 469

Johns Run at Coal Rd nr Stuarts Draft..... (SHEN) 38

Johns Run at mouth nr Ebenezer......... (ROANOKE) 414

Johns Run at mouth nr Spring Garden.... (ROANOKE) 414

Johnson Creek at Rt $724 \mathrm{nr}$ Rivermont...... (JAMES) 270

Johnson Creek at Rt $746 \mathrm{nr}$ Rivermont..... (JAMES) 270

Johnson Creek at Va, -N.C. State line

nr Ararat..................... (YADKIN)
Johnson Creek at mouth nr Otter River. (ROANOKE)

Johnson Creek at mouth nr Rivermont.......(JAMES) 270

Johnson Hollow trib at Rt 630 nr Pound.

(BIG SANDY)

Johnson Spring nr Hot Springs........... (JAMES) 209

Johnsons Creek at Rt 661 at Callaghan.... (JAMES) 210

Johnsons Creek at mouth at Callaghan..... (JAMES) 210

Joint Crack Creek at mouth at Charity... (ROANOKE) 398

Jolly Hollow Branch at Rt 92

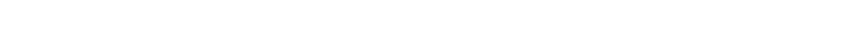

Jonas Run at mouth $n r$ Culpeper................ (RAPP) 130

Jonas Run trib No. 1 at mouth $\mathrm{nr}$ Culpeper (RAPP) 130

Jonas Run trib No. 2 at mouth $n r$ Culpeper. (RAPP) 130

Jones (Norwood) Creek at Rt 614 nr Fine Creek Mills.

(JAMES) 263

Jones 8ranch t mouth nr Kermit......... (BOLSTON) 524

Jones Creek above Mud Hole Swamp nr Montross

(RAPP) 150

Jones Creek above Woodbury Pond

nr Fine Creok Mills...

Jones Creek above reservoir

at Martinsville.............. (ROANOKE)

(JAMES)

Jones Creek at Rescue................ (JAMES)

Jones Creek at Rt 704 at Rescue.......... (JAMES)

Jones Creek at mouth at Clay Bank......... (YORK)

Jones Creek at mouth at Martinsvilie... (ROANOKE)

Jones Creek at mouth $\mathrm{nr}$ Holly Grove........ (YORK)

Jones Creek at mouth nr Montross........... (RAPP)

Jones Creek at mouth nr Robbins Chapel. . (POWELL)

Jones Creek below filtration plant at Martinsvilie.

(ROANOKE)

Jones Fork at mouth nr Jewell Valley. (BIG SANDY)

Jones Hole Swamp trib at Rt 35 nr Carson. . $\cdots$ C

Jones Run above CEO RR

at Providence Forge ............. (JAMES)

(CHOWAN)

Jones Swamp at mouth $n r$ Somerton.......... (CHOWAN)

Jonnican 8ranch at mouth nr Red House.. (ROANOKE)

Jonnikin Creek at mouth nr Museville... (ROANOKE)

Jordan Creek at mouth at Fieldale...... (ROANOKE)

Jordan River at Rt 637 nr Flint Hiii...... (RAPP)

Jordan River at U.S. Hwy 522 at Flint Hill.

(RAPP)

Jordan River at mouth nr Fiint $\mathrm{Hi} i \mathrm{\ldots} \ldots \ldots$ (RAPP)

Jordan River nr Flint Hili.............. (RAPP)

Jordan River trib nr Flint $\mathrm{H} i \mathrm{i} \ldots \ldots \ldots \ldots \ldots$ (RAPP)

Jordans Branch at Dabney Road

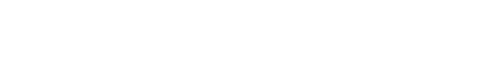

Jordans Branch at $\ddot{U} . \dot{S}$. Hwy 250

(JAMES )

Jordans $\mathrm{Branch}$ at mouth $\mathrm{z}$.

Jordon Branch at mouth nr Keokee......... (POWELL)

Joseph Spring nr Mt. Solon................ (SHEN)

Joshus Creek at mouth nr Stonewali....... (JAMES)

Joyner Branch at mouth $n r$ Capron........ (CHOWAN)

Joynes Branch (Central Branch) at mouth at Onancock.

Judith

Jugs Creek at mouth $n r$ Warsaw................. (RAPP)

Jumping Branch at mouth nr Spencer..... (ROANOKE)

Jumping Run at mouth nr Goodview....... (ROANOKE)

402

304

199

402

179

150

558

402

458

331

297

193

347
386

375

401

117

117

117

117
117

294

294

294

557

27
235

335

16

233

184

153

397

368

Karnes Spring nr Buchanan.

(JAMES)

Kates Creek at Rt 757 nr Goodview.......... (ROANOKE)

Katie Branch at mouth at Wardel1......... (CLINCE)

Katy Young Branch at Rt 658

nr Parksley................ (EASTERN)

Katy Young Branch at mouth in Hopkins. (EASTERN)

Keaton Branch at mouth nr Snow Creek... (ROANOKE)

Keatons Run at Rt 20 at Wilderness....... (RAPP)

Keatons Run at mouth nr Chanceliorsvilie.. (RAPP)

222

368 
Abbreviated basin names appear at the end of the site name. Abbreviations are as follows:

Eastern Shore (EASTERN); Potomac to Shenandoah (POT-SHEN); Shenandoah (SHEN); Potomac (POTOMAC)

Potomac to Rappahannock (POT-RAPP); Rappahannock (RAPP); Rappahannock to York (RAPP YORK); York (YORK)

York to James (YORK-JAMES); James (JAMES); James to Chowan (JAMES-CHOWAN); Chowan (CHOWAN); Roanoke (ROANOKE);

Yadkin (YADKIN); Now (NEW); Big Sandy (BIG SANDY); Holston (HOLSTON); Clinch (CLINCR); Powel1 (POWELL)]

Page

Keatons Run trib at Rt 3 at Wilderness.... (RAPP) 142

Kelly Branch at mouth nr Andover.........(POWELL) 554

Kenna Swamp at mouth nr Montross.......... (RAPP) 151

Kennedy Creek at Coal Rd nr Sherando...... (SHEN) 38

Kennedy Spring at West View............. (SHEN)

Kennon Creek at mouth nr Brandon........... (JAMES)

Kent Branch above Venable Creek

$$
\text { nr Wilmington........................ JAMES) }
$$

Kent Branch at mouth ir Pulaski........... (NEW)

Kents Creek at mouth nr Balifax.......... (ROANOKE)

Kerrs Creek at I-64 nr Lexington........ (JAMES)

Kerrs Creek at U.S. Bwy 60 at Kerrs Cragk.

(JAMES)

Kerrs Creek at U.S. Awy 60 nr Denmark..... (JAMES)

Kerrs Creek at mouth nr Lexington:....... (JAMES)

Kerseys Creek at mouth nr Crosses Corner.. (YORK)

Kershaw Branch nr Eurley............. (BIG SANDY)

Ketchum Branch at mouth nr Lodi......... (BOLSTON)

Ketron Branch at mouth nr Shelleys..... (BOLSTON)

Kettle Run at Rt 692 at Brentsville.... (POTOMAC)

Kettle Run at Rt 708 nr Nokesvilie..... (POTOMAC)

Kettle Run at Rt 709 nr Brentsville.... (POTOMAC)

Kett le Run at mouth at Brentsville..... (POTOMAC)

Kettle Run at mouth at Delaplane....... (POTOMAC)

Kettle Run trib No. 1 at Rt 708 nr Nokesville.............. (POTOMAC)

Kettle Run trib No. 2 at mouth nr Brentsville.............. (POTOMAC)

Kettle Run trtb No. 3 at mouth nr Brentsvilie............. (POTOMAC)

Kettles Creek at mouth nr Philiis...... (ROANOKE)

Kettlestick Branch at mouth nr Smoky Ordinary. .

Kettlestick Branch trib nr Purdy......... (CHOWAN)

Kettlesticks Creek at mouth nr Bishops Corner............ (CHOWAN)

Keys Run at mouth nr Port Royal............ (RAPP)

Keyser Run at Rt 622 nr Sperryvilie......... (RAPP)

Keywood Branch at mouth at Plasterco... (BOLSTON)

Kilbys Creek at Rt 231 nr Et lan........... (RAPP)

Kilbys Creek trib at Rt 231 nr Etian........ (RAPP)

Kilgore Creek at mouth nr Herald..... (BIG SANDY)

Killinger Creek at Cedar Springs........... (NEW)

Killinger Creek trib at Rt 675 at Cedar springs................ (NEW)

Killinger Spring nr Marion................... (Hólston)

Kimages Creek above Charles Lake

nr Hopewel1................. (JAMES)

Kimbaliton Branch at mouth at Kimbaliton...(NEW) 453

Kimberling Creek at Rt 42 nr Mechanicsburg ................... (NEW)

Kimberling Creek at Rt 612 nr Hoily Brook.. (NEW)

Kimberling Creek at mouth nr White Gate.... (NEW)

King Creek at mouth nr Severn........ (RAPP-YORK)

King Creek at mouth nr Yorktow........... (YORK)

King and Queen Swamp at mouth nr Alps..... (YORK)

Kings Creek above Whiteman Swamp nr Willi amsburg.

(YORK)

Kings Creek at U.S. Hwy 13 (Bypass)

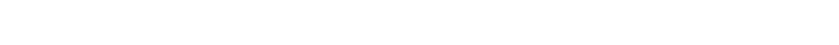

Kings Creek at marina at Cape Charies.. (EASTERN)

Kings Creek at mouth at Cape Charles... (EASTERN)

Kings Creek off Penniman Spit nr Yorktom. (YORK)

Kings Mill Creek at mouth nr Colonial Beach.............. (POTOMAC)

Kings land Creek above mouth nr Drewrys Bluff............... (JAMES) 269

Kingsiand Creek at Hopkins $\mathrm{Rd}$ nr Drewrys Bluff................ (JAMES) 269

Kingsland Creek at mouth nr Drewrys Bluff.................... (JAMES) 269

Kinsale Branch at mouth at Kinsale....... (POTOMAC) 112

Kinser Creek at mouth nr Cedar Springs..... (NEW) 434

Kinsey Run at mouth at Graves Mill........ (RAPP) 132

Kits Creek at mouth nr Rehoboth.........(CHOWAN) 349

Kits Creek at mouth nr Wightman........ (CHOWAN)

Knight Run at mouth nr Howland......... (POT-RAPP)
Knights Branch above Music Branch nr Brokenburg.

Page

Knights Crook at mouth nr Fort Mitcheli (CHOWAN) 172

Knob Fork at mouth nr Galax................. 430

Knot Hollow Creek at Rt 63

nr Tramel..................... SIG SANDY) 477

Knot Hollow Spring nr Tramme1........(BIG SANDY) 477

Knox Creek above Va. $-\mathrm{Ky}$. State line at Rt 697 nr Argo, Ky........... (BIG SANDY) 490

Knox Creek at Rt 650 at Huriey......... (BIG SANDY) 489

Knox Creek at Rt 697 at Kelsa........ (BIG SANDY) 490

Knox Creek below Pounding Mill Creek at Aurley........................ (BIG SANDY) 489

Koger Creek at mouth nr Penns Store.... (ROANOKE) 396

Krimmel Creek at mouth nr Craigs Mil1.. (HOLSTON) 519

L. M. Pugh Spring at Teas.............(HOLSTON) 493

La Roque Run at mouth nr Fivemile Fork.... (RAPP) 143

Lacey Creek trib at C\&O RR

at Windsor Shades nr Walkers....... (JAMES) 298

Lacey Creok trib tributary at C6O RR

at Windsor Shades nr Walkers.......(JAMES) 298

Lacey Spring at Lacey Spring.............. (SHEN) 56

Lafayette River at Rt 337 at Norfolk..... (JAMES) 312

Lafayette River at buoy 10 at Norfolk.... (JAMES) 312

Lafayette River at buoy 16 at Norfolk.... (JAMES) 312

Lafayette River at buoy 19 at Norfolk..... (JAMES) 312

Lafayette River at buoy 2 at Norfolk..... (JAMES) 312

Lafayette River at mouth at Norfolk...... (JAMES) 313

Lagrange Creek at mouth nr Urbanna.......... (RAPP) 156

Lagrange Creek, South Branch, at mouth nr Urbanna.

156

Lake Anna trib at Pamunkey Creek

Channel to Lake Anna.

(YORK)

Lake Burnt Milis nr Suffolk.................. (JAMES

Lake Chesdin at dam nr Petersburg......... (JAMES)

Lake Cohoon nr Suffolk.

Lake Drumond in Great Dismal Swamp.

(JAMES-CHOWAN) 320

Lake Gaston (Little River Channel) nr Henrico, N.C. . . . . . . Gaston (Pea Hil1 Creek) nr Tillans Chapel ni Henrico, N.C... (ROANOKE) Gaston (Roanoke River) at Rt 1344

Lake Gastron trib nr Tiilans Chapei

Lake Gastron trib nr Tilians Chapei

(ROANOKE) 424

lake Kilby above spiji........... (ROANOA (JAMES)

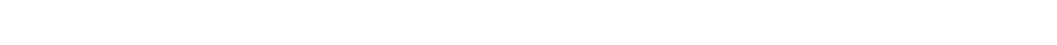

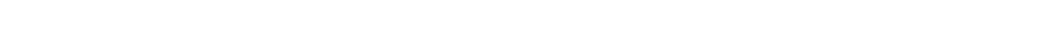

Lake Moomaw (Central) nr Hot Springs...... (JAMES) 208

Lake Moonaw (East) nr Hot Springs......... (JAMES) 208

Lake Moomaw (North) nI Hot Springs....... (JAMES) 208

Lake Moomaw (South) nr Hot Springs....... (JAMES) 208

Lake Moomaw (West) nr Hot Springs........... (JAMES) 208

Lake Moomaw nr Hot Springs.............. (JAMES) 208

Lake Prince above spillway nr Elephant Fork.

(JAMES) 307

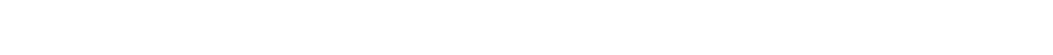

Lake Rudee at mouth at Virginia Beach........... (JAMES-CHOWAN)

Lake of the Woods at dam nr Flat Run.

Lambs Creek at mouth nr Passapatanzy.......(RAPP) 147

Lambs Creek at mouth nr Poquoson.... (YORK-JAMES) 202

Lancaster Creek at mouth nr Morattico.....(RAPP) 155

Lancaster Creek trib No. 1 at mouth

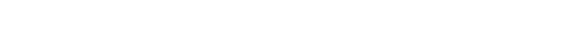

Lancaster Creek trib No. 2 at mouth

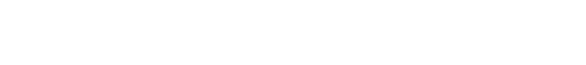

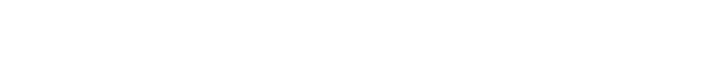

Lancaster Creek trib No, 4 at mouth

Lancaster Creok trib No. 5 at mouth

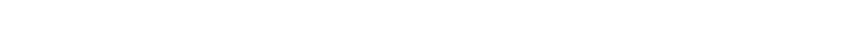


Abbreviated basin names appear at the end of the site name. Abbreviations are as follows Eastern Shore (EASTERN); Potomac to Shenandoah (POT-SHEN); Shenandoah (SHEN); POtOmac (POTOMAC);

Potomac to Rappahannock (FOT-RAPP); Rappahannock (RAPP); Rappahannock to York (RAPP-YORK); YOrk (YORK)

York to James (YORK-JAMES); James (JAMES); James to Chowan (JAMES-CHOWAN); Chowan (CHOWAN); ROanoke (ROANOKE);

Yackin (YADKIN); New (NEW); Big Sandy (BIG SANDY); Holston (HOLSTON); CIinch (CLINCH); POWell (POWELI)]

Lands Run at Lands Run Rd nr Browntown.... (SHEN)

Lane Camp Branch at mouth $\mathrm{nr} \mathrm{Ka} . . . . .$. (CIINCH)

Lanes Creek at mouth $n r$ Hudgins....... (RAPP-YORK)

Lapsley Run at Sali sbury............... (JAMES)

Lapsley Run at U.S. Hwy $220 \mathrm{nI}$ Salisbury. (JAMES)

Larimer Branch at mouth $\mathrm{nr}$ Watauga.... (MOLSTON)

Lark Branch at mouth nr Hilton......... (HOLSTON)

Lark Creek at mouth nI Gate C1ty........ (CLINCH)

Larkin Branch at mouth $\mathrm{nr}$ Omega........ (ROANOKE)

Lasley Creek at mouth nr Boswells Tavern. (YORK)

Laton Swamp at mouth nr Center Cross..... (RAPP)

Laure 1 Bed Creek at mouth nr Allison Gap.

. (HOLSTON)

Laurel Branch (North) along Rt 606 nr Prater.

(BIG SANDY)

Laurel Branch (North) at Rt 605 at Viers (South) at mouth

Laurel Branch (S
nr Colley.

(BIG SANDY)

Laurel Branch at Flannagan Reservot

nr Isom................... (BIG SANDY)

Laurel Branch at Forest Rd 70

nr Dungannon.

(BIG SANDY)

Laurel Branch at mouth nr South Clinchfield .............. (CLINCH)

Laurel Branch at mouth at Dante.

Laurel Branch at mouth at Goldbond.

(CLINCH)

(NEW)

Laurel Branch at mouth at Laurel.

(CLINCH)

Laurel Branch at mouth nr Ceres......... (HOLSTON)

Laurel Branch at mouth $\mathrm{nr}$ Cooburn........ (CL.INCH)

Laurel Branch at mouth nr Copper Valley.... (NEW)

Laurel Branch at mouth $n r$ Nebo......... (HOL.STON)

Laurel Branch at mouth nr Nora......... (BIG SANDY)

Laurel Branch at mouth nr Sanvilie..... (ROANOKE)

Laurel Creek above Beaverdam Creek at Damascus................ (HOLSTON)

Laurel Creek above $\mathrm{Rt} 9 \mathrm{i}$ at Broadford. (HOLSTON)

Laurel Creek above Whitetop Laurel

Creek nr Damascus............... (HOLSTON)

Laurel Creek along $R t 91$ at Broadford. . (HOLSTON)

Laurel Creek at $R t 718$ at Vail Mills... (HOLSTON)

Laurel Creek at Rt 72 at Georges Fork ............... (BIG SANDY)

Laurel Creek at Rt $91 \mathrm{nr}$ Damascus...... (HOLSTON)

Laurel Creek at U.S. HWy 58 at Damascus.

(HOLSTON)

aurel Creek at Va.-Tenn. State iine nr Damacus................. (HOLSTON)

Laurel Creek at mouth at Georges Fork

Laurel Creek at mouth at Broadford. (BIG SANDY)

Laurel Creek at mouth at Rocky Gap.......... (NEW)

Laurel Creek at mouth at Roetown........ (BoLSTON)

Laurel Creek at mouth at Wardeli......... (CLINCH)

Laurel Creek at mouth $\mathrm{nr}$ Huffman.......... (NEW)

Laurel Creek at mouth $n r$ Interior......... (NEW)

Laurel Creek at mouth $n r$ Pilot........... (NEW)

Laurel Creek at mouth nr Trout Dale.......... (NEW)

Laurel Fork above Va, -W. Va.

State line nr Hardscrabble...... (POT-SHEN)

Laurel Fork at Mouth of Laure1......... (CLINCH)

Laurel Fork at N.F. Pound River Lake ne Pound.

(BIG SANDY)

Laurel Fork at Pocahontas............. (NEW)

Laurel Fork at RR bridge at Whit tewood.

.. (BIG SANDY)

Laurel Fork at Rt $102 \mathrm{nr}$ Pocahontas........ (NEW)

Laurel Fork at Rt 644 at Pocahontas......... (NEW)

Laurel Fork at $R t 653$ at Mabe................... (NEW)

Laurel Fork at Va,-W.Va. State line nr Pocahontas.

(NEW)

Laure 1 Fork at mouth at whi tewood..... (BIG SANDY)

Laurel Fork at mouth nr Gladesboro........ (NEW)

Laurel Fork at mouth $\mathrm{nI}$ Hurley........ (BIG SANDY)

Laurel Fork at mouth nr Imboden......... (POWELL)

Laurel Fork at mouth nr Mabe........... (CLINCH)
Laurel Fork at mouth nr Pound Laurel Prong above Mill Prong nr Criglersvilie.

(BIG SANDY) 481

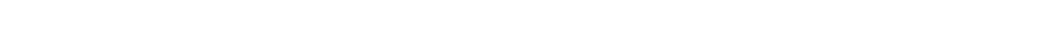

Laurel Run at Rt $628 \mathrm{nr}$ Crimora.............(SHEN) 41

Laurel Run at U.S. Hwy $340 \mathrm{nr}$ Crimora...... (SHEN) 41

Laurel Run at mouth nr Jerome.............. (SHEN) 57

Laurel Springs (Umbarger Creek)

at mouth nr Marion.............. (HOLSTON) 502

Lawless Creek at mouth nr Blairs......... (ROANOKE) 407

Lawnes Creek at mouth nr Bacons Castie... (JAMES) 303

Lawrence Cove at mouth nr Ditchley.... (POT-RAPP) 115

Lawsons Creek at Rt 658 at Turbeville..(ROANOKE) 409

Lawsons Creek at mouth at Riverdale.... (ROANOKE) 410

Lawsons Creek at mouth nr Mike.......... (ROANOKE) 386

Laymantown Creek at U.S. Hwy 460

nr Bons ack. ............... (ROANOKE) 366

Laymantown Creek at mouth nr Bonsack... (ROANOKE) 366 Layton Creek at mouth nr The Ridge..... (ROANOKE) 421 Laytons Branch at mouth nr Center Cross... (RAPP) 155 Lazaretto Creek ar Rt $49 \mathrm{nr}$ Crewe....... (CHOWAN) 323 Lazaretto Creek at mouth nr Blackstone.. (CHOWAN) 323 Leatherberry Creek at mouth

$$
\text { nr Onancock................ (EASTERN) }
$$

Leathers Run at mouth nr Criglersvilie... (RAPP)

Leatherwood Creek at Rt 650 nr Martinsvilie (Old Liberty).... (ROANOKE) 404

Leatherwood Creek at mouth nr Holly Grove (YORK) 179

Leatherwood Creek at mouth nr Irisburg. (ROANOKE)

Leatherwood Creek, West Fork, at mouth nr Martinsville.

(ROANOKE) 403

Ledbetter Creek at wouth nr Meherrin.... (CBOWAN) 348

Lee Creek at mouth nr Duncanville...... (HOLSTON) 518

Lee Mont Branch at Rt $658 \mathrm{nI}$ Lee Mont.. (EASTERN) 17

Lee Mont Branch at Rt $763 \mathrm{nr}$ Le日 Mont.. (EASTERN) 17

Lee Mont Branch at mouth nr Lee Mont... (EASTERN) 17

Lee Run at mouth $\mathrm{nr}$ Elkton.............. (SBEN) 44

Lees Branch at mouth $n x$ Sussex............ (CHOWAN) 332

Lees Creek at mouth nr Pattersons Store. (JAMES) 278

Leesville Lake at dam nr Leesville.... (ROANOKE) 377

Left Fork above Guess Fork nr Hurley. (BIG SANDY) 489

Left Fork above Right Fork at Dante..... (CLINCH) 537

Left Fork above Rt 600 above

Hurricane Creek nr Davenport... (BIG SANDY) 467

Left Fork above Sad Branch nr Davenport.

(BIG SANDY) 466

Left Fork above Tilier Fork nr Duty. (BIG SANDY) 471

Left Fork along Rt 645 at Kelsa...... (BIG SANDY) 490

Left Fork at Rt $619 \mathrm{nr}$ Murphy........ (BIG SANDY) 473

Left Fork at mouth nr Murphy........... (BIG SANDY) 472

Left Fork at mouth nr Red Ash............(CLINCB) 529

Left Fork below Laurel Fork nr Hurley.

Left Fork below Sad Branch

(BIG SANDY) nr Davenport.

(BIG SANDY)

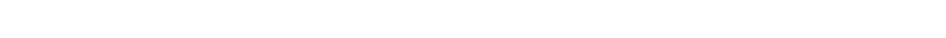

Left Hand Fork at mouth nr Evergreen... (ROANOKE)

Leigh Creek at mouth nr Pinetta.......... (YORK)

Lenah Run (Broad Run) at U.S. Hwy 50 at Lenah

(POTOMAC)

Lester Fork at Rt 650 at Huriey....... (BIG SANDY)

Lester Fork, Left Fork, at mouth nr Hurley.

(BIG SANDY)

Let Alone Creek at mouth $\mathrm{nr}$ The Ridge. (ROANOKE)

Levisa Fork along Rt $618 \mathrm{nr}$ Vandyke.. (BIG SANDY)

Levisa Fork along U.S. Hwy 460 nr Grundy.

Levisa Fork at Poetown nr Grundy..... (BIG SANDY)

Levisa Fork at Rt 1006 at Grundy...... (BIG SANDY)

Levisa Fork at Rt 617 above Grundy... (BIG SANDY)

Levisa Fork at Rt 618 nr Grimsleyville.............. (BIG SANDY)

Levisa Fork at Rt 624 at Oakwood..... (BIG SANDY)

Levisa Fork at Rt 634 at Vandyke..... (BIG SANDY)

Levisa Fork at U.S. Hwy 460 at Oakwood

(BIG SANDY)

Levisa Fork at Va,-Ky. State ine nr Big Rock................. (BIG SANDY) 
Abbreviated basin names appear at the end of the site name. Abbreviations are as follows: Eastern Shore (EASTERN); Potomac to Shenandoah (POT-SHEN); Shenandoah (SHEN); Potomac (POTOMAC); Potomac to Rappahannock (POT-RAPP); Rappahannock (RAPP); Rappahannock to York (RAPP-YORK); York (YORK): York to James (YORK-JAMES); James (JAMES); James to Chowan (JAMES-CHOWAN); ChOwan (CHOWAN); Roanoke (ROANOKE); Yadkin (YADKIN); New (NEW); Big Sandy (BIG SANDY); Holston (BOLSTON); Clinch (CLINCH); POwel1 (POWELI)]

Page

Levisa Fork below Dismal Creek nr Vansant. . F. F. . . . . . . Lovisa Fork bolow Fishtrap Dam nr Millard, Ky............ nr Vansant. . . . . at Bis Rock.

Levisa Fork below Six and Twentymile Creek nr Grundy......................... SANDY) 462

Lewis Branch at mouth ni Fairviow........(CLINCE) 551

Lewis Creek $0.75 \mathrm{mi}$ above $\mathrm{I}-81$ nr Staunton

(BIG SANDY) 459

(BIG SANDY) 464

(BIG SANDY) 459

(BIG SANDY) 463

Creek above Farrier Company

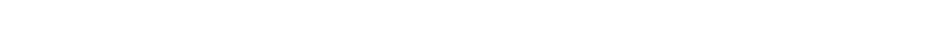

Lewts Creek above $\mathrm{s} \dot{\mathrm{P}}$ at Honaker................. (CIIHCH) 532

Lewis Croek above State School for the

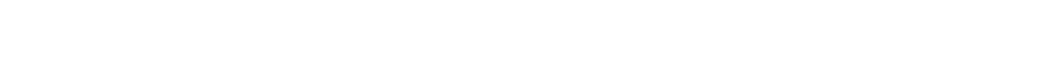

Lewis Creek at Rt 275 nr Annex...................... 35

Lewis Creek at Rt 612 above mouth

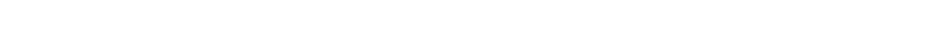

Lewis Creek at Rt 653 at Honaker............ (CLINCH) 532

Lewis Creek at Rt 793 nr Staunton.......... (SHEN) 36

Lewis Creek at Rt 80 at Honaker........ (CLINCH) 532

Lewis Creek at U.S. Bwy 11 at Staunton.....(SHEN) 35

Lewis Creek at mouth $n \mathbf{r}$ Honaker.......... (CIINCH) 532

Lewis Creek at mouth nr Verona............... (SHEN) 36

Lewis Creek below Farrier Company at Staunton.

Lewis Creek below Fiatrock Creek nr Bonaker.

(CLINCH) 531

Lewis Creek below STP at Honaker......... (CLINCH) 532

Lewis Creek below STP nr Staunton.........(SHEN) 35

Lewis Creek below Stone Branch

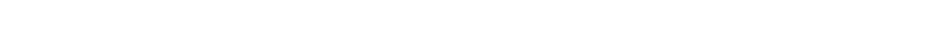

Lowis Creek off Rt 254 at Staunton.........(SHEN) 35

Lewis Fork at mouth nr Trout Dale.........(NEW) 427

Lewis Run above Brock Run nr Chancellorsville.............(YORK) 189

Lewis Run nr mouth nr Millwood........... (SBEN) 65

Liberty Branch at mouth nr Dolphin.......(CHOWAN) 325

Liberty Creek above Maiden Spring Creek nr Liberty...............(CLINCH) 530

Lick Branch at Rt 705 at Catharpin..... (POTOMAC) 97

Lick Branch at mouth nr Chatham......... (ROANOKE) 411

Lick Branch at mouth nr Duty............. (BIG SANDY) 475

Lick Branch at mouth nr Ebenezer........ (ROANOKE) 414

Lick Branch at mouth nr Ewing........... (POWELL) 563

Lick Branch at mouth nr Green Spring... (HOLSTON) 507

Lick Branch at mouth nr Grundy........ (BIG SANDY) 461

Lick Branch at mouth nr Imboden.......... (POWELL) 555

Lick Branch at mouth nr Nebo........... (BOLSTON) 512

Lick Branch at mouth nr Shiny Rock...... (ROANOKE) 419

Lick Branch above Spoon Gap Creek

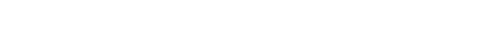

Lick Branch trib No. I at mouth nr Duty..................... (BIG SANDY)

ick Branch trib No. 2 at mouth nr Duty...................... (BIG SANDY)

Lick Creek above Rt $42 \mathrm{nr}$ Chatham Hill. (HOLSTON)

Lick Creek along Rt 670 at Birchleaf. (BIG SANDY)

Lick Creek at Hamlin................ (CLINCH)

Lick Creek at Rt 628 at st. Paui.......... (CLINCH)

Lick Creek at mouth at Birchleaf..... (BIG SANDY)

Lick Croek at mouth at Kerns.

Lick Creek at mouth nr Chatham Hiji.....(BOLSTON) 512

Lick Creek, Left Fork, at mouth

nr Birchleaf.......................... SANDY)

Lick Fork at Rt 72 nr Darwin......... (BIG SANDY)

Lick Fork at mouth nr Darwin......... (BIG SANDY)

Lick Fork at mouth nr Simpsons........... (ROANOKE)

Lick Fork at mouth nr Toshes............ (ROANOKE)

Lick Run above Mine Run nr Fivemile Fork.. (RAPP)

Lick Run at Jordan Springs

(POT - SHEN)

Lick Run at Parking Branch at Roanoke (ROANOKE) 36

lick Run at mouth nr Evington.........(ROANOKE) 381
Lick Run at mouth nr McCoy

Page

ickfort Creek at mouth

nr Drakes Branch................ (ROANOKE) 392

Licking Creek at mouth nr Chesterfield...(JAMES) 287

Licking Creek at mouth nr Richmond........ (JAMES) 267

Ilcking Run at mouth nr Catlett........(POTOMAC) 92

Licking Run nr Midland................(POTOMAC) 92

Lickinghole Creek above Howell Branch nr Crozet.

Lickinghole Creok above C\&O RR bridge nr Crozet.................... (JAMES)

Lickinghole Creek above Rt 240 nr Crozet. (JAMES)

Lickinghole Creek at Howell Branch confluence nr Crozet............ (JAMES)

Lickinghole Creek at Mechums River nr Crozet.................... (JAMES) 248

Lickinghole Creek at Rt 240 nr Crozet.... (JAMES) 248

Lickinghole Creek at mouth at Mechums River..

Lickinghole Creek at mouth nr Boswells Tavern..............(YORK) 176

Lickinghole Creek at mouth nr Greenwood.. (JAMES) 292

Lickinghole Creek below C\&O RR bridge

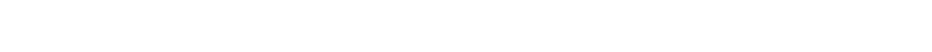

Lieutenant Run at Petersburg................... (JAMES) 283

Lishtfoot Creek at mouth nr Ante...........(CHOWAN) 354

Lightwood Swamp at mouth nr Ivor...........(CHOWAN) 343

Limestone Branch at U.S. Fwy 15 nr Leesburg.................. (POTOMAC)

Limestone Branch at mouth nr Leesburg................. (POTOMAC)

Limestone Branch trib No. $i$ at Rt $661 \mathrm{nr}$ Leesburg........... (POTOMAC)

imestone Branch trib No. 2 at private rd nr Lucketts....... (POTOMAC)

Lincolnshire Branch at mouth

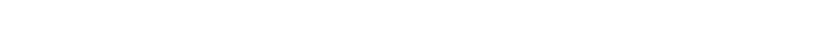

Linkhorn Bay at Alanton nr Virginia Beach.......... (JAMES-CHOWAN)

Linkhorn Bay at Bird Neck Point nr Virginia Beach......... (JAMES-CHOWAN)

Linn Camp Branch at mouth nr Whitewood.

inville Creek at Rt 753 at Broadway...... (SHEN)

Linville Creek at Rt 772 nr Linville....... (SHEN)

Linville Creek at Rt 784 nr Linville....... (SHEN)

Linville Creek at Rt 786 at Broadway........ (SHEN)

Linvil1e Creek at Rt 838 at Broadway....... (SHEN)

Linville Creek at mouth at Broadway........ (SHEN)

Linville Creek below Rt 1414 at Broadway... (SHEN)

Inville Creek below Rt 786 at Broadway... (SHEN)

Lions Creek at mouth nr Red House...... (ROANOKE)

Little (Mumpower) Creek at Sullins College at Bristol....... (BOLSTON)

Little (Mumpower) Creek at Euclid Ave at Bristol.

Little (Mumpower) Creek at U.S. Hiwy il at Bristol................ (HOLSTON)

BOLSTON) 511

Little (Mumpower) Creek at U.S. Hwy ${ }^{\text {at Bristol }}$

Little (Mumpower) Creok at Va -Tenn. State line at Bristol..........(HOLSTON)

Little (Mumpower) Creek at mouth at Bristol, Tenn.

Little (Mumpower) Creek tixib at Southern RR nr Bristol.........(BOLSTON)

Little Back Creek above Back Creek School nI Roanoke............. (ROANOKE) 459 54

Litt 10 Back Creek at Rt 39 nr Mountain Grove. .

Little Back Creek at Rt 60 nr Mountain Grove.

Little Back Creek at mouth at Mountain Grove...

little Back Creek at mouth at Poages Mill.

(JAMES)

Little Back Creek nr Sunrise............... (JAMES) 
Abbreviated basin names appear at the end of the site name. Abbreviations are as follows Eastern Shore (EASTERN); Potomac to Shenandoah (POT-SBEN); Shenandoah (SHEN); Potomac (POTOMAC);

Potomac to Rappahannock (POT-RAPP); Rappahannock (RAPP); Rappahannock to York (RAPP-YORK); York (YORK);

York to James (YORK-JAMES); James (JAMES); James to Chowan (JAMES-CHOWAN); Chowan (CHOWAN); Roanoke (ROANOKE);

Yadkin (YADKIN); New (NEW); Big Sandy (BIG SANDY); Holston (HOLSTON); Clinch (CLINCH); Powell (POWELL)]

Little Bearskin Creek at mouth ni Chatham.

Little Beartown Branch at mouth nr Chatham Hill.

(ROANOKE) 411

Beaver Creek at mouth

Little Beaver Creek at mouth
at Martinsvilie.......
Little Beaver Creek at mouth

(HOLSTON) 513 ni Iynchburs.

(ROANOKE) 402

Little Beaver Pond Creek at mout nr Clarksville.............. (ROANOKE) 419

Little Bluestone Creek at Rt 49 nr Chase City....... $\ldots$ i

(ROANOKE) 418

Little Bluestone Creok at Rt 763 nr Orgainville................ (ROANOKE) 418

Little Bluestone Creek ni Jeffress..... (ROANOKE) 418

Little Bluewing Creek at mouth nr Virgilina................ (ROANOKE) 416

Little Branch at mouth in Moliusk............(RAPP) 157

Little Branch trib No. I at mouth nr Lively. $\cdots \cdots$ No. mouth Branch trib No. 2 at mou nr Brumley Gap................(HOLSTON) 518

Ltttle Brush Creek at mouth nr Fries....... (NEW) 432

Little Buffalo Creek at mouth at Buffalo Springs.

Little Bull Run at nr Bul1 Run............... (POTOMAC)

Little Bul1 Run at Rt 705 nr Catharpin. (POTOMAC)

Little Bull Run at Sudley Mountain Rd nr Catharpin.................. (POTOMAC)

Little Bull Run at mouth nr Buil Run... (POTOMAC) Little Bull Run at mouth nr Penhook.... (ROANOKE)

Little Bundy Creek at mouth nr Bundy.... (POWELL)

Little Byrd Creek at Rt $667 \mathrm{nr}$ Fife...... (JAMES)

Little Byrd Creek at mouth nr EIk Hiil... (JAMES)

Little Calfpasture River above Cove Run nr Bells Valley.

(JAMES)

Little Calfpasture River above

Kennedy Draft nr Craigsville......(JAMES) 225

Little Calfpasture River above Smith Creek at Craigsville.

Little Calfpasture River along Rt $8 i i$ nr Augusta Springs.............(JAMES) 225

Little Calfpasture River at $\ddot{R} \ddot{\sigma} \dot{\sigma} i$ at Augusta Springs.......

Little Calfpasture River at Rt 601 below Cove Run nr Bells Valley..... (JAMES) 226

Little Calfpasture River at Rt 683 below Smith Creek nr Craigsville... (JAMES) 225

Little Calfpasture River at Rt 685 at Craigsuille................(JAMES) 225

Little Calfpasture River at mouth nr Goshen....................... (JAMES) 226

Little Calfpasture River below Allen Creek nr Bells Valley.......(JAMES) 225

Little Calfpasture River below Grassy Run at Craigsville.........(JAMES) 225

Little Calfpasture River nr Bells Valley. (JAMES) 225

Little Camp Creek at mouth nr Riner........ (NEW) 445

Little Caney Creek at mouth nr Herald.

Little Carter Creok at mouth nr Warsaw....(RAPP) 153

Little Catawba Creek at mouth nr New Castle................. (JAMES) 220

Little Cattail Creek at mouth nr Reams. (CHOWAN) 330

Little Cattail Creek trib. No. 1 at $\mathrm{Rt} 660 \mathrm{nr}$ Dinwiidie................ (CHOWAN) 330

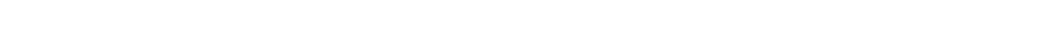

Little Cedar Creek at U.S. Ewy 19 at Lebanon........... (CLINCH) 533

Little Cedar Creek at mouth ir Lebanon... (CLINCH) 533

Little Cedar Creek below STP at Lebanon. (CLINCH) 533

Little Cherrystone Creek at $R t \mathbf{8 3 2}$ nr Chatham.

(ROANOKE) 412

Litt le Cherrystone Creek at mouth nr Spring Garden............. (ROANOKE
Little Chestnut Creek at mouth nr Sontag. (ROANOKE) 373

Little Chestnut Creek nr Sydnorsviile...(ROANOKE) 373

Little Childrey Creek at mouth nr Brookneal................. (ROANOKE) 387

Little Coldwater Branch at mouth nr Poweliton.................... (CHOWAN) 354

Little Coleman Creek at mouth nr Mayo... (ROANOKE) 416

Little Copper Creek at mouth nr Dickensonville............... CLINCH) 548

Iittle Cranberry Creek at mouth nr Woodlawn.

Little Creek Channel at Little Creek Amphibious Base nr Norfolk.............

Little Creek Channel at U.S. Coast Guard Station at Little Creek Amphtbious Base nr Norfolk.. (JAMES-CHOWAN) Creek Reservoir (central)

nr Norge. ........................ (JAMES) 300

Little Creek Reservoir (east) nr Norge... (JAMES) 300

Little Creek Reservoir (north centrai) nr Norge................ (JAMES) 300

Little Creek Reservoir (north) nr Norge.. (JAMES) 299

Little Creek Reservoir (north/northeast) nr Norge...................... (JAMES) 299

Little Creek Reservoir (northesst)

Little Creok Reservoir (northwest) nr Norge....................... (JAMES) 300

Little Creek Reservoir (south centrai) nr Norge....................... (JAMEs) 300

Little Creek Reservoir (west) nr Norge... (JAMES) 300

Little Creek Reservoir at spiliway nr Norge...................... (JAMEs) 300

Little Creek Reservotr infall nr Norbe... (JAMES) 299

Little Creek Reservoir nr Norfolk............... (JAMES-CEOWAN)

Little Creek above Burkes Garden Creek nr Shawver Mill...................... (NIJW) 453

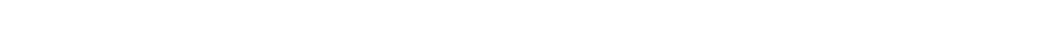

Little Creek at Rt 611 nr Denaro............. (JAMES) 278

Little Creek at Rt 619 nr Quantico........ (POTOMAC) 107

Little Creek at U.S. Bwy 1 at Triangle. (POTOMAC) 107

Little Creek at Va.-Tenn. State line nr Blackwater................ (CLINCH) 552

Little Creek at mouth at Little Creek Amphibious

Base nr Norfolk........... (JAMES-CHOWAN) 314

Little Creek at mouth at Irwin............ (JAMES) 261

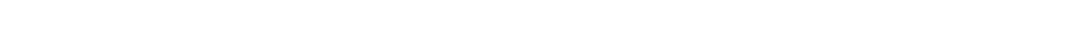

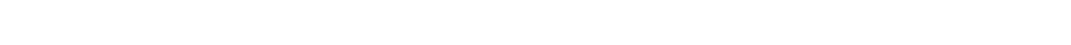

Little Creek at mouth nr Denaro............ (JAMES) 278

Little Creek at mouth nr Norfolk.. (JAMES-CHOWAN) 314

Little Creek at mouth nr Wirtz.........(ROANOKE) 370

Little Creek at mouth ar Woolwine........ (ROANOKE) 397

Little Crooked Run at mouth nr Culpeper...(RAPP) 137

Little Cub Creek at mouth nr Madisonvilie...............(ROANOKE) 387

Little Dan River at Va. -N.C State line nr Claudvilio........ (ROANOKE) 394

Little Dark Run at Rt 534 nr Madison....... (RAPP) 137

Little Dark Run at Rt 680 nr Madison........ (RAPP) 137

Little Difficult Run at Stuart Mill Rd nr Vienna.........(POTOMAC) 76

Little Difficult Run at mouth nr Vienna. ....... (POTOMAC)

Little Difficult Run, S.F., at Fox Mill Rd nr Fairfax.........(POTOMAC) 76

Little Difficult Run, S.F., at mouth nr Vienna..................... (POTOMAC) 76

Little Doe Run at mouth nr Sontag....... (ROANOKE) 373

Little Dorrell Creek at mouth nr Beulahville.

(YORK) 194

Little Dry River at mouth at Füks Run..... (SREN) 52

Little Dry Run at mouth nr Groseclose.. (HOLSTON) 499

Little Duck Branch at mouth nr Collinwood .............. (EOLSTON) 
Abbreviated basin names appear at the end of the site name. Abbreviations are as follows:

Eastern Shore (EASTERN); Potomac to Shenandoah (POT-SHEN); Shenandoah (SHEN); Potomac (POTOMAC);

Potomac to Rappahannock (POT-RAPP); Rappahannock (RAPP); Rappahannock to York (RAPP-YORK); York (YORK) :

York to James (YORK-JAMES); James (JAMES); James to Chowan (JAMES-CHOWAN); ChOWan (CHOWAN); ROAnOKe (ROANOKE);

Yadkin (YADKIN); New (NEW); Big Sandy (BIG SANDY); Holston (HOLSTON); Clinch (CLINCH); Powe11 (POWELL)]

Page

Little Eliie Creek at mouth nI Burnt Chimey...................... 370

Little Fall Creek at mouth at Danville. (ROANOKE) 407

Little Faliing River at Rt 618 at Hat Creek. . . . . . . .

(ROANOKE) 386

Little Faling River at mouth nr Brookneal................ (ROANOKE) 386

Little Falls Run at mouth nr Fredericksburg.

Litt le Fox Creek above Jackson Fork nr Murphy...................... (BIG SANDY)

Little Fox Creek above Spruce Pine Branch nr Murphy............. (BIG SANDY)

Little Fox Creek at Rt $605 \mathrm{nr}$ mouth

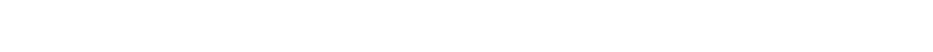

Little Fox Creek at mouth nr Fox........... (NEW) 428

Little Fox Creek below Spruce Pine Branch nr Murphy.............. (BIG SANDY)

Little Fox Creek trib at Rt 705 nr Murphy................ (BIG SANDY)

Littie Garden Creek at mouth at Oakwood....................... SANDY) 458

Little Genito Creek at mouth nr Brodnax. (CBOWAN) 351

Little Goblintown Creek at mouth

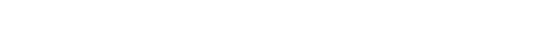

(ROANOKE) 399

Little Greenbriar Creek at mouth nr Prater................. (BIG SANDY) 477

Little Greenbrier Creek aiong $\mathrm{Rt}$ 6ii nr Vicey.................... (BIG SANDY)

Little Guinea Creek at Rt 654 nr Cumberland................. (JAMES)

Litt le Guinea Creek at mouth nr Stony Point Mills.

ittle Gawksbill Creek at Kite Böliow

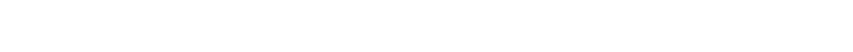

Little Gawksbili creok at mouth

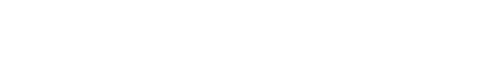
Bis Fill Hollow nr Ida.

Little Forsepen Creek at mouth nr Sare

Hounds Creek at mouth nr Blackstone...........

(ROANOKE)

(CHOWAN)

Little Hunting Creek at Geo

Mount Vernon......

Little Gunting Creek at STP at Gum Springs............... (POTOMAC)

Little Gunting Creek at U.S. Hwy 1 at Gum Springs............... (POTOMAC)

Litt le Hunting Creek at mouth at Mount Vernon.............. (POTOMAC)

Little Hunting Run at mouth Chancellorsville...............................

Little Indian Creek at Rt 602 nr Council........... Indian Creat

nr Copper Valley..........

Little Indian Creek at mouth nr Council.................. (BIG SANDY) 469

Little Indian Rum at mouth

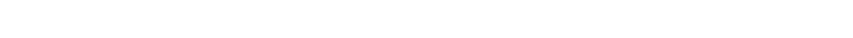

Littlo Irish Creak diversion to Lynchburs Reservoir nr Buena Vista ........

Little Isaacs Creek at Rt $6 \dot{6} \dot{3}$ nr Whitacre............ nr Gainesboro............... (POT-SHEN)

Little Ivy Creek at mouth at Vesta...... (ROANOKE)

Littie Jacks Creek at mouth nr Dickinson................... (ROANOKE)

Little Juniper Creek at mouth

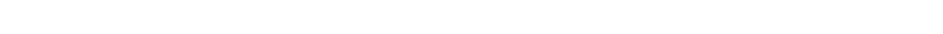

Little Laurel Branch at Flannagan Reservoir nr Blowing Rock...... (BIG SANDY) 484

Little Laurel Creek at mouth nr Bent Mountain................ (ROANOKE)
Little Laurel Creek at mouth nr Copper Valley.

Little Laurel Creek at mouth nr Konnarock................. (HOLSTON) 496

Little Ledbetter Crook at mouth nr Meherrin....................(CHOWAN) 348

Little Lick Creek at mouth nr Bartlick.................. (BIG SANDY) 480

Little Lickinghole Creek at $\mathrm{Rt} 616$ nr Georges Tavern................ (JAMES) 261

Little Lickinghole Creok nr Goochland.... (JAMES) 261

Little Lynville Creek at mouth nr Hardy.

Little Macks Creek at mouth nr Mack Creek Village.

Little Marrowbone Creek at mouth nr Ridgeway. . . . . . . . nr Penns Store......... Moccasin Creek above Big Moccasin Creek at Gate City...(ROLSTON) 523

Little Moccasin Creek above Gate City.. (HOLSTON) 523

Little Moccas in Creek above STP at Rt 1798 at Gate City.........(gOLSTON) 523

Little Moccasin Creek at U.S. Gwys $58 / 23 / 260$ at Gate City. (GOLSTON) 523

Little Moccasin Creek at mouth at Holston................. (HOLSTON)

Little Moccasin Creek at mouth at Gate City...................(EOLsTON) 523

Little Moccasin Creek diversion at Gate City................. (HOLSTON) 523

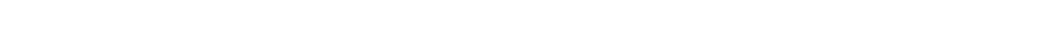

Little Moccasin Crook trib at mouth at Holston.................... (HOLSTON)

Little Mosquito Creek at mouth

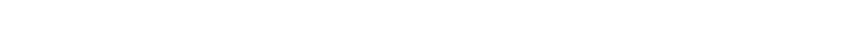

Little Mountain Run at Rt 600 nr Whitacre................ (POT-SHEN)

Little Neck Creek nr Virginia Beach.......... (JAMES-CHOWAN)

Littie Nottoway River at $\mathrm{R} t$ nr Blackstone............... (CHOWAN)

Littie Nottoway River at $\dot{R} t \quad 4 \dot{g} \dot{n}$ Crewe. (CHOWAN)

Little Nottoway River at Rt 603 nr Blackstone...............

Little Nottoway River at Rt 625 nr Blackstone..................

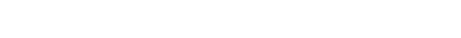

Little Opossum Creek at mouth nr Lynchburg. . . ................. (JAMES)

littie Otter River above U.S. Hiwy 460

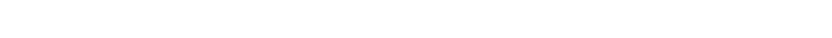

Little Otter River at Rt 122
nr Bedford..... nr Bedford................. (ROANOKE) nr Bedford............................... Otter River at $\dot{R} t \ddot{7} \dot{8}$

Littlo Otter River at Rt $784 \ldots$ (ROANOKE)

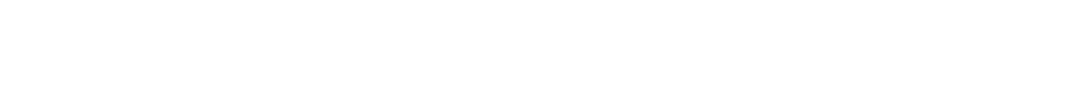

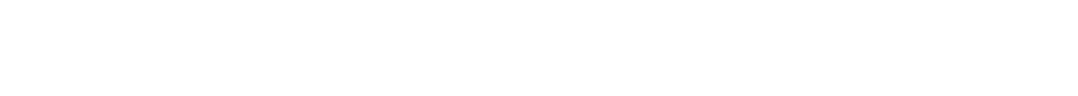

Little Otter River at U.S. Hwy 460 nr Bedford................. (ROANOKE) Otter River at mouth nr Otter Hil1................... (ROANOKE)

381 Otter River below

Little Otter River below Otter River below Johns Creek

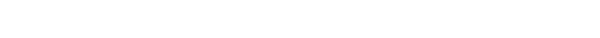

Little Passage Creek at Mud Hole Gap nr Strasburg................. (SHEN) 62

Littie Patterson Creek at Rt $\ddot{6} \dot{8}$ nr Eagle Rock. .............. nr Prater..................... SIG SANDY) 474

Little Pawpaw Creek at Rt 605 nr Colley..................... SIG SANDY)

\section{$\theta$} 6

.

.
. . .

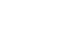

\section{(1)} (2)

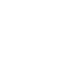

,

.

.


Abbreviated basin names appear at the end of the site name. Abbreviations are as follows

Eastern Shore (EASTERN); Potomac to Shenandoah (POT-SHEN); Shenandoah (SHEN); Potomac (POTOMAC)

Potomac to Rappahannock (POT-RAPP); Rappahannock (RAPP); Rappahannock to York (RAPP-YORK); York (YORK) ;

York to James (YORK-JAMES); James (JAMES); James to Chowan (JAMES-CHOWAN); ChOWan (CHOWAN); Roanoke (ROANOKE);

Yadkin (YADKIN); New (NEW); Big Sandy (BIG SANDY); Holston (HOLSTON); Clinch (CLINCH); Powell (POWELL)]

Little Pawpaw Creek at mouth

Little Peach Bottom Croek at mouth at Independence. (BIG SANDY) 474

Pimmit Run at Frankin Park R

(NEW) at Arlington................ (ZOTOMAC) Pimmit Run at Kirby Rd

at Arlington . . . $\ddot{6} \dot{8}$ at Arlington.............. (POTOMAC)

Little Pimit Run at Rt 689 Little falls Rd at Arlington..... (POTOMAC) Pimmit Run trib at

Little Falls Rd at Arlington..... (POTOMAC) 79

Little Pine Run at mouth nr Allisonia...... (NEW) 438

Little Riney River at Lowesville.........(JAMES) 237

Little Polecat Creek at mouth nr Halifax................. (ROANOKE) 414

Litt le Poplar Creek at mouth nr Ebony.. (ROANOKE) 423

Little Prater Creek at mouth nr Grundy.................... (BIG SANDY)

Little Reed Creek at mouth at Fieidele. (ROANOKE)

Little Reed Island Creek above Beaverdam Creak at Rt $769 \mathrm{nr}$ Hillsville........ (NEW)

Little Reed Island Creok above Hilisville.. (NEW)

Little Reed Island Creek at Rt 100

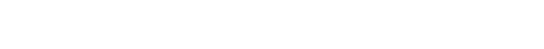

Little Reed Islend Creek at Rt 701

Little Reed Island Creek at Rt $75 \dot{5}$ Re Allisonia. Reed Island Creek at U.S. Hwy 52 nE Hillsville................... (NEW)

Little Reed Island Creek at U.s. Hiwy 58

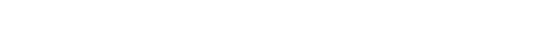

Little Reed Island Creek at mouth nr Allisonia . $\ldots \ldots \ldots \ldots$. . . . . . . . . . .

Little Reed Is land Creek below Beaverda

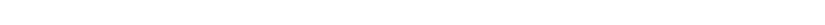

Little River ebove Laurel Creek et Wardell ................ (CLINCH)

Littie River et $I-g 5$ at Taylorsvilie...... (YORK

Little River at Rt $601 \mathrm{nr}$ Hewlett......... (YORK)

Little River et Rt $605 \mathrm{nr}$ Radford............. (NEW)

Little River at $R t 626$ at Halfway........ (PÖOMAC)

Little River et Rt $626 \mathrm{nr}$ Baywood.......... (NEW)

Little River at Rt $628 \mathrm{nr}$ Aldie........ (POTOMAC)

Little River at Rt $629 \mathrm{nr}$ Aldie......... (POTOMAC)

Little River at Rt 632 at Aldie......... (POTOMAC)

Little River at Rt $636 \mathrm{nr}$ Honaker........ (CLINCH)

Little River at Rt 658 nr Beaverdam....... (YORK)

Little River at Rt 680 nr Beaverdam........ (YORK)

Little River et Rt $685 \mathrm{nr}$ Doswell.......... (YORK)

Little River at Rt 688 nr Doswell........... (YORK)

Little River at Rt 689 at Taylorsville.... (YORK)

Littlo River at Rt 693 at Graysontown (Graysonton) . . . . . . . (NEW)

Little River at Rt $715 \mathrm{nr}$ Beaverdam....... (YORK)

Little River et Rt $718 \mathrm{nr}$ Stokesville..... (SHEN)

Little River at Rt $738 \mathrm{nr}$ Hewlett......... (YORK)

Little River at Rt $787 \mathrm{nr}$ Copper Vailey.... (NEW)

Little River at U.S. Bwy $1 \mathrm{nr}$ Ashland..... (YORK)

Little River at U.S. Hwy 15 nr Oatlands................. (POTOMAC)

Little River et U.S. Bwy ig at Wardeii. (CLINCH)

Little River at mouth nr Ashland......... (YORK)

Little River at mouth nr Baywood........... (NEW)

Little River at mouth nr Honaker.......... (CLINCH)

Little River at mouth nr Oatlends....... (POTOMAC)

Little River at mouth nr Radford...........(NEW)

Little River at mouth of Beaver Creek nr Floyd.........................

Little River below Coal Rü nr Stokesville................ SHEN)

Little River powerplant outfall at Radford Dam nr Radford........... (NEW) 447

Little River trib at mouth nr Graysontown. (NEW) 447

460 401

440

440
Little River, N.F., at mouth nr Stokesvilie........

Little River, S.F, at mouth

Little Rock Castle Creek at mouth nr Woolwine..............

Little Rockhouse B nr McClure.

Little Rocky Creok at mouth nr Lake Anna Dam.

Little Rocky Run at Rt 658

at Comptons Corner.

Little Rocky Run at U.S. Hwys 29/2i et Centreville.....

Little Rocky Run at mouth

nr Manasses Park........

nr Nettleridge..............(ROANOKE) 395

Little Sandy Creek at Rt 612 nf Moran.... (JAMES) 274

Little Sandy Creek at mouth

nr Mount Hermon................ (ROANOKE) 407

Little Sandy Creek at mouth nr Moran...... (JAMES) 274

Little Sinking Creek at Va.-Tenn.

State line nr Bristol..........(HOLsTon) 509

Little Smith Spring et Natural Bridge..... (JAMES) 223

Little Snake Creek at mouth nr Gladesboro... (NEW) 439

Little Snake Creek at mouth nr Hillsville.. (NEW) 439

Little Spencer Croek at mouth nF Patrick Springs........... (ROANOKE)

Little Spoon Creek at mouth nr Penns Store...........

Litt le Spraddle Branch at mouth

Little Sprouts Creok at mouth

(ROANOKE) 395

nf Chatham Bi $11 \ldots \ldots \ldots \ldots$
ittle Spruce Pine Branch et mout nr Duty . . . . . . . . .

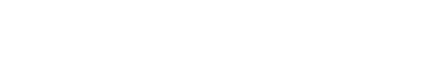

Little Stock Creek at mouth at Clinchport. Stony Creek above Bedford Reservoir nr Bedford.

Stony Creek above Woodstock Reservoir nr Columbia Furnace. ni Dungannon.

little Stony Creek at Rt 43 nr Bedford.

(CLINCH) 547

Columbia Furnace........ (SHEN) 58

Little Stony Creek at U.S. Hwy 460 at Pembroke.

(CLINCH) 543

Little Stony Creek at mouth nr Liberty Furnace.................. SHEN) 58

Little Stony Creek at mouth at Pembroke..... (NEW) 450

Little Stony Creek below Woodstock Reservoir ar Columbia Furnace....... (SHEN) 58

Little Stony Creek nr High Knob......... (CLINCH) 543

Little Stony Creek nr Kigh Knob....
Little Straightstone Creek at mouth nr Level Run

Little Sugar Run at mouth at Bene ...... (ROANOKE)

Little Swamp at mouth nr Joyner........... (CHOWAN) 332

Little Sycamore Creek at mouth nr Mot ley

(ROANOKE) 379

Little Sycamore Creek et mouth nr Charity $\ldots \ldots \ldots \ldots$ ino nr Balifax.................(ROANOKE) 415

Iittle Toby Creek at mouth et Paces.... (ROANOKE) 409

Little Tomahawk Creek at Rt 652

Little Tomahawk Creek et former mouth in Swift Creek Reservoir ni Hallsboro. (JAMES) 285

Little Toms Creek at Rt 72 at Coeburn... (CLINCH) 542

Little Toms Creek et mouth at Coeburn... (CLINCB) 542

Little Totuskey Creek at U.S. Hwy 360

Little Totuskey Creek at mouth

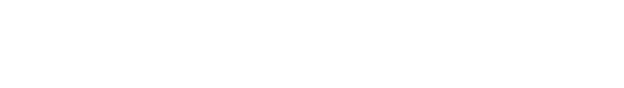

(RAPP) 154 
Abbreviated basin names appear at the end of the site name. Abbreviations are as follows: Eastern Shore (EASTERN); Potomac to Shenandoah (POT-SHEN); Shenandoah (SHEN); Potomac (POTOMAC); Potomac to Rappahannock (POT-RAPP); Rappahannock (RAPP); Rappahannock to York (RAPP-YORK); York (YORK); York to James (YORK-JAMES); James (JAMES); James to Chowan (JAMES-CHOWAN); Chowan (CHOWAN); ROanoke (ROANOKE); Yadkin (YADKIN); New (NEW); Big Sandy (BIG SANDY); Holston (HOLSTON); Clinch (CLINCH); Poweli (POWELL)]

Little Town Hill Creek at mouth at Richlands.

Little Tuckhoe Creek at mouth nr Short Pump.

(CLINCE) 528

Little Tumbling Creek at mouth

at Tannersville.........

(JAMES) 263 nr Tumbling Creok. ....

Little Walker Creek above mouth ir Poplar Hill.

(BOLSTON) 514

(HOLSTON) 516

Little Walker Creek at mouth n. Poplar $\mathrm{H111}$

Little Waiker Creek trib at mouth nr Poplar Hill. . . Woile......

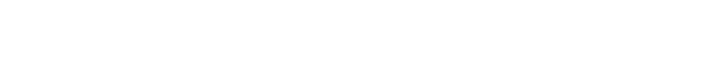

(NEW) 452

Little Westham Creek below Westhampton Lake at Richmond.......... Westhan Creek trib at mouth at Richmond.

(JAMES) 264

( JAMES)

264

( JAMES )

Little Whipping Creek at mouth n Naruna.

Little Wicomico River at Va. -Md State line nr Sunnyhank.

Iittle Widgeon Creek at mouth at Charity.

Little Willis River at U.s. Hwy is at Curdsville.................. (JAMEs) 258

Little Willis River at mouth nr Guinea Mills.................. (JAMES) 258

Little Wilson Creek at mouth at voiney...... (NEW) 427

Little Wilson Creek at mouth nr Rugby....... (NEW) 427

Little Winns Creek at U.S. EWy 58

nr Turbeville................ (ROANOKE) 408

Little Wolf Run at mouth ni Philiip.... (HOLSTON) 519

Little Yellow Branch at mouth nr Smiley.(POWELL) 562

Little Yellow Lick Branch at mouth

nI Murphy................. (BIG SANDY)

Livingston Creek at Rt 689 nr Mendota. (HOLSTON)

livingston Creek at mouth nr Mendota... (HOLSTON) 520

Lizard Creek above mouth nr Gasburg.... (ROANOKE) 424

Lizard Creek at Rt 742 nr Gasburg...... (ROANOKE) 424

Lloyds Run at mouth $n r$ Dolphin............. (CHOWAN) 325

Locket Creek at Rt $650 \mathrm{nr}$ Prospect.......... (JAMES) 273

Locket Creek at mouth nr Hampden Sydney.. (JAMES) 273

Locklies Creek at mouth nr Irvington...... (RAPP)

Locust Cove Creek at Rt 42 nr Ridgedale................ HOLSTON) 513

Locust Cove Creek at mouth nr Broadford................. (HOLsTON) 513

Locust Creek at mouth in Beaverdam............ (YORK) 173

Locust Creek at mouth nr Danripple...... (ROANOKE) 409

Locust Run at mouth nr Jeffersonton.......(RAPP) 119

Lodge Creek at Dungan Point nr Kinsale.(POTOMAC) 112

Lodge Creek at U.S. Hwy $350 \mathrm{nr}$ Calleo.. (POTOMAC) 112

Logan Creek at mouth $\mathrm{nr}$ Linde11.........(HOLSTON) 517

London Bridge Creek at old Potters Rd at Virginia Beach........... (JAMES-CHOWAN) 314

London Swamp at mouth nr Aylett.......... (YORK) 195

Lone Branch at mouth nr Jonesvilie......... (POWELI) 561

Long Branch above Hurricane Branch

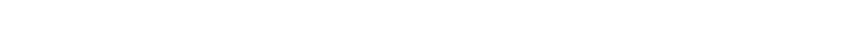

Long Branch above Littie Nottoway River nr Blackstone......................WAN)

Long Branch (Little Run) at $\dot{R} t 520$

nr Annandale..................... (POTOMAC)

Long Branch above mouth at Arington... (POTOMAC)

Long Branch at Arlington Blvd

nr Vtenna....... (POTOMAC)

Long Branch at Guinea $\dot{R} d$ nr Fairfax.... (POTOMAC)

Long Branch at Lee Hwy at Vienna....... (POTOMAC)

Long Branch at Newington Rd nr Accotink. .

Long Branch at Old Giebe Rd

at Arlington............... (POTOMAC)

Long Branch at $R$ t 624 nr Miliwood.......... (SHEN)

Long Branch at Rt $636 \mathrm{nr}$ Raccoon Ford..... (RAPP)
Long Branch at South Carlyn Springs Rd at Arlington ................ (POTOMAC) Long Branch at mouth nr Republican Grove.............. (ROANOKE)

Long Branch at mouth nr Wharncliffe, $W$. Va .......... (BIG SANDY)

Long Branch at mouth at Long Is land... (ROANOKE) Long Branch at mouth at Midway.......... (ROANOKE)

Long Branch at mouth at Sonans.......... (ROANOKE)

Long Branch at mouth at Turbeville..... (ROANOKE)

Long Branch at mouth nr Accotink........ (POTOMAC)

Long Branch at mouth nr Ammon............ (JAMES)

Long Branch at mouth nr Annandale....... (POTOMAC)

Long Branch at mouth nr Baskervilie.... (ROANOKE)

Long Branch at mouth nr Bracey.......... (ROANOKE)

Long Branch at mouth nr Brookneal....... (ROANOKE)

Long Branch at mouth nr Clintwood.... (BIG SANDY)

Long Branch at mouth nr Dye............ (CLINCH)

Long Branch at mouth nr Eorksvilie....... (CHOWAN)

Long Branch at mouth nr Eredericksburg.... (RAPP)

Long Branch at mouth nr Merrifield..... (POTOMAC)

Long Branch at mouth nr Nora........ (BIG SANDY)

Long Branch at mouth nr Patterson.... (BIG SANDY)

Long Branch at mouth nr Raccoon Ford...... (RAPP)

Long Branch at mouth nr Raven........... (CLINCH)

Long Branch at mouth nr Stafford....... (POTOMAC)

Long Branch at mouth nr Triplet......... (CHOWAN)

Long Branch trib below Ridge Rd at Arlington........ (POTOMAC)

Long Creek at 5 th St nr Fox Hi11... (YORK-JAMES)

Long Creek at Rt $655 \mathrm{nr}$ Buckner........... (YORK)

Long Creek at mouth nr Boswel1s Tavern.... (YORK)

Long Creek at mouth nr Buckner........... (YORK)

Long Creek at mouth nr Doswel1............ (YORK)

Long Creek at mouth nr Red House.......... (ROANOKE)

Long Fork at mouth nr Clintwood....... (BIG SANDY)

Long Glade Creek at Rt $546 \mathrm{nr}$ Mt. Solon... (SEEN)

Long Glade Creek at mouth at Bridgewater. (SHEN)

Long Hill Swamp at mouth nr Lightfoot.... (JAMES)

Long Hill Swamp, West Branch, at Rt 612 nr Lightfoot

Long Marsh Run at Rt $6 i 2$ nr Berryvilie... . (SHEN)

Long Marsh Run at Va. -W. Va. State line nr Berryrille......... (SHEN)

Long Marsh at U.S. Hwy 340 nr Berryvilie.. (SHEN)

Long Meadow (Lons Glade) Run at Rt 259 nr Broadway............. (SEEN)

Long Meadow (Long Glade) Run at mouth nr Broadway.

Long Meadow Run trib at Rt $25 \dot{9}$ nr Broadway.................. (SHEN)

Long Meadow Run trib tributary at Rt $259 \mathrm{nr}$ Broadway................ (SHEN)

Long Mountain Creek at mouth nr Laurel Fork. . . . . .

Long Point Branch at mouth ne Stanardsville.

Long Run above Looney Creek nr Buchanan. (JAMES)

Long Swamp at mouth nr Beach........... (JAMES)

Looney (Back) Creek at U.S. Bwy ii nr Buchanan.

( JAMES )

Looney (Looney Mi ii) Creek at mouth at Buchanan.................. (JAMES)

Looney Creek above Long Run nr Buchanan.. (JAMES)

Looney Creek along $R t 160$ nr Inman...... (POWELL)

Looney Creek at $R t 160$ at Inman......... (POWELL)

Looney Creek at Rt 58 at Appalachia..... (POWELL)

Looney Creek at U.S. Hwy 460/Rt 656 ni Grundy

Looney Creek at mouth nr Grundy. .

Looney Creek trib at Rt $160 \mathrm{nr}$ Inman.... (POWELL)

Looney Fork at mouth nr Vansant...... (BIG SANDY)

Loop Creek above Elk Garden Creek nr EIk Garden................... (CLINCH)

Lost Bent Creek at mouth nr Copper Valiey.. (NEW) Lost Creek at mouth at Norton.......... (CLINCH)

Loth Spring nr Waynesboro................ (SHEN)
80 383 392 412 409 89
279 88 422 423 387 
Abbreviated basin names appear at the end of the site name. Abbreviations are as follows: Eastern Shore (EASTERN); Potomac to Shenandoah (POT-SHEN); Shenandoah (SHEN); Potomac (POTOMAC);

Potomac to Rappahannock (POT-RAPP); Rappahannock (RAPP); Rappahannock to York (RAPP-YORK); York (YORK)

York to James (YORK-JAMES); James (JAMES); Janes to Chowan (JAMES-CHOWAN); Chowan (CEOWAN); Roanoke (ROANOKE):

Yadkin (YADKIN); New (NEW); Big Sandy (BIG SANDY); Holston (BOLSTON); Clinch (CLINCE); POWell (POWELL)]

Page

Louse Creek at mouth at Alvardo....... (EOLSTON) 498

Louse Creok at mouth $\mathrm{nr}$ Aspen........... (ROANOKE) 388

Louse Creek at mouth nr Penhook.......... (ROANOKE) 372

Lovelady Creek at mouth at Jasper........ (CLINCH) 550

Lovills Creek at Va.-N.C. State line nr Cana.

(YADKIN) 426

Low Gap Branch at mouth nr Hurley..... (Big SANDY)

Lowe Branch at mouth at Mouth of Laurel. (CLINCH)

Lower 818 Branch at Rt 685 nr Patterson.

(BIG SANDY)

Lower Big Branch at mouth nr Patterson................ (BIG SANDY)

Lower Chippokes Creek at mouth nr Bacons Castle................ (JAMES)

Lower Lewis Run at Fire Rd in Lynnwood..... (SHEN)

Lower Lewis Run at mouth nr Lynnwood....... (SHEN)

Lower Lewis Run trib at Fire Rd nr Lynnwood.

Lower Machodoc Creek at

Harrison Point nr Tidewells...... (POTOMAC) 112

Lower Machodoc Creek at Cherry Point nr Tideweils.................. (РОTOMAC)

Lower Machodoc Creek at buoy i at

Plumb Point nr Tidewells .......... (POTOMAC) 112

Lower Machodoc Creek at mouth nr Coles Point................ (POTOMAC)

Lower Machodoc Creek between

buoys $1 \& 2$ at Coles Point......(POTOMAC) 112

Lower Mill Branch at mouth at Grundy. (BIG SANDY) 461

Lower Twin Branch at Flannagan Reservolr nr Tarpon............ (BIG SANDY)

Lower spring nr Woodlawn Park nr Roanoke ................. (ROANOKE) 364

Lowry Run at U.S. Hwy $50 i$ at Buena Vista. (JAMES) 229

Lubber Run at Arlington Blvd At Arlington ............ (POTOMAC)

Lucks Branch at mouth nr Mike ........... (ROANOKE)

Lucky Run at Dinwiddie St at Ariington. (POTOMAC)

Lukas Creek at Newport News............. (JAMES)

luke Spring nr Covington................ (JAMES)

Lunga Reservoir nr Garrisonvilie ....... (POTOMAC)

Luthers Branch at mouth nr Pattersons Store................ (JAMES) 278

Iyell Branch at mouth nr Montross........ (RAPP) 152

Lyle Creek at mouth nr Lunenburg........ (CHOWAN) 348

Lynch River above Roach River nr Dyke.... (JAMES) 252

Lynch River at Rt 810 at Nortonsville.... (JAMES) 252

Lynchburg Reservoir inflow nr Buena Vista................ (JAMES)

Lynn Camp Creek at U.S. Hwy $460^{\circ}$ nr Earman Junction............ (BIG SANDY)

Lynn Camp Creek at mouth nr Harman Junction............. (BIG SANDY) 462

Lynn Camp Creek at mouth nr Nebo....... (BOLSTON) 512

Lynnhaven River at mouth at Ocean Park.

Lynnhaven River, Eastern Branch, at mouth nr Ocean Park...... (JAMES-CBOWAN) 315

Lynnhaven River, Eastern Branch. or Ocean Park....... (JAMES-CHOWAN) 315

Lymmaven River, Eastern Branch, off Wolfsnare Polnt nr Virginia Beach.

Lynnhaven River, Eastern Branch, off Trants Point nr Virginia Beach. .......... (JAMES-CHOWAN)

Lynnhaven River, Western Branch. at buoy 40 nr Ocean Park.... (JAMES-CHOWAN) 314

Lynnhaven River, Western Branch. at buoy 26 nI Ocean Park.... (JAMES-CHOWAN) 314

Lynnhaven River, Western Branch. at buoy 18 nr Ocean Park.... (JAMES-CHOWAN) 314

Lynnhaven River, Western Branch. at mouth nr Ocean Park...... (JAMES-CHOWAN) 314 Lynville Creek at Rt $676 \mathrm{nr}$ Hardy....... (ROANOKE) 368 Lynvilie Creek at mouth nr Hardy........ (ROANOKE) 368 Lyons Creek at mouth nr Poquoson.... (YORK-JAMES) 202 Lyons Fork at mouth nr Duncan Gap.... (BIG SANDY) 485
M. R. Newland Spring nr Cedar Springs..... (NEW) 433 Machine Branch at mouth nr Martinsville.

Machine Branch at mouth nr Gibson Station.

(ROANOKE) 403

Creek at mouth

(POWELL) 563

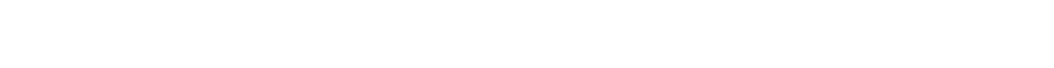

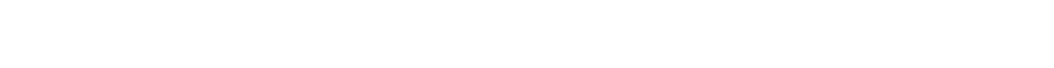

Machi pongo River nr Nassawadox......... (EASTERN) 13

Mackey Spring at Vanderpool.............(JAMES) 205

Maclins Creek at mouth nr Emporia........ (CEOWAN) 333

Madcap Creek at mouth nr Retreat........ (ROANOKE) 369

Madison Creek at mouth nr Walkerton.......(YORK) 196

Madison Run above Whito Oak Run nr Grottoes................

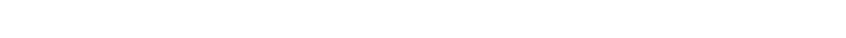

Madison Rum at mouth ne Gordongyill e....... (YORx.

Madison Run at mouth $n x$ Lynnwood........... (SHEN) 42

Magsodee Creek along U.S. Hwy 220

nr Boones Mill............... (ROANOKE) 370

Magsodee Creek at mouth $\mathrm{nr}$ Redwood....... (ROANOKE) 370

Masgodee Creek, N.F., at mouth

nr Starkey .................... (ROANOKE) 370

Maggodee Creek, S.F., at mouth

nr Starkey......................

U.S. Hwy $220 \mathrm{nr}$ Boones Mill..... (ROANOKE) 370

Maiden Creek at mouth at Glenford...... (HOLSTON) 518

Maiden Spring Creek above

Liberty Creek nr Liberty.......... (CLINCH)

Maiden Spring Creek at Rt 16

nr Thompson Valley............. (CLINCH)

Maiden Spring Creek trib at mouth nr Asberrys

(CLINCE)

530

Maiden Spring nr Liberty.............. (CLINCH)

Malden Creek at mouth ne Beulahville....... (YORK)

Mallory Creek at mouth nr Tunstall........ (YORK) 187

Mallorys Creek at mouth nr Crewe.......... (CEOWAN) 322

Mallorys Creek at mouth nr Norwood........ (JAMES) 240

Manassas Run at Rt $79 \mathrm{nr}$ Linden..........(SHEN) 64

Manassas Run at mouth nr Linden............ (SHEN) 64

Manchester Run at Hopewell............... (JAMES) 288

Manlove Branch at mouth $\mathrm{nr}$ Jarratt...... (CHOWAN) 326

Mann Branch at mouth nr Beach........... (JAMES) 286

Mann Creek at mouth nr Sandy River...... (ROANOKE) 406

Mantapike Creek at mouth nr King and Queen Court House.......(YORK) 196

Mant1lo Branch at Rt $605 \mathrm{nr}$ Studley........ (YORK) 184

Mantilo Branch at mouth nr Studley.......... (YORK) 184

Maple Branch at mouth nr Mack Croek Village................. (NEW) 442

Maple Branch at mouth nr Redwood........ (ROANOKE) 370

Maple Branch at mouth nr Retreat........ (ROANOKE) 369

Maple Swamp Branch at U.S. Hwy 58 nr Meadows of Dan.......

Maple Swamp Branch at mouth

nr Meadows of Dan............. (ROANOKE) 393

Maple Swamp at mouth nr Ladysmith......... (YORK) 191

Mapsico Creek above Kittewan Creek nr Charles City................. (JAMES)

Maracossic Creek at Rt 608

at Bowling Green...............(YORK) 193

Maracossic Creek at Rt $627 \mathrm{nr}$ Beulahvilie. (YORK) 194

Maracossic Creek at Rt 640 at Bowling Green. ... assic Creek at Rt 64

nr Bowling Green.

(YORK)

193

Maracossic Creek at Rt 646 above

Beverly Run nr Gether............. (YORK)

Maracossic Creek at Rt 721 at Sparta...... (YORK)

Maracossic Creek at mouth nr Beulahville.. (YORK)

March Swamp at Rt $667 \mathrm{nr}$ Cleopus........ (CHOWAN)

Margaret Lee Swamp at mouth nr Champiain. (RAPP) Market Swamp at mouth nr Stevensville.... (YORK)

Mar1 Creek above mill at Steoles Tavern.. (JAMES) MarI Croek below mill at Steeles Tavern.. (JAMES)

Marlboro Spring at Marlboro.............. (SHEN) 
Abbreviated basin names appear at the end of the site name. Abbreviations are as follows:

Eastern Shore (EASTERN); Potomac to Shenandoah (POT-SHEN); Shenandoah (SHEN); Potomac (POTOMAC);

Potomac to Rappahannock (POT-RAPP); Rappahannock (RAPP); Rappahannock to YOrK (RAPP-YORK); York (YORK):

York to James (YORK-JAMES); James (JAMES); James to Chowan (JAMES-CEOWAN); Chowan (CHOWAN); Roanoke (ROANOKE);

Yadkin (YADKIN); Now (NEW); Big Sandy (BIG SANDY); Holston (HOLSTON); CLinch (CLINCH); POWeli (POWELL)]

Page

Marrowbone Creek at mouth nr Red House, (ROANOKE) 386 Marrowbone Creek trib at Ridgeway...... (ROANOKE) 403 Marsh Run at Rt 609 nr Somerset............. (RAPP) 134 Marsh Run at Rt 651 at Kellys Ford ne Remington.

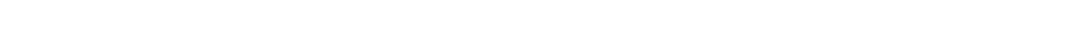

Marsh Run at mouth nr Barboursvilie.......... (RAPP) 134

Marsh Run trib at Rt $668 \mathrm{nr}$ Remington..... (RAPP) 128

Marshal1 Creek at mouth nr Nomini..... (POTOMAC) 111

Marshy Swamp at mouth nr Haynesvilie...... (RAPP) 154

Martin Branch at mouth nr Charlotte Court House........... (RCANOKE) 389

Martin Creek at Rt 680 nr Rose Hill..... (POWELL) 563

Martin Creek at Va.-Tenn. State line nr Rose Eill.

(POWELL) 563

Martin Creek nr Rose $\mathrm{Bi} i 1 \ldots . . \ldots \ldots \ldots$ (POWELL) 563

Martin Spring nr Stanley .

Martins Branch at mouth nr Brunswick.... (CHOWAN) 352

Martins Branch at mouth nr Clover...... (ROANOKE) 389

Martins Creek at Rt 648 nr Spring Mills............... (ROANOKE) 384

Martins Creek at mouth nr Poages Mili.. (ROANOKE) 367

Marumsco Creek at mouth nr Woodbridge.. (POTOMAC) 102

Mary Bird Branch at Park Rd

nr Dumfries.................... (POTOMAC)

Mary Bird Branch at $\dddot{T}$ ay ior Farm Rd nr Joplin.................... (POTOMAC) 105

Mary Bird Branch at mouth nr Dumfries.. (POTOMAC) 106

Mason Branch at mouth nr Barley.......... (CBOWAN) 355

Mason Creek at Lynchburg Turnpike at Salem................. (ROANOKE) 363

Mason Croek at Roanoke Blyd at Salem... (ROANOKE) 363

Mason Creak at Rt 864 at Mason Cove.... (ROANOKE) 363

Mason Creok at Rts $116 / 311$ at Hanging Rock......

Mason Creok at Rts $311 / 864$ nr Bennett Springs............. (ROANOKE) 363

Mason Creok at U.S. Bwy 460 at Salem... (ROANOKE) 363

Mason Cresk at mouth at Salem......... (ROANOKE) 363

Mason Creok at mouth nr Norfolk........... (JAMES) 313

Mason Creek at mouth nr North View........ (CBOWAN) 350

Mason Craek trib No. 1 at Rt 864 at Mason Cove.................. (ROANOKE)

Mason Craek trib No. 2 at Rt 864 at Mason Cove................ (ROANOKE) 363

Mason Creak trib No. 3 at Rt 864 at Mason Cove................. (ROANOKE) 363

Mason Creek trib No. 4 at Hanging Rock. (ROANOKE) 363

Masons Branch at mouth nr Adsit.........(CHOWAN) 326

Masons Mill Swamp at mouth nr Morattico...(RAPP) 156

Massanetta Springs nr Harrisonburg....... (SHEN) 37

Massaponax Creek at mouth nr Fredericksburg.............(RAPP) 146

Massaponax Creek at U.S. Hwy 1 nr Massaponax............... (RAPP) 146

Massaponax Creek at U.S. Hwy 17 nr Fredericksburg.............. (RAPP) 146

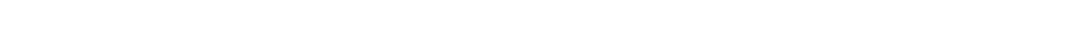

Massaponax Creek trib No. 1 at

U.S. Bwy $1 \mathrm{nr}$ Massaponax............ (RAPP) 146

Massaponax Creek trib No. 2 above

Haislip Pond outlot nr Massaponax...(RAPP) 146

Massaponax Creok trib No. 2 at mouth

nr Fredericksburg ............

Massaponax Creek trib No. 3 at mouth nr Fredericksburg................ (RAPP) 146

Massey Creak at mouth nr Woodbridge...... (PÖOMAC) 102

Massey Croek below South Branch nr Woodbridge..............(POTOMAC) 102

Massie Branch at mouth nr Dahila........ (CHOWAN) 356 Mat Cole Spring nr Murrayfield...........(BOLSTON) 495

Mat River above Ta River nr Marye.........(YORK) 190

Mat River at Rt $647 \mathrm{nr}$ Marye.............(YORK) 190

Mat River trib No. 1 at mouth nr Gatewood. (YORK) 190

Mat River trib No. 2 at mouth nr Marye.... (YORK) 190

Matadequin Creek at Rt 606 nr Tunstall... (YORK) 186

Matadequin Creek at mouth nr Tunstall.....(YORK) 186
Matneys Branch at mouth at Tannersville.

Matrimony Creek above mouth nI Ridgeway.

Matta River above Poni River nr Woodford. (YORK) 190

Matta River at Rt $617 \mathrm{nr}$ Marye.......(YORK) 190

Matta River at Rt 632 nr Woodford.......... (YORK) 190

Matta River trib No. 1 at mouth nr Marye.. (YORK) 190

Matta River trib No. 2 at mouth

nr Thornburg .................... (YORK)

Mattaponi River above Garnetts Creek nr Scotland Landing............. (YORK)

Mattaponi River above Mili Creek

nr Truhart................ (YORK)

Mattaponi River above old Mill Creek nr West Point................. (YORK)

Mattaponi River above Rt 605 nr Bowling Green. .

Mattaponi River above Rt 628

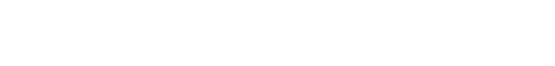
Ay lett Creek nr Aylett............(YORK)

Mattaponi River at Line Tree Bar above Walkerton.................

Mattaponi River at Muddy Point nr Wiver at $\mathrm{R} t 207$ nr Bowling Green.................... (YORK)

194

195

Mattaponi River at Rt 207

Mattaponi River at Rt 33 at West Point.... (YORK)

Mattaponi River at Rt 605 nI Bowling Green.

(YORK)

Mattaponi River at Rt 626 at woodford...... (YORK)

Mattaponi River at Rt 628 nr Beulahvi11e.. (YORK)

Mattaponi River at Rt 629 at Walkarton.... (YORK)

Mattaponi River at Rt $647 \mathrm{nr}$ Penola....... (YORK)

Mattaponi River at Rt 722 at Milford....... (YORK)

Mattaponi River at STP at West Point...... (YORK)

Mattaponi River at U.S. Hwy $301 \mathrm{nr}$ Penola. (YORK)

Mattaponi River at U.S. Hwy 360 at Aylett. (YORK) Mattaponi River at Wakama

nr King and Queen Court House...... (YORK)

Mattaponi River at mouth. at West Point.... (YORK)

Mattaponi River trib No. 1 at mouth

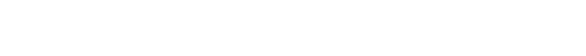

Mattaponi River trib No. 2 at mouth

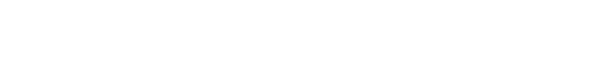
nr Walkerton.

Mattaponi River trib No. 4 at mouth nr Truhart.

Mattawoman Creek at mouth nI Machipongo

Mattawoman Creek trib at U.S. Hwy 13 nt Eastuji S.

(EASTERN)

Mattox Creek off Church Point nr Colonial Beach.

(EASTERN)

Maury (North) River above Rt 631

nI Lexington................ (JAMES)

111

at Rt 130 at $\mathrm{Glas} 80$

Maury River above Rt 39 at Rockbridge Baths

Maury River at Ben Salem Wayside nr Buena Vista.

231

226

(JAMES) 229

Maury River at Rt 39 nr Rockbridge Baths. (JAMES) 226

Maury River at Rt 631 at Lexington....... (JAMES) 227

Maury River at Rt 703 above South River nr Lexington................... JAMES) 227

Maury River at Rt $74 \dot{5}$ at Buena $v_{i}$ ista....... (JAMES) 229

Maury River at U.S. Hwy 60

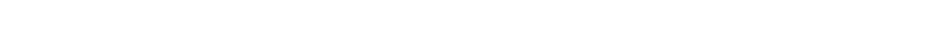

Maury River at mouth at Giasgow.............. (JAMES) 231

Maury River below N\&W RR nr Buena vista.. (JAMES) 229

Maury River nI Buena vista............. (JAMES) 229

Maxey M111 Creek at Rt $654 \mathrm{nr}$ Ballsvilie. (JAMES) 259

Maxey Mil1 Creek at mouth nr Tobaccoville.

( JAMES

260

Maxeys Creak (N.F Muddy Creok) at Rt 20 nr Centenary. 
Abbreviated basin names appear at the end of the site name. Abbreviations are as follows: Eastern Shore (EASTERN); Potomac to Shenandoah (POT-SHEN); Shenandoah (SHEN); Potomac (POTOMAC):

Potomac to Rappahannock (POT-RAPP); Rappahannock (RAPR); Rappahannock to York (RAPP-YORK); YOrk (YORK)

York to James (YORK-JAMES); James (JAMES); James to Chowan (JAMES-CHOWAN); Chowan (CHOWAN); Roanoke (ROANOKE);

Yadkin (YADKIN); New (NEW); Big Sandy (BIG SANDY); Holston (HOLSTON); Clinch (CLINCH); Powill (POWELL)]

Page

Mayberry Creek at mouth

nr Meadows of Dan....

(ROANOKE)

Mayo Creek at mouth nr Mayo............... (ROANOKE)

Mayo River below Rt 1358 nr Erice, N.C. (ROANOKE)

Mayors Rock \& Stony Man Springs nr Luray (SHEN)

Mays Branch at mouth nr Watauga........ (ROLSTON)

Mays Run at mouth nr Milford.............. (YORK)

McAfee Run at mouth nr Abbott............. (JAMES

McClure Creek (River) above Open Fork at Nora............ (BIG SANDY)

McClure Creek at Rt $65 \dot{5}$ at Wakenva... (BIG SANDY) McClure Creek below Knot Hollow Creek nr Tramme 1.

McClure Creek below Tramel Branch at Irammel............... (BIG SANDY) McClure Creek trib at $\mathrm{R} t \dot{6} 3 \mathrm{nr}$ Nora... (BIG SANDY) McClure River above Buffalo Creek at Nora. McClure River at McCiure............. (BIG SANDY) McClure River at Rt 53 below Clinchco............. (BIG SANDY)

McClure River at Rt 664 at Cinchco.. (BIG SANDY)

McClure River at Rt 725 at Haysi.... (BIG SANDY) McClure River at $R t 83$ at Eremont.... (BIG SANDY)

McClure River at mouth at Haysi......(BIG SANDY) McDonald Branch at mouth

nr Chatham Hill.............. (ROLSTON)

McDowel1 Branch at mouth nr Stanleytown. (CLINCH)

McFarland Branch at mouth at Counc1l. (BIG SANDY)

McGavock Creek at mouth nr Grahans Eorge... (NEW)

McGavock Creek at mouth nr Highland........ (NEW)

McGavock Run at mouth at Max Meadows........ (NEW)

McGhee Creek at mouth nr Wood...........(CLINCH)

McGuff Creek at mouth nr Brosville..... (ROANOKE)

McHenry Creek at Rt 91 at Plasterco.... (HOLSTON)

Mckenry Creok at mouth nr Plasterco.... (HOLSTON)

Meachim Creek at mouth nr Irvington........ (RAPP)

Meade Branch at mouth at Carterton...... (CLINCH)

Meade Creek (Russell Creek)

at Virginia City..............(CLINCH)

Meade Creek at mouth at Virginia City... (CLINCH)

Meade Fork at mouth nr Pound......... (BIG SANDY)

Meadow Branch at mouth nr Leesviiie.... (ROANOKE)

Meadow Branch at mouth nr Powellton...... (CHOWAN)

Meadow Brook at Rt $624 \mathrm{nr}$ Middletown...... (SHEN)

Meadow Creek above Rt 311 at New Castle.. (JAMES)

Meadow Creek at Fish Hatchery nr Looney.. (JAMES)

Meadow Creek at Fydraulic Rd

at Charlottesville.

Meadow Creek at New Castle Dam

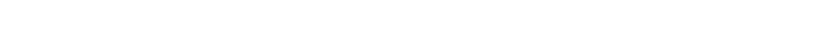

Meadow Creek at Rt $624 \mathrm{nr}$ New Castle..... (JAMES)

Meadow Creek at mouth at Charlottesville. (JAMES)

Meadow Creek at mouth at New Castle...... (JAMES)

Meadow Creok at mouth nr Galax............. (NEW)

Meadow Creek at mouth nr Graysontown....... (NEW)

Meadow Creek at mouth nr Kings Store....... (NEW)

Meadow Creek at mouth nr Saint Joy....... (JAMES)

Meadow Fork at mouth nI Robbins Chapel. (POWELL)

Meadow Run at Eire Rd nr Crimora.......... (SHEN)

Meadow Run at mouth nr Check.............. (NEW)

Meadow Run at mouth nr Crimora.............. (SHEN)

Meadow Run at mouth nr New Hope............. (SHEN)

Meadow Run nr Laurel Eill nr New Hope..... (SHEN)

Meadows Creek at mouth nr Fieldale..... (ROANOKE)

Mechumps Creek above Slayden Creek nI Ashland.

(YORK)

Mechumps Creek along $\mathrm{Rt} 614 \mathrm{nr}$ Hanover.... (YORK)

Mechumps Creek at U.S. Hwy 301 at Hanover. (YORK)

Mechumps Creek at mouth nr Hanover........ (YORK)

Mechums River above Moormans River nr Eree Union.

Mechums River at Rt $240 / \mathrm{U}$.S. Givy 250

at Mechums River................ (JAMES) 247

Mechums River at Rt 601 nr Free Union.... (JAMES) 248

Mechums River at R.t 614

nr White Hall (Ivy)
394

416

397

49

507
191

217

478

478

477

477

478

478

478

478

478

480
478

480

512

546

486

438
449

437

544

405

515

159

537

538

538

482

376
353

61

218

217

254

218

217

254

218
430

447

444

245

558
41

444

41

37

37

401

183

183

83

183

249

248
Mechums River at Rt 635 at Miller School nr Crozet........... (JAMES) 247

Mechums River below Rock Run nr Charlottesvillo.

(JAMES) 248

Mechunk (Mechum) Creek at mouth nr Nahor. (JAMES) 255

Mechunk Creek at R.t 600 nr Cismont...... (JAMES) 255

Mechunk Creek at Rt 616 at Union Milis ne Boyd Tavern........

Mechunk Creek at U.S. Hwy 250

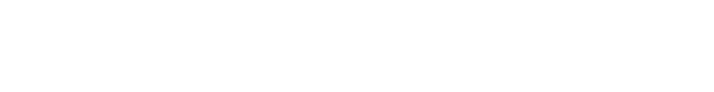

(JAMES) 255 nr Keswick.

Meherrin River above R.t 195

nr Branchvilie...............(CHOWAN) 356

Meherrin River at $\mathrm{I}-8 \mathrm{~S}$ ni south Hiil..... (CHOWAN) 351

Meherrin River at NF\&D RR nr Lawrenceville...............(CHOWAN) 351

Meherrin River at Rt $138 \mathrm{nr}$ Eorksvilie...(CHOWAN) 351 Meherrin River at Rt 195 nr Margarettsville, N C....... (CHOWAN) 356

Meherrin River at Rt 35 nr Severan, N.C. (CHOWAN) 356

Meherrin River at Rt 48 nr Lawrenceville..............(CHOWAN) 352

Meherrin River at Rt 635 nr North view... (CHOWAN) 350

Meherrin River at Rt $636 \mathrm{nr}$ North Viow... (CHOWAN) 350

Meherrin River at Rt $670 \mathrm{nr}$ Ante........ (CHOWAN) 354

Meherrin River at Rt 715

nI Lawrenceville.

Meherrin River at Rt 730

nf Bryants Corner.............(CHOWAN)

Meherrin River at U.S. Hiwy 301 at Emporia.

(CBOWAN)

Meherrin River at U.S. Hiwy 58 nr Lawrencevilie.............. (CHOWAN)

Meherrin River at Va. $-\dot{H} . \dot{C}$.

State line nr Branchville....... (CHOWAN)

Meherrin River nr Branchville ........... (CHOWAN)

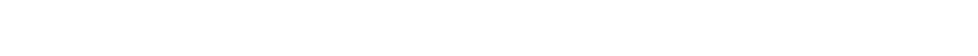

Mehtxen Creek at mouth nr Studley.......... (YORK)

Mercer Spring at Atkins............. (HOLSTON)

Merchant Creek at mouth at Attoway..... (BOLSTON)

Mercy Branch at mouth nr Narrows............ (NEW)

Meredith Branch at mouth ar Glen Ailon... (JAMES)

Meriwether Creek nr Greenfield........... (JAMES)

Merrimac Lake at dam nr Culpeper.......... (RAPP)

Merriman Run at mouth nr Union Haii.... (ROANOKE)

Merriman Spring nr Winchester......... (POT-SHEN)

Merry Branch at mouth nr Tasley........(EASTERN)

Merrybrook Run (East Branch) at Sully Rd nr Herndon..........(POTOMAC)

Messongo Creek (Messongo Creek trib)

at Hallwood. . . . . (EASTERN)

Messongo Creek above Rt 592

nr Hallwood ................. (EASTERN)

Messongo Creek at Messongo Bridge

(Rt 692) nr Hallwood.

(EASTERH)

Messongo Creok at Rt $692 \mathrm{nr}$ Haliwood... (EASTERN)

Messongo Creek at end of Rt 698 nr Saxis ........................

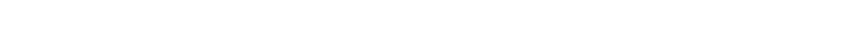

Messongo Creek at mouth nr Saxis....... (EASTERN)

Messongo Creek tr $\pm b$ (Messongo Crejk)

above Rt 693 at Hallwood....... (EASTERH)

Messongo Creek trib (Messongo Creek)

at Rt 693 at Hallwood.......... (EASTERN)

Messongo Creok trib tributary above Rt 693 at Rallwood.

Messongo Creek trib tributary (Messongo

Creek) $0.6 \mathrm{mi}$ below Hallwood..... (EASTERN)

Messongo Creek trib tributary $0.3 \mathrm{mi}$ above Rt 693 at Hallwood.

352

355

355

351

356

356

357

499

501

454

292

241

369

22

74

18

18

18

18

18

18

18

18

18

18

18

Metcalf Branch at mouth at Emporia...... (CHOWAN)

Michauk Creok at mouth nr Tuckahoe Villag

Middle Branch at mouth nr Jopi in ........ (POTOMAC)
18

355

264 
Abbreviated basin names appear at the end of the site name. Abbreviations are as follows:

Eastern Shore (EASTERN); Potomac to Shenandoah (POT-SKEN); Shenandoah (SHEN); Potomac (POTOMAC);

Potomac to Rappahannock (POT-RAPP); Rappahannock (RAPP); Rappahannock to York (RAPP-YORK); York (YORK);

York to James (YORK-JAMES); James (JAMES); James to Chowan (JAMES-CBOWAN); ChOWan (CEOWAN); Roanoke (ROANOKE);

Yadkin (YADKIN); New (NEW); Bis Sandy (BIG SANDY); Holston (BOLSTON); Clinch (CLINCE); POWell (POWELL)

Middle Creek at U.S. Bwy 460 (Business) at Cedar Bluff. Middle Creek at mouth nr Cedar Bluff.... (CLINCE) 528 Middle Creek at mouth nr Floyd......... (NEW) 444 Middle Creek at mouth nr Irisburg........ (ROANOKE) 404 Middle Fork at mouth Fouth Clinchfield.

(CLINCA) 536

Middle Fork at mouth at Breaks....... (BIG SANDY) 487

Middle Fork at mouth $\mathrm{nr}$ Nora.......... (BIG SANDY) 478

Middle Fox Creek at mouth nr Mouth of Wilson.

(NEW)

Middle Meherrin River at Rt 49 nr Rehoboth.

(CBOWAN) 350

Middle Meherrin River at mouth Tr Scotts Crossroad.

(CHOWAN) 350

Middle River above Gardner Spring nr Staunton.................. (SHEN)

Middle River above Staunton-Verona STP above Lewis Creek nr Verona....... (SHEN)

Middle River above springs nr Churchville. (SHEN)

Middle River at Rt 626 nr Verona.......... (SHEN)

Middle River at Rt 732 at Franks Mi ii Rr Staunton.

Middle River at Rt 742 nr Verona...

Middle River at Rt $769 \mathrm{nr}$ Grottoes............ (SHEN)

Middle River at Rt $780 \mathrm{nr}$ Verona........... (SHeN)

Middle River at Rt 876 at Swoope.......... (SHEN)

Middle River at U.S. Hwy 11 at Verona..... (SHEN)

Middle River at U.S. Hwy 250 nr Churchvilie.

(SHEN)

Middle River at mouth nr Grottoes......... (SHEN)

Middle River below Gardner Spring nr Staunton.

Middle River below Trimbios Miii nr Swoope

(SHEN)

Middle River below springs nr Churchville. (SEEN)

Middle River trib at Rt $705 \mathrm{nr}$ Swoope.... (SEEN) Middle Run at Booes Rd $n r$ Burke......... (POTOMAC)

Middle Run at Rt $640 \mathrm{nr}$ Lorton........ (POTOMAC)

Middle Run at mouth $n r$ Lorton.......... (POTOMAC)

Midway Creek at mouth nr Water view....... (RAPP)

Mike Run at mouth $\mathrm{nr}$ Garysville......... (JAMES)

Mikes Branch at mouth $\mathrm{nr}$ Ay lett.......... (YORK)

Mikes Creek at mouth nr South Boston... (ROANOKE)

Miles Creek at U.S. Bwy 58 nr South Bili.

(ROANOKE) 422

Miles Creek at mouth nr Ebony........... (ROANOKE)

Miles Creek nr Smiths Crossroads........ (ROANOKE)

Mil1 (Looney Mili) Creek at U.S. Hwy 11 nr Troutville......... (JAMES)

Mil1 (Looney Mi11) Creek at Rt 606

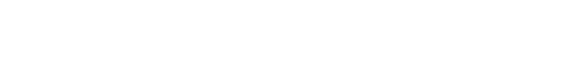

Mil1 (Looney Mi11)

JAMES

Mi1I Branch at Rt 610 at Jordan Mines ... (JAMES)

Mil1 Branch at mouth at Clays Mi11..... (ROANOKE)

Mill Branch at mouth nr Appalachia...... (POWELL)

Mill Branch at mouth $n r$ Emertion........... (RAPP)

Mil1 Branch at mouth $n r$ Guilford........ (EASTERN)

Mi11 Branch at mouth nr Morattico........ (RAPP)

Mill Branch at mouth nr Oakwood....... (BïG SANDY)

Mill Branch at mouth nr Whitewood.... (BIG SANDY)

Mill Creek (Backlick Creek) at mouth nr Rural Retreat................ (NEW)

Mill Creek above The Thorofare nr Bacons Castle................. (JAMES)

Mil1 Creek above mouth $\mathrm{nr}$ Ebony........ (ROANOKE)

Mill Creek a long Rt $629 \mathrm{nr}$ Ashwood....... (JAMES)

Mill Creek at Fish Batchery Rd nr Montebello.

Mill Creek at Flannagan Reservoir ne Tarpon.................. (BIG SANDY)

Mil1 Creek at Bampton. ................. (JAMES)

Mi11 Creek at Narrows $\ldots \ldots \ldots \ldots \ldots \ldots \ldots \ldots$ (NEW)

Mi11 Creek at Richmond................ (JAMES)

Mill Creek at Rt $16 \mathrm{nr}$ Trout Dale.......... (NEW)

Mill Creek at Rt 39 nr Millboro Springs... (JAMES)
Mill Creek at Rt 603 at Diascund.

(JAMES)

Mill Creek at Rt $610 \mathrm{nr}$ Benleys Store.... (JAMES) 239

Mill Creek at Rt $614 \mathrm{nr}$ Mt. Jackson........ (SEEN) 57

Mill Creek at Rt 629 at Raven............(CLINCB) 529

Mill Croek at Rt 631 at Lexington.........(JAMES) 227

Mi1l Croek at Rt $671 \mathrm{nr}$ Port Repubiic...... (SHEN)

Mill Creek at Rt $684 \mathrm{nr}$ Sunbeam.......... (CHOWAN)

Mi11 Creek at Rt 698 at Mt. Jackson....... (SHEN)

Mill Creek at Rt 83 at Clinchco..... (BIG SANDY)

MiII Creek at U.S. Hwy 11 at Mt. Jackson. (SHEN)

Mill Creek at U.S. Hwy 220 at Gala....... (JAMES)

Mill Croek at U.S. Hwy $301 \mathrm{nr}$ Port Royal.. (RAPP)

MilI Creek at Walker Point nr Kinsale.. (POTOMAC)

MiII Creek at mouth at Bundick......... (POTOMAC)

Mill Creek at mouth at Carbo............. (CLINCH)

Mill Creek at mouth at Clinchco....... (BIG SANDY)

Mill Creek at mouth at Goshen........... (JAMES)

Mill Creek at mouth at Hamburg........... (SEEN)

Mi11 Creek at mouth at Kelsa......... (BIG SANDY)

Mi11 Creek at mouth at Mt. Jackson........ (SHEN)

Mill Creek at mouth at Narrows ............. (NEW)

Mill Creek at mouth at Philpott.......... (ROANOKE)

Mi11 Creek at mouth at pound........... (BIG SANDY)

Mi11 Creek at mouth at Stone Mountain.. (ROANOKE)

Mill Creok at mouth nr Austinvilie......... (NEW)

Mill Creek at mouth nr Axton............ (ROANOKE)

Mi11 Creok at mouth nr Bent Mountain... (ROANOKE)

Mill Creek at mouth nr Boswells Tavern.... (YORK)

Mill Creek at mouth or Callison.......... (JAMES)

Mill Creek at mouth nr Capevil1e......... (EASTERN)

Mill Creek at mouth nr Childress............ (NEW)

Mill Creek at mouth nr C1ifford.......... (JAMES)

Mill Creek at mouth nr Dungannon......... (CLINCE)

Mill Creek at mouth nr Evington......... (ROANOKE)

Mill Creek at mouth nr Fleeton......... (POT-RAPP)

Mill Creek at mouth $\mathrm{nr}$ Hanover.......... (YORK)

Mill Creek at mouth $n r$ Bi $11 \ldots \ldots \ldots \ldots$ (CLINCE)

Mill Creek at mouth $n r$ Hodges............ (ROANOKE)

Mill Creek at mouth nr Bopeweil ............ (JAMES)

Mil1 Creek at mouth $n$ r Irvington......... (RAPP)

Mill Creek at mouth $\mathrm{nr}$ Kiptopeke....... (EASTERN)

MilI Creek at mouth nx Mike............. (ROANOKE)

Mill Creek at mouth nr Millboro Springs.. (JAMES)

Mill Creek at mouth $\mathrm{nr}$ Montpelier......... (YORK)

Mili Creek at mouth nr Murrayfield...... (BOLSTON)

Mill Creek at mouth nr Museville........ (ROANOKE)

Mill Creek at mouth nr New Kent........... (YORK)

Mi11 Creek at mouth nr Penns Store..... (ROANOKE)

Mill Creek at mouth $\mathrm{nr}$ Penola ............(YORK)

Mill Creek at mouth nr Port Repubiic...... (SHEN)

Mill Creek at mouth nr Port Royal......... (RAPP)

Mi11 Creek at mouth nr Riverdale........ (CBOWAN)

Mil1 Creek at mouth nr Rugby............. (NEW)

Mill Croek at mouth nr Sonans............ (RöANoKe)

Mill Creek at mouth nr Sylvatus............. (NEW)

Mill Creek at mouth $\mathrm{nr}$ Tacoma.......... (CLINCE)

Mill Creek at mouth $\mathrm{nr}$ Tappahannock....... (RAPP)

Mill Creek at mouth nr Trout Dale........... (NEW)

Mill Creek at mouth nr Truhart............ (YORK)

Mil1 Creek at mouth $\mathrm{nr}$ Walkers.......... (JAMES)

Mill Creek at mouth $\mathrm{nr}$ West Point......... (YORK)

Mill Creek below Rt 8 at Riner............ (NEW)

Mill Creek $n r$ Avon. .................. (JAMES)

Mill Creek nr Lexington ...... (JAMES)

Mi11 Creek trib at Rt $682 \mathrm{nr}$ Sunbeam... (CHOWAN)

Mill Creek trib at Rt 684 nr Sunbeam.... (CBOWAN)

Mill Creek trib at U.S. Hwys $58 / 221$ at Galax.

(NEW)

Mill Creek trib at mouth nr Sunbeam.

Mill Creek trib tributary at Rt 682

nr Sunbeam....................
Mill Farm Run at mouth nr Surry.

(CBOWAN)

(CHOWAN)
MI11 Prong above Laure1 Prong nr Criglersville.

Mill Race at mouth at Salem.

(RAPP)

Mill Run at mouth nr Ladysmith.

(ROANOKE)

Mi11 Run at mouth nr Laurel Milis ........... (RAPP)

Mill Run at mouth nr Littleton.

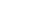

7

37 
Abbreviated basin names appear at the end of the site name. Abbreviations are as follows:

Eastern Shore (EASTERN); Potomac to Shenandoah (POT-SHEN); Shenandoah (SHEN); Potomac (POTOMAC);

Potomac to Rappahannock (POT-RAPP); Rappahannock (RAPP); Rappahannock to York (RAPP-YORK); York (YORK);

York to James (YORK-JAMES); James (JAMES); James to Chowan (JAMES-CHOWAN); ChOWan (CHOWAN); ROanoke (ROANOKE);

Yàdkin (YADKIN); New (NEW); Big Sandy (BIG SANDY); Holston (HOLSTON); Clinch (CLINCH); POWell (POWELL) I

Page

M111 Run at mouth nr Rhoadesville

Mill Run at mouth nr Sumerduck.

Mil Run at mouth nr Thoroughfare......(POTOMAC) 94

M11l Run at mouth nr Warrenton........... (POTOMAC) 91

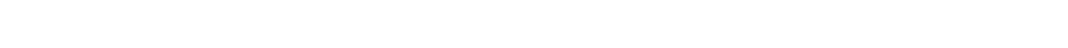

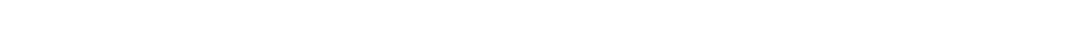

Mil1 Swamp at Rt $660 \mathrm{nr}$ Claresvilie..... (CHOWAN) 356

Mill Swamp at mouth nr Center Cross.......(RAPP) 154

Mill Swamp at mouth nr Claresville.......(CHOWAN) 356

Mil1 Swamp at mouth nr Courtland......... (CHOWAN) 337

Mill Swamp at mouth nr Raynor............ (CHOWAN) 342

Mill Swamp trib at Rt 35 nr Courtland.. (CHOWAN) 337

Mill Swamp trib at Rt $637 \mathrm{nr}$ Pons....... (CHOWAN) 342

Mill Swamp trib at mouth nr Courtiand... (CHOWAN) 337

Millbank Creek at mouth nr Port Royal..... (RAPP) 148

Milldam Creek at Rt 190

nr Blackwater........... (JAMES-CHOWAN)

Miller Branch nr Alleghany.............. (JAMES)

. 243

Miller Creek at mouth at Max Meadows.......... (NEW) 437

Miller Creek at mouth nr Scottsville...... (JAMES) 243

Miller Run at mouth nr Grottoes...........(SHEN) 42

Millerplace Branch at mouth nr Highland.... (NEW) 449

Millie Branch at mouth nr Dickinson....(ROANOKE) 374

Millington Creek at mouth nr Boswells Taver.

Millpond Branch at mouth in Randolph... (ROANOKE)

Millpond Creek at Elk Creek Channel

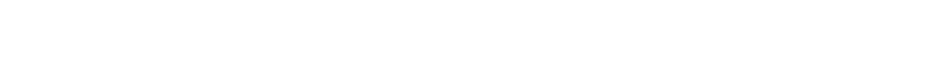

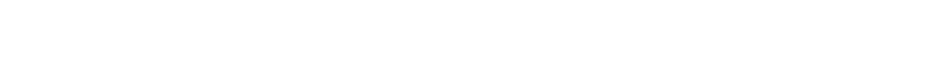

392

Millpond Creek at mouth nr Hanover........ (YORK)

Millpond Swamp at mouth nr Penola......... (YORK)

Millrun Branch at Rt 40 nr MeKenney........ (CHOWAN)

Millrun Branch at mouth nr Cherry Hill. . (CHOWAN)

Millstone Branch at mouth at South Clinchfield.

Milted Creek at mouth nr Dendron...... (CHOWAN)

Creek at mouth $\mathrm{nr}$ Taylorstown. (POTCMAC)

Mine Branch at Rt $612 \mathrm{nr}$ Crimora.......... (SHEN)

Mine Branch at mouth at Crimora............ (SHEN)

Mine Run above Mountain Run nr Burr Hili.. (RAPP)

Mine Run above Turkey Run

$$
\text { nr Fivemile Fork................. (RAPP) }
$$

Mine Run at Rt 20 nr Locust Grove.......... (RAPP)

Mine Run at Rt 611 at Burr Hill.......... (RAPP)

Mine Run at mouth nr Richardsville........ (RAPP)

Mine Run below Soapstone Branch nr Mine Run. . . . . . . . . . . . . (RAPP)

Mine Run trib No. 1 at mouth nr Mine Run.. (RAPP)

Mine Run trib No, 2 at mouth nr Burr Hill. (RAPP)

Mine Run trib No. 3 at mouth nr Burr Rill. (RAPP)

Mine Run trib No. 4 at mouth nr Burr Hill. (RAPP)

Mines Creek at mouth nr Norvello....... (ROANOKE)

Mines Run at Rt $924 \mathrm{nr}$ Briery Branch...... (SHEN)

Mink Hollow Branch at mouth nr Grit.... (ROANOKE)

Minter Creek at mouth nr Grit.......... (ROANOKE)

Mira Fork at mouth nr Indian Vailey......... (NEW)

Mira Fork trib at U.5. Hory $221 \mathrm{nr}$ Dugspur.. (NEW)

Mire Branch at mouth nr Elk Run........... (RAPP)

Mire Branch at mouth nr Holly Brook.......... (NEW)

Miry Creek at mouth nr South Boston.... (ROANOKE)

Miry Run at former mouth at Lake Chesdin. (JAMES )

Miry Run t mouth nr Rawlings.......... (CHOWAN)

Mitchell Branch at mouth ne Duncanvilie.

(HOLSTON)

Mitchell Branch at mouth nr Rondo.... (ROANOKE)

Mitchell Creek at mouth nr Chase City... (CHOWAN)

Mitchell Hill Creek at mouth nr King and Queen Court House......(YORK) 196

Mob Creek at mouth nr Moneta...........(ROANOKE) 377

Mobjack Bay at buoy $12 \mathrm{nr}$ Baron........ (RAPP-YORK) 165

Mobjack Bay at buoy $16 \mathrm{nr}$ Baron......... (RAPP-YORK) 165

Mobjack Bay at buoy $20 \mathrm{nr}$ Ware Neck... (RAPP-YORK) 163

Moccasin Creek, Middle Fork, at mouth nr Hansonville................ (HOLSTON)

Moccasin Creek, N.F., at mouth nr Hansonvilie............. (hoLston)
171

183

192

328

536

341
67

41

41
141

144

140

142

140

140

140

141
422

26

382

382
439

439

131

451

282

324

518

6

65
63

Moccasin Creek, S.F., at mouth nr Ransonvilie........ nr Capovilile. (EASTERN)

Modest Creek at mouth nr Victoria....... (CHOWAN)

Moffett (Moffets) Creek at Rt 620 nr Brownsburg. . . . . . . . . nr Brownsburg.

(JAMES) 226

Moffett Creek at Rt 42 nr Parnassus........ (SHEN) 33

Moffett Creek at mouth nr Staunton........ (SHEN) 35

Mohawk Creek at dam at Beaumont.......... (JAMES) 261

Moll Creek at mouth $\mathrm{nr}$ Collinwood.......(CLINCH) 548

Mollie Branch at mouth nr Burnt Chimey...............(ROANOKE) 370

Mollys (Molley) Creek at Rustburs....... (ROANOKE) 385

Mollys (Molley) Creek at mouth nr Mike...

(ROANOKE)

385
385

Moncuin Creek at mouth nr Manquin........ (YORK) 186

Monday Creek at Rt 646 nr Severn...... (RÄP-YORK) 165

Monger Run at mouth nr Elktom........... (SHEN)

Monroe Bay at Gum Bar Point at Colonial Beach............ (POTOMAC)

Monroe Bay at Rt 1124 nr Colonial Beach.............. (BOTOMAC)

Monroe Bay at Rt 1156

nr Colonial Beach.............. (POTOMAC)

Monroe Bay at Rt 1164 nr Colonial Beach............. (POTOMAC)

Monroe Creek at Gum Bar Point at Colonial Beach.............(POTOMAC) 110

Monterey Spring at Monterey.......... (POT-SHEN) 20

Moody Creek at mouth nr Barnes Junction............. (ROANOKE) 417

Moore Branch at mouth at Blackweil..... (HOLSTON) 516

Moore Branch at mouth nr Pungoteague... (EASTERN) 15

Moore Creek at mouth nr Blakes.......(RAPP-YORK) 162

Moore Creek below Lexington Reservoir

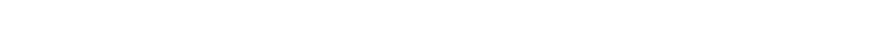

Moores Creek along U.S. Hwy 29 nr Charlottesvilie................ JAMES) 254

Moores Creek at Rt $171 \mathrm{nr}$ Poquoson... (YOORK-JAMES) 202

Moores Creek at Rt $600 \mathrm{nr}$ Poquoson..(YORK-JAMES) 202

Moores Creek at mouth at Charlottesville (JAMES) 254

Moores Creek at mouth nr Poquoson... (YORK-JAMES) 202

Moores Swamp at mouth nr Newvilie.......(CBOWAN) 331

Moores Swamp at mouth nr Purdy.......... (CHOWAN) 326

Moormans River above Mechums River nr Free Union.................. (JAMES) 250

Moormans River at Rt 601 nr Free Union... (JAMES) 250

Moormans River at Rt $614 \mathrm{nr}$ White Bal1... (JAMES) 250

Moormans River at Rt 810 above Doyles River nr White Hal1........ (JAMES)

Moormans River at Sugar Hollow nr White Hall.

Reservoir nr white

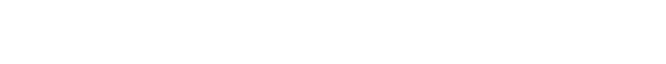
nr White $\mathrm{Hall}$.

Moormans River, N.F. above

Charlottesvilie Reservior nr White Hall.

Moormans River, N.F., above Bis Branch

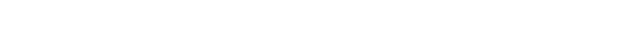

Moormans River, N.F., at former mouth in Charlottesvilie Reservoir nr White Ball.

Moormans River, N.F., below Bis Branch nr White Hall................ (JAMES)

Moormans River, N.F. , below Shop Run

nr Browns Cove................. (JAMEs) 249

Moormans River, N.F.. nI Browns Cove...... (JAMES) 249

Moormans River, N.F., nr Pinestand Mountain nr Browns Cove........... (JAMEs)

Moormans River, N.F., trib

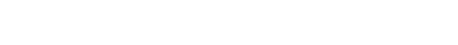

Moormans River, N.F., trib at Skyline Drive nr Harriston........ (JAMES) 
Abbreviated basin names appear at the end of the site nane. Abbreviations are as follows:

Eastern Shore (EASTERN); Potomac to Shenandoah (POT-SHEN); Shenandoah (SHEN); Potomac (POTOMAC);

Potomac to Rappahannock (POT-RAPP); Rappahannock (RAPP); Rappahannock to York (RAPP-YORK); York (YORK);

York to James (YORK-JAMES); James (JAMES); James to Chowan (JAMES-CHOWAN); Chowan (CHOWAN); Roanoke (ROANOKE);

Yadkin (YADKIN); New (NEW); Big Sandy (BIG SANDY); Holston (HOLSTON); Clinch (CLINCH); POWell (POWELL)]

Moormans River, S.F., above

Charlottesvilié Reservoir nr White Hall.

Moormans River, S. $\boldsymbol{F}$ at former mouth in Charlottesville Reservoir ne White

Morey Branch at U.S. Hwy 29 at Charlottesville............. (JAMES) 254

Morgan Mill Stream at mouth nr Miliwood... (SHEN) 65

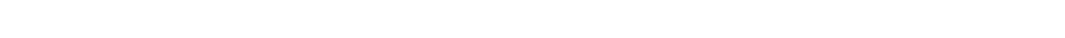

Morris Branch at mouth nr Midway.......... (ROANOKE) 416

Morris Creek at mouth nr Claremont....... (JAMES) 300

Morris Creok at mouth nr Mathews..... (RAPP-YORK) 162

Mortar Branch at mouth nr Stony Crook... (CHOWAN) 328

Mosquito Creek at mouth nr Irvington......(RAPP) 159

Moss Swamp at Desert Rd nI Cypress Chape1........... (JAMES-CHOWAN) 320

Mossy Creek Church Spring nr Mt. Solon.... (SHEN)

Mossy Creok above Todd Spring nr Mt. Solon.

Mossy Creek at Rt 731 at Mt. Solon....... (SHEN)

Mossy Creek at mouth nr Spring Creek....... (SHEN)

Mossy Creek below Todd Spring nr Mt. Solon.

Motley Branch at mouth nr Brosvilie.... (ROANOKE)

Motto River at mouth nr Cedon............ (YORK)

Motto River trib at Rt $605 \mathrm{nr}$ Cedon......... (YORK)

Motts Run at mouth nr Fivemile Fork....... (RAPP)

Mount Creek at U.S. Hwy 17

nr Rappahannock Academy ............................. 148

Mount Creek at mouth nr Port Royal......... (RAPP) 148

Mount Holly Creek above Blairs Creek at Smithfield................ (JAMES)

Mount Holly Creek at Rt 626 at Smithfield................. JAMES) 303

Mount Landing Creek at mouth nr Tappahannock......

Mountain Branch above mouth

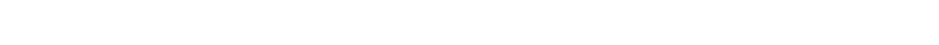

Mountain Branch at mouth nr Lebanon..... (CLINCH) 533

Mountain Creek at mouth nr South Hiil... (CHOWAN) 350

Mountain Creek at mouth nr Worsham....... (JAMES) 273

Mountain Run 300 yds below dam at Culpeper................. (RAPP)

Mountain Run 660 yds below dam at Culpeper.................(RAPP) 129

Mountain Run Lake at dan nr Culpeper......(RAPP) 128

Mountain Run above Mine Run nr Burr Hill.. (RAPP) 141

Mountain Run above Negro Run nr Gordonsville...............(YORK) 166

Mountain Run above Rt 641 nr Culpeper..... (RAPP) 128

Mountain Run above mouth nr Cascade.... (ROANOKE) 405

Mountain Run above water works intakes at Culpeper................. (RAPP) 129

Mountain Run at Pelham Lake Dam

at Culpeper.................. (RAPP) 129

Mountain Run at Rt $61 i$ nr Burr Hiii......... (RAPP) 141

Mountain Run at Rt 617 nr Unlonville....... (RAPP) 141

Mountain Run at Rt $620 \mathrm{nt}$

Kellys Ford nr Sumerduck...........(RAPP) 130

Mountain Run at Rt 641 nr Culpeper...................... 129

Mountain Run at Rt $643 \mathrm{nr}$ Gordonsvilie..... (YORK) 166

Mountain Run at Rt 663 at Stevensburg..... (RAPP) 130

Mountain Run at Rt 669 nr Culpeper.........(RAPP) 129

Mountain Run at Rt 672 nr Kellys Ford ne Sumerduck............. (RAPP)

Mountain Run at U.S. Hwy 29 (Aiternate)

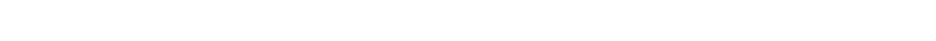

Mountain Run at U.S. Hwy 29 (Bypass) nI Culpeper.................(RAPP) 130

Mountain Run at U.S. Hwy 522 at Culpeper..(RAPP) 129

Mountain Run at mouth nr Sumerduck........ (RAPP) 130

Mountain Run trib No. 1 at Caynor Lake nI Norman

Mountain Run trib No. 1 at Rt 633 nr Norman

Mountain Run trib No. $i$ at mouth

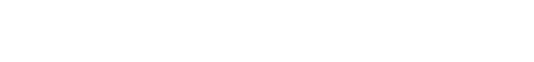

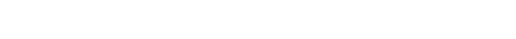

Mountain Run trib No. 2 at mouth nr Rhoadesville..........

Mountain Run trib No. 3 at mouth nr Culpeper....... . . . . . . nr Rhoadesville . . . . . . . . Mountain Run trib No. 4 at mouth
nr Sumerduck... . . . . . . .
Mountain Run trib No. 5 at mouth nr Sumerduck.

in Run trib No. 6 at U.S. Hwy 29

\section{(Alternate) nr Culpeper....
Mountain Run trib nr Gordonsvilie.}

..... (ROANOKE)

Mt. Carmel Mill Spring nr Mar
Mt. Jackson Reservolr inflow

nr Mt. Jackson. . . . . . . . . . . . (SHEN)

Mud Creok at mouth nr Darlington Heights. (JAMES)

Mud Creek at mouth nr Dryden........... (POWELL)

Mud Creek at mouth nr Water view............. (RAPP)

Mud Creok, Risht Fork, at mouth nr Robbins Chapel............... (POWELL)

Mud Fork at mouth at Falis Milis ........... (NEW)

Mud Lick Creek along Rt $685 \mathrm{nr}$ Stonega.. (POWELL)

Mud Lick Creak at mouth at Roanoke..... (ROANOKE)

Muddy Branch at Rt 661 at Cleveland..... (CLINCH)

Muddy Branch at mouth nr Artrip......... (CLINCH)

Muddy Creek above Rt 734 nr Hinton......... (SHEN)

Muddy Creek at Monroe................ (JAMES)

Muddy Creok at Onyx Hill at Hinton........ (SHEN)

Muddy Creek at Rt 20 nr Centenary......... (JAMES)

Muddy Creek at Rt $218 \mathrm{nr}$ Passapatanzy...... (RAPP)

Muddy Creok at Rt 602 nr Passapatanzy...... (RAPP)

Muddy Creek at Rt $652 \mathrm{nr}$ Elon........... (JAMES)

Muddy Creok at $\mathrm{Rt} 726$ at Mount Ci 1 inton..... (SHEN)

Muddy Creek at $\mathrm{Rt} 734$ nr Hinton......... (SHEN)

Muddy Creok at Rt 737 nr Hinton............ (SHEN)

Muddy Creek at Rt 752 at Hinton........... (SHEN)

Muddy Creok at Rt 773 nr Stultz Mili nr Singers Glen................. (SHEN)

Muddy Creek at Stultz Mill

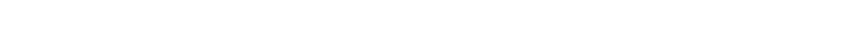

Muddy Creek at Tamworth. ................ (JAMES)

Muddy Creek at U.S. Hwy 33 at Hinton....... (SHEN)

Muddy Crook at mouth nr Cartersville..... (JAMES)

Muddy Creak at mouth $n r$ Corbin............ (RAPP)

Muddy Creek at mouth nr Dayton.............. (SHEN)

Muddy Creok at mouth nr Glenmore............ (JAMES)

Muddy Creek at mouth nr Guilford...... (EASTERN)

Muddy Crook at mouth nr Sigma..... (JAMES-CHOWAN)

Muddy Creek at mouth nr Spencer........ (ROANOKE)

Muddy Creok below Rt 752 at Hinton......... (SHEN)

Muddy Creek off Rt $752 \mathrm{nr}$ Hinton......... (SHEN)

Muddy Creok trib No. 1 trib 1 at $\mathrm{Rt} i j i$

Muddy Creek trib No. i trib 2 at Rt $7 i_{i}$ nr Singers Glen. . . nr Singers Glen................ (SHEN)

Muddy Creok trib No. 2 at Rt $77 \dot{3}$

Muddy Creek trib No. 2 at Ri $7 j i \cdots \cdots$ nI Singers Gien............... (SHEN)

Muddy Creek trib No. 2 trib 2 at Rt $773 \mathrm{nr}$ Singers Glen.

Muddy Creek trib No. 3 at Rt 760 at Mount CIinton.

Muddy Creok trib No. 3 off Rt 613 nr Mount Clinton..................

Muddy Creek trib No. 4 at Rt 752 at Mount Clinton.............. (SHEN) 
Abbreviated basin names appear at the end of the site name. Abbreviations are as follows:

Eastern Shore (EASTERN); Potomac to Shenandoah (POT-SHEN); Shenandoah (SHEN); Potomac (POTOMAC);

Potomac to Rappahannock (POT-RAPP); Rappahannock (RAPP); Rappahannock to York (RAPP YORK); York (YORK);

York to James (YORK-JAMES); James (JAMES); James to Chowan (JAMES-CHOWAN); ChOWan (CHOWAN); Roanoke (ROANOKE);

Yadkin (YADKIN); New (NEW); Big Sandy (BIG SANDY); Holston (HOLSTON); Clinch (CLINCH): POWelI (POWELL)]

Page

Muddy Creek trib No. 4 at Rt 761

at Mount clinton.

Muddy Creok trib at mouth

Muddy Creek trib tributary No.

trib 1 at Rt 777 nr Singers Glen.... (SHEN)

Muddy Fork at mouth nr Snow Creek....... (ROANOKE)

Muddy Run Spring nr Warm Springs.......... (JAMES)

Muddy Run above Connellee Millpond ni Montross

152

Muddy Run at Rt 810 nr Stanardsvilie...... (JAMES) 250

Muddy Run at U.S. Hwy 220

at Warm Springs

Muddy Run at mouth nr Rixeyvilile......... (RAPP) 127

Muddy Run at mouth nr Tappahannock........... (RAPP) 152

Muddy Run below Muddy Run Spring nr Warm Springs................. (JAMES) 206

Muddy Run trib at Rt 810 nr Boonesvilie.. (JAMES) 250

Mudilck Branch at mouth nr Hayters Gap. (HOLSTON) 517

Mudlick Creek above U.S. Hwy 460

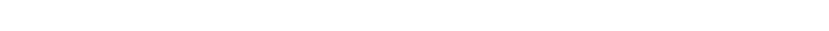

Mudlick Creek at mouth at Doran......... (CLINCH)

Mulatto Run at mouth nr Criglersvilie..... (RAPP)

Mulberry Creek at mouth nr Martinsville. (ROANOKE)

Mulberry Creek at mouth nr Morattico...... (RAPP)

Mullins Branch at mouth at Teas........ (HOLSTON)

Mullins Fork at mouth nr Pound....... (BIG SANDY)

Murray Run above U.S. Hwy 211 at Roanoke................ (ROANOKE)

Murray Run at mouth at Roanoke............ (ROANOKE)

Murray Run nr Woodlawn Park nr Roanoke. (ROANOKE)

Musgrave Branch at U.S. Hwy 58 nr Drewryville.............. (CHOWAN)

Musgrave Branch at mouth nr Drewryvilie. (CHOWAN)

Mush Pond Swamp trib at Rt 40 nr Stony Cropk.

(CHOWAN)

Music Branch above Krights Branch at Brokenburg ................ (YORK)

Mussel Swamp at mouth nr Tappahannock..... (RAPP)

My Ledys Swamp at Rt $629 \mathrm{nr}$ Saluda... (RAPP-YORK)

My Ladys Swamp at mouth nr Saluda... . (RAPP-YORX)

Myer Creek at mouth nr Irvington.......... (RAPP)

Myrtle Ditch above Feeder Ditch nr Lake Drummond............. (JAMES-CHOWAN)

Myrtlo Swamp at mouth nr Morattico....... (RAPP)

Myrtione Branch at mouth nr Chula......... (JAMES)

Naked Creok along Rt 759 at Furnace......(SHEN)

Naked Creek at U.S. Hwy 11 at Burketown... (SHEN)

Naked Creek at mouth $\mathrm{nr}$ Mt. Sidney........ (SHEN)

Naked Creek nr Charlottesvillo........... (JAMES)

Naked Creok, East Branch, along East Branch Naked Creok Trail nr Jollett. (SHEN)

Naked Creok, East Branch, at mouth at Joilett................. (SHEN)

Naked Creok, South Branch, below Bis Ugly Branch nr Furnace......... (SHEN)

Naked Creek, West Branch, at Rt $\mathbf{7} \dot{5}$ at Jollett.................. SHEN)

Namozine Creek above Rt 623 ne Winterpock................. (JAMES)

Namozine Creek at Rt $j 0 \dot{0}$ (Rt $3 \dot{3}$ ) nr Church Road................ (JAMES)

Namozine Creek at former mouth nr Winterpock................... (JAMES)

Namozine Creek trib at mouth nr Ammon.... (JAMES) Nance White Branch at mouth nr Council.

Nancy Sanford Swamp above Chandiers Millpond nr Montross.

( (BIG SANDY)

Millpond $\mathrm{nr}$ Montross................ (RAPP)
Nandua Creek at mouth nr Hacksneck..... (EASTERH)

Nansemond River above Brock Point nr Elephant Fork.
73

06

50
.

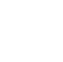

Nansemond River above Muskrat Bluff nr Elephant Fork............... (JAMES)

Nansemond River above U.S. Hwy ij nr Crittendon................. (JAMES) 308

Nansemond River at Rt 125 ne Chuckatuck... (JAMES) 307

Nansemond River at U.S. Hwy 17 nr Crittendon................... JAMES) 308

Nansemond River at U.S. Hwy 460

at Suffolk........................ (JAMES) 306 at Suffolk................. (JAMEs) 306

Nansemond River below Rt 125 nr Chuckatuck............... (JAMES)

Nansemond River below U.S. Hiry 460 (Bypass) nr Elephant Fork......... (JAMES) 307

Nansemond River nr Dumpling Is land nr Elephant Fork............... JAMES) 307

Nansemond River off Pis Point

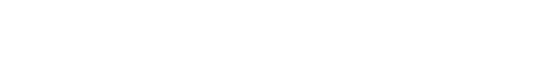
nr Driver .....................

......... (JAMES) 307

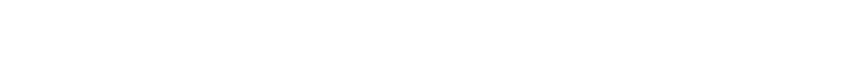

Narrow Passage Creek at U.S. Hwy $i 1$ nr Woodstock..................... (SHEN)

Narrow Passage Creek at mouth nr Woodstock. ................... SHEN)

Nassawadox Creek at Rt 606

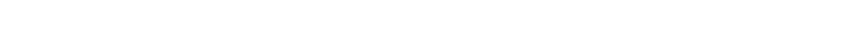

Nassawadox Creek at mouth at Silver Besch............. (EASTERH)

Nassawadox Creok nr Jamesviii........... (EASTERH) Nat Branch at mouth nr Stewartsviile... (ROANOKE)

Natural Bridge Spring nr Tezewe11....... (CLINCE)

Nawney Creak at mouth nr Back Bay. (JAMES-CHOWAN)

Neabsco Creek above STP at Dale City... (POTOMAC)

Neabsco Creok at Benita Fitzgerald Dr nr Dale City.

Neabsco Creek at Darbydale Ave at Dale City................. (POTOMAC)

Neabsco Creek at Delaney Rd (Rt 610)

Neabsco Creek at Minneviiie Rd ....... (POTOMAC) (Rt 640) at Dale City........... (POTOMAC) 103

Neabsco Creek at RF\&P RR nr Dumfries.... (POTOMAC) 103

Neabsco Creek at STP at Dale City....... (POTOMAC) 103

Neabsco Creek at U.S. Hwy 1 nr Dumfries...

Neabsco Creek Dale City............... (POTOMAC)

(POTOMAC)

103

Nebletts Mill Run (Joseph Swamp) above Rt 35 nt Homevi110......... (CHOWAN) 331

Nebletts Mill Run at Rt 35 nr Homevi ile. (CHOWAN) 331

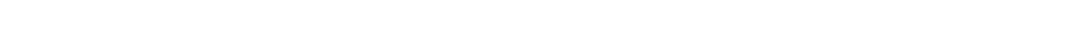

Neck Creek at Rt 617 nr Belspring......... (NEW) 449

Neck Creek at mouth at Parrott................ (NEW) 449

Neece Creek at mouth nr Nora.......... (Bं̈̈ SANDY) 478

Needstan Creek at mouth nr Montpelier..... (YORK) 181

Neff-Litz Spring nr Rural Retreat........... (NEW) 435

Negro Run above Mountain Run nr Gordonsville................ YORK) 166

Negro Run at mouth nr Calverton........... (PÓTOMAC) 92

Negro Run at mouth nr EtIan........................... 135

Negro Run at private road at Gordonsvili...(YORK) 166

Negro Run below Rt 648 nr Gordonsvilie.... (YORK) 166

Neil Umbarger Spring nI Marion.........(HOLSTON) 502

New Camp Branch above mouth nr Davenport................ (BIG SANDY)

New Castle Dam aqueduct outiet

at New Cast10.................... (JAMES)

468

Now River (Claytor Lake) above Claytor Dam nr Radford .............. (NEW)

Now River (Claytor Lake) above

Peak Creek nr Burlington Mills ........ (NEw)

New River (Claytor Lake) at Claytor Lake State Park nr Radford........... (NEW)

New River (Claytor Lake) at Rt $67 \dot{2}$

nr Draper.................... (NEW) 
Abbreviated basin names appear at the end of the site name. Abbreviations are as follows: Eastern Shore (EASTERN); Potomac to Shenandoah (POT-SHEN); Shenandoah (SHEN); Potomac (POTOMAC); Potomac to Rappahannock (POT-RAPP); Rappahannock (RAPP); Rappahannock to York (RAPP-YORK); York (YORK); York to James (YORK-JAMES); James (JAMES); James to Chowan (JAMES-CHOWAN); Chowan (CHOWAN); Roanoke (ROANOKE); Yadkin (YADKIN); New (NEW); Big Sandy (BIG SANDY); Holston (HOLSTON); Clinch (CLINCH); POWell (POWELL)]

New River Dam outfall (APCO) at Byllesby... (NEW) 432 New River above Kings Branch nr Baywood. . (NEW) 429 New River along Rt 653 at Allisonia......... (NEW) 441 New River along U.S. Hory 460 at Rich Creek. (NEW) 455 New River at Buck Dam nr Ivanhoe................ 432 New River at Byllesby Dam at Byllesby...... (NEW) 432 New River at Dublin water works nr Dubiin.. (NEW) 443

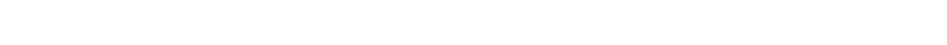

New River at N\&W RR nr Grayson............. (NEW)

New River at Rt $438 \mathrm{nr}$ Patterson............ (NEW)

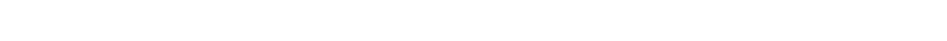

New River at Rt 721 nI Fries............. (NEW)

New River at Rt 730 at Eggleston............ (NEW)

New River at Rt 93 nr Mouth of Wilson..... (NEW)

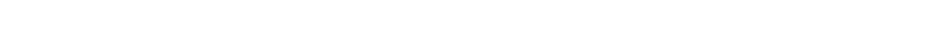

New River at STP at Radford. . .

New River at U.S. Hwy 11 at Radford......... (NEW)

New River at U.S. Ewy 211 nI Independence.. (NEW)

New River at U.S. Hwy 450 at Bluff City.... (NEW)

New River at U.S. Hwy 460 at Glen Lyn...... (NEW)

New River at powerdam at Fries............. (NEW)

New River below Fries Junction nr Grayson. (NEW)

New River below Rt 61 at Narrows........... (NEW)

New River below U.S. Hwy 11 at Radford...... (NEW)

New River diversion at APCO powerdam

$$
\text { nr Ivanhoe ................... (NEW) }
$$

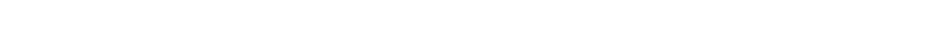

New River off Rt 693 at Allisonia.......... (NEW

New River off Rt 706 nr Independence........ (NEW)

New River trib at mouth at Ivanhoe......... (NEW)

New River, S.F., above N.F. New River nr Piney Creek, N.C.

New River, S.F., below Rts $16 / 88$ nr Jefferson, N.C.

$\ldots \ldots \ldots$. NEW

Newfound River at Rt 658 nI Montpelier.... (YORK)

Newfound River at Rt $664 \mathrm{nr}$ Montpelier.... (YORK)

Newfound River at Rt $667 \mathrm{nr}$ Ashland....... (YORK)

Newfound River at Rt 671 nr Montpelier.... (YORK)

Newfound River at Rt 680 nr Montpelier.... (YORK)

Newfound River at Rt 685 nr Ashland....... (YORK)

Newfound River at Rt 712 nr Montpelier.... (YORK)

Newfound River at Rt 715 nr Montpel1er.... (YORK)

Newfound River at Rt 781 nr Montpelier.... (YORK)

Newfound River at mouth nr Ashland........ (YORK)

Newmarket Creek at Rt 134 at Hampton. . . $\cdots$

Newmarket Creek at Rt 152

( YORK-JAMES ) nr Hampton..........

(YORK-JAMES )

Newmarket Creek at mouth

(YORK-JAMES)

N1 River above Po River nr Guinea......... (YORK)

Ni River at Rt $208 \mathrm{nr}$ Spotsylvania........ (YORK)

$\mathrm{Ni}$ River at Rt $608 \mathrm{nr}$ Spotsylvania........ (YORK)

$\mathrm{Ni}$ River at U.S. Hwy $1 \mathrm{nr}$ Thornburg......... (YORK) N1 River trib at mouth nr Chancellorsville..............(YORK)

Nibbs Creok at Rt $630 \mathrm{nr}$ Chula.......... (JAMES)

Nibbs Creek at Rt 681 nr Ameli a Court House............ (JAMES)

Nibbs Creok at mouth

nr Amelia Court House........... (JAMES)

Nibbs Creek trib at Rt 609 nr Amelia..... (JAMES)

Nicely Branch at Va.-Tenn. State line nr Bristol................. (HOLSTON)

Nicholas Creok at Rt 605 nr Ferrum..... (ROANOKE)

Nicholas Creek at Rt 623 nr Ferrum..... (ROANOKE)

Nicholas Creek at mouth nr Endicott.... (ROANOKE)

Nichols Run above Jefferson Branch nr Dranesville................. (POTOMAC)

Nichols Run at mouth nr Dranesvilie.... (POTOMAC) Nichols Run nr Dranesville............ (POTOMAC) Nicholson Creek at Rt 652 nr Drewryville................ (CHOWAN)

Nicholson Creak at mouth nr Drewryvilie. (CHOWAN) Nlckawampus Creek at Rt 600 nr Melfa... (EASTERN) Nickawampus Creek at mouth

nr Locustville................ (EASTERN)

Nickels Branch at mouth nr Dona............ (CLINCH)

433

428

433

427

181

181

182

181

181
181

181

181

181

182

203

203

203

189

189

189

189

189

276

276

277

277

509

399

399

399
Nicks Creek at U.S Hwy 11 nr Marion... (BOLSTON) Nicks Creek at mouth at Atkins........ (HOLSTON)

Nigser Run at mouth nr Warrenton.......... (RAPP) Ninemile Run above Lick Run nr Fivemile Fork.

Nininger Creek at Rt 43 nr Forest

(nI Otter Bill, nr Bedford)...... (ROANOKE)

Nobles Swamp at mouth nr Garysvilie....... (JAMES) 289

Nobusiness Creek at mouth at Holly Brook...(NEW) 451

Noels Run at Buena Vista............. (JAMES)

Nomini Bay at Kingcopsico Point nI Nomini. ................ nr Nomint. . $60 \ldots \ldots \ldots$ nr Neenah........ (POTOMAC)

Nomini Creek at Rt 600 nr Neena in Lake Chesdin nr Winterpock.... (JAMES) 280

Nordyke Creek at mouth nr Pine Grove... (BOLSTON) 519

Norris Prong at mouth nr Kilmarnock.........(RAPP) 158

Norris Run at mouth nr McCoy.............. (NEW)

North Anne River $1.0 \mathrm{mi}$ above mouth

North Anna River above ilitio River nr Doswell. .................

River nr Ashland................(YORK)

429

500

500
119

144

380
289

229

111

111

North Anna River above dam in Lake Anna..... (YORK) 174 North Anna River at I-95 nr Doswell....... (YORK) 173

North Anna River at Rt 208 in Lake Anna... (YORK)

Narth Anna River at Rt 30 at Hart Corner nr Doswell............ (YORK)

North Anna River at Rt 501 nr Hewlett..... (YORK)

North Anna River at Rt $601 \mathrm{nr}$ Partiow..... (YORK)

North Anna River at Rt 603 nr Hewlett..... (YORK)

North Anna River at Rt $658 \mathrm{nr}$ Levy......... (YORK)

North Anna River at Rt 719 nr Belmont (now in Lake Anna) ............. (YORK)

River at Rt 738 n Beaverdam . (YORK)

North Anna River at U.S. Bwy $1 \mathrm{nr}$ Dosweli. (YORK) 173

North Anna River at U.S. Hwy 522 nI Belmont......................... (YORK)

North Anna River below RF\&P RR nr Dosweil. (YORK)

North Anna River nr Doswell........... (YORK)

North Anna River nr Ruther Gien............. (YORK)

North Anna River trib No. 1 at North Anna River Channel in Lake Anna..... (YORK)

North Anna River trib No. 2 at mouth nr Beaverdarn.

North Anna River trib at mouth nr Doswell. (YORK)

North Bay above Porpoise Point nr Sand Bridgo.

(JAMES-CHOWAN)

North Bay nr Sand Bridge............ (JAMES-CHOWAN)

North Branch at Snowden Rd nr Gum Springs.

(POTOMAC)

North Branch at mouth nr Makemi Park.. (EASTERN)

North Branch trib at Snowden Rd nr Gum Springs

(POTOMAC)

North Buffalo Creek at $\ddot{R} \dot{6} \dot{6} i 2$ nr Collierstown.

(JAMES)

North Buffalo Creek at mouth nr Oakdaie.. (JAMES)

North Creek at Rt 652 at Fork Union...... (JAMES)

North Creek at mouth at Arcadia.......... (JAMES)

North Creek at mouth nr Stonewail.......... (JAMES)

North Creek below STP nr Fork Union...... (JAMES)

North Creek nr Arcadia................ (JAMES)

North End Branch at mouth nr James Store.

(RAPP-YORK)

North End Branch trib at $\dot{R} \dot{6} \dot{\delta} \dot{s}$ nr North.

(RAPP - YORK)

North Fork above Horsepen Branch nr Fredericks Hall............. (YORK)

North Fork at Rt $606 \mathrm{nr}$ Eincastie.......... (JAMES)

North Fork at Swift Millpond nr Buckner...(YORK)

North Fork at mouth at Kimberlins......... (NEW)

North Fork at mouth at Stuart.......... (RÖANOKE)

North Fork at mouth nr Fincastie........... (JAMES)

North Fork at mouth nr Green Bay........ (CHOWAN)

North Fork at mouth nr Interiar............ (NEW)
167

173

172
172

171

172
173

315 
Abbreviated basin names appear at the end of the site name. Abbreviations are as follows:

Eastern Shore (EASTERN); Potomac to Shenandoah (POT-SHEN); Shenandoah (SHEN); POtomac (POTOMAC);

Potomac to Rappahannock (POT-RAPP): Rappahannock (RAPP); Rappahannock to YOrK (RAPP-YORK); York (YORK);

York to James (YORK-JAMES); James (JAMES); James to Chowan (JAMES-CHOWAN); ChOWan (CHOWAN); ROanoke (ROANOKE);

Yadkin (YADKIN); New (NEW); BiB Sandy (BIG SANDY); Holston (HOLSTON): Clinch (CLINCH); POwell (POWELL)]

North Fork at mouth $\mathrm{nr}$ Mt. Sidnөy.........(SHEN) 32

North Holiday Creek $n r$ Toga..............(JAMES) 271

North Landing River above West Neck Creek nr Pleasant Ridge.

North Landing River above

Blackwater River nr Creeds. (JAMES-CHOWAN) 318

North Landing River at Munden..... (JAMES-CHOWAN) 318

North Landing River at Rt 165

at North Landing.......... (JAMES-CHOWAN) 317

North Landing River at Va.-N.C.

State line nr Munden........ (JAMES-CHOWAN) 319

North Landing River at West

Landing $n \mathrm{f}$ Pleasant Ridge... (JAMES-CHOWAN) 317

North Landing River bolow Pocaty

River nr Pleasant Ridge..... (JAMES-CHOWAN) 318

North Landing River nI Back Bay... (JAMES-CHOWAN) 318

North Landing River nr Creeds..... (JAMES-CHOWAN) 318

North Landing River off Walnut

Creok nr Creeds............. (JAMES-CHOWAN) 318

North Mayo River above mouth

nI Price, N.C............... (ROANOKE) 397

North Mayo River at U.S. Hwy 58

nr Spencer.............

nr Spencer . . . . . . . . . . . . (ROANOKE) 397

North Meherrin River at kt $40^{\circ}$

be low Couches Creek nr Lunenburg. . (CHOWAN) 349

North Meherrin River at Rt 40

nr Lunenburg ................. (CHOWAN) 348

North Meherrin River at Rt 687

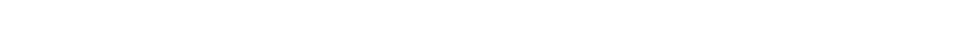

North Meherrin River at U.S. Hwy 360 (CHOWAN) 348

North Meherrin River at mouth

nr Wightman.................. (CHOWAN) 349

North Otter Creek at mouth nr Cifax.... (ROANOKE) 380

North Prong at mouth nr Woolwine....... (ROANOKE) 397

North River $1.0 \mathrm{mi}$ above Middle River nr Grottoes.

(SHEN) 32

North River above Elkhorn Lake

nr Stokesville................. (SHEN)

North River above Forest Rd

nr Stokesville...............................

North River above Ilttle River

nr Stokesville.................. (SHEN)

North River above Pleasant Run

Dr Mt. Crawford. ................ (SHEN)

North River above Rt $276 \mathrm{nr}$ Weyers Cave... (SHEN)

North River along Rt $693 \mathrm{nr}$ Burketown..... (SHEN)

North River along Rt $693 \mathrm{nr}$ Mt. Crawford. . (SHEN)

North River at C\&W RR nr Mt. Crawford..... (SHEN)

North River at Rt $276 \mathrm{nr}$ Weyers Cave....... (SHEN)

North River at Rt 42 at Bridgewater........ (SHEN)

North River at Rt $56 \mathrm{nr}$ Buckingham........ (JAMES)

North River at Rt 659 at Port Republic... (SHEN)

North River at Rt $727 \mathrm{nr}$ Bridgewater...... (SHEN)

North River at Rt 730 at Stokesville....... (SHEN)

North River at Rt $731 \mathrm{nr} \mathrm{Mt}$. Solon.......... (SHEN)

North River at Staunton Dam

nr Stokesville................ (SHEN)

North River at U.S. Bwy ii

nr Mt. Crawford...................... (SHEN)

North River at buoy $5 \mathrm{nr}$ Ware Neck... (RAPP-YORK)

North River at buoy $6 \mathrm{nr}$ Ware Neck. . (RAPP-YORK)

North River at mouth at Port Repubiic..... (SHEN)
North River at mouth nr Buckingham....... (JAMES)

North River at mouth $\mathrm{nr}$ Mobjack...... (RAPP-YORK) 163

North River below Dry River

at Bridgewater................ (SHEN)

North River below Rt $4 \dot{2}$ at Bridgewater..... (SHEN)

North River trib at U.S. Hwy 11

nr Mt. Crawford................. (SHEN)

North River trib at mouth

nx Port Republic .................. (SHEN)

North Run at Richmond............... (JAMES)

Northeast Branch at mouth

at Gloucester Point.

(YORK)

32

31

32

29
245

38

26

25
26

30

163

163

38
245

163

29
29

31

37

294

200
Northeast Creek above trib No. 2 nr Mineral.

Northeast Creek at Rt 622

nx Lake Anna Dam

Northeast Creek at U.S. Hwy 33

nr Mineral. . ...
Northeast Creek at mouth nr Cuckoo........ (YORK)

Northeast Creek at mouth $\mathrm{nr}$ Lake Anne Dam. (YORK) 172

Northeast Creek trib No. 1 nr Mineral.....(YORK) 178

Northeast Creek trib No. 2 at mouth nr Mineral.................. (YORK) 178

Northeast Creek trib No. 2 nr Mineral.....(YORK) 178

Northeast Creek trib No. $3 \mathrm{nr}$ Mineral..... (YORK) 178

Northeast Creok trib at mouth nr Lake Anna Dam.

(YORK) 172

Northeast Ditch nr Deep Creek........... (JAMES) 309

Northwest Branch at mouth at Gloucester Point

Northwest Branch at moutin

ne Poquoson. (YORK-JAMES) 203

Northwest Branch at mouth nr Severn.. (RAPP-YORK) 165

Northwest Branch off Cedar Point nr Poquoson.......................

Point nr Poguoson. (YORK-JAMES) 203

Northwest Branch off Oak Is land nr Poquos on.

(YORK-JAMES)

203

at

Causeway nr Hickory........ (JAMES-CHOWAN)

318

Northwest River at Rt 629 nr Bethel Church.

(JAMES-CHOWAN)

318

Northwest River at Rts $168 / 170$ nr Northwest. $\mathrm{Va}$ - $\mathrm{N} . \dot{\mathrm{C}}$

Northwest River at Va. $\mathrm{N} . \mathrm{C}$.
State line $\mathrm{nr}$ Northwest. State line nr Northwest.... Northwest Canal ni Hickory.

Northwest River trib No. I below

( JAMES-CHOWAN)

319

(JAMES-CHOWAN)

319 ost River trib No. 2

nr Hickory................ (JAMES-CHOWAN)

(JAMES-CHOWAN)

318

Northwost River trib No. 2

Northwest River trib No. 3 nr Saint Brides....

Northwest River trib No. 4

nr Saint Brides....

Northwest River trib No, 5
tributary at Saint Brides Rd nr Hickory.

(JAMES-CHOWAN)

318

318

318

...... (JAMES-CHOWAN)

318

tributary trib at Saint Brides Rd nr Hickory.......................

Norton Prong abovers

(JAMES-CHOWAN)
Norwood

Norwood Creek at mouth nr Manakin.........(JAMES) 263

Nottoway River Rt $630 \mathrm{nr}$ Jarratt......... (CHOWAN) 326

Nottoway River above Battle Beach nr Riverdale.

(CHOWAN) 338

Nottoway River above Rt 653 nr Sebreil...(CHOWAN) 335

Nottoway River above mouth nI Riddicksville, N.C.

Nottoway River at Point Beach nr Riverdale. Not toway River at Rt $40 \mathrm{nr}$ Blackstone... (CHOWAN) 322 Nottoway River at Rt $49 \mathrm{nr}$ Victoria..... (CHOWAN) 322 Nottoway River at Rt $609 \mathrm{nr}$ McKenney.... (CHOWAN) 325 Nottoway River at Rt $612 \mathrm{nr}$ Rawlings.... (CHOWAN) 324 Nottoway River at Rt $619 \mathrm{nr}$ Purdy........ (CHOWAN) 326 Nottoway River at Rt $626 \mathrm{nr}$ Sussex....... (CHOWAN) 331 Nottoway River at Rt $631 \mathrm{nr}$ Iittleton... (CHOWAN) 332 Nottoway River at Rt $634 \mathrm{nr}$ Littleton... (CHOWAN) 331 Nottoway River at Rt $637 \mathrm{nr}$ Stony Creek. (CHOWAN) 331 Nottoway River at Rt $645 \mathrm{nr}$ Jarratt..... (CHOWAN) 326 Nottoway River at Rt $671 \mathrm{nr}$ Handsom..... (CHOWAN) 338 Nottoway River at Rt $684 \mathrm{nr}$ Sunbeam...... (CHOWAN) 338 Nottoway River at Rt $723 \mathrm{nr}$ Burkevilie.. (CHOWAN) 322 Wot toway River at Rt 40 at Stony Crak. (CHOWAN) 337 
Abbreviated basin names appear at the end of the site name. Abbreviations are as follows:

Eastern Shore (EASTERN); Potomac to Shenandoah (POT-SHEN): Shenandoah (SHEN); Potomac (POTOMAC);

Potomac to Rappahannock (POT-RAPP); Rappahannock (RAPP); Rappahannock to York (RAPP-YORK); York (YORK);

York to James (YORK-JAMES); James (JAMES); James to Chowan (JAMES-CHOWAN); ChOWan (CHOWAN); Roanoke (ROANOKE):

Yadkin (YADKIN); New (NEW); Big Sandy (BIG SANDY); Holston (HOLSTON); Clinch (CLINCH); POWell (POWELI)]

Nottoway River at U.S. Hwy

nr McKenney................. (CHOWAN) 324

Nottoway River at U.S. Hwy 258

nr Riverdale........... (CHOWAN) 338

Nottoway River at U.S. Hwy 301

nr Stony Creek................ (CHOWAN) 327

Nottoway River at $\mathrm{Va},-\mathrm{N} . \mathrm{C}$.

State line nr Riverdale.

(CHOWAN) 339

Nottoway River at old U.S. Hwy 258 nr Riverdale.

(CHOWAN) 338

Nottoway River below Rt bio nr Rawiings. (CHOWAN) 324

Nottoway River trib No, 2 at Rt 632

nr Sussex.................. (CHOWAN) 331

Nottoway River trib at Rt 671 at Handsom.

(CHOWAN)

Nottoway River trib no. 2 at $\mathrm{Rt} 40$

nr Stony Creek............... (CHOWAN) 329

Nottoway Swamp at Rt $6 i i$ nr story........ (CHOWAN) 338

Nottoway Swamp at mouth nr Handsom....... (CHOWAN) 338

Nottoway Swamp trib No. I at Rt 650

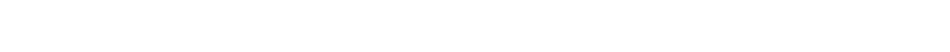

Not toway Swamp $\operatorname{trih}$ No. $2 \mathrm{nr}$ Story...... (CHOWAN) 338

Nuby Run at Rt $637 \mathrm{nr}$ Everets............. (JAMES) 307

Number Three Branch at mouth at Buffalo Springs............ (ROANOKE) 417

Nunn Creek at mouth nr Louisa............. (YORK) 167

Nutbush Creek at Va.-N.C. State Iine

nr Kerr Dam nr Boydton........... (ROANOKE) 420

Nuttree Branch at mouth nr Beach......... (JAMES) 286

Obeys Creek at mouth nr Gate City.......(CLINCH) 548

Occohannock Creek at Davis Wharf

nr Jamesville.................. (EASTERN)

Occohannock Creek at mouth
nr Jamesville................ (EASTERN)

Occoquan Reservoir above Buil Run

nr Clifton.................. (POTOMAC)

Occoquan Reservoir above Occoquan Dam nr Occoquan.................. (POTOMAC)

Occoquan Reservoir above Ryans Dam

nr Occoquan.................. (POTOMAC)

15

15

96

102

occoquan Reservoir at Jacobs Rock nr Occoquan..................(POTOMAC) 101

Occoquan Reservoir at Occoquan Dam

at Occoquan................ (POTOMAC)

102

Occoquan Reservoir at Rt 123 at Occoquan................. (POTOMAC) 102

Occoquan Reservoir at Rt 663

nr Manassas................... (POTOMAC)

Occoquan Reservoir at Ryans Dam

nr Occoquan................... (POTOMAC) 101

Occoquan Reservoir at power iines

nr Occoquan..................(POTOMAC)

102

Occoquan Reservoir below Sandy Run

$\mathrm{nr}$ Occoquan..................(POTOMAC) 101

Occoquan Reservoir nr Occoquan ............(POTOMAC) 102

Occoquan River (Creek) below Rt 234

nr Manassas................. (POTOMAC) 96

Occoquan Rtver (Creek) nr Occoquan

(Site now in Occoquan Reservoir).(POTOMAC) 101

Occoquan River at Lake Jackson Dam at Lake Jackson................ (POTOMAC) 96

Occoquan River at mouth

nr Woodbridge.................(POTOMAC) 102

Occoquan River below Occoquan Dam

at Occoquan................ (POTOMAC)

Occupacia Creek at mouth nr Champlain..... (RAPP)

Occupacia Creek trib at mouth nr Loretto.. (RAPP)

Ogle Branch at mouth $\mathrm{nr}$ Hillsville........ (NEW)

Ogle Creek at mouth nr Callaghan......... (JAMES)

Oglesby Branch at mouth $n r$ Galax............ (NEW)

old Castle Creek at mouth nr Cheriton. (EASTERN)

old Mill Creek at mouth nr Truhart........ (YORK)

old Plantation Creek at mouth nr Cheapside.

(EASTERN)

150

441

210

430

197

14
Old School House Spring nr Council... (BIG SANDY) Old Town Creek at Candvit Road at Colonial Heights.............. (JAMES)

Old Town Creek at Colonial Heights........ (JAMES)

Old Towm Creek at Rt 627 $\mathrm{nr}$ Colonial Heights............. (JAMES)

old Town Creek at Rt 628

nr Colonial Heights.

Old Town Creek at U.S. Hwy 1

(JAMES) at Colonial Heights.

(JAMES)

old Womans Creek at mouth nr Leesviile. (ROANOKE)

Oldfield Creek at mouth nr Floyd........... (NEW)

Oldfield Creek at mouth nr Laurel Fork..... (NEW)

Oldhouse Branch at mouth nr Tuckahoe villaga ............. (JAMES)

Oliver Branch at mouth nr Elk Garden.... (CLINCH)

Oliver Creek at mouth nr Boyd Tavern..... (JAMES)

Oliver Creek at mouth $n r$ Kentuck........ (ROANOKE)

Oliver Creek trib $0.3 \mathrm{mi}$ below U.S. Hwy 250 nI Troy.

Oliver Creek trib 1.2 mi below U.S. Hwy $250 \mathrm{nr}$ Troy............. (JAMES)

Oliver Creek trib $1.4 \mathrm{mi}$ above $\mathrm{Rt} 600$ nr Troy ...

Oliver Creek trib tributary nr Troy...... (JAMES) Onancock Creek at Central Branch at Onancock. Worth Fork

Onancock Croek at North Fork

at Onancock ................. (EASTERN)

Onancock Creek at buoy ii nr Onancock.. (EASTERN)

Onancock Creek at buoy $13 \mathrm{nr}$ Onancock.. (EASTERN)

Onancock Creek at buoy $16 \mathrm{nr}$ Onancock. (EASTERN)

Onancock Creek at buoy $22 \mathrm{nr}$ Onancock. . (EASTERN)

Onancock Creek at buoy $26 \mathrm{nr}$ Onancock. (EASTERN)

Onancock Creek at buoy $33 \mathrm{nr}$ Onancock. . (EASTERN)

Onancock Creek at buoy 34 at Onancock. . (EASTERN)

Onancock Creek at mouth nr Onancock.... (EASTERN)

Onemile Run at mouth at Rocky Bar......... (SHEN)

Open Fork along Rt 652 at Nora........ (BIG SANDY)

Open Fork at mouth at Nora........... (BIG SANDY)

Opequon Creek at Rt 622 at Opequon.... (POT-SEEN)

Opequon Creek at Rt 660 nr Stephenson. (POT-SEEN)

Opequon Creek at Rt $664 \mathrm{nr}$ Winchester. (POT-SHEN)

Opequon Creek at Rt 667 nr Brucetown.. (POT-SHEN)

Opequon Creek at Rt 672 nr Brucetown. (POT-SHEN)

Opequon Creek at Rt $7 \mathrm{nr}$ Berryville... (POT-SAEN)

Opequon Creek at Rt $723 \mathrm{nr}$ Boyce...... (POT-SEEN)

Opequon Creek at Rt 761 nr Wadesville. (POT-SHEN)

Opequon Creek at U.S. Hwy 11 nr Stephens City............. (POT-SHEN)

Opequon Creek at U.S. HWy $50 \mathrm{nr}$ Boyce. (POT-SHEN)

Opequon Creek at U.S. Hwy $\mathbf{5 2 2}$ nr Stephens City. ............ (POT-SEEN)

Opequon Creek at old Rt 628 nr Opequon. ............... (POT-SEEN)

Opequon Craek beiow Abrams Creek nr Winchester.............. (POT-SHEN)

Opequon Creek nr Burning Knoils nr Boyce.................... (POT-SHEN)

Opossum Branch at mouth nr Midway....... (ROANOKE)

Opossum Creek at U.S. Hwy $301 \mathrm{nr}$ Atlee.... (YORK)

Opossum Creek at U.S. Hwy 501 nr Bocock. . . . . . . . . . . . . . . . (JAMES)

Opossum Creek at mouth nr Lynchburg...... (JAMES)

Opossum Creek at mouth nr Studley......... (YORK)

Opossum Quarter Creek at mouth nr Rawlings.

(CEOWAN)

Ore Branch at mouth at Roanoke.......... (ROANOKE)

Orrix Creek at mouth nr Evington........ (ROANOKE)

Osborn Rock Spring at Osborn Rock ne Tacoma.

(CLINCE)

464

283

283

376

444

263

532

255

409

16

16

16
16

16

16

16

16

16

43

478
478

48

24

24

24

22

22

24

22

Oslin Creok at mouth $n \mathbf{c}$ ifax........... (ROANOKE)

Otter Creek at mouth

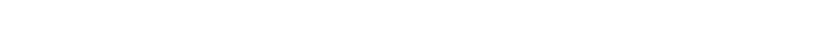

Otter Creek at mouth nr Big Is iand........ (JAMES)

Otter Creek at mouth nr Endicott........ (ROANOKF)

Otterdale Branch at Rt $667 \mathrm{nr}$ Otterdale.. (JAMES)

Otterdale Branch at mouth nr Hallsboro... (JAMES) 
Abbreviated basin names appear at the end of the site name. Abbreviations are as follows:

Eastern Shore (EASTERN); Potomac to Shenandoah (POT-SHEN); Shenandoah (SHEN); Potomac (POTOMAC);

Potomac to Rappahannock (POT-RAPP); Rappahannock (RAPP); Rappahannock to York (RAPP-YORK); York (YORK);

York to James (YORK-JAMES); James (JAMES); James to Chowan (JAMES-CHOWAN); Chowan (CHOWAN); ROanoke (ROANOKE);

Yadkin (YADKIN); New (NEW); Big Sandy (BIG SANDY); Holston (HOLSTON); Clinch (CLINCH); POWOll (POWELI.)]

Page

Otterdam Swamp at Rt $40 \mathrm{nr}$ Waverly...... (CHOWAN) 340

Otterdam Swamp at Rt 607 ne Savedge....... (CHOWAN) 340

Otterdam Swamp at U.S. Hwy 301

nr Jarratt. ..................................... 333

Otterdam Swamp at mouth nr Emporia....... (CHOWAN) 333

Otterdam Swamp at mouth nr Waverly........ (CHOWAN) 340

Otterdam Swamp trib (Buzzard Branch)

nr Waverly................................

Otterdam Swamp trib at Rt $6 \dot{6} \dot{2}$

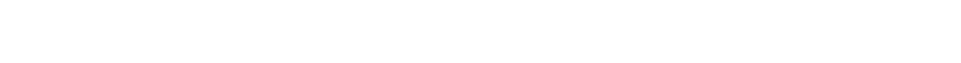

Otts Creek at Rt 620 nr Brownsburg........ (JAMES) 226

Oven Branch at Rt 35 nr Newrille........(CHOWAN) 331

Overall Run at mouth at Overall............. (SHEN)

Overall Run off Overall Run Trail nr Bertorvilie

(SHEN)

Owens Creek at Buffalo Station.......... (JAMES)

Owens Creek at mouth at Clarksvilie..... (ROANOKE)

Owens Creek at mouth ar Holly Grove........ (YORK)

Owens Creek at mouth nr Penhook......... (ROANOKE)

Owl Creek at mouth nr Keysville......... (CHOWAN)

Ow 1 Run at Rt 28 at Calverton.......... (POTOMAC)

Owl Run nr Catlett.................... (POTOMAC)

Oxford Run at Rt 172 at Poquoson.... (YORK-JAMES)

Oxford Run trib at Rt 171 at Poquoson.............. (YORK-JAMES)

P. P. Keesling Spring at Cedar Springs..... (NEW) 433

Paddy Run at mouth nr Lebanon Church...... (SHEN)

Pads Creek at Griffith

nr Longdale Furnace.............. (JAMES)

Pads Creek at mouth nr Longdale Furnace.. (JAMES)

Pagan River at Canel Run nr Lawson....... (JAMES

Pagan River at Cypress Creek nr Rescue... (JAMES)

Pagan River at Gating Point

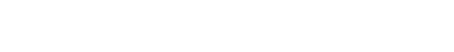

Pagan River at Goodwin Point

nr Newport News..................... (JAMES) 304

Pagan River at Jones Ċreek nr Rescue....... (JAMES) 304

Pagan River at Mount Holly Creek

at Smithfieid .......................... 304

Pagan River at Red Point nr Smithfieid... (JAMES) 304

Pagan River at Rt 10 at Smithfield....... (JAMES) 304

Pagan River at Rt 677 nr Lawson.......... (JAMIS) 303

Pagan River at buoy 19 nr Rescue.......... (JAMES). 304

Pagan River at mouth nr Newport News..... (JAMIS) 304

Pagan River at mouth nr Rescue........... (JAMES) 304

Pagan River nr Smithfield.......................................... 303

Page Branch at mouth nr Ceres...........(BOLSTON) 512

Paine Run $0.5 \mathrm{mi}$ below Rt 614

nr Harriston................. (SEEN)

Paine Run at elev $1480 \mathrm{nr}$ Harriston........ (SEEN)

Paine Run at elev 1500 nr Harriston....... (SEIEN)

Paine Run at elev $1585 \mathrm{nr}$ Harriston....... (SHEN)

Paine Run at elev 1720 nr Harriston......... (SHEN)

Paine Run at mouth at Barriston............ (SEreN)

Paine Run below Paine Run Rd nr Harriston.................... (SHEN)

Paine Run below Rt 614 nr Harriston......... (SKEN)

Paint Bank Branch at mouth at Salem..... (ROANOKE)

Paint Bank Branch nr Paint Bank........... (JAMES)

Paint Bank National Hatchery Spring nr Paint Bank................. (JAMES)

Painter Run at $R t 68 j$ nr $\dot{E}$ dinburg ......... (SHEN

Painter Run at mouth nr Edinburg.......... (SHEN)

Pamunkey Creek (N.F.) at U.S. Hwy 522 at Lake Anna................. (YORK)

Pamunikey Creek at North Anna River Channe 1 in Lake Anna..... (YORK)

Parmukey Creek at Rt 612 nr Belmont........ (YORK)

Pamunkey Creek at Rt $630 \mathrm{nr}$ Lahore......... (YORK)

Pamunkey Creek at Rt 651 nr Lahore......... (YORK)

Pamunkey Creek at Rt 669 at Lahore......... (YORK)

Pamunkey Creek trib at mouth nr Lahore.... (YORK)

Pamunikey River 1.7 mi below U.S. Hwy $360 \mathrm{nr}$ Old Church.........(YORK)
Pamunkey River $2.0 \mathrm{mi}$ below Rt 615 nr Studley.... . Cohoke M $i 1 i$ C̈reek nr New Kent. . . . . . . . . . . . nr Enfield.................... (YORK) 184

Pamunkey River above Mantilo Branch nr Studley................... (YORK) 184

Pamunkey River above Mi nr Hanover ...................(YORK) 183

Pamunkey River above Rt 30 at West Point.. (YORK) 188

Pamunkey River above Totopotomoy Creek nr Manquin...................... (YORK) 185

Pamunkey River above U.S. Hwy 301 nr Hanover...................... (YORK) 182

Pamunkey River above Whiting Swamp at Retreat. M. . . . Montagu Landing nr Tunstall....................(YORK) 186

Pamunkey River at Rt 30 at West Point..... (YORK) 188

Pamunkey River at Rt 614 nr Hanover........ (YORK) 183

Pamunkey River at Rt $615 \mathrm{nr}$ Studley......... (YORK) 184

Pamunkey River at Southern RR at White House..................(YORK) 187

Pamunkey River at Sweet Hall Landing nr New Kent.

Pamunkey River at U.S. Hwy $301 \mathrm{nr}$ Hanover, (YORK) 182

Pamunkey River at U.S. Hwy $360 \mathrm{nr}$ Manquin, (YORK) 185

Pamunkey River at white Landing nr Cohoke. (YORK) 187

Pamunkey River at Wickham Crossing nr Hanover.................... (YORK)

Pamunkey River at Wiliians ianding nr Tunstall.................(YORK) 187

Pamunkey River at mouth at West Point...... (YORK) 188

Pamunkey River below Mantilo Branch nr Studley.................(YORK) 184

Pamunkey River below Mehixen Creek

nr Enfield................. at Port Richmond ................ (YORK) 188

Pamunkey River off Rt 605 nr Enfieid........ (YORK) 184

Pamunkey River off Rt 635 at Romancoke..... (YORK) 187

Pamunkey River trib No. 1 at U.S. Hwr 301 nI Hanover........... (YORK)

Pamunkey River trib No. 2 at mouth

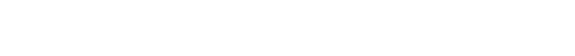

Pamunkey River trib No. 3 at mouth

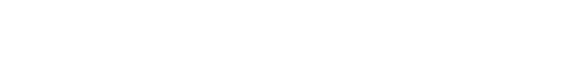

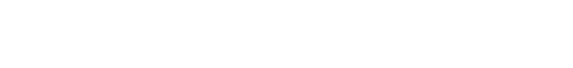

Pamunkey River trib No. 5 at mouth

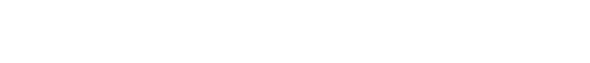

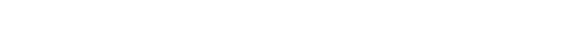

184

\section{.} 84 (n)

Pamunkey River trib No. 6 tributary at Rt $605 \mathrm{nr}$ Hanover............. (YORK) 183

Panhandle Creek at mouth nr Ciarksvilie(ROANOKE) 420

Panther Branch at mouth at Bandy........ (CLINCH) 527

Panther Creek at mouth nr Flat Ridge........ (NEW) 428

Panther Creek at mouth nr Longshoal......... (NEW) 439

Panther Skin Creek at mouth nr Upperville.............. (POTOMAC)

Pantico Run at mouth nr Montross......... (RAPP) 151

Paper Mill flume at Bristol............ (HOLSTON) 510

Parett Fletcher Branch at Rt 600 nr Davenport............... (BIG SANDY) 467

Parham Creek at mouth $\mathrm{nr}$ Bracey.......... (ROANOKE) 423

Parker Branch at Rt $810 \mathrm{nr}$ Stanardsvilie. (JAMES) 252

Parker Branch at mouth at Riverside.... (HOLSTON) 494

Parker Branch at mouth $\mathrm{nr}$ Dyke............ (JAMES) 252

Parker Branch, S.F., at mouth nr Riverside..................... (HOLSTON)

Parker Creek above U.S. Hwy ij nr Greenbush............... (EASTERN)

Parker Creek above U.S. Hwy is nr Accomac ................. (EASTERN)

Parker Creek at $\hat{N} . \vec{F}$. Parker Creek nr Accomac................. (EASTERN)

80

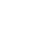

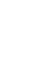

6

8

87

82

(1)

7
. 
Abbreviated basin names appear at the end of the site name. Abbreviations are as follows:

Eastern Shore (EASTERN); Potomac to Shenandoah (POT-SHEN); Shenandoah (SHEN); Potomac (POTOMAC);

Potomac to Rappahannock (POT-RAPP); Rappahannock (RAPP); Rappahannock to York (RAPP-YORK); York' (YORK);

York to James (YORK-JAMES); James (JAMES); James to Chowan (JAMES-CHOWAN); Chowan (CHOWAN); Roanoke (ROANOKE);

Yadkin (YADKIN); New (NEW); Bis Sandy (BIG SANDY); Holston (HOLSTON); Clinch (CLINCH); Powell (POWELI)]

Parker Creek at Rt $744 \mathrm{nr}$ Accomac.

Parker Creek at U.S. Hwy 13 (Business) nr Accomac.

(EASTERN)

Parker Creek at effluent nr Accomac.... (EASTERN)

Parker Creek at mouth $\mathrm{nr}$ Accomac....... (EASTERN)

Parker Creek below U.S. Bwy 13 (Business)

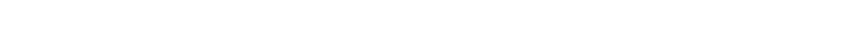

Parker Creek, N.F., at Rt 661 nr Accomac.................. (EASTERN)

Parker Creek, N.F., at mouth nr Accomac.................. (EASTERN)

Parker Run at mouth nr littioton......... (CHOWAN)

Parker Run at mouth nr Montross........... (RAPP)

Parkers Branch at Rt $604 \mathrm{nr}$ Homevilie... (CHOWAN)

Parkers Branch at mouth nr Littleton.... (CHOWAN)

Parks Creok at mouth nr Sugar Grove.... (HOLSTON)

Parrish Bill Croek at mouth at Charles City.

(JAMES)

Parrot Branch at mouth ni Penhook....... (ROANOKE)

Parrott Branch at Rt $810 \mathrm{nr}$ Crozet....... (JAMES)

Parrotts Creek at mouth nr Water View..... (RAPP)

Parsleys Creek at mouth nr Manquin........ (YORK)

Parting Creok at Bacon Hill Branch nr Exmore.

Parting Creek at end of Rt iBj at Willis Wharf nr Exmore........ (EASTERN)

Parting Creek at mouth $\mathrm{nr}$ Willis Wharf. (EASTERN)

Partridge Creek at Rt 622 at Stapleton... (JAMES)

Pasquotank River nr South Mills . N.C.......... (JAMES-CHOWAN)

Pass Run at Rt $669 \mathrm{nr}$ Thorntion Gap........ (SHEN)

Pass Run at mouth nr Springfield......... (SHEN)

Pass Run nr Luray................... (SHEN)

Passage Creek above Rt 55 at Buckton..... (SHEN)

Passage Creek at Rt 55 at Buckton......... (SHEN)

Passage Creek at Rt 774 nr Detrick........ (SHEN)

Passage Creek at Rt $776 \mathrm{nr}$ Detrick........ (SHEN)

Passage Creek at mouth nr Waterlick........ (SHEN)

Passage Creek trib, N.F.. at Rt 678 nr Detrick.......................

(SHEN)

Passage Creek, S.F., trib at Rt 678 nr Detrick.................. (SHEN)

Passapatanzy Creek at mouth at Belveder Beach.

Paterson Spring nr Spring Creek........... (SHEN)

Patricks Creek at mouth nI Poquoson............... (YORK-JAMES)

Patten Hess Branch at $\mathrm{Rt} 681$ nI Davenport.

(BIG SANDY)

Patterson Branch at mouth nr Friendship.............. (HOLSTON) 495

Patterson Branch at mouth $\mathrm{nr}$ Ridgeway. (ROANOKE) 403

Patterson Creek at Rt 682 nr Eagle Rock.. (JAMES) 219

Patterson Creek at mouth nr Eagle Rock... (JAMES) 219

Patton Branch above Johns Fork nr Duty ................... (BIG SANDY)

Patton Branch nr Duty............... (BIG SANDY)

Pattonsville Branch at mouth nr Pattonsville.............. (CLINCH) 551

Paul Spring Branch nr Paul Spring

Parkway $\mathrm{nr}$ Gum Sorings............ (POTOMAC)

Paul Spring Branch nr Sherwood

Hall tane nr Gum Springs......... (POTOMAC)

Pauls Creek at Rt $690 \mathrm{nr}$ Cana............ (YADKIN)

Pauls Creek at Va. -N.C. State line

nr Cana.................... (YADKIN)

Pauly Branch at mouth $\mathrm{nr}$ Ridgedale..... (BOLSTON)

Pawpaw Creek above Hackney Hollow

nr Prater.

Pawpaw Creek above Litilo Pawpaw Creek nr Colley.................... (BIG SANDY)

Pawpaw Creek above she Branch

nx Prater................... (BIG SANDY)

Pawpaw Creek above Tom Fork

nr Prater................... (BIG SANDY)

Pawpaw Creek above Wi idcat Branch

nr Prater.................... (BIG SANDY)
Pawpaw Creek along Rt $605 \mathrm{nr}$ Colley... (BIG SANDY) Pawpaw Creek along Rt 643 at Kelsa... (BIG SANDY) Pawpaw Creek at Rt 697 at Kelsa...... (BIG SANDY) Pawpaw Creek at mouth $\mathrm{nr}$ Colley....... (BIG SANDY) Pawpaw Creek trib at mouth nr Colley, (BIG SANDY) Payne Creek at mouth nr Kings Store........ (NEW) Paynes Creek at mouth $\mathrm{n} r$ Ottoman.......... (RAPP) Pea Hill Creek above Rt $667 \mathrm{nr}$ Gasburg. (ROANOKE) Pea Hill Creek above Va. - N.C. State line nr Gasburg.

Pea Hill Creek at Rt 626 nr Bowens Corner.

Pea Hill Creek at Rt 665 nr Gasburg.... (ROANOKE)

Pea Hill Creek at Rt 667 nI Valentines. (ROANOKE)

Pea Hill Creek trib No. 2 nr Valentines............... (ROANOKE)

Pea Hill Creek trib No. 3 nr Valentines................ (ROANOKE)

Pea Hill Creek trib No. 4 nr Valentines.............. (ROANOKE)

Pea Hill Creek trib No. 5 nr Henrico, N.C................ (ROANOKE)

Pea Hill Creek trib no. I nr Gasburg... (ROANOKE)

Pea Hill Creek trib No. 4 tributary nr Valentines.....

Peach Bottom Creek at Rt 2 Bottom Creek at Rt $69 \dot{9}$ $\mathrm{nr}$ Independence.

(ROANOKE)

474

490

490

474

474
444

424

425

424

424

424

424

424

424

425

424

424 Bot tom Creek at U.S. Hwy 58

nr Independence........

Peach Bottom Creek at mouth
nr Independence........

Peak Creek at I-8I nr Pulaski.

Peak Creak at Rt 610 at Pulaski.....

Peak Creek at Rt 99 nr Pulask1........... (NEW)

Peak Creek at U.S. Hwy 11 at Pulaski........ (NEW)

Peak Creek at mouth at Claytor Lake......... (NEW)

Peak Creek below U.S. Hwy 11 at Pulask1.... (NEW)

Peak Creek trib along U.S. Bwy $1:$ at Pulaski.

Peak Creek trib at Rt 636 nr Pulaski....... (NEW)

Peak Creek trib at Rt 99 at Pulaski........ (NEW)

Pearis Thompson Branch at mouth nr Bolly Brook.

Peckerwood Branch at mouth nr Jeffress. (ROANOKE)

Pecks Creek at mouth $n r$ Warsaw.......... (RAPP)

Pedlar River above Lynchburg Reservoir nr Buena Vista................. (JAMES)

Pedlar River at Rt $610 \mathrm{nr}$ Pedlar Milis... (JAMES)

Pedlar River at Rt 635 nr Pedlar Mills.

Pedlar River at Rt 650 at Holcomb (s) Rock. River at U.S. Hwy 60 beiow

Davis Mill Creek nr Buena Vista... (JAMES)

Pedlar River at mouth $n r$ Bis Is land...... (JAMES)

Pedlar River below Brown Mt. Creak nr Buena Vista. ........... at Pedlar Mills................ (JAMES)

Pedlar River belowils. . . . . .

nr Leedstown. .................... (RAPP)

Peedee Creek at mouth $n r$ Leedstown....... (RAPP)

Peggies Branch at mouth nr Mouth of Wilson.

Pelham Iake above dan at culpeper.......... (RAPP)

Pelhan Swamp nr Providence Forge......... (JAMES)

Pendleton Branch at mouth nr Abingdon.. (BOLSTON)

Penn Daw outfall at Huntington Ave at Alexandria ............... (POTOMAC) Pennington Branch at mouth nr Konnarock.

(HOLSTON)

Pepper Creek at mouth nr New Point... (RAPP-YORK) Pepper Mill Creek at mouth nr Dahlgren. (POTOMAC) Percy Preston Spring nr Wallace........ (HOLSTON) Periwink lo Branch at mouth at Patterson.... (NEW) Perrin Creek at mouth nr Wolftrap...... (ROANOKE) 
Abbreviated basin names appear at the end of the site name. Abbreviations are as follows: Eastern Shore (EASTERN); Potomac to Shenandoah (POT-SHEN); Shenandoah (SHEN); Potomac (POTOMAC);

Potomac to Rappahannock (POT-RAPP); Rappahannock (RAPP); Rappahannock to York (RAPP-YORK); York (YORK)

York to James (YORK-JAMES); James (JAMES); James to Chowan (JAMES-CHOWAN); Chowan (CHOWAN); ROanoke (ROANOKE);

Yadkin (YADKIN); New (NEW); Big Sandy (BIG SANDY); Holston (BOLSTON); Clinch (CLINCH); Powell (ZOWELL)]

Perry Creek at mouth nr Greenfield.... (JAMES)

241

Persimon Branch at Flannagan

Reservoir ni Terpon............ (BIG SANDY) 486

Peter Creek at mouth

nr Buffalo Springs............ (ROANOKE) 415

Peterfish Run at mouth ni Shenandoah........ (SHEN) 46

Peters Brasch at mouth ar Brunswick...... (CHOWAN) 352

Peters Branch at mouth nr Gate City..... (CLINCH) 548

Peters Branch at mouth $\mathrm{nr}$ Leatherwood.. (ROANOKE) 403

Peters Creek above mouth nr Stuart..... (ROANOKE) 394

Peters Creek at Rt $628 \mathrm{nr}$ Roanoke....... (ROANOKE) 364

Peters Creek at Shenadoah Ave at Roanoke.

ROANOKE) 364

Peters Creek at mouth at Roanoke........ (ROANOKE) 364

Peters Creek at mouth nr Mount Airy.... (ROANOKE) 413

Peters Mi11 Run along Rt 758

$$
\text { nr Detrick...................... (SHEN) }
$$

Petras Branch at mouth nr Sandy River. (ROANOKE) Peumansend Creek at mouth ni Port Royal. . (RAPP)

Phelps Croek at mouth at Brooknea1.... (ROANOKE)

Philbates Creek at mouth nr Barhamsville..(YORK)

Prillippi Branch at mouth ni Groseclose.

(HOLSTON)

Phillips Creek at mouth nr Nass awadox. (EASTERN)

Phillips Creek nI Fox Gap at mouth ar Flat Gap............... (BIG SANDY)

Prillips Creek nr Giliey above mouth ar Flat Gap Giliey above mouth (BIG SANDY)

Phillips Creek nr Giliey at mouth nr Flat Gap............... (BIG SANDY)

Philpott Reservotr at Philpott Dam ar Philpott................ (ROANOKE)

Phils Arm Run above Rt 631 nr Browntown... (SHEN)

Phils Arm Run at Rt $631 \mathrm{nr}$ Brownt own..... (SHEN)

Phils Arm Run trib at mouth nr Browntown. (SHEN)

Phils Creek at mouth nr Wilmington...... (JAMES)

Piankatank River at Jackson Creek nr Deltavilie............... (RAPP-YORK)

Piankatank River at Rt 3 ni Wiiton... (RAPP-YORK)

Piankatank River at buoy 12 nf Deltaville,............ (RAPP-YORK)

Piankatank River at buoy 13 nr Deltaville............... (RAPP-YORK)

Piankatank River at buoy

nr Deltaville................ (RAPP-YORK)

Piankatank River at mouth nr Deltavilie.

ank River below Ferry Creek

nr Dutton.
Piankatank Rlver trib No. i at mouth

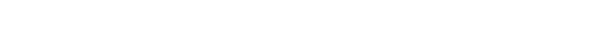

Piankatank River trib No. 2 at mouth ar Hartfield.................

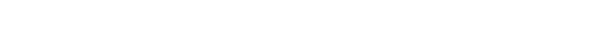

Piankatank River trib No. 4 at mouth nr Hartfield................ (RAPP-YORK)

nr Hartifield.....
Picataway Creek at mouth nr Tappahannock.

(RAPP-YORK)

(RAPP-YORK)

(RAPP-YORK)

(RAPP-YORK)

62

406
148

386

198

499

13

481

481

481

400

51

51

257

162

161

162

161

162

162

161

161

161

161

161

153

Picture Branch at mouth ne Sutheriand..... (CROWAN)

Pie Creek at mouth nr Museville........ (ROANOXE)

Pierce Branch at mouth at Sugar Grove. . (HoLSTON)

Pterce Creek at mouth at Nomini........ (POTOMAC)

Plerce Croek at mouth nr Bacons Castle... (JAMES)

Pifer Run at Rt $600 \mathrm{nr}$ Mountain Falls..... (SHEN)

Pig Swamp at mouth nr Zuni........... (CHOWAN)

Pigeon Creek above Looney Creek at Appalachi a................. (POWELL)

Pigeon Creek at mouth at Appalachia..... (POWELI)

Pigeon Run at North Anna River Channel in Lake Anna.

(YORK)

Pigeon Swamp at mouth nr Newviiie..... (CBOWAN)

Pigeonroost Creek above mouth nr Ebony. (ROANOKE)

Pigeonroost Swamp at Rt 618 nr Elberon. (CHOWAN)

P18g River $1.0 \mathrm{mi}$ below U.S. Hwy 220 (Business) at Rocky Mount.

(ROANOKE) 373

Pigg River $1.2 \mathrm{ml}$ bolow U.S. Hwy 220 (Business) nr Rocky Mount........ (ROANOKE)
P1gg River above Rt 40 nr Sandy Level (ROANOKE)

Pigg River above STP at Rocky Mount.... (ROANOKE)

Pigg River above water supply intake nf Rocky Mount.

Pigo River along Rt 605 nr Toshes...

Pigg River at Rt 40 nr Rocky Mount...... (ROANOKE)

Pigg River at Rt $40 \mathrm{nr}$ Sandy Leva1...... (ROANOKE)

PigB River at Rt 713 nr Rocky Mount.... (ROANOKE)

P1g8 River at U.S. Hwy 220 ns Rocky Mount............. (ROANOKE)

Pig8 River at U.S. Hwy 220 (Business)

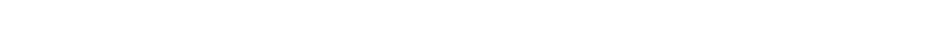

Pigg River at mouth ar Pittsville...... (ROANOKE) 376

Pike Branch at East Dr at Alexandria... (POTOMAC)

Pike Branch at Rt 611 at Alexandria.... (POTOMAC)

Pike Branch at Tolograph Rd at Alexandria...... (POTOMAC)

Pike Branch at mouth at Alexandria..... (POTOMAC)

Pike Branch at mouth at Gate City...... (BOLSTON)

Piltzer Creek at mouth ar Brokenburg...... (YORK)

Pimmit Run at Great Falls Rd nr Falls Church.............. (POTOMAC)

Pimnit Run at Leesburg Pike nr Falls Church........

Pimit Run at Old Dominion DI at McLean ................. (POTOMAC)

Pimit Run at Rt 120 at Ariington....... (POTOMAC)

Pimmit Run at Rt 695 nr Falls Church... (POTOMAC)

Pinmit Run at Westmoreland Rd nr McLean.

(POTOMAC)

Pimmit Run at mouth at Arington........ (POTOMAC)

Pimmit Run below Byron Branch at Mclean................... (POTOMAC)

Pimmtt Run below Kirby Rd at Arlington................ (POTOMAC)

Pimit Run nr North Randolph St at Arlington .................... (POTOMAC)

Pine Branch at mouth in Chock............. (NEW)

Pine Branch at mouth ar Elk Run............ (RAPP)

Pine Branch at mouth nf Isom......... (BIG SANDY)

Pine Branch at mouth nr Woodlawn........... (NEW)

Pine Camp Creek at mouth nr Coeburn...... (CLINCB)

Pine Creek above Big Lick Creek nr Dye.. (CLINCB)

Pine Creek at Rt $630 \mathrm{nI}$ Georges Fork. (BIG SANDY)

Pine Creek at Rt 682 nr Floyd............. (NEW)

Pine Creek at mouth nr Ebenezer......... (ROANOKE)

Pine Creek at mouth nr Floyd............. (NEW)

Pine Creek at mouth nr Georges Fork. (BIG SANDY)

Pine Creek at mouth nr Gladesboro......... (NEW)

Pine Craek at mouth nr Laurel Fork. ........... (NEW)

Pine Creek at mouth nr Longshoal........... (NEW)

Pine Fork at mouth nr Simpsons ............ (NEW)

Pine Hill Croek at Rt 205 ar Ninde..... (POTOMAC)

Pine HiIl Croek below Rt $205 \mathrm{nr}$ Trotum. (POTOMAC)

Pine Run above mouth nr Allisonia.......... (NEW)

Pine Run along Rt 438 nr Draper........... (NEW)

Pine Run at mouth nr Alisonia ............ (NEW)

Pine Run at mouth nr Favonia............. (NEW)

Pine Run at mouth nr Greenvili........... (SEEN)

Piney Branch above Smith Creek nr C1ifton Forse.

(JAMES)

Piney Branch above W\&OD RR at Vienna... (POTOMAC)

Piney Branch at Rt 649 nr Brentsville.. (POTOMAC)

Piney Branch at wouth nr Chester......... (JAMES)

Piney Branch at mouth ar Clifton....... (POTOMAC)

Piney Branch at mouth nr Vienna......... (POTOMAC)

Piney Creek at mouth at Narrows............ (NEW)

Piney Creek at mouth nr Free Union....... (JAMES)

Piney Creek at mouth nr Galax........... (NEW)

Piney Creek at mouth nr Midway...........(ROANOKE)

Piney Creek at mouth nr North view....... (CHOWAN)

Piney Fork at mouth nr Indian Valley ........ (NEW)

Piney River along Forest Rd nr Sperryvilie................. (RAPP)

Piney River at Alhambra ............... (JAMES)

Piney River at Rt 151 at Piney River..... (JAMES)

Piney River at Rt $674 \mathrm{nr}$ Piney River..... (JAMES)

Piney River at Rt 778 at Lowesvilie...... (JAMES)

\section{6}

373

376

372

376
373

373

373

84

84

522
188

78

78

79

79
78

79

79

79

79

79

444

131
484

432

542

530
483

414

444

483

438

438

439

444

110

438
100

435

38

212
77

77
96

286

100

77

454
250

431

392

350

439

123

237

238

238 
Abbreviated basin names appear at the end of the site name. Abbreviations are as follows:

Eastern Shore (EASTERN): Potomac to Shenandoah (POT-SHEN); Shenandoah (SHEN); Potomac (POTOMAC);

Potomac to Rappahannock (POI-RAPP); Rappahannock (RAPP); Rappahannock to YoIK (RAPP-YORK); York (YORK);

York to James (YORK-JAMES): James (JAMES): James to Chowan (JAMES-CHOWAN); Chowan (CHOWAN); Roanoke (ROANOKE);

Yadkin (YADKIN); New (NEW); Big Sandy (BIG SANDY); Holston (BOLSTON); Clinch (CLINCH); POWell (POWELL)]

Piney River at Woodson. . . . . . . . . JAMES)

Piney River at mouth nr Arrington............... (JAMES)

Piney River at mouth nr Washington........ (RAPP)

Piney River below Roses Mill

nr Piney River............... (JAMES) 238

Piney River, N.F., at mouth nr Aihambra.. (JAMES) 237

Piney River, S.F., at mouth nr Alhambra.. (JAMES) 237

Piney Run at Leesburg Pike at Reston... (POTOMAC)

Piney Run at Rt $671 \mathrm{nr}$ Lovettsville.... (POTOMAC)

Piney Run at Telegraph Rd nI Franconia. (POTOMAC)

Piney Run at mouth nr Great Falls...... (POTOMAC)

Piney Run at mouth nr Lovettsville..... (POTOMAC)

Pipe Dan Run at mouth nr Fivemile Fork.... (RAPP)

Piscataway Creek at Rt 691 nr Tappahannock .........

Piscataway Creek at U.S. Hwy 360 nr Tappahannock...........

Piscataway Creek trib

(RAPP)

Pistol Branch at mouth at Vandyke

Pitch Kettle Creek at former mouth

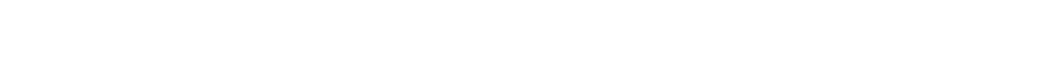

Pitts Creek at end of Rt 804

at marina nr New Church.

Pitts Creek at mouth nr Sanford............ (EASTERN)

Pitts Creek trib No. I at New Church... (EASTERN)

Pitts Creek trib No. 2 at Rt 705 nr New Church.

(EASTERN)

Plains Mill Creek at Rt 260 nr Now Market. (SHEN)

Plains Mill Creek at mouth nI New Market.. (SEEN)

Plains Mill Spring nr New Market......... (SHEN)

Plank Camp Creek at mouth nI Gate City.. (CLINCH)

Pleasant Run at Rt $653 \mathrm{nr}$ Tatum.......... (YORK)

Pleasant Run at Terrys Run Channel in Lake Anna................. (YORK) 169

Pleasant Run at mouth $\mathrm{nr} \dot{\mathrm{Mt}}$. Crawford..... (SHEN)

pleasant Run nr Rt 867 at Mt. Crawford.... (SEEN)

Plentiful Creek at Pamunkey Creek Channel in Lake Anna.............. (YORK)

Plum Branch at mouth nr Sherwi

Plum Creek at U.S. Hwy 11 at Radford........ (NEW)

Plum Creek at U.S. Hwys $460 / 19$

at Frog Level nr Tazewell.........(CLINCH)

Plum Creek at mouth at Radford.

(NEW)

Plum Creek at mouth nr Glade Spring..... (HOLSTON)

Plum Creek at mouth nr Tazewel1.........(CLINCH)

Plymouth Swamp at mouth nr Truhart........(YORK)

Po River (Glady Run) nr Snell............ (YORK)

Po River (Robertson Run) above

Glady Run nr Brokenburg...........(YORK)

Po River above $\mathrm{Ni}$ River nr Guinea.......... (YORK)

Po River at Rt $208 \mathrm{nr}$ Spotsylvania........ (YORK)

Po River at Rt 608 nr Snell.............. (YORK)

Po River at U.S. Hwy $1 \mathrm{nr}$ Thornburg........ (YORK)

Poague Run (Creek) at Rt $608 \mathrm{nr}$ Glasgow.. (JAMES)

Poague Run above Holiday Inn at Annex..... (SHEN)

Poague Run at mouth at Annex.............. (SEEN)

Poague Run below Holiday Inn at Annex..... (SEEN)

Pocaty River at Rt 190 nI Land of Promise......... (JAMES-CHOWAN)

Pocaty River at Wilson Rd

nr Pleasant Ridge..........(JAMES-CHOWAN) 317

Pocaty River at mouth nr Pleasant Ridge.......... (JAMES-CHOWAN)

Pocket Creek at mouth nr Lynch Station. (ROANOKE)

Pocomoke River at Pitts Creek

nr Sanford.................. (EASTERN) 19

Pocomoke River at $\mathrm{Va} .-M d$. State ine nr Sanford.

Pocomoke River at mouth nr Sanford.

Pocoshock Creek at U.S. HWy 360 at Richmond.

Pocoshock Creek trib at Richmond.

(JAMES) 267

Poge Branch at mouth nr Murrayfieid.... (BOLSTON)

Pohick Bay (Gunston Cove) nr Lorton.... (POTOMAC)
Pohick Creek along Pohick Rd nr Lorton.

Pohtck Creek at Hooes Rd

(BOTOMac)

Pohick Creek at Lorton $\mathrm{R} d$ at Lorton..... (POTOMAC)

Pohick Creek at Old Colchester Rd nr Lorton.

( POTOMAC)

Pohick Creek at Pohick Rd nr Lorton.... (POTOMAC)

Pohick Creek at Rt 645 at Burke........ (POTOMAC)

Pohick Creek at Shirley Hwy nr Lorton.. (POTOMAC)

Pohick Creek at U.S. Hwy 1 at Pohtck... (POTOMAC)

Pohick Creek at mouth nr Lorton........ (POTOMAC)

Pohick Creek below Keene Mill Rd at Burke.

(POTOMAC)

Pohick Creek below Old Colchester Rd nr Lorton.................... (POTOMAC)

Pohick Creek below Rt 645 at Burke...... (POTOMAC)

Pohick Creek trib at Keene Mil1 Rd nr Burke................... (POTCMAC)

Pole Branch at mouth nr Buffalo Ridge.. (ROANOKE) Pole Bridge Branch at mouth nr Murrayfield.

(HOLSTON)

Pole Bridge Branch at mouth nr Chatham. (ROANOKE) Pole Creek at mouth nr Ebony.......... (ROANOKE) Polebridge Creek at mouth nr Sanvilie.. (ROANOKE) Polecat Branch at mouth nr Madison.......... (RAPP Polecat Branch at mouth nr Snow Creek. (ROANOKE) Polecat Creek (Stevens Mill Run trib No. 1) at I-95 nr Golensville.. (YORK) Polecat Creek above Reedy Swamp nr Ladysmith. (YORK)

Polecat Creek at Rt 207 nr Ladysmith...... (YORK) Polecat Creek at Rt 601 at Penola.......... (YORK) Polecat Creek at Rt 652 nr Ladysmith....... (YORK) Polecat Creek at mouth nr Halifax....... (ROANOKE) Polecat Creek at mouth nr Penhook....... (ROANOKE) Polecat Creek at mouth nr Penola........... (YORK) Polecat Creek trib (Stevens Mill Run trib No. 2) nr Ruther Glen......... (YORK)

Polecat Draft at mouth nr Piedmont........ (SHEN) Polecat Draft nr New Hope............... (SEEN) Poletown Branch at mouth nr Grahams Forge. (NEW) Pollard Creek at mouth nr Crosses Corner.. (YORK) Pond Drain at mouth $\mathrm{nr}$ Cheapside....... (EASTERN) Pond Drain at mouth nr Interior............. (NEW) Pondlick Branch at mouth at Pulaski.......... (NEW) Poni River above Matta River nr Woodford.. (YORK) Poni River at Rt 606 nr Guinea.......... (YORK) Poni River trib No. 1 at Rt 607 nr Guinea. (YORK) Poni River trib No. 1 at Rt 660 nr Gutnea. (YORK) Poni River trib No, 1 at Swamp Edge nr Guinea. . . . . . . . . . . . . . . (YORK) Poni River trib No. 1 tributary at Rt 660 nr Guinea.

Poni River trib No. 2 at Rt 606 at Guinea. (YORK) Poni River trib No. 2 at Rt 609 at Guinea. (YORK) Poni River trib No. 2 at Swamp Edge nr Guinea.

(YORK)

Pony Mountain Branch at Rt 3 nr Culpeper.. (RAPP) Pooles Creek at mouth nr Bacons Castle... (JAMES) Poor Branch at mouth nr Oak Grove.......... (NEW) Poor Creek at Petersburg.............. (JAMES)

Poor Creek at mouth nr Greenville......... (SEEN)

Poor Creek nr Greenville............... (SEEN)

Poor Farm Draft at mouth in staunton........ (SEEN) Poor Valley Branch at mouth at Rose Ht11.

$\ldots \ldots \ldots$ (POWELL) Poore Creek at mouth nr Boswells Tavern... (YORK) Poorhouse Creek at mouth at Stuart.....(ROANOKE) Poorhouse Creek et mouth nr Otter Hill. (ROANOKE) Poorhouse Run at mouth nr Orange......... (YORK) Poorhouse Run nr mouth at lake Cohoon.... (JAMES) Popcestle Creek at mouth nr Passapatanzy.. (RAPP) Pope Swamp at mouth nr Zuni........... (CHOWAN) Popes Creek at mouth at Moses Beach.... (POTOMAC) Popes Creek at mouth nr Jeffress....... (ROANOKE) Popes Head Creek at Rt 645 at Clifton. (POTOMAC)
90

90 
Abbreviated basin names appear at the end of the site name. Abbreviations are as follows Eastern Shore (EASTERN); Potomac to Shenandoah (POT-SHEN); Shenandoah (SHEN); Potomac (POTOMAC) Potomac to Rappahannock (POT-RAPP); Rappahannock (RAPP); Rappahannock to York (RAPP-YORK); York (YORK): York to James (YORK-JAMES); James (JAMES); James to Chowan (JAMES-CHOWAN); ChOwan (CHOWAN); ROanoke (ROANOKE); Yadkin (YADKIN); New (NEW); Big Sandy (BIG SANDY); Holston (HOLSTON); Clinch (CLINCH); POwell (POWEIL)]

Popes Head Creek at Rt 654

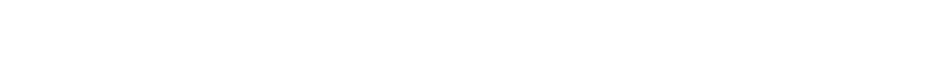

100

Popham Run at Rt $643 \mathrm{nr}$ Etlan .............................

Popham Run at Rt 645 at Etlan........... (RAPP)

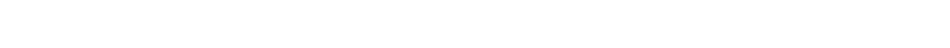

Poplar Branch at mouth nr Riner............... (NEW)

Poplar Branch at mouth nr Sago......... (ROANOKE)

Poplar Camp Creek at mouth nr Union Hall.

ROANOKE

Poplar Camp Creok at mouth nr Charity.. (ROANOKE)

Poplar Creek above mouth nr Ebony...... (ROANOKE)

Poplar Creek at N\&W RR nr Harman Junction............ (BIG SANDY)

Poplar Creek at Rt 626 nr Joyceviile... (ROANOKE)

Poplar Creek at mouth nr South Boston. (ROANOKE)

Poplar Run at Rt 633 nr Madison Mil1s..... (RAPP)

Poplar Run at mouth nr Madison Milis...... (RAPP)

Poplar Spring Branch at mouth nr Signpine. (YORK)

Poplar Swamp at mouth nr Drewryville.... (CHOWAN)

Poquoson River at Calthrop Neck nr Poquoson............... (YORK-JAMES

Poquoson River at U.S. Hwy 17

ar Poquoson ................ (YORK-JAMES)

Poquoson River at buoy 11 nr Poquoson................ (YORK-JAMES)

Poquoson River at buoy 13

nr Poquos on ........ (YORK-JAMES)

Poquoson River at mouth nr buoy 8
nr Poquoson................ (YORK-JAMES) nr Poquoson.................

at Poquoson..................... (YORK-JAME)

Poropotank River at mouth nr Gressitt.....(YORK) 199

Poropotank River trib at mouth nr Shacklefords.........

Portarfield Run at mouth nr Crimora....... (SHEN)

Porterfield Run nr Waynesboro............ (SHEN)

Portobago Creek at mouth nr Port Royai.... (RAPP)

Portobago Run at mouth nr Port Royal...... (RAPP)

Portsmouth Ditch at Martin Johnson Rd

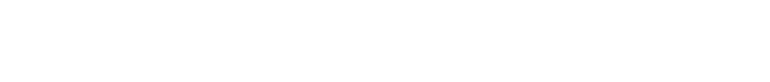
nr Deep Creek.

(JAMES )

mouth Ditch below Fivemile Ditch nr Deep Creek.

(JAMES )

(JAMES)

Possum Branch at mouth nr Lebanon......... (CLINCA)

Possum Creak at mouth nr Weber City.... (HOLSTON)

Possum Creek nr Yuma................. (HOLSTON)

Possum Hollow trib at Rt is nr Thompson Valley............(CLIMCH)

Possum Jaw Creak at Rt 42 ni Chatham Hill.

Possum Jaw Creek at mouth nr Chatham Hil1................ (HOLSTON)

Possum Run above Parsons Milipond Dam at Roxbury . . . . . . . . . . . . . (JAMES)

Possum Run at Rt 609 at Roxbury......... (JAMES)

Post Office Spring at Natural Bridge .... (JAMES)

Poston Branch at mouth nr Hayters Gap.. (HOLSTON)

Potato Run at Rt 647 nr Stevensburg....... (RAPP)

Potato Run at Rt 661 nr StevensburB....... (RAPP)

Potato Run at mouth nr Stevensburg........ (RAPP)

Potato Run below Rt $661 \mathrm{nr}$ Stevensburg.... (RAPP)

Potato Run nr Stevensburg ............... (RAPP)

Potato Run trib at mouth nr Stevensburg... (RAPP)

Potcamp Branch at mouth nr Pound..... (BIG SANDY)

Potcamp Fork at Rt 603 at Dunbar........ (POWELL)

Potcamp Fork at mouth at Dunbar......... (POWELL)

Potomac Creek at Rt $608 \mathrm{nr}$ Falmouth.... (POTOMAC)

Potomac Creek at U.S. Hwy I nr Brooke.. (POTOMAC)

Potomac Creek at buoy 5

$$
\text { nr Passapatanzy................ (POTOMAC) }
$$

at mouth nr Belle Plains (POTOMAC)

Potomac Creek off Old Landing Point nr Passapatanzy

(POTOMAC)

Potomac River above Little Falls Dan nr Washington, D.C......... (POTOMAC)
101

21

121
122

447

375

371

398

423

410

135

135
199

334

202

202

202

202

202

198

41

41

149
149

308

308

308

533

524

524

530

512

512

296

296

223
517

139

139

139

139

139

139
482

554

554

109

109

109

109

109

78
Potomac River above VEPCO discharge nr Quantico . $\cdots$.

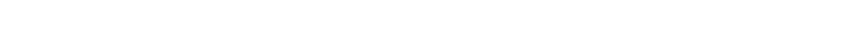

Potomac River at Chain Bridge at Washington, D.C........... (POTOMAC)

Potomac River at Coast Guard dock

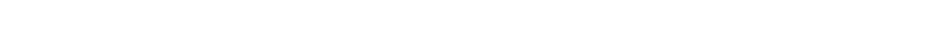

Potomac River at Lewisetta............. (POTOMAC) 113

Potomac River at Marine Corps pier at Quantico.................(POTOMAC) 107

Potomac River at Rosier Bluef nI Oxon Hill, Md ............ (РОTOMAC)

Potomac River at U.S. Hiwy 15 at Point of Rocks. Md.......... (POTOMAC)

Potomac River at U.S. Bwry 340 nI Loudoun Heights. ............ (POTOMAC)

Potomac River at Van Dorn Wilson Bridge at Alexandria........... (POTOMAC)

Potomac River at buoy 43 nr Quantico... (POTOMAC) 107

Potomac River at buoy 75 at Sheridan Point nr Mount Vernon... (POTOMAC) 85

Potomac River below VEPCO discharge nr Quantico.................. (POTOMAC) 103

Potomac River below White Point at Colonial Beach.............. (POTOMAC) 110

Potomac River nr Quantico............... (POTOMAC) 108

Potomac River trib No. 1 above mouth $\mathrm{nr}$ Lucketts.......... (POTOMAC)

Potomac River trib No. 2 above mouth nr Sterling................ (POTOMAC)

Potomac River, S.F. South Branch, above Va. $-W$. Va. State line at Palo Alto................. (POT-SHEN)

Potomac River, South Branch. above Va. $-W$. Va. State line nr Blue Grass.................. (POT-SBEN)

Potomac Run at mouth nr Hartwood........ (POTOMAC) Potter Creek at mouth nr Sandy Levei... (ROANOKE)

Potts Creek at Rt 18 at Covington........ (JAMES)

Potts Creek at Rt 18 at Jordan Mines..... (JAMES)

Potts Creek at Rt $18 \mathrm{nr}$ Covington........ (JAMES)

Potts Creek at Rt 311 at Paint Bank....... (JAMES)

Potts Creek at mouth at Covington........ (JAMES)

Pouches Swamp at Rt $623 \mathrm{nr}$ Raynor....... (CHOWAN)

Pouches Swamp at mouth nr Raymor........ (CHOWAN)

Pound Branch at mouth nr McClure..... (BIG SANDY)

Pound Fork above Straight Fork

Pound River above Cranes Nest River

(POWBLL) nr Blowing Rock............. (BIG SANDY)

Pound River above Indian Creek at Pound .................. (BIG SANDY)

Pound River at Flannagan $\dot{D}$ am nr Haysi.................... (BIG SANDY)

Pound River at Rt 624 nr Georges Fork............. (BIG SANDY)

Pound River at Rt 83 at Pound......... (BIG SANDY)

Pound River at mouth nr Bartlick...... (BIG SANDY)

Pound River below Bearpen Creek nr Pound................. (BIG SANDY)

Pound River below Boid Camp Creek

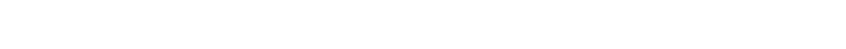

Pound River nr Haysi............... (BIG SANDY)

Pound River, N.F. . Lake at Pound..... (BIG SANDY)

Pound River, N.F., above Bad Creek nr Flat Gap................ (BIG SANDY)

Pound River, N.F., above Phiilips Creek nr Flat Gap................ (BIG SANDY)

Pound River, N.F., alons Rt $67 j$ at Gilley.................... (BIG SANDY)

Pound River, N.F. at Rt $67 i$ nr Flat Gap................. (BIG SANDY) Pound River, N.F., at dam at Pound... (BIG SANDY) Pound River, N.F., at mouth at Pound. (BIG SANDY)

Pound River, N.F., below Bad Creek nr Flat Gap.............. (BIG SANDY)
103

79

78

1

85 
Abbreviated basin names appear at the end of the site name. Abbreviations are as follows:

Eastern Shore (EASTERN); Potomac to Shenandoah (POT-SEEN); Shenandoah (SHEN); Potomac (POTOMAC);

Potomac to Rappahannock (POT-RAPP); Rappahannock (RAPP); Rappahannock to York (RAPP-YORK); York (YORK)

York to James (YORK-JAMES); James (JAMES): James to Chowan (JAMES-CHOWAN); Chowan (CHOWAN); Roanoke (ROANOKE)

Yadkin (YADKIN); New (NEW); Big Sandy (BIG SANDY); Holston (HOLSTON); Clinch (CLINCH); POweli (POWELL)]

Page

Pound River, N. F., below Phillips Creak

nI Flat Gap................... (BIG SANDY)

481

Pound River, N.E., below dam at Pound...................... BIG SANDY)

Pound River, S.F., at Rt 679

nI Dewey................. (BIG SANDY)

Pound River, S.F., at Rt 700 at Pound.................. (BIG SANDY)

Pound River, S.F., at mouth at Pound. (BIG SANDY)

Pounding Mill Branch \& tributaries above Va. - Ky. State line nr Hurley... (BIG SANDY)

Pounding Mili Branch at mouth at Pounding Mi11......(CLINCH)

Pounding Mill Creek at U.S. Hwy 60 at Covington................. (JAMES)

Pounding Mill Creok at mouth at Hurley................. (BIG SANDY)

Pounding Mili Creek at mouth nr Covington................. (JAMES) 212

Pounding Mil1 Creek nr Covington........... (JAMES) 212

Poverty Creek at mouth nr McCoy............ (NEW) 449

Powder Mill Branch at mouth at Ivanhoo..... (NEW) 433

Powder MiII Creok at U.S. Hwy 220 at Rocky Mount................ (ROANOKE) 373

Powder Mill Creek at mouth nr Redwood. (ROANOKE) 373

Powell Branch at mouth nr Chancellorsville................ (RAPP) 143

Powell Creek at Rt 10 at Garysvi ii ........ (JAMES) 289

Powell Creek at mouth nr Alberta........ (CHOWAN) 353

Powell Creek at mouth ar Westover........ (JAMES) 289

Powell River above pigeon Creek at Appalachia................ (POWELL) 555

Powell River above Rt 64 at Blackwood... (POWELL) 553

Powell River above Rt 833 at Fletchers Ford nr Rose Hi11... (POWELL) 562

Powell River along U.S. Hwys $23 / 58$

(Alternate) nr Norton.......... (POWELL) 553

Powel1 River at Blackwood............... (POWELL) 553

Powell River at Cadet at Big Stone Gap. (POWELL) 557

Powell River at Flanary Bridge nr Jonesvilie.

Powell River at Fletcher Ford nr Rose Hill................. (POWELL) 562

Powell River at Rt $60 \dot{5}$ nr Big Stone Gap.

(POWELL)

Powell River at Rt 64 at Blackwood....... (POWELL)
Powell River at Rt 70 nr Jonesville.... (POWELL)

Powell River at $\mathrm{Rt} 70 \mathrm{nr}$ Jonesville..... (POWELL)
Rowell River at Rt $790 \mathrm{nr}$ Norton...... (POWELL)

Powe11 River at Rt 819 at Norton........ (POWELL)

Powell River at Rt $833 \mathrm{nr}$ Smiley........ (POWELL)

Powell River at Short st at Big Stone Gap...

Powell River at U.S. Hwy 23 at Big Stone Gap.............. (POWELL) 556

Powell River at U.S. Hwy 421 nr Pennington Gap. (POWELL)

Poweli River at U.S Hwy 58 (Aiternate) at Dryden.................. (POWELL) 557

Powel1 River at U.S. Hwy 58 nr Woodway. (POWELL) 560

Powell River at $\mathrm{Va} .-\mathrm{Tenn}$. State Iine nr Rose Hill.................. (POWELL) 562

Roweli River below Benges Branch nI Norton................... (POWELL) 553

Powell River below S.F. Poweil River at Big Stone Gap............... (POWELL) 557

Powell River nr Appalachia............ (POWELL) 554

Powell River nr Big Stone Gap............. (POWELL) 555

Powell River, N.F., above Straight Creek at Pocket.......... (POWELL) 558

Powell River, N.F., above Bobs Branch at Pocket.................. (POWELL) 558

Rowell River, N.F., above STR at Pennington Gap..... at Pennington Gap............. (POWELL) 559

Poweli River, N.F., at Rt 630 below Dry Branch at Pennington Gap...... (POWELL)
Powell River, N.F., at Southern RR at Bundy ....................... at Penningtion Gap.............. (POWELL) 560

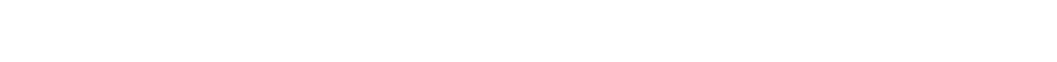

Powell River, N.F., trib at mouth at Pennington Gap............... (POWELL) 560

Powell River, S.F., at Beamantown at Bis Stone Gap................ (POWELL) 556

Powell River, S.F., at Rt 613 at East Stone Gap............. (POWELL) 556

Powell River, S.F., at U.S. Hwy 23 at Big Stone Gap............... (POWELL) 556

Powell River, S.F., at mouth at Big Stone Gap.............. (POWELL) 557

Powe11s Creek (Story Creok) at mouth nr Turbevilie................ (ROANOKE) 408

Powells Creok at Rt $643 \mathrm{nr}$ Dale City... (POTOMAC) 103

Powells Creek at Rt $684 \mathrm{nr}$ Crozet......... (JAMES) 247

Powells Creek at U.S. Hwy 1 nr Dumfries.......................

Powelis Creek at U.S. Hwy 58 nr Turbeville................. (ROANOKE) 408

Powells Creek at mouth ir Dumfries...... (POTOMAC) 103

Powers Branch at mouth nr Fairview....... (CLINCH) 550

Powhatan Croek at Rt 31 nr Jamestown..... (JAMES) 301

Powhatan Croek at Rt 5 at Five Forks..... (JAMES) 301

Powhatan Creek at mouth nr Surry.......... (JAMES) 301

Powhite Creek at Forest Hill Ave at Richmond................ (JAMES) 265

Powhite Creak at Rt 678 nr Bon Air......... (JAMES) 265

Powhite Creek at Rt 686 at Bon Air........ (JAMES) 265

Powhite Creek at mouth at Richwond........ (JAMES) 265

Powhite Creek at mouth nr Richmond....... (JAMES) 295

Prater Creek at mouth $\mathrm{nr}$ Hardy........... (ROANOKE) 367

Preacher Croek at mouth at Andover........ (POWELL) 554

Preddy Creek at mouth at Watts........... (JAMES) 253

Prentice Creek at mouth nr Ditchley...(POT-RAPP) 115

Presley Creek at mouth nr Bundick...... (POTOMAC) 113 Preston Branch at mouth at Martinsville. (ROANOKE)

Price Creek at mouth nr Hayters Gap.... (HOLSTON)

Prices Spring No. $1 \mathrm{nr}$ Luray.............. (SHEN)

Prices Spring No. 2 nr Luray............... (SHEN)

Prices Spring nr Luray .................. (SHEN)

Priest Fork above Sportsman Lake nr Murphy................. (BIG SANDY)

Priest Fork at Spruce Pine Gap nr Duty................... (BIG SANDY)

Priest Fork at mouth in Coliey........ (BIG SANDY)

Priest Fork trib No. 1 at mouth

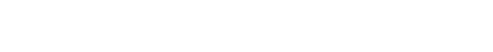

Priest Fork trib No. 2 at mouth nr Murphy................. (BIG SANDY)

BIG SANDY nr Murphy ...............

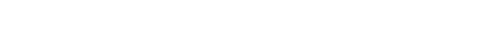

Priest Fork trib No. 4 at mouth nr Colley................ (BIG SANDY)

Proctors Creok at Centraila (Hopkins) Rd nr Centralia..................... (JAMES)

Proctors Creek at Saiem Church Rd ar Centralia

Proctors Creek at U.S. Hwy i nir Chester. (JAMES) proctors Creek at mouth nr Centraila.... (JAMES)

Proctors Creek bolow I-95 nr Centralia... (JAMES) Proctors Creek trib at mouth nr Centralia.

(JAMES)

Prospect Hill Springs at Boyce........... (SAEN)

Puckett Creak at Rt 352 at Maness........ (POWELL)

Pucketts Branch at mouth nr Barnett..... (CLINCB)

Pucketts Branch at mouth nr Church Road.. (JAMES) Pucketts Branch trib No. 1 at Rt 708

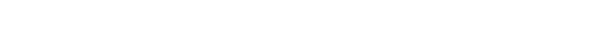

Pucketts Branch trib No. 2 at Rt 708 nr Church Road................ (JAMES)

Pudding Creek at mouth nr Chatham....... (ROANOKE)

Pughs Run at Rt $623 \mathrm{nr}$ Woodstock......... (SHEN) 
Abbreviated besin names appear at the end of the site name. Abbreviations are as follows:

Eastern Shore (EASTERN); Potomac to Shenandoah (POT-SHEN); Shenandoah (SHEN); POtOmac (POTOMAC);

Potomac to Rappahannock (POT-RAPP); Rappahannock (RAPP); Rappahannock to York (RAPP-YORK); York (YORK);

York to James (YORK-JAMES); James (JAMES); James to Chowan (JAMES-CHOWAN); Chowan (CHOWAN); Roanoke (ROANOKE);

Yadkin (YADKIN); New (NEW); Big Sandy (BIG SANDY); Holston (HOLSTON); Clinch (CLINCH); POwell (POWELL)]

Pughs Run at mouth nr Woodstock......... (SHEN)

Pughs Run trib at Rt 623 nr Columbta Furnace.

Pumpkin Croek at Rt 86 at Danvilio.

Pumpkin Creek at mouth at Cascade........ (ROANOKE) 404

Pumpkin Creek at mouth at Danville..... (ROANOKE) 407

Punch and Judy Creek at mouth nr Asberrys.................(GOLSTON) 513

Puncheon Camp Branch at mouth

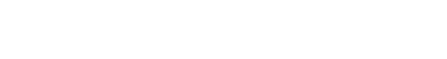

Puncheon Camp Creek at mouth nr Kelsa ..................

Puncheoncamp Branch at mouth
nr Mack Creek Village.

Pungoteague Creek at Rt 178

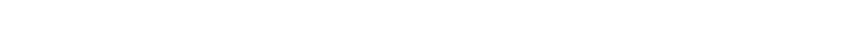

Pungoteague Creek at mouth

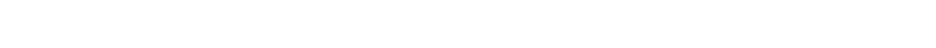

Puppy Creek at Sandidges ................ (JAMES) 238

Puppy Creek at mouth nr Charity.......... (ROANOKE) 398

Purgatory Creek above Karnes Spring

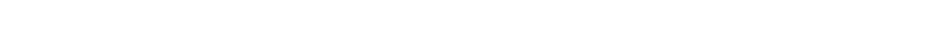

Purgatory Creek at Rt 611 nr Buchanan.... (JAMES) 222

Purgatory Creek at U.S. Hwy 11 nr Buchanan. ......

Purgatory Creek at mouth nr Crockett Spring (ROANOKE) 358

Purgatory Creek at mouth at Buchanan.....(JAMES) 222

Purgatory Creek below Karnes Spring

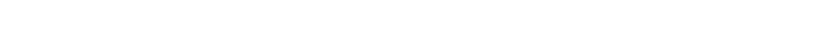

Purtan Creek at mouth nr Pinetta.......... (YORK)

Put In Creek above mouth nr Mathews.. (RAPP-YORK)

Put In Creek at Cooks Pier below Mathews. (RAPP-YORK)

Put In Creek at mouth at Mobjack..... (RAPP-YORK)

Quail Run at Rt 602 nr Elkton........... (SHEN)

Quail Run at Rt $646 \mathrm{nr}$ McGaheysvili....... (SHEN)

Quail Run at mouth nr Elkton............. (SHEN)

Quaker Run at mouth nr Criglersvilie...... (RAPP)

Quaker Swamp at Rt $610 \mathrm{nr}$ Buckhorn...... (CHOWAN)

Quaker Swamp at Rt $664 \mathrm{nr}$ Holland......... (CHOWAN)

Quaker Swamp at U.S. HWy 58 nr Lumis... (CHOWAN)

Quaker Swamp trib No, 1 nr Lumis ....... (CHOWAN)

Quaker Swamp trib No. 2 at Rt 647

Quaker Swamp trib No. 2 at Rt $64 \dot{9}$

Quaker Swang trtb No. 2 at Rt 649 trib No. 2 nr Lummis 2 at $64 \dot{9}$ trib No. 3 nr Lumis ......

Quantico Creek above pyrite mine nr Dunfries.......... . . . Fi nx Independent Hill ..... Quantico Creek at Burma Fire Rd
nr Independent Hi $11 \ldots . . . . . . . .$. (POTOMAC)

Quantico Creek along Farms Trail

Quantico Creek at Camp 4 nr Dumfries... (POTOMAC)

Quantico Creek at Rt 627 at Dumfries... (POTOMAC)

Quantico Creek at U.S. Hwy 1 at Dumfries................... (POTOMAC)

Quantico Creek at mouth at Quantico.... (POTOMAC)

Quantico Creek at pyrite mine roed nr Dumfries................... (POTOMAC) (POTOMAC) 104

Quantico Creek trib No. I at private rd nr Dumfries.......(POTOMAC) 106

Quantico Creek trib No. 1 at Rt 629 at Dumfries.................(POTOMAC) 106

Quantico Creek trib No. 2 at Camp 1 nr Dumfries....................

Quantico Creek trib No. 3 along Farms Trail nr Independence Hill. (POTOMAC) 103

Quantico Creek, S.F., above mouth nr Dumfries................ (РОTOMAC)
Quantico Creek, S.F., above trıb No. 1 nr Joplin . $\ldots \ldots$ at Camp nr Triangle.............. (POTOMAC) 106 Quantico Creek, S.F., at Mawavi Rंd nr Joplin................... (POTOMAC) 104

Quantico Creek, S.F., at Orenda Fire Rd nr Dunfries....................(POTOMAC) 106 Quantico Creek, S.F., at Perk $\ddot{R} \dot{d}$ nr Joplin.................(POTOMAC) 105

Quantico Creek, S.F., at Rt 619 nr Independent H $11 \ldots \ldots \ldots \ldots \ldots$ (POTOMAC) 104

Quantico Creek, S.F., at mouth nr Dumfries...................(POTOMAC) 106

Quantico Creak, S.F., below Camp No. 5 Lake nr Joplin................ (POTOMAC) 105

Quant tco Creek, S.F., below trib No. i nr Joplin....................(POTOMAC) 105

Quantico Creek, S.F., trib No. i at High Meadows Trail nr Joplin..((POTOMAC) 105

Quant \pm co Creek, S.F., trib No. 1 at mouth nr Jóplin............ (FOTOMAC)

Quantico Creek, S.F., trtb No. 2 at mouth or Joplin............ (POTOMAC)

Quantico Creek, S.F., trib No. 3 at mouth nr Jóplin............ (POTOMAC)

Quantico Creek, S.F., trib No. 4 at mouth nr Joplin............ (POTOMAC)

Quentico Creak, S.F., trib No. 5 at Orenda Fire'Rd nr Dumfries....(POTOMAC) 106

Quentico Creek, S.F. trib No. 6 at mouth nr Dunfries..........(POTOMAC)

Quantico Creek, S.F., trib No. 7 nr Dumfries..................... (POTOMAC)

Quantico Creek, S.F. trib No. 7 tributary at Dak Ridge campground nr Independent Hill.......... (POTOMAC) Quantico Creek, S.F., trib No. 8 at Camp No. 2 nx Joplin..........(POTOMAC) 104 Quarrel Creek at mouth nr Ante............(CHOWAN) 355 Quarter Branch at mouth nr Lovettsville............... (POTOMAC)

Quarter Branch at mouth at Sugar Grove. (HOLSTON) Querter Cove at mouth $\mathrm{n} x \mathrm{Ki}$ lmarnock....... (RAPP) Quarter Creek at mouth nr Quinque........ (JAMES) Queen Creek at mouth nr Williamsburs....... (YORK) Queens Creek at Rt 626 nr Blakes..... (RAPP-YORK) Queens Creek at mouth nr Charles City.... (JAMES) Queens Creek at mouth nr Hudgins..... (RAPP-YORK) Quicks Spring nr Verona................. (SHEN) Quillin Spring nr Gate City............. (CLINCH) Quioccasin Creek at mouth nr Tappahannock. (RAPP)

104 67 492 158 253 199 162 291 162
35 549 150

R. G. Graham Spring nr Elliston........ (ROANOKE) 359 Rabbit Branch at Guinea Rd nr Burke..... (POTOMAC) 89 Rabbtt Branch at mouth $\mathrm{nr}$ Burke........(POTOMAC) 89 Rabbit Branch below Braddock Rd nr Fairfax................. (POTOMAC)

Rabbit Branch trib at Schooi $\ddot{D r}$ nr Fairfax. (POTOMAC)

Rabbit Branch, East Fork, at Braddock Rd at Fairfax......... (POTOMAC) Rabbit Branch, West Fork, at Braddock Rd at Fatrfax..... (POTOMAC) Raccoon Branch at mouth nr Sugar Grove. (HOLSTOH) Raccoon Creek at Rt $608 \mathrm{nr}$ Sebrel1...... (CHOWAN) Raccoon Creek at U.S. Hwy $15 \mathrm{nr}$ Paimyra. (JAMES) Raccoon Creek at mouth nr Sebrell........(CHOWAN) Raccoon Creek trib at Rt $608 \mathrm{nr}$ Sebrell. (CHOWAN) Race Branch at mouth nr Randolph....... (ROANOKE) Race Fork at Rt 643 nr Kelsa........ (BIG SANDY) Racer Run at Rt $623 \mathrm{nr}$ Weshington......... (RAPP) Ragged Run along Rt 645 ni Etlan.......... (RAPP)

Ragsed Run at Rt 645 nr Etlan............ (RAPP)

Ras8ed Run at mouth nr Etlan.............. RAPP)

05

4

106

5

4

5

5


Abbreviated basin names appear at the end of the site name. Abbreviations are as follows:

Eastern Shore (EASTERN); Potomec to Shenandoah (POT-SHEN); Shenandoah (SHEN); Potomac (POTOMAC);

Potomac to Rappahannock (POT-RAPP); Rappahannock (RAPP); Rappahannock to York (RAPP-YORK); York (YORK);

York to James (YORK-JAMES); James (JAMES); James to Chowan (JAMES-CHOWAN); Chowan (CHOWAN); ROanoke (ROANOKE);

Yadkin (YADKIN); Now (NEW); Big Sandy (BIG SANDY); Holston (HOLSTON); Clinch (CLINCH); POwell (POWELL)]

Page

Rainey Creek at mouth nr Rawlings.......(CHOWAN) 325

Ramey Branch at mouth nr Coeburn..........(CLINCH) 543

Ramp Cove Branch at mouth nr Elk Garden. (CLINCH) 533

Ramsey Branch at mouth at Roetown...... (HOLSTON) 498

Ramseys Draft at Rt $716 \mathrm{nr}$ West Augusta.. (JAMES) 223

Ramseys Draft at mouth nr Deerfield...... (JAMES) 223

Randolph Creek at Rt $717 \mathrm{nr}$ Arvonia....... (JAMES) 258

Randolph Creek at mouth nr Lakeside Village.................. (JAMES)

Rangeley Creek at mouth at Fieidale.... (ROANOKE) 401
Rans Creek at mouth nr Indian Valley.......(NEW) 439

Rapidan River above Orange City water works intakes $\mathrm{nr}$ Orange........ (RAPP)

Rapidan River above U.S. Hiwy 522 nr Culpeper................(RAPP)

Rapidan River alons $\mathrm{Rt} 662$ at Graves Mili. (RAPP)

Rapidan River at Forest Trail nI Graves Mill............... (RAPP)

Rapidan River at Raccoon Ford nr Culpeper. (RAPP)

Rapıdan River at Rt $230 \mathrm{nr}$ Stanardsville.. (RAPP)

Rapidan River at Rt 231 nr Orange........ (RAPP)

Rapidan River at Rt 3 at Germanna Bridge... (RAPP)

Rapidan River at Rt $610 \mathrm{nr}$ Richardsvilie.. (RAPP)

Rapidan River at Rt 615 at Rapidan........ (RAPP)

Rapidan River at Rt 634 nr Orange......... (RAPP)

Rapidan River at Rt $662 \mathrm{nr}$ Criglersviile..(RAPP) 132

Rapidan River at School Rd nr Orange...... (RAPP) 135

Rapidan River at U.S. Hwy 15 at Madison Mills .....

Rapidan River at U.S. Hwy 29 nr Ruckersvilie..................................... 134

Rapidan River at U.S. Hwy $522 \mathrm{nr}$ Culpeper. (RAPP) 138

Rapidan River at mouth nr Chancellorsville...............RAPP) 143

Rapidan River below Rt 615 at Rapidan..... (RAPP) 138

Rapidan River below U.S. Hwy 29 nr Ruckersville................ (RAPP) 134

Rapidan River trib No. 1 at mouth nr Culpeper.................... (RAPP) 138

Rapidan River trib No. 2 at mouth nr Culpeper.................. (RAPP) 141

Rapidan River trib No. 3 at mouth nr Flat Run................... (RAPP) 142

Rapidan River trib No. 4 at mouth nr Chancellorsville...............RAPP) 143

Rapidan River trib No. 5 at mouth nr Chancellorsville............(RAPP) 143

Rappahannock River at buoy 37 or Tappehannock.

Rappahannock River (VEPCo Canei) at U.S. Hory 1 at Fredericksburg........(RAPP) 145

Rappahannock River above Carter Run nr Jeffersonton................ (RAPP) 118

Rappahannock River above $I-95$ nr Fredericksburg ............... (RAPP) 144

Rappahannock River above Motts Run nr Fredericksburg................ (RAPP) 144

Rappahannock River at Beveriy Marsh nI Champlain..

Rappahannock River at Rt 3 at Frederickshurg...............(RAPP) 145

Rappahannock River at Rt $3 \mathrm{nr}$ Irvington... (RAPP) 159

Rappahannock River at Rt 620 at

Kellys Ford nr Remington..........(RAPP) 127

Rappahannock River at Rt 635 nr Flint Hill................ (RAPP) 117

Rappahannock River at Ri $64 \dot{5}$

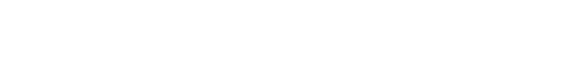

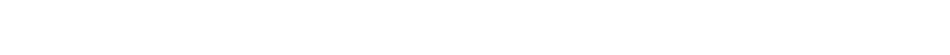

Rappahannock River at kt $6 \dot{6} \dot{\mathrm{n}} \mathrm{i}$ Remington. (RAPP) 127

Rappahannock River at Rt 802 at Fauquier White Sulphur Springs nr Turnbull...(RAPP) 119

Rappahannock River at U.S. Ewy 1 at Fredericksburg...............RAPP) 145

Rappahannock River at U.S. Hwy 211 nr Warrenton.................... (RAPP)
Rappahannock River at U.S. Hwy 29

(Alternate) at Remington. .

Rappahannock River at U.S. Hwy 29 at Remington............ Hiw

Rappahannock River at U.S. Hwy 301 at Port Royal. ' U.S. Hiwy 360 nr Tappahannock . . . at Fredericksburg.

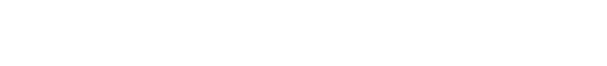
nr Fredericksburg.......

Rappahannock River at buoy 10 nr Fredericksburg.... $\ddot{i}$ nr Morattico......... nr Fredericksburg........

Rappahannock River at buoy 118 nr Fredericksburg......

Rappahannock River at buoy 120 nr Fredericksburg.... $i 2 i$ nr Fredericksburg......

Rappahannock River at buoy 13 nr Morattico........ nr Tappahannock..........

ahannock River at buoy 30

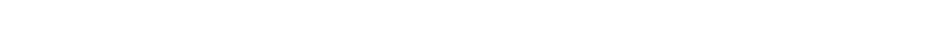

Rappahannock River at buoy 6 nr Irvington. (RAPP) 159 Rappahannock River at buoy 69 nr Port Royal

Rappahannock River at buoy 79 nr Port Royal.................... (RAPP) 148

Rappahannock River at buoy 8 nr Urbanna... (RAPP) 158

Rappahannock River at buoy 89 nr Port Royal................... (RAPP) 147

Rappahannock River at mouth nr Deitavilie. (RAPP) 159 Rappahannock River below Deep Run at Fredericksburg..................(RAPP) 145

Rappahannock River below Massaponax STP nr Fredericksburg...............(RAPP) 146

Rappahannock River below STP at Fredericksburg.....

Rappahannock River trib No, 1 at mouth $\mathrm{nr}$ Sumerduck.

Rappahannock River trib No. 2 at mouth nr Sumerduck. at mouth $\mathrm{nr}$ Hartwood. .

Rappahannock River trib No. 4 at mouth $\mathrm{nr}$ Fredericksburg..........(RAPP) 144

Rappahannock River trib No. 5 at mouth nr Fredericksburg.........(RAPP) 145

Rappahannock River trib No. 6 at Camco nr Tappahannock ............(RAPP) 152

Rappahannock Rtver trib No. 8 at Camico nr Tappahannock...........(RAPP) 152

Rappahannock River trib No. 6 at moüh nr Morattico........ nr Center Cross

Rat Creek at mouth at Dewey............ (BIG SANDY) 481

Ratcliff Fork at Rt $657 \mathrm{nr}$ Devenport. (BIG SANDY) 468

Rattle Creek at mouth nr Pine Grove.... (HOLSTON) 519

Ratt lesnake Creak at Richmond............ (JAMES) 264

Ratt lesnake Creek at Rt 46 nr Ankun....... (CHOWAN) 355

Rattlesnake Creek at mouth nr Barley.... (CBOWAN) 355

Ratt lesnake Creak at mouth nr Mike..... (ROANOKE) 385

Rattlesnake Swamp at Rt 625 at Raynor... (CHOWAN) 342

Rattlesnake Swamp at mouth nr Zuni.......(CHONAN) 342

Rattrap Creok at mouth at Locustville.. (EASTERN) 12

Raw Pump Spring nr McGaheysville.........(SEEN) 44

Readers Branch at mouth nr Hylas.......... (JAMES) 263

Reardon Spring nr Boyce.............(PÖ-SHEN) 22

Red Creek at mouth nr Saltville....... (HOLSTON) 516

Red Hill Branch at mouth at Gate City...(BOLSTON) 522 
Abbreviated basin names appear at the end of the site name. Abbreviations are as follows:

Eastern Shore (EASTERN); Potomac to Shenandoah (POT-SEEN); Shenandoah (SHEN); Potomac (POTOMAC);

Potomac to Rappahannock (POT-RAPP); Rappahannock (RAPP); Rappahannock to York (RAPP-YORK); Yorix (YORK)

York to James (YORK-JAMES); James (JAMES); James to Chowan (JAMES-CHOWAN); ChOWan (CHOWAN); ROanoke (ROANOKE);

Yadkin (YADKIN); New (NEW); Big Sandy (BIG SANDY); Holston (HOLSTON); Clinch (CLINCH); Powell (POWELL)]

Page

Red Oak Creek at mouth nr Rawlings..... (CHOWAN) 324 Redbud Creek at mouth nr Charlottesville (JAMES) 253

Redbud Run above Rt 660 ne Winchester. (POT-SHEN) 24

Redbud Run at Rt 656 nr Winchester.... (POT-SHEN) 24

Redbud Run at Rt 659 nr Winchester.... (POT-SHEN) 24

Redbud Run at U.S. Hwy 11 nr Winchester..

(POT-SHEN) Redbud Run at mouth ni Winchester...... (POT-SHEN) Reddies Creek at mouth at Sandy Level.. (ROANOKE) Reddy Creek at Rt 679 nt Spring Mills.. (ROANOKE) Redeye Creek at mouth nr Othma.

Redman Branch at mouth ni Galax.

(JAMES) 260

Reds Creek at mouth or Ridgeway............... (NEW)

Redstone Branch at mouth nr Thomas Bridge................ (HOLSTON)

Redwater Creek at mouth nr Centralia.....(JAMES) 269

Reed Creek $0.2 \mathrm{mi}$ below Rt 649 at Wytheville......

Reed Creek 0.7 mi below Rt 649

at Wytheville....... at Wytheville.

Reed Creek at B18 Isiand.

Reed Creek at Rt 21 at Grahams Forge.

Reed Creek at Rt 609 nr Collinsville.

Reed Creet at Rt 619 at Grahams Forge.

Reed Creek at Rt 637 ne Big Island....... (JAMES)

Reed Creek at Rt 640 at Wytheville.

(NEW) 436

Reed Creek at Rt 649 below Muskrat Branch nr Wythevilie...........................

Reed Creek at Rt 649 below Stones Mill

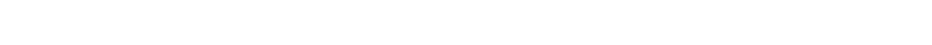

Reed Creek at Rt 667 ne Wytheville........(NEW) 436

Reed Creek at U.S. Hwy 11 at Petunia nr Wythevilie.

435

Reed Creek at U $S$ Hory 21 at hytheville....

Reed Creek at mouth at Altavista.......(ROANOKE) 379

Reed Creek at mouth at Fieldale..........(ROANOKE) 401

Reed Creek at mouth nr Barren Springs....... (NEW) 438

Reed Creek trib above Merchants Mall STP ne Max Meadows................... (NEW) 437

Reed Creek trib nr Max Meadows...................W 437

Reed Creek, S.F., (Middle Fork

Reed (reek) at mouth nr Wytheville...(NEW) 436

Reed Creek, S.F., above Neff-litz SprinB nr Cedar Springs.

Reed Creek, S.F. at Rt 625 nr Crockett.... (NEW)

Reed Creek, S $F$. at Rt 663 nr Crockett....(NEW)

Reed Creek, S.F., at Rt 667 nr Crockett..... (NEW) 436

Reed Creak, S.F., at Rt 699 nr Crockett..... (NEW) 436

Reed Creek, S.F. at Rt 749

at Cadar Springs...................... (NEW) 435

Reed Creak, S.F., below N\&W RR nr Crockett. (NEW) 436

Reed Creek, S.F., trib at Rt 90 nr Rural Retreat.

Reed Creek, S.F., trib at STP nr Rural Retreat..........

Reed Creek, S.F., trib at mouth

Reeds Creek at mouth in Fioyd.

Reeds Creek at mouth nr Robbins Chapel. (POWELL)

Reedy Branch at mouth nr Barham......... (CHOWAN)

Reedy Branch at mouth nr Baskervilie... (ROANOKE)

Reedy Branch at mouth nr Beach........... (JAMES)

Reedy Branch at mouth nr Forksvilie..... (CHOWAN)

Reedy Branch at mouth nr Jeffress...... (ROANOKE)

Reedy Branch at mouth nr Purdy.......... (CHOWAN)

Reedy Branch at mouth of

Roundabout Creek nr Drewrys Bluff.. (JAMES) 270

Reedy Branch nr Blackstone............ (CHOWAN)

Reedy Creek at Forest H1II Ave

(U.S. Hwy 6) at Richmond......... (JAMES) 266

Reedy Creek at RIchmond................. JAMES) 266

Reedy Creek at U.S. Hwy 301 nr Dawn........ (YORK) 192

Reedy Creek at mouth

nr Baltimore Corner.............. (CHOWAN) 327

Reedy Creek at mouth at South Boston... (ROANOKE) 410
Reedy Creek at mouth nr Ante.

Page

(CHOWAN) 354

Reedy Creak at mouth nr Ferncliff........(YORK) 177

Reedy Creek at mouth nr Penola............. (YORK) 193

Reedy Creek at mouth nr Rawlings........ (CHOWAN) 324

Reedy Creek at mouth nr Rehoboth........ (CHOWAN) 349

Reedy Creek trib at mouth nr Penola.......(YORK) 192

Reedy Swanp at mouth nr Ladysmith.........(YORK) 192

Reeses Creek at mouth nr Drakes Branch...... (ROANOKE) 391

Renick Run at Frontage Rd nr Buchanan.... (JAMES) 222

Rennet Bag Creek below Otter Creek nI Endi cott.

(ROANOKE) 398

Rennet Bag Creek nr Endicott........... (ROANOKE) 398

Reusens Reservoir nr Lynchburg..........(JAMES) 233

Revistown Branch at mouth nr Poweliton.. (CHOWAN) 354

Reymolds Creek at Rt $615 \mathrm{nr}$ Whiteville... (JAMES) 259

Reymolds Creek at mouth nr Randolph..... (ROANOKE) 392

Reymolds Creek at mouth nr Whitevilie.... (JAMES) 259

Rhe Brothers Spring nr Damascus....... (HOLSTON) 497

Rich Creek Spring nr Lindside............ (NEW) 455

Rich Creek at U.S. Hwy 460 at Rich Creek...(NEW) 455

Rich Creek at mouth at Rich Creek.......... (NEW) 455

Rich Creek at mouth nr Patrick Springs. (ROANOKE) 395

Rich Mountain Creek at mouth

ne Hayters Gap.

(HOLSTON)

Richardson Branch at mouth nr Glade Spring............... (HOLSTON)

Richardson Creek at mouth nr Morattico.... (RAPP)

Richardson Creek trib at mouth nr Morattico.

Richardson Creek, $\mathbb{N} . \dot{F}$, at mouth nr Morattico.

(RAPP)

Richey Branch at mouth nr Duncan Gap. (BIG SANDY)

Richland Run at mouth nr Hartwood........ (RAPP)

Richland Run trib at mouth nr Hartwood.... (RAPP)

Richmond Branch at mouth ne Stanleytown. (CLINCH)

Rickenaw Creek at mouth nr Beulahville.... (YORK)

Riga Run at mouth nr Lake Anna........... (YORK)

Right Fork above Left Fork at Dante.....(CIINCH)

Right Fork along Rt 624

at Mount Heron................ (BIG SANDY)

Right Fork at mouth at Blackey....... (BIG SANDY)

Right Fork at mouth at Mount. Heron... (BIG SANDY)

Right Fork at mouth nr Lynn spring...... (CLINCH)

Right Fork below Straight Fork at Blackey................ (BIG SANDY)

Right Hand Fork at Rt 727 nr Appomat tox.

(ROANOKE)

Right Hand Fork at mouth nt Evergreen. (ROANOKE)

Riles Run at Rt 703 nx Conicville........ (SHEN)

Riles Run at Rt 720 ne Conicville........... (SHEN)

Riles Run at mouth $n r$ Jerome............. (SHEN)

Ripley Creek at mouth nr Mount Vinco..... (JAMES

Rippin Run at mouth nx Ruckersville...... (RAPP)

Rise of Waters Spring nr Liberty......... (CLINCH)

Rita Branch at mouth nr Beach.......... (JAMES)

Rita Branch at mouth nr Chersy Hill..... (CHOWAN)

Rivanna River at Rt 6 nr Columbia........ (JAMES)

Rivanna River at Rt 600 ne Cunningham.... (JAMES)

Rivanna River at Rt 729 nt Shadwell..... (JAMES)

Rivanna River at U.S. Hwy 15 at Palmy ra. (JAMES)

Rivanna River at U.S. Hwy 250 nr Charlottesville.

(JAMES)

Rivanna River at mouth at Columbia........ (JAMES)

Rivanna River below Moores Creek ni Charlottesville......

(JAMES)

Rivanna River'nr Charlottesville...(JAMES) 253

Rivanna River, N.F., at Rt 604

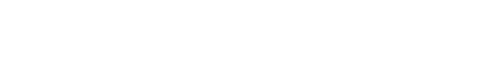
River, $N$

Rivana River, N.F. at U.S. Hwy 29 ne Earlysville...........

Rivanna River, S.F. Reser

(JAMES) River S F above is $F$

Rivanna River nr Charlottesville... (JAMES)
253

517

505

154

85

131
131

546

194

169
537

458

489

458
529

388

388

57
57

58
245

245

134
530

287

328

256
255

254

256

254

256

254

253

251

252 
Abbreviated basin names appear at the end of the site name. Abbreviations are as follows:

Eastern Shore (EASTERN): Potomac to Shenandoah (POT-SHEN); Shenandoah (SEEN); Potomac (POTOMAC);

Potomac to Rappahannock (FOT-RAPP); Rappahannock (RAPP); Rappahannock to York (RAPP-YORK); York (YORK)

York to James (YORK-JAMES); James (JAMES); James to Chowan (JAMES-CBOWAN); Chowan (CHOWAN); Roanoke (ROANOKE);

Yadkin (YADKIN); New (NEW); B Ig Sandy (BIG SANDY); Holston (BOLSTON); CIInch (CLINCH); Powell (POWELL)]

Rivanna River, S.F., at Rt 660 nr Earlysville................ (JAMES) 251

Rivanna River, S.F., at U.S. Hwy 29 nr Char Lottesville................. (JAMES) 251

Rivanna River, S.F., trib above S.F. Rivanna River Reservoir

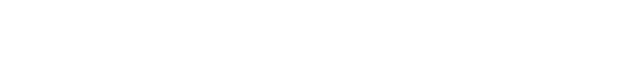

(JAMES) 251

Lake Faith Dam nr Earlysville...... (JAMES) 251

Roach River above Iynch River nr Dyke.... (JAMES) 252

Roach Rtver at Rt $603 \mathrm{nr}$ Nortonsville.... (JAMES) 252

Roach River at Rt $648 \mathrm{nr}$ Dyke........... (JAMES) 252

Road Branch at mouth $\mathrm{nr}$ Tarpon......... (BIG SANDY) 478

Road Creek at mouth nr Longshoal........... (NEW) 439

Roads Croek at mouth nr Laurel Fork.......... (NEW) 438

Roanoke (Staunton) River

at U.S. Bwy $360 \mathrm{nr}$ Clover........ (ROANOKE)

392

Roanoke (Staunton) River above

U.S. Hwy 501 at Brookneal........(ROANOKE) 384

Roanoke (Staunton) River at Rt 608

(Toler Bridgo) nr Brights......... (ROANOKE)

Roanoke (Staunton) River at Rt 620 at Clarkton.................. (ROANOKE) 387

Roanoke (Staunton) River at $\dot{R} t \mathbf{6} 6 \dot{B}$ at Altavista................ (ROANOKE)

Roanoke (Staunton) River at $\mathrm{Rt} 74 \dot{4}$ at Randolph.................. (ROANOKE) 389

Roanoke (Staunton) River at U.S.

Bwy 29 (Altornato) at Altavista. (ROANOKE) 379

Roanoke Creek (Left Roenoke Creek) above Wards Fork Creek nI Saxe... (ROANOKE) 390

Roanoke Creok (Little Roanoke Creek) at Rt 47 below Ash Camp Creak

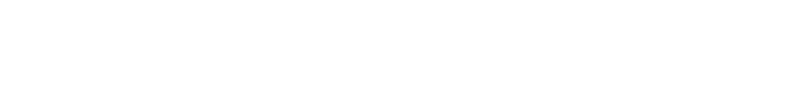
Rt 40 nr Charlotte Court Hous a... (ROANOKE) 390

Roanoke Creak (West Fork) above Spring Creek nr Eureka........... (ROANOKE) 389

Roanoke Croek at Rt 612 at Saxe.......... (ROANOKE) 391

Roanoke Creok at Rt 619 nr Drakes Branch............... (ROANOKE) 390

Roanoke Croek at mouth at Randolph...... (ROANOKE) 392

Roanoke River (Kerr Reservo1r) above Kerr Dem nr Boydton........ (ROANOKE) 420

Roanoke River (Kerr Reservotr) at former mouth of Island Creek nr Clarksvilie................ (ROANOKE)

Roanoke River (Kerr Reservolr) nr Dryburg................. (ROANOKE) 393

Roanoke River (Kerr Reservotr) nr Cozy Cabin................. (ROANOKE) 419

Roanoke River (Kerr Reservoir) above Grassy Creek nr Clarksville...... (ROANOKE) 419

Roanoke River (Kerr Reservotr) above Nutbush Creek nr Kerr Dam nr Boydton.

(ROANOKE) 420

Roanoke River (Kerr Reservoir) at Occoneechee State Park nr Clarksvillo.

Roanoke River (Kerr Reservoir) below Bluestone Creak nr Clarksville...

Roanoke River (Kerr Reservotr) below Blue Creek nr Clarksville.........

Roanoke River (Kerr Reservoir) below Butcher Creek nr Boydton........ Eastiand Creek nr Boydton.........

Roanoke River (Kerr Reservotr) below Hogan Creek nr Dryburg............. Keats Branch nr Kerr Dem
Ke River (Kerr Reservoir)

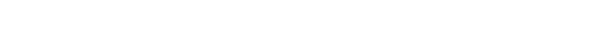

(ROANOKE) 419

(ROANOKE) 418

(ROANOKE) 419

(ROANOKE) 420

(ROANOKE) 420

(ROANOKE) 393

ke River (Lake Gaston) at I-85

(ROANOKE) 420 nr Bracey................... (ROANOKE) 423

Roanoke River (Smith Mountain Lake at buoy 12) $\mathrm{nr}$ Kasey............. (ROANOKE) 369

Roanoke River (Smith Mountain Lake) nr Smith Mountain Dam nI Penhook. (ROANOKE) 372
Roanoke River above Beaverdam Creok nr Goodview............... (ROANOKE) 368

Roanoke River above Bishop Creek nr Leesville................. (ROANOKE)

Roanoke River above Cargills Creek nr Dryburg. .............. (ROANOKE)

Roanoke River above Goose Creek at Leesville................. (ROANOKE)

Roanoke River above Prater Creek nr Bardy ................. (ROANOKE)

Roanoke River above former confluence with Dan River at Clarksvi1le.... (ROANOKE)

Roanoke River above former mouth of Dan River at Clarksville........ (ROANOKE)

Roanoke River at 14 th St at Roanoke.... (ROANOKE) Roanoke River at Niagara Dam at Ntagara................... (ROANOKE)

Roanoke River at Rt $1109 \mathrm{nr}$ Gretna..... (ROANOKE)

Roanoke River at Rt 1154 at Glenvar.... (ROANOKE)

Roanoke River at Rt 603 at Lafayette... (ROANOKE)

Roanoke Rlver at Rt $612 \mathrm{nr}$ Wabun....... (ROANOKE)

Roanoke River at Rt $634 \mathrm{nr}$ Hardy........ (ROANOKE)

Roanoke River at Rt $640 \mathrm{nr}$ Hodges....... (ROANOKE)

Roanoke River at Rt $761 \mathrm{nr}$ Long Is land. (ROANOKE)

Roanoke River at Rt 821 at Lafayette... (ROANOKE)

Roanoke River at Rts 639/760 nr Salem. . (ROANOKE)

Roanoke River at Southern RR at Randolph...............

Roanoke River at U.S. Bwy I nr South Bil1 .............. (ROANOKE)

Roanoke River at U.S. Bwy ii west of Rt 419 at Salem......... (ROANOKE)

Roanoke River at U.S. Bwy 11 at Salem.. (ROANOKE) Roanoke River at U.S. Hwy 29 (Bypass) nr Burt..................... (ROANOKE)

Roanoke River at U.S. Biny soi at Brookneal........ 58

(ROANOKE) at Clarksvilie............... (ROANOKE)

Roanoke River at Walnut St at Roanoke. . (ROANOKE)

Roanoke River below APCO powerplant at Ni agara................. (ROANOKE)

Roanoke River below Blackwater River nr Penhook................... (ROANOKE)

Roanoke River below Kerr Dem at Buggs Is land.............. (ROANOKE)

Roanoke River below Leesvilie Dam nr Leesyille ................... (ROANOKE)

Roanoke River diversion at APCO powerdam at Niagara........... (ROANOKE)

Roanoke River nr Toshes

(now in Leesville Lake).......... (ROANOKE)

Roanoke River nr Wabun ............... (ROANOKE)

Roanoke River powerplant outfali at Leesville Dem nr Loesvillo.... (ROANOKE)

Roanoke River powerplant outfall at Kerr Dem nr Boydton.......... (ROANOKE)

Roanoke River trib No. 1 (Dry Holiow trib) at mouth nr Lafayette..... (ROANOKE)

Roanoke River trib No. 2 at mouth nr Salem.................... (ROANOKE)

Roanoke River trib No. 3 at mouth at Salem.................. (ROANOKE)

Roanoke River, $\mathrm{N}, \overrightarrow{\mathrm{F}}$. along $\mathrm{Rt} i 23$ nr Lusters Gate. ........... Mïii nr Blacksburg. ................ (ROANOKE)

Roanoke River, N.F., at Ironto......... (ROANOKE)

Roanoke River, N.F. at Lusters Gate... (ROANOKE)

Roanoke River, N.F., at Rt 603

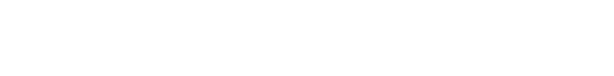
nr Lafayette. ........... at Lafayette.................. (ROANOKE)

Roanoke River, N.F... Bradshaw Creek nr Lafayette....... (ROANOKE)

Roanoke River, N.F., nr Lusters Gate... (ROANOKE) 
Abbreviated basin names appear at the ond of the site name. Abbreviations are as follows: Eastern Shore (EASTERN); Potomac to Shenandoah (POT-SHEN); Shenandoah (SHEN); Potomac (POTOMAC); Potomac to Rappahannock (POT-RAPP); Rappahannock (RAPP); Rappahannock to York (RAPP-YORK); York (YORK) York to James (YORK-JAMES); James (JAMES); James to Chowan (JAMES-CHOWAN); ChOwan (CHOWAN); Roanoke (ROANOKE); Yadkin (YADKIN); Naw (NEW); BIg Sandy (BIG SANDY); Holston (HOLSTON); Clinch (CLINCH); POwe11 (POWELL)]

Roanoke River, N.F., trib No. 1 at Rt 723 at Lusters Gate.

(ROANOKE) 360

Roanoke River, N.F., trib No. 2 nr Lusters Gate.

(ROANOKE) 361

Roanoke River, S.F., above Elijiott Creok at Rt $639 \mathrm{nr}$ Crockett Spring.....(ROANOKE) 358

Roanoke River, S.F., above $N, F$ Roanoke River at Lafayette........(ROANOKE) 360

Roanoke River, S.F., at Rt 637 nI Shawsville..

Roanoke River, S.F., at U.S. Hwys $11 / 460$ at Lafayette.

(ROANOKE) 359

Roanoke River, S.F., at U.S. Hiwy il nr Shawsilile.

(ROANOKE) 360

(ROANOKE) 359

Roanoke River, S.F, at U.S. Hwy 11 nr Elliston.

(ROANOKE) 360

Roaring Branch at U.S. Hiwy 23 nr Big Stone Gap.

Roaring Branch at mouth at Ewing

(POWELL) 555

(POWELL) 563

Roaring Branch at mouth at Harvey........ (CLINCH) 550
Roaring Fork above Rt 603 at Dunbar..... (POWELL) 554

Roaring Fork at Rt $603 \mathrm{nr}$ Norton........ (POWELL) 554

Roaring Fork at Rt $63 \mathrm{nr}$ Irammel.....(BIG SANDY) 477

Roaring Fork at mouth nr Asberrys....... (HOLSTON) 513

Roaring Fork at mouth nr Chatham........ (ROANOKE) 411

Roaring Fork at mouth nr Norton......... (POWELL) 554

Roaring Fork at mouth nr Tramme1..... (BIG SANDY) 477

Roaring Run at Rt 621 at Hooks Mi $i j$ nr Rich Patch.

(JAMES) 219

Roaring Run at mouth at Greenviije......... (SHEN)

Roaring Run at mouth at Strom............ (JAMES)

Roaring Run at mouth nr Callaway.......... (ROANOKE)

Roaring Run at mouth nr Endicott........ (ROANOKE)

Roarins Sprins Branch at mouth

Robbins Creek at mouth at Buggs Is land.

(ROANOKE)

Roberts Creek at mouth nr Bruno........ (HOLSTON)

Roberts Creek at mouth nr Poquoson. (YORK-JAMES)

Robertson Branch at mouth at Saltvilie. (HOLSTON)

Robinette Branch at Va.-Tenn. State line at Dona................... 551

Robins Branch at mouth $n \mathbf{r}$ Rondo......... (ROANOKE)

Robinson (Robertson) River

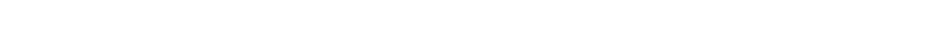

Robinson Creek at mouth nr Ante.........(CHOWAN) 354

Robinson Creak at mouth nr Urbanna...... (RAPP) 156

Robinson Fork at mouth nI Rowe.......(BIG SANDY) 457

Robinson River above Rose River nr Criglersville..............RAPP) 136

Robinson River at Rt 231

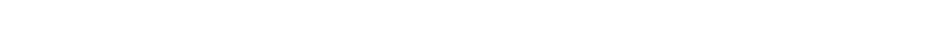

Robinson River at Rt 614 at Locust Dale... (RAPP) 137

Robinson River at Rt $614 \mathrm{nr}$ Madison....... (RAPP) 137

Robinson River at Rt 642 at Criglersville.(RAPP) 136

Robinson River at Rt $649 \mathrm{nr}$ Criglergville.(RAPP) 136

Robinson River at mouth nr Rapidan........ (RAPP) 138

Robinson River below Cedar Run nr Syria...(RAPP) 136

Robinsons Creek at mouth nr Winterpock...(JAMES) 277

Rock Branch at mouth nr Poweliton....... (CHOWAN) 353

Rock Castlo Creak at mouth

$$
\text { nr Scottsville................. (JAMES) }
$$

Rock Castle Creak at mouth nr Charity.. (ROANOKE)

Rock Creek at Rt 100 at Sylvatus.......... (NEW)

Rock Creek at mouth at sylvatus................ (NEW)

Rock Creek at mouth nr Ferncliff......... (YORK)

Rock Creek at mouth $n r$ Independence........ (NEW)

Rock Creek at mouth nr Longshoal........... (NEW)

Rock Creek nr North Anna Dam.............. (YORK)

Rock Ford Creek at mouth nr Montpelier.... (YORK)

Rock Island Run at mouth nr Warren....... (JAMES)

Rock Run at mouth at Stanleytown....... (ROANOKE)

Rock Run at mouth $n \mathbf{r}$ Goldvein............... (RAPP)

Rock Run trib No. 1 at mouth nr Goidvein.. (RAPP)

Rock Run trib No. 2 at U.S. Hwy 17

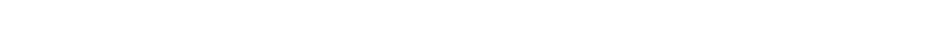

Rock Run trib No. 2 at mouth nr Goldvein... (RAPP) 131

Rock Run trib No. 3 at mouth nI Goldvein.. (RAPP) 131
Rock Station Creek at mouth

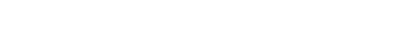
Rockcastle Creek at mout
ni Stone Mountain.

Rocketts Creek (Mill Creek) at mouth nr Othma.

378

Rocketts Creek trib at U.S. Hwy 250

nr Gun Springs................. (JAMES) 260

Rockfish River at Rt 602 at Howardsvilio.(JAMES) 242

Rockfish River at Rt $634 \mathrm{nr}$ Greenfield...(JAMES) 241

Rockfish River at U.S. Hwy 29 ne Lovingston.

(JAMES) 241

Rockfish River at mouth at Howardsvili... (JAMES) 242

Rockfish River trtb, S.F., nr Love........ (JAMES) 241

Rockfish River, N.F., above S.F. Rockfish Rtver nr Greenfield.......(JAMES) 241

Rockfish River, N.F., at Rt 6 nr Greenfield............

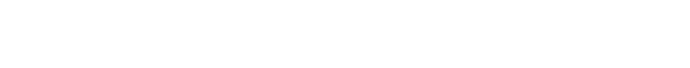

Rockhouse Branch above Hurricane Crejok ar Davenport. ............... nr Council...................... (BIG SANDY) Rockhouse Branch at mouth nr McCiure. (BIG SANDY) Rockhouse Run at mouth at Alvarado..... (HOLSTON) Rocklick Branch at mouth nr Pocket...... (POWELL) Rocklick Creek above Jacks Creek at Big Rock.................... (BIG SANDY)

467 478 498 558 463 Rocklick Creek at N\&W RR at Big Rock. (BIG SANDY) 463 Rocky Branch at Rt $612 \mathrm{nr}$ Thornton Gap.... (SHEN) 49 Rocky Branch at mouth at Fort Blackmore. (CLINCE) 545 Rocky Branch at mouth at Springfield... (POTOMAC) 88 Rocky Branch at mouth nr Boydton........ (ROANOKE) 420 Rocky Branch at mouth or Culpeper..........(RAPP) 139 Rocky Branch at mouth nr Baysi......(BIG SANDY) 478 Rocky Branch at mouth nr Jeffress....... (ROANOKE) 418 Rocky Branch at mouth nr Luray.............. (SHEN) 49 Rocky Branch at mouth nr Reams................ (CHOWAN) 329 Rocky Branch at mouth nr Richmond........ (JAMES) 294 Rocky Branch at mouth nr Stony Creak...... (CHOWAN) 328 Rocky Branch at mouth nr Vienna......... (POTOMAC) 76

Rocky Branch at mouth $n r$ Whitmell...... (ROANOKE) 406 Rocky Branch trib at Rt 619 nr Gainesville.......

( POTOMAC)

Rocky Creek at U.S. Hwy 50

nr Sweet Briar........... (JAMES)

Rocky Creek at mouth ni Middieburb...... (POTOMAC)

Rocky Creek at mouth nr Museville...... (ROANOKE)

Rocky Creek at mouth nr Rivervil1e....... (JAMES)

Rocky Ford Branch at wouth nr Sandy River.............. (ROANOKE)

Rocky Ford Creek at mouth in Genito...... (JAMES)

Rocky Fork at mouth nr Stephens......... (CLINCB)

Rocky Mountain Run at mouth nr Rocky Bar.. (SHEN)

Rocky Pen Run at mouth ni Fivemile Fork... (RAPP)

Rocky Pen Run trib at mouth nr Fivemile Fork.

(RAPP)

Rocky Run Creek at Rt $54 \dot{6}$ nr DoWitt...... (CHOWAN)

Rocky Run Creek at mouth nr Dinwiddi ... (CHOWAN)

Rocky Run at Rt $619 \mathrm{nr}$ Mine Run.......... (YORK)

Rocky Run at Rt 641 nr Dolphin......... (CHOWAN)

Rocky Run at Rt 542 at Lawrenceville..... (CBOWAN)

Rocky Run at Rt 707 at Nethers............. (RAPP)

Rocky Run at Towlston Rd

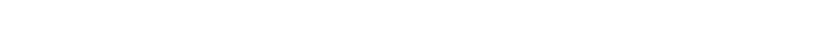

Rocky Run at U.S How $220 \mathrm{nr}$ Bolar..... (JAMES)

Rocky Run at former mouth at Lake Chesdin.

(JAMES) 282

Rocky Run at mouth at Lawrencevilie.......(CHOWAN) 353

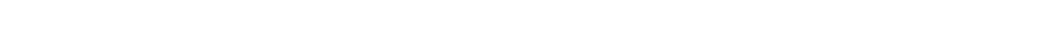

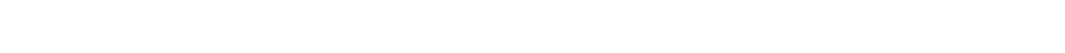

Rocky Run at mouth nr Brink.............. (CHOWAN) 355

Rocky Run at mouth nr ChristiansburB...(ROANOKE) 361

Rocky Run at mouth nr Darvills.... (CHOWAN) 324

Rocky Run at mouth nr Scotts Fork.......... (JAMES) 279

Rocky Spring Branch along U.S. Hiry ii at Groseclose................ HOLSTON)
239

69

239

406

539

144

144

327

159

353

121

77

2

1

61

499 
Abbreviated basin names appear at the end of the site name. Abbreviations are as follows Eastern Shore (EASTERN); Potomac to Shenandoah (POT-SBEN); Shenandoah (SBEN); Potomac (POTOMAC);

Potomac to Rappahannock (POT-RAPP); Rappahannock (RAPP); Rappahannock to York (RAPP-YORK); York (YORK);

York to James (YORK-JAMES); James (JAMES); James to Chowan (JAMES-CBOWAN); Chowan (CBOWAN); Roanoke (ROANOKE);

Yadkin (YADKIN); New (NEW); Bis Sandy (BIG SANDY); Bolston (BOLSTON); Clinch (CLINCH); Powell (POWELL)]

Page

Roddy Branch at mouth nr Ka.

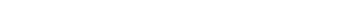

Root Creek at mouth nr Beulahvilie..........(YORK) 194

Rooty Branch at mouth nr Glen Allen....... (JAMES) 292

Rosa Swamp at mouth nI Boykins......... (CBOWAN) 357

Rose River along Rose River Trail

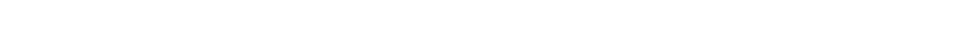

Rose River at mouth nr Crigiersvilie........(RAPP) 136

Roseg1ll Lake at dam nr Urbanna.......... (RAPP) 157

Roses Creek at Rt 646 nI Alberta........(CHOWAN) 353

Roses Creak at mouth nr Lawrencevilie... (CBOWAN) 353

Rosier Creek at mouth at Potomac Beach. (POTCMAC) 110

Ross Branch at Rt $605 \mathrm{nr}$ Accomac......(EASTERN) 12

Ross Branch at mouth $\mathrm{n}_{\mathrm{r}}$ Accomac........ (EASTERN) 12

Ross Run at mouth $\mathrm{nr}$ Richmond Heights.... (JAMES) 270

Rosson Bollow Run at mouth nr Etlan........ (RAPP) 122

Rosson Bollow Run trib at Rt 646 nr Etlan. (RAPP) 122

Rough Creek at mouth nr Castle Craig... (ROANOKE) 383

Rough Creek at mouth nr Hixburg.........(JAMES) 271

Rough Creok at mouth nr Phenix........... (ROANOKE) 388

Round B111 Swamp at Rt 614 nr Berlin....(CBOWAN) 344

Round Bill Swamp at Rt 626 at Berlin.... (CBOWAN) 343

Round Bill Swamp at mouth nr Berlin..... (CBOWAN) 344

Round Bill Swamp trib No. 1 at Rt 626

Round Rili Smom trib No 2 at Rt $626 \ldots$ (CBOWAN) nr Dory........................WAN) 343

Round Bill Swamp trib No. 3 at Rt $\dot{6} 14$ nr Berlin........................... 344

Round Hill Swamp trib No. 3 at $\mathrm{Rt} \dot{6} \dot{6}$ nt Berlin...........................WAN) 344

Round BiLl Swamp trib No. " 4 at Rt 614

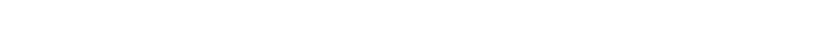

Round Meadow Creek at mouth nI Meadows of Dan............. (ROANOKE)

Roundabout Creek at mouth nr Bermuda Bundred.................. (JAMES)

Roundabout Creek at mouth nr Loui sa........ (YORK)

Rouss Spring at Winchester......... (PÖT-SHEN)

Rowanty Creek at Rt $602 \mathrm{nr}$ Stony Creek. (CHOWAN)

Rowanty Creek at Rt 618 nr Carson....... (CHOWAN)

Rowanty Creek at Rt $703 \mathrm{nr}$ Carson....... (CBOWAN)

Rowanty Creek at U.S. Hwy 301 at Stony Creek (Carson) ...... (CHOWAN)

Rowanty Creek at mouth nr Stony Creek... (CBOWAN)

Rowland Creek at mouth at Thomas Bridge ............ (BOLSTON)

Rucker Run at Rt $626 \mathrm{nr}$ shipman.......... (JAMES)

Rucker Run at U.S. Bwy 29 at Lovingston.. (JAMES)

Rucker Run at mouth nr Norwood........... (JAMES)

Rudd Branch at U.S. Bwy $58 \mathrm{nr}$ Boydton. (ROANOKE)

Rue Gut at mouth nr Bopkins........... (EASTERH)

Ruffans Run at mouth nr Remington........ (RAPP)

Ruin Branch at mouth nr Montross..........(RAPP)

Ruin Branch trib at Montross.............. (RAPP)

Rumley Branch at mouth nr Flat Gap... (Bíg SANDY)

Rumley Marsh above U.S. Bwy 60 at Providence Forge.............. (JAMES)

Rumley Marsh nr Providence Forge......... (JAMES)

Runaway Creek at mouth nI Leda.......... (ROANOKR)

Runion Creek at mouth nr Cootes Store.... (SHEN)

Rush Branch at mouth nr Nora........ (BIG SANDY)

Rush Creek at mouth nr Clintwood...... (BIG SANDY)

Rush Creek at mouth nr Friendship....... (BOLSTON)

Rush Fork above Furnace nr Floyd........... (NDW)

Rush River above Covington River

nr Washington................. (RAPP)

Rush Rtver along Rt $622 \mathrm{n} r$ Washington...... (RAPP)

Rush River at Rt 622 nr Washington........ (RAPP)

Rush River at Rt 624 at Washington........ (RAPP)

Rush River at Rt 626 at Washington........ (RAPP)

Rush River at mouth nr Washington.......... (RAPP)

Rush River at old U.S. Bwys 211/522 at Washington................ (RAPP)

Rush River trib at U.S. Bwys 21 i/ 222

Russell Branch at mouth nr Osceola..... (BOLSTON)

Russell Branch at mouth nr Sterling.... (POTOMAC)
Russel1 Branch trib at Rt 7 nt Asbburn. (POTOMAC)

Russell Creek at N\&W RR nr St. Paul..... (CLINCB)

Russell Creek at mouth nr Nettleridge... (ROANOKE)

Russell Creek at mouth nr St. Paul.......(CLINCB)

Russell Fork above Big Branch

Russell Fork above Dogpen Branch . . . (BIG SANDY) nr Counc $11 \ldots \ldots \ldots$

Russel1 Fork above Fox Creek 11 Fork above Fulier Branch

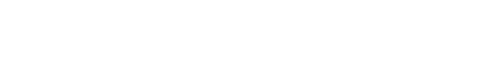

Russell Fork above Indian Creek nr Davenport. $\ldots$ itile Fox $\ddot{\text { Creok }}$

nr Murphy..................... at Council... . . . . . . .

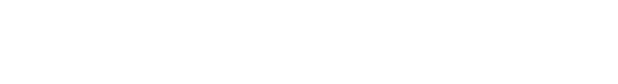

Russell Fork above Tilier Creek nr Davenport............ (BIG SANDY)

Russe11 Fork along Rt 605 at Murphy.. (BIG SANDY) Russell Fork along Rt 80 at Davenport.............. (BIG SANDY)

Russel1 Fork along Rt 80 above

Bal1 Creek nr Council......... (BIG SANDY)

Russell Fork along Rt $80 \mathrm{nr}$ Councii.. (BIG SANDY)

Russell Fork at Rt $602 \mathrm{nr}$ Counc11.... (BIG SANDY)

Russell Fork at Rt 611 at Bartlick...(BIG SANDY)

Russell Fork at Rt 80 at Elkhorn City, Ky..........(BIG SANDY)

15sel1 Fork at Rt 80 at Council.... (BIG SANDY)

Russel1 Fork at Rt $80 \mathrm{nr}$ Birchleaf... (BIG SANDY)

Russell Fork at Rt 83 at Baysi....... (BIG.SANDY)

Russell Fork at Viers nr Colley....... (BIG SANDY)

Russe11 Fork below McFarland Branch nr Council.................. (BIG SANDY)

Russel1 Fork below Rt 63 at Baysi.... (BIG SANDY) Russel1 Fork off Rt 80 at $\mathrm{Va} .-\mathrm{Ky}$. State line nr Breeks........... (BIG SANDY)

Russell Fork trib No. 1 at $\mathrm{Rt} 80$ at Council................ (BIG SANDY)

Russell Fork trib No. 2 at mouth nr Davenport. . . $\ldots \ldots \ldots$ mouth

Russell Fork trib No. 3 at mouth

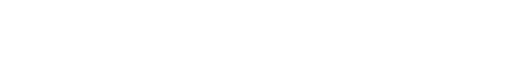
nr Haysi

(BIG SANDY)

Russell Prater Creek at Rit $\ddot{8} \dot{3}$

Russell Prater Creek at mouth at Baysi.

Russell Prater Creek at school bridge at Haysi................... (BIG SANDY) (BIG SANDY)

Russell Run at Rt 603 nr Fiat Run......... (RAPP)

Russell Run at mouth nr Flat Run.......... (RAPP)

Russia Branch at Rt 616 at Mansssas.... (POTOMAC)

Russia Branch at Rt 616 trib at Manassas.

ussian Branch at mouth at Castlewood... (CLINCH) Rutledge Creek at U.S. Bwy 60 at Amberst. (JAMES) Rutledge Creek at mouth at Danville.... (ROANOKE) Rut ledge Creek at mouth nI Amherst........ (JAMES) Rutledge Creek below Amherst STP at Amherst.

(JAMES)

Rye Cove Creek at mouth nr Mayo........ (ROANOKE) Ryefield Creek at mouth nr West Point..... (YORK)

Sad Branch above Left Fork nr Davenport. ....... (BIG SANDY)

Saddle Creek at mouth ni Bridie Creok...... (NEW) Saddle Creek trib at U.S. Bwy 58

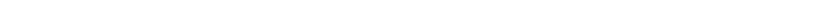

Saddle Swamp at mouth nr Penola........... (YORK) 
Abbreviated basin names appear at the end of the site name. Abbreviations are as follows:

Eastern Shore (EASTERN); POtomac to Shenandoah (POT-SHEN): Shenandoah (SHEN); POtOmac (POTOMAC);

Potomac to Rappahannock' (POT-RAPP); Rappahannock (RAPP); Rappahannock to York (RAPP-YORK); York (YORK);

York to James (YORK-JAMES); James (JAMES); James to Chowan (JAMES-CHOWAN); Chowan (CHOWAN); Roanoke (ROANOKE);

Yadkin (YADKIN); New (NEW); Bis Sandy (BIG SANDY); Holston (HOLSTON); Clinch (CLINCH); POWell (POWELL)]

Page

Saddletree Creek at U.S. Hiwy 58

nr Lawrenceville..

Saddletree Creek at mouth

nr Lawrenceville.......................WOWAN) 352

Sailor Creok at mouth ir Grady.............. (ROANOKE) 375

Saint Clair Creek at mouth

nr Saint Clair Bottom................. HOLSTON) 494

Saint Marys River above Spy Run nr Vesuvius.

(JAMES) 228

Saint Marys River at mouth nr Vesuvius... (JAMES) 228

Saint Marys River below Sugartree Branch ner Vesuvius

(JAMES) 228

Saint Marys River trib nr Vesuvius......... (JAMES) 228

Salem Run at mouth nr Barnetts.......... (JAMES) 290

Sallee Creek at U.S. Hory $60 \mathrm{nr}$ Provost... (JAMES) 260

Sallee Creek at mouth nr Provost......... (JAMES) 260

Sample Branch at mouth at Swords Creek... (CLINCH) 529

Sams Run at mouth nr Nethers.............(RAPP) 120

Sandy Bottom Branch at Rt 695 nr Makemi e Park..............(EASTERN) 18

Sandy Bottom Branch at mouth nI Makemie Park.

(EASTERN)

18

Sandy Bottom Branch trib at Rt 693 at Makemie Park.............. (EASTERN)

Sandy Branch above Rocky Run

nr Lawrencevil1e................(CHOWAN) 353

Sandy Branch at mouth nr Lawrenceville.. (CHOWAN) 353

Sandy Croek (River) at U.S. Hiwy 58 nr Ringsold.

(ROANOKE) 408

Sandy Creek at Rt 608 nr Wylliesburg... (ROANOKE) 392

Sandy Creek at Rt $650 \mathrm{nr}$ Angola.......... (JAMES) 275

Sandy Creek at Rt $713 \mathrm{nr}$ Spring Garden. (ROANOKE) 414

Sandy Creek at Rt 832 at Meadville..... (ROANOKE) 414

Sandy Creek at mouth at Danville....... (ROANOKE) 407

Sandy Creek at mouth nr Angola........... (JAMES) 275

Sandy Creek at mouth nr Claudvilie...... (ROANOKE) 394

Sandy Creak at mouth nr Clay Bank......... (YORK) 199

Sandy Creek at mouth nr Clover.......... (ROANOKE) 392

Sandy Creek at mouth nr Jeffress......... (ROANOKE) 419

Sandy Creek at mouth nr Meadville......... (ROANOKE) 414

Sandy Creek at mouth nr Phenix.......... (ROANOKE) 388

Sandy Creek at mouth nr Stewartsville.. (ROANOKE) 368

Sandy Creek nr Danvilie .............. (ROANOKE) 407

Sandy River (Prince Edward Lake)

nr Green Bay ...........................

nr Green Bay.................... JAMES) 274

Sandy River above Rt 863 nr Danvilie.... (ROANOKE) 406

Sandy River at Prince Edward Lake Dam

nr Green Bay.................. (JAMES

Sandy River at Rt 612 nr Swansonviiie... (ROANOKE) 405

Sandy River at U.S. Hwy $460 \mathrm{nr}$ Rice...... (JAMES) 274

Sandy River at U.S. Howy 58 at Danvilie. (ROANOKE) 406

Sandy River at mouth at Danvil1e....... (ROANOKE) 406

Sandy River at mouth nr Rice............. (JAMES) 274

Sandy River trib at Goodwin Lake nr Green Bay.

( JAMES)

River.

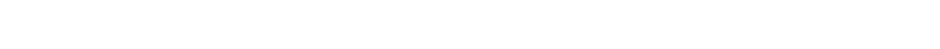

Sandy Run at Henderson $\mathrm{R} d$

nr Fairfax Station.

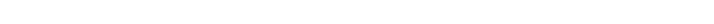

Sandy Valley Creek at mouth nr Hi ghland Springs.

Sangster Branch at Lee Chapel Rd

nr Burke.......... (POTOMAC) 90

Sappony Creek at $\dot{R} t$ 40 nr Stöny Creek... (CHOWAN) 329

Sappony Creek at Rt $619 \mathrm{nr}$ Cherry Hil1.. (CHOWAN) 328

Sappony Creek at Rt $681 \mathrm{nr}$ Stony Creek.. (CHOWAN) 328

Sappony Creek at Rts $40 / 626$

nr Stony Creek.................(CHOWAN) 328

Sappony Creek at mouth ni Stony Creek.... (CHOWAN) 329

Sappony Creek at mouth nr Winterpock..... (JAMES) 277

Sarah Creek at mouth at Gloucester Point.. (YORK) 200

Sarah Creek at mouth nr Seaford........... (YORK) 200

Samili Branch at mouth nr The Ridge.... (ROANOKE) 421

Sawmill Run at Rt $611 \mathrm{nr}$ Dooms.............(SHEN) 40
Sawmill Run at mouth at Dooms

Saylers Creek at Rt 619 nr Rice.

Saylers Creek at mouth nr Angola.

Scates Branch $1.2 \mathrm{mi}$ above mouth nr Montross ... . . . . . . . .

nr Montross ................... (POTOMAC)

Page

Scates Mill Stream at mouth nr Montross... (RAPP) 15

Scerkes Creek at mouth nr Belmont.........(YORK) 168

Schenks Branch above U.S. Hiwy 250 ar Charlottesville.

(JAMES) 254

Schiminoe Creek at U.S. Ewry 60 nr Providence Forge.

(JAMES )

Schiminoe Creek at former mouth

nr Providence Forgo.

(JAMES)

Scogins Creek at mouth nr Hartfield. (RAPP-YORK)

Scott Branch at mouth at Peterstown........ (NEW)

Scott Run at Old Georgetown Pike

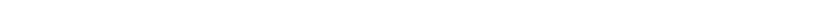

Scott Rus at mouth nr McLean........... (POTOMAC)

Scotts Branch at mouth nr Pattonsviile.. (POWELL)

Scotts Spring nr Marion.............. (hOLSTON)

Seacock Creek (Swamp) at Rt $618 \mathrm{nr}$ Ivor. (CHOWAN)

Seacock Creek at Rt 628 at Wakefield.... (CHOWAN)

Seacock Swamp (Creek) at Rt 635 nr Berlin (at Unity)

Seacock Swamp at Rt 614 nr Berlin....... (CHOWAN)

Seacock Swamp at Rt $623 \mathrm{nr}$ Berlin....... (CHOWAN)

Seacock Swamp at mouth $n r$ Berlin........ (CHOWAN)

Seacock Swamp trib No. 1 at

U.S. Hiwy 460 at Ivor. nr Ivor................................

Seacock Swamp trib No. 5 at Rt 600

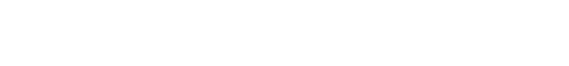

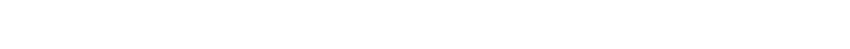

Seacock Swamp, East Fork, trib No. 3

at Rt $600 \mathrm{nr}$ BerIin............. (CHOWAN) 344

Seacock Swamp, N.F., trib No. 3 at Rt $600 \mathrm{nr}$ Berlin.

(CHOWAN)

Seacorrie Swamp trib at Rt 622 nr Manry. (CHOWAN)

Seahorn Spring nr Collierstown ......... (JAMES)

Seat Island Branch at mouth nr Dinwiddio.

Seawrisht Sprting me Mt. Sidney.

Seay Creek at Rt 600 nr Kenbridge......... (CHOWAN)

Seay Creek at mouth nr Kenbridge......... (CHOWAN)

Second Branch at mouth nr Beach........ (JAMES)

Second Swamp at Rt 156 nr Disputanta.... (CHOWAN)

Second Swamp at Rt 618 at Disputanta.... (CHOWAN)

Second Swamp at mouth nr Disputanta..... (CHOWAN)

Sedges Creek below dam in Lake Anna..... (YORK)

Seneca Creek at Rt $633 \mathrm{nr}$ Long Is land. (ROANOKE)

Seneca Creek at mouth nr Long Island... (ROANOKE)

Seng Camp Fork at mouth

$$
\text { nr Jewell valley............... (BIG SANDY) }
$$

Senior Creek at mouth nr Mollusk.......... (RAPP)

Sepulcher Creok at mouth nr Stephens..... (CLINCH) Seven Spring Creek at mouth

$$
\text { at Castlewood. }
$$

(CLINCH)

Severn River at Stomp Point buoy 2 nr Severn.

Siver at buoy $1 \mathrm{nr}$ Severn..... (RAPP-YORK)

Severn River at mouth nr Severn....... (RAPP-YORK)

Sowish Creok at mouth nr Meherrin........ (CHOWAN)

Sexton Branch at mouth nr Castlewood.... (CLINCH)

Sexton Hill Branch at mouth nr Montross... (RAPP)

Shaaf Pond Creek at Richmond........... (JAMES)

Shafer Creek at mouth nr Woodway......... (POWELL)

Shand Creek at mouth nr Rivermont........ (JAMES)

Shannon Creek at white Point nr Kinsale........................ (POTOMAC)

Shanty Creek at mouth nr King and Queen Court House

(YORK)
40

274

274

111

1

68

297 161
455

78

78

561
500

343

343

344

343

344
344

343

343

344

344

344

336

336

336
230

327

31

323
323

287

339

339

339

171

383

458

157

537

165

165

165

165
348

537

151

293

560
270

196 
Abbreviated basin names appear at the end of the site name. Abbreviations are as follows:

Eastern Shore (EASTERN); Potomac to Shenandoah (POT-SHEN); Shenandoah (SHEN); POtomac (POTOMAC);

Potomac to Rappahannock (POT-RAPP); Rappahannock (RAPP); Rappahannock to York (RAPP-YORK); York (YORK);

York to James (YORK-JAMES); James (JAMES); James to Chowan (JAMES-CHOWAN); Chowan (CBOWAN); ROanoke (ROANOKE);

Yadkin (YADKIN); Now (NEW); Big Sandy (BIG SANDY); Holston (HOLSTON); Clinch (CLINCH); POwel1 (POWELL)]

Page

Sharp Branch at mouth nr Alvarado...... (HOLSTON) Sharps Creek at Rt 20 nr Centenary........ (JAMES) Sharps Creek at Rt 611 nr Diana Mills.... (JAMES)

Sharps Creek at mouth nr Diana Mil1s..... (JAMES)

Shaws Fork at U.S. How 250 at Head Waters.................. (JAMES)

Shaws Fork at mouth nr McDowe11......... (JAMES)

She Branch at mouth nr Prater........ (BIG SANDY)

Sheep Creek at Rt 660 nI Pentcks Mili nr Thaxton..................... (ROANOKE)

Sheep Creek at mouth nr Peaks of Otter. (ROANOKE)

Sheep Run at Rt $636 \mathrm{nr}$ Stephens City...... (SEIEN)

Shelter Run nr Detrick................. (SHEN)

Shelton Branch at mouth nr spencer...... (ROANOKE)

Shenandoah River at Millville, W. Va...... (SHEN)

Shenandoah River at Riverton........... (SHEN)

Shenandoah River at Rt 624 (Morgan Ford) nr Linden............. (SHEN)

Shenandoah River at Rt $7 \mathrm{nr}$ Berryville.... (SEEN)

Shenandoah River at U.S. Hwy 50

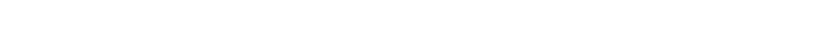

Shenandoah River at $\mathrm{Va} .-W$. State line nr Berryrille.......... (SHEN)

Shenandoah River at Warren Dam ne Front Royal.

Shenandoah River below $I-66$ ar Front Royal.

Shenandoah River powerplant diversion at Warren Dam nr Shenandoah......... (SEEN)

Shenandoah River trib at Rt $624 \mathrm{nr}$ Boyce.. (SBEN)

Shenandoah River, N.F., at Rt 917 at Fulks Run................... (SBEN)

Shenandoah River, N.F., $0.3 \mathrm{mi}$ above Rt 42 at Timberville......... (SHEN)

Shenandoah River, N.F, $1.3 \mathrm{mi}$ above Rt 42 nr Timbervi11e......... (SHEN)

Shenandoah River, N.F., $1.6 \mathrm{mi}$ above Rt 42 nr Timberville.......... (SHEN)

Shenandoah River, N.F., above Fort Run at Timberville.............. (SHEN)

Shenandoah River, N.F., above Linvilie Creek at Broadway............... (SHEN)

Shenandoah River, N.F., above Rt 259

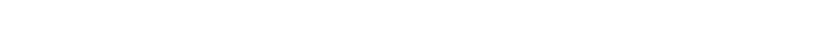

Shenandoah River, N.F., above waste ponds at Timbervilie................. (SHEN)

Shenandoah River, N.F., along Southern RR nr Riverton.......... (SBEN)

Shenandoah River, N.F., along Rt 259 nr Cootes store................ (SHEN)

Shenandoah River, N.F., along Rt 260 at Timberville.............. (SEEN)

Shenandoah River, N.F., at U.S. Ewry 11 nr Mt. Jackson.......... (SHEN)

Shenandoah River, N.F. at U.S. Hwy 522 at Riverton........... (SHEN)

Shenandoah River, N.F., at Rt 259 at Cootes Store................ (SHEN)

Shenandoah R1ver, N.F., at Rt 42 at Timberville.............. (SHEN)

Shenandoah River, N.F., at Rt 55

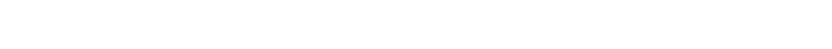

Shenandoah River, N.F., at Rt 617 at Broadway........... (SEER)

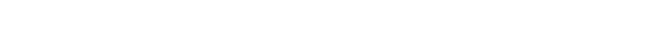
nr New Market................. (SHEN)

Shenandoah River, N.F., at Rt 648 at Strasburg................ (SEER)

Shenandoah River, N.F., at Rt 663 nI Woodstock.................. (SHEH)

Shenandoah Rtver, N.F. at Rt 675 at Edinburg................ (SHEN)

Shenandoah River, N.F., at Rt 698 at Mt. Jackson.................(SHEN)

Shenandoah River, N.F., at Rt 698 at Edinburg.................. (SHEN)

Shenandoah River, N.F., at Rt $7 \dot{7} \overrightarrow{7}$ nI Mt. Jackson. .............. (SHEN)
498

246

246

246

213

213

473

379

379

63

62
396

66

63

64

65

64

66

64

64

64

64

52

54

54

54

54

53

53

54

62

52

55

56

62

53

54

60

53

55

60

59

59

57

57

57

Shenandoah River, N.F. at Rt 758 nr hoodstock. ...... nr Quicksburg.

Shenandoah River, N.F., at campground

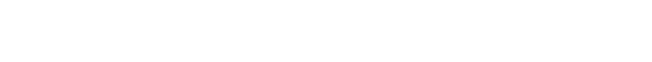

Shenandoah River, N.F., at county line

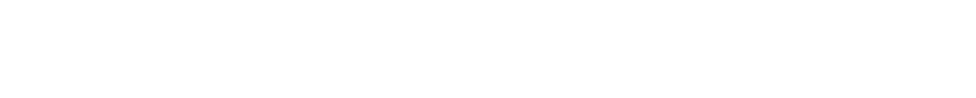

Shenandoah River, $\dot{\mathcal{F}}, \dot{F}$, at waste ponds at Timberville................ (SREN)

Shenandoah River, N.F., below Linville Creek át Broadway.......... (SHEN)

Shenandoah River, N.F. below

U.S. Hiwy 522 at Riverton........... (SHEN)

Shenandoah River, H.F., below Fort Run at rimberville................ (SEEE)

Shenandoah River, N.F., below Rt 42 at Timberville.................. (SHEN)

Shenandoah River, N.F., below Stony Creek nr Edinburg . . . . . . . . . . . .

Shenandoah River, N.F., below waste ponds at Timberville................. (SHEN)

Shenandoah River, N.F. trib No. 1 ........ (SEEN)

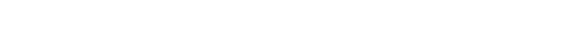

Shenandoah River, N.F., trib No. 2 at Rt 259 at Broadway............ (SEEN)

Shenandoah River, N.F., trib No. 3 at Rt 259 at Broadway........... (SHEN)

Shenandoah River, N.F., trib No. 4 at Rt 259 at Broadway............ (SEEN)

Shenandoah River, S.F., along U.S. Hwy 340 at Ǵrove Hit $\$ 11 \ldots \ldots$ (SHEN)

Shenandoah River, S.F at

U.S. Eiwy 33 bridge at Elkton....... (SHEN)

Shenandoah River, S.F., at U.S. Hwy 2 il nr Luray ............. (SHEN)

Shenandoah River, S.F., at Hazard Mil1 Recreation Area nr Bentonville..... (SHEN)

Shenandoah River, S.F., at PECO Dam at Shenandóah.................. (SHEN)

Shenandoah River, S.F., at EECO Dam nr Luray.............................. SHEN)

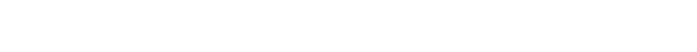
ne Newport. . $\ldots \ldots$ at Rt $\dot{6} \dot{6} \dot{0}$ at Shenandoah...... at Rt 613

$\ldots$ (SHEN) nI Bentonvilie................ (SHEN)

Shenandoah River, S.F., at Rt 619

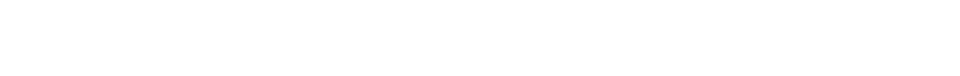
nI Rileyvilie................ (SEEN)

Shenandoah River, S.F, at Rt 649

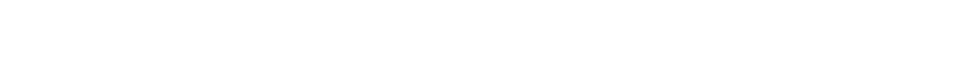

nr Luray................ at Lynswood..................... (SHEN)

Shenandoah River, S.F., at U.S. Hwy 340 at Grove Hil1................. (SHEN)

Shenandoah River, S.F., at U.s. Biry 340

Shenandoah River, S.F. at U.S. Hwy $522 \ldots$ (SEEN) at Front Royal................ (SHEN)

Shenandoah Rtver, S.F., at mouth at Front Royal................. (SEER)

Shenandoah River, S.F., at powerdam nr McGaheysvilie............... (SHER)

Shenandoah River, S.F., below Lower Lewis Run nr Lyrnwood.......... (SHEN)

Shenandoah River, S.F., below Rt 619 at Front Royal............ (SEEN)

Shenandoah River, S.F., below U.S. Howy 340 at Alma........... (SEER)

Shenandoah River, S.F., below Humes Run nr Shenandóah................ (SHER) 
Abbreviated basin names appear at the end of the site name. Abbreviations are as follows:

Eastern Shore (EASTERN); Potomac to Shenandoah (POT-SHEN); Shenandoah (SHEN); POtOmac (POTOMAC);

Potomac to Rappahannock (POT-RAPP); Rappahannock (RAPP); Rappahannock to York (RAPP-YORK); York (YORK);

York to James (YORK-JAMES); James (JAMES); James to Chowan (JAMES-CHOWAN); Chowan (CHOWAN); Roanoke (ROANOKE);

Yadkin (YADKIN); New (NEW); Big Sandy (BIG SANDY): Holston (HOLSTON); C1Inch (CLINCH); POWe11 (POWELL)]

Shenandoah River, S.F., dam powerplant outfall (PECO) at Shenandoah

Shenandoah River, S.F., dam powerplant outfall ( $\mathrm{PECO}$ ) nr Newport............. Shenandoah River, S.F., dan powerplant outfali (PECO) nr Iuray.

Shenandoah River, S.F. Dr Elkton. . .

Shenandoah River, S.F., trib nr Luray...... (SHEN)

Shingle Crook at N\&W $R R$ at Suffolk........ (JAMES)

Shingle Creek at Rt 642 (Wilroy Rd) at Suffolk

(JAMES) 307

Shingle Creek at Rt $64 \dot{2}$ at Suffoik........ (JAMES) 306

Shingle Creek at U.S. Hwy 13 at Suffolk.. (JAMES) 307

Shingle Creek trib at Rt 642 at Suffolk.. (JAMES) 306

Shining Creok at mouth nr Meredithvilie.

Shipps Bay off Coast Guard Station nr Sand Bridge

(CHOWAN) Island nr Sand Bridge...... (JAMES-CHOWAN) 316 (JAMES-CHOWAN) 316

\section{Shipps Bay off Stand ne Sand Bridge.}

Shoal Creek at mouth nr Independence.......(NEW) 428

Shockoe Creek at Rt 686 nr Java......... (ROANOKE) 413

Shockoe Creek at Rt 755 nr Irving...... (ROANOKE) 377

Shockoe Creek at mouth nr Chamblissburg............. (ROANOKE) 377

Shockoe Creek at mouth nr Markham......(ROANOKE) 413

Shoe Creek at Alhambra................................ 237

Shoemaker River along Rt 612 nr Fulks Run. (SHEN)

Shoomaker River at mouth nr Cootes Stare.. (SHEN) 52

Shooting Creek at mouth nr Charity..... (ROANOKE) 398

Shop Creek at mouth nr Montpelier.........(YORK) 179

Shop Creek trib at mouth nr Rockviiie...... (YORK) 179

Shorts Creek at U.S. HWy 52 nr Poplar Camp. (NEW) 435

Shorts Creek at mouth nr Poplar Camp....... (NEW) 435

Shotgun Hill Branch ahove mouth

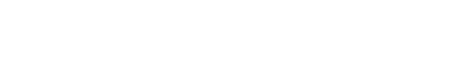

Shotgun Hill Branch at mouth

$$
\text { ne Wildern }
$$

143

Shotwell Run at mouth nr Criglersvilie.... (RAPP) 136

Shupe Branch at Forest Rd 239 nr Mabe... (CLINCH) 547

Shupe Branch at mouth nr Mabe............ (CLINCH) 547

Shupe Creek at mouth nr Flat Ridge.........(NEW) 428

Sideburn Branch at Guinea Rd at Fairfax Station.

Sideburn Branch at Poburn Rd nr Fairfax.

(POTOMAC

90

(POTOMAC)

Sideburn Branch at Rt 654 nr Fairfax Station.

(POTOMAC)

Sideburn Branch at mouth nr Burke...... (POTOMAC)

Sidney Creek at mouth nr Copper Valley..... (NEW)

Silver Creek at mouth nr Whitme11...... (ROANOKE)

Silver Lake Spring at Dayton............. (SEEN)

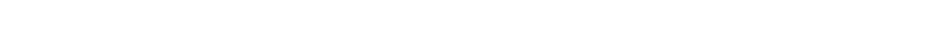

Silverleaf Banch at mouth nr Kings Store... (NEW)

Simpson Creek along U.S. Hwy 60 at Longdale Fumace.............. (JAMES)

Simpson Creek at mouth nr Longdale Furnace...

Simpsons Creek at former mouth at Round Hill.

Sims Creek at mouth nr Smiley. (POTOMAC) 70

$\ldots \ldots$ (POWELL) 561

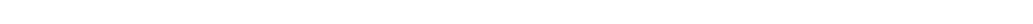

Sinking Creek at U.S. Hwy 220 at Gala.... (JAMES) 217

Sinking Creek at Va.-Tenn. State Iine nr Bristol.

Sinking Creek at mouth nr Lebanon..........(CLINCH) 534

Sinking Creek at mouth nr Williansvilie..(JAMES) 214

Sinking Creek nr Hilander Park.........(HOLSTON) 509

Sinking Creek trib at mouth nr Newport......(NEW) 450

Sirks Run at mouth nr Bergton............. (SHEN) 52

Sisson Run at mouth ne Montross.......................... 151

Six and Twentymile Creex at mouth

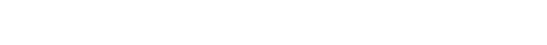

Sixteenmile Branch at U.S. Hwy 250 nr West Augusta............... (SHEN)

Skeen Creek at mouth

nr South Clinchfield.
Skeet Rock Branch at Flannagan

Reservoir nr Bartlick........... (BIG SANDY)

Skegg Branch at mouth nr Bartilck.... (BIG SANDY)

Skidmore Fork along Forest Rd

$$
\text { nr Stokesvilie.................. (SHEN) }
$$

Skidmore Fork at mouth nr Stokesvilie..... (SHEN)

Skiffes Creek above Wood Creak nr Fort Eustis.

(JAMES) es Cregk at Plantation Rd nr Lee Hall.

Skiffes Creek at mouth at Fort Eustis.... (JAMES) 302

Skiffes Creek below Bailey Creek at Fort Eustis...................... JAMEs) 302

Skimino Creek at mouth nr Clay Bank........ (YORK) 199

Skimino Creak below Barlows Pond at Rt 604 ne Light foot

Skinquarter Creok at Rt 603 . . Cl........(YORK) 199

(JAMES) 276

Slabtom Branch at mouth nr Highland.

Slate Branch at Rt 659 nr Christiansburg... (NEW) 448

Slate Branch at mouth nr Radford........... (NEW) 448

Slate Creek above Twin Branch nr Stacy ... . . . . . . . SANDY)

Slate Creek at Rt 1003 at Grundy...... (BIG SANDY)

Slate Creek at U.S. Hwy 460

at Grundy.................... (BIG SANDY)

Slate Creek at mouth at Grundy........ (BIG SANDY)

Slate River above Rt $676 \mathrm{nz}$ Arvonia...... (JAMES)

Slate River at Rt 20 nr Dillwyn........... (JAMES)

Slate River at Rt 642 nr Buckingham...... (JAMES)

Slate River at Rt 652 nr Arvonia........ (JAMES)

Slate River at U.S. Hwy 60 at Buckingham. (JAMES)

Slate River at mouth nr New Canton....... (JAMES)

Slate Run at mouth nr Brentsvilie...... (POTOMAC)

Slate Run trib No. 1 at Rt 28 at Nokesvilie............. (PoTOMAC)

Slate Run trib No. 2 at Rt 649

at Brentsville.............. (POTOMAC)

Slate Spring Branch (Fisher Branch) at mouth nr Cripple Croek...

and.......... (YORK) 183

Sled Creek at mouth nr Hilton......... (HOLSTON)

Sleepy Creek at Rt 697 nr Shockeysville............. (POT-SEEN)

Sleepy Creek, Middle Fork, at $\forall a .-\dot{w} . \dot{V} a$. State line nr Shockeysvilie..... (POT-SHEN)

Sleopy Creek, N.F., at Rt 522 nr Va. -W.Va. State line nr Shockeysville.......... (POT-SHEN)

Slemp Creek at mouth at Sugar Grove.... (HOLSTON)

Slemp Creek trib at Rt 16 nr Sugar Grove................ (HOLSTON)

Sloan (Happy) Creek (Run) nr Front Royal.. (SHEN)

Sloan Branch at mouth nr Draper........... (NEW)

Sluice Creek at mouth nx Champlain.......... (RAPP)

Smacks Creek at Rt $153 \mathrm{nr}$ Scotts Fork.... (JAMES)

Smacks Creek at mouth $\mathrm{nr}$ Chula.......... (JAMES)

Small Creek at mouth nr Charity......... (ROANOKE)

Smallmans Branch at mouth nf Clays Mill.

(ROANOKE)

Smilax Branch at Duiles Airport Rd at Reston.

(POTOMAC)

Smith Branch at mouth at Stacy........ (BIG SANDY)

Smith Branch at mouth nr Jarratt........ (CHOWAN)

Smith Branch at mouth nr Lawyers....... (ROANOKE)

Smith Branch at mouth nr Seaboard........ (CLINCH)

Smith Creek above Rt 634 nr Browntown...... (SHEN)

Smith Creek above old dam ne Clifton Forge.

Smith Creek along Rt 606 above

McGraw Gap nr Clifton Forge....... (JAMES)

Smith Creek at Rt 616 nr New Market........ (SHEN)

Smith Creek at Rt $684 \mathrm{nr}$ Craigsvilie...... (JAMES)

Smith Creek at Rt 717 nr Lacey Spring..... (SHEN)

Smith Creak at Rt 794 nr Lacey Spring..... (SEEN)

Smith Creak at Rt 798 nr Tenth Legion..... (SHEN)

Smith Creek at U.S. Hwy 1

nr Paschall, N.C............. (ROANOKE)
86

25

25

02

461

461

461

461

245

245

246
245

246

93

93

93

521

20

20

20

492

492

63
442

150

277
277

398

392

75

461

326
382

528

51

212

212

56
225

56

56
56 
Abbreviated basin names appear at the end of the site name. Abbreviations are as follows: Eastern Shore (EASTERH); Potomac to Shenandoah (POT-SHEN); Shenandoah (SEEN); Potomac (POTOMAC); Potomac to Rappahannock (POT-RAPP); Rappahannock (RAPP); Rappahannock to York (RAPP-YORK); York (YORK); York to James (YORK-JAMES); James (JAMES); James to Chowan (JAMES-CHOWAN); ChOWan (CHOWAN); ROanoke (ROANOKE); Yadk in (YADKIN); New (NEW); Big Sandy (BIG SANDY); Holston (BOLSTON); Clinch (CLINCH); Powel1 (POWELL) I

Smith Creak at U.S. BWy 211 nr New Market. (SHEN) Smith Creak at mouth at Clifton Forge.... (JAMES) Smith Creek at mouth at Rogers......... (ROANOKE) Smith Creak at mouth nr Bracey.......... (ROANOKE) Smith Creak at mouth nr Craigs Mili.... (HOLSTON) Smith Creek at mouth nr Craigsville...... (JAMES) Smith Creak at mouth nr Forksville...... (CHOWAN) Smith Creak at mouth nr McKenney......... (CHOWAN Smith Creok at mouth nr Mt. Jackson....... (SHEN)

Smith Creek below Dry Fork at Lacey Spring . . . . . . . . . . . (SEEN)

Smith Creak nr Clifton Forge (site now in reservoir).......... (JAMES)

Smith Creok trib at U.S. Hwy 1 nr South $8 \pm 11 \ldots \ldots \ldots \ldots \ldots$ (ROANOKE)

Smith Mountain Dam powerpiant outfail (APCO) nr Penhook............... (ROANOKE)

Smith Mountain Lake at Hales Ford below tales Creak nr Scruggs.... (ROANOKE)

Smith Mountain Lake at dam nr Penhook... (ROANOKE) Smith Mountain Lake nr Scrus8s.......... (ROANOKE)

Smith River (Philpott Reservotr) at Rt 623 nr Endicott.......... (ROANOKE)

Smith River (Philpott Reservoir) off Horseshoe Point nr Bassett...(ROANOKE) 399

Smtth River (Philpott Reservoir) off Goose Point nr Philpott....... (ROANOKE)

Smith River above Cooper Creek nr Bassett.

(ROANOKE)

Smtth River above Goblintown Creok

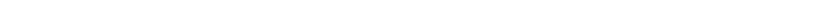

Smith River above Rt 623 nr Endicott... (ROANOKE)

Smith River above Va. $-N, C$. State line nr Spray, N.C. ..... (ROANOKE) 404

Smtth River at Deer Island nr Philpott. (ROANOKE)

Smith River at Goose Point nr Philpott. (ROANOKS)

Smith River at Martinsville Dam

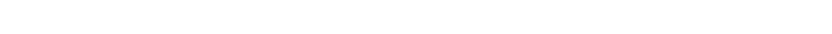

Smith River at Rt 57 (Alternate) at stanleytown.............. (ROANOKE) 401

Smith River at Rt 622 nr Starlings Crossroads.......... (ROANOKE) 404

Smith River at Rt $635 \mathrm{nr}$ Irisburg...... (ROANOKE)

Smith River at Rt 666 (north) (ROAMOKE)

Smith River at Rt 666 (south) at Bassett. . (ROANOKE)

Swith River at Rt 674 nr Philpott....... (ROANOKE)

Smith River at Rt 701 at Fieldale....... (ROANOKE)

Sinth River at Rt 704 nr Chartty....... (ROANOKE)

Smith River at U.S. Hwy 220 (Bypass) nI Fieldale................ (ROANOKE)

Smith River at WHEE radio tower

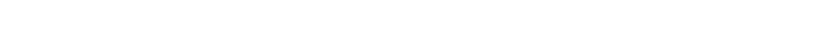

Smith River below Mulberry Creek nr Martinsville..............(ROANOKE) 403

Smith River below Nicholas Creek

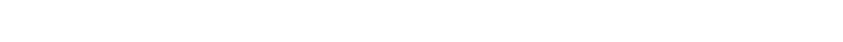

River below Fhilpott Dam nI Philpott................(ROANOKE)

Smith River below
nI Philpott. at Eden (Spray) N.C. . (ROANOKE) 400

Smith River below Rt 609 nr Fieldaij...(ROANOKT) 401

Smith River below Ryans Branch

Smith River below U. S. Hwys $58 / 220$ at Martinsvil10.............(ROAHOKE) 402

Smith River powerplant outfall at Philpott Dam nr Philpott....... (ROANOKE)

Smith River powerplant outfall at

Mertinsville Dam at Martinsville.(ROANOKE) 402

Smith Spring Branch at Natural Bridge.... (JAMES) 223

Smith Swamp at Rt 659 nr Drewryville.... (CHOWAN) 334

Smith Swamp at mouth nr Drewryvi11e..... (CHOWAN) 334

Smithfield Creek (Little Creek) nr Smitheield................... (JAMES) 304

Smoots Mill Run at Horners Pond

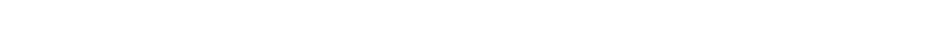

Smoots Run at mouth nr Bowling Green

(YORK)

Smyth Branch at mouth

at Yellow Springs.............. (HOLSTON) 517

Snail Creek at mouth nr Burkevilie.......(CEOWAN) 322

Snake Branch at mouth nr Stony Creek..... (CBOWAN) 328

Snake Creek at U.S. Bwy 501 nr Brookneal............... (ROANOKE) 387

Snake Creek t mouth ir Giadesboro...........(NEW) 439

Snake Run at mouth at Callaway.......... (ROANOKE) 369

Snakeden Branch at Colts Meck Dr at Reston .................... (POTOMAC)

Snakeden Branch at Soapstone $\mathrm{Dr}$ at Reston..................(POTOMAC) 76

Snakeden Branch at mouth nr Vienna..... (POTOMAC) 76

Snakeden Branch trib at Soapstone Dr at Reston.................. (POTOMAC)

Snap Creek at Rt $\ddot{7} \dot{6 j}$ nr stuitz $\ddot{\text { Mili }}$

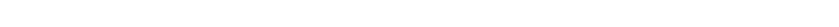

Snap Lodge Branch at mouth or Deht tt.... (CHOWAN)

Snead Branch at mouth nr Horntown...... (EASTERN) 11

Snider Branch at mouth nr Marion........ (HOLSTON) 500

Snow Creak at Rt 969 at Sago........... (ROANOKE) 375

Snow Creek at mouth nr Museville....... (ROANOKE) 375

Snyder Swamp at mouth nr Montross..........(RAPP) 151

Soap Creek at mouth at Ceres........... (HOLSTON) 511

Soapstone Branch at mouth nr Mine Run.....(RAPP) 140

Soloman Creek at mouth nr Lawrenceville. (CHOWAN) 353

Solomon Branch at mouth at Trout Dale...... (NEW) 428

Solomons Creek at mouth nr Provost....... (JAMES) 260

Somerton Creok at Rt 660 at Somerton....(CHOWAN) 347

Somerton Creek at Va.-N.C. State line

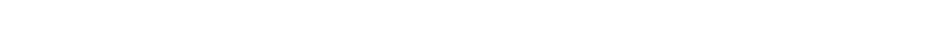

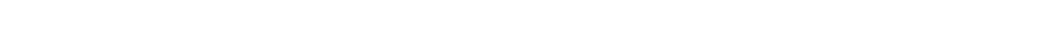

Somerton Creek trib No. 1 at Rt 643

at Somerton............WAN) 347

Somerton Creek trib No. 2 nr cieopus......(CHOWAN) 348

Songbird Creak above mouth nr Ebony..... (ROANOKE) 424

Songbird Creek at Rt 1360 nr Ebony..... (ROANOKE) 424

Sorrel1 Creek at mouth nr Speers Ferry. (CLINCH) 549

South (Saint Marys) River at Rt 608 nr Steeles Tavern............... (JAMES) 228

South Anna River 1,000 ft below Rt 231

South Anna River 600 ft below Rt $23 i$

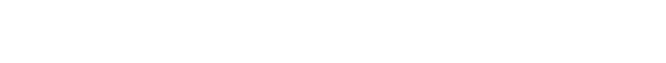

(YORK) Anna River

South Anna River above STP nr Gordonsville.

South Anna River at I-g5 nr Ashland...... (YORK)

South Anna River at Novfield Farm nr Boswells Tavern. $\ldots$ i ne Louisa.

South Anna River at $\dot{R} t 22$ nr Boswells Tavern.

South Anna River at Rt 231 nr Gordonsville.

South Anna River at Rt 601 nr South Anna... (YORK) South Anna River at Rt 603 nr Boswells Tevern.

South Anna River at Rt 604 nr Loutsa.......

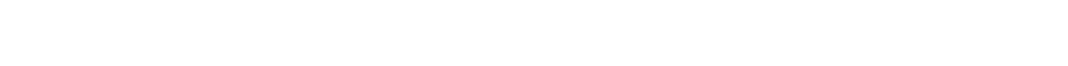

South Anna River at Rt 613 Ar Boswells Tavern. South Anna River at Rt 617 at Vontay........ (YORK) 179
South Anna River at Rt 657 n 19 (YORK) 180 South Anna River at Rt 660 nr Gordonsville................. (YORK) 175

South Anne River at Rt 667 nr Ashiand...... (YORK) 181 South Anna River at Rt 673 nr Rockville... (YORK) 179 South Anna River at Rt $675 \mathrm{nr}$ Montpelter..(YORK) 179 South Anna River at Rt $686 \mathrm{nr}$ Ashland..... (YORK) 181 South Anna River at Rt 695 nr Poindexter

South Anna River at Rt 738 nr Ashland..... (YORK) 182 
Abbreviated basin names appear at the end of the site name. Abbreviations are as follows:

Eastern Shore (EASTERN); Potomac to Shenandoah (POT-SHEN); Shenandoah (SHEN); Potomac (POTOMAC);

Potomac to Rappahannock (POT-RAPP); Rappahannock (RAPP); Rappahannock to York (RAPP-YORK); York (YORK);

York to James (YORK-JAMES); James (JAMES); James to Chowan (JAMES-CHOWAN); Chowan (CHOWAN); Roanoke (ROANOKE);

Yadkin (YADKIN); New (NEW); Big Sandy (BIG SANDY); Holston (HOLSTON); Clinch (CLINCE); POwell (POWELL)!

Page

South Anna River at U.S. Hwy $1 \mathrm{nr}$ Ashland.(YORK)

South Anna River at U.S. Hwy 15 at Boswells Tavern. (YORK)

182

South Anna River at U.S. Bwy 33 nr Ashland.

(YORK) 180

South Anna River below I-95 nr Ashiland... (YORK) 182

South Anna River below Long Creek nr Boswells Tavern.

(YORK)

South Anna River below STP nr Gordonsvilie................. (YORK)

175

South Anna River trib No. I at mouth nr Apple Grove.

(YORK)

178

Anna River trib No. 10

South Anna River trib No. il

at Rt $231 \mathrm{nr}$ Gordonsville...

South Anna River trib No. 2 at mouth nr Holly Grove.

(YORK)

175 Anna River trib No. 3 at mouth

South Anna River trib No. 4 at mouth nr Holly Grove.................

South Anna River trib No. 5 at mouth

South Anna River trib No. 6 at Rt 54 nr Ashland. $\ldots \ldots \ldots \ldots \ldots \ldots$ Niver

South Anna River trib No. 7 at mouth

Anna River trib No. 8 at mouth

nr Ashland.................. (YORK)

(YORK)

179

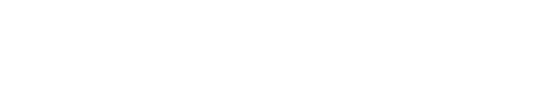
nr Gordonsvilie.

South Anna River trib No. 9 below STP

South Buckskin Creek at Rt 640 nr Jetersvilie.................. (JAMES) 278

South Buckskin Creek at mouth nr Denaro.. (JAMES) 278

South Buffalo Creek at Rt 611 nr Lexington.

South Buffalo Creek at mouth nr Oakdale.. (JAMES) 230

South Buffalo Creek trib at Rt 611 nr Lexington.

(JAMES) 230

$\begin{array}{ll}\text { South Creek at mouth nr Coliumbia.......... (JAMES) } & 247 \\ \text { South Fork at mouth at Shelileys........ (BOLS) } & 520\end{array}$

South Fork at mouth nr Jarratt........... (CHOWAN) 334

South Fork at mouth nr Plasterco......... (HOLSTON) 515

South Mayo River above mouth nr Price... (ROANOKE) 396

South Mayo River at Rt 681

nr Patrick Springs............ (ROANOKE) 395

South Mayo River at $\mathrm{Rt} 68 \mathrm{i} \mathrm{nr}$ Stuart.... (ROANOKE) 395

South Mayo River at Rt $695 \mathrm{nr}$ Spencer...(ROANOKE) 396

South Mayo River at Rt 700 nr Nettler1dge............... (ROANOKE) 395

South Mayo River at Rt 8 at Stuart...... (ROANOKE) 395

South Mayo River, N.F., at U.S. Hwy 58 at Stuart.

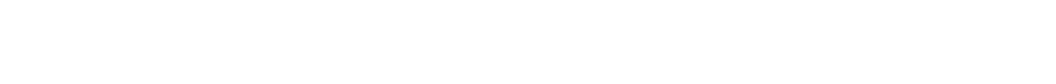

South Meherrin River at $\mathrm{R} t \mathbf{6 3 2}$ nr Chase City...............

South Meherrin River at Rt 633 nr Chase City................. (CHOWAN) 349

South Meherrin River at Rt 634 $n r$ Chase City........... Mr Wightman.................. (CHOWAN) 350

South Prong at mouth nr Ferrum............ (ROANOKE) 372

South Prong at mouth nr Binesvilie..... (ROANOKE) 406

South River (at Basic City) at Lyndhurst $\mathrm{Rd}$ at Waymesboro......... (SHEN) 40

South River above Bridge St

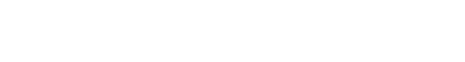

South River above Irish Creak at Cornwall................. JAMES) 228

South River above Sawmi ii Run at Dooms.... (SHEN) 40

South River above U.S. Hwy 250 at Waynesboro ..................... (SHEN)

South River above Waynesboro............... (SHEN)
South River at Bridge St at Waynesboro.... (SHEN) South River at Columbia Pipeline Crossing at Waymesboro..

South River at Hopeman Parkway in Dooms..... (SHEN)

South River at I-95 $\mathrm{nr}$ Ladysmith.........(YORK)

South River at Rt $230 \mathrm{nr}$ Stanardsvilie.... (RAPP)

South River at Rt 56 above Marl Creek at Vesuvius

(JAMES)

South River at Rt 603 nr Cedon........... (YORK)

South River at Rt 608 at Stuarts Draft.... (SHEN)

South River at Rt $608 \mathrm{nr}$ Vesuvius........ (JAMES)

South River at Rt $611 \mathrm{nr}$ Dooms............ (SHEN)

South River at Rt 612 at Crimora......... (SHEN)

South River at Rt $631 \mathrm{nr}$ Riverside....... (JAMES)

South River at Rt 632 at Lyndhurst......... (SHEN)

South River at Rt $634 \mathrm{nr}$ Waynesbora....... (SHEN)

South River at Rt $638 \mathrm{nr}$ Paige.......... (YORK)

South River at Rt 642 above Entry Run nr McMulien..................... (RAPP)

South River at Rt $656 \mathrm{nr}$ Stuarts Draft.... (SHEN)

South River at Rt 659 at Port Republic.... (SHEN)

South River at. Rt 664 at Lyndhurst........ (SHEN)

South River at Rt $664 \mathrm{nr}$ Waynesboro......... (SHEN)

South River at Rt 778 at Harriston........ (SHEN)

South River at Rt 844 at Grottoes.......... (SHER)

South River at U.S. Hwy 11 at Greenvilie.. (SHEN)

South River at U.S. Bwy 250 (Business) at Waymesboro.

South River at U.S. Hwy 250 (Bypass) at Waynesboro..................... (SHEN)

South River at mouth at Port Repubiic..... (SHEN)

South River at mouth nr Lexington........ (JAMES)

South River at mouth $n r$ Milford ........... (YORK)

South River at mouth $\mathrm{nr}$ Stanardsvilie..... (RAPP)

South River below Back Creek nr Waynesboro...................... (SHEN)

South River below Mari Creek at Vesuvius. (JAMES)

South River off Rt $619 \mathrm{nr}$ Crimora......... (SHEN)

South River spring at Vesuvius ......... (JAMES)

South River trib at U.S. Hwy 340 nr Barriston.................... (SHEN)

South River trib nr Maribrook............ (JAMES)

South Run at Burke Lake Rd nr Fairfax Station.............. (POTOMAC)

South Run at Hooes Rd $n r$ Lorton......... (POTOMAC)

South Run at Lee Chapel Rd nr Burke... (POTOMAC)

South Run at Rt 215 nr Buckland........ (POTOMAC)

South Run at Rt $738 \mathrm{nr}$ Ada............. (RAPP)

South Run at mouth nr Bucki and.......... (POTOMAC)

South Run at mouth nr Jeffersonton......... (RAPP)

South Run at mouth $n r$ Lorton........... (POTOMAC)

South Run below Hooes Rd nr Lorton..... (POTOMAC)

Southeast Ditch nr Deep Creek........... (JAMES)

Southerly Run (South Branch) at mouth nr. Hopewell..................... (JAMES)

Southern Branch at mouth nr Quinton........ (YORK)

Southwest Branch at Rt 278 nr Bampton.

(YORK-JAMES)

Southwest Branch at buoy 25 nr Hampton. .................

Southwest Branch at mouth nr Langley View....

Southwest Branch at mouth nr Severn. . (RAPP-YORK) Southwest Branch off W1lloughby

Point nr Bampton.......... (YORK-JAMES)

Southwest Creek at mouth at Stony Creek. (CHOWAN) Sowell Branch at Rt 20 nr Charlottesville............... (JAMES)

Speaks Branch at mouth $\mathrm{nr}$ Rose Hili..... (POWELL)

Speights Run nr mouth at Lake Kilby..... (JAMES)

Spencer Creek at mouth nr Sanville..... (ROANOKE) Spencers Mill Creok at mouth nr Spencer.

Spider Creek at mouth nr resubitcan Grov

Spindlers Run at an Grove............. (ROANOKE)

Spivey Swamp at mouth nr Somerton........ (CHOWAN)

Spoon Croek at mouth nr Penns Store... (ROANOKE)
Page

40

40

40

133

228

191

228

41

41

39

38

191

133

38

42

39
39

42

42

38

40

40

42

229

191

39

228

41
228

41

228

90

91

90

94
119

119

91

300

288

186

203

204

204

165

204 329

244

583 306
396 396

387 278
347 395 
Abbreviated basin names appear at the end of the site name. Abbreviations are as follows:

Eastern Shore (EASTERN); Potomec to Shenandoah (POT-SHEN); Shenandoah (SHEN); Potomac (POTOMAC);

Potomac to Rappahannock (POT-RAPP); Rappahannock (RAPP); Rappahannock to York (RAPP-YORK); York (YORK)

York to James (YORK-JAMES); James (JAMES); James to Chowan (JAMES-CHOWAN); Chowan (CHOWAN); Roanoke (ROANOKE);

Yadkin (YADXIN); New (NEW); Big Sandy (BIG SANDY); Holston (BOLSTON); C11nch (CLINCE); Rowell (POWELL)]

Page

Spoon Gap Creek at mouth

at Green Spring.

Spout Pus mouth nr Be

spout Run at mouth nr Millwood............ (SHEN)

Spreading Spring Branch at Rt 632

at Springwood.

(JAMES)

Spring Branch above U.S. Ewy 460

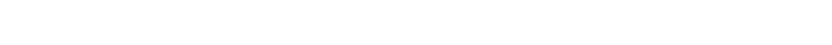

Spring Branch at Rt 613 at Waverly...... (CHOWAN)

Spring Branch at Rt 637 at Shawsville.. (ROANOKE)

Spring Branch at Rt $653 \mathrm{nr}$ Waverly...... (CBOWAN)

Spring Branch at U.S. Ewy 460

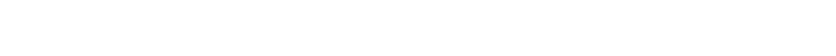

Spring Branch at mouth at Shawsville... (ROANOKE)

Spring Branch at mouth at Waynesboro...... (SHEN)

spring Branch at mouth ar Adstt......... (CBOWAN)

Spring Branch at mouth nr Barham......... (CEOWAN)

Spring Branch at mouth nr Brunswick..... (CBOWAN)

Spring Branch at mouth $n x$ Homeville.....(CHOWAN)

spring Branch at mouth nx Burley..... (BIG SANDY)

Spring Branch at mouth nr Zion Crossroads. (YORK)

Spring Creek (East Fork) at mouth nr Eureka.................. (ROANOKE)

Spring Creek above Spencer Creek nr Eureka...................... (ROANOKE)

Spring Creok at Rt 660 nr Darlington Heights............ (JAMES)

Spring Creek at Rt $665 \mathrm{nr}$ Green Spring. (BOLSTON)

Spring Creek at Rt 700 nr Bampden Sydiney. (JAMES)

Spring Creek at Rt 75 nI Green Spring.. (BOLSTON)

Spring Creek at Rt $750 \mathrm{nr}$ Spring Creek.... (SHEN)

Spring Creek at Sterles Tavern.......... (JAMES)

Spring Creek at U.S. Bory 11

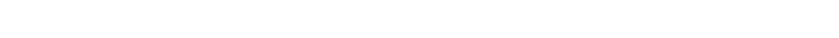

Spring Creek at mouth

nr Tuckahos Village.............. (JAMES) 264

Spring Creek at mouth nr Bampden Sydney... (JAMES) 272

Spring Creek at mouth nr Joyner.......... (CEOWAN) 332

Spring Creak at mouth nr Keysv $\$ 11$ e....... (CEOWAN) 348

Spring Croek off Rt 663 nr Green Spring......

Spring Creek trib at Rt 620 ar Steeles Tavern.

Spring Fork at mouth nr Nora........... (BIG SANDY) 478

Spring Grove Swamp at mouth nr Spring Grove.....................WOWAN) 341

Spring Eollow Run at mouth nr Woodstock... (SHEN) 59

Spring Meadow Branch at mouth nr Jarratt.................... (CHOWAN)

Spring No. 1 (BIacksburg water supply) nr Blacksburs ......... (ROANOKE)

Spring No. 2 (Blacksburg water supply) nr Blacksburg ..........(ROANOKE)

Spring No. 3 (Blacksburg water supp ly) nr Blacksburg .......... (ROANOKE)

Spring Reservoir at Lovingston .......... (JAMES)

Spring Run at mouth nr Hallsboro......... (JAMES)

Spring Run at mouth nr Surry............ (JAMES)

Sprouts Creak at Rt 42 nr Chatham Biii. (HOLSTON)

Sprouts Creek at wouth nr Chatham Bill. (BOLSTON)

Spruce Lick Branch at U.S. Bwy 250

$$
\text { nr West Augusta. }
$$

Spruce Pine Branch at mouth nr Murphy.................. (BIG SANDY)

Spruce Pine Creok at mouth nr Patterson..................... (BIG SANDY)

Spruce Pine Hollow trib at mouth nr South Clinchfield.............(CLINCE)

326

361

361

361

240

301

513

513

Spruce Run at mouth $n \mathbf{r}$ Egleston.......... (NEW)

Spur Branch at mouth nr Long Spur......... (NEW)

Spurlock Branch below Spurlock Cave

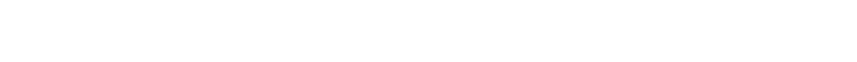

Spurlock Creek at mouth nr Floyd.......... (NEW)

Squirrel Camp Branch at mouth nr Clinchco............... (BIG SANDY)

Squirrel Creek at mouth

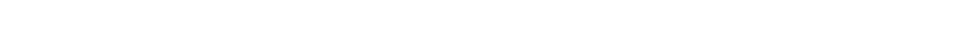

St. Johns Creok at mouth nr Rehoboth.... (CBOWAN) 350
Page

St. Peters Swamp at mouth nr New Kent.... (YORK) 187 Stacy Branch at mouth at Pound........(BIG SANDY) 481 Stacy Branch at mouth $\mathrm{nr}$ Wood........... (CLINCB) 544

Stagg Creek at Rt $54 \mathrm{nr}$ Ashland........... (YORK) 181

Stag8 Creok at Rt $585 \mathrm{nr}$ Ashland..........(YORK) 181

Stagg Creek at mouth $\mathrm{nr}$ Ashland..........(YORK) 181

Staley Creok $2.0 \mathrm{mi}$ above

Merchant Creek nr Marion.........(HOLSTON) 501

Staley Creek $2.5 \mathrm{mi}$ above

Merchant Creek nr Marion......... (BOLSTON)

Staley Creek $3.0 \mathrm{mi}$ above

Merchant Creek nr Marion......... (HOLSTON)

Staley Creek Spring nr Marion.......... (BOLSTON)

Staley Creek at Lee St at Marion........(BOLSTON)

Staley Creek at Rt $688 \mathrm{nI}$ Marion........(BOLSTON)

Staley Creek at mouth at Marion......... (BOLSTON)

Staley Creak below Fish Batchery nr Marton. ................... (BOLSTON)

Stallings Creek at Rt $683 \mathrm{nr}$ Raymor..... (CHOWAN)

Stanardsville Run above Stanardsville STP at Stanardsville............(JAMES)

Stanardsville Run below Stanardsviiie STP at Stanardsville............. (JAMES)

Standiford Cresk at mouth nr Unton Hall............... (ROANOKE)

501

501

501

501

342
74

Standrock Branch at mouth nr Boliy Brook. . . (NEW)

Stanley Valley Creek at mouth nr Wininger................... (BOLSTON)

Star Hill Branch at mouth $n$
Starks Mill Branch at mouth

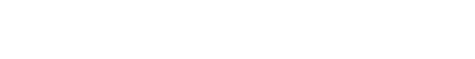

Station Creok above industrial park STP $n r$ Dot.............. (PONELL)

(CHOWAN) preok above mobile home park STP nr Dot............... (POWELL)

Station Creek at Va. -Tenn. State Line nr Gibson Station............. (POWELL)

Station Creok at mouth nr Woodway........ (POWELL)

Station Creek nr Woodway.............. (POWELL)

Staunton Branch at mouth $\mathrm{nr}$ Oak Grova....... (NEW)

Staunton Creek at mouth nr Wood......... (CLINCH)

Staunton River at elov 1280 nr Graves Mill..............

Staunton River at elev 1680 nr Graves M $\$ 11 \ldots 2000$

Staunton River at elev 2000 nr Graves M $11 \ldots . . .2440$

Staunton River at ilov 2440
nr Graves Mill...
Staunton River at alev 2950

(RAPP) nr Graves Mill.

Staunton River at mouth ne Graves Miii (RAPP)

Stave Run at Parking lot Rd at Reston. . (POTOMAC)

Stave Run below Parking Lot Rd nr Reston.

(POTOMAC)

Steel Fork at mouth nr Duncan Gap.... (BIG SANDY)

Steele Creek at Va. -Tenn. State Iine nr Bristol.

(BOLSTON)

Steele Fork at mouth nr Red House. . . . . (ROANOKE)

Steele Run at mouth at Waynesboro.......... (SHEN)

Stegers Creak at mouth nr Provost......... (JAMES)

Stephens Run at Rt 639 at Nineveh (nr Reliance) . ................ (SHEN)

Stephens Run at Rt $640 \mathrm{nr}$ Stephens City... (SHEN) Stephens Run below Rt 1012 at Stephens City ............... (SHEN)

Sterns Creek at Taylor Road nr Boone..... (JAMES)

Steve Keesling Spring at Sugar Grove... (BOLSTON) Stevens Branch at mouth nI Lawrenceville.

(CBOWAN)

Stevens Creek at mouth nr Fries.......... (NEW)

Stevens Mill Run at I-95 nr Ladysmith..... (YORK)

Stevens Mill Run trib above Stevens

Mi11 Run nx Ladysmith............. (YORK)

Stewart Branch at mouth nr Jarratt...... (CEOWAN)

Stewart Creek at mouth nr Whitmel1..... (ROANOKE)
63

354

430

192

192

326

406 
Abbreviated basin names appear at the end of the site name. Abbreviations are as follows Eastern Shore (EASTERN); Potomac to Shenandoah (POT-SHEN); Shenandoah (SHEN): Potomac (POTOMAC); Potomac to Rappahannock (POT-RAPP); Rappahannock (RAPP); Rappahannock to York (RAPP-YORK); York (YORK): York to James (YORK-JAMES); James (JAMES); James to Chowan (JAMES-CHOWAN); Chowan (CROWAN); Roanoke (ROANOKE); Yadkin (YADKIN); New (NEW); Bis Sandy (BIG SANDY); Holston (HOLSTON); Clinch (CLINCH); Powell (POWELL)]

Page

Stewarts Creek at Va. -N.C. State line

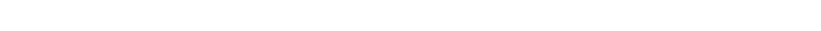

Stidham Fork at mouth nr Norton...........(CLINCH) 539 Stillhouse Branch at mouth

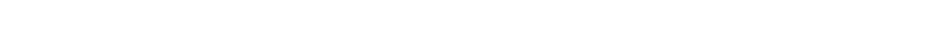

Stillhouse Branch at mouth nr Coulwood.. (CLINCH) 534

Stillhouse Branch nr Concord Church nr Coulwood

(CLINCH) 534

Stillhouse Run at mouth nr Ridgeway.... (ROANOKE)

Stiliwater Creek at mouth nr Loretto...... (RAPP)

Stiltner Creek at U.S. Gory 460 nr Grundy.

(BIG SANDY)

Stiltner Creek at mouth

nr Garman Junction ......... (BIG SANDY)

Stinking Creek at Rt 722 nr Stanleytown. (CLINCH)

Stirking Creek at mouth nr Stanleytown. (CLINCH)

Stirking River at Rt $40 \mathrm{nr}$ Mount Airy.. (ROANOKE)

Stinking River at mouth nr Mount Airy.. (ROANOKE)

Stirking River, N.F., at mouth nr Chalk Level.

(ROANOKE)

tirking River, West Fork, at mouth n Chalk Level............... (ROANOKE)

Stoakes Creek at mouth nr DiBgs....... (RARP-YORK)

Stock Creek above Little stock Creok

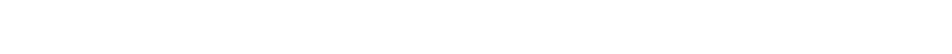
at Natural Tunnel..............(CLINCH) 547

Stock Creek at Rt 644 nr Stony Point Mills.

(JAMES) 275

Stock Creek at Rt 65 at Clinchport.......(CIINCH)

Stock Creek at Rt 871 nr Duffield........ (CLINCH)

Stock Creek at Southern RR at Clinchport.

(CLINCH)

Stock Creek at mouth nr Sunny Side....... (JAMES)
Stock Creek off Forest Rd $239 \mathrm{nr}$ Mabe... (CLINCH)

Stock Creek off Rt 871 nr Duffield...... (CLINCH)

Stockton Creek at Rt $6 \mathrm{nr}$ Afton......... (JAMES)

Stockton Creek at Rt 635 nr Crozet....... (JAMES)

Stockton Creak at U.S. Hory 250 nr Greenwood.

(JAMES) 247

tockton Creak at mouth nr Crozet........ (JAMES)

Stockton Creek trib at C\&O RR nr Greenwood.

(JAMES) 247

Stoffel Creek at U.S. ¿̈ंwy 421 nr Bristol.

Stoffel Creek at Va. -Tenn. State line at Bristol.

(HOLSTON)

511

(HOLSTON)

Stokes Creek at mouth at Riverdale...... (ROANOKE)

Stokes Creek at mouth nr Fort Mitchell.. (CHOWAN)

Stone Branch at mouth nr Honaker........ (CLINCH)

Stone Creek at Rt $765 \mathrm{nr}$ Stone Creek.... (POWELL)

Stone Creek at U.S. Hwy 421

Stone Creek at mouth at Eik Creek ............ (NEW)

(POWELL)

Stone Horse Creek at mouth nr Ashland..... (YORK) 180

Stone Mountain Creek at mouth nr Laurel Fork................... (NEW) 438

Stonecoal Branch at mouth in stacy... (BIG SANDY) 461

Stonecoal Creek at mouth nr South Clinchfield...........(CLINCH) 536

Stonemil1 Creek at mouth nr Piasterco...(HOLSTON) 515

Stonewall Creek at Stapleton........... (JAMES)

Stoney Creek at Rt 628 nr Beach........... (JAMES)

Stoney Creek at former mouth at Lake Chesdin.

(JAMES) 281

Stony Creek above Bedford Reservoir nr Bedford.

(JAMES) 281

reek above little Stony Creek

(ROANOKE) 380 nr Nellysford.

(JAMES) 241

Stony Creek above Rt $\mathbf{6} \dot{6}$ at Fort Blackmore. ................ (CLCH)

Stony Creek along NEW RR at Kimbailiton..... (NEW)

Stony Creek along Rt 675 at Columbia Furnace............... (SHEN)

Stony Creek along Rt 751 nr Neilysford... (JAMES)

Stony Creek along Rts 675/717

nr Liberty Eurnace.............. (SHEN)
Stony Creek at Kimbaliton.

Page

Stony Croek at Rt $609 \mathrm{nr}$ Carson .......(CHOWAN) 328

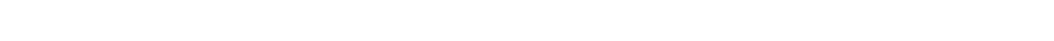

Stony Creek at Rt 619 nr Dinwiddie....... (CHOWAN) 328

Stony Creek at Rt $619 \mathrm{nr}$ Ka..............(CLINCH) 544

Stony Creek at Rt $635 \mathrm{nr}$ Goldbond............ (NEW) 453

Stony Creek at Rt $666 \mathrm{nr}$ Stony Creek.... (CHOWAN) 328

Stony Creek at Rt 675

at Columbia Furnace.................. (SHEN)

Stony Creok at Rt 682 nr Lantz Milis ......(SHEN)

Stony Creek at Rt 691 at Lantz Mills....... (SHEN) 58

Stony Creek et Rt 698 at Edinburg............ (SHEN) 58

Stony Creek at Rt $720 \mathrm{nr}$ Bayse............(SHEN) 57

Stony Creek at U,S Hwy 1 nr Dinwiddie.. (CHOWAN) 328

Stony Creok at U.S. Hwy 11 at Edinburg.... (SHEN) 58

Stony Creek at U.S. Hwy $301 / I-95$ at Stony Creex.

Stony Creek at mouth

nr Hendriciks Store............ (ROANOKE)

Stony Creek at mouth at Edinburg.......... (SHEN)

Stony Creek at mouth at Fort Blackmore.. (CLINCH)

Stony Creek at mouth at Stony Creek..... (CHOWAN)

Stony Creek at mouth nr Forksville....... (CROWAN)

Stony Creak at mouth nr Leesvilie....... (ROANOKE)

Stony Creek at mouth nr Nellysford....... (JAMES)

Stony Creek at mouth nr Peaks of Otter. (ROANOKE)

Stony Creek at mouth nr Pearisburg......... (NEW)

Stony Creek below Caney Fork nr Fort Blackmore

Stony Creek trib at Rt 263 at Orkney Springs

(CLINCH) 545

Stony Creek trib at Rt 40

at Stony Creek. ...... (CHOWAN)

(SHEN)

57

Stony Creek trib at Rts $675 / 717$

nr Liberty Furnace............... (SHEN)

329

Stony Fork at mouth nr Moneta.........(ROANOKF) 377

Stony Fork at mouth nr Rural Retreat....... (NEW) 435

Stony Run (East) at Richmond.............. JAMES) 266

Stony Run (West) at Richmond........................ 266

Stony Run at Coal Rd nr Stuarts Draft...... (SHEN) 38

Stony Run at Rt $656 \mathrm{nr}$ Greenwood......... (JAMES)

Stony Run at U.S. Hwy 220 at mouth nr Bolar............................................ 205

Stony Run at mouth at Alma............... SHEN) 46

Stony Run at mouth at Rocky Bar.........(SHEN) 43

Stony Run at mouth nr Greenwood............... (JAMES) 293

Stony Run at mouth nr Providence Forge... (JAMES) 297

Stony Run at mouth nr Tuckahoe Village... (JAMES) 263

Stony Run trib at mouth nr Providence Forge

Story Creek at Rt 40 at Forrum......(ROANOKF) 372

Story Creek at Rt $607 \mathrm{nr}$ Waidsboro..... (ROANOKE) 372

Story Creak at mouth nr Rocky Mount..... (ROANOKE) 372

Stovall (Beck) Creek at Rt 663 nr Madison Heights.

( JAMES )

235

Stovall Creok above S.F. Stovali Creek nI Lynchburg

(JAMES) 235

Straight Branch at mouth nr Laureidale. (HOLSTON) 497

Straight Creek above STP nr St. Charles. (POWELL) 559

Straight Creak above Turners Siding nr St. Charles............... (POWELL)

Straight Creok along $\mathrm{k} t \mathrm{6} 36$

at St. Charles

(POWELL) 558

Straight Creak at Rt 352 at Stone Creek. (POWELL) 559

Straight Creek at mouth at Stone Creek. (POWELL) 559

Straight Creok below Big Branch

at $\mathrm{St}$. Charles........................... 559

Straight Fork Spring at Ka.............. (CLINCH) 545

Straight Fork above Devil Fork nr Ka.... (CLINCH) 545

Straight Fork above Pound Fork nr Dunbar.

(POWELL) 553

Straight Fork at Va. $-W$. Va state jing nr Hardscrabble............... (POT-SHEN)

Straight Fork at mouth at Ka........... (CLINCH)

Straights tone Creek at Rt 668

nr Straightstone............. (ROANOKE)
20

383 
Abbreviated basin names appear at the end of the site name. Abbreviations are as follows:

Eastern Shore (EASTERN); Potomac to Shenandoah (POT-SHEN); Shenandoah (SHEN); Potomac (POTOMAC);

Potomac to Reppahannock (POT-RAPP); Rappahannock (RAPP); Rappahannock to York (RAPP-YORK); York (YORK)

York to James (YORK-JAMES); James (JAMES); James to Chowan (JAMES-CHOWAN); Chowan (CHOWAN); Roanoke (ROANOKE);

Yadkin (YADKIN); Now (NEW); B Ig Sandy (BIG SANDY); Holston (HOLSTON); Clinch (CLINCH); POWell (POWELL)]

Straightstone Creek at mouth nr Long Is land.

(ROANOKE) 383

Strait Creek above Fish Hatchery nr Blue Grass.

( POT-SHEN)

20

Strait Creek at mouth nr Blue Grass... (POT-SHEN)

Strait Creek trib at U.S. Bwy 220 nr Monterey ...........

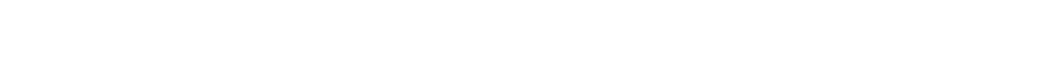

Strawfield Creek at mouth nr Penhook... (ROANOKE) 374

Strawhorn Creek at mouth nr Studley.......(YORK) 185

Streeter Creek at mouth nI Portsmouth.... (JAMES) 308

Strong Branch at mouth nr Gate City......(CLINCB) 548

Strother Run at mouth nr Criglersvilie.....(RAPP) 136

Stroubles Creek at Rt 619 nr BlacksburB ...... (NEW) 448

Stroubles Creek at Rt 659 nr Radford.......(NEW) 448

Stroubles Creek at U.S. Hwy 460

(Bypass) at Blacksburg............NEW) 448

Stroubles Creek at mouth nr Radford........(NEW) 448

Strouds Creak at mouth nr Radford..........(NEW) 447

Strow Creek at mouth nr Dye................ (CLINCH) 530

Stuart Creak at mouth nr Spray, N.C..... (ROANOKE) 404

Stuart Run above Lick Run at Millboro Springs............... (JAMES) 215

Stuart Run at Rt 629 at Green Vailey...... (JAMES) 215

Stuart Run at mouth at Millboro Springs... (JAMES) 215

Stuart Spring nr McDowe11............... (JAMES) 213

Stul1 Run at mouth nr Grottoes.......... (SBEN) 42

Sturgeon Branch at mouth nr Corn Vailey. (CLINCH) 532

Sturgeon Creok at Rt 631 nI Smoky Ordinary

Sturgeon Creek at U.S. How I

nr Warfield.......................WOWA ) 325

Sturgeon Creek at mouth nr Cherry Hiil... (CHOWAN) 325

Sturgeon Creek at mouth nr Deltaville.....(RAPP) 159

Sturgeon Swamp at mouth nI Tappahannock... (RAPP) 153

Sturgill Branch at mouth nr Konnarock. (HOLSTON) 496

Stutts Creek at mouth $\mathrm{nr}$ Redart......(RAPP-YORK) 162

Suanee Creek at Rt 618 at mouth nr Hixburg.

(JAMES) 271

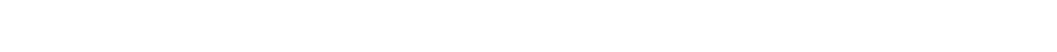

SuckeBB Branch at mouth nr Leatherwood. (ROANOKE) 403

Sugar Run above Trading Creek

nr Rubbard Springs..............(POWELL) 562

Sugar Run at Rt 684 nr Speedweii.............. (NEW) 434

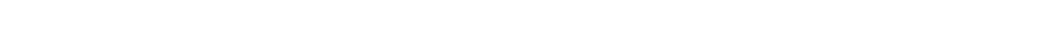

Sugar Run at mouth nr Simpsons.......... (ROANOKE) 358

SuBarland Run at Rt 606 at Herndon.....(POTOMAC) 75

Sugarland Run at Rt 7 nr Dranesville... (POTOMAC) 75

Sugarland Run at mouth nr Dranesville.. (POTOMAC) 75

Sugartree Branch nr mouth nr Vesuvius.... (JAMES) 228

Sugartree Creek at Rt $853 \mathrm{nr}$ Brosville. (ROANOKE) 406

Sugartree Creek at mouth nr Hinesville. (ROANOKE) 406

Sullens Creek at mouth nr Studley........(YORK) 184

Sullivan Branch along Rt $688 \mathrm{nr}$ Duty. (BIG SANDY) 471

Sullivan Branch at mouth nr Duty.....(BIG SANDY) 471

Sullivan Branch nr Long Ridge

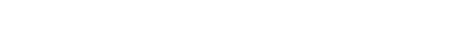

Sullivan Branch trib at mouth

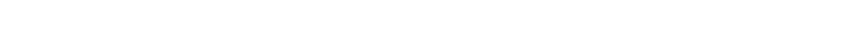

Sulphur Spring Branch at mouth at Dye... (CLINCH)

Sulphur Spring Creak at mouth at Chilhowie.............. HOLSTON) 504

Sulphur Spring Creak trib No. 1 at mouth nI Chilhowie.......... (HOLSTON)

Sulphur Spring Creek trib No. 2 at mouth $\mathrm{nr}$ Chtlhowie................ (HOLSTON) 504

Sumerduck Run at Rt 647 nr Culpeper....... (RAPP) 139

Sumerduck Run at mouth nr Culpeper.......... (RAPP) 139

Sumerduck Run at mouth nr Sumerduck.......... (RAPP) 131

Summers Creek at mouth nr Robbins Chapel.

(POWELL) 558

Sunken Meadow Creek at mouth nr Claremont.

(JAMES) 291

Surline Branch at mouth nr Winterpock..... (JAMES) 280

Surry Martin Branch at mouth at Ridgeway ................ (ROANOKE)
Susong Branch at Euclid Ave

at Bristol.................... (HOLSTON)

Swan Creek at mouth nr Long Isiand...... (ROANOKE) 383

Swans Gut Creek at mouth nr Horntown.... (EASTERN) 11

Sweat Swamp at mouth nr Boykins......... (CHOWAN)

Sweathouse Creek at mouth nr Scotts Fork.

( JAMES )

Sweden Fork at mouth nr Spring Garden. (ROANOKE)

Sweeney Creek at mouth nr Bermuda Bundred.

Sweet Springs Creek at mouth

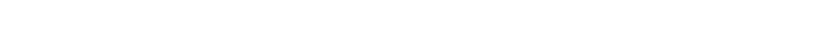

Sweet Springs Creek trib at Rt 311 at Sweet Chalybeate 360 beiow

Swift Creek at U.S. Hiry 360 below Swift Creek Reservotx nr Hallsboro. (JAMES) 286

Swift Creek Reservoir (east shore) nr Hallsboro.................... (JAMES)

Swift Creek Reservoir (middle) nr Hallsboro................... (JAMES)

Swift Creek Reservoir (southeast shore) nr Hallsboro. . . . . . . . . . . . . . (JAMES)

Swift Creak Reservoir belon Rt 669 nr Hallsboro.................. (JAMES)

Swift Creek Reservoir nr Hallsboro........ (JAMES)

Swift Creek above Rt $604 \mathrm{nr}$ Hallsboro.... (JAMES)

Swift Creak above Swift Creek Lake nr Chesterfield................. (JAMES)

Swift Creok above Third Branch

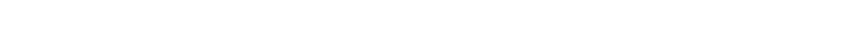

Swift Creek above dan ir Hailsboro......... (JAMES)

Swift Creek at Bradley Bridge Rd

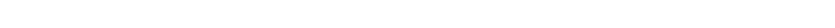

Swift Creek at Rt 604 nr Hailsboro........ (JAMES)

Swift Creek at Rt $646 \mathrm{nr}$ Hallsboro........ (JAMES)

Swift Creek at Rt $653 \mathrm{nr}$ Chesterfield.... (JAMES)

Swift Creek at Rt $654 \mathrm{nr}$ Beach.......... (JAMES)

Swift Creek at Rt $665 \mathrm{nr}$ Chesterfield.... (JAMES)

Swift Creak at Rt 667 nr Hallsboro....... (JAMES)

Swift Creek at Sherwood $D x$ at Colonial Heights............. (JAMES)

Swift Creek at Swift Creek Lake Dam nr Chesterfield.

Swift Creak at U.S. Hwy I

at Colonial Heights.............. (JAMES)

Swift Creek at mouth nr Bopeweii.......... (JAMES)

Swift Run along U.S. How 33 nr Bacon Hollow..................... JAMES) 252

Swift Run along U.S. Hwy 33 at Lydia..... (JAMES) 253

Swift Run along U.S. Hwy 33 nr Lydia..... (JAMES) 252

Swift Run at Rt $810 \mathrm{nr}$ Stanardsville...... (JAMES) 253

Swift Run at mouth nr Earlysville........ (JAMES) 253

Swift Run below U.S. Hwy 33

Swift Run trib at U.S. Biry $\ddot{3} 3$ nr Stanardsvi11e..... Swiftwater Branch at mouth
nr Snow Creek........

(JAMES)

Creek at Rt 622 at Dye...........(CLINCH) 530

Swords Creek at mouth at Swords Creek... (CLINCH) 530

Swover Creek at Rt 42 nr Conicville........(SHEN) 58

Swover Creek at mouth at Lantz M 111 s....... (SEEN) 58

Sycamore Creek at Rt $601 \mathrm{nr}$ Howardsvilie. (JAMES) 240

Sycamore Creek at Rt 643 at Sycamore... (ROANOKE) 379

Sycamore Creek at Rt 924 at Altavista.. (ROANOKE) 379

Sycamore Creek at U.S. Bwy 29 nr Altavista.

(ROANOKE) 379

Sycamore Creek at mouth at Aitavista... (ROANOKE) 379

Sycamore Creek at mouth nr Charity..... (ROANOKE) 398

Sycamore Creek at mouth nr Howardsvilie..(JAMES) 240

Sycamore Creek trib at Rt 924 at Altavista................ (ROAHOKE) 379

Sycolin Creek above mouth nr Leesburs.. (POTOMAC) 72

Sycolin Creek at mouth nr Leesburg...... (POTOMAC) 72

Sycolin Creek, S.F., at U.S. Bwy is nr Leesburg ................... (POTOMAC)

Synders Branch at highway shop bridge at Salem.................... (ROANOKE) 
Abbreviated basin names appear at the end of the site name. Abbreviations are as follows Eastern Shore (EASTERN); Potomac to Shenandoah (POT-SHEN); Shenandoah (SHEN); PotOmac (POTOMAC); Potomac to Rappahannock (POT-RAPP); Rappahannock (RAPP); Rappahannock to York (RAPP-YORK); York (YORK); York to James (YORK-JAMES); James (JAMES); James to Chowan (JAMES-CHOWAN); Chowan (CHOWAN); Roanoke (ROANOKE); Yadkin (YADKIN); New (NEW); Big Sandy (BIG SANDY); Holston (HOLSTON); CIinch (CLINCH); POWell (POWELL)]

Ta River above Mat River nr Ladysmith.....(YORK) 190 Ta River at Rt 208 nr Brokenburg .......... (YORK) 190 Ta River at Rt 738 nr Snell. ...................... 190 Tabbs Creak at mouth nr Foxwoils....... (POT-RAPP) 116 Tabbs Creek at mouth nr Poquoson.... (YORK-JAMES) 203 Tain Branch at mouth nr Lawrenceville... (CHOWAN) 353 Talbott Reservolr nr Kibler............. (ROANOKE) Tank Hollow Branch at mouth ne Stephens.

(BIG SANDY) 482

Tanker Creak at mouth nr Toshes........ (ROANOKE) 372

Tannery Spring nr Atkins.............. (HOLSTON) 499

Tanyard Branch at Rt 646 nr Hampden Syndey.

(JAMES) 274

Tanyard Branch at STP nr Chatham........ (ROANOKE) 412

Tanyard Branch at mouth at Buffalo springs ............. (ROANOKE)

417

Tanyard Branch at mouth

nr Lawrenceville.

(CHOWAN) 352

Tanyard Branch at mouth $n=$ Martinsville.

(ROANOKE) 403

Tanyard Branch at mouth at Chatham...... (ROANOKE) 412

Tanyazd Bzanch at mouth at Saxi......... (ROANOKE) 391

Tanyard Branch at mouth $\mathrm{nr}$ Birch....... (ROANOKE) 409

Tanyard Bzanch at mouth $n=$ Firldai .... (ROANOKE) 401

Tanyard Branch at mouth nr Louisa.......... (YORK) 177

Tanyard Branch at mouth nr Red House... (ROANOKE) 388

Tanyard Branch below U.S. Hiwy 15 nr Hampden Sydney............... (JAMES) 274

Tanyard Croek at mouth $\mathrm{n}$ s Axton........... (ROANOKE) 406

Tanyard Swamp at mouth ne Sparta..........(YORK) 193

Tardy Branch at mouth nr Otter River... (ROANOKE) 382

Tarpon Branch at Flannagan Reservoir ne Tarpon.

(BIG SANDY) 486

Tarrara Creok at $\mathrm{Rt} 35$ at Boykins.......(CBOWAN) 357

Tarrara Creek at Rt 667 nr Boykins...... (CHOWAN) 357

Tarrara Creek at Rt 670 at Boykins....... (CROWAN) 357

Tarrara Creek at mouth nr Boykins........ (CHOWAN) 357

Tarrara Creek trih No, 2 at Rt 667

CBOWAN) 357

Tarrara Creek trib at Boykins .............. (CHOWAN) 357

Taskinas Creek at mouth nr Croaker.........(YORK) 199

Tastine Swamp above Corbin Pond nr West Point.

(YORK)

Tate Run at mouth nr Wythevili.

Tattle Branch ahove Hall Creek nr Glade Spring.

197

(HOLSTON) 505

Tattle Branch at mouth at Chilhowie.... (BOLSTON) 504

Taylor Branch (Occohannock Cre日k) nr Painter.

(EASTERN) 15

Taylor Branch at mouth nz Hayters Gap.

Taylor Creek at Rt 180 at Pungoteague..(EASTERN) 15

Taylor Creek at mouth at Harborton.... (EASTERN) 16

Taylor Creek at mouth nr Greenfield...... (JAMES) 241

Taylor Creek at mouth $\mathrm{nr}$ Irvington........(RAPP) 158

Taylor Run above Rt 236 at Alexandria.. (POTOMAC) 84

Taylor Springs at Cedar Bluff........... (CLINCH) 527

Taylors Branch at mouth nI Scotts Fork... (JAMES) 279

Taylors Creek at Rt $610 \mathrm{nr}$ Montpelier.....(YORK) 180

Taylors Croek at Rt $611 \mathrm{nr}$ Montpolier......(YORK) 180

Taylors Creek at Rt $617 \mathrm{nr}$ Montpelier......(YORK) 180

Taylors Creek at Rt $664 \mathrm{nr}$ Holly Grove.... (YORK) 180

Taylors Creek at Rt $673 \mathrm{nr}$ Montpelier.....(YORK) 180

Taylors Croek at Rt 691 nr Montpeliar..... (YORK) 180

Taylors Croek at Rt $715 \mathrm{nz}$ Montpolier...... (YORK) 180

Taylors Creek at mouth nr Brodnax........(CHOWAN) 351

Taylors Creek at mouth nr Montpelier.......(YORK) 180

Taylors Croek trib No, 1 at mouth nr Holly Grove.

(YORK) 180

Taylors Creok trib No. 2 at mouth ne Holly Grove.

(YORK) 180

Tea Branch at mouth nr Cochran........ (CHOWAN) 353

Teels Creek at mouth nr Wirtz........... (ROANOKr) 370

Telegraph Road Spring at Prince Wiiliam Forest Park at Dumfries......... (POTOMAC) 106

Templeman Run at mouth nr Nomini....... (POTOMAC) 111

Terrapin Creek at mouth nr Leesvilie... (ROANOKE) 376

Torraptn Swamp at Rt 616 nr Raynor...... (CHOWAN) 341

Terrapin Swamp at mouth ne Raynor........ (CHOWAN) 341
Terrible Creek at mouth ne Halifax.

Terry Branch at mouth $\mathrm{nr}$ Grady.

Terrys Creek at mouth nr Floyd.

Terrys Creek at mouth ne Phenix.

Terrys Run at Pamunkey Creek Channel in Lake Anna.

$\ldots \ldots \ldots$ (YORK) 169

Terrys Run at Rt $629 \mathrm{nr}$ Tatum.

Terrys Run at Rt 651 at Lake Anna.

Terrys Run nr Vulcan nr Tatum..

Thacker Branch at mouth at Norto.......... (YORK) 169

Thalia Croek at U.S. Hwy 58

at Thalia................. (JAMES-CHOWAN) 31

at Thalia................. (JAMES-CHOWAN) 31

(ROANOKE) 415

NOKE) 375

(NEW) 444

ROANOKE) 388

Therp Creak at mouth 398 Run $n x$ Montross

The Glade at mouth at Reston........... (POTOMAC) 76

The Gulf at mouth $\mathrm{n}$ E Eastillie........ (EASTERN) 14

Third Branch at mouth nr Beach............(JAMES) 286

Thomas Creek at Rt 20 at Keene........... (JAMES) 244

Thomas Spring nr Marion...............(BOLSTON) 501

Thompson Creek at N\&W RR $n=$ Honaker..... (CLINCH) 534

Thompson Creek at $\mathrm{Rt} 39 \mathrm{nz}$ Bath Alum.... (JAMES) 215

Thompson Creek at Rt $646 \mathrm{nr}$ Coulwood.... (CLINCH) 534

Thompson Creek at Rt 663 at Artrip.......(CLINCH) 534

Thompson Creok at mouth $\mathrm{nr}$ McClung........(JAMES) 215

Thompson Creek nr gonaker..............(CLINCH) 534

Thorne Springs Branch at U.S. Hwy ii ne Duhlin.

(NEW) 443

Thorne Springs Branch at mouth nr Pulaski... (NEW) 443

Thornton (S.F. Thornton) River along U.S. Hiwy 522 at Sperryville...

(RAPP) 123

Thornton River along Rt $62.8 \mathrm{nr}$ Rixeyville.(RAPP) 126

Thornton River along U.S. Hwy 211

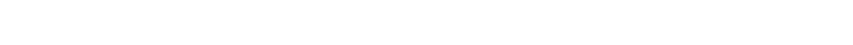

Thornton River at Rt 618 at Laurei Milis.. (RAPP)

Thornton River at Rt 620 at

Fletcher Mill nr Sperryville........ (RAPP) 124

Thornton River at Rt 626 nr Washingtion.... (RAPP) 124

Thornton River at Rt $640 \mathrm{nr}$ Laurol Milis.. (RAPP) 126

Thornton River at Rt $729 \mathrm{nr}$ Laurel Mills.. (RAPP) 126

Thornton River at U.S. Bwy 522 at Sperryville................. (RAPP) 123

Thornton River at mouth ir Rixeyviiie.....(RAPP) 126

Thornton River trib No. 1 at Rt 622 nr Laurel Mills................ (RAPP)

Thornton River trib No. 2 at Rt 626

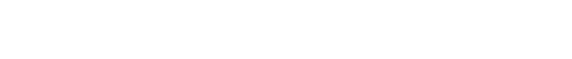

Thornton River trib No. 2 at mouth ns Laurel Mills....... nr Laural Mills.

Thornton River trib at U.S. Hwy $2 i$

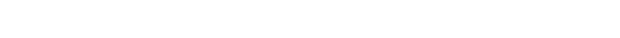

Thornton River, N.F., along Forest Rd nr Sperryvilie.

Thornton River, N.F. at

U.S. Hwys 211/522 at Sperryrille... (RAPP)

Thornton River, N.F., at Rt 612

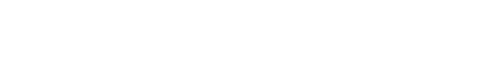

Thornton River, N.F. ne Sperryvilie...... mouth

Thornton River, N.F., trib at mouth nr Thornton Gap.

Thorntons Creek at mouth nr Achilles. (RAPP-YORK)

Thorny Branch at mouth $\mathrm{nr}$ Mt. Solon....... (SEEN)

Thorpe Branch at RIchmond.............. (JAMES)

Thrashers Creek at Sandidges.

(JAMES) 238

Three Creek at Rt $609 \mathrm{nr}$ Sebreli.

Throe Croek at Rt 611 nr Adams Grov

Three Croek at Rt $616 \mathrm{nr}$ Emporia........ (CHOWAN)

Three Creek at U.S. Hwy $301 \mathrm{nr}$ Emporia.. (CHOWAN)

Three Croek at mouth nr Sehrell......... (CHOWAN)

Three Crook trib No. 2 at Rt 612 ne Drewryville........ 612

nr Drewryville.

(CHOWAN)

(CHOWAN)
126

123 
Abbreviated basin names appear at the end of the site name. Abbreviations are as follows:

Eastern Shore (EASTERN); Potomac to Shenandoah (POT-SBEN); Shenandoah (SHEN); Potomac (POTOMAC);

Potomac to Rappahannock (POT-RAPP); Rappahannock (RAPP); Rappahannock to York (RAPP-YORK); York (YORK);

York to James (YORK-JAMES); James (JAMES); James to Chowan (JAMES-CHOWAN); Chowan (CHOWAN); Roanoke (ROANOKE)

Yadkin (YADKIN); New (NEW); Big Sandy (BIG SANDY); Holston (HOLSTON); Clinch (CLINCH); Powell (POWELL)]

Three Creek trib No. 4 at Rt 608 nr Joyner. . $\ddot{U} . \dot{s}$. Hiwy 58

Three Creek trib at

(CHOWAN)

(CHOWAN)

Three Forks at NEW RR in Duty......... (BIG SANDY)

Three Forks at mouth nr Duty......... (BIG SANDY)

Three Forks below Johns Fork nr Duty. (BIG SANDY)

Three and Twentymile Branch at mouth at Grundy.

(BIG SANDY)

Thronton River above Beech Spring

Hollow ar Sperryville.

(RAPP)

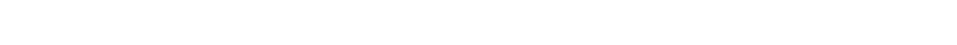

Thumb Run at mouth nr Amissville.......... (RAPP)

Thumb Run, East Branch, at mouth nr Fint Hill.

(RAPP)

Thumb Run, West Branch, at Rt 647 ne Flint Hill.

Thumb Run, West Branch, at Rt 698 ne Hume. (RAPP)

Thumb Run, West Branch, at mouth nr Flint Hill.

(RAPP)

Thweatt Branch at $R t 735$ at Sussex...... (CHOWAN)

Tide Mill Creok at Lansley

Air Force Base nr Hampton.....(YORK-JAMES) 203

Tide Mill Creek at mouth nr Hampton.................. (YORK-JAMES)

Tide Spring (ebbing \& flowing spring) nr Broadway .................... (SHEN)

Tide Spring nr Marion $\ldots \ldots \ldots$ at Birchleaf .............. (BIG SANDY)

Tiller Fork above Left Fork nr Duty.. (BIG SANDY)

Tiller Fork along Rt 601 nr Duty..... (BIG SANDY)

Tiller Fork at mouth at Duty......... (BIG SANDY)

Tiller Fork trib at mouth ne Duty.... (BIG SANDY)

Timber Branch Swamp at mouth nr Church Vtew............. (RAPP-YORK)

Timber Branch Swamp trib at Rt 610

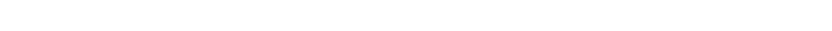

Timber Swamp at $\mathrm{Rt} 637$ nr Rayor............ (CHOWAN)

Timber Swamp at mouth nI Raynor.......... (CHOWAN)

Timberneck Creek at mouth nr Wicomico...... (YORK)

Timbertree Branch at Va.-Tenn. State line nr Maces Spring.

Timer Branch at Ivy Hill Cemetery

at Alexandria..................... (POTOMAC)

(

Tinker Creek $2 \mathrm{mi}$ above U.S. Hwy 460

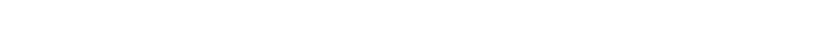

Tinker Creek at Mason Mi $\ddot{\text { ij }} \dot{\mathrm{R}}$ at Roanoke.

Tinker Creek at Preston Ave at Roanoke. (ROANOKE)

Tinker Creek at Roanoke............... (ROANOKE)

Tinker Creek at Rt 1835 at Hoilins....... (ROANOKE)

Tinker Creek at Rt 24 at Roanoke....... (ROANOKE)

Tinker Creek at Rt 604 at Cloverdale... (ROANOKE)

Tinker Creek at U.S. Bwy 11 at Cloverdale.

(ROANOKE)

Iinker Creek at U.S. Hiwy ii nr Cloverdale... (ROANOKE) 365

Iinker Creek at U.S. Hwy 11 at Holiins. (ROANOKE) 365

Tinker Creok at Walnut St nr Vinton.... (ROANOKE) 366

Tinker Creek at mouth at Roanoke........ (ROANOKE) 366

Tinker Creek below Carvin Creek nr Eollins.

(ROANOKE) 365

Tinker Creek below Nin RR nr Dalevilie. (ROANOKE) 365

Tinker Creek nI Cloverdale............(ROANOKE) 365

Tinpot Run at U.S. Hwys $15 / 29$

(Business) at Remington.......................... 127

Tinpot Run at mouth nr Remington............ (RAPP) 127

Tinsley Creek at mouth nr Melrose........ (ROANOKE) 383

Tipers Creek at mouth nr Mila......... (POT-RAPP) 114

Titlow Creek (South Branch) at mouth

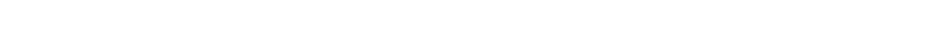

Titus Creek at mouth in Fieidale......... (ROANOKE) 401

Toe Ink Swamp at mouth at Roxbury........ (JAMES) 296

Toe Ink Swamp below Kent Lake Dam nr Roxbury.

(JAMES) 296

Toeclout Branch at mouth ir Ridgeway... (ROANOKE) 397
Tom Fork at mouth nr Prater.

(BIG SANDY)

Tom Fork at mouth nr RingBold.......... (ROANOKE)

Tomahawk Creek above Church Run nr Orange ....................... (YORK)

Tomahawk Creek above Littie Tomahawk

Creek nr Hallsboro............... (JAMES) 285

Tomahawk Creek at Lynchburg............. (JAMES) 234

Iomahawk Creek at Rt 612 nr Orange........... (YORK) 168

Tomahawk Creek at Rt $649 \mathrm{nr}$ Climax......... (ROANOKE) 375

Tomahawk Creek at Rt $652 \mathrm{nr}$ Hallsboro.... (JAMES) 285

Tomahawk Creek at former mouth in Swift Creek Reservoir nr Hallsboro. (JAMES)

at Reservois ne Hallsboro, (JAMES)

Tomahund Creek at mouth nr Claremont. (ROANOKE) 376

Tommeheton Creok at mouth nr Rawlings... (CHOWAN) 324

Tomms Ditch at mouth nr Cedar Grove... (EASTERN) 13

Toms Brook at Rt 747 nr Toms Brook......... (SHEN) 59

Toms Brook at U.S. Hwy 11

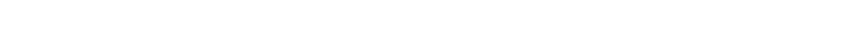

Toms Brook at mouth $\mathrm{nr}$ Toms Brook........... (SHEN)

Toms Creek above Little Toms Creek at Cooburn.

(CLINCH)

Toms Creek at May Ave at Coeburn........ (CLINCE)

Toms Creek at Rt 652 at Toms Creek....... (CLINCH)

Toms Creek at mouth at Coeburn............ (CLINCH)

Toms Creek at mouth nr McCoy................ (NEW)

Toms Creek at mouth nr Snow Creek....... (ROANOKE)

Tongue Quarter Creek at mouth nr Curdsville.

( JAMES )

Tonyham Swamp at mouth ne Providence Forge.

(JAMES)

Toole Creek at mouth nr Brumiey Gap..... (HOLSTON) Toots Creek at mouth nr Halifax........ (ROANOKE)

Totaro Creek at mouth nr Lawrenceville.. (CEOWAN)

Totier Creek at Rt $6 \mathrm{nr}$ Scottsville...... (JAMES)

Totier Creek at Rt 726 nr Scottsvilie.... (JAMES)

Totier Creek at mouth nr Scottsville..... (JAMES)

Totopotomoy Creek at Rt $605 \mathrm{nr}$ Manquin.... (YORK)

Totopotomoy Creek at Rt 606 nr Studley.... (YORK) Totopotomoy Creek at U.S. HWy 301 nr Atlee.

(YORK)

Totopotomoy Creek at mouth nr Studley..... (YORK)

Totuskey Creek at Rt $3 \mathrm{nr}$ Haynesville.... (RAPP)

Totuskey Creek at Rt 619 nr Emmerton....... (RAPP)

Totuskey Creek at mouth nr Heynesvili..... (RAPP)

Totuskey Creek trib at mouth nr Farnham... (RAPP)

Town Branch at Rt 606 at Fincastle...... (JAMES)

Town Branch at Rt 654 nr Jonesvilie...... (POWELL)

Town Branch at U.S. Hwy 220 nr Fincastie. (JAMES

Town Branch at mouth nr Jonesville...... (POWELL)

Town Branch trib at mouth at Jonesville. (ROWELL)

Town Bridge Swamp nr Urbanna............. (RAPP)

Town Creek above N\&W RR nr Phi ipott..... (ROANOKE)

Town Creek at Rt 674 at Philpott....... (ROANOKE)

Town Creek at mouth at Philpott...... (ROANOKE)

Town Creek at mouth nr Abingdon........ (HOLSTON)

Town Hill Creek at Hillcreek Rd at Doran........................... (CLCH)

Town Run at mouth nr Calverton...... (POTOMAC)

Town Run nr Calverton............... (POTOMAC)

Town Run trib No. 1 at Rt 609

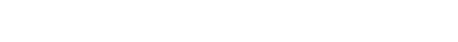

Town Run trib No. 2 at Rt 609 ar Somerville.

Town Spring overflow nr Marion............... (HOLSTON)

Townes Reservoir aqueduct outlet nr Kibler. (ROANOKE) 39

Townes Reservoir ni Kibier............ (ROANOKE) 394

Townsend Run at Rt $84 \mathrm{nr}$ Mi $i j$ Gap.......... (JAMES) 206

Trace Fork Branch along Rt 83 nr Vansant........ mouth nr Vansant................ (BIG SANDY)

Trace Fork at mouth ir Duncan Gap.... (BIG SANDY)

Trace Fork at mouth nr Herald........(BIG SANDY)

Tract Fork at Rt 640 at Pulaski........... (NEW)

Tract Fork at Rt 674 at Pulaski.................

Tract Fork ot mouth at Pulaski............ (NEW) 
Abbreviated basin names appear at the end of the site name. Abbreviations are as follows: Eastern Shore (EASTERN); Potomac to Shenandoah (POT-SREN); Shenandoah (SHEN); Potomac (POTOMAC); Potomac to Rappahannock (POT-RAPP); Rappahannock (RAPP); Rappahannock to York (RAPP-YORK); York (YORK); York to James (YORK-JAMES); James (JAMES); James to Chowan (JAMES-CHOWAN); ChOWan (CHOWAN); ROanoke (ROANOKE); Yadikin (YADKIN); Now (NEW); Big Sandy (BIG SANDY); Holston (HOLSTON); Clinch (CLINCH); POWell (POWELI)]

Pago

Trading Creek above Sugar Run nr Hubbard Springs...

Trading Creek trib at mouth nr Hubbard Springs.

(POWELL) 562

Traymer Branch at mouth

Tribulation Creok at U.S. Hwy 60 nr Amherst. . . . . . . . .

Tribulation Creok trib at Rt 643 at Amherst.

Tribulation Creek trib at u.s. Hiwy 60 at Amberst..

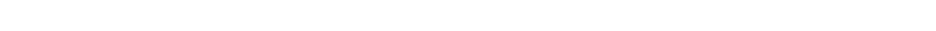

Tripps Run above Lake Barcroft nr Falls Church............... (POTOMAC) 82

Tripps Run above South Washington $\mathrm{St}$ at Falls Church .............. (POTOMAC)

Tripps Run at Arnandale Rd at Falls Church.............. (POTOMAC)

rripps Run at Lake Barcroft n: Falls Church

(POTOMAC) Run at Sleepy Holiow Rd ne Falls Church.............. (POTOMAC)

rripps Run at Southwest $\mathbf{s t}$ at Falls Church

( Run trib at Holmes Run Rd nr Falls Church.............. (POTOMAC)

Trotters Creok at mouth nr Brosviilo... (ROANOKE)

roublesome Creek at mouth at Speers Eerry.....

Troublesome Creek at mouth nr Otter River.

(ROANOKE)

(ROANOKE)

Trough Run at mouth ni Moneta.

Trout Branch at mouth nr Hillsville....... (NEW)

Trout Creak at mouth nr Abbott.

(RAPP)

Trumpet Branch at mouth at Richmond.

(JAMES)

Tryall Creek at Rt 607 nr Smoky Ordinary.

Tryall Creek at mouth nr Smoky Ordinary. (CHOWAN) 333

ruckahoe Creek at Rt 6 nr Tuckahoe Village.

Tuckahoe Creek at U.S. Hwy 250 nr Centerville.

Tuckahoe Creek at mouth nI Tuckahoe Village.............. (JAMES)

Tucker Swamp at mouth at Zuni........... (CHOWAN) Tus Fork at Rt 3 nr Wharncliffe, W.Va.......... (BIG SANDY)

uggle Creex at mouth nr Meadows of Dan..........

(ROANOKE) 393

Tumbling Creek above Laurei Bed Creek

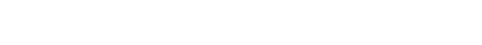

(HOLSTON) 516

Tumbling Creek above Red Creek

nr Saltville................(BOLsTON) 516

Tumbling Creek at mouth nr Piasterco... (HOLSTON) 516

Tumbling Creek below Red Creok

nr Saltvi110,................(BOLSTOR)

Tumbling Run at U.S. Hwy $1 i$ nr Strasburg.. (SEEN)

Tumbling Run at mouth nr Strasburg....... (SEEN)

Tunne 1 Branch at mouth at Crimora......... (SEEN)

Tunnels Mill Branch at mouth nr New Church.

(EASTERN)

Tunnels Mill Branch below

Hancock Branch nr Oak Hall.... (EASTERN)

Turkey Branch at mouth ne Phenix........ (ROANOKE)

Turkey Creek at mouth nr Dickinson...... (ROANOKE)

Turkey Creek at mouth nr Hallsboro........ (JAMES)

Turkey Creek at mouth $\mathrm{nr}$ Holly Grove...... (YORK)

Turkey Eg8 Creek at mouth nr Rawlings... (CHOWAN)

Turkey Fork at mouth nr E1k Creek.......... (NEW)

Turkey Is land Creek at mouth nr Barnett.. (JAMES)

Turkey Run Creek at mouth at MCCready.. (HOLSTON)

Turkey Run above Mine Run nz Fivemile Fork.

(RAPP)

Turkey Run at Rt 623 at wheatfieid......... (SREN)

Turkey Run at Rt 668 nt Brucetown..... (BOT-SEEN)

430

270

514

144 61
Turkey Run at Wakefield Chapel Ro

nz Annandale................ (POTOMAC)

Turkey Run at mouth at Watts............ (JAMES)

Turkey Run at mouth nr Annandai $\ldots . . . .$. (POTOMAC)

Turkey Run at mouth $n$ r Catlett........ (POTOMAC)

Turkey Run at mouth n Mazlbozo...... (SHEN)

Turkeycock Creek at Rt 969 at Sago....... (RÓANOKE)

Turkeycock Creek at mouth nr Spray, N.C.

(ROANOKE)

Turkeycock Creok at mouth nr Musevilio. (ROANOKE)

Turkeycock Creek, N.F., at mouth at Mountain Valley

Turkeycock Run above Rt 236

at Lincolnia ................ (POTOMAC)

Turkeycock Run at Chowan St at Alexandria.........

Turkey Alexandria.............. (POTOMAC)
Turkeycock Run at Rt 236 at Lincoinia.. (POTOMAC)

Turkeycock Run at Shirley Hwy at Alexandria ............ (POTOMAC)

Turkeycock Run at mouth at Alexandria.. (POTOMAC)

Turkeylick Branch at mouth nr Fairview. (CLINCH)

Turner Run at mouth $n \mathrm{r}$ Yellow Tavern..... (JAMES)

Turners Creek at mouth nr Ferrum....... (ROANOKE)

Turners Creek at mouth $n r$ South Anna...... (YORK)

Turnip Creek at mouth nr Crossroads.... (ROANOKE)

Turpin Creek at mouth nr Glenmore......... (JAMES)

Tuscarora Creok above Rt 653 nr Leesburg. ............ (POTOMAC)

Tuscarora Creek above STP nr Leesburg. (POTOMAC) Tuscarora Creek at Rt 643 at Leesburg.. (POTOMAC)

Tuscarora Creek at Rt $653 \mathrm{nr}$ Leesburg.. (POTOMAC)

Tuscarora Creek at U.S. HWy 15 at Leesburg. .

(POTOMAC)

Tuscarara Creek at mouth ir Lessburg... (POTOMAC)

Tuscarora Creek below STP nr Leesburg.. (POTOMAC)

Tuscarora Creek nr Leesburg........... (POTOMAC)

Tusekiah Creak at mouth nr Meherrin..... (CHOWAN)

Tussocky Creok at mouth nr Rustburg...... (JAMES)

Twittys Creok above Rt 47

at Drakes Branch ............. (ROANOKE)

Twittys Creek above STP (south) at Drakes Branch.

Twittys Creok at Drakes Branch ............ (ROANOKE)

Twittys Creek at Rt 47

at Drakes Branch.............. (ROANOKE)

Twittys Creek at Rt $642 \mathrm{nr}$ Saxe......... (ROANOKE)

Twittys Creek at mouth at Saxe......... (ROANOKE)

Twittys Creok below Gilliam Branch

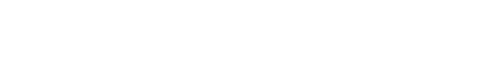

Twittys Creek below STP (south)

(ROANOKE)

(ROANOKE) 391

Twittys Creek nr Drakes Branch......... (ROANOKE)

Twomile Run at Park Rd nr McGaheysvilie... (SEEN)

Twomile Run at mouth nr Rocky Bar........ (SEEN)

Tye (Buffalo) River nr Norwood........... (JAMES)

Tye River at Roseland.................. (JAMES)

Tye River at Rt $158 \mathrm{nr}$ Lovingston....... (JAMES)

Tye River at Rt 56 at Massies Mili....... (JAMES)

Tye River at Rt 626 at Norwood......... (JAMES)

Tye River at U.S. Hwy 29 nr Tye River... (JAMES)

Tye River at mouth at Norwood.......... (JAMES)

Tye River below S.F. Tye Rtver at Rt $56 \mathrm{nr}$ Massies Mill.......... (JAMES)

Tye River nr Rosel and ................... (JAMES)

Tye River nr Tye River .............. (JAMES)

Tye River, N.F., at Nash.............. (JAMES)

Tye River, S.F., at Nash............ (JAMES)

Tygers Creek at Rt 159 at mouth at Crows. (JAMES)

Tylers Branch at mouth nr Ammon......... (JAMES)

age

87

253
87

92

61
375

404

375

3) 5

83

83

83

83

551
293

372

178

387
246

73

73
73

73

73

73
73

73

348

235

391

391

391

391

391

391

391

391
44

44

240

237

237

236
240

238

240

236

237

238
236

236

210
Underhill Branch at mouth nr Newr1l1e...(CHOWAN) 331 Union Camp out fall nr Riverdale........ (CHOWAN) 346 
Abbreviated basin names appear at the end of the site name. Abbreviations are as follows: Eastern Shore (EASTERN); Potomac to Shenandoah (POT-SHEN); Shenandoah (SHEN); Potomac (POTOMAC);

Potomac to Rappahannock (POT-RAPP); Rappahannock (RAPP); Rappahannock to York (RAPP-YORK); York (YORK);

York to James (YORK-JAMES); James (JAMES); James to Chowan (JAMES-CBOWAN); Chowan (CHOWAN); Roanoke (ROANOKE);

Yadkin (YADKIN); New (NEW); Big Sandy (BIG SANDY); Holston (BOLSTON); Clinch (CLINCE); Powell (POWELL)I

Unnamed spring nr Bacova Junction......... (JAMES) 208

Unnamed mine drain above Looney Creek at Inman......................... (POWELL) 555

Unnamed mine drain above Mud Lick Creok at Roda........................... 554

Unnamed mine drain to Aus Keen Branch Unnamed mine drain to Baileys Trace at Bonny Blue .............. (POWELL) 558

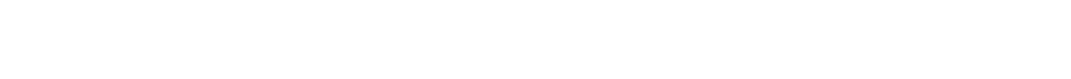
Unnamed mine drain to Burnt Popiar Fork nr Harman Junction...... (BIG SANDY) 462

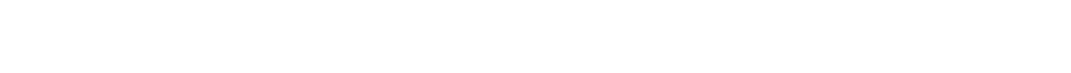

Unnamed mine drain to Dog Fork nI Harman. (BIG SANDY) 463

Unnamed mine drain to Dotson Creek nr Wise................... (BIG SANDY) 485

Unnamed mine drain to Dry Creek trib nr Dungannon.................... (CLINCE) 543

Unnamed mine drain to Fryingpan Creek at Bucu......................... SANDY) 475

Unnamed mine drain to Georges Fork at Baden nr Georges Fork........(BIG SANDY) 483

Unnamed mine drain to Georges Fork nr Georges Fork.............. (BIG SANDY) 483

Unnamed mine drain to Laurel Branch nr Carrie..................... (CLINCE) 535

Unnamed mine drain to Laurei Fork above Old House Bollow at Jewell Ridge.................(BIG SANDY) 458

Unnamed mine drain to Laurel Fork above Kinder Branch nr Jewell Ridge............... (BIG SANDY)

Unnamed mine drain to Levisa Fork at Big Rock.................. BIG SANDY) 463

Unnamed mine dratn to Meade Fork nr Pound ..................... (BIG SANDY) 482

Unnamed mine drain to Middle Fork nr Breaks.................. (BIG SANDY)

Unnamed mine drain to Phtilips Creek nr Flat Gap.................. (BIG SANDY)

Unnamed mine drain to Right Fork nr Dante................... (CLINCE)

Unnamed mine drain to Tilier Fork nr Duty................... (BIG SANDY)

Unnamed mine drain to unnamed trib to Sepulcher Creek nr Stephens.... (CLINCH)

Unnamed spring (South Salem water supply) nr South Salem........... (ROANOKE) 363

Unnamed spring along Rt 669 nr Riner.......(NEW) 447

Unnamed spring at Luray............... (SHEN) 48

Unnamed spring at Rt 777 nr Singers Gien... (SHEN) 28

Unnamed spring at Rts $600 / 658 \mathrm{nr}$ Radford...(NEW) 447

Unnamed spring at Rts $617 / 602$ nr Rtner..... (NEW) 445

Unnamed spring at Rts $628 / 624$ nr McDonalds Mil1.............(ROANOKE) 360

Unnamed spring at Rts $785 / 630$ nr McDonalds Mil1..............(ROANOKE) 360

Unnamed spring at Sparkling Springs nr Singers Glen.................. (SHEN) 28

Unnamed spring at fliter plant at Salen. . . . . .

Rt 669 nr Roger\$.............. (ROANOKE) 358

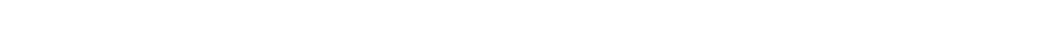

Unnamed spring nr Lacey Spring........... (SHEN) 56

Unnamed spring or Louisa....................... 167

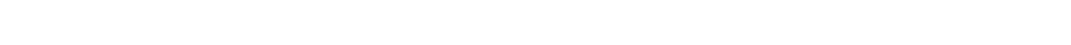

Unnamed spring nr Rts $685 / 654$ nr Blacksburg............................... 448

Unnamed spring nr Rts $8 / 601$ nr Riner........ (NEW) 445

Unnamed spring off Rt 675 nr Cedar Springs. (NEW) 434 Unnamed spring on Rt 615

nr Christiansburg ................ (ROANOKE) 358

Unnamed spring on Rt 615 nr Rogers .... (ROANOKE) 358
Unnamed spring on Rt 615 nr Rt 669 nr Pilot .................. (ROANOKE) 358

Unnamed spring on Rt $6 \dot{6} \dot{8}$ nr McDonalds Mill.............(ROANOKE) 360

Unnamed spring on Rt 678

nr Williamsville.
Unnamed spring on Rt 785 nr McDonalds Mill................(ROANOKE) 360

Unnamed springs (Roanoke water supply) at Roanoke ..................... (ROANOKE) 364

Unnamed springs (accumulation of $\overline{6}$ ) nr Rogers....................... ROANOKE) 358

Unnamed springs nr Atkins............. (EOLSTON) 500

Upham Brook (Brook Run) at STP nr Richmond.................... JAMES) 294

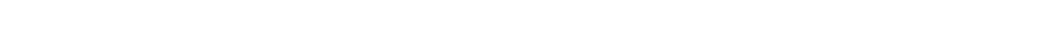

Upham Brook at Rt 161 at Richmond......... (JAMES) 294

Upham Brook at Rt 627 nr Richmond......... (JAMES) 294

Upham Brook at U.S. Ewy 1 at Richmond..... (JAMES) 294

Upham Brook at U.S. Bwy 301 nr Richmond. (JAMES) 294

Upham Brook at U.S. Hwy 33 at Richmond... (JAMES) 293

Upham Brook at Wilkinson Road

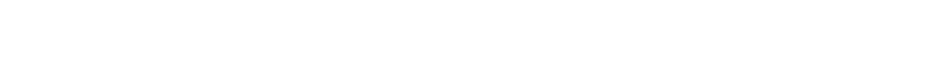

Upham Brook at mouth $\mathrm{n} r$ Richmond................ (JAMES) 294

Upper Appomattox Canal nr Petersburg..... (JAMES) 282

Upper Cascades Spring at Healing Springs. (JAMES) 208

Upper Chippokes Creek at mouth nr Claramont................... (JAMES) 291

Upper Chippokes Creek trib at mouth nr Burrowsvil1e................. (JAMES) 291

Upper Lewis Run at Fire Rd nr Lymmood..... (SHEN) 43

Upper Machodoc Creek at navigation lights nr Dahlgren....(POTOMAC) 110

Upper Machodoc Creek at Dahlgren........ (POTOMAC) 110

Upper Machodoc Creok at Rt 218 nr Ninde............... (POTOMAC) 110

Upper Machodoc Creek at Rt 616 nr Dahlgren.................. (POTOMAC) 110

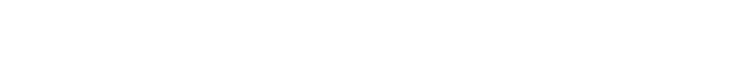

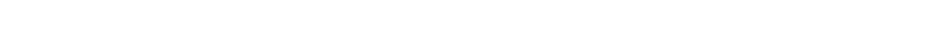

Upper Machodoc Creek at mouth nr Dahlgren..................(POTOMAC) 110

Upper Machodoc Creek at mouth of Williams Creek nr Dahlgren........(POTCMAC) 110

Upper Machodoc Creek at power cables nr Dahlgren.................. (POTOMAC) 110

Upper Mill Branch at mouth nr stacy... (BIG SANDY) 461

Upper Twin Branch at Flannagan Reservoir nr Tarpon...........(BIG SANDY) 486

Upper and lower springs nr Woodlawn Park nr Roanoke ......(ROANOKE) 364

Upper spring nr Woodlawn Park

nr Roanoke ....................... (ROANOKE) 364

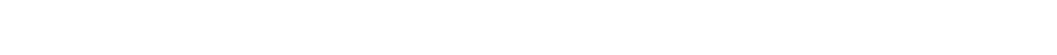

Urbanna Creek above STP nr Urbanna........... (RAPP) 156

Urbanna Creek above mouth at Urbanna......... (RAPP) 157

Urbanna Creok at Bailey Point at Urbanna...(RAPP) 157

Urbanna Creek at Rt 602 at Urbanna........ (RAPP) 157

Urbanna Creak at Urbanna............... (RAPP) 157

Urbanna Creok at mouth at Urbanna........... (RAPP) 157

Uriah Branch at mouth nr Emporia.......(CEOWAN) 333

Valentine Creek at mouth nr Grit...... (ROANOKE) 382 Valley Branch at mouth at Stanleytown...(CLINCB) 546 Valley Creek at mouth at

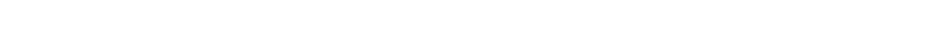

Valley Creek at mouth nr Ka............... (CLINCH) 545 Valley Creek at mouth nr Nickelsviile... (CLINCE) 548 Van Book Branch at mouth nr Bayters Gap..................... (HOLSTON)

Vaughan Spring at Rts $785 / 648$ nr Blacksburg ............... (ROANOKE) 360

Vaughans Creek at Rt $62 \dot{6}$ in Hixburs........ (JAMES) 272

Vaughans Creek at mouth nr Glass......(RAPP-YORK) 165 
Abbreviated basin names appear at the end of the site name. Abbreviations are as follows

Eastern Shore (EASTERN); Potomac to Shenandoah (POT-SHEN); Shenandoah (SHEN); Potomac (POTOMAC);

Potomac to Rappahannock (POT-RAPP); Rappahannock (RAPP); Rappahannock to York (RAPP-YORK); York (YORK);

York to James (YORK-JAMES); James (JAMES); James to Chowan (JAMES-CHOWAN); Chowan (CHOWAN); ROanoke (ROANOKE);

Yadkin (YADKIN); New (NEW); Big Sandy (BIG SANDY); Holston (HOLSTON); Clinch (CLINCH); POWOll (POWELI))

Page

Vaughans Creek at mouth nr Prospect......(JAMES) 272

Vaught Branch at mouth nr Groseclose... (BOLSTON) 499 Venable (Byrd) Creek at Rt 630 nr Wilmington.

Venable Creek above Kent Branch nr Wilmington.

(JAMES) 257

Venrick Run at mouth nr Wytheviile........... (NEw) 436

Venus Branch at mouth nr Hilton..... (HOLSTON) 521

Vilizines Swamp at mouth nr Zuni..........(CHOWAN) 342

W. G. Correll Spring at Asberrys......(HOLSTON) 51

W. K. Grubb Spring on Rt 114

nr McDonalds Mill........... (ROANOKE) 360

Wabash Creek at Rt 452 nr Poplar Hili...... (NEW) 100

Wabash Creok at mouth at Staffordsvilio.... (NOW) 452

Wabash Spring nr Poplar Hill.............. (NEW) 452

Wadinger Creek at mouth nr Dutton.... (RAPP-YORK) 161

Wahrant Swamp at Rt 632 nr Barhansvilie.. (JAMES) 299

Wahrani Swamp at former mouth

Waldrop (Waldrops) C̈rook at Rt 532

(JAMES) 299 nr Louisa...................... (YORK) 177

Waldrop Creok at mouth nr Ferncifif........(YORK) 177

Walker Branch at mouth at Buffalo Springs.............(ROANOKE) 417

Walker Branch at mouth nr Chula.......... (JAMES) 276

Walker Creek along Rt 659 ni Seven Mile Ford.

Walker Creek at Rt 602 nr Rockbridge Baths.............. (JAMES) 226

Halker Creek at Rt 502 nr. Fordwick........ (JAMES) 226

Walker Creek at Rt $605 \mathrm{nr}$ Bland..............NEW) 450

Walker Creek at Rt $622 \mathrm{nr}$ Pearisburg........(NEW) 452

WaLker Creek at Rt 645 at Seven Mile Ford..............(HOLSTON) 503

Walker Creok at Rt 650 at Staffordsville...(NEW) 452

Walker Creek at Rt 738 at Mechanicsburg.... (NEW) 451

Walker Creek at mouth nr Rockbridge Baths.............. (JAMES) 226

Walker Creek at mouth nr Seven Mile Ford. (HOLSTON) 503

Walker Creek at mouth at Dickinson...... (ROANOKE) 374

WaLker Creek at mouth nr Pearisburg..........(NEW) 452

Walker Creek below Rt 100 at Bane...........(NEW) 452

Walker Creek trib at mouth ne Seven Mile Ford.

(HOLSTON) 503

Walkers Branch at mouth nr Rhoadesviijo...(RAPP) 141

Walkers Creek at mouth $\mathrm{nr}$ Jefferson...... (JAMES) 261

Walkerton Branch at mouth at Walkerton... (YORK) 195

Wallace Branch at mouth nr Saxe....... (ROANOKE) 389

Wallace Branch, East Branch, at mouth

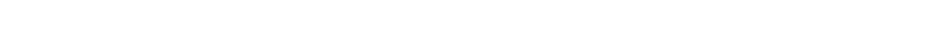

Wallace Creek at mouth nr Sutherland..... (JAMES) 282

Wallen Creek at Hunter Gap nr Blackwater................ (POWELL) 561

Wallen Creek at Rt $16 \mathrm{nr}$ Trout Dale....... (NEW) 427

Wallen Creek at Rt $616 \mathrm{nr}$ Jonesville.... (POWELL) 561

Wallen Creek at old U.S. Fwy $58 /$ Rt 421 at Stickleyvilie..........(POWELL) 561

Wallen Creek nr Stickleyrille........... (POWELL) 561

Walls Landing Croek at Capeviile........ (EASTERN) 13

Walls Landing Creek at Rt 600 at Capeville......... nr Towsend. ...........................

Walls Run above Rt 754 nr Rocky Bar........ (SEEN) 44 Walls Run at mouth nr Garysville......... (JAMES) 289 Walston Creok at mouth nr Accomac......(EASTERN) 12 Walton Creek at mouth $\mathrm{nr}$ Union Hail..... (ROANOKE) 369 Walton Fork at Rt 602 nr Mount Vinco..... (JAMES) 245 Walton Fork at mouth nr Mount vinco...... (JAMES) 245 Wancopin Creok $0.2 \mathrm{mi}$ below U.S. Hwy 50 at Middleburg........ (POTOMAC)

Wancopin Creek $0.3 \mathrm{mi}$ below U.S. HWy 50 at Middleburg.

(POTOMAC)
Wancopin Creek $0.4 \mathrm{mi}$ below

U.S. Hwy 50 at Middieburg....... (POTCMAC)

Wancopin Creek $0.7 \mathrm{mi}$ below

U.S. Hwy 50 nr Middleburg...... (POTOMAC) 70

Wancopin Creek $1.0 \mathrm{mi}$ below

U.S. Hwy $50 \mathrm{nr}$ Middleburg........ (POTOMAC)

Wancopin Creek $200 \mathrm{ft}$ below

U.S. Hwy 50 at Middleburg........(POTOMAC)

Wancopin Creek 400 ft below

U.S. Hwy 50 at Middlebur8....... (POTOMAC)

Wancopin Creek 800 ft below

U. $S$ Hory 50 t Middleburg (POTOMAC)

Wancopin Creek at mouth nr Middleburg.. (POTOMAC)

Waqua Creek at Rt 606 nr Alberta........ (CHOWAN)

Waqua Creek at Rt $712 \mathrm{nr}$ McKenney....... (CHOWAN)

Waqua Creek at U.S. Hwy 1 nr Rawlings... (CHOWAN)

Waqua Creek at mouth nr Rawlings........ (CHOWAN)

War Branch at Custers Bridge at Hinton.... (SHEN)

War Branch at U.S. Hwy 33 nr Hinton....... (SHEN)

War Branch at mouth et Hinton......... (SBEN)

War Branch at mouth nr Lacey Spring........ (SHEN)

War Fork along Rt 83 at Prater.......(BIG SANDY)

War Fork at mouth at Prater............ (BIG SANDY)

Ward Branch at mouth nr Sago.......... (ROANOKE)

Wards Creok at Rt 665 nr Free Union...... (JAMES)

Wards Creek at mouth nr Freo Union........ (JAMES)

Wards Creek at mouth nr Garysyille........ (JAMES)

Wards Fork Creek at mouth nr Saxe...... (ROANOKE)

Wards Fork Creek, East Branch, at mouth at Cullen........

Wards Fork Creek, Middle Branch

at mouth at Cullen.............. (ROANOKE)

Wards Fork Creek. West Branch, at mouth at Cullon............. (ROANOKE)

Page

Wards Mill Branch at mouth at Galax......... (NEW)

Ware Creek at Rt $600 \mathrm{nr}$ Toano ............. (YORK)

Ware Creek at U.S. HWy $17 \mathrm{nr}$ Corbin......... (RAPP)

Ware Creek at mouth nr Corbin............. (RAPP)

Ware Creek at mouth $n \mathbf{r}$ Toano............. (YORK)

Ware River at buoy $2 \mathrm{nr}$ Naxera...... (RAPP-YORK)

Ware River at buoy 21 nr Naxera...... (RAPP-YORK)

Ware River at buoy 6 nr Ware Neck... . (RAPP-YORK)

Ware River at buoy $9 \mathrm{nr}$ Ware Neck... (RAPP-YORK)

Ware River at mouth nr Naxera....... (RAPP-YORK)

Warehouse Creek above STP at Nassawdox. (EASTERN) Warehouse Creek at Rt 609 at Nassawadox. . . . . (EASTERN)

Warehouse Creek at Rt 618 at Franktown. (EASTERN)

Warehouse Creek at mouth nr Franktown. (EASTERH)

Warehouse Creek at mouth nr Reedville. (POT-RAPP)

Warehouse Creek trib at Nassawadox..... (EASTERN)

Warehouse Prong at mouth nr Harborton. (EASTERN)

Warm Spring at Warm Springs........... (JAMES)

Warm Springs Run above STP at Warm Springs

Warm Springs Run at Rt $66 \overline{7}$ nr Warm Springs................. (JAMES)

Warm Springs Run below Warm Springs...... (JAMES)

Warm Springs $\mathrm{nr}$ Hotchkiss ............ (JAMES)

Warners Big Spring nr Poplar Hi11......... (NEW)

Warren Swamp at mouth nr Carson......... (CHOWAN)

Warrington Branch at mouth at Onancock. (EASTERH)

Warwick Branch at mouth nr Zuni........ (CHOWAN)

Warwick River at James River STP at Newport News.

(JAMES)

Warwick River at Newport News............... (JAMES)

Warwick River at U.S. Hwy 60 nr Newport News.

(JAMES)

Warwick River at mouth at Nowport News... (JAMES)

Warwick Swamp at Rt 613 nr Disputanta... (CHOWAN)

Warwick Swamp at Rt 624 nr Disputanta... (CHOWAN)

Warwick Swamp at mouth nr Waverly....... (CHOWAN)

Warwick Swamp trib at Rt 601 nr Disputanta.

(CHOWAN)

Washington Ditch along NWR Rd nr Cypress Chapel....

Washington Ditch at Rt 642 nr Cypress Chapel.

(JAMES-CHOWAN)

319

319 
Abbreviated basin names appear at the end of the stte name. Abbreviations are as follows:

Eastern Shore (EASTERN); Potomac to Shenandoah (POT-SEEN); Shenandoah (SHEN); Potomec (POTOMAC);

Potomac to Rappahannock (POT-RAPP); Rappahannock (RAPP); Rappahannock to York (RAPP-YORK); York (YORK);

York to James (YORK-JAMES); James (JAMES); James to Chowan (JAMES-CEOWAN); Chowan (CHOWAN); Roanoke (ROANOKE);

Yadkin (YADKIN); New (NEW); Big Sandy (BIG SANDY); Holston (HOLSTON); CIInch (CLINCH); PoweII (POWELL)]

Watch Run nr Drewrys Bluff.

Water Creek at mouth at Newport News...... (JAMES) Waterford Run at mouth nr Rixeyville...... (RAPP) Waterview Creak at mouth nr Tappahannock.. (RAPP) Watkins Branch at mouth at Grundy.... (BIG SANDY) Watkins Branch at mouth nr Sandy River. (ROANOKE) Watson Gap Branch at mouth at North Holston.

(HOLSTON)

Wattsville Branch at mouth nr Wattsvilis.

(EASTERN)

Waverly Branch at Horners Pond nr Leedstown................... (RAPP) 149

Wayside Spring at Richmond.............. (JAMES) 266

Weatherali Creek at Glebe Harbor nr Coles Point.

(POTOMAC)

Weaver Creak at Rt 663 at Artrip......... (CLINCB)

Weavar Craek at mouth at Artrip......... (CLINCH)

Wobh Crouk above Governor Creek

nr Central Garago................ (YORK) 186

Wooks Crook at mouth nr Water viow........... (RAPP) 156

Wolis Branch at mouth $n r$ Kookeo.......... (FOWELL) 557

West Branch above Swift Croek

Reservotr nr Hallsboro.

(JAMES)

West Branch at former mouth in

Swift Craek Reservoir nr Hallsboro. (JAMES) 285

West Branch at mouth $n r$ Seaford...........(YORK) 200

West Croak at Rt $614 \mathrm{nr}$ Denaro............ (JAMES) 278

West Croek at mouth $n r$ Denaro........... (JAMES) 278

West Dry Branch Spring $n r$ Deerfield ..... (JAMES) 224

West Dry Branch at Rt $689 \mathrm{nr}$ Deerfield... (JAMES) 224

West Flume of Duniop Mills at Richmond... (JAMES) 266

West Fork above confluence with East Fork nr Galax.

West Fork at mouth at Frog Levei

nr Tazewell........................ (CLINCH)

West Fork at mouth at Richlands ........ (CLINCH)

West Fork at mouth nr Fioyd............. (NEW)

West Fork at mouth nr Indian Valioy......... (NEW)

West Fork at mouth nr Seven Mile Ford. (HOLSTON)

West Fork at mouth nr Stonega........... (POWELL)

West Fork at mouth nr Thomas Bridge.... (BOLSTON)

West Little Seneca Creek at mouth nr Castlo Crais. .

West Neck Creek at Rt 149

at Princess Anne.

West Neck Creek at Rt 149 at Pungo.

(..... (ROANOKE)

(JAMES-CHOWAN)

( JAMES-CHOWAN)

West Neck Creek at Rt 633

at London Bridge Rd

nr Princess Anne............ (JAMES-ChOWAN) 317

West Neck Creak at West Neck Rd nr Pleas ant Ridge.......... (JAMES-CHOWAN)

West Neck Creek at mouth nr Ploasant Ridge........... (JAMES-CHOWAN)

West Prong above East Prong nr Fioyd....... (NEW)

West Run along Rt $627 \mathrm{nr}$ Cedarville........ (SEEN)

West Run at Harrison Lake Dan

nr Barnetts................... (JAMES)

West Run at Rt 625 at Barnetts........... (JAMES)

West Run trib No. 1 at Rt 609

West Run trib No. 2 at Rt $609 \ldots \ldots \ldots$ (JAMES)

nr Barnett................... (JAMES) 290

West Spring at Grahams Forge.................... 437

West Swift Run at Rt 628 at Swift Run..... (SHEN) 44

West Swift Run at mouth nr Elkton......... (SHEN) 44

Westbrook Run at U.S. Hwy $340 \mathrm{nr}$ Boyce...... (SHEN) 64

Western Branch Reservolr nr Suffolk...... (JAMES) 307

Western Branch at mouth nr Elephant Fork. (JAMES) 307

Western Run at mouth nr Barnett......... (JAMES) 270

Westham Creak above James River and Kanawh Canal nr Richmond.

(JAMES) 264

Wet Branch at mouth nr Leatherwood...... (ROANOKE) 403

Wet Sleeve Creek at Banister

nr Swansonville.............. (ROANOKE) 410

Wet Sleeve Creek at mouth nr Rondo...... (ROANOKE) 410
Wheat Spring Branch at mouth nr Berryville.

Wheoler Creek at mouth nr Boswells Tavern.

Whetstone Creek nr Blackstone. (SHEN)

Whipping Creek at mouth nr Brookneal ... (ROANOKE)

Whipping Creek below Rt $635 \mathrm{nr}$ Naruna.. (ROANOKE)

Whipponock Creak at Rt 623 at Lake Chesdin. .

Whipponock Creek at Rt 627 nr Church Road.

Whipponock Creak at Re 708 nI Winterpock.

Whipponock Creak at former mouth

at Lake Chesdin..... $\ldots \ldots \ldots \ldots \ldots$ (JAMES)

at Lake Chesdin....................
Whiskey Creek above Baylor Springs

nr Churchvilie................. (SEEN)

Whiskey Creek at Rt $42 \mathrm{nr}$ Churchvilie..... (SEEN)

Whiskey Creak at Rt 836 at Churchvilie.... (SHEN)

Whiskey Creek at mouth at Churchville..... (SHEN)

Whisporing Creek at Rt 654

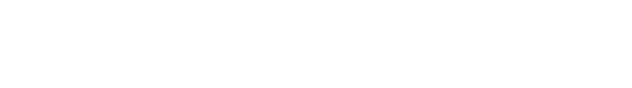

at Sprouses Corner.
Whispering Creek at mouth

nr Guinea Mills..........
Whistia Creek along U.S. Hwy 60 nr Lexington.

(JAMES)

Whit Branch at mouth nr Edgerton.......... (CEOWAN)

White Branch at mouth at Rose Eiii...... (POWELL)

White Branch at mouth nr Abingdon....... (BOLSTOR)

White Branch at mouth $n r$ Longshoal.......... (NEW)

White Branch trib at wouth at Rose Hill. (POWELL)

White Creek at mouth nr Loutsa........... (YORK)

White Eall Creak on $\mathrm{Rt} 573 \mathrm{nr}$ Othma....... (JAMES)

White House Creak at mouth

nr Poquoson................. (YORK-JAMES)

White Marsh at mouth $\mathrm{nr}$ Center Cross. (RAPP-YORK)

White Oak Branch at mouth

nI Chatham Hil1 .............. (HOLSTON)

White Oak Canyon trib at White Oak

Canyon Trail nr Syria............ (RAPP) 135

White Oak Creak at Rt $620 \mathrm{nr}$ Hebron....... (CHOWAN) 327

White Oak Creok at Rt 622

nr Baltimore Cormer............. (CHOWAN)

White Oak Creek at Rt $718 \mathrm{nr}$ Dry Fork. (ROANOKE)

White Oak Crosk at mouth

nr Boones Mill............... (ROANOKE)

Wht te Oak Creek at mouth nr Ante....... (CHOWAN)

White Oak Croek at mouth nr Charity..... (ROANOKE)

White Oak Creek at mouth nr Chatham.... (ROANOKE)

White Oak Creek at mouth $\mathrm{nr}$ DeWitt...... (CHOWAN)

White Oak Creak at mouth nr Orange........(YORK)

White Oak Creek at mouth nr Pound.... (BIG SANDY)

White Oak Run $0.15 \mathrm{mi}$ above mouth

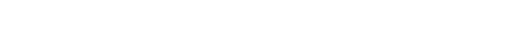

White Oak Run at Elkhorn Lake Rd

nI Stokesv \pm 11 . . . . . . . . . . . .

White Oak Run at Rt 231 nr Madison........ (RAPP)

White Oak Run at Rt $603 \mathrm{nr}$ Passapat anzy... (RAPP)

White Oak Run at mouth $n r$ Madison........ (RAPP)

White Oak Run at mouth nr Passapatanzy.... (RAPP)

White Oak Run trib at mouth

nr Fredertcksburg.

White Oak Swamp Creak at mouth

nI White oak Swamp............... (JAMES)

White Oak Swanp at Poplar Springs Rd

nr White Oak Swamp............... (JAMES) 296

Wht te Oak Swamp at Rt 156 at E1ko....... (JAMES) 296

White Oak Swamp at mouth nr Carson....... (CHOWAN) 330

White Oak Swamp at mouth nr E1ko.......... (JAMES) 296

White Point Creek nr Kinsale...........(POTOMAC) 112

White Rock Branch at mouth at Kire......... (NEW) 453

White Rock Croek at mouth at Cedar Springs. (NEW) 433

White Rock Creek at mouth at Lownoor..... (JAMES) 212 
Abbreviated basin names appear at the end of the site name. Abbreviations are as follows: Eastern Shore (EASTERN); Potomac to Shenandoah (POT-SHEN); Shenandoah (SHEN); Potomac (POTOMAC); Potomac to Rappahannock (POT-RAPP); Rappahannock (RAPP); Rappahannock to York (RAPP-YORK); York (YORK) : York to James (YORK-JAMES); James (JAMES); James to Chowan (JAMES-CBOWAN); ChOwan (CHOWAN); ROAnOke (ROANOKE); Yadkin (YADKIN); New (NEW); Big Sandy (BIG SANDY); Holston (HOLSTON); Clinch (CLINCH); POWell (POWELL)]

White Run at mouth nr Paige............ (YORK) 191 White Run at mouth nr Ruckersvilie..........(RAPP) 134 White Walnut Run at Rt 621 nr Sperryviile. (RAPP) 124 White Walnut Run at mouth

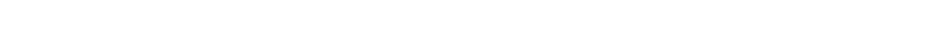
White Walnut Run at mouth nr Sperryvilie...(RAPP) 124 Whitehail Creek at mouth nr Brokenburg.... (YORK) 188 Whiteoak Branch at mouth at Tacoma...... (CLINCE) 54 Whiterock Branch at mouth nr Hayters Gap................(BOLSTON) 517 Whites Branch at mouth nr Floyd............ (NEW) 445 Whites Creek at Rt 679 at Mutton Bunk nr Modest Town................ (EASTERN) Whites Creek at mouth ni Modest Town... (EASTERN) Whitethorn Creek at Rt 676 nI Sonans... (ROANOKE) Whitethorn Creok at mouth nI Java......(ROANOKE) Whitethorn Creek trib at U.S. Hoy 29 at Gretna. Whitetop Laurel Creek at Konnarock...... (HOLSTON) Whitetop Laurel Creek nr Laureidaie.... (HOLSTON) Whiting Creek at mouth nr Urbanna......... (RAPP) Whiting Swanp at mouth nr Manquin......... (YORK) Whitieys Branch at mouth at Staffordsvilio. (NEW) Whitt Branch at mouth nr Rowe........ (BIG SANDY) Widgeon Creek at mouth at Charity.......(ROANOKE) Widow Branch at mouth nr Hill........... (CIINCH) Wildcat Branch at mouth nr Chula........ (JAMES) Wildeat Creek at mouth at East Stone Gap............... (POWELL) Wildcat Creek at mouth nr Blackstone.... (CHOWAN) Wildcat Swamp at mouth nr Wakefield..... (CHOWAN) Wilderness Branch at mouth ar Holly Brook.. (NEW) Wilderness Creek at mouth nr Rocky Gap..... (NEW) Wilderness Run at Rt 3 at Wilderness...... (RAPP) Wilderness Run at mouth nr Wilderness..... (RAPP) Wilderness Run, North, at Bill-Ewell Dr nr Wilderness.................... (RAPP)

Wilderness Run. North, trib at mouth nr Wilderness............

Wilderness Run, South, above Strawberry Branch nr Locust Grove... (RAPP) Will Brooks Spring at Wardell.......... (CLINCH) Will Cumbold Spring nr Lebanon. Willetts Creek at mouth at Glass...... (RAPP-YORK) Wililams Branch at mouth nr Dona........(CLINCH)

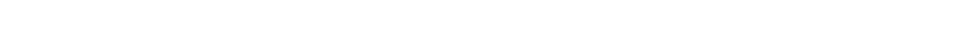
Williams Creek at Rt 206 at Dahlgren... (POTOMAC) Williams Creek at Rt 301 nr Dahlgren... (POTOMAC) WIIliams Creek at Rt $624 \mathrm{nr}$ Dahlgren...(POTOMAC) Wililiams Creek at mouth nr Dahlgren.... (POTOMAC) Wiliiams Run at mouth at Lynchburg....... (JAMES) Willis Branch at mouth at Willis....... (CLINCE) Willis River at Rt $600 \mathrm{nr}$ Curdsvilï...... (JAMES) 257 Willis River at Rt 602 nr Cartersvilie... (JAMES) 259 Willis River at Rt 608 at Trenton Mills nr Lakeside Village..........(JAMES) 259 Willts River at Rt 622 at Trents Mili.... (JAMES) 258 Willis River at Rt 634 nr Guinea Mills... (JAMES) 258 Wiliis River at Rt 690 at Lakeside Viliage (Flenagan Mills)........ (JAMES)

Willis River at U.S. Hwy 15 at Curdsvilia.

Willis River at U.S. Bwy 60 nr Hillcrest.

Wilis River at mouth nr Cartersiili.... (JAMES) 259 Willoughby Bay midway between James River and Willoughby Spit at Norfolk.... (JAMES) 313

Willoughby Bay nr Mason Creek at Norfoik. (JAMES) 313 Willoughby Bay nr Naval Air Rework Facility at Norfolk......... (JAMES) 313

Willow Springs Branch at U.S. Hwys 29/211 nr Centreville..(POTOMAC) 100

Wilna Creek at mouth nr Champlain.........(RAPP) 150 Wilson Creok (Mi11 Branch) at Rt 603 at mouth at E1lett.

Wilson Creek above Douthat Lake nr Clifton Forge.............. (JAMEs)
Wilson Creek above Littie Wilson Creek nr Rugby

Wilson Creek at Douthat iake

nr Healing Springs.

Wilson Creek at Douthat Lake dam nr Healing Springs ............

Wilson Creek at Douthat State Park nr Healing Springs.

Wilson Creok at Mouth of Wilson. . .

Wilson Creek at $R t 16$ nr Volney.................. (NEW)

Wilson Creek at Rt 603 at Ellett......... (ROANOKE) 36

Wilson Creek at Rt $629 \mathrm{nr}$ Ashwood........ (JAMES) 212

Wilson Creek at U.S. Hwy 58 at Volney....... (NEW) 427

Wilson Creek at U.S. Hwy 60 at Clifton Forge.

Wilson Creek at mouth at Clifton Forge. (JAMES)

Wilson Creek at mouth nr Edgerton....... (CHOWAN)

Wilson Creek at mouth nr Selden...... (RAPP-YORK)

Wilson Creek below Douthat Lake dam nr Healing Springs.............. (JAMES)

Wilson Creek below Douthat State Park

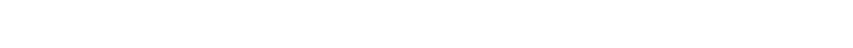

Wilson Creek nr Mouth of Wilson............. (NEW)

Wilson Run at mouth nr Criglersville...... (RAPP)

Wilton Creek at mouth nr Hartfield... (RAPP-YORK)

Winn Creek at mouth nr Halifax......... (ROANOKE)

Winningham Creek at mouth nr Crewe....... (JAMES)

Winns Creok at mouth nr Turbeville..... (ROANOKE)

Winston Isom Spring nr Lipps............ (CLINCH)

Winter Barbor out let nr Peary............ (RAPP-YORK)

Winterpock Creek at Rt 602 nr Winterpock. (JAMES)

Winterpock Creek at Rt $664 \mathrm{nr}$ Winterpock. (JAMES)

Winterpock Creek at former mouth in Lake Chesdin $n r$ Winterpock...... (JAMES)

Winterpock Creek trib No. 1 at Rt 664 at Winterpock ................ (JAMES)

Winterpock Creek trib No. 2 at $\ddot{R} \dot{6} \dot{6} \dot{4}$ at Winterpock................ (JAMES)

Winterpock Creek trib No. 3 at Rt $6 \dot{6} \dot{4}$

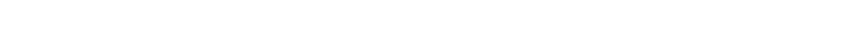

Winticomack Creek at Rt 622 nr Winterpock. ............... (JAMES)

Winticomack Creek at mouth nr Winterpock. (JAMES) Witcher Creek at mouth nI Penhook.......(ROANOKE)

Wolf Branch at mouth nr Oak Grove......... (NEW) Wolf Creek above Blind Hollow nr Abingdon.................... (HOLSTON)

Wolf Creek above Clear Fork at Rocky Gap... (NEW)

Wolf Creek at $I-77$ at Rocky Gap......... (NEW) Wolf Creek at Rt 664 above Falls Mili nr Green Spring....... (HOLSTON)

Wolf Creek at Rt 670 above STP at Vance Mill nr Abingdon........ (HOLSTON)

Wolf Creek at Rt 724 nr Narrows.................

Wolf Creek at Rt 75 at Green Spring..... (HOLSTON)

Wolf Creek at South Eolston Lake at Green Spring .............. (HOLSTON)

Wolf Creek at U.S. Ewy ii at Abingdon. . (HOLSTON) Wolf Creek at U.S. Hwy 21 nr Bastian....... (NEW) Wolf Creek at former mouth nr Green Spring.............. (HOLSTON)

Wolf Creek at mouth at Narrows.............. (NEW)

Wolf Creek at mouth nr Bedford............. (ROANOKE)

Wolf Creek at mouth nr Hayters Gap..... (HOLSTON)

Wolf Creek at mouth nr Hixburg.......... (JAMES)

Wolf Creok at mouth nr Vinton............. (ROANOKE)

Wolf Creek nr Shawver Mill (Burkes Garden). (NEW)

Wolf Creak. East Fork, at Hayters Gap.. (HOLSTON) Wolf Creek, West Fork, at mouth at Hayters Gap.

213 354 164

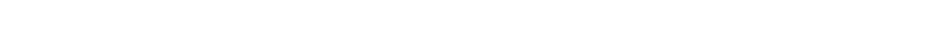

Wolf Run at mouth at Phillip.........(HOLSTON)

Wolf Run at mouth nr Clifton............. (POTOMAC)

Wolf Spring Branch at mouth nr Snowvilie... (NEW)

Wolf Swamp at mouth nr Montpolier........ (YORK)

Wolf Trap Creek (Wolf Creok) at mouth nr Wolf $\operatorname{Trap} . \ldots \ldots \ldots \ldots \ldots \ldots$ (ROANOKE)
517

101

519

101
446

180

415 
Abbreviated basin names appear at the end of the site name. Abbreviations are as follows:

Eastern Shore (EASTERN); Potomac to Shenandoah (POT-SHEN); Shenandoah (SHEN); Potomac (POTOMAC);

Potomac to Rappahannock (POT-RAPP); Rappahannock (RAPP); Rappahannock to York (RAPP-YORK); York (YORK);

York to James (YORK-JAMES); James (JAMES); James to Chowan (JAMES-CHOWAN); Chowan (CHOWAN); Roanoke (ROANOKE);

Yadkin (YADKIN); New (NEW); Big Sandy (BIG SANDY); Holston (HOLSTON); Clinch (CLINCE); Powe11 (POWELL)]

Page

Wolfes Branch at mouth nr Scotts Fork.... (JAMES) 277 Wolfpen Branch at mouth nr Holly Brook...... (NEW) 451 Wolfpen Branch at mouth nr Hurley....(BIG SANDY) 489 Wolfsnare Creek at Potters Rd at London Bridge........... (JAMES-CHOWAN) 314 Wolfsnare Creek at Rt $63 \dot{2}$ nr Virgini a Boach............. (JAMES-CHOWAN) 314 Wolftrap Branch at mouth nr Gordonsville.. (YORK) 166 Wolftrap Creek at Boulah Rd nr Vienna.. (POTOMAC) 77 Wolftrap Creek at Creok Crossing Rd

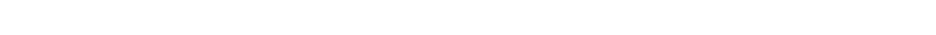
Wolftrap Creek at mouth nr Vienna...... (POTOMAC) 77

Wood Creek at mouth at Fort Eustis........ (JAMES) 302 Woodpecker Creek at mouth

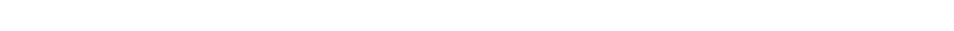

Woods Branch at mouth nr Denaro............ (JAMES) 278

Woods Creek at mouth nr Deltavilie.......... (RAPP) 159

Woods Mill Swamp at mouth nr Adner.......... (YORK) 199

Woody Creek at mouth nr Denaro........... (JAMES) 278

Wormley Creek at mouth nr Seaford.........(YORK) 200

Wreck Island Creek above quarries nr Riverville......................... JAMES) 235

Wreck Island Creek t Riverville.........(JAMES) 236

Wreck Is land Creek at Rt 605 nr Riverville................. (JAMES) 236

Wright Branch at mouth t Damescus...... (BOLSTON) 497

Wright Mill Run nr mouth at Lake Cohoon.. (JAMES) 306

Wrights Run at U.S. Hwy 522 n.r Stephens City ............ (POT-SHEN) 22

Wrights Spring at Rts $78 \dot{8} / 62 \dot{8}$ nr McDoralds Mill ............... (ROANOKE) 360

Wyatt Swamp at mouth nr Water viow......... (RAPP) 156

Yagers Spring nr Luray............... (SHEN)

Yarmouth Creek below Cranstons Pond

(TAMES) 299

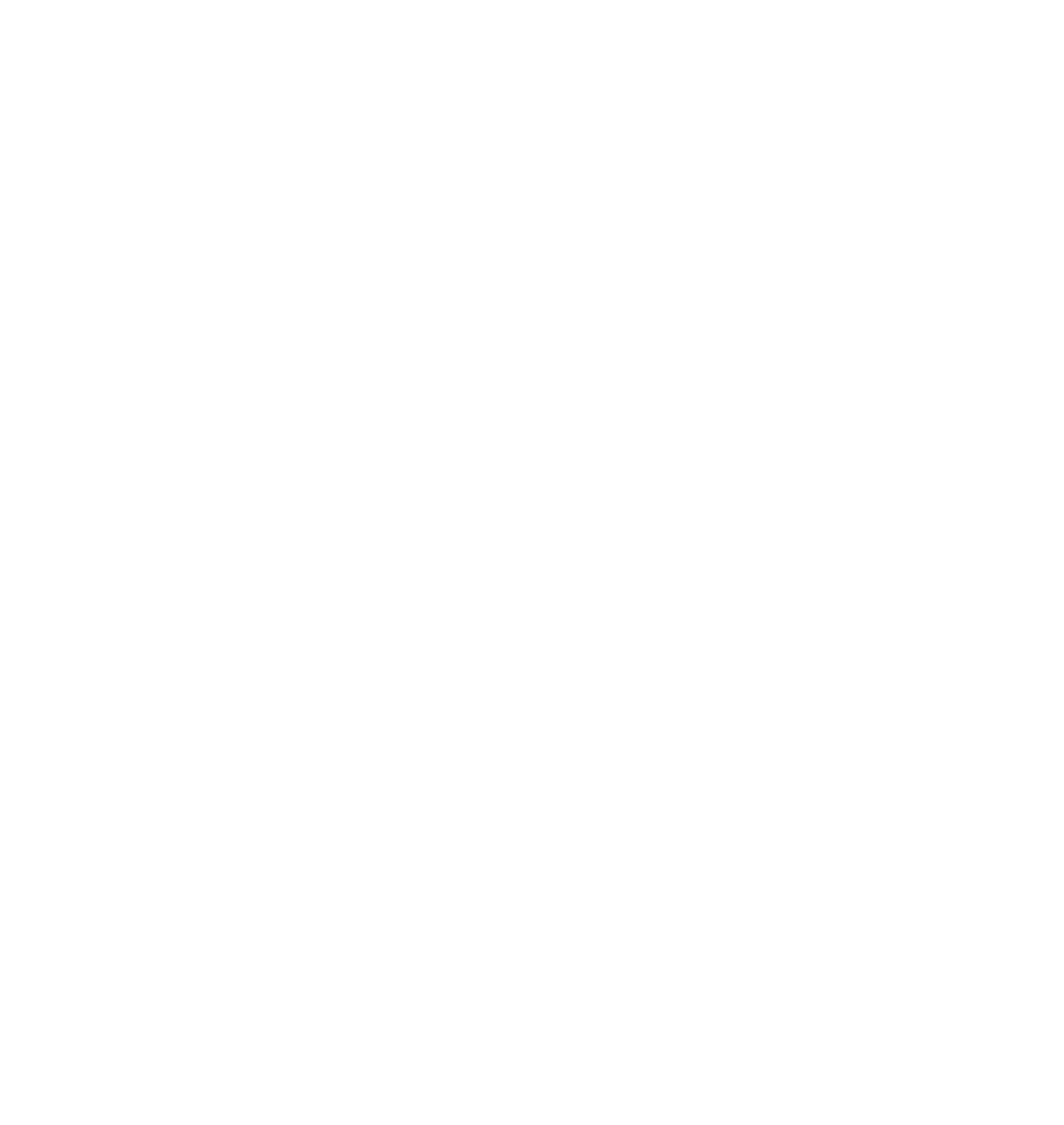

Zeke Creek at mouth nr Doran..........(CLINCH) 529

Zion Branch at mouth nr Saluda........... (RAPP-YORK) 160 